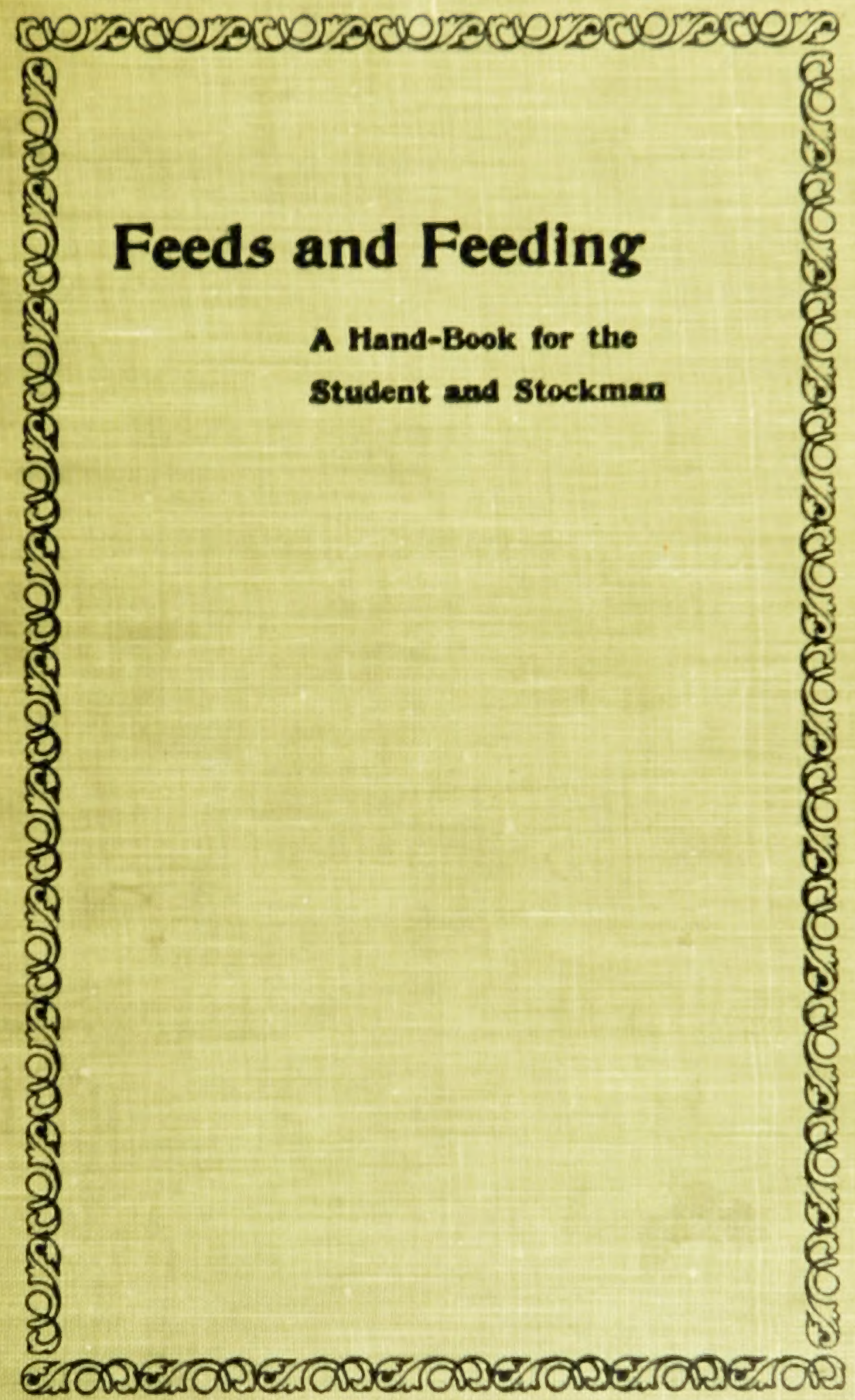




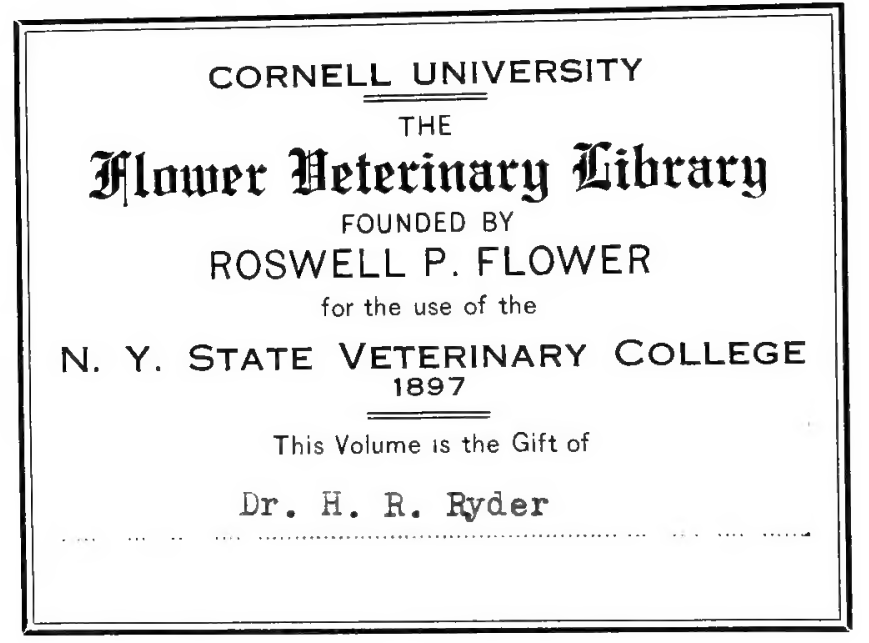


SF 95.H52 Cornell University Library

Feeds and feeding; a hand-book for the st ||||||||||||||||||||||||||||||||||||||||||||||||||||||||||||||||||||||||||||

31924000012108 

14. R. Ryder Do
Chleago
PRe. 


\section{Cornell University Library}

The original of this book is in the Cornell University Library.

There are no known copyright restrictions in the United States on the use of the text. 
.......... 



\title{
FEEDS AND FEEDING
}

\author{
A HAND-BOOK
}

FOR THE

\section{STUDENT AND STOCKMAN}

\author{
BY \\ W. A. HENRY \\ Dean of the College of Agriculture, \\ and Director of the Agricultural Experiment Station, \\ University of Wisconsin
}

\footnotetext{
"The eye of the master fattens his cattle.

- German adage.
}

SEVENTH EDITION.

PUBLISHED BY THE AUTHOR

MADISON, WIS.

1906 


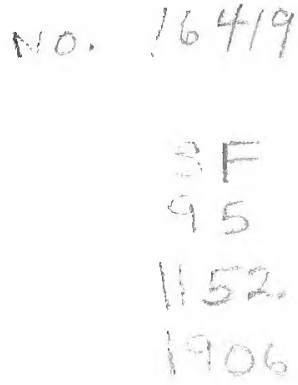

Copyright, 1898, BY W. A. HENRY.

M. J. CANTWELL, PRINTER, MADISON, WIS. 


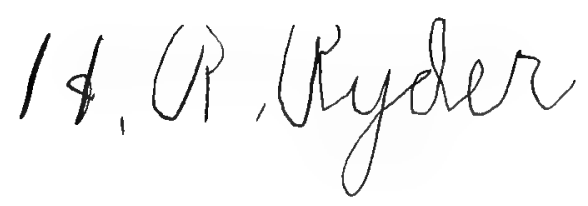

\section{PREFACE.}

Tor more than a generation past many of the ablest scientists of the old World have devoted their energies to a study of the laws of animal nutrition. American Experiment Stations, although of recent origin, have added much to our store of knowledge concerning the application of science to stock feeding. From these fruitful sources the writer has endeavored to select data important in establishing principles and helpful in directing rational practice. In addition there have been gathered from all available sources the experiences and observations of stockmen.

Much space is occupied by tables, which are usually condensed and arranged from the original sources, to which references are made. By their help it is hoped the student will be able to determine for himself to what extent the deductions drawn are warranted by the facts. Moreover, the data they contain may form the basis for new studies with those specially interested, and may make additional conclusions possible.

The stockman whose training has been solely in the school of experience often holds in light regard that which is written concerning his vocation. Let him remember that facts and truths are the same whether their repository is a book or the human mind. Held by the latter, all perish with the possessor; in the keeping of the former, the whole world may be benefited. On the other hand, novices usually undercstimate the importance of experience, often thinking that by reading they can acquire the knowledge necessary in the prosecution of their business. That stock feeding is an art and not a science, and that experience and judgment must rule in its successful conduct, is recognized in this volume by placing on the title page the adage, "The eye of the master fattens his cattle." In this we have followed the 
German author Kühn in his popular work on the same topic. In the successful management of live stock abstract knowledge cannot take the place of experience, though it will prove of the highest value when both are rightly combined. The stockman who in addition to experience possesses some knowledge of the composition of the nutrients of feeding stuffs, and has considered how the animal grows and is nourished by them, is certainly thereby better equipped for wisely and economically administer- , ing feed to the animals under his care. And in the deeper insight and wider range of vision which these studies insure, there comes keener enjoyment and a greater satisfaction to the possessor, in his daily round of duties.

Acknowledgment is due my co-worker, Prof. F. W. Woll, for assistance, especially in collating the data published by foreign investigators. His familiarity with this source of information has been of the highest utility. Mr. A. M. Troyer, a graduate student in agriculture, has assisted in preparing and verifying the tables from American sources.

Madison, WIS., February, 1898.

W. A. Henry. 


\section{CONTENTS.}

Part I. - Plant Growtil and Animal Nutrition. CHAPTER.

PAGE.

I. The Plant; How it Grows and Elaborates Food for Animals . . . . . . . . . . . . 1

II. Mastication, Digestion and Assimilation . . . . 12

III. Digestion, Respiration and Calorimetry . . . . . 26

IV. Aninual Nutrition . . . . . . . . . . . . 40

V. The Source of Muscular Energy; Composition of Animals Before and After Fattening . . . . . . 63

VI. Influence of Feed on the Animal Body . . . . . . 78

VII. Explanation of Tables of Composition and Feeding Standards - Methods of Calculating Rations for Farm Anirrals, etc. . . . . . . . . . 97

Part II.- Feeding Stuffs.

VIII. Leading Cereals and Their By-products . . . 119

IX. Minor Cereals, Oil-bearing and Leguminous Seeds and

Their By-products . . . . . . . . . . . 143

X. Indian Corn as a Forage Plant . . . . . . . . . 163

XI. The Grasses, Fresh and Cured - Straw . . . . . 178

XII. Leguminous Plants for Green Forage and Hay . . . 195

XIII. Miscellaneous Feeding Stuffs . . . . . . . . . . 211

XIV. Soiling Cattle - Preparation of Feeding Stuffs . , . 231

XV. The Ensilage of Fodders . . . . . . . . . . 245

XVI. Manurial Value of Feeding Stuffs . . . . . . . 263

\section{Part III. - Feeding Farm Animalus.}

XVII. Investigations Concerning the Horse . . . . . . 271

XVIII. Feeds for the Horse . . . . . . . . . . . . 292

XIX. Feed and Care of the Horse . . . . . . . . . 311

XX. Calf Rearing . . . . . . . . . . . . . . . 334

XXI. Results of Steer-feeding Trials at the Stations . . . 345

XXII. Factors in Steer Fattening-Final Results . . . 364

XXIII. Counsel in the Feed Lot . . . . . . . . . . 381

XXIV. The Dairy Cow - Scientific Findings . . . . . 401 
Chapter.

XXV. Station Tests with Feeding Stuffs for Dairy Cows . . 413

XXVI. Influence of Feed on Milk-Wide and Narrow Rations 437

XXVII. Public Tests of Pure-bred Dairy Cows-Cost of Producing Milk and Fat in Dairy Herds at Various Experiment Stations . . . . . . . . . 448

XXVIII. Feed and Care of the Dairy Cow . . . . . . 463

XXIX. Investigations with Sheep . . . . . . . . . . . 480

XXX. Experiments in Fattening Sheep - Wool Production . 497

XXXI. General Care of Sheep - Fattening . . . . . . . 514

XXXII. Investigations with Swine . . . . . . . . . . . 535

XXXIII. Value of Various Feeding Stuffs for Pigs . . . . . 556

XXXIV. Danish Pig-feeding Experiments . . . . . . 583

XXXV. Feeding and Management of Swine- iffect of Feed

on the Carcass of the Pig . . . . . . . . 604 


\title{
FEEDS AND FEEDING.
}

PART I.

\section{PLANT GROWTH AND ANIMAL NUTRITION.}

\author{
CHAPTER I. \\ THE PLANT; HOW IT GROWS AND ELABORATES \\ FOOD FOR ANTMALS. \\ I. Plant Growth.
}

I. Concerning plant cells. - Since plants and their products in some form, directly or indirectly, constitute the food of animals, it is proper in these studies that we briefly examine how the plant grows and elaborates this food.

The unit of plant growth is the cell. If we study a grain of corn or a corn stalk we find it made up of cells variously modified, the whole group together taking on the form of the object under consideration. In their primary condition all cells are closed sacs, and contain the juices and other substances incident to plant growth. The walls of the plant cells are composed of a woody substance called cellulose. These walls may be thin and tender to the teeth of the animal, as in the young plants of the fields, or thick, woody and tough, as in the stems of the forest trees. Before studying more intimately the plant cell, its contents, and what occurs within it, let us consider the substances essential to plant growth.

2. Elements essential to plant life.-The elementary substances required for plant life are carbon, hydrogen, oxygen, nitrogen, 
potassium, calcinm, magnesium, phosphorus, iron, chlorin and sulfur. The plant can make no use of these elements in their uncombined form, with the single exception of oxygen, of which it may utilize a small amount in elementary form. All the other elements, as well as oxygen for the most part, must be combined with one another in some form to be of use to the plant. The mineral substances which are taken up by the roots of the plant may be grouped as follows:

$\left.\begin{array}{l}\begin{array}{l}\text { Sulfates } \\ \text { Phosphates } \\ \text { Nitrates and } \\ \text { Chlorids }\end{array}\end{array}\right\}$ of $\left\{\begin{array}{l}\text { Potassium } \\ \text { Calcium } \\ \text { Magnesium and } \\ \text { Iron. }\end{array}\right.$

Nitrogen in the form of nitrates and as ammonia is taken up by the plant through its roots. Legumes (peas, clover, etc.) possess the power of fixing the free nitrogen of the air through the intermediate action of certain species of bacteria harbored by the roots. Otherwise such nitrogen is not directly available for plant growth.

3. Water required by plants.- Water, as we may judge from its abundance in plants, is of the highest importance to them. Half-grown clover plants may contain as much as 92 per cent. water, or more than is found in skim milk. The turnip contains from 87 to 92 per cent. water. When a crop of corn is partially grown, nine-tenths of its whole weight may be water. Plants exhale a large amount of water through their leaves during growth. A sunflower plant 3.3 feet high has been known to exhale 1.25 pounds of water through its leaves during twelve hours. Lawes and Gilbert found in the moist climate of England, that wheat, barley, beans, peas and clover exhaled during five months of growth about 200 times their dry weight of water. King, of the Wisconsin Station, 1 measuring the water given off through leaf evaporation as well as by the soil supporting the plants, found that for each pound of dry matter produced by the plant in root, stem, leaf and seed, there were required for corn 301, for barley 401, and for oats 501 pounds of water. The transpiration of water by the leaves causes an upward progress of that liquid from the roots through the stem of at least 1.3 inches

\footnotetext{
1 Rept. 1891.
} 
per minute. Under certain conditions the upward movement of water in plant stems may exceed 30 inches per minute.

4. How plants gather food.-Carbonic acid, which is next to water in the amount utilized by plants, is taken up by them through the medium of the leaves. Ten thousand volumes of air contain about three volumes of carbonic acid gas; thirty-two hundred cubic yards of air hold one pound of this gas. An acre of growing wheat will gather during four months one ton of carbonic acid gas, or an amount equal to all the air contrins over the same area of land to a height of three miles.

In the leaves of plants, mostly on their under side, are numerous minute openings leading into the interior. Air passing through these carries with it carbonic acid, which is absorbed by the leaf cells. The feeding roots of plants are clothed with minute hairs, which take up water from the soil, together with mineral matter and nitrogen compounds in solution. There are no direct open ings in these root hairs, the material being taken up by diffusion. Roots are capable of dissolving and absorbing solid ingredients from the soil particles with which they come in contact. Though they take up some matter which is useless to the plant, roots exercise a very considerable selective power in the materials absorbed, and do not seem to gather plant food indiscriminately.

5. Plant building.- Having learned what the plant lives upon and how it gathers its food, let us consider how it grows. In the active cells, especially those of the leaves, there is found a translucent, jelly-like substance called protoplasm. The life of the plant may be said to exist in this protoplasm. The green coloring of leaves and stems is due to a substance called chlorophyll coni tained within the protoplasm. Chlorophyll is formed only in sunlight. The carbonic acid gas gathered by the leaves is absorbed by the cells containing protoplasm charged with chlorophyll. The plant everywhere is bathed with juices called "sap," a very large portion of which is water brought in by the roots. in this sap are mineral matter and nitrogen compounds. And now for the wonderful transmutation.

The carbonic acid gas and water commingling in the cells are decomposed and their atoms re-arranged and welded into a new 
substance by the energy of sunlight and heat guided by the life principle of the protoplasm with its chlorophyll. The result of the union of the gas and water is starch, with some oxygen left as a by-product. The oxygen escapes to the air, while the starch is retained by the plant for manifold uses. It is possible that starch is not the first substance formed, but it is the first with which we have to deal.

6. Starch.-The great building material of the plant is starch. The plant has use for little or none of the starch in the cells where it is manufactured, but requires it elsewhere. Being insolable in water and forming in cells which are closed sacs, the starch cannot be transferred to other parts of the plant in its original form. The difficulty is overcome by the protoplasm of the cell changing the starch into sugar and soluble substances closely allied to starch, as we shall presently see. Sugar is soluble in the juices of the plant, and by diffusion it is readily transferred from cell to cell until it reaches the place where needed. The principle which renders starch soluble is an unorganized ferment called "diastase," which can change two thousand times its own weight of starch into soluble compounds.

The walls of the innumerable cells of the plant framework are constructed of cellulose, a substance having the same composition as starch. Where growth occurs in the enlarging plant, the newlyformed cells are tender and filled with protoplasm. Each cell divides into two or more cells, the newly-formed members growing to full size. The cell walls thas enlarged are built of soluble sugar changed to insoluble cellulose through the action of protoplasm.

7. Growth from the chemist's standpoint. - Let us review the subject of plant growth, as we have studied it to this point, from the position of the chemist, in order to fix more clearly in mind the process of plant growth.

With the chemist, " $\mathrm{O}$ " stands for oxygen, " $\mathrm{H}$ " for hydrogen, " $\mathrm{C}$ " for carbon. Water is composed of two atoms of hydrogen chemically united with one of oxygen. This molecule, which is the smallest division of the water particle, they symbolize as $\mathrm{H}_{2} \mathrm{O}$. In the same manner carbonic acid gas is indicated by $\mathrm{CO}_{2}$. 
The chemist writes the substances formed from carbonic acid gas and water in the plant thus:

$$
\begin{aligned}
& \left.\begin{array}{l}
\text { Starch } \\
\text { Cellulose }
\end{array}\right\} \mathrm{O}_{12} \mathrm{H}_{20} \mathrm{O}_{10} \\
& \text { Cane sugar } \mathrm{O}_{12} \mathrm{H}_{22} \mathrm{O}_{11} \\
& \text { Glucose } \quad \mathrm{C}_{12} \mathrm{H}_{24} \mathrm{O}_{12}
\end{aligned}
$$

Let us now consider from the chemist's standpoint how starch may be formed by the plant from carbonic acid and water, and, when once formed, how it may be changed to singar, glucose or cellulose.

This may be shown by the following equations:

Taken in by the plant.

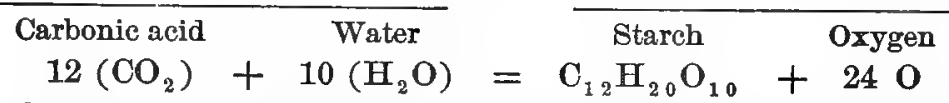

Starch by the addition of one part of water becomes cane sugar; thus:

$$
\begin{aligned}
& \text { Starch } \\
& \mathrm{C}_{12} \mathrm{H}_{20} \mathrm{O}_{10}
\end{aligned}+{ }_{\mathrm{H}_{2} \mathrm{O}}^{\text {Water }}=\begin{gathered}
\text { Cane sugar } \\
\mathrm{C}_{12} \mathrm{H}_{22} \mathrm{O}_{11}
\end{gathered}
$$

Cane sugar plus one part of water becomes glucose, thus:

$$
\begin{gathered}
\text { Cane sugar } \\
\mathrm{C}_{12} \mathrm{H}_{22} \mathrm{O}_{11}
\end{gathered}+\mathrm{H}_{2} \mathrm{O}=\begin{gathered}
\text { Water } \\
\mathrm{C}_{12} \mathrm{H}_{24} \mathrm{O}_{12}
\end{gathered}
$$

In the above we observe that 12 molecules of carbonic acid united with 10 molecules of water form 1 molecule of starch with 24 atoms of oxygen remaining. By the second equation we learn that if one molecule of water is added to the starch molecule, a molecule of cane sugar results. The addition of another molecule of water to cane sugar gives glucose. The removal of one molecule of water from cane sugar and two from glucose reduces these substances back to starch, or to cellulose.

In the above cases the hydrogen and oxygen stand in the same relation to each other as in water, there being two atoms of the former to one of the latter. For this reason, starch, cane sugar, cellulose and similar substances are called carbohydrates. ${ }^{1}$

8. Plant oils. - Another group of building materials found in the plant comes under the term "fats" or "oils." Though they

1 For information concerning scientific and technical terms the student will consult the Glossary at the end of the volume. 
are composed of the same three elements found in the carbohydrate group, the hydrogen atoms are not always twice the number of oxygen atoms. These oils are usually compounded of several simple oils, the principal of which, with their formulæ, are as follows:

$$
\begin{aligned}
& \text { Stearin } \mathrm{C}_{57} \mathrm{H}_{110} \mathrm{O}_{6} \\
& \text { Palmitin } \mathrm{C}_{51} \mathrm{H}_{98} \mathrm{O}_{6} \\
& \text { Olein } \quad \mathrm{O}_{57} \mathrm{H}_{104} \mathrm{O}_{6}
\end{aligned}
$$

Oils give off much more heat during combustion than the carbohydrates because they contain a relatively larger quantity of carbon. While found in nearly all parts of the plant, the oils and fats are chiefly stored in seeds, as flax, cotton, rape, etc. Oats, wheat and corn contain some fats or oils.

9. Protein compounds. - Thus far we have considered the plant compounds which result from the union of the three elements, carbon, hydrogen and oxygen. We now come to a more complex group of plant substances containing two additional elements, viz., nitrogen and sulfur. It is held that the nitrates taken up through the roots of plants on reaching the protoplasmic masses in the active cells are broken up, and the nitric acid and sulfur are united with starch or a starch derivative, forming a protein compound. Protein substances may be produced in protoplasmic masses which may or may not contain chlorophyll. The protoplasm of active cells, where the work of assimilation goes on, is itself a protein substance. Very little protein is found in the woody, older portions of the plant, the greater amount existing at the point of growth and in the seeds or reproductive parts. In the seed the protein exists quite largely in the germ itself, and also in the surrounding envelopes. For a definition of protein, see Glossary. The protein compounds of plants are divided into two groups - albuminoids and amides.

10. The albuminoids. - One group of protein substances is characterized by the term "albuminoids." Vegetable albumen closely resembles the white of egg, and like it, is coagulated by heat. Gluten, another albuminoid, is found in the wheat grain. It may be separated from the starchy portion of wheat flour by washing the dough in running water, the sticky mass 
. remaining constituting crude gluten. The nitrogenous portion of beans, peas, clover seeds, etc., is likewise an albuminoid called "legumin."

II. Amides.-The amides are nitrogenous bodies which are crystalline and soluble in water. Being soluble, they can pass through the cell walls of plant tissues, and thus are capable of 1 diffusing from one part of the plant to another. Since the amides :re found in the immature and growing parts of plants, it is probable that their function is the transfer of organized nitrogen rrom one part of the structure to another in the process of plant building.

12. Mineral compounds.-Though occurring in relatively small amounts, mineral matter in various combinations is essential to the life and development of all plants. The elaboration of food materials in the protoplasmic masses referred to in the previous paragraph, as well as the development of the young plants from the seed, require the presence of mineral matter, which is found everywhere in the plant substance. The leaves of plants contain more ash or mineral matter than the other portions. This is probably due to the constant evaporation of water from the leaves, the ash matter in solution being left behind.

13. The end of plant effort.-If we study the life history of an individual plant we observe that its first effort is directed toward self-establishment and enlargement. All of the food elaborated from the compounds taken from air and soil is transferred to the growing parts, that the plant may be built up and reach perfection. As the period of maturity approaches, all the energies of the plant are changed to that of reproduction or multiplication. The food materials, which were at first used for leaf multiplication and enlargement or for the growth of more and larger stems and roots, are now joined into a current which flows to the reproductive parts. First come the blossoms, and then the young, enlarging fruits. Into these the sugars, protein compounds and mineral substances gathered from air and soil, and elaborated in the green parts, are poured in a steady current. The wheat plant resulting from a single kernel bears a hundred fruits in the shape of grains; the Indian corn plant may produce 
a thousand fold. In each of these grains is a miniature plant, the germ; about which is stored a generous supply of nutriment. This is placed in compact, concentrated form, awaiting the time when the germ begins life on its own account. In the potato tuber there is a liberal storage of starch. In the beet root the stored materials are held in the form of cane sugar, reserved for seed production the following season. Each germ, or reproductive part, is surrounded with food elements, arranged after nature's choicest plan to aid in reproduction.

14. The sun the source of plant life.-Thus far we have spoken of the plant as though it accomplished all these wonderful transmutations through self-contained powers. This is incorrect. A plant can no more unite the elements of carbonic acid and water into starch, or move this starch, changed to sugar, to needed points, than can the wheels of a great factory move without the impelling force of steam or the electric current. The source of all life and power is the sun, the energy of which in the shape of light and heat is absorbed by the protoplasmic mass and its chlorophyll particles. In the plant cells the all-powerful energy of the sun, guided by the mysterious principle of life, works all the wonderful transmutations we have recorded.

15. Plants the support of animal life.- Nature has decreed that it is the function of the plant, through the sun, to build inorganic compounds into organic matter, in which operation the energy employed becomes latent. Through digestion and absorption the various plant compounds are incorporated in the animal body, or are broken down within it into simpler componnds than those of the plant structure. In this dissolution the energy which was hidden in the plant is again revealed in all the manifestations of animal life. In the coal burning in the grate we observe the re-appearance of the energy of the sun which was stored in plants ages ago. In the stalks and ears of corn which we feed to cattle, we are furnishing energy received from the sun and rendered dormant in plant building during the previous summer. When supplying plants and seeds to the animals under his care, the stockman observes in their growing bodies warmed by internal tires the energy of the sun transmitted by the plant to the animal. 


\section{How the Chemist Groups Plant Substances.}

16. Illustrations. - The agricultural chemist divides plant sub. stances into groups, differing in some cases from those made by the physiological chemist. In the following table a few stock feeds are shown as grouped by the agricultural chemist, such presentation being for the purpose of guiding the student in his consideration of this subject.

Composition of certain American feeding stuffs, as arranged by the agricultural chemist.

\begin{tabular}{|c|c|c|c|c|c|c|c|}
\hline \multirow[b]{2}{*}{ Feeding stuffs. } & \multirow{2}{*}{ 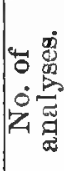 } & \multicolumn{6}{|c|}{ Percentuge composition. } \\
\hline & & Water. & Ash. & Protein. & $\begin{array}{l}\text { Crude } \\
\text { fiber. }\end{array}$ & $\begin{array}{l}\text { Nitro- } \\
\text { gen-free } \\
\text { extract. }\end{array}$ & $\begin{array}{l}\text { Ether } \\
\text { extract. }\end{array}$ \\
\hline $\begin{array}{r}\text { Fresh pasture } \\
\text { grass................. }\end{array}$ & 10 & 75.3 & 2.5 & 4.0 & 5.9 & 11.4 & .9 \\
\hline Mangels............. & 9 & 90.9 & 1.1 & 1.4 & .9 & 5.5 & .2 \\
\hline 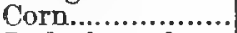 & 86 & 10.6 & 1.5 & 10.3 & 2.2 & 70.4 & 5.0 \\
\hline Red clover hay.. & 38 & 15.3 & 6.2 & 12.3 & 24.8 & 38.1 & 3.3 \\
\hline
\end{tabular}

The first columm presents the names of the feeding stuffs examined. The second column states the number of analyses from which the subsequent data are derived. As a rule these analyses have been made by chemists at different points in the country, so that when a considerable number have been secured we may regard the average as representative of the plant or plant substances under consideration. The remainder of the table comes under the general heading "Percentage composition." Let us consider its several divisions.

17. Water.-The chemist places a small quantity of the food material, usually finely divided by chopping or grinding, into a small vessel and ascertains its weight. The balance used is so delicate that a thimbleful of corn meal can be weighed with a smaller percentage of probable error than is usual when a farmer weighs a wagon-load of corn on a good scale. The sample is then placed in an oven, where it is dried at a temperature of $212^{\circ}$ Fahr. for several hours, or until a constant weight is secured. The heat drives off the water, and the difference between the two 
weights represents the amount of water which the sample originally contained.

We learn by the third column of the table that the water in pasture grass is 75.3 per cent. of the whole amount; that is, such grass is about three-fourths water. Corn carries 10.6 per centof water, while red clover hay contains $\mathbf{1 5 . 3}$ pounds to the hunared weight.

18. Ash.- Having determined the water in the sample, the chemist next burns it to ascertain its ash content. Care is taken that no charcoal is left, only the clear ash remaining. The next column shows the percentage of ash in the feeding stuffs under consideration. In 100 pounds of pasture grass there are 2.5 pounds of ash. Indian corn has only 1.5 pounds of ash for 100 of grain, while red clover hay yields 6.2 pounds. This large amount comes in part from the accumulation of ash in the leaves of the clover plant, and in some measure is due to earth washed up on the stems of the plant by rain, and to the dust which settles on plants, and on hay before it is placed in the barn. Such foreign material is really not ash, but of necessity is reporter as such.

19. Protein.-The process of determining the protein in a feeding stuff is too complicated for presentation here. Suffice it to say that the nitrogen contained therein is determined, and that the sum so secured is multiplied by 6.25 to determine the protein, since it has been found that about 16 per cent. of protein substances consist of nitrogen. By the table we find that the protein of pasture grass amounts to 4 , mangels to 1.4 , corn to 10.3 , and red clover hay to 12.3 pounds per hundred weight. $W_{e}$ are shown that pasture grass is much richer in protein than are mangels, and that clover hay is likewise richer than the grain of the corn plant.

20. Crude fiber.- The amount of crude fiber is determined by boiling a sample of the fodder successively in weak acid and alkali solutions, which dissolve all the softer parts. That which remains after washing is called "crude fiber." It consists for the most part of cellulose, which, as we have already learned, constitutes the framework of the plant. Corn grains contain only 
2.2 per cent. crude fiber, while clover hay yields nearly 25 per cent.

21. Ether extract or fat.-A sample of the fodder, dried so as to be free from water, is treated with ether, which has the power of dissolving fat, wax, resins and similar substances. The matter extracted by ether is quite commonly called "fat" in works on plant analysis. In this book it is always spoken of as "ether cxtract." In seeds nearly all the ether extract is fat or oil, and has a corresponding feeding value. In plant leaves and stems much of the ether extract is wax, chlorophyll and other substances of lower feeding value than fat. Mangels are shown by the table to yield only .2 of a ponnd of ether extract per 100, while corn reaches 5 per cent.

22. Nitrogen-free extract. - Nitrogen-free extract signifies what is left of the organic matter of the plant after deducting the preceding groups of compounds. It contains starch, sugar, pentosans, gums, organic acid and other bodies. The nitrogen-free extract and the crude fiber together constitute the carbohydrates of the plant physiologist. Nitrogen-free extract is determined by difference. The total dry matter in the fodder, minus the ash, ether extract, crude fiber, and protein equals the percentage of nitrogen-free extract present. The great difference between plants and seeds as to woody matter is shown in the table. Over 70 per cent. of the substance of corn and only about 38 per cent. of clover hay is nitrogen-free extract. 


\section{CHAPTER $\Pi$.}

MASTIOATION, DIGESTION AND ABSTMTLATION. 1

23. Prehension.-The horse when grazing gathers herbage with the lips, which are very sensitive, and act with great mobility. The food thus gathered is severed with the incisor or front teeth of the upper and lower jaws. When feeding on hay and grain, the horse still makes free use of the lips in working the food into the mouth.

The ox seizes herbage with the outstretched tongue, and by a swinging motion of the head severs it as it passes between the teeth in the lower jaw and the cartilaginous pad of the upper jaw.

The sheep, like the ox, has no teeth in the upper jaw; like the horse, it makes free use of the lips when grazing. The horse in grazing crops the herbage nearer to the ground than does the ox, and the sheep still closer than the horse.

The shape and direction of the front teeth of the hog show an omniverous feeder. Probably the grazing quality of the hog varies considerably with the breed, and also in different strains of the same breed, the skulls and jaws of hogs presenting remarkable variations in size and shape.

24. Mastication.-The food consumed by the animal is reduced to fineness by the molar teeth, assisted by the lips, tongue and cheeks, which pass it to the place for grinding and hold it in position. With herbivorous animals the lower jaw is much narrower than the upper. In the horse, when the upper and lower grinders of one side are in contact, those of the lower jaw on the other side are nearly or quite an inch to the inside of their mates above, so that grinding is possible on but one side of the mouth at a time. As mastication proceeds, the feed is mixed

${ }_{1}^{1}$ Most of the text and tables in this chapter are adapted from the Physiology of the Domestic Animals, by Robert Meade Smith, which excellent work should be consulted by the student seeking further information on these subjects. 
with saliva poured upon it from glands opening into the mouth at several points. The food materials in the mouth are gradually formed into a rounded mass or bolus for swallowing. Colin estimates that a horse requires one and one-fourth hours to masticate four pounds of dry hay, and that this amount will make from sixty to sixty-five boluses, the rate of mastication being from sixty to eighty strokes of the teeth per minute. Saliva aids mastication, and a suppression of the flow prolongs the operation. Colin diverted the flow of saliva by fistulas or openings, and recorded results as follows:

Time required by the horse in masticating hay - Colin.

\begin{tabular}{c|c|c|c}
\hline & $\begin{array}{c}\text { All the saliva } \\
\text { poured into } \\
\text { the mouth. }\end{array}$ & $\begin{array}{c}\text { Saliva of } \\
\text { one parotid } \\
\text { escaping. }\end{array}$ & $\begin{array}{c}\text { Saliva of } \\
\text { both parotids } \\
\text { escaping. }\end{array}$ \\
\hline Average duration of mastica- & & & \\
tion of one bolus, seconds.. & 31.7 & 34.2 & 74.8 \\
Strokes of teeth, number..... & 38.6 & 36.6 & 74.1 \\
\hline
\end{tabular}

The molar or grinding teeth of the horse wear faster than the incisors or cutting teeth, and the former would soon fail to meet were it not that the incisors with increasing age gradnally incline forward, forming a sharper and sharper angle. The seeds of plants are not all crushed during mastication, and those escaping are distributed over the fields in the excreta, often still possessing ability to germinate.

25. Insalivation.- While the food is being ground, it is modified by the saliva poured upon it from glands situated about the mouth cavity. By means of ingenious experiments, Colin determined the amount of saliva secreted by the horse, and found that when feeding on hay there was poured out from eleven to thirteen pounds of saliva per hour. Oats require a little more than their own weight, green fodder half, and dry fodder four times its weight of saliva during mastication. If the food of the horse for one day amounts to 11 pounds of hay and 11 pounds of other dry fodder, this will require four times its weight of saliva, or 88 pounds, to which must be added 4.4 pounds secreted during rest, making 92.4 pounds in all. 
Smith ${ }^{1}$ states that the ox secretes 112 pounds of saliva daily. In the horse the parotid glands, located at the base of the upper jaw and emptying near the second molar teeth, yield seven-tenths of all the saliva secreted.

Animals chew their food on one side of the mouth only at a time. It has been found that the parotid gland of the horse yields saliva only on the side where the food is being masticated, the other gland resting until grinding starts up on its side. The chemical composition of mixed saliva, which varies somewhat in different animals, is given for the horse as follows:

Water 992.00

Mucus and albumen.

Alkaline carbonates 1.08

Alkaline chlorids

Alkaline phosphates and phosphate of lime traces.

1000.00

The mechanical use of saliva has been mentioned; it serves a second and higher purpose. Saliva contains ptyalin, a soluble ferment which converts the starch of the food into sugar. It acts only upon the starchy matters of the food and not upon the cellulose or other constituents. Since the food remains in the mouth a comparatively short time, but little starch can be changed to sugar before the mass is swallowed. The action of the saliva on starch continues in the stomach.

26. Deglutition. - The bolus or rounded mass of food formed by the action of the teeth, the cheeks and the tongue is forced into the ossophagus or gullet and on into the stomach. The gullet of the horse being comparatively small, the boluses do not exceed an inch or an inch and a half in diameter; in the ox they may be double that size.

27. Gastric digestion.- The stomachs of our domestic animals vary greatly in size, that of the hog holding 7 to 9 quarts, the horse 17 to 19, and the ox over 300 quarts. Colin, who gives the above data, found 145 pounds of air-dry fodder in the first three compartments of the stomach of a cow which had fasted two

\footnotetext{
1 Physiology of the Domestic Animals.
} 
days. The stomach of the ox is never without considerable con'snt, even after long starvation. The digestion of the starchy matter of the food through action of the saliva continues in the stomach. After the food enters the stomach a churning motion is set up which causes it to travel from the place of entrance toward the exit. While this motion is going on, a fluid is being poured upon it from the lining of the stomach. This fluid is at tirst alkaline, but gradually becomes more and more acid.

The amount of gastric fluid poured out has not yet been defiuitely determined. Some writers place it as high as one-fourth the weight of the body daily, others a tenth, and others even less.

The composition of the gastric fluid of the sheep is as follows:

Water ............................................. 986.14

Organic matter (especially ferments)........... 4.05

Sodium chlorid ................................... $\quad 4.37$

Calcium chlorid ................................. 0.11

Hydrochloric acid............................... 4.05

Potassium chlorid ................................ 1.52

Ammonium chlorid................................ $\quad 0.47$

Calcium phosphate................................ 1.18

Magnesium phosphate ............................ 0.57

Ferric phosphate.................................. 0.33

The constituents of the gastric juice which effect changes are pepsin, rennet and acid. Pepsin is a soluble ferment which acts upon the food only in the presence of dilute acid. Rennet has the power of curdling milk, one part coagulating 400,000 parts if casein. Cane sugar is not fermentable and cannot be assimilated until it is changed to glucose and laevulose. Hydrochloric ucid is present in considerable amount in the gastric juice. Cane sugar in the food is slowly changed by this acid into laevulose and glucose. The main action of the gastric juice is, however, in converting the albuminoids into peptones, leaving the fatty matter and cellulose to be attacked later. The stomach of the horse is so small that it cannot contain a full feed at one time, and consequently that portion which is first eaten is usually pushed on from the stomach into the small intestines before it has been long acted on by the gastric juice. 
28. Gastric digestion of ruminants. - The stomach of the or and sheep is large and has four apartments, viz. - the rumen, c. paunch, the first stomach; the honey comb or reticulum, the seconid stomach; the manyplies or omasum, the third stomach; and the fourth stomach, called the rennet or abomasum. The fourth stomach corresponds to the single stomach of non-ruminants, the horse, pig, etc. After mastication the food passes from the mouth into the pannch, or first stomach. The first three stomachs secrete no fluid. In the rumen the food becomes very soft and moist, owing to the large amount of saliva secreted and because most of the water drank passes into it. The action of the saliva in converting starch into sugar continues, and a very considerable amount of cellulose may be digested through fermentations, which are favored by the high temperature and the moisture of the contents. The main purpose of the rumen is to serve as a storehouse for food. The second stomach, or reticulum, which is really a chamber or part of the paunch, contains much fluid, and serves to force the food into the cesophagus for rumination. The food, being returned to the mouth, is reduced to greater fineness by chewing, after which it is again swallowed. The second time it passes either to the rumen or the third stomach. It is probable that on being re-swallowed most of the food again drops back into the paunch, and from here the finer portions are forced directly into the third stomach. Like the first and second, the third stomach gives off no secretions, and whatever changes occur in it must be due to the action of the saliva or to fermen. tations begun in the two preceding stomachs. The action of the first three stomachs on food is preparatory, for the most part, to what occurs in the fourth. The food having been thoronghly prepared by re-chewing and by maceration in the first three stomachs, digestion goes on rapidly in the fourth. Here, as in the stomach of the horse, the albuminoids are changed to peptones. Tissues are dissolved and their oil contents set free. Cane sugar is to some extent converted into invert sugar by the action of acid. Starch which escapes conversion into sugar in the rumen passes on into the intestines. Owing to the very thorough preparation of the food in the first three stomachs, gastric diges- 
tion in the true stomach of the ox and sheep is more perfect than in that of the horse and pig. In suckling ruminants the first three stomachs are less developed than in grown animals. Colin found that the rumen of a calf held 2.6 pounds, the reticulum .22 , the manyplies .35 pounds, and the abomasum, or true stomach, 7.7 pounds. As the diet of the animal is changed to solid food, grass, hay and grains, the first stomach gradually increases in size, and attains the proportionate volume which it has in grown-up animals. It then holds nine times as much as the other three stomachs combined.

29. Bile.- Passing into the small intestine, the food is subjected to the action of three other secretions,- bile, pancreatic juice and intestinal secretion.

The bile is a greenish fluid of a neutral or alkaline reaction secreted by the liver, the largest single organ of the body. The composition of bile is given as follows:

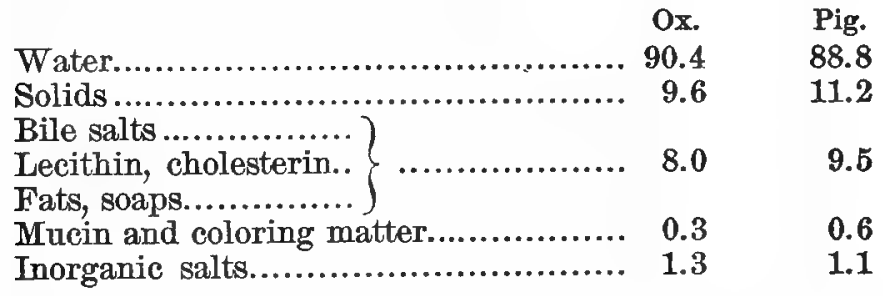

According to Colin the liver of the horse forms over 13 ponnds of bile, the ox 5.7, and the sheep .75 pounds each 24 hours. The flow of bile is continuous, increasing somewhat as the food passes into the small intestine. Bile contains a ferment in small amounts capable of converting starch into sugar. Its main use is to aid in the absorption of fats. In the small intestine some of the fat of the food is broken up into glycerin and fatty acids; the latter unite with the alkalies of the bile and pancreatic juice and form soaps. These soaps aid in forming and holding the remaining fat in permanent emulsion. Bile facilitates the passage of the emulsified fat through the membranes of the intestines, thus aiding in its absorption. It is not only a secretion in aid of digestion, but also an excretion or waste product. It prevents putrefaction and decomposition of the food in the intestinal canal. 
30. Pancreatic juice. - This colorless, alkaline fluid, secreted by the pancreas or "sweet breads," is poured into the intestine at the same time and at about the same point as the bile, so that these fluids act together. The pancreatic secretion contains more solids than the others mentioned, and has therefore a high specific gravity. It is closely allied to blood serum in composition, and contains four ferments, one of which splits fats into glycerin and fatty acids; another converts starch into sugar; a third resolves protein compounds into soluble peptones, while a fourth curdles milk. In one way the pancreatic juice resembles saliva, in that it converts starch into sugar. One part of the active ferment of the-pancreatic fluid vill convert 40,000 times its own weight of starch into sugar and dextrin. Like bile, it converts fat into fatty acids and glycerin; like pepsin, it converts protein substances into peptones. Unlike the gastric juice, the pancreatic secretion acts upon protein in an alkaline solution. Colin and others place the maximum secretion of pancreatic juice in the horse at three-fifths of a pound per hour.

31. Large intestine.-The processes of digestion are continued in the large intestine (colon) of the Herbivora. The stomach of the horse being small, that organ together with the small intestine has not sufficient capacity to accommodate the bulky, comparatively indigestible food usually supplied this animal, and is supplemented by the large intestine, which has a capacity of five or six times the stomach, permitting the retention of a large quantity of food. The large intestine of the ox, which is smaller in proportion than that of the horse, serves the same purpose.

The main office of the large intestine is to serve as a storage place for the mixed food materials and digestive juices coming from the small intestines, allowing continued action by the latter. Here a partial digestion of cellulose takes place through fermen. tations, all of the juices secreted by the various digestive organs being without effect on this component. The digestion of cellulose is as yet not olearly understood, but it seems that under certain conditions gaseous products, mainly marsh gas, are formed in its fermentations. The value of cellulose has for this reason been questioned, but the best authorities hold that the digestive 
portion possesses considerable nutritive value, although not as much as starch or sugar.

32. Intestines and stomachs of farm animals. - The length and capacity of the intestines and the capacity of the stomach of different farm animals are as follows:

Length of intestines and capacity of stomachs of farm animats.

\begin{tabular}{|c|c|c|c|c|c|c|}
\hline \multicolumn{4}{|c|}{ Length of intestine. } & \multirow{2}{*}{\multicolumn{3}{|c|}{$\begin{array}{c}\begin{array}{c}\text { Capacity of stomach and } \\
\text { intestine. }\end{array} \\
\text { Average capacity. }\end{array}$}} \\
\hline \multirow[b]{2}{*}{ Animal. } & \multirow{2}{*}{ 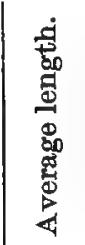 } & \multirow{2}{*}{ 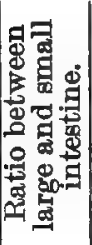 } & \multirow{2}{*}{ 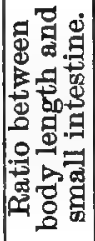 } & & & \\
\hline & & & & & 慝 & 高 \\
\hline \multirow[t]{2}{*}{$\begin{array}{l}\text { Horse. } \\
\text { Small intestine.... } \\
\text { Large intestine.... }\end{array}$} & \multirow[t]{2}{*}{$\begin{array}{l}\text { Feet. } \\
73.6 \\
24.5\end{array}$} & \multirow[t]{2}{*}{$\begin{array}{l}3 \\
1\end{array}$} & \multirow[t]{2}{*}{$1: 12$} & \begin{tabular}{|l|} 
Horse. \\
Stomach*......... \\
Small intestine.. \\
Large intestine..
\end{tabular} & $\begin{array}{r}19.0 \\
67.4 \\
137.4\end{array}$ & $\begin{array}{r}8.5 \\
30.2 \\
61.3\end{array}$ \\
\hline & & & & Total capacity.... & 223.8 & 100. \\
\hline \multirow[t]{2}{*}{$\begin{array}{l}\text { Ox. } \\
\text { Small intestine.... } \\
\text { Large intestine.... }\end{array}$} & \multirow[t]{2}{*}{$\begin{array}{r}150.9 \\
\mathbf{3 6 . 3}\end{array}$} & \multirow[t]{2}{*}{$\begin{array}{l}4.1 \\
1\end{array}$} & \multirow[t]{2}{*}{$1: 20$} & $\begin{array}{l}\text { Ox. } \\
\text { Stomach............. } \\
\text { Small intestine.. } \\
\text { Large intestine.. }\end{array}$ & $\begin{array}{r}266.9 \\
69.7 \\
40.1\end{array}$ & $\begin{array}{l}70.8 \\
18.5 \\
10.7\end{array}$ \\
\hline & & & & Total capacity.... & 376.7 & 100. \\
\hline \multirow[t]{2}{*}{$\begin{array}{l}\text { Bheep. } \\
\text { Small intestine.... } \\
\text { Large intestine... }\end{array}$} & \multirow[t]{2}{*}{$\begin{array}{l}85.9 \\
21.4\end{array}$} & \multirow[t]{2}{*}{$\begin{array}{l}4 \\
1\end{array}$} & \multirow[t]{2}{*}{$1: 27$} & $\begin{array}{l}\text { Sheep. } \\
\text { Rumen.............. } \\
\text { Reticulum ........ } \\
\text { Manyplies......... } \\
\text { Abomasum..... } \\
\text { Small intestine.. } \\
\text { Large intestine.. }\end{array}$ & $\begin{array}{r}24.7 \\
2.1 \\
1.0 \\
3.5 \\
9.5 \\
5.9\end{array}$ & $\begin{array}{r}52.9 \\
4.5 \\
2.0 \\
7.6 \\
20.4 \\
12.7\end{array}$ \\
\hline & & & & Total capacity.... & 46.7 & 100. \\
\hline \multirow[t]{2}{*}{$\begin{array}{l}\text { Hog. } \\
\text { Bmall intestine..... } \\
\text { Large intestine.... }\end{array}$} & \multirow[t]{2}{*}{$\begin{array}{l}60.0 \\
17.1\end{array}$} & \multirow[t]{2}{*}{$\begin{array}{l}3.5 \\
1\end{array}$} & \multirow[t]{2}{*}{$1: 14$} & $\begin{array}{l}\text { Hog. } \\
\text { Stomach.......... } \\
\text { Small intestine.. } \\
\text { Large intestine.. }\end{array}$ & $\begin{array}{r}8.5 \\
9.7 \\
10.8\end{array}$ & $\begin{array}{l}29.2 \\
33.5 \\
37.3\end{array}$ \\
\hline & & & & Total capacity.... & 29.0 & 100. \\
\hline
\end{tabular}

* Chauveau, Comparative Anatomy of the Domestic Animals, places the capacity at 3 to 3.5 gallons. 
Food requires from three to four days to pass through the whole digestive tract of farm animals. The last traces do not pass until considerably later. According to Weiske, ${ }^{1}$ it takes from seven to eight days before the last traces pass the digestive canal in case of the sheep. (541)

33. The intestinal juice.-The juices secreted by the small glands along the inner walls of the small intestine contain three ferments which act upon starch, cane sugar and protein. Starch is readily converted into sugar by the intestinal juice in a neutral or faintly alkaline solution. The juice further contains a special ferment which changes cane sugar into glucose and laevulose.

34. Fermentations.- Numerous organisms which find their way into the small intestine along with food substances give rise to fermentations, causing the evolution of various gases, mainly air, carbonic acid, hydrogen, ammonia, sulfuretted hydrogen and marsh gas.

35. Absorption.-The stomach and intestines form a convoluted tube passing through the body. Food materials within this tube are still outside the body. The entrance of digestion products into the body is brought about by absorption, which is of two kinds. The inner walls of the digestive tract are everywhere lined with blood vessels, and substances soluble in water and readily diffusible, such as sugar, soaps, salts and peptones, enter the blood by diffusion.

The inner surface of the small intestine is also lined with conelike projections called "villi." The cells of these villi separate from the fluid contents of the intestines, sugar, fat, peptones, salts and other materials, and deliver them into ducts of the lymphatic system, by which they are carried forward toward the heart, to be mingled with the blood. The material drawn into the lymphatics by the villi is called chyle, a substance having a milky appearance owing to the fat held in suspension. The fat in the chyle of a horse may vary from 1 per cent. when fed on hay, to 3 per cent. when fed on oats. The composition of chyle is given in the table on the next page.

Journal f. Landw., 1878, p. 175. 
Composition of chyle.

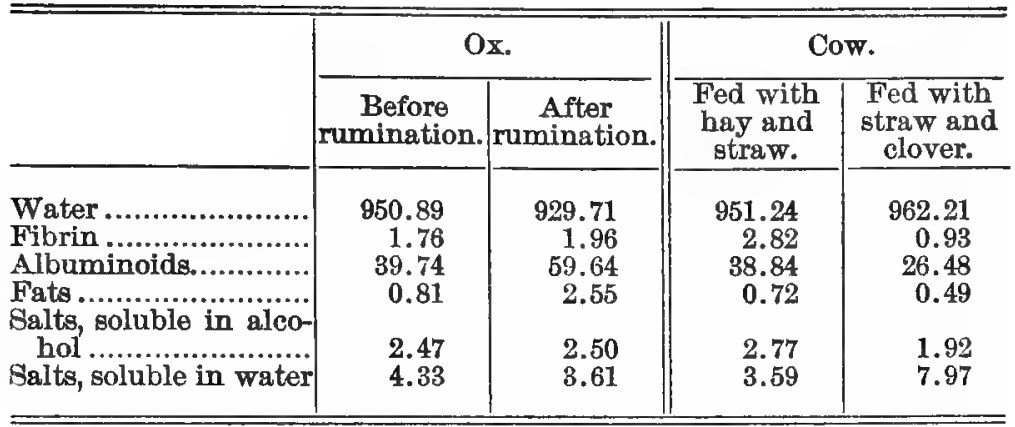

36. The circulatory system.-The arteries are the tubes or canals which carry the blood from the heart. As these tubes pass throughout the body they branch again and again, gradually growing smaller, until they end in minute divisions called capillaries. The ends of the capillaries connect in turn with the veins, which carry the blood back to the heart. The purified blood forced outward from the heart through the arteries reaches the capillaries, through which portions escape to nourish the tissues of the body. That which is not lost through the capillaries, together with the impurities gathered on the way, returns to the heart, whence it is forced to the lungs for purification. From these it returns to the heart, to be again forced over the body.

37. The lymphatics. - Besides the circulatory system there is a second one which drains the whole animal body toward the heart only, called the "Lymphatic system." The broken-down tissues of the body are removed through the lymphatic system, and the material thus drained is called lymph. Lymph varies in composition according to the stage of activity of the organs contributing it and the locality from which it is taken. Lymph and chyle, the one worn-out material from the tissues of the body, the other fresh material from the digestive tract, are poured through the lymphatics into the venous system and on to the heart, where they mingle with the blood current. It is estimated that for every 220 pounds body weight there are 7.5 pounds of lymph and 6 pounds of chyle formed daily. 
38. The blood.-Blood is the circulating medium of the body, bearing in its current both the elements of nutrition and waste. The composition of the blood of a horse is given as follows:

\section{Parts Venous Blood.}

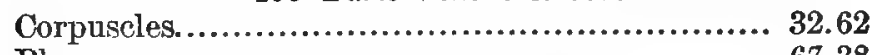

Plasma................................................. 67.38

100 Parts Plasma.

Solids ............................................... 9.16

Water ............................................ 90.84

Fibrin.............................................. 1.01

Albumen ......................................... 7.76

Fats ............................................... 0.12

Extractives ........................................ $\quad 0.40$

Soluble salts.......................................... 0.64

Insoluble salts .......................................... 0.17

The blood of the horse has been estimated at one-eighteenth the weight of the body. Colin places the blood of the ox at one twenty-third the body weight. Numerous attempts have been made to ascertain the time required for the blood to make a complete circuit of the body. Vierordt places the period of circulation for the horse at 31.5 seconds. In the case of the ox it is estimated that three pints of blood are driven through the left ventricle of the heart at each beat, and, since there are about fifty beats per minute, the circulation must be very rapid. The surging movement of the blood through the artery constitutes the pulse, and each movement marks a beat of the heart. The frequency of the pulse in our domestic animals has been placed as follows:

Beats per minute.

In the horse...................................... $36-40$

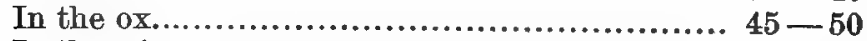

In the pig....................................... $70-80$

In the sheep...................................... $70-80$

The frequency of the pulse varies greatly with age, as shown by the following table:

Heart beats per minute.

\begin{tabular}{|c|c|c|}
\hline Newborn.......................... & $\begin{array}{c}\text { Horse. } \\
100-120\end{array}$ & $92 \stackrel{\text { Ox. }}{-132}$ \\
\hline 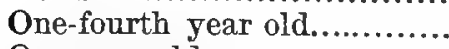 & $68-76$ & \\
\hline One year old....................... & $48-56$ & $50-6$ \\
\hline Four years of age & $38-50$ & $50-$ \\
\hline 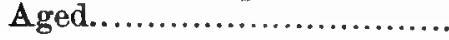 & $32-40$ & $45-50$ \\
\hline
\end{tabular}


39. Respiration.-We have seen that the blood is being constantly reinforced with nutriment. At the same time it is taking up the waste matter of the body which must be removed. This is accomplished in part by the lungs, into which the blood is forced from the heart. By a mechanical movement of the ribs the lungs are expanded and air is drawn into them. Respiration varies greatly in different animals, and at different ages for the same animal, as shown in the following table:

Respirations per minute.

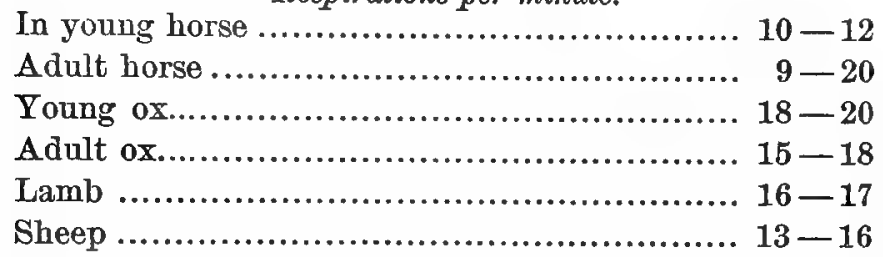

While in the lungs, the blood takes up oxygen from the inspired air, and the expired air carries with it carbonic acid and water eliminated by the blood. The difference between the air as it passes into the lungs and as it comes from them is shown in the following table:

$\begin{array}{llcc} & \text { Oxygen. } & \text { Nitrogeน. } & \text { Carbonic acid. } \\ \text { Inspired air contains...... } & 20.81 & 79.15 & .04 \\ \text { Expired air contains...... } & 16.033 & 79.557 & 4.38\end{array}$

The expired air therefore contains from 4 to 5 per cent. less oxygen and that much more carbonic acid than the inspired air. Considerable moisture also escapes with the expired air, and a small amount of other products in the form of organic matter. The amount of watery vapor given off by a man is estimated at 1.5 pounds per day.

40. Excretion from the kidneys. - A large portion of the water taken into the body is filtered from the blood as it passes through the kidneys, from which organs it is conveyed to the bladder. The amount of water excreted through the kidneys is dependent upon the quantity drank and that in the food.

Boussingault found the composition of the urine of a horse fed oats, clover and grass, a cow fed hay and potatoes, and a pig fed cooked potatoes, to be as follows: 


\begin{tabular}{|c|c|c|c|}
\hline 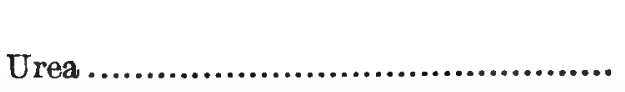 & $\begin{array}{c}\text { Horse. } \\
31.0\end{array}$ & $\begin{array}{l}\text { Cow. } \\
18.5\end{array}$ & $\begin{array}{r}\text { Pig. } \\
4.9\end{array}$ \\
\hline Potass. hippurate............................ & 4.7 & 16.5 & 0.0 \\
\hline Alkaline lactates............................. & 20.1 & 17.2 & $\ldots . .$. \\
\hline Potass. bicarb ............................... & 15.5 & 16.1 & 10.7 \\
\hline Mag. carb..................................... & 4.2 & 4.7 & 0.9 \\
\hline Calcium carb................................. & 10.8 & 0.6 & traces. \\
\hline Potass. sulph.................................. & 1.2 & 3.6 & 2.0 \\
\hline Sodium chlorid................................ & 0.7 & 1.5 & 1.3 \\
\hline Silica........................................ & 1.0 & traces. & 0.1 \\
\hline Phosphates..................................... & 0.0 & 0.0 & 1.0 \\
\hline Water and undetermined substances...... & 910.0 & 921.3 & 979.1 \\
\hline
\end{tabular}

41. Composition of urine.-The leading characteristic of urine is urea, which is the product of the decomposition of the albuminoid substances or tissues of the animal body. The other means of escape for this waste are so small that by measuring the nitrogen in the urine the nitrogenous waste of the body can be very closely determined, - a fact of the highest importance. (57) Most of the potash taken from the food passes away in the urine, while only a small amount of phosphates is contained therein. (419)

42. Excretions of the skin.- Water passes off through the sweat glands of the skin, carrying a very small per cent. of solids. The moisture given off by the sweat glands of a man is placed at from one to two pounds daily, although it may be increased to five pounds. The perspiration of animals has not been determined. Carbonic acid gas and traces of ammonia and free nitrogen are also given off by the skin.

43. Protein nutrition.-The nitrogenous substances of the food, as we have seen, are converted into soluble peptones, which are taken up by absorption, principally through the portal vein, only a small portion entering the lymphatics. In the blood the peptone is converted into serum albumen, which is conveyed to the capillaries, through which it passes, bathing and nourishing the tissues. The whole body is made up primarily of cells of various forms, modified to meet each requirement. Nourished by the serum albumen, the cells may divide again and again during 
growth, or, if no growth occurs, the serum albumen repairs the waste of body tissue incident to life and action.

44. Fat nutrition.- The fats contained in the food are largely absorbed unchanged in the form of an emulsion. A small percentage of fat enters the blood through the blood vessels lining the intestines, but the larger portion through the lymphatics. Though fats enter the circulation unchanged, they are generally in some manner modified by the animal consuming them, so that when built into fatty tissue that of each species has its own characteristies.

45. Carbohydrate nutrition.-The carbohydrates are converted into some form of sugar, which enters the blood by absorption from the intestinal canal. In the liver, sugar is converted into glycogen and held as reserve, or it is rapidly oxidized into carbonic acid and water, the intermediate products being unknown. Carbohydrates in excess of immediate requirement may be converted into fat and stored in the body. There is no starch in the body of animals. 
CHAPTER III.

DIGESTION, RESPIRATION AND CALORIMETRY.

I. Digestibility of Feeding Stuffs.

46. Variation in digestibility of feeding stuffs. - The leading vaality of feeding stuffs is digestibility. Milk is practically all ligestible. Most of the nutrients in corn meal yield to the ligestive solvents, while rye straw is of such character that a targe portion of its substance is indigestible, and therefore inert in the alimentary tract. In studying the digestibility of a given feed, the chemist first determines by analysis the percentage of each of the nutrients it contains. Weighed quantities of the feed are then given to some animal and the solid excrement voided during the trial is saved, weighed and samples of it analyzed. Knowing how much of each nutrient was fed and how much re-appears in the solid excrement, the difference is held to be the portion digested, since it must have been retained in the body.

47. A digestion trial with sheep.-As illustrating the manner of conducting digestion trials, the following description is given of one conducted by Armsby with sheep at the Wisconsin Station. ${ }^{1}$ Desiring to ascertain the digestibility of clover hay and malt sprouts by sheep, two wethers weighing 87 pounds each were selected for the trial. They were closely confined in separate apartments specially constructed for the purpose, and fed from zinc-lined feed boxes arranged to prevent the fodder from being wasted. Each day's ration was carefully weighed and samples reserved for analysis. The solid excrement as it passed from the wethers was collected by means of rubber-lined bags attached to the hind quarters of the animal by a light harness. These bags were emptied every twenty-four hours and the

Rept. 1884. 
contents weighed and sampled for analysis. Feeding progressed six days before the experiment began, in order that all residues of previous feed might have passed from the alimentary tract. During the first period each sheep was fed 700 grams (about 1.5 pounds) of clover hay daily, this allowance being consumed without waste. Water was freely supplied. The average amount and composition of the food eaten, and the solid excrement voided daily, are summarized in the following table:

Digestion trial with sheep fed clover hay, average for one dayWisconsin Station.

\begin{tabular}{|c|c|c|c|c|c|}
\hline & $\begin{array}{c}\text { Dry } \\
\text { matter. }\end{array}$ & Protein. & $\begin{array}{l}\text { Crude } \\
\text { flber. }\end{array}$ & $\begin{array}{l}\text { Nitrogen } \\
\text {-free } \\
\text { extract. }\end{array}$ & $\begin{array}{c}\text { Ether } \\
\text { extract. }\end{array}$ \\
\hline 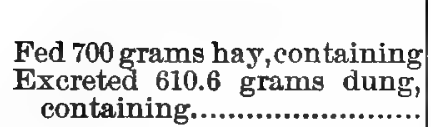 & $\begin{array}{r}\text { Grams. } \\
586.1 \\
288.6\end{array}$ & $\begin{array}{r}\text { Grams. } \\
77.7 \\
40.4\end{array}$ & $\begin{array}{c}\text { Grams. } \\
191.5 \\
101.5\end{array}$ & $\begin{array}{c}\text { Grams. } \\
276.7 \\
119.4\end{array}$ & $\begin{array}{r}\text { Grams. } \\
10.7 \\
7.9\end{array}$ \\
\hline 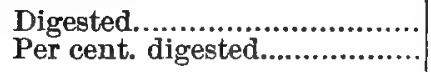 & $\begin{array}{r}297.5 \\
50.8\end{array}$ & $\begin{array}{l}37.3 \\
48.0\end{array}$ & $\begin{array}{l}90.0 \\
47.1\end{array}$ & $\begin{array}{r}157.3 \\
56.8\end{array}$ & $\begin{array}{r}2.8 \\
26.2\end{array}$ \\
\hline
\end{tabular}

The table shows that in the 700 grams of hay fed there were 586.1 grams of dry matter, and in the solid excrement for one day, 288.6 grams, leaving a difference of 297.5 grams, or 50.8 per cent., which is held to be the amount of dry matter digested for the first period of the first trial. The average for two trials was 51.2 per cent. Of the 77.7 grams of protein supplied in the ration, 40.4 grams appeared in the solid excrement. The difference, 37.3 grams, or 48 per cent., represents the amount of protein which must have been digested and taken into the body of the sheep from the alimentary tract. In the same manner the percentage of the other nutrients digested was determined. The average percentage of each nutrient digested in a given feeding stuff is termed the "coefficient of digestibility," for that nutrient and feed.

48. Digestibility of malt sprouts.-Having ascertained the digestibility of clover hay, Armsby added to the ration an allowance of malt sprouts. The sheep remained in the stanchions as before, and were fed 600 grams of clover hay and 175 grams of 
malt sprouts. Weights and analyses of feed and excrement were made as before. The digestibility of the malt sprouts as determined in this trial is shown in the following table:

Feeding trial with sheep to ascertain the digestibility of malt sprouts, average for one day's feeding - Wisconsin Station.

\begin{tabular}{|c|c|c|c|c|c|}
\hline & $\begin{array}{c}\text { Dry } \\
\text { matter. }\end{array}$ & Protein. & $\begin{array}{l}\text { Crude } \\
\text { fiber. }\end{array}$ & $\begin{array}{l}\text { Nitrogen } \\
\text {-free } \\
\text { extract. }\end{array}$ & $\begin{array}{l}\text { Ether } \\
\text { extract. }\end{array}$ \\
\hline & Grams. & Grams. & Grams. & Grams. & Grams. \\
\hline Fed 600 grams hay ................ & 500.9 & 67.4 & 163.3 & 236.3 & 9.4 \\
\hline Fed 175 grams malt sprouts... & 154.1 & 36.8 & 21.0 & 87.5 & 2.2 \\
\hline Total ............................... & 655.0 & 104.2 & 184.3 & 323.8 & 11.6 \\
\hline Excreted 681.1 grams dung.... & 295.2 & 41.5 & 100.6 & 129.0 & 5.5 \\
\hline Digested, total......... & 359.8 & 62.7 & 83.7 & 194.8 & 6.1 \\
\hline Digested from hay... & 256.4 & 33.2 & 76.8 & 135.2 & 3.8 \\
\hline Digested from malt sprouts... & 103.4 & 29.5 & 6.9 & 59.6 & 2.3 \\
\hline Per cent. digested................... & 67.1 & 80.2 & 32.9 & 68.1 & 104.6 \\
\hline
\end{tabular}

The digestibility of malt sprouts is determined indirectly in the following manner: The dry matter fed in the clover hay and malt sprouts equals 655 grams. The excreted dry matter equals 295.2 grams, so that the total quantity digested is the difference, 359.8 grams. In the previous trial, as the average of two periods, it was found that 51.2 per cent. of the dry matter in clover hay was digestible. Multiplying 500.9 grams by this factor, 256.4 results, which represents the quantity of dry matter in the hay that was digested. Subtracting this from 359.8 grams, there is left 103.4 grams, or 67.1 per cent., which must be the dry matter digested from the malt sprouts. In this manner the sereral digestion coefficients for malt sprouts are determined. The table reports 104.6 per cent. of the ether extract of the malt sprouts digested - an absurdity. Such a result may be due to an error in the work, or more probably to the fact that more ether extract was digested from the clover hay in the second trial than in the first one. The statement relative to ether extract in the next article may have a bearing on this result.

49. Digestibility of food nutrients. - Errors in digestion experiments arise, among other causes, from the addition of bile prod- 
ucts to the excreta as well as gummy substances originating from tissue changes of the alimentary tract.

The digestibility of protein in coarse fodders varies widely, ranging from 35 to 80 per cent. Usually the higher the ratio of protein to non-nitrogenous constitnents in a feed the greater the percentage of the protein digested.

Of the crude fiber from 30 to 70 per cent. is digestible by ruminants, while for the pig and the horse it is considerably less. The larger utilization of cellulose by ruminants is probably due to the fact that the food undergoes more thorough preparation for digestion in the primary stomachs. The addition to the ration of a food rich in protein aids the digestion of cellulose.

The sum of the digestible nitrogen-free extract and the digestible crude fiber about equals the total nitrogen-free extract of any given feed.

The digestibility of ether extract varies greatly in different feeding stuffs, ranging from 30 per cent. in straw to over 90 in the cereals. The digestibility of the several compounds grouped under this term cannot be as accurately determined as in case of the other nutrients, owing to a variety of substances appearing in the solid excrement, which, although dissolved from it by ether, cannot be considered as nutritive material that has escaped ligestion. The small quantity of the ether extract usually present in feeding stuffs also renders the determination of this component more liable to error.

Zuntz and Lehmann report that the work of chewing the food and digesting it, in the case of the horse, may represent a considerable proportion of the nutritive value of the food. The effort in chewing hay represents 11.2 per cent., and in oats 2.8 per cent. of the total energy yielded by the food.

50. Digestion of coarse fodders. - The leading points of Wolff's lucid statements on this subject ${ }^{1}$ are here presented, the first ones having reference to coarse fodders fed without the addition of grain.

The quantity of fodder supplied the animal does not affect the digestibility of the several constituents. Healthy animals under

1 Farm Foods, English edition. 
normal conditions only eat as much fodder as they can properly digest, and the digestive fluids are no more effective when operating on small than on large quantities.

Contrary to general opinion, green fodders are no more digestible than the same forage when carefully preserved by drying. In practice, however, much of the finer parts of the plant is lost by breaking off and falling to the ground during the process of curing. Dew and rain may also effect changes. The loss of dry matter through mechanical waste in curing may amount to 10 per cent., and the digestibility may be reduced from 4 to 5 per cent., or still more if bad weather prevails during curing. The storage of fodders even under favorable conditions for a long period may decrease their digestibility as well as palatability.

The degree of maturity affects the digestibility of plants. At Moeckern, oxen fed clover hay cut when coming into bloom digested 71 per cent. of the protein, when cut at time of full bloom 65 per cent., and 59 per cent. when cut toward the end of blooming.

Season, soil and manures influence the digestibility of fodders. Hay cut during three successive years from the same field, when fed to sheep, showed 60,64 and 65 per cent., respectively, of digestible protein. Crushing, grinding, steaming or fermenting food does not increase its digestibility, although its palatability may be thereby improved. At the Moeckern Station, boiled, scalded or fermented wheat bran showed decreased digestibility when fed to oxen. A keen appetite resulting from hard labor does not increase the digestibility of feeds.

Ruminants - oxen, cows, sheep and goats - digest the same kind of fodder equally. Horses digest from 11 to 12 per cent. less of the dry matter of hay than ruminants. They digest the protein of hay equally well with sheep, but cannot make as much use of the ether extract. Horses digest from 7 to 10 per cent. less nitrogen-free extract than sheep, and as much as 20 per cent. less crude fiber. The richer the feeding stuff the more nearly does the horse approach the farm ruminants in the powers of digestion. Neither the age nor the breed of the animal affects the powers of digestion, though single individuals often show 
striking variations from the normal. The range of digestibility due to species, breed, age and live weight does not, under ordinary conditions, vary more than from 2 to 4 per cent.

51. Coarse and concentrated feeds combined.- When there is added to a supply of coarse fodder, substances rich in protein, such as oil cake, oats, etc., the digestibility of the coarse fodder is not thereby increased. The addition of a large quantity of carbohydrates, such as sugar and starch, to a ration of coarse forage, may reduce the digestibility of the protein and crude fiber of the forage. The depression in digestibility caused by the addition of the carbohydrates is not apparent until the added starch or sugar exceeds 10 per cent. of the dry matter of the coarse forage, but is marked by the time the addition reaches 30 per cent. For example, at Weende, when sheep were fed 1.75 pounds of hay and 8 ounces of starch per head daily, the digestibility of the protein was reduced from 54 to 32 per cent. The depression is reduced or suspended by the addition of a highly nitrogenous feeding stuff, such as oil cake. The addition of fat to a ration does not increase the digestibility of the other constituents. Salt does not affect digestion, though it may increase consumption of feed and improve nutrition.

The student should not confound the digestibility of feeding stuffs with their final nutritive effect. While two animals may each digest the same amount of nutrients from the same weight of a given feed, one may give far better returns for the substances taken into the body than the other. The utilization of the nutrients of feeding materials is determined by the breed, individuality, condition of the animal, etc.

52. Artificial digestion.-While vigorously prosecuting digestion investigations with animals, the chemist has not been idle in his efforts to find an easier and more rapid method of reaching the same end. Stutzer has proposed a simple method for determining the digestibility of protein, by treating the substance under investigation with weak solutions of pepsin and afterwards of pancreatic fluid, care being taken to maintain the digesting mass at the normal temperature of the animal body. The fluids named act only on the protein of the food, hence this method 
gives only the digestibility of that nutrient. In using this method it has been found that the digestibility varies with the length of time the solution is allowed to act, the temperature maintained, etc. It is therefore only fairly accurate, but is useful as a quick method of determining the relative digestibility of the substances under comparison, rather than an absolute one for general guidance. G. Kühn has shown that the results may be reached by the use of pepsin solutions only. ${ }^{1}$

53. Water extracts. - It has been found that the total quantity of solid matter which can be extracted from a fodder by the use of boiling water measures, with considerable accuracy, the quantity of digestible nitrogen-free extract which it contains. Some of the dissolved matter, however, is protein and ash, so that this method is not directly accurate, but a guide rather, for practical purposes.

\section{Respiration Studies.}

54. The respiration apparatus.-A "respiration apparatus" is a device for measuring the products of respiration of animals confined therein. Its leading feature is an air-tight chamber in which the animal experimented on is confined, with an inlet for supplying fresh air and an outlet for drawing off the air with its respiration products. The air entering the chamber as well as the gases drawn from it are measured and analyzed, to determine the products given off by the subject on trial. The most complete and satisfactory forms of the respiration apparatus are those constructed according to the plan of Pettenkofer of the Physiological Institate at Münich, the first of which was built through the munificence of the King of Bavaria. There was recently constructed at the Wesleyan University, Connecticut, by the co-operation of the Storrs (Connecticat) Experiment Station and the United States Department of Agriculture, Washington, a very complete respiration apparatus especially designed for the study of human nutrition.?

In conducting experiments, animals or men, or both, are placed in the respiration chamber. In some cases labor is performed;

1 Landw. Vers. Sta., 44, pp. 188-256.

2 For a popular description of this apparatus and some of the results obtained, see Century Magazine, June, 1897. 
at other times the enclosed subject is kept as nearly in perfect rest as possible, with or without a normal food supply. These studies, necessarily difficult, are not only interesting but important in furthering our knowledge of the laws of nutrition.

The respiration apparatus has been used for the study of the formation of fat and the decomposition of the nitrogenous components of the body. Used in connection with weighings and analyses of food, water, and the solid and liquid voidings, the chemist is able to determine accurately what becomes of the nutrients fed to the animals under trial and the waste products given off by them, thereby measuring the effect of any given ration.

55. An illustration.-The following example, taken from one of the earlier experiments by Henneberg ${ }^{1}$ at the Weende Station, will illustrate the manner of studying the formation of flesh and fat in the body of the ox by means of the respiration apparatus and digestion experiments.

The animal experimented on was a full-grown ox, which weighed 1,570 pounds when placed in the respiration chamber. It was fed the following ration: 11 pounds of clover hay, 13.2 pounds of oat straw, 8.2 pounds of bean meal, 2.13 ounces of salt, and drank on the average 123.7 pounds of water daily. The results of one day's trial, arranged to assist the student in understanding the workings of this method of investigation, are here presented:

1 Neue Beiträge, Göttingen, 1870, I, p. xix; Krafft, Lehrb. d. Landw., III, p. 17. 
Digestion trial with ox in respiration apparatus, results for ons day-Weende Station.

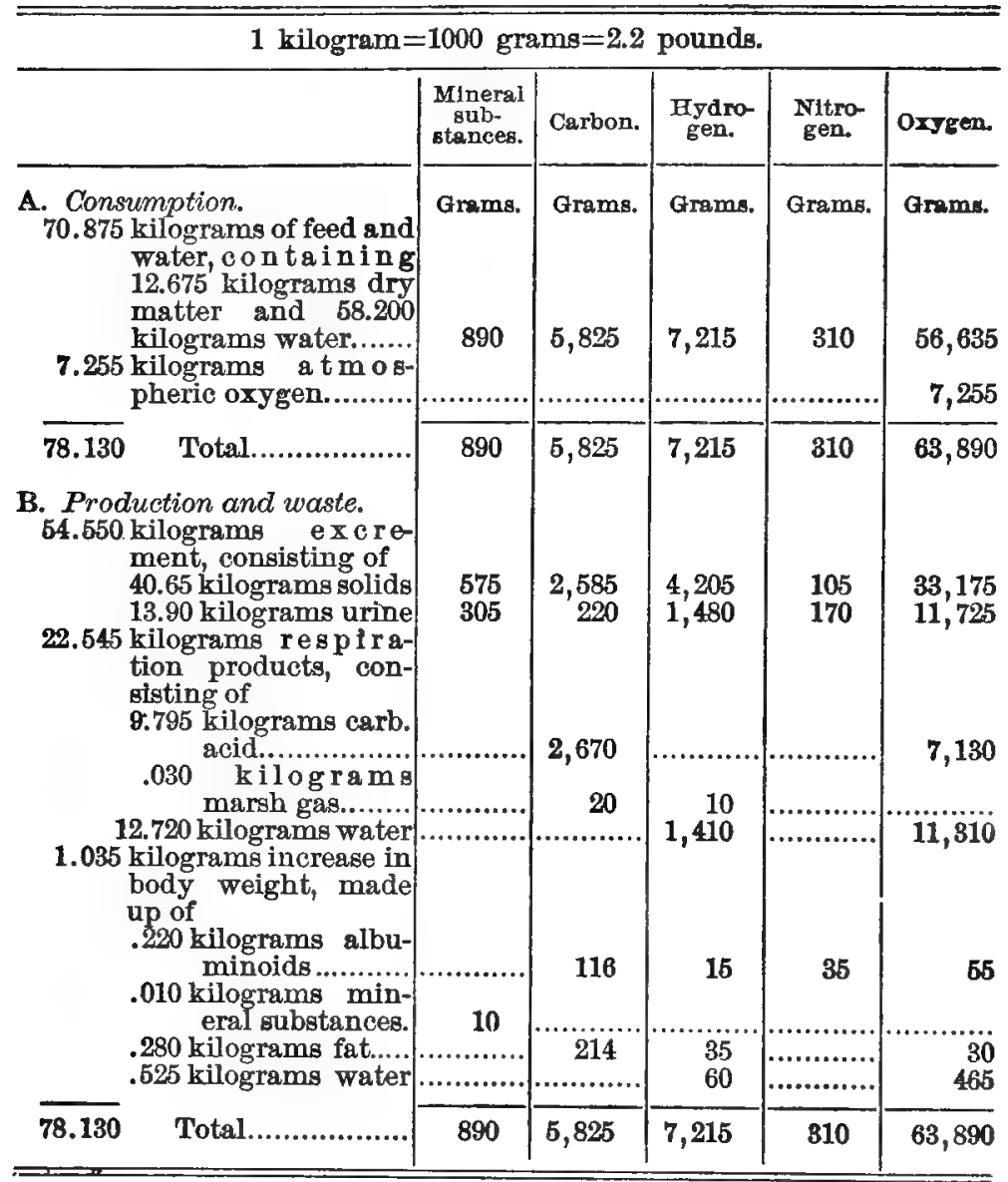

56. Intake of body. - The first division of the table records the consumption or intake of the body of the steer for one day, the results being stated in kilograms. Reducing the weight of the several substances to pounds, we have the following:

Oxygen taken into blood by way of the lungs... Pounds. Dry mattor taken into the alinentar Dry matter taken into the alimentary tract......... 27.8 Water drank and in food............................ 128.0

Total intake of body for one day............ 171.8 
From these data we learn that in twenty-four hours the steer took into the blood by way of the lungs 16 pounds of oxygen, and into the alimentary tract 27.8 pounds of dry matter and 128 pounds of water, or $\mathbf{1 7 1 . 8}$ pounds in all.

57. Waste products. - The second division of the table treats of production and waste. Let us first consider the waste by the steer for the day during which the study was conducted. The loss to the body through the several channels was as follows:

Pounds.

Passed off as solid excrement...................... 89.4

Passed off as urine .................................. 30.6

Passed off as respiration products................. 49.5

Total waste from body...................... 169.5

This shows that there passed from the steer as solid excrement 89.4 pounds, of urine 30.6 pounds, while from the lungs there were given off 49.5 pounds of waste products, somewhat more than one-half of which was water, and a little less than half carbonic acid. The total outgo from the body for the day under study, was as shown above, 169.5 pounds.

The decomposition of nitrogenous substances in the body is calculated from the quantity of nitrogen in the urine. As protein contains 16 per cent. nitrogen on the average, the quantity of protein corresponding to the nitrogen in the urine is found by multiplying by $\frac{100}{16}$, or by 6.25 . The table shows that there were .170 kilograms of nitrogen in the urine of the ox. Multiplying this by 6.25 , there results 1.062 kilograms or 2.33 pounds. This sum measures both the quantity of nitrogenons nutrients taken into the body from the food, and the body tissues which were broken down and left the body as waste during the day of the trial.

58. Fiesh production.-From the above we have the following in relation to the income and outgo of the body of the steer for one day:

Pounds.

Total substance passing into the body.............. 171.8

Total waste leaving the body....................... 169.5

Amount retained in the body. 
This shows that 2.3 pounds or only 1.3 per cent. of what entered the body was retained as a permanent portion thereof, the remainder passing away as waste. Part of the substance was inert matter, and useless, while the larger part was used as fuel for furnishing energy to the body, and passed off as waste after being so used.

Directing our attention to the portion incorporated in the body, we learn that 35 grams of nitrogen were not excreted, but retained as a portion of the body. Sixteen per cent. of albuminoid substances is nitrogen. The albuminoid tissues representing this quantity of nitrogen are determined in the following manner:

$\begin{array}{cccc}\text { Nitrogen. } & & \begin{array}{c}\text { Per cent. } \\ .035\end{array} \times & \frac{100}{16}\end{array}=\begin{gathered}\text { Albuminoids } \\ \text { or lean meat. }\end{gathered}$

The albuminoid tissues contain 53 per cent. carbon. Accordingly, the amount of carbon in tissue built during the day is as follows:

Lean meat. .22 Per cent.

Carbon. $\times \quad \frac{58}{100}$ $=\quad .116$ kilograms.

The lean meat therefore contained .116 kilograms of carbon. There remains .214 kilograms of carbon, which must have gone to form fat. Seventy-five per cent. of fat is carbon,- hence the following:

Carbon. .214 Per cent. Body fat.

59. Summary of the trial.- From this we learn that there were .28 kilograms of fat stored in the body during the day of the trial. Arranging these results, together with the mineral matter and water retained in the body, for convenient study, we learn that the nutrients stored as increase were as follows:

Pounds.

.22 kilograms of albuminoids or lean meat......... .48

.28 kilograms of fat................................ .61

.01 kilograms of mineral matter..................... .02

.525 kilograms of water............................. 1.17

Total body increase............................ $\overline{2.28}$

It was shown that the income to the body exceeded the outgo by 2.3 pounds; the table accounts for practically all of this in 
the 2.28 pounds of increase. We learn from the above that during one day of the experiment the ox took into its body 171.8 pounds of material in oxygen, water and dry matter, and from it built up 2.28 pounds of body substance, which consisted of .48 pounds of albuminoids or lean meat, .61 pounds of fat, .02 pounds of mineral matter, which went mainly to the bones, and 1.17 pounds of water, placed mostly with the lean meat and, in less proportion, with the fatty tissue.

Where the animal produces other substances than flesh, as in the case of sheep and milch cows, the method of calculating production is the same as with oxen, though somewhat more complicated.

\section{Calorimetry.}

60. Measuring the heat units of feeds.- The calorimeter is a device so arranged that when a given substance is burned therein the heat given off is taken up by water and can be accurately ascertained. While investigations have been in progress with the respiration apparatus to determine what becomes of the food taken into the body, other workers have endeavored by means of the calorimeter to ascertain the heat nnits of food materials. It has been found that the results obtained with the respiration apparatus and the calorimeter agree very closely; that is to say, in supplying the body with fuel, the protein, fat and carbohydrates of the food have been found to replace each other in almost exact proportion to the heat units they evolve when burning. Prof. Rübner found the quantity of material equal to 100 parts of fat to be as follows:

Equivalent for 100 parts of fat as shown by the respiration apparatus and calorimeter.

\begin{tabular}{|c|c|c|}
\hline $\begin{array}{l}\text { Nutritive substances, } \\
\text { water-free. }\end{array}$ & $\begin{array}{l}\text { As determined by ex- } \\
\text { periments with animals } \\
\text { in respiration apparatus. }\end{array}$ & $\begin{array}{l}\text { As determined by } \\
\text { burning in the } \\
\text { calorimeter. }\end{array}$ \\
\hline 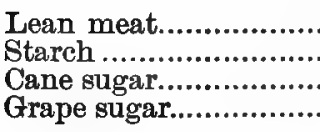 & $\begin{array}{l}243 \\
232 \\
234 \\
256\end{array}$ & $\begin{array}{l}235 \\
229 \\
235 \\
255\end{array}$ \\
\hline
\end{tabular}


By this table we learn that 235 parts of lean meat when burued in the calorimeter give off as much heat as 100 parts of fat. The respiration-apparatus tests place the equivalent at 243 parts - a very close agreement with the calorimeter. Starch evolves almost as much heat as lean meat, and cane and grape sugar somewhat more.

61. Definition of terms. - The Calorie is a term which designates the amount of heat required to raise the temperature of one kilogram of water $1^{\circ}$ Centigrade (or one pound of water $4^{\circ}$ Fahr.). If instead of the heat unit we use the unit of mechanical energy, the foot-ton, then the Calorie corresponds to 1.53 foottons; that is, its heat represents the energy required to raise a weight of 1.53 tons one foot in height. In the following table is summarized the average energy in one gram of each of the classes of nutrients.

Potential energy in nutrients of food.

Calories.

In one gram of protein

4.1
9.3
4.1

Foot-tons.

In one gram of fat (ether extract).

In one gram of carbohydrates

9.3

6.3

14.2

6.3

These figures mean that when a gram of protein, whether of body substance or furnished in feeding stuffs, is consumed in the body, it will, if transformed into heat, yield enough heat to raise the temperature of 4.1 kilograms of water $1^{\circ} \mathrm{C}$, , or, if transformed into mechanical energy, do the work executed by the steam-engine in raising a weight of one ton 6.3 feet, or 6.3 tons one foot. A gram of fat is shown to yield more than twice the Calories or foot-tons yielded by a gram of protein or carbohydrates.

Stated in another way, an ounce of protein in the form of lean meat, or one of carbohydrates in the form of starch or sugar, if transformed into heat, will raise the temperature of 113 pounds of water $1^{\circ}$ Fahr., while an ounce of fat yields heat sufficient to warm 256 pounds of water one degree. 1

1 This description is adapted from the report on the fuel value of feeding stuff's by W. O. Atwater, Third Annual Report, Storrs School Agrl. Expt. Station, 1890. The interested reader will find the subject most entertainingly discussed by the same writer in the Century Magazine for July, 1887. 
Digestion, Respiration and Calorimetry.

The Calories of food substances show how much heat these will impart when utilized for that purpose by the animal, or the theoretical amount of work they can accomplish.

Reduced to available form, the Calories in feeding stuffs may be stated as follows:

Digestible protein

In one gram.

In one pound.

4.1 Calories. 1860 Calories.

I Digestible carbohydrates. 4.1 Calories. 1860 Calories.

Digestible fat

9.3 Calories. 4220 Calories.

Knowing the digestible constituents of any feeding stuff, the student can readily determine its potential energy by using the above factors. 


\section{CHAPTER IV.}

ANIMAL NUTRITION.

\section{Formation of Body Tissues.}

62. Formation of tissues.- Since the protein of the food is the sole source of nitrogenous substances in the body, it follows that the formation of flesh is primarily dependent upon the supply of protein in the food.

In the body there is a slow but continuous breaking down of tissue. The materials which have been dissolved from the food in the process of digestion are absorbed by the blood, and through it distributed to the different parts of the body, where they are either oxidized (consumed), and heat and energy produced, carbonic acid and water being given off, or are used for the production of components of the body, mainly fat and protein (flesh). The decomposition of nutritive material in the blood, and of muscolar and other body tissues, goes on continuously as long as the animal lives, whether it is awake or asleep; being, however, more active in the former condition. The term "protein consumption" as used in this book is applied to the quantity of nitrogenous materials decomposed in the animal body, whether originating from muscular tissue or nitrogenous nutrients in solution in the fluids of the body. Protein consumption is measured by the amount of nitrogen found in the urine, since practically all the nitrogen which leaves the body passes off through this excretion. (57)

If the nitrogenous waste results from the destruction of muscular tissue, as may be the case during starvation, it is spoken of as "flesh consumption." Since fat-free muscular tissue has been found to contain, on the average, 3.4 per cent. of nitrogen, the amount of flesh consumed in the body may be found by malti- 
plying the quantity of nitrogen excreted in the urine by 29.4 $\left(\frac{1}{3} .0 .029 .4\right)$.

63. The waste of the body.-The food supplies materials for making good the waste which the animal sustains through the living process. When the supply is liberal and exceeds the demands of the system, material may be stored in the body by the formation of flesh or fat, and the animal will gain in weight. If the supply is equal to the material broken down, the live weight of the animal will remain unchanged. When the supply is cut short or entirely withheld, the tissues of the body itself are attacked and the animal loses weight.

There is a minimum amount of protein absolutely necessary for the maintenance of life. This has been determined by experiments in which dogs, cats, rabbits and other animals have been starved, and the daily excretion of nitrogen in the urine determined. During the first days of starvation the excretion of nitrogen, or, what is the same, the decomposition of protein in the body, gradually decreases until after five or six days it remains practically constant. The last portion of the protein in the fluids of the body has then been drawn upon and the body tissues are now being destroyed. After a period of continued starvation the supply from the latter source will also be exhausted and the animal dies, the time being determined by the condition of the body at the beginning of starvation. A rise in temperature occurs at the beginning of starvation, followed by a general fall until death takes place. Carnivora or flesh-eating animals can withstand hunger longer than the Herbivora. While dogs and cats have lived until their weights have decreased 33 to 40 per cent., horses and ruminants will die when their weight has been reduced 20 to 25 per cent. ${ }^{1}$ The age of the animal also influences the time that death occurs from starvation, old animals withstanding the effects of hunger better than young animals. The latter lose weight more rapidly and die after a smaller loss of weight than the former. ${ }^{2}$

1 M. Wilckens in v. d. Goltz, Handb. d. ges. Landwirtschaft, III, p. 88.

. Halliburton, Chem. Physiology, p. 834. 


\section{Exclusive Protein Feeding.}

64. Protein consumption.-In feeding Carnivora it has been found that an exclusive protein diet causes an increased decomposition of protein in the body, and that the excess does not therefore go to form flesh. The following table shows results obtained by Voit with a dog fed varying quantities of meat which had been freed from all fat: ${ }^{1}$

Feeding increasing amounts of fat-free meat to dog-Voit.

\begin{tabular}{|c|c|c|c|c|c|c|c|c|c|}
\hline & Grm & Grma & Grm & Grm & Grms. & Grms. & Grms. & Grms. & Grms. \\
\hline $\begin{array}{l}\text { Fat-free meat eaten } \\
\text { per day..................... }\end{array}$ & 0 & 300 & 500 & 900 & 1,200 & 1,500 & 2,000 & 2,500 & 2,660 \\
\hline Urea excreted ............ & 12 & $\begin{array}{l}32 \\
\end{array}$ & 40 & 68 & & 106 & 144 & 173 & 181 \\
\hline $\begin{array}{l}\text { Corresponding to } \\
\text { flesh................................. }\end{array}$ & 165 & 442 & 552 & 938 & 1,214 & 1,463 & 1,987 & 2,387 & 2,498 \\
\hline
\end{tabular}

The protein consumption with this dog varied from 165 grams (.36 pounds) per day during hunger to nearly 2,500 grams (5.5 pounds) when the largest amount of protein was fed; that is, while fed increasing quantities of lean meat the dog did not store up any of this, but turned it off into the urine as urea. Similar experiments with Herbivora have, in the main, given the same results as found with Carnivora.

From the results given in the last table it is evident that the supply of protein in the food will largely regulate the consumption of protein in the body, and consequently the quantity of nitrogen appearing in the urine. The following is a summary of experiments on goats by Stohmann:2

Armsby, Manual of Cattle Feeding, p. 128.

"Biologische Studien, Heft 1, p. 121; Armsby, loc. cit., p. 146. 
Food given and protein digested, consumed and stored in the body by goats - Stohmann.

\begin{tabular}{|c|c|c|c|c|c|}
\hline \multirow{2}{*}{$\begin{array}{c}\text { Date of } \\
\text { experiment. }\end{array}$} & \multicolumn{2}{|c|}{ Feed per day. } & \multirow{2}{*}{$\begin{array}{l}\text { Protein } \\
\text { digested per } \\
\text { day. }\end{array}$} & \multirow{2}{*}{$\begin{array}{l}\text { Protein con- } \\
\text { sumption } 1 \\
\text { per day. }^{1}\end{array}$} & \multirow{2}{*}{$\begin{array}{l}\text { Gain of } \\
\text { protein } \\
\text { per day. }\end{array}$} \\
\hline & Hay. & $\begin{array}{c}\text { Linseed } \\
\text { meal. }\end{array}$ & & & \\
\hline \begin{tabular}{r|lr|}
1 & May & $23-29$ \\
2 & June & $6-12$ \\
3 & June & $20-26$ \\
4 & July & $4-10$ \\
5 & July & $25-31$ \\
6 & Aug. & $8-14$ \\
7 & Aug. & $22-28$ \\
8 & Sept. & $5-11$ \\
9 & Sept. & $19-25$ \\
10 & Oct. & $3-9$
\end{tabular} & $\begin{array}{r}\text { Grams. } \\
1,500 \\
1,450 \\
1,400 \\
1,350 \\
1,250 \\
1,100 \\
950 \\
800 \\
1,600 \\
1,600\end{array}$ & $\begin{array}{c}\text { Grams. } \\
100 \\
150 \\
200 \\
250 \\
350 \\
500 \\
650 \\
800 \\
0 \\
0\end{array}$ & $\begin{array}{r}\text { Grams. } \\
111.6 \\
125.0 \\
132.2 \\
150.9 \\
170.5 \\
193.8 \\
221.4 \\
257.2 \\
92.9 \\
74.1\end{array}$ & $\begin{array}{r}\text { Grams. } \\
66.6 \\
79.4 \\
90.6 \\
80.1 \\
101.6 \\
117.9 \\
143.1 \\
173.7 \\
56.3 \\
41.9\end{array}$ & $\begin{array}{r}\text { Grams. } \\
1.9 \\
9.0 \\
11.1 \\
23.4 \\
18.3 \\
27.4 \\
30.6 \\
27.4 \\
-4.4 \\
6.4\end{array}$ \\
\hline
\end{tabular}

${ }^{1}$ Exclusive of the protein contained in the milk, which varied but slightly.

We observe that after the quantity of protein digested reached 150 grams daily there was practically no further increase in the protein stored up in the body, even though the amount in the food was still further augmented.

That an exclusive protein diet will not produce body tissue is well illustrated in the so-called "Banting cure" for obesity, where the patient is put on a meat and fruit diet, especially the former, with no potatoes, butter, or bread.

Pflüger" has shown that a hard-worked dog fed on "almost fat-free" meat diet can live on that food alone for seven months, and on the basis of this experiment concludes, contrary to the views of Voit and other authorities, that nitrogenous compounds may sustain life for an indefinite period.

65. Influence of previous feeding.- Beside the supply of protein in the food, the protein consumption in the body is dependent upon another factor, viz., the condition of the body of the animal as a result of previous feeding. It clearly appears from experiments made in this line ${ }^{2}$ that when a change in diet occurs the consumption of protein will increase or decrease according to the

1 Archiv d. ges. Physiologie, 52 (1892), p. 2.

3 Armsby, Manual of Cattle Feeding, 1887, p. 129. 
changes made in the supply of protein in the food. Given a supply of protein larger than is necessary to maintain the body tissues, and there will in a few days be an equilibrium between the supply and consumption of protein in the body, the time varying with different animals and with the body condition of each animal. The equilibrium will be reached sooner with alean animal than with a fat one, and sooner when the animal receives food rich in protein and poor in fat than when the opposite occurs.

III. Influence of Other Nutrients on Protein Consumption.

66. Influence of fat.-When fed alone, fat does not decrease protein consumption in the body, as is shown in the following results by Voit with a starving $\operatorname{dog}: 1$

Feeding fat only, to a starving dog - Voit.

\begin{tabular}{l|r|r|r|r|r|r|r}
\hline \hline & Grams & Grams & Grams & Grams & Grams & Grams & Grams \\
\hline Fat per day................... & 0 & 100 & 200 & 300 & 300 & 340 & 350 \\
Protein consumption........ & 170 & 185 & 155 & 187 & 165 & 205 & 291 \\
\hline
\end{tabular}

Feeding increasing quantities of fat in this case appears to have increased, rather than decreased protein consumption. (82)

67. Influence of carbohydrates.-When fed alone, carbohydrates have no influence on the consumption of protein and thus act in the same way as fat. The same amount of protein is decomposed in the body when nothing but carbohydrates are fed as when no food whatever is given.

68. Influence of mixed diet.-When the animal is fed on a mixed diet containing fat, carbohydrates and protein, the consumption of protein depends on the supply of protein in the food, as in exclusive protein feeding. The following experiment ${ }^{2}$ serves as an example:

1. Zeitschr. f. Biologie, V, p. 329. Armsby, loc. cit., p. 136.

Armsby, loc. cit., p. 137. 
Influence of mixed diet on protein consumption-Voit.

\begin{tabular}{|c|c|c|c|c|c|c|}
\hline & Grams & Grams & Grams & Grams & Grams & Grams \\
\hline 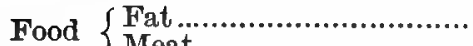 & 250 & 300 & 250 & 200 & 200 & 250 \\
\hline 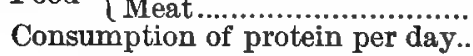 & $\begin{array}{l}150 \\
233\end{array}$ & $\begin{array}{l}176 \\
259\end{array}$ & $\begin{array}{l}250 \\
270\end{array}$ & $\begin{array}{l}500 \\
502\end{array}$ & $\begin{array}{l}800 \\
778\end{array}$ & $\begin{array}{l}1,500 \\
1,381\end{array}$ \\
\hline
\end{tabular}

It will be noticed that with the same quantities of fat in the food, the protein consumption is larger where the amount of meat fed is larger; for instance, in the first, third and sixth experiments, 250 grams of fat were fed along with 150, 250 and 1500 grams, respectively, of meat. The consumption of protein in the body of the animal was, in the order given, 233, 270 and 1,381 grams. The increase in protein consumption does not, however,

- keep pace with the increased supply of protein in the food, and the fat evidently has protected to some extent the protein in the animal body from consumption. It has been found in the same way that carbohydrates also decrease the protein consumption in the body when fed in connection with protein. Thus they save the protein of the body from decomposition, and as a result more of the protein of the food can be used for the formation of flesh in the body. The following experiment by Voit may be cited to illustrate this important fact: 1

Results of feeding meat and fat-Voit.

\begin{tabular}{|c|c|c|c|c|c|}
\hline \multirow{2}{*}{ Date. } & \multicolumn{2}{|c|}{ Food. } & \multirow{2}{*}{$\begin{array}{c}\text { Urea } \\
\text { per day. }\end{array}$} & \multirow{2}{*}{$\begin{array}{c}\text { Flesh } \\
\text { consumption } \\
\text { in body. }\end{array}$} & \multirow{2}{*}{$\begin{array}{l}\text { Difference between } \\
\text { supply and con- } \\
\text { sumption of flesh. }\end{array}$} \\
\hline & Meat. & Fat. & & & \\
\hline & Grams. & Grams. & Grams. & Grams. & Grams. \\
\hline $\begin{array}{l}\text { July } 31 \ldots \ldots \\
\text { Aug. } 1 \ldots \ldots \\
\text { Aug. } 2 \ldots \ldots \\
\text { Aug. } 3 \ldots \ldots\end{array}$ & $\begin{array}{l}1,000 \\
1,000 \\
1,000 \\
1,000\end{array}$ & $\begin{array}{c}0 \\
100 \\
300 \\
0\end{array}$ & $\begin{array}{l}81.7 \\
74.5 \\
69.3 \\
81.2\end{array}$ & $\begin{array}{r}1,140 \\
1,042 \\
970 \\
1,134\end{array}$ & $\begin{array}{r}-140 \\
-42 \\
+30 \\
-134\end{array}$ \\
\hline
\end{tabular}

We see from the above that when on an exclusive meat diet the animal lost 140 grams of protein per day, while when 300 grams of fat were added to the same quantity of meat as before it gained 30 grams. We thus learn that the addition of fat (as

\footnotetext{
1 Armsby, loc. cit., p. 138.
} 
also carbohydrates) to a protein diet makes the consumption of protein smaller than it would be without this addition. The fat as well as the carbohydrates preserve the protein from decomposition, thereby favoring the formation of new body tissue.

The following experiments with a dog by Voit also illustrate this, which is also proved by many others: 1

Influence of carbohydrates fed in connection with protein, on protein consumption - Voit.

\begin{tabular}{|c|c|c|c|}
\hline \multirow{2}{*}{ Date of experiments. } & \multicolumn{2}{|r|}{ Food. } & \multirow{2}{*}{$\begin{array}{l}\text { Protein } \\
\text { consumption. }\end{array}$} \\
\hline & Meat. & Carbohydrates. & \\
\hline & Grams. & Grams. & Grams. \\
\hline $\begin{array}{l}\text { June } 23-J u l y ~ \\
\text { July } 2,1859 \ldots \ldots \ldots \ldots \ldots\end{array}$ & $\begin{array}{l}500 \\
500\end{array}$ & $\begin{array}{c}100-300 \\
0\end{array}$ & $\begin{array}{l}502 \\
564\end{array}$ \\
\hline $\begin{array}{l}\text { July } 4-10,1864 \ldots \ldots \ldots \ldots \ldots \ldots \ldots \ldots \\
\text { July } 10-19,1864 \ldots \ldots \ldots \ldots \ldots \ldots \ldots \ldots \\
\text { July } 19-20,1864 \ldots \ldots \ldots \ldots \ldots \ldots \ldots\end{array}$ & $\begin{array}{l}800 \\
800 \\
800\end{array}$ & 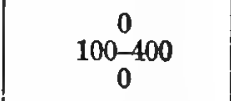 & $\begin{array}{l}826 \\
763 \\
895\end{array}$ \\
\hline $\begin{array}{l}\text { July } 23-26,1864 \ldots \ldots \ldots \ldots \ldots \ldots \ldots \\
\text { July } 26-28,1864 \ldots \ldots \ldots \ldots \ldots \ldots \ldots \\
\text { July } 28-A \text { ug. } 1,1864 \ldots \ldots \ldots \ldots \ldots\end{array}$ & $\begin{array}{l}1,000 \\
1,000 \\
1,000\end{array}$ & $\begin{array}{c}0 \\
100-400 \\
0\end{array}$ & $\begin{array}{r}1,028 \\
902 \\
1,112\end{array}$ \\
\hline 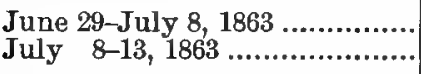 & $\begin{array}{l}1,500 \\
1,500\end{array}$ & $\begin{array}{c}0 \\
200\end{array}$ & $\begin{array}{l}1,599 \\
1,454\end{array}$ \\
\hline $\begin{array}{l}\text { Jan. } 6,1859 \ldots \ldots \ldots \ldots \ldots \ldots \ldots \ldots \ldots \ldots \\
\text { Jan. } 7-11,1859 \ldots \ldots \ldots \ldots \ldots \ldots \ldots \ldots\end{array}$ & $\begin{array}{l}2,000 \\
2,000\end{array}$ & $\stackrel{0}{0} 200-300$ & $\begin{array}{l}1,991 \\
1,792\end{array}$ \\
\hline
\end{tabular}

69. Teachings of the above in feeding practice. - From what we have learned we should expect the best results when the ration fed contains a sufficient supply of protein with a large proportion of carbohydrates to protein, $i$. e., a wide nutritive ratio (132), and this we find borne out by the results of numerous experiments with all kinds of animals. We quote the following experiments on sheep by Schulze and Märcker, arranged by Armsby according to the nutritive ratios in the different rations. The protein in the wool, amounting to about five grams, is not included in the figures for protein consumption. ${ }^{3}$

1 Zeitschrift f. Biologie, V, p. 434; Armsby, loc. cit., p. 150.

Journ. f. Landw. XVIII, pp. 1 et seq; Armsby, loc. cit., p. 153. 
Influence of wide and narrow ratios on flesh production-Schulze and Maercker.

\begin{tabular}{|c|c|c|c|c|c|}
\hline $\begin{array}{c}\text { No. of experi- } \\
\text { ment. }\end{array}$ & $\begin{array}{l}\text { Protein } \\
\text { digested } \\
\text { Grams. }\end{array}$ & $\begin{array}{l}\text { Nutritive } \\
\text { ratio. }\end{array}$ & $\begin{array}{l}\text { Protein } \\
\text { consump- } \\
\text { tion. } \\
\text { Grams. }\end{array}$ & $\begin{array}{c}\text { Gain of } \\
\text { protein. } \\
\text { Grams. }\end{array}$ & $\begin{array}{l}\text { Gain of protein } \\
\text { in per cent. of } \\
\text { an't digested. }\end{array}$ \\
\hline Experiment 6. & 30.6 & $1: 17.4$ & 24.3 & 1.4 & 4.6 \\
\hline $\begin{array}{lr}\text { Experiment } & 12 \\
\text { Experiment } & 3 \\
\text { Experiment } & 11 \\
\text { Experiment } & 2 \\
\text { Experiment } & 10 \\
\text { Experiment } & 8\end{array}$ & $\begin{array}{l}67.9 \\
59.5 \\
68.1 \\
59.7 \\
72.5 \\
85.8\end{array}$ & $\begin{array}{l:}1: 9.4 \\
1: 8.9 \\
1: 8.6 \\
1: 8.6 \\
1: 8.1 \\
1: 7.7\end{array}$ & $\begin{array}{l}54.8 \\
45.9 \\
56.2 \\
49.1 \\
54.7 \\
63.6\end{array}$ & $\begin{array}{r}8.0 \\
9.0 \\
6.8 \\
5.5 \\
12.7 \\
17.3\end{array}$ & $\begin{array}{r}11.8 \\
15.1 \\
10.0 \\
9.2 \\
17.5 \\
20.1\end{array}$ \\
\hline Average ........ & 68.9 & $\mid \ldots \ldots \ldots \ldots \ldots \ldots$ & 54.1 & 9.9 & 14.0 \\
\hline $\begin{array}{lr}\text { Experiment } & 7 \\
\text { Experiment } & 9 \\
\text { Experiment } & 17\end{array}$ & $\begin{array}{l}116.8 \\
156.6 \\
248.3\end{array}$ & $\begin{array}{l}1: 4.9 \\
1: 3.7 \\
1: 2.2\end{array}$ & $\begin{array}{r}96.0 \\
142.5 \\
237.6\end{array}$ & $\begin{array}{r}15.9 \\
9.0 \\
6.1\end{array}$ & $\begin{array}{r}13.7 \\
5.8 \\
2.5\end{array}$ \\
\hline Average... ... & 173.9 & $\cdots$ & 158.7 & 10.3 & 7.3 \\
\hline
\end{tabular}

The above experiments were not all conducted with the same animals, and therefore cannot be safely compared with one another. We notice, however, that supplying a small amount of protein with a large amount of carbohydrates, as in Experiment 6, gives a poor gain of protein and also a low percentage gain of protein digested in the food; a medium quantity of protein with a liberal supply of carbohydrates as given in the first group of experiments causes a greater consumption of protein in the body, and a larger percentage of digested protein. When we come to the last group of experiments, where the digestible carbohydrates constitute from 4.9 to 2.2 times the quantity of protein present, we again obtain poor results, there being a large waste of protein in the body, and a small gain, both relatively and absolutely, for the total protein supplied. Comparing Experiments 3 and 9, if we may safely do so, we observe that the same gain of protein to the body of the animal was obtained in one case from a little more than one-third of the quantity of digestible protein that was fed in the other case. At the same time the consumption of protein was more than three times as large in the latter case as in the former. 
70. Relative effects of fat and carbohydrates.- Experiments by a large number of investigators on the influence of fat or carbohydrates on protein consumption show that the two classes of nutrients are of practically equal value, pound for pound, for this purpose, so that so far as saving protein in the body is concerned they may replace one another. This is an important fact, and shows that the relative fuel value of these two grand divisions of food substances is not a measure of their comparative nutritive effect. (60)

The importance of the high value of carbohydrates in the formation of flesh is evident. Feeds containing much fat are comparatively costly, are difficult of digestion by Herbivora, and an undue amount of them may prove injurious. On the other hand, the carbohydrates are contained in large proportions in all the common fodders, are low-priced and are readily consumed and digested by Herbivora. The carbohydrates in the food of Herbivora effect what fat does with the Carnivora; they decrease protein consumption and enable the animal to subsist on a much smaller quantity of nitrogenous material than would otherwise be necessary.

71. Influence of amides on protein consumption.- It is now fairly well established that a large majority of the amides found in plants are nutrients proper, that is, when fed they enter the system and are oxidized in the same way as other food nutrients. The zxperiments of Hermann in feeding a dog with gelatine and tyrosin, a common amide, show that the two feeds can sustain life and even canse a production of flesh. ${ }^{1}$

Asparagin, an amide present in most young plants, has repeatedly been shown ${ }^{2}$ to cause a gain of protein in the body when fed with a fodder poor in protein.

Experiments by Zuntz, ${ }^{3}$ Potthast, ${ }^{4}$ and Weiske and Schnlze ${ }^{6}$ are in accordance with the above, and prove that asparagin is a nutrient, and that it saves muscular tissues from decomposition.

1 Vierteljahresschr. der Naturf. Ges. in Zürich XXY, p. 36.

2 Armsby, loc. cit. p. 163.

- Jahresb. d. Thier Chemie 12, p. 422.

- Jahresb. d. Thier Chemie 13, p. 344.

- Zeitschr. f. Biologio 17, 413. 
It follows, therefore, that in some of their functions at least, amides nay replace albuminoids. It has been found also by indirect xperiments that equally good results have been obtained, where umides have been substituted for part of the albuminoids in the ation for growing animals and milch cows, as were obtained When albuminoids only were fed. In corroboration of the above ve have the similar feeding value of corn silage and a correspondng quantity of dry fodder corn. (655) Silage often contains learly half its nitrogen in amide form, while dry fodder corn las not more than from 12 to 15 per cent. of its nitrogen in the orm of amides.

72. Influence of salt on protein consumption.- Experiments by Voit with dogs, and by Weiske with sheep, have shown that a noderate addition of salt to the fodder increases the activity of he secretion of the body juices and their circulation, and conequently increases the protein consumption in the body. Salt las a stimulating influence on the appetite of the animaal, faciliates the passage of albuminoids from the digestive canal into the lood, and in general increases the energy of the vital processes. the feeding of salt is therefore especially in place with horses, oung animals and milch cows when fed to their full capacity.

Another effect of salt is to increase the excretion of urine. If fter supplying salt the animal is prevented from drinking water, hen water which would otherwise pass off through the lungs and kin will be diverted to the kidneys, and if the supply from this surce is not sufficient, water will further be drawn from the body ssues. The live weight of the animal can therefore shrink apidly when salt is administered freely and little water is given; fterwards, when water is offered, much will be drank, and this, aturned to the digestive tract and tissues, will cause the animal increase rapidly in weight.

73. Influence of water on protein consumption.-Abnormally urge quantities of water cause a waste of nutrients in the bodies f animals through increased protein consumption. Voit has lown an increase in protein consumption of 25 per cent. from is source in case of a fasting dog, and Henneberg found an 
increase of 5.8 per cent. in the case of oxen. ${ }^{1}$ We are taught from these investigations that everything which gives rise to excessive drinking of water by growing, and especially fattening, animals, should be avoided; as, too high stall temperature, too much salt, too great exposure, or supplying foods carrying too much water. The normal ratio of dry matter in food to water (that in food included) is about $1: 4$ for cattle, and $1: 2$ for sheep.

\section{The Fat of the Body.}

74. Body fat from fat in the food.- According to the teachings of Voit, Wolff, and other authorities, the fat stored in the animal body may originate from three sources, viz. : directly from the fat of the food, from the carbohydrates, and from the decomposition of protein.

The fat of the food which has been acted upon by the digestive fluids in the intestines may be directly stored in the body of animals when supplied in large quantities, as has been conclusively shown in the case of Carnivora. Experiments in this line have been conducted mostly with dogs, at the Physiological Institute at Munich. Dogs have been starved for a long time until the supply of fat in the body had entirely disappeared, as shown by the increased decomposition of protein after that time. When this stage was reached they were fed for several days large quantities of fat and only a little meat. When dogs so fed were slaughtered, it was found that fat had been deposited in the lungs and in the body tissues in quantities larger than could be accounted for by the decomposition of the meat fed.

Lebedeff and Munk ${ }^{2}$ fed a dog mutton suet, and later rape oil, for a long time and in large quantities, and found that the fat deposited in the body was more like mutton suet or rape oil in its chemical properties than normal dog fat. In other experiments this could not be proved for the reason that the fatty matters supplied were decomposed more easily in the body of the aninal than the fat originating from other sources.

75. Feeding fatty acids. - Munk ${ }^{3}$ showed that neutral fat may be formed in the animal body resulting from the feeding of free

1 Armsby, Manual of Cattle Feeding, p. 135.

2 Munk, Physiologie d. Menschen, 1888, p. 273.

- Biedermann's Centralblatt, XIII (1884), p. 106. 
fatty acids. He fed a starved dog lean meat and a large quantity of fatty acids prepared from mutton suet. The animal, which had shrunk 32 per cent. in weight during nineteen days, was fed 3,200 grams of flesh and 2,850 grams of fatty acids in fourteen days, and increased 17 per cent. in weight during this period. When killed, a well-developed layer of fat was found under the skin, and also large deposits of fat on the internal organs. By use of the knife, 1,100 grams of fat were separated, which resembled mutton suet, and according to chemical analysis must have contained at least 96 per cent. of neutral mutton suet. It is known that fatty acids are formed from the fat of the food in the digestive processes through the action of the pancreatic juice, and the above experiment therefore practically proves that the fat stored in the body of animals may be derived from the fat of the food. Munk's findings have recently been corroborated by Walker, also in experiments with dogs. ${ }^{1}$

While experiments like those quoted above cannot be made with Herbivora, there is sufficient evidence to establish the fact that the fat of the food may, under favorable conditions, directly contribute to the body fat and milk fat of animals. As will be seen later on, however, the fat in the animal body is not derived from one component of the food only, bat generally from both the fat and carbohydrates, or possibly these two in conjunction with the protein of the food, according to the conditions of feeding and the relative amounts of the different components fed.

76. Fat from carbohydrates. - Liebig maintained as early as 1842 that the fat of the Herbivora must be derived in a great measure from the carbohydrates of the food, but considered that it might also be produced from its nitrogenous components. The correctness of this view was questioned by leading scientists of that time, although evidence in its favor was accumulating. In 1852 Lawes and Gilbert published the results of their pig-feeding experiments, showing that a large portion of the fat stored in the body of a fattening pig must come from other sources than the fatty matter of the food. These investigators calculated the

\footnotetext{
1 Centralbl f. Physiologie, IV, p. 590; Jahresbr. d. Thier Chemie, 21,
} p. 32 . 
total dry and organic matter, mineral matter, non-nitrogenous constituents, protein and fat stored in a fat pig in one of their experiments, for each 100 pounds of these constituents consumed as food, with the results shown below.

Substances stored, voided, etc., by a fattening pig for each 100 pounds eaten - Rothamsted Experiment Station. ${ }^{1}$

\begin{tabular}{|c|c|c|c|}
\hline & $\begin{array}{l}\text { Consumed } \\
\text { as food. }\end{array}$ & $\begin{array}{l}\text { Stored up in } \\
\text { the animal. }\end{array}$ & $\mid \begin{array}{c}\text { Expired, per- } \\
\text { spired, or voided }\end{array}$ \\
\hline & Lbs. & Lbs. & Libs. \\
\hline Total dry substance............... & 100 & 15.04 & 84.96 \\
\hline Mineral matter............... & 100 & 2.19 & 97.81 \\
\hline Organic matter...................... & 100 & 15.59 & 84.41 \\
\hline 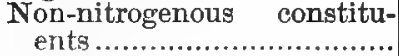 & 100 & 17.74 & 82.26 \\
\hline Nitrogenous constituents..... & 100 & 8.35 & 91.65 \\
\hline 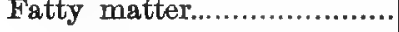 & 100 & $\$ 07.00$ & \\
\hline
\end{tabular}

In other experiments these investigators found from four to five times as much fat stored in the bodies of fattening pigs as had been supplied in the food. In spite of the evidence accumulated through this and other experiments, the view that fat may be formed from carbohydrates was opposed by many scientists until late years, but the question may now be considered settled. Of the large number of experiments bearing on this most important subject, only a few can be here noted. We select late contributions, in which all the precautions known to modern experimenters in animal physiology have been observed.

Kern ${ }^{2}$ found that on an average at least 9871 grams of fat had been stored in the bodies of two full-grown fattening sheep during 70 days' feeding, and that only 74.32 grams could be accounted for as the maximum amount formed from the digestible fat and protein in the food combined. It thus appears that 2439 grams, or 24.7 per cent. of the total quantity of fat stored in the body, must have been derived from carbohydrates.

Soxhlet ${ }^{3}$ fed three full-grown pigs of the same age for about

1 On the Composition of Foods in Relation to Respiration, and the Feeding of Animals, Report British Asso. f. Adv. of Science, 1852, p. 29; Bul. 22, Office of Expt. Sta., pp. 235-82.

2 Journ. f. Landw. 26 , p. 549.

Jahresb. Agr.-Chemie, 1881, p. 434 
ele ven months on the same preparatory ration of 2.2 to 3.3 pounds of barley meal per day, and during the five days preceding the experiment proper, 4.4 pounds of rice meal. At this time the pigs weighed 219, 220 and 213 pounds. One of the pigs was then killed and its body analyzed, while the others were put on a ration of 4.4 pounds of boiled rice, and later on 3.3 pounds of rice, with some meat extract, both of which foods are almost free from fat. One of these animals was killed after 75 days, and the other after 82 days of such feeding, and their bodies analyzed as in the case of the first animal. On the assumption that the composition of the bodies of all the pigs was the same when the first pig was killed, the investigator found the quantity of fat formed in the bodies of the two animals and its source to be as shown below:

Feeding trial with pigs to show formation of fat from carbohydrates - Soxhlet.

\begin{tabular}{l|c|c}
\hline \hline & Pig II. & Pig III. \\
\hline Fat formed in body during experiment........... & 10.082 & 22.180 \\
Taken up in the food................................. & .300 & .340 \\
Formed from components not fat in the food. & 9.782 & 21.840 \\
Nitrogen in the food.......................................... & 1.589 & 1.810 \\
Protein production .................................... & 3.462 & 7.169 \\
Fat formed through decomposition of protein. & 1.779 & 3.685 \\
Fat formed from carbohydrates........................ & $\mathbf{8 . 0 0 3}$ & 18.155 \\
\hline \hline
\end{tabular}

* Protein consumed $\times$ 51.4. (78)

Four to six times as much fat was consequently formed in the bodies of these animals as could have been derived from the fat and protein of the food. Even if there was some difference in the condition of these animals at the end of the preliminary feeding, it could not be large enough to overthrow the conclusion that the carbohydrates were the source of the greater portion of the fat produced during the experiment.

Meissl and Strohmer, ${ }^{1}$ also experimenting on swine, fed two kilograms of rice daily to a one-year old pig weighing 309 pounds. During a part of the time the pig was confined in a Pettenkofer respiration apparatus and the respiration products determined. Of the data obtained the following are reproduced:

1 Jahresb. d. Thier Chemie, 13, p. 39. 
Digested from the food......................... 765.37

Carbon, Nitrogen, grams. grams.

Outgo in respiratory and excreted products.. 476.15

Remaining in the body of the animal.......... 289.22

The surplus of nitrogen corresponds to the formation of 38 grams of protein, (58) containing 20.1 grams of carbon; there is then left for the formation of fat from the carbon surplus 269.12 grams. This would be contained in $269.12 \times 1.3$, (58) or 349.9 grams of fat. The total quantity of fat in the food amounted to 7.9 grams, so that if this was digested and deposited in the body, 342 grams of fat must have been formed from other sources. The nitrogen excreted as urea.showed a decomposition of 65.4 grams of protein in the body of the animal. This quantity of protein could at best form no more than $65.4 \times .514,(78)$ or 33.6 grams of fat, leaving 308.4 grams of fat deposited in the body to be derived from carbohydrates. Seven to eight times as much fat, therefore, originated from this source as could have been formed from the protein and the fat in the food.

The formation of fat from carbohydrates in the nutrition of ruminants, especially cattle, is conclusively proved by the results of experiments conducted by G. Kühn during 1882-90. ${ }^{1}$

77. Formation of fat in milk. - Collier ${ }^{2}$ has shown in the case of a herd of pure-bred cows that the fat in the food was sufficient to account for the fat produced in the milk during all but the first two months of their lactation period. The average ratio of fat in food to fat in milk for the whole period of lactation for all cows was $121: 100$. It should be remembered, however, that the fat in the food consumed by the cows was not wholly digested, and was, moreover, the "crude fat" or ether extract of chemical analysis. This extract contains chlorophyll and other impurities dissolved from the fodders by the ether in the process of analysis. Allowing 17.4 per cent. for impurities, Collier says there is still enough fat in the food to account for the fat recovered in the milk. The experiments with milch cows have not given as decisive

1 Landw. Vers. 44, pp. 1-581.

N. Y. Expt. Station (Geneva), 1891, p. 124. 
results as those made with sheep, pigs, geese and ducks, some of which have been reported in the preceding pages; ${ }^{1}$ but as the formation of fat from carbohydrates has been established in the case of other animals, it follows that cows also have the same ability, since the nutritive processes are essentially the same in all the higher animals.

The formation of fat from carbohydrates was long considered impossible because no intermediate steps in the transformation were known. Lately, however, it has been found that butyric, capronic and higher solid fatty acids are formed from carbohy. drates in putrefactive processes. We have seen that the fatty acids are readily taken up by the animal system and changed into fats, which may be deposited in the body or oxidized, according to the supply of nutrients and the nutritive condition of the animal. (75) This being true, there is no theoretical difficulty in the way of the formation of the fat of milk from carbohydrates.

78. Fat from protein.- It has long been known that fatty acids may be formed from protein substances in putrefactive processes, both in the animal body and elsewhere, and also through oxidizing agents. In certain diseases, especially cases of phosphorus poisoning, fatty degeneration will occur in the body; the muscles waste and a waxy fat appears in their stead, and is also deposited on the internal organs. In one case the dry matter in the liver of a man who died from phosphorus poisoning contained the enormous amount of 76.8 per cent. of fat. ${ }^{2}$ In an experiment by Bauer, ${ }^{3}$ a dog was poisoned with phosphorus after having been starved twelve days. It died seven days later. The excretion of urea was quite constant from the fifth to the twelfth day of the experiment, amounting to 7.8 grams daily. After the poisoning had begun, the excretion increased until it amounted to 23.9 grams per day, $i$. e., three times the normal amount. It was ascertained with another dog treated the same way, but kept in a respiration apparatus, that the excretion of carbonic acid and the amount of oxygen taken up decreased one-half after the phosphorus feeding

1 For a review of the extensive literature on the subject up to August, 1881, mee B. Schulze, Landw. Jahrb., XI, p. 57.

2 Wolff, Landw. Fütterungslehre, 1888, p. 44.

Zeitschr. f. Biologie, VII, p. 76; Voit, Physiologie, p. 248. 
began. In this case there was a greater decomposition of protein into urea and fat, with a smaller absorption of oxygen, and consequently a decreased oxidation of the fat, both processes combining to produce fat in the body. The muscles of the poisoned dog contained 42.4 per cent. of fat, and the liver 30 per cent., or three times more than was present in the normal nutrition of the $\mathrm{dog}$, and at least ten times more than would have been found after twenty days of starvation, if phosphorus had not been administered.

According to Henneberg, 100 pounds of protein will form 33.45 pounds of urea on decomposition; the remainder, 66.55 pounds, after uniting with $\mathbf{1 2 . 3}$ parts of water, may form 51.4 pounds of fat and 27.4 pounds of carbonic acid. The maximum quantity of fat which protein can form under the most favorable conditions is, therefore, 51.4 per cent.

\section{Formation of Fat in the Body.}

79. Concerning fat.-Having ascertained the sources of fat in the animal body, we next consider the principles governing its formation and consumption. The formation of fat in the body will take place when the supply of nutrients in the food exceeds the immediate demands of the system. To study the effect of single nutrients on fat formation and consumption, we follow the plan employed in the study of protein consumption, and investigate the conditions which are most favorable to the formation of fat in the animal body and least favorable to its consumption.

80. Feeding with fat alone.-While exclusive protein feeding induces only protein consumption in the body, and does not contribute to the formation of flesh, an exclusive fat diet has no influence on the decomposition of fat in the body, the same amount being decomposed whether much or little fat is fed. A dog experimeited with by Pettenkofer and Voit lost 96 grams of fat daily during hunger. When 100 grams of fat were fed daily, an average of 97 grams of fat was oxidized, showing that the loss of fat in the body was barely covered by the feeding of fat. ${ }^{2}$ A relatively larger decomposition of fat takes place in the bodies of very fat

\footnotetext{
1 Landw. Versuchs-Stationen, XX, p. 394.

Voit, Physiologie, p. 128.
} 
animals than in lean ones. This partially explains why the fattening of animals grows more difficult during the last stages of the fattening period. (565)

81. Feeding protein alone.-Large quantities of protein protect the body fat from oxidation, as will be seen by the following experiment by Pettenkofer and Voit ${ }^{1}$ with a dog fed exclusively on fat-free meat, and kept in a respiration apparatus:

Feeding fat-free meat to dog in respiration apparatus-Pettenliofer and Voit.

\begin{tabular}{|c|c|c|c|}
\hline Meat fed. & $\begin{array}{l}\text { Protein con- } \\
\text { sumption. }\end{array}$ & $\begin{array}{c}\text { Gain }(+) \text { or loss } \\
(-) \text { of flesh. }\end{array}$ & $\begin{array}{l}\text { Gain }(+) \text { or loss } \\
(-) \text { of body fat. }\end{array}$ \\
\hline 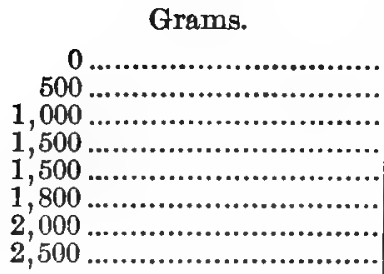 & $\begin{array}{r}\text { Grams. } \\
165 \\
599 \\
1,079 \\
1,499 \\
1,500 \\
1,757 \\
2,044 \\
2,512\end{array}$ & $\begin{array}{r}\text { Grams. } \\
-165 \\
-99 \\
-79 \\
+\quad 1 \\
+43 \\
-44 \\
-12\end{array}$ & $\begin{array}{l}\text { Grams. } \\
-95 \\
-47 \\
-19 \\
+29 \\
+4 \\
+1 \\
+58 \\
+57\end{array}$ \\
\hline
\end{tabular}

The increased feeding of fat-free meat caused an increased consumption of protein, but the decomposition of fat was checked by feeding 1,500 grams (about 3.3 pounds) of fat-free meat per day, and where larger quantities of fat-free meat were fed the animal was able to lay on fat. The consumption of protein was at the same time decreased.

82. Feeding both protein and fat.-The following experiments by Pettenkofer and Voit ${ }^{2}$ show the influence of different quantities of fat and meat on the decomposition of protein and fat in the body of a dog. Comparing the data given in the table, we notice the influence of the feed in the different combinations. Where the same quantity of protein was fed in the form of meat, with varying quantities of fat, the gain in body fat was larger when the largest quantities of fat were fed, and the gain was, as a rule, proportional to the quantity fed. With a liberal supply

1 Voit, ibid., p. 116.

Zeitschr. f. Biologie, IX, p. 30; Voit, Physiologie, p. 134. 
of protein, as in Experiments 5 and 9, about as much fat was left in the body as was supplied in the fat of the food. From this it appears that the body fat formed from the protein in the food is less stable than that derived from the fat of the food, and that fat derived from protein will be decomposed more easily in the body than the fat of the food.

Results of feeding meat and fat to a dog-Pettenkofer and Voit.

\begin{tabular}{|c|c|c|c|c|c|c|}
\hline \multirow{3}{*}{$\begin{array}{c}\text { Expt. } \\
\text { No. }\end{array}$} & \multicolumn{2}{|c|}{ Food, } & \multicolumn{4}{|c|}{ Changes in the body. } \\
\hline & \multirow{2}{*}{ Meat. } & \multirow{2}{*}{ Fat. } & \multicolumn{2}{|c|}{ Protein. } & \multicolumn{2}{|l|}{ Fat. } \\
\hline & & & $\begin{array}{l}\text { Consump- } \\
\text { tion. }\end{array}$ & Gain. & Consumption. & Gain. \\
\hline & Grams. & Grams. & Grams. & Grams. & Grams. & Grams. \\
\hline $\begin{array}{l}1 \ldots \ldots \ldots . \\
2 \ldots \ldots \ldots \\
3 \ldots \ldots \ldots \\
4 \ldots \ldots \ldots \\
5 \ldots \ldots \ldots \\
6 \ldots \ldots \ldots \\
7 \ldots \ldots \ldots \\
8 \ldots \ldots \ldots \\
9 \ldots \ldots \ldots\end{array}$ & $\begin{array}{r}400 \\
500 \\
500 \\
800 \\
1,500 \\
1,500 \\
1,500 \\
1,500 \\
1,500\end{array}$ & $\begin{array}{r}200 \\
100 \\
200 \\
350 \\
30 \\
60 \\
100 \\
100 \\
150\end{array}$ & $\begin{array}{r}450 \\
491 \\
517 \\
635 \\
1,457 \\
1,501 \\
1,402 \\
1,451 \\
1,455\end{array}$ & $\begin{array}{r}-50 \\
+\quad 9 \\
+17 \\
+165 \\
+\quad 43 \\
+\quad 1 \\
+\quad 98 \\
+49 \\
+45\end{array}$ & $\begin{array}{r}159 \\
66 \\
109 \\
136 \\
0 \\
21 \\
9 \\
0 \\
14\end{array}$ & $\begin{array}{r}41 \\
34 \\
91 \\
214 \\
32 \\
39 \\
91 \\
109 \\
136\end{array}$ \\
\hline
\end{tabular}

83. Feeding with protein and carbohydrates.-For information regarding this subject, as in the preceding ones, we have recourse to the experiments of Pettenkofer and Voit. ${ }^{1}$.

Feeding protein and carbohydrates to a dog-Pettenkofer and Voit.

\begin{tabular}{|c|c|c|c|c|c|c|c|c|c|}
\hline & Foo & & & Amount of & & Amount & & Fat. & \\
\hline Flesh & Fbs & suger & Fat & $\begin{array}{l}\text { composed } \\
\text { calculated } \\
\text { from urea } \\
\text { excreted. }\end{array}$ & $\begin{array}{l}\text { gained or } \\
\text { lost by the } \\
\text { body. }\end{array}$ & $\begin{array}{l}\text { or carbo- } \\
\text { bydirates } \\
\text { decom- } \\
\text { posed. }\end{array}$ & $\begin{array}{l}\text { From } \\
\text { fat of } \\
\text { food. }\end{array}$ & $\begin{array}{l}\text { Lost } \\
\text { from } \\
\text { the } \\
\text { body. }\end{array}$ & $\begin{array}{l}\text { Derived } \\
\text { from } \\
\text { food } \\
\text { other } \\
\text { than fat }\end{array}$ \\
\hline I & 379 & . & 17 & 211 & -211 & 379 & +17 & & 24 \\
\hline$?$ & 608 & ............ & 22 & 193 & -193 & 608 & +22 & & 22 \\
\hline 40 & 211 & & 10 & 436 & -36 & 211 & -10 & -8 & ......... \\
\hline 400 & & 227 & & 393 & +7 & 227 & & -25 & \\
\hline 400 & 344 & ....... & 6 & 413 & -13 & 344 & +6 & & 39 \\
\hline 500 & 167 & & 5 & 568 & -68 & 167 & +5 & ........... & 20 \\
\hline 500 & & 182 & & 537 & -37 & 182 & & ........... & 16 \\
\hline 800 & 379 & ........... & 14 & 608 & +192 & 379 & +14 & & 55 \\
\hline 1500 & 172 & ........... & 4 & 1475 & +25 & 172 & +4 & .......... & 43 \\
\hline 1800 & 379 & ........... & 10 & 1469 & +331 & 379 & +10 & & 112 \\
\hline 2500 & & & & 2512 & +12 & 0 & r & ............ & 57 \\
\hline
\end{tabular}

1 Los. cit., p. 145. 
Even when the food given consisted of non-nitrogenous materials only, there was a laying-on of fat; when only protein was fed, the excretion of urea was increased proportionately, and there Tas a small production of fat, which may have been derived from the small amount of fat always present in lean meat.

Voit found from a number of experiments that carbohydrates cause a decrease of fat consumption in the body, and that they are oxidized in preference to the body fat. If enough carbohydrates are fed with the protein, all the fat that may have originated from the protein may be deposited as body fat. If the quantity of carbohydrates fed is increased beyond this point, there will be no further laying-on of fat, the excess of carbohydrates being burned. In this particular the carbohydrates act differently from fat fed in conjunction with protein, since the more fat the animal can be induced to eat the larger will be the quantity of fat deposited.

Voit's position, that even the largest quantities of carbohydrates fed in connection with protein are decomposed in the animal body, is held untenable by Pflüger, ${ }^{1}$ who maintains that if an amount of fat or starch above the needs of the system be fed to an animal whose nitrogen income and outgo has been brought to a state of equilibrium, the nutritive balance will not be influenced thereby; $i$. e., the excretion of urea and oxidation of carbon will go on without increase, the excess of fat or starch passing off nndigested.

84. Relative value of fat and carbohydrates. - In experiments with fat and carbohydrates for fat production in the animal body, Pettenkofer and Voit' found that 100 parts of fat were equivalent to 172-179 parts, average 175 parts, of carbohydrates (starch) for this purpose. When considering the formation of flesh in the animal body, it was shown that carbohydrates and fat were practically of equal value, pound for pound, as aids in flesh formation. (70) Neither of these offices can be filled by fats to the extent indicated by their fuel value as determined by calorimetric investigations, (60) or as would be inferred from the quantity of

1 Pflüger's Archiv, 51 (1892), p. 317.

2 Voit, Physiologie, p. 150. 
oxygen required for their complete combustion into carbonic acid and water.

85. Effect of water on fat consumption.- Excessive water drinking and the feeding of very wet foods have a deleterious effect on the formation of fat. Any conditions which cause an excessive consumption of water must of conrse be avoided with fattening animals. Abnormally large quantities of water tax the system unnecessarily and retard the formation of flesh and fat. A high stable temperature is to be avoided, as it increases the amount of water drank and induces greater perspiration. Animals worry and lose their appetites under such conditions. Too low a temperature, on the other hand, is objectionable, since increased oxidation is then necessary to maintain the body beat.

36. Size of the body.- A small animal has a relatively larger body surface, and therefore loses more heat through radiation, than a large-sized animal. According to Henneberg, ${ }^{1}$ more than nine-tenths of all the heat produced by the animal goes to supply the loss sustained by radiation and to evaporation of water in perspiration. Of the heat lost, 26.7 per cent. is through perspiration and 65.1 per cent. is by radiation. For the same classes of animals the radiation of heat stands in the ratio of relative body surface. The body surface of animals of different classes, however, does not alone determine the quantity of nutrients needed for the preservation of the animal. According to maintenance experiments, an ox will need about.6 grams of protein and 7.4 grams of non-nitrogenous substances for every kilogram of body weight, while a full-grown sheep will need 1.2 grams of protein and 10.5 grams of non-nitrogenous substances per kilogram of body weight. ${ }^{2}$

87. Muscular exertion.-Muscular exertion of any kind increases the oxidation processes going on in the body of animals; vigorous exercise must therefore be avoided in the case of fattening stock and milch cows. While this applies to external movements, it also holds good so far as the internal organs are

\footnotetext{
Neue Beiträge, 1871, p. 227; Armsby, Manual, p. 231.

2 Wolff, Fuitterungslehre, 1888, p. 54 .
} 
concerned, especially the work of digesting feed. A bulky fodder requires more energy on the part of the animal to move it through the digestive canal, and larger quantities of digestive fluids to extract its nutritive elements than does a concentrated todder; hence the importance of supplying hard-worked horses, milch cows and fattening animals a concentrated, easily-digested ration.

88. Concerning the fattening process.- The process of fattening depends on the amount of nutrients taken up by the system over and above its requirements. It is therefore evident that anything which will decrease the oxidation processes going on in the body, that is, decrease the waste caused by the wear and tear of muscles and internal organs, will prove conducive to fat production. The quantity of oxygen taken up by the blood is dependent on the nutritive condition of the body; the more material supplied and the more energetic the processes of decomposition, the more oxygen is needed. There is, however, a limit to the amount of oxygen that can be absorbed by the blood, this limit being determined by the amount of blood in the body and its content of hæmoglobin, the characteristic coloring matter of the red blood corpuscles. A small amount of blood and a small hæmoglobin content of the same are therefore favorable to fattening. We see in this a possible explanation of the custom reported to be practiced in some parts of Europe of bleeding fattening animals.

Reference has been made to the possible formation of fat by a degenerative process from the muscles of the body through phosphorus poisoning; (78) the phosphorus in this case acts as a poison by depriving the blood of its oxygen, and the result is the formation of fatty matter from the muscular tissues.

89. Influence of light on fattening.-The influence of light on fattening has been studied by Graffenberger, ${ }^{1}$ the experiments being made with both young and full-grown rabbits. One set of animals was kept in the light, and another in a dark room. The investigator found that the content of hrmoglobin in the blood of the rabbits kept in the dark was decreased, and the amount of

\& Pftüger's Archiv, 63 (1893), p. 238. 
blood in the bodies of these animals decreased somewhat on long confinement in a dark room. The average quantity of blood in the animals kept in the light was 22.2 grams, and of those kept in a darkened room, 17.2 grams. In another experiment, the bodies of rabbits kept in light and dark rooms contained 100.5 grams and 90.6 grams of blood, respectively. According to these experiments, darkening the stable will have a stimulating influence on the formation of fat in the bodies of animals. Graffenberger also ascertained that the production of fat in animals kept in the light and those kept in the dark was as 100:126 for the first 16 days. After 46 days the ratio was as $100: 119$. With full-grown animals the increase was as $100: 216$ after 24 days, and as $100: 138$ after 75 days.

The deprivation of daylight, therefore, caused an increase in the formation of fat and an increase in live weight. The increase was larger in the case of full-grown animals than with younger ones; and further, by prolonging the absence of light the increase was relatively smaller than for the shorter time. As the development of the skeleton and liver of the animal is retarded by darkness, the prolonged absence of light has a deleterious effect upon the health of the animal. While Graffenberger corroborates the results of Moleschott, ${ }^{1}$ Platen, ${ }^{2}$ and other early investigators, that light causes an increased excretion of carbonic acid and a greater consumption of oxygen, he finds that protein consumption is not influenced by the absence or presence of daylight.

1 Wien Med. Wochenschr., 1855, No. 43.

2 Pflüger's Archiv, 11, p. 272 


\section{CHAPTER V.}

THE SOURCE OF MUSOULAR ENERGY; COMPOSITION OF ANIMALS BEFORE AND AFTER FATTENING.

\section{The Source of Muscular Energy and the Production of Force.}

90. Food the basis of life.- The altimate object of most of the food supplied to the animal is the production of work. All the manifestations of life, shown in a thousand ways by the animal, are in some manner derived from the food. The horse is kept for the direct production of labor. The cow, in furnishing milk, supplies a substance used for building up the tissues of the body or for the production of work. Doubtless the manner in which the food is converted into energy will always exceed man's power to definitely determine, but many facts in this connection already known are interesting and highly instructive.

We have learned that the substances which enter the body as food can be grouped under three great divisions: protein, carbohydrates, and ether extract. (7-9) We have further learned that when the protein of the food has entered the body proper and been broken down, the amount of this loss to the body can be measured by nitrogen found in the urea. (57) The carbohydrates and ether extract, when absorbed from the alimentary tract to nurture the body, may be built up into body fat or decomposed into carbonic acid and water, heat and energy being given off in this process. The water resulting from the decomposition cannot be used as a measure of the broken-down carbohydrates and fat, for the reason that it is mingled with water from other sources when excreted. Scientists are, nevertheless, able to determine the quantity of these substances which has been broken down, by measuring the carbonic acid exhaled in the breath of the animal. 
91. Liebig's theory.- It was held by Liebig that the exercise of force is due to the breaking-down of lean-meat tissue in the animal body, as is shown by the following: ${ }^{1}$

"The amount of azotized food (protein) necessary to restoro the equilibrium between waste and supply is directly propor. tional to the amount of tissues metamorphosed.

"The amount of living matter, which in the body loses the condition of life, is, in equal temperatures, directly proportional to the mechanical effects produced in a given time.

"The amount of tissue metamorphosed in a given time may be measured by the quantity of nitrogen in the urine.

"The sum of the mechanical effects produced in two individuals in the same temperature is proportional to the amount of nitrogen in their urine; whether the mechanical force has been employed in voluntary or involuntary motions, whether it has been consumed by limbs or by the heart and other viscera."

92. Lawes and Gilbert's trial._Lawes and Gilbert held a different view, believing that protein did not play the exclusive part in the production of energy claimed for it. Putting their doubts to test, they conducted the following experiment: ${ }^{2}$ Two pigs of similar weight and appearance were selected. To one was given all it would consume of lentil meal, a feed rich in protein, containing about 4 per cent. of nitrogen. The other pig was fed all it would consume of barley meal, containing less than 2 per cent. of nitrogen. Each pig was confined in a frame, with arrangements for collecting the fæces and urine separately. All the usual precautions for good work were observed, with the following results:

Feeding pigs protein-rich and protein-poor rations - Rothamsted Station.

\begin{tabular}{|c|c|c|c|c|}
\hline Periods. & Food. & $\begin{array}{l}\text { Nitrogen } \\
\text { in food. }\end{array}$ & $\begin{array}{c}\text { Urea } \\
\text { voided. }\end{array}$ & $\begin{array}{c}\text { Urea- } \\
\text { nitrogen. }\end{array}$ \\
\hline Days. & & Grams. & Grams. & Grams. \\
\hline 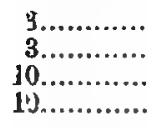 & $\begin{array}{l}\text { No. 1, lentil meal .............. } \\
\text { No. 2, barley meal............ } \\
\text { No. 1, lentil meal.............. } \\
\text { No. 2, barley meal............ }\end{array}$ & $\begin{array}{r}123 . \\
58.9 \\
120.6 \\
51.2\end{array}$ & $\begin{array}{c}134 . \\
61.5 \\
141 . \\
52.1\end{array}$ & $\begin{array}{l}62.6 \\
28.7 \\
65.8 \\
24.3\end{array}$ \\
\hline
\end{tabular}

${ }_{1}^{1}$ Organic Chemistry in its Application to Physiology and Pathology.

2 Jour. Roy. Agl. Soc., 1895; Bul. 22, Office of Expt. Sta. 
Here were two animals at rest, one getting much nitrogen in its feed and the other a limited amount. While the work performed by the pigs was equal, or very nearly so, for both were equally at rest, the amount of nitrogen excreted in the urea varied greatly, being in proportion to the amount of that element in the feed given.

93. Nitrogen excretion during hard labor.- We next present a case in which there was severe physical exertion, that we may learn whether the nitrogen excreted bears a direct relation to the work performed. In 1865, Professors Fick and Wislicenus ascended the Faulhorn, an Alpine mountain. ${ }^{1}$ In this laborious effort they were careful to note their diet and to preserve all the urine excreted during the trip, which was afterwards analyzed. From before the ascent until after returning, the food consumed contained only starch, fat and sugar. The following is a surr. mary of the results so far as they relate to the point under consideration:

Nitrogen excreted in the urine by Fick and Wislicenus while ascending Mt. Faulhorn.

\begin{tabular}{|c|c|c|c|c|}
\hline & Urea. & $\begin{array}{l}\text { Nitrogen. } \\
\text { in urea. }\end{array}$ & $\begin{array}{c}\text { Total } \\
\text { nitrogen. }\end{array}$ & $\begin{array}{l}\text { Nitrogen. } \\
\text { excreted } \\
\text { per hour } \\
\text { (average). }\end{array}$ \\
\hline \multirow{5}{*}{$\begin{array}{l}\text { Fick. } \\
\text { Night before ascent ......... } \\
\text { During ascent.................. } \\
\text { After ascent.................. } \\
\text { Night after ascent .......... }\end{array}$} & Grams. & Grams. & Grams. & Grams. \\
\hline & 12.4820 & 5.8249 & \multirow{4}{*}{$\begin{array}{l}6.9153 \\
3.3130 \\
2.4293 \\
4.8167\end{array}$} & \multirow{4}{*}{$\begin{array}{r}0.63 \\
.41 \\
.40 \\
.45\end{array}$} \\
\hline & 7.0330 & 3.2681 & & \\
\hline & 5.1718 & 2.4151 & & \\
\hline & & & & \\
\hline \multirow{5}{*}{$\begin{array}{l}\text { Wislicenus. } \\
\text { Night before ascent .......... } \\
\text { During ascent.................. } \\
\text { After ascent................... } \\
\text { Night after ascent........... }\end{array}$} & & & \multirow{5}{*}{$\begin{array}{l}6.6841 \\
3.1336 \\
2.4165 \\
5.3462\end{array}$} & \multirow{5}{*}{$\begin{array}{l}.61 \\
.39 \\
.40 \\
.51\end{array}$} \\
\hline & 11.7614 & 5.4887 & & \\
\hline & 6.6973 & 3.1254 & & \\
\hline & 5.1020 & 2.3809 & & \\
\hline & & ...................... & & \\
\hline
\end{tabular}

"The record of the actual quantities is sufficient to show that much less nitrogen was excreted by both experimenters during and after than before the ascent. But the calculated amounts of

\footnotetext{
1 Loc. cit.
} 
nitrogen excreted per hour during each of the periods, as given in the last column of the table, bring the main results more clearly to view. It is seen that, on the average, only about two-thirds as much nitrogen was excreted per hour during and after the ascent as prior to it, when there would be more or less residue in the system from the last albuminous meal."

Had the nitrogenous tissues of the body been broken down directly in proportion to the labor performed, there would have been a large increase of nitrogen in the urea of these persons during and just after their fatiguing work, but such is not the case.

In 1866, Frankland, ${ }^{1}$ studying the sources of muscular power, made numerous calorimetrical determinations of the energy evolved by the combustion of muscle, urea and various foods, or constituents of food, and concluded that the transformation of muscular tissue alone cannot account for more than a small fraction of the muscrlar power developed by animals.

94. The excretion of carbonic acid.- Let us now study the quantities of carbonic acid given off by animals under different conditions of labor and rest.

The great increase in the carbonic acid exhaled during work, and its decrease with the cessation of work, are clearly brought out in trials by Smith, ${ }^{2}$ as shown in the following table:

Amount of carbonic acid exhaled by the horse under varying conditions - Smith.

\begin{tabular}{|c|c|c|c|}
\hline & \multicolumn{3}{|c|}{ Carbonic acid exhaled per hour. } \\
\hline & $\begin{array}{l}\text { Pony (work } \\
\text { trotting). }\end{array}$ & $\begin{array}{c}\text { Horse (work } \\
\text { galloping). }\end{array}$ & $\begin{array}{l}\text { Horse (work } \\
\text { galloping). }\end{array}$ \\
\hline & Cubic feet. & Cubie feet. & Cubic feet. \\
\hline 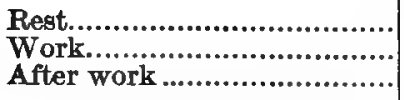 & $\begin{array}{r}0.7648 \\
2.3954 \\
.4631\end{array}$ & $\begin{array}{r}20.6265 \\
1.3133\end{array}$ & $\begin{array}{r}12.4353 \\
1.1693\end{array}$ \\
\hline
\end{tabular}

1 Phil. Mag. 1866, 4th Ser. Vol. XXXII, p. 182; loc. cit.

? Jour. Physiology, 1890, No. 1; loc. cit. 
The following table by the same investigator shows the great increase in the carbonic acid gas exhaled with increasing labor:

Carbonic acid exhaled by the horse at rest and at work - Smith.

\begin{tabular}{|c|c|c|}
\hline & \multicolumn{2}{|c|}{$\begin{array}{c}\text { Carbonic acid exhaled } \\
\text { per hour. }\end{array}$} \\
\hline & Series A. & Series B. \\
\hline & Cubic feet. & Cubic feot. \\
\hline 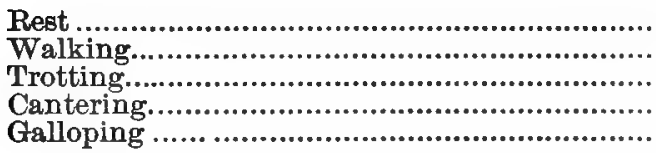 & $\begin{array}{r}1.0282 \\
1.0972 \\
2.9482 \\
4.9159 \\
14.9725\end{array}$ & $\begin{array}{l}1.2346 \\
1.0586 \\
4.8309 \\
5.0080 \\
\ldots \ldots \ldots\end{array}$ \\
\hline
\end{tabular}

These tables show the variation in the amount of carbonic acid given off by the lungs of animals during labor, and the rapid increase as the labor increases. No such findings are on record with regard to the excretion of nitrogen in the urea. The conclusion is irresistible that the carbohydrates and the fat of the food and of the body, and not protein, are the main sources of body energy.

95. Body heat does not measure the energy of food.- On this subject Wolff writes:" "The great increase in the combustion of fat during work has led to the assumption that this constitutes the chief source of muscular energy, that the work done is the result of the heat produced, and that in the animal body a conversion of heat into force takes place, just as the steam-engine produces work through the heat of the burning fuel by the intervention of steam, or as the hot-air engine executes work by means , of the heated air. The non-nitrogenous food stuffs are directly concerned in this heat production, and it has been calculated that 20 per cent. of the heat produced by their combustion is converted into work, which is a far larger proportion than that yet attained by the most efficient steam-engines, which only convert about 10 per cent. of the heat they receive into work. It is open to question, however, whether the heat produced in the body can be directly converted into mechanical work as in the case of the

1 Farm Foods, English edition, pp. 82, 83. 
air engine, or can even be considered its direct source, since the necessary conditions of alternate heating and cooling of the whole or a part do not hold good in the animal body, and make a comparison between the two impossible. . . . . The increased production of heat during work and the increased respiration are but secondary effects, the result of work, and can by no means be regarded as its primary or direct cause. The increased heat produced in work is dissipated in evaporation from the body and by greater heat radiation, and is eventually reduced again to the normal."

96. Food requirements for work vary.-Wolff further writes: ${ }^{1}$ "The food required to produce work varies with the form of muscular activity or the work done. Katzenstein, for instance, found that work done by men turning a wheel with the arms produced a greater expenditure of material in the body than the same work done with the legs. The volume of oxygen used per kilogram-meter of work done with hand-labor amounted to $\mathbf{1 . 9 6}$ cubic centimeters, but when the work was done with the legs, only from 1.19 to 1.51 cubic centimeters."

Further, the degree of practice in a particular kind of work influences the expenditure of material in the body, as Gruber found by experiments on himself. The carbonic acid produced every twenty minutes amounted to the following:

\begin{tabular}{|c|c|c|c|c|}
\hline & \multirow{2}{*}{ Rest. } & \multirow{2}{*}{ Walking. } & \multicolumn{2}{|c|}{ Climbing. } \\
\hline & & & $\begin{array}{l}\text { Out of } \\
\text { practice. }\end{array}$ & $\begin{array}{l}\text { In } \\
\text { practice. }\end{array}$ \\
\hline $\begin{array}{l}\text { Carbonic acid, grams................ } \\
\text { Work, kilogram-meter............ }\end{array}$ & 12.83 & 22.42 & $\begin{array}{r}38.83 \\
7376\end{array}$ & $\begin{array}{r}31.00 \\
7639\end{array}$ \\
\hline
\end{tabular}

Zuntz and Lehmann obtained similar results in their experiments on the horse. "It can be deduced from the total experimental results that no constant relationship can be set up between the production of work and consumption of food; the entire organization of an animal, its individual and variable pecoliarities and condition, etc., create great differences in the economical

1 Farm Foods, pp. 84, 85. 
employment of its power in doing the same piece of work; with the same individual the quality and intensity of the work prodnces great differences, and further researches are required to reduce the variations in question by regular use to an individual and perhaps a typical average value."

97. The sources of muscular energy.- Wolff further says: ${ }^{1}$ "The essential sources of muscular power are seen in the decom. position processes in the body, $i . e$, in the destruction which portions of the body or the food resorbed from the digestive tract undergo by the passage of the plasma through the tissues. To this end, as we have already seen in the case of fat-production, both nitrogenous and non-nitrogenous substances contribute. As these materials are resolved by the influence of oxygen into simple groups of atoms, the energy of chemical force which previously linked the atoms together in more complicated groupings is set at liberty, and can be employed as kinetic energy for the external work of the body. In a condition of rest, this energy serves for the internal work of the organs or is converted into electric current, etc. The animal body often stores up a certain amount of energy; as soon as this store has been rapidly exhausted by work, a period of rest is necessary to enable fresh material to flow through the tissue-cells and generate fresh energy for the production of more active work. The force-production and all phenomena resulting from the combustion of organic matter in the animal body must obey the law of the conservation of energy."

98. Conclusion.- Taking the experiments here presented and many others by the investigators for guidance, we may conclude that in the exercise of force there is greatly increased expenditure of the non-nitrogenous constituents of the food (carbohydrates and ether extract), and but little of the nitrogenous. (444) At the same time the importance of nitrogenous food must not be under-estimated, for, as Wolff tells us: "No one expects much work from men or animals fed on a diet poor in nitrogen, such as potatoes and rice. Fatness of body is never considered a sign of muscular strength."

1 Farm Foods, pp. 85, 86. 
"A highly liberal diet is absolutely necessary to preserve the flesh and fat in the body, and at the same time to keep it in a powerful condition. An addition of fat, which is the most intense respiration material, is often a desirable addition and nearly as important as albumen; and it is a suggestive fact that the working classes have a decided taste for fatty dishes, and that oats - a food proportionately rich in fat-are recognized as an excellent food for horses." "

In the above we have the strongest statements possible in faror of the importance of protein for the production of work. When we consider the large proportion of carbohydrates and ether extract in the ration, and remember that fat contains more than twice the heat units of protein, we must concede that these food-groups furnish most of the energy developed in the animal body. (433445)

II. Composition of Steers, Sheep and Pigs, and their Increase during Fattening.

99. Investigations of Lawes and Gilbert.-The only extended investigations concerning the composition of the bodies of farm animals and of the increase during fattening are those conducted. by Lawes and Gilbert of the Rothamsted (England) Station. These investigations, which were begun in 1848, were first published in 1859. ${ }^{2}$ The second part, relating to the composition of the ash of the entire animal and certain separate parts, was published in $1863 .{ }^{3}$ This work will stand for all time a witness to the high standard of painstaking research established by these pioneer English experimenters in agricultural science. Only a brief summary of their work can here be given, taken mainly from their recent contribution on The Feeding of Animals. 4

To determine the ultimate composition of steers, sheep and pigs, the entire bodies of ten animals of each group were subjected to analysis. The findings are condensed in the table here given:

\footnotetext{
1 Farm Foods, p. 91.

2 Phil. Trans., Part II, 1859; Jour. Roy. Agl. Soc., 1860.

a Phil. Trans., Part III, 1883; Rothamsted Memoirs, Vols. II, III, IV.

4 Jour. Roy. Agr. Soc., 1895. See also Bul. 22, Office of Experiment Stations.
} 
Percentage composition of the entire bodies, the carcasses and the offal of ten animals of different descriptions, or in different conditione of maturity - Lawes and Gilbert.

\begin{tabular}{|c|c|c|c|c|c|c|}
\hline Description of animal. & $\begin{array}{l}\text { Mineral } \\
\text { matter } \\
\text { (ash). }\end{array}$ & $\begin{array}{c}\text { Nitroge- } \\
\text { nous sub- } \\
\text { stance. }\end{array}$ & Fat. & $\begin{array}{c}\text { Total dry } \\
\text { sub- } \\
\text { stance. }\end{array}$ & Water. & $\begin{array}{l}\text { Contentm } \\
\text { of stom- } \\
\text { ach and } \\
\text { intestin's } \\
\text { in moist } \\
\text { state. } \\
\end{array}$ \\
\hline \multicolumn{7}{|c|}{ Division I. Per cent. In the entire animal (fasted live weight). } \\
\hline 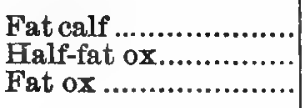 & $\begin{array}{l}3.80 \\
4.66 \\
3.92\end{array}$ & $\begin{array}{l}15.2 \\
16.6 \\
14.5\end{array}$ & $\begin{array}{l}14.8 \\
19.1 \\
30.1\end{array}$ & $\begin{array}{l}33.8 \\
40.3 \\
48.5\end{array}$ & $\begin{array}{l}63.0 \\
51.5 \\
45.5\end{array}$ & $\begin{array}{l}3.17 \\
8.19 \\
5.98\end{array}$ \\
\hline $\begin{array}{l}\text { Fat lamb ................. } \\
\text { Store sheep ............. } \\
\text { Half-fat old sheep ..... } \\
\text { Fat sheep ................. } \\
\text { Extra-fat sheep ........ }\end{array}$ & $\begin{array}{l}2.94 \\
3.16 \\
3.17 \\
2.81 \\
2.90\end{array}$ & $\begin{array}{l}12.3 \\
14.8 \\
14.0 \\
12.2 \\
10.9\end{array}$ & $\begin{array}{l}28.5 \\
18.7 \\
23.5 \\
35.6 \\
45.8\end{array}$ & $\begin{array}{l}43.7 \\
36.7 \\
40.7 \\
50.6 \\
59.6\end{array}$ & $\begin{array}{l}47.8 \\
57.3 \\
50.2 \\
43.4 \\
35.2\end{array}$ & $\begin{array}{l}8.54 \\
6.00 \\
9.05 \\
6.02 \\
5.18\end{array}$ \\
\hline 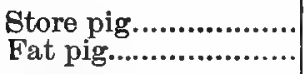 & $\begin{array}{l}2.67 \\
1.65\end{array}$ & $\begin{array}{l}13.7 \\
10.9\end{array}$ & $\begin{array}{l}23.3 \\
42.2\end{array}$ & $\begin{array}{l}39.7 \\
54.7\end{array}$ & $\begin{array}{l}55.1 \\
41.3\end{array}$ & $\begin{array}{l}5.22 \\
3.97\end{array}$ \\
\hline Means of all .......... & 3.17 & 13.5 & 28.2 & 44.9 & 49.0 & 6.13 \\
\hline \multicolumn{7}{|c|}{ Division II. Per cent. In carcass. } \\
\hline $\begin{array}{l}\text { Fat calf ..................... } \\
\text { Half-fat ox............... } \\
\text { Fat ox ..................... }\end{array}$ & $\begin{array}{l}4.48 \\
5.56 \\
4.56\end{array}$ & $\begin{array}{l}16.6 \\
17.8 \\
15.0\end{array}$ & $\begin{array}{l}16.6 \\
22.6 \\
34.8\end{array}$ & $\begin{array}{l}37.7 \\
46.0 \\
54.4\end{array}$ & $\begin{array}{l}62.3 \\
54.0 \\
45.6\end{array}$ & \\
\hline $\begin{array}{l}\text { Fat lamb................. } \\
\text { Store sheep............. } \\
\text { Half-fat old sheep..... } \\
\text { Fat sheep ................ } \\
\text { Extra-fat sheep ........ }\end{array}$ & $\begin{array}{l}3.63 \\
4.36 \\
4.13 \\
3.45 \\
2.77\end{array}$ & $\begin{array}{r}10.9 \\
14.5 \\
14.9 \\
11.5 \\
9.1\end{array}$ & $\begin{array}{l}36.9 \\
23.8 \\
31.3 \\
\mathbf{4 5 . 4} \\
55.1\end{array}$ & $\begin{array}{l}51.4 \\
42.7 \\
50.3 \\
60.3 \\
67.0\end{array}$ & $\begin{array}{l}48.6 \\
57.3 \\
49.7 \\
39.7 \\
33.0\end{array}$ & ( \\
\hline 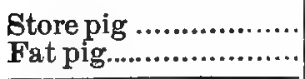 & $\begin{array}{l}2.57 \\
1.40\end{array}$ & $\begin{array}{l}14.0 \\
10.5\end{array}$ & $\begin{array}{l}28.1 \\
49.5\end{array}$ & $\begin{array}{l}44.7 \\
61.4 \\
\end{array}$ & $\begin{array}{l}55.3 \\
38.6\end{array}$ & \\
\hline Means of all. & 3.69 & 13.5 & 34.4 & 51.6 & 48.4 & \\
\hline
\end{tabular}

Division III. Per cont. In offal (excluding contents of atomach and intestines).

\begin{tabular}{|c|c|c|c|c|c|c|}
\hline 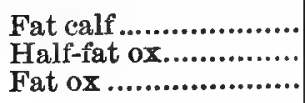 & $\begin{array}{l}3.41 \\
4.05 \\
3.40\end{array}$ & $\begin{array}{l}17.1 \\
20.6 \\
17.5\end{array}$ & $\begin{array}{l}14.6 \\
15.7 \\
26.3\end{array}$ & $\begin{array}{l}35.1 \\
40.4 \\
47.2\end{array}$ & $\begin{array}{l}64.9 \\
59.6 \\
52.8\end{array}$ & (n........... \\
\hline $\begin{array}{l}\text { Fat lamb................. } \\
\text { Store sheep ............. } \\
\text { Half-fat old sheep ..... } \\
\text { Fat sheep ................. } \\
\text { Extra-fat sheep ........ }\end{array}$ & $\begin{array}{l}2.45 \\
2.19 \\
2.72 \\
2.32 \\
3.64\end{array}$ & $\begin{array}{l}18.9 \\
18.0 \\
17.7 \\
16.1 \\
16.8\end{array}$ & $\begin{array}{l}20.1 \\
16.1 \\
18.5 \\
26.4 \\
34.5\end{array}$ & $\begin{array}{l}41.5 \\
36.3 \\
38.9 \\
44.8 \\
54.9\end{array}$ & $\begin{array}{l}58.5 \\
63.7 \\
61.1 \\
55.2 \\
45.1\end{array}$ & ….......... \\
\hline 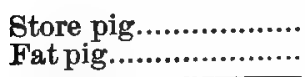 & $\begin{array}{l}3.07 \\
2.97\end{array}$ & $\begin{array}{l}14.0 \\
14.8\end{array}$ & $\begin{array}{l}15.0 \\
22.8\end{array}$ & $\begin{array}{l}32.1 \\
40.6\end{array}$ & $\begin{array}{l}67.9 \\
59.4\end{array}$ & \\
\hline Means of all ......... & 3.02 & 17.2 & 21.0 & 41.2 & 58.8 & \\
\hline
\end{tabular}


The first division of the table relates to the composition of the entire body (fasted live weight) of the animal. Referring to the second column, headed "mineral matter," we learn that in every 100 pounds of the body of the fat calf there are 3.8 pounds of ash or mineral matter; that is, if the body of the calf were consumed by fire, there would remain that amount of ash for each 100 pounds of body weight. With the half-fat ox the ash amounts to 4.66 pounds, while for the fat ox it falls to 3.92 pounds for each 100 pounds live weight.

In like manner we learn that in 100 pounds of live lean pig (fasted weight) there are 2.67 pounds of ash or mineral matter, while in the fat pig there are only 1.65 pounds. The pig has less mineral matter in its body than other farm animals.

100. Nitrogenous substance.-In the muscles, tendons, ligar ments, hide, hair, horns, blood, nerves and organic matter of the bones is found the nitrogenous substance of the body. Most of the nitrogenous substance is in the red meat or lean portion of the flesh. For each 100 pounds of body weight the fat calf has $\mathbf{1 5 . 2}$ pounds of nitrogenous substance. This is slightly increased for the half-fat $o x$, and reduced for the fat $o x$. In the lean sheep and pig there is less nitrogenous substance than in the fat calf, while for the extra-fat sheep and fat pig the lean meat constitutes only 10.9 pounds in each 100 pounds of body.

101. Fat of the body. - In the fat calf there are 14.8 pounds of fat for 100 pounds of body weight. This is increased to 19.1 for the half-fat ox and 30.1 pounds for the ox when fat. Lean sheep show 18.7 pounds of fat, while in extra fat sheep it runs up to 45.8 per 100 pounds weight. The lean pig shows 23.3 per cent. and the fat pig 42.2 per cent. of fat.

It is interesting to observe that the body of the fat calf contains almost as much fat, and that of the fat ox more than two pounds of fat, for each pound of nitrogenous or lean-meat substance. Even in lean sheep there is more fat than lean meat, and with the extra-fat sheep there is four times as much fat as dry lean meat. The same is true of the fat pig.

102. Water and dry substance in the body.- In the next two colnmns of the table is a statement of the total dry substance and 
the water in the animal's body. It is shown that 63 out of every 100 pounds live weight of the fat calf's body is water. With the half-fat $o x$, this is materially reduced, and with the fat ox it amounts to 45.5 per cent. Thus we learn that considerably more than half the body weight of the calf, and nearly half that of the fatted ox is water. In extra-fat sheep the water content falls to 35.2 pounds, the lowest of all farm animals, while for the fat pig it is 41.3 pounds for each 100 pounds. On the average, for all animals studied, 49 pounds in every 100 of body weight is water. The supreme importance of this neutral fluid to the animal system is strikingly brought out by these figures.

103. Composition of the increase while fattening.- - Lawes and Gilbert's researches furnish data showing that the process of fattening is really what the term implies - the laying-on of fat. During fattening the percentage of total dry matter in the body is considerably increased, and the fatty matter accumulated is much greater than the nitrogenous substance. The increase during fattening of moderately fattened oxen will contain scarcely more than 1.5 per cent. of mineral matter, 8 per cent. of nitrogenous substance, and 65 per cent. of fat, the total dry substance put on during fattening ranging from 70 to 75 per cent. The remainder of the increase is water. If steers grow as well as fatten, there may be more mineral matter and nitrogenous substance, less fat and more water in the added growth, than just reported. In such case about two-thirds of the increase is dry substance and one-third water, while if the steer is mature, the added weight while fattening consists of as much as threefourths dry substance and one-fourth water.

Studies of sheep lead to the conclusion that the increase during fattening will contain not less than 2 per cent. of mineral matter and frequently more - a decided increase over the ox, due largely to the growth of wool during fattening. Of the added weight of sheep during fattening, from 70 to 75 per cent. may be fat.

While fattening, the pig adds scarcely any mineral matter to the body, and rarely more than 7.5 per cent. of nitrogenous substance, the fat forming as much as 70 per cent. of the increase. Of the gain in weight made by the pig during fattening, about 75 per cent. is dry matter and 25 per cent. water. The increase of less 
highly fattened pigs contains more nitrogenous substance, more water and less fat.

104. Comparative fattening qualities of different farm animals. Gathering their results into a single table for the purpose of studying the comparative fattening qualities of farm animals, Lawes and Gilbert present the following table, giving the proportion of the various organs and parts of the body, the feed consumed weekly, gains, etc. :

Comparative fattening qualities of farm animals - Lawes and Gitbert.

\begin{tabular}{|c|c|c|c|}
\hline \multicolumn{4}{|c|}{ Relation of parts in 100 pounds live weight. } \\
\hline & Oxen. & Sheep. & Pigs. \\
\hline \multirow[t]{2}{*}{ 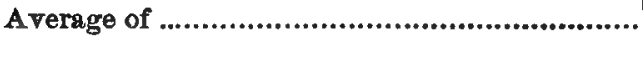 } & 16 & 249 & 59 \\
\hline & Lbs. & Lbs. & Lbs. \\
\hline \multirow{2}{*}{ 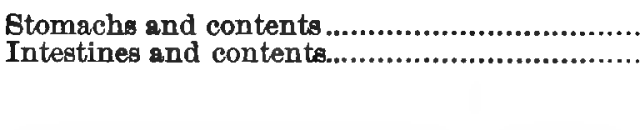 } & 11.5 & 7.4 & 1.3 \\
\hline & 143 & 10.9 & 7.5 \\
\hline \multirow{3}{*}{ 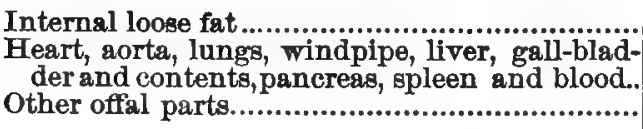 } & 4.6 & 7.0 & 1.6 \\
\hline & & & \\
\hline & $\begin{array}{r}7.0 \\
13.0\end{array}$ & $\begin{array}{r}7.3 \\
15.0\end{array}$ & $\begin{array}{l}6.6 \\
1.1\end{array}$ \\
\hline \multirow{3}{*}{ 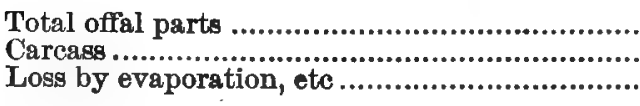 } & 38.9 & 40.2 & 16.8 \\
\hline & 59.3 & 59.7 & 82.6 \\
\hline & 1.8 & 0.1 & 0.6 \\
\hline Total .................... & 100.0 & 100.0 & 100.0 \\
\hline
\end{tabular}

Per 100 pounds live weight.

\begin{tabular}{l|c|c|c}
\hline Dry substance consumed in food per week ....... & 12.5 & 16.0 & 27.0 \\
Increase yielded per week ................................ & 1.13 & 1.76 & 6.43 \\
\hline
\end{tabular}

Per 100 pounds dry substance of food.

Fat in increase

Total dry substance in increase.

5.2

Total dry substance in excretions

\begin{tabular}{r|r|r}
5.2 & 7.0 & 15.7 \\
6.2 & 8.0 & 17.6 \\
36.5 & 31.9 & 16.7
\end{tabular}

Average fat.

\begin{tabular}{|c|c|c|c|}
\hline In lean condition & 16.0 & 18.0 & 22.0 \\
\hline 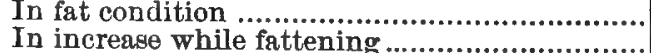 & $\begin{array}{l}30.0 \\
60.0\end{array}$ & $\begin{array}{l}33.0 \\
65.0\end{array}$ & 74.0 \\
\hline
\end{tabular}


The table presents the summaries from the study of 16 oxen, 249 sheep and 59 pigs. For the ox we learn that the stomach and contents constitute 11.5 per cent., for the sheep 7.4 per cent, and for the pig but 1.3 per cent. of the live weight. The very small size of the stomach of the pig is here made evident. It is shown that 59.3 per cent. of the live weight of the fatted ox is returned as dressed carcass. Sheep dress about the same as steers, while the pig returns 82.6 per cent. dressed weight, greatly exceeding the ox and sheep in the proportion of valuable parts.

In the second division of the table we learn that for each 100 pounds of live weight the steer consumes 12.5 pounds of dry matter, the sheep somewhat more, and the pig 27 pounds of dry matter each week. The fattening steer increases 1.13 per cent. of his live weight weekly, the sheep 1.76 per cent., while the pig makes surprising gains, increasing 6.43 per cent. of his live weight in a week.

In the next division of the table we are told of the fat and dry Bubstance in the increase, and also of the dry substance in the excretions. Here the sheep leads the steer, and the pig more than doubles the increase of either.

105. Feeds and fattening.-The following is adapted from Warington: ${ }^{1}$ Lawes and Gilbert reckon that on an average for the whole fattening period, an ox will produce 100 pounds of live weight from the consumption of 250 pounds of oil cake, 600 pounds of clover hay and 3,500 pounds of Swedes (turnips). Sheep will produce the same increase by the consumption of 250 pounds of oil cake, 300 pounds of clover hay and 4,000 pounds of Swedes. Pigs will require about 500 pounds of barley meal to yield a similar result. Taking these data, the rate of food consumption and the increase yielded will be as follows:

1 Chemistry of the Farm. 
Results with fattening animals per 100 pounds live weight, per weekWarington.

\begin{tabular}{|c|c|c|c|c|c|}
\hline & \multicolumn{2}{|c|}{$\begin{array}{l}\text { Received by the } \\
\text { animal. }\end{array}$} & \multicolumn{3}{|c|}{ Results produced. } \\
\hline & $\begin{array}{l}\text { Total } \\
\text { dry } \\
\text { food. }\end{array}$ & $\begin{array}{l}\text { Digestible } \\
\text { organic } \\
\text { matter. }\end{array}$ & $\begin{array}{l}\text { Food con- } \\
\text { sumed for } \\
\text { heat and } \\
\text { work.* }\end{array}$ & $\begin{array}{l}\text { Dry ma- } \\
\text { nuret pro- } \\
\text { duced. }\end{array}$ & $\begin{array}{l}\text { Increase in } \\
\text { live weight. }\end{array}$ \\
\hline & Lbs. & Lbs. & Lbs. & Lba. & Lbs. \\
\hline $\begin{array}{l}\text { Oxen................... } \\
\text { Sheep................ } \\
\text { Pigs.................. }\end{array}$ & $\begin{array}{l}12.5 \\
16.0 \\
27.0\end{array}$ & $\begin{array}{r}8.9 \\
12.3 \\
22.0\end{array}$ & $\begin{array}{r}6.86 \\
9.06 \\
12.58\end{array}$ & $\begin{array}{l}4.56 \\
5.10 \\
4.51\end{array}$ & $\begin{array}{l}1.13 \\
1.76 \\
6.43\end{array}$ \\
\hline
\end{tabular}

Results obtained in relation to food consumed.

\begin{tabular}{|c|c|c|c|c|c|}
\hline & \multicolumn{2}{|c|}{$\begin{array}{c}\text { Increase in live } \\
\text { weight. }\end{array}$} & \multicolumn{3}{|c|}{ On 100 pounds of dry food. } \\
\hline & $\begin{array}{l}\text { Per } 100 \\
\text { lbs. dry } \\
\text { food. }\end{array}$ & $\begin{array}{l}\text { Per } 100 \\
\text { lbs. di- } \\
\text { gested or- } \\
\text { ganic } \\
\text { matter. }\end{array}$ & $\begin{array}{l}\text { Consumed. } \\
\text { for heat and } \\
\text { work.* }\end{array}$ & $\begin{array}{l}\text { Dry manure } \\
\text { produced. } t\end{array}$ & $\begin{array}{l}\text { Dry in- } \\
\text { crease } \\
\text { yielded. }\end{array}$ \\
\hline & Lbs. & Lbs. & Lbs. & Lbs. & Lbs. \\
\hline 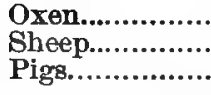 & $\begin{array}{r}9.0 \\
11.0 \\
23.8\end{array}$ & $\begin{array}{l}12.7 \\
14.3 \\
29.2\end{array}$ & $\begin{array}{l}54.9 \\
56.6 \\
46.6\end{array}$ & $\begin{array}{l}36.5 \\
31.9 \\
16.7\end{array}$ & $\begin{array}{r}6.2 \\
8.0 \\
17.6\end{array}$ \\
\hline
\end{tabular}

* In calculating the amount of food consumed for the production of heat and work, it has been assumed that the fat in the increase has been derived entirely from the fat and carbohydrates supplied by the food.

$\dagger$ The manure is exclusive of litter.

Warington tells us in the first table that pigs are able to consume far more food in proportion to their live weight than either sheep or oren. This is due to the concentrated and digestible character of the food commonly supplied the fattening pig, and to the great capacity of this animal for assimilation. The proportion of stomach is greater in the ox or sheep than in the pig, being for 100 pounds live weight, 3.2 for the ox, 2.5 for the sheep, and .7 for the pig. On the other hand, the proportion of the intestines is greater with the pig. (32) Ruminants are thus best fitted for dealing with feeds requiring prolonged digestion, while the pig excels in the capacity for assimilation. 
As a natural result of the larger consumption of food, the pig increases in weight more rapidly than the sheep or ox. Not only is the rate of increase more rapid, but the increase yielded by the pig is also far greater in proportion to the food consumed, as plainly appears from the lower division of the table. The pig, with its very large consumption of food, has, in fact, to spend a smaller proportion of it on heat and work, and has a larger surplus to store as increase. Of 100 pounds digested organic matter, the fattening ox spends about 77 for heat and work, the sheep 74, and the pig 57. The upper division of the table shows, however, that in a given time a pig converts a mnch larger amount of food into heat and work than either the sheep or ox. This greater consumption probably represents the internal work performed in laying-on increase. The pig, with its rapid feeding and high rate of increase, is undoubtedly the most economical meatmaking machine at the farmer's disposal. The returns of sheep lie between those given by oxen and pigs, being, however, much nearer the former than the latter. The German experiments place the sheep below the ox as an economic producer of increase, instead of above it, as in the Rothamsted statistics just quoted. The difference is probably due to the different breeds of animals under experiment.

106. Nitrogen and ash in carcasses of farm animals. - The table shows the quantity of nitrogen, and principal ash constitnents, in the fasted live weight of animals analyzed at Rothamsted.

Ash constituents and nitrogen in 1,000 pounds of various animals, based on live fasted weight, including contents of stomach and intestines - Lawes and Gilbert.

\begin{tabular}{|c|c|c|c|c|c|}
\hline & Nitrogen. & $\begin{array}{c}\text { Phosphoric } \\
\text { acid. }\end{array}$ & Potash. & Lime. & Magnesia. \\
\hline & Lbs. & Lbs. & Lbs. & Lbs. & Lbs. \\
\hline $\begin{array}{l}\text { Fat calf............... } \\
\text { Half-fat ox .......... } \\
\text { Fat ox.................. } \\
\text { Fat lamb............ } \\
\text { Store sheep......... } \\
\text { Fat sheep............. } \\
\text { Store pig............ } \\
\text { Fat pig............... }\end{array}$ & $\begin{array}{l}24.64 \\
27.45 \\
23.26 \\
19.71 \\
23.77 \\
19.76 \\
22.08 \\
17.65\end{array}$ & $\begin{array}{r}15.35 \\
18.39 \\
15.51 \\
11.26 \\
11.88 \\
10.40 \\
10.66 \\
6.54\end{array}$ & $\begin{array}{l}2.06 \\
2.05 \\
1.76 \\
1.66 \\
1.74 \\
1.48 \\
1.96 \\
1.38\end{array}$ & $\begin{array}{r}16.46 \\
21.11 \\
17.92 \\
12.81 \\
13.21 \\
11.84 \\
10.79 \\
6.36\end{array}$ & $\begin{array}{l}0.79 \\
0.85 \\
0.61 \\
0.52 \\
0.56 \\
0.48 \\
0.53 \\
0.32\end{array}$ \\
\hline
\end{tabular}




\section{CHAPTER VI.}

INFLUENOE OF FEED ON THE ANTMAL BODY.

L Influence of Feed on the Growing Body of the Pig.

107. Sanborn's findings. - In 1884, Sanborn, of the Missouri Agricultural College, ${ }^{1}$ observed more lean and less fat in the bodies of pigs fed ship-stuff (middlings) than in those of pigs fed corn meal. He wrote: "Does a food rich in carbohydrates and fat tend to produce an increased proportion of fat to flesh? . . . I have heretofore observed that a pig fed on ship-stuff (mid dlings), versus corn, gave an apparently better muscular development from ship-stuff. . . Experience convinces me that the exclusive use of corn meal for a feeding ration is detrimental to a vigorous and healthy muscular development, producing a pig easily subject to disease, distasteful to our consumers, and more costly than is necessary." In later bulletins ${ }^{2}$ this investigator reports studies in which pigs were fed dried blood and corn meal in opposition to corn meal only. The weights of various internal organs were ascertained, and the fat and lean of the carcasses separated by the knife, and weighed. The data thus obtained confirmed the original statement. Marked differences in the relative size of some of the internal organs were also reported.

108. Studies at other Stations. - Recognizing the great importance of this line of study from the scientific standpoint, and its significance to the breeder of swine, to the farmer interested in pig feeding, and to the consumer of pork products as well, the writer conducted several trials in the same line as Sanborn's, at the Wisconsin Station. ${ }^{8}$ In these trials dried blood, (338) mid-

1 Bul. 10.

2 Buls. 14, 19, Mo. Agrl. Col.

Repts. 1886, '87, '88,' 89. 
dlings, peas and skim milk, articles rich in protein, were fed in opposition to corn meal, which was used because it is the common pig feed of the country and is the richest in carbohydrates of its class.

The same subject was investigated at the Kansas Station ${ }^{1}$ by Shelton, who fed pigs a mixture of shorts and bran in opposition to corn meal, potatoes and tallow.

At the Alabama Station, ${ }^{2}$ Duggar fed cowpeas, which are rich in protein, in opposition to corn meal. (863)

In France, Fortier, ${ }^{8}$ likewise recognizing the importance of this work, duplicated in one instance a trial by the writer, feeding dried blood, skim milk and middlings in opposition to corn meal only, to ascertain if parallel results could be obtained in his country. Thus we have the results of feeding pigs rations rich in protein and poor in protein at five widely-separated points.

The results of these several trials are condensed in the following comprehensive tables:

1 Bul. 9.

Bul. 82.

Ext. Trav. Boc. Cent. d'Agr., Dept. Seine-Ine, 1889, 1890. 


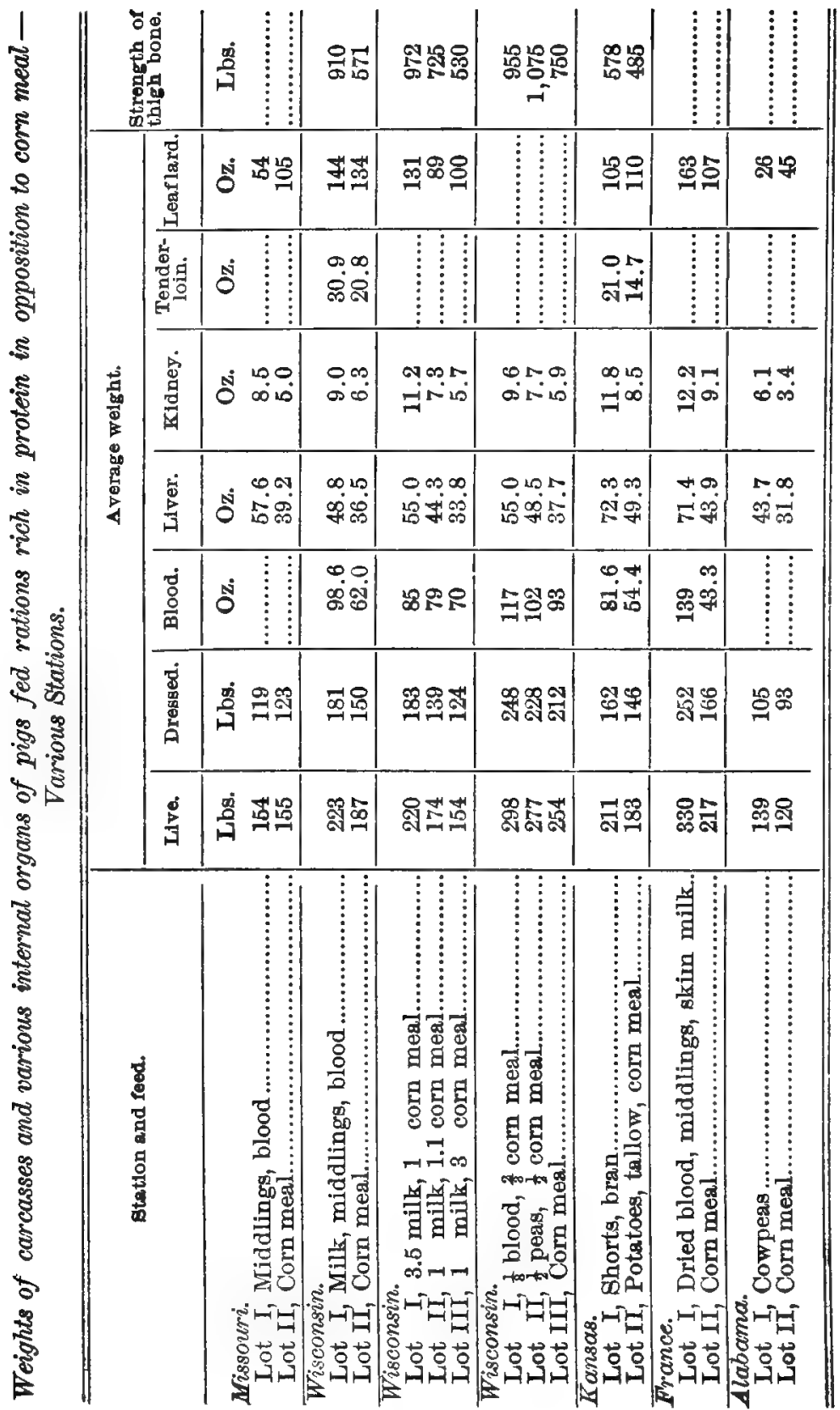


Influence of Feed on the Animal Body.

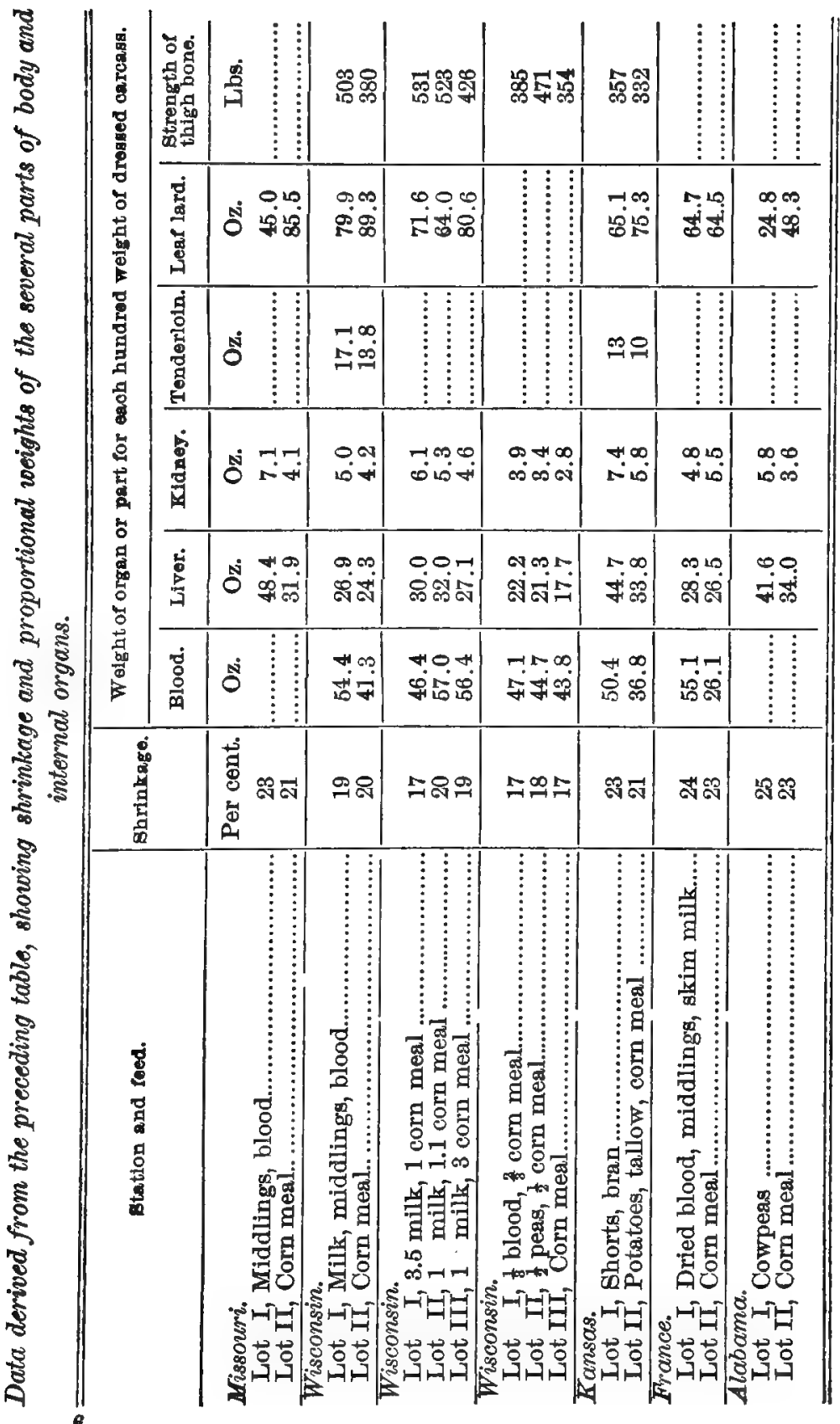


109. What the tables show.-By the first table it is shown that the protein-rich ration produced heavier gains than the others. In the several columns are given the weights of various parts and organs of the body. Since pigs fed on the several rations reached different weights at the time of slaughter, the weights are reduced to a common standard for comparison. This is done in the second table, where the weights of the different parts are stated for each 100 pounds of dressed carcass.

It is seen in the second table that the pigs fed the protein-rich rations usually show a larger shrinkage than those getting corn meal. This is accounted for in part by the larger amount of blood, heavier livers and other organs of the protein-fed pigs.

In nearly every instance the pigs receiving the protein-rich rations yielded more blood than those fed corn. In the Kansas trial the pigs getting shorts and bran had 51.2 ounces of blood to 100 pounds of carcass, while the corn-fed pigs had only 36.8 ounces. In Fortier's trials in France, the blood of the corn-mealfed pigs was less than half that of the pigs receiving the proteinrich ration, the ratio standing 55.1 to 26.1. The only exception was in the Wisconsin trial, where the pigs were made very fat by feeding milk.

In every instance the pigs fed the protein-rich rations had heavier livers than the others, the difference often being very marked. For example, in the Missouri trial the pigs fed middlings had livers weighing 48.4 ounces to 100 pounds of carcass, while those of the lot fed corn weighed only 31.9.

Generally, the kidneys of the protein-fed pigs are heaviest, though in Fortier's trials the reverse occurs.

The tenderloin muscles lying along the back of the pig are easily dissected from the remainder of the carcass, and in one trial in Wisconsin and in the Kansas trial these muscles were separated and weighed. In both cases the muscles of the pigs getting the protein-rich rations were heavier in proportion to the weight of the body than those of the pigs fed corn. This is proof of more lean meat in the carcasses of pigs fed the most protein.

The pigs getting corn meal gave more leaf lard than the others, excepting in the French trial, where the results were practically equal. 
110. Strength of thigh-bones. - In the Wisconsin and Kansas trials the strength of the thigh-bones of the pigs in the different lots was determined in the following manner: The two rounded iron-supporting edges of the testing machine were set four indisu apart, and on these the thigh-bones were placed, one at a time, always in the same position. The rounded edge of the breaking bar rested on the bone midway between the two supports. The pressure downward upon the bone, which was gradually increased, was measured on the tilting-beam of the machine, and the weight which the bone supported at the time it broke was recorded. In every instance the pigs fed the protein-rich ration possessed the strongest bones, the difference often being very marked. For example, in one Wisconsin trial the bones of the corn-fed pigs broke at 380 pounds on the average, and those of the pigs fed milk, blood and middlings at 503 pounds. These weights are for each 100 pounds of dressed carcass, and show in favor of the mixed ration by 32 per cent.

III. What analysis revealed.-In one of the Wisconsin trials we went further into details, making partial analyses of some of the body organs. In this trial there were four pigs in each lot. To the first lot was fed a ration consisting of one-third dried blood and two-thirds corn meal, by weight. The second lot received one-half pea meal and one-half corn meal, while the third was fed corn meal only. All lots received hard-wood ashes, salt and water additional. The weights and gains of the pigs are shown in the following table:

Weights and gains of pigs variously fed-Wisconsin Station.

\begin{tabular}{|c|c|c|c|}
\hline Feed. & $\begin{array}{c}\text { Average } \\
\text { weight at } \\
\text { begin- } \\
\text { ning. }\end{array}$ & $\begin{array}{l}\text { Average } \\
\text { gain dur- } \\
\text { ing trial. }\end{array}$ & $\begin{array}{l}\text { Average } \\
\text { feed per } \\
100 \text { lbs. } \\
\text { gain. }\end{array}$ \\
\hline $\begin{array}{l}\text { Lot I, } \frac{1}{8} \text { dried blood, } \frac{2}{3} \text { corn meal......... } \\
\text { Lot II, } \frac{1}{2} \text { pea meal, } \frac{1}{2} \text { corn meal........... } \\
\text { Lot III, corn meal only ..................... }\end{array}$ & $\begin{array}{l}\text { Lbs. } \\
96 \\
98 \\
99\end{array}$ & $\begin{array}{l}\text { Lbs. } \\
202 \\
180 \\
155\end{array}$ & $\begin{array}{r}\text { Lbs. } \\
409 \\
449 \\
481\end{array}$ \\
\hline
\end{tabular}

It is shown by the table that the lot fed dried blood and corn meal made the best gains with the least food, that receiving pea 
meal coming second, while corn meal gave the poorest returns with the most feed consumed for a given gain. The dry matter of the blood and dry matter and fat in the kidneys were determined with the results presented in the following table:

Results of partial analyses of blood and kidneys of pigs fed on dried blood, pea meal and corn meal-Wisconsin Station.

\begin{tabular}{|c|c|c|c|}
\hline Results for 4 pigs. & $\begin{array}{l}\text { Fed } \\
\text { blood } \\
\text { and } \\
\text { corn. }\end{array}$ & $\begin{array}{l}\text { Fed } \\
\text { peas } \\
\text { and } \\
\text { corn. }\end{array}$ & $\begin{array}{l}\text { Fed } \\
\text { corn } \\
\text { only. }\end{array}$ \\
\hline 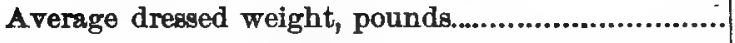 & 248 & 228 & 212 \\
\hline $\begin{array}{l}\text { Blood per } 100 \text { lbs. dressed weight, grams.................. } \\
\text { Per cent. dry matter in blood............................. } \\
\text { Dry matter in blood per } 100 \text { lbs. dressed weight, grams }\end{array}$ & $\begin{array}{r}1332 \\
24.24 \\
323\end{array}$ & $\begin{array}{r}1263 \\
24.58 \\
310\end{array}$ & $\begin{array}{r}1237 \\
24.09 \\
298\end{array}$ \\
\hline 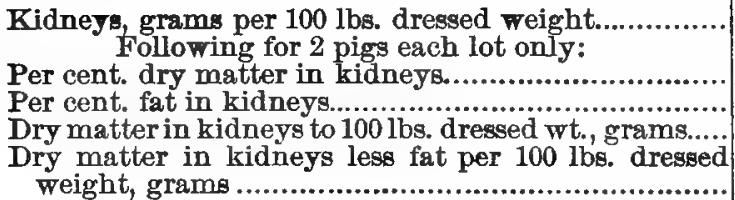 & $\begin{array}{r}111 \\
24.41 \\
4.71 \\
23.4 \\
18.8\end{array}$ & $\begin{array}{r}96 \\
25.80 \\
4.49 \\
24.4 \\
20.1\end{array}$ & $\begin{array}{r}79 \\
26.26 \\
6.41 \\
20.7 \\
15.6\end{array}$ \\
\hline
\end{tabular}

The table shows the dry matter in the blood to be quite aniform for the three lots, the corn-fed lot containing the lowest percentage. The total dry matter of the kidneys is highest with the corn-fed pigs, the difference being due to the larger amount of fat in the kidneys. The highest percentage of dry matter in the kidneys to dressed carcass is for the pigs fed peas and corn, with those fed blood and corn coming second.

112. Modifications of carcass. - That the bodies of the pigs were affected by the feed given in these trials is made plain by the colored engravings presented by Fortier of France and the writer, ${ }^{1}$ and by the half-tone reproductions from photographs by Shelton ${ }^{2}$ and the writer. ${ }^{3}$ These views show what Sanborn oripinally announced, viz., that there is more lean meat in proportio.. to fat in the carcasses of protein-fed pigs than in the carcasses of those getting corn meal.

1 Rept. Wis. Sta., 1886.

2 Bul. 9, Kan. Sta.

Rept. Wis. Sta., 1888. 
Sanborn's analyses and statements were further substantiated by the writer in the following manner: From one side of the carcass the sixth rib and the flesh lying over it were cut out. The rib and the skin were removed and the remaining flesh of the section analyzed. As before stated, the tenderloin muscle of the back, lying in the angle made by the spinous processes and the ribs, is quite free from connection with adjacent tissue. That portion of this muscle lying over the seventh and eighth ribs was selected for analysis, with the average results presented in the following table:

Analyses of sections of the carcasses of pigs fed on dried blood, pea meal and corn meal - Wisconsin Station.

\begin{tabular}{c|c|c|c||c|c|c}
\hline & \multicolumn{3}{|c||}{ Sixth-rib cut. } & \multicolumn{3}{c}{ Tenderloin muscle. } \\
\cline { 2 - 7 } $\begin{array}{c}\text { Four pigs in } \\
\text { each lot. }\end{array}$ & Water. & Fat. & $\begin{array}{c}\text { Dry lean } \\
\text { meat. }\end{array}$ & Water. & Fat. & $\begin{array}{c}\text { Dry lean } \\
\text { meat. }\end{array}$ \\
\hline & Per cent. & Per cent. & Per cent. & Per cent. & Per cent. & Per cent. \\
Blood-fed..... & 27.16 & 64.68 & 8.16 & 67.96 & 8.22 & 23.82 \\
Peas-fed..... & 28.41 & 62.94 & 8.65 & 69.49 & 6.17 & 24.34 \\
Corn-fed..... & 20.16 & 73.56 & 6.28 & 67.45 & 9.41 & 23.14 \\
\hline
\end{tabular}

For present purposes we may assume that the flesh lying over the sixth rib is representative of the whole carcass. This being true, the carcasses of the protein-fed pigs contained eight parts more water and ten parts less fat to the hondred pounds than the carcasses of the pigs fed corn. For dry lean meat the results are a little more than six per cent. for the corn-fed pigs and above eight per cent. for the other lots. There was, then, about onethird more lean meat in the carcasses of the protein-fed pigs than in the carcasses of those getting corn. The analysis reveals more fat and somewhat less lean meat percentagely in the tenderloin muscles of the corn-fed pigs.

II3. Misconception concerning the experiments.-There has been misconception concerning the purpose and interpretation of these experiments. ${ }^{1}$ A few writers have inferred that claims were advanced by some of the investigators that lean meat can

${ }^{1}$ Harris on the Pig, 2d Ed.; Agr. Science, vol. 2; Rept. Kan. Bd. Agr., Apr. 1889. 
be produced in the body of the pig at the will of the feeder. Others interpret the investigations as an attack upon Indian corn for swine feeding, while still others declare the experiments inaccurate, or that the figures show nothing unusual. These writers refer to the experiments by Lawes and Gilbert in which the carcasses of pigs fed bran, beans and lentils showed no difference in the proportion of muscle to fat over those receiving carbonaceous foods. They overlook the vital point in the problem, viz., that these later experiments were with growing pigs, while the early ones were with animals well advanced toward maturity. In the Lawes and Gilbert trials the protein feeds used were not altogether suitable for pigs. How much their results were modified by this fact it is impossible to state.

For a discussion of the practical bearing of these experiments see articles $936-940$.

II. Strengthening the Bones of Pigs Kept Exclusively on Corn.

114. Hard-wood ashes and bone meal for pigs fed corn.-When feeding corn to pigs as the exclusive ration, the writer observed a strong craving by the pigs for wood ashes, considerable quantities of which were consumed, if opportunity offered. Were the ashes a benefit to the pigs or not? To answer this question three experiments were conducted. ${ }^{1}$

In each trial six pigs, all from one litter, were used, the animals being from 105 to 128 days old when the feeding began. The previous feed had been liberal in variety and supply, and the pigs were well started in their development when the trial began. They were divided into three lots of two each, and all lots were fed liberally on corn meal, with salt and water additional. Lot I received nothing else. Lot II was allowed hard-wood ashes supplied in a separate trough. Instead of ashes, Lot III was given a spoonful of bone meal with each feed. In regard to the amount of these articles consumed, it may be stated that in one of the trials, which lasted 112 days, two pigs consumed 10.5 pounds of bone meal and 7.5 pounds of salt, and in the same time two other pigs consumed 33 pounds of hard-wood ashes and

' Rept. Wis. Expt. Sta., 1890; Bul. 25. 
8 pounds of salt. The pigs were confined in pens, with small yards at the rear for exercise. The ground in these yards was covered with boards to prevent the animals from rooting in the earth and eating quantities of it, as those not getting ashes or bone meal would have done had opportunity offered. The trials lasted from 84 to 128 days without any of the animals I dying or becoming sick, a surprising fact for the lots living wholly on corn meal, salt and water.

115. What the trials revealed.- As the trials progressed it became evident that none of the pigs were properly nurtured, though the difference in favor of those getting bone meal or ashes was very marked. The pigs allowed neither ashes nor bone meal were most plainly dwarfed. It was evident that the corn meal, salt and water did not supply all the elements essential to building a normal framework of bone and muscle. These dwarfs became so fat that the jowls and bellies of some of them nearly touched the ground.

The pigs getting ashes or bone meal grew.very well for some time, but toward the close of the trial they made only fair gains, showing that the autrients supplied were still too limited in character to allow normal development. On slaughter, the several lots showed no difference in the proportion of fat to lean, nor was there any difference in the size or character of the various internal organs. The bones, however, were a mast interesting study. In the same manner as described in the preceding topic, the thigh bones of these pigs were broken in a testing machine with the results shown below:

Results with pigs living on corn meal with or without bone meal and hard-wood ashes in addition - Wisconsin Station.

\begin{tabular}{c|c|c|c}
\hline & $\begin{array}{c}\text { When bone } \\
\text { meal was } \\
\text { fed. }\end{array}$ & $\begin{array}{c}\text { When ashes } \\
\text { were fed. }\end{array}$ & $\begin{array}{c}\text { When } \\
\text { neither was } \\
\text { fed. }\end{array}$ \\
\hline $\begin{array}{c}\text { Corn meal required to produce 100 } \\
\text { pounds of gain, pounds.............. }\end{array}$ & 487 & 491 & 629 \\
$\begin{array}{r}\text { Average breaking strength of thigh } \\
\text { bones, pounds ........................... }\end{array}$ & 680 & 581 & 301 \\
& 166 & 150 & 107 \\
\hline
\end{tabular}


After being broken, the bones were burned to determine the ash they contained.

By the table we learn that feeding bone meal or hard-wood ashes to pigs otherwise confined to a corn-meal. diet effected a saving of 23 per cent. in the corn required for 100 pounds of gain. We further find that by feeding hard-wood ashes or bone meal to pigs otherwise living wholly on corn, the strength of the thigh bones was about double that of pigs not allowed bone meal or ashes. It was further found that when the bones were burned, those of the pigs getting ashes or bone meal contained about 50 per cent. more ash than the others. This latter fact was substantiated in another interesting way. After burning, the bones of the pigs which had received no ashes or bone meal crumbled at once on handling, while those from the pigs fed ashes or bone meal still retained their form after burning and did not crumble when carefully handled.

\section{Influence of Wide and Narrow Rations on Growth and Fattening.}

II6. The Maine Station trial.-At the Maine Station, ${ }^{1}$ Jordan conducted a trial with growing and fattening steers, beginning with calves and feeding to maturity, for the purpose of determining the influence of a ration rich in protein and one relatively poor in protein on the rate of growth and character of the flesh produced. This is the most elaborate experiment of the kind yet conducted in this country, having been wisely planned and carefully carried out in all its numerous details.

117. Plan of experiment.-Four high-grade Short-horn steer calves, ranging in age from 5 to 7 months when the trial began, were used. Two of these calves were fed a ration rich in protein, as given below, while the other two received one ample in its supply of natrients but relatively poor in protein. (133-5) After feeding 17 months, one steer in each lot was slaughtered and the carcasses analyzed; after ten months' more feeding, or 27 months in all, the remaining two were slaughtered and the carcasses likewise analyzed. The four steers were fed alike at all times on roughage, which consisted mostly of timothy hay, some fodder

1 Rept. 1895. 
corn and corn silage being fed during the first winter only. The concentrates for the two lots were as follows:

Steers 1 and 2.

\section{Lot I.}

Protein-rich ration.

Linseed meal, 2 parts.

Corn meal, 1 part.

Wheat bran, 1 part, by weight.

Nutritive ratio, $1: 5.2$.
Lot II.

Steers 3 and 4.

Protein-poor ration.

Corn meal, 2 parts.

Wheat bran, 1 part, by weight.

Nutritive ratio, $1: 9.7$.

In this trial no attempt was made to force the steers to rapid growth, the aim being rather to keep them gaining steadily. The trial was carried to a successful termination, no serious interruptions of any kind occurring. The feed and gains are presented in the following table:

Total feed eaten and total gains by four steers - Maine Station.

\begin{tabular}{|c|c|c|c|c|}
\hline & \multicolumn{2}{|c|}{$\begin{array}{l}\text { Lot I. } \\
\text { Fed protein-rich } \\
\text { food. }\end{array}$} & \multicolumn{2}{|c|}{$\begin{array}{l}\text { Lot II. } \\
\text { Fed protein-poor } \\
\text { food. }\end{array}$} \\
\hline & Steer 1. & Steer 2. & Steer 3. & Steer 4. \\
\hline Number of months fed... & 17 & 27 & 27 & 17 \\
\hline Number of days fed .......... & 514 & 843 & 833 & 521 \\
\hline Total hay eaten, pounds ..................... & 3,414 & 7,783 & 6,811 & 3,520 \\
\hline Total fodder and silage eaten, pounds. & 4,173 & 4,728 & 4,493 & 4,469 \\
\hline Total mixed grains eaten, pounds ...... & 2,211 & 4,818 & 4,737 & 2,255 \\
\hline Total food eaten, pounds ...................... & 9,798 & 17,329 & 16,041 & 10,244 \\
\hline Initial weight of steers, pounds .......... & 221 & 345 & 285 & 318 \\
\hline End weight of steers, pounds .............. & 958 & 1,307 & 1,290 & 870 \\
\hline Total gain of each steer, pounds ........ & 737 & 962 & 1.005 & 552 \\
\hline
\end{tabular}

118. Digestible nutrients consumed.-The table shows the total feed consumed; the digestible nutrients in this feed are given in the accompanying table:

Digestible matter consumed by the steers - Maine Station.

\begin{tabular}{c|c|c|c|c|c}
\hline \hline & Protein. & $\begin{array}{c}\text { Carbohy- } \\
\text { drates. }\end{array}$ & $\begin{array}{c}\text { Ether ex- } \\
\text { tract. }\end{array}$ & $\begin{array}{c}\text { Total } \\
\text { feed. }\end{array}$ & $\begin{array}{c}\text { Pounds } \\
\text { matter for } \\
\text { one pound } \\
\text { gain. }\end{array}$ \\
\hline Protein-rich fed. & Lbs. & Lbs. & Lbs. & Lbs. & Lbs. \\
Steer 1, fed 17 mos. & 619 & 2,869 & 160 & 3,648 & 4.95 \\
Steer 2, fed 27 mos. & $\mathbf{1 , 2 6 5}$ & 5,853 & 321 & 7,439 & 7.73 \\
Protein-poor fed. & 700 & 6,128 & 295 & 7,123 & 7.08 \\
Steer 3, fed 27 mos. & $\mathbf{3 7 0}$ & $\mathbf{3 , 2 6 4}$ & $\mathbf{1 5 4}$ & $\mathbf{3 , 7 8 3}$ & $\mathbf{6 . 8 6}$ \\
Steer 4, fed 17 mos. & &
\end{tabular}


119. Concerning gains. - Our attention is next directed to a consideration of the gains made by two steers up to the end of the 17-months period. These are given in the following table:

Total and relative gains of two lots of steers - Maine Station.

\begin{tabular}{|c|c|c|c|c|}
\hline & $\begin{array}{c}\text { Weight } \\
\text { pair fed } \\
\text { more pro- } \\
\text { tein. }\end{array}$ & $\begin{array}{l}\text { Weight } \\
\text { pair fed } \\
\text { less pro- } \\
\text { tein. }\end{array}$ & $\begin{array}{c}\text { Greater } \\
\text { weight of } \\
\text { protein } \\
\text { pair. }\end{array}$ & $\begin{array}{l}\text { Increase } \\
\text { of differ- } \\
\text { ence in } \\
\text { weight. }\end{array}$ \\
\hline & Lbs. & Lbs. & Lbs. & Lbs. \\
\hline $\begin{array}{l}\text { At beginning of experiment... } \\
\text { At end of three months ......... } \\
\text { At end of six months ............ } \\
\text { At end of nine months.......... } \\
\text { At end of twelve months....... } \\
\text { At end of fifteen months....... } \\
\text { At end of geventeen months... }\end{array}$ & $\begin{array}{r}566 \\
778 \\
1,010 \\
1,379 \\
1,618 \\
1,861 \\
1,981\end{array}$ & $\begin{array}{r}603 \\
746 \\
921 \\
1,249 \\
1,475 \\
1,677 \\
1,807\end{array}$ & $\begin{array}{r}-37 \\
32 \\
89 \\
130 \\
143 \\
184 \\
174\end{array}$ & $\begin{array}{r}69 \\
57 \\
41 \\
13 \\
41 \\
-10\end{array}$ \\
\hline
\end{tabular}

The steers getting the richer protein ration made the more rapid gains up to 17 months of age, at which time they weighed 174 pounds more than the other pair. Jordan reports that those getting the most protein showed the effects of their food in better general appearance and greater thrift.

120. Gains of remaining steers.- As before stated, at the end of 17 months' feeding one steer from each lot was killed and the carcasses subjected to analysis. The feeding of the other two steers, one in each lot, continued for 10 months longer under the same conditions. It is interesting and significant to observe that during these last 10 months the steer getting the protein-rich ration did not gain as rapidly as the one fed the protein-poor ration, so that at the end of 27 months the two animals were nearly equal in weight. This is shown in the accompanying table:

Gain of steers fed for the longer period, 27 months - Maine Station.

\begin{tabular}{|c|c|c|}
\hline & $\begin{array}{l}\text { Protein-rich } \\
\text { fed. }\end{array}$ & $\begin{array}{l}\text { Protein-poor } \\
\text { fed. }\end{array}$ \\
\hline \multirow{3}{*}{ 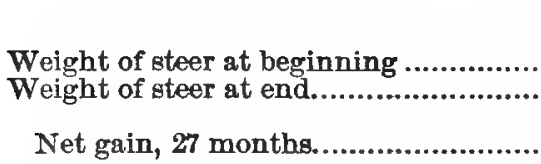 } & Lbs. & Lbs. \\
\hline & $\begin{array}{r}345 \\
1,307\end{array}$ & $\begin{array}{r}285 \\
1,290\end{array}$ \\
\hline & 962 & 1,005 \\
\hline
\end{tabular}


Here we are shown that while the steer getting the protein-rich ration gained 962 pounds in 27 months, the one receiving the protein-poor ration made a gain of 1,005 pounds, or 43 pounds more than the one fed the ration which at first gave the best returns. This result is the surprise of the investigation.

121. Digestible matter for one pound of growth. - In the following table is presented the digestible matter required for one pound of growth during different periods:

Amount of digestible matter required to produce one pound of gronoth with steers - Maine Station.

\begin{tabular}{|c|c|c|}
\hline Both steers of each lot, by periods. & $\begin{array}{c}\text { Steers fed } \\
\text { more protein. }\end{array}$ & $\begin{array}{c}\text { Steers fed less } \\
\text { protein. }\end{array}$ \\
\hline 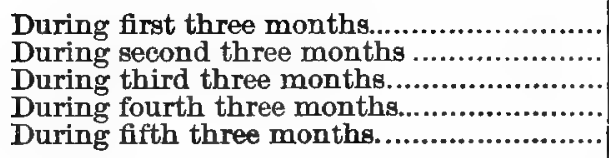 & $\begin{array}{l}4.06 \\
4.26 \\
3.83 \\
6.45 \\
6.97\end{array}$ & $\begin{array}{l}5.96 \\
5.53 \\
4.35 \\
6.87 \\
8.08\end{array}$ \\
\hline 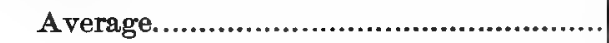 & 5.11 & 6.16 \\
\hline 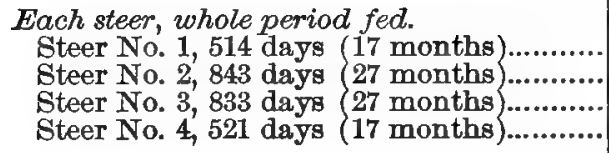 & $\begin{array}{c}4.95 \\
7.73 \\
\ldots \ldots \ldots \ldots \ldots \ldots \ldots \\
\ldots \ldots \ldots \ldots \ldots \ldots \ldots\end{array}$ & $\begin{array}{l}7.08 \\
6.86\end{array}$ \\
\hline
\end{tabular}

The above table shows that when the calves were building flesh and bone, the protein-rich ration was much more effective than the other. From the beginning to the end of 15 months' feeding, 5.11 pounds of digestible nutrients in the protein-rich ration proved as effective as 6.16 pounds of nutrients in the protein-poor ration.

In the second division of the table we learn that with the two steers fed for 27 months, 7.73 pounds of the digestible nutrients in the protein-rich ration were required during the whole period for one pound of gain, while only 7.08 pounds of digestible nutrients were required for one pound of gain with the protein-poor ration; that is, while the protein-rich ration was more effective aring the growing stages, that containing less protein but more carbohydrates proved the most efficient by the end of the 27 
months of feeding. This is the second very interesting point, and one not in accord with the usual teachings.

122. Concerning carcasses.- When slaughtered, all the internal organs of each steer, together with the. blood, were carefully weighed. It was found that there was no difference in the amount of blood or in the size of the various organs growing out of the character of the feed supplied, nor was there any marked difference in the percentage of dressed carcass to live weight for the two lots. The composition of the bodies is shown in the following table:

Composition of steers' bodies and of increased growoth - Maine Station.

\begin{tabular}{|c|c|c|c|c|c|}
\hline \multirow{2}{*}{$\begin{array}{l}\text { Entire bodies, } \\
\text { except skin. }\end{array}$} & \multicolumn{2}{|c|}{ In fresh material. } & \multicolumn{3}{|c|}{ In water-free material. } \\
\hline & Water. & $\begin{array}{l}\text { Dry sub- } \\
\text { stance. }\end{array}$ & Protein. & Fat. & Ash. \\
\hline $\begin{array}{c}\text { Two steers fed } 27 \\
\text { months, pounds...... } \\
\text { Two steers fed } 17 \\
\text { months, pounds......... }\end{array}$ & $\begin{array}{r}1,072.9 \\
829.2\end{array}$ & $\begin{array}{l}924.6 \\
593.2\end{array}$ & $\begin{array}{l}329.3 \\
248.0\end{array}$ & $\begin{array}{l}492.6 \\
276.9\end{array}$ & $\begin{array}{r}102.6 \\
68.2\end{array}$ \\
\hline 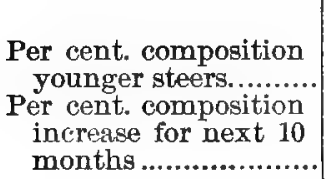 & $\begin{array}{r}243.7 \\
58.2\end{array}$ & $\begin{array}{r}331.4 \\
41.8\end{array}$ & $\begin{array}{l}81.3 \\
41.8\end{array}$ & $\begin{array}{r}215.7 \\
46.7\end{array}$ & $\begin{array}{l}34.4 \\
11.5\end{array}$ \\
\hline
\end{tabular}

Here we are shown that the bodies of the steers fed 17 months contained 58.2 per cent. water and $\mathbf{4 1 . 8}$ dry substance. Taking younger steers for the basis, the increase of the older ones during the final 10 months of feeding is shown in the last line of the table. From this we learn that 42.4 per cent. increase in weight of the steers during the last 10 months was water, while 57.6 per cent. was dry substance. 
123. Composition of carcass. - The data of the composition of the dressed carcass are given in the following table, these being divided into groups according to the feeding of the steers:

Percentage composition of dressed carcass, fresh substance-Maine Station.

\begin{tabular}{|c|c|c|c|c|}
\hline & Water. & Protein. & Fat. & Ash. \\
\hline Protein-rich food $\left\{\begin{array}{l}\text { Steer } 1, \text { fed } 17 \text { mos. } \\
\text { Steer } 2 \text {, fed } 27 \text { mos. }\end{array}\right.$ & $\begin{array}{l}59.02 \\
51.91\end{array}$ & $\begin{array}{l}17.89 \\
16.93\end{array}$ & $\begin{array}{l}18.53 \\
25.86\end{array}$ & $\begin{array}{l}4.56 \\
5.30\end{array}$ \\
\hline Protein-poor food $\left\{\begin{array}{l}\text { Steer } 3 \text {, fed } 27 \text { mos. } \\
\text { Steer 4, fed } 17 \text { mos. }\end{array}\right.$ & $\begin{array}{l}52.16 \\
56.30\end{array}$ & $\begin{array}{l}17.10 \\
17.82\end{array}$ & $\begin{array}{l}25.32 \\
20.27\end{array}$ & $\begin{array}{l}5.42 \\
5.61\end{array}$ \\
\hline
\end{tabular}

Let us first study the carcasses of the steer's fed for 17 months. That of the steer getting the protein-rich ration contained 2.7 per cent. more water, the same amount of protein, and nearly 2 per cent. less fat than the other. This is in line with other work in showing that one of the results of feeding much protein to growing animals is a carcass containing more water. For the steers carried through 27 months of feeding there is practically no difference in the composition of the carcasses.

124. Conclusion.- Reviewing this experiment we are led to conclude that rations rich in protein are more conducive to rapid growth and finer general appearance of the animal when young, than rations rich in carbohydrates and rather poor in protein. It appears that when the protein-poor ration contains enough nitrogen and ash to supply the actual demands of the body, the animal carefully conserves them, being enabled thereby to fulfill the laws of its nature as to growth. No doubt if the steers getting the least protein had been supplied with less protein and ash than nature requires for good body-building, they would plainly have shown it by an abnormal development; but, fortunately, such conditions were not laid down in this experiment. This experiment and its teachings should be compared with the feeding trials with pigs by Sanborn, the writer and others, reported in the first part of the chapter, where strongly one-sided rations were fed. 


\section{Exclusive Meal Feeding - Withholding Coarse Forage from Ruminants.}

125. Exclusive meal feeding.-In $1874 \mathrm{Mr}$. Linus W. Miller, of New York, reported that for several years he had successfully maintained a herd of dairy cows while dry in winter for a period of about eight weeks by giving to each animal as its sole feed not above three quarts of finely-ground corn meal, daily. ${ }^{1}$ It was hio practice to cut off the hay supply when meal feeding began. At first the animals were more or less restless, but they soon quieted down, all rumination ceasing. Only a small quantity of water was drank. The animals remained in fair flesh. In the spring, on changing back to normal feeding, a limited amount of hay was at first given and the supply gradually increased. Calves from cows thus maintained were strong and healthy.

A committee was appointed by L. B. Arnold, president of the American Dairyman's Association, to visit Mr. Miller's stable and report to the Association its findings. The committee reported that it found that cows weighing about 900 pounds each had been fed exclusively on corn meal for seven weeks at the time of inspection, the animals receiving on the average three quarts of corn meal each, daily. It further reported: "The cows did not ruminate. Were very quiet; did not evince any inordinate desire for food when hay was shown them; not so much as is displayed by cows that are fed on hay alone, in the usual way of feeding, a little less than they will eat. Were mnch more quiet than cows fed mostly on meal with a small feeding of hay; say, four to five pounds per day. We could not discover any signs of suffering or unrest in any way whatever."

On a second visit of the committee, thirteen days after hay feeding had been resumed in the spring, the cows were "filled up" and did not appear different from others which had been wintered in the usual way. The committee further reported that the calves from these cows "are of more than ordinary size, fleshy, strong, active and healthy."

1 Rept. American Dairyman's Association, 1874; Meal Feeding and Animal Digestion, a text-book for all who feed condensed food ( $2 \mathrm{~d}$ Ed.), by Linus W. Miller, pub. by author; Country Gentleman, 1876; Armsby, Manual of Cattle Feeding, pp. 378-383. 
This system of feeding, or absence of feeding, excited much discussion in the agricultural press at the time, but the practice seems never to have become general and the subject is now almost forgotten.

126. Sanborn's trials. - At the Utah Station, ${ }^{1}$ Sanborn maintained a calf six weeks in winter on grain and milk, when, through its cravings for coarse forage, the sawdust used for bedding was eaten, with death as a consequence. Sheep were successfully maintained for several months on grain and roots, with no coarse forage whatever. They shrank in weight at first, but after the paunch was cleared of coarse feed they made fair gains. A two-year-old steer weighing 635 pounds on April 13, was fed grain only, with water, until December 2 following, when it weighed 825 pounds. Rumination ceased upon withdrawal of coarse feed. It was observed that gains in these trials were made on about the same amount of feed as is required with pigs. Cattle so fed drank very little water, voiding a larger proportion as urine than those fed in the usual manner. The first and second stomachs of sheep and cattle so fed weighed less than the average for such animals, the first stomach notably so. When slaughtered the first stomach was found hardly half full. The blood of the steer weighed more than the average, and the lungs less.

127. Davenport's experiments.-At the Illinois Station, ${ }^{2}$ Davenport maintained calves upon skim milk or skim milk and grain for long periods. A June calf was maintained exclusively upon skim milk until the following January, seven months, by which time it refused its feed, could not hold up its head and appeared nearly dead. When straw and hay were placed before it they were greedily consumed, and three hours later the calf was ruminating in contentment, thereafter making satisfactory gains upon mixed feed. In a second experiment a calf dropped in May subsisted on skim milk only until September, when, although consuming seventy pounds of skim milk daily, the creature showed great unrest. Some grain was then fed in addition to milk, with still unfavorable indications. In October, when hay was offered, it was greedily eaten and rumination began five

'Bul. 21. 2 Bul. 46. 
and one-half hours later. Another calf was maintained from June until September upon milk and mixed grains. By the latter date it evinced no desire for feed and would not rise. Later it suddenly died.

It was observed in these trials that although enormous quantities of milk or milk and grain were consumed, there was no fat on the carcass or about the kidneys of the calf that died. The muscles, instead of being shrunken, were plump but exceedingly dense and rigid to the touch.

128. Conclusions. - The investigations of Davenport show that the quantity of food consumed by an animal is not necessarily an indication of its economic use, enormous amounts being taken by these calves in the vain effort to satisfy an abnormal appetite. Under this form of starvation, for such it was, even with the liberal supply of the particular food given, there was observed "a ravenous appetite followed by enlargement and stiffening of the joints, spells of dizziness and difficult locomotion, all followed by periods of relief, and finally by a settled feeling of indifference to food."

From these several trials it is evident that mature ruminants can be maintained for a considerable period upon a limited amount of ground grain, and if liberally supplied therewith they may even gain in weight. With young animals the demand of nature seems more imperative, and it appears that calves cannot be brought to maturity upon grain and milk, either singly or combined, as the sole feed, but must have some coarse forage, without which rumination is impossible. 


\section{CHAPTER VII.}

EXPLANATION OF TABLES OF COMPOSITION AND FEEDING STANDARDS - METHODS OF CARCULATING RATIONS FOR FARM ANIMALS, ETO.

\section{Tables of Composition and Feeding Standards.}

129. Nutrients of feeding stuffs.-- We have already learned how the chemist divides the constituents of feeding stuffs into groups, which are placed in tables for convenient reference. From Table I of the Appendix there is here abstracted the fragment marked Example Table A, for the purpose of discussing the subject of nutrients in feeding staffs.

Example Table A, showing the water and total nutrients found by the chemist in several common feeding stuffs.

\begin{tabular}{|c|c|c|c|c|c|}
\hline \multirow{2}{*}{ Feeding stuftis. } & \multicolumn{5}{|c|}{ Total in 100 pounds. } \\
\hline & Water. & Protein. & $\begin{array}{l}\text { Crude } \\
\text { fiber. }\end{array}$ & $\begin{array}{l}\text { Nitrogen- } \\
\text { free extract. }\end{array}$ & $\begin{array}{l}\text { Ether } \\
\text { extract. }\end{array}$ \\
\hline Roughage. & Lbs. & Lbs. & Lbs. & Lbs. & Lbs. \\
\hline Corn stover, field cured. & 40.5 & 3.8 & 19.7 & 31.5 & 1.1 \\
\hline Red clover hay ........... & 15.3 & 12.3 & 24.8 & 38.1 & 3.3 \\
\hline Timothy hay ............... & 13.2 & 5.9 & 29.0 & 45.0 & 2.5 \\
\hline 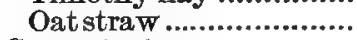 & 9.2 & 4.0 & $\mathbf{3 7 . 0}$ & 42.4 & 2.3 \\
\hline Concentrates. & & & & & \\
\hline 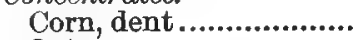 & 10.6 & 10.3 & 2.2 & 70.4 & 5.0 \\
\hline 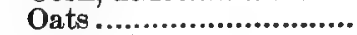 & 11.0 & 11.8 & 9.5 & 59.7 & 5.0 \\
\hline Wheat bran................... & 11.9 & 15.4 & 9.0 & 53.9 & 4.0 \\
\hline Linseed meal, O. P....... & 9.2 & 32.9 & 8.9 & 35.4 & 7.9 \\
\hline
\end{tabular}

In tables of this character the results stated are always the average of all analyses for each feed on record at the time of compilation.

The table shows that 100 pounds of average field-cured fodder corn contain 40.5 pounds of water - a much larger amonnt than the feeder will, on first thought, suppose pessible in what he has 
always regarded as "dry" forage. Of the nutrients in 100 pounds of stover, 3.8 pounds are protein, while the same weight of oat straw contains 4 pounds. Were it not for the large amount of water in corn stover, it would exceed straw in protein. Of crude fiber, the least valuable constituent of fodders, the stover contains 19.7 pounds, or only about one-half as much as oat straw. In nitrogen-free extract straw again leads, containing 42.4 pounds against 31.5 in stover. The table shows that the concentrates usually contain a higher proportion of protein than the coarse fodders, red clover and other legumes excepted. Corn is low in crude fiber, while oats are relatively high because of the husk which surrounds the oat kernel. The cereals, especially corn, are rich in nitrogen-free extract, which is principally starch. Corn and oats each contain five pounds of ether extract, and linseed meal eight pounds, practically all oil.

130. Digestion coefficients.-Elsewhere it is shown how the animal physiologist through feeding trials and analytical work ascertains what percentage of the several nutrients in a feeding stuff is digested by farm animals. Table II of the Appendix summarizes the results of digestion trials with the leading feeds. Example Table B, here given, shows the average digestion coefficients for the feeding stuffs given in Table A.

Example Table B, showing the average coefficients of digestibility for the feeding stuffs presented in Table $A$.

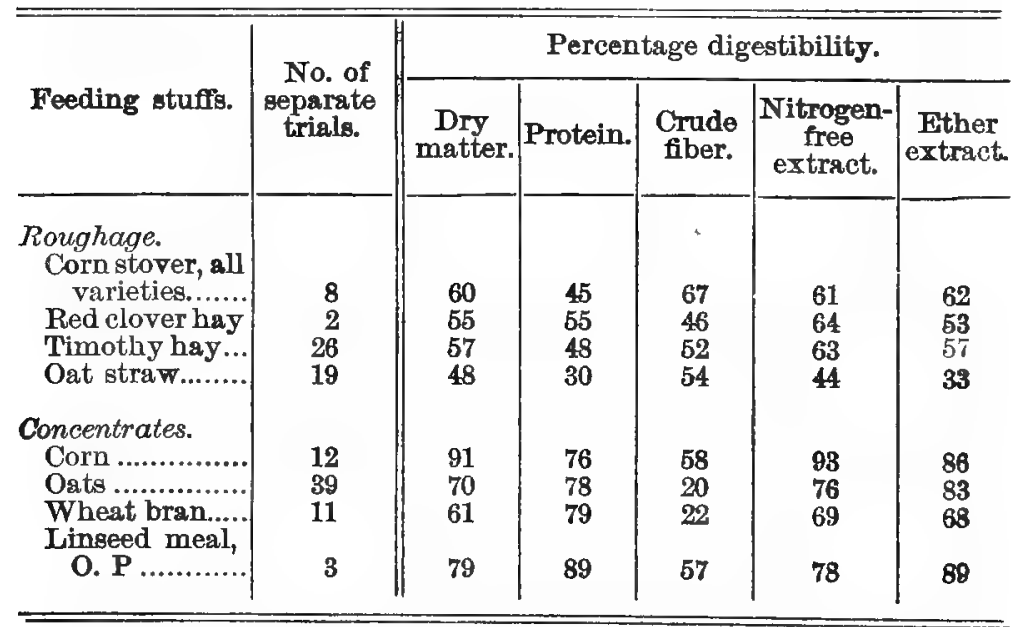


The second column of the table shows that eight feeding trials have been made with corn stover to determine the digestibility of its several components. Sixty per cent. of the dry matter, 45 of the protein, 67 of the crude fiber, 61 of the nitrogen-free extract, and 62 per cent. of the ether extract are, on the average, digested from this fodder by the fluids of the alimentary tract and absorbed by the animal body. In statements of this character, the average of a large number of determinations is more satisfactory and reliable than the data of a single trial.

Table A shows that oat straw contains more protein than corn stover. Table B shows that 45 per cent. of the protein in corn stover, and only 30 per cent. of that in oat straw, are digestible. It shows that the nutrients in the concentrates are more digestible than those in roughage, crude fiber excepted. For example, 78 per cent. of the protein in the oat grain, and only 30 per cent. of that in oat straw, are digestible. In corn stover 61 per cent. of the nitrogen-free extract is digestible, and in the corn grain 93 per cent. It thus appears that a given quantity of total nutrients in concentrated feeding stuffs is usually more valuable than the same amount in coarse forage.

131. Total digestible nutrients. - Example Table $\mathrm{C}$ is a portion of Table $\mathrm{WI}$ of the Appendix. Having learned the composition of the several common feeding stuffs from Table A, and the percentage digestibility of each of these nutrients from Table $\mathbf{B}$, the student is now in position to consider the third table, derived from them, presenting the digestible substance in 100 pounds of each of the feeding stuffs under consideration. The statement for each nutrient in this table is determined by multiplying its a composition, as given in Table $A$, by the factor of digestibility in Table B. 
Example Table $O$, showing the digestibility in feeding stuffs considered under Tables $A$ and $B$.

\begin{tabular}{|c|c|c|c|c|c|}
\hline \multirow{2}{*}{ Feeding stuffis. } & \multirow{2}{*}{$\begin{array}{c}\text { Total } \\
\text { dry } \\
\text { matter. }\end{array}$} & \multicolumn{3}{|c|}{$\begin{array}{c}\text { Total digestible substance } \\
\text { in } 100 \text { pounds. }\end{array}$} & \multirow{2}{*}{$\begin{array}{c}\text { Nutritive } \\
\text { ratio. }\end{array}$} \\
\hline & & Protein. & $\begin{array}{l}\text { Carbohy- } \\
\text { drates. }\end{array}$ & $\begin{array}{l}\text { Ether } \\
\text { extract. }\end{array}$ & \\
\hline Roughage. & Lbs. & Lbs. & Lbs. & Lbs. & \\
\hline 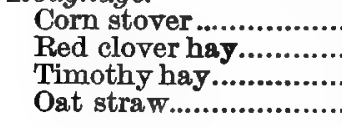 & $\begin{array}{l}59.5 \\
84.7 \\
86.8 \\
90.8\end{array}$ & $\begin{array}{l}1.7 \\
6.8 \\
2.8 \\
1.2\end{array}$ & $\begin{array}{l}32.4 \\
35.8 \\
43.4 \\
38.6\end{array}$ & $\begin{array}{l}0.7 \\
1.7 \\
1.4 \\
0.8\end{array}$ & $\begin{array}{l}1: 20 \\
1: 5.8 \\
1: 16.7 \\
1: 33.7\end{array}$ \\
\hline 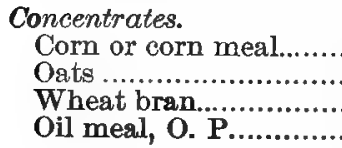 & $\begin{array}{l}89.4 \\
89.0 \\
88.1 \\
90.8\end{array}$ & $\begin{array}{r}7.8 \\
9.2 \\
12.2 \\
29.3\end{array}$ & $\begin{array}{l}66.7 \\
47.3 \\
39.2 \\
\mathbf{3 2 . 7}\end{array}$ & $\begin{array}{l}4.3 \\
4.2 \\
2.7 \\
7.0\end{array}$ & $\begin{array}{l}1: 9.8 \\
1: 6.2 \\
1: 3.7 \\
1: 1.7\end{array}$ \\
\hline
\end{tabular}

Table A shows that corn stover eontains 3.8 pounds of protein and oat straw 4 pounds; 45 per cent. of the protein in stover, and only 30 per cent. of that in straw, are digestible; consequently 100 pounds of average corn stover contain 1.7 pounds of digestible protein, while the same weight of oat straw contains only $\mathbf{1 . 2}$ pounds. Thus it is shown that although oat straw contains more total protein than corn stover, the latter has more digestible protein. In digestible protein clover hay stands in strong contrast with oat straw, -100 pounds of the former containing 6.8 pounds against 1.2 pounds for the straw. Corn contains 66.7 pounds of digestible carbohydrates per hundred weight, while corn stover contains 32.4 pounds, or one-half as much.

132. Nutritive ratio.-This expression, not heretofore used, is common with the student of feeding problems and should be understood by all, since it is helpful in studying different feeding substances. By "nutritive ratio" is meant the ratio which exists between the amount of the digestible protein in a given feeding stuff and the amount of the digestible carbohydrates and ether extract it contains. It is ascertained in the following manner: The amount of digestible ether extract is multiplied by 2.4, because ether extract is considered as having this heat value com- 
pared with the carbohydrates. ${ }^{1}$ The product obtained is added to the total quantity of digestible carbohydrates in the given fodder and the sum is divided by the digestible protein.

The method of calculating the nutritive ratio for corn stover, the digestible nutrients in which are protein 1.7 , carbohydrates 32.4, and ether extract 0.7 , is as follows:

\begin{tabular}{|c|c|c|c|c|c|}
\hline & $\begin{array}{l}\text { Ether } \\
\text { extract. }\end{array}$ & \multicolumn{3}{|c|}{$\begin{array}{c}\text { Heat } \\
\text { equivalent. }\end{array}$} & \multirow[b]{2}{*}{168} \\
\hline & .7 & $x$ & 2.4 & $=$ & \\
\hline \multicolumn{5}{|c|}{$\begin{array}{l}\text { Carbohy- } \\
\text { drates. }\end{array}$} & \\
\hline 1.68 & + & 32.4 & $=$ & 34.08 & \\
\hline 4.08 & $\div$ & 1.7 & $=$ & $20+$ & \\
\hline
\end{tabular}

In expressing the natritive ratio of corn stover thus, $1: 20$, it is meant that for each pound of digestible protein in corn stover there are 20 pounds of digestible carbohydrates and ether-extract equivalent. The nutritive ratios of the several feeds are placed in the last column of the table. The nutritive ratio of oat straw is shown by the table to be $1: 33.7$. This is called a "wide" ratio because of the very large quantity of carbohydrates contained in this feed in proportion to the protein. With Indian corn the nutritive ratio is $1: 9.8$. Such an expression is spoken of as a "medium" ratio. In oil meal the nutritive ratio is $1: 1.7$, the protein almost equaling the carbohydrates and fat combined. Such an expression is called a "narrow" nutritive ratio.

133. Wolff-Lehmann feeding standards.- Step by step we have advanced until it is shown in the last table what portion of feeding stuffs is available for the nutrition of farm animals. Let us next direct attention to the quantity of the several nutrients in feeding stuffs required by farm animals. While analytical work and digestion trials were in progress by the physiologist and chemist, feeding trials were being conducted to determine how much protein, carbohydrates and ether extract were required to properly nurture farm animals of the several classes, under various

1 American writers generally use the factor 2.2 or 2.25. See Article 61

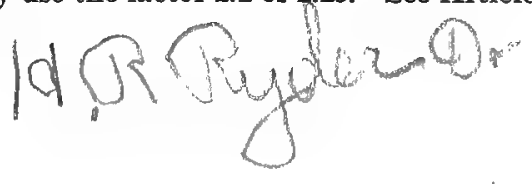


conditions. The following Frample Table $\mathrm{D}$ from Table IV of the Appendix presents the food requirements of certain farm animals:

Example Table $D$, showing the amount of dry matter and digestible nutrients required daily by farm animals per 1,000 pounds live weight.

\begin{tabular}{|c|c|c|c|c|c|}
\hline & \multirow{2}{*}{$\begin{array}{c}\text { Dry } \\
\text { matter. }\end{array}$} & \multicolumn{3}{|c|}{ Digestible nutrients. } & \multirow{2}{*}{$\begin{array}{l}\text { Nutritive } \\
\text { ratio. }\end{array}$} \\
\hline & & Protein. & $\begin{array}{c}\text { Carbohy- } \\
\text { drates. }\end{array}$ & $\begin{array}{l}\text { Ether } \\
\text { extract. }\end{array}$ & \\
\hline 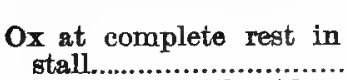 & $\begin{array}{l}\text { Lbs. } \\
18.0\end{array}$ & $\begin{array}{r}\text { Lbs. } \\
0.7\end{array}$ & $\begin{array}{r}\text { Lbs. } \\
8.0\end{array}$ & $\begin{array}{c}\text { Lbs. } \\
0.1\end{array}$ & $1: 11.8$ \\
\hline $\begin{array}{l}\text { Fattening cattle (first } \\
\text { period) ...................... }\end{array}$ & 30.0 & 2.5 & 15.0 & 0.5 & $1: 6.5$ \\
\hline $\begin{array}{l}\text { pounds daily )................ } \\
\text { Horse (medium work).... }\end{array}$ & $\begin{array}{l}29.0 \\
24.0\end{array}$ & $\begin{array}{l}2.5 \\
2.0\end{array}$ & $\begin{array}{l}13.0 \\
11.0\end{array}$ & $\begin{array}{l}0.5 \\
0.6\end{array}$ & $\begin{array}{l}1: 5.7 \\
1: 6.2\end{array}$ \\
\hline
\end{tabular}

NotE.-The "Sum of nutrients" in the larger table has been omitted from this table in order to simplify the explanation.

The first subject for consideration is the amount of nutrients required to maintain an ox weighing 1,000 pounds when at rest in the stall, neither gaining nor losing in weight. The table states this to be as follows: Dry matter, 18 pounds; digestible protein, .7 pounds; digestible carbohydrates, 8 pounds; ether extract, .1 pound. A ration containing these nutrients has a nutritive ratio of $1: 11.8$. (443) Although the ox is referred to as "at rest," nevertheless work is being accomplished. The heart is forcing blood currents through the body, and digestion and assimilation are in progress; even the act of standing and breathing constitutes work. Each of the many manifestations of life calls for food-fuel and repair material. Conceding that the above feeding standard is correct, the ox which receives less nutrients than here stated will lose in weight, while if more are allowed he will increase in weight.

\section{Calculating Rations for Farm Animals.}

134. Ration for the steer at rest.-With Table C, giving the digestible nutrients in several common feeding staffs, and Table D, stating the requirements of the ox for maintenance, we have the 
data for calculating how much feed should be supplied in order to maintain this animal.

For the trial ration, we decide to use 10 pounds of corn stover and 10 pounds of oat straw. Let us ascertain the digestible nutrients these will sapply.

Calculations for dry matter and digestible nutrients in corn stover and oat straw.

Corn stover.

In 100 pounds.

In 10 pounds.

Dry matter $59.5 \div 100 \times 10=5.95$

Protein.

$$
1.7 \div 100 \times 10=.17
$$

Carbohydrates. $32.4 \div 100 \times 10=3.24$

Ether extract

$$
.7 \div 100 \times 10=.07
$$

\section{Oat straw.}

Dry matter

$$
\begin{array}{r}
90.8 \div 100 \times 10=9.08 \\
1.2 \div 100 \times 10=.12 \\
38.6 \div 100 \times 10=3.86 \\
.8 \div 100 \times 10=.08
\end{array}
$$

Protein.

Carbohydrates.

\begin{tabular}{|c|c|c|c|c|c|}
\hline \multirow[b]{2}{*}{ Feeding stuffs. } & \multirow{2}{*}{$\begin{array}{c}\text { Dry } \\
\text { matter. }\end{array}$} & \multicolumn{3}{|c|}{ Digestible nutrients. } & \multirow{2}{*}{$\begin{array}{l}\text { Nutritive } \\
\text { ratio. }\end{array}$} \\
\hline & & Protein. & $\begin{array}{l}\text { Carbohy- } \\
\text { drates. }\end{array}$ & $\begin{array}{l}\text { Ether } \\
\text { extract. }\end{array}$ & \\
\hline $\begin{array}{l}\text { Corn stover, } 10 \text { pounds ... } \\
\text { Oat straw, } 10 \text { pounds ..... }\end{array}$ & $\begin{array}{l}\text { Lbs. } \\
\mathbf{5 . 9 5} \\
\mathbf{9 . 0 8}\end{array}$ & $\begin{array}{c}\text { Los. } \\
.17 \\
.12\end{array}$ & $\begin{array}{l}\text { Lbs. } \\
3.24 \\
3.86\end{array}$ & $\begin{array}{r}\text { Lbs. } \\
.07 \\
.08\end{array}$ & (n) \\
\hline First trial ration............. & 15.03 & .29 & 7.10 & .15 & \\
\hline Wolff-Lehmann stand'rd & 18.0 & .7 & 8. & .10 & $1: 11.8$ \\
\hline
\end{tabular}

Fther extract

Arranging these in a table, with the Wolff-Lehmann standard for comparison, we have:

First trial maintenance ration for ox at rest weighing 1,000 pounds Wolff-Lehmann Standard.

The trial ration falls below the standard in everything except ether extract, the deficiency being especially marked as to protein. 
To complete the ration there is added one pound each of oil meal and corn meal. Ascertaining the nutrients in these as before, we have the second trial maintenance ration, which is as follows:

Second trial maintenance ration for ox at rest weighing 1,000 pounds Wolf-Lehmann Standard.

\begin{tabular}{|c|c|c|c|c|c|}
\hline \multirow[b]{2}{*}{ Feeding stuffis. } & \multirow{2}{*}{$\begin{array}{c}\text { Dry } \\
\text { matter. }\end{array}$} & \multicolumn{3}{|c|}{ Digestible nutrients. } & \multirow{2}{*}{$\begin{array}{l}\text { Nutritive } \\
\text { ratio. }\end{array}$} \\
\hline & & Protein. & $\begin{array}{c}\text { Carbohy- } \\
\text { drates. }\end{array}$ & $\begin{array}{l}\text { Ether } \\
\text { extract. }\end{array}$ & \\
\hline $\begin{array}{l}\text { Ration as above } \\
\text { Oil meal, } 1 \text { pound ................ } \\
\text { Corn meal, } 1 \text { pound ........ }\end{array}$ & $\begin{array}{c}\text { Lbs. } \\
15.03 \\
.908 \\
.894\end{array}$ & $\begin{array}{l}\text { Lbs. } \\
.29 \\
.293 \\
.078\end{array}$ & $\begin{array}{l}\text { Lbs. } \\
7.10 \\
.327 \\
.667\end{array}$ & $\begin{array}{l}\text { Lbs. } \\
.15 \\
.07 \\
.043\end{array}$ & (n) \\
\hline Second trial ration .......... & 16.832 & .661 & 8.094 & .263 & $1: 13.2$ \\
\hline Wolfr-Lebmann stand'rd & 18.0 & .7 & 8.0 & .10 & $1: 11.8$ \\
\hline
\end{tabular}

This second trial ration falls below the standard by more than a pound of dry matter, bat this deficiency is of small importance. In protein the ration is almost up to the standard, exceeding it slightly in carbohydrates, and considerably in ether extract.

The nutritive ratio of this ration is $1: 13.2$ The ration approximates the standard as closely as can be attained without using fractions of pounds, and near enough for purposes of illustration. From this we learn that ten pounds each of corn stover and oat straw, and one pound each of oil meal and corn meal per day, will nurture a steer weighing 1,000 pounds so that he will neither gain nor lose in weight - that is, such a combination constitutes a "maintenance" ration.

135. A ration for the fattening steer.- Example Table $\mathbf{D}$ shows that the fattening steer (first period) requires more than three times as much protein, five times as much ether extract, and nearly twice as much carbohydrates, as constitute a maintenance ration, with the nutritive ratio narrowed to $1: 6.5$. It is apparent that more concentrated feed must enter into this ration than into the first one. For a trial ration we choose 10 pounds of corn 
stover, 8 pounds of oat straw and 12 pounds of corn. Calculating the nutrients in these as in the first instance, we have:

First trial ration for the rapid fattening of a steer weighing 1,000 pounds (first period) - Wolff-Lehmann Standard.

\begin{tabular}{|c|c|c|c|c|c|}
\hline \multirow{2}{*}{ Feeding stuffs. } & \multirow{2}{*}{$\underset{\text { matter. }}{\text { Dry }}$} & \multicolumn{3}{|c|}{ Digestible nutrients. } & \multirow{2}{*}{$\begin{array}{l}\text { Nutritive } \\
\text { ratio. }\end{array}$} \\
\hline & & Protein. & $\begin{array}{l}\text { Carbohy- } \\
\text { drates. }\end{array}$ & $\begin{array}{l}\text { Ether } \\
\text { extract. }\end{array}$ & \\
\hline & Lbs. & Lbs. & Lbs. & Lbs. & \\
\hline $\begin{array}{l}\text { Corn stover, } 10 \text { pounds ... } \\
\text { Oat straw, } 8 \text { pounds ........ } \\
\text { Corn, } 12 \text { pounds............ }\end{array}$ & $\begin{array}{c}5.95 \\
7.264 \\
10.728\end{array}$ & $\begin{array}{l}.17 \\
.096 \\
.936\end{array}$ & $\begin{array}{l}3.24 \\
3.088 \\
8.004\end{array}$ & $\begin{array}{l}.07 \\
.064 \\
.516\end{array}$ & (n) \\
\hline First trial ration.............. & 23.942 & 1.202 & 14.332 & .650 & \\
\hline Wolff-Lehmann stand'rd & 30.0 & 2.5 & 15.0 & .50 & $1: 6.5$ \\
\hline
\end{tabular}

This trial ration falls below the standard in each nutrient, especially in protein. Some feed rich in protein should be added, and accordingly 4 pounds of oil meal, O. P., are used.

Second trial ration for the rapid fattening of a steer - Wolff-Lehmann Standard.

\begin{tabular}{|c|c|c|c|c|c|}
\hline \multirow[b]{2}{*}{ Feeding stuffa. } & \multirow{2}{*}{$\begin{array}{c}\text { Dry } \\
\text { matter. }\end{array}$} & \multicolumn{3}{|c|}{ Digestible nutrients. } & \multirow{2}{*}{$\begin{array}{l}\text { Natritive } \\
\text { ratio. }\end{array}$} \\
\hline & & Protein. & $\begin{array}{l}\text { Carbohy- } \\
\text { drates. }\end{array}$ & Ether & \\
\hline $\begin{array}{l}\text { Ration as above ................ } \\
\text { Oil meal, } O . \text { P., } 4 \text { pounds }\end{array}$ & $\begin{array}{c}\text { Lbs. } \\
\mathbf{2 3 . 9 4 2} \\
\mathbf{3 . 6 3 2}\end{array}$ & $\begin{array}{l}\text { Lbs. } \\
1.202 \\
1.172\end{array}$ & $\begin{array}{c}\text { Lbs. } \\
\text { 14.332 } \\
1.308\end{array}$ & $\begin{array}{c}\text { Lbs. } \\
.65 \\
.28\end{array}$ & (n)........... \\
\hline Second trial ration .......... & 27.674 & 2.374 & 15.640 & .93 & $1: 7.5$ \\
\hline Wolff-Lehmann stand'rd & 30.0 & 2.5 & 15.00 & .50 & $1: 6.5$ \\
\hline
\end{tabular}

This ration falls below the standard by nearly 2.5 pounds of dry matter and a little more than .1 of a pound protein. There is an excess of both carbohydrates and ether extract. By reducing the allowance of corn meal one pound and increasing 
the oil meal by the same amount, the standard would be more nearly reached, although there is already a fairly close agreement. This shows that the fattening steer weighing 1,000 pounds will be nurtared to very nearly his full requirement when receiving the following ration: 10 pounds of corn stover, 8 pounds of oat straw, 12 pounds of corn, 4 pounds of oil meal.

136. Calculating a ration for the dairy cow. - In determining a ration for a dairy cow yielding 22 pounds of milk daily, we choose from the list of feeds in Table C, 8 pounds of red clover hay, 10 pounds of corn stover, 3 pounds of oat straw, for roughage, and 5 pounds each of corn meal and bran for concentrates. The digestible nutrients in these are ascertained as follows:

Calculations for dry matter and digestible nutrients in trial ration for dairy cow.

Red clover hay.

\begin{tabular}{|c|c|c|c|}
\hline $\begin{array}{l}\text { In } 100 \\
\text { pounds. }\end{array}$ & $\begin{array}{c}\text { In } 8 \\
\text { pounds. }\end{array}$ & $\begin{array}{c}\text { In } 100 \\
\text { pounds. }\end{array}$ & $\begin{array}{l}\text { In } 10 \\
\text { pounds. }\end{array}$ \\
\hline 84.7 & $=6.776$ & \multicolumn{2}{|c|}{$59.5 \div 100 \times 10=5.95$} \\
\hline 6.8 & $=.544$ & \multicolumn{2}{|c|}{$1.7 \div 100 \times 10=.17$} \\
\hline 35.8 & $=2.864$ & \multicolumn{2}{|c|}{$32.4 \div 100 \times 10=3.24$} \\
\hline 1.7 & $=.136$ & \multicolumn{2}{|c|}{$.7 \div 100 \times 10=.07$} \\
\hline \multicolumn{2}{|c|}{ Oat straw. } & \multicolumn{2}{|c|}{ Corn meal. } \\
\hline $\begin{array}{l}\text { In } 100 \\
\text { pounds. }\end{array}$ & $\begin{array}{c}\text { In } 3 \\
\text { pounds }\end{array}$ & $\begin{array}{l}\text { In } 100 \\
\text { pounds. }\end{array}$ & $\begin{array}{c}\text { In } 5 \\
\text { pounds. }\end{array}$ \\
\hline \multicolumn{2}{|c|}{$90.8 \div 100 \times 3=2.724$} & \multicolumn{2}{|c|}{$89.4 \div 100 \times 5=4.47$} \\
\hline 1.2 & .036 & \multicolumn{2}{|c|}{$7.8 \div 100 \times 5=.39$} \\
\hline $38.6-$ & 1.158 & \multicolumn{2}{|c|}{$66.7 \div 100 \times 5=3.335$} \\
\hline .8 & .024 & \multicolumn{2}{|c|}{$4.3 \div 100 \times 5=.215$} \\
\hline
\end{tabular}

Bran.
In 100
pounds. 5
$88.1 \div 100 \times 5=4.405$
$12.2 \div 100 \times 5=.61$
$39.2 \div 100 \times 5=1.96$
$2.7 \div 100 \times 5=.135$

Arranging these results in tabular form, with the Wolff-Lehmann standard for comparison, we have the following: 
First trial ration for dairy cow weighing 1,000 pounds and yielding 20 pounds of mills daily - Wolff-Lehmann Standard.

\begin{tabular}{|c|c|c|c|c|c|}
\hline \multirow{2}{*}{ Feeding stuffis. } & \multirow{2}{*}{$\begin{array}{c}\text { Dry } \\
\text { matter. }\end{array}$} & \multicolumn{3}{|c|}{ Digestible nutrients. } & \multirow{2}{*}{$\begin{array}{c}\text { Nutri- } \\
\text { tive } \\
\text { ratio. }\end{array}$} \\
\hline & & Protein & $\begin{array}{l}\text { Carbohy- } \\
\text { drates. }\end{array}$ & $\begin{array}{c}\text { Ether } \\
\text { extract. }\end{array}$ & \\
\hline & Lbs. & Lbs. & Lbs. & Lbs. & \\
\hline Red clover hay, 8 pounds .. & 6.776 & .544 & 2.864 & .136 & \\
\hline Corn stover, 10 poünds ........ & 5.95 & .17 & 3.24 & .07 & ........ \\
\hline Oat straw, 3 pounds .......... & 2.724 & .036 & 1.158 & .024 & \\
\hline Corn meal, 5 pounds. .......... & 4.47 & .39 & 3.335 & .215 & \\
\hline Bran, 5 pounds .................. & 4.405 & .61 & 1.96 & .135 & \\
\hline First trial ration ............... & 24.325 & 1.750 & 12.557 & .580 & \\
\hline Wolff-Lehmann standard.. & 29.0 & 2.5 & 13.0 & .50 & $1: 5.7$ \\
\hline
\end{tabular}

This trial ration falls considerably below the standard, especially in protein, and to correct this, 3 pounds of oil meal are added.

Second trial ration for dairy cow weighing 1,000 pounds and yielding 22 pounds of milk daily-Wolff-Lehmann Standard.

\begin{tabular}{|c|c|c|c|c|c|}
\hline \multirow{2}{*}{ Feeding stuffs. } & \multirow{2}{*}{$\begin{array}{l}\text { Dry } \\
\text { matter. }\end{array}$} & \multicolumn{3}{|c|}{ Digestible nutrients. } & \multirow{2}{*}{$\begin{array}{c}\text { Nutri- } \\
\text { tive } \\
\text { ratio. }\end{array}$} \\
\hline & & Protein. & $\begin{array}{c}\text { Carbohy- } \\
\text { drates. }\end{array}$ & $\begin{array}{l}\text { Ether } \\
\text { extract. }\end{array}$ & \\
\hline $\begin{array}{l}\text { Ration as above ................. } \\
\text { Oil menl, } 3 \text { pounds ............. }\end{array}$ & $\begin{array}{l}\text { Lbs. } \\
24.325 \\
2.724\end{array}$ & $\begin{array}{r}\text { Lbs. } \\
1.750 \\
.879\end{array}$ & $\begin{array}{r}\text { Lbs. } \\
12.557 \\
.981\end{array}$ & $\begin{array}{c}\text { Lbs. } \\
.580 \\
.21\end{array}$ & 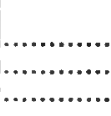 \\
\hline Second trial ration ............. & 27.049 & 2.629 & 13.538 & .79 & $1: 5.9$ \\
\hline Wolff-Lehmann standard .. & 29.0 & 2.5 & 13.0 & .50 & $1: 5.7$ \\
\hline
\end{tabular}

The second trial ration is 2 pounds below the standard in dry matter, something of little significance as it is really of satisfactory volume as it stands. All the nutrients are slightly in excess of the standard, the nutritive ratio being $1: 5.9$, while the standard calls for $1: 5.7$.

We learn from this that a satisfactory ration for a dairy cow weighing 1,000 pounds and yielding 22 pounds of milk daily may be composed of the following: Red clover hay, 8 pounds; corn 
stover, 10 pounds; corn meal and bran, each 5 ponds; oat straw and oil meal, each 3 pounds.

137. Concerning rations. - In preparing a ration it is well to start with what may be called a "trial" ration, composed of two or more kinds of coarse forage with a moderate supply of some desirable concentrate. When the nutrients these furnish have been placed in tabular form, a few trials will determine the quantity of other concentrates necessary to bring the ration up to the standard. It is usually impossible to compound rations for ruminants from common American feeding stuffs which will furnish the large amount of dry. matter called for by the WolffLehmann standard. While volume is an important factor in feeding, it is better to allow the ration to fall below the standard in dry matter than to add so much coarse forage with its large percentage of inert matter. Our sommon feeding materials are of such composition that in placing enough of them in the ration to furnish the requisite protein and carbohydrates, there is usually an excess of ether extract according to the standard, but this cannot be avoided. There is no direct way of calculating the exact quantities of the nutrients to be used in formulating rations, the desired result being reached only by repeated trials, each bringing the calculation nearer the desired standard. With the explanations given, the stockman should find no difficulty in calculating rations for the farm animals under his care.

\section{Feeding Tables and Standards.}

138. The first feeding table.-The first attempt to systematically compare various feeding stuffs one with another was by Thaer, ${ }^{1}$ who in 1810 published a table giving what he termed "hay equivalents." With common hay as the standard unit, the feeding values were in part as follows:

One hundred pounds meadow hay is equal in feeding value to -

200 pounds potatoes.

625 pounds mangels.

417 pounds rutabagas.

602 pounds cabbages.

91 pounds clover hay.

91 pounds alfalfa hay.

Naturally, opinions varied as to the comparative values of vart-

1 Thaer, Landwirtschaft, New Ed., 1880, p. 211. 
ous feeding stuffs, and so there were about as many tables of "hay equivalents" as there were writers on economic agriculture. Im. perfect as it was, Thaer's table served to draw attention to an important subject and was the beginning of something far more elaborate and useful.

139. The first feeding standard.-In 1859 Grouven ${ }^{1}$ proposed the first feeding standard for farm animals, based on the total quantity of protein, carbohydrates and ether extract found by analysis in feeding stuffs. This standard fell short of requirements, since it considered the total nutrients instead of the digestible portion.

140. Wolff's standards.-In 1864 , Dr. Emil v. Wolff, the great German scientist and author, published for the first time, in Mentzel \& v. Lengerke's Agricultural Calendar, standards based upon the digestible nutrients of feeding stuffs. In these standards the attempt was made to meet the physiological requirements of the animal by supplying sufficient protein, carbohydrates and ether extract for all the needs of the body, without waste of any of the nutrients. Wolff's feeding standards have become popular among the more progressive American farmers and stockmen and have been used wherever agricultural science is recognized. Their popularity is due in a large measure to their simplicity, ease of application, and the positive character of the statements made. In these standards, accompanied by tables of digestibility, the stockman has before him the data necessary to calculate rations for the different farm animals, little or nothing being left in uncertainty.

141. Kuehn's position.- The strength of Wolff's standards is also their weakness, for such mathematical statements cannot stand without marked qualifications when dealing with the complex problem of animal life and its nurture by food.

Julius Kühn, another German writer and investigator of the highest repute, holds" that Wolff's standards "are objectionable and misleading to the farmer." According to this anthor, Wolff

1 Feeding Standards for Domestic Animals, Expt. Sta. Rec., vol IV; also Agricultur-Chemie, Köln, 1889, p. 834.

2 Feeding Standards for Domestic Animals, Expt. Sta. Rec., vol. IV, pp. 6-13. 
is incorrect when he bases the total quantity of food to be supplied on the organic substance contained, instead of the dry matter, as originally stated by Lingenthal and Grouven. Again, Wolff places the allowance of organic matter required by the dairy cow at 25 pounds; Kühn tells us this may vary between the extremes of 20 and 33.5 pounds. Changes in the amount of dry matter supplied should, however, always be gradual. Kühn further protests against prescribing exact quantities of nutrients as norms or standards. "For the individual nutrients, as for the total amount of food, it is essential to determine the amount for each individual case, and in doing this the particular conditions should be considered." Wolff does not distinguish between digestible albuminoids and amides; Kühn holds that the lower nutritive effect of amide compounds can no longer be doubted, and that these amides can at best serve only as albuminoid conservers, like the carbohydrates, and further that the non-albuminoid protein includes compounds which do not even exert this conserving action and whose nutritive function is very doubtful.

Grouven fixed the total protein (digestible and indigestible) for the dairy cow at 2.74 pounds, while Wolff places ine standard at 2.5 of digestible albuminoids and amides. Kühn states that the cow of high productive capacity during her largest flow of milk requires more than 2.5 pounds of digestible protein, while smaller amounts than Wolff names should be given with diminishing milk flow. Again, the ether extract or so-called "fat" of food varies in nutritive effect according to its origin; that from oil cake, for example, having a higher feeding value than that found in coarse fodders. In the same way, nitrogen-free extract includes substances of variable composition, some of which are of questionable nutritive value, and to count all these as equivalent to starch for feeding purposes is far from correct. Finally, Kühn lays stress on the importance of individual feeding, declaring that the stockman must carefully study the requirements of each animal and nourish it according to its individual wants, instead of placing all members of the herd or flock on inflexible rations constructed according to definite standards. He concludes that fodders vary so greatly in composition that to use 
average analyses in calculating rations with the exactness prescribed by Wolff may lead to very unsatisfactory results.

142. The Wolff-Lehmann standard.-Wolff's feeding standards were given annually in the Mentzel-Lengerke Agricultural Cal endar from 1864 to 1896 . The calendar for 1897 was prepared by Dr. C. Lehmann of the Berlin Agricultural College. This table is changed from Wolff's in several particulars. "Dry matter" takes the place of "organic matter" in Wolff's table. A double column not used by Wolff is headed "Sum of nutrients." In the first of these columns all of the digestible crude fiber is included with the other nutrients. In the second column only one-half of the crude fiber found digestible is included. Lehmann recognizes the varying wants of dairy cows by classifying them in four divisions according to the milk they yield, the heaviest milkers receiving the most nutrients.

While Wolff's tables have heretofore been universally used in this country, it seems proper to adopt the modifications of Lehmann.

143. Introduction of standards in America.- Feeding standards were first brought to the attention of Americans by Atwater ${ }^{1}$ in 1874, and the efforts of this teacher and investigator have fortunately been continued in the same line to the present time, greatly to the advancement of scientific agriculture in this country. Armsby's Manual of Cattle Feeding, based on Wolff's book ${ }^{2}$ on the same subject, appeared in 1880 and marked an era in the educational development of this topic. From these sources the students in our agricultural colleges, writers and lecturers have come to know of feeding standards, and through them, thousands of feeders have learned to calculate rations for farm animals.

IV. The Several Feeding Standards.

144. The maintenance ration for the ox. - In 1879 Sanborn, ${ }^{8}$ of the New Hampshire Agricultural College, reported that the steer could be maintained on a smaller amount of hay than called for by Wolff's standard. Subsequent experiments by this investi-

1 Rept. Me. State Bd. Agr., 1874; Rept. Secy. Conn. Bd. Agr., $1874-5$.

2 Fütterungslehre, 1st ed., 1874; 7th ed., 1898.

Rept. N. H. Bd. Agr., 1879. See also subsequent reports. 
gator confirmed his statement that Wolff's maintenance standard was really sufficient in nutrients to allow the animal to make a gain in weight. These statements were at first controverted, ${ }^{1}$ the assumption being that the Germans must be right and the American investigator wrong. At the Cornell University Station, ${ }^{2}$ Caldwell, feeding four steers on a ration containing the following nutrients: dry substance 15.3, protein .68, carbohydrates and fat 8.6 (nutritive ratio, $1: 13.2$ ), secured the following:

\section{Weight of 4 steers, January 20,3,492 pounds. \\ Weight of 4 steers, March 21, 3,672 pounds.}

Here is a gain of 180 pounds in two months on a maintenance ration according to $\mathrm{Wolff}$.

Reviewing his own and the work of others, Caldwell wrote: "The results of the many tests to which they (standard rations) have been subjected at various places in the country make it evident that with such data as we at present have at command, no ration can be calculated that will do the same work or produce the effect for which it was calculated in all cases, and perhaps not even in a majority of cases, and that sometimes such rations entirely fail to accomplish the purpose for which they were calculated and used."

145. Kuehn's standard maintenance ration.-Investigations extending from 1882 to 1890 by G. Kühn ${ }^{3}$ show that the full-grown ox kept in perfect quiet in the stall can be maintained on .7 pounds of digestible protein and 6.6 pounds of digestible nitrogenfree extract for each one thousand pounds of live weight. If more nutrients than these are supplied, each one hundred grams of digestible starch may cause a deposit of 20 to 24 grams of fat in the body of the ox.

146. Woll's findings. - At the Wisconsin Station, ${ }^{4}$ Woll ascertained by correspondence with a number of the leading dairymen of America the composition of the rations which they had used successfully with their herds. Reports were received from the managers of 128 herds including more than 3,000 cows

\footnotetext{
1 See various articles, Rural New-Yorker, 1882

2 Rept. 1883-85.

Ldw. Vers. Stat., 44, p. 550.

- Bul. 38; Rept. 1894.
} 
Grouping the returns by sections, and calculating the dry and digestible matter in the rations reported, the following table was prepared:

Rations fed by 128 American dairymen as ascertained by WollWisconsin Station.

\begin{tabular}{|c|c|c|c|c|c|c|c|}
\hline \multirow[b]{2}{*}{$\begin{array}{l}\text { Where ration was } \\
\text { fed. }\end{array}$} & \multirow{2}{*}{$\begin{array}{l}\text { No. of } \\
\text { rations } \\
\text { fed. }\end{array}$} & \multirow[b]{2}{*}{$\begin{array}{c}\text { Dry } \\
\text { matter. }\end{array}$} & \multicolumn{4}{|c|}{ Digestible matter. } & \multirow{2}{*}{$\begin{array}{c}\text { Nutri- } \\
\text { tive } \\
\text { ratio. }\end{array}$} \\
\hline & & & $\begin{array}{l}\text { Pro- } \\
\text { tein. }\end{array}$ & $\begin{array}{c}\text { Car- } \\
\text { bohy- } \\
\text { drates. }\end{array}$ & $\begin{array}{c}\text { Ether } \\
\text { ex- } \\
\text { tract. }\end{array}$ & Total. & \\
\hline & \multirow{6}{*}{$\begin{array}{r}55 \\
56 \\
2 \\
6 \\
9\end{array}$} & Lbs. & Lbs. & Lbs. & Lbs. & Lbs. & \multirow{6}{*}{$\begin{array}{l:l}1 & : 6.8 \\
1 & : 7.2 \\
1 & : 7.2 \\
1 & : 5.3 \\
1 & : 7.4\end{array}$} \\
\hline Eastern states...... & & 24.38 & 2.20 & 13.31 & .77 & 16.28 & \\
\hline Middle states........ & & 24.64 & 2.08 & 13.37 & .72 & 16.17 & \\
\hline Southern states... & & 23.48 & 2.00 & 12.14 & 1.05 & $15: 19$ & \\
\hline Western states..... & & 29.28 & 3.05 & 14.58 & .75 & 18.38 & \\
\hline Canada................ & & 21.57 & 1.76 & 11.69 & .63 & 14.08 & \\
\hline
\end{tabular}

In these averages we observe a wide variation in the nutrients fed, the minimum falling much below Wolff's standard, while the maximum materially exceeds it. As a summary report of the rations fed by leading American dairymen, this table is valuable, representing as it does the practice of so many experienced feeders. On the other hand, it is unsatisfactory because in many cases the feed was not weighed, the figures reported being estimates.

147. Studies by the Connecticut (Storrs) Station.-Atwater and Phelps, of the Connecticut (Storrs) Station, ${ }^{1}$ studied in person the rations used by a number of dairymen in their state. Their work included weighing and sampling the feed and the milk, both of which were analyzed by the Station. (681) The following table presents the extremes observed in these studies:

Minimum and maximum rations fed by Connecticut dairymen as determined by Atwater and Phelps - Connecticut (Storrs) Station.

\begin{tabular}{r|c|c|c|c|c}
\hline & $\begin{array}{c}\text { Organic } \\
\text { matter. }\end{array}$ & $\begin{array}{c}\text { Digestible } \\
\text { protein. }\end{array}$ & $\begin{array}{c}\text { Digestible } \\
\text { ether ex- } \\
\text { tract. }\end{array}$ & $\begin{array}{c}\text { Digestible } \\
\text { earbohy- } \\
\text { drates. }\end{array}$ & $\begin{array}{c}\text { Nutri- } \\
\text { tive } \\
\text { ratio. }\end{array}$ \\
\cline { 2 - 4 } & Lbs. & Lbs. & Lbs. & Lbs. & \\
Minimum, 27 rations.... & 20.5 & 1.35 & .56 & 10.47 & $1: 4.5$ \\
Maximum, 27 rations ... & 33.7 & 3.48 & 1.36 & 18.25 & $1: 11.3$ \\
Average 27 rations... & 25.5 & 2.36 & .87 & 13.76 & $1: 6.7$ \\
\hline
\end{tabular}

1 Rept. 1896. 
148. Standard rations for dairy cows. - From the reports of 128 American dairymen gathered by Woll, that investigator deduces what he calls the American ration for dairy cows. Based on their personal study of dairy herds covering three winters as just noted, Atwater and Phelps of the Storrs Station offer a tentative standard. Below are grouped the several standards for convenient reference by the student.

American and German feeding standards for dairy cons. - Digestible. nutrients per day per 1,000 pounds live weight.

\begin{tabular}{|c|c|c|c|c|c|}
\hline \multirow{2}{*}{ Ration: } & \multirow{2}{*}{$\begin{array}{c}\text { Dry } \\
\text { matter. }\end{array}$} & \multicolumn{3}{|c|}{ Digestible nutrients. } & \multirow{2}{*}{$\begin{array}{c}\text { Nutri- } \\
\text { tive } \\
\text { ratio. }\end{array}$} \\
\hline & & Protein. & $\begin{array}{l}\text { Carbohy- } \\
\text { drates. }\end{array}$ & $\begin{array}{l}\text { Ether } \\
\text { extract. }\end{array}$ & \\
\hline & Lbs. & Lbs. & Lbs. & Lbs. & \\
\hline $\begin{array}{l}\text { Wolff original (German) } \\
\text { feeding ration .................... }\end{array}$ & $24.0^{*}$ & 2.5 & 12.5 & 0.4 & $1: 5.4$ \\
\hline $\begin{array}{l}\text { Woll proposed American } \\
\text { ration } . . . . . \ldots \ldots \ldots \ldots \ldots \ldots \ldots \ldots . . . . . . . . . .\end{array}$ & 24.5 & 2.15 & 13.27 & .74 & $1: 6.9$ \\
\hline $\begin{array}{l}\text { Atwater \& Phelps pro- } \\
\text { posed standard.................. }\end{array}$ & $25.0^{*}$ & 2.5 & 12 to 13 & .5 to .8 & $1: 5.6$ \\
\hline 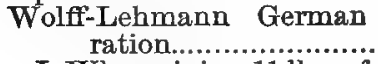 & & & & & \\
\hline $\begin{array}{r}\text { I. When giving } 11 \mathrm{lbs} \text { of } \\
\text { milk daily................... }\end{array}$ & 25.0 & 1.6 & 10.0 & 0.3 & $1: 6.7$ \\
\hline $\begin{array}{l}\text { II. When giving } 16 \frac{1}{2} \text { lbs. } \\
\text { of milk daily ............ }\end{array}$ & 27.0 & 2.0 & 11.0 & 0.4 & $1: 6.0$ \\
\hline $\begin{array}{l}\text { III. When giving } 22 \mathrm{lbs} . \\
\text { of milk daily } . . . . \ldots \ldots . .\end{array}$ & 29.0 & 2.5 & 13.0 & 0.5 & $1: 5.7$ \\
\hline $\begin{array}{l}\text { IV. When giving } 27 \frac{1}{2} \mathrm{lbs} \text {. } \\
\text { of milk daily } . . . . . . . . .\end{array}$ & 32.0 & 3.3 & 13.0 & 0.8 & $1: 4.5$ \\
\hline
\end{tabular}

* Organic matter.

Kühn's ${ }^{1}$ standard ration for a thousand-pound dairy cow under varying conditions is as follows:

Dry matter ........................................................ 20-33.5

Jigestible albuminoids.................................................. $1.5-2.4$

Digestible ether extract..................................................... $.4-$.

Digestible nitrogen-free extract, assimilable crude fiber, and amides............................................................................... 12 - 14 Nutritive ratio.................................................................. $1: 5.5-8$

Reviewing the above, it is found that Woll's proposed American dairy ration calls for less protein and more carbohydrates and ether extract than Wolff's, the nutritive ratio being $1: 6.9$ against 1 : 5.4. Atwater and Phelps' proposed standard coincides with

1 Die zweckmässigste Ernährung des Rindviehes, 1887, p. 257. 
Wolff's in protein, while the digestible carbohydrates run from 12 to 13 pounds and the fat from .5 to .8 pounds. The WolffLehmann standard gives a wide range according to the milk yield.

149. Concerning Kuehn's ration.-Kühn's method of procedure in compounding a ration is different from those already discussed. He first sets forth a basal ration composed principally of coarse forage carrying the nutriment required by the cow when giving little or no milk. This basal ration should contain 1.5 to 1.7 pounds of digestible albuminoids per thousand pounds live weight, and may exceed this with animals of exceptional capacity. A like proportion of non-nitrogenous and ether-extract nutrients go with the basal ration. To this is added an amount of concentrates sufficient to enable the cow to yield the best returns. Animals of low productive capacity are fed a small ration, while those capable of large retarns are liberally supplied with nutrients. The range of dry matter and nutrients for cows of different capacities is given in the table.

Kühn considers the albuminoids only, as available for protein nutrition, and places the amides with the carbohydrates. In constructing his ration he recognizes the great variability of feeding stuffs as to composition, and holds the individuality of the cow as something of great importance. His idea, if fully carried out, would necessitate a chemical analysis of all the different feeding stuffs used each season, something impracticable under ordinary conditions.

149a. Fuel value of rations.- In Article 61 the following fuel values are shown for the several nutrients in feeding stuffs:

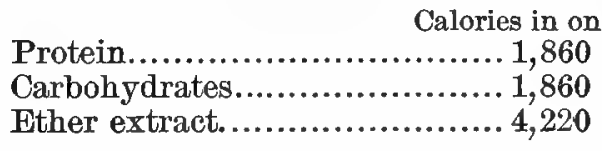

It has been proposed that these Calorie values be assigned to the digestible nutrients of the ration for the purpose of simplifying the results. Atwater writes on this point:1 "This use of fuel values gives a means of simplifying the calculation of rations. It will be understood that the proportions of fats and carbohydrates are only relative; in other words, that one may be dimin-

1 Rept. of Storrs (Conn.) Expt. Sta., 1890, p. 179. 
ished if the other be correspondingly increased. If our theories are correct, the important matter is to provide sufficient protein and sufficient total energy without varying too much from the most desirable relative proportions of the fats and carbohydrates."

The Calories in the second trial ration for the dairy cow reported under Article 136 are determined in the following manner: The digestible protein and digestible carbohydrates of the ration are added together and the sum is multiplied by 1,860 , the fuel value of one pound of these nutrients. In the same manner the ether extract is multiplied by 4,220 , its fuel value. The calculations are as follows:

\begin{tabular}{|c|c|c|c|c|}
\hline $\begin{array}{l}\text { Protein } \\
\text { Lbs. }\end{array}$ & & $\begin{array}{l}\text { In ration. } \\
\text { Carbohydrates } \\
\text { Lbs. }\end{array}$ & & $\begin{array}{l}\text { Total } \\
\text { Lbs. }\end{array}$ \\
\hline 2.629 & + & 13.538 & $=$ & 16.167 \\
\hline $\begin{array}{l}\text { Protein and } \\
\text { Carbohydrates } \\
\text { Lbs. }\end{array}$ & & $\begin{array}{l}\text { Calories in } \\
\text { one pound }\end{array}$ & & Calories. \\
\hline $\begin{array}{c}16.167 \\
\text { Ether extract } \\
\text { Lbs. }\end{array}$ & $x$ & 1,860 & $=$ & 30,070 \\
\hline .79 & $x$ & $\begin{array}{l}4,220 \\
\text { ration...... }\end{array}$ & $=$ & $\frac{3,334}{33,404}$ \\
\hline
\end{tabular}

Arranging the digestible nutrients and Calories for the standard ration for the cow when giving 22 pounds of milk daily, and for the second trial ration for the dairy cow as calculated above, the following table is derived:

\begin{tabular}{|c|c|c|c|c|}
\hline & \multicolumn{3}{|c|}{ Digestible nutrients. } & \multirow{2}{*}{ Calories. } \\
\hline & Protein. & $\begin{array}{l}\text { Carbohy- } \\
\text { drates. }\end{array}$ & $\begin{array}{l}\text { Ether } \\
\text { extract. }\end{array}$ & \\
\hline & Lbs. & Lbs. & Lbs. & \\
\hline 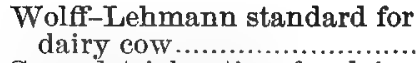 & 2.5 & 13.0 & .50 & 30,940 \\
\hline 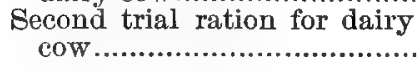 & 2.629 & 13.538 & .79 & 33,404 \\
\hline
\end{tabular}

By the table we learn that the digestible nutrients in the standard ration for the cow when giving 22 pounds of milk daily, would, on combustion, yield 30,940 Calories, while the second trial ration given in Article 136 yields 33,404 Calories, an excess above the standard of nearly 10 per cent. 
While it is important from a scientific standpoint to study the fuel value of rations, such use in compounding them for practical purposes is hardly warranted, since a statement of the several nutrients themselves is more explicit and satisfactory.

150. Conclusions relative to feeding standards. - The rast amount of work of the chemist and physiologist as shown in the several tables under discussion in this chapter nust be apparent to every student who has followed the subject to this point. When one learns that these tables after all are not what they first seem as to exactness and reliability, he is tempted to cast them aside as of no value in the conduct of his feeding operations. Due reflection will check such a course, for enormous gain has already come to our stock interests from this source. Tables of chemical composition and feeding standards are efforts toward a desired end, and the student will always study these with interest, and the prudent feeder will never ignore them in his care of live stock.

V. Placing Money Values on the Different Nutrients in Feeding Stuffs.

151. Character of the inquiry.-Since commercial fertilizers are sold on their content of nitrogen, phosphoric acid and potash, it seems possible to ascertain the values of the several common feeding stuffs from their content of digestible protein, carbohydrates and ether extract. (420) This matter takes concrete form in the questions asked at farmers' meetings and in the agricultural papers as to the relative values of different feeds; for example, the value of a ton of bran or oil meal when corn or oats are worth a certain sum per bushel.

152. Studies of values.-More than a generation ago Wolff, studying the by-products of flouring mills and oil factories, based calculations on the current prices of these several feeds, and found that, allowing the nitrogen-free extract a value of 1 , protein had a relative value of 2.4 , and ether extract 3 .

König placed the ratio of protein, fat and nitrogen-free extract at $2.7: 2.9: 1$. The German Natural History Society, ${ }^{1}$ after investigating the matter, concluded that the average values of nutrients of the leading feeding stuffs of Germany were as $3: 3: 1$

1 Landw. Jahrb. 9, p. 805. 
for protein, fat and nitrogen-free extract, respectively. Several American Stations have also endeavored to ascertain the money value of concentrates according to the nutrients they contain, with the results presented in the table below:

Taluations of nutrients in American concentrated feeding stuffsvarious Experiment Stations.

\begin{tabular}{|c|c|c|c|c|c|c|c|c|}
\hline \multirow{2}{*}{ Station. } & \multirow{2}{*}{ By } & \multirow{2}{*}{$\begin{array}{l}\text { Refer- } \\
\text { ence. }\end{array}$} & \multicolumn{3}{|c|}{$\begin{array}{l}\text { Value in cents per } \\
\text { pound. }\end{array}$} & \multicolumn{3}{|c|}{ Ratios. } \\
\hline & & & $\begin{array}{l}\text { Pro- } \\
\text { tein. }\end{array}$ & $\begin{array}{c}\text { Ether } \\
\text { ex- } \\
\text { tract. }\end{array}$ & $\begin{array}{c}\text { Car- } \\
\text { bohy- } \\
\text { drates. }\end{array}$ & $\begin{array}{l}\text { Pro- } \\
\text { tein. }\end{array}$ & $\begin{array}{c}\text { Ether } \\
\text { ex- } \\
\text { tract. }\end{array}$ & $\begin{array}{c}\text { Car- } \\
\text { bohy- } \\
\text { drates. }\end{array}$ \\
\hline Conn.. & Jenkins.. & Rept. 1888 & 1.60 & 4.2 & 0.96 & 1.7 & 4.4 & 1 \\
\hline Conn.. & Jenkins. & Rept. 1890 & 1.40 & 2.9 & 1.40 & 1.0 & 2.1 & 1 \\
\hline Del ... & Penny.... & Rept. 1889 & 1.23 & 4.45 & 0.52 & 2.4 & 8.6 & 1 \\
\hline Ind & Huston .. & Bul. 37.... & 1.00 & 2.75 & 0.63 & 1.6 & 4.4 & 1 \\
\hline N. J. & Voorhees. & Rept. 1891 & 0.91 & 5.91 & 1.12 & 0.8 & 5.3 & 1 \\
\hline Wis.. & Woll......... & Rept. 1891 & 1.52 & 3.58 & 0.47 & 3.2 & 7.6 & 1 \\
\hline Vt... & H., B. \& J & Rept. 1895 & 2.02 & -.19 & 0.91 & 2.2 & -.21 & 1 \\
\hline
\end{tabular}

The data in the above table were secured in the following manner: The market values of all the concentrated feeding stuffs in the state were tabulated, together with the pounds of digestible protein, carbohydrates and ether extract they contained. Then by a mathematical process the supposed relative value of each of the nutrients was determined, with results presented in the table. In Connecticut, for example, it was found that taking all the common concentrated feeding stuffs offered in the market at current values, each pound of protein in these feeds cost on the average 1.6 cents, one pound of fat 4.2 cents, and a pound of carbohydrates .96 cents. Hills, Boyce and Jones, of the Vermont Station, ${ }^{1}$ calculating the commercial values of concentrates for their state, found by the process usually employed that a pound of fat had a value of -.19 cents, or that it was worth less than nothing, - an absurdity of course. Surprised at this, they investigated the subject in a broad manner and came to the conclusion that the method employed to determine these values is inaccurate and without merit. At present it is impossible to state the value of one feeding stuff in terms of another from calculations based upon the nutrients contained in each.

'Rept. 1895. 


\section{PART II.}

\section{FEEDING STUFFS.}

\section{CHAPTER VIII.}

LEADING CEREALS AND THEIR BY-PRODUOTS.

I. Indian Corn and its By-products.

Digestible nutrients and fertilizing constituents.

\begin{tabular}{|c|c|c|c|c|c|c|c|}
\hline \multirow[b]{2}{*}{ Name of feed. } & \multirow{2}{*}{$\begin{array}{l}\text { Dry } \\
\text { matter } \\
\text { in } 100 \\
\text { pounds. }\end{array}$} & \multicolumn{3}{|c|}{$\begin{array}{l}\text { Digestible nutrients } \\
\text { in } 100 \text { pounds. }\end{array}$} & \multicolumn{3}{|c|}{$\begin{array}{l}\text { Fertilizing constitu- } \\
\text { ents in } 1,000 \text { pounds. }\end{array}$} \\
\hline & & $\begin{array}{l}\text { Pro- } \\
\text { tein. }\end{array}$ & $\begin{array}{c}\text { Carbo- } \\
\text { hy- } \\
\text { drates. }\end{array}$ & $\begin{array}{c}\text { Ether } \\
\text { exx- } \\
\text { tract. }\end{array}$ & $\begin{array}{l}\text { Nitro- } \\
\text { gen. }\end{array}$ & $\begin{array}{l}\text { Phos- } \\
\text { phoric } \\
\text { acid. }\end{array}$ & $\begin{array}{l}\text { Pot- } \\
\text { ash. }\end{array}$ \\
\hline & Lbs. & Lbs. & Lbs. & Lbs. & Libs. & Lbs. & Lbs. \\
\hline A verage of all analyses..... & 89.1 & 7.9 & 66.7 & 4.3 & 18.2 & 7.0 & 4.0 \\
\hline Dent corn ......................... & 89.4 & 7.8 & 66.7 & 4.3 & 16.5 & ......... & \\
\hline Flint corn..........$\ldots \ldots \ldots$ & 88.7 & 8.0 & 66.2 & 4.3 & 16.8 & & ..... \\
\hline Sweet corn. & 91.2 & 8.8 & 63.7 & 7.0 & 18.6 & $\ldots$ & \\
\hline Corn cob................ & 89.3 & 0.4 & 52.5 & 0.3 & 5.0 & .6 & 6.0 \\
\hline Corn and cob meal.. & 84.9 & 4.4 & 60.0 & 2.9 & 14.1 & 5.7 & 4.7 \\
\hline Corn bran............... & 90.9 & 7.4 & 59.8 & 4.6 & 16.3 & 12.1 & 6.8 \\
\hline Gluten meal..... & 91.8 & 25.8 & 43.3 & 11.0 & 50.3 & 3.3 & 0.5 \\
\hline Germ meal.... & 89.6 & 9.0 & 61.2 & 6.2 & 26.5 & 8.0 & 5.0 \\
\hline Starch refuse ... & 91.8 & 11.4 & 58.4 & 6.5 & 22.4 & 7.0 & 5.2 \\
\hline Grano-gluten... & 94.3 & 26.7 & 38.8 & 12.4 & 49.8 & 5.1 & 1.5 \\
\hline Hominy chops...... & 88.9 & 7.5 & 55.2 & 6.8 & 16.3 & 9.8 & 4.9 \\
\hline Glucose meal... & 91.9 & 30.3 & 35.3 & 14.5 & 57.7 & & \\
\hline sugar meal.............. & 93.2 & 18.7 & 51.7 & 8.7 & 36.3 & 4.1 & 0.3 \\
\hline Starch feed, wet............... & 34.6 & 5.5 & 21.7 & 2.3 & 9.8 & 1.0 & 1.0 \\
\hline
\end{tabular}

153. General characteristics.-Indian corn is the best relished grain available for our domestic animals, their fondness for it being remarkable. A possible explanation of this fact may lie in the large amount of oil which the corn grain carries; again, on mastication corn breaks into flinty, nutty particles, and is 
therefore more palatable than the wheat grain, for instance, which on crushing and mingling with saliva turns to a sticky dough.

154. Races of corn.-The races of corn of interest to stockmen are embraced under the terms "Dent," "Flint," and "Sweet." In dent corn the starchy material is floury in character, except a small portion near the exterior, which is corneous or flinty. In flint corn most of the starch has a corneous character, which is plainly revealed when the grain is cut across. Though different in appearance the corneous portion is chemically the same as the floury part. Dent and flint corns are practically of the same chemical composition. The flint varieties flourish along the northern rim of the corn belt with its cooler climate; dent corn flourishes where a higher temperature prevails. By planting one variety or another, corn may be profitably grown in every state in the Union. It is said that flint corn when carried from its northern home to southern districts gradually changes to dent, while under reverse conditions dent varieties assume the characteristics of flint corn.

It is often asserted that yellow corn is more nutritious than white, and sometimes the opposite is claimed. There is nothing in chemical analysis or experience to warrant either assumption. It is doubtless true that some varieties of one kind are superior to certain varieties of the other, but no uniform rule prevails.

Sweet corn is characterized by hard, wrinkly grains, due to shrinkage in drying and their corneous character. The table shows that sweet corn is somewhat richer in protein than corn of other races. It does not yield quite as much digestible carbohydrates, the difference being more than made up, however, by the larger content of fat and protein. The grain of sweet corn contains considerable glucose while ripening, and this adds much to its palatability, though not necessarily to the nutritive qualities, since sugar has the same feeding value as starch.

155. Corn a carbonaceous food.-The leading characteristic of the corn grain is the large proportion of starchy matter, coupled with the rather low protein content and a low percentage of ash. Compared with wheat, corn has somewhat less carbohydrates, less protein, but more oil. Much of the oil and protein is 
gathered in and about the corn germ lying at the base of the kernel. Rich in starch and oil, the function of corn is plainly to produce heat and fat when fed to farm animals. For fattening purposes no other grain equals corn. Lacking in protein and ash, this grain is not well suited for the production of bone and muscle in young and growing animals. See Chapter VI, also Article 421 .

156. Corn as human food.- Considering the nutrition it carries and the market price, corn is by far the cheapest food offered to mankind over a large part of the civilized world. That it has not been more generally used can be explained only in part. In the first place, corn meal cannot be made into a light, porous loaf, as can flour from the wheat grain. Again, when reduced to meal on grinding, the oil of the grain, and especially that in the germ, soon becomes rancid, and the meal loses its palatability. This trouble is remedied in part by processes of manufacture in which the germ is removed.

157. Corn cob. - Corn cobs consist largely of crude fiber and consequently have a low feeding value. When corn has not fully ripened, more nutriment remains in the cob, which is then not so hard and woody. If deleterious fermentations have not occurred, such cobs are readily eaten by cattle. Cob goes well with the grain which produces it, and many cattle feeders are satisfied with this use of an otherwise waste product, drawing their conclusions from experience and observation.

158. Corn and cob meal.- Sometimes corn together with the cob which bears it are crushed at the same operation, the resulting product being called "corn and cob meal." Great difficulty is experienced in reducing the cob to reasonable fineness. If left coarse, farm animals usually push the pieces of cob aside and consume only the meal; if ground sufficiently fine, much power is required in the reduction. Difficulty is experienced in finding mills suitable for this purpose and in providing power sufficient for reducing the cobs. Reasonably fine corn and cob meal has been found very satisfactory for stock feeding. Experiments by the Paris Omnibus Company ${ }^{1}$ showed that corn and cob

\footnotetext{
${ }^{1}$ Pott, Fühling's Landw. Zeitung. 1893. p. 483.
} 
meal proved more acceptable than pure corn meal. Stockmen quite generally report favorably on its use. $(539,633,849)$ Since the nutriment in the corn cob is small, it is not easy to understand why this compound meets wi'h general favor, especially as the cost of grinding is considerably increased. It has been suggested that pure corn meal lies heary in the animal's stomach, and while in this condition is not so readily attacked by the juices of digestion. On the other hand, the particles of cob when associated with the meal cause the mass to lie loose in the stomach, in condition for easy digestive action.

159. Weight of corn and cob.-Aside from its water content, corn shows a very uniform composition for different regions of our country. While the moistare in old corn 'varies little from 12 per cent., it may reach 20 and even 25 per cent. for ear corn freshly husked. Corn carrying as much as 20 per cent. water will not keep if stored in any considerable quantity. At the Kansas Agricultural College, Shelton ${ }^{1}$ placed 200 pounds of ear corn, which had been ripe fully six weeks before it was husked, in a box which was placed in a crib of corn with corn all about it. In July, eight months later, the corn weighed 187.5 pounds, showing a shrinkage of 6 per cent.

At the Dlinois Station, ${ }^{2}$ Morrow reports three years' investigations as showing that 1,000 bushels of ear corn, medium varieties, shrunk 115 bushels, or 11.5 per cent., between the time of gathering and when thoroughly air-dry. Corn husked November 1 required 70 pounds of ears of early, 73 pounds of medium. and 78 pounds of late maturing varieties to yield one bushel, or 56 pounds of shelled corn.

At the Kentucky Station, ${ }^{8}$ Scovell found that corn placed in a loft November 17, shrunk from 7.4 to 18.3 per cent. in weight.

About one-fifth the weight of well-dried ear corn of the better varieties consists of cob; that is, 70 pounds of well-dried ear corn will yield 56 pounds of shelled corn.

160. The pellagra corn disease.-Among the rural population of northern Italy there occurs a peculiar, fatal disease called

1 Rept. Prof. Agr., 1884.

2 Bul. 13.

s Rept. 1889. 
"pellagra," which has been traced to the almost exclusive use of corn as food by the people. The poverty of the corn grain in protein and ash may explain in some measure this ailment. According to investigations, the disease is charged by some to the presence of mould fungi. Fua found aspergillus and penicillium fungi in corn meal which had caused pellagra, and was able to separate from it several poisonous substances, evidently decomposition products. ${ }^{2}$

161. Corn by-products. - The use of corn in the manufacture of starch, glucose, beer, spirits, etc., has grown enormously of late, resulting in great quantities of by-products of high feeding value for stock. In most of the processes of manufacture the first step is to secure the starch of the corn grain as free as possible from the other constituents. The composition of the corn grain in its different parts and the various by-products left in the manufacture have been studied by Voorhees at the New Jersey Station, ${ }^{3}$ a summary of his findings being as follows: The husk or skin which covers the corn kernel consists of two layers, which on removal constitute what is known as corn bran; this contains practically all the crude fiber of the corn grain. Below the husk or skin layer, bat near the outside of the grain, comes a layer of cells rich in gluten or protein, yellow in color, and not readily separable from the remainder of the kernel. Most of the protein of the corn grain lies in this layer. Near the base of the grain is the germ, which also contains gluten, and is particularly rich in oil and mineral matters. The body of the corn grain proper is composed almost entirely of starch, the cells being packed to repletion therewith. Voorhees separated 100 grams of corn kernels into skin, germ and starch portions, and analyzing these secured the results presented in the following table:

1 Pott, Landw. Futterm., 1889, p. 410, foot note.

2 See also König, Die mensch. Nahr. u. Genussm., II, 1893, p. 474.

- Bul. 105. 
Composition of the several parts of the corn grain - New Jersey Station.

\begin{tabular}{|c|c|c|c|c|c|c|c|c|c|c|}
\hline \multirow{3}{*}{$\begin{array}{l}\text { Corn and } \\
\text { its parts. }\end{array}$} & \multirow{3}{*}{$\begin{array}{l}\text { In } 100 \\
\text { parts } \\
\text { corn. }\end{array}$} & \multirow{3}{*}{ Water. } & \multicolumn{8}{|c|}{ Composition of the water-free material. } \\
\hline & & & \multicolumn{5}{|c|}{ Nutrients. } & \multicolumn{3}{|c|}{$\begin{array}{c}\text { Fertilizing constit- } \\
\text { uents. }\end{array}$} \\
\hline & & & $\begin{array}{l}\text { Pro- } \\
\text { tein }\end{array}$ & $\begin{array}{c}\text { Car- } \\
\text { bohy- } \\
\text { drates. }\end{array}$ & $\begin{array}{l}\text { Crude } \\
\text { tlber. }\end{array}$ & $\begin{array}{l}\text { Ether } \\
\text { extract. }\end{array}$ & $\begin{array}{l}\text { Crude } \\
\text { ash. }\end{array}$ & $\begin{array}{l}\text { Nitro- } \\
\text { gen. }\end{array}$ & $\begin{array}{l}\text { Phos- } \\
\text { phoric } \\
\text { acid. }\end{array}$ & $\begin{array}{l}\text { Pot- } \\
\text { ash. }\end{array}$ \\
\hline Original & $\begin{array}{c}\text { Per } \\
\text { cent. }\end{array}$ & $\begin{array}{l}\text { Per } \\
\text { cent. }\end{array}$ & $\begin{array}{l}\text { Per } \\
\text { cent }\end{array}$ & $\begin{array}{c}\text { Per } \\
\text { cent. }\end{array}$ & Per & Per cent. & $\begin{array}{c}\text { Per } \\
\text { cent. }\end{array}$ & $\begin{array}{c}\text { Per } \\
\text { cent. }\end{array}$ & $\begin{array}{l}\text { Per } \\
\text { cent. }\end{array}$ & $\begin{array}{l}\text { Per } \\
\text { ct. }\end{array}$ \\
\hline $\begin{array}{l}\text { corn ....... } \\
\text { Skin........ } \\
\text { Germ ..... }\end{array}$ & $\begin{array}{r}100.0 \\
5.6 \\
10.1\end{array}$ & $\begin{array}{l}24.7 \\
15.3 \\
29.6\end{array}$ & $\begin{array}{r}12.6 \\
6.6 \\
21.7\end{array}$ & $\begin{array}{l}\mathbf{7 9 . 3} \\
\mathbf{7 5 . 4} \\
\mathbf{4 5 . 8}\end{array}$ & $\begin{array}{r}2.0 \\
16.5 \\
2.9\end{array}$ & $\begin{array}{r}4.3 \\
1.6 \\
29.6\end{array}$ & $\begin{array}{r}1.7 \\
1.3 \\
11.1\end{array}$ & $\begin{array}{l}2.0 \\
1.1 \\
3.5\end{array}$ & $\begin{array}{l}0.8 \\
0.2 \\
6.2\end{array}$ & $\begin{array}{l}0.5 \\
0.4 \\
2.9\end{array}$ \\
\hline $\begin{array}{l}\text { Starchy } \\
\text { part ....... }\end{array}$ & 84.3 & 24.7 & 12.2 & 85.6 & 0.7 & 1.5 & 0.7 & 2.0 & 0.4 & 0.2 \\
\hline
\end{tabular}

162. What the table shows.-The germ, which constitutes only about 10 per cent. of the kernel, contains 65 per cent. of the ether extract, 61.5 per cent. of the mineral matter, 71 per cent. of the phosphoric acid, 60 per cent. of the potash and 16.3 per cent. of the nitrogen or protein of the whole grain. The starchy portion of the grain carries very little crude fiber or ash, but is rich in carbohydrates in the form of starch. The skin yields most of the crude fiber, the whole amount being small.

163. Starch production.-Briefly described, starch is obtained from the corn grain in the following manner: The corn is generally soaked until soft and then ground to meal in running water. The hulls or husks float to the surface and are removed; the germs sink to the bottom, and the water, carrying with it the gluten and starch, passes on through long troughs, in which the starch, being the heavier of the two, settles to the bottom while the gluten floats on. The various by-products thus separated are dried and sold, either separately or combined, under various names, while the resulting starch, freed from these substances, is treated in different ways for various manufactured products.

164. Of what the by-products consist. - All the by-products combined constitute what is known as gluten feed, which is really the corn grain less the starch it carries. This feed is rich in ether extract and protein, and is well suited for dairy cows and fattening stock. 
Gluten meal does not contain either the hull or germ, and is very rich in ether extract and protein. Because of its concentration it should always be diluted or extended with some light material like wheat bran or corn bran. $(\mathbf{5 4 6 , 6 3 7 , 8 5 0 )}$ Corn bran consists of the hulls of the corn grain, and is relatively low in feeding value. Corn germ is very rich in protein and oil. Corn oil meal and corn oil cake consist of the pressed germs freed from most of the oil they carry, and are rich in ether extract and protein. These by-products should never be fed in large quantity, but mixed with other grain feeds. Often the by-products of the lactory are disposed of in a wet condition, and are then styled "wet starch" or "wet glucose feeds."

When corn is manufactured into hominy or other human food articles, the skin of the grain, the germ, etc., constitute by-prod. nets more or less similar to those above described. Unfortunately for the purchaser there is no uniformity in the composition of these by-products, and they reach the trade under whatever names the manufacturers are pleased to place upon them, thas preventing any general treatment of the subject.

165. Nitrogen and mineral matter in corn.-Compared with grains generally, corn is not rich in nitrogen and mineral matter: Compared even with hay from the leguminous plants, e. g., red clover hay, it likewise stands low. This poverty of mineral matter and nitrogen explains in some measure why the corn crop is not so exhansting to the soil as many others. The pruclent feeder in using corn should always bear in mind its low nitrogen and mineral content, and make good what is lacking by supplying the wants of his animals from other sonrces. In choosing between corn and other feed, when purchasing in the market, he shonld bear in mind that a given weight of this grain does not bring to his farm as much fertility as do many other feeding stuffs. In gluten meal, grano-gluten and cream-gluten, the nitrogen reaches a very respectable figure, though in mineral matter the standing is still low. 
II. Wheat and its By-products in Miling.

Digestible nutrients and fertilizing constituents.

\begin{tabular}{|c|c|c|c|c|c|c|c|}
\hline \multirow{2}{*}{ Name of feed. } & \multirow{2}{*}{$\begin{array}{c}\text { Dry } \\
\text { matter } \\
\text { in } 100 \\
\text { pounds. }\end{array}$} & \multicolumn{3}{|c|}{$\begin{array}{l}\text { Digestiblo nutrients } \\
\text { in } 100 \text { pounds. }\end{array}$} & \multicolumn{3}{|c|}{$\begin{array}{l}\text { Fertilizing constitu- } \\
\text { ents in } 1,000 \text { pounds. }\end{array}$} \\
\hline & & $\begin{array}{l}\text { Pro- } \\
\text { tein. }\end{array}$ & $\begin{array}{c}\text { Carbo- } \\
\text { hy- } \\
\text { drates. }\end{array}$ & $\begin{array}{l}\text { Ether } \\
\text { ex- } \\
\text { tract. }\end{array}$ & $\begin{array}{l}\text { Nitro- } \\
\text { gen. }\end{array}$ & $\begin{array}{l}\text { Phos- } \\
\text { phoric } \\
\text { acid. }\end{array}$ & $\begin{array}{l}\text { Pot- } \\
\text { ash. }\end{array}$ \\
\hline & Lbs. & Lbs. & Lbs. & Lbs. & Lbs. & Lbs. & Lbs. \\
\hline Wheat...... & 89.5 & 10.2 & 69.2 & 1.7 & 23.6 & 7.9 & 5.0 \\
\hline High & 87.6 & 8.9 & 62.4 & & 18.9 & 2.2 & 1.5 \\
\hline grade flou & 87.6 & 8.2 & 62.7 & 0 . & 28.9 & 5.6 & 3. \\
\hline Dax & 90.3 & 13.5 & 61.3 & 2. & 31.8 & 21.4 & 10. \\
\hline Wh & 88.1 & 12.2 & 39.2 & 2.7 & 26.7 & 28.9 & 16. \\
\hline Wheat bran, sp & 88.5 & 12.9 & 40.1 & 3.4 & & & \\
\hline eat & 87.7 & 12.3 & 37.1 & & & & \\
\hline & 88.2 & 12.2 & .50 .0 & 3.8 & 28.2 & 13.5 & 5.9 \\
\hline Wh & 87.9 & 12.8 & 53.0 & 3. & 26.3 & 9.5 & 6 . \\
\hline Wheat screenings............... & 88.4 & 9.8 & 51.0 & 2.2 & 24.4 & 11.7 & 8.4 \\
\hline
\end{tabular}

166. Wheat grain.-From the earliest times the wheat plant has furnished the choicest food grain for man. Wheat has probably never been degraded to stock-feeding purposes until the most recent times. During the last decade, owing to enormous production, the prices for this grain fell until they approached quite close to those received for corn. When this anomalous and discouraging situation was reached, our farmers at first hesitated, but with a sagacity most creditable to them quickly overcame their long-held and not unwarranted prejudice against this seeming perversion of nature and began to deal out wheat in large quantities to their stock. Coburn ${ }^{1}$ reports that in Kansas, during the year 1893 , more than $4,000,000$ bushels of wheat were fed to stock by the farmers of that state, and that in 1894 the amount so disposed of reached the enormous volume of $8,500,000$ bushels. Since it costs more to produce wheat than corn, it is reasonable to suppose that this grain will never become a common feed for stock, but the feeder should know its value both absolute and relative, and hold himself ready to make use of it whenever market conditions warrant.

Compared with corn, wheat carries a higher percentage of starch, less ether extract and more protein. Thus it more clearly

1 Rept. Kan. St. Bd. Agr., Sept. 30, 1894. 
furnishes a balanced ration for farm animals. It follows that this grain meets the requirements of young and growing animals better than corn, a statement which is corroborated by the experience of feeders. Because two or more kinds of feed should always be given rather than one only, the feeder should prize wheat bighly for furnishing variety to his usually too short list of available articles. It should also be remembered in considering prices that a bushel of wheat weighs seven per cent. more than a bushel of corn.

167. Wheat for feeding. - Wheat may be regarded as a satisfactory feed for all kinds of farm stock, in the hands of intelligent feeders. Mixed with corn, oats or bran it is superior to either alone for work horses. For fattening cattle and dairy cows it not only furnishes abundance of nutrients, but through variety gives edge to the appetite. When on a visit to William Watson, the prince of American feeders, some years since, the writer found him feeding whole wheat of fine quality to sheep in preparation for a fat-stock show. For sheep this grain alone or mixed with others may be fed in the entire or whole condition; for other stock it should receive some form of preparation, either grinding, boiling or soaking. During mastication wheat and wheat flour adhere to the gums, forming a pasty mass. This can be prevented by mingling bran, corn meal or some such substance with the wheat or flour. Though a feed of great palatability and healthfulness, wheat does not equal corn for fattening purposes, yielding perhaps ten per cent. less returns. (462, 543, 638-9, 759-60, 850)

168. Character of flesh from wheat feeding.-Swift \& Co. (Packers, Chicago), replying to an inquiry concerning the character of the flesh of wheat and corn-fed cattle and hogs, wrote: ${ }^{1}$ "There is quite a perceptible difference between wheat and cornfed hogs and cattle. We do not consider that wheat-fed stock yields as well as corn-fed, there being less fat. The lean meat on wheat-fed cattle has a somewhat brighter red than on corn-fed cattle. The lean meat from wheat-fed hogs is very nice, but as the yield is not so good there is no particular advantage in it to

1 Prairie Farmer, Oct. 20, 1894. 
packers; but we consider wheat-fed stock worth as much as corn-fed."

169. Damaged wheat.-When low prices prevail for wheat, only the best grades should be sold by the farmer. Shrunken and damaged grain has almost no market value at such times, while for feeding purposes it may be nearly or quite equal to grain which commands the highest price. The farmer should. carefully grade his grain at home and sell only the best.

Sometimes the farmer with such wheat on hand hesitates about feeding it, fearing disastrous results. A number of inquiries as to the advisability of feeding poor wheat have come to the writer in past years, and he has always recommended that, instead of wasting such grain, it be fed in moderate quantities mixed with other materials. No ill results have ever come to notice from such grain when fed in reasonable quantity. (763-4)

170. Composition of wheat grain.-If we examine the wheat grain we find, first of all, three membranous coats which have somewhat the character of straw, and show on analysis about the same composition, with corresponding feeding value. Beneath these comes the fourth, called the "aleurone layer," which is rich in protein, and which during the process of milling goes with the three outer layers to form bran. The embryo or germ of the grain is rich in oil, protein and mineral matter. The remaining portion of the grain consists of thin-walled cells, all packed to repletion with starch grains. Associated with the starch are grains of protein matter called gluten, which give to dough from wheat flour that tenacity which enables it to retain gas bubbles, produced by yeast fermentation, during baking, thereby yielding a light, porous bread. In producing flour the aim of the miller is to secure all of the starch and gluten possible, avoiding the other constituents of the grain. He avoids incorporating the embryo or germ because, though rich in oil and protein, it turns dark on exposure to the air and gives the flour a specked appearance; further, the germ makes a sticky dough. Nor does the miller desire the aleurone layer, rich though it is in protein, for flowr containing it has a brown tint. The amount of gluten in the wheat grain is smallest in the center and increases toward the 
outside. Gluten being a desirable constituent of flour, the miller, for this reason and for greater yield, aims to secure all of the interior content of the grain possible, up to the aleurone layer itself. In modern milling the wheat grain is first broken into a few pieces, and these are gradually reduced to flour by repeated grinding and bolting. Bran, as we have seen, consists of the three outer coatings of the wheat grain and the aleurone layer, with some of the starchy particles adhering. Shorts consist of re-ground bran. Middlings contain the finer bran particles and more flour; often with this grade there are incorporated the germs of the wheat grain. The better grades of middlings are sometimes used for human food.

In the manufacture of flour, from twenty-five to thirty-three per cent. of the weight of the wheat grain remains as offal available for stock feeding. Since the consumption of wheat in this country is about 4.5 bushels, or 270 pounds, for each person, the by-products of this grain amount to nearly 70 pounds per capita, not including the enormous amount resulting from the wheat milled for export.

171. Feeding bread.- An English writer ${ }^{1}$ reports that a cab proprietor in London some years since tried the experiment of feeding bread to horses, with economy and success, the only trouble being that many loaves were consumed by the workmen. He further states that he has seen the coachmen of Paris feeding brown bread to their horses, and that this food is given to horses in countries where hay is dear. To prevent stealing, he recommends that straw be mixed with the dough before baking.

172. Low-grade flour.- Our table shows the nutrients in lowgrade flour to vary little from those in flour of the higher grade. Such flour can rarely be used with profit by the stockman so long as still lower grades of by-products are obtainable at the usual prices. Prof. Primrose McConnell, England, ${ }^{2}$ reports having fed American low-grade flour for six months, and is "rather surprised at the beneficial results."

173. Dark feeding flour.- The lowest grade of flour, known as "dark feeding flour," "red dog," etc., usually contains the

1 The Field, England, July 15, 1893.

2 Agricultural Gazette, 1893 , p. 351. 
germs of the wheat grain, and because of this it is rich in protein and fat. Such flour has a high feeding value, especially for growing pigs, hard-worked horses and milch cows. Feeders should watch the markets for this brand, and may be able at times to use it to much profit.

174. Middlings and shorts. - "Middlings" and "shorts" are terms used interchangeably to some extent. It has become rather common of late to find shorts consisting simply of ground-over bran, almost free from floury particles, with the sweepings and dirt of the mill added. Such material is very unsatisfactory for stock feeding and should be avoided.

Middlings are especially useful for feeding pigs and horses, since neither of these animals can utilize much crude fiber. For horses they should be mixed with corn meal, oats or other feed. ing stuffs, as pure middlings are a heavy feed and liable to produce colic. For pigs, middlings mixed with corn meal or skim milk serve admirably in promoting growth and building healthy muscular bodies. $(463,641,854)$

175. Bran.- Wheat bran carries, as we have seen, a considerable amount of crude fiber, somewhat resembling straw in this particular. It differs from straw in that the inner surface of the bran flakes is made up of the aleurone layer of the wheat grain, which is very rich in protein and in addition carries some starch. Understanding its character and composition, we are in position to make the best use of this abundant by-product in feeding farm stock. With some horsemen bran is fed only occasionally, being supplied once or twice a week in the form of a "mash," made by scalding with hot water, in which case it is a mild laxative and very beneficial. Bran has, however, become a common feed in many well-managed stables. At the Stanford horse farm, a few years since, the writer found it being fed in moderate quantity to horses of all ages, from weanlings to stallions and brood mares. Bran is quite commonly used in feeding omnibus and cab horses. (45I) Hard-worked horses, which have neither the time nor energy necessary to digest feeds with much bulk, should not receive much bran, owing to its coarse, fibrous character. Growing horses, brood mares and stallions can be fed bran liberally with excellent results because of the large amount of mineral 
matter and protein it contains, its volume not working against it with these animals. In steer feeding bran serves admirably with corn in any form. Fed with this grain it gives bulk, supplies protein, and keeps the animal from cloying, as it may when long maintained on a single kind of feed, such as corn. The stockman feeding corn to his steers will find them making better gains and showing better condition by using bran for one-third of the concentrates. The light character of the bran is well shown in cases of over-feeding. Though a horse or cow may be gorged with bran, it usually suffers no marked inconvenience therefrom, while an over-feed of corn or cotton-seed meal may produce fatal gastric disturbances.

Bran is par excellence a leading feed for the dairy cow, furnish. ing not only bulk, a desirable quality in this case, but protein and ash matter, which are so much needed in the formation of milk. As a complementary food to corn meal, the combination of bran and that grain is not to be excelled. For young pigs bran is too coarse and straw-like, (896) and middlings should be substituted for it. For brood sows and older animals some bran may be fed with profit, and may prove very useful if the remainder of the ration is in concentrated form, for volume is necessary with the feed of such animals. This by-product is also very satisfactory in the sheep yard, being relished by fattening sheep, breeding ewes and growing lambs. (463, 544, 640-42, 762, 855)

176. Fertilizing ingredients. $-W e$ learn from the table that the wheat grain is somewhat richer in nitrogen and mineral matter than corn. The by-products of wheat in milling are much richer in these particulars than the grain from which they are derived. ; High-grade flour is not rich in nitrogen or mineral matter. Lowgrade flour is rich in nitrogen but low in mineral matter. Dark feeding flour is rich in nitrogen and mineral matter. Bran and shorts carry all the elements of fertility in large quantity, and for this reason are highly appreciated by those feeders whose interest reaches beyond their cattle to the lands they till. (414) When very low in price, bran may be used as a fertilizer by direct application to the land, but such perversion should not be toler ated. It should be first fed to animals and, through their drop pings, it will reach the land almost undiminished in fertility. 
The great Northwest is now largely devoted to wheat growing. Here the farmers are gathering into the wheat grains the fertility which has been accumulating for ages. (414) Prudent farmers and stockmen further east, knowing of the fertilizing ingredients in the by-products of the flouring mills, are making large use of them, and by carefully saving the droppings from their cattle and applying them to the land, are transferring the great fertility of the Northwest to other districts. In this depletion of the soil of the Northwest by almost exclusive wheat growing, and in transferring the fertility taken up by this crop to other regions in the by-products of milling, we are experiencing one of the greatest economic changes ever witnessed in American agriculture.

\section{Rye and its By-products.}

Digestible nutrients and fertilizing constituents.

\begin{tabular}{|c|c|c|c|c|c|c|c|}
\hline \multirow[b]{2}{*}{ Name of feed. } & \multirow{2}{*}{$\begin{array}{c}\text { Dry } \\
\text { matter } \\
\text { in } 100 \\
\text { pounds. }\end{array}$} & \multicolumn{3}{|c|}{$\begin{array}{l}\text { Digestible nutrients } \\
\text { in } 100 \text { pounds. }\end{array}$} & \multicolumn{3}{|c|}{$\begin{array}{l}\text { Fertilizing constitu- } \\
\text { ents in } 1,000 \text { pounds. }\end{array}$} \\
\hline & & $\begin{array}{l}\text { Pro- } \\
\text { tein. }\end{array}$ & $\begin{array}{l}\text { Carho- } \\
\text { hy- } \\
\text { drates. }\end{array}$ & $\begin{array}{l}\text { Ether } \\
\text { ex- } \\
\text { tract. }\end{array}$ & $\begin{array}{l}\text { Nitro- } \\
\text { gen. }\end{array}$ & $\begin{array}{l}\text { Phos- } \\
\text { phoric } \\
\text { acid. }\end{array}$ & Potr \\
\hline & Lbs. & Lbs. & Lbs. & Lbs. & Libs. & Lbs. & Lbs. \\
\hline 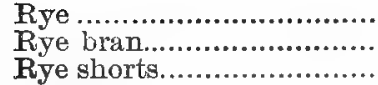 & $\begin{array}{l}88.4 \\
88.4 \\
90.7\end{array}$ & $\begin{array}{r}9.9 \\
11.5 \\
11.9\end{array}$ & $\begin{array}{l}67.6 \\
50.3 \\
45.1\end{array}$ & $\begin{array}{l}1.1 \\
2.0 \\
1.6\end{array}$ & $\begin{array}{l}17.6 \\
23.2 \\
18.4\end{array}$ & $\begin{array}{r}8.2 \\
22.8 \\
12.6\end{array}$ & $\begin{array}{r}5.4 \\
14.0 \\
8.1\end{array}$ \\
\hline
\end{tabular}

The table shows that rye does not differ materially from wheat in composition, nor are its by-products chemically dissimilar from those of the wheat grain.

177. Rye and its by-products as stock feeds.- Work horses in Germany are fed rye to a limited extent, ${ }^{1}$ each animal receiving from two to four pounds of grain daily in addition to oats or other concentrated feed.

According to Böggild, ${ }^{2}$ rye imparts a characteristic flavor to milk and may cause bitter butter. The Scandinavian Preserving Company of Copenhagen, which preserves butter by sealing in air-tight cans for shipment to distant countries, prohibits the feeding of rye on the farms of its patrons. It is probable that the limited use of rye with dairy cows will prove satisfactory.

1 Pott, Futterm., p. 395.

${ }^{2}$ Mälkeribruget i Danmark, 1st ed., p. 70. 
Fjord's experiments with pigs show that rye has a feeding value about equal to barley, and that the quality of pork from this grain is satisfactory. (891) Barley and rye were shown to be superior to rye shorts. (895) The pork from rye shorts was of an inferior quality, showing more shrinkage and being softer than that from rye and barley mixed. (466)

The use of rye and its by-products in this country is quite limited, and in consequence there is little data concerning this grain for feeding purposes. Since it is used quite extensively for human food, we may suppose that rye is not inimical to animal life, and that under proper limitations it will prove satisfactory with farm stock. It has been charged that since ergot, a fungus having medicinal effects, grows on rye heads, rye may therefore prove dangerous to farm animals and may even cause abortion. This charge seems unreasonable when we reflect upon the common use of this grain for human food in European countries. (283)

IV. Barley and its By-products in Brewing.

Digestible nutrients and fertilizing constituents.

\begin{tabular}{|c|c|c|c|c|c|c|c|}
\hline \multirow[b]{2}{*}{ Name of feed. } & \multirow{2}{*}{$\begin{array}{c}\text { Dry } \\
\text { matter } \\
\text { in } 100 \\
\text { pounds. }\end{array}$} & \multicolumn{3}{|c|}{$\begin{array}{l}\text { Digestible nutrients } \\
\text { in } 100 \text { pound.s. }\end{array}$} & \multicolumn{3}{|c|}{$\begin{array}{l}\text { Fertilizing constitu- } \\
\text { ents in } 1,000 \text { pounds. }\end{array}$} \\
\hline & & $\begin{array}{l}\text { Pro- } \\
\text { tein. }\end{array}$ & $\begin{array}{c}\text { Carbo- } \\
\text { hy- } \\
\text { arates. }\end{array}$ & $\begin{array}{l}\text { Ether } \\
\text { ex- } \\
\text { tract. }\end{array}$ & $\begin{array}{l}\text { Nitro- } \\
\text { gen. }\end{array}$ & $\begin{array}{c}\text { Phos- } \\
\text { phoric } \\
\text { acid. }\end{array}$ & $\begin{array}{l}\text { Pot- } \\
\text { ash. }\end{array}$ \\
\hline & Lbs. & Lbs. & Libs. & Lbs. & Lbs. & Lbs. & Lbs. \\
\hline Barley ............................. & 89.1 & 8.7 & 65.6 & 1.6 & 15.1 & 7.9 & 4.8 \\
\hline Malt sprouts..................... & 89.8 & 18.6 & 371 & $1 z$ & 35.5 & 14.3 & 16.3 \\
\hline Brewers' grains, wet........ & 24.3 & 3.9 & 9.3 & 1.4 & 8.9 & 3.1 & 0.5 \\
\hline Brewers' grains, dried....... & 91.8 & 15.7 & 36.3 & 5.1 & 36.2 & 10.3 & 0.9 \\
\hline
\end{tabular}

178. Characteristics. - Barley is one of the most widely cultivated cereals, growing as far north as 70 degrees latitude in Lapland near North Cape, while in this country it is found in Arizona and California flourishing beside groves of the lemon and orange. This grain, which was probably the chief bread plant with many ancient nations, is now devoted almost wholly to brewing and stock feeding. ${ }^{1}$ The use of barley as a feed for animals is still

1 For a history of the barley plant and many other interesting facts in relation thereto, see Brewer's Special Report on the Cereals, 10th U. S. Census. 
confined almost wholly to the Pacific slope, where corn and oats do not flourish in equal degree. The use of barley, most certainly its lower grades, will become more common with our stockmen when its value and special advantages are better known. The table shows that digestible protein is lower in barley than in oats, and considerably higher than in corn. The carbohydrates in this grain exceed those in oats and fall below those in corn. Barley has less oil than oats or corn.

Richardson ${ }^{1}$ finds that barley from Dakota contains the largest percentage of protein, while that from Oregon shows lowest. In these particulars the record resembles that of wheat from the same regions. According to the same author the hall of the barley grain averages 15.22 per cent. of its total weight. There are varieties of barley without beards and still others without hulls, both grown to a limited extent in this country. Brewer found a hull-less barley grown by the Pueblo Indians at Taos, N. M., for bread making, which was very nutritious, carrying is higher per cent. of protein than wheat. Cooke, of the Colorado Station, ${ }^{2}$ reports that hull-less barley yields profitable crops of grain in the mountain parks of that state at an elevation of 7,000 feet. At higher altitudes it is eut for hay, yielding a roughage containing sufficient nutriment to alone nourish hard-worked horses. In feeding trials with pigs, hull-less barley gave better returns than common barley or corn. The Arabs maintained their horses almost exclusively on barley, the grain being administered unground. This grain is fed to the horse with excellent results by the Berbers in northern Africa. ${ }^{3}$ Pott ${ }^{4}$ regards barley as the best cereal for the horse, oats only excepted.

Barley is a common feed for dairy cows in north Europe. The Danes sow barley and oats together in the proportion of one part of barley seed to two of oats. The mixed grain from this crop is ground previous to feeding, and is regarded as the best for dairy cows and other stock. Pott states that barley is beneficial in its influence on the quality of milk and butter. This grain is

1 Bul. 9, Div. of Chem., U. S. Dept. Agr., 1886.
Bul. 40.

- Expt. Sta. Record, V, p. 626.

- Landw. Futterm., p. 399. 
extensively used in England and northern Europe for pork production, and may be regarded as standing at the head of all grains for producing flesh of fine quality both as to hardness and flavor. (894) Strangely, there is a rather widespread shade of prejudice existing against the use of barley for stock feeding in this country, some even asserting that it is poisonous to farm stock. Perhaps the brewers, wishing to control the entire use of this erop, have furthered the prejudice. This charge should be dismissed as unworthy of intelligent farmers, for the experience of the old world is entirely against it. Barley often commands a low price because the grains have been tarnished during harvest by rainfall or foggy weather. Such grain has lost little or none of its nutrients, though for the brewer its value may have been much diminished. The wise stockman will use such barley for feed rather than force it on the market at the low price which it commands. $(460,857,891)$

179. Malting. - To appreciate the valne of barley by-products we should anderstand their origin. In malting, the grain is first steeped in wooden or stone cisterns, where it remains until sufficiently soft to be easily crushed between the thumb and finger without yielding a milky juice. The grains are next spread upon a frame in a mass about twenty inches deep. Here the temperature rises to about 150 degrees, and the grains begin to germinate, sending out tiny sprouts. In the third step the sprouting barley is spread upon the floor for the purpose of controlling the germination, increasing or retarding it according to circumstances.

These three steps are all for the single purpose of converting the starchy matter of the grain into soluble dextrin and sugar, which is accomplished by a natural ferment in the grain, called diastase. All of the substance of the barley grain which goes into the sprouts is waste to the malster, and yet he cannot produce malt without sprouting the grain; hence the close watching and sudden checking of growth when that point is reached. In the fourth stage the grains are kiln-dried, destroying the sprouts, which are next separated from the grain by sieves, leaving the dried barley grains with their load of soluble constituents. Such 
grain when dried is known as malt, and the dried germs are termed malt sprouts.

180. Brewers' grains. - In the manufacture of beer the brewer extracts from the malt the soluble dextrin and sugar. The liquor containing this is called wort, which upon proper fermentation and further treatment constitutes beer. The malt grains, freed from the dextrin and sugar, while in wet form are known as wet brewers' grains, a by-product of great volume at all breweries. It is evident from this presentation that the brewer who uses only the starch of the barley grain does not care for varieties of grain rich in protein, but rather the contrary. According to Richardson, Märcker found that a first-class malting barley should not carry over 8.67 per cent. protein, which is about two-thirds that found in American grains. The requirements of the stockman who seeks feeds rich in protein are in the opposite direction, so that the poorest barley for malting may be the best for feeding. Light-colored, bright barley makes beer of better color than dark, weather-stained grains; hence the lower price paid by the malster for weather-stained barley.

181. Malt for stock.-Lawes and Gilbert, ${ }^{1}$ after experimenting with malt, conclude: "A given weight of barley is more productive both of the milk of cows and of the increase in live weight of fattening animals than the amount of malt and malt dust (malt sprouts) that would be produced from it. . . . . . Irrespective of economy, malt is undoubtedly a very good food for stock; and common experience seems to show that a certain amount of it is beneficial when given in admixture, and in change, with other food to young or weakly animals, or in making up for exhibition or sale; that is, when the object is to produce a particular result irrespective of the economy required in ordinary feeding:"

Occasionally malt slightly injured by fire or other cause is offered for sale at a low price, and, knowing its value, the opportunity for purchase and feeding at a profit should not be lost by the watchful stockman. ${ }^{2}$

1 Rothamsted Memoirs, Vol. 4.

2 See Jour. Roy. Agr. Soc., 1892. 
182. Wet brewers' grains. - These grains can only be fed in the vicinity of the brewery, owing to the large amount of water they carry. This fact has led to the extensive feeding of dairy cows in the proximity of breweries, which are generally located where there is a large demand for milk. Because a certain kind of city milk supply is often in the hands of ignorant people and is not properly supervised by officials, the cows in some instances are crowded into dark sheds where the air is foul and the animals enjoy little or no exercise or sunshine. Because the wet grains are low priced and easily procured, the cows are wholly or almost entirely maintained upon them. The drippings from the wet grains pass downward through the feed boxes and under the floors of the stable, where fermentation takes place, giving rise to bad odors. Often, too, the grains accumulate in the stable and are not fed until they have become putrid. In view of all these circumstances, it is not surprising that boards of health have sometimes reached the conclusion that wet brewers' grains are not a suitable feed for dairy cows under any circumstances, and hare prohibited the sale of milk from cows fed upon them.

There is nothing whatever in wet brewers' grains which is poisonous or deleterious in milli production, provided they are properly fed while fresh. The trouble arises from the great abuse of a most excellent feeding material which is of such character that it can easily be abused. Supplied in reasonable quantity while fresh, and fed in water-tight boxes which are kept clean, with nutritious hay and other coarse provender, there is no better feed for dairy cows. So great and so frequent, however, are the dangers from their abuse, that wet brewers' grains should never be used for cows yielding milk for city supply unless they are fed under the strict supervision of competent officials. If this cannot be done, then perhaps it is best to prohibit their use altogether.

183. Dried brewer's' grains.--By removing the excessive moisture of the wet grains through drying, a product is obtained which is concentrated and no more perishable than bran. Dried brewers' grains are rich in yrotein, low in carbohydrates and rich in ether extract. They are most excellent feed for dairy cows, 
ranking with bran and oil meal in palatability and general good effects.

Sattig ${ }^{1}$ reports using dried brewers' grains and finding them a cheap winter feed for horses, the energy and general condition of the animals being pronounced as good as though they were maintained on oats. Trials in feeding the dried grains to street-car horses by the New Jersey Station gave satisfactory results, with the cost of the ration reduced several cents per day. (46I, 475)

184. Malt sprouts.-The tiny sprouts originating from the barley grain in the process of malting are separated from the grains after they have dried, by sieving. Minute as are these sprouts, they accumulate in large quantities, and malsters can furnish them by the car-load or train-load. The table shows that malt sprouts carry nearly twenty per cent. of digestible protein, with the carbohydrates and fat running low. Unfortunately this feed is not much relished by cattle, and for this reason can only be fed in limited quantity. Malt sprouts absorb a large quantity of water and should be soaked for several hours before feeding. Two or three pounds of sprouts can be profitably fed to dairy cows daily, because of their low cost and the high fertility they carry. (473)

185. Fertilizing constituents.-The barley grain itself does not differ materially from the other cereals in fertilizing components. Malt sprouts are rich in phosphoric acid and potash. In some cases sprouts are directly applied to the land as a fertilizer, but if of good quality, their feeding value should not thus be lost. Often they can be purchased at a lower price than the commercial value of the fertility they contain, so that they cost nothing as feed if the droppings of the cattle receiving them are carefully saved. Brewers' grains are rich in nitrogen and phosphates, but very low in potash.

${ }^{1}$ Milch Zeitung, 1886, p. 185. 
V. Oats and their By-products.

Digestible nutrients and fertilizing constituents.

\begin{tabular}{|c|c|c|c|c|c|c|c|}
\hline \multirow{2}{*}{ Name of feed. } & \multirow{2}{*}{$\begin{array}{c}\text { Dry } \\
\text { matter } \\
\text { in } 100 \\
\text { pounds. }\end{array}$} & \multicolumn{3}{|c|}{$\begin{array}{l}\text { Digestible nutrients } \\
\text { in } 100 \text { pounds. }\end{array}$} & \multicolumn{3}{|c|}{$\begin{array}{l}\text { Fertilising constitu- } \\
\text { ents in } 1,000 \text { pounde. }\end{array}$} \\
\hline & & $\begin{array}{l}\text { Pro- } \\
\text { tein. }\end{array}$ & $\begin{array}{l}\text { Carbo- } \\
\text { hyy- } \\
\text { drates. }\end{array}$ & $\begin{array}{l}\text { Ether } \\
\text { ex- } \\
\text { tract. }\end{array}$ & $\begin{array}{l}\text { Nitro- } \\
\text { gen. }\end{array}$ & $\begin{array}{l}\text { Phos- } \\
\text { phoric } \\
\text { acid. }\end{array}$ & $\begin{array}{l}\text { Potr } \\
\text { ash. }\end{array}$ \\
\hline & Lbs. & Lbs. & Lbs. & Lbs. & Lbs. & Libs. & Lbs. \\
\hline Oats......... & 89.0 & 9.2 & 47.3 & 4.2 & 20.6 & 8.2 & 6.2 \\
\hline Oat meal ............ & 92.1 & 11.5 & 52.1 & 5.9 & 23.5 & & \\
\hline Oat feed or shorts... & 92.3 & 12.5 & 46.9 & 2.8 & 17.2 & 9.1 & 5.3 \\
\hline Oat dust.... & 93.5 & 8.9 & 38.4 & 5.1 & 21.6 & & \\
\hline Oat hulls... & 90.6 & 1.3 & 40.1 & 0.6 & 5.2 & 2.4 & 5.2 \\
\hline
\end{tabular}

186. Concerning the oat grain.- The oat crop ranks third in importance among cereals in the United States. Owing to the uncertainty of wheat as to yield, and its falling price during recent years, the oat crop has been in the ascendency and has greatly increased. Though primarily used as feed for animals, the oat grain now holds a prominent place among nutrients for man in both Europe and America. No grain varies so widely in weight per bushel as oats. In the southern portion of our country a bushel of oats often weighs only twenty pounds, while on the Pacific coast the same volume may weigh fifty pounds. Southern oat grains have an inflated husk and bear an awn or beard which causes the grains to lie loose in the measure. The kernel is larger than that of the Northern grain. At the North the oat grain is encased in a compact holl, which is not often awned. According to Richardson, ${ }^{1}$ the hulls of oats are from twenty to forty-five per cent. of the weight of the grain, the average being about thirty per cent. Richardson states: "The proportion of husk to kernel and the compactness of the grain prove to be the all-important factors, and the weight per bushel the best means of judging the value of the grain."

At the Ohio Station, ${ }^{8}$ Hickman, studying the question whether the weight per bushel for oats indicated the net amount of kernels, secured these results:

${ }^{1}$ Bul. 9, Div. of Chemistry, U. B. Dept. Agr., Washington.

Bul. 57. 
Number of varieties in test.

\section{4}

3

7
Weight of grain

per bushel.

$36 \mathrm{lbs}$.

$34 \mathrm{lbs}$.

$30 \mathrm{lbs}$.
Per cent.

kernel.

68

67

69

Here we observe that the lightest oats yielded the highest percentage weight of kernels to hull. This test points to the conclusion that light oats are not necessarily low in actual nutriment, and is contrary to the teaching of Richardson.

The oat grain shows a higher proportion of digestible protein than corn, while in ether extract it exceeds wheat and nearly equals corn. With a rather low carbohydrate content, the nutritive ratio is such that this grain contains within itself quite a well-balanced ration for farm animals.

A luull-less variety of oats is occasionally grown in this country. For poultry and swine it serves a useful purpose, but for other farm stock, varieties of oats with hulls are preferable.

187. New oats unfit for feeding.- Storer ${ }^{1}$ treats of this question in the following words: "As all horse keepers $\mathrm{know}$, new oats are unfit to be given to working horses. They loosen the bowels of the animals, make their flesh watery, or 'soften them down,' as the term is; i. e., they render animals apt to sweat easily, and, in general, put them 'out of condition.' How or why the new oats produce these effects is not known; but in the course of a few months after harvest, and especially after cold weather has set in, the oats undergo a change of some kind, either of after-ripening or of fermentation, and are thereafter fit to be fed to horses. Probably this difference between new and old oats depends upon a change in the chemical composition of some one peculiar, and, so to say, medicinal constituent of the oat grain."

188. A stimulating principle in oats. - The mettle shown by the horse nurtured on oats has led to the supposition that this grain contains a stimulating principle. In $\mathbf{1 8 4 5}$ Norton separated an albuminoid from the oat grain which Johnston named "avenine." Later work of the chemists effectually did away with Johnston's albuminoid, and it was left to Sanson ${ }^{2}$ to announce the discovery

1 Agriculture in Some of Its Relations with Chemistry, Vol. II.

${ }^{2}$ Comptes Rendus 36, I, p. 75; Biederm. Centralbl., 1834, p. 20. 
of a stimnlating principle in the seed coats of the oat grain. This was supposed to be an alkaloid, varying in quantity in different varieties of oats and also with soil, climate, etc. Sanson concludes that one kilogram (2.2 pounds) of oats will generally contain sufficient avenine to exert a stimulating influence on the motor nerves of the horse for an hour. He claims that grinding and crushing the oats destroys or weakens the principle, for which reason ground oats are not as effective as whole oats. Careful investigations by later chemists have failed to discover any characteristic alkaloid, or in fact any nitrogenous compound of indicated character. ${ }^{1}$ Thus we are left in uncertainty as to any stimulating principle in oats. Whether found or not, all horsemen will still unite in holding this grain without a peer for nurturing their favorite animals. (456-9, 463, 465)

Oats are usually administered to horses unground, grinding being necessary only for animals whose mastication is imperfect, and for foals. For dairy cows there is no better grain than oats, but the use of oats in the dairy is often restricted by their price. (642) In Denmark oats are frequently used by dairymen, who sow this grain with barley, feeding the two in combination. (178) For very young pigs oats should be ground and the hulls sieved out because they are too woody. For pigs more or less mature, and for breeding stock especially, some oats, ground or unground, are always in place. (858)

189. By-products. - In the preparation of oat meal for human food several by-products result. Oat hulls are of low value, as the table shows, being worth little more than the same weight of wheat- or oat- chaff. Their value may be materially greater if broken kernels are found with them. Oat hulls being produced in large quantities at the oatmeal mills and having a low feeding valne, are used by unscrupulous feed dealers for mixing with corn meal and other feeding stuffs, the mixture being represented to prospective purchasers as containing ground oats, in evidence of which are the numerous hulls. In pturchasing ground feeds, where an admixtare of oats is claimed, it is always well to

1 Ldw. Vers. Sta. 36, p. 299; Rept. Conn. Sta. 1891, p. 124; Rept. Me. Expt. Sta. 1891, p. 58, corr. 
remember this possible source of frand and inspect the feed to ascertain if the oat kernels are present in proper proportion with the hulls.

In preparing oatmeal, after the grains are holled the kernels are freed from the pencil of minute hairs found at one end. These hairs, small as they are, accumulate in quantity and form the basis of "oat-dust feed." As shown by the table, oat dust has a fair feeding value, and is useful, provided broken oat kernels are present and the mass does not contain too much of the sweepings from the mill. "Oat feed" or "oat shorts" are terms which characterize by-products of variable composition; they may have a high feeding value, as shown by the table. (859) Those in position to secure products from oatmeal factories will, by studying the subject and watching for opportunities, often be able to secure feeding stuffs of high value at relatively low prices. 


\section{CHAPTER IX.}

MTNOR CEREALS, OT-BEARING AND IEGUMTNOUS SERDS AND THEIR BY-PRODUCTS.

I. Rice and its By-products.

Digestible nutrients and fertilizing constituents.

\begin{tabular}{|c|c|c|c|c|c|c|c|}
\hline \multirow[b]{2}{*}{ Name of feed. } & \multirow{2}{*}{$\begin{array}{c}\text { Dry } \\
\text { matter } \\
\text { 1n 100 } \\
\text { pounds. }\end{array}$} & \multicolumn{3}{|c|}{$\begin{array}{l}\text { Digestible nutrients } \\
\text { in } 100 \text { pounds. }\end{array}$} & \multicolumn{3}{|c|}{$\begin{array}{l}\text { Fertilizing constitu- } \\
\text { ents in } 1,000 \text { pound }\end{array}$} \\
\hline & & $\begin{array}{l}\text { Pro- } \\
\text { tein. }\end{array}$ & $\begin{array}{c}\text { Carbo- } \\
\text { hy- } \\
\text { drates. }\end{array}$ & $\begin{array}{c}\text { Ether } \\
\text { ex- } \\
\text { tract. }\end{array}$ & $\begin{array}{l}\text { Nitro- } \\
\text { gen. }\end{array}$ & $\begin{array}{l}\text { Phos- } \\
\text { phoric } \\
\text { acid. }\end{array}$ & $\begin{array}{l}\text { Pot- } \\
\text { ash. }\end{array}$ \\
\hline & Lbs. & Lbs. & Lbs. & Lbs. & Lbs. & Lbs. & Lbs. \\
\hline 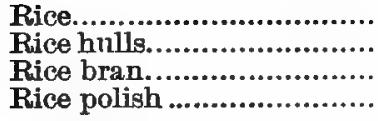 & $\begin{array}{l}87.6 \\
91.8 \\
90.3 \\
90.0\end{array}$ & $\begin{array}{l}4.8 \\
1.6 \\
5.3 \\
9.0\end{array}$ & $\begin{array}{l}72.2 \\
44.5 \\
45.1 \\
56.4\end{array}$ & $\begin{array}{l}0.3 \\
0.6 \\
7.3 \\
6.5\end{array}$ & $\begin{array}{r}10.8 \\
5.8 \\
7.1 \\
19.7\end{array}$ & $\begin{array}{r}1.8 \\
1.7 \\
2.9 \\
26.7\end{array}$ & $\begin{array}{l}0.9 \\
1.4 \\
2.4 \\
7.1\end{array}$ \\
\hline
\end{tabular}

190. Parts of the rice grain.-The rice grain is not directly ased for stock feeding, but its by-products from the mills in the South are available in considerable quantity for that purpose. According to Ross, ${ }^{1}$ the products from 162 pounds of rough rice are as follows:

95 pounds clean rice, all gradem.

8 pounds polish.

30 pounds bran.

29 pounds chaff, straw, trash, dust, etc.

191. By-products of rice.- Rice hulls are so woody that they are not useful for feeding purposes except in periods of great scarcity of coarse provender. Rice bran, composed of the outside of the rice grain and wore or less of the germ, is of moderate feeding value for dairy cows and pigs. Rice polish, a dust-like powder, is rich in nutritive elements, and very valuable for feeding cows, pigs, etc. It is rich in both nitrogen and phosphoric acid, and hence a valuable manure results from using this feed. Accord-

1 Bul. 24, La. Expt. Sta. 
ing to Pott, ${ }^{1}$ rice meal is an excellent feed for milk production. Nine pounds per day have been fed to cows with no unfavorable results. Rancid rice meal has a bad influence on milk and butter and is apt to disturb the digestion of the cow. (864)

Rice and its by-products are low in fertilizing ingredients with the exception of rice polish, which is quite rich in nitrogen and phosphoric acid.

\section{Buckwheat and its By-products.}

Digestible nutrients and fertilizing constituents.

\begin{tabular}{|c|c|c|c|c|c|c|c|}
\hline \multirow{2}{*}{ Name of feed. } & \multirow{2}{*}{$\begin{array}{c}\text { Dry } \\
\text { matter } \\
\text { in } 100 \\
\text { pounds. }\end{array}$} & \multicolumn{3}{|c|}{$\begin{array}{l}\text { Digestible nutrients } \\
\text { in } 100 \text { pounds. }\end{array}$} & \multicolumn{3}{|c|}{$\begin{array}{l}\text { Fertilizing oonstitu } \\
\text { ents in } 1,000 \text { pounds. }\end{array}$} \\
\hline & & $\begin{array}{l}\text { Pro- } \\
\text { tein. }\end{array}$ & $\left|\begin{array}{c}\text { Carbo- } \\
\text { hy- } \\
\text { drates. }\end{array}\right|$ & $\begin{array}{l}\text { Ether } \\
\text { ex- } \\
\text { tract. }\end{array}$ & $\begin{array}{l}\text { Nitro- } \\
\text { gen. }\end{array}$ & $\begin{array}{l}\text { Phos- } \\
\text { phorie } \\
\text { acid. }\end{array}$ & $\begin{array}{l}\text { Pot- } \\
\text { ash. }\end{array}$ \\
\hline & Lbs. & Lbs. & Lbs. & Lbs. & Lbs. & Lbs. & Lbs. \\
\hline Buckwheat......... & 87.4 & 7.7 & 49.2 & 1.8 & 14.4 & 4.4 & 2.7 \\
\hline Buck wheat hulls.. & 86.8 & 2.1 & 27.9 & 0.6 & 4.9 & 0.7 & 5 \\
\hline Buckwbeat bran..... & 89.5 & 7.4 & 30.4 & 1.9 & 36.4 & 17.8 & 12.8 \\
\hline Buckwheat shorts ........... & 88.9 & 21.1 & 33.5 & 5.5 & & & \\
\hline Buckwheat middlings .... & 87.3 & 22.0 & 33.4 & 5.4 & 42.8 & 21.9 & 11.4 \\
\hline
\end{tabular}

192. Concerning the buckwheat grain.-- The grain of the buckwheat plant, rarely used as stock feed, has a fair feeding value, its nutrients running somewhat lower than the leading cereals. In certain districts large quantities of bockwheat by-products are available to the stockman, who, understanding their nature and composition, may avail himself of an excellent feed at comparatively low cost. The black, woody hulls of the buckwheat grain have little feeding value, and should be used only when coarse feeds are scarce and high priced, in which case they may serve to give bulk to the feed of animals that otherwise might starve. On the other hand, that portion of the buckwheat grain immediately inside the hull which forms the middlings, is rich in protein and ether extract, and has a high feeding value. The miller, aiming to sell as much of the halls as possible, mixes them with the middlings, designating this compound "buckwheat bran." (862) The intelligent purchaser, knowing that the hulls are practically worthless, will avoid them and buy only the

\footnotetext{
1 Futtermittel, p. 551.
} 
floury middlings. Buckwheat bran and middlings are nearly always used for cow-feeding, having the reputation of producing a large flow of milk. It has been charged that buckwheat byproducts make a white, tallowy butter and pork of a low quality. These charges are probably without foundation, ${ }^{1}$ when the feeds are not given in excess.

The feeder may make liberal ase of the floury portions of the buckwheat grain, well assured that they are valuable, and that usually they are an economical feed.

193. Fertilizing constituents. - Buckwheat middlings are rich in fertility, especially in nitrogen and phosphoric acid, and this fact should enhance their value in the estimation of the farmerstockman.

III. Sorghum and Millet Seed.

Digestible nutrients and fertilizing constituents.

\begin{tabular}{|c|c|c|c|c|c|c|c|}
\hline \multirow{2}{*}{ Name of feed. } & \multirow{2}{*}{$\begin{array}{c}\text { Dry } \\
\text { matter } \\
\text { in } 100 \\
\text { pounds. }\end{array}$} & \multicolumn{3}{|c|}{$\begin{array}{l}\text { Digestible nutrients } \\
\text { in } 100 \text { pounds. }\end{array}$} & \multicolumn{3}{|c|}{$\begin{array}{l}\text { Fertilizing constitu- } \\
\text { ents in } 1,000 \text { pounds. }\end{array}$} \\
\hline & & $\begin{array}{l}\text { Pro- } \\
\text { tein. }\end{array}$ & $\left|\begin{array}{c}\text { Carbo- } \\
\text { hy- } \\
\text { drates. }\end{array}\right|$ & $\begin{array}{c}\text { Ether } \\
\text { ex- } \\
\text { tract. }\end{array}$ & $\begin{array}{l}\text { Nitro- } \\
\text { gen. }\end{array}$ & $\begin{array}{l}\text { Phos- } \\
\text { phoric } \\
\text { acid. }\end{array}$ & $\begin{array}{l}\text { Pot- } \\
\text { ash. }\end{array}$ \\
\hline \multirow{5}{*}{ 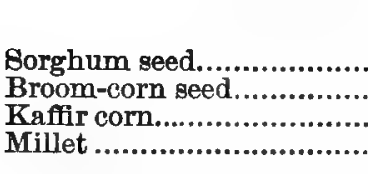 } & \multirow{5}{*}{$\begin{array}{c}\text { Lbs. } \\
87.2 \\
85.9 \\
84.8 \\
86.0\end{array}$} & \multirow{5}{*}{$\begin{array}{r}\text { Lbs. } \\
7.0 \\
7.4 \\
7.8 \\
8.9\end{array}$} & \multirow{5}{*}{$\begin{array}{c}\text { Lbs. } \\
52.1 \\
48.3 \\
57.1 \\
45.0\end{array}$} & \multirow{5}{*}{$\begin{array}{c}\text { Lbs. } \\
3.1 \\
2.9 \\
2.7 \\
3.2\end{array}$} & Lbs. & Lbs. & Lbs. \\
\hline & & & & & 14.8 & 8.1 & 4.2 \\
\hline & & & & & 16.3 & & \\
\hline & & & & & & & \\
\hline & & & & & 20.4 & 8.5 & 3.6 \\
\hline
\end{tabular}

194. Concerning sorghum.-According to Collier, ${ }^{2}$ nine-tenths of the natives of India subsist upon the grain of the sorghum plant. Sorghum and millet are the common cereal plants of much of China and Turkestan. Sorghnm seed is extensively used for human food in Africa and to some extent in the West Indies.

The sorghums may be divided into two races: saccharine and non-saccharine. In the latter the plant-stems are pithy and carry little or no sugar, the nutritive substance being mostly deposited in the numerous seeds of the ample seed-head crowning the plant. The stems of saccharine sorghums contain much

${ }^{1}$ Rept. Ottawa, Canada, Expt. Farms, 1895.

2 Sorghum, Its Culture and Uses: An address before the Chamber of Commerce, New York, 1885. 
sugar, designed primarily for conversion into starch in the seedgrains. In recent years the sorghums, especially the non-saccharine varieties, have come rapidly into favor in the semi-arid districts of the Western United States, ranging from Northwestern Texas across the Indian Territory and Kansas, into Nebraska and South Dakota. The sorghums which flourish in this region are known as Kaffir, Egyptian and Jerusalem corn. According to Coburn, ${ }^{1}$ Kansas grew 215,000 acres of Kaffir and Jerusalem corn in 1895. (274)

195. Yields of sorghum.-Burtis' ${ }^{2}$ reports the following comparative yields of Kaffir and Indian corn at the Kansas Agricultural College:

Yield of Kaffir and Indian corn - Kansas Agricultural College.

\begin{tabular}{|c|c|c|c|c|}
\hline \multirow[b]{2}{*}{ Year. } & \multicolumn{2}{|c|}{ Red Kaflir corn. } & \multicolumn{2}{|c|}{ Indian corn. } \\
\hline & $\begin{array}{c}\text { Grain per } \\
\text { acre, } \\
\text { bushels. }\end{array}$ & $\begin{array}{c}\text { Stover } \\
\text { per acre, } \\
\text { tons. }\end{array}$ & $\begin{array}{c}\text { Grain } \\
\text { per acre, } \\
\text { bushels. }\end{array}$ & $\begin{array}{l}\text { Stover } \\
\text { per acre, } \\
\text { tons. }\end{array}$ \\
\hline 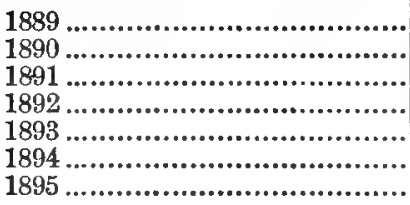 & $\begin{array}{l}71.0 \\
19.0 \\
98.0 \\
50.0 \\
49.0 \\
43.1\end{array}$ & $\begin{array}{l}9.0 \\
4.2 \\
6.0 \\
5.0 \\
5.3 \\
2.0 \\
1.5\end{array}$ & $\begin{array}{l}56.0 \\
22.0 \\
74.0 \\
30.0 \\
30.0 \\
22.0\end{array}$ & $\begin{array}{l}2.5 \\
2.5 \\
3.0 \\
4.6 \\
1.8 \\
1.0 \\
1.6\end{array}$ \\
\hline Average................ & 55.0 & 4.7 & 39.1 & 2.4 \\
\hline
\end{tabular}

By the table we learn that at Manhattan, which is in the corn belt of Kansas, Kaffir corn leads the great American cereal in yield.

The seed is sown either broadcast, in which case it is devoted to forage, or in drills, when it is cultivated like Indian corn. The seed of Kaffir corn weighs from fifty-six to sixty pounds to the bushel. Since this grain is used by millions of human beings for food, we can readily believe it valuable for feeding farm stock. Enthusiasts declare it fully equal to Indian corn for stock feeding, but this statement seems overdrawn. Probably Kaffir corn ranks

1 Rept. Kan. Bt. Bd. Agr., Dec. 1895.

Qr. Rept. Kan. Bd. Agr., Mar. 1896. 
a little below barley in feeding value. Sorghum culture is partic. ularly recommended in warm districts where Indian corn may fall short of giving fair returns for lack of sufficient moisture in the soil, and where hot, drying winds are common. In the corn districts proper, useful as the sorghums are, they will never seriously rival Indian corn. (547-8, 861)

196. Broom-corn seed.-In districts where broom corn is grown, large quantities of the seed are annually wasted through ignorance and carelessness of the growers. Broom-corn heads are cut before the seed has fully matured, and as the latter is usually removed before it has had time to become thoroughly dry, it easily ferments when left in heaps, and is wasted. With a little care in drying the seed may be sav́ed as is other grain, or it may be kept as silage, either in a regular silo or simply covered with earth, as was shown to be practicable by Miles ${ }^{1}$ years ago. Broom-corn seed will prove satisfactory for feeding cattle if used in reasonable quantity.

197. The saccharine sorghums. - At the Wisconsin University ${ }^{2}$ the writer, experimenting with sorghum for the manufacture of sugar, secured seed as a by-product at the rate of from twenty-seven to thirty-two bushels per acre; this seed weighed fifty-one pounds per bushel.

At the New Jersey Station, Cook ${ }^{8}$ secured seed at the rate of 1,300 pounds per acre from sorghum cane grown for syrnp.

Concerning the statement that sorghum seed contains tannin, a bitter principle which renders the seed unfit fur feeding stock, Wiley writes: 4 "A careful examination of sorghum seed has failed to discover the presence of tannin, and the only possible injurious principle which it can contain is the coloring matter of "the glumes." (643)

198. Millet.-Millet is grown in South Europe, parts of Asia and in Africa for human as well as for animal food. At the Massachusetts (Hatch) Station, ${ }^{5}$ Brooks grew 37.2 bushels of millet seed, weighing forty-seven pounds per bushel, on a half acre of land. Different varieties yielded as follows: ' Panicum ital-

1 Country Gentleman, March 23, 1876.

- Rept. on Amber Cane and the Ensilage of Fodders, 1881.

Rept. 1885.

1 Rept. U. S. Dept. of Agr., 1889.

- Bul. 18. 
icum, 55 bushels; Panicum crus galli, 69 bushels, and Panicum miliaceum, 28 bushels per acre. Brooks concludes that millet cannot successfully compete with Indian corn under conditions prevailing in Massachusetts. Millet seed resembles oats in composition, but we cannot point to experiments which definitely settle the feeding value of the several varieties.

Stewart" writes: "Millet meal is a highly appropriate food for young or mature horses. It has a higher proportion of albuminoids and a higher nutritive ratio than oats, but having less oil. It is found, when well ground (and it cannot properly be fed without grinding), to be one of the best rations for horses, being particularly adapted to the development of muscular strength."

The culture of sorghums and millets for grain and forage is to be recommended for the warmer districts of the United States, where there is scant rainfall and where hot, drying winds prevail. Where Indian corn flourishes, these crops are not able to compete with that great cereal. (272)

IV. Oit-bearing Seeds and their By-products.

Digestible nutrients and fertilizing constituents.

\begin{tabular}{|c|c|c|c|c|c|c|c|}
\hline \multirow[b]{2}{*}{ Name of food. } & \multirow{2}{*}{$\begin{array}{c}\text { Dry } \\
\text { matter } \\
\text { in } 100 \\
\text { pounds. }\end{array}$} & \multicolumn{3}{|c|}{$\begin{array}{l}\text { Digestible nutrients } \\
\text { in } 100 \text { pounds. }\end{array}$} & \multicolumn{3}{|c|}{$\begin{array}{l}\text { Fertilizing constitu- } \\
\text { ents in } 1,000 \text { pounds. }\end{array}$} \\
\hline & & $\begin{array}{l}\text { Pro- } \\
\text { tein. }\end{array}$ & $\begin{array}{c}\text { Carbo- } \\
\text { hy- } \\
\text { drates. }\end{array}$ & $\begin{array}{l}\text { Ether } \\
\text { ex- } \\
\text { tract. }\end{array}$ & $\begin{array}{l}\text { Nitro- } \\
\text { gen. }\end{array}$ & $\begin{array}{l}\text { Phos - } \\
\text { phorie } \\
\text { acid. }\end{array}$ & $\begin{array}{l}\text { Pot- } \\
\text { ash. }\end{array}$ \\
\hline & Lbs. & Lbs. & Lbs. & Lbs. & Lbs. & Lbs. & Lbs. \\
\hline Flax seed........................... & 90.8 & 20.6 & 17.1 & 29.0 & 36.1 & 13.9 & 10.3 \\
\hline Linseed meal, old process.. & 90.8 & 29.3 & 32.7 & 7.0 & 54.3 & 16.6 & $\mathbf{1 3} .7$ \\
\hline Linseed meal, new process. & 89.9 & 28.2 & 40.1 & 2.8 & 57.8 & 18.3 & 13.9 \\
\hline Cotton seed........................ & 89.7 & $12 . \overline{5}$ & 30.0 & 17.3 & 31.3 & 12.7 & 11.7 \\
\hline Cotton-seed meal ............... & 91.8 & 37.2 & 16.9 & 12.2 & 67.9 & 28.8 & 8.7 \\
\hline Cotton-seed hulls ............... & 88.9 & 0.3 & 33.1 & 1.7 & 6.9 & 2.5 & 10.2 \\
\hline Cocoanut meal ......... & 89.7 & 15.6 & 38.3 & 10.5 & 32.8 & 16.0 & 24.0 \\
\hline Palmunt meal .. & 89.6 & 16.0 & 52.6 & 9.0 & 26.9 & 11.0 & 5.0 \\
\hline Sunflower seed ..... & 92.5 & 12.1 & 20.8 & 29.0 & 22.8 & 12.2 & 5.6 \\
\hline Sunflower cakes... & 91.8 & 31.2 & 19.6 & 12.8 & 55.5 & 21.5 & 11.7 \\
\hline Peanut meal....... & 89.3 & 42.9 & 22.8 & 6.9 & 75.6 & 13.1 & 15.0 \\
\hline Rape-seed meal............ & 90.0 & 25.2 & 23.7 & 7.5 & 49.6 & 20.0 & 13.0 \\
\hline
\end{tabular}

199. Concerning oil-bearing seeds.-The leading oil-bearing seeds in this country are from the flax and cotton plants. Others

1 Feeding Animals 
of much importance in foreign countries are little known here. Flax grain carries a considerable quantity of protein with an excess of oil. There is no starch in well-matured flax seeds. On account of the high commercial value of the oil, flax seed is rarely used as a feed.

At the Iowa Station, ${ }^{1}$ Wilson fed ground flax seed with skim milk to calves with excellent results. (519) When flax seed was fed to cows at the rate of eight pounds per head daily, no ill results followed such heary feeding. Some feeders claim that flax seed should only be fed in a very limited quantity, since it contains a cathartic principle.

200. Oil cake and oil meal.-At the oil mills, after crushing the seeds, the oil is removed by one of two processes. In the first the crushed seed is heated and placed between cloths or in sacks which are piled one on another and the mass subjected to hydraulic pressure, to extract the oil. The residue after pressure, stripped of the wrappings, appears as hard slabs or cakes, about an inch thick by one foot in width and two in length. These slabs constitute the oil cakes of commerce, and in the entire form are shipped abroad for use by farmers in other countries. The unbroken cake is preferred for shipping, as it is the most condensed, and because the foreign feeder, suspicious of adulteration, knows that such cakes are always as pure as the seed from which they were produced. When required for feeding, the cake is reduced to the size of small hickory nuts or hazel nuts in a mill, the material being known as "nut cake." In this country the cake is usually ground to a meal at the factory and is then shipped in bags. Where the oil is secured by direct pressure from the ground flax seed as described above, the by-product is known as "old process" cake or oil meal.

201. New-process oil meal. - In the manufacture of new-process oil meal, according to Woll, ${ }^{2}$ the seed is crushed and heated to $165^{\circ} \mathrm{Fahr}$, as in the production of old-process meal. The crushed mass while warm is placed in large vertical cylinders or percolators, and over it naphtha, a volatile petroleum componnd, is

1 Buls. 14, 16, 19, 35.

2 Rept. Wis. Sta. 1895. 
poured and allowed to drain out at the bottom of the cylinder. Naphtha dissolves the oil from the ground flax seed, being repeatedly added until nearly all the oil is extracted. $\Delta$ fter this has been accomplished, steam is let into the percolator, and the naphtha which did not drain off is gradually driven out of the mass as vapor. This is so effectively done that no smell of naphtha is noticeable in the residue. From the percolators, after steaming, the meal is transferred to driers, from which it is elevated to the meal bins. This by-product is known as "new-process" oil meal.

202. The swelling process.-Woll ${ }^{1}$ gives the following simple method of ascertaining whether oil meal is new- or old-process: "Pulverize a small quantity of the meal and put a level tablespoonful of it into a tumbler; then add ten tablespoonfuls of boiling hot water to the meal, stir thoroughly and leave to settle. If the meal is new-process meal, it will settle in the course of an hour and will leave about half of the water clear on top." Oldprocess meal will remain jelly-like.

203. Adulteration of oil meal.-Adulteration of oil meal may be brought about through using immatare flax seed or that containing weed seed, or, finally, foreign matter may be added to the meal after grinding the cake. Immature flas seed contains starch, while fully mature seed contains none. Weed seeds contain much starch. If then starch grains are found in linseed meal, it is because of immature flax-seed grains, weed seeds, or both.

The manufacturer of oil meal endeavors to have the flax-seed as free from foreign substances as possible, for the reason that such foreign matter absorbs and holds oil, thereby reducing the amount available. Any serious adulterations of oil meal must therefore occur through the direct addition of foreign material to the meal after the oil has been extracted. Woll found no oil meals purposely adulterated, though he examined many samples.

204. Relative value of old- and new- process oil meal.-Woll, ${ }^{2}$ conducting artificial digestion trials with twelve samples of oldprocess and nine samples of new-process oil meal, found that $\mathbf{9 4 . 3}$ per cent. of the protein in old-process and 84.1 per cent. of pro-

1 Loc. cit.

2 Loc. cit. 
tein in the new-process meal were digestible. The lower digestibility of the new-process meal is doubtless due to the action of steam used in driving off the naphtha, as heat has been found to lower the digestibility of nitrogenous compounds in food substances generally. Because of the more complete extraction of the oil, new-process meal contains more protein than does old-process. Because of the lower digestibility of new-process meal, a given weight of this feed contains somewhat less digestible protein than does old-process meal. Old-process meal is poorer in carbohydrates but considerably richer in oil than new-process.

At the Iowa Station, ${ }^{1}$ Wilson and Reed, testing the relative merits of the two meals with fattening cattle, found that new-process gave equally as good returns as old-process meal when fed in conmection with other fodders.

205. Value of oil in oil cake.-Russian flax-seed oil cake carries more oil than does A merican. To decide the merits of oil cake containing much or little oil, tests were conducted in England by Cooke $^{2}$ under direction of the Norfolk Chamber of Agriculture, with Sir John B. Lawes and Dr. Voelcker as counselors. Sixty sheep were divided into two lots of thirty each; to the first lot was given cake containing six to seven per cent. oil, while the second lot received cake containing from fifteen to sixteen per cent. oil. The by-fodders were the same with both lots.

Results of feeding linseed cake, low in oil and rich in oil, to sheepCooke, Norfolk, England.

\begin{tabular}{l|c|c}
\hline \hline & Low-oil cake. & High-oil cake. \\
\hline Number of sheep............................. & 30 & 30 \\
Length of experiment, weeks.............. & 16 & 16 \\
Feed consumed per week. & & \\
Linseed cake, pounds..................... & 4.8 & 4.8 \\
Clover hay chaff, pounds................ & 4.8 & 4.8 \\
Swedes (turnips), pounds.............. & 87.8 & 88.0 \\
Gain in weight. & & \\
Per head during experiment, pounds & 33.5 & 38.3 \\
Increase per head, per week, pounds & 2.1 & 2.4 \\
\hline
\end{tabular}

1 Bul. 33.

- Jour. Roy. Agr. Soc., 1889. 
We observe that the cake rich in oil produced nearly five pounds more gain per head than cake low in oil. The sheep receiving the cake rich in oil brought a higher price per pound than the others. The conclusion was that, "weight for weight, linseed oil to the extent of fifteen per cent. in a cake has a much higher feeding value than have the other constituents of a linseed cake which in the absence of the oil would replace it."

206. Oil cake or oil meal as a feeding stuff.-There is no more healthful feed than oil meal or oil cake. Its general effect is to place the animal in fine condition, with a pliable skin, an oily, sleek coat and a good quality of flesh upon handling. No other farm feed has such a general beneficial effect on the digestive tract as has oil meal, and the feeder should always have a quantity on hand to deal out to his stock whenever judgment directs its use. A small quantity of oil meal may be fed to horses, but as it is fattening and does not make hard flesh, the allowance should always be limited. (472) It is with fattening steers and with sheep that oil meal shows at its best. For steers two or three pounds can be given daily in connection with other feeds. Larger amounts may be used if prices permit.

Clay $^{1}$ reports starting yearling steers on grass with two or three pounds of oil meal daily in addition to oat bran. Gradually the amount of meal was increased, until in the fall twelve pounds of meal were fed daily to each steer with satisfactory returns. (545. 553)

Voelcker, ${ }^{2}$ conducting experiments with sheep at Woburn, England, writes: "From these results it must be concluded that it is more profitable to feed sheep on linseed cake alone than on one-half linseed cake and half barley."

Owing to the price of oil meal, it should generally constitute not more than one-third of the grain ration, but to this limit it has a high value because of its helpful effect on the digestive tract, and in stimulating through its palatability a heavy consumption of the feeds with which it is mixed. For growing calves, oil meal is of great utility and has already come into general use with progressive stockmen.

1 Live Stock Rept., Chicago, Jan. 20, 1893.

2 Jour. Roy. Agr. Soc., 1892. 
The effect of oil meal on the quality of milk and butter has been questioned, but if not over two or three pounds are fed daily per cow, no ill results but much good will follow its use. (646-7) A handful of oil meal at a feed will prove healthful to growing pigs, and advertise itself in their sleek coats and general healthy appearance. (892) The American farmer should give up the use of oil meal and adopt the practice of his English brother in feeding this valuable article in the nut form, which is more palatable with cattle.

207. Castor-oil seed in linseed meal.-Fatalities are occasionally reported among cattle by English feeders through using oil meal containing the pomace or beans of the castor-oil plant, which deadly poison occasionally gets into the meal by accident, in warehouses or elsewhere. The presence of castor beans or pomace in the ration is shown by severe purging of the animal eating even a very small amount of it, followed occasionally by death. Leather ${ }^{1}$ reports a method of detecting the castor bean or castor pomace in stock feeds, which though too complicated for the feeder is useful to the chemist.

208. Fertilizing constituents in linseed meals. - Linseed cake or meal is rich in the elements of fertility, especially nitrogen, and for this reason as well as its general good qualities and nutritive effect it is a favorite feeding stuff with the English stockman. The voidings of animals receiving this feed should be carefully saved, for in the fertility they contain rests quite a fraction of the first cost of this feed.

209. Home use of oil meal.- A large portion of the oil cake produced in this country from flax seed finds a market in European countries. The quantity shipped abroad varies greatly from year to year, according to the relative prices ruling for feeding stuffs in European and American markets. Woll ${ }^{2}$ estimates that if half the oil cake manufactured in this country is shipped abroad, it means an annual loss of more than thirteen million pounds of nitrogen, four million pounds of phosphoric acid and three and a half million pounds of potash, representing an aggregate value, as

1 Analyst. Vol. 17; Jour. Roy. Agr. Soc., 1892.

2 Rept. Wis. Sta., 1895. 
commercial fertilizers, of over two million dollars. This loss of fertility to American farms is a serious matter, which can easily be prevented by feeding the oil cake at home. See Chap. XVI.

210. Cotton seed. ${ }^{1}$ - The products of the cotton plant used as food for live stock are cotton seed, cotton-seed cake or meal, and cotton-seed hulls.

The cotton erop of the United States amounts to over 9,000,000 bales annually on the average, yielding about $4,500,000$ tons of cotton seed as a by-product, since for each pound of fiber the cotton plant produces about two pounds of seed. No one can acquaint himself with the great value of cotton seed and its by-products, and then consider this enormous annual output of seed, without becoming deeply impressed with the great possibilities for stock feeding at the South. Previous to 1860 almost all this vast supply of stock feed was wasted by the Southern planter, who allowed the seed to rot back of the gin house in ignorance of its worth, while meat and other animal products were purchased at high cost from Northern farmers. The utilization of the cotton seed and its products as food for both man and beast is an excellent example of what science has accomplished for the advancement of agriculture.

According to the report of the Tenth Census, one hundred pounds of cotton seed yields approximately:

Pounds

Cotton-seed meal............. 37.5

Cotton-seed oil............... 12.5

Cotton-seed hulls............ 48.9

Short lint from hulls...... 1.1

211. Feeding cotton seed.- Seed as left by the cotton-gin is now a common feed at the South for steers and dairy cows. It is usnally supplied to cattle without treatment of any kind, though in some cases it is roasted, boiled or steamed before feeding.

Trials at the Texas Station ${ }^{2}$ by Gulley and Curtis show that seed at seven dollars per ton made cheaper though somewhat smaller gains than cotton-seed meal costing twenty dollars per

\footnotetext{
' Much of the data here presented is from Bul. 33, The Cotton Plant, nffice of Experiment Stations, U. S. Dept. Agr.

2 Buls. 6, 10.
} 
ton. Connell and Carson, of the same Station, 1 conclude that boiled or roasted cotton seed is more palatable, less laxative and produces more rapid gains than raw cotton seed, but that the latter makes the cheaper gain. They state that the advantages obtained from roasting the seed do not pay for the expense involved.

At the Mississippi Station, ${ }^{2}$ Lloyd, summarizing three years' work, concludes that steamed cotton seed is better and cheaper for producing milk and butter than either raw seed or cottonseed meal. Butter produced from cotton-seed meal cost twice as much as that produced from steamed or raw seed. The wise planter, knowing the value of whole cotton seed as a stock food, will not dispose of good seed to the oil mills at prices below its worth to him.

212. Cotton-seed cake and meal.- At the oil mills the envelope of the cotton seed is cut by machinery in such a way that the oily kernels are freed from it. These seed-envelopes are known as cotton-seed hulls; they are dry, leathery and covered with lint. The oily kernels, separated from the hulls, are crushed, heated, placed between cloths or sacks and subjected to hydraulic pressure to remove the oil. The residue is a yellowish board-like cake about one inch thick, one foot wide and two feet in length. In this form it is shipped abroad as cotton-oil cake. For home use the cake is reduced to meal by grinding, and transported in sacks the same as linseed meal.

213. Cotton-seed meal for horses. - Gebek ${ }^{3}$ reports draft horses doing well on a ration containing two pounds of cotton-seed meal. The use of cotton seed-meal for horses will be greatly extended at the South if experiments reveal equally good results.

214. Feeding steers cotton-seed meal and hulls.-The practice of fattening steers exclusively on cotton-seed hulls and cotton-seed meal was begun in the South about 1883. The business has so grown that it is estimated that 400,000 cattle were fattened at the oil mills of the South for the season of 1893-94, besides large numbers of sheep. In these establishments the ration for steers at

1 Bul. 27.

2 Bul. 21.

3 Landw. Vers. Sta., 42, p. 294. 
first consists of three or four pounds of cotton-seed meal, which is gradually increased to six, eight or even ten pounds per head daily, with all the hulls the steers will eat additional, which amounts to about four pounds of hulls for each pound of meal. The feeding period lasts from ninety to one hundred and twenty days. (558-560)

In reply to an inquiry from the writer, Swift \& Co. (Packers, Chicago) state that cotton-seed meal makes a good quality of beef. They express the opinion that a still better quality is produced where the meal is fed in connection with other concentrates.

215. Effects of cotton seed on steer fat.-At the Texas Station, ${ }^{1}$ Harrington and Adriance found the kidney, caul and body fats of steers fed raw, roasted or boiled cotton seed to have melting points of $4.1,{ }^{\circ} 3.2^{\circ}$ and $8.7^{\circ} \mathrm{C}$. higher than the corresponding fats of corn-fed steers. The influence on tallow was somewhat less than that produced with butter; while on mutton suet it was marked as with butter. Butterine from beef tallow of steers fed cotton-seed by-products might give Becchi's test, thus confusing ordinary chemical tests for pure butter.

216. Cotton-seed meal for dairy cows. - At the Maine Station, ${ }^{2}$ Jordan found that the substitution of cotton-seed meal for an equal quantity of corn meal increased the production of milk and butter to a profitable extent. At the Pennsylvania Station, 8 Hunt fed six pounds of cotton-seed meal per day to cows without apparent injury to health, and by substituting equal weights of cotton-seed meal for wheat bran increased the milk yield one-fifth. In general, feeding cotton-seed meal to dairy cows has proved satisfactory when the allowance has not exceeded five or six pounds daily for short periods, and three or four pounds for long periods. $(637,644,646,723)$

217. Effects of cotton seed on the quality of butter.-At the Texas Station, 4 Harrington and Curtis, experimenting with cotton-seed and its by-products with dairy cows, conclude that these feeds materially raise the melting point of butter and lower its

1 Bul. 29.

2 Repts. 1885-87.

Bul. 17.

- Agricultural Bcience, III, p. 79; Rept. 1889; Buls. 11, 29. 
volatile fatty acids; that when cotton seed is fed alone or forms a large part of the ration, a light-colored butter of inferior quality results. Butter produced from the heavy feeding of cotton seed showed poor flavor and had the appearance of being overworked. Fed in reasonable amount, cotton seed and its by-products produce satisfactory butter, which is firmer and will stand shipment better in warm climates than where no seed is fed. Harrington's results were corroborated by Wiley, ${ }^{1}$ and Lupton and Anderson. ${ }^{2}$

The results of recent experiments at the Iowa Station ${ }^{3}$ go in the opposite direction. The preponderance of evidence at hand shows, however, that cotton-seed meal hardens butter, gives it a tallowy consistency and makes it deficient in natural color.

218. Cotton-seed meal for calves and pigs.- At the North Carolina Station, 4 two calves getting from one to six ounces of cotton-seed meal daily, died after one month's feeding. Other instances of the same kind are reported.

The use of cotton seed and cotton-seed meal for swine has been extensively investigated at the Texas Station ${ }^{6}$ by Curtis. As a check in his experiments one lot of pigs was fed corn in each trial, and these pigs always made excellent gains, with no deaths, thereby showing that normal conditions generally prevailed. On the other hand, many pigs fed cotton seed or cotton-seed meal sickened and died in from six to eight weeks after feeding began. The mortality of the pigs receiving cotton-seed meal was 87 per cent.; when roasted seed was fed it was 75 per cent., and for boiled seed, 25 per cent. In these experiments no trouble occurred until several weeks after feeding commenced, and it was observed that pigs escaping sickness and death for thirty days beyond the time when the trouble usually began were safe from attack, though they were permanently stunted in growth. As a result of his studies Curtis concludes: "There is no profit whatever in feeding cotton seed in any form, or cotton-seed meal, to hogs of any age."

219. Cotton-seed poisoning.-According to Curtis, "the first sign of sickness appears in from six to eight weeks after cotton-

\footnotetext{
1 Proc. Soc. Prom. Agr. Science, 1889, p. 84.

2 Bul. 25, Ala. Sta.

Bul. 32.

Bul. 100.

- Bul. 21.
} 
seed meal is added to the ration. It is shown by a moping dullness of the animal, with loss of appetite and tendency to lie apart. . . . . The fatal cases all show spasmodic breathing, and in many instances the animal will turn in one direction only. . . . . When exhausted by his efforts the animal drops down suddenly, sometimes flat upon the belly, sometimes on its haunches, with his fore legs well apart to keep from falling over, almost always with evidence of more or less acute internal pain. At death a quantity of bloody foam exudes from mouth and nostrils."

Cornevin $^{1}$ fed two three-months old pigs 4.3 and 6.6 pounds, respectively, of brownish-yellow Egyptian cotton-seed meal, with fatal effect. A dog weighing fifty-three pounds was killed by subcutaneous injections of a watery extract from 1.7 pounds of seed. In all cases examination showed the digestive tract of the animals to be highly inflamed. The oil pressed from the seed had no poisonous properties.

All efforts to determine the poisonous principle in the cotton seed - if there really be one-have thus far proved futile, and the matter is still a mystery. The ill effects have been ascribed to the lint of the seed, to the leathery seed coats causing injury to the delicate lining of the digestive tract, to moulds, to changes in the composition of the meal when exposed to the air, and to some definite poisonous principle in the seed itself, as in the case of the castor-oil bean.

220. The retional use of cotton seed and cotton-seed meal.It may be stated in general terms that when cotton seed or its by. products are fed in reasonable quantity with a proper complement of other feeding stuffs, satisfactory results are secured with all farm animals except calves and swine.

Wet or mouldy cotton seed, or that which has heated, should not be fed. Good cotton-seed meal has a bright yellow color and a fresh, pleasant taste. Meal of a dull red color, due to exposure to the air, that from musty seed as well as that which has fermented, should not be used for feeding purposes.

221. Cotton-seed hulis.- Until recently cotton-seed hulls were regarded as of no value except for fuel at the mills. It was soon

\footnotetext{
1 Ann. Agron. 1896; Milch Zeit. 1897, p. 343.
} 
found, however, that cattle would eat them freely, and they have come into extensive use for steer and cow feeding, having a market value of from two to four dollars per ton. Cotton-seed hulls, as shown by the table, contain less digestible nutrients than oat straw, but since they are a by-product which would otherwise be wasted, they are of considerable advantage to feeders in proximity to the mills. Where broken kernels of the cotton seed adhere to the hulls, their feeding value is considerably increased.

222. Feriulity in cotton seed.- So rich is cotton-seed meal in fertilizing elements that much of it goes at once from the oil mills to the fertilizer works, there to be mixed with other substances, and to be sold back to planters as a fertilizer. In the lint, which is the one object songht in cotton growing, there is but a trace of nitrogen and mineral matter, while the seed is rich in these elements of fertility. In the 4,500,000 tons of seed which must be grown each year in producing the cotton erop of the South, the amount of fertility taken from the land is almost beyond comprehension. In this continuous drain of fertility by cotton growing we have a partial explanation of the present poverty of the soils in many of the cotton districts. If the zotton grower will adopt mixed farming and feed cotton seed and "otton-seed meal to his stock, returning the manure to the land, two values will be received from the crop, and a rational agricultpral practice inaugurated, which is sorely needed in a region -here nature has done so much and man so little to place agriculttre upon a substantial basis.

223. Cocoanut meal.- The residue in the manufacture of cocoaat oil is known as cocoanut or cocoa meal. It is used quite extensively by dairymen in the vicinity of San Francisco. Cocoanut meal has the reputation of producing fine butter of considerable firmuess and is therefore recommended for summer feeding to dairy sows. It may be used with advantage for swine and sheep, serving also as a partial substitute for oats with working horses. (474)

224. Palmnut meal.-This residue in the manufacture of palm oil has been extensively used in Europe as a stock food. It has good keeping qualities, is appetizing and easily digested. The 
oil palm is cultivated in Africa, South America and the West Indies, from which countries the meal is largely shipped to Europe. Palmnut meal is highly prized as a food for dairy cows.

225. Peanut meal.-The by-product in the manufacture of oil from the peanut or earth-nut is used in various European countries for stock feeding. Peanut meal is one of the richest known foods in the amount of protein it yields. Voelcker ${ }^{1}$ states that peanut cake proved on trial to be a useful feeding material for cattle, having a value about equal to beans. (892)

226. Sunflower seed cake.-The sunflower is grown in Russia on a commercial scale, one variety with small seeds producing an oil which serves as a substitute for other vegetable oils. The large seeds of another variety are consumed as a dainty by the people.

The average of five experiments conducted by the North Carolina Station ${ }^{2}$ in as many parts of the state showed a yield of sixty-five bushels of sunflower seed per acre. Mammoth Russian sunflower seed weighed 26.7 pounds per bushel, with 21.5 per cent. oil; Black Giant seed weighed 32 pounds per bushel, with 20.8 per cent. oil.

Bartlett, of the Maine Station, " concludes that, "With the same cultivation, corn produces a third more protein and twice as much carbohydrates as sunflower heads."

227. Fertilizing constituents.-In general all the oil-bearing seeds are rich in fertilizing constitnents, especially nitrogen. The extraction of the oil removes none of the fertilizing value, but concentrates it in the residue. The stockman who is interested in the fertility of his land as well as the nourishment of his stock should never forget these facts when considering the purchase of various feeding stuffs.

\footnotetext{
1 Jour. Roy. Agr. Boc., 1892.

2 Bul. 90 b.

Rept. 1895.
} 
V. Leguminous Seeds.

Digestible nutrients and fertilizing constituents.

\begin{tabular}{|c|c|c|c|c|c|c|c|}
\hline \multirow{2}{*}{ Name of feed. } & \multirow{2}{*}{$\begin{array}{c}\text { Dry } \\
\text { mantter } \\
\text { in } 100 \\
\text { pounds. }\end{array}$} & \multicolumn{3}{|c|}{$\begin{array}{l}\text { Digestible nutrients } \\
\text { in } 100 \text { pounds. }\end{array}$} & \multicolumn{3}{|c|}{$\begin{array}{l}\text { Fertilixing constitu } \\
\text { ents in } 1,000 \text { pounds. }\end{array}$} \\
\hline & & $\begin{array}{l}\text { Pro- } \\
\text { tein. }\end{array}$ & $\begin{array}{l}\text { Carbo- } \\
\text { hy- } \\
\text { drates. }\end{array}$ & $\begin{array}{c}\text { Ether } \\
\text { ex- } \\
\text { tract. }\end{array}$ & $\begin{array}{l}\text { Nitro- } \\
\text { gen. }\end{array}$ & $\begin{array}{l}\text { Phos- } \\
\text { phoric } \\
\text { acid. }\end{array}$ & $\begin{array}{l}\text { Pot- } \\
\text { ash. }\end{array}$ \\
\hline \multirow{4}{*}{ 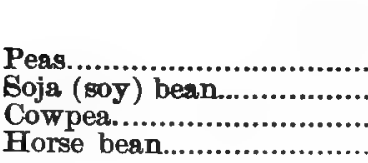 } & \multirow{4}{*}{$\begin{array}{c}\text { Lbs. } \\
89.5 \\
89.2 \\
85.2 \\
85.7\end{array}$} & \multirow{4}{*}{$\begin{array}{l}\text { Lbs. } \\
16.8 \\
29.6 \\
18.3 \\
22.4\end{array}$} & \multirow{4}{*}{$\begin{array}{l}\text { Lbs. } \\
51.8 \\
22.3 \\
54.2 \\
49.3\end{array}$} & \multirow{4}{*}{$\begin{array}{r}\text { Lbs. } \\
0.7 \\
14.4 \\
1.1 \\
1.2\end{array}$} & \multirow{4}{*}{$\begin{array}{l}\text { Lbs. } \\
30.8 \\
53.0 \\
33.3 \\
40.7\end{array}$} & Lbs. & Lbs. \\
\hline & & & & & & 8.2 & 9.9 \\
\hline & & & & & & 18.7 & 19.9 \\
\hline & & & & & & 12.0 & 12.9 \\
\hline
\end{tabular}

228. The field pea.-The field pea is extensively grown in Canada for stock feeding, succeeding also along the northern rim of the corn belt and still farther north, where in some measure it takes the place of corn for feeding purposes. The richness of the pea in protein marks it as particularly useful with growing animals, dairy cows and pigs. A part of the protein in peas as well as in other leguminous seeds is identical in composition with the casein of milk, and is termed "vegetable" casein. This has led some writers to affirm that meals from these seeds are useful in mixtures for calf feeding. Pea meal is sodden in character and too heary to be fed as the only grain allowance. It should be lightened or extended by mixing with it bran, ground oats or corn meal.

Peas may be harvested while still green by turning pigs into the pea field as soon as the seeds are well formed. Under this system the animals harvest the crop without labor to the stockman, and, receiving that sort of food which forms bone and muscle, they are prepared for final fattening on corn or other dry food. Peas are often sown with oats, the latter plants forming support for the weak vines. (111, 311, 860)

229. Soja (soy) bean.-This Japanese plant flourishes in the Southern states and as far north as Kansas. In Japan it serves for human food, but in this country it is used only by stockmen. Like all leguminous seeds, the soja bean is rich in protein, standing perhaps at the head of the list; unlike many in its class, it is also rich in oil. Because the seeds must be 
gathered by hand, the plant has generally been used only for forage. At the Kansas Station ${ }^{1}$ this plant gave yields ranging from 12.5 to 19 bushels of beans per acre. At the Massachusetts Station $^{2}$ a comparative test of soja-bean meal with cotton-seed meal terminated in favor of the former for milk and butter production. (310) See Farmers' Bul. 58, Office of Experiment Stations, Dept. Agr., Washington.

230. Cowpea.-This plant now holds an important place with Southern stockmen becanse of its rapid growth and the large amount of forage it yields. The earlier varieties will make a satisfactory growth as far north as Wisconsin, though all the seeds will not ripen before frost. As with the soja bean, the seeds which ripen first must be gathered by hand. For this reason the crop is usually cut for hay or silage.

At the Alabama Station, ${ }^{8}$ Duggar fed cowpeas to fattening pigs with excellent returns. More lean meat was found in the bodies of pigs fed cowpeas than those fed corn meal only. $(109,863)$

At the Texas Station, ${ }^{4}$ the cowpea gave yields ranging from eight to thirty-five bushels per acre. These findings point to the value of the plant for producing concentrated feed. (309)

231. Horse bean.-This legume is used in England for feeding stock, especially horses. The horse bean grows fairly well in some parts of Canada, but has never proved a success in the United States.

232. The common field bean.-Many varieties of the common field bean are grown in this country for human food. In beangrowing districts, cull beans are purchasable in large quantities, usually at low prices, and should be used by stockmen, since they are then a cheap feed. Sheep are fond of beans administered in a raw state. For other animals they should be cooked. Since they are rich in protein, corn meal is a natural addition to the porridge.

233. Fertilizing constituents. - All leguminous seeds are rich in nitrogen with from fair to rather high mineral content. The soja bean is of particular value in the nitrogen and ash it carries.

\footnotetext{
Bul. 32. 2 Rept. 1894.

- Bul. 82. Bul. 34 .
} 


\section{CHAPTER $\mathbf{X}$.}

INDTAN CORN AS A FORAGE PLANT.

Digestible nutrients and fertilizing constituents.

\begin{tabular}{|c|c|c|c|c|c|c|c|}
\hline \multirow[b]{2}{*}{ Name of feed. } & \multirow[b]{2}{*}{$\underset{\text { matter. }}{\text { Dry }}$} & \multicolumn{3}{|c|}{$\begin{array}{l}\text { Digestible nutrients } \\
\text { in } 100 \text { pounds. }\end{array}$} & \multicolumn{3}{|c|}{$\begin{array}{l}\text { Fertilizing constita- } \\
\text { ents in } 1,000 \text { pounds. }\end{array}$} \\
\hline & & $\begin{array}{l}\text { Pro- } \\
\text { tein. }\end{array}$ & $\begin{array}{c}\text { Carbo- } \\
\text { hy- } \\
\text { drates. }\end{array}$ & $\begin{array}{l}\text { Ether } \\
\text { ex- } \\
\text { tract. }\end{array}$ & $\begin{array}{l}\text { Nitro- } \\
\text { gen. }\end{array}$ & $\begin{array}{l}\text { Phos- } \\
\text { phoric } \\
\text { acid. }\end{array}$ & $\begin{array}{l}\text { Pot- } \\
\text { ash. }\end{array}$ \\
\hline Green fodder corn (aver- & Lbs. & Lbs. & Lbs. & Libs. & Lbs. & Lbs. & Lbs. \\
\hline $\begin{array}{l}\text { age, all varieties) ............ } \\
\text { Fodder corn, field-cured... }\end{array}$ & $\begin{array}{l}20.7 \\
57.8\end{array}$ & $\begin{array}{l}1.0 \\
2.5\end{array}$ & $\begin{array}{l}11.6 \\
34.6\end{array}$ & $\begin{array}{l}0.4 \\
1.2\end{array}$ & $\begin{array}{r}4.1 \\
17.6\end{array}$ & $\begin{array}{l}1.5 \\
5.4\end{array}$ & $\begin{array}{l}3.3 \\
8.9\end{array}$ \\
\hline Corn stover, field-cured.... & 59.5 & 1.7 & 32.4 & 0.7 & 10.4 & 2.9 & 14.0 \\
\hline
\end{tabular}

234. Concerning Indian corn.-Indian corn (maize) is the imperial agricultural plant of America. This giant annual grass reaches a height of from seven to fifteen feet in four or five months' growth, producing under favorable conditions from 30,000 to 50,000 ponnds of green forage per acre, of which from 5,000 to 9,000 pounds are dry matter. If grown in a dense mass but little seed forms, and we have a rank grass which cures into a bright, nutritious coarse hay. If the plants are grown at some distance one from another, a large yield of grain results, with excellent forage as a secondary product.

Were a reliable seedsman to advertise Indian corn by a new name, recounting only its actual merits while ingeniously concealing its identity, his words would either be discredited or he would have an unlimited number of purchasers for this seed-novelty at almost any figure he might name. The possibilities of American stock farms in the live stock they may carry and the animal products they may turn off is measured only by the quantity of corn and clover which the land will produce, and this, under good management, seems almost unlimited.

235. Definitions. - To avoid confusion the term "fodder corn" or "corn fodder," used in this book, is applied to stalks of corn, 
either green or dry, which are grown for forage and from which the ears or "nubbins," if they carry any, have not been removed. "Stover" applies to the dry stalks of corn from which the ears have been removed. Fodder corn or corn fodder, then, is the corn plant, either fresh or cured, with or without ears, which has been grown for forage; stover is shock corn minus the ears.

236. Thickness of planting and nutrients.-At the Hlinois Station ${ }^{1}$ Morrow and Hunt, studying the results of thick and thin seeding on the yield of nutrients, reached conclusions at the end of three years' study which are summarized in the table below. In these trials dent corn was planted in varying rates, from one kernel every three inches to one every twenty-four inches, the corn rows being three feet eight inches apart.

Results of planting corn kernels various distances apart in rows, aver. age of three years' trials - Illinois Station.

\begin{tabular}{|c|c|c|c|c|c|c|c|c|}
\hline \multicolumn{2}{|c|}{ Thickness of planting. } & \multicolumn{2}{|c|}{$\begin{array}{l}\text { Yield } \\
\text { per acre. }\end{array}$} & \multicolumn{3}{|c|}{$\begin{array}{l}\text { Digestible sub- } \\
\text { stance per acre. }\end{array}$} & \multirow{2}{*}{$\begin{array}{l}\text { Sto- } \\
\text { ver } \\
\text { per } \\
\text { acre. }\end{array}$} & \multirow{2}{*}{$\begin{array}{l}\text { Sto- } \\
\text { ver } \\
\text { for } \\
\text { each } \\
\text { lb. of } \\
\text { corn. }\end{array}$} \\
\hline $\begin{array}{l}\text { Distance between } \\
\text { kernels in row. }\end{array}$ & $\begin{array}{l}\text { Kernels } \\
\text { per } \\
\text { acre. }\end{array}$ & $\begin{array}{l}\text { Good } \\
\text { ears. }\end{array}$ & $\begin{array}{l}\text { Poor } \\
\text { ears. }\end{array}$ & $\begin{array}{l}\text { Sto- } \\
\text { ver. }\end{array}$ & Grain & Total. & & \\
\hline & & Bu. & $\mathrm{Bu}$. & Lbs. & Lbs. & Lbs. & Tons. & Lbs. \\
\hline $\begin{array}{r}3 \text { inches............... } \\
6 \text { inches.............. } \\
9 \text { inches.............. } \\
12 \text { inches.............. } \\
15 \text { inches............. } \\
24 \text { inches.............. }\end{array}$ & $\begin{array}{r}47,520 \\
23,760 \\
15,840 \\
11,880 \\
9,504 \\
5,940\end{array}$ & $\begin{array}{l}13 \\
37 \\
55 \\
73 \\
63 \\
49\end{array}$ & $\begin{array}{r}46 \\
39 \\
22 \\
16 \\
11 \\
6\end{array}$ & $\begin{array}{l}3,968 \\
3,058 \\
2,56 \\
2,480 \\
2,398 \\
2,066\end{array}$ & $\begin{array}{l}2,250 \\
2,922 \\
2,977 \\
3,113 \\
2,782 \\
2,141\end{array}$ & $\begin{array}{l}6,218 \\
5,980 \\
5,539 \\
5,593 \\
5,180 \\
4,207\end{array}$ & $\begin{array}{l}4.8 \\
3.7 \\
3.1 \\
3.0 \\
2.9 \\
2.5\end{array}$ & $\begin{array}{l}3.6 \\
1.9 \\
1.5 \\
1.3 \\
1.4 \\
1.5\end{array}$ \\
\hline
\end{tabular}

We observe that with the kernels three inches apart in the row, or 47,000 per acre, there were thirtecn bushels of sound ears and forty-six bushels of poor ears or nubbins per acre. Poor as are these returns from the standpoint of grain production, we gather the interesting and exceedingly important fact that with thick planting there were the largest returns in total digestible nutrients per acre. Over 6,000 pounds of digestible dry matter were secured in nearly five tons of stover and corn harvested. With this thickness of seeding there were 3.6 pounds of stover for each pound of grain. The largest yield of sound

1 Bul. 13. 
ear corn was returned from planting the kernels twelve inches apart in the row, or about 12,000 per acre, from which the returns were seventy-three bushels of sound ears and sixteen bushels of poor ears per acre, with only about 600 pounds less digestible matter than was returned from planting the kernels four times as thick.

Morrow holds that, for Illinois conditions, 10,000 good stalks of corn per acre (secured by planting about 12,000 kernels) give the best returns in grain. The lesson from the above table is confirmed by the work of other Stations, and teaches that when the stockman is seeking the greatest amount of nutrients possible from the corn crop he will plant the seed so thickly as to choke the ears to about half their natural size. If, on the other hand, his aim is to produce grain, with stover secondary, then he will plant the seed grains at such distances one from another as will allow each individual plant to produce one or more full-sized ears of corn. No rule can be given which is applicable in all cases for guidance as to the amount of seed corn to be planted per acre. This varies greatly and is determined by local conditions. One must know quite accurately the capacity of his land for this crop and seed accordingly, bearing in mind, as shown above, that thick seeding gives the most total nutrients, while medium seeding gives the most sound grain.

237. Increase of nutrients during maturity. - At the New York (Geneva) Station ${ }^{1}$ Ladd conducted investigations in relation to the storage of nutrients by the growing corn plant, and has arranged his data in excellent form for study. His findings are substantiated by results in the same line obtained at several other Stations. The great importance of the subject is sufficient excuse for the space here occupied. The stockman should know what the corn plants in his field are doing in the way of gathering food between early growth and maturity. He should have a keen appreciation of this wonderful process of food-gathering, and as full knowledge as possible of when and under what conditions the maximum results are obtained by the plant. Ladd's study of the corn plant extends from the time it was tasseled until the kernels were

1 Rept. 1889. 
ripe. To the novice, when a field of corm is folly tasseled, it has about completed its growth, bnt the following table shows in a most effective manner that great changes are still going on within the stalks and that the storage of nutrients has only fairly begun:

Water and dry matter in corn crop at different periods after tasseling New York (Geneva) Station.

\begin{tabular}{|c|c|c|c|c|}
\hline $\begin{array}{l}\text { Date of } \\
\text { cutting. }\end{array}$ & Stage of growth. & $\begin{array}{c}\text { Corn } \\
\text { per } \\
\text { acre. }\end{array}$ & $\begin{array}{l}\text { Water } \\
\text { per } \\
\text { acre. }\end{array}$ & $\begin{array}{c}\text { Dry } \\
\text { matter } \\
\text { per } \\
\text { acre. }\end{array}$ \\
\hline & & Tons. & Tons. & Tons. \\
\hline July 30. & Fully tasseled ................................ & 9.0 & 8.2 & .8 \\
\hline Aug. $9 . .$. & Fully silked.................................. & 12.9 & 11.3 & 1.5 \\
\hline Aug. 21... & Kernels watery to full milk ........... & 16.3 & 14.0 & 2.3 \\
\hline Sept. 7... & Kernels glazing ............................... & 16.1 & 12.5 & 3.6 \\
\hline Sept. 23... & Ripe $\ldots \ldots \ldots \ldots \ldots \ldots \ldots \ldots \ldots \ldots \ldots \ldots \ldots \ldots \ldots \ldots \ldots \ldots \ldots \ldots \ldots \ldots \ldots \ldots$ & 14.2 & 10.2 & 4.0 \\
\hline
\end{tabular}

The table shows that an acre of corn when fully tasseled weighed nine tons, more than eight of which were water. The water in the corn continued to increase in total amount ontil Angust 21, at which time the kernels had reached the full milk stage, after which it decreased. The total dry matter increased from the beginning. Between the milk and glazing stages there was the remarkable increase of over a ton of dry matter per acre of crop in seventeen days. From glazing to full ripeness there was a further increase of dry matter, though it was small.

238. Nutrients at different stages.-Ladd found the percentage of nutrients in the crop at different periods to be as given below:

Percentage of nutrients in the dry matter of ripening corn - Newo York (Geneva) Station.

\begin{tabular}{|c|c|c|c|c|c|}
\hline & July 30. & Aug. 9. & Aug. 21 & Sept. 7. & Sept. 23 \\
\hline Ash ................ & 8.6 & 6.5 & 5.0 & 4.2 & 4.6 \\
\hline 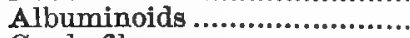 & 14.8 & 14.2 & 10.3 & 8.9 & 8.6 \\
\hline Crude fiber ............................ & 31.8 & 28.4 & 27.2 & 24.4 & 21.9 \\
\hline Nitrogen-free extract ............... & 40.4 & 45.5 & 52.6 & 58.9 & 61.0 \\
\hline 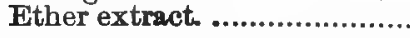 & 4.5 & 5.5 & 4.9 & 3.6 & 4.0 \\
\hline
\end{tabular}


In studying the foregoing table the reader should bear in mind the great increase in dry matter which occurs as the plant ripens.

239. Total nutrients of the corn crop.-The preceding table would be misleading were it not followed by another showing the total nutrients in the crop at different periods of maturity:

Water and nutrients in an acre of corn at different stages of maturity - New York (Geneva) Station.

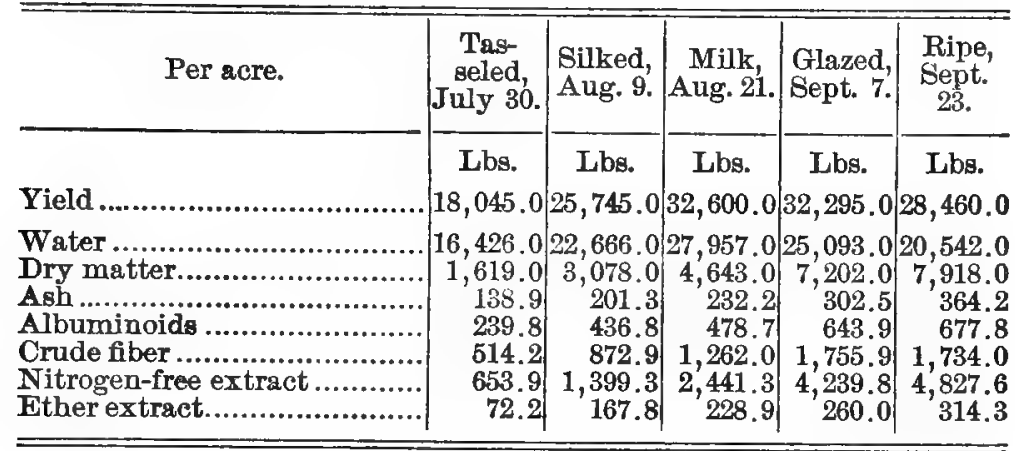

From the above we learn that the crop increased about 10,000 pounds in weight between tasseling and maturing. Of this increase about 4,000 pounds were water, the remainder being dry matter. The dry matter in the crop, which amounted to only 1,600 pounds at tasseling time, increased to 7,900 pounds when the corn was ripe. The analyses show that between the milk and the glazing stages and on to the final period of ripening there is a constant and remarkable increase in the nutrients stored by this plant.

240. Changes in protein.- Ladd also made a study of the albuminoid and amide nitrogen in the crop with the following results: Albuminoid and amide nitrogen of the ripening corn crop - Nero York (Geneva) Station.

\begin{tabular}{|c|c|c|c|c|}
\hline Date. & Stage of maturity. & $\begin{array}{c}\text { Total } \\
\text { nitrogen. }\end{array}$ & 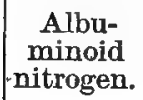 & $\begin{array}{c}\text { Amide } \\
\text { nitrogen. }\end{array}$ \\
\hline & & Lbs. & Lbs. & Lbs. \\
\hline July $30 \ldots \ldots$ & Tasseled.............................. & 38.4 & 27.4 & 11.0 \\
\hline Aug. $9 \ldots \ldots$ & Silked .............................. & 69.9 & 44.6 & 25.2 \\
\hline Aug. $21 \ldots . .$. & Kernels in milk.................. & 77.6 & 66.4 & 17.3 \\
\hline Sept. $7 \ldots . .$. & Corn glazed........................ & 103.0 & 78.5 & 24.5 \\
\hline Sept. $23 \ldots .$. & 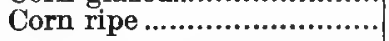 & 108.5 & 91.1 & 17.4 \\
\hline
\end{tabular}


The table shows that while there was a steady increase in the total albuminoid nitrogen up to the maturity of the plant, the amide nitrogen varied greatly at different periods, being less when the corn was ripe than at earlier dates.

241. Nitrogen-free extract. - The greatest increase in nutrients between tasseling and maturity was with the nitrogen-free extract, that part of the corn plant next in value to protein.

Increase of nitrogen-free extract in ripening corn-New York (Geneva) Station.

\begin{tabular}{|c|c|c|c|c|}
\hline Date. & Stage of maturity. & Glucose. & Sucrose. & Stareh. \\
\hline & & Lbs. & Lbs. & Lbs. \\
\hline July 30. & Tasseled.. & 58.3 & 9.1 & 122.2 \\
\hline Aug. $9 .$. & Silked..... & 300.4 & 110.8 & 491.3 \\
\hline Aug. 21... & In milk ............................ & 665.0 & 129.0 & 706.7 \\
\hline Sept. $7 \ldots$ & Glazed ............................... & 720.2 & 95.1 & $1,735.0$ \\
\hline Sept. $23 \ldots$ & Ripe................................... & 538.4 & 148.9 & $2,852,9$ \\
\hline
\end{tabular}

Concerning these changes Ladd says: "The total starch per acre increased more than twenty-three times between tasseling of corn and harvesting, a period of fifty-five days. From the stage of glazing of corn until full ripening the increase in dry matter was 716 pounds, the increase in nitrogen-free extract 587 pounds, while the increase of sugar and starch was 989 pounds, or greater by 273 pounds than the entire gain in crop. That is, much of the nitrogen-free extract, which at period of glazing of corn was in the transitory state, had been translocated and transformed into sugars and starch."

Jordan, of the Maine Station, ${ }^{1}$ studying the same subject, writes: "Owing to the relatively large production of sugars and starch in the late stages of growth, a pound of the dry substance of the mature well-eared corn plant possesses a higher nutritive value than at any earlier stage of growth." Compare with development of the timothy plant, Article 259.

242. Importance of maturity.—These tables teach the farmer that he should delay harvesting the corn crop until the plants have been allowed to accomplish their full work of gallering, elaborating and locating nutritive matter. To harvest a corn crop for forage or silage while the grain is in the milk stage is to

Rept. 1895. 
sacrifice a large part of the feeding value which would come to this crop were harvesting delayed until the corn is passing the glazing stage. In the large amount of water which the corn plant carries when quite green, the stockman learns why corn which has just tasseled, when thrown to his cattle, often shows such unsatisfactory results. Stock cannot consume enough of such forage to supply themselves with the nourishment required.

243. Distribution of nutrients in the plant.-The proportion of nutrients in the several parts of the corn plant has been studied at several Stations with interesting results. Armsby, ${ }^{1}$ studying the returns of corn crops at four Stations, reports the following yields of ears and stover:

Station.

New Jersey (Dent)

Connecticut (Flint)

Wisconsin (Dent)

Pennsylvania (Dent).........

$$
\text { Average ............. } \overline{4,415 \mathrm{lbs} .}
$$

Ears.

$4,774 \mathrm{lbs}$.

4,216 lbs.

$4,941 \mathrm{lbs}$.

$3,727 \mathrm{lbs}$.
Stover. $4,041 \mathrm{lbs}$. $4,360 \mathrm{lbs}$. $4,490 \mathrm{lbs}$. $2,460 \mathrm{lbs}$.

3,838 lbs.

We learn from the above that somewhat more than one-half the total weight of the corn crop, grown for grain, is found in the ears.

Concerning the nutrients in corn Armsby gives the following: Digestible nutrients in one acre of corn and stover-average of crop at four Stations.

\begin{tabular}{|c|c|c|c|}
\hline Digestible nutrients. & Earg. & Stover. & Total crop. \\
\hline & Lbs. & Lbs. & Lbs. \\
\hline Protein & 244 & & 327 \\
\hline Carbohydrates......................................... & 2,301 & 1,473 & 3,774 \\
\hline Fther extract.................................. & & & 147 \\
\hline Total ................................................ & 2,670 & 1,578 & 4,248 \\
\hline Per cent......................................... & 63 & 37 & 100 \\
\hline
\end{tabular}

We learn that 37 per cent. of the total digestible nutrients in a crop of corn grown for the grain is in the stover and 63 per cent. in the ears.

\footnotetext{
1 Rept. Penn. Sta., 1887.
} 
244. The corn plant under Maryland conditions. - At the Maryland Station' 1 Patterson stadied the nutrients of the corn crop of that region with the following results:

Field per acro of digestible nutrients in different portions of the corn plant - Maryland Station.

\begin{tabular}{|c|c|c|c|c|c|c|}
\hline Parts. & Ash. & $\begin{array}{l}\text { Pro- } \\
\text { tein. }\end{array}$ & $\begin{array}{l}\text { Crude } \\
\text { fiber. }\end{array}$ & $\begin{array}{l}\text { Nitrogen- } \\
\text { free extract. }\end{array}$ & $\begin{array}{l}\text { Ether } \\
\text { extract. }\end{array}$ & $\begin{array}{l}\text { Total dry } \\
\text { substance. }\end{array}$ \\
\hline Ears ......... & $\begin{array}{c}\text { Lbs. } \\
\text {........... }\end{array}$ & $\begin{array}{l}\text { Lbs. } \\
157\end{array}$ & $\begin{array}{l}\text { Lbs. } \\
\qquad 13\end{array}$ & Lbs. & $\begin{array}{c}\text { Lbs. } \\
\mathbf{3 0}\end{array}$ & $\begin{array}{l}\text { Lbs. } \\
1,530\end{array}$ \\
\hline 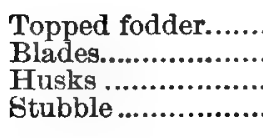 & $\begin{array}{r}5 \\
14 \\
4 \\
5\end{array}$ & $\begin{array}{r}10 \\
6 \\
6 \\
6\end{array}$ & $\begin{array}{r}190 \\
88 \\
168 \\
241\end{array}$ & $\begin{array}{l}232 \\
105 \\
246 \\
304\end{array}$ & $\begin{array}{r}13 \\
4 \\
2 \\
13\end{array}$ & $\begin{array}{l}450 \\
197 \\
426 \\
569\end{array}$ \\
\hline
\end{tabular}

We learn that for Maryland conditions 48 per cent. of the digestible matter appears in the ear and 52 per cent. in various portions of the stover.

245. What the corn plant yields in Georgia. - At the Georgia Station, ${ }^{2}$ Redding, working out results for his region, reports:

Digestible nutrients in each portion of the corn plant-Georgia Station.

\begin{tabular}{|c|c|c|}
\hline \multirow{2}{*}{ Parts. } & \multicolumn{2}{|c|}{ Per. Acre. } \\
\hline & Protein. & $\begin{array}{l}\text { Nitrogen-free } \\
\text { extract.* }\end{array}$ \\
\hline & Lbs. & Lbs. \\
\hline 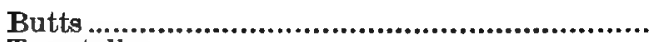 & 8.0 & 485.0 \\
\hline Top stalks...................................................... & 3.9 & 95.4 \\
\hline 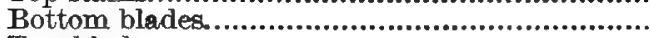 & 5.9 & 106.2 \\
\hline Top blades....................................................... & 3.5 & 68.7 \\
\hline 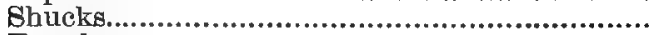 & 7.4 & 198.8 \\
\hline Tagsels...................................................... & 1.1 & 20.3 \\
\hline Grain & 159.0 & $1,604.0$ \\
\hline 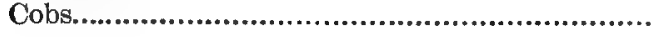 & 9.0 & 249.0 \\
\hline
\end{tabular}

* Including fat $\times 2.27$.

By the above we learn that abont two-thirds of the value of the corn crop of Georgia is found in the ears, the results corroborating Armsby's statement.

\footnotetext{
1 Bul. $20 . \quad 2$ Bul. 30.
} 
246. Losses in field curing.- Since corn forage gathered into shocks (stooks) presents a considerable surface to the weather, losses must occar through washing by rains and wasting of the leaves by the wifid. It has been found, however, that larger losses occur in shock corn than is possible from this canse alone.

At the Wisconsin Station, Woll ${ }^{1}$ determined the dry matter and protein in a crop of corn when it was cut and shocked, and again after the shocks had cured and been exposed to the weather for several months. The investigation extended over four years, with the results given in the table:

Losses of shock corn in field - Wisconsin Station.

\begin{tabular}{|c|c|c|c|c|}
\hline \multirow[t]{2}{*}{ - } & \multirow{2}{*}{$\begin{array}{c}\begin{array}{c}\text { Green } \\
\text { fodder. }\end{array} \\
\text { Lbs. }\end{array}$} & \multirow{2}{*}{$\begin{array}{r}\begin{array}{r}\text { Cured } \\
\text { fodder. }\end{array} \\
\text { Lbs. }\end{array}$} & \multicolumn{2}{|c|}{ Loss. } \\
\hline & & & Lbs. & Per cent \\
\hline Average for two varieties, total weight. & 129,014 & 31,738 & & \\
\hline 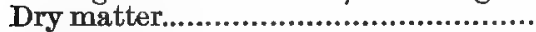 & 32,432 & 23,270 & 9,162 & 28.3 \\
\hline 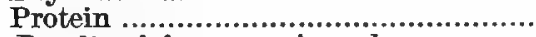 & 2,581 & 1,682 & 899 & 34.8 \\
\hline $\begin{array}{l}\text { Results of four years work. } \\
\text { Dry matter......................... }\end{array}$ & 72,164 & 54,937 & 17.227 & 23.8 \\
\hline Protein ........................................... & 5,706 & 4,317 & 1,389 & 24.3 \\
\hline
\end{tabular}

We are told of a loss of nearly one-fourth of dry matter and protein which the crop contained at harvest time by preserving corn forage in the usual manner. This seems incredible, but the subject has been studied by too many Stations with unanimity of results to admit of further question. Cooke ${ }^{2}$ has shown that heary losses occur in shock corn in the dry climate of Colorado. The substances lost through wasting are protein and nitrogen-free extract (sugar, starch, etc.), the more valuable portions of the forage. Nor is it possible to entirely prevent these losses by placing the cured fodder under shelter or in the stack, for it has been found that the forage continues to waste even under these favorable conditions.

At this time we are unable to state through what instrumentality all these losses are brought about. Some substance is washed away by rain, and the winds carry off exposed leaves and parts of the stalks on the outside of the shocks, but these sources of loss

\footnotetext{
1 A Book on Silage.

2 Bul. 30, Colo. Expt. Sta.
} 
are not sufficient to account for all the shortage. Probably fermentations are slowly but steadily wasting the substance of the forage.

In view of these facts, when calculating the value of a crop of corn forage, a deduction should be made from its worth at harvest time for its reduced value at feeding time, if the latter occurs some months after harvest.

247. Fodder corn for soiling.-Feeding corn in the green stage should become a general practice upon most farms, for the reason that, during the fall, pastures are often scanty, and if forced to subsist entirely upon them animals cannot do their best. It will be found that an acre of corn fed while green, if quite well matured, may so advance the condition of steers, dairy cows or other stock as to yield a double value over what it would if saved until winter and fed out at a time when there is often a plethora of the same material.

248. Shocking (stooking) corn.-- The process of shocking corn is too well understood to need description. The loss from weathering can be much reduced by making larger shocks than are commonly found, and exercising care in their construction. In the shock the corn stalks stand almost vertical, and if the shock be not bound too tightly there is room enough when the stalks wilt to admit currents of air which pass from below upward and out. Such currents carry off the moisture and dry the interior portion of the shock, without allowing mould to work injury to the drying material. No simple system of preservation can be more perfect for the end in view than that which we find in the common method of harvesting corn forage by standing the stalks upright in closely-bound bunches. When shock corn is pronounced dry by the farmer, it still carries a much larger percentage of water than does hay, as we learn from the table. This fact should not be overlooked when considering the amount of material required for nourishing farm animals.

249. Feeding shock corn. - In districts where corn is grown for the grain and put into shocks, farmers not infrequently follow the practice of separating the corn from the stover by husking. For steer feeding there seems no valid reason for the extra expense 
incurred by the operation, for the steers can as well perform the work. The same statement holds true in some measure for dairy cows. An ear of corn with the husks still about it possesses an aroma which is largely lost when it is thrown into the crib, where it is often polluted by vermin. That cattle appreciate the freshness of unhusked corn is shown by the eagerness with which they search the stalks for ears. Whoever has watched a cow searching through a bundle of stover for a possible ear or nubbin of corn which the would-be thrifty farmer has by accident overlooked, cannot fail to be impressed with the folly of the farmer in so carefully performing his work. It is true that when fed in this manner some corn will pass through the animal unbroken, but feeding trials have shown that despite such waste there is usually profit in the system over that of husking and reducing the corn to meal. A part of the corn can be husked to furnish grain for other parposes, and the remainder of the crop left for the cattle. By a little study to ascertain the amount of grain the shocks carry, the feeder can soon adjust the supply of corn to forage so as to give each animal its proper allowance of grain along with the fodder. Becanse one's ancestors laboriously husked corn and afterwards divided the crop with the miller for grinding is no reason why in these later days of high-priced labor and lowpriced products we should still be hnsking corn for cattle, when these animals have all day in which to do the work and willingly perform it. (581)

250. Cured fodder corn.- Corn grown and cured for forage constitutes a coarse hay of high feeding value produced at low cost. Because only a portion of the nutriment has gone into the ear, the stalks of fodder corn are more nutritions and palatable than stover, which has lost much of its substance to the grain it produced.

In feeding fodder corn to horses care should be taken that they do not get too much grain; otherwise there is no better forage for them. Corn fodder, in which the ears have been choked to half or less than half their normal size by thick planting, is one of the most valuable forms of roughage for dairy cows, steers in the first stages of fattening, and young cattle. All the corn these animals 
require can be supplied them unhusked, in which form there is no labor or expense for husking and grinding. The ears of thicklygrown fodder corn are small, palatable and easily masticated. When corn fodder is fed to cattle they should be allowed ample time to work it over before cleaning out the mangers or feed racks.

The Indian corn plant grown for hay, and carrying more or less grain, according to requirements, possesses a value not fully appreciated by stockmen generally. We have become so accustomed to growing this grass for the grain it yields and using the roughage as a sort of straw, to be eaten or wasted as accident determines, that we have almost wholly overlooked its hay-making qualities. (652)

251. Corn stover.-The forage which remains after removing the ear has a higher feeding value than is usually ascribed to it. For idle horses and growing colts corn stover may be used in winter with advantage. This forage is now commonly fed to dairy cows, and experience attests its value. By running stover through the shredder or feed cutter the proportion readily eaten by cattle may be materially increased. (653)

252. "Pulling" fodder.-At the South the custom prevails of stripping the leaves from the corn stalk while still green and curing them into a nutritious form of hay. Stubbs, of the Louisiana Station, " found that "pulling" fodder from the stalks of corn cansed a shrinkage in the yield of grain of from fifteen to twenty per cent. Redding, at the Georgia Station, ${ }^{2}$ after investigating the subject, writes: "The strongest argument against the practice is the meager results of fodder compared with the amount of labor involved. The same labor employed in mowing grass or any good forage crop, even without the use of improved harvesting machinery, would yield vastly greater results." Stock-growing at the South will never attain the dignity the situation merits until the custom of "pulling" corn leaves is abandoned and the planters address themselves to intelligent modern methods of coltivating and harvesting the many valuable forage plants which can be grown in that region.

1 Bul. 22; see also Bul. 104, N. C. Sta.

2 Bul. 10. 
253. A new corn product.-The pith of the corn stalk furnishes a packing for the walls of vessels which will prevent the entrance of water into the ship when the hull is pierced. It is found that for each pound of suitable pith there are fifteen pounds of blades, husks and stalks remaining as waste or by-products. It is proposed to grind this waste into a meal for stock feeding. At the Maryland Station, 1 Patterson found this new food substance more digestible than whole fodder, in feeding trials with steers, and quite satisfactory in comparison with corn blades. Cows and steers fed corn-stalk meal ruminated as naturally as if feeding on hay.

254. The so-called corn-stalk disease. - In the central corn districts the common practice is to remove the ears of corn from the standing stalks and turn cattle into the stalk fields to gather the ears left by the huskers and consume what they will of the roughage. Not infrequently, within a day or two after turning the cattle into the fields, they suddenly sicken and die. Thousands of cattle are lost each fall in this way, and the subject has attracted much attention and elicited several theories as to the cause. Moore ${ }^{2}$ concludes that the disease is probably due to some poisonous principle in the dried corn stalk or its leaves. Without being able to name a remedy, he prudently points a way by which all danger from this source can be avoided. He calls attention to the fact that the corn-stalk disease never attacks cattle fed shock corn or corn stover. He recommends that the stockman shock at least a portion of his corn crop and feed this to his cattle instead of turning them into the stalk fields. Possibly, too, if stockmen will feed shock corn to their cattle for a few days or weeks previous to turning them into the stalk fields, the danger may be averted, since by this practice the animals will become accustomed to this form of feed.

255. Corn smut.-Besides the direct losses caused by corn smut, it has frequently been charged that the smut masses are poisonous to cattle eating them. To settle this important matter, a number of experiments have been conducted in which the smut was fed to cattle and the effects noted.

1 Bul. 43 .

2 Bul. 10, Bur. of An. Ind., U. S. Dept. Agr; see also Bul. 58, Kan. Sta. 
The first trial reported is that by Gamgee, ${ }^{1}$ in which forty-two pounds of corn smut were fed to two cows without ill effects.

At the Wisconsin University ${ }^{2}$ the writer conducted a smatfeeding experiment with two milch cows in the following manner: Clean smut was fed with bran, only a few ounces being daily given at first, the allowance being increased as rapidly as the cows would consume it. When the quantity fed reached thirty-two ounces daily for each cow, one of them refused to eat the feed containing the smut, and the experiment with her was closed. The other cow seemed greedy for this substance, and the allowance was increased until sixty-four onnces, an amount which filled a peck measure, was fed. For a time the cow seemed to thrive on the smut and was growing fat, but was suddenly taken sick and died within a few hours after the trouble was first observed. A post-mortem examination revealed no certain cause of the fatality.

At the Michigan Station ${ }^{3}$ Smith fed corn smut to four cows, the maximum daily allowance reaching eleven pounds of fairly well cleaned smut per cow. Ten pounds of such smut filled a half bushel measure. When eating eleven pounds of smut daily, one cow showed indisposition for a time, but soon returned to normal health.

In experiments by the Burean of Animal Industry, ${ }^{4}$ U. S. Department of Agriculture, Washington, corn smut was fed to heifers without ill effects. With all the trials but one ending without disaster, it seems reasonable to conclude that corn smut is at least not a virulent poison, if indeed it is one in any sense of the word. It is probable that in the Wisconsin and Michigar cases, where one cow died and the other was indisposed, the animals suffered because of eating too much highly nitrogenous material rather than anything poisonous. Worse results might have followed the feeding of the same volume of corn meal or cotton-seed meal. It would seem that there is little or no danger from corn smut unless cattle consume a large quantity. This is possible where they are allowed to roam through stalk fields and

1 Rept. Diseases of Cattle, U. S. Dept. of Agr., Washington, 1871.

2 Rept. Bd. Regents, 1881.

Bul. 137.

- Bul. 10. 
gather what they will. There may be cases where animals seek out the smut and eat inordinately of it.

256. Fertilizing constituents. - The table shows that corn fodder carries a fair amount of nitrogen, percentagely. Because of the large tonnage, the crop takes from the land a considerable quantity of this element. Stover is quite rich in potash.

On the whole, the corn crop in any form must be regarded as a carbohydrate crop and utilized on that basis. Its complement in feeding is clover or some legume, and these latter plants should always be grown on the same farm in order to keep the fields in good fertility as well as furnish the stock nitrogen and mineral matter, in which corn is somewhat deficient. 


\section{CHAPTER XI}

THE GRASSES, FRESH AND OURED - STRAW.

\section{Grass for Pasture and Soiling.}

Digestible nutrients and fertilizing constituents.

\begin{tabular}{|c|c|c|c|c|c|c|c|}
\hline \multirow[b]{2}{*}{ Name of feed. } & \multirow{2}{*}{$\begin{array}{c}\text { Dry } \\
\text { matter } \\
\text { 1n } 100 \\
\text { pounds. }\end{array}$} & \multicolumn{3}{|c|}{$\begin{array}{l}\text { Digestible nutrient. } \\
\text { in } 100 \text { pounds. }\end{array}$} & \multicolumn{3}{|c|}{$\begin{array}{l}\text { Fertilizing constitu } \\
\text { ents in } 1,0 \% \text { pounda }\end{array}$} \\
\hline & & $\begin{array}{l}\text { Pro- } \\
\text { tein. }\end{array}$ & $\begin{array}{l}\text { Carbo- } \\
\text { hy- } \\
\text { drates. }\end{array}$ & $\begin{array}{l}\text { Ether } \\
\text { ex- } \\
\text { tract. }\end{array}$ & $\begin{array}{l}\text { Nitro- } \\
\text { gen. }\end{array}$ & $\begin{array}{c}\text { Phos- } \\
\text { phoric } \\
\text { acld. }\end{array}$ & $\begin{array}{l}\text { Pot- } \\
\text { 2sh. }\end{array}$ \\
\hline & Lbs. & Lbs. & Lbs. & Lbs. & Lbs. & Lbs. & i.bs. \\
\hline $\begin{array}{c}\text { Crass. } \\
\text { Pasture grasses (mixed) ... }\end{array}$ & 20.0 & 2.6 & 10.2 & 0.5 & 9.1 & 2.3 & 7.5 \\
\hline Kentucky blue grass.......... & 34.9 & 3.0 & 19.8 & 0.8 & & & \\
\hline Timothy, different stages.. & 38.4 & 1.2 & 19.1 & 0.6 & 4.8 & 2.6 & 7.6 \\
\hline Orchard grass, in bloom... & 27.0 & 1.5 & 11.4 & 0.5 & 4.3 & 1.6 & \\
\hline Redtop, in bloom ............... & 34.7 & 2.1 & 21.2 & 0.6 & & & \\
\hline Oat fodder.................. & 37.8 & 2.6 & 18.9 & 1.0 & 4.9 & 1.3 & 3 \\
\hline Rye fodder ............. & 23.4 & 2.1 & 14.1 & 0.4 & 3.3 & 1.5 & \\
\hline Sorghum ................ & 20.6 & 0.6 & 12.2 & 0.4 & 2.3 & 0.9 & \\
\hline Timothy................ & 86.8 & 2.8 & 43.4 & 1.4 & 12.6 & 5.3 & \\
\hline Orchard gras & 90.1 & 4.9 & 42.3 & 1.4 & 13.1 & 4.1 & 18 \\
\hline Redtop ....................... & 01.1 & 4.8 & 46.9 & 1.0 & 11.5 & 3.6 & 10 \\
\hline Kentucky blue grass... & 78.8 & 4.8 & 37.3 & 2.0 & 11.9 & 4.0 & 15 \\
\hline Hungarian grass.......... & 92.3 & 4.5 & 51.7 & 1. & 12.0 & 3.5 & 13 \\
\hline Mixed grasses................. & 87.1 & 5.9 & 40.9 & 1.2 & 14.1 & 2.7 & 15 \\
\hline 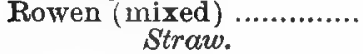 & 83.4 & 7.9 & 40.1 & 1.5 & 16.1 & 4.3 & 14 \\
\hline Wheat................ & 90.4 & 0.4 & 36.3 & 0.4 & 5.9 & 1.2 & 5.1 \\
\hline Rye & 92.9 & 0.6 & 40 . & 0.4 & 4.6 & 2.8 & 7 \\
\hline Oat. & 90.8 & 1.2 & 38.6 & 0.8 & 6.2 & 2.0 & $1 \cdot 3$ \\
\hline Barley .............. & 85.8 & 0.7 & 41.2 & 0.6 & 13.1 & 3.0 & 20.9 \\
\hline Wheat chaff...... & 85.7 & 0.3 & 23.3 & 0.5 & 7.9 & 7.0 & 4.2 \\
\hline Oat chaff .................... & 85.7 & 1.5 & 33.0 & 0.7 & & & \\
\hline
\end{tabular}

257. Concerning pastures. - The time for turning stock to pasture is hailed with delight by stockmen, for it means exercise and outdoor life to animals long confined in quarters which at best are not as satisfactory as those afforded by the change. It means dropping a large part of the "chores" which bind together with a cord of duty all the daylight hours of winter. With the live stock caring for themselves in the pasture comes the opt at!nity 
for sowing the seed and gathering the harvest from which provender for the next season is to come.

It is a fact which cannot escape the attention of stadents of agricultural economics, that our stockmen rely too blindly upon pastures for the maintenance of their cattle during half the year. But a few centuries ago the inhabitants of Great Britain trusted to the growth of natural herbage for the support of their stock not only in summer but throughout the entire year. If their animals, foraging for themselves as best they could, survived the winter, all was well; if they died from starvation, it was an "act of God." We have abandoned the crude practices of our ancestors, and now carefully store in barns abundance of provender for feeding flocks and herds during winter's rigor. We are amazed that our ancestors were so improvident as to gather no winter feed for their cattle, while for ours great barns are built and stored with provender. By turning cattle to pasture in spring and letting them forage as best they may until winter we show that all the barbaric blood has not yet been eliminated from our veins. If the summer rains are timely and abundant, the cattle are well nourished on these pastures; if drought prevails they suffer for food as surely, and often as severely, as did the live stock of England in winter, ages ago. To suffering from scant food there is added the heat of "dog days" and the ever-present annoyance of blood-sucking flies. Our stockmen will never be worthy of their calling, nor their flocks and herds yield their best returns, until ample provision is made against drought-ruined pastures in summer. Every argument which stands in favor of storing provender for stock in winter holds with equal force for providing i feed to make good any possible shortage of pastures in summer.

258. Yields of pasture grass. - At the Pennsylvania Station, ${ }^{1}$ Holter studied the yield of a pasture consisting of blue grass and white clover. By means of a lawn mower with attachment the grass as cut was gathered, with the following yields per acre:

${ }^{1}$ Rept. 1889. 
Yield of pasture grass per acre from May 1 to Oct. 15 inclusivePennsylvania Station.

\begin{tabular}{|c|c|c|}
\hline & $\begin{array}{c}\text { Total } \\
\text { substance. }\end{array}$ & $\begin{array}{c}\text { Digestible } \\
\text { matter. }\end{array}$ \\
\hline & Lbs. & Lbs. \\
\hline 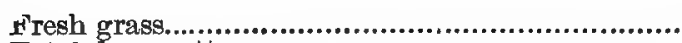 & 5,720 & \\
\hline 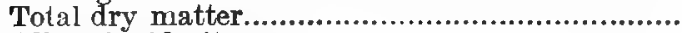 & 1,613 & $1,19 n$ \\
\hline Albuminoid nitrogen........................................ & 331 & 249 \\
\hline Non-albuminoid nitrogen ................................. & 45 & 45 \\
\hline 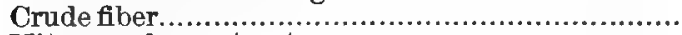 & 300 & 226 \\
\hline 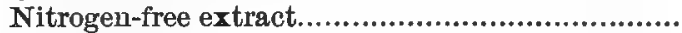 & 706 & 534 \\
\hline Ether extract ........................................................ & 94 & 70 \\
\hline 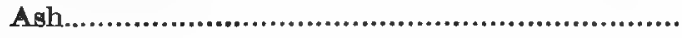 & 136 & 65 \\
\hline
\end{tabular}

At the Michigan Station, 1 Crozier cut the growing timothy from a plat of grass eight times during the scason, while on another plat of the same area the timothy was allowed to make full growth and was then cut for hay. It was found that the yield of dry matter in the hay was about four times that of the grass which was cut eight times. The per cent. of protein in the grass cut eight times was about three times that in the once-cut grass. This experiment shows that our pastures in their short herbage yield a much higher proportion of muscle-making nutrients than is obtained from grasses which are allowed to mature, but that much the largest returns are secured by allowing them to ripen. (554.)

259. Changes in grass during ripening. - At the Mllinois Station, ${ }^{2}$ Hunt studied the effects of maturity on the yield and composition of several forage plants. Timothy was examined at four periods covering about one month in all, beginning June 25, when the plants were in full bloow. The yield of hay and the total nutrients per acre for each of the four periods are given in the table at the end of this Article.

It will be seen that, on the whole, there was a steady increase in the weight of the crop as the plants progressed toward maturity. We observe only a slight increase in the total protein content after the first cutting. Between the first and last cuttings the crude fiber increased more than 300 pounds and the nitrogen-free extract more than 350 pounds, while the ether extract was reduced in total quantity as ripening progressed. It appears, then, in this

\footnotetext{
${ }^{1}$ Bul. $141 . \quad 2$ Bul. 5.
} 
study, that aside from protein, the timothy plant had not elaborated its full complement of nutrients at the-time of blossoming, and to secure the largest total quantity of nutrients in the hay wo must wait until the seeds of this grass are nearly ripe. By so doing we gain no protein or ether extract, but a very considerable quantity of crude fiber, which is of low feeding value, and still more nitrogen-free extract, which is an important addition.

Field of hay and nutrients from timothy at four periods of growthIllinois Station.

\begin{tabular}{|c|c|c|c|c|c|c|c|}
\hline \multirow[b]{2}{*}{ Date. } & \multirow{2}{*}{$\begin{array}{l}\text { Stage of develop- } \\
\text { ment. }\end{array}$} & \multirow{2}{*}{$\begin{array}{l}\text { Hay } \\
\text { per } \\
\text { acre. }\end{array}$} & \multicolumn{5}{|c|}{ Total nutrients per acre. } \\
\hline & & & $\begin{array}{l}\text { Pro- } \\
\text { tein. }\end{array}$ & $\begin{array}{l}\text { Crude } \\
\text { fiber. }\end{array}$ & $\begin{array}{l}\text { Nitrogen- } \\
\text { free } \\
\text { extract. }\end{array}$ & $\begin{array}{c}\text { Ether } \\
\text { extract. }\end{array}$ & Ash. \\
\hline & & Lbs. & Lbs. & Lbs. & Lbs. & Lbs. & Lbs. \\
\hline June 25 & Full bloom.......... & 4,480 & 240 & 1,056 & 1,602 & 165 & 224 \\
\hline July 2 & $\begin{array}{l}\text { One-half anthers } \\
\text { shed .................. }\end{array}$ & 4,320 & 225 & 1,155 & 1,663 & 152 & 228 \\
\hline July 11 & Seed in dough.... & 5,240 & 246 & 1,380 & 1,960 & 153 & 273 \\
\hline July 23 & Seed nearly ripe.. & 5,180 & 253 & 1,377 & 2,058 & 137 & 239 \\
\hline
\end{tabular}

260. Time to cut grass for hay.-Generally the admonitions are for early cutting, and where there is much hay to be gathered, work should certainly begin early in order that it be completed before the grass seeds are so ripe as to shell from the heads of the late-cut grass. Early-cut hay seems more palatable to stock, and, pound for pound, more satisfactory. On the other hand, we can secure a considerably larger quantity of the carbohydrates by delaying the harvest until the grass seeds are fully formed. In the increase of nutrients in the timothy plant up to a late period, we have a repetition of what occurs in that other grass, the Indian corn plant, in the study of which we have learned that the storage of nutrients continues up to the last stage of ripening. (241)

For the dairy cow and sheep grass should be cut early, since these animals do not relish hay that is woody and lacking in aroma, as is the case with late-cut hay. For horses and fattening cattle the choice of dates for cutting probably falls the other way, being in favor of later cutting. These animals subsist mostly on concentrated feed, and hay serves wore for "filling," as horsemen 
eay. If harvesting is delayed too long, the stems of the grasses are tough and stringy, and the seeds shatter from the heads. Such hay has little aroma and lacks palatability, if not nutrients.

Sanborn ${ }^{1}$ conducted trials with early- and late- cut hay for fattening steers, and found that the late-cut hay gave the best returns. The writer, in an unpublished experiment conducted several years since, reached the same result.

261. Points in hay making. - Important as is the subject of hay making, there is not much of a definite character that can be written concerning it. The widely varying nature of the crops to be converted into hay, the dampness or dryness of the soil of the meadows, the bumidity of the atmosphere, and the intensity and continuance of sunlight and heat, are all molifying factors in this problem and combine to keep it one of those arts which cannot be definitely discussed in books. Some points of interest and possible importance will be here considered. We have drawn largely from Storer, ${ }^{2}$ whose classic work on agriculture should be read by all.

262. The aroma of hay.- Though an unweighable quantity, the aroma of grass has real value in rendering hay more palatable. When the sun dissipates the dew from the drying grass in the meadow we detect the escaping aroma, because the dew in rising carries some of it into the atmosphere. Here is one reason wlyy hay should not remain scattered over the meadow at night. If new-mown hay lies for a time in the sunlight, the bleaching which we observe indicates that chemical changes are taking place within the grass stems and leares, and such changes are not of advantage. Green-colored, sweet-sinelling hay is really the best, and prudent stockmen in securing provender will not overlook such seemingly small points as preserving the aroma and preventing bleaching.

263. Changes during hay curing. - Grass stems remain alive, in a certaiu sense, for some time after they have been severed by the mower, and the leaves while succulent and green continue to exhale moisture in a natural way. If grasses whose leaves are still fresh are gathered into bundles so the leaves are not at once

1 Rept. New Hamp. Bd. Agr., 1880.

2 Agriculture in Some of ita Relations with Chemistry. 
withered, the leaves will continue to draw water from the stems, and in so doing rid them of moisture and hasten the drying grass toward the condition of hay. In this fact we have an explanition of one of the advantages obtained in curing grass in cocks or bundles rather than by spreading it out thinly in the hot sun. Hay which is cocked in the afternoon entraps much warm air, $i$ and the mass remains in a condition favorable to the transpiration of moisture during the night. The heat yielded by the plant in carrying on its life fumctions, and the warm air entrapped by grass gathered in the afternoon, should not be confused with that which may develop in partially cured or damp hay through fermentation. When hay that has been cocked for a time is exposed to the air in flakes, the moisture which has been diffused evenly through the mass is yielded up rapidly and such material is soon dried. While hay can be made without going through the sweating process in the cock, it is usually much better because of having undergone such action. Hay put into the barn when it is so dry that it will not pack well is not in first-class condition. It should be mowed away with just that amount of moisture which allows it to settle compactly when treaded down.

264. Treatment of hay. - Salt and lime scattered over hay when it is put into the mow tend to prevent fermentation and check the growth of molds and mildews. Salt renders hay more palatable. These materials are not essentials in hay making, but are helpful when partially cured hay is being stored during bad weather. Damp hay may be improved by placing it in alternate layers with dry straw; the straw absorbs moisture from the hay and so improves in quality. It also imbibes some of its aroma, so that cattle will more readily eat both straw and hay.

Hay from the second-growth grasses or aftermath is rich in nutrients, but it comes at a time when the ground is often damp, the days short and the sun's heat weak. This unfortunate combination renders the curing of aftermath into hay difficult and the product usually of less value than first-crop hay. Cured under favorable conditions, aftermath hay is an excellent article for winter feeding.

Now-marle bay is laxative, and should not be fed to work norses or driving horses, since their flesh becomes soft throngh its 
use. Not until the sweating process has been completed in the mow and the mass cooled off can new-crop hay be safely fed.

265. Dried versus green grass. - At the Pennsylvania Station, 1 Armsby tested dried and fresh grass for cows in the following manner: Short grass on the college lawn, cut with a lawn-mower, was divided into two portions, one of which was fed in the fresh stage to a cow, the other half being dried over a steam boiler and fed in turn to the same cow.

This investigator had previously conducted an experiment at the Wisconsin Station in which grass from nine to ten inches in height was used. Here half the grass was fed fresh, and the other half, cut at the same time, was dried in the sun and fed to the same cow. The yield of milk and butter-fat in these tests was as follows:

Daily yield of milk and fat with cows fed green and dried grassPennsylvania and Wisconsin Stations.

\begin{tabular}{|c|c|c|c|c|}
\hline \multirow{2}{*}{ Station. } & \multicolumn{2}{|c|}{ Green grass. } & \multicolumn{2}{|c|}{ Dried grass. } \\
\hline & Milk. & Fat. & Milk. & Fat. \\
\hline & Labs. & Lbs. & Lbs. & Lbs. \\
\hline 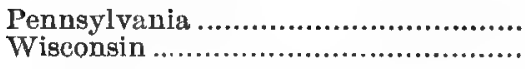 & $\begin{array}{l}26.01 \\
16.98\end{array}$ & $\begin{array}{r}1.08 \\
.92\end{array}$ & $\begin{array}{l}25.27 \\
17.81\end{array}$ & $\begin{array}{l}1.06 \\
1.00\end{array}$ \\
\hline 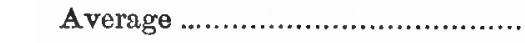 & 21.5 & 1.00 & 21.54 & 1.03 \\
\hline
\end{tabular}

These results are practically equal, showing that grass when dried in the best possible manner yields as much nutriment as will the same grass when fresh. In practice it is impossible to dry grass or other forage plants in such a manner that the product will equal the same plants in a fresh condition. In hay-making more or less of the finer portions of the forage plants are broken off and lost. Again, continued exposure of plants to the sun reduces their palatability by bleaching and the loss of aromatic compounds. Dew works injury, and rain carries away the more soluble portions. Thus, while dried forage may theoretically equal the fresh substance, in practice it falls short, the difference in value being determined by the circumstances controlling the harvest.

${ }^{1}$ Rept. 1888. 
266. Losses due to weathering. - Stöckhardt ${ }^{1}$ cured one sample of meadow hay in three days and left another in the field for thirteen days in alternate wet and dry weather. Analysis showed that the weathered hay lost 12.5 per cent. of its total dry substance, representing one-fourth of its original nutritive value. Märcker ${ }^{2}$ calculated the loss of meadow-hay exposed throngh a ' prolonged and heavy rain as 18.4 and $\mathbf{1 7 . 6}$ per cent. of the dry substance. This heavy withdrawal of the soluble portion of the hay leaves more woody fiber and indigestible matter proportionately, which renders the hay more difficult of digestion. Then, too, the aroma of forage will be dissipated by exposure.

\section{The Common Grass Plants for Pasture and Soiling.}

267. Kentucky blue grass.- This grass, often called "June grass," is found everywhere in the Northeastern states. By its persistence it often drives out red clover and timothy as meadow crops, and holds in pastures, open woodlands and roadsides against all other claimants. As shown by the table, this grass is the richest in digestible protein and ether extract of any in the list, a finding borne out by the experience of stockmen. The characteristics of Kentucky blue grass exhibited in its habits of growth should be understood by the stockman to guide him in wisely using it. Because its seed ripens with the commencement of summer, Kentucky blue grass prepares for that event by gathering much of the nutriment necessary in seed production the preceding fall. With the coming of spring it pushes forward vigorously, and early in May the fields are covered with a dense carpet of nutritious grass. With the shooting of the grass stems for seedbearing the last of May, the energies of the plant reach their culinination and there is a cessation of growth. The blue grass has entered a period of rest, and for a few months there is little evidence of life. If at this time drought occurs, the pastures turn brown and the plants appear to be dead or dying. With the coming of the fall rains all is changed and a green carpet again covers the pastures. The blue-grass plauts have passed the resting period and are again gathering nourishment for tho dext summer's seed bearing.

1 Wolff, Farm Foods, English edition, p. $155 . \quad 2$ Loc. cit. 
The prident stockuan, recomnizing these habits of growth, with alternate abundance and scarcity in food supply, realizes that he must not rely entirely upon blue-grass pasture for a uniform supply of nutriment for his cattle throughont the whole season. He stocks the pastures lightly in spring so that the overplus herbage of May and June may remain to be drawn upon during the dormant period of midsummer, or, stocking his pastures more heavily, he anticipates the midsummer shortage by providiug a liberal sipply of silage, green clover, green corn, or other forage crops. Inowing the characteristics of his pastures and acting upon this knowledge, his stock suffers little or no loss from the usual midsummer shortage, but grows steadily throughout the season.

Kentucky blue grass is primarily a pasture grass and should always be regarded as such. The small yield of hay from this grass is of fair quality both as to protein and carbohydrates, while it is quite rich in ether extract.

268. Timothy or herd's grass. - This common hay plant of the Northeastern states is successfully grown as far west as Nebraska, and Sanborn reports large yields at the Utah Station. ${ }^{1}$ Analysis shows that timothy hay varies in composition, especially in protein, according to the soil on which it is grown and the amount and character of the fertilizers used. Soils enriched by manure yield hay carrying more protein than is found in that produced on lands of low fertility. With its stiff, woody stems and few leaves the timothy plant cures rapidly into hay. Its characteristic appearance, which easily distinguishes it from the hay of other species, adds to its commercial value. Timothy seeds are large and easily recognized, and as they are produced in abumdance and hold their vitality well, they aid this grass in holding favor with the farmer. Timothy bay is ustally free from dust, is clean and rarely attacked by molds. It is relished by horses which secure most of their nourishment from oats or other grain. All these qualities combine to render hay from the timothy plant a favorite with both grower and buyer.

While timothy meets quite fully the demands of city conditions, it should not occupy an important place on well-managed

\footnotetext{
${ }^{1}$ Rept. 1892.
} 
stock farms, for the yield of forage is too small to warrant adherence to this crop alone for farm-horse feed. Fodder corn, hay from the cereals, and bright straw are substitutes that may be fed with economy and satisfaction to all horses not required for road work.

Timothy meadows afford but little aftermath, and if pastured at all closely this grass is easily destroyed. Red clover should be grown with timothy, if possible, for the combination furnishes a superior hay both in quantity and quality for many purposes. When grown together, the hay produced the first season after seeding will consist largely of clover. Many of the clover roots die at the end of this season, and the nutriment from these nourishes the timothy plants, which spring into ascendency the second season, yielding a hay in which clover forms the smaller portion. (478)

269. Orchard grass. - This grass starts very early in the spring and ripens abont two weeks in advance of timothy. For this reason it associates well with red clover. Hay from orchard grass is inclined to be harsh, woody and lacking in aroma, and is not particularly relished by stock. These defects can be partially overcome by cutting the grass very early. Orchard grass does not form an even, dense sod, but grows in tufts or tussocks, for which reason it should not be sown alone, but with other grasses and with clovers. Mixed with other grasses, orchard grass serves a useful purpose in pastures, and under favorable conditions will hold its own indefinitely.

Tracy, of the Mississippi Station, ${ }^{1}$ reports orchard gxass as making a better winter growth on heavy clay soils than any other species tested. In that region it commences growth in February and yields hay in May.

270. Redtop.-This widely disseminated grass of several species is especially valuable on damp, low lands, where it forms a close turf, furnishing excellent pasture and a valuable hay, composed of fine stems and rather numerous leaves. Redtop appears indigenous to Northern meadows and should be more generally grown wherever the land is suitable.

1 Bul. 20. 
Tracy, of the Mississippi Station, ${ }^{1}$ found no better grass for marshy lands and seepy hillsides.

27I. Mixed permanent grasses.-Nature rarely covers any large area with a single species of vegetation, and it is better to humor her by having several varieties of grass and clover in the same meadow or pasture than growing a single one, no maiter how valuable. For stock feeding at the North, a mixture of redtop, timothy and orchard grass with one or two kinds of clover will give a larger yield of aromatic, palatable hay than is possible with a single variety. There are several other varieties of grasses which will thrive in special locations. The stockman should experiment freely with the more promising varieties, that he may learn by direct experiment which combinations are best suited to his condition.

272. Hungarian grass, millet. - The millets, which are annual grasses, consist of many races and varieties mixed in hopeless confusion. German millet and Hungarian grass are the millets commonly grown in the Northern states. Sown in early summer, they thrive remarkably in hot and even dry weather, reaching the harvest perivi in August or September. In order to produce hay of fine quality, a liberal allowance of seed should be sown. With thin seeding millet stems are coarse and reed-like, forming a hay of low quality. All forms of millet grass designed for hay should be cut just as the plant is coming into blossom, to avoid the formation of hard seeds which are indigestible by horses and cattle. Hay from thickly-seeded millet, if cut early, is useful for cattle and sheep feeding. If given to horses, it should be fed very sparingly and under close supervision. (198)

For millet-hay injurious to horses, see Article 482.

At the Massachusetts Station, ${ }^{2}$ Brooks, experimenting with Japanese millet, grew crops iu which the plants reached a height of six feet, yielding from twelve to eighteen tons of green forage per acre. Millet forage was much relished by dairy cows, proving superior to flint corn fodder.

273. Grasses at the South.-In the past the Southern planter has despised grasses because they seriously interfered with the

\footnotetext{
1 Bul. $20 . \quad 2$ Rept. 1895.
} 
cultivation of the cotton crop. Now that mixed farming is gaining friends in that region, some of the many grasses which grow readily there are receiving attention, only a few of which can be mentioned.

Teosinte is a giant grass, somewhat resembling the sorghum plant. Stubbs, of the Louisiana Station, ${ }^{1}$ reports a yield of over fifty tons of green teosinte forage per acre. This plant is too tropical in character to have a forage value outside a belt bordering the gulf.

Millo-maize is a variety of sorghum which succeeds in the southern portion of our country. At the Louisiana Station, ${ }^{2}$ a yield of thirteen tons of cured forage and thirty-nine bushels of seed was obtained from one acre. Bermuda grass is now common in the South, spreading by both seed and creeping stems. Tracy, of the Mississippi Station, ${ }^{3}$ reports a yield of from two to four tons of Bermuda hay per acre in two cuttings. Bermuda grass is useful for forage and pasture, its sod resembling in some measure that formed by Kentucky blue grass at the North.

Numerous grasses can be grown with profit at the South. * With a large list of true grasses and legumes available for forage purposes, there seems no reason why the Southern states should not become a favorite region for stock growing.

274. Sorghum.- The sorghum plant, being more difficult of cultivation in the humid regions than Indian corn, gives way to the latter in the production of green forage. At the Pennsylvania Station, ${ }^{5}$ Arrnsby, studying this plant for soiling purposes, concludes that it has no special value for that state. Amber-cane sorghum gave a yield of but little over ten tons of green forage per acre, while dent corn under similar conditions returned from ten to fifteen tons. In the semi-arid region of the Southwest, sorghum grows with great vigor, withstanding drought and drying winds remarkably well. Because of these characteristics and the abundant nutriment contained in stems, leaves and seed heads, the sorghum plant is destined to occupy a prominent place in the

\footnotetext{
1 Bul. 19.

2 Bul. 22.

- Bul. 20.

- Farmers' Bul. 18, U. S. Dept. Agr.

- Rept. 1889.
} 
agriculture of this district, furnishing green forage to stock during shortage of pastures in summer and fall, and the best of dry fodder in winter. (194)

275. Dangers from second-growth sorghum.-The agricultural press reports cattle dying suddenly after eating very small quantities of second-growth sorghum. Coburn ${ }^{1}$ quotes Pritchard, the Kansas state veterinarian, as saying: "Second-growth sormhum under certain conditions is very destructive indeed to cattle, small quantities killing them almost instantly. . . Just what this destructive agent is I am unable to say." In the same report reference is made to Kaffir corn causing the same trouble. Tracy" reports that second-growth "chicken corn," a variety of sorghum found in the Gulf states, when eaten by cattle, sometimes produces fatal results within a few minutes. He says: "It seems to affect only certain animals, or perhaps only certain plants produce the ill effects, as generally only a few animals in a herd are killed, and these are commonly found near together." No one knows why second-growth sorghum should cause trouble in the way noted, and no remedy is known. Prevention is the only means at hand.

276. Sorghtum hay.-In the semi-arid region of the Southwest. the sorghum plant possesses many advantages for producing a coarse hay of high feeding value. In parts of Kansas and Texas, stockmen plant the seed by means of grain drills; at other times it is sown broadcast. Sorghum may also be planted in wide drills and cultivated like corn. This giant grass, when sown broadcast, is cut with a mower, and after partially drying is gathered int windroms, and finally into bunches of considerable size, where it remains until required for feeding, or the bunches are gathered into stacks.

When planted in drills, sorghum should be harvested in shocks, as is common with Indian corn. The stems of the saccharine sorghums are rich in sugar and are eagerly consumed by farm stock in winter. The leaves of all varieties of sorghum form a bright, palatable, nutritious hay, free from dust and very useful

1 Rept. Kan.’Bd. Agr., Sept. 1894.

${ }^{2}$ Bul. 20, Miss. Expt. Sta. 
for feeding horses especially, also for sheep and cattle. The sorghum plant may be successfully used for silage.

277. The cereals as forage plants. - Wheat, oats, barley and rye plants may serve for pasture and hay production in many cases with profit. These grasses, for such they are, may be sown at almost any time during the growing season, and will soon cover the ground with a carpet of green, affording much nutritious pasture, where otherwise nothing of value would be produced.

Rye sown in August will furnish pasture, three or four weeks later, that will continue useful until winter sets in, and is again available as soon as vegetation starts in the spring. Stewart ${ }^{1}$ states that fifty sheep may be continuously pastured in summer upon six acres of land sown to rye the previous fall, if, in addition to the pasture, they are fed a little linseed meal and corn.

Green rye, when used for soiling or pasturing cows, has the reputation of imparting a bad flavor to milk. This trouble can usually be arerted by turning the cows to pasture, immediately after milking, for two or three hours, after which time other feed should be given.

Barley furnishes an excellent pasture in a short time after seeding, and yields liberally of green forage. Sown in fields from which a grain crop has been harvested, barley will grow two or three feet in height and may even head out before heavy fall frosts. At the Alabama (Canebrake) Station ${ }^{2}$ a field seeded in the fall with barley yielded 23,100 pounds of green forage by the following March. Winter wheat can likewise be used for pasture and yields a nutritious herbage suitable for soiling. In southern Kansas winter wheat pastured by cows in mild weather is said to impart a grass flavor to what otherwise would grade as winter butter.

278. Oats or barley and peas. - The value of oats and peas and barley and peas for forage crops has been tested by Roberts and Clinton at the Cornell Station. ${ }^{3}$ They write: "Ranking next to corn as a forage crop and a close second, comes oats and peas. In the two years in which we have been conducting experi-

" "Feeding Animals."

- Bul. 9.

s Bul. 135. 
ments in the production of forage this combination has proven itself well worthy of a place on every farm where stock is kept. It is valuable either for pasture, for cutting as a soiling crop, or when allowed to mature it may be cured for hay, making a most valuable article. When planted in succession of about two weeks, the first planting being as early in the spring as conditions will permit, a succession of highly nutritious forage is produced which is greatly relished by stock. If a more general use was made of oats and peas for summer feeding it would greatly decrease the expense of the production of milk and the cost of maintaining cattle and economize land very materially. A highly nutritions forage would be obtained, rich in protein and furnishing nearly a balanced ration for milch cows. A large amount can be produced per acre and it may be grown from early spring to late fall. A slight freeze does not affect it, and it may be sown in the siy ing before frosts are over, and the late forage frequently remains in good condition until December. The oats and peas at this Station sown August 1, 1896, were in good condition for feeding until a severe freeze on the night of December 2 cut them down. For late forage, however, barley and peas are recommended instead of oats and peas. For sowing any time after July 1st, substitute barley for oats. The reason for this is that in late summer barlcy makes more rapid growth, is less likely to attacks of rust and other fungous diseases than are oats."

279. The small grains as hay crops. - Wheat, oats and barley, used as grasses, are capable of producing excellent hay if harvested at the proper time. Barley constitutes the common hay crop of the Pacifie Slope outside the alfalfa region, and there is no reason why this plant, as well as oats and wheat, should not be employed as a hay producer in other portions of the country. If the meadows fail to yield the usual supply of hay, the loss can be made good by having recourse to small grain grown as a substitute. When used for hay production, grasses from the cereal grains should be cut when the seed is in the early milk stage, at which time the stems and leaves may be easily cured into bright, dust-free hay of a quality well suited for feeding horses or dairy cows. 
Crops of the cereals which have made too heavy a growth of straw because of wet weather usually lodge badly, and when this nowurs the yield of grain is unsatisfactory. Such overgrown grain can be converted into hay with more profit than would result from a light crop of poor grain, which costs much to harvest.

280. Straw.- While primarily used for bedding purposes, the softer kinds, especially oat and barley straw, are serviceable for feeding purposes. In Canada and England chaffed straw is commonly mixed with pulped roots and the mass allowed to soften and even ferment slightly; thas prepared, cattle readily consume large quantities with satisfactory returns. Oat straw, because of its nutrients and its soft, pliable stems, leads for feeding purposes, with barley following. Wheat straw, being coarse and stifi, is not as satisfactory, though some will be eaten by cattle. Rye straw is woody, harsh and should be used for bedding purposes.

281. Chaff. - Wheat and oat chaff contain more protein than straw, and because of their fineness and softness they are useful in feeding stock. Often with chaff there are found light and broken kernels which have escaped the threshers; by these the value of chaff, so called, is materially increased.

282. Flax straw.- Where flax is grown for the seed, the straw or haulm is generally wasted. Stockmen who have fed flax straw to horses and cattle report satisfactory results from its use. Frequently some flax seed is left in the straw, which increases its value. There seems no foundation for the statement that the fiber of flax straw forms balls of indigestible matter in the stomachs of farm animals. It is no doubt digested the same as other fibrous matter - the lint of cotton, for example. Some flax straw may always be fed, and during times of searcity it will prove a boon to the stockman who overcomes his prejudice and supplies it freely to his hungry animals.

283. Ergot.-- At times the grains of the rye plant and seeds of the grasses are attacked by a fungus called ergot which canses them to become several times their normal sizc. Ergot grains are usually spur-like in form, quite rigid, and nearly black in color. Being quite large on rye, ergot grains may be detected when the observer is some distance away. On the heads of the 
smaller grasses they can only be found by close inspection, bat this is not difficult when one is familiar with their appearance. When eaten by animals ergot may produce convulsions, paralysis of the hind limbs, slowness of heart action and death by exhaustion. With pregnant animals in an advanced period of gestation it may produce abortion. Epidemics of abortion in cows hate been traced to this cause, and veterinary surgeons employ ergot to expedite languid labor. Ergotism shows itself most commonly in deranged nutrition; the limbs of the animal affected turn black and shrivel, dying as though attacked by dry gangrene. ${ }^{1}$

There have been several serious outbreaks of this disease in the last form noted in different parts of the United States, generally in the Western states. Much needless excitenent has been caused in some instances through reports current in the press that the ailment was the dreaded contagious "foot-and-month" disease. Only cattle have so far been attacked. Horses, it is said, reject hay containing ergot.

The observant stockman can usually forestall all trouble from ergot by examining the grass heads in the meadows and pastures immediately before haying and avoiding grass carrying the fungus. A little study will enable one to detect ergot grains even on grasses as fine and small as blue grass and redtop, while they are seen without difficulty on heads of timothy and wild rye.

Ergot poisoning generally makes its appearance in late winter or early spring with cattle in poor condition that are subsisting wholly or largely upon hay. It announces its presence by a diseased condition of the limbs, the extremities of which are cold and almost lifeless. The trouble may continue until the hoofs slough off with dry gangrene. Cattle that are affected should lave their feed changed at once to remove the cause of the trouble; they should be warmly housed and given a variety of nourisbing feed.

Stalker 2 affirms that cattle fed coln are never poisoned by ergot, - probably because this feed is nourishing and furnishes an abundance of heat to the body. (177)

\footnotetext{
1 For account of ergot and ergotism see aiticle Ergota, National Dispensatory; also Special Report on Diseases of Cattle and Cattle Feeding; Report Bureau Animal Industry, 1895-6. U. B. Dept. Agr., Washington.

2 Bul. 17, Iowa Sta.
} 


\section{OHAPTER XII.}

\section{LEGUMTNOUS PLANTS FOR GREEN FORAGE AND HAY.}

Digestible nutrients and fertilizing constituents.

\begin{tabular}{|c|c|c|c|c|c|c|c|}
\hline \multirow{2}{*}{ Name of feed. } & \multirow{2}{*}{$\begin{array}{c}\text { Dry } \\
\text { matter } \\
\text { in } 100 \\
\text { pounds. }\end{array}$} & \multicolumn{3}{|c|}{$\begin{array}{l}\text { Digestible nutrients } \\
\text { in } 100 \text { pounds. }\end{array}$} & \multicolumn{3}{|c|}{$\begin{array}{l}\text { Fertilizing constitu- } \\
\text { ents in } 1,000 \text { pounds. }\end{array}$} \\
\hline & & $\begin{array}{l}\text { Pro- } \\
\text { tein. }\end{array}$ & $\begin{array}{c}\text { Carbo- } \\
\text { hy- } \\
\text { drates. }\end{array}$ & $\begin{array}{l}\text { Ether } \\
\text { ex- } \\
\text { tract. }\end{array}$ & $\begin{array}{l}\text { Nitro- } \\
\text { gen. }\end{array}$ & $\begin{array}{l}\text { Phos- } \\
\text { phorio } \\
\text { acid. }\end{array}$ & $\begin{array}{l}\text { Pot- } \\
\text { ash. }\end{array}$ \\
\hline Green forage. & Lbs. & Lbs. & Lbs. & Lbs. & Lbs. & Lbs. & Lbs. \\
\hline Red clover at different & & & & & & & \\
\hline 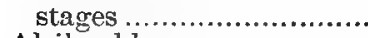 & 29.2 & 2.9 & 14.8 & 0.7 & 5.3 & 1.3 & 4.6 \\
\hline Alsike, bloom............. & 25.2 & 2.7 & 13.1 & 0.6 & 4.4 & 1.1 & 2.0 \\
\hline Crimson clover ................... & 19.1 & 2.4 & 9.1 & 0.5 & 4.3 & 1.3 & 4.9 \\
\hline 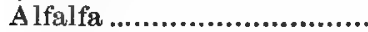 & 28.2 & 3.9 & 12.7 & 0.5 & 7.2 & 1.3 & 5.6 \\
\hline 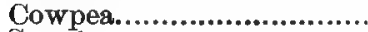 & 16.4 & 1.8 & 8.7 & 0.2 & 2.7 & 1.0 & 3.1 \\
\hline 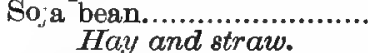 & 24.9 & 3.2 & 11.0 & 0.5 & 2.9 & 1.5 & 5.3 \\
\hline Red clover, medium .. & 84.7 & 6.8 & 35.8 & 1.7 & 20.7 & 3.8 & 22.0 \\
\hline Red clover, mammoth. & 78.8 & 5.7 & 32.0 & 1.9 & 22.3 & 5.5 & 12.2 \\
\hline Alsike clover ..................... & 90.3 & 8.4 & 42.5 & 1.5 & 23.4 & 6.7 & 22.3 \\
\hline White clover ............ & 90.3 & 11.5 & 42.2 & 1.5 & 27.5 & 5.2 & 18.1 \\
\hline Crimson clover........... & 90.4 & 10.5 & 34.9 & 1.2 & 20.5 & 4.0 & 13.1 \\
\hline Alfalfa ............................. & 91.6 & 11.0 & 39.6 & 1.2 & 21.9 & 5.1 & 16.8 \\
\hline Cowpea ................................. & 89.3 & 10.8 & 38.6 & 1.1 & 19.5 & 5.2 & 14.7 \\
\hline Soja-bean straw......... & 89.9 & 2.3 & 40.0 & 1.0 & 17.5 & 4.0 & 13.2 \\
\hline 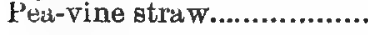 & 86.4 & 4.3 & 32.3 & 0.8 & 14.3 & 3.5 & 10.2 \\
\hline
\end{tabular}

284. Concerning legumes.-The prominent characteristic of the true grasses, including the corn plant, is their large content of carbohydrates with a meager amount of protein; in the legumes we have a relatively large proportion of protein to carbohydrates

'aud fat. Each of these great groups of agricultural plants, then, presents to the feeder what the other lacks, and so are complementary to each other.

The highest use of the corn plant is bearing grain, with a large secondary place in supplying forage. In the legumes we have for the most part forage plauts only, the seeds being generally too small to be useful for food, though beans and peas are an exception. Another warked difference between the legumes and the grasses, inchiting the cereals, is their after or residual effect upou 
the soil. When tho latter have been grown for a period upon a tract they have exhausted its fertility in some measure. Where clover is grown, although much fertility is removed with the crop, the land still seems in excellent heart for other crops which follow.

The discovery that the free nitrogen of the air can be fixed by the legumes and turned over to the soil, thus securing without cost to the farmer one of the most precious elements so largely required by plants, has at last explained what was so long a mystery, and should make us doubly appreciative of these most useful plants.

In the northeastern United States the clovers are the commonly cultivated leguminous plants. In the southern portion of our country, crimson and Japan clover, the cowpea, soja bean and other legumes flourish, while the whole wistern half of the United States is served by that wonderful representative, the alfalfa or lucern plant.

285. Red clover.-This plant is found on every well-regulated farm in the northeastern United States, where with grasses it stands prominent in rotation with corn and the cereals. Red clover serves for both pasture and hay purposes, yielding large returns.

At the Wisconsin Station, ${ }^{1}$ Woll, cutting clover three times during the season, secured the results given below:

Yield of three crops of red clover-Wisconsin Station.

\begin{tabular}{|c|c|c|c|}
\hline Date of cutting. & $\begin{array}{l}\text { Green } \\
\text { clover. }\end{array}$ & $\begin{array}{c}\text { Dry } \\
\text { matter. }\end{array}$ & $\begin{array}{c}\text { Dry } \\
\text { matter. }\end{array}$ \\
\hline & Lbs. & Per cent. & Lbs. \\
\hline 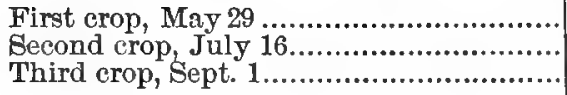 & $\begin{array}{r}29,220 \\
16,020 \\
7,221\end{array}$ & $\begin{array}{r}8.2 \\
22.5 \\
27.5\end{array}$ & $\begin{array}{l}2,402 \\
3,599 \\
1,986\end{array}$ \\
\hline
\end{tabular}

Here is a yield of over twenty-five tons of green forage per acre, which may bo regarded as representing the maximum return for this crop. From one-half to two-thirds this amount may be relied upon by the stockman as a fair crop under average conditions.

1 Rept. 1889. 
It will be seen that the first crop contained but 8.2 per cent. of dry matter, or less than is found in skim milk. It is evident that this crop was cut some time before it had reached the proper maturity for making hay. Here is an explanation why early-cut green clover, when used for soiling cattle, often gives such unsatisfactory returns; such forage is mostly water, and the cattle receiving it cannot consume enough to gain the nourishment they require. The total dry matter of the three crops amounted to nearly four tons - a most satisfactory showing.

286. Development of nutrients in the clover plant.- Hunt, of the Dlinois Station, ${ }^{1}$ has arranged the results of studies relating to the development of the clover plant for hay production, conducted by himself and others, in tables, portions of which are here presented:

Field of hay, and nutrients in the same, from the clover plant cut at different stages - various Stations.

\begin{tabular}{|c|c|c|c|c|c|c|}
\hline $\begin{array}{l}\text { Stage of growth at time of } \\
\text { cutting. }\end{array}$ & $\begin{array}{c}\text { Fresh } \\
\text { sub- } \\
\text { stance. }\end{array}$ & $\begin{array}{l}\text { Pro- } \\
\text { tein. }\end{array}$ & $\begin{array}{c}\text { Ether } \\
\text { ex- } \\
\text { tract. }\end{array}$ & $\begin{array}{l}\text { Crude } \\
\text { fiber. }\end{array}$ & $\begin{array}{l}\text { Nitro- } \\
\text { gen-free } \\
\text { extract. }\end{array}$ & Ash. \\
\hline $\begin{array}{l}\text { Medium red clover. } \\
\text { Illinois (Bunt). }\end{array}$ & & & Lbs. & & Lbs. & Lbs. \\
\hline 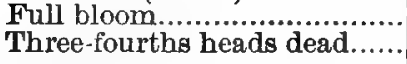 & $\begin{array}{l}3,600 \\
3,260\end{array}$ & $\begin{array}{l}400 \\
379\end{array}$ & $\begin{array}{l}197 \\
156\end{array}$ & $\begin{array}{l}660 \\
672\end{array}$ & $\begin{array}{l}1,052 \\
1,024\end{array}$ & $\begin{array}{l}217 \\
196\end{array}$ \\
\hline $\begin{array}{l}\text { Pennsylvania (Jordan). } \\
\text { Heads in bloom ..................... } \\
\text { Some heads dead.................. } \\
\text { Heads all dead .................... }\end{array}$ & $\begin{array}{l}4,210 \\
4,141 \\
3,915\end{array}$ & $\begin{array}{l}539 \\
469 \\
421\end{array}$ & $\begin{array}{r}116 \\
106 \\
94\end{array}$ & $\begin{array}{l}1,033 \\
1,248 \\
1,260\end{array}$ & $\begin{array}{l}1,731 \\
1,379 \\
1,378\end{array}$ & $\begin{array}{l}260 \\
226 \\
208\end{array}$ \\
\hline $\begin{array}{l}\text { Connecticut (Atwater). } \\
\text { Just before bloom .................. } \\
\text { Full bloom......................... } \\
\text { Nearly out of bloom ............ } \\
\text { Nearly ripe ......................... }\end{array}$ & $\begin{array}{l}1,618 \\
1,641 \\
2,054 \\
1,802\end{array}$ & $\begin{array}{l}198 \\
189 \\
230 \\
158\end{array}$ & $\begin{array}{l}24 \\
33 \\
31 \\
36\end{array}$ & $\begin{array}{l}384 \\
390 \\
523 \\
484\end{array}$ & $\begin{array}{l}664 \\
682 \\
837 \\
746\end{array}$ & $\begin{array}{r}115 \\
107 \\
129 \\
99\end{array}$ \\
\hline $\begin{array}{l}\text { Mammoth yed clover. } \\
\text { Inlinois (Hunt). } \\
\text { Beginning to bloom ............... } \\
\text { Full bloom ....................... } \\
\text { Nearly out of bloom........... }\end{array}$ & $\begin{array}{l}4,340 \\
5,440 \\
4,213\end{array}$ & $\begin{array}{l}443 \\
519 \\
386\end{array}$ & $\begin{array}{l}212 \\
237 \\
173\end{array}$ & $\begin{array}{r}971 \\
1,404 \\
1,110\end{array}$ & $\begin{array}{l}1,317 \\
1,612 \\
1,504\end{array}$ & $\begin{array}{l}252 \\
266 \\
218\end{array}$ \\
\hline
\end{tabular}

We observe that clover gave the largest returns of protein when the heads were in full bloom or just past that stage. When the crop stood until some of the heads were dead or later, the

\footnotetext{
1 Bul. 5.
} 
protein content was materially reduced, and with the heads all dead it was still further diminished. There was also a diminution in the ether extract and ash after the full-bloom stage of development was passed. The nitrogen-free extract, carrying the most valuable carbohydrates, was also materially lessened after the plant had passed the full-bloom stage. On the other hand, the crude fiber, which renders hay woody and is the least valuable portion, was increased in the period between full bloom and the time when the heads were all dead. Probably much of the loss in nutrients at this time was through the leaves and finer parts of the plant falling off and wasting on the ground.

287. The proper time for cutting clover.-The table just given throws much light on this important topic, and clearly points to full bloom as theoretically the best time for cutting clover for hay. If cut before bloom the amount of water in the crop is so excessive that the process of hay making is slow and unsatisfactory. If delayed until the blossom heads are all brown, the conversion into hay is much simplified, for the plants have then parted with much of the water they carry while developing, and are consequently easily dried. But such hay, as shown by the table, has lost much of its valuable protein and carbohydrates. Practice and theory, then, combine in setting the period when one-third of the clover heads are turning brown, as the best, all factors considered, for hay making.

288. Methods of clover hay making.- Hay making from clover has fallen into three lines, each of which has its advantages accord. ing to locality and weather conditions. Under the first system the clover is mown as soon as the dew is off, and by frequent teddings and turnings, aided by bright, hot sunshine, it is ready for raking in the afternoon, and housing before five o' clock, at which time the gathering dew shuts off further operations. Under this system the clover plant must be well ripened, indeed past its prime, for hay, and the weather very favorable, if good results are to be secured.

The second system differs from the first only in cutting the clover so late in the afternoon that the dew does not materially affect the plants because they have as yet wilted but little. The 
following day hay making proceeds as rapidly as possible, the crop being placed under cover before night-fall.

Under the third system clover is cut after the dew is off and remains without tedding until afternoon, when it is gathered into windrows, and from these into bunches or cocks before the dew falls, which stand several days, undergoing a sweating process. After sweating they are opened in flakes, which give off their moisture rapidly, and the material is soon ready for the barn. Hay curing in cocks is often protected by muslin covers or caps, which are useful in protecting the bunches from rain.

Whichever system is adopted, too great care cannot be exercised in preserving the finer parts of the plant, which are liable to be wasted, leaving only the coarse, woody stems to be gathered. Under all systems of hay production the clover plant should not be placed in barn or stack when carrying external moisture, either dew or rain. This foreign moisture appears to be more detrimental in the curing of hay than the natural sap of the plant.

289. Losses in curing. - According to Wolff, ${ }^{1}$ from twenty-five to forty per cent. of the dry substance of clover hay can be extracted by cold water. Ritthansen cured one sample of clover hay quickly and allowed another to lie a fortnight in the rain. The composition of the two samples was as follows:

Composition of good clover hay and that injured by rain - Ritthausen.

\begin{tabular}{|c|c|c|}
\hline & $\begin{array}{c}\text { Not rained. } \\
\text { upon. }\end{array}$ & $\begin{array}{l}\text { Rained } \\
\text { upon. }\end{array}$ \\
\hline & Per cent. & Per cent. \\
\hline 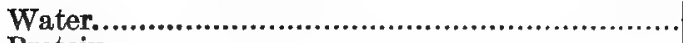 & 16.0 & 16.0 \\
\hline Protein & 14.6 & 15.8 \\
\hline 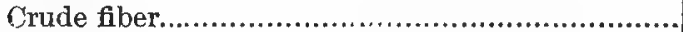 & 25.3 & 37.4 \\
\hline Nitrogen-free and ether extracts.......................... & 36.1 & 23.4 \\
\hline 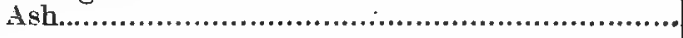 & 8.0 & 7.5 \\
\hline
\end{tabular}

We see that the sample rained upon contained more protein than did the one which was well preserved. Evidently much more of the nitrogen-free extract than protein is removed by soaking the hay with water. This explains the fact so often noticed in prac-

${ }^{1}$ Farm Foods, English edition, p. 160. 
tice, that clover liay apparently rich in protein may have little value owing to the large quantity of crude fiber and the small amount of nitrogen-free extract it contains. Contrary to the showing made above, a large portion of protein is often reinoved from hay when soaked by rain. (304)

290. Spontaneous combustion.- - It seems beyond question that barns containing clover hay and stacks of the same are occasionally consumed by fire originating through spontaneous combustion. The subject though an old one is still involved in mystery. Cohn, of Breslau, ${ }^{1}$ considers that spontaneous combustion in hay is produced through the action of a mould fungus.

Reviewing the many experiences reported, ${ }^{2}$ it seems that there is danger from spontaneous combustion only in seasons when the clover plant contains an unusual amount of moisture at haying time, or when the hay material carries to stack or barn more or less water foreign to it, $i$. e., rain or dew.

291. Use of clover hay.-Clover hay is not usually considered a satisfactory roughage for the horse, the dust it carries proving very detrimental to that animal. A limited amount of good clover hay may, however, be fed to horses of all kinds with favorable results.

For the cow there is no better roughage than good clover hay. It furnishes the large amount of protein and ash essential to milk, and is palatable and much relished. With well-cured clover hay forming one-half or two-thirds of the roughage of the ration, the dairyman is able to cut down the allowance of concentrated feed, thus reducing the cost of the ration. (653) For growing calves and young stock clover hay is most important. If it is more essential one place than another, probably the shepherd has first claim to clover hay, for his animals of all degrees will not give as favorable returns from any other form of roughage.

For soiling purposes clover holds an important place, since the crop is available early in the season and is highly relished by cattle. The writer secured a yield of clover used for soiling purposes of 27,000 pounds per acre in three cuttings. (365) At

- Veterinary Journal, 31, p. 310.

- See various articles in Breedor's Gazette, 1889. 
the Pennsylvania Station, ${ }^{1}$ yields of six to seven tons in one case and over thirteen tons in another are reported.

For pigs, clover pasture serves an excellent purpose, building good bone and a framework capable of taking on fat rapidly when the period of receiving concentrated food arrives. We can find no records of the yields of clover fields when devoted to the pasturage of swine. Our Stations should report experiments on this point. In feeding green clover one should always have in mind its extreme succulence, and that the quantity which the animal is capable of consuming may not contain the requisite nourishment.

Bloat or hoven menaces cattle and sheep pastured on the clover field. To avoid this the cattle should not be turned to pasture while very hungry or before the dew has risen. Further, some dry forage, such as hay or straw, should be placed in feed racks in the pasture. To this cattle and sheep will resort when threatened with bloat. It is said that if cattle and sheep can have access to dry roughage while feeding on pasture, they will not suffer from this ailment.

292. Mammoth clover.- The distinctive characteristies of mammoth clover are its rank growth, coarse stems, and the feature of blooming two or three weeks later than the medium variety. This variety yields but one cutting during the season, aud because of this the field is frequently used for pasture for several weeks in the spring. After removing the stock the plants shoot up and soon are ready for the mower. Wallace ${ }^{2}$ recommends that medium and mammoth clover seed be sown in equal proportions, together with grasses for pasture, holding that since the mammoth variety blooms later, there is more nearly a succession of good forage than is possible with only one variety.

293. Alsike clover.- This variety of clover has weak stems, which fall to the ground unless supported by attendant grasses. Well-made alsike hay ranks with the best, though the yield is not large. At the Mllinois Station, ${ }^{3}$ Hunt and Morrow secured 1.2 tons of alsike hay against 2.1 tons of medium clover hay per acre.

1 Rert. 1888-89.

2 "Clover Culture."

3 Bui. 15. 
This variety of clover flourishes on land too moist for other clovers, though it will not grow in really wet soils. While red clover usually dies out the second year, alsilse stands for many years, this feature increasing its value for pasture purposes.

294. Scarlet or crimson clover.-This clover is an annual, resembling the wheat plant in this phase of its habits. If sown in late summer or early fall, in the southern part of the United States it grows somewhat during the winter, and with the coming of spring advances rapidly to the hay period, which is reached by late spring, after which the plants die. In making its round of growth in the fall and spring, crimson clover resembles winter wheat. On the other hand, if sown in spring it blossoms in late summer, matures its seeds and dies, thus following the habit of spring wheat. The winter form of this plant has flourished with remarkable success from Delaware ${ }^{1}$ southward to the Carolinas. ${ }^{2}$ Crimson clover can be grown throughout the Southern states as a winter plant, but its use has not yet become general. The Northern states are too cold for fall-sown crimson clover, but it may be used as a summer crop with some advantage, though generally it is inferior to red clover. Wherever it flourishes, crimson clover will be found useful for soiling purposes, and if cut early it makes hay of fair quality.

295. Danger to horses from oversipe crimson clover.- The blossom heads of crimson clover are covered with minute hairs, whjch become rigid as the heads ripen. Investigations conducted by the Department of Agriculture, ${ }^{\mathbf{3}}$ Washington, show that death may result to horses when fed overripe crimson clover. A circular from the Department states: "If overripe crimson clover is fed to horses, the bristly hairs (of the heads) will accumulate in the stomach or intestines in spherical balls, which are increased in size by repeated additions of the same matter to their surfaces, the whole mass tending to become more compact because most of the hairs, upwardly barbed, are constantly pushing toward the center, base foremost. When a ball has reached a sufficient size (whether after a few days or several weeks we have no means of

\footnotetext{
1 Bul. 16, Del. Sta.

2 Bul. 72 , North Car. Sta.

a circular No. 8, Div. of Botany, 1896.
} 
knowing), it acts as a plug in the intestine, interfering with the vital functions, and finally, after a few hours of intense suffering, the horse dies from peritonitis or some related difficulty."

There seems no cure for this ailment. It can be avoided by curing crimson clover into hay at the proper stage for making that product. Hay from overripe crimson clover, and the refuse left when seed is threshed, should not be fed to horses.

296. Japan clover.- This plant has proved most helpful to Southern agriculture because it adds nitrogen to the soil, binds it together, prevents washing, and furnishes a nutritious food for stock. On sterile land it yields pasture only, while under favorable conditions it reaches a height of from twenty to thirty inches, furnishing as much as three tons of hay per acre, which, according to Tracy, ${ }^{1}$ is equal to the best clover hay. (650)

297. Burr clover.-This plant is best known in California, where, growing wild, it furnishes abundant winter pasture. Tracy recommends its use in the South. Its best growth is from February to May, after which it disappears. Harrington, of the Texas Station, ${ }^{2}$ reports the plant in favor with cattle, but not relished by horses.

298. Alfalfa or lucern. - This plant flourishes in the western half of the United States, and is of even more importance to that vast region than is red clover to the eastern United States. In the San Joaquin Valley, California, alfalfa reaches its highest perfection, yielding under the hot suns on the alluvial soils of that district from five to seven cuttings of from one to two tons each, annually. In Colorado and $U$ tah two to three cuttings are obtained. In the humid region, especially Kansas and Nebraska, alfalfa is grown to a limited extent, interest in the crop having much increased of late. It is also gaining favor in the East as the farmers learn to grow it.

299. Yield of alfalfa. - At the New York (Geneva) Station, ${ }^{8}$ Wheeler reports the following yields of alfalfa cut four times during the season for soiling:

\footnotetext{
1 Bul. 20, Miss. Sta.

2 Bul. 20.

s Bul. 118.
} 
Field of alfalfa during three years - New Fork (Geneva) Station.

\begin{tabular}{|c|c|c|c|c|c|c|}
\hline Year. & $\begin{array}{l}\text { Actual } \\
\text { area. }\end{array}$ & $\begin{array}{l}\text { Green } \\
\text { weight. }\end{array}$ & $\begin{array}{c}\text { Dry } \\
\text { matter. }\end{array}$ & Protein. & $\begin{array}{l}\text { Albu- } \\
\text { minoids. }\end{array}$ & $\begin{array}{l}\text { Date of first } \\
\text { cutting. }\end{array}$ \\
\hline & Acres. & Lbs. & Lbs. & Lbs. & Lbs. & \\
\hline $\begin{array}{l}1894 \ldots \\
1894 \ldots \\
1895 \ldots \\
1896 \ldots \\
1896 \ldots\end{array}$ & $\begin{array}{l}2.3 \\
1.3 \\
1.3 \\
1.3 \\
1.25\end{array}$ & $\begin{array}{l}64,596 \\
33,803 \\
37,129 \\
34,991 \\
36,514\end{array}$ & $\begin{array}{r}17,034 \\
8,116 \\
8,666 \\
8,527 \\
7,461\end{array}$ & $\begin{array}{l}2,574 \\
1,660 \\
1,452 \\
1,522 \\
1,302\end{array}$ & $\begin{array}{l}2,068 \\
1,278 \\
1,120 \\
1,167 \\
1,054\end{array}$ & $\begin{array}{l}\text { June } 1 . \\
\text { May } 11 . \\
\text { May } 15 . \\
\text { May } 27 . \\
\text { May } 12 .\end{array}$ \\
\hline
\end{tabular}

Here are returns of fourteen tons of green forage per acre, with dry matter exceeding three tons. The date of first cutting is a point of much interest to stockmen, especially dairymen who practice soiling. We learn that in 1894 the first plants were ready for soiling May 11, thus furnishing very early forage.

300. lowa experience with alfalfa.- At the Iowa Station, ${ }^{1}$ Ourtiss reports alfalfa under trial. The same season after seeding in the spring, two tons of hay were secured in three cuttings; the second season the total of three cuttings, made June 1, July 7, and September 3, was as follows for plats seeded by different methods:

\begin{tabular}{|c|c|c|c|}
\hline Plat & Broadcast ......... & $\begin{array}{c}\text { Upland, } \\
\text { tons. } \\
5.3\end{array}$ & $\begin{array}{c}\text { Bottom, } \\
\text { tons. } \\
5.52\end{array}$ \\
\hline Plat II. & 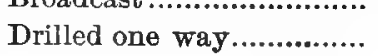 & $\begin{array}{l}0.3 \\
5.18\end{array}$ & $\begin{array}{l}0.02 \\
5.52\end{array}$ \\
\hline Plat III. & Cross drilled...................... & 5.25 & 5.12 \\
\hline lat IV. & Press drilled....................... & 5.08 & 4.22 \\
\hline
\end{tabular}

The third cutting was from five to ten per cent. lighter than the first two, which were practically equal. The hay was found to be of excellent quality, apparently no more difficult to cure than that from clover. Further experience is necessary to determine whether this plant will stand winter conditions in Iowa, but at the date of reporting all was favorable.

301. Alfalfa compared with corn.- At the Colorado Station," Cooke compared a crop of dent corn from one acre of land with returns from a like area of alfalfa three years seeded on an adjoining plat. The corn crop was a fair one, equaling fourteen tons of

1 Bul. 34.

Bul. 26. 
green forage per acre. The alfalfa was cut three times, yielding 4,600 pounds of hay at the first cutting, 3,350 pounds the second, and 3,250 pounds at the third cutting, or a total of 5.6 tons of hay per acre. The total digestible nutrients of the two crops are presented in the following table:

Comparative yield of corn forage and alfalfa hay - Colorado Station.

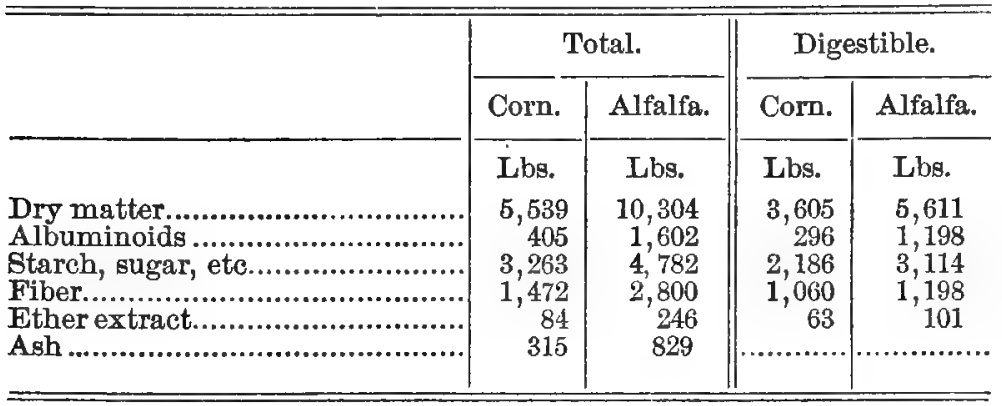

It will be seen that the alfalfa yielded nearly twice as many pounds of dry matter as the corn, with the digestible nutrients far in the lead. The protein of the alfalfa was three times that of the corn.

302. Nutrients in the alfalfa crop. - At the Utah Station, ${ }^{1}$ Widtsoe made a study of the nutrients of the alfalfa crop, and some of the facts gathered are presented in the following table:

Nutrients per acre in three cuttings of alfalfa-Utah Station.

First Cutting.

\begin{tabular}{|c|c|c|c|c|c|}
\hline Condition of growth. & $\begin{array}{l}\text { Pro- } \\
\text { tein. }\end{array}$ & $\begin{array}{l}\text { Nitrogen- } \\
\text { free ex- } \\
\text { tract. }\end{array}$ & $\begin{array}{l}\text { Crude } \\
\text { fiber. }\end{array}$ & $\begin{array}{l}\text { Ether } \\
\text { extract. }\end{array}$ & Ash. \\
\hline & Lbs. & Lbs. & Lbs. & Lbs. & Lbs. \\
\hline $\begin{array}{l}\text { May } 4 . \\
\text { Height, } 61 \text { inches.................. }\end{array}$ & 474 & 607 & 168 & 40 & 167 \\
\hline June 1. & 697 & 1,247 & 618 & 103 & 369 \\
\hline $\begin{array}{l}\text { July } 7 . \\
\text { Full flower .......................... }\end{array}$ & 745 & 2,278 & 2,108 & 118 & 461 \\
\hline $\begin{array}{l}\text { Aug. } 10 . \\
\text { Flowers fallen, leaves dry...... }\end{array}$ & 644 & 2,298 & 2,531 & 116 & 423 \\
\hline 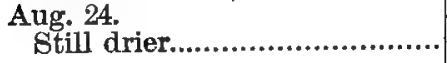 & 428 & 1,776 & 2,544 & 94 & 311 \\
\hline
\end{tabular}

\footnotetext{
- Bul. 48.
} 
Second Cutting.

\begin{tabular}{|c|c|c|c|c|c|}
\hline $\begin{array}{l}\text { July } 7 . \\
\text { Budding............................ }\end{array}$ & 334 & 657 & 357 & 50 & 197 \\
\hline $\begin{array}{l}\text { July } 20 \text {. } \\
\text { Medium bloom }\end{array}$ & 519 & 1,140 & 1,031 & 78 & 314 \\
\hline 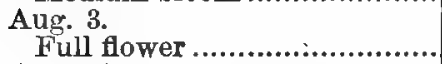 & 551 & 1,529 & 1,316 & 81 & 323 \\
\hline 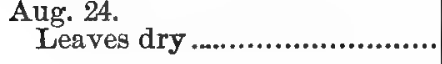 & 388 & 1,484 & 1,329 & 81 & 333 \\
\hline \multicolumn{6}{|c|}{ Third Cutting. } \\
\hline 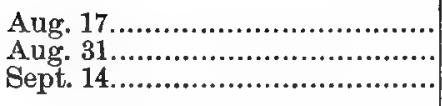 & $\begin{array}{l}138 \\
322 \\
298\end{array}$ & $\begin{array}{l}317 \\
757 \\
934\end{array}$ & $\begin{array}{l}155 \\
634 \\
818\end{array}$ & $\begin{array}{l}17 \\
33 \\
43\end{array}$ & $\begin{array}{r}85 \\
211 \\
214\end{array}$ \\
\hline
\end{tabular}

Widtsoe concludes that to insure a large yield of dry matter and albuminoids, alfalfa should be cut not earlier than the period of middle bloom, and that the blossoms should not be past full bloom. This is from two to three weeks after the flower buds appear.

303. Losses in hay making.-Headden, of the Colorado Station, " found that "a very leafy, small-stemmed alfalfa plant may have more than 60 per cent. of leaves, and, consequently, less than 40 per cent. of stems, but the stems of an average plant will amount to between 40 and 60 per cent. . . . Inasmuch as many of the smaller stems may go with the leaves, the loss in hay making can, and in some cases does, amount to from 50 to 60 and even more per cent. . . . We have been led by our experience and observation to the conclusion that the minimum loss from the falling off of leaves and stems in successful hay making amounts to from 15 to 20 per cent., and in cases where the conditions have been unfavorable to as much as 60 and even 66 per cent. of the dry crop, or, for each 1,700 pounds of hay taken off the field, at least 300 pounds of leaves and small stems are left, and, in very bad cases, as much as 1,200 pounds may be left for each 800 pounds taken. Of course, the latter is extreme, but it does occasionally happen even in this land of perpetual sunshine."

304. Damage to alfalfa hay from rain.- Headden studied the losses in alfalfa hay due to bad weather. One sample of hay re-

\footnotetext{
Bul. 3ij.
} 
mained out fifteen days, during which time it was subjected to three rain storms, amounting in all to 1.76 inches. The other sample was from hay cured without injury by rain. Samples of this hay were analyzed with the results shown below:

\begin{tabular}{|c|c|c|}
\hline & $\begin{array}{l}\text { Hay not } \\
\text { damaged. }\end{array}$ & $\begin{array}{c}\text { Hay } \\
\text { damaged. }\end{array}$ \\
\hline Ash................................ & 12.2 per cent. & 12.7 per cent. \\
\hline Crude fiber ..................... & 26.5 per cent. & 38.8 per cent. \\
\hline Ether extract ................. & 3.9 per cent. & 3.8 per cent. \\
\hline Protein ........................... & 18.7 per cent. & 11.0 per cent. \\
\hline Nitrogen-free extract...... & 38.7 per cent. & 33.6 per cent. \\
\hline
\end{tabular}

It will be seen that the crude fiber, the poorest part of the hay, was increased, and the protein and nitrogen-free extract, the more valuable portions, were materially reduced by weathering. Headden concludes that the estimate of farmers that storms reduce the value of hay one-half is reasonable. (289)

305. Alfalfa in the eastern United States. - Attempts to grow alfalfa in the Eastern states have generally ended in failure. The wonderful resnlts obtained in the West have served to keep alive an interest in this plant and stimulated renewed trials from time to time. The results obtained by several Stations show that large returns are possible under favorable conditions. In searching for the causes of failure, it appears that the most general one is insufficient care in securing a good stand of plants. To reach this end the ground seeded to alfalfa must be free from weedseeds, so that the young plants, which are weak when they first spring up, may grow untrammeled. The desired end will be accomplished by summer-fallowing the proposed alfalfa field for one season in order to reduce the soil to proper fineness, and especially to sprout and kill all weed-seeds lying near the surface. The following spring sow from twenty to thirty pounds of alfalfa seed in drills or cover lightly with a harrow.

306. Manner of growth.-The alfalfa plant is a gross feeder, its tap root reaching many feet into the soil. Headden, of the Colorado Station, ${ }^{1}$ found alfalfa roots twelve and one-half feet below the surface. This indicates that the plant should have a subsoil through which the roots may pass, with water not nearer

1 Bul. 35. 
than six feet. A gravelly or sandy subsoil affords the most favor. able conditions for downward root growth, though they are not absolutely essential. Although under favorable circumstances a fair crop of hay may be secured the first season, alfalfa requires two or three years to become well established.

Headden reports from actual count on small areas that the number of alfalfa plants per acre varied from 70,000 on a field in poor condition to 653,000 on one seeded six months before, and 526,000 on a field ten years established, the latter yielding four tons of hay per acre.

307. Alfalfa for pasture. - This plant is extensively used for pasture in the West, especially in the Salt River Valley, Arizona, where large numbers of cattle and swine are successfully grazed upon it. The hoofs of farm animals work injury to the crowns of the plant, and this shortens the life of the alfalia field given over to pasturage. Sheep crop the tender sprouts too closely. Where possible it is better to use the mower and carry the forage to the animals. With cattle and sheep feeding on green alfalfa, there is always danger from bloat, against which precautions must be taken. (29i)

At the Kansas Agricultural College, ${ }^{1}$ Shelton, pasturing pigs on half an acre of alfalfa during the summer, fed 1,760 pounds of corn additional, and secured a gain of 717 pounds. Allowing 329 pounds as the probable product from the corn, there remains to the credit of the half acre of alfalfa 388 pounds of gain. (875)

308. Alfalfa hay.- - In making hay from this plant the greatest care should be exercised in saving the leaves and finer parts, so easily wasted. The green plants cut with the mower should be gathered when partly dry with the hay rake into windrows sufficiently loose to dry still more, but compact enough to hold the leaves and finer parts. Hay making from alfalfa cannot be taught by books, but the figures presented by the Colorado Station showing the possible losses in hay making should incite the farmer and stockman to a careful study of the principles underlying successful practice in handling the crop. There is no more palatable roughage for farm animals than good alfalfa hay. This hay is best

1 Rep. Prof, of Agr., 1884. 
suited for dairy cows, fattening sheep and fattening cattle, though it is used to a limited extent for horse feeding. The large amount of protein contained in the plant, either green or cured, makes it possible for the feeder to properly maintain his animals upon alfalfa with but a linited allowance of grain or other feeding stuff. (822)

309. Cowpea.-This plant is used in the South more largely for renovating the soil than for forage, yet it has considerable value for the latter purpose. The following yields per acre are reported from the Georgia Station ${ }^{1}$ by Redding: 13,020 pounds of green matter, 2,618 pounds of dry matter, and 840 pounds of seed.

At the South Carolina Station, ${ }^{2}$ McBryde reports a yield of 3.6 tons of cowpea hay per acre. Analyses showed that this forage contained more than twice the digestible nutrients harvested in an acre of oats yielding 40 bushels, and more than 40 per cent. more than an acre of corn yielding 30 bushels.

The Southern farmer has large use for this plant by sowing late after oats or wheat, or in the corn field as a catch crop. The cowpea vine may be mixed with corn forage for making silage. Virginia and Kansas mark the northern limit of profitable culture for the cowpea in general, though early varieties may be grown with advantage in sonthern Mlinois, and even further north where sc wn on particularly warm and favorable soils. (230)

310. The soja (or soy) bean.-According to Georgeson, ${ }^{3}$ the soja bean has been grown for six years with success at the Kansas Station. A field of wheat stubble sown in July gave a crop which matured before frost. The stiff stems of this plant reach a height of from two to three feet, and the yield is better than the navy or field bean. If made into hay, as much as three tons per acre may be secured from a field of soja-bean plants. This plant is gaining friends at the South, but is too tender to be generally useful at the North in competition with red clover and alfalfa. (229)

31. The common field-pea vine.-The common field-pea is grown in Canada and the Northern states for seed and human

Bul. 17. 2 Rept. 1889.

\& Prairie Farmer, Nov. 9, 1895. 
food, and to some extent for forage. A combination of peas and oats, if cut early, forms a forage of high nutritive quality much appreciated by farm stock, especially sheep and dairy cows. In the grain which this plant furnishes and the hay which it is possible to secure from it, the stockman located far north has a fair compensation for the absence of the corn crop. (228)

312. Hairy vetch.- This plant, from Russia, is under trial with promise of success in some districts. Sown in the fall with rye, it finds support from the rye stems and furnishes much forage of fair quality. The seed may also be sown in the spring. The stems of the plant are weak, and for this reason it is not useful when grown alone. Tracy ${ }^{1}$ reports that in the South the vines of this vetch may reach a length of from ten to twelve feet, forming a dense mass of forage two feet in depth. He reports that stock of all kinds eat this plant greedily both in pasture and as hay.

313. Fertilizing constituents of legumes. - Now that it is definitely ascertained that the legumes fix the free nitrogen of the air in root, stem and leaf, this group of agricultural plants should have a double interest with the farmer-stockman who looks to the welfare of both fields and stock. In nitrogen and potash the legumes lead the cereals, while the phosphoric acid is in fair quantity. The manure from legume hay is more valuable than that from the corn plant or straw from the cereals

\footnotetext{
1 Farmers' Bul. 18, U. B. Dept. Agr.
} 


\section{CHAPTER XIII.}

\section{MISOELIANEOUS FEEDING STUFF8.}

I. Roots and Tubers.

Digestible nutrients and fertilizing constituents.

\begin{tabular}{|c|c|c|c|c|c|c|c|}
\hline \multirow[b]{2}{*}{ Namo of feed. } & \multirow{2}{*}{$\begin{array}{c}\text { Dry } \\
\text { matter } \\
\text { in } 100 \\
\text { pounds. }\end{array}$} & \multicolumn{3}{|c|}{$\begin{array}{l}\text { Digestible nutrients } \\
\text { in } 100 \text { pounds. }\end{array}$} & \multicolumn{3}{|c|}{$\begin{array}{l}\text { Fertilizing constitu- } \\
\text { ents in } 1,000 \text { pound }\end{array}$} \\
\hline & & $\begin{array}{l}\text { Pro- } \\
\text { teln. }\end{array}$ & $\begin{array}{l}\text { Carbo- } \\
\text { hy- } \\
\text { drates. }\end{array}$ & $\begin{array}{l}\text { Ether } \\
\text { ex- } \\
\text { tract. }\end{array}$ & $\begin{array}{l}\text { Nitro- } \\
\text { gen. }\end{array}$ & $\begin{array}{c}\text { Phos- } \\
\text { phoric } \\
\text { acid. }\end{array}$ & $\begin{array}{l}\text { Pot- } \\
\text { ash. }\end{array}$ \\
\hline & Lbs. & Lbs. & Lbs. & Lbs. & Lbs. & Lbs. & Lbs. \\
\hline Potato............... & 21.1 & 0.9 & 16.3 & 0.1 & 3.2 & 1.2 & \\
\hline Beet, common. & 13.0 & 1.2 & 8.8 & 0.1 & 2.4 & 0.9 & \\
\hline Beet, sugar ..... & 13.5 & 1.1 & 10.2 & 0.1 & 2.2 & 1.0 & \\
\hline Beet, mangel........ & 9.1 & 1.1 & 5.4 & 0.1 & 1.9 & 0.9 & \\
\hline Flat turnip .... & 9.5 & 1.0 & 7.2 & 0.2 & 1.8 & 1.0 & \\
\hline Ruta-baga.... & 11.4 & 1.0 & 8.1 & 0.2 & 1.9 & 1.2 & \\
\hline Carrot.......... & 11.4 & 0.8 & 7.8 & 0.2 & 1.5 & $0 . \overline{9}$ & \\
\hline Parsnip......... & 11.7 & 1.6 & 11.2 & 0.2 & 1.8 & 2.0 & \\
\hline Artichok $\theta . . .$. & 20.0 & 2.0 & 16.8 & 0.2 & 2.6 & 1.4 & 4.7 \\
\hline
\end{tabular}

314. Yield of root crops.-At the Ohio Station, ${ }^{1}$ Thorne and Hickman, as the result of trials covering twelve years, report that sugar beets gave an average yield of sixteen tons per acre on land which during the same time would yield sixty bushels of shelled corn per acre. They estimate that beets cost two dollars per ton to raise, harvest and place in the cellar. At the Ottawa (Canada) Station, ${ }^{2}$ Robertson reports mangels and carrots yielding 13.5 tons per acre, and costing for rent of land, cultivation and storage of the crop two dollars and fifty cents per ton.

Zavitz, of the Ontario Agricultural College, ${ }^{3}$ reports the yields of the three best varieties each of potatoes and roots, under test for five to six years, to be as follows:

Potatoes, 185 bushels per acre. Carrots, 28 tons per acre. Mangels, 24 tons per acre.
Turnips (fall or flat), 23 tons per acre. Swedes (ruta-bagas), 20 tons per acre. Sugar beets, 17 tons per acre.

\footnotetext{
1 Rept. 9.

2 Rept. 1892.

Rept. 1896.
} 
The yields are based on comparatively small areas, but the figures are valuable in expressing the comparative returns of the several crops.

315. Yield of digestible nutrients. - The digestible nutrients yielded by each crop are the true measure of their value to the farmer. These are presented in the following table:

Estimated yield of digestible nutrients per acre in root crops grown at the Ontario Agricultural College.

\begin{tabular}{|c|c|c|c|c|}
\hline Crop. & $\begin{array}{c}\text { Dry } \\
\text { matter. }\end{array}$ & $\begin{array}{l}\text { Pro- } \\
\text { tein. }\end{array}$ & $\begin{array}{r}\text { Car- } \\
\text { bohy- } \\
\text { drates. }\end{array}$ & $\begin{array}{l}\text { Ether } \\
\text { extract. }\end{array}$ \\
\hline & Lbs. & Lbs. & Lbs. & Lbs. \\
\hline 185 bushels of potatoes ......................... & 2,342 & 100 & 1,809 & \\
\hline 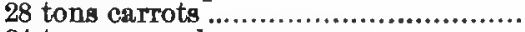 & 6,384 & 448 & 4,368 & 112 \\
\hline 24 tons mangels........................... & 4,368 & 528 & 2,592 & 48 \\
\hline 23 tons fall (flat) turnips............... & 4,370 & 460 & 3,312 & 92 \\
\hline 20 tons ruta-bagas (Swedes) .......... & 4,560 & 400 & 3,240 & 80 \\
\hline 17 tons sugar beets... & 4,590 & 374 & 3,468 & 34 \\
\hline
\end{tabular}

The potato gives the poorest returns of any crop under trial measured by the total digestible matter. The mangel and turnip lead in protein, while the carrot and sugar beet stand first in carbohydrates. The relatively low amount of protein in the sugar beet with its high content of carbohydrates, mostly sugar, shows how successfully that plant las been bred for the single purpose of sugar production.

316. The potato.-Despite the poor showing for the potato it often happens that the farmer has large quantities of these tubers which would better be fed to his stock than forced on a profitless market. According to Fjord's experiments, four pounds of potatoes are worth one pound of grain for pig feeding. Trials by the writer showed that 445 pounds of potatoes, when cooked, were equal to 100 pounds of corn meal for pigs. (4S3-6, 866, 897) For pig feeding, potatoes should be cooked and mixed with meal; for sheep and cattle they are fed sliced, with good results. Care should be exercised in regulating the amount fed, heavy feeding of raw potatoes inducing scouring. (658)

317. The carrot.-This root is wuch relished by horses of all ages and conditions. (487) Being watery, it cannot be fed in 
quantity to hard-worked or driving horses. Carrots also servo well for other stock, especially dairy cows. (900)

318. The mangel.- Though the most watery of all roots, the mangel crop stands well in total dry matter because of the large yield. At the Cornell Station, ${ }^{1}$ Roberts found the yield of dry matter practically the same in mangels and sugar beets, with the labor of harvesting tive sugar beets fully twice that of the mangels.

Because the large roots stand well out of the ground, the mangel is easily cultivated and harvested. It is mainly devoted to feeding cows, and is used to some extent for sheep feeding. When boiled and mixed with meal it is excellent for feeding swine and stock hogs. (549, 898)

319. Sugar beet.- Through careful selection this root has been marvelously developed for the single purpose of producing sugar. Because it sets deep in the ground the sugar beet is more expensive to harvest than other roots. If fed in large quantity this root induces scouring, possibly because of its high sugar content. Because of these facts, Roberts' conclusion, that it is better to grow mangels instead, should generally be followed. Farmers patronizing sugar factories having waste beets should utilize them. (766, 899)

320. Ruta-baga (Swede turnip).- - This root is next to the mangel for ease of cultivation and harvesting. Sheep prefer the rutar baga to all other roots. Like other turnips the ruta-baga may taint the milk of cows, and for this reason should be fed in only limited quantity immediately after milking. This root is a favorite with the stockmen of Canada. (489, 901)

321. Flat turnip. - This root yields less nutriment than the rutabaga, and is not as satisfactory for general use in stock feeding. Sown as a catch crop, large yields are often secured at small cost. This root is used mainly for feeding sheep, as it affects milk still more unfaviabiy than the ruta-baga.

322. Parsnip. - The parsnip is a favorite root crop with the dairy farmers on the islands of Jersey and Guernsey. Since it contains more nutriment, especially carbohydrates, than most roots, and is easily grown, its use should become more common.

${ }^{1}$ Bul. 25. 
323. Artichoke.-At the Massachusetts Station, ${ }^{1}$ Goessmann reports artichokes planted May 4 yielding a crop in November at the rate of 8.2 tons per acre. At the Arkansas Station ${ }^{2}$ the yield was from 454 to 612 bushels per acre. Schweitzer, of the Missouri Station, ${ }^{3}$ found artichokes of equal value with potatoes for pig feeding. (488, 868) The artichoke crop is harvested by allowing pigs to root out and consume the tubers.

324. Storing roots. - Roots should be stored dry in well-ventilated cellars or pits where the temperature is just above freezing. Many stockmen hold that roots are not suitable for feeding until several weeks after harvesting and storage, during which time they undergo a process of ripening which fits them for animal use.

325. Feeding roots. - In Great Britain roots take the place of much of the grain and coarse forage which would otherwise be required by stock. In such cases sheep are fed as much as 20 and cattle 100 ponnds daily. In this couniry, where they are more often used for variety than nourishment, the animal is given a smaller allowance. For horses four or five ponnds of carrots, for dairy cows twenty to thirty pounds of mangels, and for sheep four or five pounds of ruta-bagas, are a fair daily allowance of roots, and one that will greatly conduce to the healthfulness of flock and herd.

Carrots may be fed to horses without slicing.

Roots of all kinds should be sliced for sheep, and either sliced or pulped for cattle. This crop is not generally used for swine feeding in this country, but small quantities may be fed to animals of all ages with advantage. $(657,765,867)$

326. Roots modify the animal carcass.- - At the Utah Station, ${ }^{4}$ Sanborn fed roots to steers, sheep and swine, and on determining the water and fat of the carcasses wrote: "(1) The live-weight gain for cattle and sheep was greater, and for hogs less, when fed on roots. (2) The dressed weight of cattle, sheep and hogs showed in every case greater shrinkage for those fed on roots. (3) The root-fed animals contained more blood and necessarily

Rept. 10.

Bul. 31.

- Bul. 29.

$\leq$ Bul. 17. 
more water in the blood. (4) The root-fed steers had heavier vital organs. (5) The fat was always less for the root-fed animals, and affords a somewhat decisive test of their relative value."

Thus we learn that roots cause a more watery carcass than do dry feeds. For breeding stock especially, and even for animals in the early stages of fattening, may not this point be one of value instead of detriment? The shote running on elover pasture likewise has a watery carcass because of the succulent feed eaten, yet it lays on fat at small cost for food consumed. Grass-fed steers are in the best condition, because of such feed, to make rapid gains when changed to more solid food. A steer fed roots during the first part of the fattening period should remain more vigorous and make better gains for food consumed than one held on dry feed from start to finish. There is no doubt that for breeding stock the less tense flesh, a natural sequence of root feeding, is more conducive to vigorous young at birth, and to their hearty maintenance after birth, than dry feed continued without intermission throughout our long winters. The dairy cow takes kindly to succulent food, and cannot get it in better form than in that furnished by roots. If silage is not used, then let roots be fed, in a limited way at least, to our farm stock. When with dry feed we can produce beef cattle and mutton sheep equal to those of Great Britain, and dairy cows generally as good as those of Jersey, then and not until then can we say there is no place for roots or some other succulent feed on American farms.

327. Root crops not generally grown.-Despite the advice of agricultural writers urging the use of roots, and the example of the English and Canadian feeders, who rely so largely on this crop, roots are no more generally grown in the United States than they were fifty years ago. The cause for this lack of interest is explained by Storer in the following:" "Corn is remarkable, not only for its easy cultivation, but for its enormous yield both of food and of fodder. It is at once a grain crop and a forage crop; or, even wore emphatically, a bread crop and a fallow crop. Practically it has hitherto in good part, if not entirely, done away with the need of cultivating roots for cattle food in this country,

\footnotetext{
1 Agriculture, Vol. II, p. 313.
} 
and it has enormously curtailed the growing of leguminous forage crops also. It is a highly interesting and still debatable question as to how and when and where (if anywhere) systems of farming based on the supplementing of Indian corn with roots may best be practiced."

While the corn plant is so truly the superior of the root crop, stockmen should watch, lest failing to make the proper use of the one they neglect the other. Farmers as a rule should have some succulent food for their stock during the long winter; if it is not in the form of silage, then let it be roots.

II. Miscellaneous Forage Plants, Fruits, etc. 3

Digestible nutrients and fertilizing constituents.

\begin{tabular}{|c|c|c|c|c|c|c|c|}
\hline \multirow[b]{2}{*}{ Name of foed. } & \multirow{2}{*}{$\begin{array}{c}\text { Dry } \\
\text { matter } \\
\text { in l } 100 \\
\text { pounds. }\end{array}$} & \multicolumn{3}{|c|}{$\begin{array}{l}\text { Digestiblo nutrients } \\
\text { in } 100 \text { pounds. }\end{array}$} & \multicolumn{3}{|c|}{$\begin{array}{l}\text { Fertilizing constitu- } \\
\text { ents in } 1,000 \text { pounds. }\end{array}$} \\
\hline & & $\begin{array}{l}\text { Pro- } \\
\text { tein. }\end{array}$ & $\begin{array}{l}\text { Carbo- } \\
\text { hy- } \\
\text { cirites. }\end{array}$ & $\begin{array}{l}\text { Ether } \\
\text { ex- } \\
\text { tiviet. }\end{array}$ & $\begin{array}{l}\text { Nitro- } \\
\text { gen. }\end{array}$ & $\begin{array}{c}\text { Phos- } \\
\text { phoric } \\
\text { acid. }\end{array}$ & $\begin{array}{l}\text { Pot- } \\
\text { as } \mathrm{h} \text {. }\end{array}$ \\
\hline & Llos. & Lbs. & Lbs. & Lbs. & Llus. & Lus. & Lbs. \\
\hline Cabbage.... & 15.3 & 1.8 & 8.2 & 0.4 & 3.8 & 1.1 & 4.3 \\
\hline Spurry ................ & 20.0 & 1.5 & 9.8 & 0.3 & 3.8 & 2.5 & 5.9 \\
\hline Sugar-beet leaves.. & 12.0 & 1.7 & 4.6 & 0.2 & 4.1 & 1.5 & 6.2 \\
\hline Pumpkin, field...... & 9.1 & 1.0 & 5.8 & 0.3 & & & \\
\hline Pumpkin, garden... & 19.2 & 1.4 & 8.3 & 0.8 & 1.1 & 1.6 & 0.9 \\
\hline Prickly comfrey.... & 11.6 & 1.4 & 4.6 & 0.2 & 4.2 & 1.1 & 7.5 \\
\hline Rape ................... & 14.0 & 1.5 & 8.1 & 0.2 & 4.5 & 1.5 & 3.6 \\
\hline Acorns, fresh & 44.7 & 2.1 & 34.4 & 1.7 & & & \\
\hline
\end{tabular}

328. Cabbage.-This plant is grown to some extent in Europe for stock-feeding. On rich ground, yields fully equal or greater than those from roots may be obtained. No food is more highly relished by sheep or dairy cows, though for the latter cabbage must be fed with caution becanse it imparts a taint to the mill. Where soiling is practiced, cabbage may be found a jrufitable crop, though the labor required in the cultivation and the diffculties of storage will probably turn the feeder to the corn plant in its stead.

329. Spurry.-This plant, grown to a small extent in Europe, may possibly prove of value in America on soils too light and sandy for red clover. Kedzie, of the Michigan Station, ${ }^{2}$ reports

\footnotetext{
1 For description of numerous varieties of forage plants see Fodder and Forage Plints, Bul. 2, Division of Agrostology, U. S. Dept. Agr.

21301.101.
} 
quite favorably on this plant for light, sandy land. Stockmen who can grow crops of red clover and corn have no use for spurry.

330. Sugar-beet leaves. - In the vicinity of beet-sugar factories leaves from the beet are available in large quantities. Because of oxalic acid in the leares, they can be fed to stock only in limited quantity without injurious effects. In Europe beet leaves are preserved by building them up in layers, and sprinkling lime over each layer for the purpose of neutralizing the oxalic acid. The heaps thus made are covered with earth and held until required for feeding.

331. Pasmpkin.- Grown as a main crop or even as a secondary one in the corn field, the pumpkin vine often yields large returns at small cost for production. A tract of well-prepared land devoted exclusively to this vegetable will pay well under good management. For dairy cows the pumpkin is an excellent fall feed, none being more highly relished; for swine in the first stages of fattening they are useful either fresh or cooked with meal.

There is a tradition among farmers that pumpkin seeds increase the excretion from the kidneys and should be removed before feeding. In the dispensatory the pumpkin seed is given as a vermí. fuge, with no reference to any other property. Since the seeds contain nutriment they should not be wasted.

332. Prickly comfrey.-From time to time we find this plant highly praised in the agricultural press for its forage properties. At the Wisconsin Station ${ }^{1}$ a comfrey plat was found to require about the same cultivation as the same area planted to potatoes. Woll, comparing the returns from this plat, when well established, with an adjacent area of red clover seeded the year before, found that the red clover in three cuttings yielded twenty-three per cent. more dry matter and twenty-five per cent. more protein than did the comfrey. Cattle generally will not eat this plant when first offered to them, but soon overcome the objection. Generally the stockman would better give his attention to red clover, alfalfa or corn than attempt to use comfrey.

333. Cactus. - In times of scarcity several species of cactus in western Texas are used for maintaining cattle and sheep. The

\footnotetext{
1 Rept. 1889.
} 
prickles of the leaves are scorched off by fire before feeding. Carothers" reports: "During the severe dronght of last winter and the previous one many thousands of cattle were fed upon the scorched pear cactus leaves, but it was the universal experience that it was necessary to give some species of roughage with it; that if fed alone it would not be assimilated and would cause scouring or diarrhœa."

The feed is sometimes prepared by steaming the chopped leaves mixed with cotton seed, and this compound is reported as very satisfactory. ${ }^{2}$

334. Forage rape. - Though as yet grown in but a limited way the rape plant is rapidly gaining in favor in this country, mainly through the instrumentality of our Experiment Stations, which have bronght it prominently to the attention of stockmen. The Dwarf Essex is the variety commonly sown. In a few instances bird-seed rape has been sown, resulting in a product of no feeding value. Rape may be sown at any time from early spring until August in the Northern states, the seed being scattered at the rate of three or four pounds per acre broadcast, or two or three pounds per acre in drills thirty inches apart. Only in the latter form is any cultivation required. The crop is harvested by torning stock directly into the rape field to consume the abundant nutritious leares and stems, which are the parts eaten. It cannot be utilized to advantage as a dry forage, nor as silage owing to its large water content. Zavitz ${ }^{3}$ reports a yield of twenty-seven tons per acre from two pounds of seed sown in drills twenty-seven inches apart, the crop being cultivated every ten days. At the Wisconsin Station, ${ }^{4}$ Craig secured a yield of nine and threequarters tons of rape at a single cutting from a half acre of land, while a small plat yielded at the rate of thirty-six tons per acre from two cuttings.

335. Uses of rape.-For cattle, rape is highly prized by some feeders for furnishing a succulcnt feed during the fall months and preparing them for winter. It has also been fed to dairy cows, but must be used with caution lest it taint the milk. Trials at

\footnotetext{
1 Agr. Sci., Vol. I, 1887, No. 11.

2 Ste I3ul. 3, Bot. Div. U. S. Dep. Agr.

s Rept 19, Ont. Azri. Col. ${ }^{4}$ Rept. 11.
} 
the Wisconsin Station ${ }^{1}$ by Craig show that rape has a very considerable value for feeding swine, especially during the earlier stages of fattening. This feed is much relished by pigs. Being succulent it distends the digestive tract and prepares it for the heavier grain feeding which follows.

It is on sheep farms that rape will find its largest use. It can be fed to all classes of sheep with advantage, and since the animals harvest the crop the cost of feeding it is insignificant compared with the returns. Within eight weeks after seeding the plants are large enough for use, and they are then fed off by turning the sheep directly into the field to gather the forage at will. Craig, of the Wisconsin Station, ${ }^{2}$ makes the following recommendations: "The attempt should never be made to feed lambs rape without giving them a couple of hours grazing on pasture before turning them into the rape. This is necessary for the safety of the lambs, as they are otherwise very liable to bloat, and the combined feeding of pasture and rape results in greater gains."

The rape crop, which will probably grow anywhere in the United States at some season of the year, is recommended to farmers and stockmen as well worthy of trial, since it is produced at small expense for seed and culture and yields an immense amount of nutritions forage, the flavor and succulence of which are highly appreciated by cattle, especially sheep and swine. $(656,767-769,879)$

336. Acorn.- - In some of the forests of Europe this crop has considerable value for swine feeding, and is used to a limited extent in this country. The influence of acorns on the flesh of swine is uncertain, some asserting that the pork from acorn-fed swine is satisfactory, while others affirm that it is soft and undesirable.

337. Leaves and twigs. - The small branches and leaves of trees are fed regularly to farm animals in the mountain regions of Europe where herbage is scarce, and in case of failure of pastures or the hay crop they have been extensively used elsewhere. Twigs contain about fifty per cent. digestible components, mostly non-nitrogenous substances. They contain from forty to fifty per

\footnotetext{
1 Bul. $58 . \quad{ }^{2}$ Loc. cit.
} 
cent. dry matter, and generally less than two per cent. of protein. Leaves are somewhat more digestible than twigs, and the better kinds compare favorably, in feeding value, to meadow hay. Leaves of the ash, birch, linden and elder are considered of greatest value, in the order given. They are eaten with relish, especially by goats and sheep, and are often harvested in the fall and dried for winter feeding.

III. Slaughter-house and Beet-sugar Factory Refuse.

Digestible nutrients and fertilizing constituents.

\begin{tabular}{|c|c|c|c|c|c|c|c|}
\hline \multirow[b]{2}{*}{ Neme of feed. } & \multirow{2}{*}{$\begin{array}{c}\text { Dry } \\
\text { matter } \\
\text { in } 100 \\
\text { pounds. }\end{array}$} & \multicolumn{3}{|c|}{$\begin{array}{l}\text { Digestible nutrients } \\
\text { in } 100 \text { pounds. }\end{array}$} & \multicolumn{3}{|c|}{$\begin{array}{l}\text { Fertilizing constitu- } \\
\text { ents in } 1,00 \text { pounds }\end{array}$} \\
\hline & & $\begin{array}{l}\text { Pro- } \\
\text { tein. }\end{array}$ & $\begin{array}{c}\text { Carbo- } \\
\text { hy- } \\
\text { drates. }\end{array}$ & $\begin{array}{c}\text { Ether } \\
\text { ex- } \\
\text { tract. }\end{array}$ & $\begin{array}{l}\text { Nitro- } \\
\text { gen. }\end{array}$ & $\begin{array}{l}\text { Phos- } \\
\text { phoric } \\
\text { acid. }\end{array}$ & $\begin{array}{l}\text { Pot } \\
\text { ash. }\end{array}$ \\
\hline & Lbs. & Lbs. & Lbs. & Lbs. & Lbs. & Lbs. & Lbs. \\
\hline Dried blood. ...................... & 91.5 & 52.3 & .0 & 2.5 & 135.0 & 13.5 & 7.7 \\
\hline Meat serap................ & 89.3 & 66.2 & .3 & 13.7 & 113.9 & 7.0 & 1.0 \\
\hline Dried fish ............ & 89.2 & 44.1 & .0 & 10.3 & 77.5 & 120.0 & 2.0 \\
\hline Beet pulp........ & 10.2 & 0.6 & 7.3 & & 1.4 & 0.2 & 0.4 \\
\hline Beet molisses........ & 79.2 & 9.1 & 59.5 & .0 & 14.6 & 0.5 & 56.3 \\
\hline
\end{tabular}

338. Dried blood.-Dried blood from the slaughter-house is used for the most part by farmers and gardeners for fertilizing purposes. Such use seems a perversion, for it should first be employed as a feeding stuff and the voidings of the animals to which it has been fed applied to field and garden, thus securing two values. Dried blood may serve a useful purpose with the stockman, especially the pig feeder. We have learned that corn lacks protein; dried blood is a complementary food, since it is remarkably rich in protein. Pigs at weaning time will relish a tablespoonful of dried blood daily with their feed, and this allowance may be gradually increased until two ounces are fed daily to each animal. Those feeding pigs, especially if handling breeding stock, should not allow the gardeners to have first claim to such a useful adjunct to the short list of really desirable feeding materials usually available. See Chapter VI. (778, 902)

339. Flesh meal, meat scrap. - The introduction of meat scrap or flesh meal as a feed for stock is due to the efforts of Baron Liebig, at whose instance the first factory for making meat extract 
was founded in Uraguay, and who suggested the utilization of the refuse meat for stock feeding. Large quantities of flesh meal or meat scrap are now shipped from South America to Europe for use as feed and fertilizers. As shown by the table, this product is remarkably rich in protein, which gives it a high value in connection with corn for feeding stock, especially pigs.

According to Wolff, 1 flesh meal has been found satisfactory as a food for ruminants as well as for swine. When fed to cows and oxen, only a limited quantity should at first be given, the amount being increased until two or three pounds are fed daily. Lambs and sheep digest flesh meal as completely as do pigs, and thrive on this feed.

Judging from the results obtained with flesh meal, there is no reason why the better grades of meat scrap produced at our slaughter-houses should not be used for feeding stock, especially pigs. La Querriere, ${ }^{2}$ discussing meat scrap, concludes that it is excellent for horses when boiled and mixed with hay and straw. The practice of feeding meat to horses is by no means new. The Arabs prepared camels' flesh with other feed in the form of cakes which were given to their horses, thus providing a concentrated, nutritious food.

Scheurer ${ }^{3}$ has shown that meat scrap mixed with ground grain and baked into a bread can be kept for at least seven years without suffering deterioration. A division of English army horses fed American dried meat made into a biscuit with oats showed decided superiority over horses fed in the ordinary way. Such meat biscuits have been recommended for feeding race-horses. (778, 874)

340. Dried fish, fish scrap.-Two feeds made from fish have been placed on the market, viz., fish scrap, which is the dried and ground refuse in the manufacture of dried codfish, and herring cakes or fish meal, which are the whole fish, dried and ground. Both fish scrap and fish cake are used as cattle feeds in the coast regions of Europe. (551) The effects of fish cakes on milk and butter have been studied by Nilson, ${ }^{4}$ Winberg ${ }^{5}$ and

\footnotetext{
1 Farm Foods, Eng. Ed., p. 204.

- Milchzeitung, 1881, p. 753.

- Loc. cit.

Kgl. Landtbr.-Akad. Handl., 1889, 257.

Tidskrift f. Landtmaci, 1891, 522.
} 
Speir, ${ }^{1}$ who report no bad influence on the milk when reasonable quantities are fed. In Nilson's experiments, eighty parts of herring cake replaced one hundred parts of linseed cake in the ration of dairy cows. ${ }^{2}$ (66I)

With dried fish used so largely for fertilizing purposes, the stockman will readily understand the high value of manure originating from this feed.

341. Sugar-beet pulp. - With the development of the beet-sugar industry in this country there will arise much inquiry as to the value of the refuse from the fuctory for stock feeding. Beet pulp contains about ninety per cent. water and ten per cent. solids. The solid matter is composed in part of the cell walls of the beet root, and for this reason contains considerable crude fiber. This fact, and its watery character, indicate that the best use of beet pulp is to serve as a feed for cattle and sheep. Bran and clover or alfalfa hay are complementary feeding stuffs for balancing the ration.

According to Myrick, ${ }^{3}$ a system of feeding cattle in sheds and pens is in operation at the Lehi (Utah) beet sugar factory, where 2,000 head of eattle are fattened each season. Here each animal consumes from 100 to 125 pounds of pulp daily in addition to 15 pounds of hay. "These cattle command a very good market, the meat being very juicy and tender."

Feeding tests were conducted by practical farmers nuder direction of the Halle (Germany) Station, 4 in which a uniform quantity of grain aud hay was fed to cows and steers throughout the trial, with beet pulp supplied in different amounts, for the several periods. As a summary of some of these trials we have the following:

\footnotetext{
1 Trans. Highl. \& Agr. Soc., 1888, pp. 112-128.

2 Concerning the feeding of salt herrings to milch cows, see Rept. Conn. Expt. Sta., 1890, p. 180.

sugar: a New and Profitable Industry.

- Expt. Sta. Rec., Vol. 3.
} 
Yield of milk from dairy cows and gain of steers fed varying quantities of beet pulp - Halle (Germany) Station.

\begin{tabular}{|c|c|c|c|}
\hline & \multicolumn{3}{|c|}{ Cows. } \\
\hline & Period $I$ and $V$. & Period II and IV. & Period III. \\
\hline \multirow[t]{2}{*}{$\begin{array}{l}\text { Beet pulp fed................ } \\
\text { Milk yield................. }\end{array}$} & $\begin{array}{l}44 \text { pounds. } \\
29.4 \text { pounds. }\end{array}$ & $\begin{array}{l}66 \text { pounds. } \\
30.7 \text { pounds. }\end{array}$ & $\begin{array}{l}88 \text { pounds. } \\
31.1 \text { poundr. }\end{array}$ \\
\hline & \multicolumn{3}{|c|}{ Steers. } \\
\hline $\begin{array}{l}\text { Beet pulp fed................ } \\
\text { Daily gain................. }\end{array}$ & $\begin{array}{l}66 \text { pounds. } \\
3.3 \text { pounds. }\end{array}$ & $\begin{array}{l}88 \text { pounds. } \\
3.5 \text { pounds. }\end{array}$ & $\begin{array}{l}110 \text { pounds. } \\
2.8 \text { pounds. }\end{array}$ \\
\hline
\end{tabular}

With cows, eighty-eight pounds of pulp caused the largest flow of milk, while with steers the medium quantity supplied, eighty. eight pounds, gave the best returns, a larger amount materially reducing the gain.

342. Silage from beet pulp.-Beet pulp makes a very fair quality of silage, and because of the large quantity turned out by the factory in a comparatively short time, much of the pulp should be preserved in the silo in order that the period of its usefulness may be materially extended. The simplest form of preservation is effected by excavating trenches three or four feet in depth, and wide enough to drive a team and wagon through. Loads of beet pulp are deposited in this, and when the mass is several feet above the surface of the ground it is arranged with sloping sides which are covered with straw, and on this earth is placed to keep out air and frost. For storing pulp the silo, constructed in the same manner as for the preservation of green corn, will in the end be found more economical.

Beet silage is relished by cattle, and serves well for feeding them, both for flesh and milk. It has about half the value of corn silage.

343. Importance of utilizing beet pulp. - Farmers growing beets for the sugar factory should not be content with this operation, but should add to their system that of feeding a large amount of pulp - at least as much as results from the beets grown by them.

By feeding stock beet pulp and the other waste of the crop, large quantities of manure will be made which will assist in keep- 
ing the farm in high fertility, assuring large crops from the beet fields and ample forage from other lands, used in rotation, for the maintenance of live stock. A farming community which will intelligently grow beets and utilize the pulp resulting from them in the feeding of cattle will be able to grow as large crops, in addition to the beets, as were produced before adding that industry, and to maintain many more cattle than was possible before beet farming was inangurated. This statement is warranted by the conditions prevailing in the beet districts of Europe. Beet culture means more cattle and larger crops generally, rather than less, provided always that the pulp from the beets is properly utilized.

344. Molasses from the beet factory.-Beet molasses, the residue in the manufacture of sugar, is a bitter substance having purging properties. In Europe much of this material has heretofore been wasted, but through continued study by the investigators more and more of it is being utilized. It has been found that a stock food can be prepared by combining beet molasses and dried peat from bogs. The acid in the peat is said to neutralize the alkali of the molasses.

In Sweden, Insulander ${ }^{1}$ fed as much as 3.3 pounds of molasses daily to dairy cows by diluting with twice its weight of water and pouring it over the feed. Work-horses were fed 2.2 pounds daily, and pigs were successfully fed molasses with skim milk.

Clausen and Friderichsen ${ }^{2}$ have shown that beet molasses containing fifty per cent. of sugar, when mixed with fresh blood, may stand exposed to the air for a long time without putrefaction. By adding this mixture of molasses and blood to corn meal or other cereal products and drying, a very nutritious compound is obtained which is palatable with all kinds of farm stock.

345. Quantities of molasses to be fed.- According to Hollrung ${ }^{8}$ the following quantities of beet molasses may be fed with good results to farm animals, daily, per thousand pounds live weight: Draft oxen, 4.4 pounds; fattening steers, 8.8 pounds; milch cows, 2.7 pounds; fattening sheep, .55 pounds, and ewes .3 pounds.

\footnotetext{
1 Expt. Sta. Rec., Vol. 7.

A New Rational Method for the Utilization of Blood, Copenhagen, 1896.

Jahresb. Agr.-Chem., 1895, p. 446.
} 
Animals advanced in pregnancy should be allowed only half the nsual quantity.

346. Potash in beet molasses. - The high potash content of beet molasses, together with a considerable quantity of nitrogen, shows that this by-product should not be wasted, but its ultimate fertilizing constituents saved to the farm.

347. Sorghum and cane-sugar molasses.- Unlike bitter beet molasses, that from the cane plant is palatable and much relished by all farm animals. Cane molasses contains about fifty per cent. sugar and twelve per cent. gums. The nutrients it contains are about equal to those in corn, and, since starch and sugar have practically the same nutritive value, cane molasses has the same feeding value as an equal weight of corn.

At the Texas Station, ${ }^{1}$ Gulley fed molasses with cotton-seed hulls and cotton-seed meal to fattening steers with good results. When molasses was added to silage, the combination gave poorer returns than silage alone. (552)

Molasses is used to some extent for preparing animals for show or sale. Its good effect for this purpose is doubtless due to its palatability inducing large consumption of the feed substances with which it is mingled. Flesh put on through molasses feeding is not considered substantial, and this substance is said to be deleterious to breeding animals, leading to sterility, especially with males.

348. Sugar.- Lawes and Gilbert's investigations to determino the relative value of sugar and starch in foods are well summarized in the following: " In conclusion, the evidence of direct experiment clearly goes to show that all but identical amounts of the dry substance of cane sugar and of starch are both consumed by a given weight of animal within a given time, and are required to yield a given weight of increase. The practical identity in feeding-value, which from the known chemical relationship of these two substances has hitherto been assumed, is now therefore experimentally illustrated, and it probably only varies in point of fact with their slightly varying percentages of carbon."

1 Bul. 10.

2 The Equivalency of Starch and Sugar in Food, Rothamsted Memoiro. Vol. II. 
III. Cono's Milk and its By-producte.

Digestible nutrients and fertilizing constituents.

\begin{tabular}{|c|c|c|c|c|c|c|c|}
\hline \multirow[b]{2}{*}{ Find of mill } & \multirow{2}{*}{$\begin{array}{c}\text { Dry } \\
\text { matter } \\
\text { in } 100 \\
\text { pounds. }\end{array}$} & \multicolumn{3}{|c|}{$\begin{array}{l}\text { Digestible nutrients } \\
\text { in } 100 \text { pounds. }\end{array}$} & \multicolumn{3}{|c|}{$\begin{array}{l}\text { Fertilizing constitr } \\
\text { ents in } 1,000 \text { pounds. }\end{array}$} \\
\hline & & Pro- & $\mid \begin{array}{c}\text { Carbo- } \\
\text { hy- } \\
\text { dratest }\end{array}$ & $\begin{array}{c}\text { Ether } \\
\text { ex- } \\
\text { tract. } t\end{array}$ & $\begin{array}{l}\text { Nitro- } \\
\text { gen. }\end{array}$ & $\begin{array}{l}\text { Phos- } \\
\text { phorie } \\
\text { acid. }\end{array}$ & Pot \\
\hline & Lbs. & Lbs. & Lbs. & Lbs. & Lbs. & Lbs. & Lbs. \\
\hline 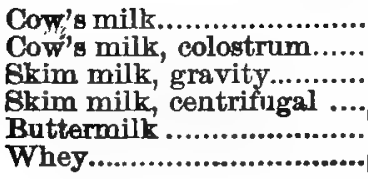 & $\begin{array}{r}12.8 \\
25.4 \\
9.6 \\
9.4 \\
9.9 \\
6.6\end{array}$ & $\begin{array}{r}3.6 \\
17.6 \\
3.1 \\
2.9 \\
3.9 \\
0.8\end{array}$ & $\begin{array}{l}4.9 \\
2.7 \\
4.7 \\
5.2 \\
4.0 \\
4.7\end{array}$ & $\begin{array}{l}3.7 \\
3.6 \\
0.8 \\
0.3 \\
1.1 \\
0.3\end{array}$ & $\begin{array}{r}5.3 \\
28.2 \\
5.6 \\
5.6 \\
4.8 \\
1.5\end{array}$ & $\begin{array}{l}1.9 \\
6.6 \\
2.0 \\
2.0 \\
1.7 \\
1.4\end{array}$ & $\begin{array}{l}1.8 \\
1.1 \\
1.9 \\
1.9 \\
1.6 \\
1.8\end{array}$ \\
\hline
\end{tabular}

* Caseln and albumen.

† Mulk sugar.

$\$$ Fats

349. Concerning milk.-Milk is a substance designed by nature for the sole purpose of nourishing young animal life. For this reason it must always possess a peculiar interest to the student of animal nutrition. It seems reasonable to suppose, from its single parpose, that milk not only contains all the nutrients necessary to sustain the life of young animals but that these are arranged in proper proportion.

350. Fat and serum. - The milk of the cow may be divided into fat and milk serum. The percentage of fat in the milk of the same cow may vary greatly both in the entire milk produced at: different periods and in different portions drawn at the same milking. The first milk drawn is poor in fat, while that last drawn is very rich, as is shown by the following table prepared by Babcock of the Wisconsin Station: ${ }^{1}$

Percentage composition of first and last milk from the cono and of the serum-Wisconsin Station.

\begin{tabular}{|c|c|c|c|c|c|}
\hline & \multicolumn{3}{|c|}{ Composition of millk. } & \multicolumn{2}{|c|}{$\begin{array}{c}\text { Composition of milk } \\
\text { serum. }\end{array}$} \\
\hline & Water. & Solids. & Fat. & Water. & Solids. \\
\hline $\begin{array}{l}\text { Trial No. } I . \\
\text { First milk.......... } \\
\text { Strippings ......... }\end{array}$ & $\begin{array}{l}88.17 \\
80.82\end{array}$ & $\begin{array}{l}11.83 \\
19.18\end{array}$ & $\begin{array}{l}1.32 \\
9.63\end{array}$ & $\begin{array}{l}89.35 \\
89.43\end{array}$ & $\begin{array}{l}10.65 \\
10.57\end{array}$ \\
\hline $\begin{array}{l}\text { Trial No. } \\
\text { First milk........... } \\
\text { Strippings ........ }\end{array}$ & $\begin{array}{l}88.73 \\
80.37\end{array}$ & $\begin{array}{l}11.27 \\
19.63\end{array}$ & $\begin{array}{r}1.07 \\
10.36\end{array}$ & $\begin{array}{l}89.69 \\
89.66\end{array}$ & $\begin{array}{l}10.31 \\
10.34\end{array}$ \\
\hline
\end{tabular}

1 Bal. 18. 
It will be seen that the last milk drawn was from seven to ten times as rich in fat as that first drawn. On the other hand, the serum, which consists of the milk solids less the fat, is substantially constant in composition.

351. Milk fat. - In the manufacture of butter, the object of the dairyman is to secure all the fat possible from the milk with but a trace of the other constituents. By the use of the centrifugal separator most of the fat is abstracted from the milk, the residue amounting to from one to three-tenths of one per cent. In gravity creaming, which was formerly the only process employed, about seven-tenths of one per cent. of fat is usually left in the skim milk. For this reason gravity skim milk is usually somewhat superior for feeding purposes to that skimmed by the centrifugal separator.

352. The nitrogenous constituents. - As the table shows, average milk contains 3.6 per cent. of nitrogenous substances, mainly casein and albumen, in the proportion of about five parts of casein to one of albumen.

In the manufacture of cheese, rennet is added to the milk for the purpose of coagulating the casein. The casein thus coagulated entraps the fat globules and carries most of them into the curd. The albumen, which does not coagulate, together with the milk sugar passes into the whey, as does some of the fat. The amount of fat present in whey varies greatly, according to the manner in which the curd is manipulated previous to drawing the whey.

353. Milk sugar.-Milk sugar in separate form is a white powder of low sweetening power, and is much less soluble than cane sugar, which it closely resembles in chemical composition. When milk sours some of the sugar is changed to lactic acid, which has the effect of coagulating or curdling the casein. When about eight-tenths of one per cent. of acid has developed, fermentation ceases, so that sour milk may still contain much of the original milk sugar. Judging from its composition, milk sugar has about the same value for feeding as the same weight of starch.

354. Ash in milk. - In each hundred pounds of milk there are about seven-tenths of a pound of mineral matter, consisting chiefly of phosphates and chlorids of potash, soda and lime. 
355. Colostrum.-- The first milk yielded by the cow after calv. ing is yellow, thick and viscous, differing from natural milk in its high protein and ash content with low fat and milk sugar. The albumen of colostrum milk may reach 13.6 per cent., while in normal milk it is about one-half of one per cent. This first milk is exceedingly important to the young animal at birth, and should never be withheld from it, for besides yielding nutriment it possesses properties which serve to cleanse the alimentary tract and properly start the work of digestion. (527)

356. Whole milk.- Whole milk is too valuable, in most instances, to be used as a feed for farm animals, though the stockman should never hesitate to supply it when required by very young or valuable animals. Young stock being prepared for exhibition can be forced ahead rapidly by the judicious use of unskimmed milk, and the knowing ones connected with our livestock exhibitions could tell, if they would, some interesting stories concerning the feeding of milk to animals whose weights, if not their ages, would indicate that they should long before have been weaned. $(500,516,659,736)$

357. Skim milk.-Because of the protein and ash it carries, skim milk is of high value in building up the muscular and bony framework of young animals. According to Pott, ${ }^{1}$ the horses of the Coöperative Dairy Association of Hamburg are fed large quantities of skim milk and buttermilk with satisfactory results. In eastern Prussia suckling foals are fed buttermilk and sour skim milk.

Where skim milk is fed care should be exercised in its administration. The vessels which hold the milk and those from which it is fed should be kept clean and wholesome. Milk should always be fed to very young animals at blood temperature, lest on entering the stomach at a lower temperature than maintained by that organ it arrest the progress of digestion. With very young animals skim milk should be fed not less than three times daily. (5ı8-20, 659, 869-7I, 886-8, 890)

358. Buttermilk.-This by-product has substantially the same composition as skim milk. Tests at the Massachusetts Station ${ }^{2}$

\footnotetext{
${ }^{1}$ Futtermittel, p. $645 . \quad{ }^{2}$ Buls. $13,18$.
} 
show that buttermilk has about the same feeding value as skim milk with pigs. In the hands of skilled feeders buttermilk may also be used in calf rearing, though many have failed in this nndertaking. Except for very young animals buttermilk may be used successfully wherever skim milk is employed as a feed. Creameries often dilute buttermilk with water, thereby reducing its value. ( 872 )

359. Whey.- Whey is an exceedingly thin food, and is so liable to misuse that many prefer to waste it rather than incur the risk attendant upon its use. Whey may be fed to pigs with profit, but it must be kept in clean vessels and fed in a cleanly manner. At the Ontario Agricultural College, 1 Day secured as good results with whey somewhat soured as with sweet whey. The feeder should not conclude from this that sour whey held in filthy tanks and vessels is a suitable feed for farm stock. $(523,528,660,873$, $887,889,890$ )

360. Fertilizing value.-The dairyman who sells butter and feeds the skim milk and buttermilk to farm animals parts with but an insignificant amount of fertility. When cheese is made, if the whey is returned to the farm, a considerable portion of the mineral matter of the milk is conserved, but most of the nitrogen is lost. If whole milk is sold, the drain of fertilizing matter is considerable. These differences should always be borne in mind in conducting the various branches of dairy farming.

\section{Condimental Foods.}

361. Findings of investigators. - Proprietary articles styled "Prepared Food," "Seed Meal," etc., costing from three to ten cents per pound, are common, and judging from the advertising space given them in newspapers a large amount of money must be received from their sale each year. It is generally claimed for these feeds that they possess great nutritive properties and medicinal qualities combined.

In England Thorley's Food is a standard article of this class, having been largely advertised for many years. Lawes and Gilbert tested its effectiveness with sheep, and conclude:" "Tho

1 Rept. 1896.

2 Rothamsted Memoirs, Vol. II. 
last column . . . shows that in both of the comparative experiments more food was consumed to produce a given amount of increase with Thorley's Food than without."

362. Nutriotone.-This condiment has been extensively advertised in the East as a food-medicine for farm animals, with the following directions for dairy cows: "Give two large tablespoonfuls with each feed. This will produce a great increase of much richer milk."

Nutriotone was tested by the Vermont1 and Maine Stations.? No advantages followed its use at the Vermont Station.

The following summarizes the findings at the Maine Station:

$\begin{array}{lll} & \text { Milk. } & \text { Fat. } \\ \text { Average for twenty-one days without nutriotone........ } & 2,281 & \text { Lbs } \\ \text { Average for twenty-one days with nutriotone............. } & 2,264 & 101 \\ \end{array}$

It will be seen that this condiment was practically without effect.

363. Condimental foods not recommended.-The basis of the better class of condimental foods is flax-seed meal, oil meal or the by-products from oleaginous seeds, locust-bean meal, etc. They are spiced with anise, cumin and other aromatic seeds. Fenugreek, slippery-elm bark, charcoal, common salt, saltpeter, copperas, etc., are added according to the notions of the compounder. Turmeric is sometimes used to give a yellow color.

As to these nostrums it may be said that vigorous, healthy animals do not make better use of their feed because of their addition. If animals are out of condition they should receive specific treatment according to their ailments. A good manager of live stock will have no use for these high-priced condimental foods or condition powders; a poor manager will never have fine stock by employing them.

\footnotetext{
1 Rept. 1894.

2 Rept. 1896.
} 


\section{CHAPTER XIV.}

\section{BOIITTE OATHLE - PREPARATION OF FEDDING BTUFAR.}

\section{Soiling.}

364. Advantages of soiling. - By "soiling" is meant supplying forage fresh from the fields to farm stock more or less confined. The first American writer to bring this subject to the attention of our people was Josiah Quincy, whose admirable essays, first printed in the Massachusetts Agricultural Journal in 1820, were later gathered into a little book entitled "The Soiling of Cattle," now out of print.

Quincy points out six distinct advantages from soiling: First, the saving of land; second, the saving of fencing; third, the economizing of food; fourth, the better condition and greater comfort of the cattle; fifth, the greater product of milk; sixth, the attainment of manure.

According to this author there are six ways in which farm animals destroy the articles destined for their food. First, by eating; second, by walking; third, by dunging; fourth, by staling; fifth, by lying down; sixth, by breathing on it. Of these six, the first only is useful; all the others are wasteful.

Quincy reports his own experience where twenty cows, kept in stalls, were fed green food supplied six times a day. They were allowed exercise in an open yard. These twenty cows sub. sisted on the green crops from seventeen acres of land where fifty acres had previously been required.

365. Station findings. - At the Wisconsin Station, ${ }^{1}$ the writer kept three cows for the summer on an excellent blue-grass pasture. During the same period three other cows were maintained in stable and yard by soiling. The cows in the pasture consumed

\footnotetext{
1 Rept. 1885.
} 
the grass from 3.7 acres; the soiled cows ate the forage from 1.5 acres. The yield of forage was as follows:

\section{Pounds.}

Green clover, three cuttings. 18,792

Green fodder corn. 23,658

Green oats 2,385

Waste from the above. $\overline{1,655}$ 43,180

The products obtained were as follows:

Pasture and soiting crops compared - Wisconsin Station.

\begin{tabular}{|c|c|c|c|c|}
\hline & $\begin{array}{l}\text { From } 3.7 \\
\text { acres past- } \\
\text { ure. }\end{array}$ & $\begin{array}{l}\text { From one } \\
\text { acre past- } \\
\text { ure. }\end{array}$ & $\begin{array}{l}\text { From } 1.5 \\
\text { acres soil- } \\
\text { ing crops. }\end{array}$ & $\begin{array}{l}\text { From one } \\
\text { acre soil- } \\
\text { ing crops. }\end{array}$ \\
\hline & Lbs. & Lbs. & $\mathrm{Lbs}$ & Lbs. \\
\hline 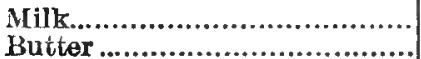 & $\begin{array}{r}6,583 \\
303\end{array}$ & $\begin{array}{r}1,780 \\
82\end{array}$ & $\begin{array}{r}7,173 \\
294\end{array}$ & $\begin{array}{r}4,782 \\
196\end{array}$ \\
\hline
\end{tabular}

This shows that in Wisconsin one acre of soiling crop equals about two and one-half acres of good blue-grass pasture for feeding dairy cows.

At the Pennsylvania Station, 1 during a test of soiling versus pasture, $\Delta$ rmsby secured the following results in digestible organic matter and albuminoids:

Digestible Digestible organic matter. albuminoids. Pounds.

Yield of one acre of pasture. 1,125 Pounds.

Yield of one acre of rye and corn. 249 328

Yield of one acre of clover and corn........ 5, 5,914 374

At the Connecticut (Storrs) Station, ${ }^{2}$ Phelps maintained four cows from June 1 to November 1 on soiling crops produced on two and one-half acres of land.

At the Iowa Station, ${ }^{8}$ Wilson maintained three cows in a darkened stable on soiling crops during the summer, while three others were given the range of "one of the best blue-grass pastures in the state, well shaded with occasional trees and in places by dense woods, with water accessible." The trial began June 20, and continued until August 8, when the cows confined

\footnotetext{
'Rent. $1889 . \quad 2$ Bul. 9. Bul. 15.
} 
in the stable were turned to pasture and those which had been in pasture were soiled in the stable. The second part of the trial continued until September 26. The yield of milk and butter for the whole period was as follows:

$\begin{array}{lcc} & \begin{array}{c}\text { Milk, } \\ \text { pounds. }\end{array} & \begin{array}{c}\text { Fat, } \\ \text { pounds. }\end{array} \\ \text { From three cows kept in stable............ } & 7,216 & 254 \\ \text { From three cows in pasture ................ } & 7,287 & 259\end{array}$

The cattle kept indoors gained more in weight than those on pasture.

366. Soiling crops. - Where cattle are maintained by soiling, provision should be made for a succession of green crops for continuous feeding. In the table below, Lindsey ${ }^{1}$ gives the crops required for the complete soiling of ten cows:

Crops, and areas for same, for soiling ten conos during the entire summer-Massachusetts (Hatch) Station.

\begin{tabular}{|c|c|c|c|c|}
\hline Crop. & Seed per acre. & $\begin{array}{l}\text { Time of } \\
\text { seeding. }\end{array}$ & Area. $r$ & Time of cutting. \\
\hline Rye.... & 2 bu... & Sept. 10-15.. & $\frac{1}{2}$ acre & May 20-May 30 \\
\hline Wheat...... & $2 \mathrm{bu} . . . .$. & Sept. 10-15..... & $\frac{1}{2}$ acre. & June 1-June 15 \\
\hline Red clover & 20 lbs .... & July 15-Aug.1 & $\frac{1}{2}$ acre. & June 15-June 25 \\
\hline Grass and clover & $\left\{\begin{array}{l}1 \\
10 \text { bu. timoth. r. clover } \\
10 \text { lbs. }\end{array}\right\}$ & Sept... & acre: & June 15-June 30 \\
\hline Vetch and oats.. & $\left\{\begin{array}{l}3 \text { bu. oats....... } \\
50 \text { ibs. vetch... }\end{array}\right\}$ & April 20... & I acre & June 25-July 10 \\
\hline Vetch and oats.. & 50 lbs. vetch..... & April $30 .$. & $\frac{1}{2}$ acre & July 10-JuIy 20 \\
\hline Peas and oat & $\left\{\begin{array}{l}1 \frac{1}{2} \text { bu. Canada } \\
1 \frac{1}{2} \text { bu. oats ..... }\end{array}\right\}$ & April 20. & $\frac{1}{2}$ acre & June $25-J u l y ~ 10$ \\
\hline Peas and oats... & $\left\{\begin{array}{l}1, \text { bu. Canada } \\
1, \text { bu. oats.... }\end{array}\right\}$ & April 30.... & $\frac{1}{2}$ acre & July $10-J u l y ~ 10$ \\
\hline Barnyard millet & 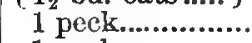 & May 10. & $\frac{1}{8}$ acre & July 25-Aug. 10 \\
\hline Barnyard millet & 1 peck.......... & May $25 .$. & acre & Aug. 10-Aug. 20 \\
\hline Soja bean .......... & 18 quarts .......... & May $20 .$. & $\frac{1}{3}$ acre & Aug. 25-Sept. 15 \\
\hline $\begin{array}{l}\text { Corn... } \\
\text { Corn ... }\end{array}$ & ......... & $\operatorname{May}_{\text {Maz } 30 \ldots}$ & $\frac{1}{3}$ acre & Aug. 25-Sept. 10 \\
\hline $\begin{array}{l}\text { Corn ............ } \\
\text { Hungarian.. }\end{array}$ & 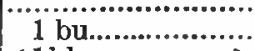 & July $15 . .$. & $\begin{array}{l}\frac{1}{3} \text { acre } \\
\frac{1}{2} \text { acre }\end{array}$ & $\begin{array}{l}\text { Sept. } 10 \text {-Sept. } 20 \\
\text { Sept. } 20 \text {-Sept. } 30\end{array}$ \\
\hline Barley and peas & $\left\{\begin{array}{l}1 \frac{1}{2} \text { bu. peas ..... } \\
1 \frac{1}{2} \text { bu. barley... }\end{array}\right\}$ & Aug. $5 \ldots$ & 1 acre & Oct. 1-Oet. 20 \\
\hline
\end{tabular}

The above will prove a guide for many, though all may not be able to follow in detail all the djrections given. ${ }^{2}$ Sta.

\footnotetext{
1 Bul. 39, Mass. (Hatch) Sta.

' l'or soiling crops recommended by Phelps, see Bul. 8, Conn. (Storrs)
} 
367. Labor involved.-Many who recognize the advantages of soiling are deterred from practicing it, arguing that the large amount of labor required in supplying the green forage daily more than offsets the benefits derived. There is both misconception and lack of knowledge on this point. Wilson ${ }^{1}$ shows that if green forage is gathered twice a week, and spread not too thickly on the barn floor, it will keep in good condition until required for feeding. Most of the crops used can be cut with a mower and gathered by the hay rake or loaded directly by means of the hay loader. Even if pitched by hand, a large quantity of material can be gathered in a very short time. A dairy cow or steer will require from sixty to one hundred pounds of green forage daily.

368. Partial soiling. - So revolutionary is the practice of complete soiling that few stockmen are ready to adopt it at once, even when conceding the merits of the system. Partial soiling is practicable with all and should be followed on every well-managed stock farm. The usual midsummer shrinkage in the milk flow of dairy cows and of flesh with beef cattle can be prevented by housing the stock in darkened stables, if flies are troublesome, during the heated portion of the day, and feeding them liberally with green forage. At night the cattle can be turned to pasture for exercise and grazing. Becanse of the extra allowance of provender supplied during the most trying time of the year, fattening steers will continue their gains, the young stock will not cease growing, and dairy cows will yield the normal flow of mill. Usually it will be found profitable to continue supplying extra feed during the fall, even though the pastures have in part recovered their ability to supply nutriment. Partial soiling rightly followed will be found a most profitable practice on many farms. By it more stock can be kept than on pastures only, and more even gains will be made during the season by all stock so fed.

In using soiling crops it should not be forgotten that growing, immature plants consist largely of water, and often cattle cannot consume enough of such forage to gain the nourishment they require. For this reason, where the crops are quite green, some tiry forage should be supplied in addition to the green.

Bul. 15, Iowa Sta. 
The use of silage will greatly extend the practice of soiling. A corn crop stored in the fall may be partially fed out during winter and the remainder utilized as needed during the summer. Many dairymen are making use of the silo for summer feeding, with excellent results.

Where lands are high priced, or where the stockman desires to i keep a large number of cattle upon a limited acreage, soiling is the best possible means to that end. Cattle fed by soiling should always be allowed exercise in the open lot where they can enjoy the sunshine and fresh air. This can be provided by making use of a small pasture.

\section{Preparation of Feed for Live Stock}

369. Concerning cooked feed.- The early writers on agriculture astually recommended the cooking or steaming of all kinds of feed. In 1812 Arthur Young ${ }^{1}$ described a gruel for stock which he claimed to be exceedingly nutritious and economical.

Morton, anthor of the Cyclopedia of Agricalture, recommended cooking or steaming feed. Later writers, however, have advanced the strongest arguments.

Prof. Mapes wrote: "Raw food is not in condition to be approximated to the tissues of animal life. The experiment, often tried, has proved that eighteen or nineteen pounds of cooked corn are equal to fifty ponnds of raw corn for hog feed."

Joseph Sullivant, a member of the Ohio State Board of Agriculture, wrote: ${ }^{3}$ "I conclude that nine pounds of pork from a bushel of raw corn fed in the ear, twelve pounds from raw meal, thirteen and a half pounds from boiled corn, and sixteen and a half pounds from cooked meal, is no more than a moderate average the feeder may expect to realize from a bushel of corn under ordinary circumstances of weather, with dry and clean feeding pens. All this is within the amounts we have shown to be probable and attainable upon our chemical basis."

Other authorities could be quoted, but these suffice to show that the teachers were generally in favor of cooking food for stock.

1 A system of preparing corn, etc., for the cheaper feeding of horses, etc.

2 Trans. Am. Inst., 1854 , p. 373.

- Rrpot. Ohio Bd. Agr., 1 s'69. 
So much for theory:- what are the results of experiment and experience ?

370. Steaming roughage for cattle. - Fifty years ago there could be found in this country a number of establishments, more or less elaborate and expensive, designed for the purpose of steaming or boiling forage for cattle. The work was usually undertaken by men of means, and was sometimes carried out with much detail and often at considerable expense. It is significant that none of these practices was long maintained.

Experiments with feeding steamed hay to oxen, made at Popelsdorf, 1 showed very decisively that steaming rendered the components of hay less digestible; especially was this trne of the protein. When the hay was fed dry, 46 per cent. of the protein was digested, while only 33 per cent. was digested from the steamed hay. (664)

We may summarize the results of cooking coarse forage for cattle by quoting the reply to an inquirer given many years ago by the editor of an agricultural journal:" "The advantages are very slight and not worth the trouble of either building the fire, cutting the wood or erecting the apparatus, to say nothing of all these combined, with danger and insurance added."

37. Cooking feed for swine.- While the practice of steaming roughage for cattle has been universally abandoned wherever undertaken, much is still said concerning the advantages of cooking feed for swine. This subject has been carefully investigated at our Stations with practically concordant resnlts, so that we are not without definite help on an important topic.

Elsewhere (836) is given a summary of numerous trials with cooked and uncooked feed for swine conducted at the Experiment Stations of this country with the surprising result of an average loss of 6 per cent. in the value of the feed because of cooking. The reader will be interested in the opinions of the various experimenters who conducted the feeding trials.

Shelton, concluding an account of a feeding trial where cooked

1 Hornberger, Landw. Jahrb. VIII, 933; see Armsby, Manusl of Cattle Feeding, p. 266.

Q Country Gentleman, 1861, p. 112.

- Rept. Prof. Agr., Kan. Agr. Col., 1885. 
corn proved inferior to uncooked, wrote: "The figtures given above need but little comment. They show as conclusively as. figures can show anything that the cooked corn was less useful than the raw grain. . . . Such an entire unanimity of results can only be explained upon the theory that the cooking was an injurious process so far as its use for food for fattening animals is concerned."

Brown, of the Ontario Agricultural College, ${ }^{1}$ conducted several triais with cooked and uncooked peas and corn and gives his conclusions as follows: "I am not at present prepared to say definitely what other kinds of food may do, raw or cooked, with pigs or otber domestic animals, or how the other animals will thrive with peas or corn, raw or boiled, but I now assert, on the strongest possible grounds, . . . . that for fast and cheap production of pork raw peas are fifty per cent. better than cooked peas or Indian corn in any shape."

The trustees of the Maine College, ${ }^{2}$ summing up the results obtained at that institution of nine years' continuous feeding of cooked and uncooked corn meal to pigs, wrote: "The results have in every case pointed to the superior value of uncooked meal for the production of pork."

No one can review the accumnlation of experimental data from our Stations, all substantially adverse to cooking feed for swine, without being convinced that the matter is practically settled so far as most feeding stuffs are concerned. A few feeds appear to require the modifying influence of heat and moisture to render them palatable and digestible with stock. Potatoes cannot be successfully fed to swine in any quantity mnless they are first cooked, and roots are more palatable if cooked and meal is added to the mass. The writer has shown that pigeon-grass seed must be cooked to be satisfactorily consumed by swine. This treatment is doubtless made necessary by the thick, woody seed-coats of this grain.

Feeders should not confuse the effects of cooked feeds apon farm stock with the advantages of supplying them with warm feed in palatable form. To the assertion that stockmen who cook feed

1 Rept. 1876. 2 Rept. Me. State Col., 1878. 
have the finest animals, the writer ventures the opinicn that one who is willing to cook feed will usually give his animals many attentions which feeders generally pass by as not worthy of their time or notice. It is this extra care and the larger variety of feeds usually supplied rather than the cooking which make animals of superior quality. For the purpose of affording variety, the various grains, roots and tubers, together with clover or alfalfa chaff, may be boiled or steamed for pigs and used as a part of the ration. The advantages of a limited quantity of such feed, when grain constitutes the remainder of the ration, are conceded.

372. Cooked feed for horses.-Supplying a limited quantity of cooked feed to horses is practiced to some extent in Europe and this country. MacNeilage ${ }^{1}$ reports that the use of boiled feed for horses is growing less common in the west of Scotland.

An excellent feed for horses is made by boiling barley and oats in a kettle with considerable water and pouring the mass over chaffed hay, allowing the whole to stand until the hay is well softened. Bran, roots and a small quantity of oil meal may be added to the pottage. Boiled feed is useful with colts, brood mares and stallions when fed two or three times a week. It may be fed once a day to draft horses which are in preparation for sale or exhibition.

373. Artificial digestion trials. - At the New York (Geneva) Station, ${ }^{2}$ Ladd determined artificially the digestibility of the nitrogenons portion of several common feeding stuffs before and after cooking, with the results shown below:

Digestion trials with cooked and uncooked feeding stuffs-Nero York (Geneva) Station.

\begin{tabular}{|c|c|c|}
\hline \multirow{2}{*}{ Feeding stuff. } & \multicolumn{2}{|c|}{$\begin{array}{l}\text { Per cent. nitrogenous sub- } \\
\text { stance digested. }\end{array}$} \\
\hline & Uncooked. & Cooked. \\
\hline 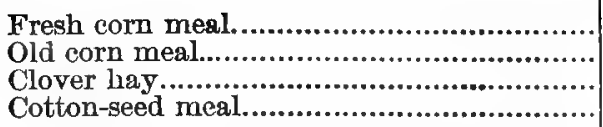 & $\begin{array}{l}68.6 \\
72.6 \\
67.7 \\
87.7\end{array}$ & $\begin{array}{l}60.5 \\
63.2 \\
53.3 \\
73.8\end{array}$ \\
\hline
\end{tabular}

1 Trans. High. and Agr. Soc., 1890.

${ }^{2}$ Rept. 1885. 
In every instance more of the nitrogenous substance was digested from the uncooked than from the cooked food. These results are substantiated by the investigations of others.

374. The function of cooked food.-A limited allowance of steamed or cooked grain mingled with chaffed hay or roots is helpful to horses because of favorable action on the digestive tract. Growing pigs and breeding swine are often materially aiden by a reasonable allowance of boiled or steamed clover or alfalfa chaff, roots or tubers to which meal has been added. Such food possesses considerable volume - a desirable characteristic for feeds designed for the class of stock mentioned. It is not conceded that feeds are generally rendered more digestible by the action of moist heat, but rather that their palatability has been increased and the physical character of the compounds thus prepared made such as to render them desirable for animals under certain conditions. As a general proposition it may be stated that it does not pay to cook food for stock when such food will be satisfactorily consumed without cooking, for cooking does not increase the digestibility of feeding stuffs, but may lower it, and there is considerable expense involved in the operation.

375. Soaking feed.-Corn often becomes hard and flinty a few months after husking, and causes sore mouths with fattening animals. So little of such feed is then eaten that gains may entirely cease or the animals even fall back in weight. Grain which is difficult of mastication should either be ground or soaked to such degree of softness as will allow the animals to consume full rations without difficulty. Soaking ean hardly increase the digestibility of feeds, though it may indirectly do so by permitting better mastication and thereby more complete action of the digestive fluids. $(477,537,665,758,837)$

376. Chaff, or cut hay and straw.-The practice of running hay and straw through the feed cutter, or chaffing it, is almost universal in establishments where large numbers of horses are kept; it is not common on ordinary stock farms. Moore ${ }^{1}$ some years since addressed letters to well-known agriculturists of England asking for information on this topic. He ascertained that 70 per

\footnotetext{
1 Jour. Roy. Agr. Soc., 1888.
} 
cent. of those replying chaffed the hay and straw fed their stock, while 20 per cent. followed partial chaffing, and 10 ner cent. were adverse to the practice.

377. Advantages of chaffing. - The advantages of chaffing (cutting) hay in establishments where large numbers of animals are fed are apparent upon a little reflection. In such places the hay if long occupies too much space, litters up the building, and the attendants are not readily able to supply each animal its proper allowance. Where hay is chaffed, the addition of a small amount of water lays the dust, and the helper can rapidly and accurately measure the quantity ordered for each animal. These advantages do not hold with the same force on stock farms, where the feeder personally supervises the supply of provender to a comparatively limited number of animals. Again, when hay and straw are chaffed, then moistened, and meal added, the mixture is in condition to be rapidly masticated and swallowed, so that the nutriment has a longer time to remain in the stomach for digestion than is possible where long, dry hay is fed. This is an item of importance with hard-worked horses which are in the stable only at night. Horses not hard worked, fattening cattle, and farma stock generally, have ample time for mastication and digestion, and with these there is less necessity, or none, for chaffing hay and straw.

378. Cutting and shredding corn forage.-Corn forage, because of the coarseness of the stalks, is an unsatisfactory material to handle in the stable unless it has first been run through the cutter or shredder. Reduced to fragments by cutting or shredding, this forage causes little trouble, and the waste, if any, is excellent for bedding.

The value of cut or shredded corn stalks for feeding purposes will vary according to the character of the fodder used, the animals to which it is fed and the manner of feeding.

At the Kansas Station, 1 Shelton experimented with stover cut in lengths varying from one-fourth inch to two inches, the rials extending through three seasons. Instead of most of the cut fodder being consumed by the cows, there was an average waste

iropt. 1889. 
of 31 per cent. of all the cut fodder. During one season's \{ris! it. was observed that the finer the fodder was cut the larger the proportion of waste. This investigator summarized his conclusions for Kansas conditions as follows: "I am abundantly satisfied from accurate experiments made to test the point, and from a large general experience, that the chief, almost only, value of cutting fodder is found in the fact that such chopped fodder can be placed in the manger and generally handled much more conveniently than the unchopped."

379. Results of shredding stover.- Quite contrary results were obtained by the writer in a series of trials at the Wisconsin Siation, ${ }^{1}$ in which shredded corn fodder or stover was used. In these trials the same amount of grain and hay was fed to each lot of cows on trial. Those fed whole roughage were supplied with such quantity as seemed necessary to their wants, for they could not bo made to consume the coarser portions of the long stalks, with the partial exception next noted. In the third trial Stowell's Evergreen sweet corn fodder, carrying a considerable quantity of ears, was fed. The stalks of this fodder were soft and pliable, and when fed whole the cows consumed almost all of them, leaving only 143 pounds of stalks ont of 1,600 pounds of fodder fed.

Shmmary of three trials when feeding shredded and unshredded corn forage to dairy cows - Wisconsin Station.

\begin{tabular}{|c|c|c|c|}
\hline & $\begin{array}{c}\text { Stover } \\
\text { fed. }\end{array}$ & $\begin{array}{l}\text { Stover } \\
\text { eaten. }\end{array}$ & $\begin{array}{c}\text { Milk } \\
\text { produced. }\end{array}$ \\
\hline 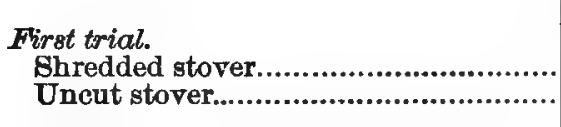 & $\begin{array}{r}\text { Lbs. } \\
721 \\
1,133\end{array}$ & $\begin{array}{l}\text { Lbs. } \\
\text { All } \\
975\end{array}$ & $\begin{array}{l}\text { Lbs } \\
1,387 \\
1,419\end{array}$ \\
\hline 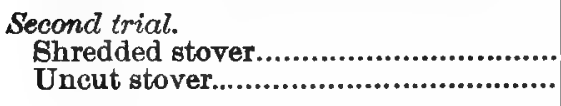 & $\begin{array}{l}1,217 \\
1,934\end{array}$ & $\underset{1,356}{\mathrm{Aul}}$ & $\begin{array}{l}1,418 \\
1,439\end{array}$ \\
\hline 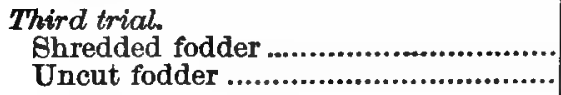 & $\begin{array}{l}1,600 \\
1,600\end{array}$ & $\begin{array}{r}\text { All } \\
1,457\end{array}$ & $\begin{array}{l}989 \\
872\end{array}$ \\
\hline
\end{tabular}

${ }^{1}$ Rept. 1886. 
Summarizing the preceding data, we have: When feeding corn forage with hay and grain, the cows getting -

3,538 pounds shredded stover or fodder produced 3,794 pounds of milk. 4,667 pounds unshredded stover or fodder produced 3,730 pounds of milk.

If we count the milk returns equal for the two lots, - though they are slightly in favor of the cows getting the shredded fodder, - we have a saving of 24 per cent. of corn forage by using it in shredded form.

Here are different results from those secured by Shelton. How can they be harmonized? In the first place, the stalks used by Shelton were much coarser and harsher than those grown in Wisconsin, and it is probable that his cattle were offered such liberal quantities of forage that they naturally chose the softer portions, wasting the remainder. Again, it is possible that the sharp edges of the fine-cut corn stalks made the mouths of the cattle sore, so that they could not eat forage as they otherwise would.

380. Long hay and dry feed. - At the Maine Station, ${ }^{1}$ Jordan fed rations of long hay and chaffed hay as follows:

During the first and third periods, each lasting thirty days, five cows were fed long hay with an allowance of dry grain fed separately. During the intermediate period the cows were fed the same amount of hay chopped fine, with the same quantity of meal as before. The cut hay and meal were first mixed, then wet, and the mixture allowed to stand for several hours before feeding. The middle period lasted fifty-one days.

Yield of milk and butter from cows fed wet and dry rations - Maino Station.

\begin{tabular}{|c|c|c|}
\hline \multirow{2}{*}{ Periods. } & \multicolumn{2}{|c|}{ A verage yield, five cows. } \\
\hline & Milk. & Butter. \\
\hline 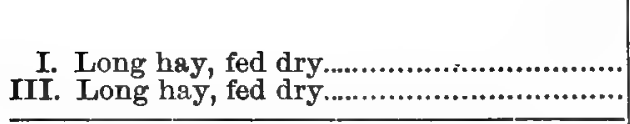 & $\begin{array}{r}\text { Lbs. } \\
130.1 \\
100.5\end{array}$ & $\begin{array}{l}\text { Lbs. } \\
5.4 \\
3.8\end{array}$ \\
\hline $\begin{array}{l}\text { Average of two periods........................ } \\
\text { II. Hay chaffed mixed with grain, fed wet. }\end{array}$ & $\begin{array}{l}115.8 \\
113.2\end{array}$ & $\begin{array}{l}4.6 \\
4.24\end{array}$ \\
\hline
\end{tabular}

'Rept. 1890. 
We learn from the above that the cows did somewhat better on the long hay and dry feed, both for milk and butter, than on the same feed supplied in chaff form, wet and mixed with grain.

381. Wet chaffed hay for calves. - At the Iowa Station, ${ }^{1}$ Speer divided a bunch of six calves into two lots of three each. To one lot was fed corn and cob meal morning and evening, with dry, long timothy hay given after the meal had been consumed. For the other lot the feeding was as follows: Some hay was run through the feed-cutter and moistened. Over this was sprinkled the corn and cob meal, and the whole thoroughly mixed. An hour and a half after the wet grain and hay mixture had been fed the calves were supplied with dry, long hay.

Feeding dry meal, and meal on moistened hay, to calves - Iowa Station.

\begin{tabular}{c|c|c|c}
\hline \hline & $\begin{array}{c}\text { Average } \\
\text { weight at } \\
\text { beginning. }\end{array}$ & $\begin{array}{c}\text { Aversge } \\
\text { gain. }\end{array}$ & $\begin{array}{c}\text { Grain for } \\
100 \text { pound } \\
\text { gain. }\end{array}$ \\
\hline Meal fed dry.................................. & 452 & Lbs. & Lbs \\
Meal fed wet, mixed with hay .......... & 480 & 68.4 & 542 \\
\hline \hline
\end{tabular}

It will be seen that the calves fed the dry meal gained somewhat more than the others, and required less feed for one hundred pounds of gain.

382. Grinding grain.- This subject is a difficult one to discuss owing to the great variety of conditions existing as to both grain and animals. Directions are here given which may serve to guide the feeder in his practice. For horses which are out of the stable during the day and worked hard, all grain, with the possible exception of oats, should be ground. For those at extremely hard work, all grain should be ground and mixed with chaffed hay. For idle horses, oats or corn should not be ground, nor need the hay or straw be chaffed. A cow yielding a large flow of milk should be regarded as a hard-working animal and her feed prepared accordingly. (633) Fattening steers and pigs may be crowded more rapidly with meal than with whole grain, though there is more danger attendant upon its use. (536, 539) Sheep

1 Bul. 12 
worth feeding can always grind their own grain. In general, idlo animals and those having ample time for mastication, rumination and digestion do not need their grain or roughage prepared as carefully as do those with only limited time for these essential operations. Experiments quite generally show increased gains from grinding grain, but in many cases they are not sufficient to pay the cost of grinding. (848)

383. Preparing roots. - Roots are prepared for stock either by slicing or pulping. For sheep they should iro cut into small, short pieces. Roots reduced to pulp are fed with chaffed hay and straw to steers and cows with excellent results. The method of preparation is as follows: A layer of chaffed hay or straw is spread upon the barn floor and over this is placed one of root-pulp, followed by chaff, and then pulp again until the heap reaches the desired size. Sometimes oil meal, corn meal or other grain is added. After forming the layers the mass is shoveled over until the ingredients are thoroughly mixed, after which it is allowed to stand until the next day, by which time a slight fermentation has started and the mixture is ready for feeding. This system has value on farms where it is desirable to feed large quantities of straw or low-grade hay which would otherwise be refused or wasted by the aninals. The serious objection to the practice is the large amount of labor involved, yet it is advantageous in some cases. 


\section{OHAPTER XV.}

\section{THE ENSILAGE OF FODDERA.}

I Silage.

Digestible nutrients and fertilizing constituents.

\begin{tabular}{|c|c|c|c|c|c|c|c|}
\hline \multirow[b]{2}{*}{ Variety of silage. } & \multirow{2}{*}{$\begin{array}{l}\text { Dry } \\
\text { matter } \\
\text { 1n } 100 \\
\text { pounds. }\end{array}$} & \multicolumn{3}{|c|}{$\begin{array}{l}\text { Digestible nutrients } \\
\text { in } 100 \text { pounds. }\end{array}$} & \multicolumn{3}{|c|}{$\begin{array}{l}\text { Fertilizing constitu- } \\
\text { ents in } 1,000 \text { pounds. }\end{array}$} \\
\hline & & $\begin{array}{l}\text { Pro- } \\
\text { tein. }\end{array}$ & $\begin{array}{c}\text { Carbo- } \\
\text { hy- } \\
\text { drates. }\end{array}$ & $\begin{array}{l}\text { Ether } \\
\text { ex- } \\
\text { tract. }\end{array}$ & $\begin{array}{l}\text { Nitro- } \\
\text { gen. }\end{array}$ & $\begin{array}{l}\text { Phos- } \\
\text { phoric } \\
\text { actd. }\end{array}$ & $\begin{array}{l}\text { Potr } \\
\text { ash. }\end{array}$ \\
\hline & Lbs. & Lbs. & Lbs. & Lbs. & Lbs. & Lbs. & Lbs. \\
\hline Corn ..... & 20.9 & 0.9 & 11.3 & 0.7 & 2.8 & 1.1 & 3.7 \\
\hline Clov & 28.0 & 2.0 & 13 & 1.0 & & & \\
\hline Sorg & 23.9 & 0.6 & 14. & 0.2 & & & \\
\hline Alfalfa ... & 27.5 & 3.0 & 8. & 1.9 & & & \\
\hline Gras & 32.0 & 1.9 & 13. & 1.6 & & & \\
\hline Cowpes v & 20.7 & 1.5 & 8.6 & 0. & & & \\
\hline Soja bean. & 25.8 & 2.7 & 8.7 & 1.3 & & & \\
\hline Barn-yard millet and soj & & & & & & & \\
\hline 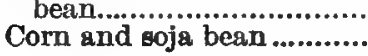 & $\begin{array}{l}21.0 \\
24.0\end{array}$ & 1.6 & 9.2 & 0.7 & & & \\
\hline & $2 \pi .0$ & 1.0 & 15.0 & 0.1 & & & \\
\hline
\end{tabular}

384. Permanency of this method of food preservation.-For more than two decades the subject of silos and silage has been prominently before the American farmer for consideration. BLuch space has been given to the matter by the agricultural press and much time devoted to discussions in relation thereto in agri. cultural gatherings. Unfortunately for this form of food preservation extravagant claims were advanced in its behalf by some of its early enthusiastic advocates. These naturally aroused the suspicion of conservative people, who Jooked upon the matter as something for the day only and unworthy of thoughtful consideration or investigation. Silos and silage have outlasted their overzealous friends, and through the experience of practical feeders and the investigations of our Experiment Stations we are now able to discuss the subject intelligently. Becanse corn is the great silo crop, a consideration of the matter turns upon the relative 
merits of fodder corn dried in the ordinary way and preserved by the system of ensilage.

385. Relative losses in drying and ensilage.-The following table presents data gathered at several Stations relative to the losses incurred in preserving green corn forage by shocking and by ensilage. In these trials a quantity of fodder was cut and placed in the shock or stook. In some cases the shocks remained in the field untouched until winter; in others they were made into larger shocks, or were placed in the barn for protection. At the time of cutting and shocking the corn, another equal portion from the same field was placed in the silo.

Relative losses incident to curing corn fodder by drying and by ensilage - Various Stations.

\begin{tabular}{|c|c|c|c|c|}
\hline \multirow[b]{2}{*}{ Btation. } & \multicolumn{2}{|c|}{ Corn silage. } & \multicolumn{2}{|c|}{ Corn fodder. } \\
\hline & $\begin{array}{c}\text { Dry } \\
\text { matter. }\end{array}$ & Protein. & $\begin{array}{c}\text { Dry } \\
\text { matter. }\end{array}$ & Protein. \\
\hline & Per cent & Per cent & Per cent & Per cent \\
\hline Vermont, Rept. 1889. & 14.7 & & $13.6^{*}$ & \\
\hline Vermont, Rept. 1891 ......................... & 20.0 & 13.0 & 19.0 & 17.0 \\
\hline Vermont, Rept. 1892 ........................ & 18.0 & 11.0 & 18.0 & 9.0 \\
\hline Vermont, Rept. 1894. & 20.0 & 12.0 & 20.0 & 12.0 \\
\hline New Jersey, Bul. 19........... & 18.0 & & 17.3 & \\
\hline Pennsylvania, Rept. $1889 . . . . . . . . .$. & 10.8 & 26.5 & 21.0 & 13.8 \\
\hline Wisconsin Rept. 1891, av. four years. & 15.6 & 16.8 & 23.8 & 24.3 \\
\hline
\end{tabular}

* Large shocks; 15.1 per cent. for small shocks.

The figures show the range of losses which may occur by either process of preserving fodders. It is evident that the systems, as commonly practiced, possess about equal merit in the proportion of nutriment they conserve.

386. Necessary losses in silage.-In considering the losses of silage the waste found in the top layer, which acts as a cover for the material below, has always been taken into account. This loss is a constant one, being no more for a deep silo than for a shallow one. By using fresh grass, wet chaff or other cheap material for covering, or by beginning to feed from the silo immediately after filling, the loss commonly occurring in the top layer may be reduced or entirely aroided. 
King, stadying the subject at the Wisconsin Station ${ }^{1}$ with a round silo, concludes after four years' experience that, omitting the losses found in the top layer and those which may occur at the bottom of the silo, the other losses need not exceed ten per cent. of dry matter for corn and eighteen per cent. for red clover.

387. Character of silo losses. - At the Maine Station, ${ }^{2}$ Jordan investigated this subject during three years, with the findings presented in the following table:

Composition of water-free substances in greon corn and silage made therefrom - Maine Station.

\begin{tabular}{|c|c|c|c|c|c|c|c|}
\hline \multirow{2}{*}{ Constitnent. } & \multicolumn{2}{|c|}{1881.} & \multicolumn{2}{|c|}{1882.} & \multicolumn{3}{|c|}{1889.} \\
\hline & $\begin{array}{l}\text { Green } \\
\text { corn. }\end{array}$ & Silage. & $\begin{array}{l}\text { Green } \\
\text { corn. }\end{array}$ & Silage. & $\begin{array}{l}\text { Green } \\
\text { corn. }\end{array}$ & Silage* & Sllage. \\
\hline & Per ct. & Per ct. & Perct. & Per et. & Per ct. & Per ct. & Per et \\
\hline 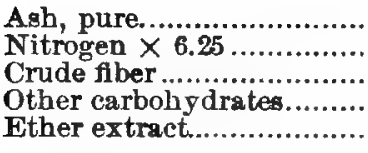 & $\begin{array}{r}5.0 \\
6.5 \\
24.2 \\
62.3 \\
1.9\end{array}$ & $\begin{array}{r}5.5 \\
7.2 \\
27.4 \\
57.0 \\
2.9\end{array}$ & $\begin{array}{r}3.7 \\
8.0 \\
35.2 \\
51.0 \\
2.0\end{array}$ & $\begin{array}{r}4.0 \\
8.9 \\
35.7 \\
49.2 \\
2.3\end{array}$ & $\begin{array}{r}3.3 \\
7.3 \\
29.3 \\
57.7 \\
2.4\end{array}$ & $\begin{array}{c}3.7 \\
7.5 \\
34.0 \\
52.1 \\
2.8+\end{array}$ & $\begin{array}{r}3.7 \\
7.3 \\
33.8 \\
52.6 \\
2.8+\end{array}$ \\
\hline Total nitrogen ............. & 1.1 & 1.2 & 1.3 & 1.4 & 1.2 & 1.2 & 1.2 \\
\hline $\begin{array}{l}\text { Albuminoid nitrogen, di- } \\
\text { rect determination.......... }\end{array}$ & 0.9 & 0.6 & 1.0 & 0.6 & 0.8 & 0.5 & 0.6 \\
\hline 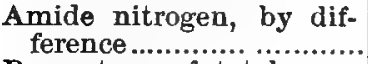 & 0.1 & 0.6 & 0.3 & 0.8 & 0.4 & 0.7 & 0.6 \\
\hline $\begin{array}{l}\text { Percentage of total non- } \\
\text { albuminoid nitrogen, by } \\
\text { difference....................... }\end{array}$ & 13.3 & 50.4 & 13.3 & 33.1 & 29.9 & 58.5 & $52 . B$ \\
\hline
\end{tabular}

* Dried quickly.

$\dagger$ Assumaed.

We learn from the above table that in the process of ensilage the crude fiber of the corn plant is not reduced or changed by the heat and moisture of the silo. The other carbohydrates, constituting as they do the more valuable non-nitrogenous portion of the forage, are diminished percentagely and in total quantity. The ether extract is increased through the formation of lactic acid. We further observe that a considerable portion of the albuminoid nitrogen in the green forage is changed to amide nitrogen. This reduction of organic nitrogen from albuminoid to simpler forms has been held to indicate a large loss in the feeding

1 Bul. 59.

Soc. Pro. Agr. Bci., 1884. 
value of the protein constituents of silage, a fact not borne out by direct feeding tests. (655)

388. Digestibility of silage and fodder corn.-The studies of the chemists on this subject have been arranged by $\mathrm{Woll}^{1}$ in the following table:

Average digestion coefficients for corn silage and green and cured fodder corn - Arranged by Woll.

\begin{tabular}{c|c|c|c|c|c|c}
\hline \hline Forage. & $\begin{array}{c}\text { Dry } \\
\text { matter. }\end{array}$ & Ash. & $\begin{array}{c}\text { Pro } \\
\text { tein. }\end{array}$ & $\begin{array}{c}\text { Crude } \\
\text { fiver. }\end{array}$ & $\begin{array}{c}\text { N.-free } \\
\text { extract. }\end{array}$ & $\begin{array}{c}\text { Ether } \\
\text { extract. }\end{array}$ \\
\hline Green fodder corn.............. & 68 & $\mathbf{3 5}$ & 61 & 61 & 74 & $\mathbf{7 4}$ \\
Cured fodder corn............. & $\mathbf{6 6}$ & $\mathbf{3 4}$ & $\mathbf{5 5}$ & 66 & 69 & $\mathbf{7 2}$ \\
Corn silage...................... & $\mathbf{6 6}$ & $\mathbf{3 1}$ & $\mathbf{6 3}$ & $\mathbf{6 7}$ & $\mathbf{7 0}$ & $\mathbf{8 1}$ \\
\hline
\end{tabular}

So far as this table shows, there is no appreciable difference in the digestibility of corn silage and dry fodder corn, both being somewhat less digestible than green fodder.

389. Yield of milk per hundred pounds of dry matter.-At several Stations feeding trials were so conducted that a compari. son can be made of the yield of milk from the same quantity of dry matter fed in silage and dry corn fodder respectively.

Milk produced from dry matter in silage and dry fodder corn - Various Stations.

\begin{tabular}{|c|c|c|c|c|}
\hline \multirow{2}{*}{ Station and reference. } & \multirow{2}{*}{$\begin{array}{l}\text { No. } \\
\text { trials. }\end{array}$} & \multirow{2}{*}{ Basis of calculation. } & \multicolumn{2}{|c|}{$\begin{array}{l}\text { Milk produced } \\
\text { per } 100 \text { pounds: }\end{array}$} \\
\hline & & & Silage. & $\begin{array}{l}\text { Fodder } \\
\text { corn. }\end{array}$ \\
\hline & & Dry matter in: & Lbs. & Lbs. \\
\hline Wisconsin, 7th Report..... & 2 & Whole ration..... & 76.9 & 86.0 \\
\hline Wisconsin, 8th Report.... & 1 & Whole ration..... & 70.4 & 78.7 \\
\hline Vermont, 1892 Report.... & 1 & Whole ration.. & 82.0 & 76.5 \\
\hline Vermont, 1892 Report........... & 1 & Whole ration... & 73.5 & 73.4 \\
\hline Pennsylvania, 1890 Report.. & 2 & Whole ration......... & 111.9 & 106.3 \\
\hline Wisconsin, 6th Report........ & 3 & Exptl. forage only & 155.0 & 146.1 \\
\hline Wisconsin, 5th Report.... & 3 & Exptl. forage only & 166.2 & 149.6 \\
\hline Vermont, 1891 Report... & 1 & Exptl. forage only & 240.0 & 218.0 \\
\hline
\end{tabular}

Reviewing the table we observe that excepting the first and second trials there were larger returns of milk, when feeding a

1. Bowk ou Silage. 
given quantity of dry matter in the form of silage, than from the same amount of dry matter in the dry fodder. The average for fourteen trials is about four per cent. more milk from the dry matter in the form of silage.

390. Feeding tests with silage and fodder corn.-Feeding tests with silage and fodder corn made at the Vermont ${ }^{1}$ and Wiscon! $\sin ^{2}$ Stations were conducted as follows: In each case two rows of corn across the field were cut and placed in shocks, while the next two rows were run through the feed-cutter and placed in the silo. By thus alternating until the silo was filled, equal quantities of material of the same composition were obtained. The dried fodder so produced was run through the feed-cutter and fed in opposition to the silage to dairy cows, with equal quantities of hay and grain.

The results at the Vermont Station were as follows:

24,858 pounds green fodder corn when dried, fed with a uniform daily allowance of hay and grain, produced 7,688 pounds of milk.

24,858 pounds of green fodder corn converted into silage, ind fed with the same daily ration of hay and grain, produced 8,525 pounds of milk.

At the Wisconsin Station the results were:

From 29,800 pounds of green fodder were obtained 24,440 pounds of silage, which, fed with 1,648 pounds of hay and 2,884 pounds of grain, produced 7,496 pounds of milk, containing 340.4 pounds of fat.

From 29,800 pounds of green fodder were obtained 7,330 pounds of fieldcured fodder corn, which, fed with 1,567 pounds of hay and 2,743 poinds of grain, produced 7,119 pounds of milk, containing 318.2 pounds of fat.

At the Vermont Station the silage ration produced 837 pounds or 11 per cent. more milk than was obtained from the dry fodder ration.

At the Wisconsin Station the silage ration yielded 377 pounds more milk and 22 pounds more fat-a difference in favor of silage of 5 per cent. in milk and 6 per cent. in fat.

391. Relative merits of silage and dry fodder corn.- We have scen that the losses of nutrients in the two methods of curing are about equal. We have further learned that the digestibility of

Rept. 1891.

2 Rept. 1891. 
corn silage and of dry fodder is practically the same. Finally, actual feeding trials with dairy cows have shown that silage usually gives better results than a corresponding amount of dry fodder. The difference in favor of silage is probably due in part to the fact that cattle usually reject the dry butts of the corn stalk, even when cut fine, while in silage this part is readily eaten. Thus, with a given amount of forage of either kind, somewhat more of that in the form of silage is consumed. Agrain, silage is more acceptable to stock than dry fodder, and a larger amount of dry matter is consumed in the same time, which conduces to greater gains in flesh or larger yields of milk. Because the animal willingly eats more food in the shape of silage, there is more nutriment left to form milk or flesh after the wants of the body are met.

It is a significant fact that the largest users of silage declare the most strongly in favor of this forage. (654-5)

392. Effects of silage on the carcass. - At the Utah Station, ${ }^{1}$ Sanborn found that the flesh of steers fed silage contained six per cent. and that of sheep two per cent. more water than the flesh of other animals of the same kind receiving dry forage. Like roots, silage makes a watery carcass, which is soft to the touch. Some have considered this a disadvantage. Is it not rather a desirable condition, within reasonable limits, for all farm stock, including fattening animals during the earlier stages of that process?

Feeding dry forage only during the long winters tends to produce a dry, firm flesh - a condition certainly not conducive to the highest degree of health if summer pastures afford the ideal feed. While silage is highly useful in the preliminary stages of steer feeding, and its continued use in moderate quantity throughout the fattening period is desirable, the proportion of this succulent food to dry forage should be diminished as fattening advances, in order that the flesh may become more solid.

393. Yield of silage corn and roots. - Corn silage and roots both claim the feeder's interest because of their palatability and succulence. Since they are equally relished by stock, the choice between

Bul. 8. 
them must finally turn upon the amount of nutriment produced from a given area of land and the cost of production. Woll ${ }^{1}$ presents the following table, showing the green substance and the dry matter yielded by both crops at four Stations:

Field and dry matter per acre of roots and green fodder corn - Four Stations.

\begin{tabular}{|c|c|c|c|c|c|c|c|c|}
\hline \multirow{2}{*}{ Crops compared. } & \multicolumn{2}{|c|}{ Matne Station. } & \multicolumn{2}{|c|}{$\begin{array}{l}\text { Pennsylvania } \\
\text { Station. }\end{array}$} & \multicolumn{2}{|c|}{ Obin Station. } & \multicolumn{2}{|c|}{$\begin{array}{l}\text { Ontario } \\
\text { College. }\end{array}$} \\
\hline & $\begin{array}{c}\text { Green } \\
\text { sub- } \\
\text { stance. }\end{array} \mid$ & $\begin{array}{c}\text { Dry } \\
\text { matter }\end{array}$ & $\begin{array}{l}\text { Green } \\
\text { sub- } \\
\text { stance. }\end{array}$ & Dry & $\begin{array}{c}\text { Green } \\
\text { sub- } \\
\text { stauce. }\end{array}$ & $\underset{\text { matter }}{\text { Dry }}$ & $\begin{array}{c}\text { Green } \\
\text { sub- } \\
\text { stance. }\end{array}$ & $\begin{array}{c}\text { Dry } \\
\text { matter }\end{array}$ \\
\hline & Libs. & Lbs. & Lbs & Lbs. & Lbs. & Lbs. & Lbs. & Lbs. \\
\hline Ruta-bagas & $31,695 \mid$ & 3,415 & & & & & 42,780 & 4,877 \\
\hline Mangels. & 15,375 & 1,613 & 16,177 & 2,382 & 31,500 & 3,000 & 55,320 & 5,034 \\
\hline Turn & 28,500 & 2,559 & & & & & 46,120 & 4,382 \\
\hline Sugar beets & 17,645 & 2,590 & 11,436 & 2,010 & & & 32,663 & 4,737 \\
\hline Fodder corn. & 39,645 & 5,580 & 18,591 & 5,522 & & 6,000 & 41,172 & 8,135 \\
\hline
\end{tabular}

It is seen that fodder corn yields about twice the dry matter that can be secured from a crop of roots grown on the same land.

394. Dry matter in silage and roots. - The value of the dry matter of roots and silage for milk production has been studied at the Ohio, ${ }^{2}$ Pennsylvania ${ }^{3}$ and Vermont ${ }^{4}$ Stations with the following results:

Milk produced by feeding one hundred pounds of dry matter in corn silage and beet rations - Three Stations.

\begin{tabular}{|c|c|c|}
\hline & $\begin{array}{c}\text { Beet } \\
\text { ration. }\end{array}$ & $\begin{array}{l}\text { Silage } \\
\text { ration. }\end{array}$ \\
\hline Ohio Station: & Lbs. & Lbs. \\
\hline 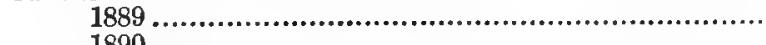 & 59 & 62 \\
\hline 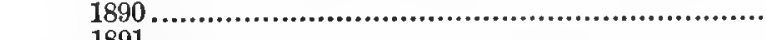 & 59 & 60 \\
\hline 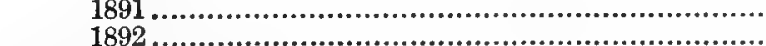 & 62 & 66 \\
\hline 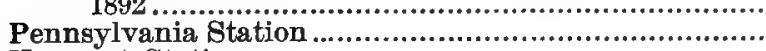 & 69 & $\begin{array}{l}76 \\
89\end{array}$ \\
\hline Vermont Station & 113 & 119 \\
\hline
\end{tabular}

It will be seen that although practically all of the dry matter of beets is digestible, while a considerable portion of that in corn silage is not, dairy cows, when fed rations consisting largely of

1 A Book on Silage.

$=$ Rept. $1893 . \quad$ Rept. $1890 . \quad 1895$. 
beets or silage, yield somewhat better returns for the dry matter in the silage. The difference in favor of the dry matter of silage in these six trials is three per cent.

395. Relative cost of beets and silage. - Armsiby, of the Pennsylvania Station, ${ }^{1}$ estimates the cost of one acre of corn placed in the silo at $\$ 21.12$, while to grow and house an acre of beets costs $\$ 56.07$.

At the Ohio Station, 2 Thorne reports that an acre of beets, harvesting $15 \frac{3}{4}$ tons and containing 3,000 pounds of dry matter, cost more than an acre of corn yielding 57 bushels of grain and containing 6,000 pounds of dry matter. The great disadvantage of roots in competition with corn silage is here made apparent. $(550,765)$

396. Removing the ears from silage corn previous to ensilage.About the year 1890 the agricultural press contained favorable notices of a system of silage making, which in brief is as follows: The ripening ears of corn are removed from the stalks and cured on the barn floor or elsewhere under cover. The corn stalks freed from the ears are then run through the feed-cutter and preserved as silage. At feeding time a part of the dry ear corn reduced to meal is fed to cattle with the silage. It was claimed that this was an economical practice. Woll summarizes the results at the Wisconsin Station, ${ }^{8}$ where silage from equal areas of land was used, thus:

33,750 pounds of silage, with ears, fed in addition to hay and grain (the feed containing $17,127.5$ pounds of dry matter in all), produced 11,835 pounds of milk.

27,571 pounds of silage with ears picked off, plus 4,341 pounds of dry ear corn, in addition to hay and grain as before (the feed containing $16,491.7$ pounds of dry matter in all), produced 11,423 pounds of milk.

Hills, of the Vermont Station, 4 reports that an acre of green corn fodder, including ears, reduced to silage, was equal in feeding value to 1.26 acres of silage from stalks stripped of their ears, fed with the meal made by grinding the dry ear corn which

1 Bul. 26.

2 Rept. 1893.

Repts. 1891, 1892

- 12ept. 1892. 
was produced by the crop. These trials show that the practice of separating and drying the ear corn in silage making is not warranted by the results, and that it is better to run the ear corn into the silo with the fodder.

397. Southern versus Northern seed corn for silage.-Digestion trials conducted during five years at the Maine Station ${ }^{1}$ by Jordan showed that sixty-five per cent. of the dry matter in the Southern corn silage was digestible as against seventy-three per cent. in the silage from corn of home-grown varieties.

Digestion trials were also conducted at the Pennsylvania Station ${ }^{2}$ during three years by Armsby. In the following table are given the findings of the Maine and Pennsylvania Stations from direct trials, and similar data from three other Stations, the Maine coefficients of digestibility being nsed in calculating the data given in the last column of the table:

Green weight, dry matter and digestible substance per acre in corn forage from southern- and northern-grown seed-Five Stations.

\begin{tabular}{|c|c|c|c|}
\hline & $\begin{array}{c}\text { Green } \\
\text { weight. }\end{array}$ & $\begin{array}{c}\text { Dry } \\
\text { matter. }\end{array}$ & $\begin{array}{l}\text { Digestible } \\
\text { substance. }\end{array}$ \\
\hline 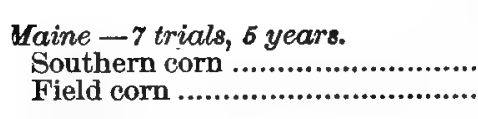 & $\begin{array}{c}\text { Lbs. } \\
34,761 \\
22,269\end{array}$ & $\begin{array}{l}\text { Lbs. } \\
5,036 \\
4,224\end{array}$ & $\begin{array}{l}\text { Lbs. } \\
3,251 \\
3,076\end{array}$ \\
\hline 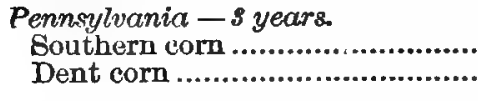 & $\begin{array}{l}32,321 \\
18.606\end{array}$ & $\begin{array}{l}7,993 \\
6,177\end{array}$ & $\begin{array}{l}5,042 \\
4,149\end{array}$ \\
\hline 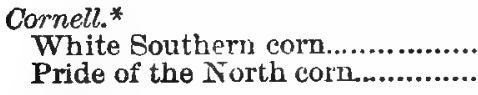 & $\begin{array}{l}34,060 \\
16.980\end{array}$ & $\begin{array}{l}7,320 \\
\mathbf{4}, 102\end{array}$ & $\begin{array}{l}4,758 \\
2,953\end{array}$ \\
\hline 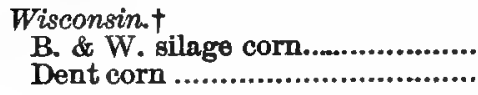 & $\begin{array}{l}47,040 \\
24,890\end{array}$ & $\begin{array}{l}8,329 \\
7,263\end{array}$ & $\begin{array}{l}5,414 \\
5,229\end{array}$ \\
\hline 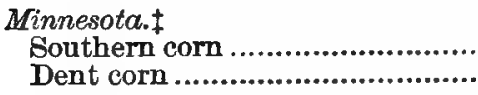 & $\begin{array}{l}43,000 \\
19,500\end{array}$ & $\begin{array}{l}7,985 \\
4,518\end{array}$ & $\begin{array}{l}3,887 \\
2,911\end{array}$ \\
\hline
\end{tabular}

* Bul. 16. †Rept. 1888. † Bul. 40.

The table shows larger yields of green forage in every instance

I Rept. 1893.

2 Rept 1802 
from Southern corn, which likewise leads in dry matter and total digestible substance, although percentagely lower in digestibility, as shown by Jordan.

398. When to use Southern corn for silage. - From the table it appears that we are assured of larger returns of total dry and digestible matter at the North by the use of large Southern varieties of corn. Southern corn should not be grown for either silo or forage purposes, however, unless the climatic conditions permit the ears to develop grains of corn which reach the glazing stage at time of harvest. This variety of corn will prove a favorite for both silage and dry forage where there is an urgent demand for the largest possible amount of coarse, palatable forage from a given acreage. By the use of Southern varieties of seed corn at the North the stockman can provide an enormous quantity of roughage, from a given area.

On the other hand the stockman who has a fair supply of hay, straw or stover at command will fill his silo with a richer feeding stuff than that produced by Southern corn, and for this purpose will use varieties of flint or dent corn which will fully mature in his locality, planting the crop in such manner as to secure a relatively large proportion of grain to roughage. Silage made from the smaller varieties of corn, carrying a considerable proportion of ears, will prove a rich feeding stuff which will materially reduce the necessity for additional grain. Corn silage, which is rich in carbohydrates, should be supplemented by clover hay, if possible, not only becanse some dry food is required, butbecause this hay is rich in protein.

399. Space occuspied by silage and dry fodder.-A cubic foot of hay in the mow weighs about five pounds. According to King ${ }^{1}$ a cubic foot of corn silage in a thirty-foot silo weighs 39.6 pounds. Estimating that hay contains 13.2 per cent. and silage 79.1 per cent. of water, we have the following:

One cubic foot of hay in the mow contains $4.34 \mathrm{lbs}$. dry matter. One culic foot of silage in a thirty-foot silo contains $8.28 \mathrm{lbs}$. dry matter.

We learn that a given volume of silage contains nearly twice as much dry matter as the same volume of hay stored in the mow.

\footnotetext{
1 Bul. 59, Wis. Sta.
} 
400. Cost of putting green corn fodder in the silo.- The cost for labor involved in placing a corn crop in the silo is reported by several Stations to be as follows:

New Hampshire (Bul. 1) $\$ 1.08$ per ton.

Massachusetts (Rept. 1884). 1.50 per ton.

Kansas (Bul. 48) .71 per ton.

Maryland (Rept. 1889) 1.43 per ton.

King, of the Wisconsin Station, " studied the operation of silo filling on four Wisconsin dairy farms, and found the average amount of green fodder placed in the silo per man, daily, to be as follows:

Farm No. 1 2.96 tons per 10 hours labor.

Farm No. 2 2.60 tons per 10 hours labor.

Farm No. 3 2.45 tons per 10 hours labor.

Farm No. 4 2.43 tons per 10 hours labor. Station Farm, 1893 2.37 tons per 10 hours labor.

Average. $\overline{2.56}$ tons per 10 hours labor.

This shows that for each man working ten hours, about two and one-half tons of green corn fodder were placed in the silo. Estimating labor at fifteen cents per hour we have 58.6 cents as the cost of putting one ton of green corn in the silo. (655)

401. Crops for the silo. - Indian corn is pre-eminently suited for silage, the solid, succulent stems, when cut into short lengths or shredded, packing closely, thereby excluding the air and forming a solid mass which keeps well. By planting the kernels rather thickly in the row the corn plants will develop the proper proportion of ear to stalk to form a silage sufficiently rich in nutrients while still furnishing a larger quantity of roughage. Investigation and experience teach that the corn crop should be well matured before it is harvested for the silo. Silage from immature corn is sour and of low feeding value. Many of the adverse reports on silage are due to the use of immature, watery corn plants. See Chapter $X$.

Red clover stands next to corn for silage purposes. There is still much to be learned concerning the proper method of converting clover into silage, if we may judge from the wide range in the

\footnotetext{
1 Rept. 1893.
} 
quality of silage commonly produced from clover. While some lots of clover silage are all that can be desired, in most instances this silage possesses a rank, disagreeable odor and is urasatisfactory, not being relished by stock. Judging from limited experience, it would appear that the best quality of clover silage is secured by cutting the clover at the usual time for hay making, and allowing the plants to lose a part of their moisture by wilting before they are placed in the silo. Green, sappy clover contains too much moisture for the best silage. The hollow stems of the rye plant and their fibrous character, even when quite green, seem to prevent its conversion into first-class silage, though it is used to some extent for this purpose. Attempts have been made to use such crops as cabbage, rape and the various roots, mangels, ruta-bagas, etc., for silage, but without success.

402. The Robertson mixture.- Robertson, of the Dominion Station, ${ }^{1}$ Ottawa, in the effort to secure a silage containing the nutrients of a balanced ration, concluded that the following mixture would prove satisfactory: Ten tons of green fodder corn, three tons of English horse beans, and one and a half tons of sunflower heads. To secure the proper proportion of these crops under Canar dian conditions, for each acre of corn there should be planted half an acre of horse beans and one-fourth of an acre of sunflowers. This mixture was found satisfactory in feeding trials with dairy cows and fattening steers. Since the horse bean does not thrive in the United States except possibly in the extreme north, some other plant must be substituted in mixtures of this character. Mr. G. F. Weston, Superintendent of the Biltmore estate, North Carolina, reports to the writer that he has found that one load of cowpea vines mixed with two loads of green corn forage produces an excellent silage for dairy cows.

403. Silage for farm stock. - Silage is pre-eminently a food for the cow, and its use will largely remain with the dairy farmer. Because of its succulence and palatability, this forage is recommended as a substitute for roots with fattening cattle. Silage proves an excellent food for sheep, being especially useful with ewes having lambs at foot. From its composition silage is

\footnotetext{
1 Rept. 1893-95.
} 
plainly not adapted to pig feeding. Some silage may be fed to idle horses, but for work horses the amount must necessarily be limited because of its bulky, soft character.

404. On the rational use of silage. - The silo and its product must now be regarded as a fixed factor in American agriculture. Those farms which carry a relatively small amount of stock do not require the silo. On such farms corn is rarely planted for forage, and the straw stacks in the barn yards, slowly rotting to manure, show that grain is grown for the market rather than for home feeding.

On the other hand many farms are heavily stocked with cattle, and everything raised finds waiting mouths with demands for still more. In such cases the feeder will find his best ally in the Indian corn plant. On heavily-manured lands enormons crops of corn forage carrying much grain may be grown, and this utilized as dry fodder serves admirably, while the silo will materially extend its availability. Corn forage carrying many small ears, placed in the pit at one operation, rests in the most compact form, safely awaiting the time for use. Dried fodder corn stored in the stack or mow deteriorates rapidly with the coming of spring, the stalks becoming brittle and losing in palatability. Silage keeps with less loss than does fodder during this time, and what is not needed for spring feeding will help out the short summer pastures. Where intensive farming is practiced the silo will prove an important factor.

405. Effect of silage upon quality of milk.-Milk-condensing factories have quite generally refused to accept milk from dairies where silage is fed. Whether there is a just foundation for this prejudice remains unsettled at the present time. Not all condensing factories, however, are averse to the use of silage by their patrons. The Michigan Condensed Milk Company, with factories at Lansing and Howell, Michigan, accepts milk from silage-fed cows. In the winter and spring of 1897 , about one-fourth of the milk received at the Lansing factory was from this source and the company was urging its patrons to erect and use silos, at the same time insisting that well-matured corn only be used. ${ }^{1}$

\footnotetext{
' From information furnished by G. H. True of the Mich. Agl. College.
} 
Experts, as a rule, can detect a silage odor or flavor in mils from silage-fed cows. The fact does not seem of much importance, however, when we know that milk furnished by many of the best dairymen, who are heary feeders of silage, is readily disposed of to critical customers in cities, who pay high prices for what they regard an excellent article. Butter from dairies where silage is properly fed meets with no objection from consumers.

In view of the fact that many thousands of silos are now in use by the best dairymen of America, there seems no longer any foundation for objections to the legitimate use of silage as a food for the dairy cow.

\section{Building and Filling the Sito.}

406. Silo construction. - Without question the round wooden silo devised by $\mathrm{King}^{1}$ is the one which will be most commonly constructed. The following brief description is adapted from King's directions: A circular foundation of stone or brick is constructed extending about three feet above ground level to secure immunity of the timbers from moisture. The top of the stone wall is necessarily thicker than the superstructure, and has a shoulder beveled outward, or inward, either form being satisfactory. Circular silos may be of any size from sixteen feet in diameter upward. For the superstructure, set $2 \times 4$ inch studding of not less than twenty-four feet in length on the foundation, standing them twelve inches apart. To the outside of the studding nail halfinch sheathing; then cover with building paper, and finally with half-inch siding. In warm districts the building paper may be omitted. Each board nailed horizontally on a round silo is part of a hoop, and all combine to give a structure of great stability. The inside of the silo can be finished in several ways. If lumber is employed, use three thicknesses of half-inch boards not over six inches wide, with two layess of building paper between, thus making an air-tight inner wall. Ventilation, which is of the highest importance to the preservation of this shell, is provided by openings at bottom and top through the outside siding, the air passing upward in the four-inch space made by the studding. Instead of wood for lining brick may be used,

\footnotetext{
1 Bul. 59, Wis. Expt. Sta.
} 
in which case only one thickness of inside boards is provided, against which the bricks rest. If large, the silo may be lined with combined sheeting and lathing, and then plastered. Smalldiameter silos should be first boarded inside and then lathed and plastered. Doors, which must be air-tight when closed, should be provided every six feet, and a dormer window in the roof admits the end of the silage carrier.

The advantages of a round silo are: The largest cubic capacity for a given amount of building material, no springing of walls through internal pressure, no corners for poor silage, and finally, great strength for a minimum amount of building material. The round silo may be connected by a passage-way with the feeding stable.

407. The rectangular silo. - Silos placed in the barn are usually of rectangular form, the girts extending horizontally with an inside lining of boards running vertically. Corners are avoided by boarding across them. When covered on the outside, ventilation may be provided by tacking cleats with holes in them to the girts and nailing the outside boarding to them.

408. Weight of silage at different depths.-King ${ }^{1}$ calculates the weight of silage two days after filling the silo to be as follows:

Weight of silage in silos of different depths - King.

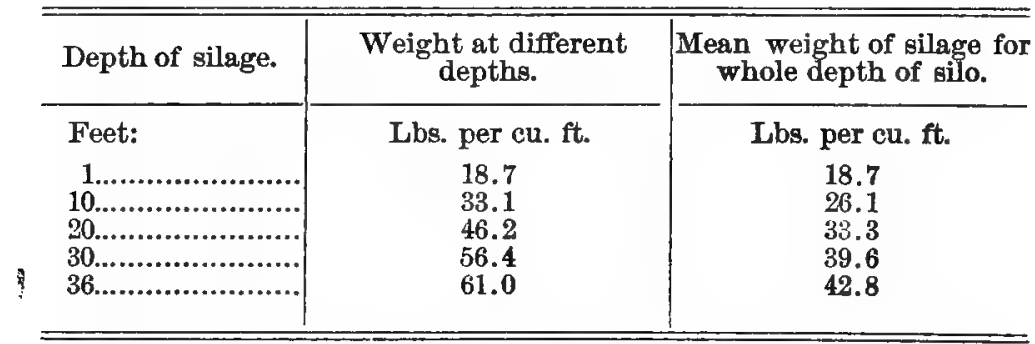

The above shows that ten feet down in the silo the silage weighs about thirty-three pounds per cubic foot, while at thirtysix feet in depth it weighs sixty-one pounds per cubic foot. The mean weight for silage at different depths is shown in the last column.

Bul. 59, Wis. Expt. Sta. 
409. Capacity of silos. - The following table by the same anthor gives the capacity of round silos at different depths and varying inside diameters:

Approximate capacity of cylindrical silos for well-matured corn silage, in tons - King.

\begin{tabular}{|c|c|c|c|c|c|c|c|c|c|c|c|c|}
\hline \multirow[b]{2}{*}{$\begin{array}{c}\text { Depth, } \\
\text { feet. }\end{array}$} & \multicolumn{12}{|c|}{ Inside Diameter in Feet. } \\
\hline & 15 & 16 & 17 & 18 & 19 & 20 & 21 & 22 & 23 & 24 & 25 & 26 \\
\hline & Tons. & Tons. & Tons. & Tons. & Tons. & Tons. & Tons. & Tons. & Tons. & Tons. & Tons. & Tons. \\
\hline $\begin{array}{l}20 \ldots \\
21 \ldots .\end{array}$ & $\begin{array}{l}58.8 \\
62.9\end{array}$ & $\begin{array}{l}67.0 \\
71.6\end{array}$ & $\begin{array}{l}75.6 \\
80.8\end{array}$ & $\begin{array}{l}84.7 \\
90.6\end{array}$ & $\begin{array}{r}94.4 \\
100.9\end{array}$ & & $\begin{array}{l}115.3 \\
123.3\end{array}$ & \begin{tabular}{l|l}
126.6 \\
135.3
\end{tabular} & $\begin{array}{l}138.3 \\
147.9\end{array}$ & $\begin{array}{l}150.6 \\
161.0\end{array}$ & $\mid \begin{array}{l}163.4 \\
174.7\end{array}$ & $\begin{array}{l}4176.8 \\
189.0\end{array}$ \\
\hline & 67.4 & 76.5 & 86.4 & 96.8 & 107.9 & 119.6 & 131.8 & 3144.7 & 158.1 & 172.2 & 186.8 & 3202.1 \\
\hline 23. & 71.7 & 81.6 & 92.1 & 103.3 & 115.1 & 127.5 & 140.6 & $\begin{array}{l}6 \\
\end{array}$ & 168.7 & 183.6 & 199.3 & 215.5 \\
\hline 24 . & 76.1 & 86.6 & 97.8 & 109.6 & 122.1 & 135.3 & 149.2 & 163.7 & 179.0 & 194.9 & 211.5 & 228.7 \\
\hline $25 \ldots$ & 80.6 & 89.6 & 103.6 & 116.1 & 4129.3 & 143.3 & 158.0 & $\begin{array}{ll}0 & 173.4\end{array}$ & 189.5 & 206.4 & 1223.9 & $9 \mid 242.2$ \\
\hline 26 .. & 85.5 & 97.2 & 109.8 & 123.0 & 137.1 & $\mid 151.9$ & 167.5 & 183.8 & 200.9 & 218.8 & 3237.4 & 256.7 \\
\hline 27. & 90.2 & 102.6 & 115.8 & 129.8 & 144.7 & 160.3 & 176.7 & 7194.0 & 212.0 & 230.8 & 250 & 270.9 \\
\hline 28. & 95.0 & 108.1 & 122.0 & 136.8 & 152.4 & 168.9 & \begin{tabular}{l|l}
186.2 \\
\end{tabular} & 204.3 & 223.3 & $\mid 243.2$ & 263 & 9285.4 \\
\hline 29. & 99.9 & 113.7 & 128.3 & 143.9 & 160.3 & 177.6 & 195.8 & $8 \mid 214.9$ & 234.9 & 255.8 & 277.6 & 300.2 \\
\hline 30. & 105.0 & 119.4 & 134.8 & 151.1 & 168.4 & 186.6 & 205.7 & $7 \mid 225.8$ & 246.8 & 3268.7 & 291.6 & 6315.3 \\
\hline & 109.8 & 124.9 & & & & & 215.3 & $\begin{array}{l}3 \\
3\end{array}$ & 258.2 & 281.8 & 305.1 & 1330.0 \\
\hline & 115.1 & 135.9 & 147.8 & 165.7 & 7184.6 & 204.6 & 225.5 & 5247.5 & 270.5 & 294.6 & 319.6 & 645.7 \\
\hline
\end{tabular}

In the above table the horizontal lines give the number of tons held by silos of the diameter marked at the top of the columns and depth marked at the side.

410. The proper horizontal feeding area.- Silage cannot be cut down in sections like hay in the mow or stack, as the air passing inward and upward would rapidly deteriorate the whole mass. The proper method is to remove a certain portion of the silage from the top of the pit each day, and experience has shown that the rate of removal should be not less than 1.2 inches per day. Every two inches in depth of corn silage weighs about five pounds per square foot near the top of the silo and ten pounds near the bottom, averaging about seven and a half pounds. On this basis the proper surface area may be placed at five square feet per cow, daily. As a guide for the proper surface area of the silo, King gives the following table, showing the inside diameter of silos which will allow the silage to be fed down at the rate of two or three inches a day when each cow is allowed forty 
pounds of silage daily; - silos to be of sufficient capacity to hold silage for 180 days:

Necessary diameter of silos for feeding different numbers of cow while removing from 2 to $\$ .2$ inches of silage daily-King.

\begin{tabular}{|c|c|c|c|c|c|c|c|c|}
\hline \multirow{3}{*}{$\begin{array}{l}\text { No. of } \\
\text { cows. }\end{array}$} & \multicolumn{4}{|c|}{$\begin{array}{l}\text { Silo } 30 \mathrm{ft} \text {. deep, no partition. } \\
\text { Mean depth fed daily, } 2 \text { inches. }\end{array}$} & \multicolumn{4}{|c|}{$\begin{array}{l}\text { Silo } 24 \mathrm{ft} \text {. deep with partition. } \\
\text { Mean depth fed daily, } 3.2 \text { inches }\end{array}$} \\
\hline & \multicolumn{2}{|c|}{ Contents. } & \multirow{2}{*}{$\begin{array}{l}\text { Round, } \\
\text { diame- } \\
\text { ter in ft. }\end{array}$} & \multirow{2}{*}{$\begin{array}{c}\text { Square, } \\
\text { sides, } \\
\text { in ft. }\end{array}$} & \multicolumn{2}{|c|}{ Contents. } & \multirow{2}{*}{$\begin{array}{l}\text { Round, } \\
\text { diame- } \\
\text { ter in ft. }\end{array}$} & \multirow{2}{*}{$\begin{array}{l}\text { Square } \\
\text { sides, } \\
\text { in ft. }\end{array}$} \\
\hline & Tons. & Cu. ft. & & & Tons. & Cu. ft. & & \\
\hline $\begin{array}{r}30 \ldots \ldots . \\
40 \ldots \ldots \\
50 \ldots \ldots \\
60 \ldots . . \\
70 \ldots . . \\
80 \ldots . . \\
90 \ldots \ldots \\
100 \ldots \ldots\end{array}$ & $\begin{array}{l}108 \\
144 \\
180 \\
216 \\
252 \\
288 \\
324 \\
360\end{array}$ & $\begin{array}{r}4,091 \\
6,545 \\
8,182 \\
9,818 \\
11,454 \\
13,091 \\
14,727 \\
16,364\end{array}$ & $\begin{array}{l}15 \\
16.75 \\
18.75 \\
20.5 \\
22 \\
22.5 \\
25 \\
26.5\end{array}$ & $\begin{array}{l}12 \times 14 \\
14 \times 16 \\
16 \times 18 \\
18 \times 18 \\
20 \times 20 \\
20 \times 22 \\
29 \times 24 \\
24 \times 24\end{array}$ & $\begin{array}{l}108 \\
144 \\
180 \\
216 \\
252 \\
288 \\
324 \\
360\end{array}$ & $\begin{array}{r}\mathbf{5}, 510 \\
\mathbf{7}, 347 \\
\mathbf{9}, 184 \\
\mathbf{1 1}, 020 \\
\mathbf{1 2}, 857 \\
\mathbf{1 4}, 691 \\
\mathbf{1 6}, 531 \\
\mathbf{1 8}, 367\end{array}$ & $\begin{array}{l}17 \\
20 \\
22 \\
24 \\
26 \\
58 \\
29.75 \\
31.25\end{array}$ & $\begin{array}{l}16 \times 16 \\
18 \times 18 \\
20 \times 20 \\
22 \times 22 \\
22 \times 26 \\
24 \times 26 \\
26 \times 28 \\
28 \times 28\end{array}$ \\
\hline
\end{tabular}

411. Rate of filling.-From seven to fifteen days should be allowed for filling the silo, as this not only permits more feed to be stored, but also insures better and sweeter silage with smaller loss of dry matter than when the operation is crowded into a period of two or three days. Time is required for the silage to settle and to expel the entangled air by heat and by setting free carbonic acid gas.

On the subject of filling King writes:" "Corn and clover may be put into the silo either whole or cut, as seems best under the circumstances. In either case good silage can be made if proper care is taken, but more care and nsually more time will be required to fill a silo with either whole corn or clover than to run 'it through the cutter first; and it is certain that more time will be required to take the silage out of the silo if put in whole. . . . To insure the best silage and the least loss of dry matter it is important that the silage should have a depth at the close of filling of not less than 24 feet, and 30 feet is better than 24 feet."

412. Filling and covering.-During filling the inpouring material should be well spread and tramped near the walls, and should also be well tramped every two or three days thereafter for a

1 Loc. cit. 
period of ten days. The contents having become settled, the surface of the pit may be covered with fresh marsh grass, weeds, chaff, cut straw or other cheap or waste substance, or a portion of the surface silage may be allowed to decay and form the covering. The application of fifteen or twenty pounds of water to each square foot of surface will cause the material at the top of the pit to ferment rapidly and soon compact itself into an impervious layer. Feeding from the silo may commence at once or may be delayed indefinitely. If only a part of the silage is used during winter the remainder may be covered again and held ontil summer, when it may. serve a useful purpose during a period of drought or short pastares. 


\section{CHAPTER XVI.}

MANURIAL VALUE OF FEEDING BTUFF\&.

413. Essential constituents of fertilizers. - Only three of the :onstituents which plants remove from the soil need be considered in this chapter, viz., nitrogen, phosphoric acid and potash, for all the others are usually held in such abundance that no thought need be given them. While it is possible for the legumes to gather nitrogen indirectly from the air, the supply from this source is not always sufficient, and it is often necessary to add nitrogen compounds to the soil for the purpose of enriching it. Phosphoric acid and potash are the two mineral compounds which are not always held by the soil in sufficient quantity to give profitable crops and must be supplied in the form of manures or fertilizers.

Farm-yard manures may benefit the soil because the vegetable matter they contain acts as a mulch and forms humus, but so far as feeding the plants is concerned their worth rests upon the nitrogen, phosphoric acid and potash they contain.

414. Fertilizing constituents of feeding stuffs.-The quantity of nitrogen, phosphoric acid and potash found in the various feeding stuffs is given in Table III of the Appendix. The examples presented below are abstracted from that table for the purpose of illustration:

Table showing fertilizing constituents in 1,000 pounds of common feeding stuffs - From Table III of the Appendix.

\begin{tabular}{|c|c|c|c|}
\hline Feeding stuffs. & Nitrogen. & $\begin{array}{c}\text { Phosphoric } \\
\text { acid. }\end{array}$ & Potash. \\
\hline & Lbs. & Lbs. & Lbs. \\
\hline 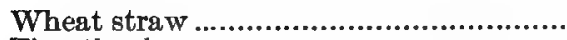 & 5.9 & 1.2 & 5.1 \\
\hline Timothy hay.......................................... & 12.6 & 5.3 & 9.0 \\
\hline 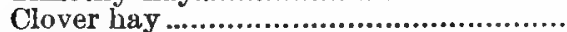 & 20.7 & 3.8 & 22.0 \\
\hline 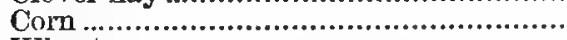 & 18.2 & 7.0 & 4.0 \\
\hline 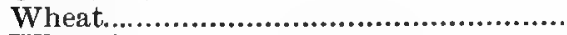 & 23.6 & 7.9 & 5.0 \\
\hline Wheat bran ........................................ & 26.7 & 28.9 & 16.1 \\
\hline 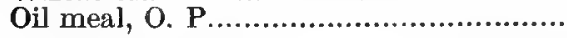 & 54.3 & 16.6 & 13.7 \\
\hline
\end{tabular}


From this table we learn that wheat straw contains 5.9 pounds of nitrogen, and timothy hay more than twice as much, or 12.6 pounds. Clover hay is richer than timothy hay in nitrogen, and especially in potash, though poorer in phosphoric acid. We observe a larger quantity of all the fertilizing constituents, especially phosphoric acid and potash, in wheat bran than in the wheat grain, from which bran is derived. This is because the starchy part of the wheat grain used for flour holds little fertility, while the outside portion of the grain which goes into the bran contains most of the nitrogen and ash.

415. Amount of excrement voided by farm animals. - Information on this subject from American experiments is quite limited, but the following will prove useful:

Voidings per day of twenty-four hours by farm animals as determined at several Stations.

\begin{tabular}{|c|c|c|c|c|}
\hline Animal. & Station. & $\begin{array}{l}\text { Solid } \\
\text { excre- } \\
\text { ment. }\end{array}$ & Urine. & Total. \\
\hline \multirow[t]{2}{*}{$\begin{array}{l}\text { Horse...... } \\
\text { Horse..... }\end{array}$} & 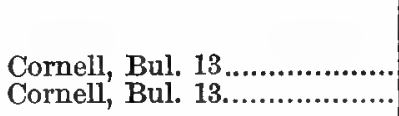 & $\begin{array}{c}\text { Lbs. } \\
\ldots \ldots \ldots \ldots \ldots\end{array}$ & 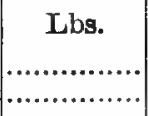 & $\begin{array}{l}\text { Lbs. } \\
54.5 \\
58.2\end{array}$ \\
\hline & Average. & . & $\ldots \ldots \ldots \ldots \ldots$ & 56.3 \\
\hline \multirow[t]{2}{*}{$\begin{array}{l}\text { Cow } \ldots \ldots \ldots \\
\text { Cow } \ldots \ldots \ldots . . . . \\
\text { Cow } \ldots \ldots \ldots . . . \\
\text { Cow } \ldots . . . .\end{array}$} & 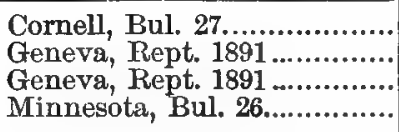 & $\begin{array}{l}64 \\
50 \\
42 \\
41\end{array}$ & $\begin{array}{l}18 \\
21 \\
15 \\
23\end{array}$ & n \\
\hline & Average. & 49 & 19 & 68 \\
\hline $\begin{array}{l}\text { Bheep...... } \\
\text { Pig ......... }\end{array}$ & $\begin{array}{l}\text { Massachusetts, Rept. } 1893 \ldots . . \\
\text { Minnesota, Bul. } 26 \text {............... }\end{array}$ & $\begin{array}{l}1.8 \\
4.3\end{array}$ & $\begin{array}{l}2.0 \\
2.9\end{array}$ & $\begin{array}{l}3.8 \\
7.2\end{array}$ \\
\hline
\end{tabular}

The table shows that the voidings of the horse amount to over 55 pounds, the cow 68 , the sheep nearly 4 , and the pig over $?$ pounds each 24 hours.

416. Manure from the ox. - At the Ontario Agricultural College, ${ }^{1}$ an ox was confined from birth to maturity in a large boxstall having a cement floor. The stall was well bedded, and the animal given exercise by leading, when required. Accuunt was

liept. 1893. 
kept of all water and food supplied, and of the voidings, with the following results:

Manure obtained from steer confined in box-stall thirty-six months Ontario Agricultural College.

Pounds. Pounds.

Weight of steer at end of thirty-six months 1,588

Water drank

Feed consumed:

Pounds.

Milk

3,862

Roots

7,270

Grain

5,857

Coarse forage

42,449

Total.

37,946

Total weight of feed and water

80,395

Total weight of excrement.

Total manure, including bedding.

69,280

Excrement per pound gain, live weight.

Manure, including bedding, per pound gain, live weight.

417. Heiden's method for calculating manure produced.-Heiden ${ }^{1}$ computed the amount of manure produced by farm animals in the following manner. He found that 47.3 per cent. of the dry matter supplied in the food of the horse re-appears in the solid and liquid voidings, which contain 77.5 per cent. water and 22.5 per cent. dry matter. From these data the following proportion is derived:

$$
22.5: 100:: 47.3:(210)
$$

By this we understand that for each 100 pounds of dry matter fed the horse there are 210 pounds of voidings. This method of calculation gives the following results for each 100 pounds of dry matter fed:

The horse voids 210 pounds of fresh manure.

The cow voids 380 pounds of fresh manure.

The sheep voids 180 pounds of fresh manure.

418. Nitrogen and ash retained and voided by farm animals. - In supplying feeding stuffs to farm animals some of the nitrogen and ash they contain are taken up for nourishment and retained in the body, or, after use, expelled in the urine. A considerable portion of the substances under discussion is not dissolved from

1 Storer's Agriculture, Vol. 1, p. 515. 
the feeds during their passage through the alimentary tract, but passes off with other useless matter in the solid voidings.

The nitrogen and ash of feeding stuffs retained and voided by the animal are given in the table below, which summarizes the Rothamsted experiments as reported by Warington: ${ }^{1}$

Per cent. of nitrogen and ash voided as excrement or secured as animal produce with various farm animals-Rothamsted Station.

\begin{tabular}{|c|c|c|c|c|c|c|}
\hline & \multicolumn{4}{|c|}{ Nitrogen. } & \multicolumn{2}{|c|}{ Ash. } \\
\hline & $\begin{array}{l}\text { Ob- } \\
\text { tained } \\
\text { as car- } \\
\text { cass or } \\
\text { milk. }\end{array}$ & $\begin{array}{l}\text { Voided } \\
\text { as solid } \\
\text { excre- } \\
\text { ment. }\end{array}$ & $\begin{array}{l}\text { Voided } \\
\text { as liq- } \\
\text { uid ex- } \\
\text { cre- } \\
\text { ment. }\end{array}$ & $\begin{array}{c}\text { In total } \\
\text { excre- } \\
\text { ment. }\end{array}$ & $\begin{array}{l}\text { Obtained } \\
\text { as live } \\
\text { weight } \\
\text { or milk. }\end{array}$ & $\begin{array}{l}\text { Voided } \\
\text { in excre- } \\
\text { ment and } \\
\text { perspired. }\end{array}$ \\
\hline $\begin{array}{l}\text { Fattening ox..... } \\
\text { Fattening sheep. } \\
\text { Fattening pig.... } \\
\text { Milch cow......... }\end{array}$ & $\begin{array}{r}3.9 \\
4.3 \\
14.7 \\
24.5\end{array}$ & $\begin{array}{l}22.6 \\
16.7 \\
22.0 \\
18.1\end{array}$ & $\begin{array}{l}73.5 \\
79.0 \\
63.3 \\
57.4\end{array}$ & $\begin{array}{l}96.1 \\
95.7 \\
85.3 \\
75.5\end{array}$ & $\begin{array}{r}2.3 \\
3.8 \\
4.0 \\
10.3\end{array}$ & $\begin{array}{l}97.7 \\
96.2 \\
96.0 \\
89.7\end{array}$ \\
\hline
\end{tabular}

The above data may be considered as representative of average results. From them we learn that the fattening ox retains only 3.9 per cent. of the nitrogen supplied in its food, voiding 22.6 per cent. in the solid excrement and 73.5 per cent. in the urine; in all, 96.1 per cent. of the nitrogen supplied this animal in his food re-appears in the excrement and less than 4 per cent. is stored in the body. This large return of nitrogen seems reasonable when we remember that during the fattening process the grown ox adds little to his body besides fat, which we know contains no nitrogen.

With the cow, 24.5 per cent. of the nitrogen in the feed is ased mainly for the production of the casein and albumen of the milk, and 75.5 per cent. appears in the excrement.

Of the ash from 2.3 to 10.3 per cent. is retained by the animal or goes into the milk. Thus it is shown that from 75 to 95 per cent. of all the fertilizing constituents of feeding stuffs reappears in the solid and liquid excrement.

449. Composition of excrement. - It is important that the farmer understand the composition of the excrement of farm animals

\footnotetext{
' Chennistry of the Farm, pp. 124-25.
} 
in order to intelligently atilize manures. The source of the fertility in manures is well illustrated by the following table from Hebert, ${ }^{1}$ which shows the location of the nitrogen, phosphoric acid and potash in the excrement of the horse and cow:

Location of nitrogen, phosphoric acid and potash in excrementHebert.

\begin{tabular}{|c|c|c|c|}
\hline & Nitrogen. & $\begin{array}{c}\text { Phosphoric } \\
\text { acid. }\end{array}$ & Potash. \\
\hline & Per cent. & Per cent. & Per cent \\
\hline 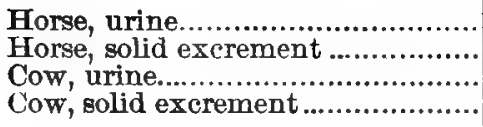 & $\begin{array}{l}1.52 \\
0.55 \\
1.05 \\
0.43\end{array}$ & $\begin{array}{c}\text { Trace. } \\
0.35 \\
\text { Trace. } \\
0.12\end{array}$ & $\begin{array}{l}0.92 \\
0.10 \\
1.36 \\
0.04\end{array}$ \\
\hline
\end{tabular}

We learn that the urine of the horse contains 1.52 per cent. of vitrogen and the solid excrement.55 per cent., or one-third as much. The reverse holds true for the phosphoric acid, for only a trace of this appears in the urine and nearly all in the solid excrement. Of the potash, .9 per cent. is found in the urine and only .1 per cent. in the solid excrement.

The fertilizing constituents which pass off with the solid excrement are largely insoluble and to this extent not directly available to plants when applied in manures. On the other hand, the constituents which appear in the urine are in soluble form and directly available to the plant.

420. Commercial fertilizers. - The soil in parts of our country is now so depleted that farmers and planters are forced to make large use of commercial fertilizers in order to secure remunerative crops. The commercial fertilizers sold in the United States during the year 1896 amounted to 1,355,000 tons. ${ }^{2}$ Placing a value on these of $\$ 20$ per ton, a reasonable estimate, we have a total of over $\$ 27,000,000$ paid out by farmers and gardeners living mainly in the Atlantic and Gulf states for commercial fertilizers in a single year. For the year 1895 the farmers of Connecticut ${ }^{3}$ expended over $\$ 700,000$, and those in New Jersey $\$ \$ 1,575,000$, for commercial fertilizers.

1 Expt. Sta. Record, Vol. 5; also Fertility of the Land, Roberts, p. 180.

- American Fertilizer, Dec., 1896.

Rept. Conn. Expt. Stir., 1805.

- Rept. N. J. Expt. Sta., 1896. 
The market value of commercial fertilizers is based on their content of nitrogen, phosphoric acid and potash. Because of the enormous quantity of fertilizers used, each of their three valuable constituents has a definite market value. The average price of these ingredients in the wholesale markets is as follows: Nitrogen, 15 ; phosphoric acid, 7, and potash 4.5 cents per pound. The prices of these articles do not fluctuate any more than do those of other standard articles of commerce.

421. Valuation of fertilizer constituents in feeding stuffs. - If we follow the plan adopted by some Eastern Stations of placing the same values on nitrogen, phosphoric acid and potash in feeding stuffs that these constituents bring when sold in commercial fertilizers, we are in a position to compare the fertilizing values of the several feeding stuffs. Wheat bran and corn are compared in the table below:

Value of the fertilizing constituents in 1,000 pounds of wheat bran and corn.

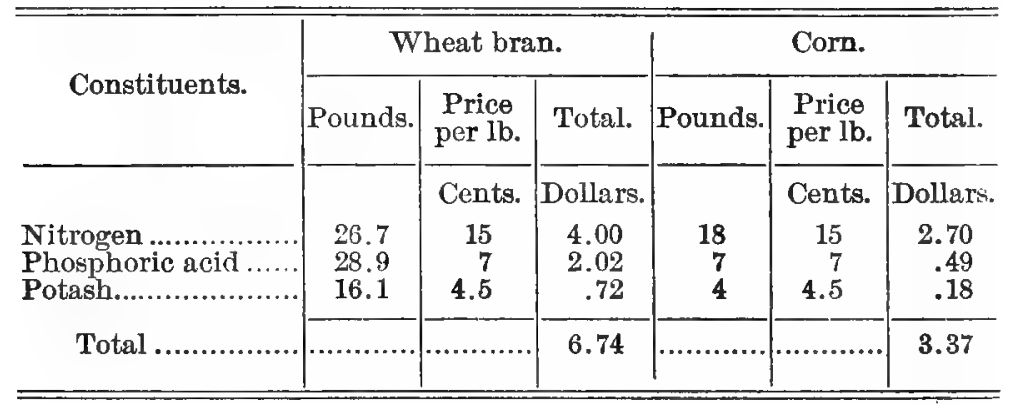

From the above we learn that the value of the fertilizing constituents in 1,000 pounds of bran is $\$ 6.74$, and in the same weight of corn one-half as much, or $\$ 3.37$. By doubling these figures we have the following:

Value of fertilizing constituents in one ton of wheat bran...... $\$ 13.48$

Value of fertilizing constituents in one ton of corn................ 6.74

422. What the figures mean.-The farmer will ask if it is here taught that he can get returns of $\$ 13.48$ by the application of one ton of bran to his land as a fertilizer. Such a deduction is not the purpose of these figures. They mean, however, that 
a ton of bran contains nitrogen, phosphoric acid and potash in such amount that if bought in the form of commercial fertilizers they would cost at least the sum named. They mean that the farmer who harvests a ton of corn and seeks to return to the field the same amount of fertility that was abstracted by this crop must pay not less than $\$ 6.74$ for the requisite fertilizers, if bought in the market. Virgin soils as a rule contain a large amount of available fertility, and pioneer farmers, drawing upon Nature's store, give little consideration to the subject. The Western farmer cultivating prairie lands, when marketing corn considers that in so doing he is selling labor and perhaps rent of the land; but rarely does he realize that he is also selling fertility, to replace which would cost as much and often more than the crop brings. The Eastern farmer and Southern planter are now cultivating soils which have been so depleted of available plant food that the subject of fertilizers is a matter of the deepest concern to them.

When one who cultirates the soil must choose between commercial fertilizers and barn-yard manures, it is reasonable to estimate that the latter have a value of at least two-thirds the former, based on their nitrogen, phosphoric acid and potash contents. Because the soils of the West are still rich in original fertility, the farmers of that region have as yet little need of commercial fertilizers, and barn-yard manures in consequence have a lower value than in the older-settled regions. For convenience of comparison, it is perhaps best to use the same valuations for nitrogen, phosphoric acid and potash in farm manures that these same compounds command when sold in the form of commercial fertilizers. Such values should always be used, however, under the limitations above presented. With sharp competition confronting every one who cultivates the soil, the careful saving of farm manures and their judicious application are vital factors in farming operations, and as essential to continued success as plowing the land or planting the crop.

423. Manure produced by farm animals. - Roberts ${ }^{1}$ gathers the following interesting data showing the daily and yearly produc-

\footnotetext{
1 The Fertility of the Land.
} 
tion of manure by farm animals maintained under average conditions:

Fertilizing constituents in solids and liquids voided by farm animals, daily and yearly - Various sources, Roberts.

\begin{tabular}{|c|c|c|c|c|c|c|c|}
\hline & \multicolumn{3}{|c|}{ Daily. } & \multicolumn{3}{|c|}{ Yearly. } & \multirow{2}{*}{$\begin{array}{l}\text { Value } \\
\text { per } \\
\text { year. }\end{array}$} \\
\hline & $\begin{array}{c}\text { Nitro- } \\
\text { gen. }\end{array}$ & $\begin{array}{l}\text { Phos. } \\
\text { acid. }\end{array}$ & $\begin{array}{l}\text { Pot- } \\
\text { ash. }\end{array}$ & $\begin{array}{l}\text { Nitro- } \\
\text { gen. }\end{array}$ & $\begin{array}{l}\text { Phos. } \\
\text { acid. }\end{array}$ & $\begin{array}{l}\text { Pot- } \\
\text { ash. }\end{array}$ & \\
\hline & Lbs. & Lbs. & Lbs. & Lus. & Lbs. & Lbs. & \\
\hline Horse (Hebert) ................ & .342 & .131 & .112 & 125.2 & 47.8 & $\begin{array}{r}43.2 \\
107.6\end{array}$ & $\$ 24.06$ \\
\hline Sheep (Müntz and Girard) & $\begin{array}{l}.467 \\
.023\end{array}$ & $\begin{array}{l}.071 \\
.014\end{array}$ & .294 & $\begin{array}{r}170.6 \\
8.4\end{array}$ & $\begin{array}{r}26.0 \\
5.6\end{array}$ & $\begin{array}{r}107.0 \\
14.3\end{array}$ & $\begin{array}{r}32.25 \\
2.29\end{array}$ \\
\hline Pig (Boussingault)............ & .0326 & .0246 & $.50^{*}$ & 11.9 & 10.6 & 11.9 & 3.06 \\
\hline
\end{tabular}

* Estimated.

424. Value of farm manure per ton.- Roberts, gathering the data at Cornell Station and elsewhere, dednces the following as the average value per ton of manures from various farm animals, nitrogen being rated at fifteen cents, phosphoric acid at seven cents and potash at four and one-half cents per pound:

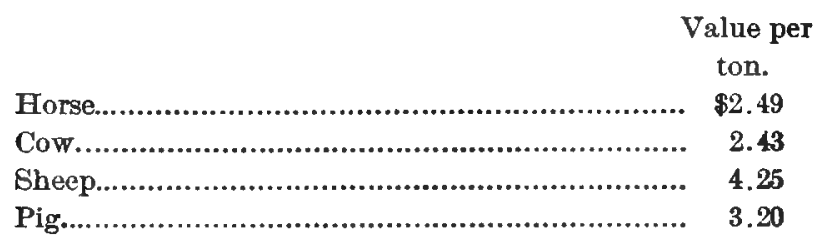

It should be borne in mind that the value of farm mantures deraids primarily upon the character of the feed given, and, in the second place, upon the animal to which the feed is supplied. Manure which oniginates from the use of concentrated feeding stuffs usually has a high value, because such feeds are rich in nitrogen, phosphoric acid and potash. Manure resulting from the use of straw and coarse forage has a correspondingly low value. 1

1 The student desiring additional information on matters treated in this chapter should consult: The Fertility of the Land, Roberts; Agricultare in Some of its Relations with Chemistry, Storer. 


\section{PART III.}

\section{FEEDING FARM ANIMALS.}

\section{CHAPTER XVIL. \\ INVESTIGATIONS CONCERNING THE HORSE.}

\section{Mare and Foal.}

425. Period of gestation.-According to Youatt, ${ }^{1}$ the average period of gestation for the mare is eleven months, but it may be diminished five weeks or extended six weeks. Of 582 mares reported by M. Tessier, the shortest period was 287 days, the longest 419 , and the average 330 days. ${ }^{2}$

426. Weight and growth of foals.-Boussingault ${ }^{8}$ found that:

"1. Foals, the issue of mares weighing from 960 to 1,100 pounds, weigh at birth about 112 pounds.

"2. During suckling, for three months the weight increases in the relation of $278: 100$, and the increase corresponds very nearly to 2.2 pounds per head per day.

"3. The increase in weight per day of foals from the end of the first to the end of the second year is about 1.3 pounds, and towards the third year the increase per day falls to something under one pound.

"4. After three full years, the period at which the horse has very nearly attained. his growth and development, any increase becomes less and less perceptible."

1 The Horse, p. 222.

- Farmers' Cyclopedia, Johnson, p. 562

- Rural Economy, Am. ed., p. 464. 
427. Weight of trotting foals at birth.- At Allen farm, Pittsfield, Mass., Meston ${ }^{1}$ recorded the weights of foals at birth as summarized in the following table:

Weight of trotting-bred foals at birth and other data relating theretoMeston, Allen Farm.

\begin{tabular}{|c|c|c|c|c|}
\hline \multirow[b]{2}{*}{ A verages. } & \multicolumn{2}{|c|}{21 colts. } & \multicolumn{2}{|c|}{23 fillies. } \\
\hline & $\begin{array}{c}15 \text { of } \\
\text { av, or } \\
\text { less wt }\end{array}$ & $\begin{array}{l}6 \text { above } \\
\text { av. wt. }\end{array}$ & $\begin{array}{c}13 \text { of } \\
\text { av. or } \\
\text { less wt. }\end{array}$ & $\begin{array}{c}10 \\
\text { above } \\
\text { av. wt. }\end{array}$ \\
\hline Weight of foals at birth, pounds........ & 98.5 & 129 & 102 & 123 \\
\hline Weight of their dams after foaling, & 1070 & 11.5 & 11080 & 1156 \\
\hline Weight of their sires, pounds .............. & 1,065 & $\begin{array}{l}1,156 \\
1,095\end{array}$ & 1,060 & 1,155 \\
\hline Period of gestation, days...................... & 343 & 337 & 338 & 340 \\
\hline Fotal growth per day, pounds ........... & & & & \\
\hline
\end{tabular}

428. Increase in weight of foals.-Meston ${ }^{2}$ recorded the increase in weight of trotting-bred foals up to four months, with the results shown in the following table:

Growth of suckling trotting-bred foals up to four months - Meston, Allen Farm.

\begin{tabular}{|c|c|c|c|c|c|c|c|}
\hline \multirow{2}{*}{ Age of foals. } & \multirow{2}{*}{$\begin{array}{l}\text { No. } \\
\text { of } \\
\text { foals. }\end{array}$} & \multirow{2}{*}{$\begin{array}{c}\text { Av. } \\
\text { growth } \\
\text { per } \\
\text { day. }\end{array}$} & \multicolumn{2}{|c|}{$\begin{array}{l}\text { Av. growth per } \\
\text { day of foals of - }\end{array}$} & \multirow{2}{*}{$\begin{array}{c}\text { No. } \\
\text { of } \\
\text { foals } \\
\text { above } \\
\text { av. } \\
\text { wt. }\end{array}$} & \multicolumn{2}{|c|}{$\begin{array}{c}\text { Extremes in } \\
\text { growth-lbs. } \\
\text { per day. }\end{array}$} \\
\hline & & & $\begin{array}{l}\text { Av. } \\
\text { wt. or } \\
\text { under. }\end{array}$ & $\begin{array}{l}\text { Above } \\
\text { av. wt. }\end{array}$ & & $\begin{array}{l}\text { Max. } \\
\text { foal. }\end{array}$ & $\begin{array}{l}\text { Min. } \\
\text { foal. }\end{array}$ \\
\hline & & Lbs. & Lbs. & Lbs. & & Lbs. & Lbs. \\
\hline From 3 to 9 days. & 15 & 3.70 & 3.76 & 3.62 & 7 & $6.00^{*}$ & 1.60 \\
\hline From 11 to 19 days. & 14 & 3.34 & 3.17 & 3.53 & 6 & 4.71 & 2.00 \\
\hline From 22 to 28 days. & 12 & 2.80 & 2.78 & $2.5 !$ & 3 & 3.01 & 2.00 \\
\hline From 31 to 39 days. & 16 & 2.67 & 2.64 & 2.79 & 5 & 3.08 & 1.82 \\
\hline From 40 to 49 days. & 15 & 2.67 & 2.55 & 2.81 & 7 & 3.23 & 1.88 \\
\hline From 52 to 59 days. & 10 & 2.46 & 2.38 & 2.56 & 3 & 2.94 & 1.72 \\
\hline From 60 to 69 days. & 11 & 2.33 & 2.22 & 2.81 & 2 & 2.94 & 1.84 \\
\hline From 70 to 79 days. & 13 & 2.35 & 2.30 & 2.39 & 7 & 3.00 & 1.55 \\
\hline From 80 to 88 days. & 8 & 2.14 & 2.13 & 2.16 & 2 & 2.68 & 1.51 \\
\hline $\begin{array}{l}\text { Over } 3 \text { and under } 4 \\
\text { months ................... }\end{array}$ & 14 & 2.10 & 2.00 & 2.28 & 5 & 2.53 & 1.75 \\
\hline
\end{tabular}

* Doultful.

1 Country Gentleman, 1894, pp. 636-7.

- Loc. cit. 
429. Mare's milk. - The following table presents the composition of mare's milk, with cow's milk for comparison, according to König: 1

Percentage composition of mare's millk; cow's mill being given for comparison-König.

\begin{tabular}{l|c|c|c|c|c}
\hline \hline & Water. & $\begin{array}{c}\text { Casein } \\
\text { and albu- } \\
\text { men. }\end{array}$ & Fat. & Sugar. & Ash. \\
\hline $\begin{array}{l}\text { Average 47 analyses mare's milk. } \\
\text { Average 793 analyses cow's milk. }\end{array}$ & \begin{tabular}{c|c}
90.78 \\
87.17
\end{tabular} & $\begin{array}{c}1.99 \\
3.55\end{array}$ & $\begin{array}{l}1.21 \\
3.69\end{array}$ & $\begin{array}{r}5.67 \\
4.88\end{array}$ & $\begin{array}{r}0.35 \\
.71\end{array}$ \\
\hline \hline
\end{tabular}

It is shown that mare's milk contains more water than that of the cow, the casein, albumen, fat and ash being about one-half that found in cow's milk, while the sugar is nearly one per cent. higher. If cow's milk is used for feeding foals, it should be diluted with water and sugar added.

The quantity of mill yielded by mares has been determined in only a few cases. According to Goltz, ${ }^{2}$ Tartarian mares produce from 450 to 500 pounds of milk per year in addition to that required by their foals. Such mares remain in milk two years.

Vieth ${ }^{3}$ reports that good milking mares on the steppes of southeastern Russia yield from 4 to 5 liters (quarts) of milk daily when milked five times a day, as is the practice.

\section{Wolff's Studies of Feed Consumed and Work Performed by the Horse.}

430. Plan of investigation.-Wolff's feeding and digestion experiments with the horse are the first extensive and systematic efforts in this line. From the necessities of the case his work was done with single animals. He first studied the comparative digestibility of various feeding stuffs with the horse, and later the relation of feed consumed to the amount of work performed. ' $\mathrm{T}$ o discuss the results of these investigations intelligently it is necessary to first consider the method adopted for measuring the work done by the horse.

${ }^{1}$ Chem. d. Mensch. Nahr. u. Genus-mittel, I. p. 1112.

' Landw. III, p. 520 .

s Ldw. Vers. Sta. 31 (1885), p. 354. 
431. Measuring the work of horses. - In measuring work done, the engineer uses as the unit a foot-pound (or foot-ton), the term meaning the work accomplished in lifting one pound (or one ton) one foot high. In comparing the work performed by horses under rrmying conditions it will be necessary to use the same expression. A nominal horse-power is 33,000 foot-pounds per minute. This amount of work was ascertained by James Watts, the inventor of the steam-engine, in a series of experiments with compound pulleys. As the capacity of animals for hard work is limited, no horse can work continuously more than eight hours a day. The work done by a horse during a day will be represented by $33,000 \times 8 \times 60=15,840,000$ foot-pounds. This is, however, an excessive amount of work. An average horse will do only about 22,000 foot-pounds per minute. This work continued for eight hours gives 10,560,000 foot-pounds, which is regarded as an ordinary day's work for a medium-sized horse.

In the Hohenheim experiments ${ }^{1}$ the following figures were obtained for eight hours, constituting a day's work:
A. Hauling on level track
Foot-pounds
B. Working in horse-sweep
$7,999,800$
$12,996,000$

Perels ${ }^{2}$ gives the following data for a day's work of eight hours for strong, well-fed horses:
A. Hauling on level track -
Foot-pounds.
Heavy work
$17,051,000$
Ordinary work
$12,996,000$
B. Working in horse-sweep
$10,136,900$

432. Wolff's dynamometer.-To measure the work performed by the horse in a given time, Wolff constructed a horse dynamometer, which may be described as a sweep, the axis of which consisted of two parts - a lower stationary cast-iron base and an upper loose cast-iron cover. This cover was connected with the sweep, and could be weighted so that the friction between the re. volving cover and the stationary base on which it rested could be increased at will. The details of the dynamometer, and the ar-

\footnotetext{
${ }^{1}$ Wolff, Ldw. Jahrb. VIII, Suppl. I, p. 115.

'Deutsche Ldw. Prease, 1878, Sept. 18; Ldw. Jahrb. VIII, Suppl. I, p. 115.
} 
rangements for controlling the work performed, are very complicated and need not be described here. ${ }^{1}$ In the first series of experiments with the dynamometer conducted during the summer of $1877,{ }^{2}$ the daily work performed by the horse during the five periods of the experiment amounted to $3,429,500,6,864,000$, $10,288,500,6,859,000$ and $3,429,500$ foot-pounds. The ration fed daily throughout the experiment was 13.2 pounds of oats, 11 pounds of hay, 3.3 pounds of cut winter-wheat straw, and .4 ounces of salt. The weight of the horse was 1,177 pounds.

433. What was shown by the digestion trials. - Digestion trials conducted during each period showed that the amount of work performed by the horse did not exert any influence on the digestibility of the ration fed. The digestion coefficients found during the five periods were: for dry matter, $57,56,56,54$, 53 per cent.; for protein, 71, 68, 70, 67, 68 per cent.; for nitrogenfree extract, 68, 70, 68, 68, 64 per cent., etc. The somewhat lower digestibility of the ration during the last period is accounted for by the influence of the storing of the hay - the digestibility of hay decreasing with age. The animal was never overworked during the digestion experiments, the hardest labor being easily within its capacity. The heavier work done during the third period was accompanied by a greater quantity of water drank and a decrease in the live weight of the animal. The results obtained were corroborated in a second trial, when a highly nitrogenous ration containing field beans was fed (16.5 pounds of hay and 8.8 pounds of beans), and also in still later experiments by the same investigator. ${ }^{3}$ The results obtained by Grandeau and Leclere with French cab horses (442) do not quite correspond with those found by Wolff with German farm horses, as given above, the former investigators finding a small depression in the digestibility of rations fed to horses doing slow work compared with that obtained when resting in the stall, and a somewhat larger depression when doing harder work. The differences obtained were within three per cent. of those found by Wolff, and are not, therefore, of much practical importance.

\footnotetext{
1 For a detailed description of the apparatus, with illustrations, see Idw. Vers. Sta. 21, 1878, p. 21.

${ }^{2}$ Ldw. Jahrb. VIII, 1879, Suppl. I, p. $73 . \quad$ Ibid., p. 78.
} 
434. Nutrients required for maintenance and work. - Wolff's experiments show that a horse of average size will do medium havd work and maintain his weight on a ration containing about 12 pounds of digestible matter. A nutritive ratio of 1:6.4 proved better than the narrow ration of $1: 3$. When, as in the later experiments, less than 9.5 pounds of digestible matter were supplied in the ration, the weight of the horse decreased, the decrease being, under otherwise similar conditions, more marked when a narrow nutritive ratio $(1: 3.4)$ was fed than when a wider ratio (1:5.6) was given. (445) When heavier work was done, a supply of 12 pounds of digestible matter did not suffice to maintain the weight of the horse. This could only be attained by furnishing larger quantities of nutrients, viz., about 15.5 pounds.

The digestible nutrients necessary to maintain a horse of 1,100 pounds in a medium nutritive condition, when not performing any mechanical work, was found in repeated experiments with three horses to be 9.25 pounds on an average, when a considerable portion, at least one-half, of the ration was made up of coarse feed, viz., meadow hay. This proportion of coarse feed will hold good for farm horses doing an average day's work in rather slow time. Horses which are required to do heavy work and in rapid time, as, for instance, mail-coach or army horses, must have rations which are easily digested, and they should consist of concentrated feeding stuffs with some chaffed straw and little or no hay. ${ }^{1}$

435. Value of the various components of fodders.-According to Wolff's experiments, the digestible albuminoids of the feed have, beyond a certain minimum, no higher value for production of work than the same quantity of starch or of the starch equivalent of digestible non-nitrogenous substances. (Chapter V, pt. 1.) He fornd that the digestible organic substances in coarse fodders, mainly meadow hay, have considerably lower value for the production of work in the case of the horse than have the same substances in concentrated feeding stuffs, - for instance, oats. The explanation given, the correctness of which is disputed by good authorities, is that the crude fiber, largely present in the coarse

1 Wolff, Ldw. Jahrb., 1887, Suppl. III. 
fodders, is of no value to the horse either for maintenance or for production of work, the decomposition of cellulose taking place in the colon through the action of ferments, after it has passed the digestive tract. For keeping a horse of 1,100 pounds weight at maintenance, 9.25 pounds of digestible matter are required in the ration, as has been seen. Of crude fiber-free nutrients, 7.28 to 7.50 pounds were found necessary, an average of 7.39 pounds. This result is an average of thirty-eight experiments with three horses and agrees closely with the findings of Grandeau and Leclerc, who obtained 7.47 pounds as the average of six closely agreeing experiments with two horses.

436. Work possible from one pound of feed.-Beyond the 7.39 pounds of digestible crude fiber-free nutrients required for the maintenance of a 1,100 pound horse, each additional .22 of a pound (100 grams) of the crude fiber-free digestible nutrients will, according to Wolff, increase the power of the horse for muscular work about 400,000 foot-pounds. The table presented below shows the total available work possible from one pound of common feeding stuff on this basis:

Work, in foot-pounds, obtainable from one pound of various food substances when fed to the horse - Wolff.

\begin{tabular}{|c|c|c|c|c|c|c|}
\hline \multirow[b]{2}{*}{ Feed. } & \multirow{2}{*}{$\begin{array}{l}\text { No. of } \\
\text { anal- } \\
\text { yses. }\end{array}$} & \multirow{2}{*}{$\begin{array}{c}\text { No. of } \\
\text { diges- } \\
\text { tion ex- } \\
\text { peri- } \\
\text { ments. }\end{array}$} & \multirow{2}{*}{$\begin{array}{l}\text { Total } \\
\text { digesti- } \\
\text { ble or- } \\
\text { ganic } \\
\text { matter. }\end{array}$} & \multirow{2}{*}{$\begin{array}{l}\text { Digesti- } \\
\text { ble } \\
\text { crude } \\
\text { fiber. }\end{array}$} & \multicolumn{2}{|c|}{ Equivalent to work. } \\
\hline & & & & & $\begin{array}{l}\text { Crude } \\
\text { fiber in- } \\
\text { cluded. }\end{array}$ & $\begin{array}{l}\text { Crude } \\
\text { fiber ex- } \\
\text { cluded. }\end{array}$ \\
\hline & & & Per ct. & Per ct. & $\begin{array}{l}\text { Foot- } \\
\text { pounds. }\end{array}$ & $\begin{array}{l}\text { Foot- } \\
\text { pounds. }\end{array}$ \\
\hline Meadow hay ......... & 16 & 23 & 40.6 & 11.4 & 736,500 & 529,800 \\
\hline Clover hay............ & 5 & 7 & 41.1 & 12.0 & 745,600 & 527,900 \\
\hline Alfalfa hay............ & 4 & 6 & 46.2 & 11.0 & 838,100 & 638.600 \\
\hline Wheat straw......... & 4 & 7 & 15.7 & 7.6 & 284,800 & 147.000 \\
\hline Oats $\ldots \ldots \ldots \ldots \ldots \ldots \ldots$ & 8 & 22 & 60.2 & 2.0 & $1,092,000$ & $1,055,000$ \\
\hline Barley ..... & 1 & 1 & 70.7 & 4.1 & $1,282,000$ & $1,209,000$ \\
\hline Corn...$\ldots \ldots \ldots \ldots \ldots \ldots$ & 1 & 1 & 80.0 & 1.5 & $1,452,000$ & $1,424,000$ \\
\hline Field beaus ........... & 1 & 5 & 72.4 & 4.5 & $1,313,000$ & $\mathbf{1}, 232,000$ \\
\hline 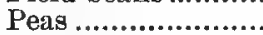 & $\mathbf{1}$ & 1 & 66.7 & 0.5 & $\hat{1}, 210,000$ & $\mathbf{1}, 201,000$ \\
\hline Lupines ................. & 1 & 1 & 63.4 & 8.7 & $1,150,000$ & 992,400 \\
\hline Linseed cake......... & 1 & 1 & 63.4 & & $1,150,000$ & $1,150,000$ \\
\hline Flaxseed ............... & 1 & $\overrightarrow{1}$ & 74.0 & ....... & $1,343,000$ & $1,343,000$ \\
\hline Potatoes..... & 1 & 1 & 21.5 & ............... & 390,000 & 390,000 \\
\hline Carrots................... & 1 & 1 & 6.0 & ............ & 108,800 & 108,800 \\
\hline
\end{tabular}


437. Feed requirements for work. - The manner of calculating the amount of feed necessary for the performance of a certain amount of work may be illustrated by an example cited by Wolff. $^{1}$ If a riding horse in average condition, weighing 937 pounds, and 1,157 pounds with rider and saddle, travels 20.5 miles daily, he performs the amount of work shown in the table, which calls for corresponding quantities of nutrients.

Nutrients required for woork of varying degrees - Wolff.

\begin{tabular}{c|c|c|c|c|c}
\hline Movement. & $\begin{array}{c}\text { Move- } \\
\text { ment } \\
\text { per } \\
\text { second. }\end{array}$ & $\begin{array}{c}\text { Time } \\
\text { required. }\end{array}$ & $\begin{array}{c}\text { Energy } \\
\text { used per } \\
\text { second. }\end{array}$ & $\begin{array}{r}\text { Total } \\
\text { energy. }\end{array}$ & $\begin{array}{l}\text { Digestible } \\
\text { nutrients } \\
\text { required. }\end{array}$ \\
\hline & Feet. & Seconds. & $\begin{array}{c}\text { Foot- } \\
\text { poun.ls. }\end{array}$ & $\begin{array}{c}\text { Foot- } \\
\text { pounds. }\end{array}$ & Lbs. \\
Walking............. & 4.1 & 26,400 & $\begin{array}{r}301.998 \\
7,971,700\end{array}$ & 2.85 \\
Slow trot............. & 8.2 & 13,200 & $\mathbf{1}, 207.978$ & $15,945,300$ & 5.70 \\
Canter ............. & 20.5 & 5,280 & $7,356.502$ & $38,842,900$ & 13.9 \\
\hline
\end{tabular}

To the digestible nutrients given in the last column must be added the quantity necessary to maintain the animal, aside from the performance of any work, which will amount to 6.70 pounds per 1,000 pounds weight ( 7.39 for 1,100 pounds), so that ordinarily the supply of digestible matter in the ration would be respectively 9.13, 11.97 and 20.17 pounds. The last two amounts called for in the last column are larger than a horse can assimilate, but a continuous canter or even slow trot for the whole distance of 20 miles represents an amount of work rarely performed by the horse. If we assume that one-third of the distance was traveled in a walk, one-third in a slow trot, and one-third in a canter, we find that the total time required would be 14,960 seconds, the total energy used 11,874,000 foot-pounds, and the corresponding feed requirements 4.25 pounds of digestible matter. This added to the feed required for maintenance amounts to 10.52 pounds of digestible matter. A horse walking 20 miles will require seven hours and twenty minutes. If equal distances are traveled in walk, trot and canter, it will take four bours and nine minutes. The total energy spent in the former

\footnotetext{
1 Landw. Jahrb., 1887, Suppl. ITI, p. 120.
} 
case with a rider will call for 9.12 pounds of digestible substances in the feed (exclusive of crude fiber), and in the latter 10.52 pounds. A daily ration of 8.8 pounds of good meadow hay and about 11 pounds of oats will supply the demand for the former effort, and 8.8 pounds of hay and $\mathbf{1 3 . 2}$ pounds of oats the latter.

438. Rate of movement. - In practice it is generally assumed that the speed of the horse per second amounts to 4.1 feet in walking; in slow trot, 8.2 feet; in rapid trot, 12.3 feet; in short canter, 16.4 feet; in canter, 20.5 feet, and in full gallop, 24.6 fert. ${ }^{1}$

The strain of work by a full-grown, well-fed horse can, according to Rueff, continue on an average for eight hours a day; for instance, a horse weighing about 900 pounds can carry 176 pounds, with a speed of 4.1 feet per second, for eight hours without suffering exhaustion, traveling in that time a little more than 22 miles. The length of time can be increased, but if more energy is called into play by increasing both the load and the speed, the animal will become exhausted. If, for instance, both the load and the speed be increased one-fourth, the working hours must be shortened one-fourth, and vice versa.

439. Influence of repidity of work. - The amount of work which a horse is able to perform on a certain ration remains practically the same whether done during a shorter or longer period of time, or by hauling a smaller or greater load. The following summary given by Wolff ${ }^{2}$ shows this statement to be correct:

Influence of rapidity of work by the horse - Wolff.

\begin{tabular}{|c|c|c|c|c|c|c|}
\hline Period. & $\begin{array}{l}\text { No. of } \\
\text { turns of } \\
\text { sweep. }\end{array}$ & Load. & $\begin{array}{l}\text { Distance } \\
\text { walked. }\end{array}$ & $\begin{array}{l}\text { Period of } \\
\text { walking. }\end{array}$ & $\begin{array}{l}\text { Total day's } \\
\text { work per- } \\
\text { formed. }\end{array}$ & $\begin{array}{l}\text { Work } \\
\text { per } \\
\text { secoud. }\end{array}$ \\
\hline - & & Lbs. & Feet. & Minutes. & $\begin{array}{c}\text { Foot- } \\
\text { pounds. }\end{array}$ & $\begin{array}{c}\text { Foot- } \\
\text { pounds. }\end{array}$ \\
\hline 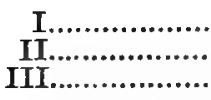 & $\begin{array}{r}1,000 \\
750 \\
600\end{array}$ & $\begin{array}{r}88 \\
132 \\
176\end{array}$ & $\begin{array}{l}86,560 \\
64,920 \\
51,950\end{array}$ & $\begin{array}{l}515 \\
396 \\
354\end{array}$ & $\begin{array}{l}12,300,200 \\
12,279,300 \\
12,078,400\end{array}$ & $\begin{array}{l}397.8 \\
517.0 \\
568.2\end{array}$ \\
\hline
\end{tabular}

The total work done remained practically the same in all cases, and the nutritive condition of the horse was apparently unchanged.

'Wolfl, Luudw. Jahrb., 1887, Suppl. III, p. $119 . \quad$ Loc. cit., p. 71. 
The ability of the horse to perform a definite amount of work was therefore the same whether it was performed in less than six hours or in more than eight hours.

440. An example of severe work.-Wolff cites the intense work of the mail-coach horses on the route from Plieningen to Stuttgart, Germany. Two strongly-built, spirited horses, in good flesl, drawing a heavy mail-coach, often carrying eight passengers, go twice daily out and home, up and down the mountain road at a trot. The total distance traveled is 35 miles, with an average speed of 7.87 feet per second. These horses are fed daily per head from 22 to 24 pounds of oats mixed with cut straw, and in addition hay ad libitum, of which they eat very littleoften none at all. The oats consumed contained from 13.2 to 14.5 pounds of digestible matter, and the day's work represents at least 21,660,000 foot-pounds per horse. When the feed equivalent of the work performed is subtracted, much less than 9.25 pounds of the digestible matter remains as the maintenance ration when calculated on the basis of a weight of 1,100 pounds per horse.

441. The German army horse. - The German army horse often travels over 40 miles in a day, one-third of the distance being in a walk, trot and gallop, respectively. This work means an expenditure of energy amounting to not less than $23,748,000$ footpounds, or a feed requirement of 14.77 pounds of digestible matter, including the food of support. The horses are fed on an average a ration consisting of only 5.5 pounds of hay, 11 pounds of oats, and some cut straw. This ration contains only about 8.8 pounds of digestible components, and "it is therefore not hard to under. stand why the horses lose heavily in weight during the maneuvers, and that, when these are over, a large number of animals have to be disposed of as not adapted for use in military service; they are also unfit for almost any other work."

\section{The Investigations of Grandean and Leclerc.}

442. Digestibility of horse feeds. - Grandeau and Leclerc ${ }^{1}$ studied the digestibility of horse feeds and the relation of food to the amount of work performed by the light draft horses of the Paris

\footnotetext{
I Anu. de la Sci. Agron., 1884, Vol. II, p. 325.
} 
Cab Company. They determined the digestibility successively of maintenance rations, rations fed horses when walking without load, and rations for light-working horses. Three horses were included in the experiments, the rations consisting of about threefourths grain and one-fourth coarse feed supplied in the following quantities:

Rations fed horses during digestion trials - Grandeau and Leclerc.

\begin{tabular}{r|r|r|r|r|r|r|r}
\hline \hline & Fay. & Straw. & Oats. & Beans. & Corn. & $\begin{array}{c}\text { Corn } \\
\text { cake. }\end{array}$ & Total. \\
\hline & Lbs. & Lbs. & Lbs. & Lbs. & Lbs. & Lbs. & Lbs. \\
Maintenance ration.... & 2.3 & 1.2 & 4.3 & .9 & 3.3 & .6 & 12.6 \\
Exercise ration .......... & 2.5 & 1.4 & 4.8 & 1.0 & 3.5 & .7 & 13.9 \\
Walking ration ......... & 3.5 & 1.9 & 6.5 & 1.4 & 4.8 & 1.0 & 19.1 \\
\hline
\end{tabular}

The three experimental rations stand in the ratio of $1: 1.1: 1.0$. Each period lasted a month, the three horses being successively put on the same rations and subjected to the same conditions. The horses weighed 972,945 and 992 pounds at the beginning of the experiments. The following average digestion coeficients for the above rations were obtained:

Digestion coefficients for ralions fed three horses - Grandeau and Leclerc.

\begin{tabular}{|c|c|c|c|c|c|c|}
\hline Exercise. & $\begin{array}{c}\text { No. } \\
\text { of } \\
\text { trials. }\end{array}$ & $\begin{array}{l}\text { Organic } \\
\text { matter. }\end{array}$ & $\begin{array}{l}\text { Pro- } \\
\text { tein. }\end{array}$ & $\begin{array}{l}\text { Cellu- } \\
\text { lose. }\end{array}$ & $\begin{array}{l}\text { Nitrogen- } \\
\text { free ex- } \\
\text { tract. }\end{array}$ & $\begin{array}{c}\text { Ether } \\
\text { extract. }\end{array}$ \\
\hline 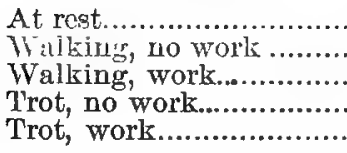 & $\begin{array}{r}21 \\
3 \\
3 \\
3 \\
6\end{array}$ & $\begin{array}{l}72 \\
72 \\
70 \\
69 \\
67\end{array}$ & $\begin{array}{l}74 \\
74 \\
72 \\
69 \\
67\end{array}$ & $\begin{array}{l}46 \\
44 \\
39 \\
40 \\
33\end{array}$ & $\begin{array}{l}77 \\
77 \\
75 \\
76 \\
73\end{array}$ & $\begin{array}{l}58 \\
5,9 \\
62 \\
53 \\
55\end{array}$ \\
\hline
\end{tabular}

The digestibility of the rations when the horses were walling a distance of about twelve miles per day was no smaller than when at rest. There was an extreme depression of 5 per cent. in the digestibility of the total organic matter and 7 per cent. in the protein when the horses were worked lard. (433) It further appears from the trble that the digestion of cellulose, which occurs principally in the colon or large intestine, is affected more 
than any other constituent by the amount of exercise or work; the motion of the horse probably determines its more rapid passage through the system. Grandeau states that the results accord with practical experience, which teaches that the digestion of horses is relatively the niost efficient when they are resting or doing little work.

443. Maintenance ratiens for horses. ${ }^{1}$ - We have seen that by "maintenance ration" is understood the minimum supply of feed which will keep a horse from losing weight while at rest in the stable with only the small amount of walking exercise necessary to preserve health. (133) In Grandeau's experiments with meadow hay as the sole diet, three horses were kept at rest for periods amounting to four or five months each, half an hour's walking exercise being allowed per day. Each horse received 17.6 pounds of hay per day, which proved exactly sufficient to maintain his weight unaltered. The three horses did not digest the hay equally well, and thus each horse was really nourished and its weight maintained by somewhat different amounts of food. The average result for each horse was as follows:

Maintenance experiments with horses fed meadow hay - Grandeo's and Leclerc.

\begin{tabular}{|c|c|c|}
\hline \multirow{2}{*}{ Weight of horse. } & \multicolumn{2}{|c|}{$\begin{array}{l}\text { Total organic matter } \\
\text { digested per day. }\end{array}$} \\
\hline & $\begin{array}{l}\text { Actual } \\
\text { amount. }\end{array}$ & $\begin{array}{l}\text { Per } 1,000 \\
\text { lbs. weight. }\end{array}$ \\
\hline & Lbs. & Lbs. \\
\hline 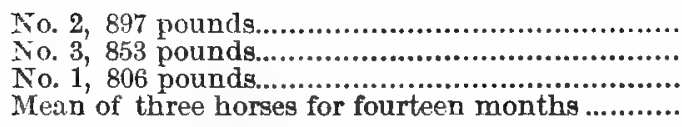 & $\begin{array}{c}5.90 \\
5.98 \\
6.31 \\
\ldots . . . \ldots \ldots . . .\end{array}$ & $\begin{array}{l}6.57 \\
7.00 \\
7.82 \\
7.02\end{array}$ \\
\hline
\end{tabular}

Grandeau and Leclerc experimented with many other rations, but in only a few cases did their maintenance diets exactly meet the wants of the horse. These results are given in the next table; they are less valuable than those obtained with meadow hav, given above.

'After Warington, London Live Stock Journal, 1894, p. 9, et seq. 
Maintenance exporiments with horses - Grandeau and Leclerc.

\begin{tabular}{|c|c|c|c|c|}
\hline \multirow[b]{2}{*}{ Diet. } & \multirow[b]{2}{*}{$\begin{array}{l}\text { Weight of } \\
\text { horse. }\end{array}$} & \multicolumn{3}{|c|}{ Total organic matter per day. } \\
\hline & & In ration. & Digested. & $\begin{array}{c}\text { Digested } \\
\text { per } 1,000 \\
\text { lbs. weight. }\end{array}$ \\
\hline & Lbs. & Lbs. & Lbs.- & Lbs. \\
\hline Hay alone (mean).............. & 868 & 14.08 & 6.09 & 7.02 \\
\hline Oats alone (crushed)........... & 913 & 8.59 & 6.41 & 7.02 \\
\hline 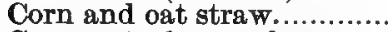 & 1,013 & 11.57 & 8.33 & 8.22 \\
\hline Corn, oats, hay and straw... & 972 & 9.48 & 7.30 & 7.50 \\
\hline Corn, oats, hay and straw... & 906 & 9.49 & 6.74 & 7.45 \\
\hline
\end{tabular}

These figures illustrate very plainly the weak point in a diet containing much hay or straw, viz., the large quantity which must be given to animals to produce a certain effect, due to the low digestibility of these feeds.

444. Protein required in maintenance rations. ${ }^{1}$ - In constructing a maintenance ration for an animal it is important to know what is the smallest quantity of protein required to replace the daily waste of the body; the ration should of course never supply less than this amount. The quantity does not seem to have been exactly determined in the case of the horse, but judging from the French experiments it must be quite small. The average amount of digestible albuminoids received daily by the three horses during fourteen months while fed entirely upon hay was only .54 pounds per 1,000 pounds live weight. This quantity corresponds to that determined by German experiments as minimum quantities for an ox of 1,000 pounds kept on a maintenance diet. The minimum for the horse is, however, less than the above average. Horse No. 3 during June and July received a daily average of only .45 pounds per 1,000 pounds weight, yet this was apparently sufficient, as the horse gained about five pounds in weight during these two months. In another case the same horse received daily, during one month, only .37 pounds of digestible albuminoids per 1,000 pounds live weight. The horse gained somewhat in weight while at rest, but the analyses of the urine showed that he lost rather more nitrogen than he

1 After Warington, loc. cit. 
received in the food. We are therefore disposed to assume about .45 pounds of digestible protein per 1,000 pounds live weight as the minimum quantity for the maintenance of a horse. Since oats contain about nine per cent. of digestible protein, about five pounds of oats daily would supply all the protein necessary to replace the wear of muscular tissue in the horse during rest. This amount of oats would contain about 4.3 pounds of organic matter, or 2.7 less than required according to the results of Grandeau's experiments. The horse would therefore be unable to hold his own on five pounds of oats alone, but would need nearly as much hay in addition. (134)

445. Nutritive ratio for work horses. - In the experiments by Grandeau conducted in 1889-90, the question of the most profitable nutritive ratio for work horses was considered. ${ }^{1}$ (132-4) In place of the ration previously fed, having a nutritive ratio of about $1: 7$, an Indian corn and straw ration, having a ratio of $1: 10$, and one of beans and straw, with a ratio of $1: 3$, were fed. The effect of these rations was studied with three horses for a year, they being at rest in the stall, or given walking or trotting exercise, or work at the sweep at a walking or trotting pace, or finally given work before the carriage. The rations varied of course with the work performed, but the same proportions of each feed given during rest were continued during the other periods, the quantities only being increased. The corn ration fed during rest was 9.4 pounds corn, 5.4 pounds cut straw; the bean ration 9 pounds beans, 8.5 pounds cut straw. The straw fed was barley straw during 1889 and oat straw during 1890 . The average weight of the three horses during the whole experiment was, for corn periods 976.8 and for bean periods 1,045.5 pounds. The increase in weight was partly due to the larger quantity in nutrients of the bean ration, amounting to about 6 per cent. In spite of the larger quantities of nutrients fed during the bean periods, the effect of the rations was about the same, and when a difference occurred it was in favor of the corn. A better utilization of the fodder must therefore have taken place during the corn periods, since there was no evidence of any difference in the

1 Ann, de la Sci. Agr., 1892, p. 1. 
nutritive condition of the horse or in its capacity for work in favor of beans. The main difference in the rations is in the greater protein content of the bean ration, the quantity of carbohydrates being practically the same in both cases.

The conclusion drawn, therefore, is that a very narrow nutritive ratio is not advantageous, but that experience must still decide how far the ration may be profitably widened. The author believes that $1: 7$ is about a correct nutritive ratio for the utilization of all components of the ration for the work horse. (434)

446. Feed required for performing work.-Grandeau's researches ${ }^{1}$ do not furnish much information as to the quantity of feed regnired for the performance of known amounts of work, for although graduated amounts of measured work were performed by the horses under each diet, it was rare that the ration proved exactly sufficient for maintaining the horses' weight without gain or loss. Some points of importance were, however, clearly made out. One of these is the effect of pace on the amount of labor exerted and the feed required therefor. Thus, a horse walking 12.5 miles per day was kept in condition with a daily ration of 19.4 pounds of hay, while one of 24 pounds was insufficient when the same distance was covered at a trot. Again, a horse walking the above distance and hauling a load, the additional work being equivalent to 1,943 foot-tons, was sufficiently nourished by a ration of 26.4 pounds of hay, but one of 32.6 pounds (all the horse would eat) was not enough to maintain its weight when the same work was done at a trot. That work is performed at least cost to the system when done slowly is a fact well recognized by every old and feeble man, but the principle has not generally been recognized as true in all cases.

Some of the reasons why rapid labor is less economically performed than slow labor are readily apparent. When a horse is trotting, the frequency of the pulse, and consequently the work performed by the heart, is much increased. The trotting or galloping horse lifts his own weight at each step, but allows it to fall again, the result appearing only as heat. The temperature of the horse rises with exertion, and much heat is lost by the

\footnotetext{
1 After Warington, loc. cit.
} 
evaporation of water through the skin and lungs. The proportion of the food employed to produce heat is thus increased, while the proportion appearing as work is diminished. There are other mechanical reasons why rapid motion generally consumes more power than slow motion, even when the distance traveled and the weight moved are the same. Grandeau gives tables showing the temperature of the body of the horse before and after work. When the work performed was at all severe, a very distinct rise in body temperature was observed - from $2^{\circ}$ to $4^{\circ} \mathrm{Fahr}$.

447. Water drank by horses.- Grandeau and Leclerc ${ }^{1}$ report the following quantities of water drank by two horses under different conditions:

Horse A. Horse B.

Lbs. daily. Lbs. daily.

Walking, performing no labor 24.9

30.7

Walking, performing labor. 28.9

35.4

Trotting, performing no labor 31.3 27.6 Trotting, performing labor 52.0

448. Loss of weight during work.- Grandean and Leclerc's investigations ${ }^{2}$ furnish abundant material for studying the loss of weight of horses and the quantities of water drank during different kinds of work. The following are some of the results:

Loss in weight of horses during work and when at rest-Grandeas and Leclerc.

\begin{tabular}{|c|c|c|c|c|c|c|c|c|c|}
\hline \multirow{3}{*}{ No. of horse. } & \multirow{3}{*}{$\begin{array}{l}\text { Av. } \\
\text { live } \\
\text { weight. }\end{array}$} & \multirow{2}{*}{\multicolumn{2}{|c|}{$\begin{array}{l}\text { Av. length of } \\
\text { trial. }\end{array}$}} & \multirow{2}{*}{\multicolumn{2}{|c|}{$\frac{\begin{array}{c}\text { Welking, no } \\
\text { work. }\end{array}}{\text { Loss in weight. }}$}} & \multirow{3}{*}{$\begin{array}{l}\text { Water } \\
\text { drank } \\
\text { per } \\
\text { day. }\end{array}$} & \multicolumn{2}{|c|}{$\begin{array}{l}\text { Walkins, } \\
\text { work. }\end{array}$} & \multirow{3}{*}{$\begin{array}{l}\text { Water } \\
\text { drank } \\
\text { per } \\
\text { day. }\end{array}$} \\
\hline & & & & & & & \multicolumn{2}{|c|}{ Loss in weight. } & \\
\hline & & A. $\mathbf{M}$. & P. M. & A. $\mathbf{M}$. & P. M. & & A. $\mathbf{M}$. & P. M. & \\
\hline \multirow[t]{2}{*}{ III $\ldots \ldots \ldots \ldots \ldots \ldots$} & $\begin{array}{c}\text { Lbs. } \\
850 \\
800\end{array}$ & $\begin{array}{r}\text { Min. } \\
145 \\
145\end{array}$ & $\begin{array}{c}\text { Min. } \\
151 \\
151\end{array}$ & $\begin{array}{c}\text { Lbs. } \\
2.0 \\
2.8\end{array}$ & $\begin{array}{c}\text { Lbs. } \\
1.6 \\
2.7\end{array}$ & $\begin{array}{l}\text { Lbs. } \\
24.9 \\
30.7\end{array}$ & $\begin{array}{c}\text { Lbs. } \\
2.8 \\
4.9\end{array}$ & $\begin{array}{c}\text { Lbe. } \\
3.9 \\
5.4\end{array}$ & $\begin{array}{l}\text { Lbs. } \\
28.9 \\
35.4\end{array}$ \\
\hline & & & & \multicolumn{2}{|c|}{$\begin{array}{l}\text { Trotting, no } \\
\text { work. }\end{array}$} & & \multicolumn{2}{|c|}{$\begin{array}{l}\text { Trotting, } \\
\text { work. }\end{array}$} & \\
\hline III $\ldots \ldots \ldots \ldots \ldots \ldots$ & $\begin{array}{l}850 \\
800\end{array}$ & $\begin{array}{l}80 \\
79\end{array}$ & $\begin{array}{l}79 \\
79\end{array}$ & $\begin{array}{l}2.7 \\
4.5\end{array}$ & $\begin{array}{l}8.2 \\
5.5\end{array}$ & $\begin{array}{l}31.3 \\
27.6\end{array}$ & $\begin{array}{l}8.0 \\
8.7\end{array}$ & $\begin{array}{r}9.1 \\
10.5\end{array}$ & $\begin{array}{l}52.0 \\
50.7\end{array}$ \\
\hline
\end{tabular}

The difference between the loss in weight of the horse when walking and trotting, or that obtained when working and idle, is

1 Loc. cit.

2 Ann. Sci. Agr., 1888, II, p. 276. 
due not only to wear of muscles and decomposition of nutritive fluids in the body of the animal, but is partly accounted for by the increased evaporation of water due to the heavier work. The water evaporated daily under varying conditions of exercise, as determined in experiments with different diets, was as follows:

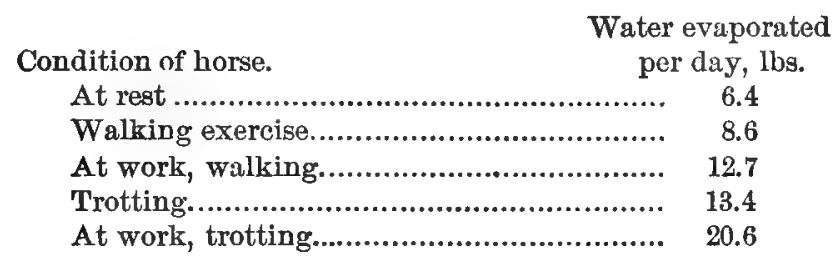

The distance trotted was the same as that walked, and the load drawn was the same. The heat consumed in the evaporation of water was quite considerable. The exhalation of water by breath and perspiration thus diminishes the quantity of food available for the production of work.

\section{Niscellaneous Findings by the Investigators.}

449. Relation of speed to work.-According to M. Fourier, 1 the daily work of a good horse has a maximum, under the best load for each speed, of about 2.95 feet per second, or 10,496 feet (two miles nearly) an hour. Taking this maximum as unity, he gives the following as the probable value of work perfornied at other speeds:

$\begin{array}{rcc}\text { Feet. } & \text { Miles. } & \text { Daily work. } \\ 6,560 & 1.25 & 0.69 \\ 10,496 & 2.00 & 1.00 \\ 13,120 & 2.50 & .99 \\ 19,680 & 3.75 & .94 \\ 26,240 & 5.00 & .83 \\ 32,800 & 6.25 & .68 \\ 39,360 & 7.50 & .51 \\ 45,920 & 8.75 & .33 \\ 52,480 & 10.00 & .18 \\ 59,040 & 11.25 & .07\end{array}$

The data presented show that the horse is at his best for draw. ing a load when moving at the rate of about two miles per hour.

1 Magnon, 'raite de Genie Rural, IIr, 175, quoted by Thurston, The Animal as a Machine and a Prime Motor, p. 52. 
If the speed be increased beyond this, then less of the energy can be devoted to drawing the load. With a speed of ten miles per hour about two-tenths of the maximum work can be performed, and a further increase of a mile and a quarter per hour reduces the possible work to less than one-tenth of the maximum.

" Where the animal must develop maximum power continuously at any considerable speed, the number required for a specific work will always be greatly increased. Thus, in coaching, the proprietors of mail-coaches, even on the admirable highways of Great Britain, maintain one horse per mile of route for each coach and worked in fours, so that, going and returning, each travels eight miles per day, working only an hour or less each day on the average. The coach weighs, loaded, two tons, and its coefficient of friction on good roads is about .035."

Draft horses moving two and one-half miles an hour are expected to do seven times the work of coach horses moving ten miles. 1

450. Work done by the horse and the mule.- Rennie? found the hauling power of a draft horse weighing 1,200 pounds equal to about 108 pounds at 2.5 miles an hour, or 22,300 footpounds per minute, for 8 hours per day - a twenty-mile haul. This is a little over two-thirds of a Watt horse-power, at which value Rennie rates the average draft horse, and this is taken to be, ordinarily, five times the power of a man. Between 2.5 and 4 miles an hour, the hauling power of the horse is nearly inversely as the speed.

The mule carries a load of 200 to 400 pounds, and its day's work consists, usually, in the transportation of the equivalent of 5,000 to 6,000 pounds one mile. The ass carries 175 pounds and upward, and its day's work is the equivalent of 3,000 to 4,000 pounds one mile.

According to Weisbach, a horse should be able to carry 240 pounds on its back 3.5 feet per second ten hours a day. Carrying 160 pounds he should be able to trot seven feet per second seven hours a day, doing in the day nearly ten per cent. less work than before.

1 Barbour, Cyclopædia of Manufactures.

2 Thurston, The Animal as a Machine and a Prime Motor, p. 59. 
The pulling power of a draft animal is said to be, as a rule, about one-fifth its weight. Its usual effort, in the case of the horse at least, is seldom in excess of one-tenth, or about one-half the maximum. One hundred pounds is a common pull for the average horse in draft vehicles.

In racing the requirement of speed reduces the work performed (carrying the rider) to the smallest amount possible. Low writes: ${ }^{1}$ "When it is considered that an ounce of additional loading to the same horse may make the difference of a yard or more in half a mile of running, it will be seen how greatly the weight borne may affect the issue in the case of horses of equal powers."

45I. Investigations by Muentz. - Müntz ${ }^{2}$ determined the digestibility of a large number of feeding stuffs for horses at rest receiving only one kind of feed at a time. The digestion coefficients for the total organic matter were: Corn, 94.5 per cent.; barley, 84.5 per cent.; beans, 84.5 per cent.; oats, 75.1 per cent.; wheat bran, 93.3 per cent.; meadow hay, 43.3 to 61.0 per cent.; wheat straw, 49.4 per cent. ; carrots, 94.6 per cent. Corn and bran thus appear to be the most digestible of the common horse feeds. (175) The digestibility attributed to wheat straw is higher than that calculated from Wolff's experiments, in which it was fed in connection with other feeds of known digestibility. Twenty-one per cent. of the organic matter was calculated as digestible in Wolff's experiments made with three lots of straw in six single trials. ${ }^{3}$

In Müntz's experiments, 33 pounds of straw were consumed daily by the horse during the last month, supplying 13 pounds of digestible matter, yet the horse died from exhaustion; the ration in fact supplied only .157 pounds of digestible protein, or about one-third of the quantity necessary for maintenance.

452. Water drank by the horse. - The amount of water drank by the horse varies with the character of the feed, as shown in the researches of the various experiments. It is smallest when the diet is largely made up of concentrates and largest when roughage only is given. With the mixed diet employed for the Paris cab horse the average proportion of water to dry matter was 2.1: 1

1 Breeds of the Dourstic Animals of the British Isles.

- Warington, London Live Stock Joumal, 1894, p. 49.

- Dietrich and König, Futterm., Vol. II, p. 1097. 
when the horse was at rest, and $3.6: 1$ when the horse did cab service. Individual horses differ greatly in the quantity of water drank. The relation of the feed eaten, work done and water drank by horses is shown by the data given in Wolff's experiments. ${ }^{1}$

Amount of water drank by horses - Wolff.

\begin{tabular}{|c|c|c|c|c|c|c|c|c|c|c|}
\hline \multirow[b]{2}{*}{ Period. } & \multicolumn{2}{|c|}{ Feed per day. } & \multicolumn{2}{|c|}{ Daily work. } & \multirow[b]{2}{*}{$\begin{array}{c}\text { Dally } \\
\text { tem- } \\
\text { pers. } \\
\text { ture. }\end{array}$} & \multirow[b]{2}{*}{$\begin{array}{l}\text { Water } \\
\text { drank. }\end{array}$} & \multicolumn{3}{|c|}{ Watcr. } & \multirow{2}{*}{$\begin{array}{c}\text { Watez } \\
\text { per lb. } \\
\text { dry } \\
\text { mat. } \\
\text { ter. }\end{array}$} \\
\hline & Hay. & Oats. & $\begin{array}{c}\text { Revo- } \\
\text { lutions } \\
\text { of } \\
\text { sweep. }\end{array}$ & $\begin{array}{l}\text { Trac- } \\
\text { tion. }\end{array}$ & & & In & $\underset{\text { In }}{\text { In }}$ & $\begin{array}{c}\text { Ex- } \\
\text { pired } \\
\text { and } \\
\text { per- } \\
\text { spired. }\end{array}$ & \\
\hline & Lbs. & Lbs. & & Lbs. & C. & Lbs. & Lbs. & Lbs. & Lbs. & Lbs. \\
\hline $\begin{array}{l}1 \ldots \ldots \ldots \\
2 \ldots \ldots \ldots \\
3 \ldots \ldots \ldots \\
4 \ldots \ldots \ldots \\
5 \ldots \ldots \ldots \\
6 \ldots \ldots \ldots\end{array}$ & $\begin{array}{r}15.4 \\
15.4 \\
15.4 \\
11.0 \\
6.6 \\
6.6\end{array}$ & $\begin{array}{l}12.1 \\
12.1 \\
12.1 \\
12.1 \\
12.1 \\
15.4\end{array}$ & $\begin{array}{r}1,000 \\
750 \\
600 \\
550 \\
350 \\
700\end{array}$ & $\begin{array}{r}88 \\
132 \\
176 \\
132 \\
132 \\
132\end{array}$ & $\begin{array}{r}-5.1 \\
-4.1 \\
10.1 \\
8.2 \\
17.5 \\
17.8\end{array}$ & $\begin{array}{l}61.5 \\
64.4 \\
58.8 \\
47.1 \\
35.8 \\
41.3\end{array}$ & $\begin{array}{l}29.6 \\
30.1 \\
29.8 \\
21.6 \\
16.9 \\
20.5\end{array}$ & $\begin{array}{l}18.3 \\
19.4 \\
19.8 \\
15.6 \\
11.4 \\
13.6\end{array}$ & $\begin{array}{l}17.7 \\
19.0 \\
13.5 \\
13.1 \\
10.0 \\
10.4\end{array}$ & $\begin{array}{l}2.8 \\
2.9 \\
2.7 \\
2.4 \\
2.4 \\
2.4\end{array}$ \\
\hline $7 \ldots \ldots \ldots$ & $\begin{array}{l}15.4 \\
24.3\end{array}$ & $\begin{array}{r}\text { Corn. } \\
7.7\end{array}$ & $\begin{array}{l}650 \\
300\end{array}$ & $\begin{array}{l}132 \\
132\end{array}$ & $\begin{array}{l}19.4 \\
19.5\end{array}$ & $\begin{array}{l}58.9 \\
73.0\end{array}$ & $\begin{array}{l}24.1 \\
35.3\end{array}$ & $\begin{array}{l}15.4 \\
21.6\end{array}$ & $\begin{array}{l}22.2 \\
18.7\end{array}$ & $\begin{array}{l}3.1 \\
3.5\end{array}$ \\
\hline
\end{tabular}

The water in the feed, which ranged from 2.5 to 4.2 pounds, is not included in the first part of the table. The figures in the last column show the number of pounds of water drank and that contained in the feed per pound of dry matter consumed. The preceding shows that the amount of water drank by the horse varies more than that of any other domestic animal and should be supplied according to requirements. The wisdom of supplying it frequently during hard labor is plainly indicated in these data.

453. Decrease in weight of the horse during work.-Rueff ${ }^{2}$ investigated the loss in weight of horses during work, correction being made for the fodder eaten and the dung dropped. Farm horses doing medium work lost on an average 7.7 pounds in weight during eleven hours. The following results were obtained with German army horses: A division of riding horses ridden for 25 minutes in walk, trot and gallop lost on an average 4 pounds in weight. A gelding 8 years old, carrying a weight of 176 pounds, in training as a school horse, lost 11 pounds in 25 minutes; another horse the same; after 24 hours only 1 pound was regained. A

\footnotetext{
1 Landw. Jahrb. 1887, Suppl. III, p. 109.

2 Landw. Wochenbl. d. k. k. Ackerbaum., 1870, 109; v. Gohren, Fütterungeslehre, $1872, \mathrm{p}, 370$.
} 
14-year-old blind stallion ridden for an hour and thirty minutes by a rider weighing 166 pounds lost 33 pounds weight; during 24 hours 22 pounds were regained. A 23-year-old mare weighing 770 pounds, ridden for a distance of six miles in walk or trot, lost 22 pounds.

454. Variation in weight.-Boussingault ${ }^{1}$ studied the variations in weight of horses while on the same feed and under similar conditions. The changes in the weights of two horses, found in fifteen daily weighings between December 16 and 31, are shown below: ${ }^{3}$

\begin{tabular}{|c|c|c|}
\hline Average, December 16 to & $\begin{array}{c}\text { Weight of } \\
\text { horse, lbs. } \\
994.4\end{array}$ & $\begin{array}{c}\text { Weight of } \\
\text { mare, lbs. } \\
1,081.9\end{array}$ \\
\hline Maximum weight........................... & $1,010.9$ & $1,092.7$ \\
\hline Minimum weight .......................... & 985.6 & $1,064.8$ \\
\hline Greatest difference above average...... & 16.5 & 10.8 \\
\hline Greatest difference below average...... & 8.8 & 17.1 \\
\hline Difference between extreme weights.. & 25.3 & 27.9 \\
\hline
\end{tabular}

Another horse 12 years old, taken fasting at four $0^{\prime}$ clock in the morning, weighed 1,051 pounds. At the same hour of the next day he weighed 1,060 ponnds, and at the same huur on the third day 1,038 pounds. Boussingault calls attention to the necessity of carrying on feeding experiments for a considerable time and with several animals, in order to escape, or at all events lessen, the errors that would be introduced into the conclusions by these accidental differences in weight.

455. Effect of disturbed conditions on horses. - Lehmann, Hageunann and Zuntz ${ }^{2}$ found that the disturbance of horses in the stable has a decided influence on the consumption of feed. The presence of many flies caused an excretion of carbonic acid of 10 per cent. above that in case of those not so annoyed.

${ }^{1}$ Ann. de la Sci. Agron., 1884, II, p. 330; Rural Economy, p. 397.

- Landw. Jahrb., XXII, 1894, p. 125. 


\section{CHAPTER XVII.}

\section{FEEDS FOR THE HORSE.}

456. Oats.- Horses nurtared on oats show mettle which can. not be reached by the use of any other feeding stuff. (188) Then, too, there is no grain so safe for horse feeding, the animal rarely being seriously injured if by accident or otherwise the groon: deals out an over supply. This safety is due in no small measure to the presence of the oat hull, which causes a given weight of grain to possess considerable volume, because of which there is less liability of mistake in measuring out the ration; further, the digestive tract cannot hold a quantity of oat grains sufficient to produce serious disorders. Unless the horse is hard pressed for time or has poor teeth, oats should be fed in the whole condition. Musty oats should be avoided.

Horsemen generally agree that new oats should not be nsed, though Boussingault, ${ }^{1}$ conducting extensive experiments with army horses, arrived at the conclusion that new oats do not possess the injurious qualities attributed to them.

457. Substitutes for oats.-According to experiments made at Hohenheim (Germany) and Paris, oats may often be profitably replaced by other concentrated and easily digested feeding stuffs for the production of work by horses. Because of their palatability it seems desirable and advantageous not to entirely omit oats from the ration, but only to reduce the allowance to a certain minimum. This is, however, very important at times on account of the high market valne of this grain. During feeding experiments at Hohenheim in 1893-94, a horse was fed a daily ration consisting of 6 pounds of meadow hay, 5 pounds of cut straw, 2 pounds of oats, 3 pounds of field beans, 8 pounds of

1 Ann. de la Sci. Agron., 1884, II, p. 331. 
cons and about 1 ounce of salt per 1,000 pounds weight. The nutritive ratio of this ration is about $1: 6.4$. In case of work horses, especially those doing rapid work, not accustomed to voluminous rations and not having the capacity for them, more intensive feeding will be in order, such, for instance, as that practiced by the Paris Omnibus Company, where 28 per cent. of the rations for horses consists of roughage (meadow hay and oat straw in the proportion of $2: 1$ ), and 72 per cent, or nearly three-fourths, of concentrates (oats, bean, corn, oil cake), the nutritive ratio being about $1: 7.2 .1$

458. Relative value of oats, beans and corn.- As a result of feeding experiments with horses at Hohenheim, Wolff ${ }^{2}$ concludes that in feeding work horses, 4 pounds of oats are equivalent to 3.5 pounds of field beans, and 4 pounds of beans to 3.5 pounds of corn. On the basis of these figures, oats, beans and corn have a relative value for horses of $4: 3.5: 3$, or perhaps more correctly, $5: 4.5: 4$.

459. Relative value of hay and oats. - According to Wolff' $\mathrm{s}^{8} \mathrm{ex}$ periments, 2.5 pounds of good meadow hay have an equal nutritive value of 1.5 pounds of oats, if the digestible crude fiber be included in both cases; without this the ratio will be $2: 1$.

460. Barley.-This useful grain for the horse has as yet been little fed in the eastern United States, probably because of its general high price. On the Pacific coast barley is extensively used for feeding horses at all kinds of work. Where the horse's teeth are good and the labor not severe, barley may be fed whole. Ground barley, when mixed with the saliva, like wheat, forms a pasty mass in the mouth, and is therefore unpleasant to the horse while eating; if, instead of grinding, the grains are crushed to flattened dises between iron rollers, they are more palatable and acceptable to the horse. (178)

461. Dried brewers' grains. - At the New Jersey Station, 4 dried brewers' grains were fed to street-car horses in place of oats. Horses averaging 1,C00 pounds in weight were required to make

1 Wolff, Ldw. Jahrb., XXIV, p. 267.

2 Loc. cit.

" Idw. Jahrb., XXIV, p. 269.

: Rept. 1892. 
four trips daily of six miles each, with increased work on Sundays. The rations were as follows:

\begin{tabular}{|c|c|}
\hline Dried Brewers' Grains Ration. & Oat Ration. \\
\hline Hay ............................... & 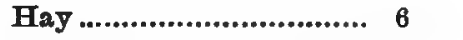 \\
\hline 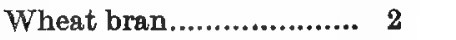 & Wheat bran ...................... 2 \\
\hline Corn, unground.................. & Corn, unground.................. \\
\hline Dried brewers' grains ....... & 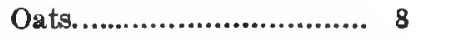 \\
\hline
\end{tabular}

Each ration was fed to a group of four horses for a month, then the two feeds reversed for a second month. Then followed a period in which the stable ration prevailed with both lots, the trial closing with a month's feeding of the two rations to the original lots, as in the first instance. The veterinarian in charge of the horses reports: "I have watched the horses closely from the beginning to the end of the experiment and have failed to discover any ill effects from the use of dried brewers' grains. The horses fed the grains have been as healthy as I have ever known them to be." The conclusions of the Station authorities were: "That in both rations the nutrients furnished were sufficient to maintain the weight of the animals under average work," and "That on the whole, a pound of dried brewers" grains was quite as useful as a pound of oats in a ration for work horses." It was found that the oat ration cost, at prevailing prices, 24.3 cents pe day, while the ration containing brewers' grains cost 19.4 centa, a difierence of 4.9 cents per day per horse, or twenty per cent. of the cost of the oat ration - an insignificant amoint perhaps for $\mathrm{at}$ single horse, but making an aggregate of great importanen for large establishments.

According to Wolff, " "The effect of dried brewers' grains has been found to be uncertain, and on that account their use has been abandoned by the German war department." While brewers' grains dried by any open-air process may be subject to criticism, the charge cannot stand for grains which are dried rapidly in partial vacuum. (183)

462. Wheat.-At the North Dakota Station, ${ }^{2}$ Shepperd fed No. 1 hard unground wheat to three horses for four weeks, sup-

1 Farm Foods, Eng. ed., p. 247.

Bul. 20. 
plying each animal about fourteen pounds daily. These horses averaged nine hours' work daily for all the working days of the month. The horses gained in weight during the trial. Concerning wheat as a horse feed Shepperd writes: "It was with difficulty that they (the horses) were kept from getting 'off feed' and otherwise deranged in digestion, when fed this ration of pure wheat. A large proportion of the kernels were passed through the alimentary tract unbroken, while other grains were broken but only partially digested. . . . The test demonstrated clearly that it is not advisable to use wheat alone as a grain ration for horses, and the less expert the feeder the greater the risk." (I66-9)

463. Bran and shorts compared with oats.-- Shepperd ${ }^{1}$ compared bran and oats as a feed for work horses and mules in summer, eight horses and four mules being used. The animals were divided into two even lots, all receiving good prairie hay for roughage. To one lot was fed oats, while the other received a mixture of bran and shorts, equal parts by weight. The horses averaged soinewhat more than seven hours work per day, the labor being quite severe.

Bran and shorts, equal parts by weight, compared with oats - North Dakota Station.

\begin{tabular}{|c|c|c|c|}
\hline & $\begin{array}{l}\text { Grain } \\
\text { eaten. }\end{array}$ & $\begin{array}{l}\text { Gain or loss } \\
\text { in weight. }\end{array}$ & $\begin{array}{l}\text { Work } \\
\text { done. }\end{array}$ \\
\hline Feeding bran and shorts. & Lbs. & Lbs. & Hours. \\
\hline Total, equal to 876 horses one day ........... & 12,910 & Loss 10 & 5,705 \\
\hline $\begin{array}{l}\text { Weekly average, per horse...................... } \\
\text { Feeding oats. }\end{array}$ & 103 & Loss $\quad 1-12$ & 46 \\
\hline 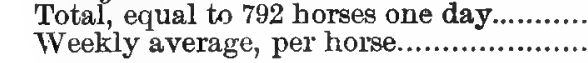 & $\begin{array}{r}11,838 \\
105\end{array}$ & $\begin{array}{l}\text { Gain } 10 \\
\text { Gain } 1-12\end{array}$ & $\begin{array}{r}4,796 \\
42\end{array}$ \\
\hline
\end{tabular}

It is shown that the horses fed bran and shorts ate somewhat less concentrates per week, lost a little in weight, but did three and one-half hours more work per week each than those fed oats. Upon the whole, bran and shorts proved of equal worth to oats for feeding horses and mules. (174-5)

464. Bran, whole wheat and shorts versus bran and shorts.Shepperd ${ }^{2}$ also compared the value of a mixture of bran, wheat

\footnotetext{
${ }^{1}$ Loc. cit. $\quad{ }^{2}$ Loc. cit.
} 
and shorts, equal parti by weight, with bran and shorts only, for horses.

Feeding bran, wheat and shorts, in opposition to bran and shortsNorth Dalkota Station.

\begin{tabular}{|c|c|c|c|}
\hline & $\begin{array}{l}\text { Grain } \\
\text { eaten. }\end{array}$ & $\begin{array}{c}\text { Gain or loss } \\
\text { in weight. }\end{array}$ & $\begin{array}{l}\text { Work } \\
\text { done. }\end{array}$ \\
\hline Feeding bran, wheat and shoits. & Lbs. & Lbs. & Hours. \\
\hline 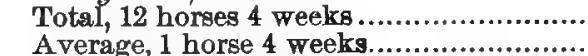 & 5,068 & Gain 20 & 1,775 \\
\hline $\begin{array}{l}\text { Average, } 1 \text { horse } 4 \text { weeks.................. } \\
\text { Feeding bran and shorts. }\end{array}$ & $42 \%$ & Gain & 148 \\
\hline Total, 12 horses 4 weeks............................ & 4,941 & Gain 160 & 1,642 \\
\hline Average, 1 horse 4 weeks........................ & 412 & Gain 13 & 137 \\
\hline
\end{tabular}

The summary shows that each horse fed whole wheat, in addition to bran and shorts, while doing eleven hours more work consumed ten pounds more grain and gained eleven pounds less per month, on the average, than those getting bran and shorts only. This indicates that whole wheat has no advantage over the same weight of bran and shorts in the ration.

465. Ground wheat and bran compared with oats. - Shepperd ${ }^{1}$ next fed a mixture of two parts ground wheat and one part bran, by weight, to one lot of work horses, while another received whole oats. The trial began in November and continued until March, with the results here given:

Whole oats compared with a mixture of two parts ground wheat and one part bran, by weight - North Dakota Station.

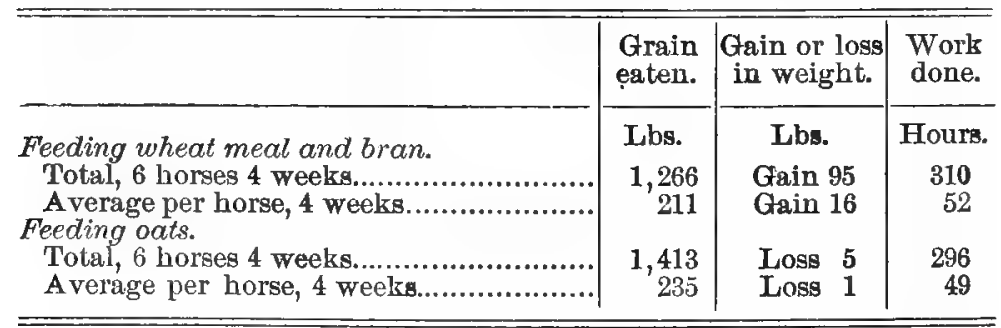

In these trials, althongh the horses getting oats ate somewhat more grain, they showed a slight loss in weight while doing somewhat less work than those fed ground wheat and bran.

1 Toe. cit. 
Shepperd concludes: "The horses did nicely on the ration consisting 'of two parts ground wheat and one part bran with prairie hay. Wheat is a concentrated food and needs this amount of bran to make it loose and cooling enough for the digestive system of the horse."

466. Boiled rye as a substitute for oats. - It having been stated that rye, boiled till the grain bursts, may be used as a substitute for an equal volume of oats in the keep of a horse, Boussingault ${ }^{1}$ tested the matter with two horses which had been previously fed a ration consisting of 22 pounds of hay and 5.5 pounds of oats. The same volume of boiled rye, containing 4.15 pounds of uncoaked grain, was then substituted for the oats. Average weight of horses: first weighing, 1,004.5 pounds; second weighing, 963 pounds; loss per head during 11 days, 41.5 pounds.

Boussinganlt writes: "In fact with such a ration as this, in which water was made to replace solid corn, no other result could reasonably be expected." (177)

467. Indian corn.- Next to oats, corn is the common grain for horses in America, being used most largely in the southern portion of the corn belt and southward in the cotton states. While conceding that corn is not the equal of oats as a grain for the horse, nevertheless, because of its low cost and the high feeding value it possesses, this grain will be extensively used where large numbers of horses must be economically maintained. Corn may be fed whole to horses, but generally it is made fine by grinding and mixed with various other concentrates. (158) Corn and cob meal is preferable to pure corn meal. Corn meal alone is a sodden substance in the animal's stomach, and should be diluted or extended with something of light character. Bran serves well for this purpose because of its lightness and cooling effect as well as the protein and mineral matter it furnishes. (45I) Corn is best suited to animals at plain, steady work. Its supply should be limited with colts and growing horses because of its lack of ash and protein. Wolff ${ }^{2}$ quotes Lehmann in the following statement: "Maize contains a high proportion of digestible carbohydrates, and tends

1 Pural Economy.

z Farm Foods, Eng. ed., p. 246. 
to make the animal fat and liable to sweat; while it improves their appearance, it somewhat detracts from their physical energy."

468. The Paris Omnibus Company's experiments.-The Paris Omnibus Company, employing nearly ten thousand horses, began feeding trials with Indian corn in 1874. ${ }^{1}$ Sixteen horses of different ages having up to the time of the experiment been fed a ration consisting of 18.7 pounds of oats, 1.8 pounds of bran, with hay and straw additional, received, gradually, more and mоге corn in the place of oats, until after one month the oats were replaced by corn. The horses weighed on an average 1194.1 pounds at the beginning of the experiment, and at the end, four months later, 1219.8 pounds. They were in good flesh and had grown fat, although they had worked hard during this time. It was found, however, that they were less spirited and seemed to lose in energy when more than nine pounds of oats were replaced by corn. The conclusions were that a mixture of 6.6 pounds of corn and 12.1 pounds of oats will prove most satisfactory for work horses, the ratio varying in each case according to the temperament of the animal. Twenty-five other horses doing 'bus service were fed 11 pounds of oats and 6.6 pounds of corn, after a longer transition period, with hay and straw as before, and after six months equally favorable results were obtained. All horses of the company were fed in this manner during 1876 and afterwards. They maintained their weight, and according to the records of the company did more work in 1876 than in 1875 on the ult ration. "Coupared with the time when only oats were fed, they are more calm at the present and lack the former abundance of vivacity; but on the other hand, work as well and as rapidly as before." The company saved $\$ 9.26$ per horse during 1876 by the partial substitution of corn for oats.

469. Müntz's experiments. - In 1881, Müntz conducted experi. ments with horses belonging to the Paris Omuibus Company, ${ }^{2}$ the first of which was with 362 horses fed 9.5 pounds oats, 6.7 pounds corn, 2.1 pounds beans, 1.1 pounds bran, 10.4 pounds hay and 11 pounds straw daily. The average weight of the

${ }^{1}$ Journ. de l'A gr. 1877, p. 127; Biederm. Centralbl. 1877, p. 255.

2 Recueil de Med. Veter., Feb. 1880; Biederm. CentralbI. 1S81, p. 767. 
horses remained the same during the experiment; the amount of work done did not change, showing that the ration met the requirements of the animals. In the second series more corn and less oats were fed, the ration being 6.8 pounds oats, 9.7 pounds corn, 3.3 pounds beans, .9 pounds bran, 6.6 pounds hay and 13.2 pounds straw. The animals gained in weight on this ration, the I work remaining the same as before.

According to the experience gained by the company, corn may be best fed crushed to horses. It was found most advantageous to grind the corn with the cobs left in. Corn and cob meal is considered a better feed than pure corn meal on account of its higher content of cellulose, which renders it more like oats. Thirty per cent. of an oat ration may be replaced by corn and cob meal. Similar reports as to the availability of corn for horse feeding are published in regard to the Berlin Street Car Company, ${ }^{1}$ the Berlin mail-horse stables, ${ }^{2}$ and the New York Omnibus Company. ${ }^{3}$

At the Utah Station, ${ }^{4}$ Sanborn found that horses fed corn and timothy did as well as those fed oats, clover and timothy hay. Mills, ${ }^{5}$ at the same Station, found that corn sustained the weight of horses better than oats.

470. An adverse report on corn feeding. - It is stated ${ }^{\circ}$ that the stookholders of the London Omnibus Company objected to the intensive feeding of corn to the horses of the company, "because the mortality had increased with the extensive feeding of corn and the horses seem to wear out much sooner." The horses fattened by the corn feeding, but the muscular system was not kept strong, and the nervous force of the animals decreased, as a result of which the veterinarian was oftener consulted than before the extensive use of corn began. Similar experiences are reported in the case of the street-car horses of Berlin. ${ }^{7}$

1 Nordd. Landw. 1881, p. 141; Biederm. Centralbl. 1881, p. 768.

2 Ldw. Blatt. f. Oldenburg, 1880, p. 180.

a Thur. Ldw. Zeit. 1880, p. 161. See also the exhaustive report on the subject by Bruckmüller on experiments conducted with army horses under the auspices of the Austrian government, Oest. Viertelj. f. Wiss. Vet. kunde, 49 (1878), p. 1; Jiederm. Centralbl. 1878, p. 420.

1 Bul. $30 . \quad$ Bul. 36.

- Fubling's Landw. Zeituug, 39, 1890, p. 63.

? Jahrsb. Agrl. Ch., 1890, p. 641 . 
471. Kloepfer's conclusions concerning corn.-Dr. Kloepfer ${ }^{2}$ draws the following conclusions from investigations conducted by himself and others concerning the value of Indian corn as a food for horses: "Corn is well adapted to replace oats, since the chemical composition of both cereals, especially as regards protein and fat, are nearly the same. The whole grain feed may be made up of corn in winter time and three-fourths of it in summer time. Five pounds of corn are equivalent to six pounds of oats. The heaviest feed should be given at night. The change from oats to corn feed should occur very gradually, the transition period lasting from two to four weeks according to the extent to which the oats are to be fed in connection with the corn. New corn should not be fed to horses. The American dent varieties of corn are the best adapted to horse feeding."

472. Feeds rich in protein compared with oats for colts.-Jordan, of the Maine Station, ${ }^{2}$ conducted feeding experiments with colts in which oats were fed against a mixture of other concentrates, such as peas and wheat middlings, in the first trial, and gluten meal, linseed meal and middlings in the second trial. In the first trial, which lasted 137 days, oats when fed to three grade Percheron colts, 9, 16 and 18 months old, produced less growth than an equal weight of a mixture of peas and middlings, the relation of growth made being as $100: 111$. In the second trial, two Percheron colts, both 11 months old, were fed oats against middlings, gluten meal and linseed meal, in the proportion of $60: 35: 15$. Ten pounds of hay were fed each colt daily in addition to the grain. The experiment lasted 84 days, the results being as follows:

Feeding mixed grain to colts in opposition to oats - Maine Station.

\begin{tabular}{|c|c|c|c|c|c|}
\hline & \multirow{2}{*}{$\begin{array}{l}\text { Period I. } \\
\text { Grain } \\
\text { mixture. }\end{array}$} & \multirow{2}{*}{$\begin{array}{l}\text { Period II. } \\
\text { Oats. }\end{array}$} & \multirow{2}{*}{$\begin{array}{l}\text { Weight at } \\
\text { beginning. }\end{array}$} & \multicolumn{2}{|c|}{ Daily gain when on - } \\
\hline & & & & $\begin{array}{l}\text { Grain } \\
\text { mixture. }\end{array}$ & Oats. \\
\hline & Lbs. & Lbs. & Lbs. & Lbs. & Lba \\
\hline $\begin{array}{l}\text { Colt I } \ldots . . . . . \\
\text { Colt II ......... }\end{array}$ & $\begin{array}{l}6 \\
5\end{array}$ & $\begin{array}{l}7 \\
6\end{array}$ & $\begin{array}{l}711 \\
602\end{array}$ & $\begin{array}{l}1.51 \\
1.16\end{array}$ & $\begin{array}{l}.43 \\
.93\end{array}$ \\
\hline
\end{tabular}

1 Biederm. Centralbl. 1895, p. 275.

2 Repts. 1891-92. 
In both experiments a greater growth was obtained from the mixed grains with both animals. (206) These trials show that when oats are high priced other concentrates may be substituted for them in colt feeding without checking growth. Some oats should be fed, if possible, because of their tonic effect.

473. Peanut meal and malt sprouts. - Rusche ${ }^{1}$ gives results of experiments showing that peanut meal and malt sprouts may be used with advantage as a feed for foals in place of oats.

474. Cocoanut meal.- The French war department investigated the value of cocoanut meal for horses. ${ }^{2}$ Ten army horses were fed cocoanut meal for four weeks in place of an equal quantity of oats in the ordinary ration. Five horses receiving the ordinary oat ration were included in the experiment and given the same work as the others. They were exercised only a little during the first period, January 12 to 30 , viz., 8 to 9 miles. They were worked harder for the next two weeks, January 31 to February $12,15-17.5$ miles. Weighings were taken before and after the change was made with averages as follows:

Cocoanut-meal ration.

\section{Pounds.}

January 12

January 31

February 12
963.4

977.5

970.9
Ordinary ration.

Pounds.

996.4

992.9

983.2

The results proved that cocoanut meal was equal and even superior to the same weight of oats. According to French prices of feeding stuffs, a substitution as in the above experiment would bring about a reduction in the cost of keeping army horses of $\$ 10$ each per year. (223)

475. Compounding rations for work horses. - At the New Jersey Station, ${ }^{3}$ Voorhees, studying to compound rations which should be low in cost but effective, conducted trials with two lots of two horses each, the work being as near uniform for each lot as could be arranged. In these trials corn meal and dried brewers' grains furnished the concentrates for one ration, while for the other corn

\footnotetext{
${ }^{1}$ Landw. 25, 1889, p. 361; Jahrsb. Agr.-Chem., 1889, p. 621.

Milch Zeit., 1883, p. 517.

- Rept. 1893.
} 
meal, wheat bran and oil meal were used. The trial continned six months with the results reported in the tables below:

Feeding low-priced rations to horses - Newo Jersey Station.

Lot I. Ration: Dried brewers' grains and corn meal.

\begin{tabular}{r|r|r|c|c|c}
\hline \hline & Hay. & $\begin{array}{c}\text { Corn } \\
\text { meal. }\end{array}$ & $\begin{array}{c}\text { Dried } \\
\text { brewers' } \\
\text { grains. }\end{array}$ & $\begin{array}{l}\text { Average } \\
\text { weight. }\end{array}$ & $\begin{array}{c}\text { Cost of } \\
\text { ration. }\end{array}$ \\
\cline { 2 - 5 } & Lbs. & Lbs. & Lbs. & Lbs. & Cents. \\
Horre 1....................... & 8.0 & 6.5 & 6.5 & 1,110 & 19.8 \\
\hline \hline
\end{tabular}

Lot II. Ration: Corn meal, wheat bran and oil meal.

\begin{tabular}{|c|c|c|c|c|c|c|}
\hline & Hay. & $\begin{array}{l}\text { Corn } \\
\text { meal. }\end{array}$ & $\begin{array}{l}\text { Wheat } \\
\text { bran. }\end{array}$ & $\begin{array}{c}\text { Oil } \\
\text { meal. }\end{array}$ & $\begin{array}{c}\text { Average } \\
\text { live } \\
\text { weight. }\end{array}$ & $\begin{array}{l}\text { Cost of } \\
\text { ration. }\end{array}$ \\
\hline & Lbs. & Lbs. & Lbs. & Lbs. & Lubs. & Cents. \\
\hline 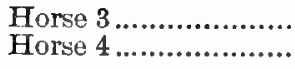 & $\begin{array}{l}8.0 \\
8.0\end{array}$ & $\begin{array}{l}6.2 \\
6.9\end{array}$ & $\begin{array}{l}5.0 \\
5.8\end{array}$ & $\begin{array}{l}1.4 \\
1.7\end{array}$ & $\begin{array}{l}1,127 \\
1,226\end{array}$ & $\begin{array}{l}20.8 \\
22.3\end{array}$ \\
\hline
\end{tabular}

The horses held their own in weight, and appeared in satis. factory condition throughout the whole period. The prices allowed for feed in the above tables are as follows: Timothy hay, $\$ 18$; wheat bran, $\$ 17.50$; corn meal, $\$ 22$; dried mewers' grains, $\$ 17$; liuseed meal, $\$ 29$. At these prices the cost of the rations was lowest where dried brewers' grains were used, and highest where wheat bran and oil meal were fed. A gardener living near the Station, guided by its teachings, fed a ration similar to No. 1 with success, and effected a saving in his feed bills for the year of about $\$ 150$ over previous cost under the customary feeding of the vicinity. Voorhees concludes: "That the kind and quality of specific nutrients contained in feeds, and not their names, should guide in the preparation of rations. That while oats are an excellent feed, it is not alone because they are oats, but because of the amount and proportion of the more valuable nutrients, fat and protein, contained in them. That dried brewers' graius are a wholesome, nutritious and palatable horse feed. and at present prices they mily be substituted for oats and a decided saving inade in the cost of the ration." 
476. Pelative merits of the grains.- Settegast ${ }^{1}$ discusses the relative value of grain feeds for horses as follows: "Among all cereals, oats are the best adapted to horse feeding; their place can hardly be filled in colt raising. In the ration for full-grown horses, rye and barley may to some extent be substituted for oats. A par. tial substitution of the seeds of legumes (beans, peas, vetches) for oats to the extent of about one-third the concentrates has been practiced in cases of continued heavy team work. The experience of late years has further shown that corn may be considered as approximating oats in value for work horses. Experiments have shown that a ration of 18.7 pounds of corn and 11 pounds of straw is profitable for omnibus horses. In periods of rest the concentrates may advantageously be decreased one-half with riding and work horses."

477. Dried and soaked grain. - Wolff ${ }^{2}$ found that in the case of healthy horses with good teeth, the utilization of beans and corn remainct about the same whether fed whole and in dry condition, or fed after having been previously soaked in water for twentyfour hours, care being taken in the latter case to guard against loss of nutrients. (375)

478. Timothy hay.- Although chemical analysis shows timothy hay not particularly rich in digestible nutrients, nevertheless it is the standard in its class throughout the northeastern United States. One reason for its popularity lies in the fact that it is easily distinguished from hay of all other grasses, and both the farmer who grows it and the horseman who feeds it feel no uncertainty as to its identity or quality. Its freedom from dust commends good timothy hay as a horse feed, and it is an excellent roughage for horses, whose sustenance comes mostly from the grain they receive. (268)

479. Clover hay. - Clover hay is generally so loaded with dust that horsemen have come to regard it with disfavor under all circumstances. This prejudice should be overcome, for well-made clover hay will serve a valuable purpose in the stable in many instances. Its relatively high content of protein makes it more nearly a balanced ration in itself, bnt the high proportion of in-

1 Thierzucht, II, 110.

2 Landw. Jahrb. 16, 1887, Sup. III, p. 21. 
digestible matter necessitates the consumption of too large a quantity to permit its extensive use with horses in active service. For growing colts and idle horses, bright, clean clover hay may often be fed with marked economy. With corn fodder or bright straw it may constitute the sole roughage for such animals.

480. Fodder corn and stover.-Fodder corn, grown so thickly as to permit of only small "nubbins" forming, and cured in the shock into a bright, dust-free forage, is one of the best articles available for roughage in horse feeding. While the stalk and husk will be left uneaten, the leaves disappear with a relish when offered to horses under any conditions. Not only are corn leaves usually quite free from dust, but they are palatable and full of nutriment. For stallions, brood mares, idle horses and growing colts, corn forage of good quality will be found an economical substitute for timothy hay. When the tonnage of a field of fodder corn is compared with the yield of timothy hay from a like area, it is apparent that the forage of the corn plant should hold a prominent place with horsemen who seek economy while at the same time wishing to supply a palatable, nutritious roughage. See Chapter $X$.

481. Straw.- Some straw can always be fed to horses, the amount varying with the work and the purpose for which the animal is used. Idle horses, having ample time for masticating and digesting their feed, can subsist almost wholly on good bright straw; hard-worked animals and those required to move rapidly can make use of only a little, - the feeder must judge from the conditions how much to supply. It is a notable fact that many horses are fed costly hay for roughage when cheaper straw or fodder corn would prove equally satisfactory. In relative value for horse feeding, the straws rank in the following order: Oat, barley, wheat, rye, the last named being of slight utility.

482. Millet hay injurious to horses.-Hinebauch, veterinarian of the North Dakota Station, ${ }^{1}$ reports that during the winter of 1891-92 an ailment passing under the name of the "millet disease" prevailed in North Dakota, about one animal in every ten so affected dying. It was called the millet disease because from ninety-five to ninety-eight animals out of every hundred affected

1 Bul. 7. 
had previonsly been fed millet. Experiments were made in feeding millet hay to a number of horses for the purpose of studying its effect. The following statement relative to one test seems quite conclusive:" "By feeding her (a mare) millet (hay) for about three months, she would become so lame in the joints of the hind legs that it was almost impossible for her to walk, and on discontinuing the feeding of millet she would gradually recover, until at the end of three or four months she would again be in normal condition. As soon as that condition was reached, would again feed millet until the mare was in such a condition that she could scarcely stand, then again quit feeding millet. We have alternated with millet and other hay, producing the conditions referred to at will, for nearly two years. In the meantime the horse has suffered in condition and does not at all resemble her former self. She is valueless as far as work is concerned, and is only kept for experimental purposes. We are able at any time to demonstrate the effect from feeding millet, by allowing her to have millet exclusively as coarse food for a portion of two months." Letters sent to veterinarians, farmers and others in the state brought replies which showed that ill results had quite generally been observed from the use of millet, manifested usually by increased action of the kidneys. The bulletin concludes: "Our experiments have thoroughly demonstrated that millet, when used entirely as a coarse food, is injurious to horses: First, in producing an increased action of the kidneys. Second, in causing lameness and swelling of the joints. Third, in producing infusion of blood into the joints. Fourth, in destroying the texture of the bone, rendering it softer and less tenacious, so that traction causes the ligaments and muscles to be torn loose."

It is remarkable that millet, one of the oldest known plants, and one that is used so extensively in various countries, should fall under this serious charge. Possibly hay from the plant is injurious in some districts while harmless elsewhere, or in some years it may prove deleterious while usually safe for feeding. Having been put on his guard, the horseman will use millet with caution, awaiting further reports from the investigators. It should

1 BuI. 26, N. Dak. Sta. 
be noted that in the cases where trouble arose millet hay was used exclusively for ronghage. Ill effects can probably be avoided by using this hay in limited quantity for roughage and not continuously. Nothing unfavorable to the use of millet hay for cattle or sheep feeding has been reported. (272)

483. Boussingault's experiments with roots. - Instigated by the terrible drought of 1840, Boussingault of France studied the value of roots and tubers in rations for horses on his farm at Bechelbronn. 1 Eight horses, separated into two groups of four each, were used in the following experiments: The ordinary ration for work horses at his farm, which maintained them in excellent condition, was, per head per day, 22 pounds of hay, 5.5 pounds of straw, and 7.25 pounds of oats. This ration was fed in all the experiments with the changes noted.

484. Steamed potatoes. - In the first experiment half the hay was replaced by lightly-steamed potatoes in the proportion of 280 pounds of potatoes to 100 pounds of hay, the theoretical equivalent of potatoes in hay value. (138) The potatoes were mashed and mixed with cut straw and put into the manger when cold. The animals were weighed after having been on this feed a few days, and again after twenty-four days. The average weight per horse was: First weighing, 1,134.9 pounds; second weighing, 1,111 pounds; average loss per horse during twenty-four days, 23.9 pounds. The allowance of 30.8 pounds of steamed potatoes could not then, under the conditions, replace the 11 pounds of hay. The weather was very inclement during the experiment, and the teams were worked hard at ordinary fall farm work. (658)

485. Potatoes substituted for hay.-This experiment, a duplicate of that just reported, was conducted under more favorable conditions for 63 days. The horses gained 10.1 pounds each on an average during this time, 30.8 pounds of potatoes proving fully equal to 11 pounds of hay. Boussingault concludes that the experiment shows that the comparative value of hay and potatoes for horses is not far from $100: 280$.

486. Hay and potatoes. - Eleven pounds of hay in the usual allowance were replaced by 30.8 pounds of potatoes, and the whole of the oats and straw by $\mathbf{1 5 . 4}$ pouuds of hay, making the ration

\footnotetext{
1 Rural Economy, p. 400.
} 
fed: Hay, 26.6 pounds; potatoes, 30.8 pounds. Boussingault refers to the experiment as follows:" "This was a ration which it was the more interesting to try, from the circumstance of Professor Liebig ${ }^{2}$ having come to the conclusion, from certain theoretical views, that it must be impossible to keep horses in health and strength upon hay and potatoes exclusively." The experiment was continued a fortnight with the following results:

\begin{tabular}{|c|c|c|c|c|}
\hline & $\begin{array}{l}\text { Group } \\
\text { No. } 1 .\end{array}$ & $\begin{array}{l}\text { Group } \\
\text { No. } 2 .\end{array}$ & $\begin{array}{l}\text { Both } \\
\text { groups. }\end{array}$ & $\begin{array}{l}\text { Mean weight } \\
\text { per horse. }\end{array}$ \\
\hline & Lbs. & Lbs. & Lbs. & $\mathbf{L b s}$. \\
\hline 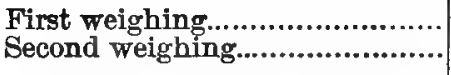 & $\begin{array}{l}4,620 \\
4,675\end{array}$ & $\begin{array}{l}4,312 \\
4,697\end{array}$ & $\begin{array}{l}8,932 \\
9,372\end{array}$ & $\begin{array}{l}1,116 \\
1,171\end{array}$ \\
\hline Gain in fourteen days.............. & 55 & 385 & 440 & 55 \\
\hline
\end{tabular}

Undonbtedly a large part of the reported gain was from the increased weight of the contents of the alimentary tract, but it was apparent that the ration was sufficient to nourish the horses. (316, 866, 897)

487. Carrot.-The records show only a single trial with this root, by Boussingault, a reported as follows: "On one occasion at the stable of Bechelbronn, when the potato in one of our rations was replaced by an equal weight of carrots, the effect was highly disadvantageous, and even in following the theoretical equivalent of the carrot ( 350 pounds carrots equal 100 pounds of good meadow hay, calculated from chemical analysis), we had still no reason to be perfectly satisfied." The carrot is not utilized in this country by horsemen for furnishing nutriment, but rather for satisfying the craving of the horse for succulent feed and for variety. When given with that end in view its worth no doubt fur exceeds that measured by the nutrients contained. (317)

488. Artichoke.- This tuber is held by Boussingault ${ }^{4}$ to be an excellent food for the horse. It is greedily eaten and horses thrive on it. In an experiment by this investigator, thirty pounds of sliced artichokes were substituted for half the hay in the ration.

\footnotetext{
' Loc. cit., p. 402.

2 Agricultural Chemistry.

Loc. cit.

4 Loc. cit.
} 
Having become accustomed to this feed the horses were weighed, and again when they had been on the feed for eleven days. The average weight per horse was: first weighing, 1,113 pounds; second weighing, 1,114 pounds, - a gain in eleven days of one pound per head. (323, 868)

489. Ruta-baga (Swede) turnip.-Boussingault fed 31 pounds of Swede turnips in place of part of the hay in the ration. The horses lost 52.8 pounds each in nine days, showing that the calculated ration was too low. In another experiment with the same horses where Swedes were introduced in the ratio of $400: 100$ of hay, the horses kept their weight at the point to which it had fallen, but did not gain.

\section{Concerning Rations for Horses.}

490. Rations fed to Paris cab horses.-The experiments by Grandean and Leclerc, the results of which are summarized in another place, (442-8) were made with horses belonging to the Paris Cab Company. The following table gives the daily standard rations of the horses used by the company at the time the experimental maintenance rations were fed, and the one finally adopted as best for work. These horses weighed from 800 . to 900 pounds each. The data, with description of the same, are taken from Lawes and Gilbert's essay on feeding farm animals. ${ }^{1}$

Rations fed to horses of the Paris Cab Company_L Lawes and Gilbert.

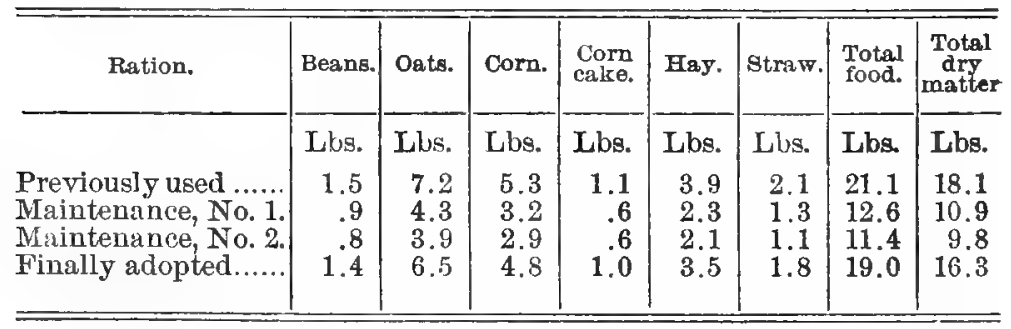

"It seems that the system of the establishment was to work the horses on alternate days, and to give less hay, straw and corn, but more oats and beans, though less total food, on the days of work. The figures in the top line, representing the 'Previous' ration,

\footnotetext{
1 Jour. Roy. Agr. Soc., 1895, p. 140.
} 
are in each case the mean of two days' rations. The 'Maintenance ration, No. 1,' was fixed at three-fifths of the 'Previous' ration; but, as the animals gained in weight, 'Maintenance ration, No. 2,' which was one-tenth less than No. 1 , was subsequently adopted. Eren then the horses rather gained in weight. Finally, as it was considered that the standard or 'Previous' ration was too high, the ration for work, as given in the bottom line of the table, which is one and one-half times as much as 'Maintenance ration, No. 1,' and about one-tenth less than the 'Previous' ration, was adopted. It is, however, said that under the new regime the horses were somewhat underfed, but whether the reduced ration is still maintained we are not aware. It will be observed that the proportion of beans fed was very small compared to that of cereals. Still, it will be seen presently that the proportion was very considerably higher than in the case of the omnibus horses of Paris."

491. Rations fed to Paris omnibus horses. - The following table presents the average ration of the horses belonging to the Paris Omnibus Company for six years (1879-80 and 1884-87 inclusive). The figures are calculated from the results given in the annual reports of the general secretary of the company, and are furnished by Lawes and Gilbert in the paper mentioned. ${ }^{1}$ The average number of horses belonging to the company was about 13,000 , and their arerage weight was 1,240 pounds.

Average rations fed to horses of the Paris Omnibus Company during six years - Lawes and Gilbert.

\begin{tabular}{|c|c|c|c|c|c|c|c|c|}
\hline Year. & Beans. & Outs. & Coru. & Hay. & Straw. & $\begin{array}{l}\text { Bran, } \\
\text { etc. }\end{array}$ & $\begin{array}{l}\text { Total } \\
\text { food. }\end{array}$ & $\begin{array}{l}\text { Total dry } \\
\text { matter. }\end{array}$ \\
\hline & Lbs. & Lbs. & Lbs. & Lbs. & Lbs. & Lbs. & Lubs. & Lbs. \\
\hline $1879 .$. & 1.4 & 10.1 & 6.9 & 9.1 & 10.5 & 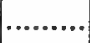 & 37.8 & 32.2 \\
\hline $1880 \ldots$ & 1.4 & 8.8 & 8.3 & 7.8 & 11.1 & ........... & 37.4 & 31.8 \\
\hline $1884 \ldots$ & 1.4 & 8.7 & 8.5 & 8.5 & 8.7 & .9 & 36.7 & 31.3 \\
\hline $1885 \ldots$ & .9 & 6.2 & 11.3 & 8.5 & 8.4 & .8 & 36.1 & 30.8 \\
\hline $1886 \ldots$ & .1 & 5.5 & 13.0 & 8.6 & 7.3 & .5 & 35.1 & 30.0 \\
\hline & & 8.1 & 10.8 & 8.7 & 8.2 & & 35.8 & 30.5 \\
\hline
\end{tabular}

"It will be seen that the actual amount of dry matter supplied per head per day is nearly twice as much as in the case of the

\footnotetext{
1 Loc. cit.
} 
cab horses previously given; that is, much more in proportion to a given live weight. It will be further seen that the proportion of beans to cereal grains is much less than in the case of the cab horses, and was reduced to a very small quantity in the later years. In fact, the grain given consisted almost exclusively of oats and corn, that of the oats being reduced but that of the corn in a greater degree increased, in later years, coincidently with the reduction in the amount of beans. On the occasion of a visit of one of us to the general secretary in 1887, it was suggested to him that the supply of the highly nitrogenous leguminous seeds might be mainly, if not exclusively, reserved for old or overworked horses; and he subsequently informed us that he had found their use in such cases advantageous." 


\section{CHAPTER XTX.}

\section{FEED AND OARE OF THE HORBF.}

492. The range of feeding stuffs for horses.- At any point of observation we find the ration for the horse usually composed of only one or two kinds of grain and the same limited number of coarse dry fodders, the feeder insisting that these are practically all that can be given this animal with safety and economy. We need not travel far, however, to find the list more or less changed, sometimes entirely so, yet with the same claim as to superiority or necessity as before. In the Northern states the almost unirersal feeds for the horse are timothy hay and oats; in the South, Indian corn serves mainly for the concentrates, with dried corn leaves for ronghage. On the Pacific coast, crushed barley is the common grain, while the hay comes from the wild oat, the barley or wheat plant. Passing to other countries, we find an interesting array of articles in the dietary of the horse, though still no large number is in use in any one locality. In Loudon ${ }^{1}$ we read: "In some sterile countries, horses are forced to subsist on dried fish, and even vegetable mould; in Arabia, on milk, flesh balls, eggs, broth, etc. In Persia, barley is a common food for good horses. In some parts of India, salt, pepper and other spices are made up into balls, as big as billiard balls, with flour and butter, and thrust down the animal's throat. . . . Meat broth (especially sheep's head) is also given to horses. . . In Bengal, a vetch, something like the tare, is used. On the western side of India, a sort of pigeon pea, called gram, is the usual food; with grass in the season, and hay all the year. Indian corn or rice is, I think, seldom if ever given to horses in India as ordinary food. In the West Indies they are fed on maize, Guinea corn, and sugar-cane tops; and, in some instances, on the sugar itself, in

\footnotetext{
1 Encyclopedia of Agriculture, 1866: Article, Feeding of Horses.
} 
the form of molasses. In France, Spain and Italy, besides the grasses, the leaves of limes, vines, the tops of acacia, the seeds of the carob tree, etc., are used."

493. Successful horse feeding a skilled art. - With each feeder using a limited variety of feeding stuffs one might at first suppose that the successful management of the horse, so far as feeding is concerned, is a simple matter, when in reality it is the very opposite. Given two grooms with similar conditions as to horses to be cared for, work performed, and feed bins to draw from. In one case the team emerges from the stable with an action and style which at once announces it in the best of condition; in the other case, the lagging step, dull eye and rough coat advertise better than words the lack of judgment in feeding and management. In the second case the unsatisfactory condition of the animals has not necessarily been brought about by any saving at the feed bin and hay mow; indeed, very frequently the poorer groom makes the more frequent request for supplies. The indescribable qualities which, rightly commingled, mark the good feeder cannot be acquired from lectures nor from books, but must, in a large measure, be born in the horseman. Study and observation will add to the ability of the feeder, but all that may be written will not make one an adept, nor cover his defects, if he does not take to the work naturally. No one can study the practices of snceessful horsemen without becoming strongly impressed with the fact that there are several ways of reaching the desired end of high finish and fine action with the horse. With the pig we can calculate about how much increase in weight is returned from a pound of corn. The horse is on a higher plane, and weight alone is uot the only or even the main object in view; nerve and action are qualities which count for more than mere avoirdupois. The skill of the "artist" horse feeder enters into the very life of the creature he manages along with the food he supplies. If the reader finds the counsel given in regard to feed and management not entirely to his satisfaction, let him remember that we have chosen that course which scems on the whole the most rational and generally applicable, conceding that good results may also be obtained by following other systems. 
494. The foal. - It is of the highest importance in horse rearing that the young start life in full health and vigor, and to this end the foal should very soon after birth take a good dranght of the colostrum or first milk of the dam. Colostrum possesses purgative properties which tend to discharge from the alimentary tract the faecal matters collected therein during foetal life. If this result is not accomplished naturally, a gentle purgative of castor oil should be administered. With the bowels cleared, the foal is in condition to utilize the more natural milk of the dam which follows, gaining strength and increasing in weight from the start. There are several dangers to the life of the young foal which should be carefully guarded against. Some dams, more frequently those with their first foal and those hard worked, fail to supply the proper amount of nourishment, and the young languish. In such cases the mare should be provided with food which will stimulate the milk flow; good pasture grass is of course the best, but if this is absent concentrates should be given in the shape of oats, rolled barley or wheat bran, with an equal weight of corn or corn and cob meal. Not infrequently the foal suffers from an over-supply of nourishment or because the milk is too rich, or from both combined, and the indigestion resulting may terminate in diarrhoea. In such cases the food allowance of the dam should be restricted and some of her milk drawn by the attendant, remembering always that the last milk carries the most fat, which substance is usually the disturbing element.

After foaling, the mare should be confined for a few days, her feed being simple in character and not too abundant; with favorable conditions, at the end of a week she should be turned to pasture, with proper protection for herself and foal from the inclemencies of the weather. Under favorable conditions the dam and foal will shift for themselves, but watchfulness should never cease in noting thrift and progress and checking the first appearance of ailment. Diarrhoa brought on by over-feeding or exposure to inclement weather is a common trouble and sliould be checked at once. Parched flour, rice-meal gruel and boiled milk are all excellent correctives for this ailment. Constipation, the other common evil, may be relieved by the use of castor oil and by 
injections of warm water to which soap has been added. In all cases of derangement, at once lessen the anount of food for both dan and foal, since nothing aids nature more at such times than to reduce the work of the digestive tract.

495. Feeding the foal before weaning.-Horsemen who are anxious to see the foals getting on, frequently induce them when quite young to take nourishment other than that supplied by the dam, the supplementary feeding often starting two months from birth. By placing the feed box from which the dam eats her grain a little raised from the ground, the foal will early begin nibbling from the mother's supply and soon acquire a taste for grain. This habit can be strengthened in no better way than that described by Splan, ${ }^{1}$ which is as follows: "With the colts all out to grass and doing well, it is time to scparate the oldest of them from the younger and commence feeding them grain, which is done in this way: Build a pen in some suitable place which is the most convenient, making it high enough so that the mare will not try to jump it, and have the space from the ground to the bottom rail or board sufficient to allow the foal to pass under. Put in a handy gate or bars, then an ample feed trough. Lead your mares and foals singly into this enclosure aud let them eat together two or three times and they will soon learn where the food is. Take out the mares, shut up the gate, leave the colts in. Keep a good supply of oats there, and you will find the foals there regularly running in and out getting their rations. To induce the dam to loiter abont this place, keep a large lump of rock salt near it and occasionally a mess of oats, and there is no further trouble. In this way, at weaning time, which is at the age of fire months, the colts have learned to eat, and the result is that when they are taken away from their dams they do not miss them so much."

496. The Palo Aito system.- The method employed on the Stanford farm in teaching foals to eat, studied by the writer in 1892, carries with it also handling and breaking them to lead by the halter. At this farm each mare with foal is kept in a separate box-stall at night, while during the day two mares with foals occupy for a time the same paddock; the foals thus

1 Life with the Trotters, p. 424 
thrown together become companions, their friendship being very marked, and proving beneficial at weaning time. In teaching them to eat, two men enter the paddock each with a pan in which are some dry crushed oats. Each foal wears a halter; over the back of the animal a quarter-inch rope, made into a large loop, is passed, this loop falling to the hock joints and passing : up along each side of the body to the withers, whence a single cord passes through a ring in the halter so as to be held by the same hand that holds the leading strap. With rope and lead strap in one hand and a pan of crushed oats in the other, the attendant serves the foal with feed, gently inducing it to move forward, from time to time, by pulling on the halter and crawing on the rope at the same time; the loop tightening about the buttocks impels the foal forward, preventing all tendency to pull at the halter and teaching the young thing that when the groom tightens on the lead strap it is to move ahead. The handling of two foals at the same time when companions, and while still with their dams, makes each more fearless and less restive than if alone. In a short time the foal is halter-broken, and can be led about the paddock without grain being held before it.

497. Weaning the foal.- The foal is weaned when five or six months old. The operation calls for good judgment and careful attention, but is not difficult if the preliminaries have been properly carried out. Having given Splan's method of teaching the foal to eat grain, we will follow him through the period of weaning." "Now we put on the halters and keep them on, leading the foals more or less while weaning them. Leave them in their boxes, two or three together, several days, and have the boxes open into a nice grass paddock. Let them run out and in, give them oats mixed with bran and sorghum cut up fine, and in a few days more turn them out in the fields away from their dams, where there is plenty of grass and water, and a large trough with feed in it constantly. They have been in the habit of taking milk a great many times a day, and they need food just as often. The best way is to keep plenty of mixed food for them, using cracked corn and oats, also unthrashed oats run through a cutting-

\footnotetext{
'Loc. cit., pp. $424-5$.
} 
box, then mixed with bran and water enough to moisten it to make the bran adhere to the oats."

At Palo Alto foals were weaned at five months of age; in this case the pair which had run together and become acquainted were put in a darkened stall in the evening, the dam being placed out of hearing. They were not allowed to suck after the first separation. The box-stalls were without projections of any kind, so that it was impossible for the foals to injure themselves, though they often reared against the sides of the stall or struck at the door in struggling to escape. The companionship of the pair, and the fact that they had been taught to eat dry food, helped them to sooner forget their dams.

498. Feeding the colt after weaning-- Colts are nondescripts, for the rearing of which no definite rules can be given, but common sense, patience and alertness should prevail. These awkward animals, utterly useless as yet, must nevertheless be carefully looked afier, the aim being to supply food liberally, with plenty of sunlight and an abundance of exercise. Oats lead in the list of feeding stuffs, but shorts and bran with barley, peas and some corn may be profitably used where economy is important. These feeds, aside from corn, are rich in bone-making material and will be found satisfactory as well as economical. Colts suffer at times from teething, and to subsist wholly upon hard, dry food may work injury. Stcamed crushed oats or barley, thickened with bran, will prove appetizing and very nourishing in such cases. Roots may be cooked and the mass extended with ground grain and bran. A limited quantity of this feed given at night in winter-time, daily, or two or three times a week, will show its effect in a better colt and a more thrifty general appearance. Withholding coarse provender and giving concentrated grain in large quantities in its place at this period is to be deprecated, for it is important that the digestive tract be developed to a moderate extent by distention with coarse feed that it may serve its purpose when the animal is grown. The "big belly" which a properly-fed colt may carry at this period is nothing to its harm, even though it annoy the short-sighted stockman who foolishly may wish to see in his growing colt the trim form of the finished product. 
A fair allowance of grain for the colt, measured in oats, is as follows:

Up to one year of age, from 2 to 3 pounds. From one to two years of age, 4 to 5 pounds.

From two to three years of age, 7 to 8 pounds.

While an ample allowance of such roughage as hay, straw and stover should be supplied, it should always be less than the animal would eat had it free access to this provender. The colt, like the mature horse, should not be allowed all the rough. ge it can consume, for such over-supply tends to gorge the ligestive tract with inert matter, and may work lasting injury.

Liberal feeding must be counterbalanced by an abundance of outdoor exercise. In no other way can colts be ruined so surely and so permanently as by liberal feeding and close confinement. Each day from three to ten hours should be spent in the open air, according to the condition of the weather and other circumstances.

499. Rearing by hand.- It occasionally happens that the foal must be reared artificially or perish. If the young thing has never received any of its mother's milk, the bowels should first of all be moved by a dose of castor oil. Cow's milk, to which at least one-fourth its volume of water, together with some sugar, has been added, (429) makes a fair substitute for mare's milk and should be given at blood temperature. Gruels may be made by boiling beans or peas and removing the skins by passing the pulp through a sieve. Oil meal made into a jelly by boiling, and shorts prepared in the same way, are excellent for the motherless foal.

500. Cow's milk for foal feeding.-- Cow's milk is often used with advantage in feeding foals. Foals suffering from distemper cannot always take solid food satisfactorily and may be nurtured on cow's milk. The foal may be taught to drink milk by pouring it upon the grain feed; the young thing eats the moistened feed, and by tipping the pan it soon learns to drink the separated milk.

At the Iowa Station, ${ }^{1}$ Wilson and Curtiss fed whole milk, and later separator skim milk, with satisfactory results, to imported Percheron, Shire and French Coach weanling fillies shortly after

1 Bul. 18. 
their arrival and while out of condition. In changing from whole milk to separator skim milk, it was necessary to reduce the amount of milk fed for a day or two to prevent scouring. Ten pounds of separator skim milk was found to effect a saving of one pound of grain. ${ }^{1}$ Grattan reports favorably on the use of skim milk for foals. Even when fed sour or lobbered, satisfactory results were obtained after they were accustomed to it. MacNeilage objects to the use of cow's milk for foals, claining "no better means of manufacturing wind-suckers was ever devised, and it is rare that yearlings so brought out count for much as two-year-olds and three-year-olds." 2 This adverse criticism is a timely warning against the too free use of milk in foal feeding. While we may give a large amount of milk to a pig, forcing its growth to the utmost, we should remember that this animal is designed for the pork barrel, while the growing colt is intended for quite a different purpose. Milk carries a large amount of bone and musclebuilding material and is very palatable. In judicious hands its use is commended. (356-7)

301. Feed and care of the stallion.-The following from Sanders $^{3}$ is replete with good counsel in relation to the stallion: "The food should mainly be good, sound oats - nothing is better; but this should be raried by an occasional ration of corn or barley; for horses, like men, are fond of a variety in their food, and an occasional change of diet is conducive to health. Wheat bran is an invaluable adjunct to the grain ration, and can never be dispensed with. It is the cheapest, safest and best of all regulators for the buwels, and it is especially rich in some of the most important elements of nutrition. No specific directions as to the quantity of food can be given. Some horses will require nearly twice as much as others; and the quantity that may be safely given will depend somewhat upon the amount of exercise in any given case. Some horsemen recommend feeding three and others four times a day; but in either case no more should be given than will be promptly eaten up clean. If any food should be left in the box it should be at once removed and the quantity at the

1 Breeder's Guzctte, Vol. VI, 1884, p. 796.

2 Trans. Highl. and Agrl. Soc., 1890, p. 152.

" "Forse Breeding," pp. 144-40. 
next time of feeding should be reduced accordingly. As a rule, it will be safe to feed as much as the horse will eat with apparent relish; and then, with plenty of exercise, he will not become overloaded with fat. The hay, as well as the grain feed, should be sound and free from mould and dust, and the stall should be kept clean, well lighted and perfectly ventilated.

"The amount of exercise to be given will vary somewhat with the condition and habit of the horse. If he be in thin flesh, and it is thought best to fatten him up, the exercise should be lighte' than it otherwise would be; and, on the other hand, if there is a tendency to become too fat, this may be corrected by increasing the amount of exercise that is given. Draft horses should rarely be led or driven faster than a walk in taking their exercise, and they will require much less of it than the roadster or the running horsea moderate 'jog' daily will benefit them. I am clearly of the opinion that in no one particular is there more faulty management on the part of lazy grooms and stable hands than in the matter of exercising stallions while doing service in the stud. They should not be walked nor jogged so long that they will become jaded or wearied, but should have enough of it daily to keep the mascles hard and firm, the appetite good and to prevent them. from laying on an undue amount of fat. No draft horse, under ordinary circumstances, should have less exercise than five miles a day, and the roadster and running horse may safely have six miles, which in some cases should be increased to eight or even ten.

"The point to be aimed at in the stable management of the stallion is so to feed, groom and exercise as to keep the horse to the very highest possible pitch of strength and vigor. The idea which prevails among many stable grooms that feeding this or that nostrum will increase the ability of a horse to get foals is sheer nonsense. Anything that adds to the health, strength and vigor of the hor'se will increase his virility or sexual power, simply becanse the sexual organs will partake of the general tone of the system; and, on the contrary, whatever tends to impair the health and vigor of the general system will have a deleterious effect upon the sexual organs. A healthy horse needs nothing 
but good food, pure air, plenty of exercise, with due attention to cleanliness and regularity in feeding and watering; and when all these things are atteuded to properly the drugs and nostrums that stable lore prescribes as ' good for a horse' would be better thrown to the dogs."

502. Food for the mare.- While in foal the mare does not necessarily require food different in quality from that fed at other times, but the quantity should be somewhat larger, all conditions being equal. Those used for breeding purposes only will do well without grain when on nutritious pasture, but if the grass is insufficient, some additional feed in the shape of grain should be given. Working mares are more sure of bringing good foals than those idle in pasture, provided judgment is used in handling and feeding. They should be worked with regularity, the labor never being severe or taxing, nor should the nature of the work ever be such as to make long intervals between feeds, for then great hunger may be followed by surfeiting. Idleness is the bane of horse rearing and should be avoided whenever possible. To place the mare in a box-stall and confine her there without suitable exercise, while supplied an abundance of feed, is to adopt a practice only too common and one carrying large risk. Abuudance of exercise must always go with liberal feeding.

As to the kind of feed for the mare in foal, oats lead, yet shorts and bran may be fed with economy and beneficial results; mashes can be given occasionally, and where possible cooked feed may be supplied at night, three times a week. Through the use of proper foods the bowels will be kept in a natural condition, and should be a little loose rather than otherwise at time of parturition.

503. Feeding the trotter.-The single requisite of speed makes the carrying of every pound of useless body weight, and more especially of feed, a serious matter in the management of the trotting horse. More important than this, even, is the effect of the food upon the character of the muscles formed from it, and especially upon the nerve and mettle of the horse. For help in this line we can draw from no better source than Hiram Woodruff? who tells how the trotter should be fed and managed.

1 The Trotting Horse of America, pp. 90-105. 
When going into winter quarters, the feed of the trotter should be reduced fully one-half in order to prevent fattening; for too much fat on the intestines and about the heart makes the trainer no end of trouble in working it off. $A$ few carrots may be given and a bran mash oceasionally, with good clean, sweet hay. Horses whose legs must undergo blistering or firing should have feed of a cooling nature, mashes and carrots being in more abundance, with less oats, in order to reduce the tendency to feverish, inflammatory symptoms. Care must be taken not to permit the animal to get flabby or washy by too much soft food while undergoing treatment. Horses turned out to the field should be fed oats twice a day, for the exposure to the severity of the weather increases the need of heat-giving food. In the spring when shedding, bran mashes are in order to keep the bowels open. Flax seed and linseed meal should not be given, for they have a tendency to relax the system too suddenly and to cause the old hair to come away before the new coat is well started.

"With the beginning of the season (we quote directly from the author), 1 while the jogging, the first part of the trotting horse's preparation, is in progress, the strength of the feed may be increased, though not up to the extent that will be requisite when the work is made longer and sharper. He may have, during this first part of the preparation, from eight to ten quarts of oats a day, according to his capacity as a feeder, and the demands made by nature for supply of strong food under work. As the oats are increased, the horse will want less hay, but may still have all he will eat up clean. After taking his feed of oats, he will not consume as much hay in general; but some horses are such gluttons that it is necessary to limit them as to hay almost from the first. There are even some who will eat the straw of their bedding when they have had all the grain and hay that should be fed to them; and, with these, it sometimes becomes necessary to put on the muzzle long before the time for the trial or the race. No carrots are now to be given, and I believe corn to be unnecessary and often mischievous. It is heating, and does not contain as much of the stuff that goes to make up hard flesh

' Loc. cit., p. 99. 
and elastic muscle as oats. There may be instances, however, in which a light feeder can be got to eat up his oats, and a handful of corn as well, when the latter is mixed with them. In such a case it is well to give it; but in no case should corn be used as a substitute for the allowance of oats the horse in training ought to have.

"While the jogging and after preparation are going on, a branmash now and then will be proper. Probably about once a week will be often enough and not too often; but this will be indicated by the condition of the horse's bowels and by his constitutional tendencies and requirements. If his bowels are relaxed, the use of the bran-mash is not apparent; and if he is of the light, washy order, never having much substance, and easily melting away when put into sharp training work, mashes are to be given more sparingly than with one of the opposite character. The trainer is never to relax his vigilance of observation, or let his judgment go to sleep and trust to arbitrary rules. . . . During the fast work, preparatory to the coming trial, the horse will have been put upon his largest allowance of strong food. Some will not eat more than eight or ten quarts of oats a day; and it is necessary to be very vigilant and careful that these light feeders are not over-marked in work. Twelve or thirteen quarts is about what a good feeder ought to have. Some will eat sixteen quarts of oats a day, but my belief is that three quarts of it does more harm than good."

Splan tells us ${ }^{1}$ that Rarus, in the hottest part of the sumsuer, consumed fifteen pounds of oats per day, which he regarded as tho maximum for a strong, energetic horse.

All horsemen agree in regarding oats as the one grain suitable for animals where speed is sought regardless of cost of food. While this opinion prevails in this country, we should remember that the Arab horse usually subsists upon barley.

504. Feeding the carriage horse.-Style and action should be prerequisites with the carriage horse, economy in feeding standing second. Oats easily lead among concentrates, for any good driver will tell us that a horse fed on oats exhibits mettle as from no other feed. For variety, rolled wheat or barley with bran

\footnotetext{
1 Life with the Trotters, p. 302.
} 
may form a portion of the ration. From ten to twelve pounds of oats, or their equivalent, should suffice for the concentrates, divided into three feeds, the evening meal being the largest. Cooked grain, having a tendency to soften the flesh, should not generally be given, though a feed once or twice a week will have a cooling effect; bran mashes will be conducive to the same end. A part of the hay may be chaffed and moistened before feeding; the remainder may be fed long, as the carriage horse has plenty of time for masticating his food. From ten to twelve pounds of hay should be allowed in order to bring the total weight of the ration within the limit of twenty or twenty-two pounds.

While the large abdomen cannot be tolerated in the carriage horse, we should not forget that there must be a certain bulk or volume to the feed in order that the digestive functions may be properly maintained. Carriage horses are usually over-fed and under or irregularly exercised, the latter trouble arising from the absence or business engagements of the owner or because of inclement weather. For these reasons mainly, the period of satisfactory service with this class of animals is usually short. Where daily driving cannot be practiced, under-feeding rather than heary feeding should prevail as the safer course. When the team is not taken from the stable during the day, the concentrates or grain portion of the ration should at once be reduced one-third or one-half, and the normal allowance should not again be given until work or exercise demands it. Such action requires firmness on the part of the feeder who wishes to treat his animals with kindness, but any other system than that of accurately gauging feed to work is harmful and ultimately disastrous.

505. Feeding the work horse.- The work horse, having but few days of idleness, possesses a hearty appetite and a vigorous digestion, so that if intelligently cared for, his lot is not altogether an unhappy one; nor is he to be commiserated when compared with his aristocratic kin, the carriage horse, which by high living and periods of enforced idleness, followed occasionally perhaps by hours of over-exertion, generally has but a brief career and that sometimes attended with many ills. Regularity in work brings regularity of feeding, and these greatly conduce to comfort and long years of usefulness. 
The concentrates for work horses can rarely consist wholly of oats because of their cost. Rolled wheat and barley are excellent substitutes, and corn meal, or preferably corn and cob meal, may form from one-third to one-half of the ration. Bran has come into general use as part feed for the horse. Shorts or middlings may be used to the extent of two or three pounds per day. This portion of the wheat grain is excellent for the horse, except that the heavy or floury middlings, if fed in quantity, are liable to induce colic with many horses. Cooked feed may be given two or three times a week for cooling the system; in its absence, bran mashes should be given. A small allowance of roots is always in order.

The work horse should be supplied with about two pounds of provender daily for each hundred pounds of weight. Of this, from ten to eighteen pounds, according to the severity of the labor performed, should be grain in some form. The heavy feeding should come at night, after the long day's work is over and when the animal has time for masticating and digesting bis food. After watering comes the administration of the grain, which should constitute one-half to two-thirds of the day's allowance. This may be fed separately, or preferably upon moistened, chaffed hay. The amount of chaffed hay with which the grain is mixed should not exceed one peck in volume.

Ground grain and chaffed hay are fed in mixed form that the animal may masticate his food and pass it to the stomach more quickly than is possible with the material whole and in dry form. A fair allowance of long hay should always be thrown into the manger for the animal to finish on, after the stomach is replenished and while he is resting but still requiring more food. The morning meal should be comparatively light, consisting mostly of grain with some chaffed hay. It should not possess much balk, and should be in condition to be easily and rapidly consumed so as to be well out of the way when the animal is led from the stable. The mid-day meal is omitted in many stables, but most horsemen hold that some grain should be given at noon, which claim seems reasonable from our knowledge of the horse's stomach and the digestive process. In any case the amount of feed given at mid-day should not be large. 
506. Preparation of feed.-The food requirements of the horse vary more than for any other farm animal because of their wide range in weight and the great diversity and severity of the labor performed. Idle horses may be maintained wholly or almost wholly upon hay, straw or corn fodder, fed uncut. Such animals have ample time for masticating food, and their systems not being taxed by labor, they are able to subsist on food which contains a large percentage of inert matter. Forage possessing considerable volume, as hay and straw, is suitable for such animals because a reasonable amount will furnish the necessary nutriment, and it is better to have the digestive tract well distended with food substances than contracted, as would be the case if concentrates possessing only the requisite nutriment were supplied.

For horses taxed to the limit of their endurance all grain should be ground and fed upon moistened, chaffed hay. Food thus prepared is more rapidly masticated and consequently remains a longer time in the stomach. A little long hay may be supplied the animal, to be consumed at leisure after the stomach is well filled. Understanding the requirements of animals representing the two extremes, one can adjust the food preparation and supply to meet the various intermediate cases as they arise.

There is always more or less dust with hay, and this roughage should always be administered in such manner as to cause the horse the least annoyance. Dusty hay should be avoided if possible. Sprinkling the hay lightly with water is the simplest way of reducing the trouble to the minimum.

507. The order of administering grain, hay and water.-Colin's investigations on the stomach of the horse ${ }^{1}$ show that this organ must fill and empty itself two or three times for each feed given. (32) In one case he administered 2,500 grams ( 5.5 pounds) of hay to a horse, which was then killed, and on opening the stomach less than one-half of the hay was found therein, the remainder having passed into the intestines. Other animals killed at longer intervals after feeding showed that the passage of the food into the intestines was not as rapid toward the end of the repast as at the beginning. From this it appears there are two periods in the di-

1 Traite d. Phys. Comp. des Animaux. 
gestion of hay; in the first, the material is pushed on, almost as soon as it enters the stomach, into the intestines by the food which follows, while toward the end of the meal the passage is slow and the digestion in the stomach more perfect.

Marlot, conducting experiments at the Agricultural College, Department of Yonne, France, fed four quarts of oats to a horse which was killed soon after. An examination of the stomach showed that three quarts of the oats had been carried by the water into the intestines. The grain of the ration being rich in protein should remain in the stomach as long as possible for the digestion of this nutrient.

Sanborn, studying the effects of watering before and after feeding, concludes as follows: ${ }^{1}$

"1. Horses watered before feeding grain retained their weight better than when watered after feeding grain. 2. Horses watered before feeding had the better appetite or ate the most. 3. Horses watered after feeding grain, in ratio to the food eaten, seemed to digest it as well as those watered before feeding. In a prior trial there was a small apparent advantage in favor of feeding after watering, on digestion. 4. It seems advisable to water both before and after feeding."

In some cases cruelty is certainly practiced towards horses in withholding a normal water supply. Splan" writes: "As to water I think every horse should have all he wants at all times. A man says: Why, will you give your horse water before a race? Yes, before the race, in the race and after the race, and any other time the horse wants to drink. . . . When I said give your horse all the water he wants before the race, I do not mean that you shall tie him up where he cannot get a drink for five or six hours on a hot day in a warm stall, and then take him to the pump and give him all he wants. What I mean is to give him water often, and in that way he will take but a sruall quantity at a time."

In general we may say that horses should have their regular and largest supply of water previous to feeding, and it may also

1 Bul. 9, Utah Expt. Sta.

2 Life with the Trotters, pn. 302-3. 
be well to supply a limited quantity after feeding. When the horses come to the stable heated and fatigued, a little fresh water, even if cold, may be given with beneficial effect - say eight or ten quarts. Then when cooled off and rested, what they still require should be supplied. When on the road a few quarts of water can be given with safety, no matter how much the horse is heated, but a large quantity should never be supplied at one time. On journeys, water should be given every few miles.

A theoretical system of feeding would require that the horse be given water first of all, and that this be followed by hay, the grain being withheld until at least some hay had been consumed. While the plan of watering first is easily followed, we cannot and should not make the horse wait for the grain, consuming his hay allowance first, for until the grain is given he is nervous and unsatisfied. In prictice the concentrates will usually be supplied before hay is given. A middle ground can be taken by watering first and then feeding ground grain sprinkled upon a small allowance of moistened chaffed hay. This will satisfy the desire of the horse by supplying the most palatable portion of his food early, and yet insure the retention of the grain in the stomach for a considerable period, since masticating and swallowing the cut hay with accompanying meal will require some time.

The small size of the stomach of the horse indicates the impropriety of long fasting. While it is a fact that horses employed by some establishments go from daylight until dark without food, it seems that where possible these fasts should be broken by a small feed of grain at mid-day.

Over-feeding with hay is the source of a long list of ills with the horse. Through carelessness or mistaken kindness the mangers are often kept filled with hay, and because of his long hours of idleness in the stable the horse falls into the habit of gorging himself with this provender. Not only is there waste of hay in such cases, but whatever is eaten beyond requirement exhausts the digestive system and weakens its influence upon the other nutrients of the ration. Staring coats, labored breathing and quick tiring are the least serious, though probably the most easily noticeable, results of this common practice. There should 
be a definite allowance of hay for the horse at each feeding time, and this should always fall short of what would be consumed if more were given. Next to failure to provide abundant and systematic exercise the common fault in horse management, where animals are used for pleasure, is that of overfeeding with hay.

508. Systematic feeding of the highest importance.-No one can review the literature of horse feeding or personally study the practices in various stables located at widely separated points, as the writer has done, without realizing that there are many successful ways of feeding and managing the horse. The uses to which this animal is put are so varied, and the feeding materials at command so diverse for different localities, that any hard-andfast rules as to kind of feed and amount to be supplied are out of the question. One thing is certain, however: Whatever feed. ing stuffs are employed and whatever order of feeding is adopted, regularity and uniformity should prevail at all times. The animal during his round of work anticipates the feeding hour. The digestive system, and indeed the whole organism of the body, becomes accustomed to this certain order, and thrift and health are the natural concomitants, while irregularity and uncertainty are always productive of unsatisfactory results.

509. Variety in feed of importance.- Horsemen sometimes state that with plenty of oats and good hay at command they care nothing for other food articles. While it is true that a horse can be maintained on this short dietary, it seems reasonable that equally good or better results are obtainable, and the cost of keeping often lessened, by adopting a more extended bill of fare. Experiments with other domestic animals plainly show the advantages of judi. ciously formed combinations of feeding stuffs over any single one. If energy and spirited action were the only qualities desirable in the horse, then perhaps oats with hay might suffice; but when we consider the number and complexity of the components of bone, tissue and nerve, we can well believe that these are better nourished by several kinds of grain and forage plants than by one or two only.

A striking illustration of the value of variety in food and its proper administration is shown by Mr. Charles Hunting, a 
superintendent having under his care some 7,000 horses employed in the collieries of North England, who writes as follows: ${ }^{1}$

"I was called to a colliery in Durham some time ago; the output at this place was decreased from fifteen to twenty score per day through the horses being unable, from want of condition, to get the work out. The animals were miserably poor, though allowed 168 pounds of oats and 154 pounds of hay each per week. The oats were not crushed and the hay was not chopped. The horses were large, none under 16 hands, many 16.2. They worked very long hours, and took heavy loads, but I confess I was astonished at their appearance after many months of such apparently liberal feeding. On September 1 their food was changed to the following:

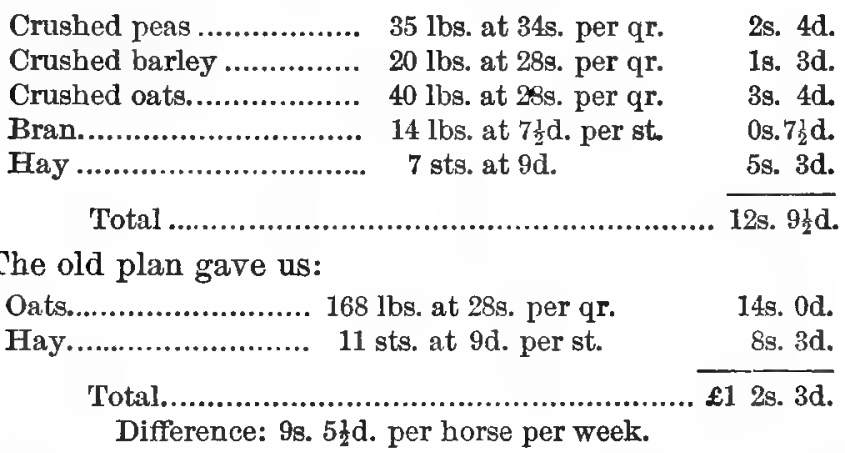

"Notice, too, that besides this saving in money, the digestive organs had 56 pounds less hay and 59 pounds less corn (grain) to digest. Or: -

\begin{tabular}{|c|c|c|}
\hline $\begin{array}{l}\text { Mixed grain.............. } \\
\text { Hay........................ }\end{array}$ & $\begin{array}{l}109 \text { lbs. } \\
98 \text { lbs. }\end{array}$ & $\begin{array}{l}\text { Old oats............... } \\
\text { Hay................... }\end{array}$ \\
\hline Total................. & 207 lbs. & Total... \\
\hline
\end{tabular}

"Result: Within three months this stud was in excellent health and condition, drawing out of the pit, without any application of engine power, about twenty to thirty scores more per day than when I first saw them. There were 149 horses on the colliery, so by this change a saving of $£ 3,66212 \mathrm{~s}$. $1 \frac{1}{2} \mathrm{~d}$. per annum was effected."

${ }^{1}$ Paper read before New Castle Farmers' Club-by Mr. Chas. Hunting, South Hetton, County of Durham, England; see The English Cart Horse Stud Book, Vol. I, p. xlv. 
510. The supervision of feeding. - In stables where many horses are maintained, a group or row of animals should remain in the care of the sarne attendant, the whole establishment being under the watchful supervision of the superintendent. While we can estimate quite closely the amount of food to be given a hundred or a thousand horses, there must always be modifications and concessions to individual members of the establishment to be recognized and provided for by the guiding mind,- one horse should kave a little more than the regulation allowance, and the next. possibly a little less, the object being to keep each in the desired condition. Usually it is not well to leave the feeding of horses to their own driver, for he has his likes and dislikes, and the favorites are pretty certain to receive more than their proper allowance of grain, while the others suffer. A watchful superintendent must ever be on the alert to see that each animal secures the needed provender.

5II. Exercise essential to the maintenance of healti.--The Arabs have a saying, "Rest and fat are the greatest enemies of the horse." The horse is par excellence the creature of motion, and in its feeding and management we should hold this point ever in view. The prudent horseman will bear in mind that correlative with liberal feeding tilere must be hearty exerciss or severe labor, and that these conditions may be happily balanced. As soon as hard labor ceases, or constant and vigorous exercise is over, it will be found absolutely necessary to reduce the allowance of food if the proper balance is to be maintained. The idle horse should be limited to less than half the grain given while on regular duty, and in some instances it were better to give none, provided the roughage supplied be of good quality.

A colt fed heavily on suitable nutrients will grow rapidly. and derelop good bone and strong musele, provided at all times there be a proper balance between exercise and feed. The highly-fed colt should be out of doors from eight to ten hours a day, and should move several miles each day either in the field, on the track, or both. A mature horse should be in the open air not less than four or five hours a day and should travel from ten to fifteen miles daily to maintain health. 
512. Rations.-The following rations given by various anthorities may serve as a general guide in determining the amount of feed which should be allowed the horse under diverse conditions:

Character of animal and work required.

Ration.

Concentrates. Roughage.

Trotting horse. - Hiram Woodruff. ${ }^{1}$

Colt, weaning time 2 pounds oats.

Hay $a d l i b$.

Colt, one year old 4 pounds oats. Hay ad lib.

Colt, two years old 6 pounds oats. Hay ad lib.

Colt, two years old, in training.... 8 pounds oats. $\{$ Hay, allowance Colt, three years old, in training... 8-12 pounds oats. $\{$ Hay, allowance Trotting horse._Splan."

Horse on circuit......................... 10 pounds oats. $\left\{\begin{array}{c}\text { Hay, fair } \\ \text { amount. }\end{array}\right.$ Horse on eircuit.......................... 15 pounds oats, in exceptional Hay, fair cases (as with Rarus). amount.

Horse variously used.-Stonehenge. ${ }^{3}$

Race horse 15 pounds oats. 6-8 pounds hay. Hack 8 pounds oats.

12 pounds hay.

Horse variously used.—Fleming.*

Pony.

4 pounds oats.

Hunter, small 12 pounds oats. Hunter, large. 16 pounds oats. $\{$ Hay, moderate $\{$ allowance.

Carriage, light work 10 pounds oats. 12 pounds hay. 10 pounds hay. 12 pounds hay.

The draft horse.-Sidney." Heavy, hard work................... $\left\{\begin{array}{r}13 \text { pounds oats. } \\ 6 \text { pounds beans. } \\ 3 \text { pounds corn. }\end{array} \quad\left\{\begin{array}{r}15 \text { pounds chaff- } \\ \text { ed clover hay. }\end{array}\right.\right.$

\section{Farm horse. - Settegast."}

Light work 6-10 pounds oats. $\left\{\begin{array}{l}6-9 \text { pounds hay. } \\ 3 \text { pounds straw. }\end{array}\right.$

Medium work 10 pounds oats. $\left\{\begin{array}{r}10 \text { pounds hay. } \\ 3 \text { pounds straw. }\end{array}\right.$

Heavy worlk 13 pounds oats. $\{12$ pounds hay. 3 pounds straw.

1 The Trotting Horse of America.

8 The Horse. 4 The Practical Horse Keeper.

2 Life with the Trotters.

6 Thierzucht, II, 1888, p. 109.

- Book of the Horse 
513. Rations for army horses. - The following are the rations allowed army horses in the countries noted:

Ration.

Government.

Weight of horse. Concentrates. Roughage.

United States, ${ }^{1}$ cavalry, 950 to 1,150 lbs. 12 lbs. oats, ) $\left.\begin{array}{l}\text { corn or } \\ \text { barley. }\end{array}\right\} 14$ lbs. hay.

United States, artillery, 1,050 to 1,200 lbs. $12 \mathrm{lbs}$. oats, corn or barley.

14 lbs. hay.

Germany, ${ }^{2}$ cavalry $.1,050$ lbs. 10 lbs. oats. * $\left\{\begin{array}{l}5.5 \text { lbs. hay. } \\ 7.7 \text { lbs. straw }\end{array}\right.$

Germany, cavalry-officers' $11 \mathrm{lbs}$, oats $\{5.5 \mathrm{lbs}$. hay.

Great Britain, ${ }^{3}$ cavalry. $10 \mathrm{lbs}$ oata 12 lbs. hay.

Great Britain, cavalry, severe duty 10 lbs. 0ats. $\left\{\begin{aligned} 12 & \text { lbs. straw. }\end{aligned}\right.$ 12-14 Ibs. oats. $\{12$ lbs. hay.

* Wolff (Article 441) refers to the German cavalry ration as containing 11 pounds of oats.

514. Rations used by street-car companies. - The rations used by street-car companies are interesting not only because they show the feed required by animals thus worked, but, because of the constant and severe labor performed by this class of animals, we can learn of the food requirements of hard-worked horses. The following rations are given by Fleming* as the daily allowance for horses of some of the principal tramway (horse-car) companies of Great Britain:

Rations for British tramway (street-car) horses - Fleming.

\begin{tabular}{|c|c|c|c|c|}
\hline London. & Liverpool. & Glasgow. & Edinburgh. & Dublin. \\
\hline Lbs. & Ijus. & Lbs. & Lbs. & Lbs. \\
\hline Corn... 7 & Corn......... 12 & Oats ... 6 & Oats......... 8 & Corn... 14 \\
\hline Oats ... 3 & Beans......... 4 & Corn.... 11 & Corn......... 4 & Oats ... 3 \\
\hline Peas ... 3 & Cut hay ... 14 & Hay ... 8.5 & Beans........ 4 & Hay ... 12 \\
\hline Hay ... 12 & Bran........ 1 & Straw.. 1 & Hay ......... 14 & Bran .. $\quad .5$ \\
\hline Straw.. 1 & & Bran... . .5 & Marshlum. 2 & \\
\hline
\end{tabular}

Special Agent Mattes, of the Department of Agriculture, has

' From information furnished by Chas. Bird, Quartermaster General U. S. Army, Washington.

2 Landw. Jahrb., 1887, Suppl. III, p. 72.

a Fleming, The Practical Horse Keeper, p. $89 . \quad$ Loc. cit., p. 88. 
gathered important information ${ }^{1}$ concerning the rations of streetcar horses on the Continent, some of which are herewith presented:

Rations for street-car horses in various European cities - Mattes.

\begin{tabular}{|c|c|c|c|c|c|c|c|c|}
\hline \multirow[b]{2}{*}{ City. } & \multicolumn{4}{|c|}{ Dally allowance per horge. } & \multicolumn{4}{|c|}{ Nutrients in ration. } \\
\hline & Corn. & Oats. & Hay. & Straw. & Prot. & Carbh. & Fat. & $\begin{array}{l}\text { Nut. } \\
\text { ratio. }\end{array}$ \\
\hline & Lbs. & Lbs. & Lbs. & Lbs. & Jibs. & Lbs. & Lbs. & Lbs. \\
\hline Bremen................... & 14.3 & $2.2^{*}$ & 8.8 & 2.2 & 2,03 & 13.18 & .75 & $1: 7.7$ \\
\hline Brussels .................. & 7.7 & 11.0 & 4.4 & 3.3 & 1.76 & 11.42 & .84 & $1: 7.7$ \\
\hline Bordeaux - & & & & & & & & \\
\hline Winter............... & 15.4 & & 13.2 & 1.1 & 1.94 & 13.96 & .75 & $1: 8.2$ \\
\hline Summer ............... & 11.0 & 4.4 & 13.2 & 1.1 & 1.94 & 12.85 & .75 & $1: 7.6$ \\
\hline Hamburg ................ & 17.6 & 1.7 & 7.7 & 4.4 & 2.01 & 15.17 & .86 & $1: 8.6$ \\
\hline Munich .................. & 6.6 & 11.0 & 5.5 & 4.4 & $1.7 \theta$ & 11.13 & .79 & $1: 7.4$ \\
\hline Vienna.................. & $\ldots . . . .$. & 15.4 & 11.0 & 2.2 & 1.83 & 13.54 & .73 & $1: 8.4$ \\
\hline
\end{tabular}

* 1.1 pounds additional of peas.

In examining these rations, we observe that corn usually constitutes a part of the ration. Most of the corn used in the United Kingdom and Germany comes from this conntry. Even with the increased cost incident to importation, many companies find it a relatively cheap food, and make large use of it.

1 Report of the Statistician, October, 1894, Department of Agrinultasan. Washington. 


\section{CHAPTER XX.}

\section{OALF REARING.}

\section{Findings of the Investigators.}

515. Birth weight of calves.-According to Krafft, 1 the weight of calves at birth is from one-twelfth to one-fourteenth the weight of the dam. This authority places the weight at birth as follows:

Birth weight. Pounds.
Light-weight calves
$48-66$
Average calves.
$66-92$
Heavy calves
$97-110$
Very heavy calves. $115-128$

516. Whole milk for calves. - Bertschinger gives the following results for feeding trials with whole milk to calves in the Canton of Zurich, Switzerland: ${ }^{2}$

Number of calves fattened 34

Duration of fattening period, weeks. $11 \frac{1}{2}$

Quantity of whole milk fed, per calf, pounds $1,682.6$

Live weight of calves at beginning, pounds........... $\quad 102.5$

Increase in weight, pounds................................. 166.4

One pound of increase, live weight, was obtained for each 10.1 pounds of whole milk fed.

Martiny ${ }^{8}$ found that from 3.5 to 6 pounds of new milk were sufficient to produce a pound of gain, live weight, with calves between the first and fifth weeks, while from 16 to 20 pounds were required for a pound of gain with older animals.

At the Pennsylvania Station, ${ }^{4}$ Hunt fed three calves full milk containing an average of 4.6 per cent. of fat for 161 days. These calves gained 1.77 pounds each daily, requiring 8.7 pounds of

' Lehrb. d. Ldw., 3, 1890, p. 85.

2 Fleischmann, Molkereiwesen, 1876, p. 150.

Die Milch, 2, 1871, pp. 9-15.

- Rept. 1891. 
whole milk and one pound each of hay and grain for one pound of growth. (356)

517. 5eeding skim milk.--Fleischmann ${ }^{1}$ quotes an experiment with six calves receiving skim milk only. Twelve pounds of skim milk were required for one pound of gain.

Beckhusen ${ }^{2}$ reports feeding trials with calves receiving skim milk and making an average daily gain of 2.1 pounds. One pound of gain was produced from 13.3 pounds of skim milk. From 6.1 to 98.9 pounds of skim milk were required for one pound of gain, according to the age of the animal. (357)

518. Separator skim milk.-Du Roi ${ }^{3}$ fed 18 calves, averaging 91.5 pounds at birth, for 37 days. Each calf received 11.4 pounds of full milk and 896.7 pounds of separator skim milk, and gained on the average 55.1 pounds, giving one pound of increase for 16 pounds of separator skim milk. In this trial one pound of new millk was considered equal to two pounds of skim milk.

519. The lowa Station tests. - Calf rearing with separator skim milk has been studied by Curtiss, of the Iowa Station, ${ }^{4}$ who gives the following recent important results. Milk from the college dairy herd was fed immediately after it had passed through the separator, the temperature being from 85 to 90 degrees Fahr. The chief object of the experiments was to determine the best grain to feed in connection with skim milk. Oil meal, oat meal and corn meal, with a little ground flax seed additional, were used. The first test, conducted during the summer, lasted sixty days, with two calves, - one Short-horn and one Holstein in each lot,- averaging 182 pounds when the trial began. The second trial, with two calves in each lot, conducted during the fall and winter, lasted ninety days. The calves were high-grade Shorthorns, from two to three weeks old when the feeding began. The third trial was conducted during the winter with four purebred Short-horns in each lot, averaging 200 pounds when the trial began. From thirteen to twenty pounds of skim milk were fed to each calf daily in these trials. The calves in Lot I were

\footnotetext{
1 Molkereiwesen, p. 368; Milch Zeitung, 1875, p. 1481.

2 Milch Zeitung, 1880, p. 214.

- Der Landbote, 1887, No. 14, and v. d. Goltz, Landw. 3, p. 420.

- Bul. 35.
} 
fed oil meal and milk. Lot II received ground oats and milk, the halls of the oats having been sieved from the ground grain in the second and third trials. Lot III received corn meal with about 10 per cent. of ground flax seed additional. A summary of the trials appears in the following table:

Summary of three trials with separator skim milk and varions meals - Iowa Station.

\begin{tabular}{|c|c|c|c|c|c|c|c|}
\hline K1nd of feed. & 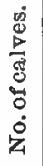 & Total feed given. & $\begin{array}{l}\text { Total } \\
\text { gain. }\end{array}$ & $\begin{array}{c}\text { Av. } \\
\text { daily } \\
\text { gain } \\
\text { per } \\
\text { head. }\end{array}$ & $\begin{array}{c}\text { Dry } \\
\text { matter } \\
\text { per } 100 \\
\text { pounds } \\
\text { of gain. }\end{array}$ & $\begin{array}{c}\text { Cost or } \\
\text { feed } \\
\text { per } \\
\text { pound } \\
\text { of } \\
\text { gain. }\end{array}$ & $\begin{array}{l}\text { Nutrf- } \\
\text { tive } \\
\text { ratio. }\end{array}$ \\
\hline $\begin{array}{l}\text { Lot } I \text { onl meal } \\
\text { and milk...................... }\end{array}$ & 8 & 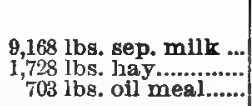 & $\begin{array}{l}\text { Lbs. } \\
873\end{array}$ & $\begin{array}{l}\text { Lbs. } \\
1.47\end{array}$ & $\begin{array}{l}\text { Lbs. } \\
339\end{array}$ & $\begin{array}{l}\text { Cts. } \\
2.8\end{array}$ & $1: 2.6$ \\
\hline $\begin{array}{l}\text { Lot II. Oat meal } \\
\text { and milk........................... }\end{array}$ & 8 & $\begin{array}{r}9,160 \text { lbs. sep. milk ... } \\
1,730 \text { lbs. hay............ } \\
875 \text { lbs. oat meal.... }\end{array}$ & 927 & 1.57 & 337 & 2.1 & $1: 3.6$ \\
\hline 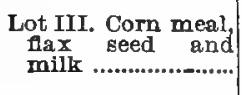 & 8 & $\begin{array}{r}\text { 9,168 lbs. sep. milk .... } \\
\text { 1,731 lbs. hay......... } \\
772 \text { lbs. corn meal... } \\
84 \text { lbs. flax seed..... }\end{array}$ & 925 & 1.56 & 830 & 2.2 & $1: 4$ \\
\hline
\end{tabular}

Commenting on the experiments, Curtiss writes: "The results of all the investigations made at this Station strongly indicate that it is not only unnecessary but poor economy and poor practice in feeding to use a highly nitrogenous product like oil meal in combination with separator skim milk. The practice has neither logical reason nor scientific theory for its support; and in the cornbelt states, with their surplus of corn and oats, there is no necessity for the purchase of a high-priced nitrogenous product to be used in supplementing the skim-milk ration." (199)

520. Gravity versus separator skim milk.-Thirty-two calves less than 10 weeks old, weighing on an average 130 pounds, were fed from 30 to 50 days on three Danish estates under the direction of the Copenhagen (Denmark) Station. 1 The calves received about 20 pounds of separator skim milk daily per head in addition to oats, peanut meal, corn, barley or hay, singly or combined. The average weight of the calves at the beginning of the experi-

1 Rept. 1894. 
ment and the gain made, together with the fat content of the skim milk, are given in the following table:

Gravity Separator skim milk. skim milk.

Average weight per head at beginning, pounds... 130.2

Daily gain per head, pounds............................ 1.50

132.7

Difference in favor of gravity skim milk, pounds.

Fat content of the milk, per cent.

.07

.60

1.43

......

.14

From the above we learn that where the gravity skim mill produced a gain of 1.5 pounds per day, the calves fed on separator skim milk gained 1.43 pounds daily. When the value of the excess of butter fat left in the gravity skim milk is taken into consideration, it will be seen that the increase in weight of the calves was of much less value than the butter which the excess fat would have made.

521. Feeding cod liver oil, oleomargarine and sugar.- At the Massachusetts Station, Lindsey ${ }^{1}$ found that cod liver oil added to the skim milk fed to calves proved unsatisfactory, the animals sometimes refusing the food containing it. A cheap grade of oleomargarine was heated to 110 degrees Fahr., and mixed with the skim milk by churning. It was found that one ounce of oil per quart of skim milk was all that the calf could take without producing indigestion. Cotton-seed oil and corn oil to the amount of one-half ounce per quart of milk were fed without bad effect. A calf fed skim milk to which was added one part oleo and two parts brown sugar gave good results, making a gain of over two pounds daily, with the kidneys well covered with fat. Calves fed on this artificial milk were superior to those receiving skim milk, but not equal in fatness to sucking calves.

522. Flax seed.- Behrens found that calves receiving about one-half pound of flax seed per day with skim milk made an average gain of 1.85 pounds per day, while those receiving skim milk only, gained 1.55 pounds.

523. Whey for calf feeding.-Graef, ${ }^{2}$ testing the relative value of whey and skim mills, secured a gain of two pounds per day with calves fed on skim milk, while those fed whey gained from 1 to 1.4 pounds only. The quantities of food are not stated. (359)

Repts. 1893-94.

2 Milch Zeitung, 1880, p. 143. 
524. Producing veal on pastures. - Krafft ${ }^{1}$ reports the fattening of calves on the low lands of the Schleswig-Holstein marshes, where veal of excellent quality is produced. One hectare (2.47 acres) of pasture is considered necessary to produce 600 kilograms $(1,320$ pounds) of gain, or 534 pounds of gain per acre. The flesh of such calves cannot be "veal" in the usual acceptation of that term.

525. Gain from skim milk fed calves and pigs.- Fleischmann, reviewing the increase of calves and swine fed skim milk, concludes that calves make greater gains from a given quantity of skim milk than do pigs. (741, 869-71, 886-8)

\section{Rearing the Calf.}

526. Feeding for beef.-Where beef is the principal object, the calf is usually allowed to draw its milk supply direct from the dam. In such cases few precautions are necessary, the most important being to see that the young thing does not get too mach milk, as this causes indigestion. If the calf remains with the dam, the udder of the cow should be stripped clean night and morning; neglect may result in soreness to the teats and udder, ending in destroying the usefulness of the dam. If the calf is getting too much feed, the supply should be diminished by stripping the cow after allowing it to take only part of the milk, remembering that the last milk yielded by the cow is the richest in fat, (615) and that it is the richness as well as the quantity that causes trouble. Where calves are separated from their dams, at first allow them to suck three times daily, soon reducing to twice a day. The greatest danger in this system comes at weaning time, when, if the calf has not been properly taught to eat solid food, it is apt to pine and shrink in weight, or at least make little gain. To aroid this, teach it to eat a little grain daily, using ground corn, bran, oil meal and hay.

The first departure from the primitive system above described is putting two calves with each cow, which is practicable and desirable where the cow yields a good flow of milk.

The sucking ealf should gain 3 pounds per day for the first month, 2.5 pounds for the second and 2 pounds for subsequent

\footnotetext{
1 Landw., 3, p. 163. Molkereiwesen, p. 373
} 
months. Hunt's experiments show that calves given full milk from the pail require from 8 to 9 pounds of whole milk for each pound of gain, and make a gain of over 1.75 pounds daily. While in the beef districts the calf will be allowed to take its own milk, there are sections where the stockman finds it more profitable to sell the fat of milk in the form of butter and use substitutes for the fat together with skim milk as feed for the calf. This system involves labor, skill and watchfulness on the part of the feeder, but its success has been demonstrated on many farms.

After weaning, good growth will be continued by using oats and corn with a little oil meal, supplying at all times plenty of bright hay or fodder corn. Nothing excels pasture grass for fleshbuilding with the beef calf, and to approximate this in winter the stockman should have roots or silage in order to keep the young animals in a sappy, growing condition. The stockman should not forget that the "calf fat" or first fat of the calf must not be lost if beef is the ultimate object.

527. Rearing the dairy calf. - The fat of milk has too high a value with the dairyman to be used for calf feeding, and experience has shown that dairy stock of the highest quality can be produced from feeding skim milk. Under this system the calf is allowed to draw milk from the dam for two or three days, early weaning being preferable for both cow and calf. The calf should always get the first milk (colostrum) of the cow, as this is necessary for properly clearing the bowels and starting the digestive functions. (355) Warm full milk is fed from the pail not less than three times daily until the calf is two or three weeks old, after which skim milk is gradually substituted. From one to two weeks should pass in changing from full milk to sisim milk. Oil meal converted to jelly by adding boiling water is relished by young calves, which soon learn to look for it at the bottom of the pail. At first a tablespoonful of oil meal is sufficient for a feed. This may be increased gradually, as the calf grows, to half a pound per day. Curtiss has shown that corn meal is an excellent and cheap addition to milk for calves; oats, shorts or other grain feeds may also be used.

The supply of full nilk for the calf should be not over 10 pounds at first, and end with 15 pounds daily. The skim milk 
should not exceed 18 pounds daily until the calf is five weeks old, and only in rare cases should an amount beyond 24 pounds be given. Many calves are destroyed by being overfed with skim milk by persons who act as though they thought to make up the lacking qualities of this feed by giving more of it. Young calves should be fed not less than three times daily until four or five weeks old. The milk should be heated to blood temperature, and the careful feeder will use a thermometer to ascertain the proper degree.

Where calves do poorly on skim milk, the results are chargeable to the abuse of that feed. Too large a supply of milk, infrequent and irregular feeding, milk too cold for digestion, and sour feeding-pails, are the causes of nine-tenths of the trouble.

The calf is best taught to drink by using the fingers. The various devices for calf feeding are usually unsatisfactory and often dangerous because of accumulations of milk in concealed places, which cannot be washed out, but remain to hecome putrid and disease-breeding. The calf is taught to eat grain by placing a handful of whole or ground oats, shorts or other feed in its mouth immediately after supplying the milk. Alluw no more grain in the feed box than will be wholly consumed between feeds. Hay from early-cut grass or clover should also be supp'ied. Calves should be tied if they annoy one another. Properly fed on skim milk, with oil meal, corn, oats or other grain additionas the careful feeder can count on a gain with calves of from on and a half to two pounds per day for the first four months.

In rearing calves intended for beef production there is listle danger in crowding them rapidly, every pound gained bringing the animal so much nearer the desired end. The dairy calf shoul $c^{2}$ be fed in such a manner as to insure a steady growth without tendency to become fat. The food should be nutritious, but not concentrated in character. Clover hay, corn stover, and silage without much corn in it, with a little straw, should constitute the roughage. Bran, barley and oats are excellent for the small allowance of grain required. A calf intended for a model dairy cow should not gain over one and one-half pounds per day for the first four months and less thereafter.

528. Whey. - In the cheese districts, calves are frequently raised upon whey, which feed is a poor substitute for eren skim milk. 
When used, whey should be fed in not too large quantity and amends made for the abstracted constituents by the addition of oil meal, ground oats, etc. Care should be taken to feed the whey while as nearly sweet as possible, and all vessels holding it sliould be scalded daily so as to be free from a sour taint. While none too good in itself, any nutritive qualities whey may possess are rendered of still less worth by allowing it to ferment or by feeding in dirty vessels. (359)

529. Hay tea.- Stewart 1 gives the following experience with a hay-tea ration for calves: "This old expedient to rear calves without milk had an excellent basis, as do most common practices. The soluble nutritive constituents of the hay are extracted by boiling, (53) and this extract contains all the food elements required to grow the animal, besides being as digestible as milk. If the hay is cut early, when it has most soluble matter, and is of good quality, the tea will grow good calves, but this extract frequently has too small a proportion of albuminous and fatty matter. Yet, if the hay tea is boiled down so as not to contain too much water for the dry substance, calves will usually thrive upon it. We tried an experiment by feeding two gallons of hay tea, in which one-fourth of a pound of flax seed and one-fourth of a pound of wheat middlings had been boiled, to each of five calves thirty days old. This experiment was continued sixty days, with a gradual increase, during the last thirty days, of the middlings to one pound per day. These calves did remarkably well, gaining an average of a little over two pounds per head per day."

530. Feed and care after weaning.- With calves properly bred for the intended purpose-thrifty, fat and sleek-coated if designed for beef production, and in fair flesh, with a bright eye, if intended for dairying - the foundation of a good herd is laid. The stockman should always bear in mind that gains are never so cheaply made, so far as feed is concerned, as with the young animal, and for this reason, if no other, it should be pushed ahead as rapidly as is consistent with the end in view.

The table of feeding stuffs (349) shows that milk contains a large proportion of protein for muscle-making as well as ash for building

\footnotetext{
' Feeding Animals, p. 246.
} 
the framework of the yonng. In the composition of milkNature's food for the young - we have a guide to the formation of rations for young, growing animals. Pasture grass is also rich in protein, and should be the main reliance when available. Oil meal and oats, mixed with corn, are the best concentrates for growing beef animals, while some oil meal, together with oats, aborts and bran, with ample roughage, are most desirable for those of the dairy type. Counteract the tendency of grain feeds to make rigid, hard flesh by the use of pasture grass in summer? and roots or silage in winter. Always keep the young things in a sappy, growing condition. For roughage, aside from pasture and silage, use corn stalks, clover or alfalfa hay, these two latter feeds being rich in protein, for building the muscular system. A liberal amount of bulky feed should always be supplied young cattle to stimulate the growth of a roomy digestive tract. This is especially important with heifers designed for the dairy. If confined indoors the calf should have before it at all times, or at frequent intervals, a sod of loamy earth. A double handful of earth is good if nothing better is at hand. Why the calf should crave earthy matter cannot always be explained, but, knowing the fact, let the creature be supplied with this substance, feeling assured that Nature makes no mistake in matters like this, even if for the present they are beyond our understanding.

531. Fall calves. - Where cattle are reared under natural conditions, the rule that the young be dropped in the spring will continue, but this practice is not necessarily the most successful in the older sections of the country. Fall-dropped calves come at a time when the little attentions they need can easily be given, and they occupy but little space in barn or shed. Subsisting on the mother's milk, or on skim milk with a little grain and hay, when spring comes the youngsters are large enough to make good use of the pastures, and the result is progress from the start, until fall, when they return to the barn or shed large enough and strong enough in digestion to make good use of the dry provender necessitated by winter conditions. 


\section{Feeding for Veal.}

532. Essentiais. - To meet the highest requirements of the market, veal should not only carry a considerable amount of fat, but the flesh must show to the practiced eye that no coarse food has been eaten by the calf from birth to the time of slaughter. For the highest grade of veal, whole nilk is the one feed allowed $\{$ and growth must be pushed as rapidly as possible, the whole prouess being completed before there is any tendency in the meat to rake on the coarse character incident to the beef period. The lemand for fine veal is growing, and can bo greatly increasen ' $y$ ' supplying a high-grade product. In this line of meat production the farmers in parts of Europe are far in the lead. Dutch butchers are extremely expert in judging whether the calf has received any other feed than whole milk. Only when whole milk has been used exclusively is the white of the eye of the veal calf free from any jellow tint, and the insides of the eye-lids, lips and nose perfectly white.

533. A Scotch system of veal making.- At Strathaven, Scotland, a region noted for the excellence of its veal, ${ }^{1}$ the calves are fed on fresh cow's milk, the youngest receiving that first drawn from the cows and the older ones the last and richer portion; (615) thus one calf is often fed portions of milk which come from two or three cows. After the third week they receive as mach milk twice a day as they will take. After feeding they are bedded, the stable being kept rather warm and dark. Lumps of chalk are placed where the calves have access to them. The fattening period continues from five to seven weeks, when a dressed weight of 100 to 120 pounds is secured.

In the vicinity of London veal calves are fed for abont ten weeks in isolated pens, as in Holland. They ordinarily dress 140 pounds.

534. The Dutch system.-In Holland, where unusually heavy, well-fatted calves are a specialty, the following practices are common, according to Forssell: ${ }^{2}$ As soon as dropped the calf is placed in a stall which is so narrow that it cannot turn around though it

Molk. Zeit., 1894, p. 547.

Fodret och Utfodringen, 1893, p. 155. 
can lie and stand comfortably. The floor of the stall is of lattice work or perforated boards and littered daily so that the animal has a perfectly dry berth. The stalls are 6.5 feet long by 1.6 broad and about 5 feet high. The calf barn is kept dark. (89) Twice or three times daily the calves get as much milk as they will drink, and during the first fourteen days only the dam's mill is fed. Eggs or other by-feeds are not given. The calf consumes about 34 pounds of full milk daily on the average for the whole fattening period of ten or twelve weeks, at which time the veal is considered to be at its best. To prevent calves from eating feed other than milk they are muzzled if straw or other roughage is used for bedding. Finely-ground shells and sand are given to prevent scouring. The dressed weight ranges from 187 to 220 pounds, or, according to Rost, 1 from 220 to 330 pounds. Ono pound of gain is made in the beginning from eight pounds of milk, and toward the close from twelve pounds, the average being ten pounds. ${ }^{2}$

The fat calf dresses from 55 to 60 per cent. of its live weight.

1 Molk. Zeit., 1894, p. 547.

I Krafit, Landwirtschaft, III, p. 163. 


\section{CHAPTER XXI.}

RESULTS OF STEER-FEEDING TRIALS AT THE STATIONS.

I. Findings with Various Feeds.

535. Difficulties of steer fattening. - Among farm animals there is none so difficult to experiment with, all things considered, as the fattening steer. In this work the returns for the feed supplied are measured by the gain of the animal from day to day. While at first it is not difficnlt to increase the weight of the steer, the problem is far from easy when the final stages of the fattening period are reached. The animal then has a dainty appetite and is easily thrown off feed by small variations in the character or amount of the provender supplied. Other influences also, such as the weather, surroundings, attendants, etc., go to produce favorable or unfavorable results. Considering the difficulties, it is not surprising that many of the early feeding trials with steers by our Stations have not furnished data which will stand the test of time. Some good work has been done, however, as these pages show.

536. Ear corn compared with corn meal.-At the Kansas Station, ${ }^{1}$ Georgeson compared ear corn and corn meal for feeding steers, with the results shown in the table:

Feeding corn and corn meal to steers-Kansas Station.

\begin{tabular}{|c|c|c|c|c|c|c|}
\hline \multirow{2}{*}{ Feed. } & \multirow{2}{*}{$\begin{array}{c}\text { Av. wt. } \\
\text { of steer } \\
\text { at be- } \\
\text { gin- } \\
\text { ning. }\end{array}$} & \multirow{2}{*}{$\begin{array}{l}\text { Total } \\
\text { grail } \\
\text { eaten. }\end{array}$} & \multirow{2}{*}{$\begin{array}{l}\text { Fodder } \\
\text { eaten. }\end{array}$} & \multirow{2}{*}{$\begin{array}{l}\text { Total } \\
\text { gain. }\end{array}$} & \multicolumn{2}{|c|}{$\begin{array}{l}\text { Feed for } 100 \\
\text { pounds gain. }\end{array}$} \\
\hline & & & & & Grain. & Stover. \\
\hline First trial. & Lbs. & Lbs. & Lbs. & Lbs. & Lbs. & Lbs. \\
\hline 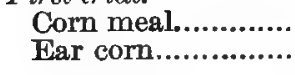 & $\begin{array}{l}1,211 \\
1,215\end{array}$ & $\begin{array}{l}3,575 \\
4,027\end{array}$ & $\begin{array}{r}940 \\
1,341\end{array}$ & $\begin{array}{l}268 \\
284\end{array}$ & $\begin{array}{l}1,334 \\
1,418\end{array}$ & $\begin{array}{l}350 \\
472\end{array}$ \\
\hline $\begin{array}{l}\text { Second trial. } \\
\quad \text { Corn meal.............. } \\
\text { Ear corn................ }\end{array}$ & $\begin{array}{l}1,129 \\
1,158\end{array}$ & $\begin{array}{l}2,646 \\
3,223\end{array}$ & $\begin{array}{l}607 \\
535\end{array}$ & $\begin{array}{l}290 \\
230\end{array}$ & $\begin{array}{r}911 \\
1,402\end{array}$ & $\begin{array}{l}209 \\
232\end{array}$ \\
\hline
\end{tabular}

1 Buls. 34,60 . 
Three-year-old Kansas range steers were fed in the first trial and two- and three-year-old grade Short-horns in the second. In each case the steers were divided into two lots of five each, one receiving ear corn and stover and the other corn meal and stover. The first trial lasted six months and the second five months.

By the table we are shown that the steers fed ear corn gained somewhat more than those fed corn meal; they required, howerer, eighty-four pounds or six per cent. more grain.

Commenting upon the first trial as above reported, Georgeson writes as follows: "This is not a very favorable showing for corn meal, and I confess the result is contrary to my expectations. A considerable percentage of the whole corn passes through the animal undigested, and it would seem that the digestive juices could act to better advantage on the fine corn meal than on the purtially-masticated grains of corn and extract more nourishment from it, but apparently this is not the case."

In the second trial there was a saving of 35 per cent. of the corn by grinding, which may be regarded as the extreme saving possible in such feeding. This result is the largest saving of grain by grinding yet reported by any of the Stations so far as the writer is able to learn. (155, 382, 532, 848)

537. Soaked corn.-- At the Kansas Station, ${ }^{1}$ Georgeson divided a bunch of ten thrifty steers into two lots of five each, giving the first corn which had been soaked until it had begun to soften, while the second received dry corn. Both lots were confined in open yards with sheds for shelter, and received the same roughage. All statements of the corn fed are based on the weight of dry corn. The trial began November 7, lasting five months, with the results shown in the table:

Results obtained when feeding soaked and dry shelled corn - Kansas ;

Station.

\begin{tabular}{|c|c|c|c|c|c|c|c|}
\hline Feed. & $\begin{array}{l}\text { Av. wt. } \\
\text { of steers. }\end{array}$ & $\begin{array}{c}\text { Total } \\
\text { corn } \\
\text { eaten. }\end{array}$ & $\begin{array}{l}\text { Total } \\
\text { fodder } \\
\text { eaten. }\end{array}$ & $\begin{array}{l}\text { Whole } \\
\text { sain. }\end{array}$ & $\begin{array}{c}\text { Av. gailn } \\
\text { per } \\
\text { bead. }\end{array}$ & $\begin{array}{c}\text { Grain } \\
\text { per loo } \\
\text { pounds } \\
\text { gain. }\end{array}$ & $\begin{array}{l}\text { Fodder } \\
\text { per los } \\
\text { pouado } \\
\text { gain. }\end{array}$ \\
\hline 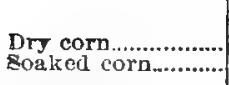 & $\begin{array}{l}\text { Lbs. } \\
1,033 \\
1,033\end{array}$ & $\begin{array}{c}\text { Lbs. } \\
16,244 \\
15,787\end{array}$ & $\begin{array}{l}\text { Lbs. } \\
8,127 \\
8,340\end{array}$ & $\begin{array}{l}\text { Lbs. } \\
1,468 \\
1,082\end{array}$ & $\begin{array}{r}\text { Lbs. } \\
294 \\
326\end{array}$ & $\begin{array}{r}\text { Lbs. } \\
1,105 \\
938\end{array}$ & $\begin{array}{r}\text { Lbs. } \\
654 \\
612\end{array}$ \\
\hline
\end{tabular}

1 Bul. 47. 
The table shows that the steers fed soaked corn did not consume quite as much grain as the other lot, yet made a better gain. In this trial there was a saving of fifteen per cent. by soaking shelled corn. (375)

538. Gain of shotes following steers.-Fortunately Georgeson placed eight thrifty shotes, averaging eighty-eight pounds per head, with each lot of steers, to pick up the corn voided in the droppings. At first they subsisted entirely on such corn, but later, when they had grown larger, they were supplied additional grain from a trough, with the following results:

Extra feed and gain of shotes following steers fed soaked and dry corn-Kansas Station.

\begin{tabular}{|c|c|c|c|}
\hline Shotes following steers fed - & $\begin{array}{l}\text { Extra } \\
\text { corn fed. }\end{array}$ & $\begin{array}{c}\text { Total gain } \\
\text { of lot. }\end{array}$ & $\begin{array}{c}\text { Corn fed } \\
\text { extra per } \\
\text { 100 lbs gain. }\end{array}$ \\
\hline & Lbs. & Lbs. & Lbs. \\
\hline $\begin{array}{l}\text { Dry corn } \ldots \ldots \ldots \ldots \ldots \ldots \ldots \ldots \ldots \ldots \ldots \ldots \ldots \ldots \ldots \ldots \\
\text { Soaked corn }\end{array}$ & $\begin{array}{l}1,272 \\
1,272\end{array}$ & $\begin{array}{l}747 \\
635\end{array}$ & $\begin{array}{l}170 \\
200\end{array}$ \\
\hline
\end{tabular}

The above shows that the shotes secured more than one-half their feed from the droppings, and that the droppings from steers getting dry corn gave the best returns.

By combining the data of feed and gain with both hogs and steers, we ascertain the grain required for the combined gain as follows:

Gain of steers and shotes when shotes followed fattening steers Kansas Station.

\begin{tabular}{l|c|c|c}
\hline \hline & $\begin{array}{c}\text { Total grain } \\
\text { fed to steers } \\
\text { and shotes. }\end{array}$ & $\begin{array}{c}\text { Total gain } \\
\text { of steers } \\
\text { and shotes. }\end{array}$ & $\begin{array}{c}\text { Corn for 100 } \\
\text { pounds } \\
\text { gain. }\end{array}$ \\
\hline Lbs. & Lbs. & Lbs. \\
$\begin{array}{r}\text { Steers fed dry corn, with shotes fol- } \\
\text { lowing...................................... }\end{array}$ & 17,516 & 2,215 & 791 \\
Eteers fed soaked corn, with shotes \\
following...................................
\end{tabular}

Combining the feed for steers and shotes and likewise the gains of both, we find that 791 pounds of corn were required for 
100 pounds of gain of steers and shotes where the steers were fed dry corn, and 752 pounds of grain for 100 pounds of gain with steers and shotes where the steers were fed soaked corn. This shows a net saving, by soaking corn for steers, of about five per cent. $(583,634,880-81)$

539. Corn and cob meal.-For information on this subject we turn to Shelton's investigations conducted at the Kansas Agricultural College ${ }^{1}$ during 1884-85. Ten steers were used each year, the trial in 1884 lasting 140 days, and that in 1885, 150 days. In each trial the steers were divided into two lots of five each; corn and cob meal was fed to one lot and corn meal to the other, the roughage in both cases consisting of oat straw, orchardgrass hay and clover hay.

Results obtained in feeding corn meal and corn and cob meal to steersKansas Agricultural College.

\begin{tabular}{|c|c|c|c|c|c|c|}
\hline Feed. & $\begin{array}{l}\text { Av. wt. } \\
\text { of steers } \\
\text { at be- } \\
\text { ginning }\end{array}$ & $\begin{array}{l}\text { Total } \\
\text { feed. }\end{array}$ & $\begin{array}{l}\text { Total } \\
\text { gain. }\end{array}$ & $\begin{array}{l}\text { Av. } \\
\text { gain per } \\
\text { steer. }\end{array}$ & $\begin{array}{c}\text { Meal } \\
\text { per } 100 \\
\text { Ibs. in- } \\
\text { crease. }\end{array}$ & $\begin{array}{c}\text { Av. } \\
\text { daily } \\
\text { gain per } \\
\text { steer. }\end{array}$ \\
\hline & Lbs. & Lbs. & Lbs. & Libs. & Lbs. & Lbs. \\
\hline Experiment, 1884. & & & & & & \\
\hline Corn and cob meal. & 815 & 11,565 & 1,580 & 316 & 732 & 2.25 \\
\hline Corn meal............. & 847 & 11,612 & 1,460 & 292 & 795 & 2.08 \\
\hline $\begin{array}{l}\text { Experiment, } 1885 \text {. } \\
\text { Corn and cob meal }\end{array}$ & 1128 & 19018 & 1025 & 205 & 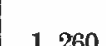 & 44 \\
\hline Corn meal............ & 1,150 & 12,654 & 1,085 & 217 & 1,166 & $\begin{array}{l}1.47 \\
1.36\end{array}$ \\
\hline
\end{tabular}

It is shown that the corn and cob meal gave the best daily gain in both cases. In one instance less corn and cob meal was required for a given gain, while in the other more was required. The average of the two trials shows that a pound of corn and cob meal is equal to a pound of pure corn meal in steer feeding.

In explanation of the marked difference in the amount of feed required for a given gain in these two trials, we have the following statement concerning the cattle: "The steers of 1883-84 were a thin, half-grown lot of 'natives,' while those in use in 1884-85 were high-grade Short-horns, mature and full-fleshed at the start." The second lot was also fed for a longer period. (158, 382, 633)

\footnotetext{
1 Repts. Prof. Agr., 1884-85.
} 
540. Corn, cob and husk. - At the Texas Station, ${ }^{1}$ Curtis fed corn, cob and husk ground coarsely to three steers, and coarselyground shelled corn to three others while on pasture, for a period of seventy days, with the following results:

Feeding ground corn, cob and husk in comparison with ground corn to steers - Texas Station.

\begin{tabular}{c|c|c|c|c}
\hline Feed. & $\begin{array}{c}\text { Total } \\
\text { feed. }\end{array}$ & $\begin{array}{c}\text { Total } \\
\text { gain. }\end{array}$ & $\begin{array}{c}\text { Av. gain } \\
\text { per day. }\end{array}$ & $\begin{array}{c}\text { Meal for } \\
100 \text { lbs. } \\
\text { gain. }\end{array}$ \\
\hline & Lbs. & Lbs. & Lbs. & Lbs. \\
Lot I. Corn, cob and husk meal.. & 2,395 & 481 & 2.29 & 498 \\
Lot II. Coarse corn meal.............. & 1,864 & 465 & 2.21 & $\mathbf{4 0 0}$ \\
\hline
\end{tabular}

The table shows that where 400 pounds of clear corn meal gave 100 pounds of increase, there were required 498 pounds of husk, cob and corn together. The weight of the cob and husk was 72 pounds for each 56 pounds of shelled corn. Omitting the cob and husk, it is found that 100 pounds of gain was made from 388 pounds of meal plus the cob and husk. This shows a saving of three per cent. by feeding the cob and husk with the grain.

54I. Time required for corn to pass through the steer.-At the Kansas Station, ${ }^{2}$ Georgeson determined the time required for corn to pass through the alimentary canal of the fattening steer in the following manner: To five steers getting white corn, 50 pounds of red corn grains were given in three feeds on January 15th, viz.: 12 M., 3 P. M. and 6 P. M. At 9 A. M. on the 16th the red kernels fed the day before began to appear in the manure. The maximum number of kernels of red corn was reached on the afternoon of the 17th, when they began to decrease, until the 19th, when only a few kernels were found on washing the droppings of each lot.

542. Whole and broken corn voided by steers. - When feeding dry and soaked corn to steers with shotes following as described in Articles 537-38, Georgeson ${ }^{3}$ determined the quantity of whole and broken corn in the voidings.

During 28 days five steers were fed 3,045 pounds (weight be-

${ }^{1}$ Bul. $2 . \quad$ Bul. 47. Loc. cit.


fore soaking) of soaked corn, and duritu that period 339 pounds of grains of corn (weight after drying) were washed from the voidings. This is 11 per cent. of the total corn consumed by the steers during the period. Another lot of five steers was fed 3,060 pounds of dry shelled corn, the voidings from which gave 486 pounds, or nearly 16 per cent. of whole and broken corn. The hogs following steers getting dry corn made greater gains than those following steers getting soaked corn. The explanation is in the, above percentages.

The corn grains which had passed through the steers wero found to contain between 55 and 60 per cent. water, those which had been soaked previous to feeding having somewhat more than the other. The corn which had been fed dry was found to absorb still more water when soaked, showing that it had not beer fully saturated, although it had passed the whole length of the alimentary canal.

543. Wheat meal.-At the Ohio Station, 1 Thorne and Hickman, testing wheat meal in opposition to corn meal during two feeding trials, secured the results shown in the table:

Feeding corn meal and wheat meal to steers - Ohio Station.

\begin{tabular}{|c|c|c|c|c|}
\hline Feed. & $\begin{array}{l}\text { No. of cat- } \\
\text { tle fed. }\end{array}$ & $\begin{array}{l}\text { Daily gain } \\
\text { per steer. }\end{array}$ & $\begin{array}{l}\text { Dry sul- } \\
\text { stance con- } \\
\text { sumed per } \\
\text { pound of } \\
\text { gain. }\end{array}$ & $\begin{array}{l}\text { Cost of feed } \\
\text { per pound } \\
\text { of gain. }\end{array}$ \\
\hline & & Lbs. & Lbs. & Cents. \\
\hline Test, 1894. & & & & \\
\hline Corn meal ................... & 8 & 2.07 & 10.31 & 7.79 \\
\hline $\begin{array}{l}\text { Wheat meal................. } \\
\text { Test, } 1895 \text {. }\end{array}$ & 7 & 1.98 & 10.02 & 7.75 \\
\hline $\begin{array}{l}\text { Test, } 1895 . \\
\text { Corn meal................... }\end{array}$ & 4 & 2.02 & 9.90 & 701 \\
\hline Wheat meal......................... & $\begin{array}{l}4 \\
4\end{array}$ & 1.70 & 11.78 & 8.95 \\
\hline
\end{tabular}

It is shown in both trials that the steers fed corn meal made the highest average daily gain, and made their gain also upon less dry matter than the others. At prevailing prices for corn and wheat, it is evident that corn is the cheaper feed. No doubt some wheat meal may bo used with satisfactory results in steer

\footnotetext{
' Bul. 60.
} 
feeding, but it should not constitute the exclusive grain feed unless prices rule lower than for corn. (166-8)

544. Bran.- An experiment is reported from Minneapolis ${ }^{1}$ in which the lightest bran made at the Pillsbury A mill was fed with hay to fifteen common steers for a period of four months. Each animal was fed separately, all feed being weighed. The steers were allowed exercise in a small yard. The steers weighed from 800 to 1,100 pounds at the time the experiment began, in May, 1886. The following summarizes the results:

Pounds.

Total bran fed................................................. 24,064

Total hay fed..................................................... 28,925

Total gain in weight, 15 steers.............................. 3,545

Average gain in weight (4 months).................... $\quad 236$

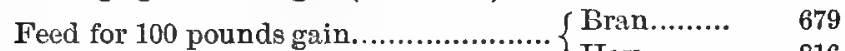

$\left\{\begin{array}{l}\text { Hay.......... } 816 \\ \text { Han }\end{array}\right.$

These satisfactory gains show that bran may be successfully used for fattening steers. (175)

545. Cil meal. - At the Kansas Station, ${ }^{2}$ Georgeson fed oil cake with hay to three steers averaging 1,050 pounds for a period of 129 days, with the following results:

Oil cake consumed per head Pounds.

1,639

Hay consumed per head................................. 1,822

Average gain per head .................................... 224

Fed for one hundred pounds gain........ \{ Oil meal... 732 Hay ......... 814

This experimenter concludes: "The exclusive diet of oil cake did not yield as good results as either the 'balanced ration' or corn. The animal organism appears to be unable to make use of so highly concentrated nitrogenous food to good advantage." (206)

At the Iowa Station, Wilson and Curtiss ${ }^{3}$ fed oil meal to steers un clover pasture, securing a gain of 100 pounds for each 400 pounds of oil meal fed. Another group of steers on a similar pasture required 532 pounds of corn meal for 100 pounds of gain.

546. Gluten meal.- At the Ohio Station, 4 Thorne and Hickman used gluten meal during two feeding trials, in one of which oil meal was fed in opposition. In calculating the results, old-

1 Fugitive pamphlet, published in 1886.

2 Bul. 39. Bul. 60. 
process oil meal was figured at $\$ 26$ per ton, and gluten meal at 818 per ton, the current market prices.

Feeding oil meal and gluten meal - Ohio Station.

\begin{tabular}{|c|c|c|c|c|}
\hline Feed. & $\begin{array}{c}\text { Number } \\
\text { of cattle } \\
\text { compared. }\end{array}$ & $\begin{array}{l}\text { Daily } \\
\text { gain } \\
\text { per } \\
\text { steer. }\end{array}$ & $\begin{array}{c}\text { Dry sub- } \\
\text { stance } \\
\text { consumed } \\
\text { per pound } \\
\text { of gain. }\end{array}$ & $\begin{array}{l}\text { Cost of } \\
\text { feed per } \\
\text { pound } \\
\text { gain. }\end{array}$ \\
\hline & \multirow{7}{*}{$\begin{array}{r}12 \\
11 \\
4 \\
8 \\
4 \\
4\end{array}$} & Lbs. & \multirow{7}{*}{$\begin{array}{r}\text { Lbs. } \\
10.78 \\
10.05 \\
10.31 \\
10.10 \\
9.90 \\
11.07\end{array}$} & \multirow{7}{*}{$\begin{array}{c}\text { Cents. } \\
8.52 \\
7.31 \\
7.42 \\
7.49 \\
7.01 \\
7.40\end{array}$} \\
\hline Oil meal ......................................... & & 1.96 & & \\
\hline Gluten meal..................................... & & 2.11 & & \\
\hline Mixed meals with gluten meal ........ & & 2.15 & & \\
\hline Mixed meals without gluten meal... & & 1.98 & & \\
\hline Mixed meals with gluten meal ........ & & 2.02 & & \\
\hline Mixed meals without gluten meal... & & 2.05 & & \\
\hline
\end{tabular}

It is seen that gluten meal was a cheaper feed than oil meal at the prices stated. Where gluten meal was fed with other grains, it always cheapened the cost of production. These experimenters conclude: The results warrant the statement that " for fattening cattle these feeding stuffs (gluten meal and oil meal) are approximately of equal value, pound for pound, and that the one which can be bought for the least money is the one to use." As yet the feeding value of this class of corn by-products has been passed unnoticed by those who fatten cattle; if experience shall confiri their worth as substitutes for oil meal in the feed lot they will acquire a new interest with many. (16!-164)

547. Kaffir corn. - At the Kansas Station, ${ }^{1}$ Georgeson divided a bunch of twelve grade Short-horn and three grade Hereford three-year-old steers into three lots of five each. For concentrates the first lot was fed corn meal, the second red Kaffir-corn meal, and the third white Kaffir-corn meal. In each case the grain was ground so fine that about three-fourths of the meal passed through a sieve having a one-twentieth inch mesh. The roughage during the first part of the trial consisted of Kaffir-corn stover; later corn stover and alfalfa hay were fed. One hundred pounds of the stover were fed daily to each lot of steers, and the rejected portion weighed and deducted from the total, so that the weights in the table are the amounts of forage actually consumed. The

1 Bul. 67. 
results of the trial, which lasted 175 days, are presented in the following table:

Feeding Kaffir-corn meal in comparison with corn meal to steers Kansas Station.

\begin{tabular}{|c|c|c|c|c|c|c|}
\hline \multirow{2}{*}{ Feed. } & \multirow{2}{*}{$\begin{array}{c}\text { Av. wt. } \\
\text { at be- } \\
\text { gin- } \\
\text { ning. }\end{array}$} & \multicolumn{2}{|c|}{ Feed eaten. } & \multirow{2}{*}{$\begin{array}{c}\text { Av. } \\
\text { gain } \\
\text { per } \\
\text { steer. }\end{array}$} & \multicolumn{2}{|c|}{$\begin{array}{l}\text { Feed for } 100 \\
\text { pounds gain. }\end{array}$} \\
\hline & & Grain. & $\begin{array}{l}\text { Rough- } \\
\text { age. }\end{array}$ & & Grain. & $\begin{array}{l}\text { Rough- } \\
\text { age. }\end{array}$ \\
\hline & Lbs. & Lbs. & Lbs. & Lbs. & Lbs. & Lbs. \\
\hline $\begin{array}{l}\text { Lot I, corn meal ......... } \\
\text { Lot II, red Kaffir-corn }\end{array}$ & 1,036 & 16,271 & 9,297 & 326 & 997 & 569 \\
\hline 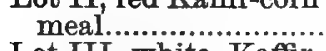 & 1,021 & 16,271 & 10,300 & 299 & 1,086 & 688 \\
\hline $\begin{array}{l}\text { Lot III, white Kaffir- } \\
\text { corn meal.................. }\end{array}$ & 1,025 & 16,271 & 10,828 & 313 & 1,041 & 692 \\
\hline
\end{tabular}

Commenting on the above, Georgeson writes: "The fact that these lots show so little difference in their gains and the value received for the grain fed is a gratifying proof of the value of Kaffir corn. The feeding value of corn has long been known, but this is the first experiment in which Kaffir corn has been tested so thoroughly and for so long a period under normal conditions. The steers were fair representatives of the grade cattle raised in the Central West. They were neither high-bred cattle nor common scrubs. The conditions of the experiment were those that prevail with the average farmer and feeder. They were fed in open lots, where they could seek the shelter of a small shed when desired, but they were not pampered or petted in any way. The results obtained in this case can be obtained by any feeder in the state without providing better quarters or giving more attention to their feed and care than can be and is furnished by the average farmer anywhere." (195)

548. Value of droppings from steers fed Kaffir corn.- In the trial above reported, seven shotes were placed with each lot of steers to gain what they could from the droppings. Each lot was fed substantially the same amount of corn from a trough, the allowance being small in order to force the shotes to thoroughly work over the droppings. Samples of the steers' droppings were washed and the undigested meal separated, dried and weighed 
to ascertain the portion which passed through them. The extra feed given the shotes, the available meal in the droppings, the gains, etc., are shown in the following table:

Feed and gain of shotes following steers fed corn meal and Kaffir. corn-Kansas Station.

\begin{tabular}{|c|c|c|c|}
\hline & $\begin{array}{l}\text { Lot I, } \\
\text { following } \\
\text { steers fed } \\
\text { corn } \\
\text { meal. }\end{array}$ & $\begin{array}{c}\text { Lot II, } \\
\text { following } \\
\text { steers fed } \\
\text { red Kaffir } \\
\text { corn. }\end{array}$ & $\begin{array}{l}\text { Lot III, } \\
\text { following } \\
\text { steers fed } \\
\text { white } \\
\text { Kaffir } \\
\text { corn. }\end{array}$ \\
\hline & Lbs. & Lbs. & Lbs. \\
\hline Grain eaten from trough..................... & 2,520 & 2,520 & 2,480 \\
\hline Calculated feed available in manure....... & 705 & 1,475 & 1,842 \\
\hline 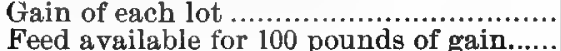 & $\begin{array}{l}635 \\
507\end{array}$ & 698 & 725 \\
\hline ed avalabie ior lov pounds or galli...... & & 572 & 596 \\
\hline
\end{tabular}

It will be seen that the shotes following the steers fed corn meal made 100 pounds of gain from 507 pounds of calculated grain in the droppings and the extra allowance supplied from the trough. The shotes following the steers fed Kaffir corn made larger gains from the same allowance of extra grain fed in the trough than those following the steers fed corn meal. This shows that they secured more nutriment from the droppings than did the shotes following the corn-fed steers.

Georgeson summarizes this portion of the experiment in the following words: "The experiment proves that hogs can utilize Kaffir-corn feed in the manure and bring out the value in pork in about the same ratio of values that exists between corn and Kaffir corn."

Such results in conjunction with those reported in the preceding article show the worth of Kaffir corn in the feed lot, and will enhance its value in the minds of stockmen of the Southwest in districts where the rainfall is scant for maximum corn crops though sufficient for this sorghum.

549. Roots. - The British stockman, the best feeder the world knows, has made large use of roots for fattening purposes. The American farmer, and especially the stockman at the West, has made little or no use of them. For information on this subject we 
naturally turn to Canada, where we find the following experiment by Brown. ' Six animals were divided into lots of two each and given roots, hay, bran and pea meal, with the following results:

Result of 84 days trial with roots for cattle feeding-Ontario Agricultural College.

\begin{tabular}{|c|c|c|c|c|c|c|}
\hline \multirow{2}{*}{ Roots fed. } & \multirow{2}{*}{$\begin{array}{l}\text { Wt. of } \\
\text { animals } \\
\text { at be- } \\
\text { gin- } \\
\text { ning. }\end{array}$} & \multirow{2}{*}{$\begin{array}{l}\text { Daily } \\
\text { in- } \\
\text { crease. }\end{array}$} & \multicolumn{4}{|c|}{ Feed per steer, daily. } \\
\hline & & & Hay. & Bran. & Pea meal. & Roots. \\
\hline & Lbs. & Lbs. & Lbs. & Lbs. & Lbs. & Lbs. \\
\hline Sugar beets................... & 1,059 & 2.31 & 10.5 & 3 & 6.5 & 52 \\
\hline Mangels.............. & 1,063 & 2.38 & 11.5 & 3 & 6.5 & 55 \\
\hline Turnips................ & 1,061 & 2.30 & 12 & 3 & 6.5 & 52 \\
\hline Average... & 1,061 & 2.33 & 11.3 & 3 & 6.5 & 53 \\
\hline 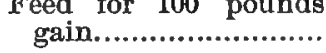 & & & 485 & 129 & 279 & 2,275 \\
\hline
\end{tabular}

The table shows that somewhat more than a ton of roots, together with 400 pounds of pea meal and bran and 500 pounds of hay, were required for 100 pounds of increase. (318)

550. Silage compared with roots. - The use of silage for cattle feeding originated with dairymen, and down to the present time steer feeders have always regarded silage as possibly suitable for dairy cows, but too sloppy and sour for beef making. A few have ruade use of silage with favorable results.

At the Ontario Agricultural College, ${ }^{2}$ Shaw fed three groups of grade Short-horn steers of two each on silage and roots. The hay was timothy and clover, the roots turnips and mangels, and the ineal equal weights of ground peas, barley and oats. The feed consumed per animal daily was:
Group I
$\{57.47$ pounds silage.
\{11.72 pounds meal.
Group II
30.6 pounds silage.
Group Ir. 11.13 pounds meal.
Group III 9.3 pounds hay.
43.07 pounds roots.
11.12 pounds meal.
11.22 pounds hay.

1 Rept. Ont. Agr. Col., 1883.

2 Rept. 1891. 
The following table shows the result of the trial, beginning December 11 and lasting 146 days:

Feeding steers with roots and silage-Ontario Agricultural College.

\begin{tabular}{|c|c|c|c|}
\hline & $\begin{array}{c}\text { Lot I. } \\
\text { Silage } \\
\text { and meal. }\end{array}$ & $\begin{array}{c}\text { Iot II. } \\
\text { Silage, } \\
\text { hay and } \\
\text { meal. }\end{array}$ & $\begin{array}{l}\text { Lot III. } \\
\text { Roots, } \\
\text { hay and } \\
\text { meal. }\end{array}$ \\
\hline & Lbs. & Lbs. & Lbs. \\
\hline 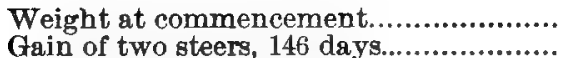 & 2,789 & 2,735 & 2,672 \\
\hline 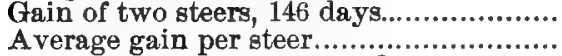 & $\begin{array}{l}555 \\
277\end{array}$ & $\begin{array}{l}448 \\
204\end{array}$ & 537 \\
\hline & 1.90 & 1.53 & 1.84 \\
\hline
\end{tabular}

From the table we learn that the steers fed the largest amount of silage daily made the greatest total gain with the highest daily rate of increase. Placing a reasonable value upon silage and roots, the gains from silage were made at a lower cost than those from roots.

At the Wisconsin Station' ${ }^{1}$ the writer fed silage to steers with excellent results. In one trial, four two- and three-year-old steers, fed on corn silage only, made a gain of 222 pounds in 36 days, or 1.5 pounds per day each. It required 3,558 pounds of silage to make 100 pounds gain. (393-5)

551. Fish scrap for fattening steers. - Fink fed three-year-old steers $^{2}$ of the Holstein breed 3.3 pounds of fish scrap per head per day, the remainder of the ration consisting of hay, potatoes, straw, rye, barley and oats. The average daily gain per head during 90 days was 3.3 pounds. The quality of meat was satisfactory. $(340,661)$

552. Molasses. - Georgeson ${ }^{3}$ fed molasses with corn meal and corn fodder to three steers for a period of nineteen weeks with the following results:

Total feed required for 100 pounds gain.

Molasses

Pounds

Corn meal. 598

Stover.

1 Rept. 1888.

2 Milch Zeit. 25 (1896), p. 51.

Bul. 39, Kan. Expt. Sta. 
Commenting on this Georgeson writes: "A mixture of molasses and corn meal proved to be a very inferior fattening material." (347)

553. The " balanced" ration. - It is reasonable to suppose, and experiment proves, that a combination of two or more varieties of grain gives more economical returns for a given weight of feed than a single kind. This is illustrated in experiments by Georgeson at the Kansas Station." In three trials, one lot of steers was fed a "balanced ration," containing a "judicious mixture of corn meal, oil meal, bran and shorts, the proportion of the albuminoids and carbohydrates in the feed to approximate the requirements of the feeding standard, and in addition to this mixture to have what corn fodder and hay they would eat." Against steers thus fed were others whose allowance consisted of ear corn, with corn stover and prairie hay for roughage. The data given are averages for one steer:

Result of three years" experiments feeding a "balanced ration" against ear corn - Kansas Station.

A. Experiment of 1892, lasting 6 months with 5 steers on each side.

\begin{tabular}{|c|c|c|c|c|c|c|}
\hline Rations. & $\begin{array}{l}\text { Av. wt. } \\
\text { per steer. }\end{array}$ & $\begin{array}{l}\text { Av. amt. } \\
\text { grain per } \\
\text { steor. }\end{array}$ & $\begin{array}{c}\text { Fodder } \\
\text { per steer. }\end{array}$ & $\begin{array}{l}\text { Av.gain } \\
\text { during } \\
\text { expt. }\end{array}$ & $\begin{array}{c}\text { Grain } \\
\text { per } 100 \\
\text { lbs. gain. }\end{array}$ & $\begin{array}{c}\text { Fodder } \\
\text { per } 100 \\
\text { lbs. galn. }\end{array}$ \\
\hline & Lbs. & Lbs. & Lbs. & Lbs. & Lbs. & Lbs. \\
\hline Balanced ration........ & 1,198 & 4,357 & 1,422 & 436 & 1,001 & 326 \\
\hline Ear corn .................... & 1,213 & 4,027 & 1,341 & 284 & 1,418 & 472 \\
\hline
\end{tabular}

B. Experiment of 1893 , lasting 4 months, 3 to 5 steers on each side.

\begin{tabular}{l|l|r|r|r|r|l}
\hline Bal. ration, 3 steers... & 1,083 & 2,965 & 869 & 309 & 961 & 280 \\
Ear coru, 5 steers..... & $\mathbf{1}, 073$ & $\mathbf{2}, 723$ & $\mathbf{1 , 2 1 4}$ & $\mathbf{2 7 4}$ & $! 94$ & $\mathbf{4 4 3}$ \\
\hline
\end{tabular}

C. Experiment of 1896, lasting 5 months with 5 stecrs on each side.

\begin{tabular}{l|l|l|l|l|r|r}
\hline Balanced ration........ & 1,123 & 3,055 & 973 & 406 & 752 & 240 \\
Ear corn................... & 1,158 & 3,223 & 535 & 230 & 1,402 & 233 \\
\hline
\end{tabular}

The average of three trials shows:

Corn consumed for 100 pounds gain.............. 1,271 pounds. Mixed grains consumed for 100 pounds gain... 905 pounds

These figures shcw that 28 per cent. less grain was required

Buls. 34, 39 and 60 . 
for 100 pounds of gain when feeding the so-called "balanced ration" than where ear corn alone was given. At most Western points the "balanced ration" will cost 28 per cent. more than a corn ration, but in many localities it will prove much cheaper than corn alone. ${ }^{1}$

554. Pasturing steers. - Though a large portion of the gain made by cattle originates from pasture, we have little data upon the subject. This lack of information is due no doubt to the great difference in the productive power of pastures, and from the lack of uniformity of herbage growth from year to year. Morrow ${ }^{2}$ conducted interesting investigations on the gain of steers maintained wholly on tame pastures from May 1 to November 1. The gains with different lots are as follows:

4 head of yeariing steers, maintained on pasture alone, showed an average gain of 332 pounds each.

10 head of yearling steers, maintained on pasture alone, showed an average gain of 285 pounds each.

2 head of yearling steers, maintained on pasture alone, showed an average gain of 440 pounds each.

These gains are probably fully equal to the average obtained with cattle on Western tame pastures of good quality. They show that from such pastures we may look for a gain of from 300 to 400 pounds per head for the season with yearling steers. (258)

555. Feeding grain to steers on pasture. - At the Iowa Station, ${ }^{8}$ Wilson and Curtiss, fattening steers on pasture with and without grain, obtained the following results:

10 steers on pasture only, gained 2.01 pounds each daily.

10 steers on pasture with grain, gained 2.13 pounds each daily.

The steers fed grain received ten pounds of corn and cob meal each daily.

At the Missouri Agricultural College, 4 Sanborn conducted two trials in feeding steers on grain while on pasture, both at a loss.

1 For a discussion of these experiments by Georgeson, see Qr. Rept. Kan. Bd. Agr., Dec. 1897.

2 Bul. 1, Col. of Agr.,. Univ. of Ill.

Bul. 28.

- Bul. 8. 
Morrow ${ }^{1}$ secured the following gains with steers full fed with grain for the season, while on pasture:

\section{Yearlings.}

2 head of steers showed an average gain of ...... 507 pounds each.

4 head of steers showed an average gain of ...... 284 pounds each.

Two-year-olds.

7 head of steers showed an average gain of ...... 466 pounds each.

8 head of steers showed an averige gain of ....... 380 pounds each.

4 head of steers showed an average gain of ...... 406 pounds each.

Summarizing his experience, Morrow concludes: "The results from two years' trial indicate that a grain ration to young steers on good pasture is not usually profitable. The value of the increase in weight by the grain-fed steers over those having grass only will not repay the cost of food and labor. The increased value of the animals from earlier maturity and better quality may make grain feeding profitable." (666-7)

556. Water drank during fattening. - The amount of water drank by fattening steers, which varies greatly, may be placed at from 50 to 125 pound per day. Georgeson ${ }^{2}$ kept a record of the water drank by fattening steers, with results as follows:

Water drank by fattening steers in winter - Kansas Station.

\begin{tabular}{|c|c|c|c|}
\hline Feed. & $\begin{array}{l}\text { Water } \\
\text { drank } \\
\text { daily per } \\
\text { steer. }\end{array}$ & $\begin{array}{c}\text { Water } \\
\text { drank } \\
\text { per pound } \\
\text { gain. }\end{array}$ & $\begin{array}{c}\text { Water } \\
\text { drank } \\
\text { per pound } \\
\text { of feed. }\end{array}$ \\
\hline $\begin{array}{c}\text { First trial: } \\
\text { Lot } \quad \text { I, Corn meal, bran, shorts, oil meal }\end{array}$ & Lbs. & Lbs. & Lbb. \\
\hline 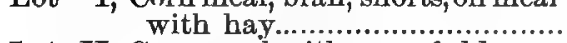 & 75 & 31 & 2.4 \\
\hline Lot II, Corn meal with corn fodder...... & 47 & 33 & 1.8 \\
\hline $\begin{array}{l}\text { Lot III, Ear corn with corn fodder.......... } \\
\text { Second trial: }\end{array}$ & 49 & 31 & 1.6 \\
\hline Lot I, Corn meal, bran, shorts, oil meal & 79 & 33 & 2.5 \\
\hline 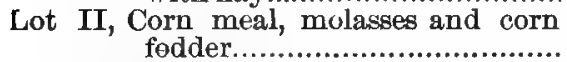 & 73 & 56 & 2.4 \\
\hline Lot III, Oil cake, hay ......................... & 91 & 57 & 3.4 \\
\hline Lot IV, Ear corn, corn fodder .............. & 56 & 27 & 1.8 \\
\hline
\end{tabular}

In the above we observe that where the most protein was fed the largest amount of water was drank; the smallest amount with the ear-corn and corn-fodder ration.

\footnotetext{
1 Bul. 1, Col. of Agr., Univ. of IIl. $\quad 2$ Buls. 34, 39, Kan. Sta.
} 
At the North Carolina Station, 1 Emery, feeding steers on cotton-seed meal and hulls, found the following in regard to water and dry matter consumed by fattening steers:

Dry matter eaten and water drank daily by fattening steers per 1,000 pounds live weight-North Carolina Station.

\begin{tabular}{|c|c|c|}
\hline & $\begin{array}{c}\text { Tied } \\
\text { steers. }\end{array}$ & $\begin{array}{l}\text { Loose } \\
\text { steers. }\end{array}$ \\
\hline & Lbs. & Lbs. \\
\hline 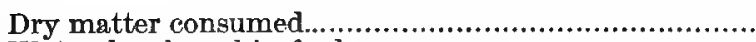 & 21.3 & 21.1 \\
\hline 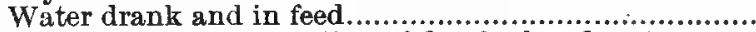 & 58.3 & 53.9 \\
\hline Total average consumption of dry food and water......... & 79.6 & 75.0 \\
\hline Pounds water to one pound dry food.............................. & 2.7 & 2.6 \\
\hline
\end{tabular}

557. Variation in individual weight while fattening.-The stockman who will weigh a fattening steer daily for a few weeks will be surprised at the variation in the weights recorded. Even thrifty steers that are steadily fattening, so far as the feeder can judge, will show surprising variations in weight from day to day, and even from week to week. Much data could be given on this point, but a few figures from one of Georgeson's experiments at the Kansas Station ${ }^{2}$ will suffice:

Weekly weight of steers during a feeding trial - Kansas Station.

\begin{tabular}{|c|c|c|c|c|c|c|}
\hline Date. & $\begin{array}{l}\text { Weight } \\
\text { of stcer } \\
\text { No. 1. }\end{array}$ & $\begin{array}{l}\text { Gain } \\
\text { or } \\
\text { loss. }\end{array}$ & $\begin{array}{l}\text { Weight } \\
\text { of steer } \\
\text { No. } 2 \text {. }\end{array}$ & $\begin{array}{c}\text { Gain } \\
\text { or } \\
\text { loss. }\end{array}$ & $\begin{array}{l}\text { Weight } \\
\text { of steer } \\
\text { No. } 3 .\end{array}$ & $\begin{array}{l}\text { Gain } \\
\text { or } \\
\text { loss. }\end{array}$ \\
\hline Nov 30 & Lbs. & Lbs. & Lbs. & Lbs. & Lbs. & Lbs. \\
\hline $\begin{array}{l}\text { Dec. } 7 \ldots \ldots \ldots \ldots \ldots \\
\text { Dec. } 14 \ldots \ldots \ldots \ldots \ldots \ldots \ldots \\
\text { Dec. } 21 \ldots \ldots \ldots \ldots \ldots \ldots \ldots \\
\text { Dec. } 28 \ldots \ldots \ldots \ldots \ldots \ldots \ldots\end{array}$ & $\begin{array}{l}1,269 \\
1,280 \\
1,278 \\
1,325\end{array}$ & $\begin{array}{r}37 \\
11 \\
-2 \\
47\end{array}$ & $\begin{array}{l}1,205 \\
1,213 \\
1,226 \\
1,250\end{array}$ & $\begin{array}{r}15 \\
8 \\
13 \\
24\end{array}$ & $\begin{array}{l}1,240 \\
1,236 \\
1,244 \\
1,270\end{array}$ & $\begin{array}{r}38 \\
-4 \\
8 \\
26\end{array}$ \\
\hline 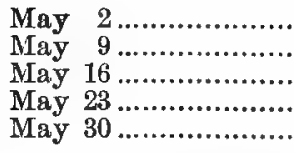 & $\begin{array}{l}1,545 \\
1,565 \\
1,597 \\
1,598 \\
1,610\end{array}$ & $\begin{array}{l}\dddot{20} \\
32 \\
1 \\
12\end{array}$ & $\begin{array}{l}1,583 \\
1,603 \\
1,620 \\
1,643 \\
1,606\end{array}$ & $\begin{array}{r}20 \\
17 \\
23 \\
-37\end{array}$ & $\begin{array}{l}1,567 \\
1,593 \\
1,619 \\
1,626 \\
1,593\end{array}$ & $\begin{array}{r}26 \\
26 \\
7 \\
-33\end{array}$ \\
\hline
\end{tabular}

These variations, which are not extraordinary, show how diffcult it is to determine the true weight of a steer at any given

\footnotetext{
1 Bul. 93. $\quad{ }^{2}$ Bul. 34.
} 
period. Our Experiment Stations are now generally adopting the practice of weighing the steer for three successive days and taking the average of these three weights as the true weight of the steer on the second day. It has been supposed that this variation is due to a difference in the amount of water drank from day to day, but this explanation does not always seem sufficient. It is probably due in many cases to the irregular movement of the contents of the digestive tract, which movement is influenced by changes in the character and quality of the food consumed, the exercise or confinement enforced, and the effect of the weather.

\section{Beef Making at the South.}

558. What Southern Stations have found.-For generations the effort of the South has been toward cotton production, which demands scrupulously clean culture. Until recently grass has been a despised plant, but it is now overrunning many of the old plantations, and while restoring the soil to something like its former fertility and clothing the gashed fields with a carpet of green, it is giving good returns in nutritious food to the cattle grazing upon it. Many a worn-out cotton plantation can be made to yield in Bermuda grass, Johnson grass, Japan clover, corn, sorghum and other plants, an amount of feed that would surprise Northern stockmen.

559. Cotton seed for beef production. - Equally important with the growth of grass is the enormous production of cotton seed, which furnishes a most valuable feed for cattle. Cotton seed, either raw, boiled or roasted, furnishes a nutritious food for cattle, while meal from the seed is the richest stock food produced in this country. The hulls of the cotton seed have been found to possess considerable feeding value as a substitute for hay. Because of their abundance and availability they constitute a factor of importance in steer feeding at the South.

Several of the Southern Experiment Stations have been doing useful work in showing the value and importance of the cotton seed and its by-products for steer feeding. While it is impossible to report all the results in this line, the following examplee 
are given as representing the territory interested and furnishing data concerning the important points of the subject:

Results obtained with steers fed cotton seed in various forms at Southern Experiment Stations.

Results by McConnell, Texas Station.1

\begin{tabular}{|c|c|c|c|c|c|c|}
\hline \multirow{2}{*}{ 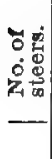 } & \multirow{2}{*}{$\begin{array}{c}\begin{array}{c}\text { A v.wt. } \\
\text { at be- } \\
\text { gin- } \\
\text { ning. }\end{array} \\
\text { Lbs. }\end{array}$} & \multirow{2}{*}{$\begin{array}{c}\begin{array}{c}\text { Gain } \\
\text { per } \\
\text { head. }\end{array} \\
\text { Lbs. }\end{array}$} & \multirow{2}{*}{$\begin{array}{c}\text { Ay, } \\
\text { dally } \\
\text { gain } \\
\text { per } \\
\text { head. } \\
\text { Lbs. }\end{array}$} & \multicolumn{3}{|c|}{ Feed for 100 lbs. of gain. } \\
\hline & & & & Lbs. & Lbs. & Lbs. \\
\hline $\begin{array}{l}4 \\
4 \\
4 \\
4 \\
4\end{array}$ & $\begin{array}{l}638 \\
625 \\
630 \\
576 \\
615\end{array}$ & $\begin{array}{l}186 \\
199 \\
207 \\
192 \\
203\end{array}$ & $\begin{array}{l}1.86 \\
1.99 \\
2.07 \\
1.92 \\
2.08\end{array}$ & 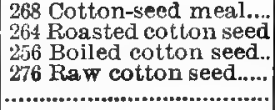 & 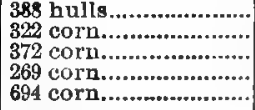 & $\begin{array}{l}1074 \text { gllage. } \\
216 \text { hay. } \\
201 \text { hay. } \\
276 \text { hay. } \\
371 \text { hay. }\end{array}$ \\
\hline $\begin{array}{l}4 \\
4 \\
4 \\
4 \\
4\end{array}$ & $\begin{array}{l}513 \\
513 \\
509 \\
511 \\
522\end{array}$ & $\begin{array}{l}266 \\
222 \\
223 \\
208 \\
193\end{array}$ & $\begin{array}{l}2.66 \\
2.22 \\
2.23 \\
2.08 \\
1.98\end{array}$ & 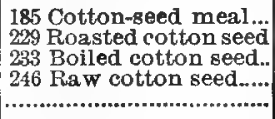 & 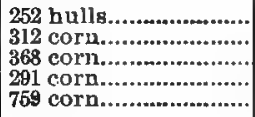 & $\begin{array}{l}713 \text { silage. } \\
158 \text { hay. } \\
128 \text { hay. } \\
155 \text { hay. } \\
185 \text { hay. }\end{array}$ \\
\hline
\end{tabular}

Results by Emery, North Carolina Station.*

\begin{tabular}{l|l|l|l|l|l|l}
\hline 4 & 796 & 178 & 1.78 & 224 Raw cotton seed..... & 1021 cotton-seed hull.s & $\ldots . . . . . . . . . . . . . . . .$. \\
\hline & 784 & 184 & 1.84 & 231 Raw cotton seed..... & 1016 cotton-seed hulls & \\
\hline
\end{tabular}

Results by Bennett and Monke, Arkansas Station."

\begin{tabular}{|c|c|c|c|c|c|c|}
\hline 2 & 589 & 247 & 2.74 & 209 Cotton-seed meal. & 707 cotton-seed bulls & \\
\hline 2 & 721 & 221 & 2.45 & 185 Cotton-seed meal.... & 603 cotton-seed hulls: & 425 pea hay. \\
\hline $\mathbf{2}$ & 710 & 176 & 1.95 & 175 Raw cotton seed.... & 580 cotton-seed hulls. & 412 pea haJ \\
\hline
\end{tabular}

Results by Stubbs, Louislana Station."

\begin{tabular}{r|r|r|r|r|r|r}
\hline 6 & 774 & 154 & 2.2 & 298 Cotton-seed meal... & 1053 cotton-seed hulls & 85 molesses. \\
5 & 727 & 153 & 2.8 & 231 Cotton-seed meal... & \%72 cotton-seed hulls & 62 molasses. \\
\hline
\end{tabular}

${ }^{1}$ Bul. 27. Bul. 98, 3d Ann. Rept. Ark. Expt. Sta. Bul. 34, 2d Ser.

This table shows the high value of the cotton seed, whether raw, roasted or boiled, and also of its by-product, cotton-seed, meal, for beef production. No grain raised at the North equals it, pound for pound, for beef production. When we reflect that for every pound of cotton fiber grown there are two pounds of seed, no argument is needed to convince us that the South is capable of producing the beef required for home consumption.

Connell found, as shown by the preceding table, that the cheapest ration was raw cotton seed with about equal weights of corn 
and hay. Such a mixture is not only economical, but will probably make better meat than cotton-seed meal or cotton seed fed as the sole concentrate.

Connell and Carson, of the Texas Station, ${ }^{1}$ having fed cottonseed meal and hulls in varying proportions to fattening steers, conclude that the largest daily gain can be secured by feeding three pounds of hulls for each pound of meal. If a larger proportion of meal is fed the cost of the gain will be somewhat increased. When the price of a ton of cotton-seed meal is to the price of a ton of hulls as 5 to 1 , then a pound of meal should be fed for each five pounds of hulls. For example, if meal is worth $\$ 15$ a ton and the hulls $\$ 3$, then five pounds of hulls should be fed for each pound of meal. If the hulls are worth less in proportion, then more hulls should be fed in proportion to the meal. (210-215)

560. "Fat sickness." - Cattle fed on cotton-seed meal and hulls are occasionally afflicted with inflammation of the eyes, which may terminate in total loss of sight. The trouble has been attributed to damaged cotton seed, to mal-nutrition, etc., but nothing definite has yet been determined. "Fat sickness" may attack thrifty, fat cattle. Cattle fattened on meal are said to be especially liable to attacks when turned to pasture. The trouble is prevalent during certain seasons, while in other years no cattle are affected. It is reasonable to suppose that furnishing a larger. variety of food in the ration would prevent the difficulty.

1 Bul. 41. 


\section{CHAPTER XXII.}

\section{FAOTORS IN STEER FATTENING-FINAI RESULTR}

\section{Conditions Affecting Results.}

561. Influence of shelter and confinement. - At the Kansas Station, ${ }^{1}$ Georgeson, testing the influence of shelter, confined five steers by tying in a stable, allowing five others to run loose in an open yard with a shed at one side for shelter. The steers were Western cattle three years old past, fed ear corn and stover. The trial began November 30, lasting six months. The following year it was duplicated with grade Short-horns six months younger than those in the preceding trial. The second trial began Decem. ber 20, continuing four months. The third trial followed the plan of the other two. The steers were mostly grade Shorthorns, two and one-half to three years old, and were put into the feed lot October 23 , - the feeding continuing five months. The results of the three trials are herewith summarized:

Results of three trials with steers fed in barn and in yard-Kansas Station.

\begin{tabular}{|c|c|c|c|c|c|}
\hline Where fed. & $\begin{array}{c}\text { Ear } \\
\text { corn } \\
\text { eaten. }\end{array}$ & $\begin{array}{l}\text { Fodder } \\
\text { eaten. }\end{array}$ & Gain. & $\begin{array}{l}\text { Ear corn } \\
\text { per } 100 \\
\text { lbs. gain. }\end{array}$ & $\begin{array}{l}\text { Fodder } \\
\text { per } 100 \\
\text { lbs. gain. }\end{array}$ \\
\hline 1892. Lasting six months. & Lbs. & Lbs. & Lbs. & Lbs. & Lbs. \\
\hline 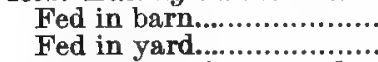 & $\begin{array}{l}4,027 \\
4,871\end{array}$ & $\begin{array}{r}1,341 \\
907\end{array}$ & $\begin{array}{l}284 \\
313\end{array}$ & $\begin{array}{l}1,418 \\
1,556\end{array}$ & $\begin{array}{l}472 \\
290\end{array}$ \\
\hline 189s. Lasting four months. & & & & & \\
\hline 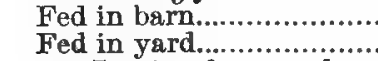 & $\begin{array}{l}2,723 \\
3,158\end{array}$ & $\begin{array}{l}1,214 \\
1,444\end{array}$ & $\begin{array}{l}274 \\
276\end{array}$ & $\begin{array}{r}994 \\
1,144\end{array}$ & $\begin{array}{l}443 \\
523\end{array}$ \\
\hline 1895. Lasting five months. & & & & & \\
\hline 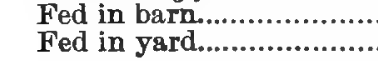 & $\begin{array}{l}3,223 \\
3,372\end{array}$ & $\begin{array}{l}535 \\
457\end{array}$ & $\begin{array}{l}230 \\
217\end{array}$ & $\begin{array}{l}1,401 \\
1,554\end{array}$ & $\begin{array}{l}233 \\
210\end{array}$ \\
\hline
\end{tabular}

In all the trials the steers running in the yard consumed more grain than those confined, and on the whole made larger gains,

1 Buls. 34, 39. 
at a cost, however, of about 12 per cent. more grain for a given amount of increase.

Moscrop' ${ }^{1}$ reports a feeding trial at Yorkshire, England, in which three lots of steers of four each were nsed. The first four were confined by tying in the stable, the second placed separately in boxes, each $10 \times 10$ feet, while the third group occupied an open lot, along one side of which was a shed. Each lot of steers received the same amount of Indian corn and oil cake, thus throwing the difference in the amount of feed consumed on the turnips and straw chaff which were fed additional. The steers in the open lot with shed for shelter made somewhat the most rapid gain, consuming, however, about 50 per cent. more turnips than those confined by tying. Those in the boxes consumed 25 per cent. more.

At the Woburn Station, England, equally good results were obtained in two trials with steers running in a yard with shed for shelter, fed in test with others confined in box-stalls. ?

Thorne and Hickman at the Ohio Station, ${ }^{8}$ feeding steers in the barn in opposition to others in the open yard with shed to run under, conclude: "The differences here indicated are not suffi. cient to justify the assertion that either method of caring for cattle was better than the other."

At the North Carolina Station, 4 Emery, testing the effects of close confinement and liberty of movement, concludes that if cattle are well fed and kept quiet and contented, it does not matter, in feeding for fattening purposes, whether they are tied or turned loose in a limited range.

Sanborn, experimenting first in Missouri, ${ }^{5}$ and later in Utah, ${ }^{\circ}$ with steers concludes: "It now looks as though the true method of wintering cattle consists in giving the freedom of warm quarters with liberty of outdoor runs at their pleasure." (630)

562. Changes during fattening to be avoided.-Sometimes as grass springs up in May the stockman is not ready to dispose of

1 Trans. High. and Agr. Soc., 1872.

- Jour. Roy. Agr. Soc., 1887, 1890.

- Bul. 60.

- Syn. of Expt. Mo. Expt. Sta.

- Rept. 1892. 
his cattle, and mast choose between continuing stall or yard feeding and turning the cattle to pasture for a short time before disposing of them. What to do in such cases is often perplexing. We have some help in the experiments of Thorne and Hickman at the Ohio Station. ${ }^{1}$

About May 1 a group of steers which had been fed experimentally during the winter was divided, part being turned to grass and part kept in the stable, grain and hay feeding being continued, practically to the full demands of both. The results are shown in the following table:

Results of turning partially-fattened steers to pasture - Ohio Station.

\begin{tabular}{|c|c|c|c|c|c|c|}
\hline Treatment. & $\begin{array}{l}\text { Number } \\
\text { of cattle. }\end{array}$ & $\begin{array}{c}\text { Dry sub- } \\
\text { stance } \\
\text { con- } \\
\text { sumed } \\
\text { per steer } \\
\text { per day. }\end{array}$ & $\begin{array}{l}\text { Daily } \\
\text { cost of } \\
\text { food per } \\
\text { steer. }\end{array}$ & $\begin{array}{l}\text { Daily } \\
\text { gain per } \\
\text { steer. }\end{array}$ & $\begin{array}{l}\text { Dry sub- } \\
\text { stance } \\
\text { con- } \\
\text { suined } \\
\text { per lb. of } \\
\text { gain. }\end{array}$ & $\begin{array}{l}\text { Cost of } \\
\text { food per } \\
\text { pound } \\
\text { of gain. }\end{array}$ \\
\hline $\begin{array}{l}\text { Lot I, kept in barn } \\
\text { Lot II, pastured } 30\end{array}$ & 16 & $\begin{array}{l}\text { Lbs. } \\
20.16\end{array}$ & $\begin{array}{r}\text { Cents. } \\
15.33\end{array}$ & $\begin{array}{l}\text { Lbs. } \\
2.00\end{array}$ & $\begin{array}{l}\text { Lbs. } \\
10.00\end{array}$ & $\begin{array}{c}\text { Cents. } \\
7.66\end{array}$ \\
\hline days ........................ & 15 & 15.39 & 12.93 & 1.42 & 10.84 & 9.10 \\
\hline $\begin{array}{l}\text { Lot I, kept in barn } \\
\text { Lot II, pastured } 45\end{array}$ & 8 & 20.99 & 16.09 & 1.76 & 11.95 & 9.15 \\
\hline days .................... & 8 & 15.21 & 12.55 & 1.37 & 10.68 & 9.14 \\
\hline
\end{tabular}

We observe that the steers turned to pasture ate nearly as much grain and half as much hay as those kept in the barn. Even with this aid the change from barn to pasture did not result farorably, as is shown by the smaller daily gain in each case and by the increased cost of gain in one instance and equal cost in the other.

At the Iowa Station, ${ }^{2}$ Wilson and Curtiss, changing 20 Shorthorn and Angus steers from feed lot to pasture, though still giving grain, secured a gain of only . 6 of a pound per head daily during the 15 days in which the gradual change was being made. These investigators, ${ }^{3}$ in changing another lot of steers back from pasture to feed lot in the fall, likewise secured a gain of only .6 of a pound per head daily during the 15 days in which the change occurred. These steers usually made a gain of about two pounds

\footnotetext{
${ }^{1}$ Bul. 60. 'Bul. 28. ' B Bul. 20, Iowa Sta
} 
each daily. Commenting on the result they write: "A chang. ing period is a losing period, if the change is radical."

These trials accord with the experience of stockmen, who find it unsatisfactory to change wholly or nearly finished cattle from one set of conditions to another, no matter what the new conditions. When steers are to be sold at no distant date, it is best to continue them under the existing system of feed and confinement, rather than change to new conditions, even though the latter may appear more favorable.

563. Effect of age on rate of gain. - The daily rate of gain with cattle on full feed is directly affected by the age of the animal. This is illustrated by the records of the fat-stock shows. Some of the results obtained in England are shown in the following table:

Age and weight of steers slaughtered at the Smithfield (England) FatStock Show, 1888-95.1

\begin{tabular}{|c|c|c|c|c|c|}
\hline & $\begin{array}{l}\text { No. of } \\
\text { animals. }\end{array}$ & Age. & $\begin{array}{l}\text { Average } \\
\text { daily } \\
\text { gain. }\end{array}$ & $\begin{array}{l}\text { Live wt. } \\
\text { at slaugh- } \\
\text { tering. }\end{array}$ & $\begin{array}{l}\text { Dressed } \\
\text { meat to } \\
\text { live wt. }\end{array}$ \\
\hline Short-horn. & & Days. & Lbs. & Lbs. & Per cent. \\
\hline 1 year old.................... & 5 & 642 & 2.11 & 1,355 & 66.13 \\
\hline 2 years old.................. & 18 & 963 & 1.92 & 1,842 & 67.48 \\
\hline 3 years old................... & 16 & 1,321 & 1.70 & 2,251 & 99.38 \\
\hline \multicolumn{6}{|l|}{ Hereford. } \\
\hline 1 year old.................... & 16 & 663 & 1.97 & 1,308 & 65.08 \\
\hline 2 years old.................. & 13 & 1,020 & 1.78 & 1,817 & 67.15 \\
\hline 3 years old.................. & 8 & 1,349 & 1.64 & 2,218 & 69.18 \\
\hline \multicolumn{6}{|l|}{ Devon. } \\
\hline 1 year old.... & 13 & 634 & 1.75 & 1,112 & 66.01 \\
\hline 2 years old ..................... & 19 & 1,045 & 1.51 & 1,583 & 67.73 \\
\hline $\begin{array}{l}3 \text { years old................... } \\
\text { Aberdeen-Anqus. }\end{array}$ & 16 & 1,311 & 1.37 & 1,796 & 67.32 \\
\hline \multicolumn{5}{|l|}{ Aberdeen-Angus. } & 65.37 \\
\hline 2 years old................... & 21 & 1,008 & 1.74 & 1,765 & 66.67 \\
\hline 3 years old................. & 2 & $\mathbf{1}, 346$ & 1.59 & 2,138 & 67.39 \\
\hline \multicolumn{6}{|l|}{ Sussex. } \\
\hline 1 year old...................... & 17 & 677 & 2.15 & 1,452 & 65.42 \\
\hline 2 years old................... & 18 & 989 & 1.86 & 1,837 & 68.18 \\
\hline $\begin{array}{l}3 \text { years old................... } \\
\text { Red Polled. }\end{array}$ & 12 & 1,285 & 1.61 & 2,064 & 67.98 \\
\hline 2 years old................. & 12 & 1,002 & 1.64 & 1,631 & 65.73 \\
\hline 3 years old................. & 6 & 1,362 & 1.49 & 2,022 & 65.77 \\
\hline \multicolumn{6}{|l|}{ Galloway. } \\
\hline 2 years old................... & 7 & 1,027 & 1.64 & 1,688 & 64.45 \\
\hline 3 years old................... & 4 & $1,344 \mid$ & 1.47 & 1,969 & 64.84 \\
\hline
\end{tabular}

1 Reported annually in the Live Stock Journal and Agricultural Gazette, London. 
This same problem has been worked out by Stewart, ${ }^{1}$ who summarizes the records of eight annual exhibits at the American FatStock Show, Chicago, as follows:

Age and rate of gain of animals exhibited at the American Fat-Stock Show, Chicago, 1878-85-Stewart.

\begin{tabular}{|c|c|c|c|}
\hline Number of animals. & Age. & $\begin{array}{l}\text { Average } \\
\text { weight. }\end{array}$ & $\begin{array}{l}\text { Gain per } \\
\text { day. }\end{array}$ \\
\hline & Days. & Lbs. & Lbs. \\
\hline 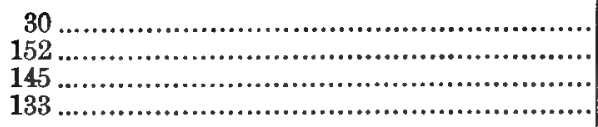 & $\begin{array}{r}297 \\
612 \\
943 \\
1,283\end{array}$ & $\begin{array}{r}780 \\
1,334 \\
1,639 \\
1,938\end{array}$ & $\begin{array}{l}2.63 \\
2.18 \\
1.74 \\
1.51\end{array}$ \\
\hline
\end{tabular}

The above shows that choice cattle fed for exhibition made an average daily gain of 2.63 pounds up to 297 days of age; after this the gain gradually fell off with increasing age, until when the animals averaged 1,283 days of age, the rate of gain for the whele period was only 1.51 pounds daily.

The point under consideration is more strongly brought out in the following table, ${ }^{2}$ which shows the gains by periods:

Gain of steers exhibited at American Fat-Stock Show, by periodsStewart.

\begin{tabular}{|c|c|c|c|}
\hline Period. & $\begin{array}{l}\text { Length } \\
\text { of } \\
\text { period. }\end{array}$ & $\begin{array}{c}\text { Average } \\
\text { gain per } \\
\text { head. }\end{array}$ & $\begin{array}{l}\text { Average } \\
\text { daily gain } \\
\text { per head. }\end{array}$ \\
\hline & Days. & Lbs. & Lbs. \\
\hline First period.......................................... & 297 & 780 & 2.63 \\
\hline Second period......................................... & 315 & 554 & 1.76 \\
\hline Third period................................. & 331 & 305 & .92 \\
\hline Fourth period................................. & 340 & 299 & .88 \\
\hline
\end{tabular}

The table shows that up to 297 days the cattle made an arerage daily gain (including birth weight) of 2.63 pounds, while for the final period of 340 days there was a gain of only .88 pounds daily per head. The gradual decrease in the ability of the steer to lay on flesh is apparent to every one upon a little thought. There must come a time in the life history of the animal when there is no increase in weight no matter what amount of food is consuned;

\footnotetext{
1 Feeding Animsis, 3d ed., App.

Loc. cit.
} 
all the animal can or will then eat constitutes the food of support, or is wasted. (595-6)

564. Cost of gain increases with age.-We have seen that the daily gain possible with steers decreases as the age of the animal increases. The results obtained at our Stations and the records of the fat-stock shows teach that each pound of gain costs more with increasing age, as illustrated in the following table:

Cost of 100 pounds gain, live weight, with steers of different ages.

\begin{tabular}{|c|c|c|c|c|c|c|}
\hline & \multicolumn{2}{|c|}{ 1-12 months old. } & \multicolumn{2}{|c|}{ 12-24 months old } & \multicolumn{2}{|c|}{ 24-36 months old } \\
\hline & $\begin{array}{l}\text { No. of } \\
\text { ani- } \\
\text { mals. }\end{array}$ & $\begin{array}{l}\text { Cost of } \\
\text { food. }\end{array}$ & $\begin{array}{l}\text { No. of } \\
\text { ani- } \\
\text { mals. }\end{array}$ & $\begin{array}{l}\text { Cost of } \\
\text { food. }\end{array}$ & $\begin{array}{l}\text { No. of } \\
\text { ani- } \\
\text { mals. }\end{array}$ & $\begin{array}{l}\text { Cost of } \\
\text { food. }\end{array}$ \\
\hline $\begin{array}{l}\text { Fat-Stock Show, ' } 82 .{ }^{1} \\
\text { Fat-Stock Show, '83.. } \\
\text { Michigan Station }{ }^{2} . . . \\
\text { Wisconsin Station }{ }^{3} . . \\
\text { Massachusetts Sta- } \\
\text { tion } 4 . . . . . . . . . . . . . . . . .\end{array}$ & $\begin{array}{r}9 \\
6 \\
10 \\
16\end{array}$ & $\begin{array}{r}\$ 4.03 \\
3.70 \\
1.87 \\
4.20\end{array}$ & $\begin{array}{r}5 \\
4 \\
10 \\
11 \\
2\end{array}$ & $\begin{array}{r}\$ 7.98 \\
8.12 \\
7.37 \\
6.13 \\
7.49\end{array}$ & $\begin{array}{c}2 \\
\ldots \ldots\end{array}$ & $\begin{array}{c}\$ 12.54 \\
\ldots \ldots \ldots \ldots \\
9.57 \\
\ldots \ldots \ldots \ldots\end{array}$ \\
\hline
\end{tabular}

${ }^{1}$ Rept. Il. Bd. Agr., 1884. ${ }^{2}$ Bul. 44. ${ }^{2}$ Rept. 1886. ‘ Rept. 1891.

The table shows that in every instance the cost of gain with the steer during the first twelve months of growth is less than for later periods. At the Fat-Stock Show for 1882 the feed for 100 pounds of gain with steers up to twelve months cost $\$ 4.03$; between twelve and twenty-four months it was $\$ 7.98$, while between twentyfour and thirty-six months the cost reached $\$ 12.54$.

565. Cost of gain increases with length of fattening period.Other conditions being equal, the longer the fattening period the larger the quantity of feed required to produce a given gain. This is brought out by Georgeson, of the Kansas Station, ${ }^{1}$ who found the grain required for 100 pounds of gain with fattening steers for different periods to be as follows:

\section{Feed for 100 lbs. gain.}

Up to 56 days the steers required... 730 pounds of grain. Up to 84 days the steers required... 807 pounds of grain.

Up to 112 days the steers required... 840 pounds of grain.

Up to 140 days the steers required... 901 pounds of grain.

Up to 168 days the steers required... 927 pounds of grain. Up to 182 days the steers required... 1000 pounds of grain.
Increase of feed required.

10 per cent.

15 per cent.

23 per cent.

27 per cent.

37 per cent.

- Bul. 34. 
We learn by the preceding data that while at first only 730 pounds of grain were required for 100 pounds of gain, for the whole six-months period over 1,000 pounds were required. The increase of feed percentagely is shown in the last column. It begins with 10 per cent. and increases to 37 per cent. The heavy cost of thoroughly fattening the steer and the importance of selling at the earliest possible date are here made plain. (80, 594, 847)

5F5. Feed for 100 pounds gain during fattening. - By consulting the tables in the preceding chapter the student can ascertain the feed requirements of steers while fattening. The grain in addition to roughage required for 100 pounds of gain will be found to range from 400 to 1,500 pounds. This wide range of requirements can but excite keen interest among students of stock management. The lowest requirements are reported from the Texas Station (540), where, however, the steers were of light weight, and were probably very thin in flesh at the beginning of the feeding period, so that a part of the increase was due to a natural filling-up process. Further, these steers were on pusture and the feeding period was short. Where as much as 1,500 pounds of grain were required for 100 pounds of gain, it was for a sixmonths feeding period, with corn only for concentrates, and the animals were well fattejed.

In general, taking the available data we have presented for the basis, it may be stated that about 1,000 pounds of grain will be required for 100 pounds of gain with well-fattened steers, on the average, besides 500 pounds of coarse food in the shape of hay, stover, etc. Steers in thin flesh, those fed for short periods only, and Iots handled under unusually favorable conditions will give the required gain for a considerably less amount of grain than just stated, while those fed for long periods may require 50 per cent. more. $(757,845)$

567. Dry matter required for 100 pounds of gain.- Thorne ${ }^{1}$ summarizes the results of feeding trials at Stations in eight states with 132 steers, and finds that 1,023 pounds of dry matter were required for each 100 pounds of gain.

Lawes and Gilbert ${ }^{2}$ tell us that from 12 to 13 pounds of dry

1 Bul. 60, Ohio Expt. Sta.

Rothamsted Memoirs, Vol. II. 
substance are required for each pound of increase, live weight, with fattening steers. The feeding trials at many of our Stations have usually covered only short periods, and these, as we have seen, are favorable to heavy gains for feed consumed. This being true, the figures given by Lawes and Gilbert should hold standard for the present at least.

568. Cost of 100 pounds gain with fattening steers. - The cost of the gain made by steers will vary according to the section of country in which the feeding is carried on. In the statements which follow, the current market prices for feed at the point of feeding are used.

At the Massachusetts Station ${ }^{1}$ the cost of feed for each 100 pounds increase, live weight, of steers was found to be $\$ 10.58$. This high cost is representative of conditions prevailing in the Eastern States, where feeding stuffs are much higher priced than in the great agricultural districts of the West. (812)

At the Kansas Station, with 20 range steers three years old past, fed for 182 days, Georgeson ${ }^{2}$ secured the results shown in the following table:

Amount of feed and cost of same for 100 pounds of gain with range steers fed six months - Kansas Station.

\begin{tabular}{|c|c|c|c|c|c|c|}
\hline Feed given. & $\begin{array}{l}\text { Cost of } \\
\text { food per } \\
\text { head. }\end{array}$ & $\begin{array}{c}\text { Daily } \\
\text { gain per } \\
\text { head. }\end{array}$ & $\begin{array}{l}\text { Gain in } \\
182 \text { days } \\
\text { per } \\
\text { head. }\end{array}$ & $\begin{array}{l}\text { Grain } \\
\text { for } \\
100 \text { lbs. } \\
\text { gain. }\end{array}$ & $\begin{array}{l}\text { Hay or } \\
\text { stover } \\
\text { for } 100 \\
\text { los. } \\
\text { gain. }\end{array}$ & $\begin{array}{l}\text { Cost for } \\
100 \text { lbs. } \\
\text { gain. }\end{array}$ \\
\hline $\begin{array}{l}\text { Lot I. } \\
\text { Corn meal, oil meal, } \\
\text { shorts, bran and }\end{array}$ & & Lbs. & Lbs. & Lbs. & Lbs. & \\
\hline $\begin{array}{l}\text { tame hay........... } \\
\text { cot II. }\end{array}$ & $\$ 31.00$ & 2.4 & 436 & 1,000 & 320 & $\$ 7.11$ \\
\hline $\begin{array}{l}\text { Corn meal, stover. } \\
\text { Lot III. }\end{array}$ & 21.11 & 1.47 & 268 & 1,334 & 350 & 7.87 \\
\hline $\begin{array}{l}\text { Ear corn, stover, } \\
\text { fed in barn......... }\end{array}$ & 20.85 & 1.56 & 284 & 1,410 & 470 & 7.34 \\
\hline $\begin{array}{l}\text { Ear corn, stover, } \\
\text { fed in yard......... }\end{array}$ & 25.20 & 1.72 & 313 & 1,556 & 280 & 8.05 \\
\hline
\end{tabular}

${ }^{I}$ Rept. 1894.

2 Bul. 34. 
f we include all charges - interest, taxes, labor, feed and risk it will be found that one hundred pounds of gain made during fattening, by well-finished steers, cost from eight to ten dollars at the West and from ten to twelve dollars at the East.

At the Iowa Station, ${ }^{1}$ Wilson and Curtiss fed 18 steers of nine different breeds with results as follows:

Cost of feed with steers during three feeding periods of 92 days each-Iowa Station.

\begin{tabular}{|c|c|c|c|}
\hline Date. & Kind of feed. & $\begin{array}{l}\text { Gain per } \\
\text { head per } \\
\text { day. }\end{array}$ & $\begin{array}{c}\text { Cost of } \\
\text { feed per } \\
100 \text { lbs. } \\
\text { gain. }\end{array}$ \\
\hline \multirow[b]{2}{*}{ March to May... } & Lot I-II. & Lbs. & \\
\hline & 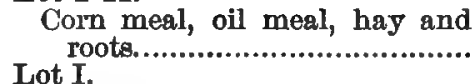 & 2.48 & $\$ 5.93$ \\
\hline \multirow[t]{2}{*}{ June to Aug...... } & Corn meal, clover pasture......... & 2.32 & 4.31 \\
\hline & $\begin{array}{l}\text { Lot II. } \\
\text { Oil meal, clover pasture............ }\end{array}$ & 2.03 & 6.21 \\
\hline \multirow[t]{2}{*}{ Oct. to Dec....... } & $\begin{array}{l}\text { Snapped corn, corn meal, oil } \\
\text { meal, roots and hay................ } \\
\text { Lot II. }\end{array}$ & 3.26 & 5.92 \\
\hline & $\begin{array}{l}\text { Snapped corn, corn meal, oil } \\
\text { meal, roots and hay................. }\end{array}$ & 2.8 & 6.38 \\
\hline
\end{tabular}

These trials are representative of conditions in the Mississippi Valley. We observe that the lowest cost was $\$ 4.31$ for 100 pounds of gain, in Iowa, with steers getting corn meal on clover pasture. The highest cost was $\$ 8.05$ for steers at the Kansas Station getting ear corn.

\section{Value of Breed in Beef Making.}

569. Amount of feed consumed. - Every person with experience in the cattle business concedes that "blood tells" in beef production. Where there is such unanimity of expression the fact must exist, but the reasons given are not always the same and so are worthy of careful examination.

Occasionally the claim is advanced that well-bred cattle eat less than natives or scrubs. This opinion is not generally held by owners of pure-bred or high-grade stock, who know that their

1 Bul. 20. 
animals when gaining rapidly are hearty feeders, though when mature they require only a small amount of provender for maintenance. Nothing in the tables given in this chapter warrants the statement that pure-bred or high-grade cattle of the beef breeds are small eaters.

570. Less feed for a given gain.-The second claim, and a more reasonable one, is that cattle bred specifically for beef give better returns for a given amount of feed than those bred for milk production or those of promiscuous or low breeding. This claim is quite generally advanced by stockmen, and is usually conceded without calling for proof.

A few Stations have undertaken the difficult task of testing the comparative merits of the several breeds. While the number of animals tested is not large, by combining all the data at hand we get some light on the question though we cannot hope to entirely settle it. Figures are given in the nert table from trials at five Stations where pure-bred and native steers were fed in comparison for periods varying from ninety-two days to eighteen months:

Grain required for 100 pounds of gain with steers of several breeds as found at various Experiment Stations.

\begin{tabular}{|c|c|c|c|c|c|c|c|c|c|c|c|c|}
\hline Btation. & $\begin{array}{l}\text { Length } \\
\text { of } \\
\text { period. }\end{array}$ & $\begin{array}{l}\text { Age at } \\
\text { begin- } \\
\text { ning. }\end{array}$ & 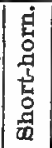 & 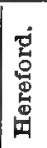 & 逍 & 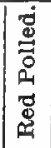 & 兽 & 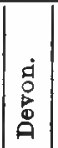 & 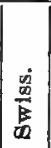 & 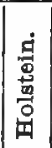 & $\begin{array}{c}\stackrel{\Delta}{0} \\
\stackrel{0}{0} \\
\stackrel{D}{2}\end{array}$ & $\frac{3}{3}$ \\
\hline & & & $1 \mathrm{bs}$. & lbs. & lbs. & 1 bs. & lbs. & 1bs. & lbs. & ibs. & lbs. & lbs. \\
\hline Iowa $(a)$ & 92 days.. & 2 yrs... & 659 & 874 & 744 & 753 & 977 & 663. & 712 & 870 & 861 & .... \\
\hline Iowa $(b) \ldots \ldots \ldots$ & 6 mos... & 2 y rs... & 965 & & 947 & ...... & & & & & & \\
\hline 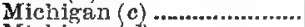 & 1 yr ..... & 1 yr.... & 557 & 561 & ...... & ....... & 581 & 477 & ..... & 56.5 & 557 & \\
\hline 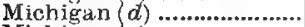 & 1 yr ..... & 2 yrs... & 796 & 916 & ..... & ...... & 763 & 755 & ...... & 939 & 807 & ....... \\
\hline Michigan $(e)$....................... & $18 \mathrm{mos} \ldots$ & 1 yr.... & 493 & 552 & & $\ldots . .$. & 612 & 478 & ...... & 665 & ...... & $\cdots \cdots$ \\
\hline Ontario $(f) \ldots \ldots \ldots$ & 1 yr ..... & 1 yr.... & 597 & 793 & 698 & $\ldots . . .$. & 653 & 495 & ...... & 686 & ....... & 191 \\
\hline Kansas $(g)$ & 161 days.. & 3 yrs... & 777 & $\because \cdots$ & & -...... & ...... & $\cdots \cdots$ & $\cdots \cdots$ & ...... & $\cdots \cdots$ & 876 \\
\hline Missouri $(h) \ldots \ldots \ldots \ldots \ldots$ & 18 mos... & 1 yr.... & 7004 & 742 & 661 & & $\mid-\cdots \cdots$ & ...... & ....... & $\cdots$ & ....... & 631 \\
\hline
\end{tabular}
(a) Bul. 20.
(b) Bul. 28.
(c) Bul. 44.
(d) Bul. 44.
(e) Bul.69.
(f) Rept. 1892.
(g) Bul. 51 .
(h) Bul. 24.

There were two steers in each Michigan trial and in the first Iowa trial. In the second Iowa trial there were ten Shorthorn and ten Angus steers; in the Ontario trial there was only one of each; in the Kansas trial there were six Short-horns and 
aix Natives; in the Missouri trial there were six Short-horns, three Herefords, four Angus and four Natives. The student should not take averages of the trials in drawing conclusions, since the conditions at the different Stations varied greatly, but they should be studied separately. The tests cover periods ranging from 92 days to 18 months. The least amount of grain ( 477 pounds) for 100 pounds of gain was with Devon steers, and the largest amount (977 pounds) was with Galloways.

Reviewing the data of the table it will be seen that while we can single out cases where the beef-bred steer has produced 100 pounds of gain with less feed than the dairy-bred or native steer, yet the largest amount of feed consumed by any animal for a given gain also stands charged to one of the beef type. We are thus unable from the data at hand to show that a pound of feed goes further in making gain with beef-bred animals than with those not specially designed for that purpose. These figures are a surprise to the writer, as they must be to the reader; but as they represent practically all the work done at the Stations to date they should stand for the present.

57l. Early maturity.- The most common claim for superiority in the beef breeds is that animals so bred mature earlier than others. Consulting the figures given in the next table we find that steers of the strictly dairy breeds reached as heavy weight as did several of the beef-breed representatives. Holstein steers made substantially as large daily gains as did any of the others, and Jersey and Native steers rivaled the Devons. So far as data from the Stations go, we have no evidence that beef-bred animals make more rapid growth than do others. The claim of early maturity, then, is not substantiated by the data at hand if daily gain in live weight is the sole measure used. The degree of maturity of the animal is not measured entirely, however, by its weight, so that this division of the subject cannot be considered as covered by the data presented in regard to daily gain.

572. Dressed weight of carcass. - This topic naturally follows that just presented, and fortunately, from the experiments last quoted, we have data at command. The animals used in the several tests at the Stations were slunghtered and the weight of the 
carcasses reported. Gathering the data into a table we have the following:

Dressed weight of carcass of different breeds of cattle - Various Stations.

\begin{tabular}{|c|c|c|c|c|c|c|c|}
\hline Breed. & $\begin{array}{l}\text { No. of } \\
\text { ani- } \\
\text { mals. }\end{array}$ & $\begin{array}{c}\text { No. of } \\
\text { sta- } \\
\text { tions. }\end{array}$ & $\begin{array}{l}\text { Av. } \\
\text { age. }\end{array}$ & $\begin{array}{l}\text { Av. live } \\
\text { weight. }\end{array}$ & $\begin{array}{l}\text { Daily } \\
\text { gain } \\
\text { from } \\
\text { birth. }\end{array}$ & $\begin{array}{c}\text { Limits } \\
\text { of dressed } \\
\text { weight. }\end{array}$ & $\begin{array}{l}\text { Av. } \\
\text { dressed } \\
\text { weight. }\end{array}$ \\
\hline & & & Days. & Lbs. & Lbs. & Per cent. & Per ct. \\
\hline Hereford .... & 11 & 4 & 983 & 1,515 & 1.54 & $63.0-68.0$ & 65.0 \\
\hline Red Polled ........ & 2 & 1 & 1,000 & 1,520 & 1.52 & $63.8-66.5$ & 65.2 \\
\hline Aberdeen-Angus & $1 \overline{6}$ & 4 & 976 & 1,493 & 1.53 & $63.2-69.0$ & 64.8 \\
\hline Swiss................. & 2 & 1 & 1,000 & 1,570 & 1.57 & 64.8 & 64.8 \\
\hline Short-horn ........ & 26 & $\overline{5}$ & 1,011 & 1,510 & 1.50 & $62.1-68$ & 64.4 \\
\hline Galloway........... & 6 & 3 & 923 & 1,503 & 1.62 & $62.0-66.7$ & 63.9 \\
\hline Devon............... & 7 & 3 & 1,021 & 1,376 & 1.35 & $62.5-65.8$ & 63.6 \\
\hline Ayrshire. & 1 & 1 & 1,095 & 1,320 & 1.20 & & 63.3 \\
\hline Sussex.......... & 1 & 1 & 1,021 & 1,625 & 1.59 & & 63.0 \\
\hline Holstein...... & 6 & 3 & 937 & 1,469 & 1.57 & $60.6-64.4$ & 62.6 \\
\hline Jersey ............... & 3 & 2 & 1,058 & 1,440 & 1.36 & $58.7-63.9$ & 60.5 \\
\hline Native .............. & 9 & 3 & 1,038 & 1,259 & 1.26 & $57.9-61.5$ & 60.2 \\
\hline
\end{tabular}

The data referring to live weight at the time of slaughter and daily gain from birth have already been discussed; let us now consider the dressed weights of cattle of the several breeds. The Red Polls give the largest percentage of dressed carcass to live weight, but the figures are the average for two animals only, and the best of these is lower than the best of the representatives of five other breeds. Were as many animals included as there are of the Short-horns, for example, they would no doubt rank lower in the list. (See Article 563.)

The last column of the table is one of great significance and worthy of study by all interested in the problem under discussion. We find that steers of the so-called beef breeds yield from 64 to 65 per cent. of dressed carcass to live weight, while Native steers and those of the dairy breeds dress from 60 to 63 per cent. Jersey and Native steers dress the lowest. On the average, eleven Hereford steers fed and slaughtered at four Experiment Stations yielded eight per cent. more dressed carcass to live weight than did nime Native steers fed at three Experiment Stations. The weights of the native and dairy-bred steers are so great that we may be sure they were fully as mature and as well 
fatted as their competitors. Here is the first marked difference between beef-bred and other cattle.

573. Percentage of loose tallow to dressed weight. - At the Iowa Station, 1 Wilson and Curtiss found a larger anount of fat about the internal organs of steers of the dairy breeds than about the viscera of animals of the beef breeds, as is shcwn by the fol. lowing table:

Dressed weight of carcass and "loose" tallow of steers of various , breeds - Iowa Station.

\begin{tabular}{|c|c|c|c|}
\hline Breed. & $\begin{array}{l}\text { Average } \\
\text { dressed } \\
\text { weight. }\end{array}$ & $\begin{array}{l}\text { Loose } \\
\text { tallow. }\end{array}$ & $\begin{array}{l}\text { Per cent. of loose } \\
\text { tallow to beef. }\end{array}$ \\
\hline & Lbs. & Lbs. & \\
\hline Short-horn................................ & 1,092 & 145 & 13.3 \\
\hline Hereford..................................... & 1,022 & 129 & 12.6 \\
\hline Red Poll................................. & 990 & 125 & 12.6 \\
\hline Galloway................................... & 1,088 & 147 & 13.5 \\
\hline 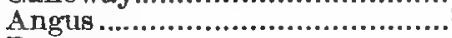 & $\mathbf{1}, 137$ & 156.5 & 13.8 \\
\hline 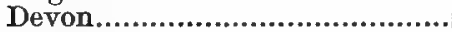 & 815 & 122.5 & 15.0 \\
\hline Swiss....................................... & 1,017 & 119 & 11.7 \\
\hline Holstein................................. & 862 & 155 & 17.9 \\
\hline 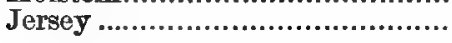 & 880 & 165.5 & 18.8 \\
\hline
\end{tabular}

The above table presents most important data. The Short-horn steers dressing about 1,100 pounds yielded 145 pounds, or 13.3 per cent., of loose tallow. Jersey steers averaging 880 pounds yielded over 165 pounds, or 18.8 per cent., of loose tallow. These figures are corroborated by findings in the same direction at the Michigan ${ }^{2}$ and Missouri Stations. ${ }^{8}$ Commenting on the character of the carcasses of steers of the various breeds slaughtered at the Michigan Station, Davenport wrote: "Note the excess of rough tallow in Walton (a Holstein steer) as compared with the others. Walton was 'all cow,' as the saying goes, and the fat about his kidneys was astonishing."

From these data we may conclude that there is a specific dif. ference between the beef and dairy breeds in the disposition of fat in the body. It appears that the beef representatives, when fattening, place a large portion of the fat between the muscular fibers of the tissues. Steers of the dairy breeds, on the other

\footnotetext{
' Bul. 20. $\quad 2$ Bul. '24. Bul. 69.
} 
hand, deposit much fat about the intestines and the kidneys. Fat intimately commingled with the muscular fibers of the tissues renders such meat tender and toothsome; when placed in separate masses anywhere in the body, and especially within the body cavity, it has a low value as a merchantable article. While fat stored as in the dairy breeds may be best placed for animals designed for milk production, such disposition is certainly against their usefulness in beef production. In this distinction we have a remarkable example of the effort toward specialization in the beef and dairy breeds, and the lesson is important and farreaching. Here, then, is the second distinct characteristic of the - beef-bred steer.

574. Proportion of valuable parts in carcass.- Georgeson of the Kansas Station, ${ }^{1}$ and Wilson and Curtiss of the Iowa Station, ${ }^{2}$ closed feeding trials with breed representatives by forwarding the animals to Swift \& Co., Packers, Chicago and Kansas City, for slaughter. The accompanying table presents the proportion of the several parts yielded by the dressed carcasses:

Percentage of the various cuts in the dressed carcasses of Holstein, $\mathrm{Na}$ tive and Short-horn steers - Kansas and Iowa Experiment Stations.

\begin{tabular}{|c|c|c|c|c|}
\hline & \multicolumn{2}{|c|}{ Kansas. } & \multicolumn{2}{|c|}{ Iowa. } \\
\hline & $\begin{array}{l}\text { Short- } \\
\text { horn. }\end{array}$ & Native. & $\begin{array}{l}\text { Short- } \\
\text { horn. }\end{array}$ & Holstein. \\
\hline 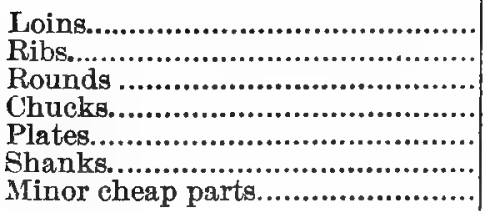 & $\begin{array}{r}16.6 \\
9.6 \\
22.9 \\
20.6 \\
13.5 \\
6.1 \\
10.7\end{array}$ & $\begin{array}{r}17.0 \\
10.1 \\
22.4 \\
20.8 \\
12.8 \\
5.8 \\
11.1\end{array}$ & $\begin{array}{r}17.1 \\
9.9 \\
22.9 \\
21.1 \\
15.4 \\
5.7 \\
7.9\end{array}$ & $\begin{array}{r}16.6 \\
10.2 \\
23.3 \\
21.9 \\
14.2 \\
6.4 \\
7.4\end{array}$ \\
\hline
\end{tabular}

So far as the figures go, there is nothing to show the superiority of the beef breeds in yielding a larger percentage of high-priced cuts. Of course, since the percentage of dressed carcass to live weight is greater in the beef breeds, they actually yield somewhat more pounds of valuable parts than the non-beef breeds. But such data are not final on the point in question. The thickness

\footnotetext{
${ }^{2}$ Bul. $51 . \quad 2$ Bul. 20.
} 
of the flesh over the carcass, which is one factor of its worth in the market, is not indicated by percentages of the several parts. A thin-fleshed steer will not cut up percentagely much different from one that furnishes thick cuts of meat.

575. Judigment of the market.-Difference in quality is quickly noted in the market and prices vary accordingly. The eighteen steers representing nine breeds fattened by the Iowa Station, when shipped to Chicago, were passed upon by a committee of three stock buyers, with the results shown in the following table:

Value placed by experts on steers of nine breeds sold by the Iowa Experiment Station at the Union Stock Yards, Chicago.

\begin{tabular}{|c|c|c|}
\hline Breeds. & $\begin{array}{c}\text { Average } \\
\text { live } \\
\text { weight. }\end{array}$ & $\begin{array}{l}\text { Experts' } \\
\text { valuation } \\
\text { per cwt. }\end{array}$ \\
\hline 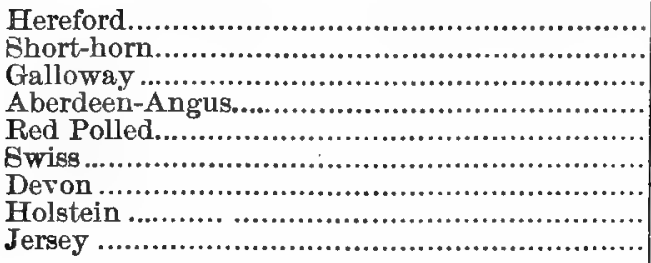 & $\begin{array}{l}1,525 \mathrm{lbs} . \\
1,660 \mathrm{lbs} . \\
1,635 \mathrm{lbs} . \\
1,725 \mathrm{lbs} . \\
1,520 \mathrm{lbs} . \\
1,570 \mathrm{lbs} . \\
1,290 \mathrm{lbs} . \\
1,410 \mathrm{lbs} . \\
1,430 \mathrm{lbs} .\end{array}$ & $\begin{array}{l}\$ 6.621 \\
6.37 \\
6.371 \\
6.37 \\
6.25 \\
6.00 \\
5.75 \\
5.00 \\
4.50\end{array}$ \\
\hline
\end{tabular}

Here is a difference between the highest and lowest valuations of $\$ 2.12$ per hundred weight, or about 32 per cent.

In the slaughter test of the Kansas Short-horns and Natives before referred to, the loins of the best Short-horns were rated at 18 cents per pound, while those of the Natives were placed as low as 14 cents. There is not this difference in actual food value between the carcasses or cuts, but the exactions of the market are all-powerful and must be recognized as final in this discussion.

576. Quality.-Beyond that which can be expressed in figures: or stated percentagely lies that indefinable something described by the word "quality," which enters into this as into all other objects of barter. No one can compare a bunch of well-fed beefbred steers with one representing the dairy breeds or natives with. out being impressed by a difference not measured by the scales. Speaking of the breed tests, Wilson and Curtiss write: "The carcasses of the dairy breeds lacked in thickness of cuts, and the 
marbling of the fat and lean was not equal to that of the others (beef breeds)." Georgeson, reviewing his results, writes: . . "The Short-horns gave the best returns, not simply because the gross weight of their carcasses was greater than that of the scrubs, but also because their meat was esteened better by experts in the packing-house who were asked to judge of the quality and assign "prices." Of the Ontario native, Shaw wrote: "There was a lack of thickness of carcass throughout, the deficiency in depth of rib and loin being very noticeable, and the absence of what may be termed fleshiness was conspicuous."

577. In conclusion.- In our study of the value of specific breeding for beef production we have found, as shown in the preceding articles, that the steer bred for beef does not consume less feed than do others of the same weight, nor does he necessarily reach a given weight in less days, though generally such is the case. Nor do our figures show that 100 pounds of gain, live weight, can be made by the beef steer with less feed than other cattle require.

The first specific difference is found in the marked superiority of true beef cattle in yielding a larger percentage of dressed weight to live carcass. A second difference of deep significance is in the disposition of the fat, the beef steer placing this surplus material where it serves its highest purpose as human foodamong the muscular fibers of the tissues, - while the dairy-bred animal deposits it in quantity about the viscera.

While if we divide the dressed carcass into the several parts required by the trade we cannot show that the proportion of these varies in cattle of different breeds, yet the thickness of the flesh of these parts is certainly in favor of the beef breeds.

These differences, with others which cannot be distinctly speci. fied coming under the term "quality," combine to make the beef steer what his name indicates - an animal specifically designed for the most farorable production of the best neat.

\section{Other Findings.}

578. Dressed weight of cattle.-The percentage of dressed carcass to live weight of cattle varies according to several conditions, the leading of which are: 1 , the age of the animal; 2 , the 
degree to which it has been fattened; and 3, the breed or beef character. This last point has already been noted. Let us consider the other two conditions.

In studying the effects of age we turn to the records of the American Fat-Stock Show ${ }^{1}$ for the year 1884, which show:

Slaughter test at the American Fat-Stock Show, Chicago.

\begin{tabular}{c|c|c|c|c}
\hline Age of animals. & $\begin{array}{c}\text { Number } \\
\text { of ani- } \\
\text { mals. }\end{array}$ & $\begin{array}{c}\text { Live } \\
\text { weight at } \\
\text { slaughter. }\end{array}$ & $\begin{array}{c}\text { Weight } \\
\text { of dressed } \\
\text { carcass. }\end{array}$ & $\begin{array}{c}\text { Per cent. of } \\
\text { dressed car- } \\
\text { cass to live } \\
\text { weight. }\end{array}$ \\
\hline & & Lbs. & Lbs. & \\
Three years and under four.. & 10 & 2,025 & 1,378 & 67 \\
Two years and under three.. & 11 & 1,631 & 1,089 & 66 \\
One year and under two..... & 6 & 1,240 & 789 & 63 \\
Under one year................ & 1 & 930 & 562 & 60 \\
\hline \hline
\end{tabular}

Here we find that three-year-old steers dressed 67 per cent. of the shrunken live weight of the animal, while those under one year gave only 60 per cent. of dressed carcass. The importance of maturity on the returns of dressed carcass is here shown.

The degree of fattening also determines the percentage of valuable parts. In fattening, the weight of the secondary parts of the steer is not materially increased; for example, the head, hide, hoofs and viscera do not increase much in weight, while the carcass proper weighs more because of the large percentage of fat added. Common steers but little fattened may yield no more than fifty per cent. of live weight in carcass, dressing away one-half.

579. Shrinkage due to shipping.- At the Kansas Station, ${ }^{2}$ Georgeson found that steers weighing 1,350 pounds shrank from 9 to 68 pounds per head, the average being 27 pounds, when shipped from Manhattan to Kansas City, a distance of about one hundred miles. Steers weighing 1,550 pounds, shipped from the Iowa Station ${ }^{3}$ to Chicago, about three hundred miles, shrunk 71.5 pounds. Steers shipped from the Ohio Station at Wooster 4 to Pittsburg, about one hundred and fifty miles, weighed somewhat more Monday, after watering, than at home Saturday before watering.

'Breeder's Gratte, Chicago, 1884, p. 824. ' Bul. 39. 'Bul. 20. ‘ Bul. 60. 


\section{CHAPTER XXIII.}

COUNSEL IN THE FEED LOT.

\section{Feed and Management of Fattening Cattle.}

580. Indian corn.- Indian corn must continue the great grain food for steer fattening in the United States. While we cannot vie with England in luxuriance of pasture, the advantage given our farmers by the corn plant more than offsets this, and places us at the front in beef production. No concentrate is so relished by cattle as corn, the kernels of which carry considerable oil, rendering them toothsome and palatable to a degree not equaled by other grain. Not only does corn carry oil, but it is loaded with starch, likewise a fat-former, thus affording the nutriment needed for filling the tissues of the steer's body with fat, rendering the muscles tender and juicy. The success of steer feeding in America must depend largely upon the supply of Indian corn available for this purpose.

581. Beef returns per acre of corn.- Stewart 1 reports a trial conducted by himself with ten steers averaging 1,175 pounds, which were fed four measured acres of shock corn estimated to gield 40 bushels of grain per acre. The nnhusked shock corn was run through a feed cutter, and 40 pounds of the mixture, with 2 pounds of linseed meal, given daily. The four acres of corn lasted 70 days, each steer gaining 200 pounds on the average in that time. Allowing for the oil meal, the author concludes that this corn crop gave a return of 400 pounds of beef per acre, which, at five cents per pound for the increase, yields $\$ 20$ for an acre of corn so fed. This is about twice the returns obtained by Morrow from an acre of Illinois pasture grazed by yearling steers.

582. Plain feeding of corn recommended. - The practice, common in the corn belt, of supplying unhusked or unground corn to steers, has developed the feeling among Eastern feeders that the

\footnotetext{
Feeding Animals, p. 311.
} 
method is wasteful and could be immensely improved by grinding the grain. No one can study the Western situation without becoming impressed with the belief that the better class of these feeders are, after all, about right in this practice. Corn is never so acceptable to a steer as when unhusked. There is a freshness and palatability about an ear of corn wrapt in Nature's covering which every steer recognizes and shows by the eagerness with which he consumes it.

Feeding shock corn is a satisfactory practice in many instances, for the crop is then handled with the least labor. The fodder with its wealth of ears is thrown into long feed racks standing in an open lot or under a shed, the steers doing the husking and grinding. Some fodder is eaten, and the waste ears and grains are eagerly picked up by shotes running with the steers.

Snapped corn, i. e., ears severed from the stalks but still wrapt in the husks, is successfully used for steer feeding. Husked ear corn is extensively fed, though the grains are not so fresh as in the two forms named above and are not always so acceptable because of another condition, viz., hardness of the grains. Corn in the crib exposed to the dry air of the West often becomes very hard and the grains injure the mouth of the steer in the process of mastication. To avoid this difficulty the ears are chopped or broken into pieces or fed after soaking. Soaking does not render the grain more digestible, but enables the steer to erush it with more ease and often to consume a larger quantity.

Trials at the Stations show that corn meal gives larger gains with steers than the same weight of unground grain. It is probable also that meal permits of a higher finish with steers than unground corn. Practical experience and studies by the Stations show that pigs following steers fed corn meal get very little from the droppings; not because such droppings are without nutriment, but rather because the meal in the droppings is in a form which cannot be utilized by the pig.

Reviewing the subject from the standpoint of experiment and practice, the writer is of the opinion that where corn is cheap the Western custom of feeding it whole to steers with lively shotes following is the most economical, all things considered, if ration. 
ally iracticed. In general, directions for feeding cheap corn may be summed up by the single statement: Let the feeder supply this grain to his cattle in the most inexpensive manner possible so long as they consume full rations without difficulty in mastication. $(536,538)$

583. Preparing corn for feeding. - Not infrequently the feeder must prepare corn for his cattle, - the large size of the ears, the dryness of the grain, or other conditions rendering some treatment necessary. Soaking the corn has already been referred to and may often be practiced with advantage. The simplest form of reduction is the rather crude but common practice of breaking the ears, in the feed box, into three or four pieces, using a hatchet. Another satisfactory method of preparation is to reduce the ears, with or without husks, to a reasonable degree of fineness by runining them through a crusher, which breaks the cobs into many pieces, cracking some of the kernels. Corn and cob meal has been found very satisfactory by feeders, the animals not getting "off feed" so easily as when pure meal is fed.

As before stated, larger returns can be secured from corn meal than from whole grain, but there are several disadvantages attendant upon its use. Little or nothing can be gained by pigs following steers fed corn meal, and because of its heavy nature indigestion and other difficulties commonly attend its use. Corn meal should never be fed alone in large quantity, but should be diluted or given increased bulk by the addition of bran, oil meal or other substance, in which case the dangers incident to its use are usually overcome. The claim that toward the close of the fattening period corn meal is especially useful in giving more finish is probably correct, on the theory that the digestive organs have become weakened by the continued feeding of whole corn, and their activities are in some measure renewed when the steer is given meal.

The amount of corn to be fed fattening steers and the gain made are shown in the preceding chapter.

584. Bran.- This by-product was at first regarded with favor only by dairymen. Gradually the steer feeder is learning its value in colinection with other grain in the feed box. Becanse of its 
bulky character and its cooling, slightly laxative properties, bran is a most excellent dilutent for corn meal, cotton-seed meal and other heavy food substances. Where it can be obtained at a reasonable price, the stockman will find much satisfaction in mixing one-third its weight of bran with corn meal. (544)

585. Oil meal.- Oil meal is an article of great importance in the feed lot. The highly carbonaceous Indian corn has the reputation of rapidly "burning ap" the digestive tract of the steer when fed continuously in large quantity. Oil meal, though an exceedingly rich food, is of the opposite nature, and when fed in reasonable amount has a cooling and generally beneficial effect on the system. The feeder who uses from two to four pounds of oil meal a day with corn in any form will be pleased with the result. A steer fed oil meal has a glossy coat and a handling quality not attained without the use of this feed. (206) This quality indicates the value of oil meal for the finishing period in steer fattening. The feeder should use oil cake in nut form rather than as meal.

586. Roots. - In steer feeding, roots are valuable, especially in the earlier stages, because of their cooling effect and the nutriment they afford. At first 50 or 60 pounds of roots may be fed daily to each steer. As the fattening period progresses, the quantity should be diminished to allow the flesh to become firm. For steer feeding, roots should always be sliced or pulped. In the latter case the pulped mass is mixed with chaffed hay or straw and held until the dry forage has become moist and soft. The mangel is preferred for steer feeding. (325-6, 549)

587. Silage.-If the stockman desires a cheap, succulent feed for his cattle in winter, he will find it in corn silage. The same quantity of nutriment that a root crop yields can be produced more economically in corn forage stored in the shape of silage, and this article can be fed with satisfaction to steers during the early stages of fattening. At first as much as 40 or 50 pounds of silage may be given daily to each steer; when the full grain. feeding period arrives let the allowance be cut down to 25 or 30 pounds per day. A limited use of this feed will keep the system cool and the appetite vigorous. (550) 
538. Turning to pasture.- There are two theories in regard to the proper time for turning steers to grass, each with points of advantage. It is generally advocated by American writers that stock be kept in the yard until the pastures furnish an abundance of nutritious grass. Often when stock is turned on such pastures the ration of the feed-lot is at once cut off, in which case the change is so violent as to give the cattle a serious set-back. Under the other system the cattle are turned to pasture as soon as the grass begins to grow, and while the springing blades are still watery and furnish little nutriment. The lack of feed in the pasture forces the stock to rely on the feed rack to satisfy hunger. While the first grass yields little nutriment, it still has an effect on the digestive system and prepares the animal gradually for the change from dry feed to the rich grass which soon follows. It is a wellknown fact that stock shrink badly when changed from feedlot to pasture, and it is possible that the practice of turning early to grass, at the same time keeping up heavy feeding, is better than holding cattle longer on dry food only and then shifting at once to full pasture. In any event, let grain and some dry forage be still offered the cattle when first turned to grass.

589. Large versus small pastures. - The subject of large or small pastures is frequently discussed. The majority of experienced American feeders favor a single large range rather than numerous small pastures. Grasses, both in variety and quality, are never quite the same over the whole of a large pasture, and cattle soon detect the slight differences and satisfy their desire for variety by ranging from one spot to another. In large pastures the habits of the animals become regular, and it is interesting to study their movements. The herd will be found in the morning on one side of the valley, feeding on the more abundant vegetation; later as the sun's heat increases they appear on the hillside, where there is a movement of air and where the grasses are shorter but more nutritious; while at noon they are to be seen resting in the shade at still another point. This regularity in grazing certainly conduces to comfort and quiet and is of importance to profitable returns. Where the pastures are cut np ilito several lots, the fresh bite of rank herbage which comes with each change leads to irregularity and unrest, thus reducing the gains. 
590. The possibilities of pastures.-Sir J. B. Lawes' 1 noports a pasture of 14 acres in Leicestershire, England, on which 17 oxen were grazed without artificial food throughout the season, returning from 500 to 600 pounds of increase, live weight, per acre.

From Morrow's trials (554-5) we are led to estimate that in the Mississippi Valley, on the richer farming lands, we may look for about 200 pounds of gain with steers from each acre of tame pasture. This gives land capable of these results a value of from fifty to one hundred dollars per acre for that purpose at a reasonable rate of interest on the money invested.

591. Grain feeding on pastures. - The writer once heard J. D. Gillett, the great Mlinois steer feeder of the last generation, say that he conld not afford to fatten steers in winter. His cattle were fattened in the summer and fall, subsisting in winter in stalkfields and on the dry grasses of the pastures. In sunmer they luxuriated in rich old blue-grass pastures where the feed boxes always stood loaded with grain. The great success attained by this feeder is sufficient evidence of the wisdom of his practice with the conditions and markets then prevailing - good prices for well-fattened cattle.

Wallace, ${ }^{2}$ in summarizing the experience of numerous cattle feeders in the West, writes: "The general opinion seems to be that good steers fed grain on grass will gain from 75 to 100 pounds per month, and that steers on good pasture will, during the two or three most favorable grazing months, gain almost as much on grass alone. . . . From all the facts I have been able to obtain, I am inclined to the opinion that in general there is not much money in feeding grain to steers that are on full pasture of the best kind."

Where pastures carry a sufficient growth of grass for full feed even during mid-summer, it is usually best to allow the cattle to subsist entirely on natural herbage, for this is of low cost, and animals relying upon their own exertions gather their food vigorously and willingly, wasting no time in standing idly waiting for food. Where the pastures run short in mid-summer, and the lack of food, together with flies and heat, are cutting down gains already made, feeding with grain should be practiced.

1 Rept. Ont. Agrr. Col., 1886.

- Live Stock Report, Chicago, June 3, 1892. 
Where steers are grained on pasture, the feeder begins in the spring by supplying about one peck of corn per head, increasing the amount to fully one-third of a bushel daily by mid-summer for grown steers. The corn is dealt out once a day in a feed box in the lot. Pigs should follow to save the waste. Instead of giving corn only, it is better, when possible, to substitute two or three pounds of oil meal or bran for the same weight of corn. The feed should always be supplied at the same hour. Where grain is fed, not over half the usual area of pasture land is required. Pasture-fed steers eat about as much grain as if confined to the feed lot. (555)

592. Water.-It goes without saying that the fattening steer must be supplied with sufficient water to slake his thirst, for otherwise he would grow restless and fail to make proper gain. No effort should be made, however, to induce him to consume large quantities of water, which is considered to have a somewhat depleting effect on the body tissues. (73) Many good feeders insist that there be water before the cattle at all times, and usu- . ally this is the more convenient arrangement. If water is supplied but once a day, care should be taken that all animals have opportunity for a good fill.

593. Salting.- A nimals fed large quantities of nutritious food, such as fattening steers receive, show a strong desire for salt, and this craving should be satisfied by a reasonable supply. The excessive use of salt leads to a heavy consumption of water, thereby increasing the flow of urine - a result not desirable. (72-3, 85) Kühn ${ }^{1}$ recommends one ounce of salt per day, for a steer weighing 1,000 pounds, at the beginning of the fattening s period, one and one-third of an ounce at the middle, and one and two-thirds of an ounce at the close. The form of salt to be supplied to cattle, granular or rock, is a matter of convenience with the stockman.

594. What fattening the steer means. - It is important to have a clear knowledge of what the fattening process is. The grown steer, with framework of bone overlaid with muscles and encased

1 Ermähr. d. Rindviehes, 9th ed., p. 325. 
in hide, requires a certain amount of nutriment for mere existence. To supply this only, enables him to continue existence, but does not appease his appetite, which craves still more food. if provender beyond the requirements for maintenance is supplied, more or less of the surplus is converted into fat and stowed away among the muscular tissues of the body, in the bones, under the hide and about the viscera. This fat is fuel in the animal economy, for which Nature shows an eagerness by manufacturing and laying up a certain amount against the time of need. Impelled by a hearty appetite, the steer at first gains rapidly in fat, gratifying the feeder in the increase reported by the scales. After fat tening has progressed a few months, the appetite of the steer loses its keen edge, and he shows a daintiness when taking his food not at first exhibited. If placed on the scales from time to time, he shows smaller and smaller gains. Every pound of increase now requires more pounds of feed than at first. The fattening process may be likened to inflating a bicycle tire or a football with air. The operation is rapid and easy at first, but becomes more and more difficult until the limit is reached. Finally, the steer, though consuming a fair amount of feed, shows no gain whatever. He has been fattened to his limit, and though he may be held there for a time he will soon begin to retrograde, just as a ripened apple grows poorer in quality after perfection has been reached. The feeder, recognizing this, should aim to fatten his cattle rapidly, and, as soon as they are acceptably fat, dispose of them without delay. To continue fattening longer than demanded by the market, or to hold cattle when once fattened, adds greatly to their cost. (565)

595. Cost of feeding increases with age.-Excluding birth weight, the steer maintains a practically uniform rate of gain until he becomes two years old. While this is true in relation to gain in weight, we have shown that the cost of producing the gain in the second year is about double that for the first, and for the third the cost is about three times that of the first year. Recognizing these facts, the stockman who grows the cattle he feeds should place them on the market at as early a date as possible, other conditions being equal. (563-4) 
596. Cost of finished steer.-Anything from the lips or pen of that king of feeders of the last generation, J. D. Gillett, should be preserved. Here is Mr. Gillett's estimate of the cost of growing a steer up to thirty-six months of age: 1

\section{Cost of steer twelve months old.}

Value of calf at birth

Expenses of dam of calf, chargeable to calf for one year as follows: eight per cent. interest on $\$ 50$, value of cow.

Keep of yearling and feed of cow 12 months.

Insurance on cow.

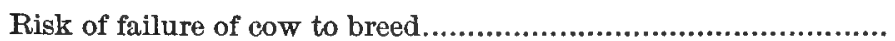

Loss of calves by death, etc

No corn fed up to 12 months.

Value of pasture and keep up to 12 months.

Total.

Weight of calf at 12 months, 700 pounds, at five cents. 3500

Profit at 12 months of age.

Cost from twelve to twenty-four months of age.

Value of steer at 12 months of age.

Value of shock corn, 110 bushels, at 35 cents..

Pasture 12 to 24 months..................................................... 300

Interest and risk............................................................. 280

Total................................................................... 7930

Less 500 pounds pork made on droppings of steer, at five cents... $\quad 2500$

Net cost 12 to 24 months

Weight of steer at 24 months 1,600 pounds, at six and a half cents 10400 Profit at 24 months of age.............................................. $49 \quad 70$

Cost from twenty-four to thirty-six months of age.

Value of steer at 24 months of age. $\$ 10400$

Value of shock corn consumed in entire year, 125 bus., at 35 cents $\quad 4375$

Pasture, May 1 to Nov. 1..................................................... 400

Interest and risk........................................................... 832

Total....................................................................... 16007

Less 500 pounds pork at five cents, made on droppings of steer... 2500

Cost at 36 months of age........................................ 13507

Weight at 36 months of age, 2,200 pounds, at seven cents.......... 15400

Profit at 36 months of age............................................ 1893

1 Fugitive paper copied into Farmer's' Review, Chicago, Dec. 7, 1882. 
In those days prices for grain, interest rates, and especially prices of fat cattle, were higher than at present, and the student in using the figures must make allowance for the changes wrought by time: the lesson taught still stands.

597. Modern market demands. - Some readers will recall the period when it was not considered advisable to fatten a steer until he was five years old; a much larger number will recollect the early exhibits at the American Fat-Stock Show, Chicago, where prizes were given for "big steers" often five or more years old and weighing up to two tons. The long-legged, raw-boned creatures that competed for premiums in those days are a thing of the past, though there is still room for improvement. The butcher now calls for " handy" steers, ranging from 1,200 to 1,500 pounds in weight. These are well described in the following, taken from Bell's Messenger:" "The winner now has to be short-legged, broad and deep, full in the flank, well sprung ribs, and good twist. His bottom lines should be as straight as his top lines, and as wide, and he should have no thick, patchy fat anywhere. Experience has shown that thick-bodied, short-legged steers, with full flanks, pay the feeder best, and give best profit to the butcher. Big ones are no longer needed. Small sizes are best, with plenty of quality, and with youth on their side the meat is juicy and tender. Age is counted in months now, instead of years, and the change is for the better."

To produce steers which meet these requirements a high degree of skill and judgment must be exercised in breeding and feeding. From the tables we are taught the important lesson that less feed is required to bring animals to the required standard because of the smaller size of the individuals when fattened. High skill in breeding and feeding thus oppose the plainer breeding and slower feeding of former times.

598. Early maturity. - What can be accomplished in the way of early maturity is illustrated by results obtained by Mr. W. A. Harris, of Linwood, Kansas. ${ }^{2}$ Mr. Harris fed pure-bred and grade Short-horn calves, coming in December, January and Feb-

Quoted in Live Stock Rept., Chicago, July 19, 1895.

2 Breeder's Gazette, Chicago, 18j0, p. 437. 
ruary, nntil the following December, at which time they averaged eleven months old. These calves received most of their dam's milk until six or seven months old. Mr. Harris calculates that they consumed -

20 bushels of ear corn, worth........................................ \$5

1,000 pounds of bran, worth ..................................... 6

300 pounds of oil meal, worth..................................... 3

Total cost of grain ............................................. $\$ 14$

In addition they had pastures and what hay they wonld eat, valued at $\$ 4$. These calves weighed from 910 to 920 pounds each at eleven months and sold from $\$ 3.80$ to $\$ 5$ per hundred, which returns are certainly satisfactory when the short time for turning the capital involved is considered. All farmers are not in position to follow such forcing methods as these, yet it is well to bear this extreme example in mind, and consider whether or not the results cannot be approximated if not actually attained.

599. Low-pressure feeding.- Under the system just recommended, much costly concentrated feed is required. There are farms on which the high-pressure system is not advisable, but where cattle may be profitably fed by following an almost opposite method. On farms where there are large quantities of hay, straw and corn forage, together with ample pastures, it is possible to practice a system which utilizes all these, reserving most of the grain grown for use during the final fattening period. Under this system the calves designed ultimately for beef are fed a small amount of grain only during the first year, receiving an abundance of roughage in winter and running on good pastures in summer. Such stock should more than hold its weight in winter and gain heavily on the pastures in summer. Heavy feeding with grain begins when the steers are two years old. Well-bred steers from 30 to 36 months old raised in this manner, fed grain in quantity only during the last five or six months, should weigh from 1,300 to 1,500 pounds - a size ample for market demands.

600. The feed lot.-Dry, protected yards, with sheds on the windward side under which the animals may lie in comfort, form the ideal place for steer feeding. To keep the steer stanchioned or confined by a rope in the stable entails nseless labor on the 
stockman, prevents proper exercise, and conduces to a filthy appearance of the animal, thus working against the best gains and the highest sale price. Crude as has been much of the open-yard feeding in the West, the cattle so fed have really experienced more comfort than had they been confined in the stable, as is common in the East. The fattening steer places the excess food in an increasing layer of fat under the skin, which retains the heat. His food is heating in character, and, being in a plethoric condition, he much prefers the open air and sunshine with the freedom of the yard, even in winter, to the confinement of the stable with its foul air and cramped quarters.

601. Feed racks. - Let the sheds be so constructed as to afford protection from the winds and driving storms. Either under the shed, where accessible by wagon, or in an open lot which the shed faces, and close by, arrange racks for fodder and boxes for grain. It is not well to have feed boxes and fodder rack combined, since the litter from the forage falling upon the feed renders it distasteful to cattle with dainty appetites.

602. Frequency of feeding.- There is nothing helpful on this point from experiments, and when we turn to feeders for light we find a diversity of opinion as to the proper practice. It is reasonable that all young animals should be fed at least three times a day, while those approaching maturity and not heavily fed are amply provided for in two feeds. Maturing cattle prosper, and perhaps do their best, when supplied grain but once a day, with roughage to run to at pleasure. It is certain that many of the best feeders at the West supply grain but once a day. The oncefed steer goes to the trough with paunch well emptied and appetite at the best; flling himsclf to the utmost, he has ample time for rumination and subsequent digestion.

603. Getting cattle to full feed.-The fattening steer should be brought to full feed gradually, the time required in reaching that point varying from one to two months. Steers which have previously been fed grain take to it readily, while those which have always lived on roughage and pastures must be carefully managed in this particular. Young cattle are more dificult to bring to full feed than mature ones. By supplying an abundance of rough- 
age of good quality there is less danger in bringing cattle to full feed.

When once the feeding period is well inaugurated, all sudden changes in attendants, place and manner of feeding as well as of the feed itself should be carefully avoided. Everything should move with quiet, clock-like regularity. The cattle come to know not only the hour but almost the minute of the feeder's arrival and watch for him. On his coming they expect the same sort of feed as before and the same little attentions. All of this means better gains than are possible from any irregular system. If changes in feed are necessary, as they sometimes are,- - for example, changing from ear corn or shelled corn to corn meal,- the transition should be gradual rather than immediate and violent. Sometimes stockmen are tempted to give their cattle bits of unusual food in expectation of stimulating the appetite and getting heavier gains. This practice is often worse than useless. The gourmand steer is content with uniformity in his rations, and if not led to anticipate unusual attentions is satisfied with a limited bill of fare, provided always the supply is ample.

604. Close attention required.-The ability to fatten cattle rapidly and profitably is a gift, to be increased and strengthened by experience and study. The ability to carry a steer through a six months" fattening period without once getting him "off feed" is possessed by many a stockman; but how this faculty is attained is something he cannot always impart to others. In general, when the steer has reached full feed, all the grain he will readily consume should be supplied, but any left in the feed box, to be breathed over, is worse than wasted.

Scouring, the bane of the stock feeder, should be carefully aroided, since a single day's laxness will cut off a week's gain. This trouble is generally induced by over-feeding, by unwholesome food, or by a faulty combination in the ration. Over-feeding comes from a desire of the attendant to push his cattle to better gains, or from carelessness and irregularity in measuring out the feed supply. The ideal stockman has a quick discernment which takes in every animal in the lot at a glance, and a quiet judgment which guides the hand in dealing out feed ample 
for the wants of all, but not a pound excess. Cattle of the same age, or at least those of equal size and strength, should be fed in the same enclosure. Weak animals, and those unable for any rear son to crowd to the feed trough and get their share, should be placed where they can be supplied in quiet.

605. Other points to be observed.- The droppings of the steer are an excellent index of the progress of fattening. While they should never be hard, they should still be thick enough to "pile up" and have that unctuous appearance which indicates a healthy action of the liver. There is an odor from the droppings of thrifty, well-fed steers known and quickly recognized by every good feeder. Thin droppings and those with a sour smell indicate something wrong in the feed yard.

The conduct of the steer is a further guide in marking the progress of fattening. The manner in which he approaches the feed box; his quiet pose while ruminating and audible breathing when lying down, showing the lungs cramped by the well-filled paunch; the quiet eye which stands full from the fattening socket; the oily coat, - all are points that awaken the interest, admiration and satisfaction of the successful feeder.

606. Preparing steers for shipment.-Clay" writes: "A day or two previous to shipping, feed the cattle in a pen, and feed hay only. The secret of shipping all classes of cattle is to place them on the cars full of food but with as little moisture as possible. A steer full of water is apt to have loose bowels and show up badly in the yards; properly haudled cattle should arrive in the sale pens dry behind and ready for a good fill of water; not very thirsty but in good condition to drink freely. Many shippers think that by salting their cattle or feeding them oats they can fool the buyers, but it always goes against them to use unnatural amounts. As to feed on the road, nothing equals good sweet hay, which excels corn or other grains because it is easily digested and does not fever the animal. Of water in mid-summer, care must be taken to supply the animal wants, whereas in winter a steer call go for many hours without a drink. Cattle should arrive at the sale yards at from 5 to 8 A. M., appearing on the scene as

\footnotetext{
' Live Stock Report, Chicago, Sept. 28, 1894.
} 
near the latter hour as possible, since they always look better just after they have been fed and watered."

Funkhouser ${ }^{1}$ advises feeding all the hay the cattle will eat, and reducing the grain fed at least one-half two or three days before shipping. For steers in transit allow 250 pounds of hay and one and one-half bushels of grain per car. Steers on pasture that have had corn should be taken off pasture twenty-four hours before shipping, and allowed half a feed of corn with plenty of hay.

\section{Rations for Fattening Steers.}

607. Theoretical rations for fattening steers.-To show the amount of feed a steer should receive according to the Wolff-Lehmann standard, two rations are presented which are reasonably close to the requirements. In the first, corn is the leading concentrate, with oil meal additional to furnish the protein; in the second, silage furnishes the roughage, with bran, corn and cob meal and cotton-seed meal for the concentrates. See Chapter VII, Part II.

Rations compounded in accordance with the Wolf-Lehmann feeding standard for steers weighing 1,000 pounds, first period.

\begin{tabular}{|c|c|c|c|c|}
\hline & \multirow[b]{2}{*}{$\underset{\text { matter. }}{\text { Dry }}$} & \multicolumn{3}{|c|}{ Digestible nutrients. } \\
\hline & & $\begin{array}{l}\text { Pro- } \\
\text { tein. }\end{array}$ & $\begin{array}{c}\text { Carbo- } \\
\text { hy- } \\
\text { drates. }\end{array}$ & $\begin{array}{l}\text { Ether } \\
\text { extract. }\end{array}$ \\
\hline $\begin{array}{c}\text { Ration No. } 1 . \\
\text { Wolff-Lehmann standard................... }\end{array}$ & $\begin{array}{l}\text { Lbs. } \\
30\end{array}$ & $\begin{array}{l}\text { Lbs. } \\
2.50\end{array}$ & $\begin{array}{l}\text { Lbs. } \\
15.00\end{array}$ & $\begin{array}{r}\text { Lbs. } \\
.50\end{array}$ \\
\hline 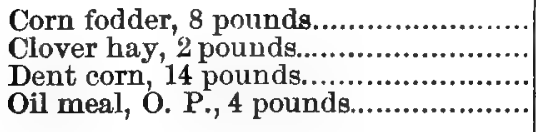 & $\begin{array}{r}4.62 \\
1.69 \\
12.52 \\
3.63\end{array}$ & $\begin{array}{r}.20 \\
.13 \\
1.09 \\
1.17\end{array}$ & $\begin{array}{r}2.77 \\
.72 \\
9.34 \\
1.31\end{array}$ & $\begin{array}{l}.03 \\
.03 \\
.60 \\
.28\end{array}$ \\
\hline 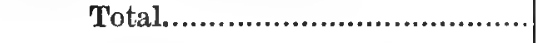 & 22.46 & 2.59 & 14.14 & .94 \\
\hline 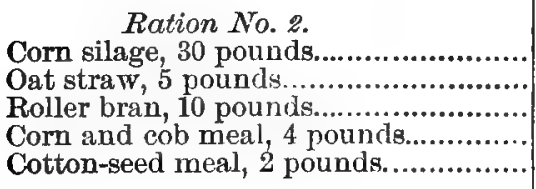 & $\begin{array}{l}6.27 \\
4.54 \\
8.81 \\
3.40 \\
1.84\end{array}$ & $\begin{array}{r}.27 \\
.06 \\
1.22 \\
.18 \\
.74\end{array}$ & $\begin{array}{r}3.39 \\
1.93 \\
3.92 \\
2.40 \\
.38\end{array}$ & $\begin{array}{l}.21 \\
.04 \\
.27 \\
.12 \\
.24\end{array}$ \\
\hline Total............... & 24.86 & 2.47 & 12.02 & .88 \\
\hline
\end{tabular}

' Breeder's Gazette, Chicago, Jan. 18, 1893. 
In both rations there is much less dry matter than is called for by the standard. This departure is not of much significance, as the ration possesses a reasonable volume. The carbohydrates are less than called for by the standard, but this is nearly made good by the excess of ether extract.

These rations are constructed on purely theoretical grounds, but will be found satisfactory where the feeding-stuffs called for are reasonable in price.

608. Rations used at the Experiment Stations.- In the feeding trials at various Experiment Stations numerous rations have been used, a few of which are here presented, care being taken in their selection to present as wide a range of feeding materials as possible.

\section{Ontario Agricultural College. 1}

\section{Roots and barley.}

Av. wt. of steers fed.

Daily gain......................

Hay

Roots

Bran

Barley
Lbs. 1,061

2.14

12.

5.

11.25

Roots and corn.

Lbs.

Av. wt. of steers fed......... 1,106

\begin{tabular}{ll} 
Daily gain....................... & 2.31 \\
\hline Hay .............................. & 9.5
\end{tabular}

Roots

34.

Bran

3.5

Corn

9.25

Iowa Experiment Station. ${ }^{2}$

Corn and oil meal.

Lbs.

Av. wt. of steers fed........ 1,340

Daily gain

2.8

Snapped corn

22.5

Corn meal

\section{7}

4.2

Hay

5.7

Oregon Experiment Station. ${ }^{8}$

Wheat and silage.

Lbs.

Av. wt. of steers fed. 847

Daily gain ...................... 2.

Chopped wheat............. 10.3

Clover hay.

8.

Oil meal

Corn silage.

18.

\section{Kansas Experiment Station.}

"Balanced" ration. Lbs. Av. wt. of steers fed........ 1,083

\begin{tabular}{l} 
Daily gain .................... \\
\hline Corn meal
\end{tabular}

Corn meal.

10.

Shorts

5.

Corn and stover.

Lbs.

Bran

2.

Oil meal.

4.

Tame hay

6.5

\begin{tabular}{lr} 
Daily gain ..................... & 1.7 \\
\hline Ear corn....................... & 26.7
\end{tabular}

Stover
${ }^{1}$ Rept. 1883.
2 Bul. 20.
s Bul. 37.
- Buls. 34 and 39. 


\section{Texas Experiment Station. ${ }^{1}$}

Cotton-seed meal and hulls. Lbs.

Av. wt. of steers fed.

Daily gain

Cotton-seed meal

Cotton-seed hulls.

Corn silage.
638

1.76

5.

7.2

20.
Corn and cotton seed. Av. wt. of steers fed.

Lbs.

\begin{tabular}{ll} 
Daily gain & \\
\hline Corn................................ & 5.3
\end{tabular}

Cotton seed .................... $\quad \mathbf{5 . 2}$

Hay ........................... 5.3

\section{Fattening Range Cattle.}

609. Description of operations. - About the year 1885 several companies controlling Western ranges undertook the experiment of moving cattle to points in the corn belt for fattening while in transit to the stock markets. Two results were sought, - a higher finish, and relieving an overstocked range. Of the several efforts in this direction, that of the Standard Cattle Co., with ranches in Wyoming and Montana, and a feeding establishment at Ames, Neb., is the best example. The possessions of this company at Ames include a number of farms aggregating several thousand acres, with additional rented lands lying in the Platte valley possessing a rich, black, sandy soil, well adapted to corn growing.

The barn of this company is 682 feet long and over 200 feet wide, with a capacity for 3,008 steers, each animal occupying a separate stall $4 \times 8$ feet. There are eight double rows of cattle with heads toward each other. A tramway extends between each double row of cattle, down which a car travels used for distributing the meal and hay, which are placed in broad, flat feeding boxes, the sides of which act as rails for the car wheels. On each side of the feed boxes next to the steers is a narrow trough through which fresh water for drinking continually flows. The pumps which lift this water also send a flood down the ditch behind the steers, into which passes from each stall the voidings of the animals, the whole wasting into the Platte river. The roof of this monster barn begins low at the sides and rises by steps with windows in each rise, so that the interior is well lighted and easily ventilated. A mill and elevator adjoining is connected by a tramway. The arrangements permit feeding the cattle and cleaning the stable with the minimum of labor. Each season, in addition to the

1 Bul. 27. 
cattle in the stable, several thousand are fed in bunches of a few hundred each on the outlying farms of the company. These steers are fed grain in open boxes, supplied once or twice a day, and hay from long racks filled whenever occasion requires.

This mammoth business has from its inception been under the care of Mr. R. M. Allen, General Manager of the Company, who gives personal supervision to the work in all departments. From a careful examination of the feeding operations as conducted at the stable and the several outdoor quarters in 1890, at which time over 7,000 cattle were receiving grain, the writer believes the experiment of wholesale range cattle feeding at Ames has as fair a trial as can possibly be given.

Fortunately for the student, Mr. Allen has kept complete records of all feeding operations from the beginning. The results are an accumulation of data bearing on the question of the wholesale feeding of range cattle, which because of the magnitude of the operations, the many years covered by them, and the unusual care and accuracy with which the records have been kept, have become invaluable to the student of animal husbandry, as well as of keen interest to many who have to deal with the problem of cattle-feeding at the West.

610. The data obtained.-The tables here presented give the most important data of the operations at Ames down to the present, covering eleven years' operations, during which time 49,648 cattle have been fed. These cattle were mostly steers from Wyoming and Montana ranges with some Texans and spayed heifers. The cattle were four and five years old when fed. They were wild when brought to the feeding station, and were unused to feed and confinement. These conditions combined to make the preliminary feeding period a long one, and the quantity of feed required for a given gain large. Notwithstanding this the operation as a whole is thoroughly representative of its class, and furnishes an important and instructive lesson. ${ }^{1}$

1 The data presented were kindly furnished by Mr. Allen. A more eztended account of the operations is given by Coburn in the Quarterly Report of the Kansas State Board of Agriculture, December, 1897. 
Number of cattle marketed and gains - Standard Cattle Co., Allen.

\begin{tabular}{|c|c|c|c|c|c|c|}
\hline Year. & $\begin{array}{l}\text { Number } \\
\text { of cattle } \\
\text { marketed. }\end{array}$ & $\begin{array}{l}\text { Number } \\
\text { of days } \\
\text { fed. }\end{array}$ & $\begin{array}{c}\text { Av. wt. } \\
\text { of cattle } \\
\text { when } \\
\text { received. }\end{array}$ & $\begin{array}{c}\text { Av. wt. } \\
\text { of cattle } \\
\text { at } \\
\text { market. }\end{array}$ & $\begin{array}{l}\text { Av. } \\
\text { gain. }\end{array}$ & $\begin{array}{l}\text { Shrink- } \\
\text { age per } \\
\text { head. }\end{array}$ \\
\hline & & & Lbs. & Ibs. & Lbs. & Lbs. \\
\hline $1886-87 .$. & 5,417 & 151 & 959 & 1,097 & 138 & 13.2 \\
\hline $1887-88 .$. & 5,586 & 202 & 989 & 1,235 & 246 & 62.3 \\
\hline 1888.89. & 4,269 & 180 & 1,036 & 1,298 & 262 & 24.9 \\
\hline $1889-90$. & 6,033 & 197 & 870 & 1,119 & 249 & 22.8 \\
\hline $1890-91 .$. & 7,298 & 222 & 1,032 & 1,272 & 240 & 35.9 \\
\hline $1891-92$. & 2,176 & 252 & 1,116 & 1,399 & 283 & 71.6 \\
\hline $1892-93$. & 1,222 & 126 & 955 & 1,175 & 220 & 59.2 \\
\hline $1893-94 .$. & 2,539 & 182 & 1,053 & 1,281 & 228 & 54.3 \\
\hline $1894-95 .$. & 5,878 & 152 & 1,073 & 1,290 & 217 & 42.8 \\
\hline & 3,775 & 171 & 1,154 & 1,392 & 238 & 46.6 \\
\hline 189 & 5,454 & 215 & 1,066 & 1,304 & 238 & 41.8 \\
\hline
\end{tabular}

Amount of grain and hay fed to cattle reported in previous table.

\begin{tabular}{|c|c|c|c|c|c|c|}
\hline Year. & Corn. & Oats. & Bran. & Oll meal. & Hay. & Stover. \\
\hline & Lbs. & Lbs. & Lbs. & Lbs. & Tons. & Tons. \\
\hline 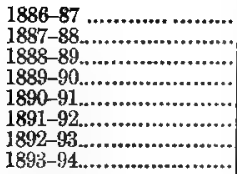 & $\begin{array}{r}9,693,702 \\
17,060,838 \\
10,421,864 \\
21,061,820 \\
19,389,664 \\
9,987,798 \\
2,192,680 \\
6,740,328\end{array}$ & 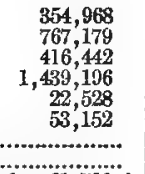 & $\begin{array}{r}1,453,176 \\
624,885 \\
428,530 \\
2,451,255 \\
1,208,010 \\
6,132 \\
10,470 \\
241,895\end{array}$ & $\begin{array}{r}1,143,000 \\
660,752 \\
706,966 \\
390,856 \\
8,717,890 \\
270,690 \\
151,480 \\
481,320\end{array}$ & $\begin{array}{l}6,050 \\
7,817 \\
4,682 \\
3,340 \\
7,805 \\
4,302 \\
1,101 \\
2,042\end{array}$ & (n) \\
\hline $1894-95 \ldots \ldots \ldots$ & $9,388,121$ & $\left\{\begin{array}{r}61,790 \\
1,443,606 *\}\end{array}\right.$ & $2,022,140$ & $2,517,532$ & 3,546 & 1,433 \\
\hline $1895-96 \ldots \ldots \ldots$ & $8,728,384$ & $(1,849,536)$ & $1,121,090$ & 798,040 & 1,451 & 2,864 \\
\hline 1896-97_........................... & $21,288,792$ & $\left\{\begin{array}{c}34,208 \\
194,688 \dagger \\
15,250_{+}^{-}\end{array}\right\}$ & 718,000 & 228,000 & 4,087 & 5,988 \\
\hline
\end{tabular}

* Wheat. †Barley. †Peas.

Daily feed consumed and daily gains.

\begin{tabular}{|c|c|c|c|c|c|c|}
\hline Year. & $\begin{array}{c}\text { No. of } \\
\text { cattle fed. }\end{array}$ & $\begin{array}{l}\text { No. of } \\
\text { days fed. }\end{array}$ & $\begin{array}{l}\text { "Grain per } \\
\text { head per } \\
\text { day. }\end{array}$ & $\begin{array}{c}\text { Hay per } \\
\text { head per } \\
\text { day. }\end{array}$ & $\begin{array}{c}\text { Stover per } \\
\text { head per } \\
\text { day. }\end{array}$ & $\begin{array}{l}\text { Ar. gain } \\
\text { of cattlo } \\
\text { per day. }\end{array}$ \\
\hline 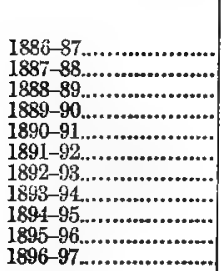 & $\begin{array}{l}5,532 \\
5,717 \\
1,355 \\
7,090 \\
7,376 \\
2,198 \\
1,269 \\
2,609 \\
5,925 \\
3,827 \\
5,495\end{array}$ & $\begin{array}{l}151 \\
202 \\
180 \\
197 \\
222 \\
252 \\
126 \\
182 \\
152 \\
171 \\
215\end{array}$ & $\begin{array}{l}\text { Lbs. } \\
15.1 \\
16.5 \\
15.3 \\
18 \\
15 \\
19 \\
14.7 \\
15.7 \\
17 \\
19 \\
19\end{array}$ & $\begin{array}{r}\text { Lbs. } \\
12.1 \\
13.5 \\
11.9 \\
4.8 \\
9.5 \\
15.9 \\
13.7 \\
8.6 \\
7.8 \\
4.5 \\
6.9\end{array}$ & 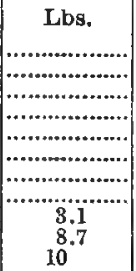 & $\begin{array}{r}\text { Lbs. } \\
.9 \\
1.2 \\
1.4 \\
1.3 \\
1.1 \\
1.1 \\
1.7 \\
1.3 \\
1.4 \\
1.4 \\
1.1\end{array}$ \\
\hline
\end{tabular}


Cost for food and labor of feeding cattle, seasons of 1894-95, 1895-96 and 1896-97-Standard Cattle Co., Allen.

\begin{tabular}{|c|c|c|c|c|c|c|}
\hline & \multicolumn{2}{|c|}{$1894-95}$. & \multicolumn{2}{|c|}{$1895-96}$. & \multicolumn{2}{|c|}{$1896-97}$. \\
\hline & $\begin{array}{l}\text { Amount } \\
\text { per head. }\end{array}$ & $\begin{array}{l}\text { Cost per } \\
\text { head. }\end{array}$ & $\begin{array}{l}\text { Amount } \\
\text { per head. }\end{array}$ & $\begin{array}{l}\text { Cost per } \\
\text { head. }\end{array}$ & $\begin{array}{l}\text { Amount } \\
\text { per head. }\end{array}$ & $\begin{array}{l}\text { Cost per } \\
\text { head. }\end{array}$ \\
\hline & Bu. & & Bu. & & Bu. & \\
\hline Corn........................ & 28.3 & $\$ 1213$ & 40.7 & $\$ 719$ & 69.1 & $\$ 855$ \\
\hline Oats ...................... & .3 & 09 & 8.6 & 217 & .2 & 03 \\
\hline Bran........................ & 6.1 & 244 & 5.2 & 159 & 2.3 & 46 \\
\hline Oil cake................ & 7.6 & 427 & 3.7 & 167 & .7 & 37 \\
\hline Wheat.................. & & 213 & n............. & & & \\
\hline & & ............... & (....................... & (............ & 7 & $\begin{array}{l}04 \\
17\end{array}$ \\
\hline Hay ...................... & $\begin{array}{r}\text { Tons. } \\
.6\end{array}$ & 361 & $\begin{array}{r}\text { Tons. } \\
.4\end{array}$ & 63 & Tons. & 78 \\
\hline $\begin{array}{l}\text { Stover .................... } \\
\text { Forgge beets. }\end{array}$ & & & & & 1.1 & 155 \\
\hline Forage beets.......... & .................... & 12 & ….............. & 124 & ................. & 71 \\
\hline 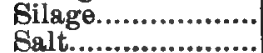 & ................... & 03 & .................. & 07 & ................... & 10 \\
\hline Salt............................... & a................ & & …................ & & $\ldots \ldots \ldots \ldots \ldots$ & \\
\hline Total grain....... & $\begin{array}{l}\text { Bu. } \\
46.4\end{array}$ & & $\begin{array}{l}\mathrm{Bu} . \\
58.2\end{array}$ & & $\begin{array}{l}\mathrm{Bu.} \\
74.8\end{array}$ & \\
\hline $\begin{array}{l}\text { Total hay and } \\
\text { stover.................... }\end{array}$ & $\begin{array}{r}\text { Tons. } \\
.6\end{array}$ & \} 2485 & $\begin{array}{r}\text { Tong. } \\
.4\end{array}$ & \} 1458 & $\begin{array}{r}\text { Tons. } \\
1.8\end{array}$ & \\
\hline Labor.................... & ..................... & 171 & (................... & 255 & (............. & 167 \\
\hline 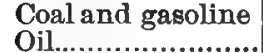 & (.................. & 24 & ................. & 16 & (.......... & $\begin{array}{l}35 \\
02\end{array}$ \\
\hline Insurance............. & ............... & 21 & ................. & & ,.............. & \\
\hline Horse forage ........ & ................... & 33 & ................ & 45 & ................ & 23 \\
\hline Total labor......... & $\mid \ldots \ldots \ldots \ldots$ & 249 & …............. & 316 & ................. & 227 \\
\hline $\begin{array}{l}\text { Total food and } \\
\text { labor................... }\end{array}$ & & 2734 & & 1774 & & 1507 \\
\hline Av. No. days fed. & & 152 & & 171 & & 215 \\
\hline in pounds......... & & 217 & & 238 & & 238 \\
\hline 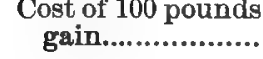 & $\$ 12$ & & $\$ 7$ & 45 & & 33 \\
\hline
\end{tabular}




\section{CHAPTER XXIV.}

\section{THE DAIRY OOW - SOIENTIFIO FINDINGS.}

611. Period of gestation.- "The average period of gestation for the cow is 284 days; small cows, heifers with their first calf, and old animals, usually go a day or two less; bulls are carried a day or two longer than cow-calves." 1

612. Economy of the dairy cow.- Not only is dairying the leading animal industry of our country at this time, but so it must continue indefinitely, for the reason that the cow is a more economical producer of food for human beings than is the ox or the pig. This is ably shown by Lawes and Gilbert ${ }^{2}$ in the following table:

Comparison of the constituents of food carried off in mille and in the fattening increase of the ox-Lawes and Gilbert.

(1 Imperial gallon =1 quarts = 10.33 lbs.) $\left|\begin{array}{c}\text { Nitrog- } \\ \text { enous } \\ \text { sub- } \\ \text { stance. }\end{array}\right|$ Fat. $\left|\begin{array}{c}\text { Non-nitro- } \\ \text { genous } \\ \text { sustances } \\ \text { not fat } \\ \text { (sugar). }\end{array}\right| \begin{aligned} & \text { Mineral } \\ & \text { matter. }\end{aligned} \mid \begin{gathered}\text { Total } \\ \text { solid } \\ \text { matter. }\end{gathered}$

In milk per week - Cow.

\begin{tabular}{|c|c|c|c|c|c|}
\hline & & & & & \\
\hline 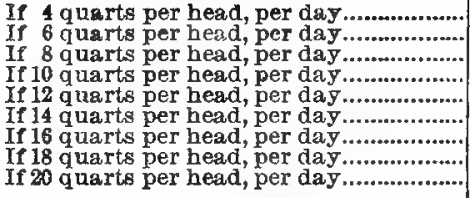 & $\begin{array}{r}2.64 \\
3.96 \\
5.28 \\
6.60 \\
7.92 \\
9.24 \\
10.56 \\
11.88 \\
13.20\end{array}$ & $\begin{array}{r}2.53 \\
3.80 \\
5.06 \\
6.33 \\
7.59 \\
8.86 \\
10.12 \\
11.39 \\
12.65\end{array}$ & $\begin{array}{r}3.33 \\
1.99 \\
6.66 \\
8.32 \\
9.99 \\
11.65 \\
13.32 \\
14.98 \\
16.65\end{array}$ & $\begin{array}{r}.54 \\
. .81 \\
1.08 \\
1.35 \\
1.62 \\
1.89 \\
2.16 \\
2.43 \\
2.70\end{array}$ & $\begin{array}{r}9.04 \\
13.56 \\
18.08 \\
22.00 \\
27.12 \\
81.64 \\
36.16 \\
40.68 \\
45.20\end{array}$ \\
\hline
\end{tabular}

In Increase in live weight per week - Ox.

\begin{tabular}{|c|c|c|c|c|c|}
\hline 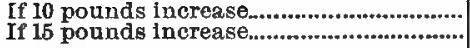 & 1.75 & $\begin{array}{l}6.35 \\
9.53\end{array}$ & $\mid+\ldots+\ldots+\cdots+\cdots+\cdots$ & .15 & $\begin{array}{r}7.25 \\
10.88\end{array}$ \\
\hline
\end{tabular}

We are shown by the table that the fattening steer, gaining 15 pounds weekly, yields 1.13 pounds of nitrogenous substance or

${ }^{1}$ Sheldon, Dairy Farming. $\quad$ ' Jour. Roy. Agr. Soc., 1895. 
water-free lean meat, while the dairy cow during the same period, when yielding 10 quarts of milk daily, returns in this milk 6.6 pounds of nitrogenous substance, casein and albumen, or six times as much. Of mineral matter the ox stores during the week .22 pounds, while the dairy cow secretes in her milk 1.35 pounds, or again, about six times as much. The steer adds to his carcass 9.53 pounds of fat, while in the milk of the cow there are 6.33 pounds of fat, or two-thirds as much. During this time, however, the cow has secreted in her milk 8.32 pounds of milk sugar, against which there is no comparable substance in the flesh of the ox. Reducing this sugar to its fat equivalent, (60) the cow is shown to have yielded as much fat or fat equivalent as has the steer. Commenting on this table, Lawes and Gilbert write: 1

"Thus, as compared with fattening increase, which may, in a sense, be said to be little more than an accumulation of reserve material from excess of food, milk is a special product of a special gland for a special normal exigency of the animal."

Thorne, of the Ohio Station, ${ }^{2}$ comparing the returns from steers and dairy cows, concludes that the steer gains three pounds in live weight when consuming the same quantity of feed as the cow when producing one pound of butter-fat.

In this country, where stock foods are still so abundant and population sparse, we use the flesh of animals freely, even wastefully. When population grows dense, the ox will be the first to disappear from our agriculture because it is not an economical producer of human food, while the dairy cow will remain an economical instrument for that purpose. (695)

613. Yield of products. - A good dairy cow will yield in one year 6,600 pounds of milk, in which there are:

285 pounds of fat.

376 pounds of milk sugar.

220 pounds of casein and albumen.

49 pounds of ash.

Total, $\overline{930}$ pounds of solids.

These substances are practically all digestible.

\footnotetext{
Loc. cit. 1893.
} 
614. Ratio of milk yield to body weight. - Kraemer ${ }^{1}$ states that cows yield during the year from four to eight times their body weight in milk, and that each pound of dry matter fed will return from four- to eight-tenths of a pound of milk, these returns being gauged by the character of the cow, as follows:

$\begin{array}{lcc}\begin{array}{l}\text { Character } \\ \text { of cow. }\end{array} & \begin{array}{c}\text { Yield of milk } \\ \text { in body weight. }\end{array} & \begin{array}{c}\text { Milk per pound } d r y \\ \text { matter } \text { in feed. }\end{array} \\ \text { Poor................................ } & 4 \text { times. } & .4 \text { pounds. } \\ \text { Medium .......................... } & 5 \text { times. } & .5 \text { pounds. } \\ \text { Good ............................. } & 6 \text { times. } & .6 \text { pounds. } \\ \text { Very good......................... } & 7 \text { times. } & .7 \text { pounds. } \\ \text { Excellent........................... } & 8 \text { times. } & .8 \text { pounds. }\end{array}$

615. Percentage fat in successive portions of milk.-At the New York (Geneva) Station, ${ }^{2}$ Collier examined the milk from 5 cows as drawn, pint by pint, and found the fat in the successive lots as follows: $.85,1.43,1.68,2.02,2.23,2.65,3.27,3.74,4.05,4.86$, 4.48, 4.30, 5.23, while the average of the whole milk was 3.21. The average per cent. of fat in the first and last pints was .85 and 5.23 , an increase of about 500 per cent. The average per cent. of fat in the first and last halves of the milk was 1.92 and 4.35, an increase of 127 per cent.

The above shows the poverty in fat of the first milk drawn from the cow and the richness of that last drawn. It shows that those who allow calves to have the first milk from the cow and reserve the strippings withhold the richest milk.

616. Concerning fat globules.-Collier ${ }^{3}$ places the average secretion of milk by the cow at .7 of a pound or 19.6 cubic inches per hour. One ten-thousandth of a cubic millimeter of milk was found to contain on an average 152 fat globules. (828) From ; these data he concludes that the average cow in the Geneva Station herd secreted 138,210,000 fat globules each second. According to Babcock ${ }^{4}$ the number of fat globules in a quart of milk of average composition is not less than 2,000,000,000,000. These figures are beyond comprehension, and should increase our interest in the marvelons processes of animal life Appreciating

\footnotetext{
1 Die Schule der Schweizer-käsers.

2 Rept. 1891.

Rept. New York (Geneva) Sta., 1892.

1 Bul. 18, Wis. Expt. Sta.
} 
these facts the thoughtful dairyman will not regard the dairy cow an idler.

617. Relation of live weight to yield.-The relation of live weight to yield of milk and fat by cows is illustrated in the following table by Woll, ${ }^{1}$ which gives a summary of the results of Breed Test No. 1, conducted at the World's Columbian Exposition, Chicago, 1893, the data given being the average and total figures for seventy-five animals. (See Chapter XXVI, Part I.) The cows are grouped according to their live weight into three sets, the first including the lightest animals, the second representing the medium, and the third the heavy cows. The scale of prices for feeds is of course arbitrary, but being the same for all animals it serves the desired purpose.

Relation of average live weight of cows to yield of milk and fatColumbian Dairy Test No. 1, fifteen days - Woll.

\begin{tabular}{|c|c|c|c|c|c|c|c|}
\hline \multirow{2}{*}{ Breed. } & \multirow{2}{*}{$\begin{array}{l}\text { Live } \\
\text { wt. }\end{array}$} & \multicolumn{2}{|c|}{ Yield of- } & \multicolumn{2}{|c|}{$\begin{array}{l}\text { Yield per 1,000 } \\
\text { lbs. live weight. }\end{array}$} & \multirow{2}{*}{$\begin{array}{c}\text { Cost } \\
\text { of } \\
\text { food. }\end{array}$} & \multirow{2}{*}{$\begin{array}{l}\text { Cost of } \\
\text { producing } \\
\text { 100 lbs. } \\
\text { of fat. }\end{array}$} \\
\hline & & Milk. & Fat. & Milk. & Fat. & & \\
\hline 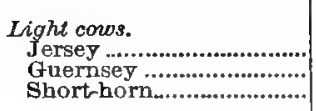 & $\begin{array}{r}\text { Lbs. } \\
846 \\
839 \\
988\end{array}$ & $\begin{array}{l}\text { Lbs. } \\
\text { al0.1 } \\
422.0 \\
\mathbf{4 3 4 . 3}\end{array}$ & $\begin{array}{l}\text { Lbs. } \\
22.91 \\
18.49 \\
15.86\end{array}$ & $\begin{array}{c}\text { Lbs. } \\
603.0 \\
502.9 \\
439.5\end{array}$ & $\begin{array}{l}\text { Lbs. } \\
27.08 \\
222.04 \\
16.05\end{array}$ & $\begin{array}{rl}8 & 77 \\
3 & 00 \\
3 & 50\end{array}$ & $\begin{array}{r}\$ 1645 \\
1623 \\
2206\end{array}$ \\
\hline Average & 891 & 455.5 & 19.09 & 511.2 & 21.42 & $\$ 32$ & $\$ 1793$ \\
\hline 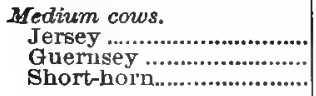 & $\begin{array}{r}923 \\
923 \\
1,127\end{array}$ & $\begin{array}{l}532.1 \\
417.8 \\
510.0\end{array}$ & $\begin{array}{l}24.74 \\
18.97 \\
18.47\end{array}$ & $\begin{array}{l}576.5 \\
452.6 \\
452.7\end{array}$ & $\begin{array}{l}26.80 \\
20.55 \\
16.40\end{array}$ & 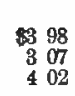 & $\begin{array}{rl}\$ 16 & 09 \\
16 & 14 \\
21 & 74\end{array}$ \\
\hline 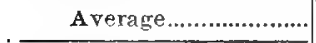 & 991 & 486.6 & 20.73 & 490.9 & 20.91 & $\$ 369$ & $\$ 1779$ \\
\hline 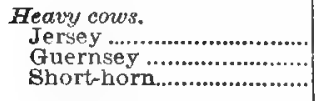 & $\begin{array}{r}999 \\
1,001 \\
1,302\end{array}$ & $\begin{array}{l}557.3 \\
475.0 \\
524.7\end{array}$ & $\begin{array}{l}24.74 \\
21.10 \\
18.22\end{array}$ & $\begin{array}{l}557.8 \\
474.5 \\
403.1\end{array}$ & $\begin{array}{l}24.77 \\
21.38 \\
14.00\end{array}$ & $\begin{array}{r}404 \\
308 \\
409\end{array}$ & $\begin{array}{r}\$ 1633 \\
1440 \\
2245\end{array}$ \\
\hline 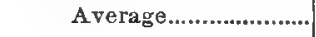 & 1,101 & 519.0 & 21.45 & 471.4 & 19.48 & $\$ 74$ & $\$ 1742$ \\
\hline
\end{tabular}

The different groups include the same number of cows of each breed, so that the influeuce of breed is practically eliminated. The results show that the lightest cows produced less milk and fat than the other two groups, the cost of feed also being less. The yield of milk and fat per 1,000 pounds live weight was greatest with the light cows and least with the heaviest cows. Calcu-

1 Hoard's Dairyman, March 30, June 22, 1894. 
lating the cost of 100 pounds of fat, the results favor the heaviest cows, though the difference is small.

618. Large versus small cows.-Brandl ${ }^{1}$ conducted three experiments with light and heavy dairy cows, each lasting four weeks, the second commencing seventy days after the close of the first, and the third a year after the beginning of the first. Thirty of the heaviest milkers in the herd were separated into two lots of fifteen cows each, according to live weight. The cows were kept under similar conditions as to feed and care during the trial, nome being bred after the beginning of the experiment. The average weight of the heavy cows was 1,205 pounds and of the light cows 979 pounds. The leading conclusions from the experiments are:

1. The milk of the small cows is richer in fat than that of the large ones.

2. Large cows eat a greater amount of feed than small cows; per thousand pounds live weight they eat less.

3. Small cows produce less milk than large cows, absolutely and relatively.

4. When in thin flesh small cows may produce more per thousand pounds live weight than large cows.

5. Large farrow cows are more persistent milkers; on the other hand, small cows show a greater tendency to fatten on the same feed, with a decrease in milk flow.

6. The loss in selling ten of the large cows amounted to five guilden per head on the average, after having been kept nearly a year, while the loss for ten small cows was twelve guilden per head.

619. Dairy compared with beef type. - At the Minnesota Station $^{2}$ Haecker conducted a trial which shows in a marked way the difference between cows of the so-called dairy type and the blocky beef cow. The Station herd was separated into four lots, Group I including those of the beef type, Group II showing less tendency to the beef type, Group MI embracing spare cows lacking in depth, and Group IV spare cows with deep bodies, representing the dairy type.

\footnotetext{
'Jahresber. f. Agr. Chemie., 1894, 474. $\quad$ Bul. 35.
} 
The resnlts of this interesting trial are shown in the following table:

Beef and dairy type covos compared - Minnesota Station.

\begin{tabular}{|c|c|c|c|c|c|c|}
\hline Group. & $\begin{array}{l}\text { No. of } \\
\text { ani- } \\
\text { mals. }\end{array}$ & $\mid$\begin{tabular}{|c|} 
Av, live \\
weight.
\end{tabular} & $\begin{array}{c}\text { Dry } \\
\text { matter } \\
\text { eaten } \\
\text { per day. }\end{array}$ & $\begin{array}{c}\text { Dry } \\
\text { matter } \\
\text { per } 1,000 \\
\text { lbs. of } \\
\text { live wt. }\end{array}$ & $\begin{array}{l}\text { Dry } \\
\text { matter } \\
\text { per lb. } \\
\text { of fat. }\end{array}$ & $\begin{array}{l}\text { Cost of } \\
\text { one lb. } \\
\text { of fat. }\end{array}$ \\
\hline & & Lbs. & Lbs. & Lbs. & Lbs. & Cents. \\
\hline I. Beef type.............. & 3 & 1.240 & 20.81 & 16.66 & 31.25 & 17.5 \\
\hline II. Less of beef type... & 4 & 945 & 20.37 & 21.02 & 26.42 & 15.1 \\
\hline body................ & 3 & 875 & 19.95 & 23.00 & 25.54 & 14.6 \\
\hline IV. Dairy type........... & 12 & 951 & 21.86 & 23.58 & 21.15 & 12.1 \\
\hline
\end{tabular}

Discussing the results, Haecker writes: "The productive capacity of the cow depends more upon type and conformation than upon size or breed. Those of the beef type produced fat at a cost of seventeen and a half cents per pound; those carrying a medium amount of flesh produced fat at a cost of fifteen and onetenth cents per pound; the spare cows lacking in depth of body produced fat at a cost of fourteen and six-tenths cents per pound, and the spare cows having deep bodies produced fat at a cost of twelve and one-tenth cents per pound."

620. Effect of age of cow on productivity of feed.-Studying the Ohio Station herd, Thorne ${ }^{1}$ reports on the influence of age as follows:

Effect of age of cow on returns for feed given - Ohio Station.

\begin{tabular}{|c|c|c|c|c|c|}
\hline \multirow{2}{*}{ Age. } & \multirow{2}{*}{$\begin{array}{l}\text { No. of } \\
\text { cows. }\end{array}$} & \multirow{2}{*}{$\begin{array}{l}\text { Days since } \\
\text { calving. }\end{array}$} & \multirow{2}{*}{$\begin{array}{l}\text { Fat per } 100 \\
\text { lbs. dry } \\
\text { matter. }\end{array}$} & \multicolumn{2}{|c|}{ Live weight. } \\
\hline & & & & Gain. & Loss. \\
\hline & & & Lbs. & Lbs. & Lbs. \\
\hline 3 and 4 years... & 7 & 127 & 2.95 & 33 & \\
\hline 5 years............ & 1 & 260 & 2.99 & 23 & \\
\hline 6 years............. & 10 & 135 & 3.45 & 29 & \\
\hline 7 year's...... & 6 & 157 & 3.62 & & 11 \\
\hline 8 years...... & 4 & 115 & 3.14 & 28 & \\
\hline 9 years.... & 5 & 172 & 3.05 & & 12 \\
\hline 10 years. & 6 & 105 & 3.22 & & 9 \\
\hline 11 and 13 years. & 2 & 133 & 2.75 & & 15 \\
\hline
\end{tabular}

1 Rept. Ohio Sts., 1893. 
We learn that from her first calf up to and including the Beventh year, the cow gives gradually increasing returns for a given quantity of feed; after the seventh year they gradually diminish until the eleventh to the thirteenth year, when the returns from feed are less than with the heifer. There is an increase in weight during the first years, followed in later years by some loss in weight. This table is in harmony with the experience of dairymen as to the most profitable years in the lifo of the cow.

621. Advance in lactation and productivity of feed.- Thorne ${ }^{1}$ also studied the feed consumption and fat returns of thirty-one cows used in tests at the Ohio and Wisconsin Stations, and deduced the table given below for the purpose of showing the returns from the cow as the lactation period advances:

Returns for feed consumed as time since calving increases-Ohio and Wisconsin Stations.

\begin{tabular}{|c|c|c|c|c|}
\hline \multirow{2}{*}{ Distance from calving. } & \multirow{2}{*}{$\begin{array}{l}\text { No. } \\
\text { of } \\
\text { cows. }\end{array}$} & \multirow{2}{*}{$\begin{array}{c}\text { Fat per } \\
100 \mathrm{lbs} . \\
\text { dry } \\
\text { matter. }\end{array}$} & \multicolumn{2}{|c|}{ Live weight. } \\
\hline & & & Grain. & Loss. \\
\hline & & Lbs. & Lbs. & Lbs. \\
\hline Less than 60 days; average 39 days......... & 3 & 4.16 & & .04 \\
\hline From 60 to 120 days; average 91 days...... & 9 & 3.32 & .11 & \\
\hline From 120 to 180 days; average 142 days.. & 13 & 3.05 & .27 & (.............. \\
\hline More than 180 days; average 256 days.... & 6 & 2.90 & .34 & ............... \\
\hline
\end{tabular}

We learn that shortly after calving the cow is at her best in the fat she returns for feed consumed, and that during this period there is usually a loss in body weight. As time since calving increases the return of fat for feed consumed is reduced, the cow, when well nurtured, increasing somewhat in weight. During the last stages of lactation the cow returns only about threefourths as much fat for feed consumed as shortly after calving.

622. Influence of time from calving on milk flow. - Sturtevant, 2 studying the diminution in milk flow of cows from month to month after calving, reached the conclusion that this decrease

1 Loc. cit.

2 Rept. New York (Genera) Bta., 188 . 
may be placed at about nine per cent. of the yield for the preceding month. The actual average yield of a herd and the theoretical yield, according to this factor, appear in the following table:

Monthly decrease in milk flow of dairy covs, actual and theoreticalSturtevant.

\begin{tabular}{|c|c|c|c|c|}
\hline & \multicolumn{2}{|c|}{ For whole herd. } & \multicolumn{2}{|c|}{$\begin{array}{l}\text { For cows that went } \\
\text { dry between } 8 \text { th and } \\
12 \text { th month. }\end{array}$} \\
\hline & $\begin{array}{l}\text { Actual } \\
\text { daily milk } \\
\text { yield. }\end{array}$ & $\begin{array}{l}\text { Theoretical } \\
\text { daily milk } \\
\text { yield. }\end{array}$ & $\begin{array}{c}\text { Actual } \\
\text { daily milk } \\
\text { yield. }\end{array}$ & $\begin{array}{l}\text { Theoretical } \\
\text { daily milk } \\
\text { yield. }\end{array}$ \\
\hline & Lbs. & Lbs. & Lbs. & Lbs. \\
\hline 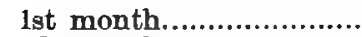 & 25.7 & 25.7 & 26.9 & 26.9 \\
\hline 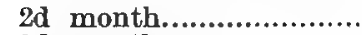 & 24.4 & 23.4 & 25.2 & 24.5 \\
\hline 3d month..................... & 22.0 & 21.3 & 22.8 & 22.3 \\
\hline 4th month...................... & 19.9 & 19.4 & 20.6 & 21.3 \\
\hline 5 th month...................... & 17.3 & 17.7 & 18.7 & 18.5 \\
\hline 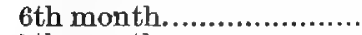 & 16.5 & 16.1 & 17.0 & 16.9 \\
\hline 7th month...................... & 14.9 & 14.7 & 15.0 & 15.4 \\
\hline 8th mouth..................... & . 13.4 & 13.4 & 12.7 & 14.0 \\
\hline 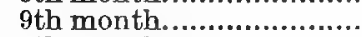 & 12.3 & 12.2 & 11.6 & 12.8 \\
\hline 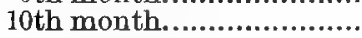 & 11.1 & 11.1 & 10.4 & 11.6 \\
\hline
\end{tabular}

In the table given above, the theoretical yield for each month was obtained by subtracting nine per cent. of the yield for the previous month from the yield for that month. We observe that the actual yield agrees closely with the theoretical in showing the possible yield of milk by the cow in any given month.

623. Heavy feeders may be the most profitable.- At the Pennsylvania Station, ${ }^{1}$ Waters and Hess, studying the returns from nine cows in the Station herd during a trial lasting 150 days, secured important data relative to the food consumed and the yield of butter. Cows which had been tested the previous year were used in this trial. Some of these had excellent butter records, while others were of average or low productive power. All were fed liberally according to their capacity for consuming food. Records were kept of consumption and production.

In a table prepared by these investigators are summarized the butter yielded by each cow the preceding season, the cost of the

\footnotetext{
I Rept. 1895.
} 
feed eaten daring the test and the net profit per cow daily. These results are shown below:

Net profits of individual dairy covs -Pennsylvania Station.

\begin{tabular}{|c|c|c|c|c|c|}
\hline Cow. & $\begin{array}{l}\text { Yield of } \\
\text { butter } \\
\text { previous } \\
\text { year. }\end{array}$ & $\begin{array}{l}\text { Yield of } \\
\text { butter } \\
\text { duringex- } \\
\text { periment. }\end{array}$ & $-\begin{array}{c}\text { Digestible } \\
\text { material } \\
\text { consumed } \\
\text { daily. }\end{array}$ & $\begin{array}{c}\text { Average } \\
\text { daily cost } \\
\text { of feed. }\end{array}$ & $\begin{array}{l}\text { Average } \\
\text { daily net } \\
\text { profit. }\end{array}$ \\
\hline & Lbs. & Lbs. & Lbs. & Cents. & Cents. \\
\hline No. $1, \ldots . . . . . . . . . . . . .$. & 365 & 211 & 15.8 & 18 & 25 \\
\hline No. $2 \ldots \ldots \ldots \ldots \ldots \ldots$ & 345 & 182 & 15.3 & 18 & 22 \\
\hline No. $3, \ldots \ldots \ldots \ldots \ldots \ldots$ & 365 & 164 & 14.1 & 17 & 17 \\
\hline No. $4 \ldots \ldots \ldots \ldots \ldots \ldots \ldots$ & 322 & 156 & 15.0 & 17 & 14 \\
\hline No. $5 \ldots . . . . . . . . . .$. & 318 & 152 & 14.5 & 17 & 14 \\
\hline No. 6.............. & 340 & 135 & 13.3 & 15 & 12 \\
\hline No. $7 \ldots \ldots \ldots \ldots \ldots$ & 276 & 127 & 14.5 & 17 & 9 \\
\hline No. 8.............. & 231 & 117 & 13.7 & 16 & 8 \\
\hline No. $9 . \ldots . . . . . . . .$. & 178 & 90 & 13.7 & 16 & 3 \\
\hline
\end{tabular}

We observe that, as a rule, the cows which ate the most gave the largest net returns; the smallest eaters gave the least.

624. Another illustration.- Armsby ${ }^{1}$ presents an interesting study of the cows used in the ninety-day test at the Columbian Exposition, 1893. (Chapter XXVII, Part I.) These cows were arranged in eleven groups, irrespective of breed, according to the amount of total solids produced during ninety days.

Showing of the ninety-day butter test, Columbian Exposition-Armsby.

\begin{tabular}{|c|c|c|c|c|c|c|}
\hline \multirow{2}{*}{ Average of- } & \multicolumn{2}{|c|}{ Average total yield of- } & \multirow{2}{*}{$\begin{array}{l}\text { Cost of } \\
\text { feed. }\end{array}$} & \multirow{2}{*}{ Net } & \multicolumn{2}{|c|}{ Feed cost per lb. } \\
\hline & Solids. & Fat. & & & Solids. & Fat. \\
\hline & Lbs. & Lbs. & & & Cents. & Cents. \\
\hline 8 cows.... & 478.13 & 154.11 & $\$ 2484$ & $\$ 5741$ & 5.19 & 16.11 \\
\hline 6 cows..... & 446.24 & 140.78 & 2278 & 5230 & 5.11 & 16.18 \\
\hline 8 cows..... & 427.90 & 139.84 & 2297 & 5166 & 5.37 & 16.43 \\
\hline 6 cows........... & 400.60 & 126.41 & 2095 & 4601 & 5.23 & 16.58 \\
\hline 8 cows.......... & 375.83 & 125.68 & 2159 & 4518 & 5.77 & 17.17 \\
\hline 8 cows............... & 346.70 & 107.53 & 2055 & 3587 & 5.93 & 19.11 \\
\hline 7 cows............. & 829.99 & -101.91 & 2075 & 3336 & 6.29 & 20.36 \\
\hline 5 cows........... & 315.09 & 99.07 & $193 f$ & 3323 & 6.14 & 19.54 \\
\hline 7 cows........... & 301.63 & 98.23 & 1891 & 3279 & 6.27 & 19.25 \\
\hline 6 cows....... & 278.94 & 90.00 & 1918 & 2834 & 6.87 & 21.31 \\
\hline 4 cows.......... & 253.34 & 79.29 & 1985 & 2198 & 7.84 & 25.04 \\
\hline
\end{tabular}

* Computed as in test, except live weight not included.

1 Jersey Bulletin, Dec. 23, 1896. 
The table shows that the cows yielding the largest amount of solids and fat consumed the most feed; further, and what is of the most importance, they gave the largest net profit. The cows giving the smallest yield cost 20 per cent. less to feed, but the net profits from them were 60 per cent. less than from the heary feeders. It does not follow that every large feeder in a dairy herd is an economical cow; the wise dairyman will not judge his cows by the amount of feed, but rather by the milk yield and fat test, taking cognizance, in the second place, of the feed consumed.

625. Amount of water drank. - In feeding experiments at the Copenhagen Station ${ }^{1}$ the water drank by seventy-six cows on two estates was as follows:

Av. water drank per day.

Ordinary ration. 97.9 pounds.

Same, 2 lbs. grain replaced by $20 \mathrm{lbs}$. roots ...... 81.4 pounds.

Same, 4 lbs. griin replaced by 40 lbs. roots ..... 61.6 pounds.

Same, plus $40 \mathrm{lbs}$. roots.................................. 74.8 pounds.

At the Pennsyllvania Station, ${ }^{2}$ Armsby found that cows averaging 773 pounds in weight, confined to stalls in summer where an average temperature of $70^{\circ} \mathrm{Fahr}$. prevailed, and living on fresh grass, drank 61 pounds of water per head per day, while cows averaging 735 pounds, confined in stalls where a temperature of $73^{\circ}$ prevailed, drank 107 pounds when fed on dry grass.

At the Wisconsin Station ${ }^{8}$ the sane investigator found that more water was drank with narrow rations than with wide ones. Thus, with a nutritive ratio of $1: 5.5$, there were 4.03 pounds of water drank for each pound of dry matter, while with a ratio of $1: 8.0$ only 3.70 pounds were drank.

In general it may be said that cows require about four pounds of water for each pound of dry matter in the feed consumed. (73)

Sturtevant, of the New York (Geneva) Station, ${ }^{4}$ writes: "A water supply should be sufficient to furnish an average of eight gallons daily per head for the cows kept, in order to be assured of a full supply."

626. Relation of water drank or in food to milk yield.- Collier, reporting findings in this matter at the Geneva Station, ${ }^{6}$ writes:

${ }^{1}$ Rept. 1890, p. 8. "Rept. 1888. ' Rept. $1886 . \quad$ Rept. 1886.

"Proc. of "New York Famers" 1892-93. 
"We have found that our cows which averaged 898 pounds in weight drank each month 1,660 pounds of water, and their food contained in addition 775 pounds, or a total of 2,435 pounds of water for a milk yield of 529 pounds, an average of 4.6 pounds of water for one pound of milk. These same cows while dry drank each month 1,054 pounds of water, and there were 532 pounds in their food, an aggregate of 1,586 pounds, or 65.1 per cent. of the amount they had during lactation."

627. Warm versus cold water. - At the Wisconsin Station, ${ }^{1}$ King conducted two trials where water warmed to a temperature of $70^{\circ}$ Fahr. was supplied to one lot of cows in opposition to water at a temperature of $32^{\circ}$ given a second lot. In the first trial the cows receiving the warm water gave 6 per cent. more milk than those getting cold water, while in the second trial there is a difference of only one per cent. in favor of the warmer water. The cows given the warm water drank from 8 to 10 pounds more daily than those supplied cold water.

At the Indiana Station, ${ }^{2}$ Wolf found that when the temperature of the water supplied was reduced from $79^{\circ}$ to $38^{\circ} \mathrm{Fahr}$, the cows fell off 8 per cent. in milk yield.

628. Drinking at will.-Backhaus ${ }^{3}$ reports trials with cows kept in an ordinary stable where water was given them twice daily; they were then changed to stalls having troughs with a constant water supply in each manger. Under this change the milk yield increased on an average about one pound per cow daily, there being no decrease in the fat content. The increased yield due to a constant supply of water was estimated at 225 pounds of milk per cow annually. (7\%)

629. Salt for milch cows. ${ }^{4}$ - Three cows were fed from June 20 to July 15 without an allowance of salt; the milk yielded from July 4 to 18 amounted to 454 pounds. From July 18 to August 1, 4 ounces of salt were given daily to each cow, and the yield of milk during this time was 564 pounds, an increase of 110 pounds.

630. Value of shelter.-At the Indiana Station, ${ }^{5}$ Plumb tested the value of shelter with six grade cows divided into two lots of

1 Repts. 1889-90. 2 Bul. 24. 3 Milch Zeit., 1892, pp. 509-12.

- Loc. cit., 1895, p. 186. Bul. 47. 
three each, the lots being as nearly equal in all respects as possible. One lot was housed in the stable except on pleasant days, when an hour's exercise was allowed. On disagreeable days they were turned ont to drink and immediately returned to their stalls. The lot subjected to exposure was turned into the yard at 8 A. M., regardless of the weather, and returned to the barn at $4 \mathrm{P}$. M. In a protected corner of the barnyard was an open shed furnishing shelter, and under this the mid-day feed of hay was given. Evidently the cows most exposed were even then under more comfortable conditions than are cows on many dairy farms at the North during winter. The trial lasted 48 days, during which time the exposed cows ate 512 pounds less hay, but 388 pounds more corn meal and 368 pounds more bran than the housed lot. Despite the extra feed they shrank 33 pounds in weight, while the sheltered lot gained 231 pounds and gave 161 pounds more milk. Plumb, summarizing the result, gives the following financial statement:

Saving in cost of feed eaten $\$ 423$

Value of extra milk, 161 pounds.............................. 279

Value of 231 pounds gain at 2.5 cents per pound ........ 577

Amount saved by sheltering three cows 48 days...\$12 79

Amount saved by sheltering one cow 48 days....... 426

These results, showing the great importance of sheltering dairy cows, stand in strong contrast with experimental data in regard to shelter in winter for fattening sheep and steers. (561, 697, 750)

63: Influence of work on quality of milk. - The composition and quality of the milk of two cows employed in plowing was studied by Dornic. ${ }^{1}$ It was found that the composition of the milk was but slightly changed becanse of the work performed. The quantity of milk decreased 15.5 and 10.5 per cent. respectively. The quality was impaired, its keeping ability being lowered, and the acidity increased 1 to 2 degrees.

632. Effects of grooming.- - In experiments by Backhaus ${ }^{2}$ with cows, a difference of 2.5 to 8.3 per cent. in the yield of milk and fat was noted in favor of grooming cows.

1 Milch Zeit., 1896, p. 331.

= Jour. f. Landw., 41, 1893, p. 332 


\section{OHAPTER XXV.}

BTATION TESTE WITH FEEDING STUFFS FOR DATRY COWS.

\section{Concentrated Feeds.}

633. Whole corn compared with corn and cob meal. - In a feeding trial with seven cows at the Ohio Station, ${ }^{1}$ corn and cob meal fed with hay was compared with ear corn. The average yield per cow during a fourteen-day period was:

Daily milk Per cent. fat yield. in milk.

When fed corn and cob meal........... 16.2 pounds. $\quad 3.57$

When fed whole ear corn................. 15.7 pounds. $\quad 3.76$

It will be seen that during the corn and cob meal period the yield of milk was one-half pound more daily for each cow. This has little significance, however, when it is remembered that the period of lactation was advanced two weeks during the second trial. (158, 382, 539)

634. Waste in feeding whole ear corn.- At the Wisconsin Station, Woll, ${ }^{2}$ observing unbroken grains of corn in the excrement of cows fed dry ear corn and also those getting ear corn in silage, ascertained the amount of grain passed by the cows during twentyfour hours. The droppings were washed and the grains of corn collected. The figures in the table give the weight of the corn calculated to the same water content as when fed:

Amount of corn found in excrement of covs-Wisconsin Station.

\begin{tabular}{|c|c|c|}
\hline & $\begin{array}{c}\text { Cow fed } \\
\text { dry } \\
\text { corn. }\end{array}$ & $\begin{array}{c}\text { Cow fed } \\
\text { silage } \\
\text { corn. }\end{array}$ \\
\hline Weight of corn as fed, pounds......................... & \multirow{5}{*}{$\begin{array}{c}5.75 \\
84.75 \\
1.25 \\
1.05 \\
18.3\end{array}$} & \multirow{5}{*}{$\begin{array}{l}12.23 \\
74 \\
1 \\
.367 \\
3.0\end{array}$} \\
\hline $\begin{array}{l}\text { Weight of droppings for twenty-four hours, } \\
\text { pounds }\end{array}$ & & \\
\hline Undigested kernels of corn, quarts................... & & \\
\hline Weight of kernels, pounds............................. & & \\
\hline Per cent. of corn appearing in droppings ......... & & \\
\hline
\end{tabular}

1 Rept. 1S83. 2Rept. 1892. 
We learn by this table that over 18 per cent. of the dry ear corn and only 3 per cent. of the silage corn passed through the alimentary tract in practically unbroken form. The voided corn was tested in a seed germinator, 43 per cent. of the dry corn grains and none of the silage kernels germinating. (538)

635. Maize feed versus corn meal and bran.- At the Vermont Station, Hills ${ }^{1}$ compared maize feed with corn meal and bran, equal parts by weight, for dairy cows. The roughage consisted of two parts of hay and one of silage.

Maize feed versus corn meal and bran-Vermont Station.

\begin{tabular}{|c|c|c|c|c|}
\hline \multicolumn{3}{|c|}{ Feed eaten. } & \multicolumn{2}{|c|}{ Products. } \\
\hline Roughage. & Maize feed. & $\begin{array}{l}\text { Corn meal } \\
\text { and bran. }\end{array}$ & Milk. & Fat. \\
\hline Lbs. & Lbs. & Lbs. & Lbs. & Lbs. \\
\hline $\begin{array}{l}2,424 \\
2,427\end{array}$ & 1,000 & 1,008 & $\begin{array}{l}2,388 \\
2,164\end{array}$ & $\begin{array}{l}114.3 \\
102.2\end{array}$ \\
\hline \multicolumn{3}{|c|}{ 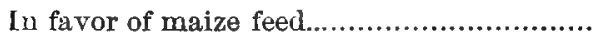 } & 224 & 12.1 \\
\hline
\end{tabular}

636. Gluten meal compared with corn meal and bran.-In trials by Hills at the Vermont Station ${ }^{2}$ cows were fed daily eight pounds of corn meal and bran, equal parts by weight, during the first and third periods. In the second period gluten meal was substituted for half the corn and bran mixture.

Gluten weal, corn meal and bran compared with corn meal and bran only-Termont Station.

\begin{tabular}{|c|c|c|c|c|}
\hline \multicolumn{3}{|c|}{ Feed eaten. } & \multicolumn{2}{|c|}{ Products. } \\
\hline Roughage. & $\begin{array}{c}\text { Gluten meal, } \\
\text { corn meal and } \\
\text { bran. }\end{array}$ & $\begin{array}{l}\text { Corn meal } \\
\text { and bran } \\
\text { only. }\end{array}$ & Milk. & Fat. \\
\hline Lbs. & Lbs. & Lbs. & Lbs. & Lbs. \\
\hline $\begin{array}{l}2,846 \\
2,924\end{array}$ & $\begin{array}{r}1,000 \\
\ldots \ldots \ldots \ldots \ldots \ldots\end{array}$ & 1,000 & $\begin{array}{l}3,048 \\
2,760\end{array}$ & $\begin{array}{l}142.2 \\
125.6\end{array}$ \\
\hline \multicolumn{3}{|c|}{ In favor of gluten ineal.............................. } & 288 & 16.6 \\
\hline
\end{tabular}

1 Bul. 48.

2 Loc. cit. 
Because of the heavy character of the gluten meal it was deemed advisable that not over one-half of the concentrates in the ration consist of this material. The roughage was of equal parts silage and hay, by weight.

There was a gain of $\mathbf{1 0 . 4}$ per cent. of milk and 13.2 per cent. of fat by substituting gluten. meal for half the corn meal and bran of the ration.

The results of this trial and that with maize feed substantiate the claim of high nutritive value for these by-products of the glucose and starch factories. (161-4)

637. Gluten meal compared with cotton-seed meal.-At the Maine Station, ${ }^{1}$ Bartlett fed six cows, averaging 900 pounds each, for two months on rations containing cotton-seed meal and gluten meal, with the results shown in the table:

Feeding cotton-seed meal and gluten meal - Maine Station.

\begin{tabular}{|c|c|c|c|}
\hline \multicolumn{2}{|c|}{ Ration. } & \multicolumn{2}{|c|}{$\begin{array}{l}\text { Average daily } \\
\text { products, per } \\
\text { cow. }\end{array}$} \\
\hline & & Milk. & Fat. \\
\hline $\begin{array}{l}\text { Timothy hay, } 15 \text { pounds... } \\
\text { Silage, } 20 \text { pounds............... } \\
\ldots \ldots \ldots \ldots \ldots \ldots \ldots \ldots \ldots \ldots \ldots \ldots \ldots\end{array}$ & $\begin{array}{l}\text { Gluten meal, } 3 \text { pounds ....... } \\
\text { Corn meal, } 2 \text { pounds .......... } \\
\text { Bran, } 2 \text { pounds ................. }\end{array}$ & $\begin{array}{c}\text { Lbs. } \\
18.6 \\
\cdots \cdots \cdots \\
\cdots \ldots \ldots . . .\end{array}$ & $\begin{array}{l}\text { Lbs. } \\
0.92 \\
\ldots \ldots \ldots \ldots\end{array}$ \\
\hline $\begin{array}{l}\text { Timothy hay, } 15 \text { pounds... } \\
\text { Silage, } 20 \text { pounds............. } \\
\text {..................................... }\end{array}$ & $\begin{array}{l}\text { Cotton-seed meal, } 2 \text { pounds } \\
\text { Corn meal, } 2.5 \text { pounds ......... } \\
\text { Bran, } 3 \text { pounds .................. }\end{array}$ & $\begin{array}{c}18.9 \\
\ldots \ldots \ldots \ldots \\
\ldots \ldots \ldots \ldots\end{array}$ & $\begin{array}{l}0.96 \\
\ldots \ldots \ldots \ldots \ldots\end{array}$ \\
\hline
\end{tabular}

Bartlett concludes: "The foregoing data indicate that gluten meal is fully equal to cotton-seed meal when fed in sufficient quantity to make the amount of digestible nutrients equal in each ration. It is not equal to cotton-seed meal pound for pound as a source of protein, as it contains, on an average, about one-quarter less of that nutrient. It makes a very good quality of butter, but slightly softer than that made from cotton-seed meal when fed in the quantity used in this experiment." (161-4, 210-12, 216-17)

638. Wheat meal compared with corn meal. - At the Maine Station, ${ }^{2}$ Bartlett also compared wheat meal with corn meal, six cows

${ }^{1}$ Rept. 1896. 
being used. In the first and third periods all received the follow. ing ration: Timothy hay, eighteen pounds; wheat meal, five pounds; cotton-seed meal, two pounds. In the second period corn meal was substituted for wheat meal.

Wheat meal compared with corn meal - Maine Station.

\begin{tabular}{l|c|c|c|c|c}
\hline \hline & $\begin{array}{c}\text { Average daily } \\
\text { yield. }\end{array}$ & \multicolumn{2}{|c|}{ Weight. } & $\begin{array}{c}\text { Water } \\
\text { drank } \\
\text { daily. }\end{array}$ \\
\cline { 2 - 6 } & Milk. & Fat. & Gain. & Loss. & \\
\hline & Lbs. & Lbs. & Lbs. & Lbs. & Lbs. \\
Period II, wheat meal .......... & 19.7 & .87 & 8 & $\ldots \ldots \ldots . .$. & 61 \\
Period II, corn meal.......... & 18.8 & .85 & $\ldots . . . . .$. & 76 & 64 \\
Period III, wheat meal ......... & 17.0 & .84 & 6 & $\ldots . . . . . .$. & 68 \\
\hline \hline
\end{tabular}

Making allowance for decreased milk flow as the lactation period lengthened, the results may be regarded as practically equal. There was a slight gain in weight by the cows during the two wheat-meal periods, while when corn meal was fed there was a decided decrease. We conclude that wheat meal is at least equal to corn meal as a feed for the dairy cow. (166-8)

639. Wheat meal compared with mixed grain. - At the Ontario Agricultural College, ${ }^{1}$ Dean fed one lot of cows wheat meal, and another mixed grain consisting of one-half oats and one-fourth each of ground barley and peas. Nine pounds of grain were fed daily with hay, straw and silage, the trial lasting sixty days.

Feeding wheat meal in comparison with mixed grain meal-Ontario Agricultural College.

\begin{tabular}{c|c|c|c}
\hline Grain fed. & $\begin{array}{c}\text { Milk per cow } \\
\text { daily. }\end{array}$ & $\begin{array}{c}\text { Total increase in } \\
\text { live weight. }\end{array}$ & $\begin{array}{c}\text { Cost of produc- } \\
\text { ing } 100 \text { lbs. of } \\
\text { milk. }\end{array}$ \\
\hline Mixed meal..................................... & $\begin{array}{l}26.8 \text { pounds. } \\
24.1 \text { pounds. }\end{array}$ & $\begin{array}{l}38.5 \text { pounds. } \\
10 . \text { pounds. }\end{array}$ & $\begin{array}{l}46 \text { cents. } \\
57 \text { cents. }\end{array}$ \\
\hline
\end{tabular}

The milk flow was better maintained on the mixed-meal ration than on the ground-wheat ration. The cost of producing 100 pounds of milk was calculated on the basis of ordinary Ontario

1 Rept. 1893. 
prices for cattle feeds, viz. : hay $\$ 6.50$, straw $\$ 2$, silage $\$ 1.75$, per ton; oats $24 \frac{1}{2}$ cents, peas 57 cents, barley 38 cents and wheat 60 cents, per bushel. (166-8)

640. Wheat bran compared with mixed grain.--During the years 1893-94 extensive feeding trials were conducted by the Copenhagen Experiment Station ${ }^{1}$ on the estates of dairy farmers. In these trials 447 cows were used. One lot of cows on each estate was fed a mixture of barley and oats; a second was fed one-half wheat bran and one-half grain mixture, while a third lot received wheat bran only. The results briefly summarized were as follows:

Feeding mixed grain and wheat bran to 447 dairy cows-Copenhagen (Denmark) Station.

\begin{tabular}{|c|c|c|c|}
\hline & $\begin{array}{l}\text { Mixed } \\
\text { grain. }\end{array}$ & $\begin{array}{l}\text { One-half } \\
\text { grain, one- } \\
\text { half bran. }\end{array}$ & $\begin{array}{l}\text { Wheat } \\
\text { bran } \\
\text { only. }\end{array}$ \\
\hline $\begin{array}{l}\text { Average millk yield per cow, pounds......... } \\
\text { Average per cent. solids in millk ................ } \\
\text { Average per cent. fat in milk .................. }\end{array}$ & $\begin{array}{l}21.9 \\
11.66 \\
3.04\end{array}$ & $\begin{array}{r}22.1 \\
11.75 \\
3.11\end{array}$ & $\begin{array}{r}22.1 \\
11.77 \\
3.12\end{array}$ \\
\hline
\end{tabular}

These results agree closely, and from them we may assume that wheat bran is of equal feeding value for milch cows with a mixture of barley and oats.

The findings of this test are of great value because of the large number of cows used in it and from the further fact that the animals were on various large farms under normal conditions, while all the observations were taken and recorded by Station officials. (175)

641. Shorts compared with wheat bran.-The Copenhagen Station also conducted trials with wheat shorts in comparison with wheat bran, 240 cows on several estates being used in trials during the years 1893-94. The shorts gave a slightly larger milk yield on three of the estates, but the difference was small.

Combining the results of this trial with those reported in the preceding article, we learn that bran, shorts and mixed grain are practically of equal value for feeding the dairy cow. (174)

129 th Rept. 1894. 
642. Ground oats compared with wheat bran.- At the Wisconsin Station, ${ }^{1}$ Woll compared ground oats with wheat bran in two feeding trials with six cows. Ten pounds of these concentrates were given each cow daily with the results shown below:

Returns from feeding ground oats and bran - Wisconsin Station.

\begin{tabular}{|c|c|c|c|}
\hline & $\begin{array}{l}\text { Daily millk } \\
\text { yield. }\end{array}$ & $\begin{array}{l}\text { Daily fat } \\
\text { yield. }\end{array}$ & $\begin{array}{l}\text { Per cent. } \\
\text { fat. }\end{array}$ \\
\hline & Lbs. & Lbs. & \\
\hline 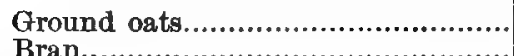 & 21.07 & .933 & 4.65 \\
\hline 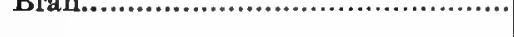 & & & \\
\hline In favor of oats............................ & 1.88 & .088 & -.03 \\
\hline
\end{tabular}

Here is a return of 10 per cent. more milk and fat from oats than from bran. The high value of oats in the dairy is well illustrated in this trial. (175, 186)

643. Sorghum-seed meal.- At the New Jersey Station, ${ }^{2}$ Cook tested the relative merits of amber cane sorghum-seed meal and corn meal for milk production. Three cows were fed the following ration per 1,000 pounds live weight: Twenty pounds brewers' grains, nine pounds corn meal, five pounds corn stover, and five pounds bran. After receiving this ration twenty days, sorghumseed meal was gradually substituted for the corn meal until it replaced the latter - the same amount, nine pounds, being fed. When this feed had been used twenty days the ration was gradually changed back to corn meal. The results for the three periods are as follows:

Period I. Cows fed corn meal averaged 28.1 pounds of milk each daily. Period II. Cows fed sorghum meal averaged 24.6 pounds of milk each daily.

Period III. Cows fed corn meal averaged 27 pounds of milk each daily.

It was observed that when the full sorghum-meal ration was reached the yield of mills dropped immediately. On the other hand, when changing from sorghum back to corn meal there was an increase in the milk flow. These trials show that sorghum meal is 10 per cent. less valuable than corn meal for milk production. (197)

\footnotetext{
Rept. 1890.

2 Rept. 1882.
} 
644. Cotton seed and its by-products. - At the Mississippi Station, ${ }^{1}$ Lloyd tested cotton seed and its by-products in various forms for millk and butter production with the results summarized in the following table: ${ }^{2}$

Feeding cotton seed and its by-products to dairy cows - Mississippi Station.

\begin{tabular}{|c|c|c|c|c|c|c|c|c|}
\hline & Ration. & 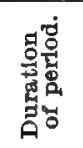 & 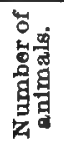 & 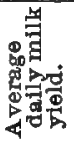 & 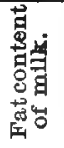 & 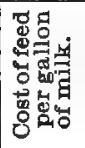 & 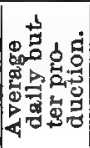 & 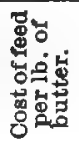 \\
\hline $\begin{array}{r}\text { Four } \\
9.5\end{array}$ & $\begin{array}{l}\text { grade Jerseys and one } \\
\text { grade Holstein. (a) } \\
\text { pounds raw cotton seed, } \\
9.2 \text { pounds Bermuda }\end{array}$ & Days. & & $\begin{array}{l}\text { Gal- } \\
\text { lons. }\end{array}$ & $\begin{array}{l}\text { Per } \\
\text { cent. }\end{array}$ & Conts. & Pound. & Conts. \\
\hline 10.0 & $\begin{array}{l}\text { pay row roasted cotton } \\
\text { pound, } 10.5 \text { pounds Ber- } \\
\text { seed }\end{array}$ & 35 & 5 & 1.10 & 5.62 & 7.7 & .498 & 17.4 \\
\hline 10.4 & $\begin{array}{l}\text { muda hay } \\
\text { pounds boiled cotton } \\
\text { seed, } 8.5 \text { pounds Ber- }\end{array}$ & 35 & 5 & 1.22 & 5.55 & 8.5 & .545 & 19.1 \\
\hline 9.8 & $\begin{array}{l}\text { muda hay.......... } \\
\text { pounds corn } 9.9\end{array}$ & 35 & 5 & .87 & 5.64 & 8.8 & .439 & 19.6 \\
\hline 9.5 & $\begin{array}{l}\text { pounds Bermuda hay.. } \\
\text { pounds raw cotton seed, } \\
8.5 \text { pounds timothy }\end{array}$ & 35 & 5 & 1.47 & 3.86 & 12.8 & .455 & 41.4 \\
\hline 9.5 & $\begin{array}{l}\text { hay........... } \\
\text { pounds raw cotton seed, } \\
10.9 \text { pounds Bermuda }\end{array}$ & 35 & 5 & .81 & 5.43 & 12.8 & .396 & 29.5 \\
\hline & 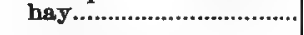 & 35 & $\mathbf{5}$ & 1.30 & 5.38 & 12.3 & .660 & 28.5 \\
\hline $\begin{array}{l}\text { Four } \\
7.8\end{array}$ & $\begin{array}{l}\text { grade Jerseys and one } \\
\text { grade Holstein. (b) } \\
\text { pounds raw cotton seed, } \\
7.7 \text { pounds Bermuda }\end{array}$ & & & & & & & \\
\hline 8 & pounds raw cotton seed, & 86 & $\mathbf{b}$ & 1.09 & 5.95 & 6.3 & .522 & 13.2 \\
\hline 9.8 & $\begin{array}{l}\text { hay, } 9.8 \text { pounds silage } \\
\text { pounds boiled cotton } \\
\text { geed, } 7.5 \text { pounds Ber- } \\
\text { muda hay, } 9.9 \text { pounds }\end{array}$ & 35 & $\mathbf{5}$ & .87 & 5.78 & 8.8 & .438 & 18.4 \\
\hline 9.8 & $\begin{array}{l}\text { silage } \\
\text { pounds boiled cotton } \\
\text { seed, } 6.5 \text { pounds timo- } \\
\text { thy hay, } 9.9 \text { pounds sil- }\end{array}$ & 35 & 5 & 1.56 & 5.84 & 4.9 & .717 & 10.9 \\
\hline 8.8 & $\begin{array}{l}\text { age couds } \\
\text { meal, } 10.2 \text { pouton-seed } \\
\text { muda hay, } 9.9 \text { pounds } \\
\text { silage....... }\end{array}$ & 35 & b & 1.30 & 5.87 & 8.4 & .603 & 18.1 \\
\hline 8.8 & 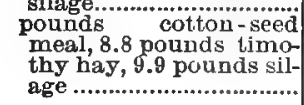 & 35 & $\mathbf{5}$ & 1.51 & 5.70 & 12.6 & .685 & 28.1 \\
\hline
\end{tabular}

(a) Bul. 15. - Cost of feed in these six experiments, per ton: Raw cotton seed, A; boiled cotton seed, $\$ 6.30$; roasted cotton seed, $\$ 7.20$; cotton-seed meal, $\$ 20$; Bermudi hay, 12.50; corn meal, $\$ 25$; timothy hay, $\$ 20.80$.

(b) Bul. 21. - Roasted and boiled cotton seed and cotton-seed meal were same pricen as in note $(a)$; Bermuda hay, $\$ 10$; timothy hay, $\$ 21.46$; and silage $\$ 2$ per ton.

1 Buls. 15, 21.

2 The Cotton Plant: Its History, etc., p. 412. 
It will be seen that the cheapest returns were obtained from reeding boiled cotton seed, Bermuda hay and silage; next in economy came raw cotton seed, while cotton-seed meal, at the price charged, stood third in cost. Cotton seed was found to be much cheaper than corn meal. (216-17, 723)

645. Cotton-seed meal compared with bran.- At the Pennsylvania Station, ' Hunt obtained about one-fifth more milk when the cows were fed cotton-seed meal in place of bran, the cotton-seed neal (six pounds) constituting about three-fifths of the concentrates and about one-fowrth of the total feed eaten. The percentages of fat in the milk were not influenced by changes in feed.

646. Linseed meal versus cotton-seed meal.-At the Pennsylvania Station, ${ }^{2}$ Waters and Hess compared linseed neal with cotton-seed meal. Nine cows were used in this trial, the ration in one period consisting of cotton-seed meal, chopped wheat and corn stover; later, the cows were fed the same ration, except that linseed meal (old process) was substituted for the cotton-seed meal. The results of the trial were as follows:

Linseed meal (old process) and cotton-seed meal compared-Pennsylvania Station.

\begin{tabular}{|c|c|c|}
\hline \multirow[b]{2}{*}{ Feeds given. } & \multicolumn{2}{|c|}{ Cows fed on - } \\
\hline & Linseed meal. & $\begin{array}{l}\text { Cotton-seed } \\
\text { meal. }\end{array}$ \\
\hline & \multicolumn{2}{|c|}{ Ration. } \\
\hline Oil meal or cotton-seed meal.... & \multirow{3}{*}{$\begin{array}{l}5.99 \text { pounds. } \\
5.99 \text { pounds. } \\
9.31 \text { pounds. }\end{array}$} & \multirow{3}{*}{$\begin{array}{l}5.26 \text { pounds } \\
6.69 \text { pounds } \\
9.28 \text { pounds }\end{array}$} \\
\hline Chopped wheat ................................... & & \\
\hline 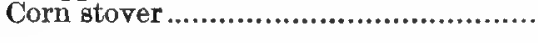 & & \\
\hline Digestible nutrients............................ & \multirow{2}{*}{$\begin{array}{l}12.74 \text { pounds. } \\
1: 4.4\end{array}$} & \multirow{2}{*}{$\begin{array}{l}12.87 \text { pounds. } \\
1: 3.9\end{array}$} \\
\hline \multirow{2}{*}{ 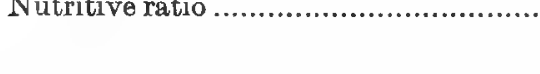 } & & \\
\hline & \multicolumn{2}{|c|}{ Product, 9 cows, 30 days. } \\
\hline Milk......... & $4,087.7$ pounds. & 4,381.9 pounds. \\
\hline 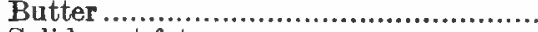 & 258.3 pounds. & 254.0 pounds. \\
\hline Solids not fat.................................... & 379.8 pounds. & 405.8 pounds. \\
\hline \multirow[t]{2}{*}{ Average per cent. fat in milk............... } & 5.1 & 4.7 \\
\hline & \multicolumn{2}{|c|}{ Summary. } \\
\hline Digestible matter for 100 pounds milk. & 91.2 pounds. & 87.7 pounds. \\
\hline Digestible matter for 1 pound butter..... & 14.4 pounds. & 15.0 pounds. \\
\hline
\end{tabular}

\footnotetext{
1 Rept. $1891 . \quad{ }^{2}$ Rept. 1895.
} 
Though the rations are not identical they so nearly coincide in digestible nutrients that the results are comparable. It will be seen that the cows receiving cotton-seed meal were fed slightly more digestible matter with a somewhat narrower nutritive ratio.

In these trials cotton-seed meal produced more millk than did linseed meal, while the latter gave somewhat better returns in butter. All things considered, neither feed showed an advantage over the other. (206-216)

647. 0il cake compared with grain.- - During feeding trials with cows conducted by the Copenhagen Station ${ }^{1}$ in 1891 and 1892, the comparative feeding value of grain and oil cake of various kinds was studied, two hundred and forty cows on various estates being used in the trials. The grain fed was a mixture of barley and oats; the oil cake consisted of equal parts by weight of palm nut, rape seed, and sunflower-seed cake. In each series of experiments, three lots of cows were fed as follows: Lot I, $\frac{3}{4}$ grain, $\frac{1}{4}$ oil cake; Lot $I$, $\frac{1}{2}$ grain, $\frac{1}{2}$ oil cake; Lot $I I, \frac{1}{4}$ grain and $\frac{3}{4}$ oil cake. The yield and fat content of the milk obtained during the experiments are as shown below, the figures being the average of the experiments continued for two years:

Feeding grain and oil cale in varying proportions to 240 dairy cows Copenhagen (Denmark) Station.

\begin{tabular}{|c|c|c|c|}
\hline & $\begin{array}{l}\text { Lot } \mathbf{I} \text {. } \\
\text { 3 grain, } \\
4 \text { oil cake. }\end{array}$ & $\begin{array}{l}\text { Lot II. } \\
\frac{1}{2} \text { grain, } \\
\frac{1}{2} \text { oil cake. }\end{array}$ & $\begin{array}{l}\text { Lot IXx. } \\
\frac{1}{4} \text { grain, } \\
\frac{3}{4} \text { oil take. }\end{array}$ \\
\hline $\begin{array}{l}\text { Average daily milk yield, pounds.. } \\
\text { Average per cent. of milk solids.... } \\
\text { Average per cent. of fat................ }\end{array}$ & $\begin{array}{r}21.7 \\
11.90 \\
3.20\end{array}$ & $\begin{array}{r}22.9 \\
11.85 \\
3.17\end{array}$ & $\begin{array}{r}23.4 \\
11.84 \\
3.20\end{array}$ \\
\hline
\end{tabular}

It was shown that for each one hundred pounds of oil cake substituted for the same amount of mixed grain there was a gain of sixty-six pounds of milk, provided the oil cake did not constitute more than half of the grain ration. The feeding of tlis amount of oil cake in the ration therefore proved economical.

648. Dried distillery grains compared with oats.-Experimeris: were made in 1893 by Gripenberg at the Mustiala (Finiand;

+27th Rept. 1892. 
Agricultural College' with four milch cows, in a comparison of dried distillers' grains with oats for milk and butter production. Hay and roots were fed in addition to the grain, the results being as follows:

Oats compared with dried distillers' grains for dairy cows - Mustiala (Finland) Agricultural College.

\begin{tabular}{|c|c|c|c|}
\hline & \multicolumn{2}{|c|}{ Daily yield. } & \multirow{2}{*}{ Per cent. fat. } \\
\hline & Milk. & Fat. & \\
\hline & Lbs. & Lbs. & \\
\hline 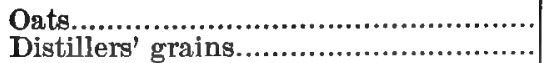 & $\begin{array}{l}28.9 \\
32.3\end{array}$ & $\begin{array}{l}.88 \\
.96\end{array}$ & $\begin{array}{l}3.05 \\
2.97\end{array}$ \\
\hline
\end{tabular}

The dried distillers' grains produced about 12 per cent. more milk and 9 per cent. more fat than did the oats, thus showing a high feeding value.

\section{Coarse Feed.}

649. Upland prairie hay versus timothy hay.- At the Minnesota Station, ${ }^{2}$ Haecker compared these hays as feed for dairy cows. The prairie hay was composed of native grasses grown on the uplands of Minnesota, and was of excellent quality. The timothy hay was medium fine, rather short, cut early and properly cured, showing fine aroma and good color. Sixteen cows were used in the trial, each group receiving the same quantity of grain and hay. The experiment lasted about three months, with the results shown in the table:

Comparison of native upland prairie hay and timothy hay - Minnesota Station.

\begin{tabular}{|c|c|c|c|c|c|c|c|c|}
\hline & \multicolumn{3}{|c|}{ Feed given. } & \multicolumn{3}{|c|}{$\begin{array}{l}\text { Digestible nutrients in } \\
\text { rations. }\end{array}$} & \multicolumn{2}{|c|}{ Returns. } \\
\hline & Grain. & $\begin{array}{l}\text { Sil- } \\
\text { age. }\end{array}$ & Hay. & $\begin{array}{l}\text { Pro- } \\
\text { tein. }\end{array}$ & $\begin{array}{c}\text { Carbo- } \\
\text { hy- } \\
\text { drates. }\end{array}$ & $\begin{array}{c}\text { Ether } \\
\text { extract. }\end{array}$ & Milk. & Fat. \\
\hline & Lbs. & Lbs. & Lbs. & Lbs. & Lbs. & Lbs. & Lbs. & Lbs. \\
\hline $\begin{array}{l}\text { Prairie hay..... } \\
\text { Timothy hay.. }\end{array}$ & $\begin{array}{l}2,013 \\
2,016\end{array}$ & $\begin{array}{l}1,680 \\
1,680\end{array}$ & $\begin{array}{l}1,840 \\
1,840\end{array}$ & $\begin{array}{l}2.1 \\
2.2\end{array}$ & $\begin{array}{l}12.5 \\
13.1\end{array}$ & $\begin{array}{l}.69 \\
.74\end{array}$ & $\begin{array}{l}2,580 \\
2,547\end{array}$ & $\begin{array}{l}120.7 \\
121.3\end{array}$ \\
\hline
\end{tabular}

1 Biet. $1893 . \quad 2$ Bul. 35. 
It will be seen that almost identical quantities of milk and fat were produced by the two lots of cows, the excess of milk being in favor of prairie hay, and the excess of fat in favor of timothy. From this we conclude that upland prairie hay of good quality is fully as valuable for feeding dairy cows as a good grade of timothy hay.

650. Japan clover hay versus Bermuda hay.-In an experiment with sixty cows conducted at the Mississippi Station ${ }^{1}$ by Lloyd, half were fed mixed hay (Japan clover and some chicken corn) and the other half Bermuda hay. Cotton seed, cotton-seed meal or corn meal was fed in connection with the hay. The mixed hay was valued at $\$ 7$ and the Bermuda hay at $\$ 10$ per ton. The experiment was continued about twelve weeks. The arerage results obtained per cow daily were as follows, the yield of fat given in the table being calculated from the yield of butter by multiplying by .82 , the percentage of pure fat contained:

Feeding mixed hay and Bermuda hay to dairy cows - Mississippi Station.

\begin{tabular}{|c|c|c|c|c|c|}
\hline & \multicolumn{2}{|c|}{ Daily yield. } & \multirow{2}{*}{$\begin{array}{l}\text { Per cent. } \\
\text { fat. }\end{array}$} & \multicolumn{2}{|c|}{ Average cost of one- } \\
\hline & Milk. & Fat. & & Gal. milk. & Lb. butter. \\
\hline & Lbs. & Lbs. & & Cents. & Cents. \\
\hline 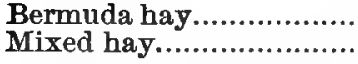 & $\begin{array}{l}8.6 \\
8.0\end{array}$ & $\begin{array}{l}.35 \\
.34\end{array}$ & $\begin{array}{l}4.08 \\
4.23\end{array}$ & $\begin{array}{l}11.3 \\
10.6\end{array}$ & $\begin{array}{l}26.6 \\
24.3\end{array}$ \\
\hline
\end{tabular}

Bermuda hay produced somewhat more milk and slightly more fat than did the Japan clover hay. At the prices charged the mixed hay was the cheaper; at equal prices there would be little difference in cost of products. (296)

65I. Timothy hay versus meadow fox-tail hay.- An experiment was conducted at Mustiala (Finland) Agricultural College ${ }^{2}$ for the purpose of obtaining data concerning the relative value of timothy and meadow fox-tail (Alopecurus) hay for milk and butter production. The cows received similar quantities of both kinds of hay, ranging from $\mathbf{1 1 . 7}$ to $\mathbf{1 7 . 6}$ pounds per head per day, and oat straw ad libitum. The same amount of concentrates and roots

\footnotetext{
1 Bul. 13. ' 2 Biet. 1893.
} 
was fed to each cow. Teu cows were included in the experiment, with the daily yield of milk and fat as follows:

Feeding timothy and meadow fox-tail hay to dairy coros - Mustiala (Finland) Agricultural College.

\begin{tabular}{|c|c|c|c|}
\hline & \multicolumn{2}{|c|}{ Daily yield. } & \multirow{2}{*}{ Per cent. fat. } \\
\hline & Milk. & Fat. & \\
\hline & Lbs. & Lbs. & \\
\hline 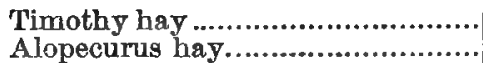 & $\begin{array}{l}23.5 \\
24.8\end{array}$ & $\begin{array}{l}.71 \\
.77\end{array}$ & $\begin{array}{l}2.97 \\
3.08\end{array}$ \\
\hline
\end{tabular}

The fox-tail hay produced 5.5 per cent. more milk and 8.4 per cent. more fat than the timothy.

652. Fodder corn compared with timothy hay.- At the Pennkylvania Station, 1 Hunt and Caldwell fed fodder corn and timothy hay to cows to determine the relative merits of these two common roughage crops. There were four cows in each lot, the trial lasting forty-five days, with the results shown in the table:

Fodder corn versus timothy hay-Pennsylvania Station.

\begin{tabular}{|c|c|c|}
\hline & $\begin{array}{c}\text { Cows fed } \\
\text { hay. }\end{array}$ & $\begin{array}{c}\text { Cows fed } \\
\text { fodder corn. }\end{array}$ \\
\hline & Lbs. & Lbs. \\
\hline 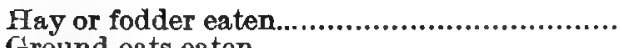 & 4,237 & 4,102 \\
\hline 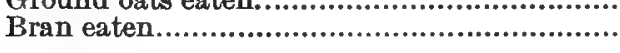 & 540 & $\begin{array}{l}540 \\
540\end{array}$ \\
\hline 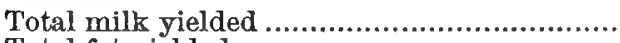 & 3,084 & 2,921 \\
\hline Total fat yielded ............................................ & 116 & 120 \\
\hline Gain or loss of cows in weight.... & 84 gain. & 23 loss. \\
\hline
\end{tabular}

It will be seen that the cows ate somewhat more hay than fodder, the grain fed being the same in both cases. More milk was obtained from the hay, but the fodder corn yielded more butter, the cows in this lot giving slightly richer milk than the others. The cows fed hay gained in weight, while those on fodder corn lost. The trial shows these feeds to be substantially equal, pound for pound. This being true, the high value of

\footnotetext{
1 Rept. 1892.
} 
fodder corn is apparent; for while two tons of timothy hay per acre is a good return, these investigators report that the fodder corn used in the trial yielded at the rate of 8,885 pounds per acre. The trial suggests the possibility that timothy hay conduces to the storage of fat in the body of the cow, while fodder corn turns the fat into the milk. (250)

653. Corn stover versus mixed hay and clover hay.-At the Wisconsin Station ${ }^{1}$ the writer compared corn stover with mixed hay and clover hay for dairy cows, under the following conditions: A crop of yellow dent corn yielding 4,490 pounds of stalks when dried in the shock, and 4,941 pounds of ears per acre, was harvested in the usual manner. After drying, the corn was husked and the stalks reserved for feeding. Uncut stalks were fed in comparison with uncut hay. The mixed hay consisted of onethird clover and two-thirds timothy. The clover hay used was from medium red clover, cut early to preserve the leaves and heads in good condition. Four good cows were used, forming two lots of two each, one lot getting hay, while the other was fed stover. After three weeks the feeding was reversed, and the trial continued for the same period. The concentrates of the ration consisted of five parts corn meal and seven parts wheat bran by weight, fed dry. The results of the trial are here summarized.

Comparing corn stover with mixed hay, when each was supplemented by 280 pounds of corn meal and 392 pounds of wheat bran, it was found that -

2,374 pounds of corn stover returned 1,120.7 pounds of milk, making 57 pounds of butter.

755 pounds of mixed hay returned 1,064 pounds of milk, making 56.1 pounds of butter.

Comparing corn stover with clover hay, grain being fed as above, it was found that-

1,867 pounds of corn stover returned $1,079.3$ pounds of milk, making 52.2 pounds of butter.

643 pounds of clover hay returned 1,059 pounds of milk, making 54.5 pounds of butter.

The returns being practically equal, we conclude that one ton of mixed clover and timothy hay is worth three tons of corn stover, or corn stalks, fed as were these.

\footnotetext{
1 Rept. 1884.
} 
In the second trial one ton of clover hay was found to be worth somewhat more than three tons of corn stover.

As before noted, the corn stover was fed uncut, and the parts left uneaten, day by day, were saved and weighed. It was found that thirty-four per cent. of the fodder remained unconsumed in the coarser portions of the corn stalks. (25I)

Dairymen will be interested in learning the quantity of feed required for a unit of milk and butter in the above trial. These are given in the following table:

Feed for 100 pounds of mille and 100 pounds of butter as shovn in the trial just reported.

When feeding corn stover.

For 100 pounds of mille.

193 pounds stover.

60 pounds corn meal and bran.
For 100 pounds of butter. 3,880 pounds of stover. 1,233 pounds corn meal and bran.

When feeding mixed hay.

71 pounds mixed hay.

62 pounds corn meal and bran.
1,348 pounds mixed hay.

1,200 pounds corn meal and bran.

When feeding clover hay.

60 pounds clover hay.

1,179 pounds clover hay.

63 pounds corn meal and bran. 1,231 pounds corn meal and bran.

654. Silage compared with hay.- - At the Maine Station, ${ }^{1}$ Jordan compared silage made from various kinds of corn with "good hay" (mostly timothy) for milk production. Four cows were fed, first hay, later hay and silage, and again hay. During the whole period each cow received the same amount of concentrates daily. The following results were secured:

On hay and grain. Feb. 17 to Mch. 9 On hay, silage and grain....Mch. 10 to May 11 ..... On hay and grain. ..May 12 to May 25. 21.7 pounds milk. 22.5 pounds milk. 19.6 pounds milk.

Here is an increase when changing from hay to silage and hay, and a decrease when changing back from silage to hay. The effects of the two feeds are shown in another table by the same investigator, who groups the milk yield of the four cows in

${ }^{1}$ Rept. 1889. 
fourteen-day periods just preceding or following a change in the roughage supplied.

Total yield of milk, four cows, 14 days.

On hay. 1,212 pounds.

Changed to silage and hay. 1,297 pounds.

An increase of 82 pounds, or 7 per cent.

On silage and hay 1,200 pounds. Changed to hay 1,098 pounds.

A decrease of 102 pounds, or 8 per cent.

We observe that when the cows were changed from hay to silage and hay there was an increase of 7 per cent. in the milk flow, and when changed back a shrinkage of 8 per cent. There was no difference in the composition of the milk because of the different feeds. Jordan concludes: "In this experiment the addition of silage to the ration resulted in a somewhat increased production of milk solids, which was not caused by an increase in the digestible food material eaten, but which must have been due either to the superior value of the nutrients of the silage over those of the hay or to the general physiological effect of feeding a greater variety of foods. In other words, 8.8 pounds of silage proved to be somewhat superior to 1.98 pounds of hay (mostly timothy), the quantity of digestible material being the same in the two cases. - . Assuming the digestible matter of hay and silage to be of equal value, pound for pound, when hay is worth $\$ 10$ per ton, silage of the kind used in this experiment would be worth $\$ 2.25$ per ton. But this silage contained more water than the average. . . . Had it been of average quality, then the ton value reckoned on the above basis would be $\$ 2.62$. But in this case we should give the silage the credit of the increased milk production, which seems to have been at the rate of 85 pounds of milk to each ton of silage." (390-91)

655. Silage versus fodder corn. - At the New Jersey Station ${ }^{1}$ Voorhees and Lane conducted a trial with silage and fodder corn for milk production.

A field of fifteen acres was planted to corn in rows three feet six inches apart, with the stalks eight inches apart in the row.

1 Bul. 122. 
The crop was harrested the first week in September, when the ears were beginning to glaze. The corn from twelve acres was run through the feed-cutter and placed in a silo, 11.25 tons being the average yield of green forage per acre. The crop of three acres was harvested by cutting and shocking in the usual manner. After curing for one month the forage was stored in the barn, the average yield being 4.1 tons of dry fodder per acre. The cost of placing the crop in the silo was $\$ 11.22$ per acre. (400) The cost for cutting, shocking, storing the fodder and running it through the feed-cutter was 10.31 per acre.

The total losses in dry matter were assumed to be practically equal for the two methods. The changes in the fodder were found to be an increase in crude fiber and a decrease in protein, ash and nitrogen-free extract. The changes in the silo resulted in the conversion of albout two-thirds of the albuminoids into amides. (385-7) Two lots of four cows each were fed silage and fodder respectively, the feeds for the lots being reversed at the close of the first period in order that both lots might be tested upon the same feed. The rations were so compounded that the fodder or silage furnished at least one-half the total dry matter and twothirds the digestible carbohydrates. The silage was eaten without waste, while a portion of the fodder was left uneaten. Both lots of cows gained in weight during the trial. The production of milk and fat is shown in the following table:

Feeding silage and dry forage to dairy cows - New Jersey Station.

\begin{tabular}{|c|c|c|c|c|c|c|}
\hline & $\begin{array}{r}\text { No. of } \\
\text { days. }\end{array}$ & $\begin{array}{c}\text { Total } \\
\text { yield of } \\
\text { milk. }\end{array}$ & $=\begin{array}{c}\text { Av. } \\
\text { yield } \\
\text { per day } \\
\text { per coow }\end{array}$ & $\begin{array}{c}\text { Av. per } \\
\text { cent. of } \\
\text { fat. }\end{array}$ & $\begin{array}{l}\text { Total } \\
\text { yield of } \\
\text { fat. }\end{array}$ & $\left\{\begin{array}{l}\text { Av. fat } \\
\text { per diuy } \\
\text { per coif }\end{array}\right.$ \\
\hline & & Lbs. & Lbs. & & Lbs. & Lbs. \\
\hline Bilage............................ & 24 & $2,276.2$ & 23.7 & 3.78 & 86.15 & .897 \\
\hline Dry fodder ration.......... & 24 & $2,017.9$ & 21.0 & 3.86 & 78.02 & .813 \\
\hline Gain from silage.......... & ........ & 258.3 & 2.7 & -0.08 & 8.13 & .084 \\
\hline Per cent. of inerease..... & ........... & & & ............. & 10.4 & .............. \\
\hline
\end{tabular}

It will be seen that the silage ration produced 12.8 per cent. more milk and 10.4 per cent. more fat than did the dry forage.

656. Rape for milch cows. - At the Ontario Agricultural College, ${ }^{1}$ Shaw investigated the value of rape for milch cows. Fonr

\footnotetext{
${ }^{1}$ Rept. 1892.
} 
cows were separated into two lots and fed during four periods lasting fifty-three days. Rape was fed during Periods II and IV. The cows were pastured during Period I, and fed hay and silarg $\theta$ during Period III. Five pounds of meal were fed daily per head throughout the trial. Lot I received forty pounds of rape per day, and hay ad libitum; Lot II was fed rape ad libitum, consuming on an average seventy-six pounds daily. The average daily millk yield for each lot was as follows:

\begin{tabular}{|c|c|c|}
\hline & Rape. & No rape. \\
\hline sot II. ............................. & 18.20 pounds. & 17.74 pounds. \\
\hline
\end{tabular}

The rape was fed both before and after milking without imparting any perceptible taint to the milk in either case. The results obtained are promising for rape as a feed for the dairy cow. (334-5)

657. Roots versus concentrated feeds.-. At the Copenhagen Station, ${ }^{1}$ eighteen series of experiments were conducted for three consecutive years with 636 cows separated into 62 lots. The addition of 40 pounds of mangels or 50 pounds of turnips to an ordinary ration for milch cows increased the daily milk yield by 2.75 pounds, the cows increasing 3.63 pounds per head in live weight, eating 3.08 pounds less straw daily. In two preceding years, 2.86 and 1.76 pounds more milk were obtained on heavy root feeding, the average weight being 5.5 and 3.74 pounds more, and the quantity of straw eaten .55 and 1.98 pounds less per head daily. No appreciable difference in the chemical composition of the milk was observed resulting from the more intense feeding. These experiments show that one pound of concentrates, made up of grain, bran and oil cake, proved equal to ten pounds of mangels in feeding dairy cows. There was no appreciable difference in the water content of the milk produced by feeding varying quantities of roots. The water found in the milk was within .24 of one per cent. for the different lots of cows, the lowest water content appearing in the milk from cows receiving the largest quantity of roots. These extensive experiments completely refute the charge that milk can be indirectly watered by feeding roots. (325)

\footnotetext{
120 th Rept. 1890.
} 
658. Feeding potatoes.-According to Cornevin ${ }^{1}$ milch cows may be maintained exclusively on a ration of potatoes, eating about seven per cent. of their weight daily. Feeding exclusively on potatoes increases the milk flow, but the cows shrink in weight and take their feed with repugnance if it is continued for any length of time. Steamed potatoes are readily eaten by milch cows, but, if fed exclusively, digestion troubles will soon appear and rumination be disturbed or suspended.

In feeding potatoes in connection with other feeds, Cornevin obtained the best results when the potatoes furnished fifty per cent. of the total dry matter of the ration. It was found that raw potatoes favored milk secretion, while steamed potatoes increased the live weight and produced a deposition of fat. (316, 484-6, 866, 897)

\section{Miscellaneous Feeding Substances.}

659. Feeding milk and skim milk. - At the Iowa Station, ${ }^{2}$ Wilson fed full milk and afterwards skim milk to dairy cows. The cows shrunk in weight on full milk and gained on skim milk. The results obtained were fairly satisfactory.

Holdelleisz ${ }^{3}$ recommends feeding" skim milk to cows. He states that they easily digest rations containing five, six or even eight liters (quarts) of skim milk, even if sour; that skim milk has a farorable influence on the production of milk, and that it saves grain. The practice has been followed by a few American dairy. men, who report goud results. ${ }^{*}$ (357, 736, 869-71, 886-8)

660. Whey for milch cows. - Schrodt5 fed whey to milch cows at the Kiel Dairy Station. The ration consisted of 11 pounds clover hay, 5.5 pounds barley straw, 10 pounds mangels, 5.5 pounds wheat bran and 2.2 pounds palm-nut meal. During one period 11 pounds of sweet whey were fed and during another 22 pounds. The whey had a favorable influence on the quantity of milk yielded, and no deleterious effect on the quality of the butter. $(359,873,887,889)$

1 Jahresber. Agr. Chemie, 1894, p. 480.

2 Bul. 17.

s Allg. Ztg. f. deutsche Landw.,Vol. 16, No.7; Buerstenbinder, Jahresb., 1886 , p. $44 . \quad 1$ Bul. 38, Wis. Expt. Sta.

6 Iandw. Wocheubl. f. Schl. Hol., 1882, p. 237; Jahresber. f. Agr. Chemie, 1882 , p. 441. 
661. Fish scrap. - According to Kühn, ${ }^{1}$ milk and butter of normal quality were produced on a daily allowance of 2.3 pounds of fat-free fish scrap supplied with a variety of other feed, no deleterious effects resulting. (340, 55I, 779)

662. Feeding fat to dairy cows. - At the Cornell Station, ${ }^{2}$ Wing conducted two trials in which tallow was fed to dairy cows in addition to the usual feed. In each trial fire cows were used. In the first the cows were on pasture, receiving in addition eight pounds of grain. In the second they were on winter feed, receiving a like allowance of grain. The milk yield and its composition were ascertained for one week before the trial began. After this preliminary period, beef tallow was added to the ration, commencing with four ounces per day for each cow. When this was readily eaten, more tallow was added, until after the fourth week the allowance for each cow reached two pounds daily. With this amount added to the ration the trial continued six weeks longer, or until the tenth week, at which time tallow was dropped from the ration, the observations continuing two weeks longer. In the table below appear the results found with two cows by weekly periods, these being representative of all the animals under trial:

Adding tallow to the ration of dairy conos; data for two cons, representative of ten-Cornell Station.

\begin{tabular}{|c|c|c|c|c|c|c|c|c|}
\hline & \multicolumn{4}{|c|}{ Cow No. 1.} & \multicolumn{4}{|c|}{ Cow No. 2.} \\
\hline & $\begin{array}{c}\text { Tallow } \\
\text { fed } \\
\text { daily. }\end{array}$ & $\begin{array}{l}\text { Av. } \\
\text { milik } \\
\text { yield } \\
\text { daily. }\end{array}$ & $\begin{array}{l}\text { Per } \\
\text { cent. } \\
\text { fat. }\end{array}$ & $\begin{array}{c}\text { Av. } \\
\text { yield } \\
\text { butter } \\
\text { fat } \\
\text { daily. }\end{array}$ & $\begin{array}{c}\text { Tallow } \\
\text { fed } \\
\text { dally. }\end{array}$ & $\begin{array}{l}\text { Av. } \\
\text { milk } \\
\text { yleld } \\
\text { daily. }\end{array}$ & $\mid \begin{array}{c}\text { Per } \\
\text { cent. } \\
\text { fat. }\end{array}$ & $\begin{array}{c}\text { Av. yleld } \\
\text { butter fat } \\
\text { dally. }\end{array}$ \\
\hline 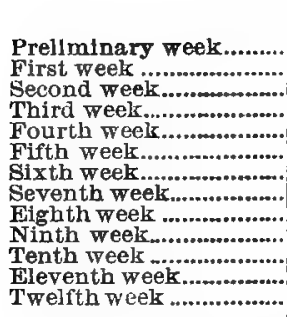 & $\begin{array}{c}\mathrm{Oz} . \\
\ldots \ldots \ldots \\
6 \\
13 \\
20 \\
29 \\
32 \\
32 \\
32 \\
32 \\
32 \\
32 \\
\ldots \ldots \ldots \ldots \\
\ldots \ldots \ldots . . .\end{array}$ & $\begin{array}{l}\text { Lbs. } \\
47.2 \\
48.9 \\
49.5 \\
46.1 \\
43.8 \\
46.2 \\
42.7 \\
43.3 \\
44.1 \\
41.5 \\
36.8 \\
42.6 \\
41.2\end{array}$ & $\begin{array}{l}3.5 \\
3.5 \\
3.5 \\
3.6 \\
\mathbf{3 . 7} \\
3.2 \\
3.6 \\
3.4 \\
3.0 \\
3.3 \\
3.0 \\
3.1 \\
3.3\end{array}$ & $\begin{array}{l}\text { Lbs. } \\
1.66 \\
1.69 \\
1.72 \\
1.66 \\
1.60 \\
1.50 \\
1.51 \\
1.45 \\
1.32 \\
1.37 \\
1.08 \\
1.32 \\
1.36\end{array}$ & $\begin{array}{r}\text { Oz. } \\
\\
\ldots \ldots \ldots \\
7 \\
13 \\
\mathbf{2 0} \\
27 \\
30 \\
32 \\
\mathbf{3 0} \\
\mathbf{3 2} \\
\mathbf{3 2} \\
\mathbf{3 2} \\
\ldots \ldots \ldots \ldots\end{array}$ & $\begin{array}{l}\text { Lbs. } \\
25.9 \\
27.3 \\
26.3 \\
24.6 \\
23.6 \\
21.8 \\
21.2 \\
20.3 \\
23.4 \\
22.6 \\
19.8 \\
21.9 \\
21.3\end{array}$ & $\begin{array}{l}4.4 \\
4.7 \\
4.8 \\
4.0 \\
5.0 \\
4.8 \\
4.9 \\
5.0 \\
4.7 \\
4.6 \\
4.5 \\
4.2 \\
4.3\end{array}$ & $\begin{array}{l}\text { Lbn. } \\
1.14 \\
1.29 \\
1.20 \\
1.19 \\
1.19 \\
1.04 \\
1.08 \\
1.01 \\
1.10 \\
1.08 \\
0.89 \\
0.91 \\
0.90\end{array}$ \\
\hline
\end{tabular}

1 Jahresber. f. Agr. Chemie, 1894, p. 482.

Bul. 92. 
It will be seen that, despite the addition of tallow to the ration in increasing amount up to two pounds per cow daily, there was the normal gradual falling off in the millk flow, the percentage of fat in the milk remaining substantially the same. With cow No. 2 there was possibly an increase of three-tenths or four-tenths of one per cent. fat for a time succeeding the first use of tallow; there was, however, a diminution in the milk flow, so that the total fat secreted was increased by not more than one-tenth of a pound daily, and even this increase might not have been due to the feeding of tallow. After feeding this cow tallow four weeks, the total fat in the milk had fallen below the amount she was giving at the time tallow feeding began. Wing concludes: "In this quite extended trial there bas been no increase in fat in the milk by feeding tallow to the cows in addition to a liberal grain ration. These results were obtained with ten different cows of two breeds of various ages in various periods of lactation, extending over a period of ten weeks, for at least six of which they ate two pounds per head per day of tallow."

At the New Hampshire Station, ${ }^{1}$ Wood fed cotton-seed oil, palm oil, corn oil, cocoanut oil, oleo oil and stearin in an ordinary ration to cows, and concludes: "That the first effect of an increase of fat in the cow's ration is to increase the per cent. of fat in the milk; that with the continuance of such a ration the tendency is for the milk to return to its normal condition; that the increase in fat is due not to the oils, but to the unnatural character of the ration."

663. Feeding potassium chlorid. - Bieler ${ }^{2}$ fed twenty-five grams (about one ounce) of potassium chlorid per day per cow, and noticed an appreciable increase in the yield of milk, but the solids and fat decreased simultaneously. The effect of the potassium chlorid on the milk secretion covered only a few days, when it again became normal.

664. Cooking feed.- Spear ${ }^{3}$ fed cooked meal to four cows and uncooked meal to four others during a period of thirteen weeks. The cows receiving the cooked feed gave six-tenths of a pound of

1 Bul. 20.

2 Hilger's Jahresber., 1893, 403.

Trans, High. and Agrl. Soc., 1891. 
milk more per day than those getting uncooked feed, with no difference in the quality of the milk. These returns do not pay for the labor involved, and are in conformity with the results obtained with other farm animals when given cooked feed. (370, 836)

665. Feeding grain in form of slop.- It is frequently asserted that sloppy feeds increase the milk flow. This matter was tested by Dean at the Ontario Agricultural College. ${ }^{1}$ For roughage the cows were fed silage and pasture; for concentrates, two pounds of ground wheat and four pounds of bran. The results appear below:

Effect of wetting the feed supplied dairy cons - Ontario Station.

\begin{tabular}{|c|c|c|}
\hline Form of feed. & $\begin{array}{l}\text { Milk yield, } \\
\text { two-week } \\
\text { periods. }\end{array}$ & $\begin{array}{l}\text { Per cent. } \\
\text { of fat } \\
\text { in milk. }\end{array}$ \\
\hline $\begin{array}{l}\text { Eight cows. } \\
\quad \text { Fed dry feed } \ldots \ldots \ldots \ldots \ldots \ldots \ldots \ldots \ldots \ldots \ldots \ldots \ldots \ldots \ldots \ldots \ldots \ldots \ldots \ldots \ldots \ldots \ldots \ldots \ldots \ldots \ldots \ldots \ldots \ldots \ldots \ldots \ldots \ldots \ldots\end{array}$ & $\begin{array}{l}\text { Lbs. } \\
3,062 \\
3,157 \\
2,940\end{array}$ & $\begin{array}{l}3.96 \\
3.82 \\
3.86\end{array}$ \\
\hline 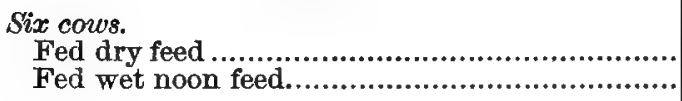 & $\begin{array}{l}1,110 \\
1,085\end{array}$ & $\begin{array}{l}3.60 \\
3.63\end{array}$ \\
\hline
\end{tabular}

There is nothing in the above to indicate that feeding meal in the form of slop induces a greater flow or changes the character of the milk. Dean's conclusions are, "This experiment would indicate that slopping is an expensive way to feed cows."

666. Feeding grain to cows on pasture.-The utility of feeding grain to cows on pasture has been studied at the Cornell Station ${ }^{2}$ during several seasons.

In the first trial cows receiving grain while on a luxuriant pasture gave less milk, but an equal amount of fat, with those getting no grain on the same pasture.

The next season, with the pastares luxuriant except for a short time in midsummer, the lot receiving grain and that without grain did equally well.

\footnotetext{
1 Repts. 1893-94.
}

\& Buls. 13, 22, 36, 49 . 
In the third trial both lots were soiled with grass, one lot getting grass only, while the second received grain in addition. "In this trial the grain-fed cows gave just enough more fat to pay for the grain received.

In order to determine the value of grain for cows on pasture under practical conditions, a fourth trial was conducted with a herd of cows owned by a New York farmer. This herd, consisting of sixteen cows which had been lightly fed during the winter, was divided into two lots of eight each, all grazing in the same pasture. Each cow of Lot I was fed four quarts daily of a mixture of two parts corn meal, one part wheat bran and one part cotton-seed meal, by weight. The test began May 23. August 10, the pastures becoming poor, both lots were fed green fodder corn. On September 9, grcen millet was substituted for the fodder corn. October 1, meadow grass was substituted for the millet, and this was followed October 13 with pumpkins in generous quantity. It will be noted that the cows getting no grain were much better fed than those on most farms. The findings of the trial, which lasted twenty-two weeks, are here presented:

Feeding grain to cows on pasture - Trial by Cornell Station.

\begin{tabular}{|c|c|c|}
\hline & Lot I. & Lot II. \\
\hline & $\begin{array}{c}\text { Pasture } \\
\text { with grain. }\end{array}$ & $\begin{array}{c}\text { Pasture } \\
\text { without grain. }\end{array}$ \\
\hline 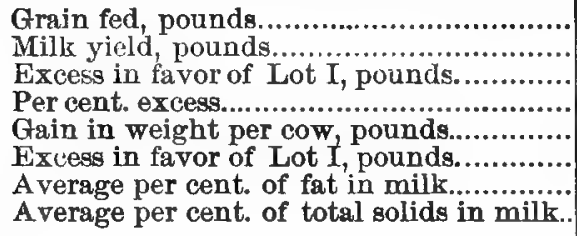 & $\begin{array}{r}5,200 \\
22,629 \\
4,931 \\
28 \\
166 \\
53 \\
4.67 \\
14.08\end{array}$ & 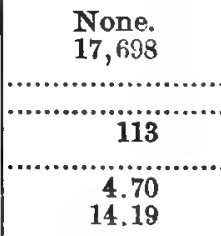 \\
\hline
\end{tabular}

We learn from the above that the eight cows in Lot I were fed 5,200 pounds of grain and gave 4,931 pounds or 28 per cent. more milk than those getting no grain. Both lots gained in weight, Lot I leading by fifty-three pounds on the average for each cow. The ase of grain did not change the composition of the mille. 
Remembering that this trial was conducted on a New York dairy farm, we are taught that even when the midsummer and fall shortage in pasture is overcome by the use of fodder corn, pumpkins, ete., the result of feeding grain is to secure about one pound of millk extra for each pound of grain fed. (555)

667. Residual effects of grain feeding.-The following year the - herd was turned to pasture as usual, no grain being supplied to either lot. Beginning April 1 a record was kept of milk yields. Six cows in each lot of the previous year still remained upon the farm. Their yield of milk for six months was as follows:

Lot I. Lot II.

Fed grain Fed no grain previous year. previous year.

Average yield per cow, six months, pounds......... 3,440 2,960

In favor of Lot I, pounds................................. 480

Per cent. in favor of Lot I ............................... 16

It will be seen that the cows in Lot I averaged 480 pounds of milk, or 16 per cent. more than those in Lot II. Commenting on this, Roberts writes: "It seems reasonable to assume that this increased production was due to the grain fed the preceding year, especially in the case of the younger animals. Indeed it was plainly evident that the grain-fed two-year-olds and three-yearolds developed into better animals than their stable mates having no grain."

At the Kansas Station, ${ }^{1}$ Shelton, when feeding from 10.8 to 12.5 pounds of corn meal, bran or oats daily to cows on "ample pasturage, consisting for the most part of orchard grass and red clover," found an incresse in milk flow, due to the grain fed, varying from 16 to 31 per cent.; yet this increase was not suffcient to directly pay for the extra feed supplied.

At the North Dakota Station, ${ }^{2}$ Kaufman fed bran and shorts to cows grazing on a pasture of mixed tame grasses and clover, other cows in the same pasture receiving no grain. The results show only about 6 per cent. increase in the yield of fat because of the grain fed. The cows getting grain increased in weight more than the others, but the combined results were too small to pay for the grain fed.

\footnotetext{
1 Rept. $1888 . \quad$ ' $\quad 16$.
} 
These findings coincide with those obtained when feeding grain to steers on pasture. (555) From all the evidence at hand we may conclude that where pastures are luxuriant there are no profits from feeding cows grain; where there is not ample feed the increased milk returns will certainly compensate for the grain or green forage fed. The possible residual effect of feeding cows on pasture, as pointed out by Roberts, is important and should not be overlooked. Where pastures are short, unless green forage or grain is fed to cows the milk flow will decrease, and later, should the pastures revive, it will be fonnd almost impossible to bring the milk yield back to the normal. The increase in value of the droppings from grain-fed cows should also be considered, and will often prove the turning point in favor of a reasonable use of grain, especially kinds rich in fertilizing elements. 


\section{OHAPTER XXVI.}

INFLUENOE OF FEED ON MILK - WIDE AND NARROW RATIONB.

I. Feed in Relation to Milk.

668. Possible modifications of milk by feed.- If feed has any influence on the character of milk, we may suppose these modifications will take one or more of the following forms:

(a) An increase or decrease in the total quantity of milk yielded.

(b) Increasing or decreasing the ratio of solids to water in the milk.

(c) Changing the ratio of one or more components of the milk with relation to the others.

(d) Changing the chemical or physical character of one or moro components.

(e) Changing the flavor or odor of milk or derivatives from it.

Let us consider these several possible changes in the order presented.

\section{(a) Effect of Feed on Quantity.}

669. Liberal and meager rations. - Most dairymen have learned that under liberal feeding the dairy cow is stimulated to the best milk returns within her capacity. So generous is the cow in this particular that dairymen will concede they rarely supply their animals sufficient feed to induce the largest flow of milk possible with all members of the herd. With scant rations or those of fanlty character, the normal milk flow of the cow is diminished, though she will still yield this fluid for a time while undergoing starvation. Milk being designed for the support of the young, Nature has provided for its supply to the limit of animal endurance.

670. Infiluence of character of ration.-The abundance and proportion of the several nutrients in the ration and the quantity of inert matter it contains may affect the flow of milk. This is il- 
lustrated by an experiment at the Ontario Agricultural College' by Dean, in which six cows were divided into three lots of two each. The ration marked I consisted exclusively of coarse feed, supplying more carbohydrates and less protein than the cow required. It contained a large quantity of inert matter. Ration II contained an ample supply of carbohydrates and an over-supply of protein, the latter being contained in rich, heavy oil meals. Ration III contained an excess of nutrients. $\mathrm{By}$ alternating the rations for the three groups of cows, the influence of a decreasing milk flow was eliminated from the results, which were as follows:

Feeding an improperly compounded and a well balanced ration to dairy cows - Ontario Agricultural College.

\begin{tabular}{|c|c|c|c|c|c|}
\hline Ration. & $\begin{array}{c}\text { Total } \\
\text { digesti- } \\
\text { blemat- } \\
\text { ter. }\end{array}$ & $\begin{array}{l}\text { Nutri- } \\
\text { tive } \\
\text { ratio. }\end{array}$ & $\begin{array}{l}\text { Av. live } \\
\text { weight. }\end{array}$ & $\begin{array}{l}\text { Daily } \\
\text { yield of } \\
\text { milk. }\end{array}$ & Fat. \\
\hline & Lbs. & & Lbs. & Lbs. & Per ct \\
\hline 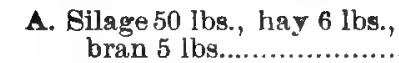 & 10.79 & $1: 8.4$ & 1,068 & 29.7 & 3.82 \\
\hline $\begin{array}{l}\text { I. Silage } 30 \text { lbs., oat straw } \\
20 \text { lbs. hay } 10 \mathrm{lbs} . .\end{array}$ & 1589 & & 1014 & 018 & . \\
\hline II. Hay 20 lbs., oil meal 4 & & $1: 20.0$ & 1,014 & 21.8 & 3.67 \\
\hline 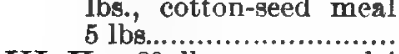 & 14.76 & $1: 3.9$ & 1,091 & 29.3 & 3.49 \\
\hline $\begin{array}{l}\text { III. Hay } 20 \text { lbs., pea meal } 4 \\
\text { lbs., oat meal } 5 \text { lbs., } \\
\text { corn meal } 8 \text { lbs ........... }\end{array}$ & 20.27 & $1: 6.8$ & 1,110 & 31.8 & 3.25 \\
\hline
\end{tabular}

Under $A$ is given the preliminary ration fed to all the cows; with this there was an average daily milk yield of 29.7 pounds. When ration $I$ was fed the cows dropped to 21.8 pounds of milk. In this ration we find a liberal allowance of carbohydrates with too little protein and too much inert matter. 'Though the cows were filled with feed they were poorly nurtured. Under II there was abundant nutrition, but the oil meals given were heavy in character and too liberal in quantity for the best results though the milk flow was increased to nearly the normal. With III we have a better balanced ration; the cows were over-fed, but the better character of the ration secured larger returns than were possible under previons feeding, the amount of milk now reach.

' Rept. 1891. 
ing 51.8 pminds daily. It is evident that the character and quantity of feed given directly affect the flow of milk, and over-feeding or the use of improperly componnded rations may bring poor results as well as under-feeding.

\section{(6) Increasing or Decreasing the Ratio of Solids to Water in Milk.}

671. Influence of succulent feed.- - It is commonly asserted that ancculent feed causes thinner milk, i. e., renders it more watery. Schmoeger, ${ }^{1}$ at the Proskan Dairy Institute, showed that feeding 30 liters (quarts) of distillery slop daily per head to a herd of 37 cows did not affect the composition of milk, the average solids being 11.83 per cent. and fat 3.29 per cent. with the slop feeding as against 11.61 per cent. and 3.28 per cent., respectively, during the previous period.

Trials by Armsby, feeding green and dried grass to milch cows. showed no change in the composition of the milk because of the more succulent grass. (265) In the Danish experiments, where roots were fed, the highest per cent. of solids appeared in the milk of cows receiving the largest quantity of roots. (657)

672. Influence of pasture.- The effect of pasture on the composition of milk should here receive consideration. The Copenhagen Station ${ }^{2}$ conducted trials with 240 cows for two years. The per cent. of fat in the milk of these cows, when stall-fed with dry feed and when on pasture, was as follows:

Lot A.

Stall feeding, dry feed.... 3.27 per cent.

Pasture.
Lot B.

3.25 per cent. 3.39 per cent.
Lot C.

3.26 per cent. 3.39 per cent.

There was a slightly higher fat content with cows on pasture in all cases.

At the Vermont Station, ${ }^{8}$ Hills, studying the change in cornposition of milk of cows changed from barn to pasture during five years, concludes: "The evidence appears overwhelming that cows on early pasturage - May and June - make not only more, but richer, milk than during the last months of their barn life." In these cases the higher fat content is always accompanied by a

'Milch Zeit., 1883, 129.

2 Rept. 27, 1891-92.

Rept. 1893. 
higher percentage of total solids; that is, the milk from the pasture contains less water.

Sebelien ${ }^{1}$ calls attention to similar changes in the composition of milk produced by Norwegian cows while on mountain pastures as compared with that produced in the valleys.

Conclusions are not uniform in this particular, as shown by the findings of Lawes and Gilbert, ${ }^{2}$ who write: "The yield of mill was, however, in a much greater degree increased by grazing than by any other change in the food; and with us, at any rate, the influence of roots comes next in order to that of grass, though far behind it, in this respect. But with grazing, as has been shown, the percentage composition of the milk is considerably reduced; though, owing to the greatly increased quantity jielded, the amount of constituents removed in the milk whilst grazing may, nevertheless, be greater per head per day than under any other conditions."

With such conflict of opinion may we not agree with Sebelien, who suggests that the general feeling of well-being, the influence of sunlight, the pleasant spring weather and an outdoor life have more to do with the change produced, whether the fat is increased or decreased percentagely, than does the change in feed itself.

With the coming of spring, the cows that have long been confined to their quarters in the stable find life irksome; the roughage at this time becomes dry and loses in aroma and palatability. Then, too, the animals are shedding their coats. These factors combine against normal milk production in the last days of confinement, and make the contrast of pasture life with its succulent feed all the more marked.

673. Watery feed does not necessarily make watery milk.- Reviewing the subject broadly, we may conclude that succulent feeds have no deleterious effect upon the composition of milk; on the other hand, in many cases they may have a beneficial influence. It is entirely possible that such highly-diluted feeds as distillery slops, beet chips and wet brewers' grains, when fed in abnormal quantities for long periods, may prove prejudicial, though we can point to no definite experiments showing such results.

\footnotetext{
' Tidskr. f. n. Landbr., II, 208.

'Jour. Roy. Agrl. Soc., 1895.
} 
(c) Changing One or More Components of the Milk.

674. Opinions and early experiments.-In the whole realm of dairying no subject arises so frequently for discussion as the influence of feed on the amount of fat in milk. Though the Babcock test is fast clearing away uncertainties, many dairymen still hold that certain feeds or feed combinations cause the cow to pro' duce milk richer or poorer in fat than the normal. Scientists, too, have been divided on this question, some holding with the practical dairymen, so called, while others urge that the results of investigations do not warrant their position.

In $1869 \mathrm{Kühn}^{1}$ wrote: "The system of feeding is one of secondary importance for milk production; the yield of milk is primarily dependent on the development or productive capacity of the milk glands of each cow, and even with changes from light to heavy feed the supply does not increase in proportion to the nutrients supplied. The same holds true where the farmer aims to increase any single component of the milk, as fat, since it is not possible to attain a one-sided increase of this or any other component in the milk by changes in the system of feeding. No such changes can, at any rate, be reached as are of practical importance."

The author of the above, however, in 1874-77 conducted trials ${ }^{2}$ in which palm-nut meal in particular, and also malt sprouts, peanut meal and cotton-seed meal, when fed to dairy cows, appeared

- to have an influence on the quality of milk, the fat content being increased. Usually these experiments were made with single cows and the feeding periods were of short duration, thus giving the immediate influence of a change of feed undue prominence. in later experiments with palm-nut meal, where all the necessary precautions were taken, the later conclusions of Kühn were not substantiated.

Numerous investigations, direct and indirect, on this point have been conducted at American Stations, a reference to which, even, would occupy too much space. The most marked example of seeming change in composition through feed influence was by

- Landw. Vers. Sta., 12, p. 441.

2 Jour. f. Landw., $1874-77$. 
Patrick, at the Iowa Station, ${ }^{1}$ where .58 per cent. more fat was found in the milk of cows getting sugar meal than was found in the milk of the same cows when fed corn and cob meal. Amerscan findings do not generally show any marked permanent change in the fat content of milk brought about by feed; indeed, when Patrick $^{2}$ again fed sugar meal, only a slight difference was found in its favor, some cows giving adverse results. We may conclude in this case, then, that these results were accidental, or rathes that they were due to other than the assigned cause.

675. Danish experiments. - The experiments with cows by the Copenhagen Station ${ }^{3}$ furnish reliable data on this important sub. ject, because of the large number of animals employed and the character of the feeds supplied. Friis, treating of this subject, writes: "In the comparative feeding trials with milch cows now conducted for several years by this Station, in which 1,639 cows have been included (separated into 161 lots on ten estates in different parts of our country), it has been repeatedly found that the changes made in the feed of the lots have practically had no influence on the chemical composition of the milk. In these experiments grain has been fed against roots, against oil cake, and against wheat bran or shorts; grain and oil cake have been fe. against roots, or roots have been fed as additional food."

676. Possible exceptions. - It is possible that a cow which has long been illy nurtured and is in poor condition will give milk abnormally low in fat, and that the railk will increase in richness of fat with increased feed supply and the approach of the body to normal conditions. When a cow is fed a starvation ration the milk may be richer or poorer in fat than the normal, the quantity decreasing rapidly. There is little known that is definite or satisfactory on these points.

(d) Ohanges in Character or Composition of One or More of the Components of Milk.

677. Effect of feed on composition of butter-fat.- It is generally agreed that feed affects in some way the character of the fat of milk, which is shown practically by the varying character

\footnotetext{
'Bul. 14. Bul. 15, Inwa Sta. ' Rept. 1894
} 
of butter. A number of investigators have studied the variations in hardness, melting point, volatile fatty acids, etc., of butter-fat, due, it is generally supposed, to the different feeding stuffs employed in nurturing the cow. While each investigator has arrived at certain conclusions seemingly warranted by the trials he has conducted, on classification these findings show little agreement, so that Frear, ${ }^{1}$ studying all the available data, was forced to write: "They do not, howerer, suffice either for the framing of a theory as to the relation of the several food constituents to the fats of the milk, or for the quantitative measure of the influence of a given food."

As with scientists, so with practical feeders, - we can find them stating with much assurnce that this or that particular feed has this or that influance on the character of the butter made while feeding it; when we classify these opinions, however, we find them discordant and standing in opposition on the same article.

As to cotton-seed meal there is fairly uniform agreement that it makes a hard butter; while often deleterious, therefore, it may be useful in firming butter required for the summer trade. (For the influence of cotton-seed meal on butter see Article 217.) The changes in the quality of butter due to length of time from calving are generally greater than those wrought by any special system of feeding. As originally shown by Nilson, ${ }^{2}$ fat from fresh cows contains a larger amonnt of volatile fatty acids than is found at any later stage of the lactation period; as a result, butter from such cows has a high flavor, comparatively speaking, while that from strippers is deficient in flavor and of tallowy consistence.

(e) Feed Influences on Flavor and Odor of Milk or Its Derivatives.

678. Flavors of milk, butter, etc.-Besides the variations already referred to which are supposably measurable by the chemist, there are immeasurable ones which may exert a potent influence on the quality of milk and its products, these being perceived by the sense of taste or sinell — usually by the former. Certain articles eaten by cows - leeks, onions, turnips, etc. - give flavors detected

'Agrl. Science, 1893.

${ }^{2}$ Kgl. Landtbruks Ak. Handl., 1885, 45. 
by the majority of persons using milk. Rye, when pastured, gives an unpleasant flavor to milk, not detected by all, but by wany. Grass has a marked effect on the flavor of butter, derected by all in spring when the cows are first changed from dry feed to pasture. This flavor is soon unnoticed, but whether it really disappears, or is unobserved because of familiarity brought about by daily use, is an open question. The intensity of flavors and odors in milk originating from certain feeds probably varies with different cows, the milk of some showing these faults in a more marked degree than others. Often odors and flavors in milk charged to the cow are due to contamination of the milk after it is drawn and while left in the stable or elsewhere.

679. A review of the subject.-Reviewing the matter, it seems from the data at hand that it is possible to vary the composition of cow's milk for short periods by marked changes in the character of the feed supplied, there being an increase of one or two-tenths of one per cent. of fat when feeds rich in protein are given, though sometimes the change is the other way. The extensive Danish investigations conclusively show that the dairy farmer cannot hope to mensurably increase the percentage of fat in his milk by any practicable system of feeding.

It is remarkable that dairymen have so generally held an erroneous opinion regarding the ability of feed to permanently affect the quality of milk. They have doubtless been led into this error because with any marked improvement of the ration for the cow there has always come a larger flow of milk, and consequently a larger total amount of fat. It would appear that the variations in the fat percentage of milk are oftener brought about by nervous influences than through the character of the feed supplied. Even the variations found when first changing to new rations may be a nervous rather than a feed effect, thus explaining why the change is but temporary.

When the function of milk is considered, the view here held as to its stability of composition seems rational. If the milk of the dam were subject to marked or violent fluctuations, varying in composition with every small change in quantity or quality of food-supply, the welfare of the young animal receiving it would 
be constantly threatened. Nature has wisely provided that this vital food shall remain quite constant in composition so far as nutritive influences are concerned, though the quantity must vary with the abundance or scantiness of the feed supplied.

It is not apparent why nervous impulses should affect the composition of milk so readily while feed does not. It appears that the milk glands are under nervous control, and whatever threatens the existence of the dam or her young, or mars her equanimity, is immediately reflected in the milk secretion.

680. Conclusion.- The dairyman who wishes to improve the quality of his milk must look to breed rather than to the character of the feed. Within the breed he must select those animals shown by the fat test to yield high percentages of the desired in. gredient. Securing suitable animals, he will reach the quantity of fat sought by supplying his cows with rations ample in quantity, rich in digestible components and altogether palatable and wholesome.

\section{Wide and Narrow Rations.}

681. Storrs Station studies. - The Storrs (Connecticut) Station is conducting an important investigation in relation to the cost of nutrients supplied dairy cows and the milk and butter returns. A representative of the Station is located with a chosen dairyman for a period of twelve days, during which time he weighs the feed and milk of each cow of the herd, sending samples to the Station for analysis. From the results of the analyses and the reports of the representative, the Station authorities formulate a new ration, presumed by them to be superior to that being fed. After the new ration has been nsed for a time, the herd is again visited, the representative remaining twelve days, as before, to study the effects of the ration. In every instance narrower rations have been substituted for the original, showing that the Station finds the dairyman not feeding liberally enough of protein, according to its understanding of the needs of the cow. (147-8) Under this system nine herds have been studied by the Station authorities. The nutrients of the rations found on the first visit, and those used 
later upon recommendation of the Station, are given in the following table:

Rations fed by Connecticut dairymen and those adopted by them on recommendation of the Storrs Station.

\begin{tabular}{|c|c|c|c|c|}
\hline & \multirow{2}{*}{$\begin{array}{l}\text { Av. } \\
\text { wt. } \\
\text { per } \\
\text { cow. }\end{array}$} & \multicolumn{3}{|c|}{ Pation fed. } \\
\hline & & $\begin{array}{l}\text { Digesti- } \\
\text { ble pro- } \\
\text { tein. }\end{array}$ & $\begin{array}{l}\text { Calor- } \\
\text { ies. }\end{array}$ & $\begin{array}{c}\text { Nutri- } \\
\text { tive } \\
\text { ratio. }\end{array}$ \\
\hline 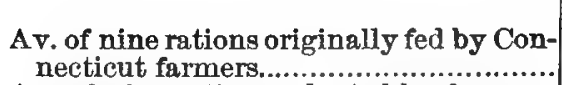 & $\begin{array}{r}\text { Lbs. } \\
750\end{array}$ & $\begin{array}{l}\text { Lbs. } \\
1.68\end{array}$ & 26,650 & $1: 7.5$ \\
\hline $\begin{array}{l}\text { Av. of nine rations adopted by farmers } \\
\text { on recommendation of Storrs Station.. }\end{array}$ & 750 & 2.17 & 25,900 & $1: 5.6$ \\
\hline
\end{tabular}

It will be seen that the change is mainly in supplying more protein in the ration, thus narrowing the nutritive ratio. The dairymen found by following the Station's advice that they were able to effect a saving in feed cost of about six cents per hundred pounds of milk and two cents for each pound of butter produced.

682. Influence of feed prices on economy of rations.- The best ration for Connecticut dairymen, or the most scientifically com. pounded, may not be the most satisfactory for Western conditions, because of difference in price for leading feed-stuffs, for at the West the carbohydrates are lower priced relatively than in the East. To illustrate this point let us calculate the cost of milk and butter for feed consumed, based on the different conditions. In the followiug table is given the Connecticut prices reported by the Station and average Wostern prices for common feeding-stuff's:

Prices for feeding stuffs used in the Connecticut feeding trials and those prevailing in the dairy district of the West.

\begin{tabular}{|c|c|c|c|c|c|}
\hline Kind of feed. & $\begin{array}{l}\text { Con- } \\
\text { nectl- } \\
\text { cut. }\end{array}$ & $\begin{array}{l}\text { West- } \\
\text { ern. }\end{array}$ & Kind of feed. & $\begin{array}{l}\text { Con- } \\
\text { eecti- } \\
\text { cuth }\end{array}$ & $\begin{array}{l}\text { West- } \\
\text { ern. }\end{array}$ \\
\hline 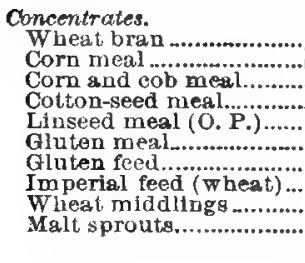 & $\begin{array}{l}\$ 13-19 \\
14-21 \\
16-20 \\
21-26 \\
29-30 \\
18-25 \\
11-19 \\
18 \\
14-20 \\
14\end{array}$ & $\begin{array}{l}512 \\
12 \\
12 \\
28 \\
20 \\
18 \\
11 \\
18 \\
13 \\
12\end{array}$ & 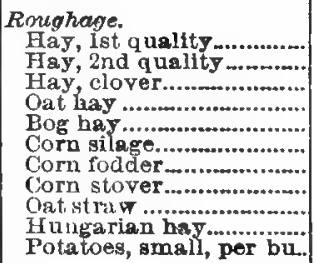 & $\begin{array}{rl}\$ 18 & 00-18 \\
12 & 00 \\
11 & 00 \\
12 & 00-14 \\
8 & 00 \\
2 & 50 \\
10 & 00 \\
8 & 00 \\
10 & 00 \\
12 & 00 \\
10\end{array}$ & $\begin{array}{l}800 \\
800 \\
800 \\
800 \\
300 \\
200 \\
500 \\
400 \\
800 \\
800 \\
10\end{array}$ \\
\hline
\end{tabular}


With these prices for feed we have calculated the cost of producing 100 pounds of milk and one pound of butter with the nine herds of cows used in the Connecticut investigations, and find the result as follows:

Cost of feed for producing 100 pounds of milk and one pound of butter under Connecticut and Western conditions.

\begin{tabular}{|c|c|c|c|c|c|c|}
\hline & \multicolumn{2}{|c|}{ Wide ration. } & \multicolumn{2}{|c|}{ Narrow ration. } & \multicolumn{2}{|c|}{$\begin{array}{l}\text { Result of using } \\
\text { narrow ration. }\end{array}$} \\
\hline & $\begin{array}{c}100 \mathrm{lbs} . \\
\text { milk. }\end{array}$ & $\begin{array}{c}1 \mathrm{lb} . \\
\text { butter. }\end{array}$ & $\begin{array}{l}100 \text { lbs. } \\
\text { milk. }\end{array}$ & $\begin{array}{l}1 \mathrm{lb} . \\
\text { butter. }\end{array}$ & Milk. & Butter. \\
\hline & Dollars. & Cents. & Dollars. & Cents. & Cents. & Centis. \\
\hline $\begin{array}{r}\text { At Con ne cticut } \\
\text { prices for feerl..... }\end{array}$ & 1.13 & .21 & $1.0,7$ & 19.0 & $\underset{6}{\text { Saved }}$ & $\underset{2}{\text { Saved }}$ \\
\hline $\begin{array}{l}\text { At Vestern prices } \\
\text { for feed............... }\end{array}$ & .629 & .115 & .689 & .12 .3 & $\underset{6}{\text { Lost }}$ & $\begin{array}{l}\text { Lost } \\
.8\end{array}$ \\
\hline
\end{tabular}

It will be seen that the Connecticut farmer effects a saving of six cents on a hundred pounds of milk and two cents on a pound of butter by adopting the narrow ration recommended by the Station. Were the Western farmer to follow the Station's counsel, he would lose six cents on a hundred pounds of milk and eighttenths of a cont on a pound of britter. 


\section{CHAPTER XXVII.}

PUBLIC TESTS OF PURE-BRED DAIRY COWS-COST OF PRODUU-

ING MILK AND FAT IN DAIRY HERDS AT VARIOUS EXPERIMENT STATIONS.

\section{Test at the World's Columbian Exposition, Chicago, 1893.}

683. Concerning the test.-The authorities in charge of the World's Columbian Exposition, Chicago, 1893, in co-opera!ion with representatives of the various dairy and cattle breeders' associations of America, planned a test of dairy breeds to occur during the six months of the Exposition. The original plan embraced herds of animals representing all the leading dairy breeds. Each herd was to be managed by the association entering it, account being taken of all feed consumed and products returned. The general supervision of the cows and the manufacture of the milk was in charge of a committee representing the Association of American Agricultural Colleges and Experiment Stations and representatives of the breed associations participating in the test. Commodious stables were constructed, silos built and filled, and a large dairy building erected. The outcome was the entrance of three herds of twenty-five cows each in the contest, the Jersey, Guernsey and Short-horn breeds being represented. The data of this contest are said to fill 900 pages of record books. ${ }^{1}$

1 Most unfortunately the official records of this test have never been published although certain summaries have been given to the publie through various channels. The Association of Agricultural Colleges, in whose charge the records were left, has offered to deposit them with the Agricultural Department at Washington, where doubtless they will be available for reference in the future. For reports of the test, see numbers of the Breeder's Gazette, Chicago, 1890-1893, incluaive. The most complete summary appears in Jersey Bulletin, Iudianapolis, Dec. 20, 1893. Another summary was published by James Cheesman, Southborough, Mass., printed originally in Journal of the British Dairy Farmers' Association, London, 1894; also in pamphlet form by the author. Another summary was published in pamphlet form by Valancey E. Fuller, Superintendent of the Jersey herd during the contest. The tables here presented are from the Jersey Bulletin and the Cheesman report. 
Only the briefest summary of the more important results can be here presented, bat these should prove useful to dairy students and others, the accuracy of the figures being unquestioned.

684. Prices charged for feed.-The prices charged for feed consumed by the cows during the contest, fixed by the chief of the Agricultural Division of the Exposition, appear in the table below:

Prices charged per ton for feed consumed by cows - Columbian Dairy Contest.

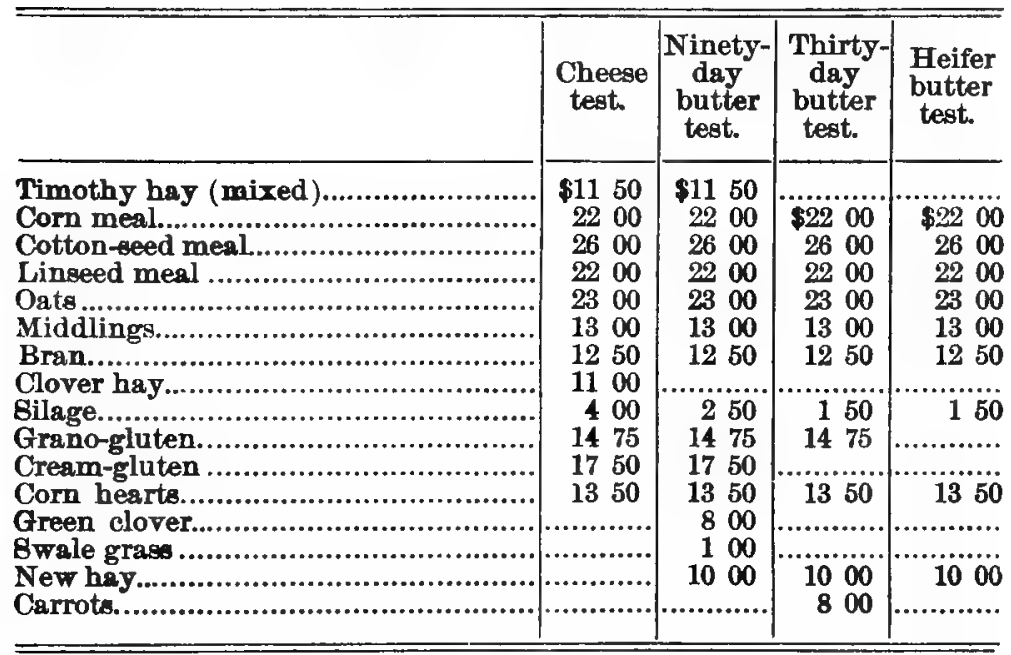

685. Allowance for products. - A scale of prices for productio was also fixed by the Division Chief, that for cheese ranging from eight to sixteen cents per pound, according to the score of these products as determined by expert judges. Whey was rated at eight cents per hundred pounds. In the butter contests all the fat produced by the cows was calculated as butter on the basis of eighty per cent. fat in the butter. The price allowed for the butter was forty-five cents or less per pound, depending upon its quality as scored by experts. Solids not fat in the skim milk and buttermilk were credited at two cents per pound. The live weight gained by the cows during the trial was rated to their credit at four and a half cents per pound. 
686. Description of the tests. - The first test was for cheese production, the trial beginning May 12 and continuing fifteen days, with twenty-five cows in each herd.

The next trial was for the production of butter, with credits for butter, solids not fat, and gains in live weight. There were twentyfive cows in each herd, the trial beginning June 1 and continuing ninety days.

The third trial, beginning August 30, lasted thirty days, there being fifteen cows in each herd. In this trial butter only was credited.

The contest ended with a test of heifers, lasting twenty-one days, - fat, solids, and live weight being credited.

Summaries of each of the trials are presented in the following tables:

Cheese test May 12-26, 1893, fifteen days, twenty-five cows in each herd.

\begin{tabular}{|c|c|c|c|c|c|c|c|}
\hline \multirow{2}{*}{ Breed. } & \multirow{2}{*}{$\begin{array}{l}\text { Price } \\
\text { per lb. } \\
\text { cheese. }\end{array}$} & \multicolumn{4}{|c|}{ Value of products. } & \multirow{2}{*}{$\begin{array}{l}\text { Total } \\
\text { cost of } \\
\text { feed. }\end{array}$} & \multirow{2}{*}{$\begin{array}{l}\text { Total } \\
\text { net } \\
\text { gain. }\end{array}$} \\
\hline & & Cheese & Whey. & $\begin{array}{l}\text { Live } \\
\text { wt. } \\
\text { gained }\end{array}$ & Total. & & \\
\hline 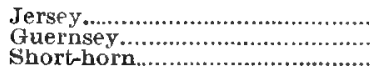 & $\begin{array}{l}.13 \% 6 \\
.1195 \\
.1300\end{array}$ & $\begin{array}{rr}8193 & 98 \\
135 & 22 \\
140 & 14\end{array}$ & $\begin{array}{rl}99 & 26 \\
7 & 73 \\
867\end{array}$ & $\begin{array}{rl}\$ 1472 \\
21 & 60 \\
3191\end{array}$ & $\begin{array}{r}\$ 21796 \\
16455 \\
18072\end{array}$ & $\begin{array}{rl}\$ 98 & 14 \\
76 & 2.7 \\
99 & 36\end{array}$ & $\begin{array}{rl}\$ 119 & 82 \\
88 & 30 \\
81 & 36\end{array}$ \\
\hline
\end{tabular}

Feed Consumed.

\begin{tabular}{|c|c|c|c|c|c|c|c|c|c|c|}
\hline Breed. & $\overrightarrow{3}$ & 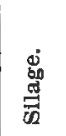 & 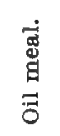 & 焉离 & 焉 & 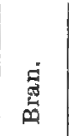 & $\underset{\overparen{B}}{\stackrel{D}{0}}$ & 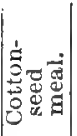 & 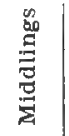 & 题焉 \\
\hline & Lbs. & $\begin{array}{l}\text { Lbs. } \\
3.840\end{array}$ & $\begin{array}{r}\text { Lbs. } \\
370\end{array}$ & $\begin{array}{l}\text { Lbs. } \\
2,391\end{array}$ & $\begin{array}{c}\text { Lbs. } \\
600\end{array}$ & $\begin{array}{l}\text { Lbs. } \\
2,204\end{array}$ & $\begin{array}{r}\text { Lbs. } \\
450\end{array}$ & Lbs. & $\begin{array}{c}\text { Lbs. } \\
1,66\end{array}$ & Lbs. \\
\hline 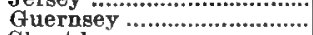 & 5,000 & $\begin{array}{l}0,040 \\
1,705\end{array}$ & 519 & $\begin{array}{r}2,001 \\
450\end{array}$ & 995 & 1,533 & 410 & $\begin{array}{r}1,100 \\
386\end{array}$ & & 677 \\
\hline 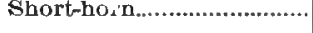 & 4,781 & 5,978 & 371 & & 997 & 1,194 & 1,645 & 682 & 948 & \\
\hline
\end{tabular}

Returns from i'eed.

\begin{tabular}{|c|c|c|c|c|c|c|c|c|}
\hline Breed. & 象 & 象营 & 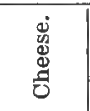 & 逭 & $\begin{array}{l}5+3 \\
50 \\
50 \\
0\end{array}$ & 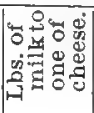 & 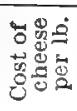 & 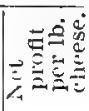 \\
\hline 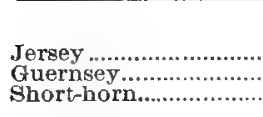 & $\begin{array}{c}\text { Lbs. } \\
13,296.4 \\
10,938.6 \\
12,186.9\end{array}$ & $\begin{array}{c}\text { Lbs. } \\
1,877.4 \\
1,503.8 \\
1,544.3\end{array}$ & $\begin{array}{c}\text { Lbs. } \\
1,451.8 \\
1,170.6 \\
1,077.6\end{array}$ & $\begin{array}{r}\text { Lbs. } \\
11,679 \\
9,667 \\
10,839\end{array}$ & $\begin{array}{c}\text { Lbs. } \\
3227 \\
480 \\
709\end{array}$ & $\begin{array}{r}\text { Lbs. } \\
9.16 \\
9.67 \\
11.31\end{array}$ & $\begin{array}{l}\$ .018 \\
.017 \\
.042\end{array}$ & $\begin{array}{l}.083 \\
.078 \\
.076\end{array}$ \\
\hline
\end{tabular}


Public Tests of Pure-bred Dairy Cows.

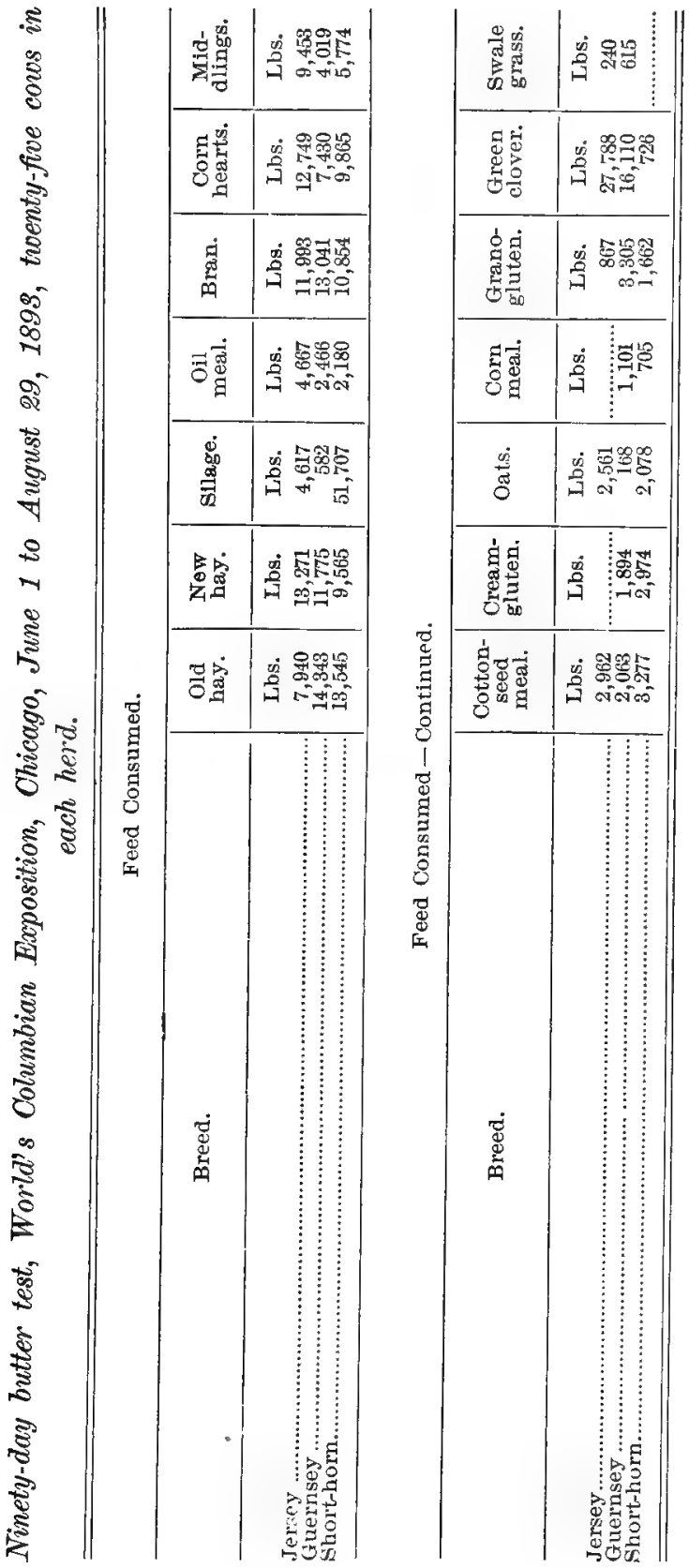


Feeds and reeding.

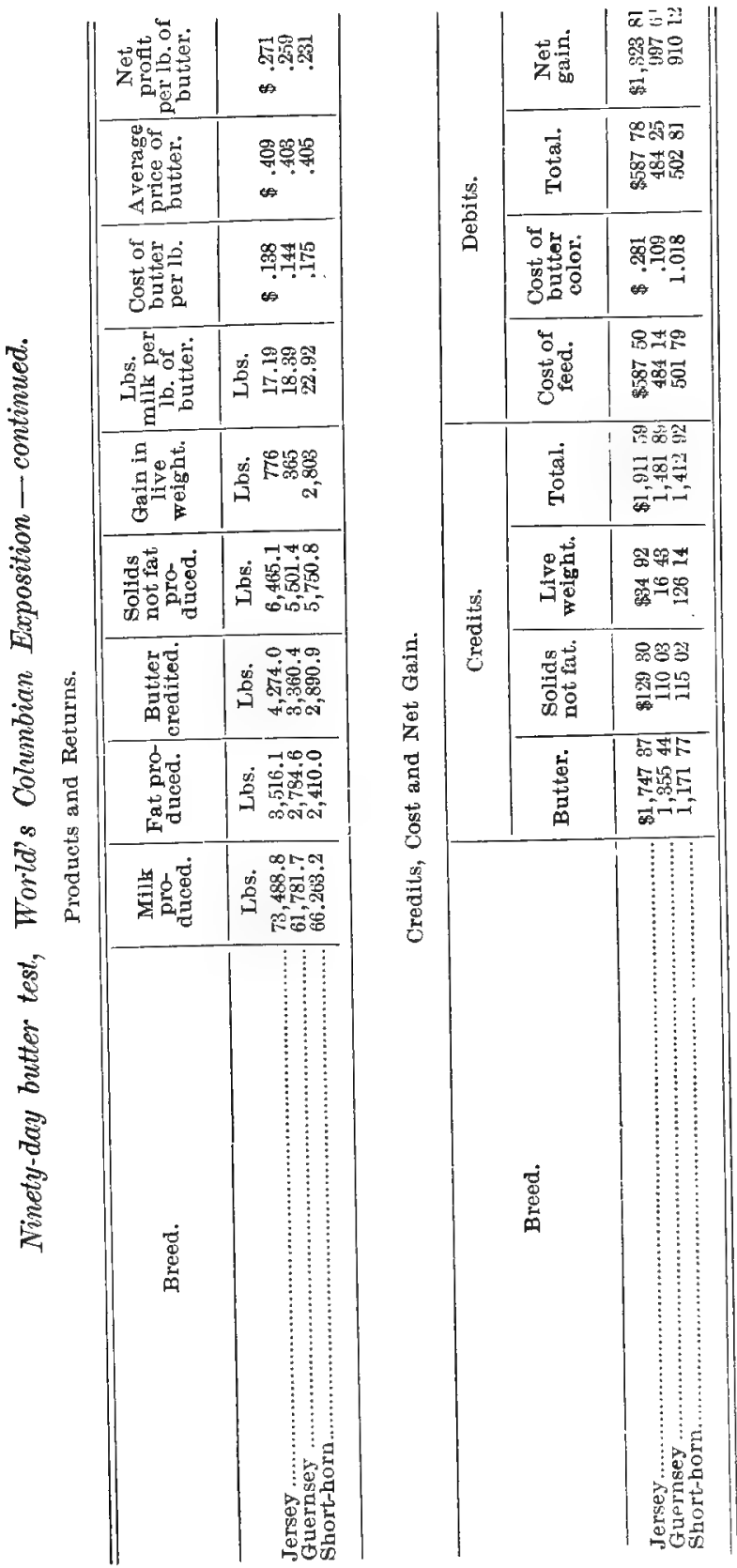


Public Tests of Pure-bred Dairy Cows.

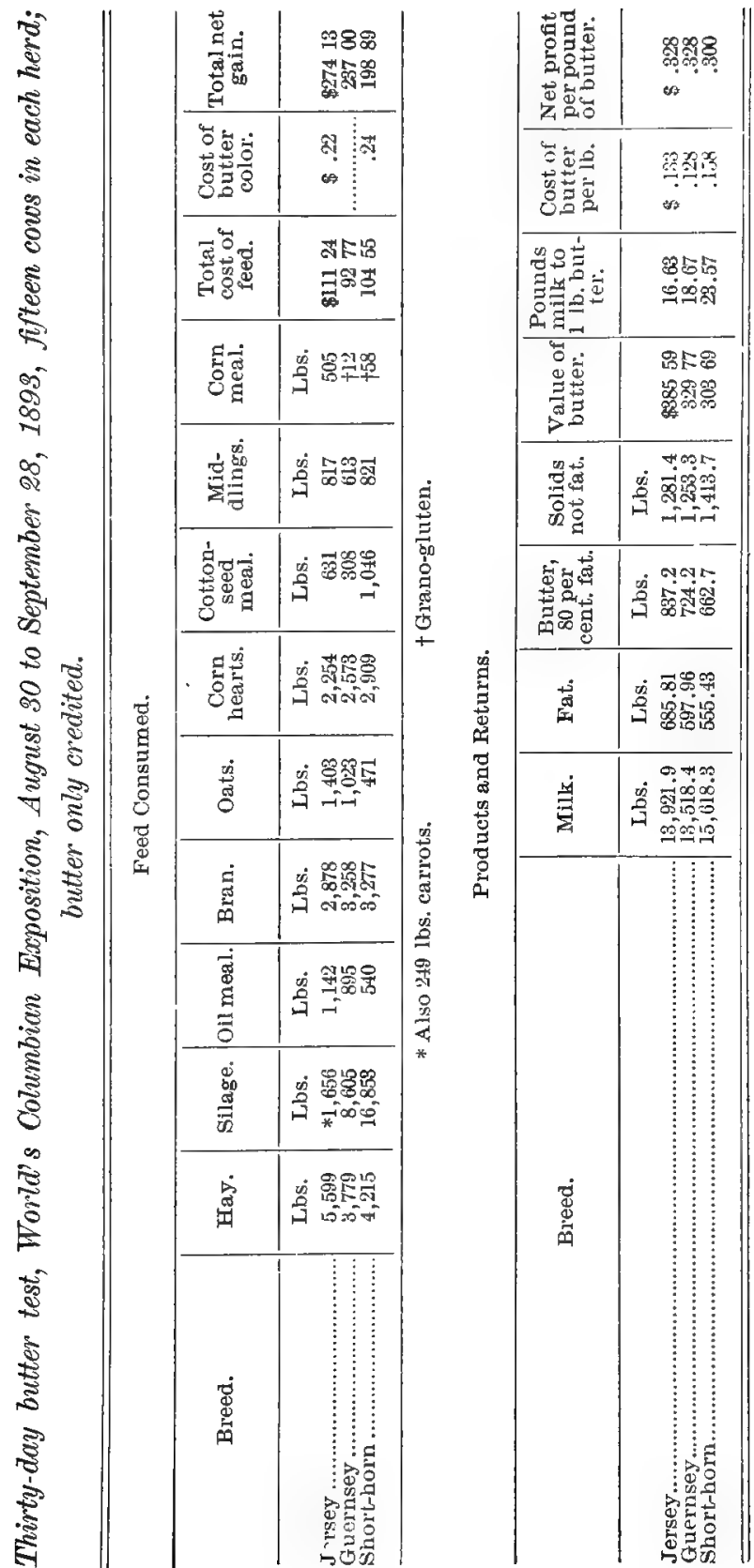




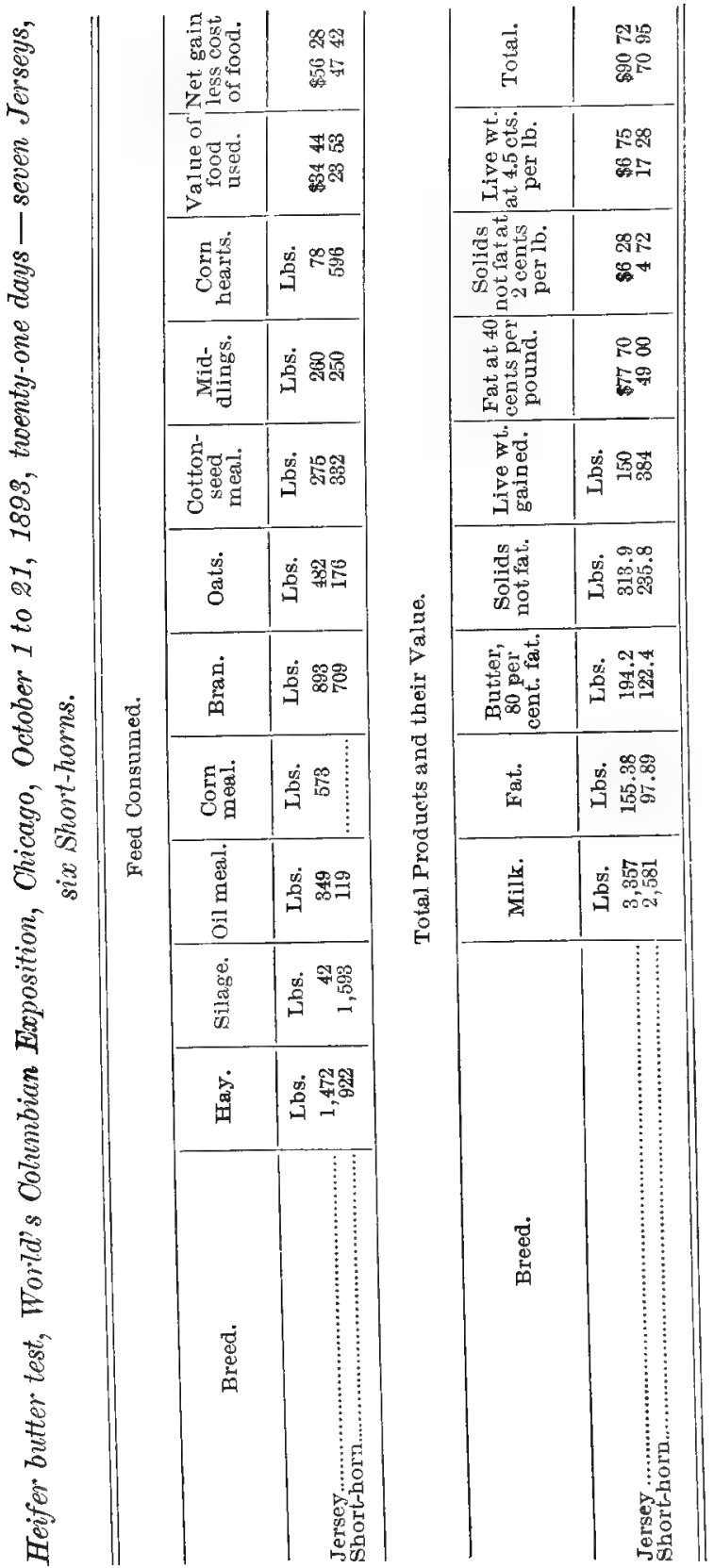


Best cow in each breed in the several tests, World's Columbian Exposition, Chicago, 1893.

Cheese test - Fifteen days.

\begin{tabular}{|c|c|c|c|c|c|c|c|c|c|}
\hline \multirow[b]{2}{*}{ Breed. } & \multicolumn{3}{|c|}{ Products. } & \multicolumn{4}{|c|}{ Value of products. } & \multirow{2}{*}{$\begin{array}{l}\text { Value } \\
\text { of food } \\
\text { eaten. }\end{array}$} & \multirow{2}{*}{$\begin{array}{l}\text { Net } \\
\text { gain. }\end{array}$} \\
\hline & $\stackrel{ت}{ت}$ & 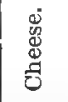 & $\stackrel{8}{E}$ & $\begin{array}{l}\dot{0} \\
\stackrel{d}{ \pm ்} \\
\stackrel{1}{0}\end{array}$ & Whey. & $\begin{array}{c}\text { Gdin } \\
\text { or loss } \\
\text { of live } \\
\text { weight }\end{array}$ & Total. & & \\
\hline $\begin{array}{l}\text { Jersey, Ida Marigold } \\
\text { Guernsey, Sweet Ada } \\
\text { Short-horn, Nora ....... }\end{array}$ & $\begin{array}{c}\text { Lbs. } \\
674 \\
535 \\
663\end{array}$ & $\begin{array}{c}\text { Lbs. } \\
70.9 \\
54.1 \\
60.7\end{array}$ & $\begin{array}{l}\text { Lbs. } \\
586.6 \\
472.7 \\
590.0\end{array}$ & $\begin{array}{rl}\$ 9 & 47 \\
6 & 47 \\
788\end{array}$ & $\begin{array}{l}.47 \\
.38 \\
.47\end{array}$ & $\begin{array}{rr}\$ 1 & 26 \\
1 & 67 \\
2 & 52\end{array}$ & $\begin{aligned} \$ 1120 \\
852 \\
1087\end{aligned}$ & $\begin{array}{rl}\$ 4 & 23 \\
3 & 25 \\
4 & 60\end{array}$ & $\begin{array}{rl}\$ 6 & 97 \\
5 & 27 \\
6 & 27\end{array}$ \\
\hline
\end{tabular}

Butter test - Ninety days.

\begin{tabular}{|c|c|c|c|c|c|c|c|c|}
\hline Breed. & 密 & 虔 & 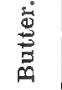 & $\begin{array}{l}\text { Cost of } \\
\text { food. }\end{array}$ & $\begin{array}{c}\text { Live } \\
\text { wt. }\end{array}$ & Credit. & Debit. & $\begin{array}{l}\text { Net } \\
\text { profit. }\end{array}$ \\
\hline $\begin{array}{l}\text { Jersey, Brown Bessie } \ldots . . . \ldots \ldots \ldots . . . \\
\text { Guernsey, Materna................... } \\
\text { Sbort-horn, Nora.................... }\end{array}$ & $\begin{array}{l}\text { Lbs. } \\
3,634 \\
3,512 \\
3,680\end{array}$ & $\begin{array}{r}\text { Lbs. } \\
178 \\
153 \\
134\end{array}$ & $\begin{array}{c}\text { Lbs. } \\
217 \\
185 \\
166\end{array}$ & $\begin{array}{rl}\$ 25 & 51 \\
22 & 69 \\
24 & 11\end{array}$ & $\begin{array}{l}\text { Lbs. } \\
+81 \\
+13 \\
+115\end{array}$ & $\begin{array}{rl}\$ 98 & 75 \\
81 & 11 \\
76 & 80\end{array}$ & $\begin{array}{rl}\$ 25 & 53 \\
23 & 28 \\
24 & 17\end{array}$ & $\begin{array}{r}87322 \\
5782 \\
5263\end{array}$ \\
\hline
\end{tabular}

Butter test-Thirty days.

Breed.

Jersey, Brown Bessie.

Guernsey, Purity.

Short-horn, Kitty Clay 4th

\begin{tabular}{|c|c|c|c|}
\hline Butter. & $\begin{array}{l}\text { Credit } \\
\text { sales. }\end{array}$ & $\begin{array}{l}\text { Debit } \\
\text { food. }\end{array}$ & $\begin{array}{l}\text { Net } \\
\text { profit. }\end{array}$ \\
\hline Lbs. & & & \\
\hline $\begin{array}{l}72.24 \\
54.80 \\
62.24\end{array}$ & $\begin{array}{rr}933 & 27 \\
24 & 95 \\
28 & 53\end{array}$ & $\begin{array}{r}1987 \\
558 \\
849\end{array}$ & $\begin{array}{r}\$ 2469 \\
1938 \\
2004\end{array}$ \\
\hline
\end{tabular}

Heifer test - Twenty one days.

\begin{tabular}{|c|c|c|c|c|c|c|c|c|}
\hline reed. & Milk. & Butter. & $\begin{array}{c}\text { Value } \\
\text { of but- } \\
\text { ter. }\end{array}$ & $\begin{array}{c}\text { Value } \\
\text { of } \\
\text { solids } \\
\text { not fat. }\end{array}$ & $\begin{array}{c}\text { Value } \\
\text { of live } \\
\text { wt. } \\
\text { gain- } \\
\text { ed. }\end{array}$ & $\begin{array}{c}\text { Total } \\
\text { credit. }\end{array}$ & $\begin{array}{c}\text { Cost of } \\
\text { food. }\end{array}$ & Profit. \\
\hline 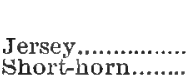 & $\begin{array}{c}\text { Lbs. } \\
563 \\
591\end{array}$ & $\begin{array}{l}\text { Lbs. } \\
37.5 \\
26.1\end{array}$ & $\begin{aligned} \$ 1500 \\
1044\end{aligned}$ & $\begin{array}{rl}\$ 1 & 07 \\
1 & 04\end{array}$ & $\begin{array}{rl}90 & 86 \\
3 & 51\end{array}$ & $\begin{array}{r}\$ 1692 \\
1499\end{array}$ & $\begin{array}{r}\$ 570 \\
402\end{array}$ & $\begin{array}{rl}\$ 11 & 22 \\
1097\end{array}$ \\
\hline
\end{tabular}

II. Experiment Station Breed Tests.

687. Tests at the Stations.- Tests of pure-bred dairy cows covering considerable periods of time have been conducted at three Experiment Stations, viz.: New York (Geneva), ${ }^{1}$ Maine, ${ }^{2}$ and New Jersey. ${ }^{3}$

\footnotetext{
${ }^{1}$ Rept. 1894. ${ }^{2}$ Rept. $1890 . \quad{ }^{3}$ Rept. 1890.
} 
The results of the tests with each breed are considered in the following table:

Trials with pure-bred dairy cons at three American Stations.

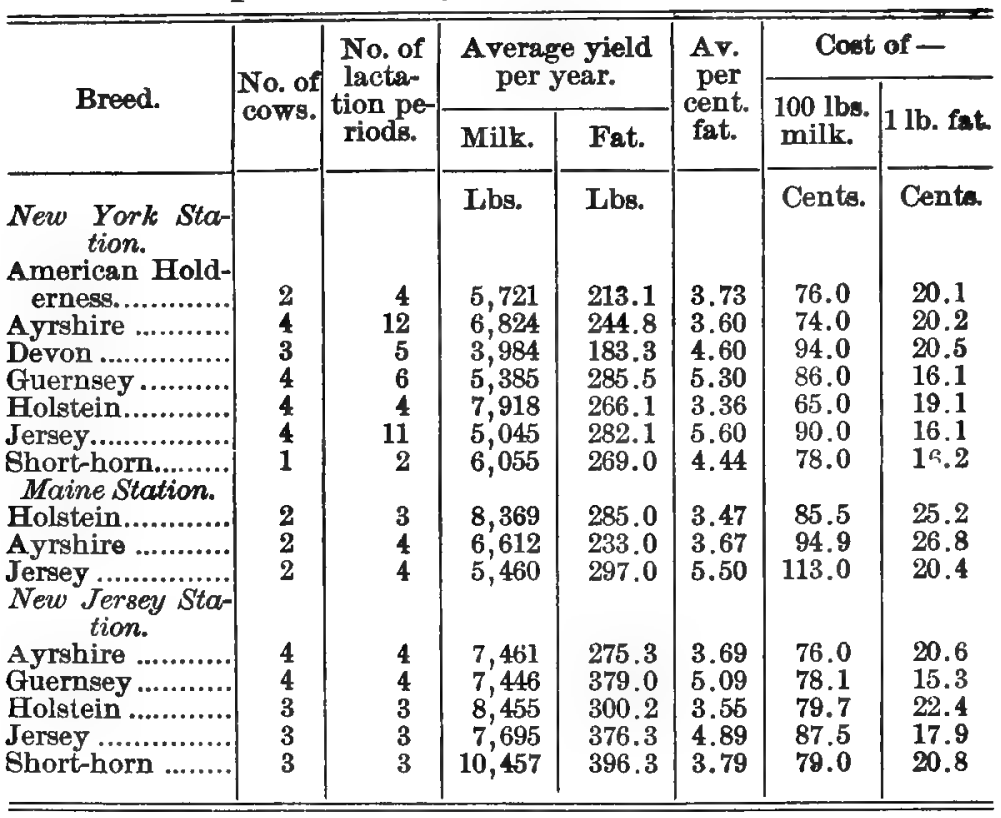

688. Combining the results.-To secure better averages the figures last presented are combined in the following table, the cows being grouped by breeds:

Summary of trials with pure-bred dairy conos at three American Stations.

\begin{tabular}{|c|c|c|c|c|c|c|c|}
\hline \multirow{3}{*}{ Breed. } & \multirow{3}{*}{$\begin{array}{l}\text { No. of } \\
\text { cows. }\end{array}$} & \multirow{3}{*}{$\begin{array}{l}\text { No. of } \\
\text { lacta- } \\
\text { tion pe- } \\
\text { riods. }\end{array}$} & \multirow{2}{*}{\multicolumn{2}{|c|}{$\begin{array}{c}\text { Average yield } \\
\text { per year. }\end{array}$}} & \multirow{3}{*}{$\begin{array}{l}\text { Av. } \\
\text { per } \\
\text { cent. } \\
\text { fat. }\end{array}$} & \multicolumn{2}{|c|}{ Cost of - } \\
\hline & & & & & & & \\
\hline & & & Milk. & Fat. & & milk. & 1 lb. fat. \\
\hline & & & Lbs. & Lbs. & & Cents. & Cents. \\
\hline \multicolumn{7}{|l|}{ American Hold- } & 20.1 \\
\hline Ayrshire............ & 10 & 20 & 6,909 & 248.5 & 3.60 & 78.5 & 21.5 \\
\hline Devon............... & 3 & 5 & 3,984 & 183.3 & 4.60 & 94.0 & 20.5 \\
\hline Guernsey ........... & 8 & 10 & 6,210 & 322.9 & 5.20 & 82.8 & 15.8 \\
\hline \multicolumn{8}{|l|}{ Holstein - Frieg- } \\
\hline ian...................... & 9 & 10 & 8,215 & 282.0 & 3.43 & 74.7 & 21.5 \\
\hline Jersey ................ & 9 & 18 & 5,579 & 301.1 & 5.40 & 94.7 & 17.4 \\
\hline Short-horn......... & 4 & 5 & 8,696 & 345.4 & 3.97 & 78.7 & 19.4 \\
\hline
\end{tabular}


In the preceding table the results for forty-five pare-bred cows carried through seventy-two lactation periods are reported. The valuations of feed stuffs by the different Stations vary somewhat, so that the averages are not strictly correct in the combinations as made; yet it is believed that these condensed figures are on the whole in the best form for comparative study.

\section{Station Findings with Dairy Herds.}

689. The Station herds reported.-The practical dairyman is interested in learning the results of operations conducted with dairy herds for an entire year, knowing that such records, when correctly reported, are of special value. Fortunately we are able to present yearly tests at four widely-separated Stations to aid those interested in reaching conclusions as to the cost of feed required in producing a given quantity of milk and fat.

Wing, of the Cornell Station, ${ }^{1}$ reports the returns from a herd of twenty cows, mostly Holstein and Jersey grades. Pure-bred and grades of the leading dairy breeds constituted the herd of twenty-three cows at the Minnesota Station, ${ }^{2}$ reported by Haecker. Soule tells of the returns from a herd of twelve cows embracing Short-horns and Jerseys at the Missouri Station. ${ }^{8}$ The fifteen cows in the Utah Station ${ }^{4}$ herd, reported by Linfield, were common animals selected in the vicinity of the Station by means of the Babcock test. Of course the cows were better than the average in the vicinity.

690. Prices allowed for feed.- The prices for feed as given below are those assumed by the Station authorities presenting the data of the herd trials. The student should compare these prices with those ruling about him for feeding stuffs of the same class. If the dairyman wishes to compare the results of these trials with what he has accomplished with his own herd he can do so without difficulty by placing that value on each feeding stuff used which represents its selling price in his local market. Naturally the prices vary considerably, being highest in New York and lowest at the West.
1 Bul. 52.
2 Bul. 35.
- Bul. 26.
- Bul. 43. 
Prices used in calculating cost of producing mithe and fot in dairy herds at four Stations.

New York.

Hay, per ton.

Wilage, per ton........... 175

Wheat bran, per ton.......... 1800

Oats, per bushel................ 35

Cotton-seed meal, per ton... 2500

Corn meal, per ton............ 2000

Corn stover, per ton............ 300

Fresh grass, per ton............ 175

Roots, per ton.................... 200

Pasture, per week.............. 30

\section{Missouri.}

Hay, per ton.

Corn chop, per ton.............

Oil cake, per ton................

Cotton-seed meal, per ton...

Bran, per ton.................... 1200

Pasture, per season............. 300
Minnesota.

Flay, timothy, per ton....... \$5 60

320

560

200

480

1400

1400

2600

1800

1100

200

350

691. Cost of milk and fat.-From the data collected we are able to learn the cost of feed required by the dairy cow in producing one hundred pounds of milk and one pound of fat at four widely-separated American Experiment Stations, the data being summarized in the table below:

Cost of feed required in the production of one hundred pounds of milk and one pound of fat, by months - Four Stations.

\begin{tabular}{|c|c|c|c|c|c|c|c|c|c|c|}
\hline & \multicolumn{2}{|c|}{ New York. } & \multicolumn{2}{|c|}{ Minnesota. } & \multicolumn{2}{|c|}{ Missouri. } & \multicolumn{2}{|c|}{ Utah. } & \multicolumn{2}{|c|}{ Average. } \\
\hline $\begin{array}{l}\text { Number of cows.............. } \\
\text { Average weight of cow } \\
\text { Average fat per cow........... }\end{array}$ & $\begin{array}{r}20 \\
1,125 \\
286\end{array}$ & 8 lbs. & & $\begin{array}{l}3 \\
6 \text { lbs. } \\
1 \text { lbs. }\end{array}$ & & $\begin{array}{l}2 \\
20 \mathrm{lbs} . \\
18 \mathrm{lbs} .\end{array}$ & & $\begin{array}{l}5 \\
0 \mathrm{lbs} . \\
2 \mathrm{lbs} .\end{array}$ & & \\
\hline Month. & تِ & $\begin{array}{l}\dot{\theta} \\
\Phi \\
0 \\
0\end{array}$ & 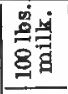 & $\begin{array}{l}\dot{0} \\
\Phi+\infty \\
0 \\
0\end{array}$ & 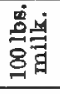 & 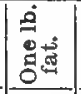 & 臬豆 & 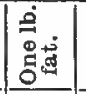 & 照 & 蒙 \\
\hline 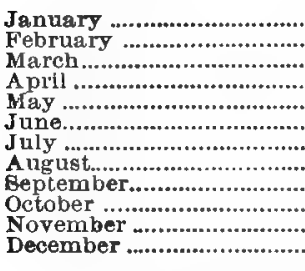 & $\begin{array}{l}.64 \\
.68 \\
.71 \\
.71 \\
.58 \\
.28 \\
.38 \\
.65 \\
.61 \\
.41 \\
.65 \\
.68\end{array}$ & $\begin{array}{l}.17 \\
.18 \\
.18 \\
.18 \\
.145 \\
.075 \\
.095 \\
.155 \\
.125 \\
.105 \\
.175 \\
.165 \\
\end{array}$ & $\begin{array}{l}.65 \\
.67 \\
.67 \\
.71 \\
.59 \\
.32 \\
.37 \\
.51 \\
.51 \\
.60 \\
.68 \\
.65\end{array}$ & $\mid \begin{array}{r}.149 \\
.151 \\
.165 \\
.162 \\
.132 \\
.076 \\
.078 \\
.114 \\
.106 \\
.140 \\
.159 \\
.164\end{array}$ & $\begin{array}{r}.94 \\
1.01 \\
1.21 \\
1.01 \\
.43 \\
.24 \\
.23 \\
.14 \\
.21 \\
.42 \\
.65 \\
1.03\end{array}$ & $\mid \begin{array}{r}.240 \\
.253 \\
.299 \\
.234 \\
.096 \\
.053 \\
.053 \\
.033 \\
.052 \\
.098 \\
.153 \\
.265\end{array}$ & $\begin{array}{l}.56 \\
.62 \\
.59 \\
.49 \\
.48 \\
.15 \\
.19 \\
.21 \\
.28 \\
.38 \\
.59 \\
.63\end{array}$ & $\mid \begin{array}{c}.138 \\
.160 \\
.142 \\
.121 \\
.113 \\
.038 \\
.049 \\
.051 \\
.066 \\
.091 \\
.135 \\
.143\end{array}$ & $\begin{array}{l}.68 \\
.72 \\
.76 \\
.71 \\
.54 \\
.26 \\
.31 \\
.42 \\
.41 \\
.47 \\
.65 \\
.71\end{array}$ & $\begin{array}{l}.164 \\
.179 \\
.187 \\
.171 \\
.125 \\
.064 \\
.072 \\
.098 \\
.094 \\
.112 \\
.157 \\
.17\end{array}$ \\
\hline 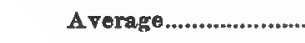 & $\$ .57$ & $\$ .145$ & $\$ .58$ & $\$ .133$ & $\$ .68$ & $\$ .152$ & $\$ .43$ & 5.104 & $\$ .55$ & $\$ .133$ \\
\hline
\end{tabular}


The New York and Minnesota herds evidently contained the must carefully selected cows, and this tended to reduce the cost of milk and fat production. We observe that milk and fat cost the most during the winter months, the high price continuing into March in Utah, and through April at the other Stations. In May there is a diminution in cost at all Stations except Utah. During : June at three of the Stations the milk and fat reach their lowest cost for food consumed, the cows then being on pasture. In Missouri the lowest price was reached in August - quite contrary to dairy experience in most states. With the passing of summer comes increased cost, until by November winter prices have again been reached. It is evident from these figures that milk of the lowest cost is produced in summer on pasture. The average cost of 100 pounds of milk at the four Stations for the year is 55 cents; the cost of one pound of fat is $\mathbf{1 3 . 3}$ cents.

692. Feed consumed by the dairy cow, yearly. - The data presented by three of the Stations reporting are in such form that we can determine the average amount of feed required for keeping a dairy cow one year, the cost for the same and the returns in milk and fat. These are as follows:

Average amount of feed consumed and returns for feed, per year, by dairy cows - Three Stations.

\begin{tabular}{|c|c|c|c|c|c|c|c|}
\hline \multirow{3}{*}{ Station. } & \multicolumn{4}{|c|}{ Feed eaten per cow. } & \multirow{3}{*}{$\begin{array}{c}\text { Aver- } \\
\text { age cost } \\
\text { of feed } \\
\text { per cow. }\end{array}$} & \multirow{2}{*}{\multicolumn{2}{|c|}{$\begin{array}{l}\text { Av. returns } \\
\text { per cow, per } \\
\text { year. }\end{array}$}} \\
\hline & \multirow{2}{*}{$\begin{array}{c}\text { Past- } \\
\text { ure. }\end{array}$} & \multirow{2}{*}{$\begin{array}{c}\begin{array}{c}\text { Concen- } \\
\text { trates. }\end{array} \\
\text { Bran, grain, } \\
\text { oil meal, etc. }\end{array}$} & \multicolumn{2}{|c|}{ Roughage. } & & & \\
\hline & & & $\begin{array}{l}\text { Roots, sil- } \\
\text { age, green } \\
\text { fodder. }\end{array}$ & Hay. & & Milk. & Fat. \\
\hline & Days. & Lbs. & Lbs. & Lbs. & & Lbs. & Lbb. \\
\hline Minnesota. & 131 & 3,435 & 5,306 & 2,029 & $\$ 3782$ & 6,408 & 301 \\
\hline $\begin{array}{l}\text { Missouri .... } \\
\text { Utah.......... }\end{array}$ & $\begin{array}{l}191 \\
123\end{array}$ & $\begin{array}{l}3,027 \\
1,534\end{array}$ & 1,535 & $\begin{array}{l}3,480 \\
4,301\end{array}$ & $\begin{array}{l}3530 \\
2228\end{array}$ & $\begin{array}{l}5,927 \\
5,655\end{array}$ & $\begin{array}{l}248 \\
230\end{array}$ \\
\hline
\end{tabular}

We learn that the number of days on pasture varied from 123 in Utah to 191 in Missouri. The Minnesota cows consumed one and three-fourths tons of concentrates or grain feed each, over two and one-half tons of roots and about one ton of hay. At the 
other Stations, with a smaller allowance of concentrates, there was an increase in hay consumption. The average cost of keep. ing a cow ranged from $\$ 22.28$ in Utah to $\$ 37.82$ in Minnesota. The butter returns varied from 230 to 301 pounds and the milk from 5,655 to 6,408 pounds per cow.

693. Herd record for one year.- We turn with interest to a report of the Station herd at Cornell University, ${ }^{1}$ where the cosi of feed consumed and the returns from each cow in the herd, twenty in number, are reported separately. When Prof. Roberts took charge of the herd in 1875 the yield of milk was 3,000 pounds per cow; now descendants of these cows average more than 7,000 pounds of milk each. The prices allowed for feeding stuffs consumed have already been stated. The returns from the twenty cows are given in the following table:

Cost of feed, milk and fat as determined during a year's trial with a herd of twenty cows - Cornell Station.

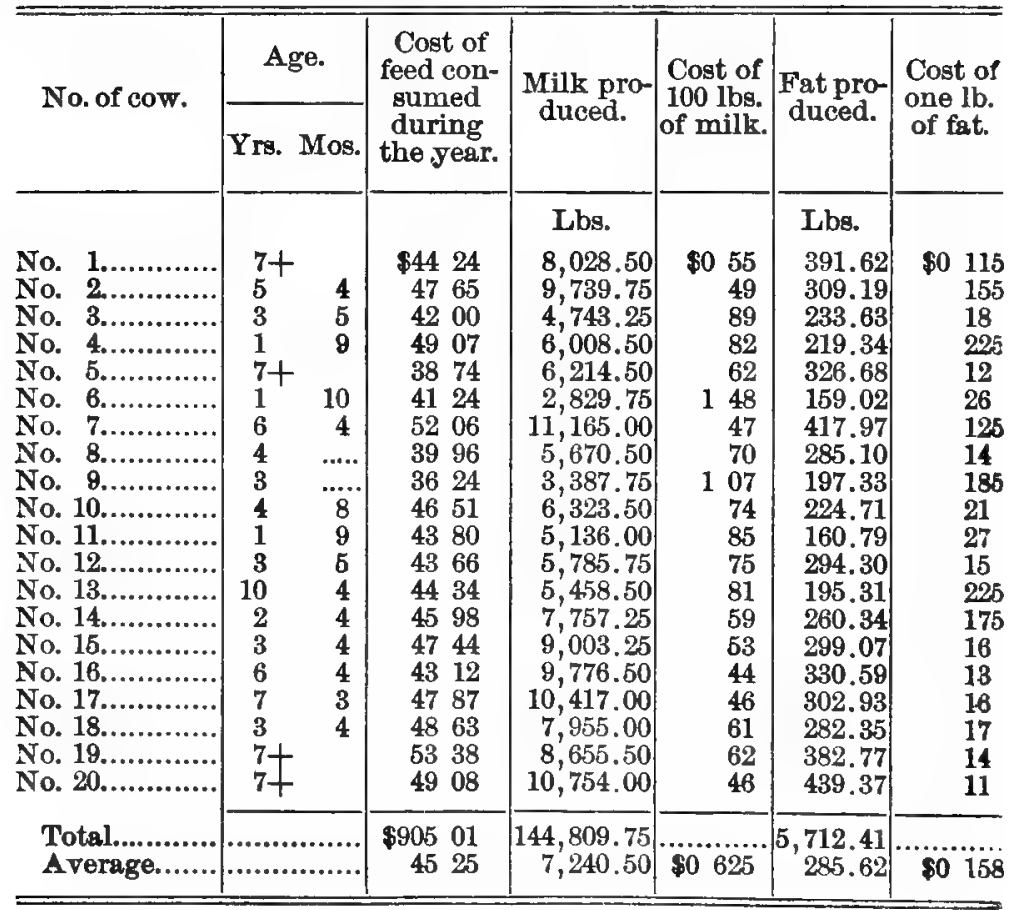

1 Bul. 52. 
The preceding table is especially valuable because it covers a year's findings with all the cows of the herd, none being omitted. in order to raise the average.

We observe a wide range in the cost of feed consumed by the several cows, a still wider one in the yield of milk, and a marked difference in the cost of producing milk and fat. It is apparent from this table that even in well-nurtured dairy herds, where all conditions are favorable, it is of the highest importance to study feed consumption and the returns of milk and fat of each cow that the poor ones may be eliminated and only the best reserved for future breeders and producers.

694. Dry matter required.- Another lesson from the Cornell herd is here presented. The dry matter in the feed required for producing one hundred pounds of milk and one pound of butterfat with each of the cows during seven months - November to April inclusive - is given in the following table:

Dry matter required in food by covos for one hundred pounds of milk and one pound of fat-Cornell station.

\begin{tabular}{|c|c|c|c|c|}
\hline \multirow[b]{2}{*}{ No. of cow. } & \multicolumn{2}{|c|}{ Dry matter consumed. } & \multirow[b]{2}{*}{ Live wt. } & \multirow{2}{*}{$\begin{array}{l}\text { Dry matter } \\
\text { consumed } \\
\text { per } 1,000 \text { lbs. } \\
\text { live wt. } \\
\text { per day. }\end{array}$} \\
\hline & $\begin{array}{c}\text { For each } \\
100 \text { lbs. } \\
\text { milk. }\end{array}$ & $\begin{array}{l}\text { For each } \\
\text { lb. fat. }\end{array}$ & & \\
\hline 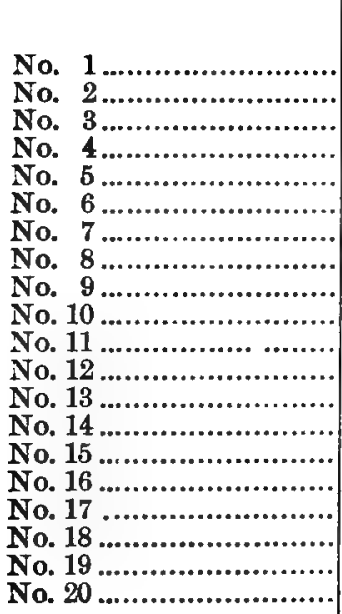 & $\begin{array}{r}\text { Lbs. } \\
79 \\
87 \\
136 \\
148 \\
92 \\
249 \\
81 \\
106 \\
141 \\
123 \\
140 \\
137 \\
120 \\
101 \\
91 \\
94 \\
74 \\
102 \\
104 \\
83\end{array}$ & $\begin{array}{c}\text { Lbs. } \\
17 \\
28 \\
27 \\
42 \\
17 \\
44 \\
22 \\
21 \\
25 \\
36 \\
47 \\
26 \\
33 \\
31 \\
28 \\
28 \\
25 \\
28 \\
23 \\
19\end{array}$ & $\begin{array}{r}\text { Lbs. } \\
858 \\
1,326 \\
946 \\
972 \\
1,123 \\
815 \\
1, \mathbf{4 7 4} \\
1,071 \\
829 \\
1,270 \\
1,001 \\
1,030 \\
1,283 \\
1,007 \\
1,160 \\
1,305 \\
1,520 \\
1,183 \\
1,239 \\
1,040\end{array}$ & $\begin{array}{l}\text { Lbs. } \\
28.8 \\
22.8 \\
25.8 \\
25.9 \\
22.9 \\
29.2 \\
21.3 \\
22.6 \\
30.8 \\
20.7 \\
25.1 \\
22.9 \\
23.4 \\
26.1 \\
25.4 \\
22.2 \\
21.6 \\
25.5 \\
24.7 \\
26.4\end{array}$ \\
\hline Average ................ & 104 & 27 & & 24.7 \\
\hline
\end{tabular}


The average for the herd of 20 cows shows that 104 pounds of dry matter in the feed produced 100 pounds of milk, and 27 pounds produced 1 pound of butter-fat; 24.7 pounds of dry matter were consumed daily per 1,000 pounds of live weight. Eleven cows whose average weight was 1,004 pounds consumed more than 24 pounds of dry matter per 1,000 pounds live weight daily. Nine cows whose average weight was 1,267 pounds ate less thar 24 pounds of dry matter per 1,000 pounds live weight. This indicates that large cows may consume smaller quantities of feec in proportion to their weight than small cows. (740) 


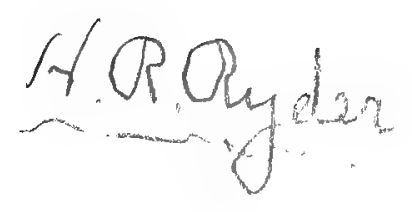

\section{CHAPTER XXVII. \\ FEED AND OARE OF THE DAIRY OOW.}

I. Care and Management.

695. Dairying based on maternity of the cow.- Nature's practice of accumulating fat beneath the skin and between the muscular fibers of the animal body is to store heat and energy-producing material against a time of need. The process at first goes on rapidly, but after a time the system becomes gorged, and a further storage of fat is accomplished only at a high cost for feed consumed. (565) How different with the dairy cow, which eats heartily the food given her, not for the purpose of storing fat to protect herself against a time of possible bodily want, but for the nurture of her young. Food given at night is digested and converted into milk ready for the calf in the morning, the assimilated products disappearing from day to day almost as soon as elaborated, making easy way for more of the same kind from the same source. Doubtless it is because the milk product is daily given up by the cow that she so greatly excels the steer in the economical production of human food; for the steer, gaining in weight and fat, must vitalize and carry about as a part of the body, day after day, all the added flesh. (612)

The appropriation by man of the milk designed by nature for the calf makes possible the great art of dairying. Taking advantage of the all-powerful impulse of motherhood for the preservation of the young of the species, man stimulates the dairy cow by abundant feed and favorable surroundings to produce much more milk than is really needed by the calf were it still the object of her care. In so doing he has made the dairy cow more or less an artificial creature.

The basis, then, of onr dairy system is the maternity of the cow, and successful dairying depends upon rationally recognizing 
this fact. To W. D. Hoard, of Wisconsin, belongs the credit of bringing this subject to the attention of dairymen." No one can fairly consider the dairy problem from this standpoint without regarding the cow in a new light and thereby becoming a better dairyman.

696. Caring for the cow.- While our purpose is to cover the question of feeding, that subject cannot be wisely considered unless certain matters concerning the handling of the cow be first discussed. Though it cannot be affirmed that the digestion of food by the cow is affected by the character of her surroundings, it is certain that the yield of milk and its character are directly influenced thereby, so that the results to the dairyman are the same. Good returns from a given supply of feed, no matter how abundant and satisfactory, cannot be looked for, unless the cow also has comfortable quarters and is intelligently handled.

697. Necessity for shelter.-In another article (561) it is shown that the steer, gorged with food, and each day adding to the layer of heat-holding fat just beneath the skin, can withstand considerable cold, often showing preference for the open shed to the close stable. The condition of the dairy cow is in strong opposition to this, her system being relaxed by the annual drain of maternity and the semi-daily heary loss of nutrients drawn from her in the abundant milk flow. The observant stockman will at once detect the fundamental difference in the condition of the dairy cow and the fattening ox in regard to ability to withstand exposure to the weather. To be profitably managed and yield wholesome milk a cow must be comfortably housed in a wellventilated stable in winter, the temperature of which should not fall below forty degrees as the minimum, or rise above sixty degrees as the maximum. In such a stable, provided with abundance of sunlight, she is in condition, so far as environment is concerned, to yield the highest returns for the feed given. (630)

698. Exercise.- With the fattening animal soon to be slaughtered, confinement more or less close is advisable, since it prevents waste of tissue and conserves the feed. The end in view with the dairy cow is radically different, for she must give milk

' Bul. No. 1, Wisconsin Farmers' Institute, and elsewhere. 
almost daily during the whole period of her usefulness, and the milk so yielded must be wholesome in character, fit in all particnlars for the most delicate. It is certainly reasonable to hold that the cow cannot maintain the high standard of bodily health and vigor essential to the production of healthful milk when she is closely confined in the stable for long periods without opportunity for outdoor air and exercise. She should be allowed several hours' exercise daily out of doors, or in quarters other than where she passes most of her time, the change affording opportunity to breathe the pure air and drink in the sunshine, as well as to exercise the muscles which have not been called into action while in confinement, and resting those taxed by occupying a forced position in the narrow stall or stanchion.

699. Professor Roberts' system. - At the North, where the winters are severe, it is difficult to give cattle the requisite exercise without forcing them to undergo exposure during inclement weather. At the Cornell Station, ${ }^{1}$ Professor Roberts has for years followed a plan of seemingly great value in its teachings to the dairymen of the North. Here the cows stand in stanchions while feeding and being milked, but are afterward turned into a covered enclosure, where they are free to stand or lie at will; thus they have a feed room and an exercise room each specially adapted to its purpose. The accumulations from the horse stable are spread over the floor of the covered yard, and this in turn is covered liberally with straw, on which land plaster is sprinkled to prevent odors arising. This perfect system of saving manure should of itself, in a few years, pay for the cost of the additional space required. By this plan the stable proper can be reduced to the smallest size compatible with holding the animals while being milked and fed. It can be kept scrupulously clean and properly aired, since the cows are out of it several hours daily. The animals come to their provender at meal time with the best of appetites, and return to their larger quarters to ruminate in comfort.

700. Regularity and kindness.- - To skilful feeding the successful dairyman will add regularity and kindness in the management of

i Bul. 13; The Fertility of the Land, p. 201. 
his herd. The true dairy cow is easily affected by unfavorable conditions.

Babcock of the Wisconsin Station, ${ }^{1}$ after careful studies with cows in many ways, writes: "The elaboration of milk does not proceed at a uniform rate from milking to milking, but is most active at the time of milking, and is dependent not only upon the stimulus which the milk glands derive from the manipulation of the teats and udder, but upon the nervous condition of the animal at the time of milking.

"In consequence of this, slight changes in the conditions under which the milking is done may have a decided influence upon both the yield and quality of milk. As a general rule the quality of milk, measured by the per cent. of fat which it contains, is more sensitive to changes of this kind than is the yield of milk. Among the changes which appear to have most influence in this respect, the following are of especial importance, viz.: Change in the interval between milkings and in the rate of milking; change of milkers and manner of milking, especially if the manipulation of the teats and udder be different; change of environment and any circumstance which excites or even slightly disturbs the animal at the time - excitement between milkings, if the cow has become quiet before milking, appears to have comparatively little influence. As would be expected there is a great difference in cows in this respect, some being very sensitive, while others are scarcely affected at all. In our experiments cows that have been giving milk for a long time have been less sensitive in this respect than fresh cows that were giving a large quantity of milk, but this may have been due to individual characteristics of the animals tested and not to the advanced period of lactation. I would recommend, therefore, in order to obtain the best results from any cow, that first of all she be treated kindly, all sources of excitement being avoided so far as possible. She should also be fed and milked at regular intervals by the same person, and all conditious should be maintained as nearly uniform as possible at all times. It is my opinion that kind treatment and pleasant surroundings will have a greater influence upon the quality of

\footnotetext{
1 Rept. 1889.
} 
milk than the kind of food, provided the ration given contains sufficient nutriment for the maintenance of the animal."

701. Feed and care of the bull. - The ration for the bull calf should be rich in muscle- and bone-making material and ample in amount. As much growth as possible should be secured from pasture, because flesh from this source is the best that can be mañe, and also because of the vigor and tone this form of feed insures. In order to retain the young bull in pasture, a fence may be constructed with strong posts eight feet apart set deep in the ground; to these six or more strands of doubled barbed-wire are fastened. This makes an enclosure that will easily hold the young fellow, and here in the air and sunshine, with grass under foot, he will build a framework and establish a constitution which will not leave him old at four or five years, as we have come to think bulls to be. In winter, if possible, allow the bull exercise in an open lot with shed on one side to protect from the storm. The feed supply should consist of ample roughage, such as clover hay, corn stover and oat straw, with shorts, bran and oats for concentrates, these, however, being not too abundant.

If the mature bull must be confined to the shed or housed in sum. mer there should be a liberal allowance of green feed, which will alleviate in some measure the hardship of continued confinement. A reform is needed in our present methods of confining bulls, leaving them more in the pasture than at present. To do this the enclosure must be made secure with plank fences, supplemented by wires for older animals, to insure safety, for there is too great risk of life in allowing these creatures to run at large with the herd in pasture.

702. Fall and spring cows.- On the plains of the West, where we find the cow under natural conditions, calves must be dropped in the spring in order to become strong enough to withstand the rigor of the following winter. In dairy districts the cow is under artificial conditions, and nature need not be followed in all particulars. Cows fresh in the spring yield most of their milk during periods of low prices for dairy products, and on returning to winter quarters the milk flow is not stimulated by the feed and conditions there prevailing. The cow that is fresh in the fall 
gives a liberal supply of milk during winter, and when spring comes will flush again under the stimulus of fresh pastures. Fallfresh cows will probably yield from ten to fifteen per cent. more milk in the twelve-month than those calving in the spring.

703. Care before and after calving.- There is a strong natural tendency with most good cows to become fat when not yielding milk. The pregnant dry cow should receive such feed supply as will allow her to attain, without difficulty, a good body condition. Grass is the best feed for this purpose, and if the dry cow can flesh up on grass alone it should be done. Dairy cows are so heavily fed with grain while giving milk that this opportunity for change of feed and for recuperation should be utilized by the dairyman. While there is a diversity of opinion among dairymen as to the ideal condition of the cow at calving time, it is reasonable to hold that she should be in good flesh, though not "butcher fat." Before calving the feed should be cooling in character. Silage, roots, clover, hay, and fodder corn without ears, are all desirable for roughage. Bran, middlings, oats, and a little oil meal should prove satisfactory for concentrates. Immediately before calving let the supply of feed be relatively small. After calving, tepid water only should be given, as cold water may bring on a threatening ailment. If nourishment is needed, a little oat meal or ground oats in the water given will prove helpful. Let the feed supplied after calving be light for a few days and always under, rather than equal to, the desire of the cow. The use of a clinical thermometer in ascertaining the temperature of the cow from time to time for a few days before and after calving, or until all danger is past, is a most helpful means of determining the general condition of the animal and an aid in forestalling serious trouble.

704. Frequency of feeding.- The frequency with which feed should be supplied cows has not been settled, and perhaps never will be until the members of the human family agree on the num. ber of meals a day and the character of each best suited to thair own needs. From the large size of the paunch and the apparent necessity for rumination, it does not seem essential to supply leed many times a day. The common practice of feeding twice a day, 
once in the morning and once late in the afternoon, with an arm. ful of roughage to pick over at midday, appears a reasonable one, and conforms well with the labor requirements of the stable. There are dairymen who are never through feeding. They give first a little of this, then a little of that, keeping themselves busy in the stable most of the day in caring for their cows. The cows of such persons usually yield good returns, and their owners ascribe success to their particular system of feeding, when instead it is the general good care and not the particular system that should be credited. As with mankind, habit rules in these matters; and any system which is reasonable, having once been established, should not be set aside unless the feeder is sure of advantage from the change, which should be gradual, if possible.

705. Order of feeding concentrates, roughage and water.- The digestive tract of the cow is provided with a large storage room for the reception of feed. $(28,32)$ In the paunch the various articles swallowed are rapidly and thoroughly commingled by the churning action of that organ. Hay and grain are soon thoroughly intermixed, and gradually soften in the warm liquid there so abundant. This being true, the order of supplying the several constituents of the ration is not of importance from a physiological standpoint. The cow seems best satisfied when receiving the concentrates or more appetizing portion of the ration first, and after this has been disposed of she begins in contentment to chew the hay, silage or other roughage placed before her. As barn operations are usually conducted, watering follow's dry feed.

706. Preparation of feed.-As the dairy cow when giving a large flow of milk is accomplishing much work, it is best to prepare the feed for rapid mastication when possible without too great cost. Grain should generally be ground and roots sliced. Where labor is high priced, as at the West, it is preferable in many cases to feed the cow in the most simple manner, even though as large returns do not follow.

707. Dry feed.-C Cows take kindly to dry feed, and as a rulo prefer it to that in a sloppy condition. Because of the thorough admixture of the contents of the rumen, where there is abundance of moisture, there seems no occasion for converting meal 
into slop before feeding. By supplying the feed dry the mangers can be kept more wholesome with less labor in administering it.

708. Liberal feeding. - The dairyman should never forget that about sixty per cent. of all the cow can eat is required to sustain her body, and only after this amount is provided can there be any returns to him. (134) Having incurred the expense necessary to operate a dairy, in the purchase of lands, buildings and cows, he is certainly shortsighted who will withhold any part of the forty per cent. of provender which will produce returns for himself. When the dairyman has reached the point of liberal feeding, he should begin to study the individual needs of the members. Since some cows can profitably utilize more feed than others the distribution of concentrates should proceed with discrimination, some animals being fed more and others less than the average of the herd.

709. Confinement during heated periods. - Whether or not the dairyman practice soiling, there are periods in summer when cows should be in the stable during the day and turned to pasture at night. During heated periods, when flies are troublesome, cows fall off greatly in their milk, this shrinkage measuring in some degree their suffering. At such times it is best to place them in darkened stables and supply green forage supplemented with meal. For exercise turn them out at night in yard or pasture. Knowing how difficult it is to bring cows back to their normal flow after these periods of shrinkage, the wise dairyman will not be unwilling to provide for their comfort at such times.

710. Water.-That the cow requires a liberal supply of water goes without saying; for not only must the wants of the body be met, but a considerable quantity is drained off with the mills twice daily. (73) Being creatures of habit, cows can subsist when supplied water once each day, but an opportanity to reach the trough morning and evening is preferable. It is becoming quite common to supply water to cows individually in small troughs or vessels placed in front of them in the stable. If this supply can be kept wholesome the practice is satisfactory; but close inspection will show that in many cases, perhaps a majority, these individual watering devices are traps for filth and foul-smell- 
Ing water. The dairyman should convince himself, by using his nose as well as his eyes, that the water in these devices is pure and wholesome.

Whatever method of watering is employed, let uniformity prevail, the cows having opportunity to secure all they wish without fear of one another or of being forced to undergo hardship in

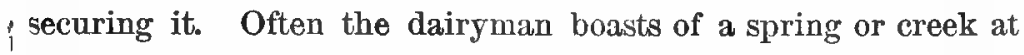
which his cows may help themselves. These sources of supply are sometimes a long distance from the stable, and the animals are daily forced to make journeys to them, often in inclement weather, thereby experiencing discomfort and actual hardship. $\Delta$ good well with wind-mill will prove superior to springs and brooks in most cases, because with these water can be delivered when and where it is needed. (628)

7II. Salt.- Though little is known from investigation on this subject, it is evident from the extreme fondness of dairy cows for salt that this article should be regularly and abundantly supplied them. The necessity for salt increases with the amount of concentrates given. From three-fourths to one ounce of salt daily is a reasonable allowance. It should be supplied daily rather than at irregular or infrequent periods in larger quantities. The practice of placing large lumps of rock salt where they are accessible to the herd is satisfactory, provided the salt is kept under cover in a clean box. $(72,629)$

\section{Feed for the Dairy Coro.}

712. Necessity for concentrated feed.-The dairy cow when yielding a liberal supply of milk should be regarded as an animal at hard labor. We have seen that the work-horse must have more grain and less roughage as his labor increases, and the same is true with the cow. (Chapter XVII, Part II.) A portion of the provender must therefore take the form of grain or concentrates. Moreover, if she is yielding a large amount of milk, i. e., working hard, it is best to aid her by reducing the grain to fineness by grinding. The dry cow is doing little work and can subsist on less feed, and this may be coarser in character.

713. The relation of concentrates to roughage.-The relation of concentrates to roughage should always be borne in mind. 
The rule should be to feed nearly as much roughage as the cow will consume without overtaxing her; then supply sufficient concentrates to bring the digestible matter up to the required stand. ard. About four-tenths of the digestible nutrients should be given in the form of concentrates and six-tenths in the roughage. It will not do to feed all grain in expectation of better returns. A satisfactory ration must possess a certain bulk or volume in order to properly distend the abdomen. Without this the processes of digestion cannot proceed normally. This should never be forgotten, even when forcing cows in dairy contests. (Chapter VII.)

714. Concerning the various feed stuffs. - In general, the various feeding stuffs used by dairymen have been fully considered in earlier chapters, so that only some of the more common ones need be here taken up, and these only in a brief way.

715. Corn.-To this grain is due in no small measure the pre-eminence of the great dairy district of the West, in which Indian corn flourishes. No article is more palatable to the cow than corn in almost any form, and her fondness for it has often led to its abuse. Milk production calls for a large amount of protein in the ration, and this protein constituent is not abnodant in corn; for this reason corn should not form more than one-half or three-fifths of the concentrates.

Where labor is high priced and corn cheap, it will be found economical to feed corn without husking. The simplest way is to use shock corn, throwing the long stalks with the ears into the leed mangers. The cows at first search for the ears, and having cansumed these strip off the leaves, even eating the finer portions of the stalks. By supplying corn on the stalk for the evening feed, so as to allow the cows a long period for working them over, all will be consumed before morning except some of the coarser por. tions of the stalks, thus reducing the labor of removing the waste. Dairymen, however, will generally prefer to run their shock corn through the feed-cutter or shredder, which leaves the material in a form relished by the cow and easily handled. The broken ears of corn are then easily masticated, the cobs also being consumed.

With unhusked corn caro must be taken to supply only the rafuisite amount of grain, which can be determined by selecting 
an average shock, husking out the ears and ascertaining how much shelled corn it carries. In feeding corn in this manner some of the grain will pass into the droppings undigested, but this need not be wasted if lusty shotes are given the opportunity of searching it out. $(538,634)$

716. Corn meal.- When exposed to the air corn becomes dry and should then be ground before feeding. Corn meal is a heavy, rich feed and should always be lightened or extended by the use of bran, shorts, oil meal, or some other feed of light character. Corn and cob meal will be found satisfactory for dairy feeding, and is recommended whenever it is possible to secure it at not too great expense for grinding.

717. By-products of corn.-Gluten meal, cream-gluten, granogluten, corn germ and other by-products of corn are all excellent articles for feeding the cow, and their use is strongly commended. Eastern dairymen have learned to appreciate these articles and use them extensively, while Western dairymen, often living at no great distance from the factories where they are produced, know little or nothing concerning them. (161-4, 635-7)

718. Oats. - It is not difficult to believe that oats, the most valuable grain for the horse, are also a prime feed for the dairy cow. The husk of the oat, though carrying little nutriment, renders this grain a feed of light character in the stomach and easy of digestion. With the data given us by Woll, (642) the dairy farmer is in position to easily determine whether he can afford to feed the oats he may grow, or exchange them for bran or other common feeds.

The by-products of oat-meal factories are valuable just in the proportion in which the kernels of the oat grain appear in them. Often there are sufficient fragments of kernels in these articles to warrant the payment of a fair price for them; but when the hulls only are offered the dairyman would better let them alone, for they are no better than the roughage in his mows and stacks.

719. Wheat bran and middlings. - Next to corn, wheat bran is the great cow feed of this country. Rich in ash and protein, carrying a fair amount of starchy matter, its light, chaffy character renders it the natural complement of heavy corn meal. 
Though its nutritive constituents approximate those of cottonseed meal, it mixes well with that feed, causing it to lie more lightly in the stomach.

The large amount of mineral matter in bran is another factor of much importance in milk production. In milk there is much mineral matter, placed there for the framework of the calf, and bran supplies this more abundantly than most feeding stuffs.

Middlings, like bran, are extensively fed to dairy cows. Being themselves heavy in character, they do not mix well with heavy feeds like cotton-seed meal and corn meal. Dairymen will find middlings much relished by cows and yielding satisfactory returns. Bran and middlings are conceded by all who have fed them to favorably affect the flow of milk. (174-5)

Cows may be fed as much as six to eight pounds of bran daily and from four to six pounds of middlings.

720. Rye.- This grain is fed in small quantities to milch cows in Denmark. It is said to have a somewhat deleterious influence on the quality of butter. The same statement applies to rye bran. Not over three pounds of ground rye or rye bran should be fed in one day to milch cows.

721. Barley. - The common grain for milch cows in Denmark is barley and oats, generally sown and harvested together, the proportion of barley and oats in the mixture being 2:3, or 1:2. Barley alone is not fed extensively to cows, wheat bran being preferred on the score of cheapness and influence on the milk secretion. Barley will prove beneficial to cows fed heavily with roots, since it counteracts their laxative influence. From three to five pounds of ground barley will suffice in the ration of the cow, bran proving an excellent complementary feed. (178)

722. Brewers' grains. - Fresh brewers' grains constitute one of the best of feeds for the dairy cow. She is fond of them, and they influence most favorably the flow of milk. Fed while fresh, in reasonable quantity, supplemented by bright hay or corn fodder for dry feed, the grains being supplied in tight feed-boxes which can be kept clean, and with all other conditions favorable to the healthfulness of the cow, no valid objection can be raised against this form of feed. From twenty to thirty pounds of wet grains 
should constitute a day's allowance. Because the grains are low priced is no reason for over-feeding with them. Corn meal is an excellent complementary feed, two or three pounds being used daily with the grains. Because of their sloppy character, some dry feed should always be supplied with the grains unless the cows are at pasture in summer. (182)

Dried brewers' grains can be economically transported and form an excellent feed for cows. Their purpose in the ration will be largely to supply protein, which they carry in abundance. It seems strange that American dried brewers' grains should find their market largely in distant Germany. Four or five pounds of dried grains will furnish a considerable portion of the protein required in the ration and prove very acceptable to the cow. (I83)

723. Cotton seed and its by-products. - Vanderford, of the Tennessee Station, ${ }^{1}$ concludes as follows, after a study of cotton seed and its by-products for cows: "We can recommend as giving satisfactory results the use of as much as 15 pounds of cutton-seed hulls in the dairy ration per 1,000 pounds live wei, nc. A larger proportion has, with our cows, caused a weakenir $g$ of the digestive powers, evidenced in some cases by a tender.cy to diarrhoea, in others to constipation."

Of cotton-seed meal he writes: "We do not think it advisable to feed more than five pounds of cotton-seed rueal daily to milch cows. For butter-making it is not advisable to exceed three pounds daily. Many years of close observation elsewhere, as well as the results of recent experiments, induce the writer to believe that it is not safe to feed cotton-seed meal as the sole addi. tion to the daily allowance of coarse fodders, particularly during the three months preceding and month after calving."

Connell and Clayton, ${ }^{2}$ experimenting with cotton-seed meal and cotton seed, found boiled cotton seed the cheapest available feed. Lloyd, ${ }^{3}$ testing cotton seed and cotton-seed meal, reached the following results, when cotton seed was valued at six dollars per ton and cotton-seed meal at twenty dollars per ton: "By comparing the averages of the lots fed on steamed seed, raw seed, and on

Bul. April, 1893.

Bul. 33, Texas Expt. Sta.

3 Bul. 21, Miss. Expt. Sta. 
cotton-seed meal (the rations of hay being the same in each case), it was found that, with steamed seed, milk was produced at a cost of 6.5 cents per gallon and butter at 14.3 cents per pound; with raw seed, milk was produced at 7.25 cents per gallon and butier at 15.58 cents per pound; and from cotton-seed meal, milk was produced at a cost of 11.13 cents per gallon and butter at 25.02 cents per pound."

While the seed may be fed raw, it is stated that cooking prevents it from imparting an undesirable flavor to butter. (210-12, 216-17, 644)

724. Clover hay.-No dry forage can prove superior to good clover hay for the cow, because of its palatability and its relatively high protein content. This hay should generally be fed long, since it is fresher and shows less dust when so handled than after passing through the feed-cutter. From ten to twelve ponnds is a sufficient allowance for a day's feed. Corn fodder, corn stover or corn silage are complementary forms of roughage. (291)

725. Timothy hay. - Generally dairymen cannot afford to feed timothy hay because of the high price it commands compared with its very moderate value for roughage when fed to the cow, and also because of the small yield returned per acre. Where prices are high, if there is timothy hay on hand, let it be sold and fodder corn used in its place. Often a ton of timothy hay can bo sold for a sum that will purchase a ton of bran, i.t which case the bran should be used with fodder corn or other roughage.

726. Millet hay. - Hay from millet or Hungarian grass, when well preserved, is useful for feeding if supplied once a day for roughage. Since millet is not rich in protein, not over six or eight pounds should be fed daily. (482) Clover hay is a complementary roughage feed because rich in protein.

727. Fodder corn.-In this country successful dairying rests largely upon the judicious use of the corn plant for forage. The best forage is secured where the seed grains of corn are planted just thick enough to grow stalks which will carry a generous supply of small ears or nubbins. Harvested at the right time, a large yield of forage is secured, which is so palatable that, preserved either as silage or cured in the shock, practically all of the 
material is available as feed for the cow if rightly handled. Next to the direct care of the herd, the greatest study of the dairyman should be in learning to economically grow, harvest and administer the corn plant.

The cow may receive from ten to fifteen pounds of fodder corn daily with advantage. If this has been grown with a "nubbin" or small ear on most of the stalks, a fair allowance of the roughage will furnish as much grain as should be fed. (250)

728. Corn stover.- Where corn is grown for the grain, the straw or stover which remains after husking the ears, though of less value than fodder corn, may still serve an important place in the feed stable. Cows are fond of the finer parts of the corn stalk, and if the stover is run through a feed-cutter and not too liberally supplied, but a small part of the stalks will be wasted. Where the stalks are coarse and inert, as they are in the southern part of the corn belt and further south, this statement does not apply, for there corn stalks are not much relished by cows, though in silage form they are readily eaten. (25I)

729. Roots. - In Europe dairymen make large use of roots. In this country, where Indian corn flourishes, silage from corn will be found more economical considering cost of production, and is equally satisfactory with the root crop for feeding cows. Where the dairyman does not have silage it will be well to feed soine roots. Mangels are the best for cows and should be pulped or sliced. Canadian dairymen often pulp the roots and mix this with chaffed hay, allowing the mass to stand a day before feeding. From twenty to forty pounds of mangels is a day's allowance. Sugar beets also serve for feeding cows. Being much richer than mangels, a smaller quantity should be fed. (325)

730. Silage.-Silage, principally from the corn plant, is now a factor of first importance on thousands of American dairy farms. That silage is well liked by the cow, that she thrives on it and yields milk liberally, that properly fed it does not impair her health,-all these points have been settled in favor of the silo and its product. Since corn silage is rich in carbohydrates and low in protein, slover hay is the common complementary roughage. 
The character of silage is such that, even though cows seemingly thrive on it when fed alone, some dry roughage should be supplied with it. In northern latitudes the cow should not be wholly maintained in winter on silage. Good corn silage always contains a liberal supply of ears, and the amount to be fed depends directly upon the proportion of ears to forage. From thirty to fifty pounds is the usual daily allowance for a cow. (See Chapter XV.)

731. Rations for dairy cows. - The young dairyman scans reports to ascertain what others are feeding their cows; the dairyman with years of experience is not averse to knowing of the practices of others, though he may be slow in changing to that which is new. (136)

In 1894 , Woll, of the Wisconsin Station, ${ }^{1}$ by correspondence secured data concerning the rations fed by more than a hundred dairymen scattered over the United States. (146) As most of them were noted in their specialty, we can place no better guide before the reader than a group of rations from this source:

Colorado. -20 lbs. alfalfa hay, 5 lbs. oat straw, $2 \frac{1}{2}$ lbs. wheat bran, $2 \frac{1}{2}$ lbs shorts, 5 lbs. oats, $1 \frac{1}{2}$ lbs. cotton-seed meal.

Connecticut. - 35 lbs. corn silage, 10 lbs. hay, 3 lbs. hran, 3 lbs. corn and cob meal, 2 lbs. cotton-seed meal, 2 lbs. Chicago gluten meal.

Illinois. - 10 lbs. timothy hay, 10 lbs. clover hay, 8 lbs. corn, $1 \frac{1}{2}$ lbs. oats

Indiana. $-30 \mathrm{lbs}$. corn silage, 5 lbs. clover hay, 3 lbs. corn fodder, $1 \mathrm{lb}$. oat straw, 1 lb. wheat straw, 5 lbs. bran, 2 lbs. oil meal, 2 lbs. cotton-seed meal.

Iowa. - 50 lbs. corn silage, 5 lbs. hay, 5 lbs. corn fodder, 1 lb. oat straw,

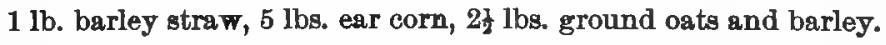

Kentucky. - 32.5 lbs. corn silage, 6 lbs. clover hay, 3 lbs. corn fodder, 5 lbs. corn meal, 4 lbs. ship-stuff, 2 lbs. oil meal.

Massachusetts. $40 \mathrm{lbs}$. corn silage, 5 lbs. English hay, $5 \mathrm{lbs}$. clover hay, 2 Ibs. bran, 2 lbs. gluten maeal, 1 lb. cotton-seed meal, $1 \mathrm{lb}$. oil meal.

Michigan. -27.5 lbs. corn silage, $3 \frac{1}{2}$ lbs. clover hay, $3 \frac{1}{2}$ lbs. timothy hay, $3.6 \mathrm{lbs}$. bran, $\frac{1}{2} \mathrm{lb}$. onte, $1 \mathrm{lb}$. rye, $\frac{3}{2} \mathrm{lb}$. oil meal.

1 Bul. 38 . 
Minnesota. -8 lbs. corn stover, 7 lbs. clover and timothy hay, 5 lbs. sheaf oats, 3 lbs. ruta-bagas, 2 lbs. bran, 3 lbs. oats, 3 lbs. corn meal, 2 lbs. oil meal.

Nebraska.-20 lbs. prairie hay, 10 lbs. corn stover, 5.7 lbs. corn meal, 2.9 lbs. bran, 1.4 lbs. oil meal.

New Hampshire.-10 lbs. clover and witch-grass hay, 10 lbs. corn stover, 5 lbs. unthrashed barley, 2 lbs, corn and cob meal, 2 lbs. shorts, 2 lbs. cotton-seed meal.

New Jersey.-24 lbs. corn silage, 8 lbs. corn meal, 2 lbs. bran, 4 lbs. oats, 2 lbs. oil meal.

New York. - 25 lbs. corn silage, 7 lbs. mixed hay, 4 lbs. corn meal, 5 lbs. bran, $\frac{1}{2}$ lb. oil meal, 光 lb. cotton-seed meal.

North Carolina. - 30 lbs. corn silage, 8 lbs. fodder corn, 3 lbs. corm meal, 3 lbs. bran, 1 lb. cotton-seed meal.

Ohio.- 10 lbs. clover hay, 20 lbs. corn stover, 8 lbs. corn meal, 3 lbs. corn and cob meal, $1 \mathrm{lb}$. bran, $8 \mathrm{lbs}$. roots.

Pennsylvania. - 45 lbs. corn silage, 7 lbs. mixed hay, 6 lbs. bran, 2 lbs. cotton-seed meal.

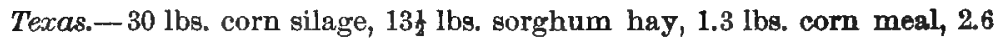
lbs. cotton-seed meal, $2.2 \mathrm{lbs}$. cotton seed, $1.3 \mathrm{lbs}$. wheat bran.

Utah.- 35 lbs. alfalfa hay, $6 \frac{2}{3} \mathrm{lbs}$. wheat bran, $3 \frac{1}{\mathrm{~g}} \mathrm{lbs}$. barley.

Vermont. - 35 lbs. corn silage, 10 lbs. mixed hay, 2 lbs. bran, 3.2 lbs. corn meal, $1 \mathrm{lb}$. oil meal, $8 \mathrm{lb}$. cotton-seed meal.

West Virginia. -48 lbs. corn silage, $2 \frac{1}{2}$ lbs. corn and cob meal, 21 lbs. ground wheat, $2 \frac{1}{2}$ lbs. oats, $2 \frac{1}{2}$ lbs. barley meal.

Washington.-15 lbs. alfalfa hay, 7 lbs. bran, 7 lbs. shorts, 2 lbs. malt sprouts.

Wisconsin. $-40 \mathrm{lbs}$. corn silage, 8 lbs. clover hay, 6 lbs. bran, 2 lbs. pes meal.

Canada.-45 lbs. turnips, 7 lbs. wheat chaff, 15 lbs. silage, $2 \frac{1}{2}$ lbe. oats, $2 \frac{1}{2}$ 1bs. pea meal. 


\section{CHAPTER XXIX.}

\section{INVESTIGATIONS WITH SHEEP.}

732. Periods of gestation.-Tessier, in a report to the Academy of Sciences, Paris, ${ }^{1}$ gives the results of his observations on the period of gestation of 912 ewes. The shortest period for the ewe carrying her lamb was 146 days, and the longest 161, a range of 15 days. More than three-fourths of the ewes yeaned between the 150th and 154th day after impregnation, bringing the average about 152 days, or 21 weelss and 5 days. Randall's statement ${ }^{2}$ as to the period of gestation coincides with that of Tessier.

733. Composition of ewe's milk.-Königa gives the composition of ewe's milk as below. For comparison, the table gives the average composition of cow's milk as stated by the same author.

Composition of ewe's milk, cow's milk being given for comparisonKönig.

\begin{tabular}{|c|c|c|c|c|c|}
\hline & Water. & $\begin{array}{l}\text { Casein } \\
\text { and } \\
\text { albumen. }\end{array}$ & Fat. & Sugar. & Ash. \\
\hline & Per et. & Per ct. & Per ct. & Per ct. & Per ct. \\
\hline 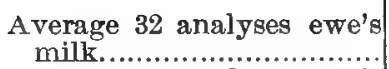 & 80.82 & 6.52 & 6.86 & 4.91 & .89 \\
\hline 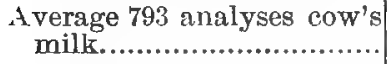 & 87.17 & 3.55 & 3.69 & 4.88 & .71 \\
\hline
\end{tabular}

734. Ewe's milk. - In America sheep are not generally used for producing milk for man, as in many districts abroad, especially in mountain regions, where this milk is extensively employed, partly for direct consumption and partly for the mannfacture of cheese. Ewe's milk differs from cow's milk mainly in its greater proportion of fat and protein. Much higher percentages than

1 According to Colman, Sheep of Great Britain, p. 250.

2 The Practical Shepherd, p. 207.

Chem. d. mensch. Nahr.-u. Genuss-mittel, I, 1112 
the average given in the preceding table have often been found by investigators. ${ }^{1}$

The yield of milk by sheep will vary greatly according to the condition of feed and the breed. Martiny states ${ }^{2}$ that the yield of Friesian milk sheep in Westphalia, Germany, is about four quarts of milk duily for four months. These sheep lamb once a year, dropping two or three lambs. Three sheep are estimated to consume as much feed as one cow. Ordinary sheep yield from 100 to 150 pounds of milk per year, while the milk breeds produce 300 pounds or more. ${ }^{\text {B }}$

The period of lactation for sheep is from four to six months.

735. Weight of lambs at birth. - The weight of lambs at birth will vary with the breed, ranging from 5.5 to 12 and even 15 pounds, the latter weight being unusual.

At the Ontario Agricultural College, 4 Brown reports the following weights of pure-bred and grade lambs from Canadian ewes:

Weight of lambs at birth - Ontario Agrioultural College.

\begin{tabular}{|c|c|c|}
\hline Breed. & Pure-bred. & $\begin{array}{l}\text { Cross bred } \\
\text { with Canadian } \\
\text { grade ewes. }\end{array}$ \\
\hline & Lbs. & Lbs. \\
\hline Lincoln...... & 9.0 & 8.3 \\
\hline 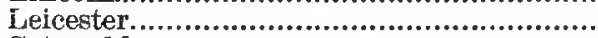 & 9.25 & 9.5 \\
\hline 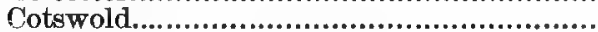 & 7.0 & 8.0 \\
\hline Highland & 7.25 & 9.0 \\
\hline Cheviot................................................ & 12.0 & 9.0 \\
\hline 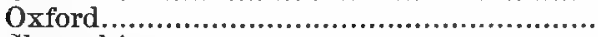 & 11.0 & 10.5 \\
\hline 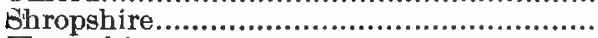 & 9.5 & 9.5 \\
\hline Hampshire............................................ & 9.0 & 10.0 \\
\hline Southdown .............................................. & 7.5 & 10.5 \\
\hline Merino..................................................... & $\ldots . .$. & 8.0 \\
\hline
\end{tabular}

736. Feeding milk to lambs. - At the Wisconsin Station ${ }^{5}$ the writer endeavored to ascertain whether lambs make as good use of food given them as other farm animals, by rearing them on

1 See Staz. Sper. Ag. Ital. 23, p. 572; Analyst, 1893, p. 248; Fleischmann, Milchwirtschaft, 1893 , p. 54 .

${ }^{2}$ Die Milch, 1871, p. 183.

s Concerning yield of milk from sheep, see Weiske, Journ. f. Landw., 1881 , p. 451; Rodiczky, Oestr. Ldw. Wochenbl., 1886, No. 47; Besana, Analyst, 1893, p. 248; Goltz, Landw., III, p. 460; Shepperd, Agri. Science, VI, p. 397.

Rept. 1885. 
cow's milk and other appropriate feeding stuffs. The four lambs in the trial were from large high-grade merino ewes sired by a pure-bred Shropshire ram. They were vigorous, growthy specimens, ten days old at the beginning of the trial, averaging ten pounds each in weight. At first they were fed cow's milk at blood heat, this milk constituting their only food for twenty-one days, after which skim milk, oats and green clover were supplied. The following data show the food required for 100 pounds of gain with these lambs, beginning at 10 days of age:

\section{Period.}

Feed given.

Feed per 100 Ubs. gain.

Pounds.

First period, 21 days

Cow's milk

$57 y$

Second period, 115 days.

Sweet skim milk............... 830

$\{$ Ground oats........................... 118

Green clover ......................... 262 Third period, 21 days (after with-
holding milk)

Ground oats...................... 291

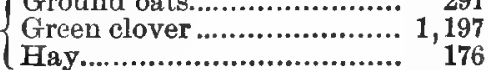

At the close of the last period, when 167 days old, the lambs averaged 79 pounds each, showing a daily gain, including birth weight, of nearly one-half pound each. $(356,659)$

The heary gains which followed the use of cow's milk in this trial suggest the profitable use of that article in forcing lambs to meet the requirements of special markets, e. g., "Christmas lambs."

737. Lambs compared with pigs. - At the Michigan Agricultural College, ${ }^{1}$ Miles fed Essex pigs, eleven days old, cow's milk for four weeks, with the results shown in the following table:

Cow's milk required for 100 pounds gain by young Essex pigs Michigan Agricultural College.

\begin{tabular}{c|c|c|c|c}
\hline 1st week. & $\begin{array}{c}\text { 2d week. } \\
720 \text { lbs. }\end{array}$ & 3d week. & 4th week. & $\begin{array}{c}\text { Av. for four } \\
\text { weeks. } \\
925 \text { lbs. }\end{array}$ \\
\hline
\end{tabular}

During the third week of the trial the pigs were "off feed," so that the average is somewhat too high.

Making reasonable allowance for this, the lambs fed in the Wis. consin trial noted above lead in the gains made from cow's mill.

${ }^{1}$ Rept. Mich. Bd. of Agr., 1866, p. 61. 
738. Relative economy of lambs and pigs.- Elsewhere (831) is shown the feed required by pigs before weaning for 100 pounds of gain. From these figures and those reported in Article 736 the data given below are deduced.

Feed required for 100 pounds of increase by young pigs and lambsWisconsin Station.

\begin{tabular}{|c|c|c|}
\hline Feed. & Pigs. & Lambs. \\
\hline & Lbs. & Lbs. \\
\hline 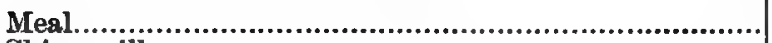 & 231 & 119 \\
\hline 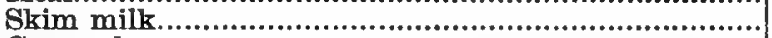 & 534 & 830 \\
\hline 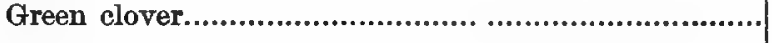 & & 262 \\
\hline 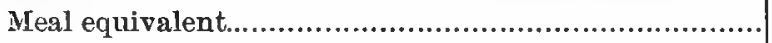 & 320 & 284 \\
\hline
\end{tabular}

The above data show that before weaning pigs require 231 pounds of meal and 534 pounds of skim milk for 100 pounds of gain. Estimating 6 pounds of milk equal to one of meal, according to the Danish formula, (888) we have 320 pounds of meal or equivalent as the feed for 100 pounds of gain with pigs before weaning. During the second period of the trial with lambs, the following quantities of feed were required for 100 pounds of gain: 119 pounds of meal, 830 of milk and 262 pounds of green clover. Estimating the milk at the same equivalent in meal as before, and ten pounds of green clover equal to one of meal, we have 284 pounds of grain or grain equivalent as the feed required for 100 pounds of gain with young lambs, or thirty-six pounds less than that required by the pigs. From this it is apparent that lambs make at least as economical gains for feed consumed as do pigs of the same age.

739. The milking qualities of ewes. - Instructive experiments were conducted by Shepperd, ${ }^{1}$ at the Wisconsin Station, to determine the milking qualities of high-grade Shropshire ewes. Lambs at foot were muzzled except at regular periods, when each was allowed to take milk from its dam while the attendant drew nilk from the other teat. The amount of milk yielded by the ewes was determined by weighing each lamb on a delicate scallo

1 Agricultural Science, VI, pp. 397-405. 
immediately before and after sucking. The results are shown below:

Field, per cent. of fat and specific gravity of eroe's milk - Wisconsin Station.

\begin{tabular}{c|c|c|c|c}
\hline No. of ewe. & $\begin{array}{c}\text { No. of days } \\
\text { tested. }\end{array}$ & $\begin{array}{c}\text { Daily milk } \\
\text { yield. }\end{array}$ & Per cent. fat. & $\begin{array}{c}\text { Specific } \\
\text { gravity. }\end{array}$ \\
\hline 1 & 10 & $3.96 \mathrm{lbs}$. & 5.2 & $\mathbf{1 . 0 3 7}$ \\
2 & 6 & $2.83 \mathrm{lbs}$. & 5.4 & 1.049 \\
3 & 6 & $3.03 \mathrm{lbs}$. & 5.62 & 1.027 \\
$\mathbf{4}$ & 6 & $2.51 \mathrm{lbs}$. & 6.25 & $\mathbf{1 . 0 3 6}$ \\
\hline
\end{tabular}

From the above we learn that four ewes gave from 2.5 to 4 pounds of milk each daily, containing from 5.2 to 6.25 per cent. of fat. The milk was of high specific gravity, showing a large content of solids. (825)

740. Feed required for 100 pounds of milk. - Ewes fed singly and in groups of two were given weighed quantities of feed and water, and the milk yield noted. The concentrates fed consisted of three parts bran and one part oil meal. This with clover hay of good quality, though a little coarse, and a few sliced potatoes, constituted the ration. The results were as follows:

Quantity of feed and water consumed by eves in producing 100 pounds of milk - Wisconsin Station.

\begin{tabular}{|c|c|c|c|c|}
\hline No. of ewe. & Grain. & Clover hay. & Potatoes. & Water. \\
\hline \multirow{4}{*}{$\left.\begin{array}{l}1 \\
1 \\
2 \\
3 \\
4\end{array}\right\}$} & Lbs. & Lbs. & Lbs. & Lbs. \\
\hline & 51 & 61.6 & 38 & 293 \\
\hline & 59 & 55.5 & 29 & 417 \\
\hline & 72 & 63 & 36 & 404 \\
\hline
\end{tabular}

The above figures are helpful to the student in comparing the sheep with other domestic animals as an economical producer of milk. They show the ewe to be as economical as the cow in turning hay and grain into milk. It should not be forgotten that while yielding milk the ewe is also growing a fleece. (694)

74I. Value of ewe's milk for lamb growing.- In conducting his. studies with ewes and lambs, Shepperd noted the amount of milk. 
consumed by lambs and their gains, with the results reported in the table. In these trials the lamb was kept separate from the ewe, except when sucking. It was weighed both before and after sucking to ascertain the amount of milk yielded by the ewe. The results appear in the following table:

Daily gain, and gain per pound of eve's milk, by young lambsWisconsin Station.

\begin{tabular}{c|c|c|c}
\hline No. of lamb. & Age of lamb. & Gain per day. & $\begin{array}{c}\text { Gain per lb. of } \\
\text { milk. }\end{array}$ \\
\cline { 2 - 4 } & Days. & Lbs. & Lbs. \\
$\mathbf{1}$ & 25 & .62 & .156 \\
$\mathbf{3}$ & 28 & .47 & .166 \\
$\mathbf{4}$ & 36 & .44 & .145 \\
\hline
\end{tabular}

Here were daily gains ranging from .4 to over .6 of a pound per lamb, each pound of milk producing about.15 of a pound increase, live weight. Shepperd concludes his report with the statement that the gain of lambs, during the first month of their lives at least, is largely controlled by the quantity of milk yielded by the ewe, and as a consequence that ewes should be carefully selected for their milking qualities. (525, 825-8)

742. Influence of shearing on milk yield. - Weiske ${ }^{1}$ conducted an experiment to ascertain the influence of shearing on the production of milk by sheep. A Southdown-Merino ewe weighing 77 pounds was fed the following ration directly after lambing: Meadow hay, 1.1 pounds; beets, 2.2 pounds; ground barley, 1.1 pounds. On this food she produced the following quantities of milk:

Days after lambing, May.. $\quad 1, \quad 2, \quad 3, \quad 4, \quad 5, \quad 6, \quad 7, \quad 8,9$. Pounds of milk................. 1.2, 1.4, 1.6, 1.7, 1.9, 2.0, 2.0, 2.2, 2.2.

The milk contained from 14.28 to 16.51 per cent. total solids. During days following the last one noted above, the milk yield remained at 2.2 pounds, but decreased, when the ewe was shorn, May 20, as follows:

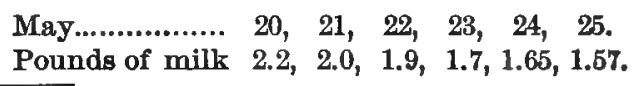

' Der Landwirt, 1879, p. 329. 
When half a pound of flax seed was added to the ration the milk production increased as follows:

$$
\begin{aligned}
& \text { May.............. 26, 27, 28, 29, 30, } 31 . \\
& \text { Pounds of milk 1.5, 1.7, 2.0, 2.1, 2.0, 2.1. }
\end{aligned}
$$

The influence of the flax seed in overcoming the shock to the system through shearing is shown by a return to the normal milk flow through its use.

743. Soiling ewes and lambs.-Because of their daintiness and the large variety of plants they crop, soiling sheep is impracticable. Desiring to ascertain, regardless of cost, the amount of food required by sheep for growth in summer, the writer conducted the trial reported below." Ten large Merino ewes were chosen, each with a lamb at foot one month old, when the trial began, June 3. The lambs were vigorous, their sire being an imported Shropshire. With patience and laborious attention to every detail, the shepherd fed the lot successfully, with the results given in the following table:

Feed required for 100 pounds gain when soiling ewes and lambsWisconsin Station.

\begin{tabular}{c|c|c|c|c}
\hline Periods. & \multicolumn{3}{|c}{ Feed for 100 pounds gain. } \\
\cline { 2 - 5 } & $\begin{array}{c}\text { Green } \\
\text { clover. }\end{array}$ & $\begin{array}{c}\text { Green corn } \\
\text { fodder. }\end{array}$ & Hay. & Oats. \\
\hline Eroes and lambs, before weaning. & Lbs. & Lbs. & Lbs. & Lbs. \\
1st period, June 3-July 29 (57 days) & 2,882 & $\mathbf{4 7 8}$ & $\ldots \ldots . .$. & 45 \\
2d period, July 29-Sept. 16 (49 days) & 555 & $\mathbf{2 , 4 0 0}$ & $\ldots \ldots . .$. & $\mathbf{4 5}$ \\
Lambs only, after weaning. & & 915 & 292 & $\mathbf{4 1 3}$ \\
\hline
\end{tabular}

Placing a fair price on the substances consumed, we find that 100 pounds of increase was made at a reasonable cost. When we remember that the ewes would have preferred to do their own foraging, and would have eaten many weeds and weed seeds as well as better forage, we must conclude that evidence points to the sheep as one of the most economical meat prodncers on the farm.

744. Sheep compared with lambs for fattening.-This impor. tant subject has received little attention at our Stations. The only

Rept. Wis. Expt. Bta., 1890. 
trial reported is by Hayes of the Minnesota Station. ${ }^{1}$ Ten North Dakota half-bred Shropshire lambs were fed in opposition to ten Montana two-year-old grade Merino wethers. The feed consisted of wheat screenings and hay, the trial lasting eighty-four duys, with results given below:

Feeding lambs in opposition to mature wethers - Minnesota Station.

\begin{tabular}{|c|c|c|c|c|c|c|c|}
\hline \multirow{2}{*}{ Breed. } & \multicolumn{2}{|c|}{ Total feed. } & \multirow{2}{*}{$\begin{array}{l}\text { Av. wt } \\
\text { at be- } \\
\text { gin- } \\
\text { ning. }\end{array}$} & \multirow{2}{*}{$\begin{array}{l}\text { Total } \\
\text { gain. }\end{array}$} & \multirow{2}{*}{$\begin{array}{l}\text { Daily } \\
\text { gain. }\end{array}$} & \multicolumn{2}{|c|}{$\begin{array}{c}\text { Feed for } 100 \\
\text { lbs. gain. }\end{array}$} \\
\hline & Grain. & Hay. & & & & Grain. & Hay. \\
\hline \multirow{4}{*}{ 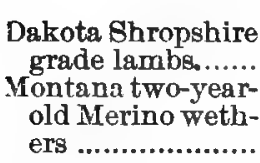 } & Lbs. & Lbs. & Lbs. & Lbs. & Lbs. & Lbs. & Lbs. \\
\hline & 1,776 & 609 & 74 & 244 & .29 & 728 & 250 \\
\hline & & & & & & & \\
\hline & 2,110 & 542 & 107 & 172 & .20 & 1,227 & 31 a \\
\hline
\end{tabular}

We observe that the lambs gave the usual returns from wheat screenings and made satisfactory gains. On the other hand, the wethers gained only one-fifth of a pound per day, and consumed 70 per cent. more grain for a given gain than the lambs. Possibly when more trials are on record, the feeding qualities of lambs and mature sheep will show less difference than in this rase; but it is well known that young animals give the best returns for feed consumed.

745. Iowa Station breed test.-The most extensive breed test conducted in this country was at the Iowa Station ${ }^{2}$ by Wilson and Curtiss. In the first trial there were ten wether lambs in each lot, most of which were selected in Canada especially for the trial. The Merinos in the first trial were of the National Delaine strain, raised in Iowa. The Range lambs were from Wyoming. In the second trial there were nine lambs in each lot, rastly from Canada. The Merinos in this trial were of the Rambouillet strain, bred in Ohio. In the first trial the feeding lasted ninety days and in the second one hundred and five days, and was alike in all particulars for each lot. In closing the ex. periment the lambs were shipped to Chicago and there valued by

1 Rept. 1893.

2 Buls. 33, 35. 
experts both before and after slanghter. The leading results of the trials are summarized in the following tables:

Weight and gain of fattening wether lambs in breed test-Iova Station.

\begin{tabular}{|c|c|c|c|c|c|c|c|c|}
\hline \multirow{2}{*}{ Breed. } & \multicolumn{2}{|c|}{ Av. age. } & \multicolumn{2}{|c|}{$\begin{array}{l}\text { Av. wt. at } \\
\text { veginning. }\end{array}$} & \multicolumn{2}{|c|}{$\begin{array}{l}\text { Av. daily } \\
\text { gain. }\end{array}$} & \multicolumn{2}{|c|}{$\begin{array}{l}\text { Dry matter } \\
\text { per } 100 \text { lbs } \\
\text { gain. }\end{array}$} \\
\hline & $\begin{array}{l}\text { First } \\
\text { trial. }\end{array}$ & $\begin{array}{l}\text { Sec- } \\
\text { ond } \\
\text { trial. }\end{array}$ & $\begin{array}{l}\text { First } \\
\text { trial. }\end{array}$ & $\begin{array}{l}\text { Sec- } \\
\text { ond } \\
\text { trial. }\end{array}$ & $\begin{array}{l}\text { First } \\
\text { trial. }\end{array}$ & $\begin{array}{l}\text { Sec- } \\
\text { ond } \\
\text { trial. }\end{array}$ & $\begin{array}{l}\text { First } \\
\text { trial. }\end{array}$ & $\begin{array}{l}\text { Sec- } \\
\text { ond } \\
\text { trial. }\end{array}$ \\
\hline & Days. & Days. & Lbs. & Lbs. & Lbs. & Lbs. & Lbs. & Lbs. \\
\hline 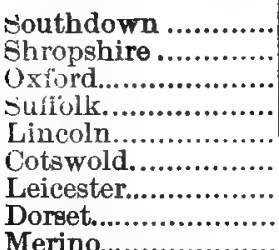 & $\begin{array}{l}374 \\
371 \\
374 \\
394 \\
345 \\
347 \\
362 \\
367 \\
362\end{array}$ & $\begin{array}{l}289 \\
279 \\
279 \\
285 \\
291 \\
268 \\
277 \\
277\end{array}$ & $\begin{array}{r}91 \\
101 \\
119 \\
117 \\
121 \\
118 \\
132 \\
101 \\
82\end{array}$ & $\begin{array}{l}65 \\
88 \\
95 \\
92 \\
94 \\
85 \\
86 \\
83\end{array}$ & $\begin{array}{l}.45 \\
.48 \\
.52 \\
.55 \\
.55 \\
.62 \\
.52 \\
.48 \\
29\end{array}$ & $\begin{array}{l}.35 \\
.36 \\
.40 \\
.40 \\
.46 \\
.50 \\
.44 \\
.43\end{array}$ & $\begin{array}{l}738 \\
718 \\
740 \\
740 \\
729 \\
653 \\
749 \\
785 \\
935\end{array}$ & $\begin{array}{r}989 \\
1,026 \\
1,031 \\
1,036 \\
910 \\
848 \\
93 \\
989\end{array}$ \\
\hline 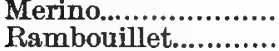 & 362 & 255 & 82 & 74 & & .37 & & 1,02 \\
\hline Shropshire ewes....... & 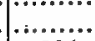 & 255 & & 67 & & .31 & & 1,030 \\
\hline Range.................... & 331 & & 71 & & .37 & & 684 & \\
\hline
\end{tabular}

Price and woight of dressed carcass and of fleece in breed testIowa Station.

\begin{tabular}{|c|c|c|c|c|c|c|c|c|}
\hline \multirow{2}{*}{ Breed. } & \multicolumn{2}{|c|}{$\begin{array}{l}\text { Price per } 100 \\
\text { lbs. live wt. }\end{array}$} & \multicolumn{2}{|c|}{$\begin{array}{l}\text { Per cent. } \\
\text { dressed car- } \\
\text { cass. }\end{array}$} & \multicolumn{2}{|c|}{$\begin{array}{l}\text { Av. wt. of } \\
\text { fleece. }\end{array}$} & \multicolumn{2}{|c|}{$\begin{array}{c}\text { Value of } \\
\text { fleece per } \\
\text { head. }\end{array}$} \\
\hline & $\begin{array}{l}\text { First } \\
\text { trial. }\end{array}$ & $\begin{array}{l}\text { Sec- } \\
\text { ond } \\
\text { trial. }\end{array}$ & $\begin{array}{l}\text { First } \\
\text { trial. }\end{array}$ & $\begin{array}{l}\text { Sec- } \\
\text { ond } \\
\text { trial. }\end{array}$ & $\begin{array}{l}\text { First } \\
\text { trial. }\end{array}$ & $\begin{array}{l}\text { Sec- } \\
\text { ond } \\
\text { trial. }\end{array}$ & $\begin{array}{l}\text { First } \\
\text { trial. }\end{array}$ & $\begin{array}{l}\text { Sec- } \\
\text { ond } \\
\text { trial. }\end{array}$ \\
\hline & & & & & Lbs. & Lbs. & & \\
\hline Southdown & $\$ 475$ & $\$ 575$ & 55.4 & 55.26 & 6.8 & 4.6 & $\$ 075$ & $\$ 061$ \\
\hline Shropshire & 463 & 560 & 56.3 & 52.88 & 8.8 & 7.8 & & 110 \\
\hline Oxford .... & 450 & 540 & 55.2 & 50.08 & 11.0 & 8.0 & 144 & 116 \\
\hline Suffolk.. & 425 & 500 & 53.6 & 52.54 & 7.7 & 5.2 & 86 & 7 \\
\hline Lincoln.. & 450 & $\begin{array}{ll}5 & 25\end{array}$ & 55.7 & 51.08 & 12.9 & $10 . \overline{4}$ & $\begin{array}{ll}1 & 79\end{array}$ & 156 \\
\hline Cotswold. & 450 & 525 & 54.9 & 53.57 & 12.7 & 9.8 & 166 & 146 \\
\hline Leicester... & 450 & 525 & 57.8 & 51.87 & 11.6 & 8.9 & 176 & 13 \\
\hline Dorset... & 375 & 550 & 52.6 & 54.11 & 6.8 & 6.0 & 77 & $8 ?$ \\
\hline Merino............ & 425 & & 51.8 & & 9.9 & & 100 & \\
\hline Ramabouillet....... & - & 500 & & 49.57 & ........ & 6.6 & & 7 \\
\hline Bhropshire ewes.. & . & 565 & & 54.55 & & & & \\
\hline Range...... & 450 & & 55.6 & & 5.1 & & 67 & \\
\hline
\end{tabular}


746. L awes and Gibert's breed test. - These investigators tested the comparative fattening qualities of the different English breeds of sheep. ${ }^{1}$ Their data of the feed requirements for gain by the various breeds during fattening are as follows:

Feed required for 100 pounds gain, live weight, with sheep of various breeds - Rothamsted Station.

\begin{tabular}{c|c|c|c|c|c}
\hline \hline Breeds. & $\begin{array}{c}\text { Av. wt. } \\
\text { at be- } \\
\text { gin- } \\
\text { ning. }\end{array}$ & $\begin{array}{c}\text { Av. total } \\
\text { increase } \\
\text { per head. }\end{array}$ & \multicolumn{2}{|c|}{$\begin{array}{c}\text { Feed consumed to produce 100 } \\
\text { lbs. increase, live weight. }\end{array}$} \\
\cline { 2 - 6 } & Lbs. & Lbs. & Lil cake. & Clover hay. & Swedes. \\
\hline & 88 & 53 & 297 & 285 & 3,836 \\
Sussex................... & 114 & 70 & 291 & 261 & 3,967 \\
Hampshire........... & 95 & 45 & 264 & 252 & 3,725 \\
Cross-bred wethers. & 91 & 43 & 263 & 250 & 3,671 \\
Cross-bred ewes...... & 101 & 45 & 264 & 251 & 3,761 \\
Leicester ............... & 120 & 64 & 253 & 217 & 3,558 \\
\hline
\end{tabular}

747. Ontario College breed test.- - At the Ontario Agricultural College, ${ }^{2}$ Brown fed grade lambs of different breeds to test their relative fattening qualities, the trial beginning in November and closing in March, with the following results:

Trial with grade wether lambs of several breeds - Ontario Agricultural College.

\begin{tabular}{|c|c|c|c|c|c|c|c|c|}
\hline \multirow[b]{2}{*}{ Breed. } & \multirow{2}{*}{$\begin{array}{l}\text { Wt. on } \\
\text { entry. }\end{array}$} & \multirow{2}{*}{ Gain. } & \multicolumn{6}{|c|}{ Feed for 100 pounds gain. } \\
\hline & & & Hay. & Roots. & $\begin{array}{c}\text { Oil } \\
\text { eake. }\end{array}$ & Oats. & Peas. & Bran. \\
\hline & Lbs. & Lbs. & Lbs, & Lbs. & Lbs. & Lbs. & Lbs. & Lbs. \\
\hline Cotswold........... & 106 & 41 & 493 & 920 & 195 & 136 & 273 & 83 \\
\hline Leicester............ & 109 & 31 & 465 & 1,239 & 252 & 181 & 358 & 110 \\
\hline Oxford................ & 95 & 41 & 341 & 937 & 188 & 134 & 268 & 80 \\
\hline Bhropshire.... & 122 & 43 & 386 & 1,007 & 200 & 130 & 263 & 81 \\
\hline Bouthdown ...... & 120 & 37 & 368 & 1,139 & 235 & 157 & 315 & 93 \\
\hline Average.... & 110 & 39 & 411 & 1,048 & 214 & 148 & 295 & 89 \\
\hline
\end{tabular}

The results of these trials present interesting studies, but should not be regarded as determining the relative merits of the several breeds.

Jour. Roy. Agrl. Soc., 1851, 1852, 1855; Rothamsted Memoirs, Vol. Il.

2 Rept. 1885. 
748. "Sels-feed" for fattening lambs.- Some feeders follow the practice of placing quantities of grain sufficient to last a week or roore in a box arranged so that the grain passes down into the feed trough as rapidly as the sheep consume the supply below. The purpose of the "self-feed" is to save the time and labor of the shepherd, and also to allow the animals to have grain before them at all times. Trials with self-feed are reported from the Michigan Station ${ }^{1}$ with ten lambs in each lot, and Minnesota Station ${ }^{2}$ with eight lambs in each lot, the results being given below:

Trials with "self-feed" for fattening lambs - Michigan and Minu". sota Stations.

\begin{tabular}{|c|c|c|c|c|c|c|c|}
\hline & \multicolumn{2}{|c|}{ Feed given. } & \multirow{2}{*}{$\mid \begin{array}{c}\text { Wt.at } \\
\text { begin- } \\
\text { ning. }\end{array}$} & \multirow{2}{*}{ Gain. } & \multirow{2}{*}{$\begin{array}{l}\text { Daily } \\
\text { gain. }\end{array}$} & \multicolumn{2}{|c|}{$\begin{array}{c}\text { Feed for } 100 \\
\text { lbs. gain. }\end{array}$} \\
\hline & Grain. & Hay. & & & & Hay. & Grain. \\
\hline Michigan. & Lbs. & Lbs. & Lbs. & Lbs. & Lbs. & Lbs. & Lbs \\
\hline Belf-feed. & & & & & & & \\
\hline Corn & 1,506 & 961 & 82 & 248 & .23 & 387 & 607 \\
\hline $\begin{array}{l}\text { Corn and tran......... } \\
\text { Regular feed. }\end{array}$ & $\mathbf{1}, 838$ & 959 & 80 & 237 & .22 & 405 & 776 \\
\hline Corn $\ldots . . . . . . . . . . . . . .$. & 1,579 & 1,097 & 82 & 328 & .31 & 334 & 481 \\
\hline $\begin{array}{l}\text { Corn and bran.......... } \\
\text { Minnesota. } \\
\text { Self-feed. }\end{array}$ & 1,703 & 1,124 & 80 & 267 & .25 & 421 & 638 \\
\hline $\begin{array}{l}\text { Wheat screenings... } \\
\text { Regular. }\end{array}$ & 3,023 & 432 & 84 & 333 & .35 & 130 & 908 \\
\hline Wheat screenings... & 2,225 & 753 & 78 & 300 & .32 & 251 & 742 \\
\hline
\end{tabular}

Mumford, ${ }^{\circ}$ reviewing his studies with the self-feed, writes: "The experiments are quite conclusive, extending as they do orer a period of three years under varying conditions and with aifferent lots of sheep. We are led to the conclusion that fattening lambs by means of a self-feed is an expensive practice, and that economy of production requires more attention to the variation in the appetites of the animals than can be given by this method."

749. Fettening shorn lambs.-At the Michigan Station, ${ }^{4} \mathrm{Mum}$ ford divided a bunch of twenty lambs into two lots of ten each. One lot was shorn and the other left unshorn, both receiving sirnilar treatment as to feed and care. The grain consisted of corn and wheat, equal parts by weight, fed with good clover hay.

\footnotetext{
${ }^{1}$ Bul. 113. ${ }^{2}$ Bul. $44 . \quad$ 'Bul. 128, Mich. Expt. Sta. ‘ Bul. 128.
} 
The trial began in November, lasting thirteen weeks. Both lots were kept in a barn, the window in the pen containing unshorn lambs being kept open, while that in the pen of the shorn lambs was kept closed. In spite of this care the shorn lambs suffered from the cold. The result of the trial is tabulated below:

Feeding shorn and unshorn lambs - Michigan Station.

\begin{tabular}{c|c|c|c|c|c|c|c}
\hline & \multicolumn{2}{|c|}{ Feed eaten. } & $\begin{array}{c}\text { Av.wt. } \\
\text { at be } \\
\text { gining. }\end{array}$ & $\begin{array}{c}\text { Total } \\
\text { gain. }\end{array}$ & $\begin{array}{l}\text { Daily } \\
\text { gain. }\end{array}$ & $\begin{array}{c}\text { Feed for 100 lbs. } \\
\text { gain. }\end{array}$ \\
\cline { 2 - 7 } & Grain. & Hay. & & & & Grain. & Hay. \\
\cline { 2 - 7 } & Lbs. & Lbs. & Lbs. & Lbs. & Lbs. & Lbs. & Lbs. \\
Unshorn...... & 1,164 & 1,173 & 85 & 230 & .25 & 506 & 510 \\
Shorn ........ & 1,266 & 1,336 & 84 & 161 & .18 & 786 & 830 \\
\hline
\end{tabular}

The shorn lambs ate more food, drank less water and made 30 per cent. less gain than the unshorn lambs.

At the Wisconsin Station, ${ }^{1}$ Craig studied the subject during four years, the first trial beginning in December, and subsequent ones earlier, the last two beginning in October. As with Mum. ford, Craig's results were unfavorable to shearing fattening lambs after winter begun, while they favored early shearing. His conclusions are:

"1. Fall shearing is a beneficial practice to prepare lambs that are six months old for the early winter market.

"2. To secure the benefits of fall shearing it should be done early in the season, at least not later than October.

" 3 . When done under such circumstances, the removal of the fleece hastens the fattening, and the gain is made at a slightly cheaper rate.

"4. The results show that by shearing in the fall and again in the spring more wool is obtained than from a single spring shearing, but the market value of the two clippings is not any greater than that of the single clipping in which the fibers of the fleece are longer.

"5. When the lambs are to be fattened during three or four of the winter months, there appears to be no practical advantage in fall shearing."

1 Rept. 1894. 
750. Exposure versus confinement.- Next to feed, the feeding place and the method of confinement are of importance in fattening sheep. At the Minnesota Station, ${ }^{1}$ Shaw fed four lots of eight lambs each under various conditions as to confinement. Lot I was kept out of doors continuously in a yard sheltered from the wind by a low building at one side. Lots II and III were confined in yards with an open shed for shelter. Lot IV was kept in a compartment of the barn haring one large window facing the east, for ventilation. The feed for all lots was the same. The table below presents the results:

Effect of various methods of confinement on fattening lambs - Minnesota Station.

\begin{tabular}{|c|c|c|c|c|c|}
\hline \multirow[b]{2}{*}{ Where fed. } & \multirow{2}{*}{$\begin{array}{c}\text { Aver- } \\
\text { age } \\
\text { weight. }\end{array}$} & \multirow{2}{*}{$\begin{array}{l}\text { Av. } \\
\text { daily } \\
\text { gain. }\end{array}$} & \multicolumn{3}{|c|}{ Feed for $100 \mathrm{lbs}$ gain. } \\
\hline & & & $\begin{array}{l}\text { Wheat } \\
\text { screen- } \\
\text { ings. }\end{array}$ & $\underset{\text { meal. }}{\text { Oil }}$ & Hay \\
\hline & Lbs. & Lbs. & Lbs. & Lbs. & Lbs. \\
\hline $\begin{array}{l}\text { Lot I, out of doors........... } \\
\text { Lot II, in lot with shed... } \\
\text { Lot III, in lot with shed... } \\
\text { Lot IV, in stable.............. }\end{array}$ & $\begin{array}{l}80 \\
84 \\
78 \\
78\end{array}$ & $\begin{array}{l}.28 \\
.36 \\
.32 \\
.28\end{array}$ & $\begin{array}{l}804 \\
817 \\
668 \\
722\end{array}$ & $\begin{array}{l}90 \\
91 \\
74 \\
80\end{array}$ & $\begin{array}{l}316 \\
127 \\
251 \\
283\end{array}$ \\
\hline
\end{tabular}

It will be seen that the lot kept out of doors made as rapic gains as that confined in the stable, but required somewhat more feed for a given gain. Lots II and III, kept in the shed, made the largest and Lot $\mathrm{WI}$ the cheapest gain.

At the ilichigan Station, ${ }^{2}$ Munford kept one lot of lambs cun. tinuously in an open yard in winter where they were sometimes drenched with rain and covered with snow. A second lot was fed in a barn, at no time being allowed to go outside. The results were slightly in favor of the lambs kept indoors, but the difference was far less than would be supposed by persons who are not familiar with the hardiness of fattening sheep. The results of this trial do not show that rain and snow are beneficial to the fattening sheep, but rather that indoor confinement may be as damaging as outdoor exposure. (561, 630)

\footnotetext{
'Bul. 44. $\quad$ Bul. 128.
} 
75l. Water drank.-Several Stations have weighed the water drank by lambs while fattening. The following table presents a range of results helpful to those seeking information on this point:

Water drank by lambs on various rations during fattening - Michigan and Cornell Stations.

\begin{tabular}{|c|c|c|c|c|c|c|c|c|c|}
\hline \multirow{2}{*}{ Grain fed. } & \multirow{2}{*}{ 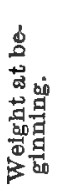 } & \multirow{2}{*}{ 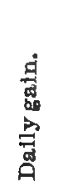 } & \multirow{2}{*}{ 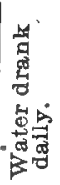 } & \multicolumn{4}{|c|}{$\begin{array}{l}\text { Feed and water per } 100 \\
\text { lbs. gain. }\end{array}$} & \multirow{2}{*}{ 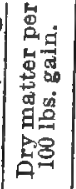 } & \multirow{2}{*}{ Romarka. } \\
\hline & & & & 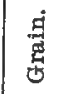 & $\stackrel{\dot{c}}{\dot{m}}$ & 弯 & $\underset{8}{\stackrel{5}{9}}$ & & \\
\hline \multirow{4}{*}{ 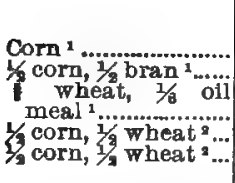 } & Lbs. & Lbs. & Lbs. & Lbs. & Lbs. & Lbs. & Lbs. & Lbs. & \multirow{8}{*}{$\begin{array}{l}\text { Confined. } \\
\text { Conflned. } \\
\text { Conflned. } \\
\text { Freedom of yard. } \\
\text { Shorn } 2 \mathrm{~d} \text { weels of } \\
\text { experiment. } \\
\text { Conflned. } \\
\text { Conflned. }\end{array}$} \\
\hline & $\begin{array}{l}82 \\
50\end{array}$ & $\begin{array}{l}.81 \\
.25\end{array}$ & $\begin{array}{l}8.02 \\
3.85\end{array}$ & $\begin{array}{l}481 \\
639\end{array}$ & $\begin{array}{l}834 \\
421\end{array}$ & 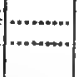 & $\begin{array}{r}966 \\
1,515\end{array}$ & $\begin{array}{l}702 \\
913\end{array}$ & \\
\hline & $\begin{array}{l}80 \\
85 \\
84\end{array}$ & .28 & $\begin{array}{l}4.83 \\
1.35 \\
2.09\end{array}$ & $\begin{array}{l}526 \\
583 \\
786\end{array}$ & $\begin{array}{l}394 \\
530 \\
890\end{array}$ & (............... & 1,740 & $\begin{array}{r}804 \\
965 \\
007\end{array}$ & \\
\hline & & .18 & 2.08 & 786 & & |............ & 1,148 & 1,397 & \\
\hline $\begin{array}{l}\text { Corn and roots } 1 . . . . \\
\text { Sugar beets }\end{array}$ & $\begin{array}{l}81 \\
84\end{array}$ & .38 & 1.87 & 406 & 243 & $\begin{array}{r}685 \\
4900\end{array}$ & 495 & 641 & \\
\hline $\begin{array}{l}\text { part oil ineal, } 2 \\
\text { parts cotton-seed }\end{array}$ & & & & & 1,015 & 4,800 & 314 & 1,010 & \\
\hline $\begin{array}{l}\text { meal, } 4 \text { pts. brans } \\
7 \text { parts corn, } 1 \text { part }\end{array}$ & 59 & .19 & 3.02 & 505 & 457 & $890 *$ & 1,598 & 1,035 & \\
\hline parts corn, 1 part & 56 & .22 & 1.10 & 470 & 486 & 501 & 505 & 880 & \\
\hline
\end{tabular}

* Silage.

752. Weight of fattened sheep.-At the Ontario College, ${ }^{4}$ Brown reports the following weights of fat shorn shearlings (sheep once shorn):

Live weight of fat shorn wethers at 445 days - Ontario Agricultural College.

\begin{tabular}{|c|c|c|c|c|}
\hline & $\begin{array}{c}\text { Average } \\
\text { weight of } \\
\text { tops. }\end{array}$ & $\begin{array}{c}\text { A verage } \\
\text { weight of } \\
\text { culls. }\end{array}$ & $\begin{array}{c}\text { Mean } \\
\text { weight. }\end{array}$ & $\begin{array}{l}\text { Daily } \\
\text { gain per } \\
\text { head. }\end{array}$ \\
\hline & Lbs. & Lbs. & Lbs. & Lbe. \\
\hline Leicester high grades............ & 242 & & 242 & .54 \\
\hline Leicester grades............................ & 189 & ............... & 189 & .40 \\
\hline 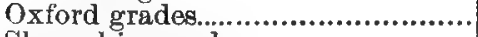 & 186 & 147 & 167 & .37 \\
\hline Shropshire grades .......................... & 185 & 148 & 167 & .37 \\
\hline Southdown grades........................ & 165 & 133 & 149 & .33 \\
\hline Merino grades....................... & 138 & (........... & 138 & .31 \\
\hline Mean ....................................... & 184 & ................. & 175 & .39 \\
\hline
\end{tabular}

' Bul. 113, Mich. Sta.

"Bul. 47, Cornell Bta.
2 Bul. 128, Mich. Sta.

1 Rept. 1882. 
The weight of fat sheep of the several breeds competing for prizes at the American Fat-Stock Show, Chicago, during the years 1878 to 1884 , both inclusive, ${ }^{1}$ are shown in the following table:

Weight of fat sheep of various breeds - American Fat-Stock Bhono, Chicago.

\begin{tabular}{|c|c|c|c|c|c|c|}
\hline Breed. & $\begin{array}{l}\text { Wether } \\
2 \text { yrs. } \\
\text { old or } \\
\text { over. }\end{array}$ & $\begin{array}{l}\text { Wether } \\
1 \text { yr. } \\
\text { and un- } \\
\text { der } 2 \\
\text { Jrs. }\end{array}$ & $\begin{array}{l}\text { Wether } \\
\text { under } 1 \\
\text { yr. old. }\end{array}$ & $\begin{array}{l}\text { Ewe 2 } \\
\text { yrs. or } \\
\text { over. }\end{array}$ & $\mid \begin{array}{c}\text { Ewe 1 } \\
\text { yr. } \\
\text { and } \\
\text { under } \\
2 \text { yrs. }\end{array}$ & $\begin{array}{c}\text { Ewe } \\
\text { under } \\
1 \text { yr. } \\
\text { old. }\end{array}$ \\
\hline & Lbs. & Lbs. & Lbs. & Lbs. & Lbs. & Lbes. \\
\hline Cotewold............................. & 258 & 199 & 142 & 273 & 235 & 127 \\
\hline $\begin{array}{l}\text { Other long } \\
\text { Southdown. }\end{array}$ & 263 & 239 & 151 & 238 & 204 & 112 \\
\hline 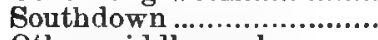 & 205 & 172 & 119 & 169 & 130 & 97 \\
\hline Other middle wools ............ & 223 & 181 & 117 & 211 & 208 & 87 \\
\hline American $n$ & 137 & 112 & 79 & 101 & 73 & 52 \\
\hline Grades or crosses. & 221 & 188 & 118 & 213 & 165 & 122 \\
\hline
\end{tabular}

753. Daily gain for various breeds. - The best daily gains ${ }^{2}$ with fal wethers at the American Fat-Stock Show, Chicago, between the years 1879 and 1882, both inclusive, are as follows:

Weight and daily gain of wether making the most rapid gain - American Fat-Stock Show, Chicago.

Wethers two and under three years.

\begin{tabular}{|c|c|c|c|c|}
\hline Year. & Breed. & $\begin{array}{l}\text { Age in } \\
\text { days. }\end{array}$ & Weight. & $\begin{array}{l}\text { Av. gain per } \\
\text { day since } \\
\text { birth. }\end{array}$ \\
\hline & & & Lbs. & Lbs, \\
\hline $\begin{array}{l}1879 \ldots \\
1881 \ldots\end{array}$ & 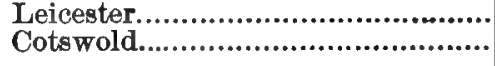 & $\begin{array}{l}969 \\
933\end{array}$ & $\begin{array}{l}300 \\
281\end{array}$ & $\begin{array}{l}.31 \\
.30\end{array}$ \\
\hline
\end{tabular}

Wethers one and under two years.

\begin{tabular}{|c|c|c|c|c|}
\hline 878. & 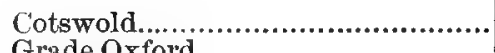 & 535 & $\frac{220}{200}$ & .41 \\
\hline $\begin{array}{l}1830 \ldots \\
1882 \ldots\end{array}$ & 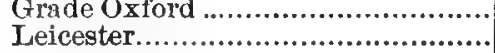 & $\begin{array}{l}612 \\
600\end{array}$ & $\begin{array}{l}232 \\
295\end{array}$ & $\begin{array}{l}.38 \\
.49\end{array}$ \\
\hline
\end{tabular}

Wethers under one year.

\begin{tabular}{|c|c|c|c|c|}
\hline 1878. & 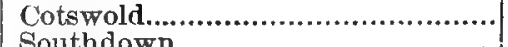 & 170 & 152 & .89 \\
\hline 1882. & Southdown & 235 & $\begin{array}{l}193 \\
178\end{array}$ & .75 \\
\hline
\end{tabular}

- Trans. Dept. Agr. Ill., 1884, p. $228 . \quad 2$ Loc. cit. 
754. Weight of carcass. - Lawes and Gilbert ${ }^{1}$ found in trials with sheep of the various breeds the following weights of dressed carcass with well-fattened animals:

Marketable produce for each 100 pounds unfasted weight of sheep, cluding wool - Rothamsted Station.

\begin{tabular}{|c|c|c|c|c|}
\hline \multirow[t]{2}{*}{ Breed. } & \multicolumn{2}{|c|}{$\begin{array}{c}\text { Mutton } \\
\text { (less tallow). }\end{array}$} & \multicolumn{2}{|c|}{ Wool. } \\
\hline & Lbs. & Ozs. & Lbs. & Ozs. \\
\hline $\begin{array}{l}\text { Sussex } \\
\text { Hampshires }\end{array}$ & 53 & 3 & 4 & 0 \\
\hline 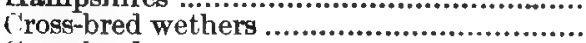 & 51 & $\underset{2}{\mathbf{6}}$ & 4 & 10 \\
\hline 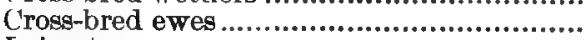 & 50 & 10 & 5 & 8 \\
\hline 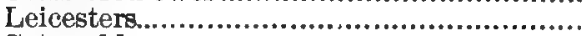 & 50 & 11 & 5 & \\
\hline Cotswolds & 53 & 6 & 5 & 4 \\
\hline
\end{tabular}

Relative to live and dead weights, the conclusions of these investigators are:

"Hoggets or tegs (ewes or wethers under twelve months old) in a leau or store condition will contain about one-half of their weight carcass, and about one-half offal.

"Shorn sheep, sufficiently fat for the market, will contain about 56 pounds of carcass in every 100 pounds of the unfasted live weight.

"Sheep in an ordinary state of fatness yield from 7 pounds to 14 pounds of offal or loose fat per head, according to breed and size; the long-wools giving the least, and the Downs the most."

755. Fat-Stock Show test.- At the American Fat-Stock Show in $1884,{ }^{2}$ animals competing for prizes were slaughtered, with the results shown in the following table:

Slaughter tests with sheep at the American Fat-Stock Shoro, Chicago.

\begin{tabular}{c|c|c|c|c}
\hline Age of animals. & Number. & $\begin{array}{c}\text { Live weight } \\
\text { at slaughter. }\end{array}$ & $\begin{array}{c}\text { Weight of } \\
\text { dressed car- } \\
\text { cass. }\end{array}$ & Per cent. \\
\hline & & Lbs. & Lbs. & \\
Two years or over..... & 2 & 248 & 166 & 62 \\
One year, under two... & 4 & 171 & 105 & 61 \\
Under one year .......... & 2 & 99 & 67 & 57 \\
\hline
\end{tabular}

${ }^{1}$ Jour. lioy. Agr. Soc., 1555, p. b4; Rothausled Memoins, 1852, Vol. II

- Breeder's Gazette, 1884, p. 824. 
756. Shrinkage in shipping. - Cooke, of the Colorado Station, ${ }^{1}$ after fattening selected Western sheep and lambs on alfalfa hay, wheat, corn and roots, shipped them from Fort Collins, Colorado, to Chicago, with results shown in the table:

Shrinkage and dressed weight of Western sheep, shipped from Colorado to Ohicago - Colorado Station.

\begin{tabular}{c|c|c|c|c|c}
\hline Kind. & $\begin{array}{c}\text { Weight at } \\
\text { Fort } \\
\text { Collins. }\end{array}$ & $\begin{array}{c}\text { Weight at } \\
\text { Chicago } \\
\text { stock } \\
\text { yard. }\end{array}$ & $\begin{array}{c}\text { Per cent. } \\
\text { shrinkage }\end{array}$ & $\begin{array}{c}\text { Per cent. } \\
\text { dressed } \\
\text { carcass to } \\
\text { Chicago } \\
\text { weight. }\end{array}$ & $\begin{array}{c}\text { Per cent. } \\
\text { tallow to } \\
\text { Chicago } \\
\text { weight. }\end{array}$ \\
\hline & Lbs. & Lbs. & & & \\
Western lambs ...... & 149.0 & 135 & 9.4 & 57.0 & 9.0 \\
Western wetherg... & 168.0 & 153 & 9.0 & 55.0 & 8.3 \\
Mexican sheep...... & 99.5 & 92 & 6.5 & 53.5 & 8.5 \\
\hline \hline
\end{tabular}

By the above we learn that selected Western lambs weighing 149 pounds at Fort Collins, Colorado, shrunk 14 pounds, or 9.4 per cent, on shipment to Chicago. These lambs dressed 57 per cent. of their Chicago weight, 9 per cent. of which was tallow; that is, for each 100 pounds live weight there were 9 pounds of tallow and 48 pounds of carcass ready for the butcher's block.

'Bul. 32. 


\section{CHAPTER XXX.}

EXPERTMENTS IN FATTENING SHEEP - WOOL PRODUOTION.

\section{Feeds and Fattening.}

757. Indian corn.-Since a large proportion of the sheep in this country are fattened on corn, both student and stockman are interested in learning the quantity of this grain required for a given gain. In the table below are preseuted the results of five trials with corn for fattening lambs at three Stations. The average of these trials should constitute reliable data as to the quantity of corn and hay required to produce one hundred pounds of gain with lambs.

Fattening lambs on corn and hay - Michigan, Wisconsin and Minnesota Stations.

\begin{tabular}{|c|c|c|c|c|c|c|c|c|}
\hline \multirow{2}{*}{ Where fed. } & \multirow{2}{*}{$\begin{array}{l}\text { Days } \\
\text { fed. }\end{array}$} & \multicolumn{2}{|c|}{ Feed eaten. } & \multirow{2}{*}{$\begin{array}{l}\text { Av. } \\
\text { wt. at } \\
\text { begin- } \\
\text { ning. }\end{array}$} & \multirow{2}{*}{ Gain. } & \multirow{2}{*}{$\begin{array}{l}\text { Av. } \\
\text { daily } \\
\text { gain. }\end{array}$} & \multicolumn{2}{|c|}{$\begin{array}{l}\text { Feed for } 100 \\
\text { lbs gain. }\end{array}$} \\
\hline & & Corn. & Нау. & & & & Corn. & Hay. \\
\hline & & Lbs. & Lbs. & Lbs. & Lbs. & Lbs. & Lbs. & Lbs. \\
\hline Michigan *.... & 105 & 1,579 & 1,097 & 82 & 328 & .31 & 481 & 334 \\
\hline Michigan *............... & 105 & 1,506 & 961 & 82 & 248 & .24 & 607 & 387 \\
\hline Aichigan $† . . . . . . . . . . . .$. & 91 & 1,208 & 1,142 & 85 & 233 & .26 & 518 & 490 \\
\hline $\begin{array}{l}\text { Wisconsil } \\
\text { dinnesote }\end{array}$ & 56 & $\begin{array}{r}428 \\
\end{array}$ & 288 & 86 & 104 & .37 & 411 & 277 \\
\hline & & 1,103 & & & & & 523 & \\
\hline Av. of 5 trials.. & 88 & $\mathbf{1}, 165$ & 867 & 81 & 225 & .29 & 508 & 378 \\
\hline
\end{tabular}

* Bul. 113. † Bul. 128. † Rept. 1895. \& Bul. 31.

In the Wisconsin trial there were 5 lambs; in the other trials there were 10 lambs.

From this table we learn that lambs averaging 81 pounds each during feeding trials averaging 13 weeks in length made gains of three-tenths of a pound per head daily, requiring about 500 pounds of corn and 400 pounds of hay for 100 pounds of increase, live weight. (566, 845) 
758. Dry versus soaked com for sheep.-Mueller'1 fed sheep on dry and soaked corn. Twenty sheep nearly two years old were fed 1.4 pounds of whole corn per day per head, ten animals receiving the grain dry and ten receiving it soaked with as much water as it would absorb. At the end of a period of ten weeks the live weight of the sheep fed dry corn had increased 6.6 pounds more per head than the lot receiving soaked corn; after four weeks more, the live weight of the former lot had increased 12.1 pounds per head more than the second lot. The author explains the poorer utilization of the soaked corn by the decreased secretion of saliva when grain so treated was fed. (375)

759. Wheat.-The low price ruling for wheat in recent years has stimulated much interest in its use for fattening sheep. A trial at the Michigan Station' ${ }^{2}$ by Mumford, in which wheat was fed, in opposition to corn, to lots of ten lambs each, is summarized in the following table:

Feeding lambs wheat in opposition to corn-Michigan Station.

\begin{tabular}{|c|c|c|c|c|c|c|c|c|}
\hline \multirow{2}{*}{ Grain. } & \multirow{2}{*}{$\begin{array}{l}\text { Days } \\
\text { fed. }\end{array}$} & \multicolumn{2}{|c|}{ Feed eaten. } & \multirow{2}{*}{$\begin{array}{c}\text { Ar. wt. at } \\
\text { begin- } \\
\text { ning. }\end{array}$} & \multirow{2}{*}{ Gain. } & \multirow{2}{*}{$\begin{array}{l}\text { Av. } \\
\text { daily } \\
\text { gain. }\end{array}$} & \multicolumn{2}{|c|}{$\begin{array}{c}\text { Feed for } 100 \\
\text { lbs. gain. }\end{array}$} \\
\hline & & Grain. & Hay. & & & & Grain. & Hay. \\
\hline & & Lbs. & Lbs. & Lbs. & Lbs. & Lbs. & Lbs. & Lbs. \\
\hline $\begin{array}{l}\text { Corn............ } \\
\text { Wheat ........ }\end{array}$ & $\begin{array}{l}91 \\
91\end{array}$ & $\begin{array}{l}1,208 \\
1,201\end{array}$ & $\begin{array}{l}1,142 \\
1,199\end{array}$ & $\begin{array}{l}85 \\
85\end{array}$ & $\begin{array}{l}233 \\
217\end{array}$ & $\begin{array}{l}.26 \\
.24\end{array}$ & $\begin{array}{l}518 \\
553\end{array}$ & $\begin{array}{l}490 \\
552\end{array}$ \\
\hline
\end{tabular}

By the above we learn that the lambs fed wheat required more feed for a given gain and did not make quite so large daily gains as those fed corn. (166-8, 852)

760. English experience with wheat. - Voelcker conducted three trials at the Woburn (England) Station to ascertain the feeding value of wheat as a grain for fattening sheep. ${ }^{8}$ Wheat meal was found unsatisfactory owing to the fact that the meal adhered to the jaws of the sheep when eating it, forming a sticky mass Whole wheat was substituted, and the effect was remarkable; the sheep which would barely clean up the half-pound allowance of

${ }^{1}$ Braunschw. Landw. Zeit., 1885, p. 209; Jahresb. Agr.-Chemie, 1885, p. 576 .

Bul. 128 Jour. Roy. Agr. Soc., 1886-88. 
wheat meal readily ate three-fourths of a pound of whole wheat. Accordingly, during the remainder of the first and the two following trials, whole wheat was fed. The following table summarizes the results of the last two trials:

Feeding whole wheat to sheep - Woburn (England) Station.

\begin{tabular}{|c|c|c|c|c|c|c|}
\hline & \multirow{2}{*}{$\begin{array}{c}\text { Days } \\
\text { fed. }\end{array}$} & \multirow{2}{*}{$\begin{array}{c}\text { Av. } \\
\text { wt. at } \\
\text { begin- } \\
\text { ning. }\end{array}$} & \multicolumn{3}{|c|}{ Feed given daily. } & \multirow{2}{*}{$\begin{array}{l}\text { Av. } \\
\text { gain } \\
\text { per } \\
\text { day. }\end{array}$} \\
\hline & & & $\begin{array}{l}\text { Swede } \\
\text { turnips. }\end{array}$ & $\begin{array}{l}\text { Chaffed } \\
\text { hay. }\end{array}$ & Wheat. & \\
\hline 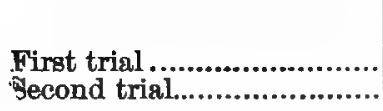 & $\begin{array}{r}95 \\
112\end{array}$ & $\begin{array}{r}\text { Lbs. } \\
156 \\
119\end{array}$ & $\begin{array}{c}\text { Lbs. } \\
28 \\
20\end{array}$ & $\begin{array}{c}\text { Lbs. } \\
\frac{1}{2} \\
\frac{1}{4}\end{array}$ & $\begin{array}{c}\text { Lbs. } \\
\text { 量 } \\
\text { 妾 }\end{array}$ & $\begin{array}{c}\text { Lbs. } \\
.3 \\
.4\end{array}$ \\
\hline
\end{tabular}

These gains are satisfactory considering the length of the trials. Voelcker concludes from three seasons' experiments with wheat, sil meal, and cotton-seed meal, that whole wheat produced the cheapest gain at current prices for stock foods in England.

761. Oats. - At the Michigan Station, ${ }^{1}$ Mumford compared oats with corn in a feeding trial lasting 119 days with ten lambs in each lot, averaging 83 pounds, with results presented in the table:

Feeding oats in opposition to corn - Michigan Station.

\begin{tabular}{|c|c|c|c|c|c|c|c|c|c|}
\hline \multirow{2}{*}{ Grain. } & \multicolumn{3}{|c|}{ Feed eaten. } & \multirow{2}{*}{$\begin{array}{l}\text { Av. } \\
\text { wt. at } \\
\text { begin- } \\
\text { ning. }\end{array}$} & \multirow{2}{*}{ Gain. } & \multirow{2}{*}{$\begin{array}{l}\text { Av. } \\
\text { daily } \\
\text { gain. }\end{array}$} & \multicolumn{3}{|c|}{$\begin{array}{l}\text { Feed for } 100 \text { lbs. } \\
\text { gain. }\end{array}$} \\
\hline & Grain & Hay. & Roots & & & & Grain & Hay. & Roots \\
\hline & Lbs. & Lbs. & Lbs. & Lbs. & Lbs. & Lbs. & Lbs. & Lbs. & Lbs. \\
\hline Oats.... & 1,963 & 1,694 & 1,190 & 83 & 379 & .31 & 518 & 447 & 314 \\
\hline Corn..... & 1,757 & 1,675 & 1,190 & 83 & 443 & .37 & 396 & 378 & 268 \\
\hline
\end{tabular}

In this trial the oats did not give as large daily gains as did the corn; further, it required 122 pounds or 31 per cent. more oats than corn for a given gain. Since 500 pounds of corn is shown to be the usual grain requirement for 100 pounds of gain with lambs, it is probable that further trials will show oats not far below corn in value, though they can hardly equal it.

762. Bran.- At the Michigan Station, ${ }^{2}$ Mumford fed corn in opposition to bran during a period of 119 days, to two lots of ten

\footnotetext{
1 Bul. 107. 2 Bul. 107.
} 
lambs averaging 83 pounds in weight, with the results given in the table:

Feeding trial with bran and corn in opposition - Michigan Station.

\begin{tabular}{|c|c|c|c|c|c|c|c|c|c|}
\hline \multirow{2}{*}{ Grain. } & \multicolumn{3}{|c|}{ Feed eaten. } & \multirow{2}{*}{\begin{tabular}{|c} 
Av. \\
wt. at \\
begin- \\
ing.
\end{tabular}} & \multirow{2}{*}{ Gain. } & \multirow{2}{*}{$\begin{array}{l}\text { Av. } \\
\text { daili } \\
\text { gain. }\end{array}$} & \multicolumn{3}{|c|}{$\begin{array}{l}\text { Feed for } 100 \text { lbs. } \\
\text { gain. }\end{array}$} \\
\hline & Grain & Hay. & Roots & & & & Grain & Hау. & Roots \\
\hline & Lbs. & Lbs. & Lbs. & Lbs. & Lbs. & Lbs. & Lbs. & Lbs. & Lbs. \\
\hline Corn. & 1,757 & 1,675 & 1,190 & 83 & 443 & .37 & 396 & 378 & 289 \\
\hline 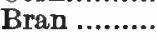 & 1,779 & 1,728 & 1,190 & 82 & 242 & .20 & 735 & 714 & 492 \\
\hline
\end{tabular}

We learn from this trial that it required nearly twice as much bran as corn for the same gain. (175)

763. Wheat screenings. - At the Minnesota Station, ${ }^{1}$ Shaw fed lambs wheat screenings in opposition to wheat. Concerning the former he wrote: "The screenings were under rather than over the average in quality, having but little wheat of any kind in them."

One-tenth of the ration consisted of oil meal. There were eight lambs in each lot, the trial lasting $\mathbf{1 1 7}$ days, with results given below:

Feeding wheat screenings in opposition to wheat - Minnesota Station.

\begin{tabular}{|c|c|c|c|c|c|c|c|}
\hline \multirow{2}{*}{ Grain. } & \multicolumn{2}{|c|}{ Feed eaten. } & \multirow{2}{*}{$\begin{array}{l}\text { Wt. } \\
\text { at } \\
\text { begin- } \\
\text { ning. }\end{array}$} & \multirow{2}{*}{ Gain. } & \multirow{2}{*}{$\begin{array}{l}\text { Daily } \\
\text { gain. }\end{array}$} & \multicolumn{2}{|c|}{$\begin{array}{l}\text { Feed for } 100 \\
\text { lbs gain. }\end{array}$} \\
\hline & Grain & Hay. & & & & Grain & Hay. \\
\hline & Lbs. & Lbs. & Lbs. & Lbs. & Lus. & Lbs. & $\mathbf{L b s}$ \\
\hline 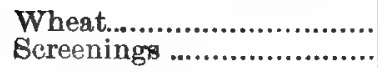 & $\begin{array}{l}1,753 \\
2,225\end{array}$ & $\begin{array}{l}772 \\
753\end{array}$ & $\begin{array}{l}80 \\
78\end{array}$ & $\begin{array}{l}278 \\
300\end{array}$ & $\begin{array}{l}.30 \\
.32\end{array}$ & $\begin{array}{l}631 \\
742\end{array}$ & $\begin{array}{l}277 \\
251\end{array}$ \\
\hline
\end{tabular}

By the above we learn that it required about 18 per cent. more wheat screenings than wheat to produce a given gain. The high feeding value of screenings for sheep in comparison with their cost in the Northwest is illustrated in this trial. (169)

764. Shrunken wheat, wild buckwheat and pigeon-grass seed.At the Minnesota Station, ${ }^{2}$ Hayes fed four lots of ten lambs each for 84 days on rations of cracked corn, small wheat, wild buck-

- Bul. 44. $\quad$ Rept. 1893. 
wheat and pigeon-grass seed, respectively, with the results presented in the table below:

Feeding cracked corn, small wheat, wild buckwheat and pigeon-grass seed-Minnesota Station.

\begin{tabular}{|c|c|c|c|c|c|c|c|}
\hline \multirow{2}{*}{ Grain. } & \multicolumn{2}{|c|}{ Feed eaten. } & \multirow{2}{*}{$\begin{array}{l}\text { Av. } \\
\text { wt. at } \\
\text { begin- } \\
\text { ning. }\end{array}$} & \multirow{2}{*}{ Gain. } & \multirow{2}{*}{$\begin{array}{l}\text { Daily } \\
\text { gain. }\end{array}$} & \multicolumn{2}{|c|}{$\begin{array}{l}\text { Feed for } 100 \\
\text { lbs. gain. }\end{array}$} \\
\hline & Grain & Hay. & & & & Grain & Hay. \\
\hline & Lbs. & Lbs. & Libs. & Lbs. & Lbs. & Lbs. & Lbs. \\
\hline Cracked corn.................... & 1,103 & 849 & 71 & 211 & .25 & 523 & 402 \\
\hline Small wheat.......... & 1,505 & 742 & 74 & 202 & .24 & 745 & 367 \\
\hline Pigeon-grass seed............. & 1,975 & 427 & 74 & 226 & .27 & 874 & 189 \\
\hline Wild buck wheat............... & 1,034 & 591 & 75 & 237 & .28 & 816 & 249 \\
\hline
\end{tabular}

The table shows that corn gave normal results, 523 pounds of that grain and 402 pounds of hay making 100 pounds of gain. Of the other mill and elevator by-products there were required for 100 pounds gain with lambs the following amounts: small wheat, 745 pounds; wild bnckwheat, 816; pigeon-grass seed, 874 pounds.

765. Corn silage versus roots.- At the Michigan Station, ${ }^{1}$ Mumford compared corn silage with roots for fattening lambs, with eight in each lot in the first trial and twenty in each lot in the second. In the first trial, lasting 84 days, sugar beets and corn silage were used, and in the second, lasting 119 days, rutabaga turnips and corn silage were fed. In the first trial the lambs weighed 87 pounds, and in the second 73 pounds each, at the beginning. The grain fed consisted of two parts oats and one part bran in the first trial, and equal parts of oats and bran in the second. The table shows the results:

Feeding corn silage in opposition to roots - Michigan Station.

\begin{tabular}{|c|c|c|c|c|c|c|c|c|c|c|}
\hline \multirow{2}{*}{ Trial. } & \multicolumn{4}{|c|}{ Feed eaten. } & \multirow{2}{*}{ Gain. } & \multirow{2}{*}{$\begin{array}{l}\text { Av. } \\
\text { daily } \\
\text { gain. }\end{array}$} & \multicolumn{4}{|c|}{ Feed for 100 lbs. gain. } \\
\hline & Grain & Hay. & Roots & Silage & & & Grain & Hay. & Roots & Silago \\
\hline \multirow{4}{*}{$\begin{array}{l}\text { First ... } \\
\text { Second }\end{array}$} & Lbs. & Lbs. & Lbs. & Lbs. & \multirow{4}{*}{$\begin{array}{r}\text { Lbs. } \\
288 \\
238 \\
589 \\
586\end{array}$} & Lbs. & \multirow{4}{*}{$\begin{array}{r}\text { Lbs. } \\
233 \\
282 \\
398 \\
400\end{array}$} & \multirow{4}{*}{$\begin{array}{r}\text { Lbs. } \\
233 \\
225 \\
413 \\
337\end{array}$} & \multirow{4}{*}{$\begin{array}{c}\text { Lbs. } \\
1,101 \\
\ldots \ldots \ldots \\
2,277 \\
\ldots \ldots \ldots\end{array}$} & Lbs. \\
\hline & 672 & 672 & 3,172 & & & .43 & & & & \\
\hline & $\begin{array}{r}672 \\
2,345\end{array}$ & $\begin{array}{r}536 \\
2,439\end{array}$ & 13,413 & $\left|\begin{array}{c}3,014 \\
\ldots \ldots \ldots\end{array}\right|$ & & $\begin{array}{l}.36 \\
.24\end{array}$ & & & & $\mid \begin{array}{l}1,268 \\
\ldots \ldots \ldots\end{array}$ \\
\hline & 2,345 & 1,974 & $\ldots \ldots \ldots$ & 8,108 & & .24 & & & & 1,383 \\
\hline
\end{tabular}

${ }^{1}$ Buls, 84, 107. 
In the first trial, where sugar beets were fed in opposition to corn silage, roots gave somewhat better results, while in the second, where ruta-bagas were fed, the results were slightly in favor of the corn silage. Until further trials we may consider roots and corn silage practically equal in feeding value for fattening lambs. Feeding roots or silage cut down the amount of grain required in fattening the lambs 25 to 40 per cent. (325, 393-5)

766. Sugar beets.-At the Michigan Station, ${ }^{1}$ Mamford fed sugar beets and hay only to lots of ten lambs each for 91 days. with the following results:

\section{Feeding sugar beets and hay to fattening lambs - Michigan Station.}

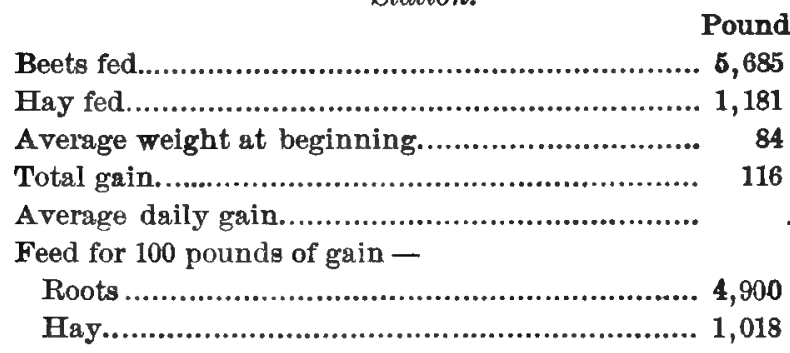

We observe that the lambs made only half the usual daily gain when a full allowance of grain was given. Placing a value on roots proportionate to cost of production, we find that the use of roots without grain for lambs cannot be recommended, since root feeding is more expensive than a combination of roots and grain. ( 39 )

767. Rape.-At the Ontario Agricultural College, ${ }^{2}$ Shaw di. vided a field of rape into three plats of an acre each, by means of hurdle fences, and placed fifteen lambs on each acre. To the lambs on the first acre no additional feed was given; those on the second received half a pound of oats each daily; those on the third were allowed an adjoining pasture, thus being provided with rape and grass at the same time. The acre of rape lasted the fifteen lambs fifty-eight days in each instance, though the

\footnotetext{
1 Bul. 128.

Rept. 1891.
} 
second acre was not eaten as bare as the others. The results are summarized below:

Feeding three acres of rape with 15 lambs to each acre - Ontaris Agrioultural College.

\begin{tabular}{|c|c|c|c|}
\hline & $\begin{array}{l}\text { Acre I. } \\
\text { Rape } \\
\text { only. }\end{array}$ & $\begin{array}{l}\text { Acre II. } \\
\text { Rape and } \\
\text { oats. }\end{array}$ & $\begin{array}{l}\text { Acre III. } \\
\text { Rape and } \\
\text { pasture. }\end{array}$ \\
\hline & \multirow{6}{*}{$\begin{array}{c}\text { Lbs. } \\
1,069 . \\
71 . \\
1,413 . \\
344 . \\
22.93 \\
.39\end{array}$} & \multirow{6}{*}{$\begin{array}{c}\text { Lbs. } \\
1,065 . \\
71 . \\
1,413 . \\
348 . \\
23.67 \\
.40\end{array}$} & \multirow{6}{*}{$\begin{array}{c}\text { Lbs. } \\
1,064 . \\
71 . \\
1,484 . \\
420 . \\
28.0 \\
.47\end{array}$} \\
\hline Weight of 15 lambs at commencement... & & & \\
\hline A verage weight of lambs......................... & & & \\
\hline $\begin{array}{l}\text { Weight of lambs at close................................... } \\
\text { Increased weight from } 1 \text { acre of rape... }\end{array}$ & & & \\
\hline Average individual increase................... & & & \\
\hline Average daily increase............................. & & & \\
\hline
\end{tabular}

In this trial the oats did not increase the returns, while the pasture proved very beneficial. In another trial ${ }^{1}$ six lambs feeding on one-sixth of an acre gained 120 pounds in 42 days, the monthly gain being 14.28 pounds per lamb. At this rate one acre of rape would pasture 25 lambs two months and yield 762 pounds of increase. We may regard this amount as representing the extreme returns possible. (334-5)

Trials with rape for lamb feeding were conducted at the Wisconsin Station ${ }^{2}$ by Craig. In these trials corn, oats, oil meal, etc., were fed to lambs running on a rape pasture, with the results summarized below:

Results of three feeding trials with lambs on rape - Wisconsin Station.

\begin{tabular}{c|c|c|c|c|c|c}
\hline \hline $\begin{array}{c}\text { No. of } \\
\text { lambs. }\end{array}$ & $\begin{array}{c}\text { Av. wt. at } \\
\text { begin- } \\
\text { ning. }\end{array}$ & $\begin{array}{c}\text { Area of } \\
\text { rape plat. }\end{array}$ & $\begin{array}{c}\text { Length of } \\
\text { feeding } \\
\text { period. }\end{array}$ & $\begin{array}{c}\text { Grain } \\
\text { eaten. }\end{array}$ & $\begin{array}{c}\text { Total } \\
\text { gain. }\end{array}$ & $\begin{array}{c}\text { Av. daily } \\
\text { gain. }\end{array}$ \\
\hline & Lbs. & Acres. & Days. & Lbs. & Lbs. & Lbs. \\
16 & 79 & 77 & 25 & 251 & 149 & .37 \\
21 & 77 & $\frac{7}{70}$ & 70 & 1,440 & 414 & .28 \\
21 & 97 & $\frac{1}{16}$ & 14 & 480 & 142 & .48 \\
\hline
\end{tabular}

The above figures are commended to stockmen looking for additional feeding stuffs for sheep. Based on the returns from the second trial, an acre of rape, with somewhat less than one and

1 Loc. cit. $\quad$ Rept. 1894. 
one-half tons of grain additional, will return 800 pounds of increase with lambs. After allowing liberally for the ralue of the grain, there are profitable returns from the rape field.

768. Rape compared with blue-grass pasture.- At the Wisconsin Station ${ }^{1}$ Craig studied the influence of rape forage and blue. grass pasture in the fattening of lambs. A bunch of 96 grade Shropshire lambs from Northern Wisconsin was divided into twe lots of 48 each, one grazing on blue-grass pasture and the other hurdled on a rape field. In addition to this feed they were supplied a grain mixture of equal parts of peas and corn by weight. The lambs were fed on pasture or rape for four weeks, after which they were placed in feeding pens and the grain ration increased. During the preliminary feeding of four weeks the 48 lambs on the rape pasture consumed .64 acres of rape, gaining 50 per cent. inore in weight than the lot on blue-grass pasture. The result of the trial are summarized in the table below:

Rape compared with blue-grass pasture in preparing lambs for fattening - Wisconsin Station.

\begin{tabular}{|c|c|c|c|c|c|c|c|}
\hline \multicolumn{3}{|c|}{$\begin{array}{l}\text { Preliminary period of four weeks on } \\
\text { pasture with light grain ration. }\end{array}$} & \multicolumn{5}{|c|}{$\begin{array}{l}\text { Fattening period of twelve } \\
\text { weeks in pens. }\end{array}$} \\
\hline \multirow{2}{*}{ Pasture. } & \multirow{2}{*}{$\begin{array}{c}\text { Av. } \\
\text { wt. at } \\
\text { begin- } \\
\text { ning. }\end{array}$} & \multirow{2}{*}{$\begin{array}{c}\text { Av. } \\
\text { gain } \\
\text { per } \\
\text { week. }\end{array}$} & \multirow{2}{*}{$\begin{array}{l}\text { Hay } \\
\text { eaten. }\end{array}$} & \multirow{2}{*}{$\begin{array}{l}\text { Grain } \\
\text { eaten. }\end{array}$} & \multirow{2}{*}{$\begin{array}{l}\text { Av. } \\
\text { gain } \\
\text { per } \\
\text { head. }\end{array}$} & \multicolumn{2}{|c|}{$\begin{array}{l}\text { Feed for } 100 \\
\text { pounds gain. }\end{array}$} \\
\hline & & & & & & Hay. & Grain \\
\hline & Lbs. & Lbs. & Lbs. & Lbs. & Lbs. & Lbs. & Lbs. \\
\hline Rape............................... & 63 & 2.6 & 2,488 & 4,084 & 20 & 261 & 429 \\
\hline 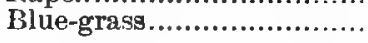 & 67 & 1.7 & 2,704 & 4,084 & 18 & 315 & 476 \\
\hline
\end{tabular}

During the four weeks preliminary feeding, the lambs on rape with some grain gained 2.6 pounds per head weekly, while those on blue-grass gained but 1.7 pounds. During the twelve weeks fattening which followed the preliminary period just described the rape-fed lambs gained 20 pounds, while those on the blue-grass pasture gained 18 pounds. The amount of grain required for 100 pounds of gain was also less with the lambs previously fed on rape. This trial tends to establish a secondary value for rape in sheep feeding.

i Rept. 18:17. 
769. Rape as a second crop. - In another trial Shaw ${ }^{1}$ sowed rape August 12 on ground which had grown a crop of winter wheat the same season. On October 17, sixty lambs were turned into this field and pastured twenty-five days without other feed, with results as follows:

Pounds.

Weight of 60 lambs at beginning of experiment........... 3,423

Weight at close .......................................................... 3,813

Increase in weight ................................................ 390

Increase in weight per acre....................................... 179

Average individual increase.................................... 6.5

Average daily individual increase............................... $\quad .26$

This is a most favorable showing for rape as a second crop. The feeder watching for opportunity to increase profits will not be slow in following this example.

770. Alfalfa hay.- At the Michigan Station, ${ }^{2} \mathrm{H}$. W. Mnmford fed one lot of ten lambs on a ration containing alfalfa hay for roughage, giving a second lot of ten, clover hay, both receiving the same allowance of shelled corn and roots. The results of tise trial, which lasted fourteen weeks, are summarized in the follow. ing table:

Alfalfa hay compared with clover hay - Michigan Siation.

\begin{tabular}{|c|c|c|c|c|c|c|c|c|}
\hline \multirow{2}{*}{ Ration. } & \multirow{2}{*}{$\begin{array}{c}\text { Av. } \\
\text { weekly } \\
\text { gain per } \\
\text { lamb. }\end{array}$} & \multicolumn{2}{|c|}{$\begin{array}{l}\text { Feed per } 100 \\
\text { lbs. gain. }\end{array}$} & \multicolumn{3}{|c|}{$\begin{array}{l}\text { Digestible nutri- } \\
\text { ents per day per } \\
1,000 \text { pounds. }\end{array}$} & \multirow{2}{*}{$\begin{array}{l}\text { Nu- } \\
\text { tri- } \\
\text { tive } \\
\text { ratio. }\end{array}$} & \multirow{2}{*}{$\begin{array}{c}\text { Dry } \\
\text { mat- } \\
\text { ter } \\
\text { per } \\
100 \\
\text { los. } \\
\text { gain. }\end{array}$} \\
\hline & & $\begin{array}{l}\text { Rough- } \\
\text { age. }\end{array}$ & Grain & $\begin{array}{l}\text { Pro- } \\
\text { tein. }\end{array}$ & $\begin{array}{l}\text { Car- } \\
\text { bohy- } \\
\text { drates }\end{array}$ & $\begin{array}{c}\text { Ether } \\
\text { ex- } \\
\text { tract. }\end{array}$ & & \\
\hline \multirow{3}{*}{$\begin{array}{l}\text { Alfa } 1 \text { f a, cor } n \\
\text { and roots....... } \\
\text { Clover hay, corn } \\
\text { and roots........ }\end{array}$} & Lbs. & Lbs. & Lbs. & Lbs. & Lbs. & Lbs. & & Lbs. \\
\hline & 2.70 & 354 & 423 & 20 & 10.0 & 87 & $1.1 . \mathrm{J}$ & 71 \\
\hline & 2.01 & th & 423 & 2.0 & 10.0 & . or & 1.0 .4 & 10 \\
\hline
\end{tabular}

It will be seen that the dry matter consumed for 100 ponnds of gain was practically equal for the two lots, but the heavier gains ware made by those getting alfalfa. Commenting on this trial. Mumford writes: "By feeding to each lamb an average of 1.3 pounds of alfalfa hay per day, with corn and roots, the lambs so

\footnotetext{
'Rept. Ont. Agr. Col., $1801 . \quad 2$ Tinl. 196.
} 
fed gained an average of 2.45 pounds per week, or 34.4 pounds during the whole period of fourteen weeks." (822)

771. Fattening Western sheep on alfalfa hay.-At the Colorado Station, ${ }^{1}$ Cooke conducted an experiment in feeding wheat, corn, sugar beets and alfalfa hay to Western and Mexican yearlings and lambs, averaging 88 pounds each, during a period of 98 days. with results shown in the following table:

Feeding Western and Mexican sheep - Colorado Station.

\begin{tabular}{|c|c|c|c|c|c|c|c|c|}
\hline \multirow{2}{*}{ Grain. } & \multicolumn{3}{|c|}{ Feed eaten. } & \multirow{2}{*}{ Gain. } & \multirow{2}{*}{$\begin{array}{l}\text { Daily } \\
\text { gain. }\end{array}$} & \multicolumn{3}{|c|}{$\begin{array}{l}\text { Feed for } 100 \\
\text { lbs. gain. }\end{array}$} \\
\hline & Grain & Hay. & Beets. & & & Grain & Hay. & Beets. \\
\hline \multirow{4}{*}{ 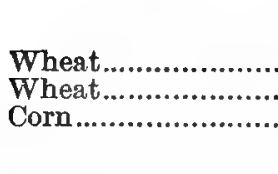 } & \multirow{4}{*}{$\begin{array}{r}\text { Lbs. } \\
980 \\
1,315 \\
1,315 \\
\ldots \ldots \ldots \ldots\end{array}$} & Lbs. & Lbs. & \multirow{4}{*}{$\begin{array}{r}\text { Lbs. } \\
661 \\
640 \\
575 \\
607\end{array}$} & \multirow{4}{*}{$\begin{array}{r}\text { Lbs. } \\
.34 \\
.33 \\
.29 \\
.31\end{array}$} & \multirow{4}{*}{$\begin{array}{r}\text { Lbs. } \\
148 \\
205 \\
229 \\
\ldots \ldots \ldots . . .\end{array}$} & \multirow{4}{*}{$\begin{array}{r}\text { Lbs. } \\
758 \\
959 \\
988 \\
779\end{array}$} & Lbs. \\
\hline & & 5,009 & 8,150 & & & & & 1,233 \\
\hline & & $\begin{array}{l}6,139 \\
5,682\end{array}$ & & & & & & \\
\hline & & 4,728 & 9,792 & & & & & 1,613 \\
\hline
\end{tabular}

In all cases the daily gains of the sheep were satisfactory. Because of its nutritive quality and palatability, alfalfa hay is more than mere "filling," assisting materially in fattening, thus reducing the amount of grain which would otherwise be required.

772. Oat straw.-At the Michigan Station, ${ }^{2}$ H. W. Mumford fed one lot of ten lambs upon oat straw for roughage, and a second lot of ten upon clover hay and cut corn stover, both getting corn and roots in addition. The results of the trial, which lasted four. teen weeks, are shown in the following table:

Oat straw compared with corn stover - Michigan Station.

\begin{tabular}{|c|c|c|c|c|c|c|c|c|}
\hline \multirow{2}{*}{ Ration. } & \multirow{2}{*}{$\begin{array}{c}\text { Av. } \\
\text { weekly } \\
\text { gain per } \\
\text { lamb. }\end{array}$} & \multicolumn{2}{|c|}{$\begin{array}{l}\text { Feed per } 100 \\
\text { lbs. gain. }\end{array}$} & \multicolumn{3}{|c|}{$\begin{array}{l}\text { Digestible nutri- } \\
\text { ents per day per } \\
1,000 \text { pounds. }\end{array}$} & \multirow{2}{*}{$\begin{array}{l}\text { Nu- } \\
\text { tri- } \\
\text { tive } \\
\text { ratio. }\end{array}$} & \multirow{2}{*}{$\begin{array}{c}\text { Dry } \\
\text { mat } \\
\text { ter } \\
\text { per } \\
100 \\
\text { lbs } \\
\text { gain. }\end{array}$} \\
\hline & & $\begin{array}{l}\text { Rough- } \\
\text { age. }\end{array}$ & Grain & $\begin{array}{l}\text { Pro- } \\
\text { tein. }\end{array}$ & $\begin{array}{l}\text { Car- } \\
\text { bohy- } \\
\text { drates }\end{array}$ & $\begin{array}{l}\text { Ether } \\
\text { ex- } \\
\text { tract. }\end{array}$ & & \\
\hline \multirow{3}{*}{$\begin{array}{l}\text { Oat straw, corn } \\
\text { and roots....... } \\
\text { Clover hay, corn } \\
\text { stover, corn } \\
\text { and roots....... }\end{array}$} & Lbs. & Lbs. & Lbs. & Lbs. & Lbs. & Lbs. & & Lbs. \\
\hline & 2.03 & 396 & 478 & 1.5 & 16.3 & .78 & $1: 12.6$ & 833 \\
\hline & 2.38 & 344 & 408 & 1.8 & 15.2 & .82 & $1: 9.7$ & 653 \\
\hline
\end{tabular}

1 Bul. 32

2 Bul. 136. 
It will be seen that though oat straw was useful it was inferior to the combination of clover hay and corn stover; 180 pounds, or 27 per cent., more dry matter being required for the same gain. Commenting on oat straw as a feed for lambs, Mumford writes: "Lambs fed on oat straw as the fodder part of the ration consumed an average of 1.25 pounds per lamb per day. The average total gain of each lamb was 28.5 pounds, or 2.03 pounds per week. The results of this experiment seem to indicate that the value of oat straw in the fodder ration of fattening lambs has been hitherto rnderrated."

773. Millet hay. - At the Michigan Station, ${ }^{1} \mathrm{H}$. W. Mumford fed two lots of lambs of ten each, giving to one millet hay for roughage and the other clover hay and oat straw, both lots receiving corn and roots additional. The trial, which lasted fourteen weeks, gave the results summarized in the table.

Millet hay compared with clover hay and oat straw - Michigan Station.

\begin{tabular}{|c|c|c|c|c|c|c|c|c|}
\hline \multirow{2}{*}{ Ration. } & \multirow{2}{*}{$\begin{array}{l}\text { Av. } \\
\text { weekly } \\
\text { gain per } \\
\text { lamb. }\end{array}$} & \multicolumn{2}{|c|}{$\begin{array}{l}\text { Feed per } 100 \\
\text { lbs. gain. }\end{array}$} & \multicolumn{3}{|c|}{$\begin{array}{l}\text { Digestible nutri- } \\
\text { ents per day per } \\
1,000 \text { pounds. }\end{array}$} & \multirow{2}{*}{$\begin{array}{c}\mathrm{Nu}- \\
\text { tri- } \\
\text { tive } \\
\text { ratio. }\end{array}$} & \multirow{2}{*}{$\begin{array}{c}\text { Dry } \\
\text { mat- } \\
\text { ter } \\
\text { per } \\
100 \\
\text { lbs. } \\
\text { gain. }\end{array}$} \\
\hline & & $\begin{array}{l}\text { Rough- } \\
\text { age. }\end{array}$ & Grain & $\begin{array}{l}\text { Pro- } \\
\text { tein. }\end{array}$ & $\begin{array}{c}\text { Car- } \\
\text { bohy- } \\
\text { drates }\end{array}$ & $\begin{array}{l}\text { Ether } \\
\text { ex- } \\
\text { tract. }\end{array}$ & & \\
\hline \multirow{3}{*}{$\begin{array}{l}\text { Millet hay, corn } \\
\text { and roots....... } \\
\text { Clover hay, oat } \\
\text { straw, corn } \\
\text { and roots....... }\end{array}$} & Lbs. & Lbs. & Lbs. & Lbs. & Lbs. & Lbs. & & Lbs. \\
\hline & 1.84 & 355 & 523 & 1.8 & 16.1 & .81 & $1: 10.4$ & 846 \\
\hline & 2.26 & 357 & 430 & 1.8 & 15.6 & .83 & $1: 9.9$ & 738 \\
\hline
\end{tabular}

The clover-hay oat-straw ration proved superior to that containing millet hay, the difference being 14 per cent. in favor of the former measured by the dry matter consumed per 100 pounds of gain. Commenting on the use of millet hay for feeding lambs, Mumford writes: "More care is necessary in feeding millet hay to fattening lambs than any other coarse fodder. Unless fed in small quantities it induces scour. Each lamb in the lot receiving millet hay was fed an average of .9 of a pound per day

1 Bul. 136. 
throughout the feeding period and gained 25.8 pounds per lamb." The gain for the other lot was 31.7 pounds per head. (272, 482)

774. Corn stover. - At the Michigan Station, ${ }^{1}$ H. W. Mumford fed corn stover to one lot of ten lambs, and clover hay and bean straw to a second lot of ten, both getting corn and roots in addition. The results of this trial, which lasted fourteen weeks, are presented in the following table:

Corn stover compared with clover hay and bean straw-Michigan Station.

\begin{tabular}{|c|c|c|c|c|}
\hline \multirow{2}{*}{ Ration. } & \multirow{2}{*}{$\begin{array}{l}\text { Average } \\
\text { weekly } \\
\text { gain per } \\
\text { lamb. }\end{array}$} & \multicolumn{2}{|c|}{$\begin{array}{l}\text { Feed per } 100 \\
\text { pounds. }\end{array}$} & \multirow{2}{*}{$\begin{array}{l}\text { Dry matter } \\
\text { per } 100 \\
\text { pounds gain }\end{array}$} \\
\hline & & Roughage & Grain. & \\
\hline \multirow{3}{*}{ 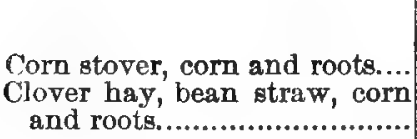 } & Lbs. & Lbs. & Lbs. & Lbs. \\
\hline & 2.15 & 383 & 451 & 676 \\
\hline & 2.30 & 373 & 421 & 735 \\
\hline
\end{tabular}

Regarding this trial Mumford says: "The principal objection to feeding corn stalks (stover) to lambs is that, when fed in the bundle from racks, the lambs waste a large percentage of the fodder. The only satisfactory method of feeding them is in racks after they have been cut in a cutting box or silage machine. The stalks fed in this experiment were cut with an ordinary silage cutter and fed from racks. The average daily ration of this fodder was 1.18 pounds for each of the ten lambs. Each lamb in the lot receiving corn stalks as the fodder ration gained an average of 2.15 pounds per week, or 30.2 pounds for the whole period. Such flattering results should make every sheep feeder value his corn stalks highly, and induce him to take every pos. sible precaution to properly preserve them."

775. Grain for lambs before weaning.-- At the Wisconsin Station, ${ }^{2}$ Craig fed grain to high-grade Shropshire lambs before weaning, corn, oats, bran and peas being used in the different trials. The grain was placed in a trough where it was accessible to the lambs through a "creep," while it could not be reached by the dams. The lambs were induced to eat grain at as early a

\footnotetext{
1 Bul. $136 . \quad$ Ropt. 1897.
} 
date as possible. On an average they were fed grain ten weeks before being weaned. The results of the trials, which were continued during three seasons with 66 lambs in all, are shown in the following table:

Feeding various grains to lambs before weaning - Wisconsin Station.

\begin{tabular}{|c|c|c|c|}
\hline Grain fed. & $\begin{array}{l}\text { Av. wt. at } \\
\text { beginning. }\end{array}$ & $\begin{array}{l}\text { Av, gain } \\
\text { per weel. }\end{array}$ & $\begin{array}{c}\text { Grain per } \\
100 \text { lbs. gain }\end{array}$ \\
\hline & Lbs. & Lbs. & Lbs. \\
\hline Corn meal...................................... & 42 & 3.8 & 63 \\
\hline Whole oats.......... & 42 & 3.8 & 86 \\
\hline 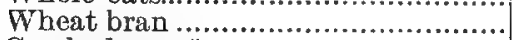 & 41 & 3.5 & 77 \\
\hline Cracked peas *.................................. & 38 & 3.7 & 73 \\
\hline
\end{tabular}

* Average of two trials.

It is shown by the table that corn meal was the most economlcal feed during these trials, less being required than of other grains and as good weekly returns secured. Corn meal will prove satisfactory for young lambs before weaning if they are designed for the butcher.

776. Corn alone and in combination.- At the Wisconsin Station $^{1}$ grain in combination was fed against corn meal alone to highgrade Shropshire lambs before and after weaning. The results of one trial with five lambs in each of three lots are shown in the following table:

Corn meal compared with grain mixtures - Wisconsin Station.

\begin{tabular}{c|c|c|c|c}
\hline Grain ration. & $\begin{array}{c}\text { Av. wt. at } \\
\text { beginning }\end{array}$ & $\begin{array}{c}\text { Av. gain in } \\
8 \text { weeks. }\end{array}$ & $\begin{array}{c}\text { Total grain } \\
\text { eaten. }\end{array}$ & $\begin{array}{c}\text { Grain eaten } \\
\text { per 100 lbs. } \\
\text { gain. }\end{array}$ \\
\hline Corn meal only............ & 58 & Lbs. & Lbs. & Lbs. \\
Corn meal and oats...... & 60 & 28 & 37 & 26 \\
Corn meal and peas..... & 57 & 28 & 43 & 31 \\
\hline
\end{tabular}

After weaning -8 weeks.

\begin{tabular}{l|l|l|l|l}
\hline Corn meal only............ & 86 & 19 & 131 & $\mathbf{1 3}$ \\
Corn meal and oats....... & 88 & $\mathbf{1 9}$ & $\mathbf{1 3 1}$ & $\mathbf{1 4}$ \\
Corn meal and peas...... & 85 & 20 & $\mathbf{1 3 3}$ & $\mathbf{1 3}$ \\
\hline
\end{tabular}

' Rept. 1897. 
It is shown that corn meal alone proved a more economical feed than in combination with oats or peas before weaning and of equal value to these combinations after weaning.

It is probable that corn meal will force the largest and most economical gain with lambs both before and after weaning, the protein they require being secured from the dam's millk and pasture grase. It is not prudent, however, to use corn alone for ewe lambs which are to be used later for breeding purposes, for this grain builds fat and not bone and muscle.

777. Feeding grain to lambs before weaning.-At the Wisconsin Station, ${ }^{1}$ Craig conducted trials with lambs receiving grain before weaning, other lots fed in comparison getting none. Among the conclusions reached are the following:

"The continuous grain feeding from birth until the lambs were about ten months old did not produce any noticeable difference in the carcasses in respect to the mixture of fat and lean.

"The lambs that were fed grain continuously from birth until about ten months old sheared a heavier fleece of either washed or unwashed wool than those that did not receive any grain previous to the third or fattening period.

"The wool from the lambs that were fed grain from birth contained more yolk or grease than that irom those that had no grain previous to the fattening period.

"The continuous grain feeding materially influenced the early maturity of the lambs. In three of the trials the lambs so fed weighed as much per head seven weeks before the conclusion of the trials as those that had no grain weighed at the end of the trials. In the remaining two trials, the grain-fed lambs equaled the average weight of those that did not receive any grain, four weeks before. The cost of securing these (equal) weights did not materially differ in most of the trials.

"When the lambs are to be sold at weaning time in July, at the age of three or four months, it is profitable to feed grain before weaning.

"When the lambs are to be sold when about seven months old in November, it will pay to feed them grain both before and after weaning.

\footnotetext{
1 Rept. 1896.
} 
"When the lambs are fed grain continuously from birth, they are fit for the market at any time, so that advantage may be taken of any favorable fluctuation that may occur in market prices."

778. Meat scrap and dried blood.- Wildt ${ }^{1}$ determined the digestibility of meat scrap and dried blood in experiments with sheep and found them able to digest the following percentages:

Meat scrap: protein 95, fat 98.

Dried blood: protein 62, fat 100 .

Regnard ${ }^{2}$ obtained excellent results when feeding dried blood to lambs in place of milk, supplying about one-half pound daily for each 100 pounds live weight. Sheep may gradually be taught to eat both the above mentioned feeds. (338-9)

779. Fish scrap.- According to Kellner, ${ }^{3}$ sheep are able to digest 90 per cent. of the protein in fish scrap and 76 per cent. of the crude fat. Fish scrap is somewhat less digestible, therefore, than meat scrap. It should only be fed sparingly, especially in the beginning, the maximum allowance being from one-half to two-thirds of a pound daily per hundred pounds of sheep. (340, 661)

780. Influence of protein on the carcass. - At the Wisconsin Station, 4 Craig found that Shropshire-Merino wether lambs, when fed on shelled corn, corn silage and corn fodder - a carbohydrate ration, - averaged, when fat, 112 pounds, and dressed 49 per cent. of their live weight. Another lot under similar conditions, fed oats, oil meal, clover silage and clover hay - a protein ration, - weighed 117 pounds, and dressed 51 per cent. of their live weight. At the Cornell Station ${ }^{5}$ Roberts fed rations varying from carbonaceous to highly nitrogenous to grade Shropshire and Southdown lambs, which dressed from 45 to 51 per cent. of their live weight, equally high returns being secured from the carbonaceous food. 6

1 Landw. Vers. Stat., 1877, p. 20.

Pott, Landw. Futtermittel, p. 656.

- Landw. Vers. Stat., 1877, p. 430.

- Rept. 1891.

- Bul. 8.

- See Reports Storrs Expt. Bta., 1894-96. 


\section{Wool Production.}

781. Influence of soil and climate.-The effects of geological formations and soils generally are quite marked on the characteristics of sheep. Brown ${ }^{1}$ shows that soil in the vegetation it produces, and climate, were prime factors in evolving the various breeds of English sheep; the rich low lands with their abundance of nutritious grasses producing the heavy-bodied, plethoric Long. wools, while the next higher grade of lands with less abundant herbage gives the Downs and Middle-wools, leaving to the mountains and more scant herbage the active, still lighter breeds.

Coleman ${ }^{2}$ states that the peculiar luster of the Lincoln wool diminishes when these sheep pass to a less congenial soil; that wool in certain districts of Yorkshire brings a higher price than that of other localities, the advantage being probably due to a favorable combination of soil and climate. He further states that limestone soils, while for many reasons peculiarly suited to sheep raising, have a tendency to produce a harshness in wool which renders it less valuable than that from sheep living on clays or gravels.

While a dry, porous soil is no doubt directly favorable to the general healthfulness of sheep, there seems a further possible beneficial result through a finer, more nutritious quality of the food plants grown on such soils. Chemical analysis may not be able to discover or measure this difference in composition or quality, yet its existence seems probable.

The ability of man to overcome the differences marked by nature is frequently surprising. Darwin ${ }^{3}$ quotes Lasterye: "The preservation of the (Spanish) Merino race in its utmost parity at the Cape of Good Hope, in the marshes of Holland, and under the rigorous climate of Sweden, furnishes an additional support of this my unalterable principle that fine-wool sheep may be kept wherever industrious men and intelligent breeders exist."

At the Wisconsin Station, ${ }^{4}$ Craig found that lambs fed grain from an early age grew faster than those getting no grain, and

1 British Sheep Farming.

2 Cattle, Sheep and Pigs of Great Britain.

- Aninals and Plants under Domestication.

- Rept. 1896. 
further, that the better-fed lambs each sheared about one ponnd more of wool. On scouring the wool from the different lots, the returns of washed wool were practically equal - the higher feed. ing had produced more yolk but not more wool.

Gohren states ${ }^{1}$ that the absolute quantity and quality of wool produced is less a function of feeding than of breeding. Compare with Chapter XXVI.

782. Frequency of shearing.- Another question of interest is the effect of removing the wool from sheep several times instead. of once each year. An experiment was conducted with Ram bouillet sheep, by Weiske and Dehmel, ${ }^{2}$ to study the influence of frequent shearing on the yield of wool. Two animals were shorn every other month for a year, and two at the beginning and at the end of the experiment. The sheep received the same feed and treatment throughout the year. The average yield of wool was as follows:

\begin{tabular}{|c|c|c|c|}
\hline Growth of wool. & $\begin{array}{l}\text { Unwashed } \\
\text { wool. }\end{array}$ & $\begin{array}{l}\text { Pure wool } \\
\text { fiber. }\end{array}$ & $\begin{array}{l}\text { Per ct. } \\
\text { yolk. }\end{array}$ \\
\hline 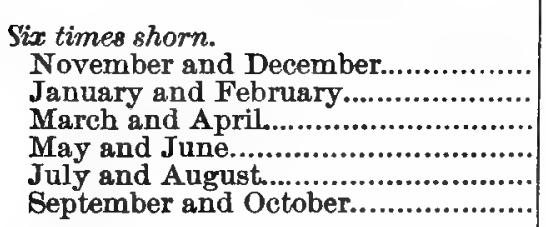 & $\begin{array}{l}\text { Lbs. } \\
1.75 \\
1.82 \\
2.40 \\
2.18 \\
2.28 \\
2.01\end{array}$ & $\begin{array}{r}\text { Lbs. } \\
.69 \\
.84 \\
1.04 \\
.91 \\
.96 \\
.82\end{array}$ & $\begin{array}{l}61.4 \\
54.1 \\
51.6 \\
58.2 \\
57.3 \\
58.5\end{array}$ \\
\hline 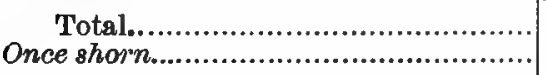 & $\begin{array}{l}12.44 \\
12.80\end{array}$ & $\begin{array}{l}5.26 \\
4.30\end{array}$ & $\begin{array}{l}57.7 \\
65.8\end{array}$ \\
\hline
\end{tabular}

The sheep shorn six times produced somewhat less unwashed wool but about 22 per cent. more pure wool fiber than those shorn once. The wool from the once-shorn sheep contained more yolk than the other.

1 Fütterungslebre, 1872 , p. 511.

2 Jour. f. Landw., 1882. 


\section{CHAPTER XXXI.}

GENERAL OARE OF SHEEP - FATTENING.

I. Shepherd and Flock.

783. Food of the sheep.- The sheep is the plant-scavenger of the farm. Through its dainty nibbling of herbage, we might suppose its likes were few and dislikes many, yet every plant at some period of its growth seems palatable. If sufficient numvers of sheep are kept on one field for any length of time, everything green is eaten, many species of plants being entirely destroyed.

While sheep, like other farm animals, exhibit strong preferences for certain food articles, necessity may cause them to subsist upon substances far removed from the usual dietary. Low ${ }^{1}$ reports that the sheep of the Shetland Islands feed upon seaweed during the winter months, knowing by instinct the first ebbing of the tide, and that they are fed dried fish when normal foods are scarce.

McDonald " writes of Iceland sheep: "The only kindness which these animals receive from their keepers in the winter is being fed on fish-bones and frozen offal, when their natural food is buried too deep even for their ingenuity and patience."

While sheep may subsist upon articles such as are mentioned above, the organs of mastication and digestion plainly indicate that plants in some form constitute their natural food. The cutting teeth in the lower jaw of the sheep fit against the cartilaginous pad above in such manner that, when feeding, the herbage is torn off rather than cut. The faeces of the sheep show the finest grinding of any of our farm animals, minute weed seeds being generally crushed and destroyed.

1 The Breeds of the Domestic Animals of the British Islands.

2 Cattle, Sheep and Deer. 
784. Mutton breeds and the Merinos compared.-The Merino sheep is peculiarly a wool-bearer, and nearly all lines descended from the Spanish stock have been selected with that single end in view. The story of the Spanish Merino in its home country forms one of the most interesting chapters extant in the history of live stock. ${ }^{1}$ In their pilgrimage from South to Central Spain each spring, and their return in the fall, the Spanish flocks make annual journeys covering in all about one thousand miles. Only the strongest and most rugged animals survive the long, fatiguing and perilous marches. The ability to exist in enormous flocks, to range over a vast territory, and to subsist upon scant food, are the leading of the many remarkable qualities wrought by stern fate into the very fiber and constitution of the Merino sheep.

Almost opposite in some respects are the English mutton breeds of sheep, which have been reared in small flocks confined to limited pastures, the best specimens being saved and nurtured by kindly hands with intelligent attention to all their wants. They have been sheltered from storms and given roughage and grain from barn and stack, whenever the fields were scant of herbage or the weather severe. In general, the life of the English mutton sheep has been one of plenty almost to surfeit and quiet contentment. In this country we cannot hope to attain the wonderful success reached by British sheep-owners unless we follow closely or improve upon their methods. The rules and practices prevalent in this country in handling Merino sheep will prove satisfactory with the matton breeds, and the feeder in the very inception of his flock experience should duly consider the habits and characteristics of the animals he is handling.

785. Size of the flock. - The sheep is distinctively a gregarious animal. The American Merino of to-day, improved as it is over its ancestors, still shows in a marked manner the result of inherit. ance by its adaptability to exist in large flocks and thrive under ordinary conditions of care and keep. With reasonable oversight, thousands of Merino sheep can be held in single bands where the range is ample; and for the period of fattening tens of thousands can be successfully fed together, as is now commonly

\footnotetext{
1 Low's Domestic Animals of the British Islands, Vol. II.
} 
done with range sheep brought to feeding points in the TransMissouri corn states.

To give the highest returns the English mutton sheep must be kept in small flocks, where each member can receive attention when needed from the shepherd. Of the mutton breeds, two hundred sheep are probably as many as can be successfully managed in one flock, and to secure the best returns from so large a number as this, one should have experience in their management. The novice would better begin with a flock of twenty-five, increasing the number as experience grows into intelligent, welldirected management.

786. Quarters for the flock. - Above every other animal on the farm, the sheep to be profitable must be kept dry as to coat and feet; inattention to either of these essentials will result disastrously. With dry quarters sheep will stand a considerable degree of cold without inconvenience; indeed, their quarters should not be as warm as for other farm animals. One thickness of closely-matched boards will make the barn or shed where sheep are confined sufficiently warm in the Northern states except for winter lambs. Ventilation is of great importance and should be ample, care being taken to avoid direct drafts.

The amount of space provided for each sheep will vary with the size of the animal. A ewe weighing 100 pounds will require about ten square feet of ground space, while one weighing 150 pounds should have fifteen square feet. A space $40 \times 40$ feet square will therefore accommodate about 160 sheep weighing 100 pounds each, or 100 weighing 160 pounds, not allowing for feed racks. Provide 15 inches running length of feed rack for each sleep weighing 100 pounds, and two feet for those weighing 200 pounds.

787. Winter care of the flock.-The flock should be so divided into groups that all members of the division are of the same age, strength and general characteristics. A flock or division of mutton sheep, to give the highest returns, should not contain over fifty members. Aged breeding ewes should constitute one band, the shearing ewes another, the ewe lambs a third, and the wether lambs a fourth. These bands should be again divided if there is 
a marked difference between their strongest and weakest members. The wise flock-master will give attentive care to the division of his flock that each member may have an equal chance with its fellows at the feed trough and in enjoying comforts and attentions from his hand.

788. Feed for breeding ewes. - There is no better roughage in winter for breeding ewes than clover hay, alfalfa hay being its counterpart at the West. Then follow corn fodder, cut in the lall while the leaves are still green, pea straw, oat straw, barley straw, etc. In addition to roughage each breeding ewe should receive half a pound of grain daily, consisting of oats, bran, peas, or a mixture of these. Oil meal is acceptable, and a tablespoonful or two may be given to each ewe daily. Corn should form a small part, at most, of the ration for breeding ewes, which should always be kept in good condition and carry more flesh than most American farmers think proper. To winter them on straw, or straw with a little hay and no grain, is to perpetuate a flock that will gradually but surely degenerate.

789. Date of lambing. - The lamb dropped in late winter or early spring is more valuable than one coming in early summer. Under good management the early-yeaned lamb comes into the world with comfortable surroundings and a kind master in attendance to give attentions conducive to comfort and growth. With the coming of spring the young thing is of sufficient size and strength to pass out with its dam and make the most of the fresh grass and genial sunshine. Where there are poor accommodations or cold quarters, lambs should not be dropped in northern latitudes earlier than the month of May, and on pasture. The ambitious flock-master will not be content with this second-rate system, but will provide suitable quarters that his ewes may lamb early.

790. Flushing the ewes. - With the mutton breeds twin lambs are very desirable, and, to secure a large percentage of these, English flock-masters practice what is called "flushing" the ewes at breeding time. The ewes are given an extra supply of nutritions, highly palatable food for two or three weeks before the desired date of breeding that they may be rapidly gaining in flesh 
at that time. Well-fed ewes have more twin lambs than those poorly nurtured.

791. At lambing time.-As lambing time approaches the shepherd should take quarters in the sheep barn or close by, and remain in attendance until the season is over. Lambs of mutton breeds are often in need of quick, intelligent attention from the shepherd as they enter the world. If the young lamb is nnable to draw milk within a few minutes after birth, it should have help to secure this first and most important feed. To this end the ewe must sometimes be held and the lamb aided, the whole being accomplished by that patient skill so characteristic of the good shepherd, but so impossible of description. With twins, one is usually weaker than the other, and frequently the mother cares for only the stronger one; here the shepherd's tact serves well in promptly helping the weaker member to its full share of food. Lambs can be successfully reared on cow's milk, though close attention is necessary in its successful use during the first month. Warm cow's milk can be fed from a teapot over the spout of which a rubber "cot" with opening in end has been placed; or a nursing bottle may be used. At first the lamb should be fed fifteen or eighteen times a day; later, half a dozen times.

The shepherd, rooming close by the lying-in quarters, should be in attendance every two or three hours in the night when the lambing season is on, to help the weak ones and see that all are prospering. With the first fill of milk from the dam the newborn lamb becomes comfortable and is usually able thereafter to take care of itself. Lambs of the mutton breeds are often weak at birth, but under good management gain rapidly in strength.

For two or three days after parturition the ewe should be supplied sparingly with dry food of the same character as that given before lambing. Succulent feed should be supplied with the demand for more milk by the young.

792. Teaching the young lamb to eat.- When about two weeks old the lusty young lamb will be found nibbling at the feed trough beside its dam, and the shepherd should provide specially for its wants in order to early accustom it to take additional food. This is accomplished by having an enclosure or room adjoining the 
ewe-pen into which the lambs find their way, while the mothers are prevented from entering because of the limited size of the openings, called the "lamb-creep." In this space place a low, flat-bottomed trough, with an obstruction lengthwise across the top to prevent the lamb from jumping into it. In this trough sprinkle a little meal especially palatable to the lamb, such as ground oats, bran, shorts, corn meal, oil meal -one or all,-varying the mixture to suit the changing tastes of the young things. They will at first take but little of this feed, but soon becone regular attendants at the trough through habit impelled by hearty appetite. The feed in the trough at any time should not be more than will be consnmed before the next supply is due. If for any reason there is an over-supply, it should be removed and the trough thoroughly cleaned before the next allowance is placed therein. Feed should be fresh and have no smell of the stable about it; that left over from time to time can be given to the pigs.

793. Turning to pasture.-With the springing of the grass, ewes and lambs should be turned to pasture for a short time during the warmer part of the day. It is generally best to accomplish the change to pasture gradually and while the grass is short. After a few hours spent in the sunshine, nibbling at the grass, the ewes and lambs should be returned to shelter, where a full feed awaits them. When the grass has become ample and nutritious, stable feeding may be dropped for ewes, or both ewes and lambs, according to the plan followed. With good pasture, breeding ewes need no grain; indeed, we may look forward to the pasture season as marking the time to "draw the grain from their systems," as it is termed by feeders.

In some instances pastures are so stimulating to the milk flow of ewes that the over-supply of rich milk thereby induced causes digestive derangement and sudden death with young lambs. The shepherd should watch closely and forestall such trouble by removing the ewes from the pasture after a few hours grazing each day, and giving hay or other dry feeds, thereby shutting off a part of the milk flow.

794. Weaning lambs. - If it is desirable to push the lambs in growth beyond the possibilities of the pasture, at a convenient 
point let there be a "lamb-creep," which is a passage-way made of slats or pickets so placed that the lambs can pass through, while the ewes are prevented because of their size. In a space accessible by way of the creep, place a trough for feeding grain. Whenever the lamb passes through the creep it should find something in this trough tempting the appetite,- oats, bran, pea meal and corn meal constituting the leading articles. Grain never gives such large returns as when fed to thrifty young animals, and the growing lamb is no exception. Lambs of the mutton breeds, more or less helpless at birth, are lusty at four months of age, and will be found grazing regularly beside their dams in pasture when not at rest or eating grain beyond the lamb-creep. At this age, for their own good as well as that of the ewes, weaning time is at hand. Let them then be so far separated from their dams that neither can hear the bleating of the other. For a few days the ewes should be held on short pasture or kept in the yard upon dry feed. Their udders should be examined, and if necessary, as is often the case with the best mothers, they should be drained of milk a few times lest inflammation arise. At weaning time the lambs should be put on the best pasture and given a liberal supply of grain in addition, in order to mitigate the effects of weaning. To this end new clover seeding is especially relished, while young second-crop clover is also satisfactory. An especially choice bite may always be provided for the lambs at this important time by a little forethought on the part of the stockman.

795. Water and salt.-Opinions with regard to the amount of water necessary for sheep vary more than with any other domestic animal. Miller of Canada, who has had large experience with English mutton sheep, writes:1 "I have noticed that wherever sheep are fed so that they will not drink water they are fed in nearly the proper manner. In this country, where we have such warm summers, it is hard to do that, but the nearer we come to it the nearer we are feeding in a perfect way." In countries with heary dews and ample succulent foed in summer, and where root crops are largely used in winter, water may possibly be denied sheep, but under most conditions it is a necessity and shonld

\footnotetext{
1 Wis. Farm Inst. Bul. 7.
} 
never be withheld. A sheep should have from one to six quarts of water daily, according to feed and weather.

Sheep require salt, and it should be supplied them at regular intervals. In winter it may be given in a trough used only for this purpose. In summer, salt may be rendered otherwise useful by seattering it on the sprouts growing about the stump and I brush patches, or over noxious weeds. In consuming salt so placed a flock will destroy many harmful plants.

796. Vermin.- Sheep are subject at all times to attacks of ticks and lice. Wherever these animals are kept there should be a dipping tank ready for use at any time. At shearing time the ticks leave the sheep and pass to the lambs. The lambs should then be dipped.

There should be frequent examinations of the flock to note its freedom from vermin, and the trouble forestalled by dipping if any trouble is apparent. No flock can thrive while its members are infected by parasites.

\section{Fattening Sheep and Lambs.}

797. Mature sheep.- It is generally conceded unwise to feed yearlings for the block, since they are shedding teeth and are therefore not in condition to give good returns for feed and care. Unless prices for wool rule high the stockman cannot afford to carry wethers past the period when they may be fed off as lambs. Culls from the flock can be prepared for the butcher at any time by the use of a little extra grain. In the vicinity of cities, profitable sales can be made of fat culls offered at times when regular feeders have failed to supply the market.

798. Fat lambs. - The demand for well-fattened lambs steadily increases, the tender, juicy meat finding favor among Americans. Not only do prices for fat lambs rule high as compared with mature sheep and farm animals generally, but there are other advantages in favor of feeding off lambs before they reach maturity. A given weight of feed goes further with lambs than with mature sheep; the money invested is sooner turned, and there is less risk from death and accident. Thus everything tends toward hurrying lambs to market as rapidly as they can be fattened and as early as they can be disposed of to secure the highest prices. 
799. Quarters for fattening.-Fattening sheep should be protected from wet coats and feet at all times. Ideal quarters in the Northern states are a dry, littered yard, with a sunny exposure, provided with a well-bedded, comfortable shed extending along the wind ward side to break the cold winds and driving storms. In such quarters the air is bracing, the sunshine invigorating, and, covered with a heavy coat and filled with rich grain, the animals are warm and comfortable, and comfort is essential to the highest gains. If confined in barns warm enough for dairy cows, sheep sweat badly in winter. Stone basements are not satisfactory places for fattening sheep; if used, ample ventilation must be provided. Damp walls are a sure indication of lack of ventilation and impending trouble.

800. Feed racks. - Grain and roughage should be fed separately. Racks for roughage in the yards should be large, so that a considerable quantity of hay may be deposited in them, thus making that part of the feeding simple. If sheep are fed in closed quarters, the hay should be supplied daily, since they dislike feed that has been "blown upon," as shepherds say. Grain troughe should have a wide, flat bottom, thus forcing the sheep to consume the grain slowly, rather than bolt it by mouthfuls. Not less than fifteen inches of linear trough space should be provided for each animal fed. There is no need of incurring heavy expense in arranging yards, sheds, racks and troughs unless the improvements are to be permanent.

801. Corn.-Corn is the best single grain for lambs, causing them to put on fat rapidly and not forcing growth, as is the case with some other concentrates. It is shown elsewhere (757) that about 500 pounds of corn and 400 pounds of clover hay may be regarded as the standard allowance for producing 100 pounds of gain with lambs where all conditions are favorable. From this data the feeder can readily calculate the cost and possible profits of fattening lambs.

802. Wheat.- Trials show that wheat is not as valuable as corn for fattening sheep, being worth about ten per cent. less. At the Colorado Station, Cooke observed that lambs fed on wheat grew in frame and muscle rather than fattened. This conclusion is reasonable judging from the composition and character of this grain. 
803. Wheat screenings. - Enormous quantities of broken and shrunken wheat are annually turned out by the elevators and mills of the Northwest. There are also large quantities of pigeongrass seed, wild buckwheat, etc., screened from grain. All these, usually in combination, are sold at low rates. Reports of feeding trials show these substances of valne in the feed lot, and their ase should be carefully considered in localities where they can be obtained without the payment of heavy freight bills. If possible, sorn should be mixed with screenings, as these no doubt, like wheat, tend to produce growth as well as to fatten.

804. Oats.- Where oats are low in price they may be used for sheep feeding and will produce excellent matton. Like wheat, jats conduce to growth in lambs rather than immediate fattening; hence it is best to mix corn with them for fattening lambs when possible.

805. Bran.- Experiments show that bran is not especially desirable for fattening sheep, a large quantity being required for a given gain. Like wheat and oats, bran conduces to growth rather than fattening; its bulky character is also against its use for this purpose, though a limited quantity may be useful. It is better in most cases to supply the sheep with concentrated food like corn, and cheaper roughage like clover hay, to furnish the bulk required in feed during fattening.

806. Grinding grain.- Of all farm animals the sheep is best able to do its own grinding, and, except in rare cases, whole grain only should be furnished. The common saying of feeders, that a sheep which cannot grind its own grain is not worth feeding, is a truthful one. Valuable breeding sheep with poor teeth may be perpetuated in usefulness by being fed ground grain. At the Colorado Station, Cooke, in feeding Western sheep on wheat, observed that much of the grain passed through the animals unbroken. This experience is certainly unusual, but shows what may occasionally happen.

807. Roughage. - The Eastern stockman should provide clover hay in abundance for his flock, both red and alsike varieties proving satisfactory. So long as there is an ample supply of good clover hay, sheep show little desire for other varieties of 
forage. The clover should be cut early in order to secure the leaves and heads, which are the parts desired.

In the irrigated regions of the West alfalfa furnishes a hay saperior even to red clover in palatability and the nutriment which it carries. Alfalfa hay of good quality not only answers for roughage, but because of its abundant nutriment serves as a partial substitute for grain, thus materially reducing the cost of feeding and fattening.

Next in value to hay from the legumes come the dry leaves of the corn plant. For sheep feeding, corn should be cut early and cured in well-made shocks. It can be fed uncut, or if more convenient may be run through the feed-cutter, though cutting will not induce sheep to eat any of the coarser parts, as is the case with cattle.

808. Dipping.- Before sheep are admitted to the fattening pens they should be carefully examined by an experienced shepherd, and if any evidence of skin disease or vermin is found the flock should be dipped in the most thorough manner. At the West, scab stands an ever-present menace to profitable fattening. In the East, lice and ticks infest the flocks of farmers and sheepraisers who are not especially careful in flock management. To attempt to fatten sheep afflicted with any of these pests is to court loss and possibly disaster. Sheep which are seemingly free from ticks will, if infested by them, show irritability and restlessness as soon as fattening begins.

809. Length of feeding period and gains. - The feeding period with sheep and lambs should last from twelve to fifteen weeks, according to the condition of the sheep in the beginning and the rapidity with which they gain. The tables in the preceding chapter show that lambs, when gaining normally, increase in weight at least a quarter of a pound per day. For a feeding period of 100 days the gains should therefore reach from 25 to 30 pounds per head. This weight, mostly fat, added to the carcass of a lamb weighing originally 80 to 100 pounds, brings it to the size desired by the market.

810. Feed consumed. - As a result of carefally conducted experiments with sheep of different breeds, Lawes and Gilbert ${ }^{1}$

\footnotetext{
1 Rothamsted Memoirs, Vol. II.
} 
write as follows concerming the consumption of food by sheep while being fattened:

"Sheep of different breeds consume quantities of food in pro. portion to their respective weights when at an equal age, stage of feeding, etc.; that is to say, three sheep weighing 100 pounds each will consume the same quantity of food as two sheep of 150 pounds each.

"Sheep on good fattening food, such as oil cake or corn, with chaff and roots, will consume weekly about 4.75 pounds of oil cake, 4.75 pounds of hay, and about 70 pounds of roots, for every 100 pounds of their live weight.

"When fed as above, they will consume every week about oneseventh of their own weight of the dry substance of food; that is, after deducting the moisture it contains."

81I. Rate of increase.-Lawes and Gilbert drew the following conclusions from the same experiments concerning the rate of increase:

"Sheep well fed and under cover will increase abont two per cent. per week upon their weight; that is to say, 100 pounds live weight will increase from 1.75 pounds to 2 pounds per week.

"To increase 100 pounds in live weight, sheep will consume about 225 pounds of oil cake or corn, 225 pounds of hay-chaff, and from 3,000 to 3,750 pounds of roots.

"The increase of a fattening sheep is at the rate of about one pound live weight to eight or nine pounds of the dry substance of the food consumed."

812. Cost of gain.-The numerous trials reported elsewhere giving the quantities of feed required for 100 pounds of gain will enable the feeder to calculate very closely what it will cost to produce 100 ponnds of gain with fattening lambs. For instance, if it require 3500 pounds of corn and 400 of elover hay for 100 pounds of gain, and corn is worth 28 cents a bushel (50 cents per 100 pounds) and hay $\$ 8$ per ton (40 cents per 100 pounds), the cost will be as follows:

500 pounds of corn at 50 cents................. $\$ 2 \quad 50$

400 pounds of hay at 40 cents.................. 160

Cost of 100 pounds gain, live weight..... $\$ 10$ 
This may be considered as the minimum cost of feed for producing 100 pounds of gain with lambs at the price named for corn and clover hay. Often the feed required will for various causes exceed the amount here stated; again, sheep require more feed for a given gain than lambs. The cost with other combinations of feed may easily be worked out in the same manner from data in the tables. Comparing the cost of gains made by lambs and steers, it will be found that the former give the best returns for the feed supplied. $(\mathbf{5 6 6 , 8 8 2})$ Sheep will probably cost from twenty-five to thirty per cent. more for a given gain than lambs.

813. Hints on sheep feeding.- Sheep feeders do not begin operations at an early hour in winter, preferring not to disturb their animals until the day breaks. Usually grain is first given, followed by hay and water. The trough in which grain is fed should be kept clean at all times, and there should be ample room, that each animal may get its share of grain. Nowhere does the skill of the feeder show more plainly than in getting sheep to full grain feed without a member of the flock getting "off feed." Western sheep may not be able to take over one-tenth of a pound of grain per day at first. If so, two months or ten weeks may be required in getting the flock to full feed. English mutton sheep take to grain more readily, and in some cases no more than three or four weeks need intervene between starting and full feeding. In no case should this operation be hurried, for it means waste of feed and the permanent injury if not loss of some of the animals.

814. Regularity and quiet. - While regularity and quiet are of importance at all times in the management of stock, they are paramount in successfully handling fattening sheep. Sheep, like other animals, are creatures of habit and should always be handled by the same attendant, who should move among them quietly, giving notice of his approach by speaking to his flock, and closing doors and gates gently. Dogs and strangers should be kept from the feeding pens at all times if possible.

815. Maintenance food for breeding ewes in winter.-At the Wisconsin Station, ${ }^{1}$ Craig conducted trials to ascertain the amount of food required to maintain pregnant ewes in good condition in

${ }^{1}$ Rept. 1893. 
winter. The ewes were Shropshires and Shropshire-Merino crosses ranging from 148 to 177 pounds each in weight at the beginning of the trial. Each lot was fed separately and received one-half pound of oats or bran per head daily. In addition to this, roughage was supplied as shown in the table. The figures given below are calculated for 100 ewes averaging about 160 pounds each.

Feed required in winter to maintain 100 pregnant breeding ewes, weighing from 148 to 177 pounds each - Wisconsin Station.

\begin{tabular}{|c|c|c|c|c|c|}
\hline Roughage fed. & $\begin{array}{l}\text { Coarse } \\
\text { forage. }\end{array}$ & Sugar beets. & $\begin{array}{c}\text { Oats or } \\
\text { bran. }\end{array}$ & $\begin{array}{l}\text { Amount } \\
\text { of refuse. }\end{array}$ & $\begin{array}{l}\text { Increase } \\
\text { in live wt. } \\
\text { per head, } \\
8 \text { weeks. }\end{array}$ \\
\hline & Lbs. & Lbs. & Lbs. & Per cent. & Lbs. \\
\hline Corn fodder (cut) & 175 & 310 & 50 & 20 & 10.6 \\
\hline Oat straw............. & 110 & 310 & 50 & 22 & I. \\
\hline \multirow[t]{2}{*}{ Blue-grass hay.... } & 150 & 310 & 50 & 6.2 & 4.8 \\
\hline & & Corn silage. & & & \\
\hline Oat hay (uncut).. & 210 & 250 & 60 & 33 & 19.1 \\
\hline Oat hay (cut)...... & 150 & 240 & 50 & 35 & 4.7 \\
\hline \multirow[t]{2}{*}{ Alsike clover hay } & 200 & 280 & 50 & 16 & 19. \\
\hline & & Hay. & & & \\
\hline Corn silage......... & 220 & 150 & 50 & .6 & 1.6 \\
\hline Sugar beets......... & 330 & 150 & 50 & & 7. \\
\hline Clover silage....... & 260 & 150 & 50 & 12.9 & 7.3 \\
\hline
\end{tabular}

By the above we note that to maintain a flock of 100 breeding ewes weighing about 16,000 pounds, there are required daily 50 pounds of oats or bran, 175 pounds of corn fodder and 310 pounds of sugar beets. The stockman can easily calculate the cost of this ration. Under Western conditions the cost of maintaining a flock of 100 large ewes will be about $\$ 1$ per day, or one cent per head when kept on corn fodder, sugar beets and oats. Reviewing these findings, Craig reports that alsike clover hay was considered one of the best feeds in the list, being eaten with relish and comparatively small waste. Cut (chaffed) oat hay was found unsatisfactory, as the pieces gathered in the wool about the necks of the sheep, and it was not so well eaten. Corn silage was found desirable unless it contained much corn, which is injurious to breeding ewes. 
816. Rations for fattening lambs. - At various Stations different feeding stuffs and combinations of feeds have been used with lambs for fattening purposes. Examples are here presented to aid the feeder in forming satisfactory combinations of grain and roughage and to guide in determining the quantities required. In all cases the rations are calculated for 100 head. The weight of the lambs is given in each example.

\section{Michigan Experiment Station. ${ }^{1}$}

Corn and clover hay. Lbs. Av. wt. of lambs fed.......... 82

Daily gain........................... . .31

Shelled corn ..................... 149

Clover hay ........................ 104

Michigan Experiment Station. ${ }^{1}$

Corn, oil meal and clover hay.

Lbs.

Av. wt. of lambs fed. 83

Daily gain.

Corn. 132

Oil meal. 33

Clover hay 110

Michigan Experiment Station. ${ }^{3}$ Corn, wheat and clover hay. Lbs. Av. wt. of lambs fed.......... 85 Daily gain. .25

Shelled corn...................... 64

Wheat.............................. 64

Clover hay ...................... 129

Wisconsin Experiment Station. ${ }^{2}$

Corn, peas and corn fodder. Lbs. Av. wt. of lambs fed.......... 76

Daily gain....................... .32

Shelled corn..................... 87

Peas.

Corn fodder. 183
Wisconsin Experiment Station." Corn and corn fodder. Lbs. Av. wt. of lambs fed.......... 76

Daily gain...................... $\quad .27$

Shelled corn ..................... 154

Corn fodder...................... 188

Michigan Experiment Station. ${ }^{1}$

Corn, bran and clover hay.

Av. wt. of lambs fed.......... 80

Daily gain....................... .25

Shelled corn........................ 81

Bran .............................. 81

Clover hay ...................... 107

Wisconsin Experiment Station. ${ }^{2}$ Corn, oats and hay. Lbs. Av. wt. of lambs fed.......... 89

Daily gain...................... . 38

Shelled corn...................... 94

Oats............................. 94

Hay............................ 95

Michigan Experiment Station."

Oats, hay and roots. Lbs.

Av. wt. of lambs fed.......... 83

Daily gain........................ . 31

Oats ................................. 164

Clover hay....................... 140

Ruta-bagas..................... 100

- Bul. 128. ^ Bul. 107. 
Minnesota Experiment Station. 1

Wheat screenings and timothy hay.

Lbs.

Av. wt. of lambs fed

74

Daily gain.

Wheat screenings

Timothy hay.

72

Minnesota Experiment Station. ${ }^{1}$

Barley, oil meal and timothy hay.

Lbs.

Av. wt. of lambs fed 76

Daily gain......................... .33

Barley........................... 170

Oil meal............................ 19

Timothy hay
Texas Experiment Station. ${ }^{2}$

Cotton-seed meal and cotton-seed hulls.

Av. wt. of lambs fed........... 62

Daily gain......................... .28

Cotton-seed meal .............. 97

Cotton-seed hulls............... 97

Colorado Experiment Station."

Cracked corn and alfalfa hay.

Lbs.

Av. wt. of lambs fed. 89

Daily gain....................... .29

Alfalfa hay.

290

Corn.

67

\section{UI. Winter or "Christmas Lamb" Raising.}

817. Requirements of the market. - In our large cities there is a demand for "Christmas" or winter lambs. There are several obstacles to be met in raising lambs satisfactory for this market, the most difficult of which is breeding the ewes at the right season, and the proper nurture of the young lambs to develop carcasses which will meet the fastidious requirements of the gourmand. A leader in this high-art branch of sheep farming is Mr. J. S. Woodward, of Lockport, N. Y., who has been in the business twenty-five years. The facts given below are condensed from an essay by Mr. Woodward in the Wisconsin Farmers' Institute Bulletin No. 7.

"Christmas lambs," as they are frequently called, should present a well-developed leg of mutton with plenty of lean meat, tender and juicy, with a good thick caul to spread over the carcass when on exhibition. A dressed lamb weighing twenty-five pounds, fulfilling the requirements, is superior to one weighing twice that which is lean and bony.

818. Mating.-Mr. Woodward prefers grade Merinos not less than two years old coming three, because they are the best mothers. He mates short-legged, heary-bodied, stocky ewes

\footnotetext{
1 Bul. 31.

2 Bul. 10.

- Bul. 32.
} 
with a Dorset ram, preferring that breed because the lambs are often doubles, are hardy and fatten quickly. Some breeders prefer Haupshires for sires, because of their large, growthy lambs.

One of the greatest difficulties in breeding Christmas lambs is to have them dropped sufficiently early to be large enough for sale when the market demands them. The breed and condition of the ewe has much to do in this matter. The ram is turned with the ewes about the first of June. It has been found that keeping the ewes shut up and away from most of their food for a few days, and giving them extra food before turning in the rams, conduces to breeding. Even with favorable conditions all ewes will not breed at the desired time, and to secure 400 lambs about 500 ewes are necessary. The ewes which fail to breed are sold early, and those breeding late give lambs useful for later sales. Ewes which are successful breeders are kept as long as possible, since it is found that one lambing in November is more likely to breed at the right time the following year than one lambing in April or May.

819. Care and feed of ewes.- The barns in which the ewes are kept are such as permit maintaining an average temperature as nearly 50 deg. Fahr. as possible in winter, the mercury never going below 40 degrees. The folds or pens in this barn have 320 square feet space for each 20 owes, in addition to which is an annex $6 \times 18$ feet adjoining each pen, into which the lambs only can go for extra food. The ewes are shorn in January, the object being to keep them cooler and allow more space. Mr. Woodward claims further that shorn ewes give more milk. For roughage the ewes are fed clover hay, corn silage, mangels and some flat turnips; the concentrates consist of linseed meal, bran and a little corn meal. The object is to get the ewe fat, and Mr. Woodward does not care how fat she is, provided the end is reached with such foods as are described above. In warm quarters succulent feed may be given with safety.

820. Feeding the lambs. - The lambs get their additional food in the side pens, beginning to eat when two weeks old. At first anmixed new-process linseed meal is used. The troughs are cleaned every morning and a fresh supply of meal put in, giving 
all the lambs will eat. When a few weeks old cracked corn is added to the ration, and later barley and a few oats. Some clover hay, cut when in foll bloom and kept in a special mow, serves for roughage. Every effort is made to induce the young things to not only eat, but to eat a large quantity, and keep eating. Weak lambs are fed new milk from a teapot with a rubber cot, having a hole punctured in the end of it, placed on the spout. Ewes bereft of their lambs through sale are given a lamb from twins to raise. To force the ewe to own a lamb, a movable partition is used to separate her and the lamb from the flock, and the lamb is helped to suck twenty times a day until owned by its fostermother. Water weakly tinctured with the essence of peppermint sprinkled over the nose of the ewe and over the lamb frequently helps to effect an adoption. Through this system of forcing the best lambs weigh from 40 to 47 ponnds alive at six weeks, and as much as 34 pounds dressed. These lambs are dressed in a special manner, the carcass being covered with white muslin and sewed up in burlap. To be profitable they should bring five dollars or more per head. This specialty in sheep husbandry can only be profitably carried on by experts who have gained experience through patient, well-directed effort and who have markets not too far distant that will pay the high prices such products must command.

\section{Fattening Plains Sheep.}

821. Fattening in the corn belt. - A new industry has sprung up in the West within the last decade - that of fattening "Plains" sheep in the corn-growing centers. In the winter of 1889 and $1890,{ }^{1} 625,000$ head of plains sheep were fattened in the state of Nebraska alone, the great corn crop of that year forming the basis of operations. Briefly, the system is as follows: During the summer, Plains sheep purchased in New Mexico, Colorado, or other Western ranges, are gradually moved eastward, grazing as they go. Often they are dipped en route to destroy or make sure there is no scab, the bane of the feeder under this system. By the time the corn is ripe the sheep have reached some point where it is for

1 Special Report on the Sheep Industry, U. S. Dept. of Agr., pp. 845-94. 
sale in vast quantities and at a low price. A corral or enclosure is made of pickets, and into this the sheep are driven, to remain until fattened. Sometimes there are sheds for shelter, usually not. Often 20,000 to 30,000 , divided into a few bunches, are fed at a single point. Wild hay is unloaded against the picket fence, through which the sheep feed. The only labor in handling the hay after unloading is for an attendant to keep it moved up close to the fence. From one and a half to two bushels of corn fed in troughs are required per day for 100 head of sheep. To this is usually added a few pounds of oil meal. The feeding continues about 100 days, the sheep gaining on an average about 15 pounds per head during that time. The profit comes mainly from increasing the original value of the sheep. The industry is an irregular and uncertain one. If scab breaks out, as it is liable to do, there is often a heary loss to the feeder. Again, the profit depends upon the price of corn, which varies greatly from year to year and cannot be foretold much in advance of the time for feeding. Large numbers of Montana sheep are fed in much the same manner in Minnesota on the screenings from mills and elevators. This feed is proving excellent for the purpose. Because of bits of straw and chaff in the screenings fattening sheep do not surfeit so easily on screenings as on corn, and they may even be fed without giving any hay in addition.

822. Cooke's report - Fattening on alfalfa hay and grain. - In Bulletin 32 of the Colorado Station, Cooke gathers a large amount of information concerning fattening Western sheep in Colorado on grain and alfalfa hay grown by irrigation. According to this anthor more than 117,000 sheep and lambs fed in Colorado were shipped to the Chicago market during the season of 1895 . It is estimated these sheep consumed 136,000 bushels of wheat, 95,000 bushels of corn, 840 tons of other grain, and more than 27,000 tons of alfalfa hay. The sheep and lambs used were Colorado-grown or from New Mexico or Idaho. New Mexico and Colorado sheep are usually driven to the places where fed. The location for feeding is selected because of the abundance of alfalfa hay, together with an available snpply of grain. A summary of the system from the bulletin is as follows: 
"In feeding southern (New Mexico) lambs they are put on hay alone from one to three weeks and then grain feeding begins. In feeding sheep on a large scale, the grain is fed in a separate corral. The sheep are kept in bunches of about 400 . The grain is put in feed troughs, the gates are opened, and they are allowed about ten minutes to eat the grain; then they are driven back and the next bunch brought in. By this method all of the sheep lave a chance to get some grain, and even the greediest sheep cannot get very much.

"The first grain fed is merely sprinkled in the trough to get the sheep used to it. The principal skill in feeding sheep is to increase the grain so gradually that the sheep will eat it greedily all the time. Most feeders use pails and reckon feed by tht number of bucketfuls fed per day. A bucketful of 20 pounds to 400 sheep twice a day is one-tenth of a pound per day, and this is as much of an increase as it is considered safe to make at any one time, and it is customary to increase only one-half of this.

"Lambs put in the pens in November will receive their first grain at the beginning of December, and for the first week will get less than one-tenth of a pound per day per head; that is, the feeder will use a week in getting them up from nothing to one-tenth of a pound. The rest of the month to the first of January they will not get over one-fourth pound. Some hold through the whole month of January on one-fourth pound, while some gradually increase through the month to one-half pound.

"This is all considered preparatory, and real grain feeding begins the first of February. Feeders vary in the speed with which they increase the grain; but by the first of March few will be feeding less than one pound, and the sheep are kept on full feed from then until they go on the market. If nothing but wheat is fed, it is hard to get the sheep to eat over a pound per head per day. . . . The hay fed to sheep in Colorado is all alfalfa. It is fed in racks that are about 14 feet wide. These racks are simply low fences inclosing a space of 14 feet wide and any desired length. The fences are made of three 8-inch boards running lengthwise of the racks, the bottom one resting on the ground, the others above with 8-inch spaces, making a fence 40 
inches high. The hay is pitched into the middle by the wagonload and pushed up to the sides two or three times per day as fast as the sheep need it. There should be rack enough so that most of the sheep can eat at the same time. This will require about one foot per head for lambs and 15 inches per head for older sheep. - . A large part of the feeding yards in Colorado are located on the banks of streams, or near enough to rivers so that ditches can be run through the yards and the surplus water returned to the river. . . . During the coldest winter, sheep will drink only a quart of water per head, but in warm weather 5 to 6 quarts is an ordinary amount. . . . Opinions differ as to the amount of salt required in fattening sheep. The most common practice is to keep lumps of rock salt where the sheep can lick them. . . . Southern lambs are so light of fleece that they never need shearing in the fall. But if they are to be fed until the last of May they get very fat, and their thick fleece at that time makes them suffer from the heat. . . . If sheared six weeks before shipping they will grow enough more rapidly to make up the weight of the wool, shrink less in shipping and pack quite a number more in the car, lessening the freight charges per head. . . . With Western sheep the case is quite different; they are larger, the fleece is longer and grows earlier. They have to be sheared if they are to be fed late in the spring. - . This fall shearing applies only to good, well-grown lambs. Wethers and ewes do not need shearing if they are to be marketed before April 15. If they are to be held until late in May they had better be sheared in the spring rather than in the fall." (308, 770-7I) 


\section{CHAPTER XXXII.}

\section{INVESTIGATIONS WITH SWINE.}

823. Period of gestation.-According to Coburn, ${ }^{1}$ young sows carry their pigs from 100 to 106 days; old sows from 112 to 115 days.

Spencer," writing of English pigs, says: "The variations in the time which a sow will carry her pigs are very slight, and these are pretty well regulated by the age and condition of the sow; thus, old and weakly sows and yelts (young sows) will most frequently bring forth a day or two before the expiration of the sixteen weeks. Sows in fair condition will generally farrow on the one hundred and twelfth day, while strong and vigorons sows will frequently go a few days over time."

824. Weight of pigs at farrowing time.-A number of observations have been made by the writer at the Wisconsin Station ${ }^{*}$ in relation to the weight of pigs at farrowing. The findings with seven sows are reported below:

Weights of pigs in order farroroed - Wisconsin Station.

\begin{tabular}{|c|c|c|c|c|c|c|c|c|c|c|c|}
\hline Breed. & No. 1 & No. 2 & No. & No. 4 & No. 5 & No. 6 & No. 7 & No. 8 & No. 9 & No. 10 & Total. \\
\hline $\begin{array}{l}\text { Pure-bred Berk- } \\
\text { shire. }\end{array}$ & $\begin{array}{r}\text { Ibs. } \\
2.1\end{array}$ & $\begin{array}{r}\text { Lbs. } \\
1.9\end{array}$ & $\begin{array}{r}\text { Lbs. } \\
2.2\end{array}$ & $\begin{array}{r}\text { Lbs. } \\
2.0\end{array}$ & $\begin{array}{l}\text { Lbs. } \\
* 1.5\end{array}$ & $\begin{array}{r}\text { Lbs. } \\
1.8\end{array}$ & $\begin{array}{r}\text { Lbs. } \\
1.9\end{array}$ & $\begin{array}{l}\text { Lbs. } \\
* 1.9\end{array}$ & $\begin{array}{r}\text { Lbs. } \\
2.6\end{array}$ & $\begin{array}{l}\text { Lbs. } \\
* 1.3\end{array}$ & $\begin{array}{l}\text { Lbs. } \\
19.2\end{array}$ \\
\hline Cross-bred Pol.- & & & & & & & & & & & \\
\hline $\begin{array}{l}\text { Chester White } \\
\text { Pure-bred Pol.- }\end{array}$ & 2.7 & 2.4 & 2.3 & 2.0 & 2.0 & 2.7 & 8.1 & 2.1 & 2.3 & & 22.5 \\
\hline $\begin{array}{l}\text { China... } \\
\text { Purebred Pol. }\end{array}$ & 2.1 & 2.7 & 2.5 & 2.8 & 3.0 & 8.0 & 2.6 & & & & 18.7 \\
\hline 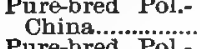 & 2.5 & 2.3 & 2.3 & 2.4 & 2.0 & 1.8 & & & & & 13.4 \\
\hline $\begin{array}{r}\text { Pure-bred Pol.- } \\
\text { China...................... }\end{array}$ & 2.0 & 1.8 & 2.2 & 2.1 & 2.1 & 2.3 & & & & & 12.6 \\
\hline $\begin{array}{l}\text { Cross-bred Pol.- } \\
\text { Chest White }\end{array}$ & 97 & 0 & 89 & 0 & 80 & O & & & & & \\
\hline Pure-bred Pol.- & 2.1 & 2.2 & 2.2 & 2.4 & 2.2 & 2.4 & & & & & 13.5 \\
\hline 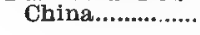 & $* 2.6$ & 2.7 & 2.7 & 2.8 & 2.4 & 2.4 & & & & ........ & 15.6 \\
\hline
\end{tabular}

* Farrowed dead.

The sows under study ranged in age from one to four years and in weight from 240 to 577 pounds before farrowing. As the pigs

1 Swine Husbandry.

2 "Pigs, Breeds and Management." ' Rept. 1897. 
were farrowed they were marked by the attendant in order to observe any differences in weight or other conditions.

It will be seen that the number of pigs in the several litters ranged from 6 to 10 and the weight of the litters from 13.5 to 22.5 pounds each. The pigs when farrowed weighed from 1.3 to 2.6 pounds each."

Frequently in a litter of pigs there is one member much weaker than the others, and this is styled the "runt" or "teatman." It is sometimes spoken of as the last pig farrowed, this occurrence seeming in some unknown way to mark its inferiority. As the table shows, the last pig farrowed was not necessarily lighter in weight than the others, and the attendant observed no weakness or other mark indicating its inferiority.

825. Milk yielded by the sow.- So far as known to the writer there is no reference in agricultural literature to the quantity of milk yielded by the sow. At the Wisconsin Station, ${ }^{1}$ Woll and the writer ascertained the milk yield of four sows whose age, weight, etc., are given in the following table:

Data concerning age, feed, etc., of sows - Wisconsin Station.

\begin{tabular}{|c|c|c|c|c|c|c|c|c|}
\hline \multirow{2}{*}{$\begin{array}{l}\text { No. } \\
\text { of } \\
\text { sow. }\end{array}$} & \multirow{2}{*}{ Age. } & \multirow{2}{*}{$\begin{array}{l}\text { Date of } \\
\text { farrow- } \\
\text { ing. }\end{array}$} & \multirow{2}{*}{$\begin{array}{l}\text { Weight } \\
\text { after } \\
\text { farrow- } \\
\text { ing. }\end{array}$} & \multirow{2}{*}{$\begin{array}{l}\text { No. } \\
\text { of } \\
\text { pigs. }\end{array}$} & \multicolumn{4}{|c|}{ Feed consumed daily by sows. } \\
\hline & & & & & Date. & $\begin{array}{c}\text { Mid- } \\
\text { dlings }\end{array}$ & $\begin{array}{l}\text { Corn } \\
\text { meal. }\end{array}$ & $\begin{array}{l}\text { Skim } \\
\text { milk. }\end{array}$ \\
\hline & Yr. & & Lubs. & & & Lbs. & Lbs. & Lbs. \\
\hline 1 & 2 & April 1 & 438 & 7 & $\begin{array}{l}\text { April 2-5 } \\
\text { April 19-21 } \\
\text { May 5-8 }\end{array}$ & $\begin{array}{l}4 \\
4 \\
4\end{array}$ & $\begin{array}{l}4 \\
4 \\
4\end{array}$ & $\begin{array}{l}8 \\
8 \\
8\end{array}$ \\
\hline 2 & 2 & April 1 & 458 & 6 & $\begin{array}{l}\text { April 10-12 } \\
\text { June 1-3 } \\
\text { June 18-20 }\end{array}$ & $\begin{array}{l}1.5 \\
3.5 \\
4\end{array}$ & $\begin{array}{l}1.5 \\
3.5 \\
4\end{array}$ & $\begin{array}{r}6 \\
14 \\
10\end{array}$ \\
\hline 3 & 1 & April 10 & 220 & 6 & $\begin{array}{l}\text { May 30-June 2 } \\
\text { June 17-19 }\end{array}$ & $\begin{array}{l}4 \\
4.5\end{array}$ & $\begin{array}{l}4 \\
4.5\end{array}$ & $\begin{array}{l}16 \\
18\end{array}$ \\
\hline 4 & 1 & May 1 & 286 & 8 & June 2-4 & 4 & 4 & 16 \\
\hline
\end{tabular}

The litter of pigs was confined in a pen separate from the sow during three-day periods. At intervals of two hours by day, and from four to five by night, the attendant would weigh the pigs

1 Rept. 1897. 
together in a basket and immediately place them with the dam. The pigs soon drained the udders of the dam, and directly this was accomplished they were gathered into the basket and once more weighed. The difference between the first and second weights of the pigs was credited as milk yielded by the dam. The sows used were pure-bred Poland-Chinas with the exception ' of No. 4, which was a cross-bred Poland-China Chester White.

826. Quantity of milk yielded.- As before stated, the yield of milk by each sow was determined for periods of three days, the first observation occurring shortly after farrowing. Subsequent determinations were at intervals of about two weeks. The weights of milk yielded by the several sows are given in the following table:

Milk yielded daily by four sonos, in pounds, avoirdupois - Wisconsin Station.

\begin{tabular}{|c|c|c|c|c|c|c|c|c|c|c|c|c|c|c|c|c|}
\hline \multirow[b]{2}{*}{ Date. } & \multicolumn{4}{|c|}{ Sow No. 1,6 pigs } & \multicolumn{4}{|c|}{ Sow No. 2, 6 pigs } & \multicolumn{4}{|c|}{ Sow No. 3,7 pigs } & \multicolumn{4}{|c|}{ Sow No.4, 8 pigs } \\
\hline & $\begin{array}{l}\dot{\vec{z}} \\
\overrightarrow{\tilde{g}} \\
\dot{\vec{\omega}}\end{array}$ & 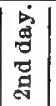 & 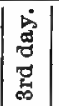 & 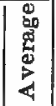 & $\begin{array}{l}\dot{\vec{g}} \\
\vec{g} \\
\overrightarrow{0} \\
\dot{\underline{D}}\end{array}$ & 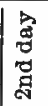 & 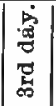 & 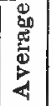 & 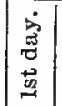 & 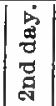 & 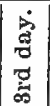 & 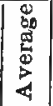 & $\begin{array}{l}\dot{\vec{g}} \\
\vec{g} \\
\dot{a}\end{array}$ & 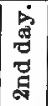 & 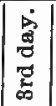 & 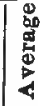 \\
\hline 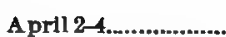 & 3.2 & 3.3 & 3.7 & 3.4 & & & & & & & & & & & & \\
\hline & & & 10 & & 3.4 & 3.7 & 1.4 & 3.8 & a..... & ...... & ....... & ...... & $\mid \cdots . . . .6$ & $\cdots \cdots$ & $\ldots . .$. & $\ldots . . .$. \\
\hline $\begin{array}{l}\text { April } 19-21 \\
\text { April } 26-28\end{array}$ & 7.7. & 8.7 & 8.4 & 8.3 & 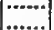 & 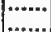 & ..... & 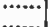 & 4.3 & 4.6 & 5 & 47 & $\cdots \cdots \cdot$ & $\cdots \cdot \cdots$ & & $\cdots$ \\
\hline $\mathrm{Apr}$ & ........ & ........ & {$[\cdots . . . .1$} & ....... & 4.6 & 4.7 & 5.3 & 4.9 & & & $\mid \begin{array}{l}0.0 . \\
\ldots . . .\end{array}$ & & $\cdots \cdots$ & $\cdots \cdots$ & $\cdots$ & $\cdots$ \\
\hline & 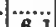 & 50 & {[} & a & [.... & $\cdots$ & $\cdots$ & $\cdots \cdots$ & ...... & $\cdots \cdots$ & $\cdots \cdots$ & $\cdots \cdots$ & 3.5 & 4.1 & 5.1 & 4.2 \\
\hline & & 0.8 & & ...... & & & & & $\mid 7.8$ & {$[7.6]$} & 7.7 & |7.7 & [....... & ...... & (....... & …..... \\
\hline & ....... & & ....... & ....... & 6.1 & 5.0 & 4.8 & $5.0 \mid$ & & & & & & & & \\
\hline & $\cdots \cdots$ & & $\ldots$. & ....... & & & & & 73 & $\because 7$ & 68 & $\cdots$ & 7.2 & 7.1 & 7.2 & 7.2 \\
\hline & a...... & $\ldots .$. & ….... & (....... & 5.3 & 5.4 & {$[-1 . i]$} & 5.3 & 60 & 10.4 & 0.0 & 1.1 & & & & \\
\hline & ....... & 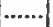 & ....... & $\ldots . . .$. & & & & & & & & & 7.2 & {$[7.5$} & 7.3 & 7.3 \\
\hline & $\cdots \cdots$ & ...... & $\cdots \cdots$ & $\ldots . .$. & $\cdots \cdots$ & $\because \cdots$ & $\because$ & 13 & 2.3 & 2.0 & 1.9 & 2.1 & $\cdots \cdots$ & & & \\
\hline & $|\cdots \cdots \cdot|$ & (....... & [....... & ….... & & ....... & ....... & $\ldots . . .$. & -....... & {$[\cdots . . . . .$.} & (....... & ….... & [3.5 & 3.2 & 3.2 & 3.3 \\
\hline Avero & & & $\ldots . .$. & 5.8 & & ....... & ....... & 4.1 & ....... & ...... & ...... & & 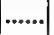 & 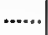 & 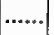 & 5.5 \\
\hline
\end{tabular}

The table shows that the average daily milk yield ranged from 4.1 pounds with sow No. 2 to 5.8 pounds with sow No. 1 . The highest yield of milk on any one day was 8.7 pounds by sow No. 1, twenty days after farrowing. (739)

827. Composition of sow's milk.-During the experiment samples of the sows' milk were obtained and subjected to chemical analysis. Great difficulty was experienced in securing the samples, the sows being quite unwilling to allow any milk to be drawn 
by the attendant. After considerable experimenting it was found that the best way to obtain a sample was to allow the pigs to partly empty the udder, when one was gently pushed aside by the attendant, who quickly drew what milk he could before the dam was aware of the operation. Even after the attendant had become familiar with the difficulties and learned the best method of proceeding, only about 30 ce., or one fluid ounce of milk, could be obtained as the result of half a dozen efforts. From the four sows nine samples of milk were secured, which were analyzed with the results given below:

Composition of sow's mill-Wisconsin Station.

\begin{tabular}{|c|c|c|c|c|c|c|c|c|c|c|c|c|}
\hline \multirow[b]{2}{*}{ 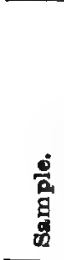 } & \multirow[b]{2}{*}{ 察 } & \multirow[b]{2}{*}{ 官 } & \multirow[b]{2}{*}{ 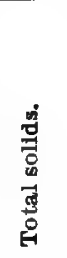 } & \multirow[b]{2}{*}{ 产 } & \multirow{2}{*}{ 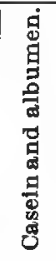 } & \multirow[b]{2}{*}{ 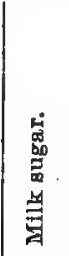 } & \multirow[b]{2}{*}{ वं } & \multirow[b]{2}{*}{ 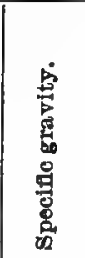 } & \multirow[b]{2}{*}{ 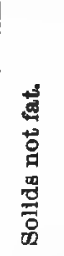 } & \multirow{2}{*}{ 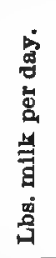 } & \multicolumn{2}{|c|}{$\begin{array}{c}\text { Microscop- } \\
\text { ic exam- } \\
\text { nation. }\end{array}$} \\
\hline & & & & & & & & & & & 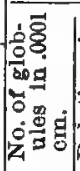 & 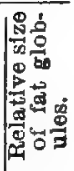 \\
\hline $\begin{array}{l}1 \\
2 \\
3 \\
4 \\
5 \\
6 \\
7 \\
8 \\
9\end{array}$ & $\begin{array}{l}\text { April 1. } \\
\text { April 12. } \\
\text { April 21. } \\
\text { May 6.... } \\
\text { June 2... } \\
\text { June 3... } \\
\text { June 4... } \\
\text { ………........ } \\
\text {................ }\end{array}$ & $\begin{array}{l}\text { No.1 } \\
\text { No.2 } \\
\text { No.1 } \\
\text { No.1 } \\
\text { No.3 } \\
\text { No.2 } \\
\text { No.4 } \\
\text { No.3 } \\
\text { No.2 }\end{array}$ & $\begin{array}{l}25.09 \\
18.40 \\
20.27 \\
17.96 \\
17.12 \\
20.46 \\
20.54 \\
18.22 \\
18.70\end{array}$ & $\begin{array}{r}16.10 \\
8.66 \\
8.32 \\
7.20 \\
3.89 \\
8.53 \\
8.02 \\
6.67 \\
7.09\end{array}$ & $\begin{array}{l}6.05 \\
5.11 \\
5.95 \\
5.33 \\
6.09 \\
6.12 \\
5.77 \\
6.67 \\
7.28\end{array}$ & $\begin{array}{l}\quad 2 \\
4 \\
5.14 \\
4.48 \\
5.82 \\
4.68 \\
5.96 \\
4.08 \\
3.07\end{array}$ & \begin{tabular}{|l|}
.94 \\
.83 \\
.96 \\
1.32 \\
1.13 \\
.79 \\
1.12 \\
1.32
\end{tabular} & $\begin{array}{l}1.0454 \\
1.0558 \\
1.0396 \\
1.0350 \\
1.0388\end{array}$ & $\begin{array}{r}8.99 \\
9.74 \\
11.95 \\
10.76 \\
13.29 \\
11.93 \\
12.52 \\
10.87 \\
11.67\end{array}$ & $\begin{array}{l}3.40 \\
3.83 \\
8.27 \\
5.80 \\
7.10 \\
5.27 \\
7.39 \\
3.07 \\
1.33\end{array}$ & 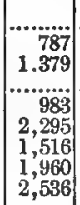 & $\begin{array}{r}110 \\
60 \\
\ldots \ldots \\
40 \\
37 \\
53 \\
32 \\
28\end{array}$ \\
\hline $\begin{array}{l}\text { Ave } \\
\text { Ave } \\
\text { Ave }\end{array}$ & $\begin{array}{l}\text { all sam } \\
\text { of } 7 \mathrm{saI} \\
\text { of } 5 \mathrm{san}\end{array}$ & les... & $\begin{array}{l}19.65 \\
119.05 \\
19.02\end{array}$ & $\begin{array}{l}8.24 \\
7.05 \\
6.78\end{array}$ & $\begin{array}{l}6.04 \\
6.20 \\
6.39\end{array}$ & $\begin{array}{c}(4.75) \\
4.75 \\
4.72\end{array}$ & $\begin{array}{l}(1.07) \\
1.07 \\
1.14\end{array}$ & $\left(\begin{array}{l}(1.0: 899) \\
(1.0389) \\
1.038 .5\end{array}\right.$ & $\begin{array}{l}11.41 \\
11.99 \\
12.24\end{array}$ & $\begin{array}{l}5.04 \\
5.45 \\
4.52\end{array}$ & $\begin{array}{c}1,635 \\
\cdots \cdots \\
\cdots \cdots \\
\cdots\end{array}$ & $\begin{array}{l}51 \\
\cdots \cdots . . \\
\cdots \cdots . . .\end{array}$ \\
\hline
\end{tabular}

828. What the table shows. - From the table we learn that the fat in the milk under examination ranged from a little less than 4 to over 16 per cent. The data for average composition show that sow's milk is richer in all components than cow's milk, this being especially true in regard to fat and sugar. On the average these sows yielded about one-third of a porud of fat each, daily. The microscopical examination showed that the fat globules in the milk of these sows were very minute, averaging only onequarter the size of those in cow's milk. On the other hand, the number of globules in a given volume of sow's milk was about eight times as many as are found in cow's milk. (616) 
Judging from the composition of sow's milk as shown by these analyses, where cow's milk is fed to very young pigs some sugar and cream should be added to make it resemble the milk they would normally receive.

829. Individual gain of young pigs. - Since the student may wish to know the individual gains of the members of the litter when quite young, the following table is given showing weight and gains of sow and pigs studied by the writer at the Wisconsin Station. ${ }^{1}$ The data cover 70 days before and 49 after weaning.

Before the pigs were weaned the sow consumed 463 pounds of corn meal and 1,207 pounds of skim milk. The pigs, fed at a separate trough, during the same time consumed 122 pounds of corn meal and 367 pounds of skim milk. During forty-nine days immediately after weaning, the pigs consumed 651 pounds of corn meal and 1,953 pounds of skim milk.

Weight of pigs at birth and individual gains before and after wean. ing - Wisconsin Station.

Before weaning.

\begin{tabular}{|c|c|c|c|c|c|c|c|c|c|c|}
\hline \multirow{2}{*}{ Dat6. } & \multirow{2}{*}{$\begin{array}{l}\text { Days } \\
\text { from } \\
\text { birth. }\end{array}$} & \multirow{2}{*}{$\begin{array}{l}\text { Wt. } \\
\text { of } \\
\text { sow. }\end{array}$} & \multicolumn{8}{|c|}{ Welght of pigs. } \\
\hline & & & No. 1 & No. 2 & No. 3 & No. & No. 6 & No. 6 & No. 7 & No. 8 \\
\hline May 24. & & $\begin{array}{r}\text { Lbs. } \\
332\end{array}$ & Lbs. & Lbs. & Lbs. & Lbs. & Lbs. & Lbs. & Lbs. & Lbs. \\
\hline May $25 . \ldots$ & 0 & & 3.6 & 3.2 & 3.3 & 3.2 & 3.4 & 3.2 & 2.8 & 1.9 \\
\hline (1) & 14 & 290 & $10 \cdot \frac{1}{7}$ & 5.1 & $\begin{array}{l}5.9 \\
9.9\end{array}$ & 6.4 & 6.3 & 5.8 & 4.8 & 3.0 \\
\hline (1) & ${ }_{21}^{14}$ & 277 & $\begin{array}{l}10.7 \\
19.0\end{array}$ & 11.5 & $\begin{array}{c}9.8 \\
13.5\end{array}$ & 13.5 & 12.5 & 12.5 & 10.8 & $\frac{5.1}{7.8}$ \\
\hline g) & 29 & 278 & 19.4 & 14.5 & 17.4 & 17.8 & 15.6 & 16.0 & 14.1 & 10.4 \\
\hline 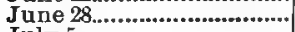 & & 280 & 24.2 & 16.4 & 22.2 & 23.1 & & 20.9 & 18.2 & \\
\hline . & 49 & 293 & 28.0 & 18.7 & 25.5 & 26.5 & $\begin{array}{l}23.5 \\
20.5\end{array}$ & 24.2 & 22.0 & 16.5 \\
\hline …...... & 56 & 278 & $\begin{array}{l}04.0 \\
40.5\end{array}$ & 22.5 & 37.0 & $\begin{array}{l}43.5 \\
43.5\end{array}$ & 38.0 & 38.0 & 35.5 & 26.5 \\
\hline$\ldots$ & 89 & 268 & 47.0 & 24.5 & 44.0 & 51. & 45.5 & 45.0 & 42.5 & 31.0 \\
\hline A & 70 & 261 & 50.5 & 25.0 & 50.0 & 60.5 & 50.0 & 51.0 & 47.0 & 37.5 \\
\hline Gain.................................. & ............. & -29 & 46.9 & 21.8 & 46.7 & 67.3 & 46.6 & $\$ 7.8$ & 44.2 & 35.6 \\
\hline
\end{tabular}

After weaning.

\begin{tabular}{|c|c|c|c|c|c|c|c|c|c|c|}
\hline $\begin{array}{l}\text { August } 2 \\
\text { August } 9 \ldots \\
\text { August } 16 \\
\text { August } 23 \\
\text { Beptember } 6 \ldots \\
\text { Beptember } 13 \\
\text { Beptember } 20\end{array}$ & $\begin{array}{l}0 \\
7 \\
14 \\
21 \\
35 \\
42 \\
49\end{array}$ & 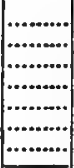 & $\begin{array}{l}50.5 \\
53.0 \\
57.0 \\
62.5 \\
69.0 \\
77.5 \\
85.5\end{array}$ & $\begin{array}{l}25.0 \\
25.0 \\
27.5 \\
33.5 \\
43.0 \\
48.0 \\
56.0\end{array}$ & $\begin{array}{r}50.0 \\
57.5 \\
63.5 \\
72.5 \\
84.0 \\
94.0 \\
104.0\end{array}$ & $\begin{array}{r}60.5 \\
68.0 \\
75.0 \\
86.5 \\
10.0 \\
105.0 \\
114.0\end{array}$ & $\begin{array}{l}50.0 \\
57.5 \\
61.0 \\
67.0 \\
80.0 \\
86.0 \\
92.0\end{array}$ & $\begin{array}{l}51.0 \\
55.0 \\
59.0 \\
69.0 \\
76.0 \\
88.0 \\
93.0\end{array}$ & $\begin{array}{l}47.5 \\
54.5 \\
61.0 \\
72.0 \\
79.0 \\
88.0 \\
98.0\end{array}$ & $\begin{array}{l}37.5 \\
44.0 \\
50.0 \\
56.0 \\
64.0 \\
74.0 \\
82.0\end{array}$ \\
\hline Gain. & $\ldots$ & |............. & 35.0 & 31.0 & 54.0 & 53.5 & 42.0 & 42.0 & 45.5 & $\mathbf{4 4 . 6}$ \\
\hline
\end{tabular}

${ }^{2}$ Rept. 1890. 
It will be seen that the sow lost 29 pounds in weight while suckling her pigs, the pigs gaining from 21.8 to 57.3 pounds each in the ten weeks between farrowing and weaning. For the seven weeks succeeding weaning, the individual gains ranged from 31 to 54 pounds.

830. Weight of pigs at birth - Early gains. - At the Wisconsin Station, ${ }^{1}$ the writer kept records of the birth-weight and also weekly gains of twelve litters, numbering 86 pigs in all, for a period of ten weeks, at the close of which they were weaned. After weaning the records were continued with eight litters, containing 62 pigs in all, for seven weeks. The dams were pure-bred or high-grade Poland-Chinas or Chester Whites. The results are shown below.

Average birth-weight and weekly gains of pigs before and after weaning - Wisconsin Station.

\begin{tabular}{|c|c|c|c|c|c|}
\hline \multicolumn{3}{|c|}{$\begin{array}{c}\text { Before weaning, ten weeks, average } \\
\text { of } 12 \text { litters, } 86 \text { pigs. }\end{array}$} & \multicolumn{3}{|c|}{$\begin{array}{l}\text { After weaning, } 7 \text { weeks, average of } \\
8 \text { litters, } 62 \text { pigs. }\end{array}$} \\
\hline Week. & Average weight. & Gain. & Week. & Average weight & Gain. \\
\hline & Lbs. & Lbs. & & Lbs. & Lbs. \\
\hline $\begin{array}{c}\text { At birth.. } \\
1 \\
2 \\
2 \\
3 \\
4 \\
5 \\
6 \\
7 \\
8 \\
9 \\
10\end{array}$ & $\begin{array}{r}2.5 \\
4.4 \\
7.0 \\
9.8 \\
12.5 \\
15.6 \\
18.6 \\
22.6 \\
27.8 \\
33.1 \\
38.5\end{array}$ & $\begin{array}{l}1.9 \\
2.6 \\
2.8 \\
2.7 \\
3.1 \\
3.0 \\
4.0 \\
5.2 \\
5.3 \\
5.4\end{array}$ & $\begin{array}{l}10 \\
11 \\
12 \\
13 \\
14 \\
15 \\
16 \\
17\end{array}$ & $\begin{array}{l}41.5 \\
46.7 \\
52.0 \\
58.3 \\
64.2 \\
69.8 \\
76.5 \\
84.1\end{array}$ & $\begin{array}{l}5.2 \\
5.3 \\
6.3 \\
5.9 \\
5.6 \\
6.7 \\
\mathbf{7 . 6}\end{array}$ \\
\hline
\end{tabular}

The heaviest pig in these litters weighed 3.6 pounds at birth and the lightest 1.6 pounds, the average for the lot being 2.5 pounds.

During the first week after birth the pigs made a gain of $\mathbf{1 . 9}$ pounds. Overlooking irregularities, we may say that the pigs made a weekly gain of three pounds per head the fifth week after birth, four pounds the seventh week and five and one-half pounds the tenth week. At the end of the seventh week after weaning,

i Repts. 1889, 1890, 1897. 
when 119 days old, they were gaining more than seven pounds each, weekly, or over a pound per day.

831. Feeding pigs through the dam.-The question whether a pound of food goes further when fed directly to young pigs or when first fed to the dam is an interesting one to the stockman. The writer has conducted trials with eight litters of pigs, noting feed and gains, for information on this subject. 1 In all cases the dams and pigs were weighed separately each week, and record kept of the food eaten by each sow and her litter before weaning, and of the pigs after weaning. The pigs were taught to eat at an early date, and encouraged to do so by placing food in a trough where it was accessible to them but not to the dam. The feed consisted of corn meal, middlings, oats, barley and skim milk. At ten weeks the pigs were weaned, the feeding continuing for seven weeks. We were thus enabled to measure the feed required for gain by the sow and pigs before weaning, and by the same pigs after weaning. In all cases the loss in weight by the sow while suckling her young is taken into account, the results reported being the net gains after deducting such loss.

Feed required for 100 pounds of gain with sow and pigs before weaning, and by the same pigs after weaning - Wisconsin Station.

\begin{tabular}{|c|c|c|c|c|}
\hline & \multicolumn{2}{|c|}{$\begin{array}{l}\text { Sows and } \\
\text { pigs before } \\
\text { weaning. }\end{array}$} & \multicolumn{2}{|c|}{ Pigs after weaning. } \\
\hline & Meal. & Milk. & Meal. & Milk. \\
\hline & Lbs. & Lbs. & Lbs. & Lbs. \\
\hline I............................................ & 241 & 563 & 251 & 587 \\
\hline Lot II... & 288 & 649 & 215 & 577 \\
\hline Lot III.... & 198 & 654 & 213 & 449 \\
\hline [........................................ & 240 & 528 & 177 & 542 \\
\hline V & 184 & 482 & 187 & 562 \\
\hline Lot VI.......................................... & 254 & 509 & 251 & 502 \\
\hline Lot VII........................................... & 235 & 474 & 259 & 518 \\
\hline Lot VIII..................................................... & 208 & 416 & 286 & 571 \\
\hline 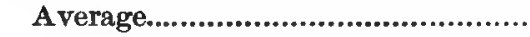 & 231 & 534 & 230 & 539 \\
\hline
\end{tabular}

It will be seen that the sow and pigs together before weaning, and the pigs alone after weaning, required almost identical quan-

= Loc. cit. 
tities of milk and meal for the production of 100 pounds net gain. At first thought it appears impossible that as good gains can be secured with young pigs from a given amount of feed administered through the sow as can be obtained by direct feeding. A possible explanation lies in the fact that the body of the very young pig contains a large proportion of water, so that less dry matter is required for a pound of gain than with older animals. Again, each pound of flesh lost by the dam during this time may have, yielded more than a pound of increase with her young.

832. Effects of feed on teeth and skull.-Schwartzkopff, of the Minnesota Station, ${ }^{1}$ treating of the influence of feed upon the formation of the skull and the dentition of pigs, writes:

"1. The order of succession of teeth in our precocions pigs runs the same as in the primitive hog.

"2. The times when the teeth appear are variable, according to race, feeding and health. The same breeds raised under the same conditions will show the same appearance.

"3. The form of the skull depends upon nutrition, health, and more or less employment of certain muscles of the head and neck. Skulls of poorly nourished pigs are more long and slender than from those well nourished. Pigs which are prevented from rooting will acquire a short, high and rounded head, while those that are forced to root to secure a portion of their food will develop a long and slender form of head."

833. Length of intestines. - Darwin ${ }^{2}$ states that the nature of the food supplied the pig by man has evidently changed the length of the intestines. He quotes Cuvier as reporting the total length of the intestines of the wild boar to be nine times the body length; in the domestic boar 13.5 to 1 ; in the Siam boar 16 to 1 . The writer ${ }^{3}$ measured the intestines of 39 fattened hogs and found that the large intestine varied from 13 to 16 feet, and the small intestine from 54 to 60 feet, in length. The arerage extreme body length of these animals was 3.5 feet. This makes the small intestine alone from 16 to 19 times the length of the body, and the large and small intestines combined about 21 times the body

1 Bul. 7; Breeder's Gazette, 1889, pp. 536-7.

2 Animals and Plants under Domestication.

- Rept. Wis. Ex. Sta., 1889. 
length. From these figures it appears that the intestines of pigs of the improved breeds are longer in proportion to the body than those given by Cuvier. This may indicate that the modern pig can digest his food more thoroughly than his ancestors, and also that he can eat a larger quantity of food in a given time.

834. Water drank.- We find little recorded on this subject, possibly because the matter is not considered of importance by zany. In a feeding trial by the writer at the Wisconsin Station, 1 a group of ten pigs divided into two lots of five each, one lot getting barley meal and the other corn meal, was fed for a period of eight weeks, with the results given below:

Feed and water consumed by pigs fattened on barley meal and corn meal - Wisconsin Station.

\begin{tabular}{c|c|c|c|c|c|c}
\hline \hline Feed given. & $\begin{array}{c}\text { Av. wt. } \\
\text { pigs at be- } \\
\text { ginning. }\end{array}$ & $\begin{array}{c}\text { Total } \\
\text { grain } \\
\text { eaten. }\end{array}$ & $\begin{array}{c}\text { rotal } \\
\text { gain. }\end{array}$ & $\begin{array}{c}\text { Total } \\
\text { water } \\
\text { consumed }\end{array}$ & $\begin{array}{c}\text { Feed } \\
\text { eaten per } \\
100 \text { lbs. } \\
\text { gain. }\end{array}$ & $\begin{array}{c}\text { Water } \\
\text { consumed } \\
\text { per 100 lbs } \\
\text { feed eaten }\end{array}$ \\
\cline { 2 - 5 } & Lbs. & Lbs. & Lbs. & Lbs. & Lbs. & Lbs. \\
Barley meal.. & 208 & 2,832 & 601 & 9,056 & 471 & 320 \\
Corn meal... & 209 & 3,100 & 713 & 6,620 & 435 & 213 \\
\hline \hline
\end{tabular}

The weight of water reported includes that required for soak ing the meal and also that drank from a second trough.

It will be seen that the pigs fed corn meal consumed about two pounds of water, and the barley-fed pigs over three pounds, for each pound of meal eaten. The pigs getting corn meal consumed over 900 pounds of water, and the barley-fed pigs about 1,500 pounds, for each 100 pounds of gain in live weight. Pigs fed corn meal appear to require less water than when on other feeds. (375)

835. Breed tests. - A number of breed tests with swine have been conducted by the Stations. In the following trial by the writer at the Wisconsin Station ${ }^{2}$ a boar and four sows of the Berkshire breed were fed in comparison with a boar and four sows of the Poland-China breed. The animals were registered, coming from several breeders of repute. The pigs ran on blue-grass pastare in summer and fall and were comfortably housed in winter.

\footnotetext{
1 Rept. $1890 . \quad$ Rept. 1894.
} 
Feed was supplied to each animal separately, and a record kept of everything consumed except the pasture grass. The weight and gain of the pigs during the trial of 224 days are given in the table:

Weight and gain of pure-bred Berkshire and Poland-China pigsWisconsin Station.

\begin{tabular}{|c|c|c|c|c|c|}
\hline & \multirow{2}{*}{ Boar. } & \multicolumn{4}{|c|}{ Bow number - } \\
\hline & & 1 & 2 & 3 & 4 \\
\hline Poland-Chinas. & Lbs. & Lubs. & Lbs. & Lbs. & Lbs. \\
\hline 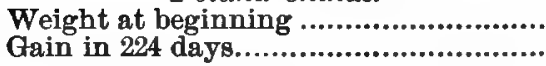 & $\begin{array}{r}70 \\
223\end{array}$ & $\begin{array}{l}103 \\
232\end{array}$ & $\begin{array}{l}121 \\
245\end{array}$ & $\begin{array}{l}105 \\
237\end{array}$ & $\begin{array}{l}102 \\
231\end{array}$ \\
\hline 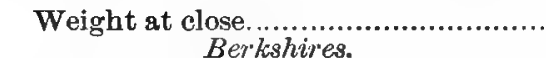 & 293 & 335 & 366 & 342 & 333 \\
\hline 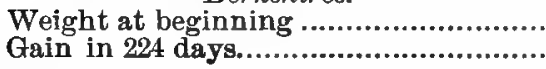 & $\begin{array}{l}172 \\
208\end{array}$ & $\begin{array}{r}99 \\
236\end{array}$ & $\begin{array}{r}85 \\
220\end{array}$ & $\begin{array}{r}86 \\
256\end{array}$ & $\begin{array}{r}65 \\
247\end{array}$ \\
\hline Weight at close......................... & 380 & 335 & 305 & 342 & 312 \\
\hline
\end{tabular}

As these pigs were to be used for breeding purposes they were supplied with a variety of nutritious foods, - shorts, corn meal, oil meal, with some milk and whey, - the purpose being to secure good bone and muscle rather than fat. In calculating results five pounds of skim milk and ten pounds of whey were counted equal to one pound of grain. The total gain and the feed required for 100 pounds of gain are as follows:

\begin{tabular}{lr} 
Total gain of lot.................... $1,168 \mathrm{lbs}$. & \multicolumn{1}{c}{ Berkshires. } \\
Feed for 100 pounds of gain...... $524 \mathrm{lbs}$ & $1,167 \mathrm{lbs}$.
\end{tabular}

It will be seen that the Poland-Chinas gained one pound mora than the Berkshires, and required 12 pounds more grain for $10 \mathrm{C}$ pounds of gain. At the close of the trial the Berkshire sows, ranging between 305 and 342 pounds in weight, were practically mature in bone and muscle and carried considerable fat. The Poland-China sows ranged from 333 to 366 pounds and were not fully developed, being of a larger type than the Berkshires. Tu have fed them to the same degree of maturity as the Berkshires would have necessitated a further gain in weight of from 25 to 50 pounds each. Having carefully watched the animals throughcis: 
the trial, the writer is convinced that with these representatives of the two leading Western breeds of swine there was practically no difference in the food requirements for a given gain.

Summing up the breed trials with swine conducted by American Stations, we have the results given below:

Tests with pure-bred swine-Various Experiment Stations.

\begin{tabular}{|c|c|c|c|c|c|c|c|c|}
\hline Breed, & 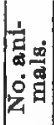 & 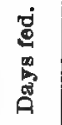 & 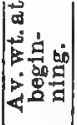 & 공 & 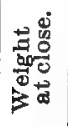 & 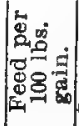 & 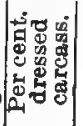 & Feed. \\
\hline $\begin{array}{l}\text { Massachusetts.* } \\
\text { Bmall Yorlyhire......... } \\
\text { Berkshire .................. } \\
\text { Poland-China ............. } \\
\text { Tamworth.................. }\end{array}$ & $\begin{array}{l}6 \\
7 \\
4 \\
4\end{array}$ & $\begin{array}{l}149 \\
140 \\
134 \\
114\end{array}$ & $\begin{array}{c}\text { Lbs. } \\
33 \\
22 \\
30 \\
32\end{array}$ & $\begin{array}{l}\text { Lbs. } \\
1.12 \\
1.16 \\
1.31 \\
1.40\end{array}$ & $\begin{array}{c}\text { Lbs. } \\
200 \\
183 \\
208 \\
191\end{array}$ & $\begin{array}{r}\text { Lbs. } \\
316 \\
289 \\
307 \\
304\end{array}$ & $\begin{array}{l}83.6 \\
81.6 \\
81.7 \\
82.8\end{array}$ & $\begin{array}{l}\text { Corn meal, bran and } \\
\text { gluten meal with } \\
\text { elther buttermilk } \\
\text { or skim milk. }\end{array}$ \\
\hline $\begin{array}{l}\text { Vermont.t } \\
\text { Smsil Yorkshlre........ } \\
\text { Berkshire .................. } \\
\text { Poland-China ............ } \\
\text { Chester White........... }\end{array}$ & $\begin{array}{l}9 \\
6 \\
3 \\
5\end{array}$ & $\begin{array}{l}184 \\
172 \\
160 \\
172\end{array}$ & $\begin{array}{l}23 \\
26 \\
34 \\
40\end{array}$ & $\begin{array}{l}1.04 \\
1.17 \\
1.20 \\
1.36\end{array}$ & $\begin{array}{l}201 \\
227 \\
228 \\
262\end{array}$ & $\begin{array}{l}353 \\
321 \\
371 \\
335\end{array}$ & $\begin{array}{l}84.1 \\
83 \\
84 \\
84.5\end{array}$ & $\begin{array}{l}\text { Corn meal and bran } \\
\text { with efther skim } \\
\text { milk or butter- } \\
\text { milk. }\end{array}$ \\
\hline 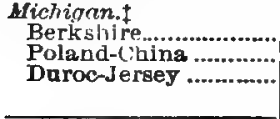 & $\begin{array}{l}4 \\
4 \\
4\end{array}$ & $\begin{array}{l}154 \\
154 \\
154\end{array}$ & $\begin{array}{l}81 \\
81 \\
89\end{array}$ & $\begin{array}{l}1.23 \\
1.20 \\
1.47\end{array}$ & $\begin{array}{l}272 \\
264 \\
320\end{array}$ & $\begin{array}{l}460 \\
514 \\
467\end{array}$ & $\begin{array}{l}83.5 \\
84.7 \\
83.2\end{array}$ & $\begin{array}{l}2 \text { parti middlings } \\
\text { with } 1 \text { part each of } \\
\text { ground oats and } \\
\text { corn. }\end{array}$ \\
\hline 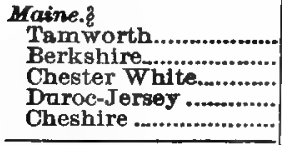 & $\begin{array}{l}3 \\
3 \\
2 \\
2 \\
1\end{array}$ & $\begin{array}{l}273 \\
266 \\
140 \\
157 \\
157\end{array}$ & $\begin{array}{l}19 \\
28 \\
65 \\
57 \\
82\end{array}$ & $\begin{array}{l}.95 \\
.90 \\
1.15 \\
1.03 \\
1.16\end{array}$ & $\begin{array}{l}278 \\
267 \\
225 \\
219 \\
265\end{array}$ & $\begin{array}{l}488 \\
493 \\
443 \\
464 \\
500\end{array}$ & 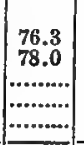 & $\begin{array}{l}\text { Oats, peas, corn } \\
\text { meal, skim milk } \\
\text { and middlings. }\end{array}$ \\
\hline 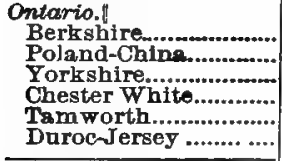 & $\begin{array}{l}\mathbf{2} \\
\mathbf{2} \\
\mathbf{2} \\
\mathbf{2} \\
\mathbf{2} \\
\mathbf{2}\end{array}$ & $\begin{array}{l}117 \\
117 \\
117 \\
117 \\
117 \\
117\end{array}$ & $\begin{array}{l}68 \\
69 \\
50 \\
62 \\
54 \\
62\end{array}$ & $\begin{array}{l}1.01 \\
1.03 \\
1.08 \\
1.05 \\
1.00 \\
1.16\end{array}$ & $\begin{array}{l}185 \\
190 \\
177 \\
185 \\
171 \\
199\end{array}$ & $\begin{array}{l}\mathbf{4 7 5} \\
507 \\
589 \\
557 \\
469 \\
580\end{array}$ & $\begin{array}{l}77.18 \\
77.18 \\
74.45 \\
77.10 \\
75.79 \\
77.21\end{array}$ & Mesl mixtures. \\
\hline 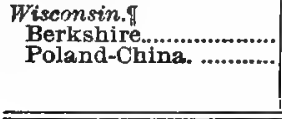 & $\begin{array}{l}5 \\
5\end{array}$ & $\begin{array}{l}224 \\
224\end{array}$ & $\begin{array}{l}101 \\
100\end{array}$ & $\begin{array}{l}1.04 \\
104\end{array}$ & $\begin{array}{l}834 \\
333\end{array}$ & $\begin{array}{l}512 \\
524\end{array}$ & $\mid \cdots \ldots \ldots$ & $\begin{array}{l}\text { Corn meal, shorts, } \\
\text { cotton-seed meal, } \\
\text { oll mesl, skim } \\
\text { milk and whey. }\end{array}$ \\
\hline
\end{tabular}

* Rept. 1891. †Repts. 1890-2-3-1. † Bul. 60. Z Rept. 1893. I Ag. College, Rept. 1896. I Rept. 1894.

The remarkably small amount of feed required to produce one hundred pounds of gain with the pigs fed in the Massachusetts and Vermont trials is doubtless due to the large quantity of skim milk and buttermilk fed and to the age of the pigs.

836. Cooking feed for swine.- Experiments with cooked feed for pigs have been so numerous that all cannot be here presented. 
Those given are selected becanse they are strictly representative, covering a wide range of country, feeds and conditions.

At the Kausas Agricultural College, ${ }^{1}$ Shelton fed one lot of five pigs cooked shelled corn, while a second lot of four, similar in all respects, was given uncooked shelled corn, the trial lasting ninety days. In cooking, the corn was placed in a barrel and water poured over it. Into this mass a pipe carried steam at a pressure ranging from 30 to 60 pounds. The kernels were cooked until they were sufficiently soft to be easily mashed between the thumb and finger.

At the Iowa Agricultural College, 2 Stalker conducted trials for 120 days in summer with cooked and uncooked shelled corn fed to Berkshire pigs.

At the Dominion (Canada) Station, ${ }^{8}$ Robertson fed grade Chester Whites a mixture of ground peas, barley and rye, the trials beginning in December and lasting 141 days.

At the Ohio Station, * Devol fed pure-bred Poland-Chinas and Berkshires for 112 days in winter. One lot of three pigs received the meal cooked, while to the second lot it was given dry and uncooked.

At the Wisconsin Station, ${ }^{6}$ the writer has conducted many trials with cooked and uncooked feed for pigs. Only the later ones are here reported. These trials lasted from 56 to 84 days each, the kinds of feed experimented with being given in the table.

The five trials reported from the Wiscousin Station, as will be seen by consulting the table, are slightly in favor of cooked feed, the difference being very small, however. These are the only feeding trials reported from any Experiment Station, so far as known to the writer, where the results are favorable to cooking. Ten other trials by the writer with cooked and uncooked feed for swine all gave results unfavorable to cooking. These and a number of trials at other Stations with cooked and nncooked feed for swine are not here included for lack of space. With this explanation

1 Rept. Prof. Agr., 1885.

2 Coburn, Swine Hus 3ndry, p. 134.

- Ottawa, Rept. 1891.

- Rept. 1887. 'Repts. 1886-87-94. 
of the conditions of the several trials, let us examine the results grouped in the table below:

Feeding cooked and uncooked feed to pigs - Various Stations.

\begin{tabular}{|c|c|c|c|c|c|c|c|c|}
\hline \multirow[b]{2}{*}{ Btation and reed. } & \multirow{2}{*}{ 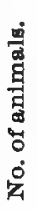 } & \multirow{2}{*}{ 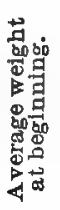 } & \multirow[b]{2}{*}{ 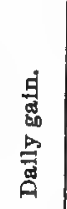 } & \multicolumn{2}{|c|}{$\begin{array}{l}\text { Gratn } \\
\text { eaten. }\end{array}$} & \multirow[b]{2}{*}{ 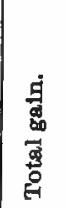 } & \multicolumn{2}{|c|}{$\begin{array}{l}\text { Feed for } 100 \\
\text { lbs. gain. }\end{array}$} \\
\hline & & & & $\frac{d}{8}$ & 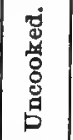 & & 형 & 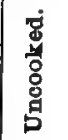 \\
\hline $\begin{array}{l}\text { Kansas. } \\
\text { Shelled corn. (Cooked with steam } \\
\text { vs. grain fed dry.) }\end{array}$ & $\begin{array}{l}5 \\
4\end{array}$ & $\begin{array}{l}\text { Lbs. } \\
219 \\
252\end{array}$ & $\begin{array}{l}\text { Lbs. } \\
1.15 \\
1.68\end{array}$ & $\begin{array}{c}\text { Lbs. } \\
3,894 \\
\ldots \ldots \ldots . . .\end{array}$ & Lbs. & $\begin{array}{l}\text { Lbs. } \\
520 \\
605\end{array}$ & $\begin{array}{c}\text { Lbs. } \\
749 \\
7 . \ldots . . .\end{array}$ & $\begin{array}{l}\text { Lbs. } \\
630\end{array}$ \\
\hline $\begin{array}{l}\text { Towa. } \\
\text { Shelled corn. (Not stated how } \\
\text { cooked.) }\end{array}$ & $\begin{array}{l}8 \\
3\end{array}$ & $\begin{array}{l}156 \\
164\end{array}$ & $\begin{array}{r}.87 \\
1.10\end{array}$ & 1,680 & 1,680 & $\begin{array}{l}812 \\
379\end{array}$ & $\begin{array}{r}598 \\
\ldots\end{array}$ & 48 \\
\hline $\begin{array}{l}\text { Corn meal. (Not stated how } \\
\text { cooked.) }\end{array}$ & $\begin{array}{l}\mathbf{3} \\
\mathbf{3}\end{array}$ & $\frac{173}{168}$ & 1.08 & $\begin{array}{r}1,680 \\
\ldots \ldots\end{array}$ & 1,680 & 299 & 562 & 44 \\
\hline $\begin{array}{l}\text { ottawa. } \\
\text { Ground peas, barley, rye, equal } \\
\text { parts. (Cooked with stream.) }\end{array}$ & 4 & $\begin{array}{l}76 \\
77\end{array}$ & $\begin{array}{r}1.09 \\
.86\end{array}$ & 2,828 & $\dddot{2,39}$ & $\begin{array}{l}702 \\
564\end{array}$ & 417 & 425 \\
\hline $\begin{array}{l}\text { hio. } \\
\text { Corn mesl. (Cooked to s mush.) }\end{array}$ & $\begin{array}{l}3 \\
3\end{array}$ & $\begin{array}{l}191 \\
205\end{array}$ & $\begin{array}{l}1.20 \\
1.14\end{array}$ & $\begin{array}{c}2,886 \\
\ldots \ldots \ldots\end{array}$ & $\ddot{2}, 116$ & $\begin{array}{l}404 \\
888\end{array}$ & 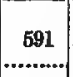 & 552 \\
\hline & 7 & $\begin{array}{r}97 \\
100\end{array}$ & $\begin{array}{l}1.16 \\
1.20\end{array}$ & $\begin{array}{r}3,041 \\
\ldots \ldots \ldots\end{array}$ & 3,198 & $\begin{array}{l}684 \\
707\end{array}$ & $\begin{array}{r}444 \\
0\end{array}$ & 452 \\
\hline \multirow[t]{2}{*}{$\begin{array}{l}\text { Corn meal and shorts, equal parts. } \\
\text { (Cooked in large kettle.) Three } \\
\text { trials. }\end{array}$} & $\begin{array}{l}4 \\
4\end{array}$ & $\begin{array}{l}75 \\
80\end{array}$ & $\begin{array}{l}1.15 \\
1.09\end{array}$ & $\begin{array}{r}1,617 \\
\ldots \ldots \ldots\end{array}$ & 1,603 & $\begin{array}{l}386 \\
366\end{array}$ & $\begin{array}{r}419 \\
\ldots . . . .\end{array}$ & 438 \\
\hline & $\frac{2}{2}$ & $\begin{array}{l}141 \\
138\end{array}$ & $\begin{array}{l}1.29 \\
1.26\end{array}$ & $\begin{array}{r}678 \\
\ldots . .0 .\end{array}$ & ……..... & $\begin{array}{l}145 \\
141\end{array}$ & $\begin{array}{r}468 \\
\hdashline\end{array}$ & 488 \\
\hline \multirow{2}{*}{$\begin{array}{l}\text { Wisconsin. } \\
\text { Two parts corn meal, one part } \\
\text { shorts. (Cooked in large kettle.) } \\
\text { Two trlals. }\end{array}$} & $\begin{array}{l}10 \\
10\end{array}$ & $\begin{array}{l}103 \\
106\end{array}$ & $\begin{array}{l}1.03 \\
1.11\end{array}$ & $\begin{array}{r}3,204 \\
\cdots\end{array}$ & $\dddot{8}, \mathbf{5 1 6}$ & $\begin{array}{l}724 \\
779\end{array}$ & 443 & $\cdots 451$ \\
\hline & $\begin{array}{l}4 \\
4\end{array}$ & $\begin{array}{l}147 \\
151\end{array}$ & $\begin{array}{l}1.37 \\
1.33\end{array}$ & 1,282 & 1,317 & $\begin{array}{l}307 \\
298\end{array}$ & $\begin{array}{r}121 \\
\ldots \ldots \ldots . . .\end{array}$ & 49 \\
\hline Average of ten trials. & & & & & & & 505 & 476 \\
\hline
\end{tabular}

Including all the trials then, so far as known, that have been farorable to cooking feed, and omitting many, for lack of space, that are unfavorable to that operation, the average shows that 476 pounds of uncooked meal or grain were required for 100 pounds of gain with pigs, while after it was cooked 505 pounds were required. This shows a loss of six per cent. of the feeding value of these substances through cooking.

837. Soaked meal versus dry meal. - At the Wisconsin Station, 1 the writer conducted two trials, lasting sirty-eight days each, with wet and dry meal, the feed ased being corn meal and shorts,

1 Rept. 1888. 
equal parts. One lot of pigs was fed dry meal, while the meal for the other lot was moistened with water after being placed in the trough.

At the Minnesota Station, ${ }^{1}$ Smith conducted trials, lasting 112 days, with corn meal, shorts and oil meal, fed wet to one lot of pigs and dry to a second lot.

At the Oregon Station, ${ }^{2}$ French fed two lots of Berkshire pigs on a mixture of shorts, wheat, oats and bran. The pigs were two and one-half months old at the beginning of the trial, which lasted 182 days. . The grain mixture was fed dry to one lot, and allowed to soak between times of feeding for the other.

At the Missouri Station, ${ }^{a}$ four lots of pigs were fed wheat and wheat chop by Conner for 100 days, dry grain being used in comparison with grain that had been soaked thirty-six hours. The results of these trials are summarized in the table:

Results of feeding pigs wet and dry meal-Four Stations.

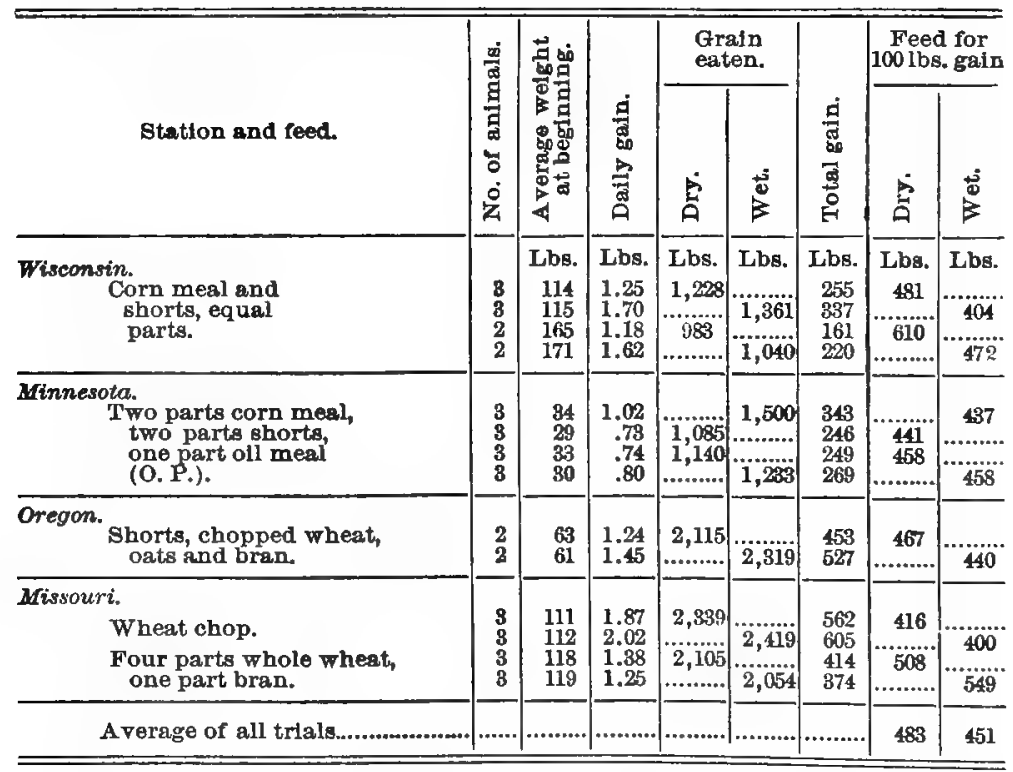

The table shows that on the average 451 pounds of grain or meal, when wet or soaked, were equal in feeding value to 483
${ }^{1}$ Bul. 22.
2 Bul. 28.
Bul. 29. 
pounds of dry grain or meal, a difference of 7 per cent. in favor of using wet or soaked meal.

The results show that the soaking of corn is about as useful in increasing its feeding value as grinding. Experiment Stations should give more data on both these important matters.

838. Value of exercise.- At the Utah Station, ${ }^{1}$ Mills gathered data on this subject with pigs during trials lasting four years. Some of the animals were confined in small pens, others in yards, while still others had the run of pastures. The pigs used were the common stock of the region, weighing about 75 pounds each when the trials began. A summary of these trials is as follows:

Results of four years' trials with pigs confined in pens and allonod exercise in yards and pastures - Utah Station.

\begin{tabular}{l|c|c}
\hline \hline & $\begin{array}{c}\text { Daily } \\
\text { gain. }\end{array}$ & $\begin{array}{c}\text { Feed for } \\
100 \text { lbs. } \\
\text { of gain. }\end{array}$ \\
\hline $\begin{array}{l}\text { Pigs confined in small pens...................................... } \\
\text { Pigs allowed exercise in yards and run of pastures. }\end{array}$ & $\begin{array}{c}.10 \mathrm{lbs} . \\
512 \mathrm{lbs} . \\
420 \mathrm{lbs} .\end{array}$ \\
\hline
\end{tabular}

These figures show .2 of a pound greater daily gain, and a saving of 92 pounds of grain, or 18 per cent. of the feed, in making 100 pounds of gain, in favor of yard and pasture over close confinement. The reader should remember that the results were obtained with shotes, and that the pastures should be credited with the food they furnished, which is of course an unknown amount. (903)

839. Value of shelter.-At the Kansas Agricultural College, 2 Shelton tested the value of shelter during winter with ten purebred Berkshires, weighing from 200 to 250 pounds each, divided into two lots of five each. One lot was placed in a warm basement, each pig occupying a pen by itself. The pigs in the other lot were likewise kept in separate pens, but in an open yard, the only protection being a board fence on the north. The trial began November 27, lasting ten weeks. The outdoor temperature ranged from 12 degrees below to 31 above zero, Fahr., and the indoor temperature from 19 to 42 degrees above. The pigs were given all the

\footnotetext{
' Bul. 40. $\quad 2$ Rept. Prof. Agr., 1883.
} 
shelled corn they would consume without waste, with the results stated below:

Sheltering pigs in basement of barn as opposed to keeping in the open yard-Kansas Agricultural College.

\begin{tabular}{|c|c|c|c|}
\hline & $\begin{array}{l}\text { Total feed } \\
\text { consumed. }\end{array}$ & Total gain. & $\begin{array}{l}\text { Feed for } \\
100 \text { lbs. } \\
\text { gain. }\end{array}$ \\
\hline 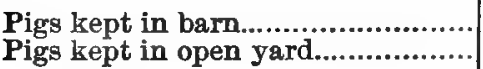 & $\begin{array}{l}2,878 \mathrm{lbs} . \\
2,844 \mathrm{lbs} .\end{array}$ & $\begin{array}{l}604 \mathrm{lbs} . \\
479 \mathrm{lbs} .\end{array}$ & $\begin{array}{l}476 \mathrm{lbs} . \\
593 \mathrm{lbs} .\end{array}$ \\
\hline
\end{tabular}

We learn from the above that the pigs kept in the open yard required 117 pounds, or 25 per cent., more corn for 100 pounds of gain than those given shelter.

840. Food of support.-Sanborn's investigations' in this line are the only ones reported for this country. In these trials pigs were fed middlings, the aim being to supply just sufficient food to keep the animal at even weight-neither gaining nor losing. The difficulties of such an undertaking are apparent to the thoughtful stockman. The findings are as follows:

Maintenance allowance or food of support for the pig-Missouri Agricultural College.

\begin{tabular}{c|r|r|r|r|r|r}
\hline \hline $\begin{array}{c}\text { No. of } \\
\text { pigs. }\end{array}$ & $\begin{array}{c}\text { Av.wt. } \\
\text { during } \\
\text { trial. }\end{array}$ & $\begin{array}{c}\text { Days } \\
\text { fed. }\end{array}$ & $\begin{array}{c}\text { Feed } \\
\text { eaten. }\end{array}$ & $\begin{array}{c}\text { Total } \\
\text { gain. }\end{array}$ & $\begin{array}{c}\text { Per cent. } \\
\text { of live wt. } \\
\text { eaten } \\
\text { daily. }\end{array}$ & Time. \\
\hline & Lbs. & & Lbs. & Lbs. & & \\
3 & 48 & 21 & 63 & 1.5 & 2.1 & Summer. \\
6 & 172 & 18 & 352 & 20.0 & 1.9 & Winter warm). \\
6 & 173 & 10 & 172 & 3.0 & 1.7 & Winter warm). \\
12 & 175 & 28 & 1,184 & 3.0 & 2.0 & Summer. \\
\hline
\end{tabular}

In these trials the pigs always made a slight gain, but it was so small that we may ignore it, the error being on the right side. We learn that pigs weighing 48 pounds require 2.1 pounds of middlings for the maintenance or support of one hundred pounds of live weight, and that pigs weighing from 172 to 175 pounds required from 1.7 to 2 per cent. of their live weight in middlings

1 Bul. 28, Mo. Agr. Col. 
for maintenance. In general, then, and until this matter is worked out more fully, we may say that a pig requires for its mainrenance two pounds of feed of value equal to middlings for each 100 pounds of live weight.

841. Weight, gain, and feed consumed by pigs. - At many of our Stations records of weights and gains of pigs and feed coni sumed by them have been so reported as to permit of studies concerning the influence of increased size and weight of the animal on the consumption of feed. All of the available data from trials of this character conducted in this country up to the time of going to press enter into the composition of the table given below. In compiling this table, six pounds of skim milk or twelve pounds of whey are calculated as equal to one pound of grain, according to the Danish valuation of these articles. For convenience of study, the data are presented for each period covering fifty pounds of growth, the actual average weight of the pigs, however, being given for each division.

Data relative to feed, weight and gain of pigs - Many American Stations.

\begin{tabular}{|c|c|c|c|c|c|c|c|c|}
\hline $\begin{array}{l}\text { Weight of pigs in } \\
\text { pounds. }\end{array}$ & 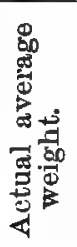 & 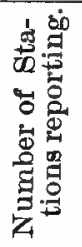 & 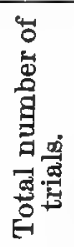 & 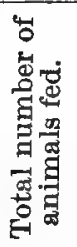 & 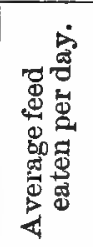 & 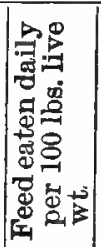 & 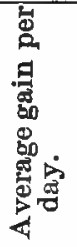 & 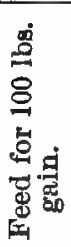 \\
\hline 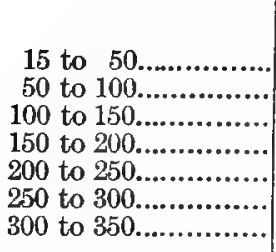 & $\begin{array}{r}\text { Lbs. } \\
38 \\
78 \\
128 \\
174 \\
226 \\
271 \\
320\end{array}$ & $\begin{array}{r}9 \\
13 \\
13 \\
11 \\
12 \\
8 \\
3\end{array}$ & $\begin{array}{r}41 \\
100 \\
119 \\
107 \\
72 \\
46 \\
19\end{array}$ & $\begin{array}{l}174 \\
417 \\
495 \\
48 ! \\
300 \\
223 \\
105\end{array}$ & $\begin{array}{l}2.23 \\
3.35 \\
4.79 \\
5.91 \\
6.57 \\
7.40 \\
7.50\end{array}$ & $\begin{array}{l}\text { Lbs. } \\
5.95 \\
4.32 \\
3.75 \\
3.43 \\
2.91 \\
2.74 \\
2.35\end{array}$ & $\begin{array}{r}\text { Lbs. } \\
.76 \\
.83 \\
1.10 \\
1.24 \\
1.33 \\
1.46 \\
1.40\end{array}$ & $\begin{array}{r}\text { Lbs. } \\
293 \\
400 \\
437 \\
482 \\
498 \\
511 \\
535\end{array}$ \\
\hline 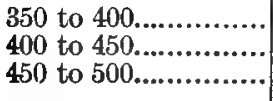 & $\begin{array}{l}378 \\
429 \\
471\end{array}$ & $\begin{array}{l}1 \\
1 \\
1\end{array}$ & $\begin{array}{l}5 \\
5 \\
2\end{array}$ & $\begin{array}{l}36 \\
36 \\
18\end{array}$ & $\begin{array}{r}8.52 \\
8.18 \\
10.00\end{array}$ & $\begin{array}{l}2.25 \\
1.91 \\
2.12\end{array}$ & $\begin{array}{l}1.98 \\
1.71 \\
1.77\end{array}$ & $\begin{array}{l}431 \\
479 \\
562\end{array}$ \\
\hline
\end{tabular}

In the above table the large number of trials reported for pigs weighing up to 350 pounds each furnishes reliable data After this point is reached the number of animals is too small to 
give reliable averages. The heavy-weight hogs reported in the last three lines of the table were fed by the writer. They were mature specimens, with large frames and in lean flesh when feeding began, having been summered on pasture without grain. The figures are introduced to show what may be accomplished with mature hogs when they are in thin flesh at the beginning of fattening.

We learn from the main portion of the table that from 105 to 495 pigs were employed in calculating each line of data. The number of trials furnishing the data varied from 19 to 119 , and were conducted by from 3 to 13 Experiment Stations.

842. Amount of feed consumed daily by the pig.-The sixth colunu of the table shows the average amount of feed consumed daily by pigs of different weights. From it we learn that pigs weighing less than 50 pounds each, averaging 38 pounds, consumed on the average 2.23 pounds of grain or grain equivalent daily. As the animal increased in weight there was a gradual increase in the amount of food consumed, until we find the 450pound hog eating 10 pounds of grain daily, or more than four times as much as the 50-pound pig.

843. Feed per 100 pounds live weight. - In the seventh column it is shown that pigs weighing 38 pounds consumed 5.95 pounds of feed daily for each 100 pounds of live weight. This is about. six per cent. of their live weight. As the pigs grew larger they consumed less feed daily for 100 pounds of live weight, until with the heaviest hogs the feed consumed was but little more than two per cent. of their live weight. Here was a decrease of about two-thirds in the daily feed consumption per 100 pounds between early weight and maturity.

844. Average daily gain. - In the next colnmn are presented data concerning the daily gain of the pig. It is shown that the 38-pound pig gained .76 of a pound, or 2 per cent. of its own weight, daily. As it increased in size the pig made larger daily gains, the maximum being reached with those weighing 271 pounds, which made a daily gain of 1.46 pounds. With large, thin hogs the gain reached 1.98 pounds, or practically two pounds per day, but these animals, because of their mature frames and thin flesh, were fed under exceptional circumstances. 
845. Feed for 100 pounds of gain.-The last column is of interest to all, especially the practical feeder, for it teaches a most interesting and important lesson concerning the feed requirements of pigs. Those which averaged 38 pounds each made 100 pounds of gain from 293 pounds of feed. This exceedingly small allowance of feed for gain was probably due in part to the fact that the I young pigs used in these trials received much skim milk, which was practically all digestible, the other feed given being also more highly digestible than that usually supplied older animals. With pigs weighing 78 pounds, 400 pounds of feed were required for 100 pounds of gain. There was a gradual increase in feed requirements for 100 pounds of gain, until the hog weighing 320 pounds required 535 pounds of grain for 100 of gain. This is 135 pounds, or 33 per cent., more feed than was required by the 78pound pig. (566, 757, 907)

846. Percentage gain of pigs from birth to maturity. - In a preceding table (830) were given the birth-weight and weekly gains of twelve litters of pigs. In the table just presented the weights and gains for older animals were given. Combining data from both these tables the following is deduced, which presents the weekly gain in pounds and percentagely of pigs from birth to maturity:

Weekly gain of pigs from birth to maturity-Wisconsin Station.

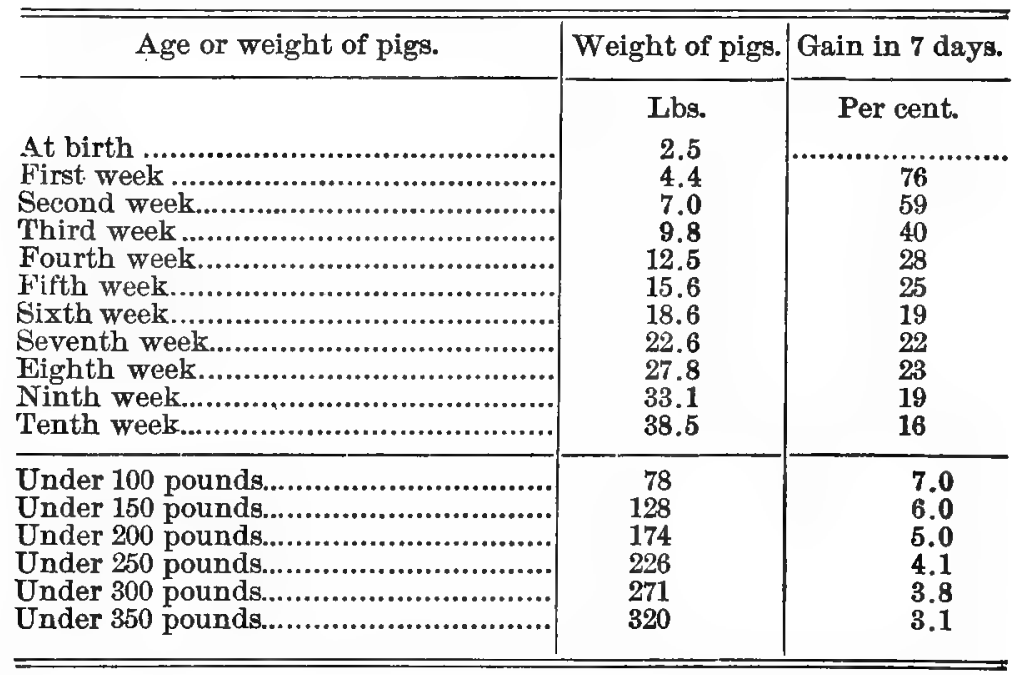


The table shows that the pigs areraged 2.5 pounds in weight when farrowed. When these pigs were one week old they weighed on the average 4.4 pounds each $-a$ gain of 76 per cent. of their farrow weight in one week. When the pigs were two weeks old they weighed on the average 7 pounds each, an increase of 59 per cent. over their weight at the close of the preceding week. Gradually the percentage of weekly increase diminished, until with the close of the ténth week it stood at 16 per cent.

Here the data furnished by the first table closes, and what follows is drawn from the second. Under this division, when the pigs reached an average of 78 pounds each, they gained 7 per cent. of their live weight in one week. Gradually the percentage of increase was reduced, until with the hog weighing 320 pounds it was 3.1 per cent. Had the trials been prolonged there would have come a time when the animals would have eaten no more feed than would maintain them, making no gain whatever, or even falling back in weight.

In comparing figures like those in the last table we should not forget that the bodies of very young animals are composed largely of water, while with mature ones the proportion of water in the increase is small, the gain being mostly fat. (102)

847. Length of the fattening period.- The following example illustrates how pigs require more and more feed for a given gain as the period of confinement and high feeding lengthens. (565) In a trial conducted by the nriter at the Wisconsin Station, ${ }^{1}$ eighteen cross-bred Poland-China Chester White hogs of unusually good bone and constitution were used. Previous to the trial these animals had been on an experiment in the rape and clover field, where they had received a fair allowance of grain, because of which they were in rather high flesh, though they had not reached their normal size. The feed during this trial consisted of twothirds corn or corn meal and one-third wheat middlings - softcoal ashes and salt being supplied in addition.

Owing to the strong constitutions and general high quality of these hogs, the writer believes these results are fully as favorable for a long feeding period as stockmen can hope to attain under the best conditions.

\footnotetext{
1 Rept. 1897.
} 
In the following table appear the data gathered during this trial:

Influence of length of fattening period on the food consumption and gain of hogs - Wisconsin Station.

\begin{tabular}{|c|c|c|c|c|c|}
\hline & \multirow{2}{*}{$\begin{array}{l}\text { Aver- } \\
\text { age } \\
\text { weight. }\end{array}$} & \multirow{2}{*}{$\begin{array}{l}\text { Aver- } \\
\text { age } \\
\text { weekly } \\
\text { gain. }\end{array}$} & \multirow{2}{*}{$\begin{array}{c}\text { Feed } \\
\text { eaten } \\
\text { during } \\
\text { week } \\
\text { per hog. }\end{array}$} & \multicolumn{2}{|c|}{$\begin{array}{l}\text { Feed for } 100 \text { pounds } \\
\text { of gain. }\end{array}$} \\
\hline & & & & $\begin{array}{c}\text { By } \\
\text { weeks. }\end{array}$ & $\begin{array}{l}\text { By four-week } \\
\text { periods. }\end{array}$ \\
\hline 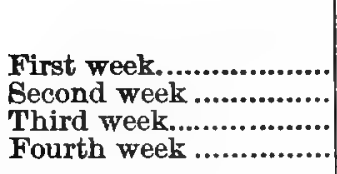 & $\begin{array}{r}\text { Lbs. } \\
222 \\
235 \\
246 \\
257\end{array}$ & $\begin{array}{l}\text { Lbs. } \\
11.4 \\
13.3 \\
10.5 \\
10.7\end{array}$ & $\begin{array}{c}\text { Lbs. } \\
41 \\
48 \\
50 \\
50\end{array}$ & $\begin{array}{r}\text { Lbs. } \\
362 \\
362 \\
475 \\
473\end{array}$ & $\begin{array}{l}\text { First } \\
\text { four weeks, } \\
418 \mathrm{lbs} \text {. }\end{array}$ \\
\hline $\begin{array}{l}\text { Fifth week:.................. } \\
\text { Sixth week................... } \\
\text { Seventh week ............... } \\
\text { Eighth week ............... }\end{array}$ & $\begin{array}{l}270 \\
281 \\
294 \\
303\end{array}$ & $\begin{array}{r}13.9 \\
10.1 \\
13.1 \\
8.9\end{array}$ & $\begin{array}{l}51 \\
51 \\
51 \\
51\end{array}$ & $\begin{array}{l}368 \\
510 \\
391 \\
574\end{array}$ & $\begin{array}{l}\text { Second } \\
\text { four weeks, } \\
461 \mathrm{lbs} .\end{array}$ \\
\hline 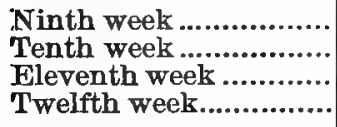 & $\begin{array}{l}313 \\
322 \\
332 \\
340\end{array}$ & $\begin{array}{r}10.5 \\
8.9 \\
9.6 \\
8.8\end{array}$ & $\begin{array}{l}52 \\
52 \\
52 \\
52\end{array}$ & $\begin{array}{l}499 \\
587 \\
549 \\
598\end{array}$ & $\begin{array}{l}\text { Third } \\
\text { four weeks, } \\
559 \mathrm{lbs} \text {. }\end{array}$ \\
\hline
\end{tabular}

Studying the table, it is seen that the heaviest weekly gains and the smallest amount of feed consumed per week were at the beginning of the trial. As the trial continued, the weekly gain in weight gradually diminished, while the feed consumed per week gradually increased. In consequence of these two opposite factors, the amount of feed required to produce 100 pounds of gain increased from week to week as the trial progressed. During the first week of the trial 362 pounds of feed made 100 pounds of gain, while during the last week 598 pounds were required. Grouping the results into periods of four weeks each, we find that for the first four weeks 418 pounds of feed were required for 100 pounds of gain. During the second four weeks there were required 461 pounds of feed, or ten per cent. more, for 100 pounds of gain. For the last four weeks, 559 pounds of feed were required, or an increase of 33 per cent. for 100 pounds of gain.

The lesson is plain that the gain of fattening hogs after the first four or five weeks of confinement is secured only by constantly increasing quantities of feed for a given weight of increase. 


\section{CHAPTER XXXIII.}

VALUE OF VARIOUS FEEDING GTUFFS FOR PICS.

848. Corn meal compared with corn.-The question whether corn shall be ground before it is fed to fattening swine is one of great importance because of the vast quantity of this grain annually used for this purpose. The subject has not received the attention it merits from investigators at the Stations, only a few trials being on record. Those reported in the following table are upon the point in question:

Feeding shelled corn in opposition to corn meal - Kentucky, Missouri and Ohio Stations.

\begin{tabular}{|c|c|c|c|c|c|c|c|c|}
\hline \multirow[b]{2}{*}{ Where fed. } & \multirow{2}{*}{ 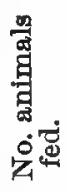 } & \multirow{2}{*}{ 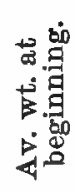 } & \multirow{2}{*}{ 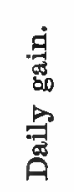 } & \multicolumn{2}{|c|}{ Grain eaten. } & \multirow[b]{2}{*}{ 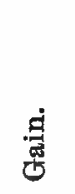 } & \multicolumn{2}{|c|}{$\begin{array}{l}\text { Feed for } 100 \\
\text { pounds gain. }\end{array}$} \\
\hline & & & & 总葛 & 㤩苋 & & 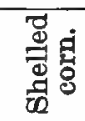 & 皇要 \\
\hline \multirow{3}{*}{ Kentucky*........ } & \multirow{7}{*}{$\begin{array}{l}2 \\
2 \\
4 \\
4 \\
4 \\
4 \\
3 \\
3\end{array}$} & Lbs. & Lbs. & Lbs. & Lbs. & Lbs. & Lbs. & Lbs. \\
\hline & & 100 & 1.39 & & 753 & 175 & & 430 \\
\hline & & $\begin{array}{l}100 \\
160\end{array}$ & 1.44 & 780 & 3196 & 182 & 429 & 507 \\
\hline Missouri & & 150 & 1.90 & 2,864 & & 594 & 482 & \\
\hline \multirow{3}{*}{ Ohio $\neq \ldots . . . . . . \ldots \ldots\{$} & & $\begin{array}{l}85 \\
86\end{array}$ & $\begin{array}{l}.54 \\
35\end{array}$ & 7.239 & 1,612 & $\begin{array}{l}250 \\
164\end{array}$ & 755 & 645 \\
\hline & & 205 & 1.14 & & 2,116 & 383 & & 552 \\
\hline & & 199 & 1.20 & 2,039 & ................ & 404 & 505 & .......... \\
\hline Av. of trials.. & & & & & & & 543 & 532 \\
\hline
\end{tabular}

* Rept. 1889.

$\dagger$ Buls. 1, 10.

† Rept. 1887.

Averaging these trials, we find that 532 pounds of corn meal or 543 pounds of whole corn were required for 100 pounds of gain. This shows that two per cent. only was saved by grinding.

To secure more information on this subject, the writer began investigations in 1896 with whole and ground corn for pigs, and has completed four trials as reported on the following page. ${ }^{2}$

1 Repts. Wis. Exp. Sta., 1896-97. 
In these trials the pigs were divided into even lots, one lot rreceiving corn meal ground fine and the other shelled corn. Some middlings was fed in order to secure more economical gains, the allowance being the same for both lots on trial. The corn used was Number 2 Iowa yellow dent, containing about twelve per cent. moisture. Summarizing the results we have the following:

Feeding pigs whole corn or shelled corn, with middlings additional Wisconsin Station.

\begin{tabular}{|c|c|c|c|c|c|}
\hline \multirow{2}{*}{ Feed. } & \multirow{2}{*}{$\begin{array}{l}\text { Av. wt. } \\
\text { at be- } \\
\text { gin- } \\
\text { ning. }\end{array}$} & \multirow[b]{2}{*}{$\begin{array}{l}\text { Av. } \\
\text { gain. }\end{array}$} & \multirow{2}{*}{$\begin{array}{l}\text { Av. } \\
\text { daily } \\
\text { gain. }\end{array}$} & \multicolumn{2}{|c|}{$\begin{array}{l}\text { Total feed for } \\
100 \mathrm{lbs} \text {. gain. }\end{array}$} \\
\hline & & & & $\begin{array}{l}\text { Corn- } \\
\text { meal } \\
\text { ration. }\end{array}$ & $\begin{array}{l}\text { Whole- } \\
\text { corn } \\
\text { ration. }\end{array}$ \\
\hline 1896. & Lbs. & Lbs. & Lbs. & Lbs. & Lbs. \\
\hline $\begin{array}{l}\text { First trial, } 9 \text { pigs in each lot. } \\
\text { Lot I. Fed corn meal........ } \\
\text { Lot II. Fed shelled corn..... }\end{array}$ & $\begin{array}{l}346 \\
354\end{array}$ & $\begin{array}{l}150 \\
137\end{array}$ & $\begin{array}{l}2.14 \\
1.96\end{array}$ & 443 & 481 \\
\hline Second trial, 10 pigs in each lot & & & & & 200 \\
\hline $\begin{array}{l}\text { Lot I. Fed corn meal......... } \\
\text { Lot II. Fed shelled corn.... }\end{array}$ & $\begin{array}{l}223 \\
225\end{array}$ & $\begin{array}{r}108 \\
79\end{array}$ & $\begin{array}{l}1.54 \\
1.13\end{array}$ & 487 & 391 \\
\hline $\begin{array}{l}1897 . \\
\text { Mrot trial, } 9 \text { pigs in each lot. } \\
\text { Lot I. Fed corn meal....... } \\
\text { Lot II. Fed shelled corn.... }\end{array}$ & $\begin{array}{l}210 \\
212\end{array}$ & $\begin{array}{l}150 \\
109\end{array}$ & $\begin{array}{l}1.78 \\
1.30\end{array}$ & 442 & "̈01". \\
\hline lecond trial, 7 pigs in each lot. & & & & & \\
\hline $\begin{array}{l}\text { Lot I. Fed corn meal........ } \\
\text { Lot II. Fed shelled corm.... }\end{array}$ & $\begin{array}{l}198 \\
183\end{array}$ & $\begin{array}{l}82 \\
79\end{array}$ & $\begin{array}{l}1.30 \\
1.25\end{array}$ & $\begin{array}{c}462 \\
\cdots \ldots \ldots \ldots\end{array}$ & 424 \\
\hline $\begin{array}{l}\text { Average of four trials, } 70 \\
\text { pigs in all...................... }\end{array}$ & & & & 459 & 499 \\
\hline
\end{tabular}

In the trials reported above, seventy pigs in all were used. With so large a number the average presents figures of value on the question under consideration. It will be seen that in three of the four trials, corn meal was more economical than whole corn. The average for the four trials shows that 459 pounds of corn meal and middlings, or 499 pounds of whole corn and middlings, were required to make 100 pounds of gain. The saving effected by grinding the corn was eight per cent. $(382,536)$

849. Value of corn and cob meal.-Sanborn reports experiments with corn and cob meal for pig feeding from the New Hampshire1 and Missouri Agricultural Colleges. 2

${ }^{1}$ Rept. New Hamp. Bd. Agr. 1880, pp. 259-262.

Bul. 1, Col. of Agr., 1883. 
Shelton, of the Kansas Agricultural College, ${ }^{1}$ also conducted a trial with the same material. Their findings are summarized in the following table:

Feeding corn and cob meal in comparison with corn meal to pigs Nero Hampshire, Missouri and Kansas Agricultural Colleges.

\begin{tabular}{l|r|c|c|c|c|c|c}
\hline \hline & $\begin{array}{c}\text { Av. } \\
\text { wt. at } \\
\text { be- } \\
\text { gin- } \\
\text { ning. }\end{array}$ & $\begin{array}{c}\text { Corn } \\
\text { nd cob } \\
\text { meal } \\
\text { eaten. }\end{array}$ & $\begin{array}{c}\text { Corn } \\
\text { meal } \\
\text { eaten. }\end{array}$ & $\begin{array}{c}\text { Corn } \\
\text { and cob } \\
\text { meal. }\end{array}$ & $\begin{array}{c}\text { Corn } \\
\text { meal. }\end{array}$ & $\begin{array}{c}\text { Corn while on - } \\
\text { and cob } \\
\text { meal. }\end{array}$ & $\begin{array}{c}\text { Feed for } 100 \\
\text { pounds gain. } \\
\text { meal. }\end{array}$ \\
\hline & Lbs. & Lbs. & Lbs. & Lbs. & Lbs. & Lbs. & Lbs. \\
New Hampshire & 52 & 1,915 & 1,527 & 416 & 317 & 460 & 482 \\
Missouri............ & 161 & 2,893 & 3,196 & 456 & 638 & 634 & 501 \\
Kansas ............ & 199 & 3,619 & 3,832 & 557 & 572 & 650 & 670 \\
\hline
\end{tabular}

In the New Hampshire and Kansas trials, corn and cob meal proved superior to the same weight of corn meal, while in the Missouri trial corn meal was more valuable.

Practical experience is strongly in favor of using the cob with the grain when feeding meal to farm animals. (158)

850. Gluten meal and corn compared with wheat. - At the Cornell Station, ${ }^{2}$ Watson divided a bunch of twelve pigs into two lots of six each, the first lot receiving wheat meal and the second a mixture of corn meal and gluten meal, both being fed skin milk in addition. Feeding began October 10 and continued four months, with the results shown in the table:

Corn and gluten meal compared with wheat meal-Cornell Station.

\begin{tabular}{|c|c|c|c|c|c|c|c|}
\hline & \multirow[b]{2}{*}{$\begin{array}{c}\text { Av. } \\
\text { wt. at } \\
\text { begin- } \\
\text { ning. }\end{array}$} & \multirow[b]{2}{*}{$\begin{array}{l}\text { Av. } \\
\text { gain. }\end{array}$} & \multicolumn{3}{|c|}{ Feed consumed. } & \multicolumn{2}{|c|}{$\begin{array}{l}\text { Feed for } 101 \\
\text { lbs. gain. }\end{array}$} \\
\hline & & & $\begin{array}{l}\text { Bkim } \\
\text { milk. }\end{array}$ & Wheat. & $\begin{array}{l}\text { Corn } \\
\text { meal } \\
\text { and } \\
\text { gluten } \\
\text { meal. }\end{array}$ & Milk. & Grain \\
\hline $\begin{array}{l}\text { Lot I, fed wheat..... } \\
\text { Lot II, fed corn meal } \\
\text { and gluten meal... }\end{array}$ & $\begin{array}{c}\text { Lbs. } \\
61 \\
66\end{array}$ & $\begin{array}{r}\text { Lbs. } \\
198\end{array}$ & $\begin{array}{l}\text { Lbs. } \\
8,110 \\
8,110\end{array}$ & $\begin{array}{l}\text { Lbs. } \\
3,473\end{array}$ & $\begin{array}{c}\text { Lbs. } \\
\ldots \ldots \\
3,561\end{array}$ & $\begin{array}{r}\text { Lbs. } \\
682 \\
621\end{array}$ & $\begin{array}{r}\text { Lbs. } \\
292 \\
272\end{array}$ \\
\hline
\end{tabular}

Rept. 1884.

2 Bul. 89. 
The table shows that a combination of gluten meal and corn meal was about seven per cent. superior to wheat meal when both were fed in connection with skim milk. (161-4, 166-8)

851. Wheat.-Because of the low price of wheat during recent years, a number of Stations have endeavored to determine it value as a feed for fattening pigs. Trials at four of the Stations are summarized in the following table:

Summary of tests with wheat meal and corn meal for pig feedingVarious Stations.

\begin{tabular}{|c|c|c|c|c|c|c|c|}
\hline \multirow{2}{*}{ Station. } & \multicolumn{2}{|c|}{$\begin{array}{l}\text { Av. wt. at } \\
\text { beginning. }\end{array}$} & \multirow{2}{*}{$\begin{array}{l}\text { No. of } \\
\text { days } \\
\text { fed. }\end{array}$} & \multicolumn{2}{|c|}{ Feed eaten. } & \multicolumn{2}{|c|}{$\begin{array}{l}\text { Feed for } 100 \\
\text { lbs. gain. }\end{array}$} \\
\hline & $\begin{array}{l}\text { Corn } \\
\text { meal } \\
\text { fed. }\end{array}$ & $\begin{array}{c}\text { Wheat } \\
\text { meal } \\
\text { fed. }\end{array}$ & & $\begin{array}{l}\text { Corn } \\
\text { meal. }\end{array}$ & $\begin{array}{l}\text { Wheat } \\
\text { meal. }\end{array}$ & $\begin{array}{l}\text { Corn } \\
\text { meal. }\end{array}$ & $\begin{array}{l}\text { Wheat } \\
\text { meal. }\end{array}$ \\
\hline & Lbs. & Lbs. & & Lbs. & Lbs. & Lbs. & Lbs. \\
\hline Kansas*... & 152 & 163 & 77 & 2,294 & 2,257 & 439 & 411 \\
\hline Ohiot................ & 136 & 137 & 70 & 1,228 & 1,273 & 453 & 438 \\
\hline South Dakota $\ddagger . .$. & 96 & 103 & 90 & 1,159 & 1,144 & 458 & 481 \\
\hline Wisconsin & 243 & 247 & 63 & 1,212 & 1,206 & 499 & 522 \\
\hline Wisconsin & 247 & 247 & 126 & 6,014 & 6,054 & 496 & 465 \\
\hline Average & & & & & & 469 & 463 \\
\hline
\end{tabular}

* Bul. 53. † Kan. State Bd. Agr., Sept. 30, 1894. $\ddagger$ Bul. 38. \& Rept. 1895.

The average of the above five trials at four Stations shows that six pounds more of corn meal than of wheat meal were required to produce one hundred pounds of gain, live weight, with pigs. The difference being so small, we may conclude that wheat meal and corn meal are practically of equal value for fattening swine.

852. Combining wheat and corn meal.- In the preceding article it was shown that wheat meal and corn meal were practically of equal value for pig feeding. At the Wisconsin Station, while feeding wheat meal to pigs, the writer fed a mixture of corn meal and wheat meal to other lots to test the value of mixtures over single feeds. By these feeding trials it was shown that a mixture of wheat and corn meal, equal parts, was more effective than wheat meal alone, the saving by feeding the mixture amounting to three per cent. In these results we have a good illustration of the economy of feeding grains in combination rather than 
singly. (759) The results of these trials in which a mixture of wheat meal and corn meal were fed in opposition to wheat meal alone, are as follows:

Feeding wheat meal and a mixture of wheat and corn meal-Wisconsin Station.

\begin{tabular}{|c|c|c|c|c|c|c|c|}
\hline & \multicolumn{2}{|c|}{$\begin{array}{c}\text { Av. weight at } \\
\text { beginning. }\end{array}$} & \multirow[b]{2}{*}{$\begin{array}{l}\text { No. of } \\
\text { days } \\
\text { fed. }\end{array}$} & \multicolumn{2}{|c|}{$\begin{array}{l}\text { Total feed con- } \\
\text { sumed. }\end{array}$} & \multicolumn{2}{|c|}{$\begin{array}{c}\text { Feed for } 100 \text { lbs } \\
\text { gain. }\end{array}$} \\
\hline & $\begin{array}{l}\text { Wheat } \\
\text { meal. }\end{array}$ & $\begin{array}{c}\text { Half } \\
\text { corn } \\
\text { meal, } \\
\text { half } \\
\text { wheat } \\
\text { meal. }\end{array}$ & & $\begin{array}{l}\text { Wheat } \\
\text { meal. }\end{array}$ & $\begin{array}{c}\text { Half } \\
\text { corn } \\
\text { meal, } \\
\text { half } \\
\text { wheat } \\
\text { meal. }\end{array}$ & $\begin{array}{l}\text { Wheat } \\
\text { meal. }\end{array}$ & $\begin{array}{c}\text { Half } \\
\text { corn } \\
\text { meal, } \\
\text { half } \\
\text { wheat } \\
\text { meal. }\end{array}$ \\
\hline & Lbs. & Lbs. & & Lbs. & Lbs. & Lbs. & Lbs. \\
\hline $\begin{array}{l}\text { First trial.... } \\
\text { Second trial. } \\
\text { Third trial... } \\
\text { Fourth trial. }\end{array}$ & $\begin{array}{l}113 \\
119 \\
247 \\
247\end{array}$ & $\begin{array}{l}116 \\
112 \\
246 \\
241\end{array}$ & $\begin{array}{r}70 \\
70 \\
63 \\
126\end{array}$ & $\begin{array}{r}975 \\
1,054 \\
1,206 \\
6,054\end{array}$ & $\begin{array}{r}988 \\
1,054 \\
1,227 \\
6,088\end{array}$ & $\begin{array}{l}510 \\
502 \\
522 \\
465\end{array}$ & $\begin{array}{l}502 \\
488 \\
491 \\
460\end{array}$ \\
\hline Average.. & & & & & . . & 500 & 485 \\
\hline
\end{tabular}

853. Feeding sheaf wheat.-The value of unthreshed wheat was determined by French, at the Oregon Station. 1 Twelve high-grade Berkshire pigs abont eight months old were divided into two lots of six each, the first being fed a mixture of three parts chopped (coarse-gronnd) wheat and one part each of shorts and ground oats, the second lot being supplied with wheat in the sheaf. Sample sheafs when threshed showed that thirty-five per cent. of their weight was grain, and the grain consumed was calculated on this basis. The results of the trial, which lasted from September 3 to October 29, are summarized below:

Feeding sheaf wheat in comparison with ground wheat, shorts and ground oats - Oregon Station.

\begin{tabular}{l|c|c|c|c}
\hline \hline & $\begin{array}{c}\text { Av. wt. at } \\
\text { begin- } \\
\text { ning. }\end{array}$ & $\begin{array}{c}\text { Average } \\
\text { gain. }\end{array}$ & $\begin{array}{c}\text { Total } \\
\text { grain } \\
\text { fed. }\end{array}$ & $\begin{array}{c}\text { Feed for } \\
100 \text { lbs. } \\
\text { gain. }\end{array}$ \\
\hline & Lbs. & Lbs. & Lbs. & Lbs. \\
Lot I, fed grain mixture...... & 187 & 150 & 3,587 & 397 \\
Lot II, fed gheaf wheat......... & 188 & 45 & 1,988 & 744 \\
\hline \hline
\end{tabular}

1 Bul. 42. 
It will be seen that the pigs fed sheaf wheat consumed about one-half as much grain as did the other lot and made only onethird the gain. French reports that the pigs fed sheaf wheat worked from three to four hours daily in separating the grain from the straw, and the table shows that even with this exertion they were not able to secure sufficient feed to permit rapid gains.

854. Middlings. - At the $W$ isconsin Station, ${ }^{1}$ the writer fed three lots of three pigs each on corn meal and middlings, giving the first corn meal, the second middlings, and the third a mixtnre of the two, equal parts.

At the Missouri Agricultural College, ${ }^{2}$ Sanborn conducted two trials with middlings in comparison with corn and corn meal. The results of these trials are summarized below:

Comparative value of middlings and corn meal for pig feeding Wisconsin Station and Missouri Agrioultural College.

\begin{tabular}{|c|c|c|c|c|}
\hline Station and feed. & $\begin{array}{l}\text { Days } \\
\text { fed. }\end{array}$ & $\begin{array}{l}\text { Feed } \\
\text { eaten. }\end{array}$ & Gain. & $\begin{array}{c}\text { Feed for } \\
100 \text { lbs. } \\
\text { gain. }\end{array}$ \\
\hline Wisconsin Station. & & Lbs. & Lbs. & Lbs. \\
\hline 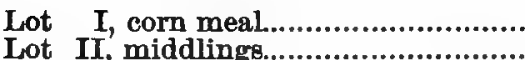 & 42 & 659 & 104 & $\begin{array}{l}537 \\
522\end{array}$ \\
\hline Lot III, equal parts middilings and & & 001 & 90 & \\
\hline Missouri College. & & 270 & 100 & 439 \\
\hline Lot I, corn meal ............... & 116 & 1,612 & 250 & 645 \\
\hline 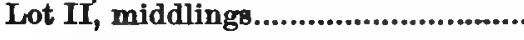 & 116 & t,524 & 252 & 605 \\
\hline Missouri College. & & & & \\
\hline 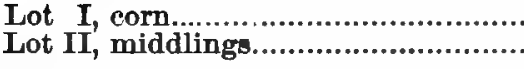 & $\begin{array}{l}46 \\
46\end{array}$ & $\begin{array}{l}397 \\
\mathbf{3 3 4}\end{array}$ & $\begin{array}{l}79 \\
91\end{array}$ & $\begin{array}{l}502 \\
367\end{array}$ \\
\hline
\end{tabular}

In these trials middlings proved superior to corn, Sanborn's second trial showing a remarkably high value for this feed. This investigator, commenting ${ }^{3}$ on this by-product of wheat milling, writes: "The economy of ship-stuff (middlings) compared with corn has been noted by me every year for seven years, the figures of which are as 108 to $100 . "$

The economy of feeding middlings and corn meal in combination instead of separately is shown in the Wisconsin trial, where

\footnotetext{
1 Rept. 1885.

'Buls. 10, 14.

Bul. 14. 
439 pounds of the corn-middlings mixture proved as valuable as 522 of middlings or 537 of corn meal when fed separately. Whilo middlings were superior to corn when fed alone, a combination of the two proved twenty per cent. more economical than middlings alone. (107, 174)

855. Wheat bran compared with middlings.-At the Maine Station, ${ }^{1}$ Jordan fed pigs, weighing 200 pounds each, with bran and kkin milk in one case, and middlings and skim milk in another, the trial lasting seventy-two days, with results as below:

\section{Lot A fed:}

413 pounds middlings

$1,126$ pounds skim milk $\}$

Lot B fed:

$\left.\begin{array}{r}413 \text { pounds bran } \\ 1,126 \text { pounds skim milk }\end{array}\right\}$
Gain.

110 pounds.

The results show that with the same allowance of feed the middlings were twice as valuable as the bran. (174-5, 896)

856. Bran with corn for pig feeding.-At the Alabama Station, 2 Duggar fed Essex pigs corn and an equal mixtare of corn and wheat bran for a period of sixteen weeks, there being three pigs on each feed. The results are shown in the following table:

Feeding corn or a mixture of corn and wheat bran-Alabama Station.

\begin{tabular}{|c|c|c|c|c|}
\hline Grain fed. & $\begin{array}{l}\text { Av. wt. } \\
\text { at be- } \\
\text { gin- } \\
\text { ning. }\end{array}$ & $\begin{array}{l}\text { Food } \\
\text { eaten. }\end{array}$ & Gain. & $\begin{array}{l}\text { Food } \\
\text { for } 100 \\
\text { pounds } \\
\text { gain. }\end{array}$ \\
\hline 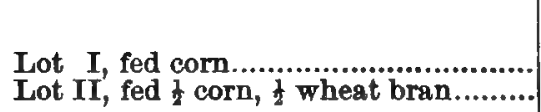 & $\begin{array}{c}\text { Lbs. } \\
58 \\
60\end{array}$ & $\begin{array}{r}\text { Lbs. } \\
844 \\
1,044\end{array}$ & $\begin{array}{r}\text { Lbs. } \\
173 \\
203\end{array}$ & $\begin{array}{r}\text { Lbs. } \\
487 \\
521\end{array}$ \\
\hline
\end{tabular}

The two trials just reported show that wheat bran cannot successfully be used in large amount in pig feeding, especially with young animals. This fact is doubtless due to the coarse, fibrous character of bran and the large percentage of inert matter it carries.

857. Barley meal.-To ascertain the value of barley for pig feeding the writer conducted trials at the Wisconsin Station ${ }^{8}$ in

\footnotetext{
1 Rept. 1889. Bul. 82. Rept. 1890.
} 
which barley meal was fed in opposition to corn meal. In the first trial there were five pigs in each lot, and in the second six. The results are summarized below:

Feeding barley meal and corn meal to pigs - Wisconsin Station.

\begin{tabular}{|c|c|c|c|c|}
\hline Grain fed. & $\begin{array}{l}\text { Av. wt. } \\
\text { at begin- } \\
\text { ning. }\end{array}$ & $\begin{array}{l}\text { Food } \\
\text { eaten. }\end{array}$ & Gain. & $\begin{array}{c}\text { Grain } \\
\text { consumed } \\
\text { for } 100 \\
\text { lbs. gain. }\end{array}$ \\
\hline & Lbs. & Lbs. & IJbs. & Lbs. \\
\hline 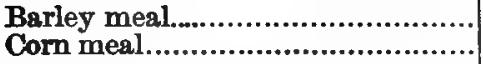 & $\begin{array}{l}208 \\
209\end{array}$ & $\begin{array}{l}2,832 \\
3,100\end{array}$ & $\begin{array}{l}601 \\
713\end{array}$ & $\begin{array}{l}471 \\
435\end{array}$ \\
\hline
\end{tabular}

Barley meal and milk v8. corn meal and milk.

\begin{tabular}{|c|c|c|c|c|c|c|c|c|}
\hline \multirow{2}{*}{ Grain fed. } & \multirow{2}{*}{$\begin{array}{l}\text { Av. wt. } \\
\text { at be- } \\
\text { gin- } \\
\text { ning. }\end{array}$} & \multicolumn{2}{|c|}{ Feed eaten. } & \multirow{2}{*}{ 焉焉 } & \multirow{2}{*}{ Gain. } & \multicolumn{3}{|c|}{$\begin{array}{l}\text { Feed and water } \\
\text { for } 100 \text { lbs. gain. }\end{array}$} \\
\hline & & Grain & Milk. & & & Grain & Milk. & $\begin{array}{l}\text { W'ter } \\
\text { drank }\end{array}$ \\
\hline & Lbs. & Lbs. & Lbs. & Lbs. & Lbs. & Lbs. & Lbs. & Lbs. \\
\hline $\begin{array}{l}\text { Barley meal.......... } \\
\text { Corn meal............... }\end{array}$ & $\begin{array}{l}79 \\
73\end{array}$ & $\begin{array}{l}1,993 \\
1,807\end{array}$ & $\begin{array}{l}2,404 \\
2,192\end{array}$ & $\begin{array}{l}3,511 \\
1,686\end{array}$ & $\begin{array}{l}604 \\
591\end{array}$ & $\begin{array}{l}330 \\
306\end{array}$ & $\begin{array}{l}\mathbf{3 9 8} \\
\mathbf{3 7 1}\end{array}$ & $\begin{array}{l}581 \\
285\end{array}$ \\
\hline
\end{tabular}

By the first table we learn that -

471 pounds of barley meal produced 100 pounds of gain.

435 pounds of corn meal produced 100 pounds of gain.

This shows a difference of thirty-six pounds in favor of corn meal. In the second trial there is a difference of twenty-four pounds of meal and twenty-seven pounds of skim milk. Averaging both trials we find that it required eight per cent. more barley meal than corn meal to produce a given gain. These results coincide with Fjord's experiments in showing that barley is somewhat less valuable than corn for fattening swine, though the difference is not large. $(178,894)$ When we take into account the fact that barley has been found by the Danes to be the best single grain for the production of bacon of the highest quality, its value in swine feeding is apparent.

It is interesting to note in the second trial that the barley-fed pigs drank about twice as much water as those getting corn meal. 
858. Oats. - At the Wisconsin Station, ${ }^{1}$ the writer conducted trials with whole and ground oats fed with corn meal to pigs, with results shown in the table:

Feeding whole and ground oats with corn meal to pigs - Wisconsin Station.

\begin{tabular}{|c|c|c|c|c|c|}
\hline Feed. & $\mid \begin{array}{c}\text { Av. wt. } \\
\text { at be- } \\
\text { ginning }\end{array}$ & $\begin{array}{l}\text { Daily } \\
\text { gain. }\end{array}$ & $\begin{array}{l}\text { Feed } \\
\text { eaten. }\end{array}$ & Gain. & $\begin{array}{l}\text { Grain } \\
\text { for } 100 \\
\text { pounds } \\
\text { gain. }\end{array}$ \\
\hline Whole oats. & Lbs. & Lbs. & Lbs. & Lbs. & Lbs. \\
\hline $\begin{array}{l}\text { whole oats, } \frac{1}{3} \text { corn meal ...... } \\
\text { whole oats, } \frac{2}{3} \text { corn meal ..... }\end{array}$ & $\begin{array}{l}117 \\
114\end{array}$ & $\begin{array}{l}.68 \\
.82\end{array}$ & $\begin{array}{l}1,388 \\
1,457\end{array}$ & $\begin{array}{l}246 \\
296\end{array}$ & $\begin{array}{l}564 \\
492\end{array}$ \\
\hline Ground oats. & & & & & \\
\hline $\begin{array}{l}\text { ground oats, } \frac{1}{3} \text { corn meal ..... } \\
\frac{1}{3} \text { ground oats, }\end{array}$ & $\begin{array}{l}113 \\
114\end{array}$ & $\begin{array}{l}1.03 \\
1.27\end{array}$ & $\begin{array}{l}1,593 \\
1,839\end{array}$ & $\begin{array}{l}871 \\
457\end{array}$ & $\begin{array}{l}429 \\
402\end{array}$ \\
\hline
\end{tabular}

We learn from the above that the best returns were secured when feeding a ration consisting of one-third ground oats and two-thirds corn meal. Whole oats gave poorer returns than ground oats. The feed requirements for 100 pounds of gain in both trials where ground oats were used were very low, and show the high value of this grain for pig feeding when ground and fed in combination with corn meal. (186-7)

859. Oat feed.-Oat feed was tested at the Massachusetts Station $^{2}$ by Lindsey. Six grade Chester White pigs from the same litter were divided into two lots, with four pigs in the first and two in the second. One lot received oat feed, the other corn meal, both getting skim milk, with the following results:

Oat feed in comparison with corn meal - Massachusetts Station.

\begin{tabular}{c|c|c|c|c|c}
\hline \hline & \multicolumn{2}{|c|}{ Total feed. } & & $\begin{array}{c}\text { Feed for 100 lbs. } \\
\text { gain. }\end{array}$ \\
\cline { 2 - 3 } & Milk. & Meal. & & Milk. & Meal. \\
\hline & Lbs. & Lbs. & Lbs. & Lbs. & Lbs. \\
Four pigs getting oat feed...... & $\mathbf{5 , 3 8 9}$ & $\mathbf{8 6 9}$ & $\mathbf{3 7 7}$ & $\mathbf{1 , 4 2 9}$ & 231 \\
Two pigg getting corn meal... & $\mathbf{2 , 6 9 5}$ & $\mathbf{4 3 5}$ & $\mathbf{2 2 5}$ & $\mathbf{1 , 1 9 8}$ & $\mathbf{1 9 3}$ \\
\hline
\end{tabular}

About 20 per cent. more oat feed than corn meal was required

1 Rept. 1889. 2 Rept. 1897. 
to produce 100 pounds of gain. The lower value of this feed was doubtless due to the oat hulls it contained. (189)

860. Peas.- At the Utah Station, ${ }^{1}$ Mills fed one lot of pigs on ground peas and bran, and another upon corn and bran, equal parts. The trial, which was conducted in winter, lasted 161 days

At the South Dakota Station, ${ }^{2}$ Chilcott fed soaked peas to one lot of pigs, and soaked corn meal to a second. The trial was conducted during the fall, lasting 90 days, with results as follows:

Feeding peas to pigs - Utah and South Dakota Stations.

\begin{tabular}{|c|c|c|c|c|c|c|c|}
\hline Station. & Feed. & $\begin{array}{c}\text { No. of } \\
\text { animals } \\
\text { on trial. }\end{array}$ & $\begin{array}{c}\text { Av. wt } \\
\text { at be- } \\
\text { ginning }\end{array}$ & $\begin{array}{l}\text { Daily } \\
\text { gain. }\end{array}$ & $\begin{array}{l}\text { Grain } \\
\text { eaten. }\end{array}$ & Gain. & $\begin{array}{l}\text { Grain } \\
\text { for100 } \\
\text { Ibs, } \\
\text { gain. }\end{array}$ \\
\hline Utah. & $\begin{array}{l}\text { Ground peas and } \\
\text { bran, equal parts, } \\
\text { fed wet............... } \\
\text { Corn and bran....... }\end{array}$ & $\begin{array}{l}3 \\
3\end{array}$ & $\begin{array}{l}\text { Lbs. } \\
111 \\
112\end{array}$ & $\begin{array}{r}\text { Lbs. } \\
1.09 \\
.63\end{array}$ & $\begin{array}{l}\text { Lbs. } \\
\mathbf{1}, 919 \\
\mathbf{1}, \mathbf{3 7 9}\end{array}$ & \begin{tabular}{|l} 
Lbs. \\
\\
528 \\
303
\end{tabular} & $\begin{array}{l}\text { Lbs. } \\
\\
363 \\
455\end{array}$ \\
\hline $\begin{array}{c}\text { South } \\
\text { Dakota. }\end{array}$ & $\begin{array}{l}\text { Canada field peas, } \\
\text { unground, soaked } \\
\text { Corn meal, soaked.. }\end{array}$ & $\begin{array}{l}2 \\
2\end{array}$ & $\begin{array}{l}82 \\
95\end{array}$ & $\begin{array}{l}1.21 \\
1.40\end{array}$ & $\begin{array}{r}918 \\
1,159\end{array}$ & $\begin{array}{l}218 \\
253\end{array}$ & $\begin{array}{l}421 \\
458\end{array}$ \\
\hline
\end{tabular}

In both cases peas proved superior to corn. (228)

861. Kaffir corn.- At the Kansas Station, ${ }^{8}$ Georgeson fed red Kaffir-corn meal in opposition to corn meal and soja-bean meal, with the results given below:

Feeding Kaffir-corn meal to pigs - Kansas Station.

\begin{tabular}{|c|c|c|c|c|c|c|}
\hline Feed. & $\begin{array}{c}\text { No. of } \\
\text { animals } \\
\text { on trial. }\end{array}$ & $\begin{array}{l}\text { Av. wt. } \\
\text { at be- } \\
\text { ginning }\end{array}$ & $\begin{array}{l}\text { Daily } \\
\text { gain } \\
\text { per } \\
\text { head. }\end{array}$ & $\begin{array}{l}\text { Grain } \\
\text { eaten. }\end{array}$ & Gain. & $\begin{array}{c}\text { Grain } \\
\text { for } \\
100 \\
\text { lbs. } \\
\text { gain. }\end{array}$ \\
\hline First trial. & & Lbs. & Lbs. & Lbs. & Lbs. & Lbs. \\
\hline Kaffir-corn meal............... & 4 & 153 & 1.37 & 2,180 & 423 & 515 \\
\hline Corn meal............................ & 4 & 152 & 1.70 & 2,294 & 523 & 439 \\
\hline $\begin{array}{l}\text { Second trial. } \\
\quad \text { Kaffir-corn meal, shorts..... }\end{array}$ & 3 & 63 & .50 & 1,188 & 191 & 621 \\
\hline Corn meal, shorts............... & 8 & 64 & .80 & 1,477 & 306 & 482 \\
\hline 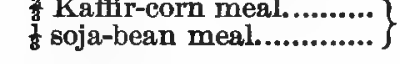 & $\mathbf{3}$ & 62 & 1.44 & 2,166 & 547 & 396 \\
\hline $\left.\begin{array}{c}\frac{2}{3} \text { corn meal ....................... } \\
\frac{1}{8} \text { soja-bean meal............ }\end{array}\right\}$ & 3 & 62 & 1.46 & 2,048 & 554 & 369 \\
\hline
\end{tabular}
I Bul. 34.
${ }^{2}$ Bul. 38.
Buls. 53, 61. 
The table indicates that Kaffir-corn meal falls from seventeen to twenty-nine per cent. below corn meal in value for pig feeding. This grain, though rich in carbohydrates, lacks protein, and is therefore not suitable for fecding alone to young pigs. The advantage of adding some substance rich in protein to the ration of corn or Kaffir corn is shown in the last trial, where the soja-bean meal materially increased the daily gain of the pigs, and cut down the requirements of feed for 100 pounds of gain in a marked degree. It is probable that if Kaffir corn were boiled it would prove more satisfactory in pig feeding, as was shown to be the case with pigeon-grass seed. $(195,865)$

862. Buckwheat. - At the Ottawa Station, ${ }^{1}$ Robertson fed lots of five pigs each on ground buckwheat and ground wheat, the trial lasting 77 days. A second trial with six pigs in each lot was conducted for 140 days. For half the ration one lot received ground buckwheat, the other ground wheat; the other half of the ration consisted of ground barley, rye and wheat, and wheat bran. In all trials the meal was soaked thirty hours before feeding. The results were as follows:

Feeding buckwheat in comparison with wheat and mixed grainOttawa Station.

\begin{tabular}{|c|c|c|c|c|}
\hline Feed given. & $\begin{array}{l}\text { Av. wt. } \\
\text { at be- } \\
\text { gin- } \\
\text { ning. }\end{array}$ & $\begin{array}{l}\text { Feed } \\
\text { eaten. }\end{array}$ & Gain. & $\begin{array}{l}\text { Feed } \\
\text { for } 100 \\
\text { lbs. } \\
\text { gain. }\end{array}$ \\
\hline Fivst trial. & Lbs. & Lbs. & Lbs. & Lbs. \\
\hline 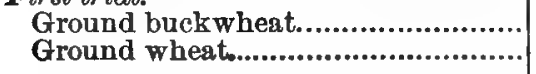 & $\begin{array}{r}103 \\
97\end{array}$ & $\begin{array}{l}2,109 \\
1,272\end{array}$ & $\begin{array}{l}474 \\
310\end{array}$ & $\begin{array}{l}445 \\
410\end{array}$ \\
\hline $\begin{array}{l}\text { Second trial. } \\
\text { ground buck wheat, } \\
\text { barley, rye, wheat, and wheat bran. } \\
\text { ground wheat, } \frac{1}{2} \text { mixture barley, } \\
\text { rye, wheat, and wheat bran.......... }\end{array}$ & 49 & $\begin{array}{l}3,238 \\
2,463\end{array}$ & 800 & $\begin{array}{l}405 \\
380\end{array}$ \\
\hline
\end{tabular}

This shows that though buckwheat has a high value it does not quite equal wheat as a feed for pigs. Six per cent. more grain was required in the buck wheat mixture than in the wheat mixture for 100 pounds of gain. (192)

1 Repts. 1894-95. 
863. Cowpeas.- At the Alabama Station, ${ }^{1}$ Duggar fed lots of four Essex pigs each upon corn, cowpeas, or a mixture of the two, for a period of sixteen weeks, with the results given in the table:

Feeding corn or coropeas, or equal mixtures of the two-Alabama Station.

\begin{tabular}{|c|c|c|c|c|}
\hline & $\begin{array}{l}\text { Av. wt. } \\
\text { at be- } \\
\text { gin- } \\
\text { ning. }\end{array}$ & $\begin{array}{l}\text { Feed } \\
\text { eaten. }\end{array}$ & Gain. & $\begin{array}{c}\text { Feed } \\
\text { for } 100 \\
\text { lbs. } \\
\text { gain. }\end{array}$ \\
\hline & Lbs. & Lbs. & Lbs. & Lbs. \\
\hline 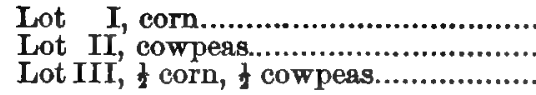 & $\begin{array}{l}58 \\
60 \\
62\end{array}$ & $\begin{array}{l}844 \\
954 \\
909\end{array}$ & $\begin{array}{l}173 \\
198 \\
210\end{array}$ & $\begin{array}{l}487 \\
481 \\
433\end{array}$ \\
\hline
\end{tabular}

The above shows that corn and cowpeas were practically equal for producing gain, while a mixture of the two proved superior to either alone. $(108,230)$

864. Rice meal. - At the Massachusetts Station, ${ }^{2}$ Lindsey tested the value of rice meal for pig feeding in the following manner: A litter of six ten-week-old pigs was divided into two lots of three each. The first lot was fed rice meal, and the second corn meal, both getting skim milk in addition. The result of the trial was as follows:

Feeding rice meal and corn meal to pigs - Massachusetts Station.

\begin{tabular}{|c|c|c|c|c|c|}
\hline \multirow{2}{*}{ Feed. } & \multicolumn{2}{|c|}{ Feed eaten. } & \multirow[t]{2}{*}{ Gain. } & \multicolumn{2}{|c|}{$\begin{array}{l}\text { Feed for } 100 \text { lbs. } \\
\text { gain. }\end{array}$} \\
\hline & Milk. & Meal. & & Milk. & Meal. \\
\hline & Lbs. & Lbs. & Lbs. & Lbs. & Lbs. \\
\hline 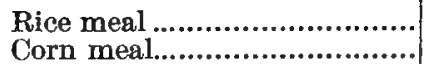 & $\begin{array}{l}3,519 \\
3,519\end{array}$ & $\begin{array}{l}867 \\
867\end{array}$ & $\begin{array}{l}385 \\
386\end{array}$ & $\begin{array}{l}914 \\
912\end{array}$ & 225 \\
\hline
\end{tabular}

This trial shows that, when fed in connection with skim milk, rice meal has practically the same value as corn meal and skim milk. (191)

865. Pigeon-grass seed.-Two trials were conducted by the writer at the Wisconsin Station ${ }^{3}$ with pigeon-grass seed screened

\footnotetext{
1 Bul. 82. Rept. 1897. Rept. 1894
} 
from wheat, to test its value for pig feeding. The pigs used wero pure-bred Polands and Berkshires, six on each feed. A preliminary trial showed that the pigs would eat but little of the raw meal, though after cooking it was consumed with relish. Accordingly the trial was planned as follows: Lot I received a ration consisting of two-thirds pigeon-grass meal, thoroughly cooked, mixed with one-third corn meal, uncooked. Lot II received corn meal, uncooked, only. To Lot III was fed a ration of onethird pigeon-grass seed meal and two-thirds corn meal, both uncooked. Lot III consumed the ration containing this proportion of pigeon-grass seed meal without serious objection. The table summarizes the results:

Feeding pigeon-grass meal, cooked and uncooked, with corn additional to pigs - Wisconsin Station.

\begin{tabular}{|c|c|c|c|c|c|}
\hline \multirow[b]{2}{*}{ Kind and condition of feed. } & \multirow{2}{*}{$\begin{array}{c}\text { Av. wt. } \\
\text { at be } \\
\text { ginning }\end{array}$} & \multirow{2}{*}{ Gain. } & \multicolumn{2}{|c|}{ Feed eaten. } & \multirow{2}{*}{$\begin{array}{l}\text { Grain } \\
\text { for } 100 \\
\text { pound. } \\
\text { gain. }\end{array}$} \\
\hline & & & $\begin{array}{l}\text { Corn } \\
\text { meal. }\end{array}$ & $\begin{array}{c}\text { Pigeon- } \\
\text { grass } \\
\text { meal. }\end{array}$ & \\
\hline $\begin{array}{l}\text { Lot I, } \frac{2}{3} \text { cooked pigeon-grass meal, } \\
\frac{1}{8} \text { corn meal, uncooked .............. } \\
\text { Lot II, corn meal only, uncooked. } \\
\text { Lot III, } \frac{1}{8} \text { pigeon-grass meal, un- } \\
\text { cooked, } \frac{2}{3} \text { corn meal, uncooked. }\end{array}$ & $\begin{array}{r}\text { Lbs. } \\
238 \\
238\end{array}$ & $\begin{array}{r}\text { Lbs. } \\
264 \\
224\end{array}$ & $\begin{array}{r}\text { Lbs. } \\
416 \\
1,199\end{array}$ & $\begin{array}{c}\text { Lbs. } \\
965\end{array}$ & $\begin{array}{r}\text { Lbs. } \\
\mathbf{5 2 2} \\
\mathbf{5 3 5}\end{array}$ \\
\hline
\end{tabular}

The above shows that the ration containing two-thirds cooked pigeon-grass meal and one-third uncooked corn meal was superior to corn meal only. The third lot, fed one-third pigeon-grass meal and two-thirds corn meal, both uncooked, gave poorer returns than the others. It is evident that pigeon-grass seed when cooked is a valuable feed for swine, and the trials show it was much relished. To be satisfactory for pig feeding the seed of this grass should be both ground and cooked.

866. Potatoes. - At the Wisconsin Station, ${ }^{1}$ the writer conducted trials with cooked potatoes mixed with uncooked corn meal, fed in opposition to uncooked corn meal only, to fattening pigs. The potatoes were cooked in as little water as possible, it

1 Rept. 1890. 
being found that they were most relished when so prepared. After cooking they were mashed in the kettle and corn meal added, the whole forming a thick mush. In the first trial there were three pigs in each lot, and two in the second, the trials lasting forty-two days.

Feeding cooked potatoes with corn meal added, and corn meal only, to fattening pigs - Wisconsin Station.

Corn meal alone.

\begin{tabular}{|c|c|c|c|c|}
\hline & $\begin{array}{l}\text { Av. wt. at } \\
\text { beginning }\end{array}$ & Grain fed. & Gain. & $\begin{array}{l}\text { Corn meal } \\
\text { for } 100 \text { lbs. } \\
\text { gain. }\end{array}$ \\
\hline & Lbs. & Lbs. & Lbs. & Lbs. \\
\hline 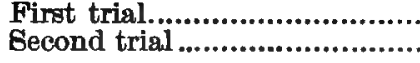 & $\begin{array}{l}243 \\
216\end{array}$ & $\begin{array}{l}983 \\
578\end{array}$ & $\begin{array}{l}224 \\
131\end{array}$ & $\begin{array}{l}438 \\
441\end{array}$ \\
\hline
\end{tabular}

Corn meal and potatoes.

\begin{tabular}{|c|c|c|c|c|c|c|}
\hline & \multirow{2}{*}{$\begin{array}{l}\text { Av. wt. } \\
\text { at be- } \\
\text { ginning }\end{array}$} & \multicolumn{2}{|c|}{ Feed eaten. } & \multirow{2}{*}{ Gain. } & \multicolumn{2}{|c|}{$\begin{array}{c}\text { Feed for } 100 \text { lbs } \\
\text { gain. }\end{array}$} \\
\hline & & $\begin{array}{l}\text { Corn } \\
\text { meal. }\end{array}$ & $\begin{array}{l}\text { Pota- } \\
\text { toes. }\end{array}$ & & $\begin{array}{l}\text { Corn } \\
\text { meal. }\end{array}$ & $\begin{array}{l}\text { Pota- } \\
\text { toes. }\end{array}$ \\
\hline & Lbs. & Lbs. & Lbs. & Lbs. & Lbs. & Lbs. \\
\hline $\begin{array}{l}\text { First trial.................... } \\
\text { Second trial.............. }\end{array}$ & $\begin{array}{l}242 \\
223\end{array}$ & $\begin{array}{l}444 \\
351\end{array}$ & $\begin{array}{l}1,332 \\
1,053\end{array}$ & $\begin{array}{l}153 \\
150\end{array}$ & $\begin{array}{l}290 \\
234\end{array}$ & $\begin{array}{l}870 \\
702\end{array}$ \\
\hline
\end{tabular}

Combining the first and second trials we have the following:

440 pounds of corn meal produced 100 pounds of gain.

262 pounds of corn meal with 786 pounds of cooked potatoes produced 100 pounds of gain.

From this we find that 786 pounds of cooked potatoes, when fed with corn meal, effected a saving of 178 pounds of corn meal; to save 100 pounds of corn meal would therefore require 441 pounds of potatoes. In Fjord's experiments, 400 pounds of potatoes were held equal to 100 pounds of grain. As corn is somewhat more valuable for fattening the pig than the grains used by Fjord, these results may be considered concordant in determining the value of potatoes and meal. (897) In general, we may say that a bushel of corn is worth four and one-half bushels of potatoes for fattening 
purposes when cooked and fed with corn meal. Potatoes may have a higher value than the rating here given, in furnishing variety in ration to growing animals. (316, 658)

867. Roots. - At the Ottawa Station, 1 Robertson fed a mixture of peas, barley and rye, steamed and warm, to one lot of pigs, giving a second lot the same feed, with sugar beets additional. For a third lot the grain was uncooked. The fourth lot received the same feed as the third, with sugar beets additional.

At the Utah Station, ${ }^{2}$ Sanborn fed wheat to one lot of pigs and wheat and roots to a second. In a second trial a mixture of oats, peas, wheat and barley was fed to one lot, with roots additional to a second.

At the Ohio Station, ${ }^{8}$ Devol fed corn to one lot of pigs and corn and roots, mostly carrots, to a second lot. The results of these trials are summarized in the following table:

Feeding grain with and without roots -Ottawa, Utah and Ohio Stations.

\begin{tabular}{|c|c|c|c|c|c|c|c|}
\hline \multirow{2}{*}{ Station. } & \multirow{2}{*}{$\begin{array}{l}\text { No. of } \\
\text { ani- } \\
\text { mals. }\end{array}$} & \multirow{2}{*}{$\begin{array}{l}\text { Av. wt. } \\
\text { at be- } \\
\text { gin- } \\
\text { ning. }\end{array}$} & \multicolumn{2}{|c|}{ Feed eaten. } & \multirow{2}{*}{ Gain. } & \multicolumn{2}{|c|}{$\begin{array}{c}\text { Feed for } 100 \\
\text { lbs. gain. }\end{array}$} \\
\hline & & & Grain & Roots & & Grain & Roots \\
\hline \multirow{5}{*}{$\begin{array}{l}\text { Ottawa. } \\
\text { Grain only ............. } \\
\text { Grain and roots...... } \\
\text { Grain only ............. } \\
\text { Grain and roots...... }\end{array}$} & \multirow{5}{*}{$\begin{array}{l}4 \\
4 \\
4 \\
4\end{array}$} & Lbs. & Lbs. & Lbs. & \multirow{5}{*}{\begin{tabular}{|r|} 
Lbs. \\
702 \\
625 \\
564 \\
571
\end{tabular}} & Lbs. & Lbs. \\
\hline & & 75 & 2,928 & & & 416 & \\
\hline & & 47 & 2,411 & 1,538 & & 386 & 246 \\
\hline & & 77 & 2,398 & I & & 425 & \\
\hline & & 50 & 2,223 & 1,563 & & 389 & 273 \\
\hline \multicolumn{8}{|l|}{ Utah. } \\
\hline Grain only ........ & \multirow{4}{*}{$\begin{array}{l}3 \\
3 \\
2 \\
2 \\
2\end{array}$} & \multirow{4}{*}{$\begin{array}{l}95 \\
90 \\
61 \\
65\end{array}$} & 358 & & \multirow{4}{*}{$\begin{array}{r}59 \\
52 \\
172 \\
152\end{array}$} & \multirow{4}{*}{$\begin{array}{l}607 \\
231 \\
651 \\
329\end{array}$} & \\
\hline Grain and roots....... & & & 120 & 828 & & & 1,592 \\
\hline Grain only ................ & & & 1,120 & & & & \\
\hline Grain and roots...... & & & 500 & 2,346 & & & 1,543 \\
\hline \multicolumn{8}{|l|}{ Ohio. } \\
\hline Grain only ............... & 5 & 140 & 2,520 & & 432 & 583 & \\
\hline Grain and roots....... & 5 & 141 & 2,562 & 1,213 & 472 & 543 & 257 \\
\hline
\end{tabular}

Averaging the above trials we learn that feeding 400 pounds of roots saved 65 pounds of grain. On this basis, 615 pounds of roots would save 100 pounds of grain. The results conform closely with the Danish findings, in which one pound of barley proved equal to
Rept. 1891.
Rept. 1891.
- Rept. 1884 
six to eight pounds of mangels and four to eight pounds of fodder beets. (325)

868. Artichoke.-Schweitzer, of the Missouri Station, ${ }^{1}$ reports a trial by Porter in which artichokes were fed with wheat meal to pigs, 325 pounds of wheat meal and 820 pounds of artichokes giving 100 pounds increase. Artichokes were found to have the same feeding value as potatoes. $(323,488)$

868a. Milk.-Scheven ${ }^{2}$ found that when whole (unskimmed) milk was fed to pigs twelve weeks old, from 900 to 1,620 pounds produced 100 pounds of gain, the average being 1,253 pounds. Studying the value of skim milk, this investigator found that 1,613 pounds of sweet skim milk and 1,545 pounds of sour skim milk produced 100 pounds of gain. He concludes that skim milk is rendered more useful by combining it with starchy feeds.

869. Feeding separator skim milk. - At the Wisconsin Station, ${ }^{8}$ the writer conducted nineteen trials with eighty-eight pigs of all ages, to determine the value of separator skim milk in combination with corn meal. The proportion of milk to meal varied from one to nine pounds of milk for each pound of meal fed. For convenience the results are arranged in groups; the first gronp comprising the trials in which not over three pounds of skim milk were fed with one pound of corn meal, the second when from three to five pounds of milk were given with each pound of corn meal, etc. The quantity of meal and milk required for 100 pounds of gain is here shown:

Separator skim milk and corn meal required for 100 pounds of gainWisconsin Station.

\begin{tabular}{|c|c|c|c|}
\hline & \multirow{2}{*}{$\begin{array}{l}\text { No. of } \\
\text { trials. }\end{array}$} & \multicolumn{2}{|c|}{$\begin{array}{l}\text { Feed for } 100 \\
\text { pounds gain. }\end{array}$} \\
\hline & & Meal. & Milk. \\
\hline $\begin{array}{l}\text { When feeding: } \\
1 \text { pound corn meal to } 1-3 \text { pounds skim milk. } \\
1 \text { pound corn meal to } 3-5 \text { pounds skim milk.. } \\
1 \text { pound corn meal to } 5-7 \text { pounds skim milk. } \\
1 \text { pound corn meal to } 7-9 \text { pounds skim milk. }\end{array}$ & $\begin{array}{l}\mathbf{3} \\
\mathbf{8} \\
\mathbf{5} \\
\mathbf{3}\end{array}$ & $\begin{array}{c}\text { Lbs. } \\
321 \\
265 \\
250 \\
207\end{array}$ & $\begin{array}{r}\text { Lls. } \\
585 \\
1,048 \\
1,434 \\
1,616\end{array}$ \\
\hline
\end{tabular}
1 Bul. 29.
2 Martiny, Die Milch.
- Rept. 1895. 
Assuming that 500 ponnds of corn meal, fed alone, would have produced 100 pounds of gain with these pigs, we find that with the first group 585 pounds of skim milk effected a saving of 179 pounds of corn meal. On this basis, 327 pounds of skim milk equals 100 pounds of corn meal when not over three pounds of milk are fed with each pound of meal. Calculating the value of skim milk in connection with corn meal for pig feeding according to the proportion fed with the meal, we deduce the following:

When feeding 1 pound of corn meal with from 1-3 pounds of separator skim milk, 327 pounds of skim milk saves 100 pounds of meal.

When feeding 1 pound of corn meal with from 3-5 pounds of separator skim milk, 446 pounds of skim milk saves 100 pounds of meal.

When feeding 1 pound of corn meal with from $5-7$ pounds of separator skim milk, 574 pounds of skim milk saves 100 pounds of meal.

When feeding 1 pound of corn meal with from 7-9 pounds of separator skim milk, 552 pounds of skim milk saves 100 pounds of meal. Average of all, 475 pounds of skim milk equals 100 pounds of meal.

Fjord's experiments show six pounds of skim milk equal to one pound of grain. The difference in the ratios is doubtless due to the fact that Fjord fed a much larger proportion of milk to meal than was usually employed in the Wisconsin trials. (357, 888)

870. Placing a money value on separator skim milk. - The feeder wishing to know the money value of skim milk measured in corn at varying prices will find the following table of value:

Value of separator skim milk in combination with corn meal for pig feeding, with corn at varying prices.

\begin{tabular}{|c|c|c|c|}
\hline \multirow[b]{2}{*}{ Value of corn. } & \multicolumn{3}{|c|}{ Value of 100 pounds of skim milk. } \\
\hline & $\begin{array}{l}\text { When feed- } \\
\text { ing } 1 \text { to } 3 \\
\text { pounds of } \\
\text { milk for } 1 \\
\text { pound of } \\
\text { corn meal. }\end{array}$ & $\begin{array}{l}\text { When feed- } \\
\text { ing } 7 \text { to } 9 \\
\text { pounds of } \\
\text { milk for } 1 \\
\text { pound of } \\
\text { corn meal. }\end{array}$ & $\begin{array}{l}\text { Aver } \\
\text { age of } \\
\text { all trials }\end{array}$ \\
\hline & Cents. & Cents. & Cents. \\
\hline 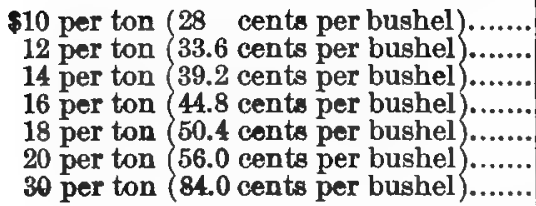 & $\begin{array}{l}15 \\
18 \\
21 \\
24 \\
28 \\
31 \\
46\end{array}$ & $\begin{array}{r}9 \\
11 \\
13 \\
15 \\
16 \\
18 \\
27\end{array}$ & $\begin{array}{l}11 \\
13 \\
15 \\
17 \\
19 \\
21 \\
32\end{array}$ \\
\hline
\end{tabular}


The table shows that when corn is worth $\$ 10$ per ton (28 cents per bushel), separator skim milk has a value for pig feeding of 15 cents per hundred pounds, provided not more than three pounds of milk are fed with each pound of meal. If, however, the feeder gives nine pounds of milk with each pound of meal, then skim milk is worth only nine cents per hundred pounds. The average of the trials is eleven cents. With higher values for corn there is a relative increase in value for skim milk.

In the above we have measured skim milk with corn meal for making gains with pigs. Those familiar with this feeding stuff, appreciating its worth for bone and muscle building, know that in many cases it has a higher value than is here given, especially for growing pigs.

87I. Sweet and sour milk compared.-At the Vermont Station, ${ }^{1}$ Cooke fed sweet and sour milk to pigs, there being three animals in each lot in the first trial, and four in each lot in the second. The sour milk was allowed to reach the loppered or coagulated stage before being fed.

Feeding sweet and sour skim mith to very young pigs - Vermont Station.

\begin{tabular}{|c|c|c|c|c|c|c|}
\hline \multirow{2}{*}{ Feed. } & \multirow{2}{*}{$\begin{array}{c}\text { Av. wt. } \\
\text { of pigg } \\
\text { at be- } \\
\text { ginning }\end{array}$} & \multicolumn{2}{|c|}{ Foed eaten. } & \multirow{2}{*}{ Gain. } & \multicolumn{2}{|c|}{$\begin{array}{l}\text { Feed for } 100 \mathrm{lbs} . \\
\text { gain. }\end{array}$} \\
\hline & & Milk. & Grain. & & Milk. & Grain. \\
\hline First trial. & Lbs. & Lbs & Lbs. & Lbs. & Lbs. & Lbs. \\
\hline $\begin{array}{l}\text { Sweet skim milk... } \\
\text { Sour skim milk.... }\end{array}$ & $\begin{array}{l}16 \\
17\end{array}$ & $\begin{array}{l}6,057 \\
5,996\end{array}$ & $\begin{array}{l}935 \\
926\end{array}$ & $\begin{array}{l}473 \\
524\end{array}$ & $\begin{array}{l}1,280 \\
1,144\end{array}$ & $\begin{array}{l}198 \\
177\end{array}$ \\
\hline $\begin{array}{l}\text { Second trial. } \\
\text { Sweet milk............ } \\
\text { Sour milk............. }\end{array}$ & $\begin{array}{l}31 \\
29\end{array}$ & $\begin{array}{l}9,632 \\
9,632\end{array}$ & $\begin{array}{l}2,100 \\
2,100\end{array}$ & $\begin{array}{l}955 \\
963\end{array}$ & $\begin{array}{l}1,009 \\
1,000\end{array}$ & $\begin{array}{l}220 \\
218\end{array}$ \\
\hline
\end{tabular}

In the second trial the results were practically equal; in the first trial the pigs getting sour milk gave better returns. Of these, Cooke writes: "It was evident within three weeks after the pigs were put on the separate diets that those having sour milk were eating their food with a better relish, were looking sleeker and growing faster, although both lots ate their food up clean."

\footnotetext{
1 Repts. 1891-92.
} 
The evident superiority of sour milk over sweet milk (868a) for pig feeding - in most cases at least - awaits explanation from the investigators.

872. Buttermilk. - At the Massachusetts Station, ${ }^{1}$ Goessmann fed lots of three pigs each on buttermilk and skim milk to ascertain their relative value. Both lots received corn meal additional, with results shown in the table:

Feeding buttermilk and skim milk - Massachusetts Station.

\begin{tabular}{|c|c|c|c|c|c|c|}
\hline \multirow{2}{*}{ Feed. } & \multirow{2}{*}{$\begin{array}{l}\text { Av. wt. } \\
\text { at be- } \\
\text { ginning }\end{array}$} & \multicolumn{2}{|c|}{ Feed eaten. } & \multirow{2}{*}{ Gain. } & \multicolumn{2}{|c|}{$\begin{array}{l}\text { Feed for } 100 \text { lbs. } \\
\text { gain. }\end{array}$} \\
\hline & & Milk. & $\begin{array}{l}\text { Corn } \\
\text { meal. }\end{array}$ & & Milk. & $\begin{array}{l}\text { Corn } \\
\text { meal. }\end{array}$ \\
\hline & Lbs. & Lbs. & Lbs. & Lbs. & Lbs. & Lbs. \\
\hline $\begin{array}{l}\text { Buttermilk............... } \\
\text { Skim milk ................... }\end{array}$ & $\begin{array}{l}48 \\
49\end{array}$ & $\begin{array}{l}8,372 \\
8,692\end{array}$ & $\begin{array}{l}718 \\
713\end{array}$ & $\begin{array}{l}619 \\
618\end{array}$ & $\begin{array}{l}1,351 \\
1,390\end{array}$ & $\begin{array}{l}116 \\
115\end{array}$ \\
\hline
\end{tabular}

It will be seen that buttermilk gave as good returns as skim milk. In general it may be assumed that when no water has been added to buttermilk it has a feeding value with pigs equal to skim milk. (358)

873. Whey. - At the Wisconsin Station, ${ }^{2}$ the writer conducted several trials with whey for pig feeding, two of which are reported below. At the Ontario Agricultural College, ${ }^{8}$ Dean reports two trials with this by-product. In these trials, one lot of pigs was maintained on meal only, the pigs at the Wisconsin Station getting a mixture of corn meal and middlings, and those at the Ontario College wheat and barley mixed with an equal weight of shorts.

The whey used in these trials was from the manufacture of fullcream cheese; hence it contained a considerable quantity of fat and some casein. In Fjord's experiments, in Denmark, 1,200 pounds of whey equaled 100 pounds of meal. $(887,889)$ The whey used by this investigator was the by-product from the manufacture of skim cheese from centrifugal skim milk. Such whey is necessarily poorer in fat than that used in American trials. $(359,660)$
Rept. 1884.
Rept. 1891.
- Rept. 1896. 
The results of the Wisconsin and Ontario trials with whey as a feed for pigs is shown in the following table:

Feeding trials with grain and whey-Wisconsin Station and Ontario College.

Wisconsin Station.

\begin{tabular}{|c|c|c|c|c|}
\hline & \multirow{2}{*}{$\begin{array}{l}\text { No. of } \\
\text { pigs in } \\
\text { trial. }\end{array}$} & \multirow{2}{*}{$\begin{array}{l}\text { Daily } \\
\text { gain } \\
\text { per } \\
\text { head. }\end{array}$} & \multicolumn{2}{|c|}{$\begin{array}{l}\text { Feed for } 100 \mathrm{lbs} \\
\text { gain. }\end{array}$} \\
\hline & & & Meal. & Whey. \\
\hline 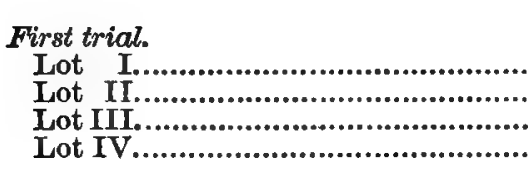 & $\begin{array}{l}\mathbf{3} \\
\mathbf{3} \\
\mathbf{3} \\
\mathbf{3}\end{array}$ & $\begin{array}{l}\text { Lbs. } \\
1.00 \\
1.47 \\
1.11 \\
1.13\end{array}$ & $\begin{array}{r}\text { Lbs. } \\
463 \\
327 \\
257 \\
181\end{array}$ & $\begin{array}{r}\text { Lbs. } \\
1,815 \\
1,871\end{array}$ \\
\hline 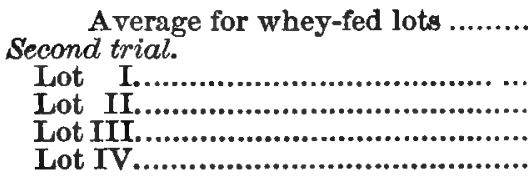 & $\begin{array}{l}4 \\
4 \\
4 \\
4\end{array}$ & $\begin{array}{l}.93 \\
1.21 \\
1.12 \\
1.09\end{array}$ & $\begin{array}{l}486 \\
372 \\
289 \\
232\end{array}$ & $\begin{array}{l}1,100 \\
1,726 \\
2,309\end{array}$ \\
\hline Average for whey-fed lots .... & & & 298 & 1,712 \\
\hline
\end{tabular}

Ontario Agricultural College.

\begin{tabular}{|c|c|c|c|c|}
\hline $\begin{array}{l}\text { Lot I } \\
\text { Lot II }\end{array}$ & $\begin{array}{l}5 \\
5 \\
6\end{array}$ & $\begin{array}{l}1.43 \\
1.76 \\
1.78\end{array}$ & $\begin{array}{l}494 \\
381 \\
383\end{array}$ & $\begin{array}{l}860 \\
819\end{array}$ \\
\hline
\end{tabular}

Averaging the results of the trials we find that 481 pounds of grain produced 100 pounds gain. 303 pounds of grain with 1,398 pounds of whey produced 100 pounds gairm.

This shows that 1,398 pounds of whey saved 178 pounds of grain. On this basis, 785 pounds of whey equals 100 pounds of grain.

874. Meat scrap.-An experiment by Watson at the Cornell Station ${ }^{1}$ throws light on the value of meat scrap for feeding pigs. A bunch of twelve pigs divided into two lots of six each was fed four months, beginning October 10, as follows: Lot I received corn meal only, while Lot II was fed one part meat scrap to two

1 Bul. 89. 
parts corn meal, by weight. The results of the trial are shown in the following table:

Feeding corn meal and meat scrap in comparison with corn meal only-Cornell Station.

\begin{tabular}{|c|c|c|c|c|c|c|}
\hline & \multirow{2}{*}{$\begin{array}{l}\text { Av. wt. } \\
\text { at be- } \\
\text { gin- } \\
\text { ning. }\end{array}$} & \multirow{2}{*}{$\begin{array}{l}\text { Av. } \\
\text { gain. }\end{array}$} & \multicolumn{2}{|c|}{ Feed consumed. } & \multicolumn{2}{|c|}{$\begin{array}{l}\text { Feed for } 100 \\
\text { lbs. gain. }\end{array}$} \\
\hline & & & $\begin{array}{l}\text { Corn } \\
\text { meal. }\end{array}$ & $\begin{array}{c}\text { Corn meal } \\
\text { and meat } \\
\text { scrap. }\end{array}$ & $\begin{array}{l}\text { Corn } \\
\text { meal. }\end{array}$ & $\begin{array}{l}\text { Corn meal } \\
\text { and meat } \\
\text { scrap. }\end{array}$ \\
\hline 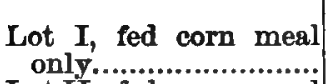 & $\begin{array}{c}\text { Lbs. } \\
64\end{array}$ & $\begin{array}{c}\text { Lbs. } \\
103\end{array}$ & $\begin{array}{l}\text { Lbs. } \\
2,639\end{array}$ & $\begin{array}{r}\text { Lbs. } \\
\ldots \ldots \ldots \ldots . . .\end{array}$ & $\begin{array}{c}\text { Lbs. } \\
426\end{array}$ & Lbs. \\
\hline $\begin{array}{l}\text { Lot II, fed corn meal } \\
\text { and meat scrap......... }\end{array}$ & 84 & 173 & …....... & 4,147 & .......... & 400 \\
\hline
\end{tabular}

The meat scrap caused a large consumption of feed - something desired by feeders. The pigs fed meat scrap gained 70 per cent. more than those fed corn meal only, but the saving in feed for a given gain was only 6 per cent. Somewhat more lean meat was found in the carcass of the pigs receiving the meat scrap. (339)

875. Pasture. - At the Utah Station, ${ }^{1}$ Mills conducted trials covering four seasons, with pigs in pens and on pastures consisting of alfalfa and grass, principally the former. (307) Some pigs were fed all the grain they would consume, while others received a limited supply or none at all.

Feeding pigs varying amounts of grain on pasture - Utah Station.

\begin{tabular}{|c|c|c|c|}
\hline Where and how fed. & $\begin{array}{l}\text { No. of } \\
\text { trials. }\end{array}$ & $\begin{array}{c}\text { Average } \\
\text { daily gain }\end{array}$ & $\begin{array}{l}\text { Grain for } \\
100 \text { pounds } \\
\text { of gain. }\end{array}$ \\
\hline $\begin{array}{l}\text { In yard, fed grass, full grain ration........ } \\
\text { In pasture, full grain ration................ } \\
\text { In pasture, three-fourths grain ration.. } \\
\text { In pasture, one-half grain ration......... } \\
\text { In pasture, one-fourth grain ration...... } \\
\text { In pasture, no grain............................. } \\
\text { In pen, fed grass only...................... }\end{array}$ & $\begin{array}{l}\mathbf{4} \\
\mathbf{4} \\
\mathbf{2} \\
\mathbf{2} \\
\mathbf{2} \\
\mathbf{3} \\
\mathbf{1}\end{array}$ & $\begin{array}{c}\text { Lbs. } \\
1.1 \\
1.3 \\
1.2 \\
.87 \\
.64 \\
.36 \\
* .26\end{array}$ & 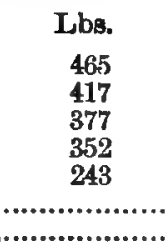 \\
\hline
\end{tabular}

* Loss.

We learn that the pigs confined in the yard and fed grass with

1 Bul. 40. 
a. full grain ration made an average daily gain of 1.1 pounds, requiring 465 pounds of grain for 100 pounds of gain, while those in the pasture, likewise receiving a full feed of grain, made a daily gain of 1.3 pounds, requiring only 417 pounds for 100 of gain. There was a saving of 10 per cent. by feeding on pasture instead of in the Jard, where grass was supplied in addition to the grain.

The table also shows that when feeding three-fourths of a full grain allowance the pigs made a daily gain of 1.2 pounds, requiring only 377 pounds of grain for 100 of gain. With still less grain the daily gain was much reduced, but so also was the amount of feed required for 100 pounds of gain. Finally, three trials on pasture without grain showed an average daily gain of .36 of a pound a day, or $2 \frac{1}{2}$ pounds a week - a very satisfactory result. When grass was cut and carried to pigs confined in pen, they could not be maintained on this feed alone, shrinking in weight at the rate of .26 pounds daily. (307) These results show that the pig cannot be successfully nourished by soiling, as can cattle, especially the dairy cow.

876. Clover hay with meal.-Stewart ${ }^{1}$ fed pigs averaging serenty-five pounds each with corn meal, two quarts of short-cut clover hay being added to each day's allowance, and the whole wet with hot water and allowed to stand from ten to twelve hours before feeding. Another lot received meal prepared in the same way but without the clover mixture. The lot getting clover hay showed the best appetite, the greatest thrift and made the steadiest gains. The pigs getting meal gained 110 pounds each in 120 days, while those having the cut clover hay mixed with their meal gained 143 pounds, or 30 per cent. more. (927) The possible value of moistened clover hay as a by-feed with pigs is well illustrated by this trial.

877. Corn and blue-grass pasture.-At the Mlinois Station, ${ }^{2}$ Morrow conducted four trials during three seasons with pigs ranging on blue-grass pasture. One lot was given a full feed of corn, the second a half feed only. As a check, a bunch of three pigs

\footnotetext{
1 Feeding Animals, p. 472.

2 Bul. 16.
} 
in this line. Unpublished data secured by the writer coincide with these findings. It is possible that pigs may make satisfactory gains on pastures alone, but no Station has yet shown that they can do so, if we except Utah, where alfalfa was grazed.

879. Rape forage.-At the Wisconsin Station, ${ }^{2}$ Craig conducted two trials with rape forage as a feed for swine, in preparation for the final fattening period. In the first trial there were twenty grade Poland-China pigs; in the second, thirty-eight grade Chester Whites. In each case the pigs were divided into two even lots, the first having a run in a rape field, with grain additional, and the second, confined in a pen, receiving grain only. The first trial lasted 76 days and the second 42 days, during which time the feed consumed and the gains were as shown in the following table:

Feeding grain with and without rape forage-Wisconsin Station.

\begin{tabular}{|c|c|c|c|c|}
\hline & Corn. & $\begin{array}{l}\text { Mid- } \\
\text { dlings. }\end{array}$ & Rape. & Gain. \\
\hline 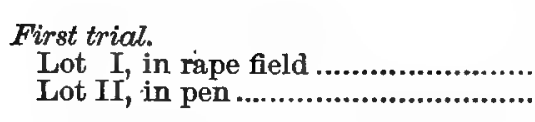 & $\begin{array}{l}\text { Lbs. } \\
1,386 \\
2,096\end{array}$ & $\begin{array}{r}\text { Libs. } \\
690 \\
1,042\end{array}$ & $\begin{array}{l}\text { Acres. } \\
\quad .82 \\
\quad 82\end{array}$ & $\begin{array}{r}\text { Lbs. } \\
853 \\
857\end{array}$ \\
\hline 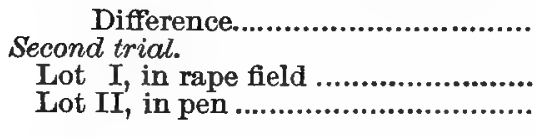 & $\begin{array}{l}2,220 \\
3,106\end{array}$ & $\begin{array}{l}1,109 \\
1,553\end{array}$ & .6 & $\begin{array}{l}1,066 \\
1,076\end{array}$ \\
\hline Difference......... & 886 & 444 & & . ............. \\
\hline
\end{tabular}

Summarizing the two trials and calling the gains equal, we learn that .92 acres of rape saved 2,392 pounds of grain. This shows one acre of rape equivalent to 2,600 pounds of grain in pig feeding. Since rape can be used as a catch crop, and costs but two or three dollars an acre for seed and planting and nothing for harvesting, the value of this crop in swine feeding is apparent. (334-5)

880. Droppings of corn-fed steers and pasture.-At the Illinois Station, ${ }^{2}$ Morrow grazed three yearling steers on a two-acre bluegrass pasture, giving a full feed of corn additional. Two pigs were

\footnotetext{
1 Rept. 1897. 'Bul. 16.
} 
placed in the same lot to subsist upon the droppings of the steers and the pasture. As a check trial, other pigs were confined in a similar pasture and fed shelled corn. During two trials, lasting twelve weeks each, the gains made by the pigs were as follows:

Furst trial. Becond trial. Average gain of pigs following steers on pasture. 59 pounds. 59 pounds. Average gain of pigs fed corn on pasture......... 72 pounds. 99 pounds.

It will be seen that the pigs following the steers made excellent gains compared with those ranging on pasture and receiving in addition a full feed of corn. Since the nutriment in the droppings would otherwise have been wasted, the great importance of following up grain-fed steers with pigs is apparent. Morrow states that when the pigs following the steers were finally fattened they gained in weight for a time at the rate of 3.2 pounds each daily, and returned as much as $\mathbf{1 6 . 8}$ pounds of increase from one bushel of corn. This trial shows the value of the droppings of grain-fed steers in preparing shotes for final fattening. (538)

881. Droppings of corn-fed steers for pigs.- The writer ${ }^{1}$ divided a bunch of twelve steers into two lots of six each, giving to the first shelled corn and to the second corn meal. Each steer received thirteen pounds of corn or corn meal daily, with half that weight of wheat bran in addition. With each lot were placed three pigs, averaging 175 pounds each, to subsist on the droppings, their further needs being supplied by corn fed in a trough. As a check, three pigs were placed in a pen and fed corn. The results are shown below:

Gains of pigs following corn-fed steers - Wisconsin Station.

\begin{tabular}{|c|c|c|}
\hline & $\begin{array}{l}\text { Feed for } 100 \\
\text { pounds gain }\end{array}$ & $\begin{array}{l}\text { Per cent. corn } \\
\text { saved by pigs } \\
\text { eating drop- } \\
\text { pings of steers. }\end{array}$ \\
\hline $\begin{array}{l}\text { Pigs in pen ............................................. } \\
\text { Pigs following steers getting corn meal..... } \\
\text { Pigs following steers getting whole corn.... }\end{array}$ & $\begin{array}{l}564 \mathrm{lbs} . \\
479 \mathrm{lbs} . \\
272 \mathrm{lbs} .\end{array}$ & $\begin{array}{l}15 \\
52\end{array}$ \\
\hline
\end{tabular}

The above shows a saving of 15 per cent. in the feed required

Wis. Expt. Sta., Rept. 1886. 
by pigs following steers getting corn meal, and 52 per cent. with those following steers getting whole corn.

These results are in conformity with the experience of stockmen, who have learned that the droppings of meal-fed steers are not as valuable as those from steers getting whole corn. (538)

882. Gain from a bushel of corn.- In the table below are given the results of a large number of feeding trials by Morrow, at the Illinois Station, ' in which whole corn only was fed to pigs:

Results of feeding whole corn only to rigs - Illinois Station.

\begin{tabular}{|c|c|c|c|c|c|c|c|}
\hline $\begin{array}{l}\text { No. } \\
\text { of } \\
\text { lot. }\end{array}$ & Time of feeding. & $\begin{array}{c}\text { No. of } \\
\text { days. }\end{array}$ & $\begin{array}{l}\text { No. of } \\
\text { pigs. }\end{array}$ & $\begin{array}{l}\text { Av. wt. } \\
\text { of pigs. }\end{array}$ & $\begin{array}{c}\text { Gain } \\
\text { per day. }\end{array}$ & $\begin{array}{c}\text { Corn for } \\
100 \text { lbs. } \\
\text { gain. }\end{array}$ & $\begin{array}{c}\text { Gain } \\
\text { per bu. } \\
\text { of corn } \\
\text { fed. }\end{array}$ \\
\hline & & & & Lbs. & Lbs. & Lbs. & Lbs. \\
\hline 1 & Nov. 24 to Dec. 29. & 35 & 2 & 290 & 2.56 & 418 & 13.4 \\
\hline$* 1$ & Nov. 24 to Dec. 22 . & 28 & 2 & 284 & 2.70 & 382 & 14.7 \\
\hline *1 & Dec. 15 to Dec. 22. & 7 & $\mathbf{2}$ & 311 & 3.21 & 333 & 16.8 \\
\hline 2 & May 5 to June 2. & 28 & 5 & 153 & 1.39 & 437 & 12.8 \\
\hline 2 & June 2 to June 30. & 28 & 5 & 192 & 1.38 & 484 & 11.6 \\
\hline 2 & June 30 to July 28 . & 28 & 5 & 224 & .85 & 646 & 8.7 \\
\hline 3 & April 29 to May 27. & 28 & 2 & 209 & 1.40 & 380 & 14.7 \\
\hline 4 & June 10 to July 22. & 42 & 2 & 212 & .90 & 535 & 10.5 \\
\hline 5 & July 30 to Sept. 10. & 42 & 3 & 66 & .77 & 441 & 12.7 \\
\hline 6 & June 17 to Sept. 9. & 84 & 3 & 207 & .60 & 676 & 8.3 \\
\hline 7 & Dec. 30 to Feb. 4 . & 56 & 5 & 109 & .51 & 808 & 6.9 \\
\hline 8 & Jan. 24 to Feb. 4 . & 28 & 6 & 106 & 1.05 & 465 & 12.0 \\
\hline 9 & Nov, 22 to Jan. 4. & 42 & 2 & 210 & 1.30 & 500 & 11.2 \\
\hline 10 & Jan. 17 to Feb. 21. & 35 & 4 & 192 & 1.29 & 460 & 12.2 \\
\hline 11 & Nov. 3 to Dec. 15. & 42 & 3 & 120 & .74 & 605 & 9.3 \\
\hline 11 & Dec. 15 to Dec. 22 . & 7 & 3 & 138 & .55 & 620 & 8.9 \\
\hline \multicolumn{2}{|c|}{ Totals and averages..... } & & 50 & 173 & 1.09 & 534 & 10.9 \\
\hline
\end{tabular}

* Omitted from averages.

The above shows that on an average the pigs gained about 1.1 pounds per day, and that a bushel of corn weighing 56 pounds produced 10.9 pounds of gain, live weight. The table shows a wide range of returns - as low as 6.9 pounds of gain from a bushel of corn in one case, while at the other extreme we have 16.8 pounds. This last return, for one week only, was with pigs which had previously followed steers fed corn on blue-grass pasture. While, then, the gains may range from 6 to 16 pounds, we may conclude that 11 pounds of increase, live weight, is a satisfactory return from a bushel of whole corn. $(568,812)$

1 Bul. 16. 
883. Pork production at the South. - At the Arkansas Station, 1 Bennett fed corn meal and bran to a sow and five pigs on clover pasture. At weaning time the sow was renoved and the experiment continued with the five pigs. From March 30 to July 26 the pigs were kept on clover. From that date until September 21 they were maintained on sorgham stalks and sorghum seed. From the latter date until November 15 they were confined in a field planted with Spanish peanuts. The total feed eaten by the sow while suckling the pigs, and by the five pigs during growth and fattening, was as follows:

Grain.

Bran fed. 98 pounds.

Corn fed during growth and fattening. $33+$ bushels

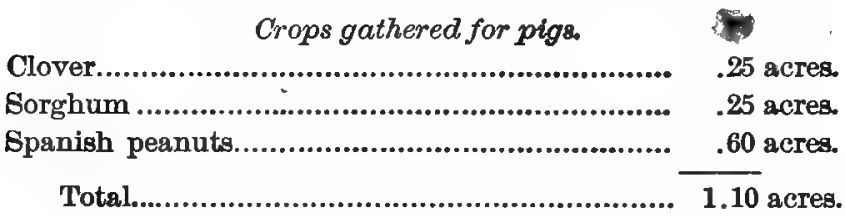

The combined weight of the five pigs when ten months old was es follows:
Weight before slaughtering. 1,215 pounds.
Weight after slaughtering. 1,032 pounds.
A verage weight before slaughtering 243 pounds
A verage dressed weight. 206 pounds

Clover was found very satisfactory for pasture while it remained fresh and grain was fed in addition. Seed and stalks of sorghum also proved satisfactory. While feeding on Spanish peanuts the pigs grew rapidly. Bennett concludes that two weeks' final feeding with corn will suffice to harden the flesh of pigs fed on peanuts.

1 Bul. 41. 


\section{CHAPTER XXXIV.}

\section{DANISH PIG-FEEDING EXPERIMENTS.}

\section{Trials with Various Feeds.}

884. The work of Fjord and Friis.-Since the year 1880 a large number of pig-feeding experiments have been conducted by the Danish Experiment Station at Copenhagen, under the direction of the late Professor J. N. Fjord and his successor, F. Frijs. These experiments are exceedingly valuable because of the variety of conditions under which they were conducted, the large number of animals included, and the care bestowed on the details of the work.

The feeding was conducted on the co-operative plan on a number of Danish estates, or large farms, under the direct supervision of the officials of the Station, who planned the experiments, made the weighings, sampled and analyzed the feeds and conducted the slaughtering tests. In these trials the pigs were divided into selected even lots composed of five to ten animals each, the different lots being so fed as to express the comparative value of the feeds nnder examination. In a majority of cases the object in view was the relative feeding value of different swine foods under good farm conditions. Incidentally a number of other problems were included, such as the value of shelter, the influence of water on fattening, breed experiments, question of sex in fattening, influence of season on fattening, etc. The results of these experiments have been published in the periodical reports (Beretninger) of the Station, of which thirty. nine have appeared to date.

The Danish pound equals 1.1 pounds avoirdupois. As the results stated are nearly always relative, they are given in Danish pounds, as they appear in the original reports. Wherever avoirdupois pounds are given, it is so stated. 
885. Slaughtering tests. - On the completion of the feeding trials the animals were usually shipped to a Danish pork-packing house, where they were slaughtered in the presence of one of the Station officers. Weighings were made and notes taken by experts as to the quality of the carcass, the thickness of the layer of fat over the shoulder and loin, as well as any characteristic differences in the lots attributable to the system of feeding followed or to other causes. The carcasses were grouped in four classes, according to their quality. Class I contained those carcasses which graded best; Class IV was the poorest, with Classes II and III intermediate. The grading was always with special reference to the demands of the English market. The quality of the meat, whether hard or soft, the thickness of the layer of external fat, the size of the carcass, and other points determining their commercial value, were the deciding factors. As an illustration of the grading we present the figures given below, which are the results of an examination and grading of 158 animals used in one trial: 1

Illustration of pork grading for English market requirements-Copenhagen Station.

\begin{tabular}{l|c|c|c|c|c}
\hline Grade of pork. & $\begin{array}{c}\text { No. of } \\
\text { ani- } \\
\text { mals. }\end{array}$ & $\begin{array}{c}\text { Live } \\
\text { weight. }\end{array}$ & $\begin{array}{c}\text { Shrink- } \\
\text { age. }\end{array}$ & $\begin{array}{c}\text { Thickness } \\
\text { of fat on } \\
\text { shoulder. }\end{array}$ & $\begin{array}{c}\text { Thick- } \\
\text { ness of } \\
\text { fat on } \\
\text { loin. }\end{array}$ \\
\hline & & Lbs. & Per cent. & Inches. & Inches. \\
Highest, Class I ........... & 98 & 158 & 25.9 & 1.7 & 1.0 \\
Next best, Class II ...... & 49 & 170 & 24.7 & 2.0 & 1.3 \\
Lowest,* Class III...... & 10 & 181 & 23.2 & 2.2 & 1.5 \\
\hline \hline
\end{tabular}

* One animal only in Class IV.

It will be seen that the best grade included the lightest animals, these falling under 175 pounds avoirdupois. The shrinkage with this grade was heary - nearly 26 per cent. The fat on the shoulder and loin was much thinner than with those in the poorest grade. The flesh also was much firmer.

886. Centrifugal versus gravity skim milk.-Seven experiments" were conducter with 72 animals in all, the trials lasting 4 to 6

${ }^{1}$ Rept. 10, 1887. Rept. 2, 1884. 
weeks. Barley, oats, corn and peanut meal were fed separately or combined; in all cases more or less skim milk was given in addition to the grain. The pigs were all less than 12 weeks old, averaging 6 weeks, and weighing less than 40 pounds at the beginning of the trials. The feed consumed and the average gain are shown below:

Gain of pigs fed gravity and separator stim milk with grain - Copenhagen Station.

\begin{tabular}{|c|c|c|}
\hline & $\begin{array}{l}\text { Gravity skim } \\
\text { milk. }\end{array}$ & $\begin{array}{l}\text { Centrifugal } \\
\text { skim milk. }\end{array}$ \\
\hline Average daily gain per head...................... & \multirow{3}{*}{$\begin{array}{c}.776 \mathrm{lbs} . \\
.035 \mathrm{lbs} . \\
.63 \text { per cent. }\end{array}$} & \multirow[t]{2}{*}{$.741 \mathrm{lbs}}$. \\
\hline Difference in favor of gravity skimming.... & & \\
\hline Per cent. of fat in skim milk........................ & & .15 per cent. \\
\hline
\end{tabular}

The pigs in these trials were fed about 8 pounds of milk a day on the average. Of gravity skim milk 100 pounds produced a little over .4 pounds more gain in live weight than the same quantity of centrifugal skim milk. The pigs fed gravity skim milk gained as much in 23 days as the others in 24 days. Allowing a fair value for the butter fat, centrifuging the milk is shown to be the more profitable method. (357, 659, 869-7I)

887. Skim milk compared with whey.-The relative value of separator skim milk and whey left in the manufacture of skim cheese from separator skim milk was studied ${ }^{1}$ in experiments conducted during 1885-87. In one series, where three pounds of whey were fed against one pound of skim milk, the weight of the pigs fed varied from 79 to 110 pounds. These trials included 34 animals, the feeding lasting from 53 to 60 days. There was a daily gain of .91 pounds for the lots fed skim milk and 1.22 pounds for those fed whey.

Another series of experiments ${ }^{2}$ was conducted on six different farms with 258 animals in all, varying from 28 to 174 pounds each at the beginning of the trials, the feeding periods running from 50 to 160 days. In this series, which included nineteen trials, two pounds of whey were fed against one pound of separator

Rept. 1887.

Rept. 10, p. 26. 
skim milk. The average gain for the animals in both lots was exactly the same, viz., 1.13 pounds daily.

The conclusion drawn is that one pound of separator skim milk equals two pounds of whey obtained in the manufacture of cheese from separator skim milk. Such whey is necessarily very free from fat, and consequently has as low a feeding value as whey can possess.

These results were corroborated by similar experiments conducted during 1887-88, as well as by still later trials. ${ }^{1}$

The results of investigations at the Wisconsin Station and the Ontario Agricultural College (873) show that whey has a higher feeding value for pigs than is here reported. The reason for this lies in the fact that in the American trials the whey contained more fat and probably more casein than that fed at the Danish Station. (359, 660)

888. Skim milk compared with grain.-Centrifugal skim milk was compared ${ }^{2}$ with rye and barley, being first fed in the ratio of 5 pounds of milk to 1 of grain; in later experiments, 6 pounds of mills to 1 of grain. Groups containing 175 pigs in all were divided into 35 lots. The milk fed varied in amount as shown in the table, which gives also the average grain consumed daily and the gain made per animal.

Skim millk compared with barley and rye-Copenhagen Station.

\begin{tabular}{|c|c|c|}
\hline \multirow[b]{2}{*}{ Feed given daily. } & \multicolumn{2}{|c|}{ Average daily increase. } \\
\hline & $\begin{array}{l}\text { When fed } \\
\text { barley. }\end{array}$ & $\begin{array}{l}\text { When fed } \\
\text { rye. }\end{array}$ \\
\hline 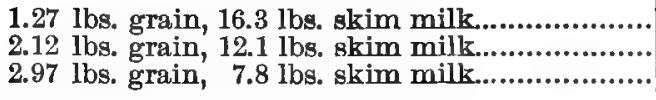 & $\begin{array}{l}.79 \mathrm{lbs} . \\
.91 \mathrm{lbs} . \\
.99 \mathrm{lbs} .\end{array}$ & $\begin{array}{l}.81 \mathrm{lbs} . \\
.91 \mathrm{lbs} . \\
1.00 \mathrm{lbs} .\end{array}$ \\
\hline
\end{tabular}

It will be seen that greater gains were made where the quantity of skim milk fed was decreased. The results show that 5 pounds of milk could not replace 1 pound of grain, where rye or barley was fed with the skim milk. In the second and third series of trials 60 pigs were used in each series. When the allowance of

\footnotetext{
1 Rept. 15, p. 28.

- Rept. 10, 1887.
} 
akim milk was decreased in the ratio of 1 pound of grain to 6 pounds of skim milk on the average, the following results were obtained:

Comparison of centrifugal skim mills with rye and barley-Copen. hagen Station.

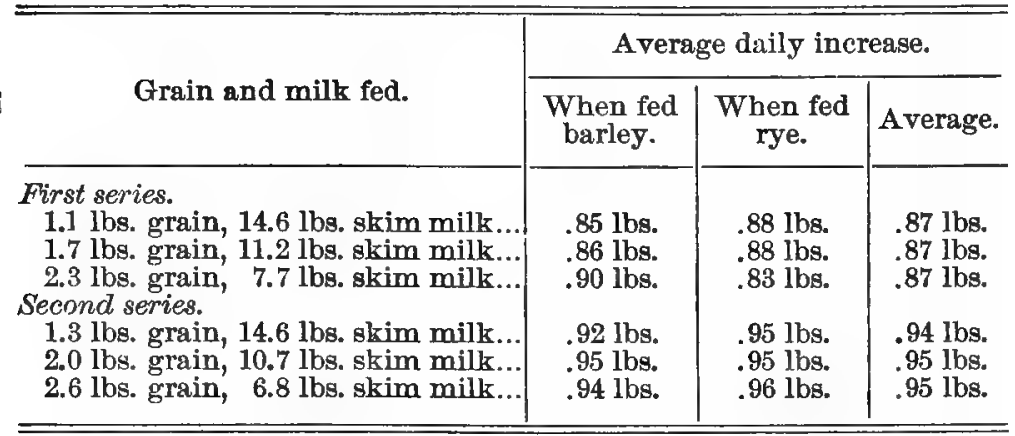

In later work at that Station these feeds have always been substituted for one another in the proportion of 6 pounds of separator skim milk for 1 pound of grain. If all experiments in this line are averaged, we find that the daily gain per head was practically identical, whether much or little grain was replaced by skim milk, in the ratio of 1 to 6 , showing that the comparative feeding value of these feeds is expressed by this ratio. (869)

889. Grain compared with whey. - Two series of experiments ${ }^{1}$ with sixty animals in all were conducted, in which one pound of grain was fed as an equivalent to twelve pounds of whey from separator skim-milk cheese. In these trials the average weight of the pigs fed was about 50 pounds, the experiments lasting 115 days each, with results shown below:

Feeding whey and grain to pigs - Copenhagen Station.

Feed per pig daily. Daily increase per head.

1.3 lbs. grain, $27.1 \mathrm{lbs}$. whey, $1 \mathrm{lb}$. buttermilk.................... $.945 \mathrm{lbs}$.

$1.95 \mathrm{lbs}$. grain, $19.3 \mathrm{lbs}$. whey, $1 \mathrm{lb}$. buttermilk .................. .950 lbs.

2.6 lbs. grain, 11.5 lbs. whey, 1 lb. buttermilk .................. .955 lbs.

The results show that one pound of rye or barley is equal to twelve pounds of whey from centrifugal skim-milk cheese. We have already shown that one pound of rye or barley is equivalent

1 Rept. 1887, p. 38. 
to six pounds of skim milk. One pound of skim milk is therefore equal to two pounds of whey. $(660,873)$

890. Quality of skim-milk and whey-fed pork. - Slaughter tests 1 show the quality of skim-milk pork somewhat superior to that, produced from whey, as indicated in the following table:

Results of slaughter tests with pigs fed whey and skim milk - Copenhagen Station.

\begin{tabular}{|c|c|c|}
\hline & $\begin{array}{l}\text { Bkim } \\
\text { milk. }\end{array}$ & Whey. \\
\hline Shrinkage in slaughtering, per cent....................... & \multirow{2}{*}{24.6} & \multirow[t]{2}{*}{24.9} \\
\hline Percentage classification of carcasses. & & \\
\hline Class 1 Class II & $\begin{array}{l}73.0 \\
27.0\end{array}$ & \multirow{2}{*}{$\begin{array}{r}48.0 \\
44.0 \\
8.0\end{array}$} \\
\hline 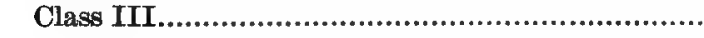 & & \\
\hline
\end{tabular}

891. Rye compared with barley.-The average of 11 experiments, ${ }^{2}$ with 110 animals, shows a daily gain of .865 pounds for barley-fed pigs and .873 pounds for those fed rye. These gains being practically equal show similar values for rye and barley as pig feeds. An examination of the carcasses at slaughtering time gave the following classification:

Results with barley and rye-fed pigs - Copenhagen Station.

\begin{tabular}{|c|c|c|}
\hline & Barley fed. & Rye-fed. \\
\hline Per cent. dressed weight......................... & 74.3 per cent. & 75 per cent. \\
\hline 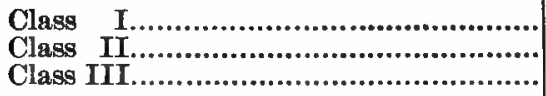 & $\begin{array}{l}68.0 \text { per cent. } \\
21.0 \text { per cent. } \\
11.0 \text { per cent. }\end{array}$ & $\begin{array}{l}63 \text { per cent. } \\
34 \text { per cent. } \\
3 \text { per cent. }\end{array}$ \\
\hline
\end{tabular}

The results indicate a practical equality between the two feeds for pork production. (177-8)

While rye is shown to be of equal value with barley for pig feeding we will learn later (895) that its by-product, rye shorts, is very unsatisfactory for this purpose.

892. Grain compared with oil cake. - Experiments were conducted in 1887-88 on 12 estates with 406 animals in all, divided

1 Rept. 1887, p. 52.

2 Ibid., p. 37 .

- Rept. 15, 1889 
into 77 lots, each containing at least 5 pigs. The experiments lasted from 65 to 1.68 days, averaging 110 days. Sunflower-seed cake, hemp-seed cake, palm-nut meal, peanut meal and blood bread were each fed against rye or barley. The oil cake was fed in connection with skim milk in some of the experiments, and with whey in others. The lots fed grain and oil cake received half their concentrates in the form of oil cake; those fed grain only, received skim milk or whey in addition. The averages of these extensive trials in which whey or barley meal was fed in opposition to oil cakes are shown in the following table, which condenses the results so that they may be easily compared by the student:

Feeding various forms of oil cake in comparison with grain - Copen. hagen Station.

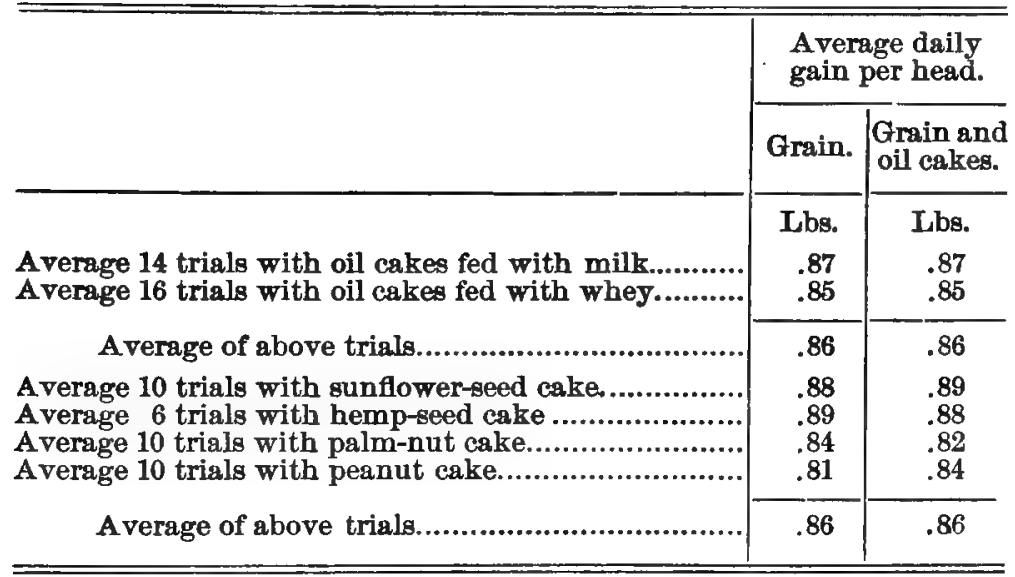

These results prove conclusively, it would seem, that a pound of oil cake has no more value for pigs than a pound of rye or barley, no matter with what other substance or under what conditions it may be fed. (206)

893. Slaughter tests of pigs fed in the preceding experiments. 1 Sunflower-seed cake and hemp-seed cake fed in connection with skim milk produced a soft quality of pork, which would command a lower price in the general market than that produced by

Loc. cit. 
the corresponding grain-fed lots. When fed in connection with whey, the quality of the pork compared favorably with that produced from barley or rye. There is no evidence that peanut or palm-nut cake injured the quality of the pork when fed with either skim milk or whey. These points are shown in the following table, which summarizes the results obtained at slaughtering time with some of the pigs fed in the trials reported in the preceding article:

Average data at slaughtering time with pigs fed various forms of oil cake-Copenhagen Station.

\begin{tabular}{|c|c|c|c|c|c|c|c|}
\hline \multirow{2}{*}{ Feed. } & \multirow{2}{*}{$\begin{array}{l}\text { Av. } \\
\text { live } \\
\text { wt. }\end{array}$} & \multirow{2}{*}{$\begin{array}{c}\text { Shrink } \\
\text { age. }\end{array}$} & \multirow{2}{*}{$\begin{array}{l}\text { Av. } \\
\text { thick- } \\
\text { ness of } \\
\text { pork. }\end{array}$} & \multicolumn{4}{|c|}{$\begin{array}{l}\text { No. of pigs } \\
\text { in class. }\end{array}$} \\
\hline & & & & 1 & 2 & 3 & 4 \\
\hline Sunflower-seed cake. & Lbs. & Per et. & Inches. & & & & \\
\hline \multirow{3}{*}{ 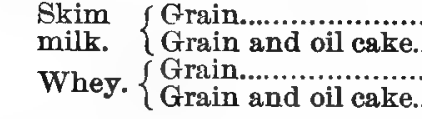 } & 161 & 24.4 & 1.3 & 14 & & 1 & \\
\hline & 161 & 25.3 & 1.3 & 1 & 1 & & 12 \\
\hline & $\begin{array}{l}163 \\
162\end{array}$ & 26.4 & 1.5 & $\begin{array}{l}4 \\
8\end{array}$ & $\begin{array}{l}3 \\
5\end{array}$ & $\begin{array}{l}3 \\
2\end{array}$ & \\
\hline \multicolumn{8}{|l|}{ Peanut cake. } \\
\hline \multirow{4}{*}{ 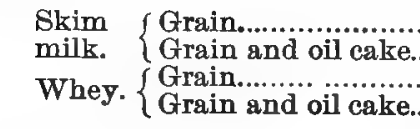 } & 160 & 24.7 & 1.4 & 5 & 5 & & \\
\hline & 162 & 23.5 & 1.3 & 11 & 1 & 2 & \\
\hline & 156 & 24.8 & 1.5 & 9 & 5 & 2 & \\
\hline & 156 & 24 & & 15 & & & \\
\hline \multicolumn{8}{|l|}{ Hemp-seed cake. } \\
\hline \multirow{4}{*}{ 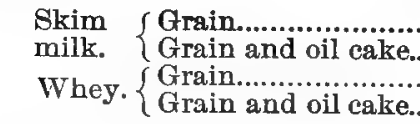 } & 184 & 28.3 & 1.5 & 10 & & & \\
\hline & 178 & 28.9 & 1.4 & 8 & 2 & & \\
\hline & 159 & 27 & 1.5 & 10 & 1 & 1 & $\cdots$ \\
\hline & 162 & 29 & & 11 & 1 & ....... & $\cdots$ \\
\hline \multicolumn{8}{|l|}{ Palm-nut cake. } \\
\hline Skim \{ Grail & 185 & 28.1 & 1.5 & 6 & 4 & ....... & \\
\hline milk. $\mathrm{Gr}$ & 178 & & 1.5 & 12 & 1 & & $\ldots$ \\
\hline Whey. $\left\{\begin{array}{l}G r \\
G r\end{array}\right.$ & $\begin{array}{l}167 \\
174\end{array}$ & 29 & $\begin{array}{l}1.5 \\
1.6\end{array}$ & 20 & 1 & ...... & $\cdots$ \\
\hline & 174 & & & 10 & 4 & & \\
\hline
\end{tabular}

In experiments ${ }^{1}$ conducted in the years 1891-94, the same kinds of oil cake used in the preceding trials were compared with barley, but the ratio of barley to oil cake in these trials, instead of being 1 to 1 , as in the first trials, was 1 to 2 or 2 to 1 . In all the series one lot of pigs was fed barley alone, for the sake of comparison. A small quantity of buttermilk and skim milk was also

Rept. 30, 1895. 
fed with the different rations. The gains made by the different lots were as follows:

Later trials with feeding grain in comparison with oil cakes - Copenhagen Station.

\begin{tabular}{|c|c|c|c|c|c|c|}
\hline \multirow[b]{2}{*}{ Feed. } & \multicolumn{3}{|c|}{$\begin{array}{c}\text { Average weight at } \\
\text { beginning. }\end{array}$} & \multicolumn{3}{|c|}{ Daily gain. } \\
\hline & $\begin{array}{l}\text { Bar- } \\
\text { ley. }\end{array}$ & $\begin{array}{l}\frac{2}{8} \text { bar- } \\
\text { ley, } \\
\frac{1}{8} \text { oil } \\
\text { cake. }\end{array}$ & $\begin{array}{l}\frac{1}{8} \text { bar- } \\
\text { ley } \\
\frac{2}{8} \text { oll } \\
\text { cake. }\end{array}$ & $\begin{array}{l}\text { Bar- } \\
\text { ley }\end{array}$ & $\begin{array}{l}\text { g bar- } \\
\text { ley, } \\
\frac{7}{c} \text { oil } \\
\text { cake. }\end{array}$ & $\begin{array}{l}\frac{1}{8} \text { bar- } \\
\text { ley, } \\
\frac{2}{8} \text { oil } \\
\text { cake. }\end{array}$ \\
\hline Sunflower-seed cake. & Lbs. & Lbs. & Lbs. & Lbs. & Lbs. & Lbs. \\
\hline $\begin{array}{l}\text { With skim milk, } 4 \text { trials.............. } \\
\text { With whey, } 2 \text { trials .................... } \\
\text { Palm-nut meal. }\end{array}$ & $\begin{array}{l}70.6 \\
60.5\end{array}$ & $\begin{array}{l}71.6 \\
60.6\end{array}$ & $\begin{array}{l}70.1 \\
60.4\end{array}$ & $\begin{array}{l}1.15 \\
1.17\end{array}$ & $\begin{array}{l}1.12 \\
1.21\end{array}$ & $\begin{array}{l}1.01 \\
1.13\end{array}$ \\
\hline 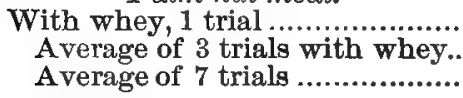 & $\begin{array}{l}71.2 \\
64.1 \\
67.8\end{array}$ & $\begin{array}{l}73.2 \\
64.8 \\
68.7\end{array}$ & $\begin{array}{l}72.2 \\
64.3 \\
67.6\end{array}$ & $\begin{array}{l}1.23 \\
1.19 \\
1.17\end{array}$ & $\begin{array}{l}1.19 \\
1.20 \\
1.16\end{array}$ & $\begin{array}{l}1.16 \\
1.14 \\
1.06\end{array}$ \\
\hline
\end{tabular}

These experiments in connection with those previously made show that the rations containing less than half the concentrates in the form of oil cake were nearly as effective as a pure grain ration, and that increasing the quantity of oil cake fed produced poorer results, the difference being greater when skim milk was fed than when feeding whey. When roots were fed in both rations the effect of the oil cake was still not so good, so far as gain in live weight goes, as in case of pure grain feeding. These results are of peculiar interest, since the higher protein content of the oil cakes would a priori indicate a higher feeding value for them than the cereals possess. In feeding trials with cows at the same Station (647) and elsewhere, oil cake has always been found superior to grain in nutritive value. They show that oil in feeds has not the high nutritive value with pigs assigned it by trials with the ruminants. While we accept these results and should act upon them in the practical feeding of the pig, we await the studies of the investigators to show why oil in feeds is less valuable with this animal than with the cow.

894. Rye or Barley versus Indian corn.-In 1888-9, seven. teen experiments ${ }^{1}$ were made with 444 pigs, on 13 different

1 Rept. 19, 1890. 
estates, in two of which Indian corn was compared with barley or rye. The grains were fed against one another in equal quantities by weight, with results given below:

Trials with barley or rye fed in opposition to Indian corn-Copenhagen Station.

\begin{tabular}{|c|c|c|c|c|c|c|}
\hline & \multicolumn{3}{|c|}{ Average weight. } & \multicolumn{3}{|c|}{$\begin{array}{c}\text { Average gain per } \\
\text { day. }\end{array}$} \\
\hline & $\begin{array}{c}\text { Lot I. } \\
\text { Bar- } \\
\text { ley or } \\
\text { rye. }\end{array}$ & $\begin{array}{l}\text { Lot } \\
\text { II. } \\
\text { 1 bar- } \\
\text { ley or } \\
\text { rye, } \frac{1}{2} \\
\text { corn. }\end{array}$ & $\begin{array}{l}\text { Lot } \\
\text { III. } \\
\text { Corn. }\end{array}$ & $\begin{array}{l}\text { Lot } I . \\
\text { Birr- } \\
\text { ley or } \\
\text { rye. }\end{array}$ & $\begin{array}{l}\text { Lot } \\
\text { II. } \\
\text { I bar- } \\
\text { ley or } \\
\text { rye, } \\
\text { corn. }\end{array}$ & $\begin{array}{l}\text { Lot } \\
\text { III. } \\
\text { Corn. }\end{array}$ \\
\hline Feed per day per head. & Lbs. & Lbs. & Lbs. & Lbs. & Lbs. & Lbs. \\
\hline $\begin{array}{c}\text { 3.61 lbs. grain, } 9.7 \text { lbs. skim milk, } \\
19.4 \text { lbs. whey, } 1 \text { lb. buttermilk. } \\
\text { Grading. }\end{array}$ & 79.8 & 79.9 & 79.9 & 1.32 & 1.36 & 1.35 \\
\hline $\begin{array}{l}\text { Softness of pork, points............. } \\
\text { No. of carcasses in highest grade. } \\
\text { No. of carcasses in lowest grade.. }\end{array}$ & (n....... & ln..... & $\left|\begin{array}{ll}\cdots \ldots \ldots \\
\cdots \cdots \cdots \\
\cdots \cdots \cdots\end{array}\right|$ & $\begin{array}{l}1.8 \\
8 \\
1\end{array}$ & $\begin{array}{l}2.3 \\
5 \\
7\end{array}$ & $\begin{array}{l}2.6 \\
3 \\
10\end{array}$ \\
\hline
\end{tabular}

The gain made on corn was slightly higher than that made on either barley (857) or rye, and about equal to that made on a mixture of the two. The slaughter tests show that the shrinkage was practically the same for the three lots. Corn made the softest pork, and also gave the largest number of carcasses in the fourth, or lowest, grade.

The experiments were continued during 1892-93.1 Since the quality of the pork seemed inferior when corn was fed thronghout the fattening period, experiments were made in which corn was fed until the pigs of the different lots weighed 120,140, or 160 pounds, after which barley was fed for grain until the close of the fattening period. (919) For comparison, one lot was fed barley and another corn exclusively, in each trial. Diairy refuse was given in addition in all cases. The grains were substituted, pound for pound, for one another in the rations fed the different lots. Results are available from five series of experiments with 115 pigs in all, the trials lasting from 100 to 140 days. It was found that the lots fed corn all the time made somewhat heavier

1 Rept. 1895. 
gains, the average daily increase being .04 pounds per head higher, as shown below:

Feeding pigs on corn, and finishing them with barley - Copenhagen Station.

\begin{tabular}{l|c|c|c|c|c}
\hline \hline & $\begin{array}{c}\text { Barley } \\
\text { only. }\end{array}$ & $\begin{array}{c}\text { Corn to } \\
120 \text { lbs. }\end{array}$ & $\begin{array}{c}\text { Corn to } \\
140 \text { lbs. }\end{array}$ & $\begin{array}{c}\text { Corn to } \\
160 \text { lbs. }\end{array}$ & $\begin{array}{c}\text { Corn } \\
\text { only. }\end{array}$ \\
\hline & Lbs. & Lbs. & Lbs. & Lbs. & Lbs. \\
Av. wt. at beginning............ & 46 & 49 & 46 & 45 & 46 \\
Av. daily gain, live weight... & 1.10 & $1.09^{*}$ & 1.14 & $1.10^{*}$ & 1.14 \\
\hline \hline
\end{tabular}

* Average for four trials.

The tests and data obtained at slaughtering time furnished valuable information concerning the quality of the pork produced, as summarized in the table below:

Average results at slaughtering time of pigs fed barley or cornCopenhagen Station.

\begin{tabular}{|c|c|c|c|c|c|c|c|c|}
\hline \multirow{2}{*}{ Feed. } & \multirow{2}{*}{$\begin{array}{c}\text { Av. wt. } \\
\text { at } \\
\text { slaugh- } \\
\text { tering. }\end{array}$} & \multirow{2}{*}{$\begin{array}{l}\text { Shrink- } \\
\text { age. }\end{array}$} & \multirow{2}{*}{$\begin{array}{c}\text { Thick- } \\
\text { ness of } \\
\text { pork. }\end{array}$} & \multirow{2}{*}{$\begin{array}{c}\text { Soft- } \\
\text { ness of } \\
\text { pork. }\end{array}$} & \multicolumn{4}{|c|}{$\begin{array}{l}\text { Per cent. } \\
\text { in class. }\end{array}$} \\
\hline & & & & & I. & II. & |III. & IV. \\
\hline & Lbs. & Per cent. & Inches. & Points. & & & & \\
\hline Barley all time.... & 183 & 23.9 & 1.3 & 1.4 & 57 & 35 & 4 & 4 \\
\hline Corn till 120 lbs... & 181 & 22.0 & 1.5 & 1.6 & 28 & 50 & 22 & \\
\hline Corn till 140 lbs... & 186 & 21.7 & 1.5 & 2.0 & 25 & 58 & 17 & $\cdots$ \\
\hline Corn till $160 \mathrm{lbs}$... & 183 & 22.2 & 1.5 & 2.3 & 45 & 30 & 25 & \\
\hline Corn all time....... & 185 & 21.1 & 1.5 & 2.7 & 29 & 33 & 24 & 14 \\
\hline
\end{tabular}

Exclusive barley feeding gave pork of the highest quality, (178) while exclusive corn feeding produced a poor quality. The pork increased in softness the longer the pigs were fed corn, the lowest quality resulting where corn was fed all the time. (155)

895. Grain compared with rye shorts. ${ }^{1}$ - In comparing rye and barley, or rye alone, with rye shorts in three series of experiments, the grain alone always produced better results than equal mixtures of grain and rye shorts, and these mixtures were again better than rye shorts alone. The daily gains made were.77 pounds for barley or rye alone, .70 pounds for grain and rye shorts mixed half and half, .61 pounds for rye shorts only, in one series

Rept. 19, 1890. 
of trials; in another, 1.22 pounds, 1.20 pounds, and 1.08 ponnds, respectively. The third series cannot be used, because the pigs fed rye shorts became sick. The quality of the pork produced where rye shorts were fed was poor, especially where all rye shorts were given, as will be seen in the table below:

Quality of pork made when feeding grain and rye shorts - Copenhagen Station.

\begin{tabular}{|c|c|c|c|c|c|c|c|c|}
\hline \multirow{2}{*}{ Feed. } & \multirow{2}{*}{$\begin{array}{l}\text { Wt. at } \\
\text { slaugh- } \\
\text { tering. }\end{array}$} & \multirow{2}{*}{$\begin{array}{l}\text { Shrink- } \\
\text { age. }\end{array}$} & \multirow{2}{*}{$\begin{array}{l}\text { Thick- } \\
\text { ness of } \\
\text { pork. }\end{array}$} & \multirow{2}{*}{$\begin{array}{l}\text { Soft- } \\
\text { ness of } \\
\text { pork. }\end{array}$} & \multicolumn{4}{|c|}{ Class. } \\
\hline & & & & & I. & II. & IUI. & IV. \\
\hline $\begin{array}{c}\text { Grain (rye and } \\
\text { barley)................. }\end{array}$ & $\begin{array}{r}\text { Lbs. } \\
162\end{array}$ & $\begin{array}{l}\text { Lbs. } \\
24.2\end{array}$ & $\begin{array}{c}\text { Inches. } \\
1.5\end{array}$ & $\begin{array}{c}\text { Points. } \\
1.7\end{array}$ & 8 & 6 & 7 & 1 \\
\hline $\begin{array}{l}\text { Half grain, half } \\
\text { rye shorts......... } \\
\text { Rye shorts.......... }\end{array}$ & $\begin{array}{l}159 \\
145\end{array}$ & $\begin{array}{l}24.9 \\
26.6\end{array}$ & $\begin{array}{l}1.4 \\
1.3\end{array}$ & $\begin{array}{l}2.5 \\
3.7\end{array}$ & $\begin{array}{l}1 \\
1\end{array}$ & $\begin{array}{l}4 \\
1\end{array}$ & $\begin{array}{c}2 \\
\ldots . . .\end{array}$ & $\begin{array}{r}7 \\
16\end{array}$ \\
\hline
\end{tabular}

The number of points for softness of pork increased rapidly with the feeding of rye shorts, and the classification of the carcasses showed that a poor quality of pork was produced when this feed was given.

896. Wheat bran compared with rye and barley.-Trials with wheat bran compared with barley or rye for pigs $^{1}$ were conducted during 1890-92 on five different farms and included 115 pigs, the trials lasting 112 days. Wheat bran was fed against rye on some farms and against barley on others, skim milk or whey being fed in addition. In four out of five trials the largest average gain was made by the lots fed grain, closely followed by those receiving a mixture of five parts barley or rye and seven parts wheat bran for every ten parts of grain fed the other lots. Bran alone did not produce as good results as a mixture of equal parts of grain and bran. The one-sided bran feeding in several instances caused sickness among the pigs, while none occurred in the other lots. Wheat bran has an appreciably lower nutritive value than barley or rye for pig feeding. In scoring the carcasses, the pork produced on wheat bran was found to be of poorer quality than that produced on grain, and shrank more in dressing, although the results were not so unfavorable with wheat bran as were the previous experiments with rye shorts. (175, 177-8, 855)

\footnotetext{
${ }^{1}$ Rept. 26, 1892.
} 
897. Grain compared with boiled potatoes. - Three series of experiments $^{1}$ were made to test the comparative value of cooked potatoes with grain, when both were fed in connection with skim milk or whey. Four pounds of potatoes were fed against one pound of grain, and the gains made were practically the same. Four pounds of boiled potatoes should thus be considered equal ; to one pound of grain in pig feeding. The quality of the pork produced from potato feeding was good and did not differ appreciably from that of lots differently fed.

898. Comparative feeding value of mangels $^{2}$ and grain. ${ }^{3}$ - For the purpose of determining the comparative value of mangels and grain as feeds for pigs the trials reported below were conducted. All lots received skim milk or whey in addition to the grain and roots, except Lots $\mathrm{E}$ and $\mathrm{F}$, to which an equivalent of additional roots was given. The average daily gains are shown below:

Average daily gain of pigs fed grain and mangels - Copenhagen Station.

\begin{tabular}{|c|c|c|c|c|}
\hline & \multicolumn{2}{|c|}{$\begin{array}{l}10 \mathrm{lbs} \text {. roots }= \\
1 \mathrm{lb} \text {. of grain. }\end{array}$} & \multicolumn{2}{|c|}{$\begin{array}{l}8 \mathrm{lbs} \text {. roots }= \\
1 \mathrm{lb} \text {. of grain. }\end{array}$} \\
\hline & Grain. & Roots. & Grain. & Roots. \\
\hline 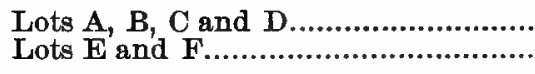 & $\begin{array}{c}.76 \mathrm{lbs} . \\
\ldots \ldots \ldots \ldots\end{array}$ & $\begin{array}{l}.83 \mathrm{lbs} . \\
.86 \mathrm{lbs} .\end{array}$ & $.85 \mathrm{lbs}$. & $\begin{array}{l}.86 \mathrm{lbs} . \\
.89 \mathrm{lbs} .\end{array}$ \\
\hline
\end{tabular}

The above shows that ten pounds of mangels were more than equal, and eight pounds about equal, to one pound of grain in these trials.

The quality of the pork produced by the different lots was very satisfactory; even where one-fourth of the daily feed was given in the form of roots, no deleterious effect was noticed. (3i8)

899. Grain compared with beets of different sugar content.-A preliminary feeding experiment ${ }^{4}$ with beets of different sugar content was made in $\mathbf{1 8 9 0}$ to ascertain their comparative feeding valnes. Mangels containing 12.71 per cent. dry matter and 8.93 per

\footnotetext{
1 Rept. 19, 1890.

2 In the Danish experiments all roots were fed uncooked, unless otherwise noted, and either whole or sliced, generally the latter. (316, 658, B66)

Rept. 1890. Rept. 26, 1892.
} 
cent. sugar were fed against fodder beets containing 13 . Bb per cent. dry matter and 13.8 per cent. sugar, or against barley. The experiment included 25 pigs averaging 79 pounds rach, and lasted 70 days.

The indications were that for pigs one pound of baxley had a feeding value equal to six to eight pounds of mangels, or four to eight pounds of fodder beets.

In experiments ${ }^{1}$ during 1891-92, lots including 204 pigs were fed four kinds of roots in addition to dairy refuse and gl:ain. The roots used were: (1) Eckendorf mangels, containing $1 \mathrm{t}$ per cent. dry matter and 6.7 per cent. sugar; (2) Elvetham maxgels, containing 13.6 per cent. dry matter and 8.9 per cent. sugar; (3) fodder sugar beets, containing 16.5 per cent. dry matter and 10.9 per cent. sugar; (4) sugar beets, containing 21.2 per cent. dry matter and 14 per cent. sugar. The lots fed barley only, made the largest gain, closely followed by those half of whose grain was replaced by roots in the following ratio: For 1 pound of barley was substituted 7.5 pounds of Eckendorf margels, 6.5 pounds of Elvetham mangels, 5 pounds of fodder beets and 4 pounds of sugar beets. These quantities of the different kinds of roots proved nearly equivalent in feeding value. The authorities conclude that about 40 per cent. of the daily ration of the pig may be advantageously made up of roots. The data sersured at slaughtering time led to the conclusion that the feeding of roots to the extent practiced in these experiments produced pork of a quality fully equal to that resulting from grain feeding. (320)

900. Carrots compared with mangels. - In 1892-94, ${ }^{2}$ experiments were conducted on nine different estates with 893 pigs, divided into 175 lots. It was found in the comparative trials that carrots and mangels containing equal quantities of dry matter had similar values in pig feeding; in other words, the arnount of dry matter in roots is of importance rather than the total weight or the quantity of sugar contained. (317)

901. Turnips compared with whey.-When feeding barley and whey to pigs, turnips were substituted for part of the whey. In two experiments ${ }^{8}$ with 30 animals, barley and whey gave an in-

\footnotetext{
${ }^{1}$ Rept. 26, 1892. $\quad{ }^{2}$ Rept. 30, 1895. a Ibid.
} 
crease of 1.08 pounds daily per head, while turnips gave only .96 pounds, showing that whey had a higher feeding value, pound for pound, than turnips. (320)

902. Grain compared with blood bread.-Blood bread prepared from blood and barley meal, baked in an oven the same as ordinary bread, was compared ${ }^{1}$ with grain in two trials with 40 animals, lasting 138 and 120 days, respectively. Four lots of pigs were fed grain and four lots blood bread. Two lots in each trial received skim milk and two whey in addition to the concentrated feed. The results are as follows:

Results of feeding blood bread in comparison with grain - Copenhagen Station.

\begin{tabular}{|c|c|c|c|c|}
\hline \multirow[b]{2}{*}{ Feed per head per day. } & \multicolumn{2}{|c|}{ Average weight. } & \multicolumn{2}{|c|}{$\begin{array}{l}\text { Av. daily gain } \\
\text { per head. }\end{array}$} \\
\hline & $\begin{array}{l}\text { Grain } \\
\text { (rye, or } \\
\text { rye and } \\
\text { barley). }\end{array}$ & $\begin{array}{l}\text { Blood } \\
\text { bread. }\end{array}$ & $\begin{array}{l}\text { Grain } \\
\text { fed. }\end{array}$ & $\begin{array}{l}\text { Blood } \\
\text { bread } \\
\text { fed. }\end{array}$ \\
\hline & Lbs. & Lbs. & Lbs. & Lbs. \\
\hline $\begin{array}{l}1.64 \text { lbs. conc. feed, } 15.5 \text { lbs. milk..... } \\
2.46 \text { lbs. conc. feed, } 10.6 \text { lbs. milk .... }\end{array}$ & $\begin{array}{l}58.6 \\
58.4\end{array}$ & $\begin{array}{l}58.4 \\
58.4\end{array}$ & $\begin{array}{l}.98 \\
.97\end{array}$ & .74 \\
\hline Average........................................... & & & .98 & .70 \\
\hline $\begin{array}{l}1.77 \mathrm{lbs} \text {. conc. feed, } 20.6 \text { lbs. whey, } \\
1.4 \mathrm{lbs} \text {. skim milk ................................. }\end{array}$ & 61.6 & 61.4 & 1.00 & .79 \\
\hline 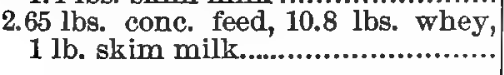 & 61.6 & 61.4 & 1.13 & .87 \\
\hline 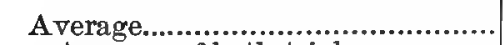 & ................... & ............. & 1.07 & .83 \\
\hline Average of both trials ................ & & & 1.02 & .76 \\
\hline
\end{tabular}

The blood bread contained more water than was supposed when the experiments were started. Its average percentage chemical composition was as follows:

Water, 59.6; protein, 20; starch, 16.1; fat, .4; cellulose, 2.4; ash, 1.5.

The trials showed the blood bread decidedly inferior to ryo or barley when fed in connection with skim milk or whey. It was concluded that had it contained less water different results might have been secured. It is possible, however, that baking the bread may have lowered its feeding value for pigs, the same as

Rept. 15, 1889. 
does cooking feed. A study at slaughtering time of the carcasses of the pigs fed as described on the preceding page gave the results shown in the following table:

Average data at slaughtering time with hogs fed blood bread and grain-Copenhagen Station.

\begin{tabular}{|c|c|c|c|c|c|c|c|c|}
\hline \multirow{2}{*}{ Feed. } & \multirow{2}{*}{$\begin{array}{l}\text { Aver- } \\
\text { age live } \\
\text { weight. }\end{array}$} & \multirow{2}{*}{$\begin{array}{l}\text { Shrink- } \\
\text { age. }\end{array}$} & \multirow{2}{*}{$\begin{array}{l}\text { Aver- } \\
\text { age } \\
\text { thick- } \\
\text { ness of } \\
\text { pork. }\end{array}$} & \multirow{2}{*}{$\begin{array}{l}\text { Softness } \\
\text { of pork. }\end{array}$} & \multicolumn{4}{|c|}{$\begin{array}{l}\text { No. of carcasses } \\
\text { in class. }\end{array}$} \\
\hline & & & & & I. & II. & III. & IV. \\
\hline & Lbs. & Lbs. & Inches. & Points. & & & & \\
\hline $\begin{array}{l}\text { Grain with milk...... } \\
\text { Blood bread with } \\
\text { milk ...................... }\end{array}$ & $\begin{array}{l}192 \\
182\end{array}$ & $\begin{array}{l}26.0 \\
32.2\end{array}$ & $\begin{array}{l}1.6 \\
1.3\end{array}$ & $\begin{array}{l}1.7 \\
3.4\end{array}$ & $\begin{array}{r}7 \\
10\end{array}$ & 3 & & \\
\hline $\begin{array}{l}\text { Grain with whey.... } \\
\text { Blood bread with }\end{array}$ & 173 & 26.4 & 1.4 & 2.8 & 7 & & & 2 \\
\hline whey ....................... & 158 & 29.2 & 1.2 & 4.6 & 5 & & & 5 \\
\hline
\end{tabular}

The results show that the quality of the pork produced by the lot fed blood bread was on the whole inferior to that produced by the grain-fed lot.

In regard to shrinkage, and the quality of pork as shown by the number of points for softness for the different lots, the live weights of the lots fed blood bread and milk were more in accord with the demands of the market than those of the corresponding lots fed grain. This explains why all animals in this lot were placed in Class I. Besides yielding soft pork with considerable shrinkage, the blood bread showed a tendency to produce too thin an external layer of fat, making what the pork-packers call a "skinny" carcass. (338)

\section{Various Problems in Pig Feeding.}

903. Shelter for pigs.-Two experiments ${ }^{1}$ were made with eight pigs each, separated into two lots, each pig receiving the following feed daily: 6.2 pounds skim milk; 6.5 pounds whey; 2.2 pounds rye, barley, corn and peanut meal, mixed.

Lot I ran in the open yard during the day, while Lot II was

Rept. 10, 1887. 
kept indoors. The experiment lasted 130 days, with the average weights and gains shown in the table:

Results of shelter tests with pigs-Copenhagen Station.

\begin{tabular}{|c|c|c|c|c|c|}
\hline & \multicolumn{2}{|c|}{ Experiment I. } & \multicolumn{2}{|c|}{ Experiment II. } & \multirow[b]{2}{*}{$\begin{array}{l}\text { Av. daily } \\
\text { gain, } \\
\text { both } \\
\text { trials. }\end{array}$} \\
\hline & $\begin{array}{c}\text { Av. wt. } \\
\text { at be- } \\
\text { gin- } \\
\text { ning. }\end{array}$ & $\begin{array}{l}\text { Av. } \\
\text { daily } \\
\text { gain. }\end{array}$ & $\begin{array}{l}\text { Av. wt. } \\
\text { at be- } \\
\text { gin- } \\
\text { ning. }\end{array}$ & $\begin{array}{l}\text { Av. } \\
\text { daily } \\
\text { gain. }\end{array}$ & \\
\hline & Lbs. & Lbs. & Lbs. & Lbs. & Lbs. \\
\hline $\begin{array}{l}\text { Pigs kept indoors................. } \\
\text { Pigs kept outdoors............... }\end{array}$ & $\begin{array}{l}64.5 \\
64.0\end{array}$ & $\begin{array}{l}.80 \\
.91\end{array}$ & $\begin{array}{l}63.8 \\
62.5\end{array}$ & $\begin{array}{l}.81 \\
.87\end{array}$ & $\begin{array}{l}.80 \\
.89\end{array}$ \\
\hline
\end{tabular}

The number of animals in the trial is too small to allow generalization, but the result favors exercise for light pigs. (83-4)

904. Effect of addition of water to feed. - Three experiments ${ }^{1}$ were conducted. with 68 pigs, the trials continning 60, 120 and 160 days, respectively. In Experiment $I$ the skim milk and buttermilk fed Lot A was diluted with twice its volume of water; Lot B received one-half this quantity of water. In Experiments II and III as much water was added to the milk of Lot $A$ as there was skim milk. Lot B was allowed water at will, supplied separately. The feed eaten and gains are shown in the table:

Results of watering the feed of pigs-Copenhagen Station.

\begin{tabular}{|c|c|c|c|c|c|c|c|}
\hline & $\begin{array}{l}\text { Skim } \\
\text { milk. }\end{array}$ & $\begin{array}{c}\text { Butter- } \\
\text { milk. }\end{array}$ & $\frac{\dot{8}}{8}$ & Grain. & Water. & $\begin{array}{l}\text { Av. } \\
\text { wt. }\end{array}$ & $\begin{array}{l}\text { Daily } \\
\text { gains } \\
\text { made. }\end{array}$ \\
\hline & Lbs. & Lbs. & Lbs. & Lbg. & Lbs. & Lbs. & Lbs. \\
\hline $\begin{array}{l}\text { Expt. I, Lot A... } \\
\text { Expt. I, Lot B... }\end{array}$ & $\begin{array}{l}3.0 \\
3.0\end{array}$ & $\begin{array}{l}3.0 \\
3.0\end{array}$ & $\begin{array}{l}8.0 \\
8.0\end{array}$ & $\begin{array}{l}2.3 \\
2.3\end{array}$ & $\begin{array}{r}12.0 \\
6.0\end{array}$ & $\begin{array}{l}127.8 \\
129.0\end{array}$ & $\begin{array}{l}.73 \\
.71\end{array}$ \\
\hline $\begin{array}{l}\text { Expt. II, Lot A.. } \\
\text { Expt. II, Lot B. }\end{array}$ & $\begin{array}{l}14.5 \\
14.5\end{array}$ & $\begin{array}{l}1.0 \\
1.0\end{array}$ & ( & $\begin{array}{l}2.6 \\
2.6\end{array}$ & $\begin{array}{c}14.5 \\
2.6^{*}\end{array}$ & $\begin{array}{l}72.7 \\
72.2\end{array}$ & $\begin{array}{r}.92 \\
1.02\end{array}$ \\
\hline $\begin{array}{l}\text { Expt. III, Lot A } \\
\text { Expt. III, Lot B }\end{array}$ & $\begin{array}{l}10.5 \\
10.5\end{array}$ & $\begin{array}{l}1.0 \\
1.0\end{array}$ & & $\begin{array}{l}1.3 \\
1.3\end{array}$ & $\begin{array}{l}10.5 \\
1.0^{*}\end{array}$ & $\begin{array}{l}27.0 \\
29.3\end{array}$ & $\begin{array}{l}.68 \\
.67\end{array}$ \\
\hline
\end{tabular}

* Water ad libitum.

The average of the three trials shows a daily gain of .78 pounds for Lot A, getting water with their feed, and .80 pounds for Lot

1 Rept. 10, 1887. 
$B$, getting less water. $A s$ the results are practically equal, it cannot be said that the addition of water to the skim milk was a disadvantage in these trials.

905. Winter and summer feeding compared.- Pig-feeding experiments conducted by the Copenhagen Station ${ }^{1}$ since 1887 have been summarized with a view of obtaining information concerning the amount of feed required for 100 pounds of growth in winter and in summer. In all trials the skim milk, whey, roots, etc., fed have been reduced to their grain equivalent as determined by the various trials. The animals were separated into three groups, according to their live weight. The following average results as to feed eaten for one hundred pounds of increased live weight were obtained:

Feed consumed for one hundred pounds increase with pigs in winter and in summer - Copenhagen Station.

\begin{tabular}{|c|c|c|c|c|c|c|}
\hline \multirow{2}{*}{$\begin{array}{l}\text { Period of } \\
\text { growth and } \\
\text { a verage weight } \\
\text { of pigs. }\end{array}$} & \multicolumn{2}{|c|}{ No. of experiments } & \multicolumn{2}{|c|}{$\begin{array}{l}\text { Feed eaten (grain } \\
\text { equivalent) per } \\
\text { day per head. }\end{array}$} & \multicolumn{2}{|c|}{$\begin{array}{c}\text { Feed (grain equiv- } \\
\text { alent) for } 100 \\
\text { lbs. gain. }\end{array}$} \\
\hline & Winter. & Summer. & Winter. & Summer. & Winter. & Summer. \\
\hline & & & Lbs. & Lbs. & Lbs. & Lbs. \\
\hline $\begin{array}{l}35 \text { to } 75 \text { lbs..... } \\
75 \text { to } 115 \text { Ibs.... }\end{array}$ & $\begin{array}{l}10 \\
43\end{array}$ & $\begin{array}{l}17 \\
39\end{array}$ & $\begin{array}{l}2.66 \\
3.96\end{array}$ & $\begin{array}{l}2.65 \\
3.92\end{array}$ & $\begin{array}{l}371 \\
446\end{array}$ & $\begin{array}{l}346 \\
397\end{array}$ \\
\hline 115 to 155 lbs.... & 47 & 43 & 5.26 & 5.25 & 516 & 457 \\
\hline $\begin{array}{c}\text { Totals and } \\
\text { averages ... }\end{array}$ & 100 & 99 & 3.96 & 3.94 & 444 & 400 \\
\hline
\end{tabular}

The table gives the average results of 100 experiments in winter and 99 in summer. Since each trial included from 20 to 30 animals, or more, we have the average results obtained with feeding at least 2,500 animals. The feed for one pound of gain, given in "totals and averages," is the arithmetical mean of each set of three figures in the different columns, the data for each period of growth being considered of equal value without regard to the number of experiments included in each, since all the groups contain an ample number of experiments to give a true expression of the feed requirements of the animals embraced within each period.

\footnotetext{
Rept. 30, 1895.
} 
We note that the pigs ate only a little more feed in winter than in summer, and that it required 44 pounds or 11 per cent. more feed in winter than in summer to produce 100 pounds of gain. The figures given doubtless express the feed requirements of pigs under ordinary conditions in Denmark. The climate of Denmark is tempered by cool summers and is not excessively cold in winter. The average temperatures observed during the trials are given in the following table, the figures being for the air, stable and feed:

Temperatures recorded in pig-feeding trials - Copenhagen Station.

\begin{tabular}{|c|c|c|c|c|c|c|c|c|}
\hline \multirow{3}{*}{$\begin{array}{l}\text { Period of } \\
\text { growth. }\end{array}$} & \multicolumn{2}{|c|}{$\begin{array}{l}\text { No. of experi- } \\
\text { ments. }\end{array}$} & \multicolumn{6}{|c|}{ Temperature, degrees Fahrenheit. } \\
\hline & \multirow{2}{*}{ Winter. } & \multirow{2}{*}{ Summer. } & \multicolumn{3}{|c|}{ Winter. } & \multicolumn{3}{|c|}{ Summer. } \\
\hline & & & Air. & Stable. & Feed. & Air. & Stable. & Feed. \\
\hline $\begin{array}{l}35 \text { to } 75 \mathrm{lbs} . . . \\
75 \text { to } 115 \mathrm{ll} \text {.... } \\
115 \text { to } 155 \text { lbs... }\end{array}$ & $\begin{array}{r}9 \\
36 \\
25\end{array}$ & $\begin{array}{l}17 \\
35 \\
24\end{array}$ & $\begin{array}{l}35.6 \\
34.3 \\
36.0\end{array} \mid$ & $\begin{array}{l}47.7 \\
48.7 \\
49.1\end{array}$ & $\begin{array}{l}50.2 \\
51.1 \\
52.9\end{array}$ & $\mid \begin{array}{l}58.8 \\
59.2 \\
56.1\end{array}$ & $\begin{array}{l}61.2 \\
61.2 \\
59.9\end{array}$ & $\begin{array}{l}59.4 \\
59.9 \\
58.3\end{array}$ \\
\hline
\end{tabular}

The table shows there was an average difference of only 20 or 25 degrees Fahr. between the summer and winter temperature when the experiments were conducted. These differences show a narrower range than prevails in most parts of the United States.

906. Light versus heavy feeding. - In two series of experiments with 60 animals in all, 1 the influence of the intensity of feeding on gain was made a special object of investigation. One experiment lasted 120 days, the other 210 days. The feeds used were barley, buttermilk, skim milk and whey.

Results from heavy and light feeding - Copenhagen Station.

\begin{tabular}{|c|c|c|c|c|}
\hline Feeding. & $\begin{array}{c}\text { Grain fed } \\
\text { daily. }\end{array}$ & $\begin{array}{l}\text { Av. wt. of } \\
\text { pigs at be- } \\
\text { ginning of } \\
\text { exp't. }\end{array}$ & $\begin{array}{l}\text { Gain per } \\
\text { day. }\end{array}$ & $\begin{array}{l}\text { Grain for } \\
100 \text { lbs. } \\
\text { gain. }\end{array}$ \\
\hline & Lbs. & Lbs. & Lbs. & $\mathrm{Lbs}$ \\
\hline Light................................. & 3.61 & 34.9 & .92 & 391 \\
\hline Medium................................. & 4.23 & 35.0 & 1.07 & 397 \\
\hline 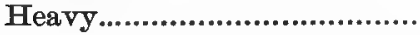 & 4.51 & 35.1 & 1.12 & 404 \\
\hline
\end{tabular}

1 Rept. 30, 1895. 
These results indicate a tendency toward a poorer utilization of the feed in the heavier feeding; the differences obtained are not, however, so great as in the case of winter and summer feeding.

907. Feed required for 100 pounds of gain. - In the following table $^{1}$ the grain or its equivalent required for 100 pounds of gain is reported for 355 animals in 16 experiments. These trials were with pigs ranging from 35 to 315 pounds, live weight. The figures given in the second line of the table are the arithmetical means of all figures for pigs coming within the range of live weight given in each column. Seven experiments supplying additional data for the five intermediate periods are given in the third line. The results of these important investigations are summarized in the following table:

Grain or equivalent fed to produce 100 pounds gain with pigs Copenhagen Station.

\begin{tabular}{|c|c|c|c|c|c|c|c|}
\hline & \multicolumn{7}{|c|}{ Average weight of pigs in lots - } \\
\hline & $\begin{array}{l}\mathrm{I} \\
35-75 \\
\text { lbs. }\end{array}$ & $\begin{array}{l}\text { II. } \\
75-115 \\
\text { lbs. }\end{array}$ & $\begin{array}{c}\text { III. } \\
115-155 \\
\text { lbs. }\end{array}$ & $\begin{array}{l}\text { IV. } \\
\text { 155-195 } \\
\text { lbs. }\end{array}$ & $\begin{array}{c}\mathrm{V} \\
195-235 \\
\text { lbs. }\end{array}$ & $\begin{array}{c}\text { VI. } \\
235-275 \\
\text { lbs. }\end{array}$ & $\begin{array}{l}\text { VII. } \\
275-315 \\
\text { lbs. }\end{array}$ \\
\hline $\begin{array}{l}\text { No. of experiments..... } \\
\text { Av. feed required, lbs.. } \\
\text { Av. feed required in } \\
\text { seven comparative } \\
\text { experiments, lbs....... }\end{array}$ & $\begin{array}{r}3 \\
376 \\
\\
\ldots \ldots\end{array}$ & $\begin{array}{r}10 \\
435\end{array}$ & $\begin{array}{r}13 \\
466\end{array}$ & $\begin{array}{r}15 \\
513\end{array}$ & $\begin{array}{r}14 \\
540\end{array}$ & $\begin{array}{r}11 \\
614\end{array}$ & $\begin{array}{r}3 \\
639\end{array}$ \\
\hline
\end{tabular}

We notice a steady increase in the feed required to produce 100 pounds of gain with increasing weight of the animals. Pigs weighing 275 pounds required nearly twice as much feed for 100 pounds of increase as those weighing from 35 to 75 pounds. (845)

908. Barrows compared with sows.-The following table, ${ }^{2}$ which includes data obtained from 1,216 animals, gives information concerning the comparative fattening qualities of barrows and sows.

Although data from a large number of animals were employed in the computation, the table shows no practical difference in

\footnotetext{
1 Rept. 30, $1895 . \quad$ Loc. cit.
} 
the results obtained for the two sexes as regards either gain, shrinkage, or quality of carcass.

Comparative fattening qualities of barrows and sows - Copenhagen Station.

\begin{tabular}{|c|c|c|c|c|}
\hline & \multirow{2}{*}{ Barrow. } & \multirow{2}{*}{ Sow. } & \multicolumn{2}{|c|}{$\begin{array}{l}\text { No. of animals } \\
\text { in trials. }\end{array}$} \\
\hline & & & Barrow. & Sow. \\
\hline 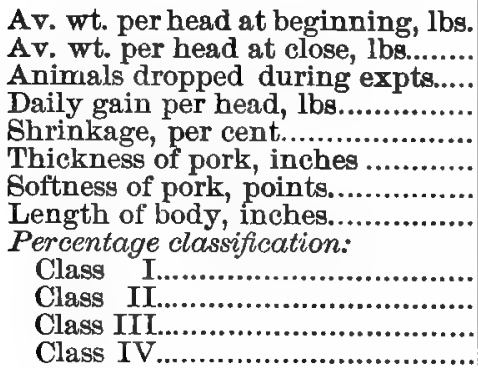 & $\begin{array}{l}54 \\
167 \\
\ldots \ldots \ldots \\
.987 \\
22.6 \\
1.5 \\
1.4 \\
33.3 \\
44 \\
33 \\
20 \\
3\end{array}$ & $\begin{array}{c}55 \\
165 \\
73.975 \\
23.2 \\
1.4 \\
1.5 \\
33.7 \\
56 \\
29 \\
12 \\
3\end{array}$ & $\begin{array}{c}586 \\
675 \\
11 \\
575 \\
364 \\
\ldots \ldots \ldots \ldots . . .\end{array}$ & $\begin{array}{r}630 \\
613 \\
17 \\
613 \\
373 \\
\ldots \ldots \ldots \ldots \\
209 \\
108 \\
43 \\
13\end{array}$ \\
\hline
\end{tabular}

909. Breed tests. -Four essentially pare breeds of swine, ${ }^{1}$ including 120 animals in all, were compared, the trials lasting 148 to 168 days each, with the following average daily gains:

Results of breed tests - Copenhagen Station.

\begin{tabular}{|c|c|c|c|c|c|c|}
\hline \multirow{2}{*}{ Breed. } & \multicolumn{3}{|c|}{$\begin{array}{l}\text { Average weight at begin- } \\
\text { ning of trials. }\end{array}$} & \multicolumn{3}{|c|}{$\begin{array}{c}\text { Average daily gain } \\
\text { per head. }\end{array}$} \\
\hline & I. & II. & III. & I. & II. & III. \\
\hline & Lbs. & Lbs. & Lbs. & Lbs. & Lbs. & Lbs. \\
\hline Vendsyssel...... & 20.5 & 30.4 & & .99 & .94 & \\
\hline 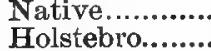 & 20.3 & ............ & 19.9 & .91 & …........ & .92 \\
\hline Tam worth ....... & 19.9 & 30.2 & & & 97 & \\
\hline Poland-China. & & & 19.8 & & & .93 \\
\hline
\end{tabular}

The animals of the native breeds made the poorest gain, and the Vendsyssel and Tamworth the best, but the differences were small. Neither did the data obtained at slaughtering time show any appreciable difference between the breeds as to value of carcass, except that the Poland-China breed proved superior to the native, on account of the greater hardness of the pork. (835)

1 Rept. 15, 1889. 


\section{CHAPTER XXXV.}

FEEDING AND MANAGEMENT OF SWINE-EFFEOT OF FFED ON THE OARCASS OF THE PIG.

\section{Feeding and Management.}

910. Breeding stock. - In the successful management of breeding stock the prime requisite is ample pasture, that the animals may be maintained in the open air and sunshine, away from pens and yards, during as large a portion of the year as possible. Roaming in pastures covered with nutritious clovers and grasses, the pigs will develop healthy bodies. The pasture will not alone suffice for nutriment and should be supplemented by foods especially adapted to bone and muscle building. Pigs of the larger breeds should receive sufficient nutriment to insure about one pound of growth per day, in order to reach the standard weight of 300 pounds when one year old. (84i)

The boar should be kept on pasture as much as possible, and when confined should be provided with a large lot for exereise. After the growth of the framework is completed this animal should receive only sufficient feed to continue in fair condition, all tendency to grossness being avoided. It is especially important to supply coarse feeds, as roots, whole oats, bran, and boiled chaffed clover hay.

911. Feed for the brood sow. - The feed for the sow before farrowing should be nutritious but not concentrated. Heavy, concentrated feed stuffs may be extended or given volume by using bran, which serves well for this purpose, and roots, which are much relished, and by supplying chaffed clover or alfalfa hay softened with boiling water. Some corn may be fed, but meals rich in protein-oats, peas, middlings and barley-should supply most of the nutriment. Breeders differ in their management of sows before farrowing, some insisting that they be held in thin flesh, while others would have them in high condition. They will prove satisfactory when in good flesh, provided it is put on 
under proper regulations as to character of feed and amonnt of exercise. As farrowing-time approaches let the feed be sloppy and limited in quantity. Any tendency to costiveness should be overcome by feeding bran, oil meal, roots, or other feeds of a corrective character. For two or three days after farrowing supply only a limited quantity of feed. A thin, warm slop made of middlings, oatmeal with a very little oil meal, poured a little at a time into the feeding trough, will quench the thirst of the new mother and answer all requirements. Eating her young, an act quite common with brood sows, is unnatural, and reflects upon the management of the feeder, indicating that feed and exercise have not been properly regulated.

912. Importance of exercise. - Sows carrying much flesh, made while confined in small pens, will prove at best unsatisfactory breeders. In summer, exercise is easily secured by the use of pasture, but winter conditions at the North are so adverse to outdoor life of the pig that much ingenuity is called for on the part of the herdsman to attain the desired end. Sows will gain exercise in winter, when the weather is not too severe, if turned into sheltered yards where horses and cattle will not annoy them. If litter from the stable is thrown in the yard, exercise will be gained while working this over in search of waste grains. Some exercise can also be forced by scattering grains of corn or oats, preferably the latter, very thinly over the feeding floor. In gathering the grains the sows will be kept upon their feet for some time. If exercise can be secured in no other way, the sows should be driven for some time each day by the herdsman along a lane or roadway or about the yard.

913. Feeding sow and pigs.- If all goes well at farrowingtime, the feed may be gradually increased after two or three days, with the increasing flow of milk and the growing demands of the pigs, nntil a full ration is supplied. Brood sows should be heavily fed, for the gains of young pigs are made at low cost for feed consumed. (831) Good brood sows with large litters will usually fall off in weight despite the best of care and feed, but such decrease is no reflection upon the skill of the feeder. In feeding a brood sow the herdsman can draw upon all feeds at his 
command. Middlings, ground oats and corn meal are particnlarly useful and should be liberally supplied; some bran, ground peas, barley and other grains will also prove helpful. The byproducts of the dairy - skim milk and buttermilk - are always in place and may be used to almost any extent. Cooked roots, potatoes or pumpkins with a liberal admixture of meal form an acceptable ration.

At farrowing-time, as soon as the young pigs have drawn theix first sustenance, it is well to at once separate them from the dam, placing them near by in a chaff-lined box or barrel. Sows which have been properly handled before farrowing will not usually resist such separation. Here the pigs are safe from harm, and the attendant can pass them to the dam at intervals of a few hours for nourishment. Mature sows are often so clumsy that unless some precaution is taken they will kill their young by lying upon them. After two or three days the pigs are sufficiently strong and active to be entirely given over to the care of the dam. Pigs often injure the teats or udders of the sow while sucking, because of sharp teeth. Their mouths should be examined and the injurious members filed or broken off - a simple operation.

When two or three weeks old, pigs will take a little nourishment provided for them in a separate trough, which should be located at a convenient point in pen or lot accessible to the pigs but not to the dam. At first, place only a pint or two of feed in the trough, and when this is eaten give more. Skim milk will be the most relished, but in its absence a thin porridge of middlings or sieved ground oats with a little oil meal will prove satisfactory. Soaked grains of corn scattered over the feeding floor will keep the young things busy and on their feet, getting exercise while securing nourishment. The pigs should be encouraged to eat as much as possible from the side trough.

914. Exercise for young pigs. - Well-nurtured young pigs often become very fat, and many die unless abundant exercise is provided. If sufficient exercise cannot be given, danger can in part be averted by reducing the feed supply, though by this growth is more or less checked. In the absence of more natural exercise, the herdsman should turn the pigs out of doors two or three 
times a day and drive them about the yard for a time. Selle ${ }^{1}$ describes a means of exercise for winter pigs as follows: Wagon loads of sods are placed in the cellar in the fall. In winter these sods, with bits of meat scrap or cracklings added, are thrown into the pens, to be worked over by the young pigs. In searching for cracklings or scraps in the sods the pigs get exercise by rooting as well as some feed.

Upon the first appearance of scouring or other ailment, the supply of food should be reduced and the diet changed if possible. Carefully remove all excrement and change the animals to new quarters if they can be provided.

915. Weaning the pigs. - Pigs are generally weaned when from seven to ten weeks old. This is best accomplished by first re moving the two strongest members of the litter to a separate pen, and aiter two or three days taking away others, always choosing the most vigorous, until all are removed. Under this practice the milk flow of the dam will gradually diminish until it ceases. Many breeders allow pigs to wean themselves, - a result reached without difficulty where they are liberally supplied with palatable nourishment at a side trough. When the pigs are weaned they should be placed in groups of not over twenty, care being taken that the members in each group are the same size. Where large numbers of pigs of varying sizes range together, the weaker ones are at a disadvantage at the feed trough and are liable to permanent injury from lack of feed and the rough treatment they receive.

916. Feeding shotes.-Under good management, the period between weaning and fattening the pig is bridged without difficulty. First, let this animal be kept upon natural earth, having the freedom of the pasture as long as possible. There is no better place for the growing pig intended for either breeding or fattening than a wood-lot of mixed herbage or a pasture carpeted with blue grass, clover or alfalfa. Pigs should wear no rings in their noses unless much rooting is done, for this cruel restriction works injury to the animal in several ways. While on pasture, the shote should still receive feed possessing bulk and carrying a

\footnotetext{
1 Wis. Farmers' Institute Bul., 1894.
} 
liberal supply of protein for muscle building and ash for the bones. If these are amply supplied, some corn may be fed without harm. The feeder should aim to keep the pig steadily increasing in weight from one-half to one pound per day, according to the size of the animal. (830)

917. Fattening the pig. - Pigs are now prepared for market at all ages and the feeder should be governed by local requirements. A pig which has been reared on pasture supplemented with feeding stuffs rich in protein and ash can be rapidly and economically fitted for the market. Having been supplied with nutritious, cooling grasses and other plants of the field, the digestive tract of this animal becomes ample in size, healthy, active, and easily able to digest large quantities of feed, the whole system being in condition to assimilate the nutriment supplied and utilize it to the fullest extent.

\section{Feed for Swine.}

918. Feeding corn. - In this country Indian corn must continue the common feeding stuff for swine. Because it is rich in carbohydrates and fat and low in protein and ash, the special function of this grain in pig feeding is the production of fat. (155) Having a proper knowledge of its composition and limitations, the feeder is in position to wisely use this great cereal. For breeding stock, corn should constitute not over half the ration at any time, the amount being smallest with young animals. As the body increases in size and nears maturity, the demand for protein and ash becomes less, and the proportion of corn to other grain can be gradually increased, until during the fattening stage the ration may, if desired, consist almost wholly of this grain.

Whether corn should be fed whole or as meal depends upon circumstances. (848) If the kernels are so hard as to cause sore mouths, thereby preventing easy mastication, the grain should be ground. If no trouble arises from this source, the utility of grinding hinges on the relative cost of grain and grinding. We have seen (848) that some grain is saved by reduction to meal, and the feeder can easily estimate whether he should incur the extra expense of grinding. Where grinding is not possible 
hard corn may be prepared for feeding by soaking the grains. Ear corn and shelled corn can be satisfactorily fed to fattening pigs upon a feeding floor of matched lumber, swept clean each day. Corn meal should always be soaked with water before feeding, the dry meal being unpalatable. Remembering that feeds in combination are better than the same feeds given singly, the prudent stockman will provide some complementary feed for pigs getting corn, even though the proportion of the secondary feed be small. (894)

919. Demand for leaner pork. - Consumers at home and abroad are calling for leaner pork, and the feeder should cater to market requirements. The demand can be met by using more proteinrich feeds, with less corn, during the growth of the pig, and especially by shortening the fattening period. Feeding the byproducts of milling, oats, barley, or the waste products of the dairy, with corn, the fattening period not being unduly prolonged, produces pork which will easily meet the requirements of the most discriminating market. (894)

920. Why lard rules low in price.- Millions of barrels of mineral oil are now obtained yearly from the oil wells, and an enormous quantity of vegetable oil is produced from the cotton seed. The combined effect of these two articles is to limit the use of animal fats to the dining-table, while formerly they served for both lubricants and illuminants as well as for human food. The introduction and general use of the oils named has brought about one of the greatest economic changes of recent times. In this change we have an explanation of the low prices ruling for lard and tallow. Despite the low price for animal fats, consumers are calling for still less fat in pork, or at least a larger proportion of lean to fat. So long as oil can be secured from the earth and from the cotton seed, we cannot hope for high prices for lard or other animal fats. With these conditions confronting us, there seems no alternative but to produce more lean and less fat pork.

921. Wheat. - We have seen (851) that wheat divides honors with corn in its ability to produce gain with pigs, and because it contains more protein and ash it comes nearer fulfilling the re- 
quirements of an all-around feed. Wheat is much superior to corn for young pigs and shotes. $(\mathbf{1 6 7 , 8 0 2})$ The flesh of wheatfed pigs is considered very satisfactory, generally carrying less tat than that from corn-fed animals. Because the grains are small and hard, wheat should always be reduced to meal before it is fed. Soaked wheat has proved unsatisfactory with many feeders. As we have seen, (852) wheat and corn meal in combination give better gains than either separately.

922. Middlings. - As a feed for swine at all periods of their development, middlings stand pre-eminent. Because it contains much protein and ash and is not loaded with crude-fiber like bran, this feeding stuff is particularly suited to the nourishment of very young pigs, ranking next to the by-products of the dairy for that purpose. (107) Middlings serve admirably with corn for feeding pigs during the fattening period. Like other milling by-products, middlings are said to produce soft pork, and therefore should never be fed alone, but always with corn, barley or other grains.

923. Bran. - This part of the wheat grain carries much protein and mineral matter, but its fibrous, chaffy character renders it unfit for the digestive apparatus of the young pig, which has but a limited capacity. (896) Middlings rather than bran should be fed to young pigs, but as they increase in size some bran may be fed with advantrige, especially where it is desirable to add volume to the feed. Bran may be fed with good results to breeding stock and to a limited extent to fattening swine, the amount in the latter case being restricted, lest the volume of the feed be too much increased. Harris ${ }^{1}$ recommends that bran be supplied to pigs in a separate trough, where they can eat it at will.

924. Barley.- Judging from the European standard, barley leads the cereals in the quality of pork produced. (894) In quantity of product returned from feeding a given weight of grain it yields to corn. $(857,894)$ Because consumers are growing more critical, the pig feeder should study the uses of barley in the feeding pen that he may profit by using it whenever opportunity offers. Barley flourishes in the Western states, and in

\footnotetext{
1 The Pig, p. 233.
} 
conjunction with alfalfa may prove instrumental in turning many sections into profitable centers of pork production. This becomes all the more a certainty because consumers are learning to appreciate the higher grades of pork.

925. Peas. - Where this plant flourishes, farmers will find peas an excellent feed for swine. Because of the large amount of protein they contain peas can be used with advantage in feeding young pigs, shotes, and in the production of lean pork. Farmers living north of the corn belt may find pork production still profitable through the proper use of peas. For feeding swine, peas should be ground, and, because of the high protein content and the heavy character of the meal they make, they should always be fed in conjunction with corn, barley, or other cereals. (860)

926. Dairy by-products. - No materials are more generally useful in all stages of swine feeding than skim milk and buttermilk. They should be supplied only in limited quantity to brood sows before farrowing; after farrowing the limit need scarcely be set. As trials show, (869) the best returns are secured when not over three pounds of milk are fed with each pound of meal in the ration. Feeding trials have also shown (108) that skim mill favors the development of muscle and builds the strongest bones. Cooke's trials (871) indicate that sour milk has a high feeding value with pigs. Buttermilk, when not diluted with washings from the creamery, is as valuable as skim milk for pigs. As a complementary feed corn meal stands first, since it is rich in carbohydrates, while the milk furnishes protein and ash, the bone and muscle building elements. Breeders of pure-bred swine will find dairy by-products of the highest utility in producing pigs of model form and strong bone. (See Chapter VI.)

927. Clover hay.-An omniverous feeder by nature, the pig suffers seriously when forced to subsist upon the cereals alone. Such feeds lack the bulk or volume essential to healthy, vigorous digestive action. An excellent corrective for concentrated feeds in winter is found in well-made clover hay. For pig feeding, clover hay should be run through the feed-cutter and the chaff well soaked by pouring scalding water over it. To the material so softened add meal, and feed the mixture once a day to all pigs 
except those in the last stages of fattening. While the pig gets some nourishment from the hay, much of the advantage is doubtless due to the normal distention of the digestive tract effected by this material. (876)

928. Pasture.- Experienced feeders appreciate the valne of pasture for swine. Doubtless the returns from an acre of pasture-land have been overstated by some writers, but its advantages, on the whole, have not been overdrawn. The results at the Utah Station (875) show that a gain of one-third of a pound daily is possible with thrifty shotes on good alfalfa pasture. For pasture, alfalfa and red clover doubtless lead all other plants of the field, (875) white clover, blue grass and rape following in value. Pasture plants, to be satisfactory with swine, must be short and tender, all effort to make them eat the long stems being useless. Rooting in pastures tends to lengthen the skull, increase the size of the animal's head and enlarge the muscles running along the back of the neck. (832) Where health and lean meat are the objects sought, pigs should have no rings in their noses, and should be allowed to govern their own actions as to how much they tear up the sod in search of animal and vegetable food. All means for preventing rooting are at best necessary evils. When on pasture pigs should be fed grain, the amount of green forage consumed about supporting them, leaving the additional food to be utilized in increasing their weight.

929. Administration of feed.-- Suckling pigs take nourishment from the dam about every two hours, and we may accept Nature's guidance for the frequency of feeding very young animals. At weaning time the pigs should receive feed at least three times daily, with water always accessible. Since the digestive tract of this animal is of limited volume, probably the best results in fattening can be obtained with three feeds daily; but habit controls here as elsewhere, and stockmen can easily accustom their animals to expect feed morning and evening only, meanwhile being content.

Since meal when dry is more slowly masticated than wher. moistened, it might be supposed that the greater addition of saiva consequent upon slow eating would increase the digestibivity of 
meal so fed, but the trials so far made favor moistening the feed with water. Observation shows that the pig does not take kindly to dry meal, eating it very slowly, and often rooting much of it out of the trough. On the whole sloppy feeds are best for the pig. (837)

930. Confinement. - It is possible to confine a few pigs in a sty when young and carry them successfully to the end of their career, but only a limited number of animals can be managed in one pen under such a system. When handled in large numbers pigs should be given ample range during the growing period, and be confined to pens only during the fattening stage. Experiments show that the best gains for feed consumed are secured during the first four weeks of confinement; that up to eight weeks good results are possible; while if the feeding period is extended to twelve weeks the gains during the last four weeks are made at a greatly increased consumption for a given gain. As a rule pigs should not be fed over eight weeks in a pen, though they may be held somewhat longer if a rising market is assured, or for other good cause. ( $838,847,903$ )

931. Variety in feeding stuffs. - In feeding pigs we may always rely upon two feeding stuffs giving better results than one, and, guided by this, the feeder should have a variety at command. (852) Usually he has on hand one leading variety of grain or meal; let him intelligently search for complementary feeds. For example, if corn is relied upon as the main feed, this aliment, so rich in carbonaceous matter, should be supplemented with one rich in protein and ash. Milk, middlings, oat meal and pea meal naturally supplement corn, and, if volume is desired, bran will prove helpful.

932. Ball-feeding show pigs.--Stephens ${ }^{3}$ describes how, toward the close of the feeding period, English pigs fed for exhibitions are induced to put on the last possible ounce of fat. Equal quantities of bean, corn, barley and wheat meals are used, and three parts of this mixture added to one part of middlings, with the addition of a little linseed meal. This material is moistened with milk to form a dough and made into balls the size of an egg.

\footnotetext{
' Book of the Farm.
} 
After the pigs have eaten all they will of the ordinary feed they are given a dessert of these balls dipped in milk. The pigs soon learn to sit on their haunches and are fed the dainty morsels one after another in turn, each pig, after eating the thinner food given him in the trough, consuming about a gallon more of these ball mixtures.

933. Influence of feed on quality of pork.-Brewer ${ }^{1}$ summarizes his experience in regard to the influence of the food of swine on the quality of the flesh produced, as follows:

"The best flavored pork and the heaviest weight of the same was obtained in case of milk-fed swine; next to milk came the cereals - corn, barley, oats and peas. Potatoes produced a soft, light pork which loses a good deal in boiling. The meat of swine fed on flour-mill by-products was yellow, without body, and of a poor flavor. Oil meals produced a loose, oily pork of an unpleasant flavor. Beans produced a hard, indigestible and flavorless pork, and acorns one that was light, hard and unhealthy."

No extended work has yet been done in this country on the influence of feeds on pork, and for the present we must be guided by the statements of foreign observers, mainly the Danish investigators. Here is an important field for our Experiment Stations. (885, also various articles in Chapter XXXIV.)

934. Correctives for swise.-Every stockman who has kept pigs in confinement has observed their strange craving for seemingly unnatural substances, - sand rock, soft brick, mortar, rotten wood, charcoal, soft coal, ashes, soap suds and many other articles being greedily devoured when offered. Such objects lie outside the range of nutritive substances, and we are puzzled to know why they should be so eagerly consumed. In the wild state, the hog ranges through woods and open tracts, living upon small animals, larvæ, and vegetation generally. This material is of such character and is gathered in such manner that some of the soil is swallowed with it. With rings in its nose to prevent rooting while in the pasture, confined on board floors during the fattening period and given feeds containing little ash, the pig's life is passed under unnatural conditions. Another cause

\footnotetext{
${ }^{1}$ Gohren. Futterungslehre, 1872, p. 420.
} 
for this craving may be intestinal worms, which are checked or destroyed by some of the substances consumed. Unsatisfactory or incomplete as such explanations may be, the fact remains that the pig seeks out these unnatural substances and greedily consumes them. The feeder would best supply what the pig craves in this direction and search for explanations later if he wishes.

Ashes either from wood or coal will always be in place in the feeding pen and even in the feed lot. It is surprising how much of these will be consumed by a bunch of pigs. Feeding trials show that pigs when confined to an exclusive corn diet are greatly benefited by ashes, this substance causing the feed to be more effective and adding to the strength of the bones - the latter result probably being due to the lime in the ashes. (114) Bone meal is another substance useful for strengthening the bones of pigs. By saving the droppings, substantially all the value of this high-grade fertilizer may be secured for field and garden after it has served its purpose with the pigs.

935. Corn-cob charcoal. - Corn cobs are abundant in districts where swine feeding is largely practiced. They can serve no better purpose so far as needed than in producing charcoal for use in the feeding pens.

The following directions for reducing cobs to charcoal are given by Theodore Louis, ${ }^{1}$ a breeder of high repute in the Northwest: "Dig a hole in the ground five feet deep, one foot in diameter at the bottom and five feet at the top, for the charcoal pit. Take the corn cobs, which have been saved in a dry place, and, starting a fire in the bottom of this pit, keep adding cobs so that the Hame is gradually drawn to the top of the pit, which will be thus filled with the cobs. Then take a sheet iron cover, similar to a pot lid in form, and over five feet in diameter, so as to amply cover the hole and close up the burning mass, sealing the edges of this lid in turn with earth. At the end of twelve hours you may uncover and take out a fine sample of corn-cob charcoal."

Charcoal so produced may be fed directly, or, better still, compounded as directed by Mr. Louis in the following manner:

\footnotetext{
1 Farm, Stock and Home, July 15, 1894.
} 
"Take 6 bushels of this cob charcoal, or 3 bushels of common charcoal; 8 pounds of salt; 2 quarts of air-slacked lime; 1 bushel of wood ashes. Break the charcoal well down, with shovel or other implement, and thoroughly mix. Then take $1 \frac{1}{4}$ pounds of copperas and dissolve in hot water, and with an ordinary watering pot sprinkle over the whole mass and then again mix thoroughly. Put this mixture into the self-feeding boxes, and place them where hogs of all ages can eat of their contents at pleasure."

Where corn cobs are burned for fuel in the prairie districts the ashes should be saved for the pigs.

\section{Discussion of the Experiments Reported in Chapter VI on the Effects of Feed on the Body of the Pig.}

936. Lessons from the experiments.-The practical bearings of the investigations on the mal-nutrition of pigs reported in Chapter VI are here presented. These experiments were conducted at several Stations in widely separated states and countries and with different feeds, yet the results were concordant in showing that the frame of the growing animal and the vital organs can be greatly modified by improper nutrition, - the muscles produced by such feeding being less than normal in size, the bones robbed of their strength, the vital organs, such as the liver and kidneys, modified, and even the blond reduced in quantity. Are there not lessons here for the student, and the breeder and feeder as well, which, if understood and appreciated, will help to a better management of farm animals, especially the pig?

937. Limits of bone and muscle development. - In studying these experiments we should understand the limitations of nature in the development of the muscle and bone systems. No feeds or combinations of feeds are known which will cause an animal to develop bone and muscle beyond what is set by inheritance. It was shown that pigs fed skim milk, dried blood and other proteinrich feeds had stronger bones and larger muscles (more lean meat) than those receiving corn meal only, but this does not show that these animals had increased in bone and muscle beyond the normal.

In supplying pigs in these experiments with feeds rich in protein and ash, their bodies were developed in bone and muscle to 
the limit of their constitutions set by inheritance. On the other hand, the growing pigs which received corn only during the trials were prevented, through lack of sufficient proper nutrients, from developing normal frames of bone and muscle. Pigs can be fed to produce bone and lean meat only as such flesh and bone are the sequence of normal development. It is entirely possible, on I the other hand, to so feed or mal-nurture them as to prevent a normal growth of bone and muscle or lean meat while storing abnormally large quantities of fat.

938. The fat of the body. - Study will show that the deposition of fat in the body is a matter of feed and conditions, controlled primarily by inheritance or constitution and having a wide range for the individual. Fat is reserve fuel stored in the body against a time of need. This true, Nature, which has set close limits to the development of the animal frame, shows no such restriction in the accumulation of fat. If conditions and feed are favorable, the animal stores large quantities of fat, the ability to do so being set by inheritance, character of feed, amount of exercise, etc.

939. Illustration from the human frame.-We can best illustrate the above by reference to the human frame. No person by. what he eats, in kind or quantity, can increase in bone or muscle beyond the normal of constitutional inheritance. On the other hand, the amount of fatty matter which is deposited in the tissues of the human body varies with different individuals, according to constitution, habits, character of food and amount of exercise taken. The grown athlete cannot add a pound of muscle to his body because of the food he eats; indeed, when he goes into training he reduces his weight, losing fat and water from the tissues. While a human being cannot add to his stature nor increase the muscles of his body by the kind of food he eats, the fat stored in the tissues may in extreme cases even double the normal weight of the body.

940. Lessons for breeder and feeder.-The observant feeder and breeder of swine studying these trials must be impressed with the plastic character of the body of the growing animal. He learns that the bones and muscles as well as some of the internal organs of the body can be thrown out of their normal relation 
one to another through an unbalanced or improper food supply. He sees it possible for immature animals to live a long time without showing disease, while being dwarfed in form and made prematurely fat. He learns that Nature's plan is to grow the framework first and lay on fat afterwards. He understands that while no farmer would feed his pigs as these were fed, wrong feeding may nevertheless unconsciously be practiced by many. He concludes, rightly, that if a pig or other young animal is mal-nurtured so as to modify its bones, muscles and vital organs ever so little, and the animal so affected is later used for breeding purposes, the descendants likewise being mal-nturtured, the cumulative ill effects may in a few generations become very marked. He sees disaster through the excessive use of corn, rich in carbohydrates but poor in bone and muscle elements, as the sole feed for young pigs. On the other hand, he studies the long list of feeding stuffs complementary to corn which will build strong bones and ample muscles. By the judicious use of feed mixtures he secures animals of great vigor, and selecting the best of these in framework and constitution, he holds his herd to a high standard.

The feeder learns that the young pig should be nurtured upon a combination of feeding stuffs that will first develop a normal frame of bone and muscle. Having the desired frame, if the market demands lean meat, he will produce this to the limit of the pig's normal development, adding fat at the close of the feeding period to the extent desired by the market. In America corn is the common feeding stuff for swine, and pigs show such fondness for it that harm often results because the practice of the feeder and breeder is guided by the appetite of the animal rather than by a knowledge of the composition and limitations of feeds. Let us not despise corn because, when wrongly and excessively used as it purposely was in these experiments with young, growing pigs, it failed to develop the normal framework of bone and muscle. Each feed has its function in the nutrition of animals, and only by its abuse can unfavorable results follow. This grain has enabled the United States to take first rank among nations in the quantity of pork produced, and upon its judicious use rests future success. 


\section{APPENDIX.}

Tlate I. Averlge Composition of Amerioan Feeding STUFFs.

This table is mainly from Farmers' Bulletin 22, U. S. Depart ment of Agriculture, 1895, which in turn is based on Jenkins and Winton's tables in Bulletin 11, Office of Experiment Stations, Department of Agriculture, Washington.

Analyses not from the source above mentioned are in most casts from the following: Zusammensetzung der Futterm., Dietricl $\chi$ and König; Farm Foods, Wolff, English edition, Cousins; Woll, Haudbook for Farmers and Dairymen; Holland, Report Massachusetts (Hatch) Experiment Station, 1896; Jenkins and Winton's tables, and Bulletin 87, New Jersey Experiment Station.

\begin{tabular}{|c|c|c|c|c|c|c|c|}
\hline \multirow[b]{2}{*}{ Feeding stuffs. } & \multicolumn{6}{|c|}{ Percentage composition. } & \multirow{2}{*}{ 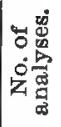 } \\
\hline & Water. & Ash. & $\begin{array}{l}\text { Pro- } \\
\text { tein. }\end{array}$ & $\begin{array}{l}\text { Crude } \\
\text { fiber. }\end{array}$ & $\begin{array}{l}\text { Nitro- } \\
\text { gen-free } \\
\text { extract. }\end{array}$ & $\begin{array}{c}\text { Ether } \\
\text { ex- } \\
\text { tract. }\end{array}$ & \\
\hline CONCENTRATES. & & & & & & & \\
\hline Corn, dent.. & 10.6 & 1.5 & 10.3 & 2.2 & 70.4 & 5.0 & 86 \\
\hline Corn, flint..... & 11.3 & 1.4 & 10.5 & 1.7 & 70.1 & 5.0 & 68 \\
\hline Corn, sweet.... & 8.8 & 1.9 & 11.6 & 2.8 & 66.8 & 8.1 & 26 \\
\hline Corn meal.... & 15.0 & 1.4 & 9.2 & 1.9 & 68.7 & 3.8 & 77 \\
\hline Corn cob.... & 10.7 & 1.4 & 2.4 & 30.1 & 54.9 & 0.5 & 18 \\
\hline Corn and cob meal.. & 15.1 & 1.5 & 8.5 & 6.6 & 64.8 & 3.5 & \\
\hline Corn bran....... & 9.1 & 1.3 & 9.0 & 12.7 & 62.2 & 5.8 & 5 \\
\hline Corn germ & 10.7 & 4.0 & 9.8 & 4.1 & 64.0 & 7.4 & 3 \\
\hline Hominy che & 11.1 & 2.5 & 9. & 3.8 & 64.5 & 8.3 & 12 \\
\hline Germ meal & 8.1 & 1.3 & 11. & 9.9 & 62.5 & 7.1 & \\
\hline Dried starch and sugar feed & 10.9 & 0.9 & 19.7 & 4.7 & 54.8 & 9.0 & 4 \\
\hline Starch feed, wet.................. & 65.4 & 0.3 & 6.1 & 3.1 & 22.0 & 3.1 & 12 \\
\hline Maize feed, Chicago............. & 9.1 & 0.9 & 22.8 & 7.6 & 52.7 & 6.9 & 3 \\
\hline Grano-gluten...................... & 5.8 & 2.8 & 31.1 & 12.0 & 33.4 & 14.9 & \\
\hline Cream gluten...................... & 8.1 & 0.7 & 36.1 & 1.3 & 39.0 & 14.8 & 3 \\
\hline Gluten me & 8.2 & 0.9 & 29.3 & 3. & 46.5 & 11.8 & 20 \\
\hline Gluten feed........................ & 7.8 & 1.1 & 24.0 & 5.3 & 51.2 & 10.6 & 11 \\
\hline Wheat, 8 & 10.5 & 1.8 & 11 & 1.8 & 71.9 & 2.1 & 310 \\
\hline Wheat, sprir & 10.4 & 1.9 & 12.5 & 1.8 & 71.2 & 2.2 & 13 \\
\hline Wheat, winter................. & 10.5 & 1.8 & 11.8 & 1.8 & 72.0 & 2.1 & 262 \\
\hline
\end{tabular}


TABLE I. Average composition of American feeding stuffe - continued.

\begin{tabular}{|c|c|c|c|c|c|c|c|}
\hline \multirow[b]{2}{*}{ Feeding stufrs. } & \multicolumn{6}{|c|}{ Percentage composition. } & \multirow{2}{*}{ 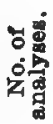 } \\
\hline & Water. & Ash. & $\begin{array}{l}\text { Pro- } \\
\text { tein. }\end{array}$ & $\begin{array}{l}\text { Crude } \\
\text { fiber. }\end{array}$ & $\begin{array}{c}\text { Nitro- } \\
\text { gen-free } \\
\text { extract. }\end{array}$ & $\begin{array}{l}\text { Ether } \\
\text { ex- } \\
\text { tract. }\end{array}$ & \\
\hline CONCENTRATES - cOn. & & & & & & & \\
\hline Flour, high grade............. & 12.2 & 0.6 & 14.9 & 0.3 & 70.0 & 2.0 & 1 \\
\hline Flour, low grade................. & 12.0 & 2.0 & 18.0 & 0.9 & 63.3 & 3.9 & 1 \\
\hline Flour, dark feeding............ & 9.7 & 4.3 & 19.9 & 3.8 & 56.2 & 6.2 & 1 \\
\hline Bran, all analyses................ & 11.9 & 5.8 & 15.4 & 9.0 & 53.9 & 4.0 & 88 \\
\hline Bran, spring wheat............. & 11.5 & 5.4 & 16.1 & 8.0 & 54.5 & 4.5 & 10 \\
\hline Bran, winter wheat............. & 12.3 & 5.9 & 16.0 & 8.1 & 53.7 & 4.0 & 7 \\
\hline Middlings.......................... & 12.1 & 3.3 & 15.6 & 4.6 & 60.4 & 4.0 & 32 \\
\hline 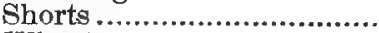 & 11.8 & 4.6 & 14.9 & 7.4 & 56.8 & 4.5 & 12 \\
\hline Wheat sereenings............... & 11.6 & 2.9 & 12.5 & 4.9 & 65.1 & 3.0 & 10 \\
\hline Rye ...... & 11.6 & 1.9 & 10.6 & 1.7 & 72.5 & 1.7 & 6 \\
\hline Rye flour...... & 13.1 & 0.7 & 6.7 & 0.4 & 78.3 & 0.8 & 4 \\
\hline Rye bran...... & 11.6 & 3.6 & 14.7 & 3.5 & 63.8 & 2.8 & 7 \\
\hline Rye shorts.......................... & 9.3 & 5.9 & 18.0 & 5.1 & 59.9 & 2.8 & 1 \\
\hline Barley...... & 10.9 & 2.4 & 12.4 & 2.7 & 69.8 & 1.8 & 10 \\
\hline Bailey meal ....................... & 11.9 & 2.6 & 10.5 & 6.5 & 66.3 & 2.2 & 3 \\
\hline Barley screenings............. & 12.2 & 3.6 & 12.3 & 7.3 & 61.8 & 2.8 & 2 \\
\hline Brewers' grains, wet....... & 75.7 & 1.0 & 5.4 & 3.8 & 12.5 & 1.6 & 15 \\
\hline Brewers' grains, dried......... & 8.2 & 3.6 & 19.9 & 11.0 & 51.7 & 5.6 & 3 \\
\hline Malt sprouts......................... & 10.2 & 5.7 & 23.2 & 10.7 & 48.5 & 1.7 & 4 \\
\hline Oats. & 11.0 & 3.0 & 11.8 & 9.5 & 59.7 & 5.0 & 30 \\
\hline Oat meal. & 7.9 & 2.0 & 14.7 & 0.9 & 67.4 & 7.1 & 6 \\
\hline Oat feed... & 7.7 & 3.7 & 16.0 & 6.1 & 59.4 & 7.1 & 4 \\
\hline Oat dust... & 6.5 & 6.9 & 13.5 & 18.2 & 50.2 & 4.8 & 2 \\
\hline Oat hulls ............................ & 7.3 & 6.7 & 3.3 & 29.7 & 52.1 & $\mathbf{1 . 0}$ & $\mathbf{1}$ \\
\hline Rice . & 12.4 & 0.4 & 7.4 & 0.2 & 79.2 & 0.4 & 10 \\
\hline Rice meal... & 10.2 & 8.1 & 12.0 & 5.4 & 51.2 & 13.1 & 2 \\
\hline Rice hulls... & 8.2 & 13.2 & 3.6 & 35.7 & 38.6 & 0.7 & $\overline{3}$ \\
\hline Rice bran.... & 9.7 & 10.0 & 12.1 & 9.5 & 49.9 & 8.8 & 5 \\
\hline Rice polish ........................ & 10.0 & 6.7 & 11.7 & 6.3 & 58.0 & 7.3 & 4 \\
\hline Buckwheat. & 12.6 & 2.0 & 10.0 & 8.7 & 64.5 & 2.2 & 8 \\
\hline Buckwheat flor & 14.6 & 1.0 & 6.9 & 0.3 & 75.8 & 1.4 & 4 \\
\hline Buckwheat hulls ..... & 13.2 & 2.2 & 4.6 & 43.5 & 35.3 & 1.1 & 2 \\
\hline Buck wheat bran....... & 10.5 & 3.0 & 12.4 & 31.9 & 38.8 & 3.3 & 2 \\
\hline Buckwheat shorts ............ & 11.1 & 5.1 & 27.1 & 8.3 & 40.8 & 7.6 & 2 \\
\hline Buck wheat middlings...... & 13.2 & 4.8 & 28.9 & 4.1 & 41.9 & 7.1 & 3 \\
\hline Sorgh & 12.8 & 2.1 & 9.1 & 2.6 & 69.8 & 3.6 & 10 \\
\hline Broom-corn seed.... & 11.5 & 3.4 & 10.2 & 7.1 & 63.6 & 3.0 & \\
\hline Kaffir-corn seed ..... & 9.3 & 1.5 & 9.9 & 1.4 & 74.9 & 3.0 & 1 \\
\hline Millet seed....................... & 14.0 & 3.3 & 11.8 & 9.5 & 57.4 & 4.0 & \\
\hline Hungarian grass seed ...... & 9.5 & 5.0 & 9.9 & 7.7 & 63.2 & 4.7 & 1 \\
\hline Flax seed......... & 9.2 & 4.3 & 22.6 & 7.1 & 23.2 & 33.7 & 50 \\
\hline Flax seed, ground............. & 8.1 & 4. & 21.6 & 7.3 & 27.9 & 30.4 & 2 \\
\hline Linseed meal, old process... & 9.2 & 5.7 & 32.9 & 8.9 & 35.4 & 7.9 & 21 \\
\hline Linseed meal, new process. & 10.1 & 5.8 & 33.2 & 9.5 & 38.4 & 3.0 & 14 \\
\hline
\end{tabular}


TABLE I. Average composition of American feeding stuffs-continued.

\begin{tabular}{|c|c|c|c|c|c|c|c|}
\hline \multirow[b]{2}{*}{ Feeding stuffs. } & \multicolumn{6}{|c|}{ Percentage composition. } & \multirow{2}{*}{ 岁总 } \\
\hline & Water. & Ash. & $\begin{array}{l}\text { Pro- } \\
\text { teln. }\end{array}$ & $\begin{array}{l}\text { Crude } \\
\text { flber. }\end{array}$ & $\begin{array}{c}\text { Nitro- } \\
\text { gen-free } \\
\text { extract. }\end{array}$ & $\begin{array}{c}\text { Ether } \\
\text { ex- } \\
\text { tract. }\end{array}$ & \\
\hline \multicolumn{8}{|l|}{ Concentrates - con. } \\
\hline Cotton seed..................... & 10.3 & 3.5 & 18.4 & 23.2 & 24.7 & 19.9 & 5 \\
\hline Cotton seed, roaste & 6.1 & 5.5 & 16.8 & 20.4 & 23.5 & 27.7 & 2 \\
\hline Cotton-seed meal ... & 8.2 & 7.2 & 42.3 & 5.6 & 23.6 & 13.1 & 35 \\
\hline Cotton-seed hulls ................ & 11.1 & 2.8 & 4.2 & 46.3 & 33.4 & 2.2 & 20 \\
\hline \multirow{2}{*}{\multicolumn{8}{|c|}{ 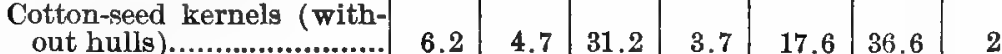 }} \\
\hline & 6.2 & 4.7 & 31.2 & 3.7 & 17.6 & 36.6 & 2 \\
\hline Cocoanut cake ..................... & 10.3 & 5.9 & 19.7 & 14.4 & 38.7 & 11.0 & \\
\hline Palm-nut meal ... & 10.4 & 4.3 & 16.8 & 24.0 & 35.0 & 9.5 & 600 \\
\hline Sunflower seed .... & 86 & 2.6 & 16.3 & 29.9 & 21.4 & 21.2 & 2 \\
\hline Sunflower-seed cake ............ & 10.8 & 6.7 & 32.8 & 13.5 & 27.1 & 9.1 & \\
\hline \multicolumn{8}{|c|}{ Peanut kernel (without } \\
\hline 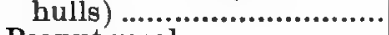 & 7.5 & 2.4 & 27.9 & 7.0 & 15.6 & 39.6 & 7 \\
\hline Peanut meal........................ & 10.7 & 4.9 & 47.6 & 5.1 & 23.7 & 8.0 & 2480 \\
\hline Rape-seed cake ...................... & 10.0 & 7.9 & 31.2 & 11.3 & 30.0 & 9.6 & 500 \\
\hline Pea 1 & 10.5 & 2.6 & 20.2 & 14.4 & 51,1 & 1.2 & 2 \\
\hline Soja bean.. & 10.8 & 4.7 & 34.0 & 4.8 & 28.8 & 16.9 & 8 \\
\hline Cowper....... & 14.8 & 3.2 & 20.8 & 4.1 & 55.7 & 1.4 & 5 \\
\hline Horse bean .......................... & 11.3 & 3.8 & 26.6 & 7.2 & 50.1 & 1.0 & 1 \\
\hline \multicolumn{8}{|l|}{ ROUGHAGE. } \\
\hline Corn forage, field cured. & & & & & & & \\
\hline Fodd & 42.2 & 2.7 & 4.5 & 14.3 & 34.7 & 1.6 & 35 \\
\hline Corn & 40.5 & 3.4 & 3.8 & 19.7 & 31.5 & 1.1 & 60 \\
\hline Corn husks & 50.9 & 1.8 & 2.5 & 15.8 & 28.3 & 0.7 & 16 \\
\hline Corn leaves................ & 30.0 & 5.5 & 6.0 & 21.4 & 35.7 & 1.4 & 17 \\
\hline \multicolumn{8}{|l|}{ Corn forage, green. } \\
\hline Fodder corn, all varieties.... & 79.3 & 1.2 & 1.8 & 5.0 & 12.2 & 0.5 & 126 \\
\hline Den & 79.0 & 1.2 & 1.7 & $5 \cdot 6$ & 12.0 & 0.5 & 63 \\
\hline glazed.... & 73.4 & 1.5 & 2.0 & 6.7 & 15.5 & 0.9 & 7 \\
\hline Flin & 79.8 & 1.1 & 2.0 & 4. & 12.1 & 0.7 & 40 \\
\hline Flint, ke & 77.1 & 1.1 & 2.7 & 4.3 & 14.6 & 0.8 & 10 \\
\hline Sw & 79. & 1.3 & 1.9 & 4.4 & 12.8 & 0.5 & 21 \\
\hline Leav & 66.2 & 2.9 & 2.1 & 8.7 & 19.0 & 1.1 & 4 \\
\hline Stripped stalks ..................... & 76.1 & 0.7 & 0.5 & 7.3 & 14.9 & 0.5 & 4 \\
\hline \multicolumn{8}{|l|}{ Hay from grasses. } \\
\hline Hay from mi & 15.3 & 5.5 & 7.4 & 27.2 & 42.1 & 2.5 & 126 \\
\hline Timothy, all analyses.... & 13.2 & 4.4 & 5.9 & 29.0 & 45.0 & 2.5 & 68 \\
\hline Timothy, cut in full bloom.. & 15.0 & 4.5 & 6.0 & 29.6 & 41.9 & 3.0 & 12 \\
\hline 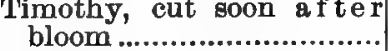 & 14.2 & 4.4 & 5.7 & 28.1 & 44.6 & 3.0 & \\
\hline Timothy, cut when nearly & & & & & & & 11 \\
\hline & 14.1 & 3.9 & 5.0 & 31.1 & 43.7 & 2.2 & 12 \\
\hline Orchard grass......................... & 9.9 & 6.0 & 8.1 & 32.4 & 41.0 & 2.6 & 10 \\
\hline 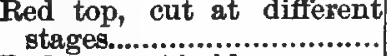 & 8.9 & 5.2 & 7.9 & 28.6 & 47.5 & 1.9 & $\boldsymbol{9}$ \\
\hline Red top, cut in bloom.......... & 8.7 & 4.9 & 8.0 & 29.9 & 46.4 & 2.1 & 3 \\
\hline Kentucky blue grass..... & 21.2 & 6.3 & 7.8 & 23.0 & 37.8 & 3.9 & 10 \\
\hline
\end{tabular}


TABLE I. Average composition of American feeding stafis - continued.

\begin{tabular}{|c|c|c|c|c|c|c|c|}
\hline \multirow[b]{2}{*}{ Feeding stuffis. } & \multicolumn{6}{|c|}{ Percentage composition. } & \multirow{2}{*}{ 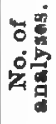 } \\
\hline & Water. & Ash. & $\begin{array}{l}\text { Pro- } \\
\text { tein. }\end{array}$ & $\begin{array}{l}\text { Crude } \\
\text { fber. }\end{array}$ & $\begin{array}{c}\text { Nitro- } \\
\text { gen-free } \\
\text { extract. }\end{array}$ & $\begin{array}{l}\text { Ether } \\
\text { ex- } \\
\text { tract. }\end{array}$ & \\
\hline $\begin{array}{l}\text { RoUGH } \triangle G \mathrm{E} \text { - continued. } \\
\text { Hay from grasses - con. }\end{array}$ & & & & & & & \\
\hline $\begin{array}{l}\text { Kentucky blue grass, cut } \\
\text { when seed in milk........... }\end{array}$ & 24.4 & $\mathbf{7 . 0}$ & 6.3 & 24.5 & 34.2 & 3.6 & 4 \\
\hline $\begin{array}{l}\text { Kentucky blue grass, cut } \\
\text { when seed ripe................. }\end{array}$ & 27.8 & 6.4 & 5.8 & 23.8 & 33.2 & 3.0 & 4 \\
\hline Hungarian grass................ & 7.7 & 6.0 & 7.5 & 27.7 & 49.0 & 2.1 & 13 \\
\hline Meadow fescue ................... & 20.0 & 6.8 & 7.0 & 25.9 & 38.4 & 2.7 & 9 \\
\hline Italian rye grass................... & 8.5 & 6.9 & 7.5 & 30.5 & 45.0 & 1.7 & 4 \\
\hline Perennial rye grass ............. & 14.0 & 7.9 & 10.1 & 25.4 & 40.5 & 2.1 & 4 \\
\hline Rowen (mixed) .................. & 16.6 & 6.8 & 11.6 & 22.5 & 39.4 & 3.1 & 23 \\
\hline Mixed grasses and clovers... & 12.9 & 5.5 & 10.1 & 27.6 & 41.3 & 2.6 & 17 \\
\hline Barley hay, cut in milk ..... & 15.0 & 4.2 & 8.8 & 24.7 & 44.9 & 2.4 & 1 \\
\hline Oat hay, cut in milk .......... & 15.0 & 5.2 & 9.3 & 29.2 & 39.0 & 2.3 & 1 \\
\hline Swamp hay....................... & 11.6 & 6.7 & 7.2 & 26.6 & 45.9 & 2.0 & 8 \\
\hline Salt-marsh hay................... & 10.4 & 7.7 & 5.5 & 30.0 & 44.1 & 2.4 & 10 \\
\hline Wild-oat grass..................... & 14.3 & 3.8 & 5.0 & 25.0 & 48.8 & 3.3 & 1 \\
\hline Buttercups ......................... & 9.3 & 5.6 & 9.9 & 30.6 & 41.1 & 3.5 & 2 \\
\hline White daisy....................... & 10.3 & 6.6 & 7.7 & 30.0 & 42.0 & 3.4 & 2 \\
\hline Johnson grass .................... & 10.2 & 6.1 & 7.2 & 28.5 & 45.9 & 2.1 & 2 \\
\hline Fresh grass. & & & & & & & \\
\hline Pasture grass ......... & 80.0 & 2.0 & 3.5 & 4.0 & 9.7 & 0.8 & \\
\hline Kentucky blue grass........... & 65.1 & 2.8 & 4.1 & 9.1 & 17.6 & 1.3 & 18 \\
\hline Timothy, different stages... & 61.6 & 2.1 & 3.1 & 11.8 & 20.2 & 1.2 & 50 \\
\hline Orchard grass, in bloom...... & 73.0 & 2.0 & 2.6 & 8.2 & 13.3 & 0.9 & 4 \\
\hline Red top, in bloom .............. & 65.3 & 2.3 & 2.8 & 11.0 & 17.7 & 0.9 & 5 \\
\hline Oat fodder.............................. & 62.2 & 2.5 & 3.4 & 11.2 & 19.3 & 1.4 & 6 \\
\hline Rye fodder .............. & 76.6 & 1.8 & 2.6 & 11.6 & 6.8 & 0.6 & 7 \\
\hline Sorghum fodder ................... & 79.4 & 1.1 & 1.3 & 6.1 & 11.6 & 0.5 & 11 \\
\hline Barley fodder...................... & 79.0 & 1.8 & 2.7 & 7.9 & 8.0 & 0.6 & 1 \\
\hline Hungarian grass................. & 71.1 & 1.7 & 3.1 & 9.2 & 14.2 & 0.7 & 14 \\
\hline Mearlow fescue, in bloom... & 69.9 & 1.8 & 2.4 & 10.8 & 14.3 & 0.8 & 4 \\
\hline Italiau rye grass, coming & & & & & & & \\
\hline $\begin{array}{l}\text { into bloom..................... } \\
\text { Tall oat grass, in bloom. }\end{array}$ & 73.2 & 2.5 & 3.1 & 6.8 & 13.3 & 1.3 & 24 \\
\hline Tall oat grass, in bloom...... & 69.5 & 2.0 & 2.4 & 9.4 & 15.8 & 0.9 & 3 \\
\hline Japanese millet.................... & 75.0 & 1.5 & 2.1 & 7.8 & 13.1 & 0.5 & 12 \\
\hline Barnyard millet................... & 75.0 & 1.9 & 2.4 & 7.0 & 13.1 & 0.6 & 2 \\
\hline Hay from legumes. & & & & & & & \\
\hline Red clover...... & 15.3 & 6.2 & 12.3 & 24.8 & 38.1 & $\mathbf{3 . 3}$ & 38 \\
\hline Red clover, in bloom.... & 20.8 & 6.6 & 12.4 & 21.9 & 33.8 & 4.5 & 6 \\
\hline Red clorer, mammoth........ & 21.2 & 6.1 & 10.7 & 24.5 & 33.6 & 3.9 & 10 \\
\hline Alsike clover ........................ & 9.7 & 8.3 & 12.8 & 25.6 & 40.7 & 2.9 & 9 \\
\hline White clover ..................... & 9.7 & 8.3 & 15.7 & 24.1 & 39.3 & 2.9 & 7 \\
\hline Crimson clover ................. & 9.6 & 8.6 & 15.2 & 27.2 & 36.6 & 2.8 & 7 \\
\hline Japan clover..................... & 11.0 & 8.5 & 13.8 & 24.0 & 39.0 & 3.7 & 2 \\
\hline Alfalfa .......................................... & 8.4 & 7.4 & 14.3 & 25.0 & 42.7 & 2.2 & 21 \\
\hline 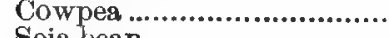 & 10.7 & 7.5 & 16.6 & 20.1 & 42.2 & 2.2 & 8 \\
\hline Soja bean.............................. & 11.3 & 7.2 & 15.4 & 22.3 & 38.6 & 5.2 & 6 \\
\hline 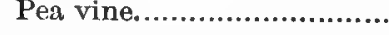 & 15.0 & 6.7 & 13.7 & 24.7 & 37.6 & 2.3 & 1 \\
\hline
\end{tabular}


Appendix.

TABLE I. Average composition of American feeding stuffs - continued

\begin{tabular}{|c|c|c|c|c|c|c|c|}
\hline \multirow[b]{2}{*}{ Feeding stuffs. } & \multicolumn{6}{|c|}{ Percentage composition. } & \multirow{2}{*}{ 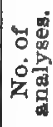 } \\
\hline & Water. & Ash. & $\begin{array}{l}\text { Pro- } \\
\text { tein. }\end{array}$ & $\begin{array}{l}\text { Orude } \\
\text { flber. }\end{array}$ & $\begin{array}{l}\text { Nitro- } \\
\text { gen-free } \\
\text { extract. }\end{array}$ & $\begin{array}{l}\text { Ether } \\
\text { ex- } \\
\text { tract. }\end{array}$ & \\
\hline \multicolumn{8}{|l|}{$\begin{array}{l}\text { ROUGHAGE - continued. } \\
\text { Hay from legumes - con. }\end{array}$} \\
\hline 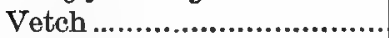 & 11.3 & 7.9 & 17.0 & 25.4 & 36.1 & 2.3 & 5 \\
\hline Serradella .......................... & 9.2 & 7.2 & 15.2 & 21.6 & 44.2 & 2.6 & 3 \\
\hline Flat pea...... & 8.4 & 7.9 & 22.9 & 26.2 & 31.4 & 3.2 & 5 \\
\hline Peanut vines (without nuts) & 7.6 & 10.8 & 10.7 & 23.6 & 42.7 & 4.6 & 6 \\
\hline Sanfoin............................. & 15.0 & 7.3 & 14.8 & 20.4 & 39.5 & 3.0 & 1 \\
\hline \multicolumn{8}{|c|}{\begin{tabular}{l|l} 
Fresh legumes. &
\end{tabular}} \\
\hline Red clover, different stages. & 70.8 & 2.1 & 4.4 & 8.1 & 13.5 & 1.1 & 43 \\
\hline Alsike clover & 74.8 & 2.0 & 3.9 & 7.4 & 11.0 & 0.9 & 4 \\
\hline Crimson clover...... & 80.9 & 1.7 & 3.1 & 5.2 & 8.4 & 0.7 & 3 \\
\hline Alfalfa ................................... & 71.8 & 2.7 & 4.8 & 7.4 & 12.3 & 1.0 & 23 \\
\hline Cowpea.... & 83.6 & 1.7 & 2.4 & 4.8 & 7.1 & 0.4 & 10 \\
\hline Soja bean & 75.1 & 2.6 & 4.0 & 6.7 & 10.6 & 1.0 & 7 \\
\hline Serradella... & 79.5 & 3.2 & 2.7 & 5.4 & 8.6 & 0.7 & 9 \\
\hline Horse bean ... & 84.2 & 1.2 & 2.8 & 4.9 & 6.5 & 0.4 & 2 \\
\hline Flat pea........................... & 66.7 & 2.9 & 8.7 & 7.9 & 12.2 & 1.6 & 2 \\
\hline Straw. & & & & & & & \\
\hline Wheat................ & 9.6 & 4.2 & 3.4 & 38.1 & 43.4 & 1.3 & \\
\hline Rye...... & 7.1 & 3.2 & 3.0 & 38.9 & 46.6 & 1.2 & 7 \\
\hline Oät....... & 9.2 & 5.1 & 4.0 & 37.0 & 42.4 & 2.3 & 12 \\
\hline Barley .. & $14 . \overline{2}$ & 5.7 & 3.5 & 36.0 & 39.0 & 1.5 & 97 \\
\hline Wheat chaff.. & 14.3 & 9.2 & 4.5 & 36.0 & 34.6 & 1.4 & \\
\hline Oat chaff .... & 14.3 & 10.0 & 4.0 & 34.0 & 36.2 & 1.5 & \\
\hline Buckwheat & 9.9 & 5.5 & 5.2 & 43.0 & 35.1 & 1.3 & 3 \\
\hline ล̌oja k & 10.1 & 5.8 & 4.6 & 40.4 & 37.4 & 1.7 & 4 \\
\hline 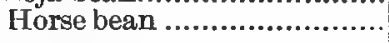 & 9.2 & 8.7 & 8.8 & 37.6 & 34.3 & 1.4 & 1 \\
\hline Silage. & & & & & & & \\
\hline Corn .... & 79.1 & 1.4 & 1.7 & 6.0 & 11.0 & 0.8 & 99 \\
\hline Sors & 76.1 & 1.1 & 0.8 & 6.4 & 15.3 & 0.3 & 6 \\
\hline Red clover. & 72.0 & 2.6 & 4.2 & 8.4 & 11.6 & 1.2 & 5 \\
\hline Soja bean & 74.2 & 2.8 & 4.1 & 9.7 & 6.9 & 2.2 & 1 \\
\hline Apple po & 85.0 & 0.6 & 1.2 & 3.3 & 8.8 & 1.1 & 1 \\
\hline Cowpea vine....................... & 79.3 & 2.9 & 2.7 & 6.0 & 7.6 & 1.5 & 2 \\
\hline Cowpea and soja-bean vines, & 608 & 15 & 20 & 05 & 111 & & \\
\hline $\begin{array}{l}\text { mixed........ } \\
\text { Field-pea vin }\end{array}$ & 69.8 & $\begin{array}{l}4.5 \\
3.5\end{array}$ & $\begin{array}{l}3.8 \\
5.9\end{array}$ & $\begin{array}{r}9.0 \\
13.0\end{array}$ & 26.0 & 1.3 & 1 \\
\hline Barnyard millet and soja & 00.1 & & & & & & \\
\hline & 79.0 & 2.8 & 2.8 & 7.2 & 7.2 & 1.0 & 9 \\
\hline Corn and soja bean ............. & 76.0 & 2.4 & 2.5 & 7.2 & 11.1 & 0.8 & \\
\hline Rye .................................... & 80.8 & 1.6 & 2.4 & 5.8 & 9.2 & 0.3 & 1 \\
\hline Roots and tubers. & & & & & ' & & \\
\hline Potato..... & 78.9 & 1.0 & 2.1 & 0.6 & 17.3 & 0.1 & 12 \\
\hline Beets, common ................ & 88.5 & 1.0 & ].5 & 0.9 & 8.0 & 0.1 & 9 \\
\hline Beet, sugar ................... & 86.5 & 0.9 & 1.8 & 0.9 & 9.8 & 0.1 & 19 \\
\hline Beet, mangel ..................... & 90.9 & 1.1 & 1.4 & 0.9 & 5.5 & 0.2 & 9 \\
\hline Turnip & 90.5 & 0.8 & 1.1 & 1.2 & 6.2 & 0.2 & $\mathbf{3}$ \\
\hline Ruta-baga........................ & 88.6 & 1.2 & 1.2 & 1.3 & 7.5 & 0.2 & 4 \\
\hline
\end{tabular}


TABLE I. Average composition of American feeding stuff's - continued.

\begin{tabular}{|c|c|c|c|c|c|c|c|}
\hline \multirow[b]{2}{*}{ Feeding stuffe. } & \multicolumn{6}{|c|}{ Percentage composition. } & \multirow{2}{*}{ 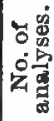 } \\
\hline & Water. & Ash. & $\begin{array}{l}\text { Pro- } \\
\text { tein. }\end{array}$ & $\begin{array}{l}\text { Grude } \\
\text { fber. }\end{array}$ & $\begin{array}{l}\text { Nitro- } \\
\text { gen-free } \\
\text { extract. }\end{array}$ & $\begin{array}{l}\text { Ether } \\
\text { ex- } \\
\text { tract. }\end{array}$ & \\
\hline \multicolumn{8}{|l|}{ Roots and tubers - con. } \\
\hline Carrot... & 88.6 & 1.0 & 1.1 & 1.3 & 7.6 & 0.4 & \\
\hline Pars & 88.3 & 0.7 & & 1.0 & 10.2 & 0.2 & \\
\hline Artichok & 79.5 & 1. & & 0.8 & 15.9 & 0.2 & \\
\hline Sweet potato & 71.1 & 1.0 & 1.5 & 1.3 & 24.7 & 0.4 & \\
\hline \multicolumn{8}{|l|}{ MisceluaNeOUs. } \\
\hline Cabbage................. & 90.5 & 1.4 & 2.4 & 1.5 & 3.9 & 0.4 & \\
\hline Spu & 75.7 & 4.0 & 2.0 & 4.9 & 12.7 & 0.8 & \\
\hline Suge & 88.0 & 2.4 & 2.6 & 2.2 & 4.4 & 0.4 & \\
\hline okin (fi & 90.9 & 0.5 & 1. & 1.7 & 5.2 & 0.4 & \\
\hline Pumpkin ( $g$ & 80.8 & 0.9 & 1.8 & 1.8 & 7.9 & 0.8 & \\
\hline Pric & 88.4 & 2.2 & 2 & 1. & 5.1 & 0.3 & 41 \\
\hline Rap & 84.5 & 2.0 & & 2.6 & 8.4 & 0.5 & \\
\hline Acó & 55.3 & 1.0 & 2.5 & 4.4 & 34.8 & 1.9 & \\
\hline Apples ........... & 80.8 & 0.4 & 0.7 & 1.2 & 16.6 & 0.4 & \\
\hline Cow & 87.2 & 0.7 & 3.6 & & 4.9 & 3.7 & 793 \\
\hline Cow & 74.6 & 1.6 & 17.6 & & 2.7 & 3.6 & \pm \\
\hline Mar & 91.0 & 0.4 & 2.1 & ... & 5.3 & 1.2 & \\
\hline & 81.3 & 0.8 & 6. & & 4.7 & 6.8 & \\
\hline G & 86.9 & 0.9 & & ... & 4.4 & 4.1 & \\
\hline & 0.8 & & 6. & $\cdots$ & 4.8 & 7.1 & \\
\hline & 90.4 & 0.7 & 3.3 & $\ldots$ & 4.7 & 0.9 & 96 \\
\hline trifugal... & 90.6 & & 3 & & 5.3 & 0.3 & \\
\hline Butt & 90.1 & 0.7 & 4. & & 4.0 & 1.1 & \\
\hline 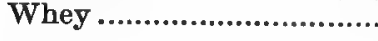 & 93.8 & 0.4 & 0.6 & & 5.1 & 0.1 & \\
\hline Driec & & 4.7 & 84 & & & 2.5 & \\
\hline & 10.7 & & 71. & & 0.3 & 13.7 & 144 \\
\hline Drie & 10.8 & 29.2 & 48.4 & & & 11.6 & \\
\hline & 89.8 & 0.6 & 0.9 & 2.4 & 6.3 & & 16 \\
\hline & 20.8 & 10.6 & 9. & & 59.5 & ......... & 35 \\
\hline & 76.7 & 0.5 & 1.4 & 3.9 & 16.2 & 1.3 & \\
\hline tsse .......... & 83.9 & 0.6 & 0.6 & 3.2 & $11.7^{*}$ & & \\
\hline ps .................... & 93.7 & 0.2 & 1.9 & 0.6 & 2.8 & 0.9 & \\
\hline t from distil & & & & & & & \\
\hline lery slops.... & 5.0 & 11.3 & 27.4 & 8.0 & 36.1 & 12.3 & \\
\hline
\end{tabular}

* Includes fat.
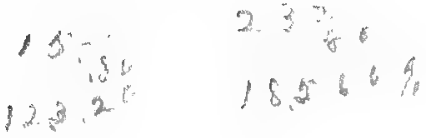
Table II. Average Digestibility of American Feeding

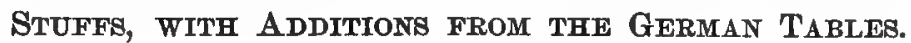

The data of this table are mainly from digestion trials conducted by American Experiment Stations, as compiled by Lindsey in the report of the Massachusetts (Hatch) Experiment Station for 1896. Coefficients from this source are marked " $M$ " in the last column of the table. To render the table more complete, additions have been made from the German tables. Those marked "L" are from Mentzel \& Lengerke's Landw. Kalender for 1898. Those marked " $\mathrm{K}$ " are from Zusammensetzung der Futtermittel, Dietrich and König.

A. Experiments with Ruminants.

\begin{tabular}{|c|c|c|c|c|c|c|c|}
\hline Feeding sturrs & 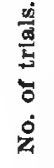 & 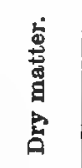 & $\begin{array}{l}\frac{j}{9} \\
\frac{9}{0} \\
2\end{array}$ & 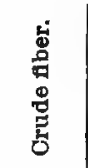 & 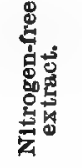 & 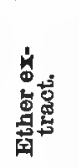 & 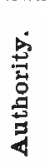 \\
\hline Concentrates. & & $\begin{array}{l}\text { Per } \\
\text { cent. }\end{array}$ & $\begin{array}{c}\text { Per } \\
\text { cent. }\end{array}$ & $\begin{array}{l}\text { Per } \\
\text { cent. }\end{array}$ & $\begin{array}{l}\text { Per } \\
\text { cent. }\end{array}$ & $\begin{array}{l}\text { Per } \\
\text { cent. }\end{array}$ & \\
\hline Dent corn ... & 12 & 91 & 76 & 58 & 93 & 86 & $\mathbf{K}$. \\
\hline Corn meal........... & 5 & 88 & 60 & & 93 & 92 & M. \\
\hline Corn cob..................................... & 2 & 59 & 17. & 65 & 60 & 50 . & M. \\
\hline Corn and cob meal................... & 3 & 79 & 52 & 45 & 88 & 84 & M. \\
\hline Gluten meal.............................. & 8 & 87 & 88 & ........ & 88 & 93 & M. \\
\hline Gluten meal (Chicago) ............. & 2 & 88 & 89 & & 93 & 93 & M. \\
\hline Gluten meal (King's).............. & 2 & 81 & 91 & & 79 & 94 & M. \\
\hline Gluten feed & 8 & 84 & 85 & 72 & 87 & 83 & M. \\
\hline Gluten feed (Buffalo).............. & 4 & 83 & 86 & 66 & 84 & 87 & $M$. \\
\hline Gluten feed (Pope's) & 2 & 87 & 86 & 77 & 90 & 81 & M. \\
\hline Gluten feed (Peoria)............... & 2 & 86 & 83 & 78 & 90 & 79 & M. \\
\hline Gluten feed (Atlas) & 2 & 80 & 73 & & 84 & 91 & M. \\
\hline Maize feed (Chicago) ............... & 2 & 84 & 84 & 72 & 85 & 90 & M. \\
\hline Cream gluten (Pope's)............. & 2 & 93 & 84 & & 88 & 98 & M. \\
\hline Wheat bran ........................... & 11 & $61^{\wedge}$ & $79^{x}$ & 22 * & 69 & 68 & M. \\
\hline Wheat bran, spring wheat...... & 2 & 63 & 80 & 24 & 70 & 76 & M. \\
\hline Wheat bran, winter wheat...... & 3 & 62 & 77 & 27 & 65 & 64 & M. \\
\hline Wheat middlings...................... & 4 & 79 & 82 & 36 & 85 & 85 & M. \\
\hline Rye meal................................... & 2 & 87 & 84 & & 92 & 64 & M. \\
\hline 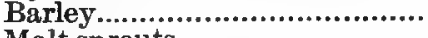 & 4 & 86 & 70 & 50 & 92 & 89 & L. \\
\hline Malt sprouts................ & 1 & 67 & 80 & 34 & 69 & 100 & M. \\
\hline Brewers' grains, wet................ & 12 & 63 & 73 & 40 & 62 & 86 & L. \\
\hline Brewers' grains, dried ............ & 2 & 62 & 79 & 53 & 59 & 91 & $\mathbf{M}$. \\
\hline 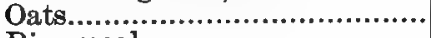 & 39 & 70 & 78 & 20 & 76 & 83 & L. \\
\hline Rice meal................................... & 12 & 75 & 63 & 26 & 86 & 85 & L. \\
\hline Flax seed............. & 7 & 77 & 91 & 61 & 55 & 86 & L. \\
\hline Linseed meal, old process........ & 3 & 79 & 89 & 57 & 78 & 89 & M. \\
\hline Linseed meal, new process...... & 3 & 80 & 85 & 74 & 84 & 93 & M. \\
\hline
\end{tabular}


TABLE II. Average digestibility of American feeding stufin - continued.

\begin{tabular}{|c|c|c|c|c|c|c|c|}
\hline Feeding stuffs. & 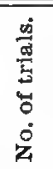 & $\begin{array}{l}\text { 焉 } \\
\text { 晋 } \\
\text { 它 }\end{array}$ & $\begin{array}{l}\text { 畐 } \\
\text { 总 } \\
\text { 足 }\end{array}$ & 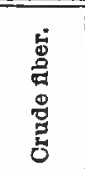 & 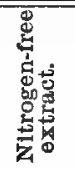 & 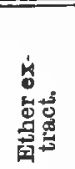 & 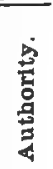 \\
\hline CONCENTRATES - continued. & & $\begin{array}{l}\text { Per } \\
\text { cent. }\end{array}$ & $\begin{array}{l}\text { Per } \\
\text { cent. }\end{array}$ & $\begin{array}{l}\text { Per } \\
\text { cent. }\end{array}$ & $\begin{array}{l}\text { Per } \\
\text { cent. }\end{array}$ & $\begin{array}{l}\text { Per } \\
\text { cent. }\end{array}$ & \\
\hline Cotton seed........................... & 2 & 66 & 68 & 76 & 50 & 87 & M. \\
\hline Cotton seed, roasted ........... & $\overline{2}$ & 56 & 47 & 66 & 51 & 72 & M. \\
\hline Cotton-seed meal .................. & 6 & 76 & 88 & 32 & 64 & 93 & M. \\
\hline Cotton-seed hulls ................... & 13 & 41 & 6 & 47 & 34 & 79 & M. \\
\hline $\begin{array}{l}\text { Cotton-seed hulls, when fed } \\
\text { with cotton-seed meal .......... }\end{array}$ & 3 & 41 & & 38 & 49 & 78 & $\mathbf{M}$. \\
\hline $\begin{array}{l}\text { Cotton-seed hulls, when fed } \\
\text { with cotton-seed meal ......... }\end{array}$ & 11 & 45 & & 46 & 51 & 76 & M. \\
\hline 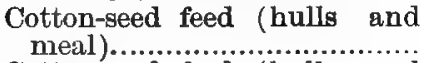 & 3 & 46 & 45 & 37 & 50 & 82 & M. \\
\hline Cotton-seed feed (hulls and & & & & & & & $M$ \\
\hline 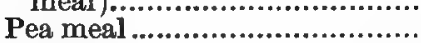 & $\begin{array}{r}11 \\
2\end{array}$ & $\begin{array}{l}55 \\
87\end{array}$ & $\begin{array}{l}62 \\
83\end{array}$ & $\begin{array}{l}46 \\
26\end{array}$ & $\begin{array}{l}54 \\
94\end{array}$ & $\begin{array}{l}85 \\
55\end{array}$ & M. \\
\hline Soja-bean meal ...................... & 10 & 79 & 87 & & 73 & 85 & M. \\
\hline Peauut feed ............................ & 2 & 32 & 71 & 12 & 49 & 90 & \\
\hline ROUGHAGE, & & & & & & & \\
\hline Fodder corn, field-cured. & & & & & & & \\
\hline 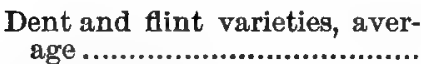 & 23 & 68 & 55 & 65 & 73 & 74 & M. \\
\hline Dent, mature.......................... & 14 & 66 & 48 & 57 & 72 & 76 & $\mathrm{M}$. \\
\hline Dent, in milk........................... & 11 & 63 & 50 & 64 & 66 & 75 & M. \\
\hline 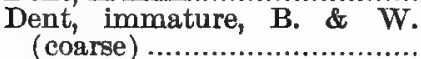 & 4 & 57 & 27 & 59 & 61 & 76 & M. \\
\hline Dent, immature, no ears formed & 8 & 65 & 62 & 71 & 64 & 66 & M. \\
\hline Flint, mature......................... & 9 & 71 & 65 & 76 & 73 & 70 & M. \\
\hline Flint, ears just forming.. ......... & $\mathbf{3}$ & 70 & 70 & 72 & 71 & 67 & M. \\
\hline Sweet, mature........................ & 6 & 67 & 64 & 74 & 68 & 74 & M. \\
\hline Corn stover, field-cured. & & & & & & & \\
\hline Corn stover, all varieties ........ & 8 & 60 & 45 & 67 & 61 & 62 & M. \\
\hline Corn stover $\ldots \ldots \ldots \ldots \ldots \ldots \ldots \ldots$ & 4 & 62 & 52 & 67 & 64 & 52 & M. \\
\hline Corn stover, shredded, fed dry. & 2 & 57 & 40 & 65 & 56 & 72 & M. \\
\hline Corn stover, shredded, fed wet. & $\overline{2}$ & 60 & 36 & 70 & 59 & 74 & M. \\
\hline Corn stover, tops and blades... & 2 & 60 & 55 & 71 & 62 & 71 & M. \\
\hline Corn stover, leaves.................. & 2 & 56 & 56 & 61 & 59 & 63 & $\mathbf{M}$. \\
\hline Corn stover, stalk below ear... & 2 & 67 & 21 & 74 & 69 & 80 & M. \\
\hline Corn stover, stalk above ear.... & 2 & 55 & 22 & 71 & 54 & 64 & \\
\hline Coln stover, husks. ............. & 2 & 72 & 30 & 80 & & 33 & M. \\
\hline Corn stover, leaves below enr... & 2 & 65 & 35 & 78 & 68 & 56 & M. \\
\hline Corn forage, green. & & & & & & & \\
\hline Dent fodder corn, average glaz- & & & & & & & \\
\hline ing and mature....................... & $\begin{array}{r}13 \\
4\end{array}$ & $\begin{array}{l}66 \\
65\end{array}$ & $\begin{array}{l}53 \\
51\end{array}$ & $\begin{array}{l}52 \\
55\end{array}$ & 74 & 76 & M. \\
\hline Dent fodder corn, grlazing....... & 9 & 67 & 54 & 51 & 75 & 78 & $M$ \\
\hline Dent fodder corn, in milk...... & 9 & 70 & 61 & 64 & 76 & 78 & M. \\
\hline Dent fodder corn, immature ... & 11 & 68 & 66 & 67 & 71 & 68 & $\mathbf{M}$. \\
\hline
\end{tabular}


TaBLe II. Average digestibility of American feeding stuffi - continued.

\begin{tabular}{|c|c|c|c|c|c|c|c|}
\hline Feeding stufra. & 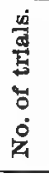 & 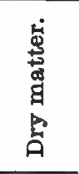 & 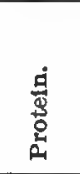 & 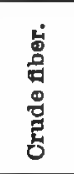 & 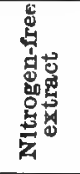 & 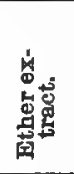 & 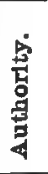 \\
\hline $\begin{array}{c}\text { RoughaGE-continued. } \\
\text { Corn forage, green - continued }\end{array}$ & & $\begin{array}{l}\text { Per } \\
\text { cent. }\end{array}$ & $\begin{array}{l}\text { Per } \\
\text { cent. }\end{array}$ & $\begin{array}{l}\text { Per } \\
\text { cent. }\end{array}$ & $\begin{array}{l}\text { Per } \\
\text { cent. }\end{array}$ & $\begin{array}{l}\text { Per } \\
\text { cent. }\end{array}$ & \\
\hline $\begin{array}{l}\text { Dent fodder corn, glazing, } B . \\
\text { \& W. (coarse) .................... } \\
\text { Sweet fodder corn, roasting ear }\end{array}$ & 2 & 52 & 24 & 46 & 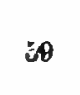 & 78 & M. \\
\hline $\begin{array}{l}\text { stage ................................. } \\
\text { Sweet fodder corn, in milk...... }\end{array}$ & $\begin{array}{l}6 \\
2\end{array}$ & $\begin{array}{l}72 \\
77\end{array}$ & $\begin{array}{l}62 \\
77\end{array}$ & $\begin{array}{l}60 \\
75\end{array}$ & 81 & $\begin{array}{l}79 \\
74\end{array}$ & $\begin{array}{l}\text { M. } \\
\text { M. }\end{array}$ \\
\hline Hay from grasses. & & & & & & & \\
\hline 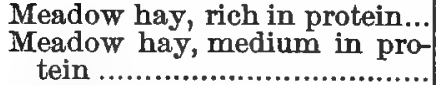 & 48 & 67 & 66 & 63 & 68 & 57 & L. \\
\hline Meadow hay, poor in protein.. & 28 & 56 & 50 & 56 & 59 & 49 & L. \\
\hline 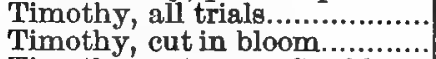 & $\begin{array}{r}26 \\
5\end{array}$ & $\begin{array}{l}57 \\
60\end{array}$ & $\begin{array}{l}48^{\circ} \\
56\end{array}$ & $\begin{array}{l}52 \\
58\end{array}$ & $\begin{array}{l}63 \\
63\end{array}$ & $\begin{array}{l}57 \\
57\end{array}$ & $\begin{array}{l}\text { M. } \\
\text { M. }\end{array}$ \\
\hline Timothy, cut soon after bloom & 10 & 53 & 45 & 47 & 60 & 53 & M. \\
\hline Orehard grass.......................... & 3 & 56 & 60 & 61 & 55 & 55 & M. \\
\hline $\begin{array}{l}\text { Red top.............................. } \\
\text { Hungarian }\end{array}$ & 3 & 60 & 61 & 61 & 62 & 51 & M. \\
\hline 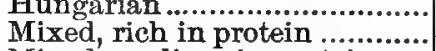 & $\begin{array}{r}2 \\
20\end{array}$ & $\begin{array}{l}65 \\
58\end{array}$ & $\begin{array}{l}60 \\
58\end{array}$ & $\begin{array}{l}68 \\
60\end{array}$ & $\begin{array}{l}67 \\
59\end{array}$ & $\begin{array}{l}64 \\
48\end{array}$ & $\begin{array}{l}\text { M. } \\
\text { M. }\end{array}$ \\
\hline Mixed, medium in protein...... & 2 & & 40 & 49 & 58 & 50 & M. \\
\hline Rowen, average........................ & 8 & 65 & 68 & 66 & 64 & 47 & M. \\
\hline Dried pasture grass........... & 1 & 71 & 72 & 77 & 73 & 60 & M. \\
\hline Barley hay ............................. & 4 & 59 & 65 & 62 & 63 & 41 & M. \\
\hline $\begin{array}{l}\text { Oats and vetch ........................... } \\
\text { Timothy and clover, poorly }\end{array}$ & 2 & 58 & 60 & 66 & 54 & 19 & M. \\
\hline Blue-joint grass (Calame & 2 & 55 & 38 & 53 & 60 & 58 & M. \\
\hline tis Canadensis) in bloom...... & 2 & 69 & 70 & 72 & 69 & 52 & M. \\
\hline Blue-joint grass, past bloom.... & 1 & 40 & 57 & 37 & 43 & 37 & M. \\
\hline $\begin{array}{l}\text { Wild-oat grass (Danthonica } \\
\text { spicata) ............................ } \\
\text { Cats-tail millet (Pennesetum }\end{array}$ & 3 & 64 & 58 & 68 & 65 & 50 & M. \\
\hline 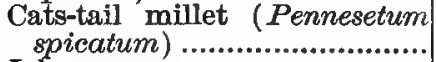 & 2 & 62 & 63 & 67 & 59 & 46 & \\
\hline $\begin{array}{l}\text { Johnson grass ....................... } \\
\text { Witch (quack) grass ( Triticum }\end{array}$ & 1 & 55 & 45 & 58 & 54 & 39 & M. \\
\hline repens) & 4 & 61 & 58 & 62 & 66 & 57 & M. \\
\hline $\begin{array}{l}\text { Sorghum fodder (leaves).......... } \\
\text { Sorghum bagasse (stalks after }\end{array}$ & 2 & 63 & 61 & 70 & 65 & 47 & M. \\
\hline juice is removed) ................. & 1 & 61 & 14 & 64 & 65 & 46 & M. \\
\hline 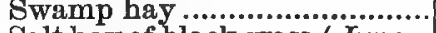 & 2 & 39 & 34 & 33 & 46 & 44 & M. \\
\hline 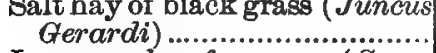 & 2 & 60 & 63 & 60 & 56 & 41 & M. \\
\hline $\begin{array}{l}\text { Low meadow fox grass (Spar- } \\
\text { tina juncea) } \ldots \ldots \ldots \ldots \ldots \ldots \ldots \ldots \ldots\end{array}$ & 2 & 53 & 57 & 51 & 52 & 24 & M. \\
\hline High-grown salt hay (largely & & & & & & & \\
\hline $\begin{array}{l}\text { Spartina juncea) ................... } \\
\text { Branch grass (Spartina juncea }\end{array}$ & 2 & 53 & 63 & 50 & 53 & 47 & M. \\
\hline $\begin{array}{l}\text { with Spartina stricta, var. } \\
\text { glabra) ...................................... }\end{array}$ & $\ddot{z}$ & 56 & 62 & 52 & 54 & 31 & M. \\
\hline
\end{tabular}


TABLE II. Average digestibility of American feeding stuft's - continued.

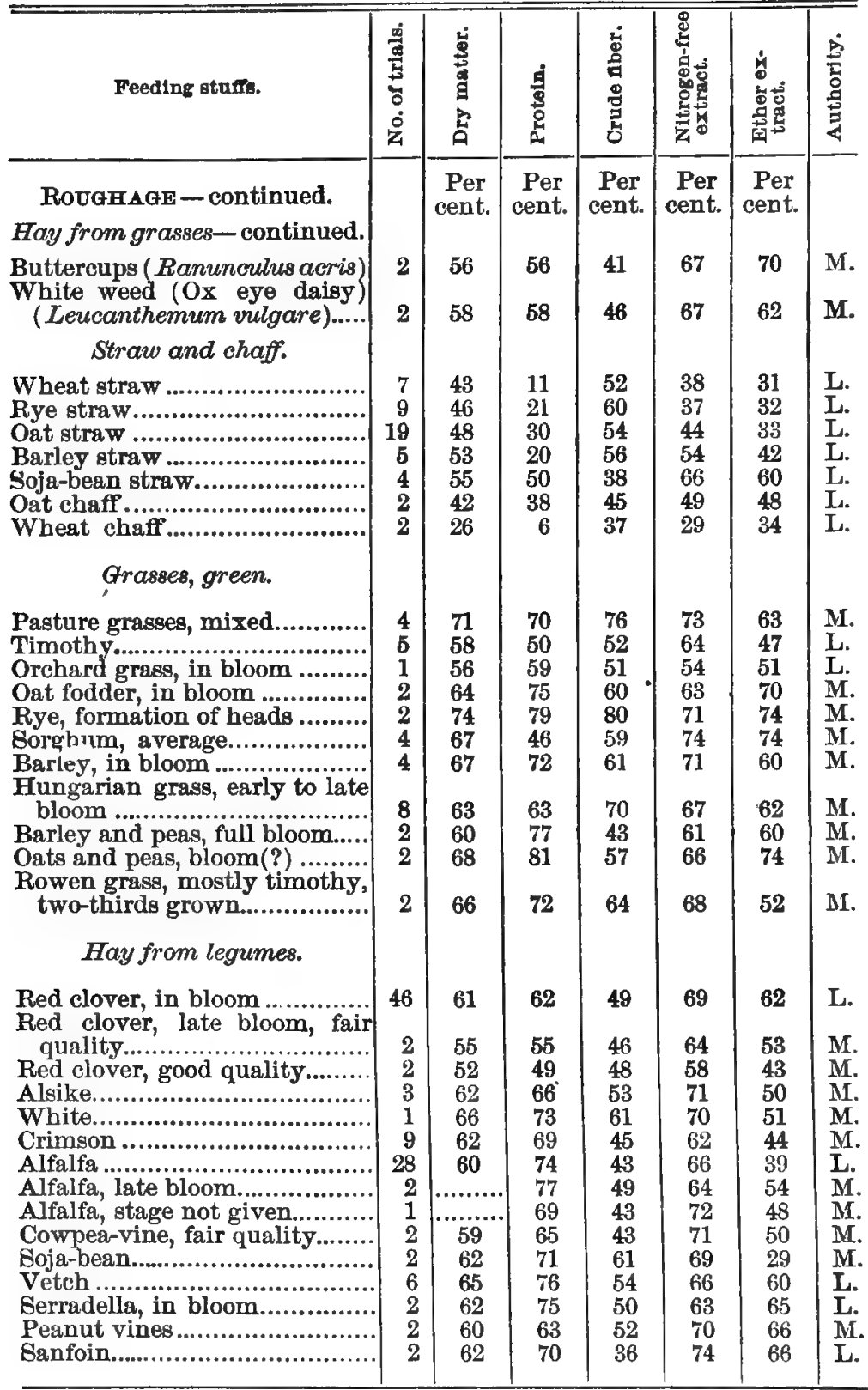


TABLE II. Average digestibility of American feeding stuffs-continued.

\begin{tabular}{|c|c|c|c|c|c|c|c|}
\hline Feeding stufrim. & 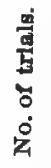 & 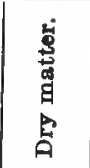 & 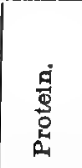 & 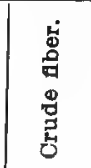 & 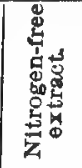 & 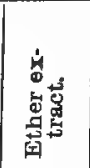 & 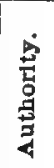 \\
\hline $\begin{array}{l}\text { RoUGHAGE - continued. } \\
\text { Legumes, green. }\end{array}$ & \multirow{9}{*}{$\begin{array}{l}2 \\
2 \\
3 \\
2 \\
2 \\
2 \\
2 \\
2\end{array}$} & $\begin{array}{l}\text { Per } \\
\text { cent. }\end{array}$ & $\begin{array}{l}\text { Per } \\
\text { cent. }\end{array}$ & $\begin{array}{l}\text { Per } \\
\text { cent. }\end{array}$ & $\begin{array}{l}\text { Per } \\
\text { cent. }\end{array}$ & $\begin{array}{l}\text { Per } \\
\text { cent. }\end{array}$ & \\
\hline Red clover, late bloom............. & & 66 & 67 & 53 & 78 & 65 & M. \\
\hline IRowen, late bloom ................ & & 61 & 62 & 52 & 65 & 61 & M. \\
\hline Crimson clover, late bloom...... & & 69 & 77 & 56 & 74 & 66 & $\mathbf{M}$. \\
\hline Alfalfa & & 67 & 81 & 45 & 76 & 52 & $\mathrm{~L}$. \\
\hline Cowpea, ready for soiling........ & & 76 & 74 & 57 & 84 & 59 & M. \\
\hline Soja bean, before bloom.......... & & 66 & 79 & 50 & 72 & 54 & $M$. \\
\hline $\begin{array}{l}\text { Soja bean, seed half grown ..... } \\
\text { Canada peas, just before bloom }\end{array}$ & & 62 & 69 & 41 & 73 & $\begin{array}{l}54 \\
52\end{array}$ & $\mathbf{M}$ \\
\hline Silage. & & 11 & 02 & 02 & $\sqrt{1}$ & & \\
\hline 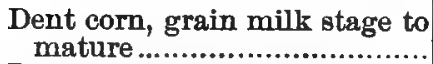 & 17 & 64 & 52 & 62 & 69 & 85 & M. \\
\hline Dent corn, immature .................. & 13 & 64 & 54 & 70 & 66 & 71 & M. \\
\hline Dent corn, stage uncertain...... & 4 & 60 & 24 & 56 & 68 & 70 & M. \\
\hline Dent corn, fine crushed (steers) & 2 & 64 & 38 & 75 & 65 & 76 & M. \\
\hline Dent corn, fine crushed (sheep) & 2 & 54 & 22 & 64 & 55 & 68 & M. \\
\hline 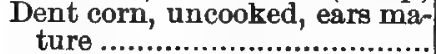 & 1 & & 45 & 59 & 71 & 86 & M. \\
\hline Dent corn, cooked, ears mature & 1 & ........ & 39 & 70 & 75 & 87 & M. \\
\hline Flint, ears glazing...$\ldots \ldots \ldots \ldots \ldots \ldots$ & 11 & 75 & 65 & 77 & 79 & 82 & M. \\
\hline Sweet, some ears matured....... & 2 & 68 & 54 & 71 & 72 & 83 & M. \\
\hline Soja bean................................. & 4 & 55 & 66 & 49 & 57 & 61 & M. \\
\hline 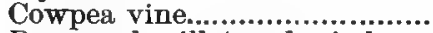 & 4 & 60 & 57 & 52 & 72 & 63 & M. \\
\hline Barnyard millet and soja bean & 4 & 59 & 57 & 69 & 59 & 72 & M. \\
\hline Corn and soja bean................. & 3 & 69 & 65 & 65 & 75 & 82 & M. \\
\hline Roots and tubers. & & & & & & & \\
\hline Potato........................... & 23 & 85 & 61 & & 90 & & L. \\
\hline Potato.............. & 3 & 77 & 44 & & 91 & ........... & M. \\
\hline Peet, mangel............................ & 18 & 88 & 77 & \%.... & 96 & .......... & L. \\
\hline Beet, mangel............................ & 2 & 79 & 75 & 43 & 91 & $\cdots \cdots \cdots$ & M. \\
\hline 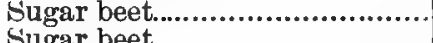 & 28 & 89 & 62 & 100 & $\begin{array}{r}90 \\
100\end{array}$ & 50 & L. \\
\hline 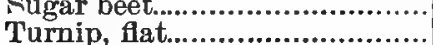 & $\begin{array}{l}2 \\
2\end{array}$ & $\begin{array}{l}90 \\
93\end{array}$ & 90 & 100 & 97 & 98 & M. \\
\hline Ruta-baga............................ & $\overline{2}$ & 87 & 80 & 74 & 95 & 84 & M. \\
\hline Miscellaneods. & & & & & & & \\
\hline Cow's milk....... & 5 & 98 & 94 & & 98 & 100 & L. \\
\hline Acorns, fresh ...................... & 2 & 88 & 83 & 62 & 91 & 88 & L. \\
\hline Dried blood................................ & 2 & 63 & 62 & .......... & 100 & 100 & L. \\
\hline Meat scrap............................... & 5 & 93 & 93 & .......... & $\ldots$ & 98 & L. \\
\hline 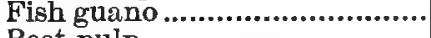 & 2 & & $\begin{array}{l}90 \\
63\end{array}$ & 83 & 84 & 76 & H. \\
\hline Beet pulp................................. & 7 & 82 & 63 & & & & \\
\hline
\end{tabular}


TABLI II. Average digestibility of American feeding stuffs - continued. B. Experiments with Pigs.

\begin{tabular}{|c|c|c|c|c|c|c|c|}
\hline Feeding stuffs. & 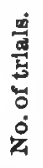 & 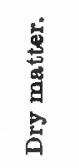 & 递 & 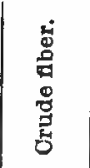 & 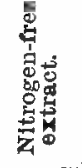 & 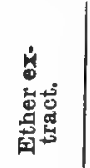 & 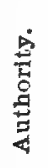 \\
\hline & & $\begin{array}{l}\text { Per } \\
\text { cent. }\end{array}$ & $\begin{array}{l}\text { Per } \\
\text { cent. }\end{array}$ & $\begin{array}{c}\text { Per } \\
\text { cent. }\end{array}$ & $\begin{array}{c}\text { Per } \\
\text { cent. }\end{array}$ & $\begin{array}{c}\text { Per } \\
\text { cent. }\end{array}$ & \\
\hline Corn meal........... & 4 & 92 & 86 & 40 & 95 & 76 & L. \\
\hline Corn meal..................... & 2 & 90 & 88 & 39 & 94 & 80 & M. \\
\hline Corn kernels, whole ................ & 1 & 83 & 69 & 38 & 89 & 46 & $M$. \\
\hline Corn and cob meal................... & 1 & 76 & 76 & 29 & 84 & 82 & M. \\
\hline 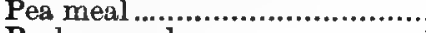 & 1 & 90 & 89 & 78 & 95 & 50 & M. \\
\hline Barley meal............................ & 8 & 82 & 76 & 15 & 90 & 65 & L. \\
\hline Barley meal............................. & 1 & 80 & 81 & 49 & 87 & 57 & $\mathbf{M}$ \\
\hline Wheat, whole.......................... & $?$ & 72 & 70 & 30 & 74 & 60 & M. \\
\hline Wheat, cracked....................... & $?$ & 82 & 80 & 60 & 83 & 70 & M. \\
\hline Wheat shorts........................... & 2 & 77 & 73 & 37 & 87 & & M. \\
\hline 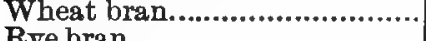 & 2 & 61 & 75 & 34 & $\begin{array}{l}66 \\
75\end{array}$ & $\begin{array}{l}72 \\
58\end{array}$ & M. \\
\hline 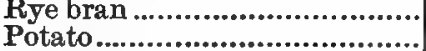 & $\begin{array}{l}2 \\
8\end{array}$ & $\begin{array}{l}67 \\
93\end{array}$ & $\begin{array}{l}66 \\
73\end{array}$ & $\begin{array}{r}9 \\
55\end{array}$ & $\begin{array}{l}75 \\
98\end{array}$ & 58 & $\begin{array}{l}\text { L. } \\
\text { L. }\end{array}$ \\
\hline Potato.......................................... & 4 & 97 & 84 & . & 98 & ..... & $\vec{M}$. \\
\hline Dried blood................................. & $\mathbf{1}$ & 72 & 72 & ........... & 92 & & L. \\
\hline Flesh meal ................................. & 8 & 92 & 97 & ......... & ..... & 87 & L. \\
\hline Bour milk ................................. & 1 & 95 & 96 & (......... & 99 & 95 & L. \\
\hline
\end{tabular}


Table MI. Average Digestible Nutrients and FertulIzIng Constituents in American Feeding Stuffs.

The data of this table for the digestible nutrients are derived mainly from the two preceding tables. In other cases they are from Bulletin 22, Office of Experiment Stations, U. S. Department of Agriculture, Washington; Handbook for Farmers and Dairymen, Woll; Farm Foods, Wolff (English edition, Cousins), and Zusammensetzung der Futtermittel, Dietrich and König.

The fertilizing constituents are principally from the Year Book for 1895, U. S. Department of Agriculture, Washington, with additions from Wolff, Dietrich and König, and Bulletin 87, New Jersey Experiment Station.

\begin{tabular}{|c|c|c|c|c|c|c|c|}
\hline \multirow{2}{*}{ Name of reed. } & \multirow{2}{*}{$\begin{array}{c}\text { Dry } \\
\text { matter } \\
\text { in } 100 \\
\text { pounds. }\end{array}$} & \multicolumn{3}{|c|}{$\begin{array}{l}\text { Digestible nutrients } \\
\text { in } 100 \text { pounds. }\end{array}$} & \multicolumn{3}{|c|}{$\begin{array}{l}\text { Fertilizing constitu- } \\
\text { ents in } 1,000 \text { pounds. }\end{array}$} \\
\hline & & $\begin{array}{l}\text { Pro- } \\
\text { tein. }\end{array}$ & $\begin{array}{c}\text { Carbo- } \\
\text { hy- } \\
\text { drates. }\end{array}$ & $\begin{array}{c}\text { Ether } \\
\text { ex- } \\
\text { tract. }\end{array}$ & $\begin{array}{l}\text { Nitro- } \\
\text { gen. }\end{array}$ & $\begin{array}{l}\text { Phos- } \\
\text { phoric } \\
\text { acid }\end{array}$ & $\begin{array}{l}\text { Pot- } \\
\text { ash. }\end{array}$ \\
\hline CONCENTRATHS. & Lbs. & Lbs. & Lobs. & Lbs. & Lbs. & Lbs. & Lbs. \\
\hline Corn, all ans & 89.1 & 7.9 & 66.7 & 4.3 & 18.2 & 7.0 & 4.0 \\
\hline Dent corn ... & 89.4 & 7.8 & 66.7 & 4. & 16.5 & & \\
\hline lint corn... & 88.7 & 8.0 & 66.2 & 4. & 16.8 & & \\
\hline weet corn. & 91.2 & 8.8 & 63.7 & 7.0 & 18.6 & & \\
\hline Corn cob.... & 89.3 & 0.4 & 52.5 & 0.3 & 5.0 & & 6.0 \\
\hline Corn and co & 84.9 & 4.4 & 60.0 & 2.9 & 14.1 & 5.7 & 4.7 \\
\hline Corn bran.. & 90.9 & 7.4 & 59.8 & 4.6 & 16.3 & 12.1 & 6.8 \\
\hline Gluten $\mathrm{m}$ & 91.8 & 25.8 & 43.3 & 11.0 & 50. & 3.3 & 0.5 \\
\hline Germo mea & 89.6 & 9.0 & 61.2 & 6.2 & 26.5 & 8.0 & 5.0 \\
\hline Starch ref & 91.8 & 11.4 & 58.4 & 6.5 & 22.4 & 7.0 & 5.2 \\
\hline 10-glu & 94.3 & 26.7 & 38.8 & 12.4 & 49.8 & 5.1 & 1.5 \\
\hline Hominy eh & 88.9 & 7.5 & 55.2 & 0.8 & 16.3 & 9.8 & 4.9 \\
\hline Glucose m & 01.9 & 30.3 & 35.3 & 14.5 & 57.7 & & \\
\hline Sugar me: & 93.2 & 18.7 & 51.7 & 8.7 & 36 & 4.1 & 0.3 \\
\hline Gluten feed. & 92.2 & 20.4 & 48.4 & 8.8 & 38.4 & 4.1 & 0.3 \\
\hline Wheat. & 89.5 & 10.2 & 69.2 & 1.7 & 23. & 7.9 & 5.0 \\
\hline Hi & 87.6 & 8.9 & 62 & 0. & & 2.2 & 1.5 \\
\hline Lo & 87.6 & 8.2 & 62.7 & 0. & 28 & 5.6 & 3.5 \\
\hline Dark feedir & 90.3 & 13.5 & 61.3 & & 31 & 21.4 & 10.9 \\
\hline Wheat bra & 88.1 & 12.2 & 39.2 & 2. & 26.7 & 28.9 & 16.1 \\
\hline ng wheat & 88.5 & 12.9 & 40.1 & 3. & & & \\
\hline Wheat bran, winter wheat & 87.7 & 12.3 & 37.1 & 2.6 & & & \\
\hline & 88.2 & 12.2 & 50.0 & 3 . & 28.2 & 13.5 & 5.9 \\
\hline Wheat $\mathrm{m}$ & 87.9 & 12.8 & 53.0 & 3. & 26.3 & 9.5 & 6.3 \\
\hline Wheat screenings.... & 88.4 & 9.8 & 51.0 & & 24.4 & 11.7 & 8.4 \\
\hline Ry & 88.4 & 9.9 & 67.6 & 1.1 & 17.6 & 8.2 & 5.4 \\
\hline & & 11.5 & & 2. & & 22.8 & 14.0 \\
\hline Rye shorts....................... & 90.7 & 11.9 & 45.1 & 1.6 & 18.4 & 12.6 & 8.1 \\
\hline & & 8.7 & 65.6 & 1 & 15.1 & 7.9 & 4. \\
\hline Malt sprouts..... & 89.8 & 18.6 & 37.1 & & 35.5 & 14.3 & 16.3 \\
\hline
\end{tabular}


TABLE III. Digestible nutrients and fertilizing constituents - con.

\begin{tabular}{|c|c|c|c|c|c|c|c|}
\hline \multirow[b]{2}{*}{ Name of reed. } & \multirow{2}{*}{$\begin{array}{c}\text { Dry } \\
\text { matter } \\
\text { in } 100 \\
\text { pounds. }\end{array}$} & \multicolumn{3}{|c|}{$\begin{array}{l}\text { Digestible nutrients } \\
\text { in } 100 \text { ponnds. }\end{array}$} & \multicolumn{3}{|c|}{$\begin{array}{l}\text { Fertilizing constitu- } \\
\text { ents in } 1,000 \text { pounds. }\end{array}$} \\
\hline & & $\begin{array}{l}\text { Pro- } \\
\text { tein. }\end{array}$ & $\mid \begin{array}{c}\text { Carbo- } \\
\text { hy- } \\
\text { arates. }\end{array}$ & $\begin{array}{l}\text { Ether } \\
\text { ex- } \\
\text { tract. }\end{array}$ & $\begin{array}{l}\text { N1tro- } \\
\text { gen. }\end{array}$ & $\begin{array}{l}\text { Phos- } \\
\text { phorlic } \\
\text { acid. }\end{array}$ & Pot- \\
\hline CoNCENTRATHS- continued. & Lbs. & Lbs. & Lbs. & Lbs. & Lbs. & Lbs. & Lbs. \\
\hline $\begin{array}{l}\text { Brewers' grains, wet.......... } \\
\text { Brewers' grains, dried...... }\end{array}$ & $\begin{array}{l}24.3 \\
91.8\end{array}$ & $\begin{array}{r}3.9 \\
15.7\end{array}$ & $\begin{array}{r}9.3 \\
36.3\end{array}$ & $\begin{array}{l}1.4 \\
5.1\end{array}$ & $\begin{array}{r}8.9 \\
36.2\end{array}$ & $\begin{array}{r}3.1 \\
10.3\end{array}$ & $\begin{array}{l}0.5 \\
0.9\end{array}$ \\
\hline Oats......... & 89.0 & 9.2 & 47.3 & 4.2 & 20.6 & 8.2 & 6.2 \\
\hline Oat meal ............................. & 92.1 & 11.5 & 52.1 & 5.9 & 23.5 & & \\
\hline 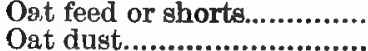 & 92.3 & 12.5 & 46.9 & 2.8 & 17.2 & 9.1 & 5.3 \\
\hline 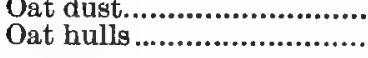 & $\begin{array}{l}93.5 \\
90.6\end{array}$ & $\begin{array}{l}8.9 \\
1.3\end{array}$ & $\begin{array}{l}38.4 \\
40.1\end{array}$ & $\begin{array}{l}5.1 \\
0.6\end{array}$ & $\begin{array}{r}21.6 \\
5.2\end{array}$ & 2.4 & 5.2 \\
\hline Rice. & 87.6 & 4.8 & 72.2 & 0.3 & 10.8 & 1.8 & 0.9 \\
\hline Rice hulls. & 91.8 & 1.6 & 44.5 & 0.6 & 5.8 & 1.7 & 1.4 \\
\hline Rice bran...... & 90.3 & 5.3 & 45.1 & 7.3 & 7.1 & 2.9 & 2.4 \\
\hline Rice polish ........................... & 90.0 & 9.0 & 56.4 & 6.5 & 19.7 & 26.7 & 7.1 \\
\hline Buckwheat. & 87.4 & 7.7 & 49.2 & 1.8 & 14.4 & 4.4 & 2.1 \\
\hline Buckwheat hulls..... & 86.8 & 2.1 & 27.9 & 0.6 & 4.9 & 0.7 & 5.2 \\
\hline Buck wheat bran ......... & 89.5 & 7.4 & 30.4 & 1.9 & 36.4 & 17.8 & 12.8 \\
\hline Buckwheat shorts ............. & 88.9 & 21.1 & 33.5 & 5.5 & & & \\
\hline Buck wheat middlings ...... & 87.3 & 22.0 & 33.4 & 5.4 & 42.8 & 21.9 & 11.4 \\
\hline Sorghum seed...... & 87.2 & 7.0 & 52.1 & 3.1 & 14.8 & 8.1 & 4.2 \\
\hline Broom-corn seed.. & 85.9 & 7.4 & 48.3 & 2.9 & 16.3 & & ........ \\
\hline 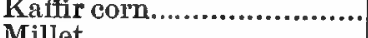 & 84.8 & 7.8 & 57.1 & 2.7 & & & \\
\hline Millet .. & 86.0 & 8.9 & 45.0 & 3.2 & 20.4 & 8.5 & 3.6 \\
\hline Flax seed.. & 90.8 & 20.6 & 17.1 & 29.0 & 36.1 & 13.9 & 10.3 \\
\hline Linseed meal, old process.. & 90.8 & 29.3 & 32.7 & 7.0 & 54.3 & 16.6 & 13.7 \\
\hline Linseed meal, new process. & 89.9 & 28.2 & 40.1 & 2.8 & 57.8 & 18.3 & 13.9 \\
\hline Cotton seed.......................... & 89.7 & 12.5 & 30.0 & 17.3 & 31.3 & 12.7 & 11.7 \\
\hline Cotton-seed meal ................ & 91.8 & 37.2 & 16.9 & 12.2 & 67.9 & 28.8 & 8.7 \\
\hline Cotton-seed hulls ............... & 88.9 & 0.3 & 33.1 & 1.7 & 6.9 & 2.5 & 10.2 \\
\hline Cocoanut meal .................... & 89.7 & 15.6 & 38.3 & 10.5 & 32.8 & 16.0 & 24.0 \\
\hline Palm-nut meal.... & 89.6 & 16.0 & 52.6 & 9.0 & 26.9 & 11.0 & 5.0 \\
\hline Sunfiower seed ................... & 92.5 & 12.1 & 20.8 & 29.0 & 2.2 .8 & 12.2 & 5.6 \\
\hline Sunflower-seed cakes ........ & 91.8 & 31.2 & 19.6 & 12.8 & 55.5 & 21.5 & 11.7 \\
\hline Peanut meal........................ & 89.3 & 42.9 & 22.8 & 6.9 & 75.6 & 13.1 & 15.0 \\
\hline Rape-seed meal.................... & 90.0 & 25.2 & 23.7 & 7.5 & 49.6 & 20.0 & 13.0 \\
\hline 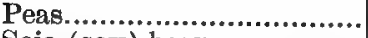 & 89.5 & 16.8 & 51.8 & 0.7 & 30.8 & 8.2 & 9.9 \\
\hline Soja (soy) bean................. & 89.2 & 29.6 & 22.3 & 14.4 & 53.0 & 18.7 & 19.8 \\
\hline 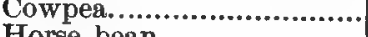 & 85.2 & 18.3 & 54.2 & 1.1 & 33.3 & & \\
\hline Horse bean................................ & 85.7 & 22.4 & 49.3 & 1.2 & 40.7 & 12.0 & 12.9 \\
\hline ROUGHAGE. & & & & & & & \\
\hline Fodder corn. & & & & & & & \\
\hline Fodder corn, green.............. & 20.7 & 1.0 & 11.6 & 0.4 & 4.1 & 1.5 & 3.3 \\
\hline Fodder corn, field-cured.... & 57.8 & 2.5 & 34.6 & 1.2 & 17.6 & 5.4 & 8.9 \\
\hline Corn stover, field-cured..... & 59.5 & 1.7 & 32.4 & 0.7 & 10.4 & 2.9 & 14:0 0 \\
\hline
\end{tabular}


Appendix.

TABLE III. Digestible nutrients and fertilizing constituents - con.

\begin{tabular}{|c|c|c|c|c|c|c|c|}
\hline \multirow{2}{*}{ Name of peed. } & \multirow{2}{*}{$\begin{array}{l}\text { Dry } \\
\text { matter } \\
\text { in } 100 \\
\text { pounds. }\end{array}$} & \multicolumn{3}{|c|}{$\begin{array}{l}\text { Digestible nutrients } \\
\text { in } 100 \text { pounds. }\end{array}$} & \multicolumn{3}{|c|}{$\begin{array}{l}\text { Fertilizing constitu- } \\
\text { ents in } 1,000 \text { pounds. }\end{array}$} \\
\hline & & $\begin{array}{l}\text { Pro- } \\
\text { teln. }\end{array}$ & $\begin{array}{l}\text { Carbo- } \\
\text { hy- } \\
\text { drates. }\end{array}$ & $\begin{array}{l}\text { Ether } \\
\text { ex- } \\
\text { tract. }\end{array}$ & $\begin{array}{c}\text { Nitro- } \\
\text { gen. }\end{array}$ & $\begin{array}{l}\text { Phos- } \\
\text { phoric } \\
\text { acld. }\end{array}$ & $\begin{array}{l}\text { Pot- } \\
\text { ask. }\end{array}$ \\
\hline $\begin{array}{c}\text { ROUGHAGE-continued. } \\
\text { Fresh grass. }\end{array}$ & Lbs. & Lbs. & Lbs. & Lbs. & Lbs. & Libs. & Lbse. \\
\hline Pasture grasses (mixed) ... & 20.0 & 2.5 & 10.2 & 0.5 & 9.1 & 2.3 & 7.5 \\
\hline Kentucky blue grass......... & 34.9 & 3.0 & 19.8 & 0.8 & & & \\
\hline Timothy, different & 38.4 & 1.2 & 19.1 & 0.6 & 4.8 & 2.6 & 7.f \\
\hline $\begin{array}{l}\text { Orchard grass, in bloom.... } \\
\text { Redtop, in bloom }\end{array}$ & 27.0 & 1.5 & 11.4 & 0.5 & 4.3 & 1.6 & 7.6 \\
\hline $\begin{array}{l}\text { Redtop, in b. } \\
\text { Oat fodder... }\end{array}$ & 34.7 & 2.1 & 21.2 & 0.6 & & & \\
\hline odder.... & $\begin{array}{l}37.8 \\
23.4\end{array}$ & 2.6 & 18.9 & 1.0 & $\begin{array}{l}4.9 \\
3.3\end{array}$ & 1.3 & $\begin{array}{l}3.8 \\
7.3\end{array}$ \\
\hline Sorghum ........ & 20.6 & 0.6 & $\begin{array}{l}14.1 \\
12.2\end{array}$ & $\begin{array}{l}0.4 \\
0.4\end{array}$ & $\begin{array}{l}5.3 \\
2.3\end{array}$ & $\begin{array}{l}1.0 \\
0.9\end{array}$ & 2.3 \\
\hline Meadow fescue, in bloom.. & 30.1 & 1.5 & 16.8 & 0.4 & & & \\
\hline Hungarian & 28.9 & 2.0 & 16.0 & 0.4 & 3.9 & 1.6 & 5.5 \\
\hline barley.......... & 21.0 & 1.9 & 10.2 & 0.4 & & & $\cdots$ \\
\hline Peas and oats..................... & 16.0 & 1.8 & 7.1 & 0.2 & & & ...... \\
\hline Peas and bar & 16.0 & 1.7 & 7.2 & 0.2 & & .......... & ...... \\
\hline Hay. & & & & & & & \\
\hline 'Timothy............. & 86.8 & 2.8 & 43.4 & 1.4 & 12.6 & 5.3 & 9.0 \\
\hline Orchard grass....... & 90.1 & 4.9 & 42.3 & 1.4 & 13.1 & 4.1 & 18.8 \\
\hline & 91.1 & 4.8 & 46.9 & 1.0 & 11.5 & 3.6 & 10.2 \\
\hline Kentucky blue & 78.8 & 4.8 & 37.3 & 2.0 & 11.9 & 4.0 & 15.7 \\
\hline Hungarian grass.... & 92.3 & 4.5 & 51.7 & 1.3 & 12.0 & 3.5 & 13.0 \\
\hline & 87.1 & 5.9 & 40.9 & 1.2 & 14.1 & 2.7 & 15.5 \\
\hline Rowen (mixed) .... & 83.4 & 7.9 & 40.1 & 1.5 & 16.1 & 4.3 & 14.9 \\
\hline Meadow fescue..... & 80.0 & 4.2 & 43.3 & 1.7 & 9.9 & 4.0 & 21.0 \\
\hline Soja & 88.7 & 10.8 & 38.7 & 1.5 & 33.2 & 6.7 & 10.8 \\
\hline Gat ha & 91.1 & 4.3 & 46.4 & 1.5 & & & 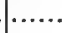 \\
\hline swamp hay........ & 88.4 & 2.4 & 29.9 & 0.9 & & $\cdots$ & \\
\hline Marsh or swamp hay........ & 92.1 & 3.5 & 44.7 & -0.7 & & & ..... \\
\hline White daisy ..................... & 85.0 & 3.8 & 40.7 & 1.2 & & & \\
\hline Straw. & & & & & & & \\
\hline Wheat...... & 90.4 & 0.4 & 36.3 & 0.4 & 5.9 & 1.2 & 5.1 \\
\hline Rye .......... & 92.9 & 0.6 & 40.6 & 0.4 & 4.6 & 2.8 & 7.9 \\
\hline Oat...... & 90.8 & 1.2 & 38.6 & 0.8 & 6.2 & 2.0 & 12.4 \\
\hline Barl & 85.8 & 0.7 & 41.2 & 0.6 & 13.1 & 3.0 & 20.9 \\
\hline Wheat chaff...................... & 85.7 & 0.3 & 23.3 & 0.5 & 7.9 & 7.0 & 4.2 \\
\hline Oat chaff $. . . . . . . . . . . . \ldots \ldots \ldots \ldots . . . . .$. & 85.7 & 1.5 & 33.0 & 0.7 & & & \\
\hline Fresh legumes. & & & & & & & \\
\hline fferent stages & 29.2 & 2.9 & 14.8 & 0.7 & 5.3 & 1.3 & 4.6 \\
\hline bloo & 25.2 & 2.7 & 13.1 & 0.6 & 4.4 & 1.1 & 2.0 \\
\hline n clover...... & 19.1 & 2.4 & 9.1 & 0.5 & 4.3 & 1.3 & 4.9 \\
\hline Alfal & 28.2 & 3.9 & 12.7 & 0.5 & 7.2 & 1.3 & 5.6 \\
\hline Cow & 16.4 & 1.8 & 8.7 & 0.2 & 2.7 & 1.0 & 3.1 \\
\hline 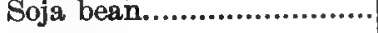 & 24.9 & 3.2 & 11.0 & 0.5 & 2.9 & 1.5 & 5.3 \\
\hline Legume hay and straw. & & & & & & & \\
\hline Red & 84.7 & 6.8 & 35.8 & 1.7 & 20.7 & 3.8 & 22.0 \\
\hline $\operatorname{Rec}$ & .78 .8 & 5.7 & 32.0 & 1.9 & 22.3 & 5.5 & 12.2 \\
\hline Alsike clover ....................... & 90.3 & 8.4 & 42.5 & 1.5 & 23.4 & 6.7 & 22.3 \\
\hline & 90.3 & 11.5 & 42.2 & 1.5 & 27.5 & 5.2 & 18.1 \\
\hline Crimson clover....... & $90.4^{\prime}$ & 10.5 & 34.9 & 1.2 & 20.5 & 4.0 & 13.1 \\
\hline
\end{tabular}


TaBLE III. Digestible nutrients and fertilizing constituents - con.

\begin{tabular}{|c|c|c|c|c|c|c|c|}
\hline \multirow[b]{2}{*}{ Name of feed. } & \multirow{2}{*}{$\begin{array}{c}\text { Dry } \\
\text { matter } \\
\text { in } 100 \\
\text { pounds. }\end{array}$} & \multicolumn{3}{|c|}{$\begin{array}{l}\text { Digestible nutrients } \\
\text { in } 100 \text { pounds. }\end{array}$} & \multicolumn{3}{|c|}{$\begin{array}{l}\text { Fertilizing constítin- } \\
\text { ents in } 1,000 \text { pounds. }\end{array}$} \\
\hline & & $\begin{array}{l}\text { Pro- } \\
\text { tein. }\end{array}$ & $\left|\begin{array}{c}\text { Carbo- } \\
\text { hy- } \\
\text { drates. }\end{array}\right|$ & $\begin{array}{l}\text { Ether } \\
\text { ex- } \\
\text { tract. }\end{array}$ & $\begin{array}{c}\text { Nitro- } \\
\text { gen. }\end{array}$ & $\begin{array}{c}\text { Phos } \\
\text { phortc } \\
\text { acid. }\end{array}$ & $\begin{array}{l}\text { Pot- } \\
\text { ash. }\end{array}$ \\
\hline $\begin{array}{c}\text { RovGHAGE-continued. } \\
\text { Legume hay and straw-con. }\end{array}$ & Lbs. & Lbs. & Lbs. & Lbs. & Lbs. & Lbs. & Lbs. \\
\hline 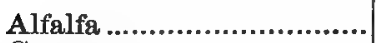 & 91.6 & 11.0 & 39.6 & 1.2 & 21.9 & 5.1 & 16.8 \\
\hline Cowpea.. & 89.3 & 10.8 & 38.6 & 1.1 & 19.5 & 5.2 & 14.7 \\
\hline Soja-bean str & 89.9 & 2.3 & 40.0 & 1.0 & 17.5 & 4.0 & 13.2 \\
\hline Pea-vine straw................. & 86.4 & 4.3 & 32.3 & 0.8 & 14.3 & 3.5 & 10.2 \\
\hline Silago. & & & & & & & \\
\hline 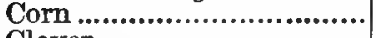 & 20.9 & 0.9 & 11.3 & 0.7 & 2.8 & 1.1 & 3.7 \\
\hline Clover....... & 28.0 & 2.0 & 13.5 & 1.0 & & & \\
\hline Sorghum ............ & 23.9 & 0.6 & 14.9 & 0.2 & & $\cdots \cdots \cdot \cdot$ & $\cdots \cdots$ \\
\hline Alfalfa ............... & 27.5 & $3.0^{-}$ & 8.5 & 1.9 & .... & (n...... & $\ldots \ldots$ \\
\hline Grass...... & 32.0 & 1.9 & 13.4 & $\begin{array}{l}1.6 \\
0.9\end{array}$ & & $\cdots \cdots \cdots$ & $\cdots \cdots$ \\
\hline Cowpea vine ....................... & 20.7 & 1.5 & 8.6 & & ……. & - …..... & $\cdots \cdots$ \\
\hline 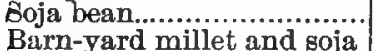 & 25.8 & 2.7 & 8.7 & 1.3 & …....... & ........... & $\cdots \cdots$ \\
\hline 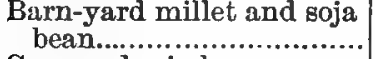 & 21.0 & 1.6 & 9.2 & 0.7 & & & \\
\hline Corn and soja bean ............ & 24.0 & 1.6 & 13.0 & 0.7 & 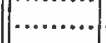 & & $\ldots \ldots$ \\
\hline Roots and tubers. & & & & & & & \\
\hline Pntato............................... & 21.1 & 0.9 & 16.3 & 0.1 & 3.2 & 1.2 & 4.6 \\
\hline Beet, comr & 13.0 & 1.2 & 8.8 & 0.1 & 2.4 & 0.9 & 4.4 \\
\hline .............. & 13.5 & 1.1 & 10.2 & 0.1 & 2.2 & 1.0 & 4.8 \\
\hline ................ & 9.1 & 1.1 & 5.4 & 0.1 & 1.9 & 0.9 & 3.8 \\
\hline Flat turn & 9.5 & 1.0 & 7.2 & 0.2 & 1.8 & 1.0 & 3.9 \\
\hline Ruta-baga & 11.4 & 1.0 & 8.1 & 0.2 & 1.9 & 1.2 & 4.9 \\
\hline Carrot & 11.4 & 0.8 & 7.8 & 0.2 & 1.5 & 0.9 & 5.1 \\
\hline Pars & 11.7 & 1.6 & 11.2 & 0.2 & 1.8 & 2.0 & 4.4 \\
\hline Artichoke...................... & 20.0 & 2.0 & 16.8 & 0.2 & 2.6 & 1.4 & 4.7 \\
\hline Miscellaingous. & & & & & & & \\
\hline Cabbage.. & 15.3 & 1.8 & 8.2 & 0.4 & 3.8 & 1.1 & 4.3 \\
\hline Spu & 20.0 & 1.5 & 9.8 & 0.3 & 3.8 & 2.5 & 5.9 \\
\hline -beet lea & 12.0 & 1.7 & 4.6 & 0.2 & 4.1 & 1.5 & 6.2 \\
\hline Pumpkin, & 9.1 & 1.0 & 5.8 & 0.3 & & & \\
\hline en............... & 19.2 & 1.4 & 8.3 & 0.8 & 1.1 & 1.6 & 0.9 \\
\hline Prickly comfrey................ & 11.6 & 1.4 & 4.6 & 0.2 & 4.2 & 1.1 & 7.5 \\
\hline Rape ............................ & 14.0 & 1.5 & 8.1 & 0.2 & 4.5 & 1.5 & 3.6 \\
\hline Acorns, fresh ..................... & 44.7 & 2.1 & 34.4 & 1.7 & & & \\
\hline Dried bloo & 91.5 & 52.3 & .0 & 2.5 & 135.0 & 13.5 & 7.7 \\
\hline & 89.3 & 66.2 & .3 & 13.7 & 113.9 & 7.0 & 1.0 \\
\hline Dried fish. & 89.2 & 44.1 & .0 & 10.3 & 77.5 & 120.0 & 2.0 \\
\hline Beet pulp.. & 10.2 & 0.6 & 7.3 & & 1.4 & 0.2 & 0.4 \\
\hline Beet molasses....................... & 79.2 & 9.1 & 59.5 & .0 & 14.6 & 0.5 & 56.3 \\
\hline Cow & 12.8 & 3.6 & 4.9 & 3.7 & 5.3 & 1.9 & 1.8 \\
\hline & 25.4 & 17.6 & 2.7 & 3.6 & 28.2 & 6.6 & 1.1 \\
\hline Skim milk, gravity............ & 9.6 & 3.1 & 4.7 & 0.8 & 5.6 & 2.0 & 1.9 \\
\hline atrifugal .... & 9.4 & 2.9 & 5.2 & 0.3 & 5.6 & 2.0 & 1.9 \\
\hline Buttermilk ... & 9.9 & 3.9 & 4.0 & 1.1 & 4.8 & 1.7 & 1.6 \\
\hline Whey............ & 6.6 & 0.8 & 4.7 & 0.3 & 1.5 & 1.4 & 1.8 \\
\hline
\end{tabular}


Table IV. Feeding Standarda for Farm Animals.

The table of feeding standards here presented is taken from Mentzel \& Lengerke's Landw. Kalender for 1898. It comprises the standards originally prepared by Dr. Emil v. Wolff for that publication, modified by Dr. C. Lehmann. The standards having been described at length in Chapter VII of this work, little ' remains to be added for the guidance of the student in their use.

The standards are arranged to meet the requirements of farm animals under normal conditions. The student should not accept the statements in the standards as absolute, but rather as data of a helpful nature, to be varied in practice as circumstances suggest.

The statements in the column headed "Dry Matter" should be regarded as approximate only, since the digestive tract of the animal readily adapts itself to variations of 10 per cent. or more from the standard of volume.

The column headed "Sum of Nutrients" combines the data of the three preceding columns, the ether extract being multiplied by 2.4 before adding. In the first column of this division of the table, marked "Crude Fiber $=1$," all the digestible nutrients are included. In the second division, marked "Crude Fiber $=\frac{1}{2}$," it is generally assumed that about 30 per cent. of the digestible nonnitrogenous nutrients consists of crude fiber, and one-half of this, or 15 per cent., is deducted. Rations containing much coarse forage should therefore be somewhat increased because of their lower nutritive value.

The standards are for animals of normal size. Those of small breeds will require somewhat more nutrients, amounting in some cases to .3 of a pound of nitrogenous and 1.5 pounds of nonnitrogenous digestible nutrients daily for 1,000 pounds of live weight of animals.

Narrowing the nutritive ratio in feeding full-grown animals is for the purpose of lessening the depression of digestibility, (51) to enliven the temperament, or to increase the production of milk at the expense of laying on fat.

The different standards given for the same class of animals according to performance illustrate the manner and direction in which desirable changes should be made. 
In considering the fattening standards the student should bear in mind that the most rapid fattening is usually the most economical, so that the standards given may often be profitably increased.

Standards for milch cows are given for the middle of the lactation period with animals yielding milk of average composition.

The standards for growing animals contemplate only a moderate amount of exercise; if much is taken, add 15 per cent.mostly non-nitrogenons nutrients - to the ration. If no exercise is taken, deduct 15 per cent. from the standard.

\begin{tabular}{|c|c|c|c|c|c|c|c|}
\hline \multirow{4}{*}{ Animal. } & \multicolumn{7}{|c|}{ Per day per 1,000 pounds live weight. } \\
\hline & \multirow{3}{*}{ 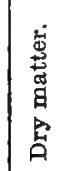 } & \multicolumn{6}{|c|}{ Digestible nutrients. } \\
\hline & & \multirow{2}{*}{ 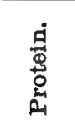 } & \multirow{2}{*}{ 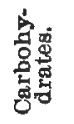 } & \multirow{2}{*}{ 总总 } & \multicolumn{2}{|c|}{$\begin{array}{c}\text { Sum of } \\
\text { nutrients. }\end{array}$} & \multirow{2}{*}{ 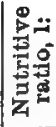 } \\
\hline & & & & & \multicolumn{2}{|c|}{$\begin{array}{l}\text { Crude flber } \\
=1 \quad=3 / 2\end{array}$} & \\
\hline 1. Oxen. & Lbs & Lbs. & Lbs. & Lbs. & Lbs. & Lbs. & \\
\hline At rest in stall. & 18 & 0.7 & 8.0 & 0.1 & 8.9 & 7.5 & 11.8 \\
\hline At light work ..... & 22 & 1.4 & 10.0 & 0.3 & 12.1 & 9.7 & 7.7 \\
\hline At medium work. & 25 & 2.0 & 11.5 & 0.5 & 14.7 & 12.0 & 6.5 \\
\hline At heavy work..... & 38 & 2.8 & 13.0 & 0.8 & 17.7 & 15.0 & 5.3 \\
\hline \multicolumn{8}{|l|}{ 2. Fattening cattle. } \\
\hline First period...... & 30 & 2.5 & 15.0 & 0.5 & 18.7 & 15.6 & 6.5 \\
\hline Second period.. & 30 & 3.0 & 14.5 & 0.7 & 19.2 & 17.0 & 5.4 \\
\hline Third period........ & 26 & 2.7 & 15.0 & 0.7 & 19.4 & 17.2 & 6.2 \\
\hline \multicolumn{8}{|l|}{ 3. Milch cows. } \\
\hline When yielding daily - & & & & & & & \\
\hline 11.0 pounds of milk. & 25 & 1.6 & 10.0 & 0.3 & 12.3 & 10.2 & 6.7 \\
\hline 16.6 pounds of milk... & 27 & 2.0 & 11.0 & 0.4 & 14.0 & 12.2 & 6.0 \\
\hline $\begin{array}{l}22.0 \text { pounds of milk... } \\
27.5 \text { pounds of milk. }\end{array}$ & 29 & 2.5 & 13.0 & $\begin{array}{l}0.5 \\
0.8\end{array}$ & 16.7 & 14.4 & 5.7 \\
\hline \multicolumn{8}{|l|}{ 4. Sheep. } \\
\hline Coarse wool & 20 & 1.2 & 10.5 & 0.2 & 12.2 & 10.0 & 9.1 \\
\hline Fine wool .... & 23 & 1.5 & 12.0 & 0.3 & 14.2 & 12.0 & 8.5 \\
\hline \multicolumn{8}{|l|}{ 5. Breeding ewes. } \\
\hline With lambs.... & 25 & 2.9 & 15.0 & 0.5 & 19.1 & 16.3 & 5.6 \\
\hline \multicolumn{8}{|l|}{ 6. Fattening sheep. } \\
\hline First period. & 30 & 3.0 & 15.0 & 0.5 & 19.2 & 16.5 & 5.4 \\
\hline Second period .................... & 28 & 3.5 & 14.5 & 0.6 & 19.4 & 16.9 & 4.5 \\
\hline \multicolumn{8}{|l|}{ 7. Horses. } \\
\hline Light work. . & 20 & 1.5 & 9.5 & 0.4 & 12.0 & 10.0 & 7.0 \\
\hline Medium work. & 24 & 2.0 & 11.0 & 0.6 & 14.5 & 12.8 & 6.2 \\
\hline Heavy work.. & 26 & 2.5 & 13.3 & 0.8 & 17.7 & 15.5 & 6.0 \\
\hline 8. Brood sows........ & 22 & 2.5 & 15.5 & 0.4 & 19 & 0 & 6.6 \\
\hline
\end{tabular}


TaBLE IV. Feeding standards for farm animals-continued.

\begin{tabular}{|c|c|c|c|c|c|c|c|}
\hline \multirow{4}{*}{ Animal. } & \multicolumn{7}{|c|}{ Per day per 1,000 pounds live welght. } \\
\hline & \multirow{3}{*}{ 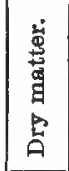 } & \multicolumn{6}{|c|}{ Digestjble nutrients. } \\
\hline & & \multirow{2}{*}{$\begin{array}{l}\frac{d}{8} \\
\stackrel{8}{0} \\
\stackrel{4}{A}\end{array}$} & \multirow{2}{*}{ 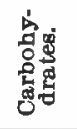 } & \multirow{2}{*}{ 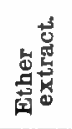 } & \multicolumn{2}{|c|}{$\begin{array}{c}\text { Sum of } \\
\text { nutrients. }\end{array}$} & \multirow{2}{*}{ 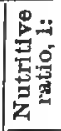 } \\
\hline & & & & & \multicolumn{2}{|c|}{ Crude tlber } & \\
\hline 9. Fattening swine. & Lbs & Lbs. & Lbs. & Lbs. & Lbs. & Lbs. & \\
\hline First period..... & 36 & 4.5 & 25.0 & 0.7 & \multicolumn{2}{|c|}{31.2} & 5.9 \\
\hline Second period ... & 32 & 4.0 & 24.0 & 0.5 & \multicolumn{2}{|c|}{29.2} & 6.3 \\
\hline Third period..... & 25 & 2.7 & 18.0 & 0.4 & \multicolumn{2}{|c|}{22.0} & 7.0 \\
\hline \multicolumn{8}{|l|}{ 10. Growing cattle. } \\
\hline $\begin{array}{c}\text { Dairy breeds. } \\
\text { Age in } \\
\text { months. }\end{array}$ & & & & & & & \\
\hline $2-3 \ldots \ldots \ldots \ldots \ldots \ldots$ & 23 & 4.0 & 13.0 & 2.0 & 21.8 & 21.0 & 4.5 \\
\hline ........3 300... & 24 & 3.0 & 12.8 & 1.0 & 18.2 & 17.0 & 5.1 \\
\hline .....500.. & 27 & 2.0 & 12.5 & 0.5 & 15.7 & 13.7 & 6.8 \\
\hline ….........700. & 26 & 1.8 & 125 & 0.4 & 15.3 & 12.8 & 7.5 \\
\hline $18-24 \ldots \ldots \ldots \ldots \ldots . . . .900$ & 26 & 1.5 & 12.0 & 0.3 & 14.2 & 11.8 & 8.5 \\
\hline \multicolumn{8}{|l|}{ 11. Growing cattle. } \\
\hline $\begin{array}{c}\text { Beer breeds. } \\
2-3 \ldots \ldots \ldots \ldots \\
160\end{array}$ & 23 & 4.2 & 13.0 & 2.0 & 20.0 & 21.5 & 4.2 \\
\hline $3-6 \ldots \ldots \ldots \ldots \ldots \ldots . . . . . . . . .330$. & 24 & 3.5 & 12.8 & 1.5 & 19.9 & 19.0 & 4.7 \\
\hline ( & 25 & 2.5 & 13.2 & 0.7 & 17.4 & 15.8 & 6.0 \\
\hline $12-18 \ldots \ldots \ldots \ldots \ldots . . . . . .750 \ldots$ & 24 & 2.0 & 12.5 & 0.5 & 15.7 & 13.9 & 6.8 \\
\hline $18-24 \ldots \ldots \ldots \ldots \ldots \ldots .950 \ldots \ldots \ldots \ldots$ & 24 & 1.8 & 12.0 & 0.4 & 14.8 & 13.2 & 7.2 \\
\hline \multicolumn{8}{|l|}{ 12. Growing sheep. } \\
\hline & 25 & 3.4 & 15.4 & 0.7 & 20.5 & 18.4 & \\
\hline 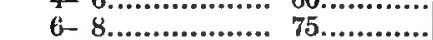 & 25 & $\begin{array}{l}0.2 \\
2.8\end{array}$ & 13.8 & 0.6 & 18.0 & $\begin{array}{l}10.4 \\
15.8\end{array}$ & $\begin{array}{l}5.0 \\
5.4\end{array}$ \\
\hline $8-11 \ldots \ldots \ldots \ldots \ldots \ldots \ldots$ & 23 & 2.1 & 11.5 & 0.5 & 14.8 & 12.8 & 6.0 \\
\hline $11-15 \ldots \ldots \ldots \ldots \ldots, 90 \ldots \ldots$ & 22 & 1.8 & 11.2 & 0.4 & 14.0 & 12.0 & 7.0 \\
\hline $15-20 \ldots \ldots \ldots \ldots \ldots \ldots \ldots \ldots \ldots \ldots$ & 22 & 1.5 & 10.8 & 0.3 & 13.0 & 11.0 & 7.7 \\
\hline \multirow{2}{*}{\multicolumn{8}{|c|}{$\begin{array}{l}\text { 13. Growing sheep. } \\
\text { Mutton breeds. }\end{array}$}} \\
\hline & & 4.4 & 15.5 & 0.9 & 22.1 & 20.9 & 4.0 \\
\hline $6-8 \ldots \ldots \ldots \ldots . . . . . . .80$ & 26 & 3.5 & 15.0 & 0.7 & 20.2 & 17.8 & 4.8 \\
\hline $8-11 \ldots \ldots \ldots \ldots \ldots . . \ldots 100 \ldots$ & 24 & 3.0 & 14.3 & 0.5 & 18.5 & 16.3 & 5.2 \\
\hline $11-15 \ldots \ldots \ldots \ldots \ldots \ldots . . .120 \ldots$ & 23 & 2.2 & 12.6 & 0.5 & 16.0 & 138 & 6.3 \\
\hline $15-20 \ldots \ldots \ldots \ldots \ldots \ldots \ldots$ & 22 & 2.0 & 12.0 & 0.4 & 15.0 & 12.8 & 6.5 \\
\hline \multicolumn{8}{|l|}{ 14. Growing swine. } \\
\hline \begin{tabular}{c}
\multicolumn{3}{c}{ Breeding stock. } \\
$2-3 \ldots \ldots \ldots \ldots \ldots \ldots$ \\
$50 \ldots \ldots$
\end{tabular} & 44 & 7.6 & 28.0 & 1.0 & \multicolumn{2}{|c|}{38.0} & 4.0 \\
\hline $3-5 \ldots \ldots \ldots \ldots \ldots \ldots \ldots$ & $\begin{array}{l}44 \\
35\end{array}$ & 5.0 & 23.1 & 0.8 & \multicolumn{2}{|c|}{$\begin{array}{l}30.0 \\
30.0\end{array}$} & 5.0 \\
\hline $5-6 \ldots \ldots \ldots \ldots \ldots . . . . . . . . . .$. & 32 & 3.7 & 21.3 & 0.4 & \multicolumn{2}{|c|}{26.0} & 6.0 \\
\hline 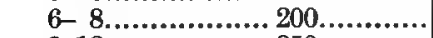 & 28 & 2.8 & 18.7 & 0.3 & & .2 & 7.0 \\
\hline $8-12 \ldots \ldots \ldots \ldots \ldots \ldots . \ldots . \ldots \ldots$ & 25 & 2.1 & 15.3 & 0.2 & \multicolumn{2}{|c|}{17.9} & 7.5 \\
\hline \multicolumn{8}{|l|}{ 15. Growing, fattening swine. } \\
\hline $2-3 \ldots \ldots \ldots \ldots \ldots$ & 44 & 7.6 & 28.0 & 1.0 & & 3.0 & 4.0 \\
\hline $3-5 \ldots \ldots \ldots \ldots \ldots \ldots \ldots$ & 35 & 5.0 & 23.1 & 0.8 & & .0 & 5.0 \\
\hline 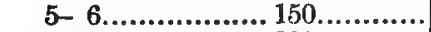 & 33 & 4.3 & 22.3 & 0.6 & & .0 & 5.5 \\
\hline $6-8 \ldots \ldots \ldots \ldots \ldots \ldots . . . . . .200 \ldots$ & 30 & 3.6 & 20.5 & 0.4 & & 1 & 6.0 \\
\hline $9-12 \ldots \ldots \ldots \ldots \ldots \ldots$ & 26 & 3.0 & 18.3 & 0.3 & & .0 & 6.4 \\
\hline
\end{tabular}




\section{GLOSSARY.}

Technical terms which may not have been explained in the body of the book are here defined. The botanical names of a number of agricultural plants are also given to aid the reader who might otherwise be uncertain which species or variety is meant.

Abomasum. The fourth stomach of ruminants. (28)

Ad libitum. At pleasure. In case of feeding farm animals, all they will eat of any particular feeding stuff.

Albuminoids. The more complex forms of protein. They are usually insoluble in water or may be rendered so by heat. (10) See Protein.

Alfalfa. Medicago sativa.

Aliment. Food, nutriment.

Alimentary tract or canal. The duct comprising the stomach, intestines, etc., by which food (aliment) is conveyed through the body, and the useless parts evacuated. (32)

Alsike clover. Trifolium hybridum.

Amides. Protein compounds simpler than the albuminoids, which are capable of transference in the plant, or such as have been reduced to their present form from the albuminoids. (7I) See Protein.

Artichoke. Helianthus tuberosus.

Ash. The portion of a feeding stuff which remains after it has been burned.

Assimilate. The conversion of digested nutrients into the fluid or solid substances of the body.

Balanced ration. A combination of farm foods containing the various nutrients in such proportion and amount as will nurture the animal for twenty-four hours, with the least waste of nutrients.

Barnyard millet. Panicum crus-galli.

Bolus. A rounded mass; the portion of the food ready to be swallowed at one time.

Burr clover. Medicago maculata.

Calorie. The amount of heat required to raise the temperature of one kilogram of water one degree Centigrade (or one pound of water four degrees Fahrenheit). (61)

Carbhydrates. See Carbohydrates.

Carbohydrates. A group of nutrients rich in earbon and containing oxygen and hydrogen in the proportion in which they form water. The carbohydrates do not contain nitrrgen. 
Carnivorous. A term applied to animals that feed chiefly on flesh.

Casein. The protein substance of milk which is coagulated by rennet or acids.

Castor oil bean. The seed of Ricinus communis.

Cathartic. A medicine that acts as a purge.

Cellulose. The cell tissue of plants. The lint of cotton and wood pulp are almost pure cellulose. See Crude fiber.

Chyle. A milky fluid found in the lacteals, consisting of digested but unassimilated nutrients in solution, and the digested fatty matter of the food in a state of emulsion. (35)

Concentrates. The more nutritious portion of the rations of farm animals, embracing such feeding stuff's as corn, oil meal, etc.

Corn. See Indian corn.

Corn fodder, or fodder corn. Stalks of corn, either green or dried, which are grown for forage and from which the ears or nubbins, if they carry any, have not been removed.

Corn stover. See Stover.

Cowpea. Dolichos katiang, var. sinensis.

Crimson clover. Trifolium incarnatum.

Crude fiber. The framework forming the walls of the cells of plants. It is composed of cellulose and lignin, the latter being the more woody portion. (20)

Crude protein. See Protein.

Diastase. The ferment found in seeds while germinating, especially in malting barley, by aid of which starch is converted into glucose.

Digestible matter. The part of feeding stuffs brought into solution or semi-solution by the digestive fluids.

Digestible nutrients. The portion of any food constituent that is digested by animals.

Digestion coefficient. The percentage of any particular nutrient of a feeding stuff which is found to be digestible.

Digestive tract. Bee Alimentary tract.

Dry matter. The portion of a feeding stuff remaining after the water or moisture contained therein has been driven off by heat.

Emulsion. A milk-like mixture of a liquid and a solid, or of two liquids in which one of the constituents, generally fat or oil, is present in suspension in an exceedingly fine mechanical condition.

Ensilage. As a noun, the forage preserved in a silo; now usually termed silage, which see. As a verb, to place in a silo.

Ergot. A parasitic fungus of poisonous qualities found on some of the cereals and grasses. (283)

Ether extract. That which is dissolved from a water-free feeding stuff by means of ether. It is often termed "fat" by agricultural writers. (21) 
Excrement. The indigestible or refuse matter of farm foods voided by animals.

fertilizing constituents. The nitrogen and mineral oomponents of feeding stuffs. Generally the term applies only to nitrogen, phosphoric acid and potash, since these are most apt to be lacking in the soil or present in insufficient quantities.

Field pea. Pisum arvense.

Fodder corn. Bee Corn fodder.

Feot-ton. The work performed in raising a weight of one ton to a height of one foot.

Glucose, fruit sugar. The form of sugar found in fruits, honey, etc.; also in the alimentary canal. It can be obtained by treating starch or cane sugar (sucrose) with dilute mineral acids.

olycogen. A carbohydrate resembling starch, found in the liver.

Grain equivalent. The term used to designate the comparative value of grain and less concentrated feeding stuffs, such as milk, whey, roots, etc.

Gram. A metric weight. 453.6 grams equal one pound avoirdupois.

Hairy vetch. Vicia villosa.

Herbivorous. A term applied to animals that subsist on vegetable foods.

Herd's grass. See Timothy.

Hungarian grass, German millet. Setaria italica, var. germanica.

Ibid. In the same place; preceding reference.

Indian corn, or maize. Zea mays.

Intestine. The lower part of the alimentary canal. (32)

Japan clover. Lespedeza striata.

Japanese millet. Setaria italica, vars.

June grass. See Kentucky blue grass.

Kaffir corn. Sorghum vulgare.

Kentucky blue grass, or June grass. Poa pratensis.

Kilogram. A metric weight equal to $2.2+$ pounds.

Lacteals. Minute tubes which take the chyle from the alimentary canal and convey it to the thoracic duct. See Lymphatics.

Legumes. Plants belonging to the botanical family Leguminosæ. Examples: red clover, peas, beans.

Levulose. Invert sugar, obtained with dextrose or grape sugar when cane sugar is heated with dilute mineral acids.

Liter. A metric measure of capacity equaling $1.05+$ quarts.

Loc. cit. In the place referred to; preceding reference.

Lucern. See Alfalfa.

Iymph. The colorless fluid found in the lymphatics of the animal body.

Lymphatics. The vein-like vessels that convey lymph. (37)

Lymphatic system. The system of lynıph vessels which collect and convey the lymph. (37) 
Maintenance ration. An allowance of food sufficient to maintain a resting cnimal - neither gaining nor losing in weight.

Mammoth ciover. Trifolium medium.

Mangel, mangel-wurzel. Beta vulgaris.

Masticate. To crush or grind food with the teeth. (34)

Meadow fescue. Festuca pratensis.

Metabofism. The process by which, on the one hand, the digested food is built up into living matter, and on the other, the living matter is broken down into simpler products within a cell or organism.

Beter. A metric unit of length equaling 3.28 feet.

Millet, common. Panicum miliaceum.

Millo maize. S'orghum vulgare or Andropogon sorghum, var.

Mineral matter. See Ash. (18)

Nitrogen-free extract. The portion of a feeding stuff remaining when the moisture, ash, ether extract, crude fiber and nitrogen are deducted; it includes starch, sugar, gums, etc. (22)

Nitrogenous substance. siny food substance containing nitrogen. See Protein.

P.strient. Any food constituent or group of food constituents capable of nourishing animals. Sugar, carbohydrates and protein are nutricnts.

Nutritive ratio. The proportion of digestible protein to digestible carbohydrates and ether extract in a ration, the percentage of ether extract being multiplied by 2.4 and added to the carbohydrates.

0il meal. As understood by American farners, this term applies only to linseed oil cake reduced to meal by grinding. (200)

0masum. The third stomach of ruminants. (28)

Omniverous. Eating or living upon animal or vegetable food indiscriminately.

Orchard grass. Dactylis glomerata.

Organic matter. The part of a feeding stuff which is destroyed oy ourning.

Parsnip. Pastinaca sativa.

Pepsin. The digestivn ferment found in the stomach of animals. (27)

Period of gestation The length of time of carrying the young; from conception to birth.

Period of lactation. The time during which the animal suckles her young; with dairy cows, the period from calving to drying off.

Prickly comfrey. Symphytum asperrimum.

Protein. A term used to characterize the constituents of feeding stuffs which contain nitrogen. The organic part of the bones, muscles, tendons, internal organs, skin, etc., of the animal body are formed from the protein nutrients of feeding stuffs. Wheat gluten and white of egg are examples of protein. On the average, 16 per cent. 
of protein compounds is nitrogen, the other elements being the same as in carbohydrates and fat. The protein compounds in feeding stuffs can be divided into albuminoids and amides, which see. The terms "nitrogenous compound " and " nitrogenow substance" have the same meaning as protein.

Protoplasm. The jelly-like or granular substance of living plant-cells. (5) Provender. Forage, grain, or feed of any kind.

Peyalin. The ferment contained in the saliva. (25)

Pumpkin. Cucurbita pepo.

Rape. Brassica napus.

Ration. The allowance of provender given to an animal during twentyfour hours.

Red clover. Trifolium pratense.

Redtop. Agrostis vulgaris.

Rennet. The ferment found in the lining of the rennet stomach of young mammals. (27)

Respiration apparatus. An apparatus for determining the waste mattor thrown off by the lungs of an animal. $(54,55)$

Reticulum, or honey comb. The second stomach of ruminants. (28)

Roughage. The coarse portion of a ration, including such feeding aturs as hay, corn fodder, silage, roots, etc. See Concentrates.

Rumen, of paunch. The first stomach of ruminants. (28)

Ruminant. An animal that chews the cud.

Ruta-baga, Swedish turnip, Swedes. Brassica campestris, var.

Saliva. The secretion of the salivary glands of the mouth, the office of which is to moisten the food and through its ferment, ptyalin, partially digest the starchy components of the food. (25)

Scarlet or crimson clover. Trifolium incarnatum.

Silage. A succulent forage preserved in the silo.

Silo. An air-tight structure used for the preservation of forage in a suoculent condition.

Soiling. The system of feeding farm animals in a barn or enclosure with fresh grass or green fodders, as corn, rye, oats, etc.

Soja bean, or soy bean. Soja hispida.

Sorghum. Sorghum vulgare, var. saccharatum.

Spurry. Spergula arvensis.

Stover. The dry stalks of corn from which the ears have been removed. Succulent feed. Feed containing much water, as grass, silage, roote.

Swedish clover. See Algike clover.

Teosinte. Euchlaena luxurians.

Timethy, or Herd's grass. Phleum pratense.

Villi. Minute hair-like projections on the inside of the intestines, through which the larger portion of the digested nutrients is absorbed. (35)

White clover. Trifolium repens. 


\section{INDEX.}

The references are to pagea.

Abomasam, 16.

Absorption, 20.

Acorn, 219.

Age, effect of on gain of steers, 867 .

Age of cow, effect of on productivity of feed, 406 .

Albuminoids, 6.

Alíalfa or lucern, 203.

compared with corn, 204.

for past ure, 208.

in eastern United States, 207.

Iowa experience with, 204 .

losses in hay making, 206.

manner of growth, 207.

yield of, 203.

Alfalfa crop, nutrients in, 205.

Alfalfa hay, 208.

damage from rain, 206.

fattoning Western sheep on, 506 .

for sheep, 505.

and grain for fattening sheep, 532.

Alsike clover, 201.

American Fat Stock Show, slaughter teats, 380.

American ration for dairy cows, 114

Amides, 7. influence on protein consumption, 48.

Animal body, dry substance in, 72.

fat in, 72 .

influence of feed on, 78.

nitrogenous subatance in, 72 .

water in, 72 .

Animal carcass, modifleation by roots, 214 .

Animal nutrition, 40.

Artichoke, 214.

for horses, 307.

for pigs, 571 .

Artificial digestion, 81 . trials, 238 .

Ash, 7, 10 . retained and volded by farm mimals, 265.

Ashes, for pigs fed on corn, 86 . for swine, 614 .

Asparagin, a nutrient, 48. influence on proteln consumption, 18.

Balanced ration, for steers, 357.

Ball-feeding show pigs, 613.

Barley, characteristies of, 133. fertilizing constituents of, 138 .

for cows, 474.

for horses, 298.

for wrine, 562,610 .
Barley vs. centrifagal sirim milk for ptsa, 586.

vs. Indian com for ples, 591 .

v8. rye for plgs, 588 .

Barley and its by-products in browing, 18 . Barley and peas, 191.

Barrows v8. sows in swine feeding, 60 .

Beef, feeding for, 838. production, cotton seed for, $\mathbf{8 6 1}$. making, at the South, 361.

value of breed in, 372 .

returns per acre of corn, 381 . see Steer feeding.

Beef and dairy cows compared, 405.

Beet molasses, 224. potash in, 225.

Beet pulp, means of utillzing, 223 . sllage from, 223 .

Beets of different sugar content va. grata for pigs, 585.

Beets and sllage, relative cost, 252.

Beets, see Roots.

Bile, 17.

Blood, the, 22. plasma, composition of, 22 venous, composition of, 22. dried, feeding pigs on, 78. for sheep, 511 .

Blood bread vs. grain for pigs, 597.

Body fat, source of, 50 .

Body heat not a roeasure of the enerty of food, 67 .

Body tissues, formation of, 40 .

Body waste, the, 11.

Bone and muscle development, limits, c16.

Bone meal for corn-fed pigs, 86.

Bones, strength of pig's, 83.

Bran for sheep, $499,623$.

for steers, 383 .

for swine, 610 .

vs. oats for horses, 295.

Bran and shorts vs. bran for horses, see Wheat bran.

Breed, value of, in beef making, 372.

Breed tests with pigs, $543,608$.

with cows, 455 .

with steers, 373,375 .

with sheep, 487-89.

Brewers' grains, 136.

for cows, 474.

dried, 137.

for horses, 293.

wet, 137. 
Brood sow, feed for, 604.

importance of exercise for, 605 .

Broom-corn seed, 147.

Buckw heat, for pigs, 566. wild, for sheep, 500 .

Buck wheat grain, 14.

Buokwheat and its by-products, 144. fertilizing constituents or, 145.

Bull, feed and care of, 167.

Burr clover, 203.

Butter, effect of cotton seed on quality of, 156.

Butter fat, effect of feed on composition of, 442.

see Fat and Milk fat.

Buttermilk, 228.

for pigs, 574 .

Cubbage, 216.

Cactus, 217.

Galf, composition of, 7 . renring, $334,338$.

dairy, rearing, 339.

see Calves.

Calorie, 38.

Calorimeter, 87.

Calorimetry, 87.

Calves, birth welght of, 834 .

cod liver oil for, 337 .

cotton-seed menl for, 157.

fall, 842.

flax seed for, 337.

feed and care after weaning, 34.

gravity $\nabla s$. separator skim mllk, 890.

hay tea for, 341 .

oleomargarine for, 337 .

separator skim milk for, 335.

skim milk fed, gain from, 338.

skim milk for, 895 .

sugar for, 837.

veal, feeding, 343 .

wet chaffed hay for, 243.

whey for, 337,840 .

withholding coarse food from, 95 .

whole milk for, 334.

Calving, influence of time from, on milk How, 407.

Cane sugar, 6. molasses, 225.

Carbohydrate nutrition, 25.

Carbohydrates, influence on proteln consumption, 44.

potential energy of, 38 . source of fat, 51 .

Carbohydrates and fat, effects of, 48 . value of, 59.

Carbonic acid, excretion of, 66.

Carcass, modifications of, 84 . of farm animals, nitrogen and ash, 77 .

Carriage horse, feeding of, $3 \% 2$.

Carrots, 212.

for horses, B07.

ve. mangels for pigs, 590 .

Castor oll seed in linseed meal, 158.

Cattle, dressed weight of, 878 .
Cattle, fattenlng, feed and maugement 381.

range, fattening, 397.

see Steer.

Cellulose, 5.

Cereals, as forage plants, 101.

Chaff, 239 .

Chaffing, advantages of, 240.

Charcoal, for pigs, 615.

cob, how to make, 615 .

Chewing hay, work performed in, 2.

Chewing oats, work performed in, 29.

Christmas-lamb ralsing, 529.

Chyle, 20.

composition of, 21.

Circulatory system, the, 21.

Clover, red, 108.

mammoth, 201.

alsike, 201.

crimson or scarlet, 202 .

Japan, 203.

burr, 203.

proper time for cutting, 198.

Clover plant, development of nutrients, $1 F$.

Clover hay, for cows, 476.

for horses, 303.

for sheep, 506 .

for $\mathrm{swine}, 611$.

losses in curing, 199.

making, methods of, 198.

spontrneous combustion of, 200 .

use of, 200.

with meal for pigs, 577.

Canrse and concentrated feeds, digestion of, 31.

Coarse fodders, digestiblitity of, 29.

Cosrse forage, withholding from rumlnants, 94.

Cocoanut meal, 159.

for horses, 801.

Cod liver oil for calves, 337.

Coeffleients of digestibllity, 98.

Colon, 18.

Colostrum, 228.

Colt, feeding after weaning, 316 . proteln feeds $\nabla$. oats for, 300 . rations for, 831. see Foal.

Columbian Exposition, dairy tests, 44.

Commercial fertilizers, 267.

Composition of feeding stuffs, 97.

Concentrated feeds for dairy cops, 413.

Concentrates, 97.

Condimental foods, 228 . notes conceraing, 229 . not recommended, 280.

Confinement, of fattening steers, 364 . vs. exposure, for sheep, 492.

Cooked feed, value of, 235.

function of, 239 .

for cows, 432.

for horses, 288 .

for swine, 236, 645 .

experiments with, for swlne, 545. 
Corn, 119.

a carbonaceous food, 120.

alone and in combination, for wheep, 509 .

amount passing through atoer, 89.

28 human food, 121.

beef returns per acre, $\mathbf{8 8 1}$.

composition of, 125.

composition of the several parts of, 124."

dry Vs. soaked, for sheep, 198.

for cows, 472.

for fattening cattle, 381 .

for horses, 297.

adverse report, 299.

Kloepfer's conclusions, 800 .

ior sheep, 497 , 522 .

for steers, plain feeding of, recommended, 381 .

for swine, 608 .

gain from a bushel of, with pigs, 581 . nltrogen and mineral matter in, 125. preparation of, for leeding, 383.

races of, 120.

soaked, for steers, 346 .

time required to pass through teer, 849.

vs. ofl cake for pigs, 588.

vs. rye or barley for pigs, 591 .

whole va. corn and cob meal for cows, 413.

waste in feeding to cows, 413 .

Corn and blue-grass pasture for pigs, 57 .

Corn and its by-products, 119.

Corn and cob, weight of, 122.

Corn and cob meal, $12 \mathrm{I}$.

for pigs, 557.

for steers, 348 .

Corn by-products, 123.

for cows, 473 .

Corn belt, fattening sheep In, 531 .

Corn cob, 121.

Corn cob and husks, for steers, 349 .

Corn cob charcoal, for awine, 615.

Corn crop, nutrients of, 167.

Im portance of maturity, 168.

increase of nutrients during maturity, 165.

Influence of thickness of planting, 164. losses in fleld-curing, 171.

Corn fodder, fertllizing constituents of, 177 . pulling of, 174. see Fodder corn.

Corn forage, cutting and shredding, 240. shock, feeding, 172 . shocking, 172 . stooking, 172 .

Corn-fed pigs, strengthening bones of, 86 .

Corn meal for cows, 473 .

only, for cows, 94 .

only, for pigs, $78,86$.

マ8. corn for pigs, 556 .

see Corn.

Corn plant, changes in proteln, 167. distribution of nutrients $1 \mathrm{n}, 169$. in Georgia, 170.
Corn plant, Inorease of nutrients durins maturity, 165.

nl trogen-free cxtract $1 \mathrm{n}, 188$.

nutrients at different stages, 166.

southeru, time to cut for sllage, 254.

v8. northern, for allage, 253.

under Maryland conditions, 170.

Corn product, a new, 175.

Corn silage, see Silage corn. -

Corn smut, 175.

feeding experiments with, 176.

Corn stover, 174.

for cows, 477 .

for sheep, 508.

v8. mlyed hay and clover hay for $\infty$ wh, 425.

see Stover.

Corn-stalk disease, the so-called, 176.

Correctives for swine, 614.

Cost of finished steer, 389.

Cotton seed, 154.

effect of, on butter, 158.

on steer fat, 156.

feeding of, 154.

fertility in, 159 .

for beef production, 361 .

Cotton seed and its by-products for cows, $419,475$.

Cotton seed and cotton-seed meal, rational use of, 158.

Cotton-seed cake and meal, 155.

Cotton-seed hulls, 158.

Cotton-seed meal, for calves, 157.

for dairy cows, 156.

for horses, 155 .

for pigs, 157 .

v8. wheat bran for cows, 420.

Cotton-seed meal and hulls for steers, 155.

Cotton-seed polsoning, 157.

Cows, advanes in lactation of, and productivity of feed, 407.

amount of water drank by, 410.

annual feed consumption of, 450 .

barley for, 474.

brewers' grains for, 474.

by-products of corn for, 473.

care before and after calving, 408.

caring for, 404.

clover hay for, 476.

concerning feeding atuffs for, $\mathbf{4 7 2}$.

confinement during heated periods, $\mathbf{7}$.

consumption of dry matter by, 401 .

cooking feed for, 432.

corn for, 472.

corn meal for, 473.

corn otover for, 477.

corn stover vs. hay for, 425.

cotton seed and its by-products for, 11 , 475.

cotton-seed meal vs. bran for, 420 .

dairy, compared with beef type, 405 .

rations for, 478.

test at Columbian Exposition, 48.

dairying based on maternity of, 468 . 
Dows, Danish experimentz with, 44. distllery grains, dried, vs. oats for, 421. drinking at w11l, 411.

dry feed for, 109.

- frect of age on productivity of feed, 406. effect of grooming, $\$ 12$.

exercise for, 464 .

fall and spring, 467.

foeding exclusively with meal, $\theta 4$.

feeding fat to, 431 .

feeding grain in form of slop to, 433 .

feeding potassium chlorid to, 432 .

fish scrap for, 431.

fodder corn for, 478 .

fodder corn vs. timothy hay for, 424

frequener in feeding of, 468.

gluten feed vs. corn meal and bran for, 414.

gluten meal 75. cotton-seed meal for, 415.

heavy feeders the most profitable, 408.

influence of work on quality of milk, 412.

Japan clover hay vs. Bermuda hay for, 423.

large vs. small, 405 .

linseed meal vs. cotton-seed meal for, 420.

liberal and meager rations for, 137 .

liberal feeding of, 470.

maize feed vs, corn meal and bran for, 114.

milk of, and its by-products, 226.

milk and skim milk for, 430 .

millet hay for, 476 .

necessity of shelter for, 464 .

onts for, 473.

oats, ground, vs. wheat bran for, 418.

oi] cake vs. grain for, 421 .

on pasture, feeding grain to, 488.

order of feeding, $46 \theta$.

potstoes for, 130.

preparation of feed tor, 180 .

rape for, 428 .

record for one year of, at Cornell star tion, 460 .

regularity and kindness in handling, 465.

relation of concentrates and roughage for, 471.

relation of water drank to milk yleld, 410.

residual effect of grain feeding, 435.

Roberts' systern of caring for, $\mathbf{4 6 5}$.

roots for, 477 .

roots vs, concentrated foedn for, 420.

rye for, 474 .

galt for, 471 .

shorts v8, wheat bran for, 417.

vilage for, 477

dlage vg. fodder corn for, 427.

uilage ru. has for, 426 .

vorghum-seed meal for, 418.

timothy hay for, 476.
Cows, timothy hay $\nabla 8$. meadow fortell hay for, 423.

upland pralrle hay vi. timothy hay for, 422.

value of shelter for, 411.

warm vs. cold water for, 411.

water for, 470 .

wheat bran and middlings for, 473 .

wheat bran $\nabla 8$. mixed grain for, 417 .

wheat meal $\nabla$ s. corn meal for, 415.

wheat meal $\nabla s$. mixed grain for, 416.

whey for, 480 .

whole corn vs. corn and cob meal, 413

wide and narrow rations for, 445 .

see Dalry cow.

Cowpea, 162, 209.

Cowpeas for pigs, 567 .

Crimson clover, 202.

overripe, dangerons to horses, 202.

Crops for the silo, 255.

Crude fiber, 10.

Dairy by-products for gwine, 611.

Dairy ealf, rearing, 339.

Dairy cow, American rations for the, 114.

calculating ration for, 108 .

cal' 8 and management of, 463 .

cotton-seed meal for, 158.

economy of, 401.

feed for, 471 .

feed and care of, 463.

Investigations concerning, 101.

period of gestation, 401.

pure-bred, public tests of, 448 .

tests at Ex periment Stations, 455.

ratio of milk yield to bodg weight, 402 .

relation of live Felght to yield of, 404 .

rations for, 478 .

standard rations for, 114.

Jield of products, 402

see Cov.

Dalry herds, Station findings with, 457.

Danish oxperiments in cow feeding, 442 .

Danish pig-feeding experiments, 583 . slaughtering tesis, 584 .

Deglutition, 14.

Diastase, 4.

Digestible matter for one pound of erow th. 91.

Digestible nutrients, total, 99.

Digestibility, depression in, 31 . not affected by fat, $\mathbf{8 1}$.

not affected by salt, 31 .

of coarse and concentrated feeds combined, 31 .

of reeds by varlous animals, 30 .

of fodder, affected by weather, 30 .

of fodder, not alfected by drying, 80 . of nutrienta, 28 .

Digestion, artificial, 91.

Digestion coefficients, 98.

Digestion tria], with sheep, 26.

With ox in respiration apparatus, 34 .

Dipping fattening sheep, 524.

Distillery grains, dried, Vs, oats for cows,421. 
Drled blood, 2200.

for plgs, 78.

for sheep, 511.

biried brewors' gralng, 197. for horses, 293.

airied fish, 221.

bry matter required for 100 pounds of gain with steers, 370 .

Dry substance in the animal body, $\pi$.

Dutch system of veal maling, the, 843 .

Dynamometer, Wolfra, 274.

; $12 \mathrm{r}$ coru $\nabla \mathrm{s}$. corn meal for steers, 845.

Ensilage, see Silage.

Exgot, 193.

inther extract, 11. potential energy of, 38.

Fwes, breeding, food for, 517.

maintenance food for, in winter, 526. care and fued of, 530 .

feed required for 100 pounds of milk, 484.

fushing, 517 .

milking qualities of, 488 .

Swe's milk, composition of, 480 .

value of, for lamb growing, 484.

Exwes and lambs, soiling of, 486 .

Exclusive meal feeding, 94 .

sxcrement, amount of, volded by farm animals, 264.

composition of, 266.

Biscretions, from the kidneys, 23. of the skin, 24 .

Extercise for cows, 464 .

importance of, in horse management, 330.

value of, for plgs, 549 .

Fisperiment Stations, findings with dalry herds by, 457 .

trials of pure-bred dalry cows at, 455 .

Bxposure vs. conflnement for sheep, 492.

Farm animals, amount of excrement voided by, 264.

calculating rations for, 102.

comparative fattening qualities of, 74.

manure produced by, 269.

nitrogen and ash in carcass of, 77 .

nitrogen and ash retained and poidei by, 265 ,

Tirm manure, value of, per ton, 270 .

Farm stock, silage for, 256.

Gat, 11.

cost of production, 448,458 .

equivalent of foods for 100 parts of, 97.

feeding to dairy cows, 431.

feeding with, 56 .

in milk, formation of, 54 .

in the animal body, 72 .

formation of, 56 .

influence of, on proteln consumption, 44.

potential energy of, 88 .

ralue of, for fal formation, 59.

Fat and carbohydrates, relative effects of,

48.
Fut consumption, infuence of water on, 60 .

Fat formation, from carbohydrates, 61.

from protein, 55.

method of studying, 89.

Influeaco of feeding fat on, 66.

influence of feeding protein on, 57.

infuence of feeding protein and carbohydrates on, 58.

Influence of feeding protein and fat on, 57.

Fat nutrition, 25.

Fat of cow's milk, 228.

Fet of the body, disposition of, 617. Bource of, 50 .

Fat sickness, 363 .

Fat, see Butter fat.

Fat-Stock Show, sheep at, 495.

Fattening and feeds, 75.

Fattening, composition of increase during, 78.

influence of light on, 61.

Fattening of steers, feed for 100 ponnds gain during, 870 .

Fattering period, cost of gain increasex with length of, 869 .

for pigs, length of, 554 .

Fattening process, concerning the, 61.

Fattening qualities, comparative, of different farm animals, 74.

Fattening sheep, quarters for, $52 \pi$.

Fattening shorn lambs, 490.

Frtty acids, feeding of, 50 .

Feed, influence of, on animal body, 78,616. effect of, on composition of butter fat, 442.

on milk, a review of, 444.

on teeth and skull of pigs, 542 .

on the body of the pig, 78 .

on quality of pork, 614 .

concentrated, necessity of, for cows, 471 . coolxing, for swine, 236.

dry, for cows, 469.

for the dairy cow, 471.

for live stock, preparation of, 235 .

influence of cost of, on economy of ra-

tíons, 446.

preparation of, for cows, 469.

required for 100 pounds gein with pigs, $551,602$.

requirements for work with horsed, 278 . goaking of, 239 .

succulent, influence of, on milk, 439 .

wet, does not necessarily make watery milk, 440.

Feed and care of the bull, 467 . of the dairy cow, 463 .

Feed consumption, andual, by dairy cows, 459.

Feed lot, counsel in the, 381.

Feed racks for fattening sheep, 522.

Feeding, liberal, of cows, 470. exclusively with meal, 94. frequency of, for cown, 168. order of, for cows, 469 . 
Feeding, prevlous, Influence of, 43 .

Feeding horses, order of adminlstoring feeds, 325 .

Feeding dark flour, 129.

Feeding, for beef, 338 .

swine, light v8. heavy, 601.

exclusively on corn, $78,86$.

Feeding standards, concluslons relative to, 117.

explanations of, $97,108$.

introduction of, in America, 111.

Wolff-Lehmann, 101.

Feeding stuffe, digestibility of, 26.

fertilizing constituents of, 263.

for cows, 472.

manu rial value of, 268 .

money value of different autrients in, 117.

uutrients of, 87 .

valuation of fertlilzing constituents in, 268.

variation in digestibility of, 28.

Feeding tables, explanation of, 108.

Feed required in fattening, 75 .

Feeds, order of administering to horges, 325.

Fermentations in the stomach, 20.

Fertilizers, commercial, 267. essential constituents of, 283.

Fertilizing constituents in feeding stuffs, valuation of, 268.

Field bean, 162.

Fteld-curing corn, losses in, 171.

Field pea, 161. common, vine of, 209.

Fish scrap, 221.

for cows, 431.

for fattening steers, 356 .

for sheep, 511 .

Flat turnip, 213.

Flavor of milk, butter, otc., feed influonces on, 443.

Flax seed, 148.

for calves, $149,337$.

Flax straw, 193.

Flesh consumption, 40.

Flesh formation, method of studying, 33.

Flesh meal, 220.

Flesh production, 35 .

influence of wide and narrow rations on, 47.

Flour, dark, feeding of, 129. low-grade, feeding of, 129.

Flock, quarters for, 516.

size of, 515 .

winter care of, 616. see Sheep.

Foale, 313.

feeding, cow's milk for, 317.

feeding before weaning, 314 .

increase in welght of, 272 .

Palo Alto system of feeding, 314

rearing by hand, 317 .

trotting, weight at birth, 272 .

weanting, 815 .
Foals, welght and growth of, 271. see Colt.

Fodders, coarse, digestibllity of, 29.

pulling of, 174.

value of components of, for horses, 278.

Fodder corn and silage, feeding teat with, 249.

Fodder corn, cured, 173.

digestibility of, 248.

for cows, 476 .

for horses, 304 .

for soiling, 172 .

dry, and silage, relative merits of, 249.

dry, milk produced from dry matter , in, 248.

green, cost of placing in silo, 255.

v8. timothy hay for cows, 424 . see Corn fodder.

Frood, the basis of life, 63.

energy of, not measured by body beat, 67.

Food nutrients, digestibility of, 28.

Food requirements for work, 68 .

Forage, rape, 218.

coarse, withholding of, from rumt nants, 94 .

Force, production of, 63 .

Formation of body tissues, 40 .

Fuel value of rations, 115.

Gain, cost of, in steers, increases with age, 369.

Increases with length of fattentag period, 369 .

Gastric digestion, 14.

of ruminants, 16 .

Gastric fluid, composition of, 15.

Glucose, 5.

Gluten meal ys. corn meal and bran for cows, 414.

Gluten meal Vs. cotton-seed meal for cow th 415.

for steers, 351.

Gluten meal and corn vs, whent for plgk. 658.

Glycogen, 25.

Grain, feeding, to cows on pasture, 433.

in form of slop to cows, 433.

to lambs before weaning, 510 .

for lambs before weaning, 508 .

grinding, 243.

mixed, v8. oats for colts, 300 .

relative merits of, for horses, 305 .

v8. beets for pigs, 595 .

78. bolled potatoes for pigs, 595 .

Va. blood bread for plgs, 597.

vs. mangels for pigs, 505 .

vs. rye shorts for pigs, 593.

Grain-feeding cows on pasture, 433. steers on pasture, 358 . residual effect of, 495 .

Grain feeds vs, skim milk for plgs, 588. vB. whey for pigs, 587.

Grass, changes in, during rlpening, 180. dry vs. green, 184. 
Grass, for pasture and solling, 178. Hungarian, 188.

mixed, 188.

orchard, 187.

redtop, 187.

timothy, 186.

time to cut for hay, 181.

Grasses, at the South, 188. mixed, permanent, 188 . see Hay and Pasture.

Grinding grain, 243.

for fattening sheep, 523 .

Grooming cows, effect of, 412.

Growth and fattening, influence of wide and narrow rations on, 88.

Hairy vetch, 210.

Hard-wood ashes for corn-fed ples, 86.

Hay, 180, 185.

aroma of, 182.

chaffing, 239.

long and chaffed, experiments with, 242.

time to cut grass for, 181.

treatment of, 183.

wet chafied, for calves, 243.

gee Grasses and Legumes.

Hay and oats, relative value of, for horses, 293.

Hay and potatoes for horres, 306.

Hay crops, the small grains as, 192.

Hay curing, changes during, 182.

Hay inaking, losses due to weathering, 185. points in, 182 .

Hay tea for calves, 341.

Heart-beats per minute, in horse and ox, 22.

Heat-units of feeds, measurement of, 37.

Heating water for cows, 411.

Helden's method for calculating aroount of manure produced, 265.

Hemp-seed cake vs. grain for plgs, 688.

Herd record for one year, 460 .

Herd's grass, 186.

Elogs, see Pigs.

Honey-comb stomach, the, 16.

Horse bean, 102.

Horses, adverse report on feeding corn to, 299.

army, rations for, 332.

artichokes lor, 307.

barley for, 293 .

bran and shorts vs, oats for, 295.

bran, wheat and shorts vs. bran and shorts for, 295.

carriage, feeding of, 322.

carrots for, 307.

clover hay for, 303 .

cocoanut meal for, 301.

cooked feed for, 238.

conclusions concerning corn for, 800 .

dried brewers' grains for, 203.

effect of disturbed conditions on, 291.

experiments in feeding, 306.

feed and care of, 811.

feed consumed and work performed by, 273.
Horseb, feeds for, 292.

feed required by, for performing work, 285.

foed requirements for work, 278.

fodder corn for, 304 .

German army, 280.

importance of exerclse for, 830.

vartety of feed for, 328 .

Indian corn for, 297.

influence of rapidity of work, 279.

investigations concerning, 271 .

loss of weight of, during work, 286, 200.

maintenance rations for, 282.

malt sprouts for, 301 .

measuring the work of, 274.

millet hay infurious to, 304 .

nutrients required for maintenance and work, 276.

oats for, 292 .

order of administering grain, hay and water, 325.

Paris Cab, rations fed to, 308.

Parls Omnibus, rations fed to, 300.

penuut meal for, 301 .

potatoes $\nabla s$. bay for, 306 .

preparation of feed for, 325 .

protein required in maintenance ra tions for, 283.

range of feeding stuffs for, 311 .

rate of movement, 270 .

rations for, 308,331 .

relation of speed to work of, 287.

relative merits of grains for, 303 .

results of digestion trials with, $275,224$.

roots for, 306 .

ruta-bagas for, 308.

steamed potatoes for, 306 .

stover for, 304 .

straw for, 304 .

street-car, rations for, 332.

substitutes for oats for, 292 .

systematic feeding of, of highest importance, 328 .

thme used in masticating hay, 13.

timothy hay for, 303 .

variation in weight of, 291.

water drank by, 286, 289.

wheat and bran va. oats for, 296 .

work done by, 288.

wheat for, 204.

work, compounding rations for, 301 .

work, feeding of, 323.

work, nutritive ratio for, 284.

Horse feeding, successful, a skilled art, 312 supervision of, 330 .

Horse-feeding experiments, 278, 280, 298.

Horse feeds, digestion of, 280.

Hangarian grass, 188. see Millet.

HJdrochloric scid in gastric Juloe, 15.

Increase during fattening, composition of, 73.

Indian corn, see Corn.

Insalivation, 18. 
Intake of body in respiration and feeding, B4.

Intestinal juice, the, 20.

Intestines, large, 18.

length of, of pigs, 542 .

of farm animals, length and capacity of, 19.

Japan clover, 203.

Japan clover hay $\mathrm{vB}$. Bermuda hay for eows, 423.

Japanese millet, 188.

June grass, 185.

Kaffir corn, value of, In steer droppings, 358 .

for pigs, 565 .

for steers, 352.

red, yield of, 146 .

Kentucky blue grass, 185.

Kidneys, excretion from, 23.

Xübn's rations, method of compounding, 115.

Kühn's ktandard maintenance ration, 112. Labor, hard, nitrogen excretion during, 65 . Lactation of cow, advance in, and productivity of feed, 407.

Lamb growing, value of ewe's milk for, 484.

Lambing, date of, 517.

Lambing time, care of sheep at, 518.

Lambs, compared with pigs, 482.

fat, 521 .

fattening, rations for, $5: 8$.

"self-feed" for, 490.

feeding grain to, before weaning, 510 .

feeding milk to, 481 .

feeding of, 530 .

grain for, before weaning, 608.

shorn, fattening of, 490.

vs. sheep for fattening, 486.

water drank by, during fattening, 498. weaning of, 519

weight at birth, 481 .

wiyter or Christmas, raising, 529. see Sheep.

Lambs and pigs, relative economy of, 489.

Lard, cause of low price of, 609 .

Enrge intestine, 18.

Leaver and twigs, 219.

Legumes, 195. fertilizing constituents of, 210.

Leguminous plants for green forage and hay, 195.

Leguminous seeds, 161. fertilizing constituents of, 162.

Liebig's theory conceruing the function of protein, 64.

Light, influenco of, on fattening, 61,

Linseed meal, 149.

castor oll seed in, 153.

fertilizing constituents of, 153 .

vs. cotton-seed meal for cows, 120 . see 011 meal.

Low-grade flour, feeding of, 129.

Lucern, see Alfalfa.

Lymphatic system, the, 2 .

Lym phatics, the, 21.
Maintenance food for breeding ewes, 528.

Maintenanee rations, for horses, 282.

for oxen, 111.

Kühn's, 112.

protein required in, 283.

Malze, see Corn.

Maize feed vs. corn meal and bran for cowt, 414.

Malt for stock, 186.

Malting, 135 .

Malt sprouts, 138.

digestibility of, 27.

for horses, 301.

Mammoth olover, 201.

Mangels, 213.

v8. carrots for plgs, 696.

จB. grain for pigs, $\mathbf{5 9 5}$.

Manure, from the ox, 264. produced by farm animals, 269. produced, Heiden's method for calou. lating amount of, 265.

Manurial value of feeding stuffe, 263.

Many plies, 16.

Mare, food for, 320 .

period of gestation of, 271 .

see Horse.

Mare's milk, composition of, 273.

Miare and foal, investigations concernlng, 271.

Mastication, 12.

time required by horse for, 13 .

Matiug sheep, 529.

Meal feeding, exclusive, 94 .

Meat scrap, 220.

for pigs, 575 .

for sheep, 511.

Middlings for $\$$ wine, 610 .

vs. corn for pigs, 661. see Shorts.

Milch cows, salt for, 411. see Cors.

Milk, 226.

changing components of, 441.

changing ratio of solids to water in, 439.

cost of production of, $448,458$.

cow's, for fosl feeding, 317.

effect of feed on quantity of, 437.

ewe's, composition of, 480.

feed required for 100 pounds of, 484 .

value of, for lamb growing, 484 .

fat globules of, 403 .

feeding of, to lambs, 481 .

fecd in relation to, 437 .

infiuence of character of rations on, 437 . influence of feed on, 437.

influence of feed on flavor of, 143.

tnfluence of feed on, review of, 444.

influence of pasture on, 439 .

influence or succulent feed on, 499.

mare's, 273.

nitrogenous constituents or, 227 .

modification of, by feeding, 437 .

per cent. of fat in successive portions of, 405 . 
Wilk, sow's, concernlng, 696. quantity yielded, 587 . composition of, 537. Bweet vs, sour, for plgs, $57 \mathrm{r}$. whole, 228.

for calves, 834 .

for pigs, 571 .

Milk and its by-products, fortilisine ralue of, 2229 .

Milk and skim milk for cows, $\mathbf{4 3 0}$.

Mulk ash, 227.

( Milk fat, $220,227$.

Milk flow, influence of time from alving on, 407.

Milk serum, 228.

Milk sugar, 227.

Milk yield, influence of shearing wool on, 485.

Bilking qualities of ewes, 488.

Millet, 147, 188.

Japanese, 188.

Millet hay, for cows, 476 .

1njurious to horses, 304 .

for sheep, 607.

see Hangarian grass.

Millo maize, 189.

Mineral compounds, 7.

Molnases, for steers, 356 . from the beet factory, 224 .

Money value of different nutrients in feed-

ing stuffs, 117.

Mule, the, work done by, 288.

Muscular energy, source of, $63,69$.

Muscular exertion, 60.

Mutton breeds and the Merinos compared, 515.

Narrow and wide rations, intuence of, on flesh production, 47.

Nitrogen, excretion during hard labor, 65. retained and voided by farm animals, 265.

Nitrogen-free extract, 11.

Nitrogenous substances, calculation of composition, 35 . in the animal body, 72 see Protein.

Nutrients, total, digestibility of, 99 . In feeding stuffe, 97. placing money value on, 117. valuation of, in concentrated foeding stuffs, 117.

Nutriotone, 230 .

Nutrition, animal, 10.

Nutritive ratio, 100 .

Oat feed for pigs, 564 .

Dat grain, the, 139.

Oat atraw for sheep, 506.

Oats, a stimulating principle in, 140. by-products of, 11 .

for $\mathrm{CON} \mathrm{s}, 473$.

for fattoning sheep, 523 .

for horses, 292.

boiled rJe as a substitute for, 297.

substitutes for, 292
Oats, for plgs, 504

for sheep, 499 .

ground, vs. wheat bran for cows, 418.

new, unfit for feeding, 140.

ve. bran and shorts, for horses, 295.

Oate and hay, relative value of, for horken, 293.

Oats and peas, 191.

Oate and their by-products, 199.

Oats, beans and corn, relative value of, for horses, 293.

Oil-bearing seeds and their by-produots, 148.

Oil cake, value of oil in, 151.

V8. grain for pigs, 588 .

vs. grain for cowa, 421.

O1l calre and ofl meal, $14 y$. as a feeding stuff, 152 .

Oil meal, adulteration of, 150.

for steers, 351,384 .

home use of, 153.

new-process, 149.

relative value of old-and new-process, 150.

swelling process of, 150 .

see Linseed meal.

Olein, 6.

Oleomargarlne for calves, 897.

Omasum, 16.

Orchard grass, 187.

Ox, maintenance ration for, 111. masure from, 264. see Bteer.

Palmitin, 6.

Palm-nut cake ve. grain for ples, 683.

Palro-nut meal, 159.

Pancreatic fuice, 18.

Paris Omnibus Co., horse experiments conducted by, 208.

Parsnip, 213.

Pasture, concerning, 178. droppings of corn-fed steers on, for plest, 579.

feedin srain to steers on, 358

feeding pigs on, only, 578 .

for pigs, 576, 612.

grain-feeding steers on, 386 .

grasses for, 178.

influence of, on millk, 439 .

possibilities of, for steor feeding, 386 . producing real on, 338 .

small vs. large, for steers, 385.

time for turning steers to, $\mathbf{3 8 5}$.

turning sheep to, 519.

Pasture grasa, yield of, 178.

Pasturing steers, 358.

Paunch, 16.

Peanut cake vt. grain for piga, 688.

Peanut meal, 160. for horses, 301.

Pear cactus, 218.

Peas, 161. for pigs, 565, 611

Pea-vine hay, 209. 
Pellagra corn disease, the, 122.

Pepsin, 15.

Permanent grasses, mixed, 188.

Plgeon-grass seed, for plgs, 567 . for sheep, 500 .

Pigs, amount of feed consumed by, 562 . artichokes for, 571 .

average dally gain by, 552.

barley meal for, 562 .

barley vs. centrifugal skim milk for, 586.

breed tests of, 543 .

buckwheat for, 566 .

buttermilk for, 574 .

carrots VE. mangels for, 596 .

centrifugal v8. gravity akim milk for, 584.

clover hay with meal for, 677 .

compared with lambs, 482 .

composition of, 70 .

corn and blue-grass pasture for, 577 .

corn-fed, hard-wood askes and bone meal for, 86.

strengthening the bones of, 86 .

corn meal vs, corn for, 556.

cotton-seed meal for, 157.

cowpeas for, 567 .

droppings of corn-fed ateers for, 680.

early gains of, 540 .

effect of addition of water to the feed for, 599 .

effects of feed on teeth and skull of, 542 . fattening, 608.

fat 78. lean, experiments with, 78 .

experiments with, misconception concerning, 85.

feed for 100 pounds of gain of, 553, 602 . feed for 100 pounds live weight of, 552 .

feeding of, 605 .

on pasture only, 578 .

through the dam, 541 .

following corn-fed steers, gains of, 680.

food of support, 550.

for shows, ball-feeding of, 613 .

gain from a bushel of corn by, 581 .

gluten meal and corn vs. whedt for, 558 .

grain vs. beets of different sugar content for, 595 .

$\nabla 8$. blood bread for, 597 .

vs. bolled potatoes for, 695 .

Vs. oll cake for, 588.

vs. rye shorts for, 693 .

hemp-seed cake vs. grain for, 588 .

Increase, composition of, during fatten-

ing, 70.

influence of, on the growing body of, 78 .

Kaffir corn for, 565 .

length of fattening period for, 654 .

length of intestines, 542.

mangels $\vee 8$. grain for, 596.

meat scrap for, 675 .

middlings vo. corn meal for, 561 .

ont feed for, 564 .

onte for, 604
Plga, palm-nut cake va. grain for, 588.

partial analyses of blood and kidney. of, 84.

pesture for, 576.

percentage gain of, from birth to maturity, 653.

peanut cake $\nabla$ s. grain for, 588.

peas for, 565 .

plgeon-grass seed for, 567 .

potatoes for, 568 .

rape forage for, 579 .

rice meal for, 567 .

roots for, 570 .

rye or barley $\nabla 8$. Indlan corn for, 591.

rye vs. barley for, 588 ,

vs. centrifugal skim milk for, 586 .

separator skim milk for, 571 .

sheaf wheat for, 560 .

shelter for, 598 .

skim milk fed, gain from, 338 .

skim milk vs. grain for, 586 .

vs. whey for, 585 .

soaked meal vs. dry meal for, 547.

strength of thigh bones of, 83.

sunflower-seed cake vs. grain for, 588. sweet vs. sour milk for, 573 .

turnipg v8. whey for, 596.

value of corn and cob meal for, 557.

value of exercise for, 549 .

value of shelter for, 549 .

value of various feeding stuffis for, 553 .

water drank by, 543 .

weaning, 607.

welght, gain and feed consumed by, 551 . at birth, 535,540 .

wheat for, 559 .

wheat and corn meal for, 659.

wheat bran $\nabla 8$. middlings for, 502 , vs. rye and barley for, 594 . with corn for, 562 .

whey for, 574.

whey vs. graln for, 574, 587.

whole milk for, 571 .

winter v8. summer feeding of, 300 . young, exercise for, 606.

see Swlne.

Pigs and lambs, relative economy of, 48.

Pig feeding, centrifugal vs. gravity gkim milk, 584 .

Pig-feeding experiments, Danish, 583.

lessons for the breeder and feeder, 617. lessons from experiments in, 616 .

Plains sheep, fattening of, 691.

Plant building, 3.

Plant cells, 1.

Plant effort, the end of, 7.

Plant growth, 1.

from the chemist's standpoint, 4

Plant ${ }^{\prime f e}$, the sun the source of, \&.

Plant oils, 5.

Plant substences, how grouped by the chemist, 9.

Plants, elements essentlal to, 1. how food in gathered by, 3. 
Fisnta, the support of animal life, 8. water required by, 2 .

Planting corn, influence of thickness in, 164.

Poisoning from cotton seed, 157.

Pork, Infiuence of feed on quality of, 614 . lean, demand for, 609 . production at the South, 682. skim milk and whey fed, quallty of, 588.

Potassium chlorid, feeding of, to cows, 432.

Putato, 212.

boiled vs. grain for plgs, 695 .

for $\operatorname{cow} 8,430$.

for pigs, 568 .

steamed, for horses, 308.

vs. hay for horses, 306 .

Potential energy of food nutrients, 88.

Prehension, 12.

Prickly comfrey, 217.

Protein, 10.

Influence of, on fat formation, 67.

potential energy of, 38 .

the source of fat, 55 .

Protein and carbohydrates, influence of

feeding, on fat formation, 58.

Frotein and fat, influence of feeding, on fat

formation, 57 .

Protein compounds, 6.

Protein consumption, 42.

influence of amides on, 48.

influence of carbohydrates on, 44.

influence of carbohydrates fed with protein on, 46.

Influence of fat on, 44.

influence of mixed diet on, 44.

influence of salt on, 49.

influence of various nutrients on, 4.

influence of water on, 49.

Protein feeding, oxclusive, 44.

Protein nutrition, 24.

Protein, see Nitrogenous substances.

Pulp, sugar beet, 222.

Pulse, frequency of, in farm anlmals, 22.

Pumpkin, 217.

Pure-bred steers, quality of, 378.

Range cattle, fattening, 397.

Rape, for milch cow8, 428.

for pigs, 579 .

for sheep, 502 .

second crop for sheep, 505 .

use of, 218 .

vs. blue-grass pasture for sheep, 504 .

Rations, calculating, 102.

fed by American dairymen, 113.

fed by Connecticut dairymen, 113.

fed to Paris Omnibus Co. horses, 309.

for army horses, 332 .

for dairy cows, 478 .

for farm animals, calculating, 102.

for fattening lambs, 528 .

for fattening steers, 396.

for horses, 308, 331.

for street-car horses, 332.
Rations, for work horses, 801.

fuel value of, 115.

Infinence of character of, on milk, 487.

influence of feed prices on economy if, 446.

liberal and meager, for mllk productlon, 437.

theoretical, for fattening steers, 395.

wide and narrow, for cows, 437, 445.

infuence of, on growth and fattenIng, 88.

Red clover, 196.

yield of three crops of, 196.

see Clover.

Red top, 187.

Rennet, 15.

Reunet stomach, 16.

Reepiration, 23.

exchange of gases $\mathrm{fn}, 23$.

per minute in farm animals, 23.

Respiration epparatus, 32.

digestion trial with ox in, 84.

lllustration of use or, 33.

Respiration studies, 32 .

Reticulum, 16.

Rice grain, parts of, 143.

Flee and its by-products, 143.

Hice meal for pigg, 567 .

Robertson mixture, for sllage, $25 \mathrm{~A}$.

Roots, dry matter in, 251.

feeding of, 214.

for cows, 477.

for horses, 306 .

for pigs, 570 .

for steers, 854, 834

modifleation of anfmal carcass by, 214

preparation of, 244 .

storilig of, 214.

v8. concentrated feed for cows, 428. yleld of, 250.

Root crops, not generally grown, 215. yleld of, 211.

yield of digestible nutrients, 212

Roots and tubers, 211. see Bects, Turnips, Carrots, etc.

Roughage, 97 .

for cattle, steaming of, 236 .

for fattening sheep, 523 .

Rumen, 18.

Ruminants, gastric digestion of, 16. withholding coarse formge from, 94.

Ruta-bagas, 213.

for horses, 308.

Rye, for cows, 474 .

v8. barley for pigs, 588.

v8. centrifugal skim milk for plgs, 586 .

bolled, as a substitute for osts, 297.

Rye and barley vs. wheat bran for pigs, 694.

Rye and its by-products, 132.

as stock feeds, 132.

Rye or barley $\nabla 8$. Indian corn for pigs, 591.

Rye shorts v8. grain for pigs, 693.

Saliva, composition of, 14 . secretion of, 14. 
Salt, for COW 47 L for sheep, 520.

for steers, 387.

infuence of, on protein ensumption, 49.

Scarlet or crimson elover, 202.

Scotch system of veal making, 343.

Self-feed for fattening lambs, 490.

Separator skim milk, for calves, 335. placing a money value on, 572 .

Shearing, frequency of, 513. influence of, on milk yleld, 485.

Sheep, at American Fat-Stock Bhow, 495. alfalfa hay for, 505 .

attacks of vermin, 521 .

bran for, 253,499 .

breed tests of, 487,489 .

care of, at lambing time, 518.

comparison of the Mutton breeds and

the Merinos, 515.

composition of, 70 .

corn alone and in comblnation for, 509. corn for, 497,522 .

corn sllage vs. roots for, 501.

corn stover for, 508 .

cost of gain, 525 .

daily gain of, for the various breeds of, 494.

dipping, 524 .

dried blood for, 511 .

dry vs. soaked corn for, 498.

English experience with wheat for, 498.

exposure vs. confinement of, 492

fattened, weight of, 498 .

fattening, 514 .

feed consumed by, 524 .

feed racks for, 522 .

reeding, hints on, 526 .

flsh serap for, 511.

food of, 614 .

general care of, 514.

grinding grain for, 523 .

increase during fattening, 70 .

influence of protein on carcass of, 511.

in the corn belt, 581 .

investigations with, 480.

length of feeding perlod and galns of, 524.

mating of, 520 .

mature, 521.

meat scrap for, 511.

millet hay for, 607 .

on alfalfa hay and grain, 692

oat straw for, 506 .

oats for, 499,523 .

period of gestation, 480 .

Plains, fattening of, 581 .

rape for, 502

rape, second crop of, for, 505.

rape vs. blue-grass pasture for, 504 .

regularity and quiet for, 526 .

rate of increase, 525 .

roughage for, 528.

shrinkage of, in shlpping, 496.
Sheep, shrunken wheat, wlld buckwhest and pigeon-grass seed for, 500 .

sugar beets for, 502.

turning to pasture, 519 .

v8. lambs for fattening, 486 .

water and salt for, 520 .

weight of carcass of, 495.

Western, fattening on alfalfa hay, 504

wheat for, 498, 552 .

wheat screenings for, $500,523$.

see Lambs.

Shelter, for pigs, 598.

influence of, in fattening steers, 864

necessity of, for cows, 164 .

value of, for cows, 411.

for pigs, 549 .

Shephera and nock, 614.

Shock corn, feeding of, 172 .

Shorts, 130 .

vs. wheat bran for cows, 117.

see Middlings.

Shotes, foeding, 607 .

following steers, Eain of, 347.

Shrinkage in shipping of sheep, 496.

Sllage, 245.

digestibllity of, 248.

effect of, on quality of milk, 257.

on carcass of steers, 250 .

for cows, 477 .

for farm stock, 258.

for steers, 384 .

from beet pulp, 223.

importance of proper horizontal area

in feeding, 260.

milk produced from dry matter $1 \mathrm{n}, 2 \mathrm{~A}$. on the rational use of, 257 .

$r$ relative losses in, and drylng, 246 . -

Southern v8. Northern seed corn for. 253.

time of cutting southern corn for, 254.

vs. fodder corn for cows, 427 .

va. hay for cows, 426.

v8. roots for steers, 355 .

weight of, at different depths, 259.

Silage and beets, relative cost of, 252 .

Silage and dry fodder corn, relative merite of, 249 .

space occupied by, 254 .

Stlage and fodder corn, feeding tests witb. 249.

Sllage and roots, dry matter in, 251.

silage, corn and roots, yield of, 250.

Slage, corn, removing ears from, provloue to ensilage, 252.

corn, vs. roots for sheep, $60 \mathrm{~L}$. yield of, 250 .

Stlo, capacity of, 260 .

Alling and covering, 261 .

building and flling of, 258 .

crops for, 255.

rate of flling, 281.

rectangular, 259.

Silo construction, 258.

Silo losses, character of, $2 \mathbf{2 7}$. 
Blloing fodders, permanency of mothod of, 245.

Size of the body, a factor in feeding, 60 .

gkim milk, 228 .

centrifugal vs. gravity, for plgs, 584. for calves, 835 .

gravity vs, separator, for calves, 336.

separator, for plgs, 671.

plaoing a money value on, 572.

vs. grain for pigs, 586 .

vs. whey for pigs, 685 .

skim milk-and whey-fod pork, quality of, 588.

Skin, excretions of, 24.

Slaughtering tests of plgs, 680.

Slop, feeding grain in form of, to cows, 433.

Small graius, the, as hay crops, 102.

Smut-feeding experiments, 176.

Smut on corn, 175.

Soalied meal vs. dry meal for plg8, 547.

Soaking feed, 239.

Boiling, advantage of, 231.

experiments, concerning value of, 231 .

fodder corn for, 172 .

labor involved in, 234.

partial, 234.

Solling cattle, 231.

Solling crops, 233.

Solling crops and pastare compared, 232.

Soiling ewes and lambs, 486.

Soja bean, 161, 209.

Sorghum, 145, 189.

non-saccharine, 145.

saccharine, 145, 147.

second growth, dangers from, 199.

yield of, 146.

Sorghum hay, 190.

Sorghum molasses, 225.

Sorghum-seed meal for cows, 418.

South, the, pork production at, 582 .

southern 78 . Northern seed corn for silage, 253.

Suws, milk ylelded by, 530.

composition of milk of, 537.

quantity of milk yielded by, 557 .

vs. barrows in swine feeding, 602 .

tows and pigs, feeding of, 605 .

Siby bean, 161, 209.

ispontaneous combustion, 200 .

Spurry, 216.

Stallion, the, feed and care of, 318.

standard Cattle Co., amount of grain and hay fed to cattle, 398.

cost of feeding cattle, 400 .

daily feed consumed and gains of steers, 399.

number of cattle marketed and gains, 399.

Btandard rations for dairy cows, 114.

Btarch, 4, 5.

Starch production, 124.

Bteaming roughage for cattle, 236.

Btearin, 6.

Steer, at rest, rations for, 102.
Steer, mount of corn passing throusm unbroken, 949.

amount of feed consumed, 872.

balanced ratton for, 857 .

bran for, 383.

changes during fattening of, to be avolded, 385.

composition of carcass of, 70, 92.

composition of inereased growth of, 92 . coru and cob meal for, 348.

corn, cob and husks for, 949.

corn-fed, droppings of, for ptgs, 580 .

dropplngs of, on pasture, 579.

cost of feeding increases with age, 388.

cost of tlnished, 389.

cost of gain increases with length of

fattening period, 369 .

dressed weight of carcass of, 874.

dry matter required for 100 pounda of galn in, 370.

ear corn vs. corn meal for, 345 .

early maturity of, 374,390 .

offect of age on rate of gain of, 867.

effect of silage on carcass of, 250.

explanation of fattening process, 387.

rattening, cost of 100 pounds of gais with, 370.

experiments with, 88 .

flsh serap for, 356 .

Indian corn for, 381 .

ratione for, 104,395 .

rations used at Experiment stw tions, 396.

salt for, 387 .

variation in indivldual weight, 890 .

water for, 387.

water drank by, 359.

fed Kaffir corn, value of dropplngs from, 353.

feed for 100 pounds of gain during fat tening, 370.

frequency of feeding, 392 .

finished, cost of, 389 .

gluten meal for, 351 .

grain-feeding of, on pastures, 386.

influence of wide and narrow rationa on, 88 .

increase during fattening, 70.

Kaffir corn for, 352.

low-pressure feeding, 391.

molasses for, 356 .

modern market demands, 380.

oil meal for, 351, 384.

on pasture, feeding grain to, 358 .

pasturing of, 358 .

percentage of loose tallow to dresued weight of, 376.

preparing corn for feeding, 388.

preparing for shipment, 394.

proportion of valuable parts in carcass of, 377 .

pure-bred, amount of feed consumed by, 372 .

less feed with, for given gain, 878. 
Bteer, value of, 878.

roots for, $354,384$.

salt for, 387 .

silage for, 384

silage v8. roots for, 355 .

soaked corn for, 346 .

time required for corn to pass through, 349 .

turning to pasture, 385 .

water drank during fattening, 359.

water for, 387.

wheat bran for, 351.

wheat meal for, 350 .

withholding coarse feed from, 95 .

Bteer fat, effect of cotton seed on, 156,

steer fattening, difficulties of, 345 .

Influence of shelter and confinement, 364.

Steer feeding, by Standard Cattle Co., 398 . close attention required, 395 .

cost of gain lncreases with age, 360 .

demands of modern market, 890 .

ractors in, 364 .

feed lot for, 391 .

feed racks for, 392.

low-pressure, 391.

trials, results of, 345 .

what Southern Stations have found, 361.

see $O x$ and Cattle.

Stomachs of farm animals, capacity of, $14,19$.

Btover, 174.

for horses, 304.

results of shredding, 241 .

seo Corn stover.

Btraw, 193.

cut, 239 .

for horses, $\mathbf{3 0 4}$.

Bugar, 225.

for ealves, 337.

Bugar beet, 213.

for sheep, 502 .

leaves, 217.

pulp, 222.

Sunflower-seed cake, 160 .

vs. grain for pigs, 588

Support, food of, for pigs, 550.

Swede turnip, 213.

Swedish clover, see Alsike.

Swelling process, with linseed mesl, 150.

Swine, administration of feeds to, 612.

barley for, 610 .

bran for, 610.

breed tests of, 543,603 .

breeding stock, management of, 604 .

clover hay for, 611 .

conflnement for, 613 .

cooking feed for, 236,545 .

corn-cob charcoal for, 615 .

correctives for, Rl4.

dairy by-products for, 611 .

feed for, 608.

reediug corn to, 608 .
Swine, light va. heavy feeding of, 801. management of, 604 .

middlings for, 610 .

need of variety in feeding stu fis for, 61 .

pasture for, 612 .

pess for, 611.

period of gestation, 535 .

pure-bred, tests with, 543.

wheat for, 609 .

see Pigs.

Tallow, in carcass of steers, relation of, to dressed weight, 376 .

Teosinte, 189.

Thigh bones of pigs, strength of, 83 .

Timothy, or Herd's grass, 186. yield of hay and nutrients from, 181 .

Timothy hay, for cows, 476. for horses, 303 .

v8. meadow foxtall hay for cows, 22.

Trotter, feeding the, 320 .

Turnips vs. whey for pigs, 596.

Upland prairie hay $\mathrm{vg}$. timothy hay for cows, 428.

Urine, composition of, 23, 24 .

Valuations of nutrients in feeding stuffi, 117.

Veal, essentials in feeding for, 343. feeding for, 343.

production of, on pastures, 338.

Veal making, a scotch system of, s43.

the Duteh system of, 813 .

Vermin on sheep, 521 .

Villi, 20.

Waste products in resplration and feeding, 35.

Water, $\theta$.

drank by fattening lambs, 193.

by horses, $286,289$.

by pigs, 699 .

effect of addition of, to feed for piga, 599.

effect or, on fat consumption, 60 .

for cows, 470 .

for sheep, 520 .

infiuence of, on proteln consumption, 48.

in the animal body, 72 .

warm vs. cold for cows, 411.

Water extracts, 32.

Weaning lambs, 519.

Weight, of horses, variation In, 291. loss of, in horses duriug work, 286, 200. of pigs, gain and feed consumed by, 5,1

Wheat, for feeding, 127. for horses, 294

for pigs, 559 .

for sheep, 498,522 .

English experience with, 108.

for swine, 609 .

sheaf, for pigs, 500 .

damaged, 128.

shrunken, for sheep, 500 .

Wheat and bran vs, oats for horses,

Wheat and corn meal for pigs, 559 . 
Whot and its by-products in milling, 129. Wheat bran, 130 .

and middlings for cows, 473 .

for steers, $\mathbf{3 5 1}$.

v8. middlings for plgs, 562 .

vs. mixed grain for cows, 417.

vs. rye and barley for plgs, 504.

with corn for plgs, 562 . see Bran.

Wheat bread, feeding of, 129.

Wheat feeding, character of flesh from, 127.

Wheat grain, 126.

composition of, 128.

fertilizing ingredients of, 191.

Wheat meal for steers, 350 .

76. corn meal for cows, 415; for pigs, 559.

78. mixed grain for cows, 416,

Wheat middlings, 130.

Wheat sereenings for sheep, 500, 528 .

Wheat shorts, 130. see Shorts and Middlings.

Whey, 229.

for calves, $337,340$.

for milch cows, 430 .

for pigs, 574.

v8. grain for pigs, 587.

v8. skim milk for pigs, 685.

v8. turnips for pigs, 696 .

Wide and narrow rations, influence of, on nesh production, 47.

Winter lamb raising, 529.

Winter vs. summer feeding of pigs, 600 .

Wolff's dynamometer, 274.

feeding standards, 109.

investigations in horse feeding by, 273 .
Wolff-I ehmann foeding standards, 101, 111.

Wool production, 497 .

influence of soll and climate on, 512.

Work, by cows, influence of, on quality of milk, 412.

feed required for performing, by horsen, 285.

food requirements for, 68 .

obtainable from food substances when fed to horse, 277.

Work horses, compounding rations for, 824 . feeding of, 323 .

nutritive ratio for, 284 .

World's Columbian Exposition, teat of daíry cows at, 448.

Yleld of alfalfa per acre, 204 .

Yield of corn varies with thlekness of planting, 164.

Yield of digestible nutrients in root orop, 212.

Field of hay and nutrients of timothy, four periods of growth, 181.

Yield of milk per cow, various Experiment Stations, 459.

Yield of milk at different stages of lectar thion, 408.

Yleld of milk per cow yearly, 400 .

Yield of nutrients in clover orop at different stages of maturity, 187.

Yleld of nutrients in corn crop at various stages of maturity, 167.

Field of nutrients in pasture grasm per scre, 180.

Yleld of red clover crop, 194

Yield of root orops, 211. 


